\title{
ALLGEMEINE PSYCHOLOGIE \\ auf personalistischer Grundlage \\ VON
}

WILLIAM STERN

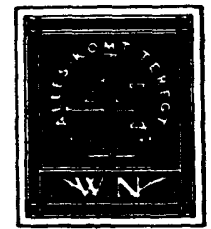

HAAG

MIRTINTS NIJHOFF

1935 
Copyright 1935 by Martinus Nijhoff, The Hague, Holland All rights reserved, including the right to translate or to reproduce this book or parts thereot in any form
Dem Andenken meiner Freunde

Otto Lipmann

und

Martha Muchore

PRINTED IN THE NETHERLANDS 


\title{
I N H A L T
}

\section{ERSTER HAUPTTEIL}

\section{GRUNDRISS}

\author{
ERSTES KAPITEL
}

A L LGE MEINE PSYCHOLOGIE

I. DER WEITESTE SINN VON „PSYCHOLOGIE” . . . . . . . 5

1. Das Schema . . . . . . . . . . . . . . . . 5

2. Naive und künstlerische Psychologie . . . . . . . . . 7

II. PHILOSOPHISCHE PSYCHOLOGIE . . . . . . . . . . . 9

1. Vorbemerkung . . . . . . . . . . . . . 9

2. Ubersicht .. . . . . . . . . . . . . . . . . 10

a. Das Wesen der Seele. . . . . . . . . . . . . . . 10

b. Die seelischen Subjekte. . . . . . . . . . . . . . 10

c. Die Beschaffenheit des Seelischen . . . . . . . . . 11

$d$. Seele und Leib . . . . . . . . . . . . . . . . . 11

e. Erkenntnistheoretische Probleme . . . . . . . . . 12

III. PSYCHOLOGIE ALS ERFAHRUNGSWISSENSCHAFT . . . . . . 13

1. Vorbemerkung . . . . . . . . . . . . . . . . 13

2. Aufgaben. . . . . . . . . . . . . . . . 15

a. Beschreibung. . . . . . . . . . . . . 15

b. Klassifikation und Bezeichnung. . . . . . . . 16

c. Analyse und Ganzheitsbezug . . . . . . . . . . . 18

d. Verknüpfen, Verallgemeinern, Erklären. . . . . . . 22

e. Verstehen und Deuten . . . . . . . . . . . 25

ZWEITES KAPITEL

SON DERGEBIETE DER PSYCHOLOGIE

I. SEELENLEBEN UND WELT . . . . . . . . . . . . . 30

1. Seelenleben und Naturwelt . . . . . . . . . . . 30

a. Psychophysik . . . . . . . . . . . . . . 31

b. Physiologische Psychologie . . . . . . . . . . 31 
c. Biologische Psychologie . . . . . . . . . . 32

2. Seelenleben und Kulturwelt . . . . . . . . . . . 36

a. Gemeinschaftspsychologie (Völker-Ps., Sozial-Ps.) . . 36

b. Historische Psychologie . . . . . . . . . . . . . 38

c. Kulturpsychologie im engeren Sinne . . . . . . . . 39

II. DIFFERENZIERUNGEN DES SEELENLEBENS . . . . . . . . 40

1. Differentielle Psychologie. Charakterologie . . . . . . 40

2. Entwicklungspsychologie. . . . . . . . . . . . . . 43

3. Kindes- und Jugend-Psychologie . . . . . . . . . . 45

4. Psychopathologie . . . . . . . . . . . . . . . . 47

a. Abnormität und Normalität . . . . . . . . 47

b. Tiefenpsychologie . . . . . . . . . . . . 50

5. Tierpsychologie . . . . . . . . . . . . . . . . 54

III. PRAKTISCHE ANWENDUNGEN DER PSYChOLOGIE. . . . . 56

1. Psychologie und Leben . . . . . . . . . . . . 56

2. Problemkreise. . . . . . . . . . . . . . 58

3. Einwände . . . . . . . . . . . . . 61

\section{DRITTES KAPITEL}

DAS MATERIAL DER PSYCHOLOGIE U N D DIE METHODEN SEINER GEWIN N UNG

I. SELBSTERFASSUNG UND FREMDERFASSUNG . . . . . . . 67

1. Selbsterfassung . . . . . . . . . . . . 67

2. Die Erfassung des Fremdseelischen. . . . . . . . 73

II. BEOBACHTUNG DES NATÜRLICHEN VERHALTENS . . . . . 76

1. Allgemeines. . . . . . . . . . . . . . . . . 76

2. Systematische Beobachtungsmethoden . . . . . . 78

a. Psychographie . . . . . . . . . . . . 78

b. Kasuistik . . . . . . . . . . . . . . . . . . . 79

c. Beobachtung von Entwicklungsabläufen . . . . . . 79

III. EXAKTE METHODEN . . . . . . . . . . . . . . . 80

1. Experiment und Messung . . . . . . . . . . . 80

2. Hauptarten des psychologischen Experiments . . . . . 87

a. Reaktionsversuche . . . . . . . . . . 87

b. Eindrucksversuche . . . . . . . . . . . . 88

c. Ausdrucksmethoden . . . . . . . . . . . . 89

d. Selbsterfassungsmethoden . . . . . . . . . . 89

e. Leistungsmethoden . . . . . . . . . . . . . . 89

IV. FERNMETHODEN . . . . . . . . . . . . . . 90

1. Erhebung .. . . . . . . . . . . . . 90

2. Sammlung .. . . . . . . . . . . . . . . 92

3. Historische Methoden . . . . . . . . . . . 93 


\section{VIERTES KAPITEL}

PERSONALISTISCHEGRUNDLEGUNG

DER P Y Y HOIOG I E

I. DAS SUbSTRAT DES SEELISChen . . . . . . . . . . . . 95

1. Fragen . . . . . . . . . . . . . . . 96

2. Definitionen . . . . . . . . . . . . . . . . . 98

II. LEBEN UND ERLEBEN

1. Die Modi des Lebens. . . . . . . . . . . . . . . . 99

2. Das Erleben . . . . . . . . . . . . . . . 102

a. Spaltung. . . . . . . . . . . . . . . . . 102

b. Erscheinen . . . . . . . . . . . . . 105

III. DAS PSYCHISCHE. . . . . . . . . . . . . . . . . . . 108

1. Das aktuelle Erleben . . . . . . . . . . . . . 108

a. „Erlebnis”. . . . . . . . . . . . . . . . 108

b. Phaenomene . . . . . . . . . . . . . 109

c. Zustände und Akte . . . . . . . . . . . . . . 110

2. Dispositionen . . . . . . . . . . . . . . . 111

a. Unselbständigkeit . . . . . . . . . . . . . 112

b. Spielraumbreite. . . . . . . . . . . . . . . . . 112

c. Rüstung und Richtung . . . . . . . . . . . . 113

d. Variabilität . . . . . . . . . . . . . 113

e. „Psychisch” . . . . . . . . . . . . . . . . 115

3. Person und Persönlichkeit . . . . . . . . . . . 115

4. Das Verhältnis des Psychischen zum Physischen . . . . 117

IV. DIE PERSONALE Welt. . . . . . . . . . . . . . . . . 123

1. Die Modi der personalen Welt. . . . . . . . . . . 123

2. Die Beziehung Person/Welt. . . . . . . . . . . . . 125

a. Wechselbestimmung. . . . . . . . . . . . . . . 125

b. Qualität der Person/Welt-Beziehung . . . . . . . 126

V. DIE PERSONALEN DIMENSIONEN . . . . . . . . . . . . 128

1. Die Aussen/Innen-Dimension . . . . . . . . . . . . 129

a. Aussen/Innen . . . . . . . . . . . . . . . . . 129

b. Gegenwart . . . . . . . . . . . . . . . . . . . 130

c. Die zwei Äste. . . . . . . . . . . . . . . . . . 131

2. Eigenpersonale Dimensionen . . . . . . . . . . 133

a. Allgemeines . . . . . . . . . . . . . . . . . 133

b. Der Eigenraum der Person . . . . . . . . . . . . 134

c. Die Eigenzeit der Person . . . . . . . . . . . . . 135

3. Dimensionale Wechselbestimmung von Person und Welt 136

a. Erweiterung . . . . . . . . . . . 136

b. Umzentrierung . . . . . . . . . . . . . . . . . 137

c. Objektivation und Subjektivation der Dimensionen . 137

4. Zur Psychologie der Dimensionen . . . . . . . . . 139

GLIEDERUNG DES STOFFES. . . . . . . . . . . . . . . 141 


\title{
ZWEITER HAUPTTEIL
}

\section{SINNESWAHRNEHMUNG}

\author{
FUNFTES KAPITEL
}

GR UNDBEGRIFEE UND GRUNDTATSACHEN

I. WAHRNEHMUNG UND EMPFINDUNG .......... . . 145

II. GESTALT UND UNGESTALT . . . . . . . . . . . . . . 149

III. VERSCHIEDENHEIT UND GEMEINSCHAFT DER SINNE. . . . 157

1. Sinnesmodalitäten . . . . . . . . . . . . 157

a. Die Vielheit. . . . . . . . . . . . . . . 157

b. Die Reize. . . . . . . . . . . . . . . 157

c. Die Sinnesorgane . . . . . . . . . . . . . . . . 158

d. Die spezifischen Erlebnisbereiche .. . . . . . . 162

2. Der spezifische Objektbezug der Wahrnehmung und die "spezifische Sinnesenergie" . . . . . . . . . . . 163

3. Wechselbeziehungen der Sinne. . . . . . . . . 166

\section{SECHSTES KAPITEL}

\section{DIE ENTWICKIUNG DER SINNE}

I. SENSIBILITÄT . . . . . . . . . . . . . . . . 168

II. GEGENSTÄNDLICHE UND INTROZEPTIVE WAHRNEHMÚNG . . 173

\section{SIEBENTES KAPITEL}

DIESIN NESSPEZIFISCHEN ERSCHEINUNGEN UND I H R E S Y STE M A T I K

I. DIE MODALITÄTEN DES ,FÜNFTEN" SINNES . . . . . . 178

II. GESCHMACK UND GERUCH . . . . . . . . . . . . . . 182

III. GEHÖR . . . . . . . . . . . . . . . . . . 183

1. Geräusche. . . . . . . . . . . . . . 183

2. Töne und Klänge . . . . . . . . . . . . 185

IV. GESICHT. . . . . . . . . . . . . . . . . . . . 190

1. Das System der Farben . . . . . . . . . . . . 190

2. Erscheinungsweisen der Farben . . . . . . . 194

\section{ACHTES KAPITEL}

Z U S A M M N H ̈ N G E D ER SI N N E

I. INTERSENSORIELIE WAHRNEHMUNG, INSBES. DES RAUMES UND DER ZEIT . . . . . . . . . . . . . . . . . . . 198 1. Allgemeines . . . . . . . . . . . . . . 198 
2. Raumwahrnehmung . . . . . . . . . . 200

a. Der intersensorielle Charakter . . . . . . . . 200

b. Raumwahrnehmung durch das Auge . . . . . . 201

c. Raumwahrnehmung durch den Tastsinn. . . . . . 205

d. Der Wahrnehmungsraum . . . . . . . . . . . 206

e. Räumliche Konstanz der Objekte .. . . . . . . 208

3. Zeitwahrnehmung . . . . . . . . . . . . . . 211

II. VERWANDTSCHAFT DER SINNE . . . . . . . . . . . . . 214

III. VERTRETUNG DER SINNE . . . . . . . . . . . . . 219

\section{NEUNTES KAPITEL}

TÄUSCHUNGEN, GRENZEN UND SCH WELLEN DER W A H R N E H M U N G

I. SINNESSTÄUSCHUNGEN . . . . . . . . . . . . . 223

1. Kriterien . . . . . . . . . . . . . . . 223

2. Arten der Täuschungen . . . . . . . . . . . 225

3. Ursachen .. . . . . . . . . . . . . . . . 226

a. Physikalische Täuschungen . . . . . . . . . . . 227

b. Periphere Täuschungen. . . . . . . . . . . . . 227

c. Personale (zentrale) Täuschungen . . . . . . . . 229

d. Ein Beispiel . . . . . . . . . . . . . . . . . 232

II. GRENZEN UND SCHWELLEN DER WAHRNEHMUNG. . . . . . 233

1. Der Reihencharakter der Wahrnehmungen . . . . . . 233

2. Die Schwellen und das Weber-Fechner'sche Gesetz. . . 235

a. Äussere und innere Schwellen . . . . . . . . . 235

b. Experimentelle Untersuchungen zum Weber-Fechnerschen Gesetz . . . . . . . . . . . . 237

c. Erklärungsversuche . . . . . . . . . . . . . 241

3. Personalistische Deutung der Schwellenerscheinungen. . 243

DRITTER HAUPTTEIL

GEDACHTNIS

ZEHNTES KAPITEL

M N E M E

I. MNEMISCHE ERSCHEINUNGEN IM ALLGEMEINEN . . . . . 254

II. ZUR THEORIE DER MNEMISCHEN ERSCHEINUNGEN . . . . 258

III. WIEDERHOLUNGSWIRKUNGEN. . . . . . . . . . . . 261

IV. ÜBER TIERISCHE MNEME . . . . . . . . . . . . . . 264 


\section{ELFTES KAPITEL}

PRIMITIVFORMEN DES GEDÄCHTNISSES

I. DAS UNMITTELbaRE GedëchtNis . . . . . . . . . 269

1. Zeithof und Anschauungsbild . . . . . . . . . . . 269

2. Merkfähigkeit . . . . . . . . . . . . . . . 273

3. Perseverationen . . . . . . . . . . . . . . . 276

II. DAS GebUndenE GedÄChtNis . . . . . . . . . . . . 277

1. Das Vertrautheitserlebnis . . . . . . . . . . 277

2. Verwertungswirkungen . . . . . . . . . . 282

a. Hauptformen . . . . . . . . . . . . . . . . . 282

b. „Komplex"-Theorieen . . . . . . . . . . . 283

ZWÖLFTES KAPITEL

D A S F R E I E G E D Ä C H T N I S

I. DIE GEDÄCHTNISVORSTELLUNG . . . . . . . . . 287

1. Vorstellung und Wahrnehmung . . . . . . . . . . 287

2. Vorstellungstypen . . . . . . . . . . . . . 292

3. Kenntnisse und Erinnerungen . . . . . . . . . . . . 292

II. ASSOZIATION UND EINSTELLUNG. . . . . . . . . . . 293

1. Der empirische Begriff der Assoziation . . . . . . . . 294

2. Mechanistische Assoziationstheorieen . . . . . . . 297

3. Personalistische Deutung der Assoziationen, Empfänglichkeit und Einstellung . . . . . . . . . 299

a. Stiftung von Assoziationen . . . . . . . . . . . 299

b. Wiederauslösung von Assoziationen . . . . . . 302

4. Assoziationsexperimente . . . . . . . . . . . . 304

a. Allgemein-psychologische Probleme . . . . . 306

b. Diagnostische Probleme. . . . . . . . . . . 307

\section{DREIZEHNTES KAPITEL}

ERWERB UND BESITZ VON KEN N T ISSEN

I. AlLGEMEINES ... . . . . . . . . . . . . . . . . 310

1. Gebundene und freie Bildungsinhalte. . . . . . . 310

2. Der Erwerb von Kenntnissen . . . . . . . . . . . . 312

a. Das Sich-Merken . . . . . . . . . . . . . . 312

b. Das Lernen . . . . . . . . . . . . . . . . . . . 313

II. DAS WILLENTLICHE LERNEN . . . . . . . . . . . . 315

1. Psychische Faktoren des Lernens . . . . . . . . 316

a. Lernwille . . . . . . . . . . . . . . . 316

b. Interesse . . . . . . . . . . . . . . 317 
c. Intelligenz . . . . . . . . . . . . . . . . 319

2. Experimentelle Untersuchungen . . . . . . . . . . . 323

a. Aufgaben und Methoden . . . . . . . . . . . 323

b. Umfang des Lernstoffes . . . . . . . . . . . . . 325

c. Fraktionierung . . . . . . . . . . . . . . . . . 326

d. Verteilung der Wiederholungen . . . . . . . . . . 328

e. Lerntempo . . . . . . . . . . . . . . . . . . 329

III. BEHALTEN UND VERGESSEN VON KENNTNISSEN . . . . . . 330

1. Der Lernverlust . . . . . . . . . . . . . . . . . . 330

2. Experimentelle Untersuchungen . . . . . . . . . . . 332

3. Auslösung der Reproduktionen. . . . . . . . . . . . 334

a. Freisteigende Vorstellungen . . . . . . . . . . . . 334

b. Einlinige und vielseitige Auslösung . . . . . . . . . 334

c. Das Sich-Besinnen . . . . . . . . . . . . 335

\section{VIERZEHNTES KAPITEL}

ER I N N E R U N G

I. Allgemeines . . . . . . . . . . . . . . . . . . . . 337

1. Wesen der Erinnerung . . . . . . . . . . . . . . . 337

2. Zur Entwicklungspsychologie der Erinnerung . . . . . 341

II. DER SUBJEKTBEZUG DER ERINNERUNG. . . . . . . . . . 344

1. Kontinuität und Spaltung . . . . . . . . . . . . . 344

2. Erinnerungswandel und Erinnerungsmythos . . . . . . 347

III. DER OBJEKTBEZUG DER ERINNERUNG . . . . . . . . . . 349

1. Erinnerungstreue und ihre Untersuchung . . . . . . . 349

2. Ergebnisse der Aussageuntersuchungen . . . . . . . 352

a. Grenzen der Erinnerungstreue . . . . . . . . . . 352

b. Wahrnehmung und Aufmerksamkeit . . . . . . . 352

c. Verhörs- und Suggestions-Wirkung. . . . . . . . . 354

d. Temporalisation . . . . . . . . . . . . . . . . . 357

e. Alltäglichkeit und Ungewöhnlichkeit . . . . . . . 358

f. Gestaltungstendenzen . . . . . . . . . . . . . . 359

g. Charakterologische und biologische Faktoren . . . . 361

3. Thesen über praktische Anwendungen . . . . . . . 363

VIERTER HAUPTTEIL

DENKEN und PHANTASIE

FUNFZEHNTES KAPITEL

D A D E N K E N

I. DENKPSYCHOLOGIE . . . . . . . . . . . . . . 367

1. Allgemeines . . . . . . . . . . . . 367 
2. Erscheinungsweisen des Denkens . . . . . . . 369

a. Das „Denken an Ețwas" . . . . . . . . . . . . 370

b. Das „Wissen um Etwas" . . . . . . . . . . . . . 370

c. Das "Verstehen von Abstraktem" . . . . . . . . . 371

d. Das „Nachdenken über ein Problem”. . . . . . . . 372

II. GEDANKE UND VORSTELLUNG . . . . . . . . . . . . . 372

1. Unterschiede und Beziehungen . . . . . . . . 372

2. Zeichen und Symbole . . . . . . . . . . 375

III. DER DENKVOLLZUG. . . . . . . . . . . . . . 382

1. Denkantriebe . . . . . . . . . . . . . 383

a. Niedere und höhere Denkantriebe . . . . . . . 383

b. Situationsbedingtheit und Denkschwelle . . . . . 385

c. Problembewusstsein . . . . . . . . . . . . 386

d. Denkimperative . . . . . . . . . . . . . . 387

2. Denkhandlung und Denkbereitschaft . . . . . . . 390

a. Denken als Tätigkeit . . . . . . . . . . . . . . . 390

b. Grenzen der Aktivität. Denkbereitschaft . . . . . 392

\section{SECHSZEHNTES KAPITEL}

H A UPT A R T E N DER GE D A N K E N

I. GEgENSTANDSGEDANKEN . . . . . . . . . . . . . 396

1. Das Denken individueller Gegenstände . . . . . . . 396

2. Das Denken allgemeiner Gegenstände . . . . . . 398

II. BEZIEHUNGSGEDANKEN . . . . . . . . . . . . . . . . 402

1. Praekategoriale Beziehungen . . . . . . . . . . . . 403

2. Gleichheit, Verschiedenheit, Ähnlichkeit. . . . . . 405

3. Kausalität und Finalität . . . . . . . . . . . . . . 407

III. SINNGEDANKEN . . . . . . . . . . . . . . . . . . . 414

\section{SIEBZEHNTES KAPITEL}

DEN KDISPOSITIONEN BEI MEN SCH UND TIER

I. DER MENSCHLICHE INTELLEKT . . . . . . . . . . 418

1. Terminologisches. . . . . . . . . . . . . . . . . . 418

2. Personale Bedeutung des Intellekts . . . . . . . . . 419

a. Dienstbedeutung. . . . . . . . . . . . . . . . 419

b. Strahlbedeutung . . . . . . . . . . . . . . . 422

II. GRADE UND ARTEN DER MENSCHLICHEN INTELLIGENZ . . . 422

1. Bedeutung der Intelligenzprüfungen . . . . . . . 422

2. Begriffsbestimmung der Intelligenz . . . . . . . 424

3. Erforschung und Prüfung der Intelligenzgrade . . . . 426

4. Intelligenztypen . . . . . . . . . . . . . . 429

a. Reaktiv/Spontan ... . . . . . . . 429 
b. Objektiv/Subjektiv. . . . . . . . . . . . . 429

c. Analytisch/Synthetisch . . . . . . . . . . . . 430

d. Theoretisch/Praktisch . . . . . . . . . . 430

5. Die einzelnen Intelligenzfunktionen . . . . . . . . . 431

6. Talente . . . . . . . . . . . . . . . . . . . . . 433

a. Wesen des Talents. . . . . . . . . . . . . . . . 433

b. Häufigkeitsverteilung der Talente . . . . . . . . 435

c. Analyse der Talente . . . . . . . . . . . . . . . 436

III. TIERISCHE INTELLIGENZ . . . . . . . . . . . . . . . . 438

1. Das Problem . . . . . . . . . . . . . . . . . . . 438

2. Einsicht . . . . . . . . . . . . . . . . . 440

3. Intelligente Neuleistungen. . . . . . . . . . . . . . 441

4. Die Grenzen der tierischen Intelligenz . . . . . . . . 442

\section{ACHTZEHNTES KAPITEL}

P H A N T A S I E

I. WESEN DER PHANTASIE . . . . . . . . . . . . . . 446

1. Bewusstseinspsychologische Betrachtung . . . . . . . 446

2. Personalistische Betrachtung . . . . . . . . . . . 447

a. Unstimmigkeit zur Objektwelt . . . . . . . . 447

b. Spontaneität . . . . . . . . . . . . . . 4 449

c. Symptomatik und Symbolik . . . . . . . . . . . 451

d. Schöpfung .. . . . . . . . . . . . . . . . 454

e. Gebundene Phantasiewirkungen . . . . . . . . . 456

II. Phantasie im alltagsleben . . . . . . . . . . . . . 457

1. Gegenwarts- und Vergangenheits-Phantasieen . . . . . 457

a. Gegenwart . . . . . . . . . . . . . . . . 457

b. Vergangenheit . . . . . . . . . . . . . 459

2. Zukunfts-Phantasieen .. . . . . . . . . . . 460

a. Vorwegnahme. . . . . . . . . . . . . . . 460

b. Wunsch-Phantasieen . . . . . . . . . . . 462

c. Furcht-Phantasieen . . . . . . . . . . . . . . . 462

d. Objektivierende Vorwegnahme. . . . . . . . . . . 464

3. Dauerphantasieen . . . . . . . . . . . . . 465

\section{NEUNZEHNTES KAPITEL}

SON DERFUNKTIONEN DER PHANTASIE

(TR ̈ U M N, SPIELEN, SCHAFFEN)

I. DAS tRÄUMen . . . . . . . . . . . . . . . . . . . . 469

1. Traumreize . . . . . . . . . . . . . . . . . . . . 470

a. Sensorische Reize . . . . . . . . . . . . 470

Stern, Psychologie $\quad$ II $^{*}$ 
b. Mnemische Reize . . . . . . . . . . . . . . . 472

2. Traumphantasieen . . . . . . . . . . . . . . . 473

a. Dimensionale Verwandlungen . . . . . . . . . 474

b. Verändertes Ich-Erleben . . . . . . . . . . . . 475

c. Traumdeutung . . . . . . . . . . . . . . . . 477

II. DAS SPIElEN . . . . . . . . . . . . . . . . . . . . 481

1. Das Spiel in den verschiedenen Lebensstufen . . . . 481

2. Spieltheorieen. . . . . . . . . . . . . . . . . . . 484

a. Der personalistische Grundgedanke . . . . . . . . 484

b. Gegenwartstheorieen . . . . . . . . . . . . . 485

c. Vergangenheitstheorie . . . . . . . . . . . . 491

d. Zukunftstheorieen . . . . . . . . . . . . . . . 493

III. DAS SChAFFEN. (INSBes. DAS KÜNStlerische SChaffen). . 496

1. Phantasma und Werk . . . . . . . . . . . . . . . 496

2. Individuelles und kollektives Schaffen . . . . . . . . 498

a. Kunstwerk und Mythos . . . . . . . . . . . . . 498

b. Die Individualisierung des Schaffens . . . . . . . . 500

3. Originalität und Verantwortung . . . . . . . . . 501

4. Die Welt des Scheins . . . . . . . . . . . . . . . . 504

5. Wissenschattliche Phantasie. . . . . . . . . 505

\section{FÜNFTER HAUPTTEIL \\ STREBEN. HANDELN. LEISTEN}

\section{ZWANZIGSTES KAPITEL}

PRIMITIVFORMENDESTUNS UND STREBENS

I. REFLEXE . . . . . . . . . . . . . . . . . . . . . 514

1. Angeborene Reflexe . . . . . . . . . . . . . . 514

2. Erworbene Reflexe . . . . . . . . . . . . 516

II. TRIEBE . . . . . . . . . . . . . . . . . . . . . . . 520

1. Trieb als Richtungsdisposition. . . . . . . . . . 520

2. Humantriebe . . . . . . . . . . . . . . . 522

3. Drang und Hemmung . . . . . . . . . . . . . . . 522

III. BedÜRfNisse . . . . . . . . . . . . . . . . . . . . 527

1. Dynamik der Bedürfnisse . . . . . . . . . . . . . . 527

2. Innere und äussere Bedingungen der Bedürfnisse. . . 528

IV. InstinktF. . . . . . . . . . . . . . . 534

1. Instinkte als Rüstungsdispositionen . . . . . . . . . 534

2. Entwicklung und Elastizität der Instinkte . . . . . 537

a. Entwicklung der Instinkte. . . . . . . . . . . 537

b. Elastizität der Instinkte. . . . . . . . . . 538

3. Die Instinkte beim Menschen . . . . . . . . . . . . 540 


\section{EINUNDZWANZIGSTES KAPITEL}

D A S W OLL N

I. Allgemeines . . . . . . . . . . . . . . . . . . . . 546

1. Begriff . . . . . . . . . . . . . . . . . . . . . . 546

2. Beispiele . . . . . . . . . . . . . . . . . . . . . 548

3. Körperliche Merkmale des Wollens . . . . . . . . . . 550

4. Zukunftsbezug des Wollens .. . . . . . . . . . . . 551

5. Fremdbezug und Selbstbezug des Wollens . . . . . . . 553

a. Fremdbezug . . . . . . . . . . . . . . . . . . 554

b. Körperlicher Selbstbezug . . . . . . . . . . . . 555

c. Psychischer Selbstbezug . . . . . . . . . . . . . 557

II. motivation des wollens. . . . . . . . . . . 558

1. Phaenomotive. . . . . . . . . . . . . . 559

2. Genomotive und Phaenomotive . . . . . . . . 563

a. Homogonie der Motive . . . . . . . . . . . . 563

b. Heterogonie der Motive. . . . . . . . . . . . . . 565

c. Weitere Bedeutung der Phaenomotive . . . . . . . 568

d. Experimentelle Motivuntersuchungen . . . . . . 570

III. KÖNNEN UND VERSUCHEN . . . . . . . . . . . . . . . 570

1. Das Könnensbewusstsein . . . . . . . . . . . . 570

2. Das unterwertige Könnensbewusstsein . . . . . . . . 572

3. Die Versuchshandlung . . . . . . . . . . . . . . . 573

4. Das überwertige Könnensbewusstsein . . . . . . . 574

\section{ZWEIUNDZWANZIGSTES KAPITEL}

DER A BLA UF DER WILLENSHANDLUNGEN

I. DER WILlENSRUCK . . . . . . . . . . . . . . . 577

II. DIE DURCHFÜHRUNG . . . . . . . . . . . . . . . 579

1. Einleitendes . . . . . . . . . . . . 579

2. Dynamik . . . . . . . . . . . . . . . . . 580

3. Bewusstsein und Unbewusstheit . . . . . . . . . . . 583

4. Vorsatz . . . . . . . . . . . . . . 584

5. Planung .. . . . . . . . . . . . . . 586

a. Gestalt der Planung . . . . . . . . . . . . . . . 586

b. Typen der Planhandlung . . . . . . . . . . . . . 588

III. DiE NACHPERIODE . . . . . . . . . . . . . . . . . 590

1. Motivationen nach der Tat . . . . . . . . . . . 590

2. Beurteilung der Tatmotive . . . . . . . . . . 594 


\section{DREIUNDZWANZIGSTES KAPITEL}

DIE WI LLEN S ISPOSITIONEN

I. WillenshaltUNG UND GESINNUNG .......... . 598

1. Willenshaltung . . . . . . . . . . . . . . . 598

2. Gesinnung . . . . . . . . . . . . . . . 601

II. ZUR THEORIE DES ChARAKTERS . . . . . . . . . . . . . 603

III. CHARAKTERZÜGE UND CHARAKTERTYPEN . . . . . . . . 609

1. Telische Züge und Typen . . . . . . . . . . . . . . 609

a. Das personale Zwecksystem . . . . . . . . . . . . 609

b. Telische Charaktertypen . . . . . . . . . . 613

2. Dynamische Züge und Typen . . . . . . . . . . 617

3. Strukturelle Züge und Typen . . . . . . . . . . . . 619

\section{VIERUNDZWANZIGSTES KAPITEL}

S U G G E T T O N

I. DER BEGRIFF . . . . . . . . . . . . . . . . . . 625

II. EMPFANG DER SUGGESTION. . . . . . . . . . . . . . . 628

III. AUSC̈BUNG DER SUGGESTION . . . . . . . . . . . . . . 630

1. Suggestive Persönlichkeiten . . . . . . . . . . . . . 630

2. Massen- und Sach-Suggestion . . . . . . . . . . 631

3. Autosuggestion . . . . . . . . . . . . . . . . . . 633

4. Kontrasuggestion . . . . . . . . . . . . . . . . 634

IV. EXPERIMENTELLE UNTERSUCHUNGEN . . . . . . . . 635

1. Suggestive Faktoren . . . . . . . . . . . . . . . . 635

2. Prüfungen der Suggestibilität . . . . . . . . . . 637

FÜNFUNDZWANZIGSTES KAPITEL

DIELEISTUNG UND IHRE PERIODIK

I. OBJEKTIVE UND PERSONALE LEISTUNG. . . . . . . . . . 639

1. Objektive Leistung. . . . . . . . . . . . . . . . . 639

2. Personale Leistung . . . . . . . . . . . . . . . . . 640

3. Das Verhältnis beider Leistungsarten. Die Selbstbeanspruchung. . . . . . . . . . . . . . . . . . . 641

II. PERIODIZITÄT . . . . . . . . . . . . . . . . . . . 644

1. Allgemeines . . . . . . . . . . . . . . . . 644

2. Kleinst-Periodik (Rhythmik) . . . . . . . . . 645

3. Tageswellen . . . . . . . . . . . . . . . . . . 648

4. Perioden höherer Ordnung . . . . . . . . . . . . 651 


\section{SECHSUNDZWANZIGSTES KAPITEL}

A U F M E R K S A M K E I T

I. ZIELBEWUSSTSEIN . . . . . . . . . . . . . . . . 654

1. Bewusstseinsstruktur . . . . . . . . . . . . . 654

2. Richtungen der Aufmerksamkeit . . . . . . . . . 657

II. DYNAMIK DER AUFMERKSAMKEIT . . . . . . . . . . . . 658

1. Konzentration und Zerstreutheit. . . . . . . . . . . 658

2. Das Aufmerksamkeitsfeld . . . . . . . . . . . . . . 662

3. Ablaufsweisen der Aufmerksa mkeit. . . . . . . . 666

III. ÄUSSERE UND INNERE BEDINGUNGEN DER AUFMERKSAMKEIT 667

1. Reaktive und spontane Aufmerksamkeit. . . . . . . . 667

2. Konstanz und Wechsel im Aufmerksamkeitsverhalten. . 670

IV. ZUR DIFFERENTIELLEN PSYCHOLOGIE DER AUFMERKSAMKEIT 673

1. Gegenständliche Typen . . . . . . . . . . . . . 673

2. Dynamische Typen . . . . . . . . . . . . 674

SIEBENUNDZWANZIGSTES KAPITEL

$$
\text { Ü B U N G U N D E R M Ü D U N G }
$$

I. ÜBUNG . . . . . . . . . . . . . . . . . . . . 677

1. Reifung, $\ddot{C}$ bung, Einstellung . . . . . . . . . . 677

2. Akute und Dauer-Čbung . . . . . . . . . . . . 680

3. Mitübung . . . . . . . . . . . . . . . . . . . . . 684

4. Übbarkeit und Übungsfähigkeit . . . . . . . . . 686

a. Ubbarkeit . . . . . . . . . . . . . . . . . 686

b. Ubungsfähigkeit . . . . . . . . . . . . . . . 689

II. ERMÜDUNG . . . . . . . . . . . . . . . . . . . . 691

1. Ermüdung und Müdigkeit . . . . . . . . . . . . . . 691

a. Müdigkeit . . . . . . . . . . . . . . 691

b. Ursachen der Ermüdung . . . . . . . . . . . . 693

2. Spezifische und ausstrahlende Ermüdung . . . . . . . 695

3. Ermüdungsmessungen . . . . . . . . . . . . . . . 698

4. Erholung. Übermüdung. Sättigung . . . . . . . . . 700 


\section{SECHSTER HAUPTTEIL GEFÜHL}

\section{ACHTUNDZWANZIGSTES KAPITEL}

D I E GEF ÜH LSPSYCHOLOGIE NACH I H REN BISHERIGEN THEORIEEN UND BEFUNDEN

I. Ältere theorieEN UND ERGeBNisSe . . . . . . . . 706

1. Analyse und Klassifikation der Gefühle . . . . . . . 706

a. „Elementargefühle" . . . . . . . . . . . . 706

b. Das Lust/Unlust Schema . . . . . . . . . . . . . 707

c. Wundt's System . . . . . . . . . . . . . . 710

d. ,Gefühlsempfindungen" (Stumpf) . . . . . . . . . 711

2. Körperliche Grundlagen des Gefühlslebens. . . . . . . 712

a. Korrelationen . . . . . . . . . . . . . . . . . 712

b. Die James-Lange'sche Hypothese . . . . . . . . . 715

II. NEUERE THEORIEEN UND GESICHTSPUNKTE . . . . . . . . 717

1. Biologisch fundierte Gefühlstheorieen . . . . . . . . 717

a. Biologische Polarität . . . . . . . . . . . . . . 717

b. Grenzen der biologischen Polaritätstheorie . . . . 719

c. Innere Sekretion. . . . . . . . . . . . . . . . 722

2. Rein psychologische Standpunkte . . . . . . . . 723

a. „Emotionalismus”. . . . . . . . . . . . . . . 723

b. „Subjektivität” der Gefühle . . . . . . . . . . . 724

\section{NEUNUNDZWANZIGSTES KAPITEL}

PERSONALE MERKMALE DER GEF ÜHLE

I. PERSONNÄHE DER GEFÜhle . . . . . . . . . . . . . . 729

II. POlarität UNd AMbIVAlENZ der GefÜhle . . . . . . . 733

1. Doppelte Polarität . . . . . . . . . . . . . . . . . 733

2. Asy mmetrie des Gefühlspole . . . . . . . . . . . 739

3. Ambivalenz . . . . . . . . . . . . . . . . . . . . 741

III. ABSTUFUNGEN DER GEFÜHLE . . . . . . . . . . . . . . 743

1. Formale Abstufungen . . . . . . . . . . . . . . . 744

a. Stärke . . . . . . . . . . . . . . . . . . 744

b. Breite . . . . . . . . . . . . . . . . . . 746

c. Dauer . . . . . . . . . . . . . . . . . . . 747

2. Personale Abstufungen . . . . . . . . . . . . . . . 747

a. Ticfe. . . . . . . . . . . . . . . . 748

b. Echtheit . . . . . . . . . . . . . 749

c. Ernst . . . . . . . . . . . . . . . . 750

d. Niveau . . . . . . . . . . . . . 752 


\section{DREISSIGSTES KAPITEL}

ZEITBEZUG DER G E F Ü H $\mathbf{L}$ E

I. DAS ZEITSCHEMA . . . . . . . . . . . . . . . . . . 754

II. PRAESENZGEFÜHLE . . . . . . . . . . . . . . . . . . 755

1. Zumutesein. Stimmung. Affekt . . . . . . . . . . . 756

a. Zumutesein . . . . . . . . . . . . . . . . . . . 756

b. Stimmung. . . . . . . . . . . . . . . 759

c. Affekt . . . . . . . . . . . . . . . . 761

2. Gefühlssteuerungen und Gefühlstönungen . . . . . . 762

a. Gefühlssteuerungen. . . . . . . . . . . . . 762

b. Gefühlstönungen . . . . . . . . . . . . . . 764

III. VORGREIFENDE GEFÜHLE . . . . . . . . . . . . . . . 766

1. Gefühl als Vorstufe . . . . . . . . . . . . . 766

2. Antriebs- und Ahnungsgefühle . . . . . . . . . 767

a. Antriebsgefühle . . . . . . . . . . . . . . . . . 768

b. Ahnungsgefühle . . . . . . . . . . . . . . . . 770

3. Erwartung. Furcht. Hoffnung . . . . . . . . . . . 774

a. Erwartung. . . . . . . . . . . . . . . 774

b. Furcht . . . . . . . . . . . . . . 776

c. Hoffnung . . . . . . . . . . . . . . . . . . 780

IV. RÜCKGREIFENDE GEFÜHLE . . . . . . . . . . . . . . . 782

1. Positive Gefühlsbeziehungen zur Vergangenheit . . . . 782

2. Negative Gefühlsbeziehungen zur Vergangenheit . . . 786

\section{EINUNDDREISSIGSTES KAPITEL}

GEF UUH LS DISPOSITION E N

I. RÜSTUNGSDISPOSITIONEN. INSBES. TEMPERAMENTE . . . . 788

II. RICHTUNGSDISPOSITIONEN (NEIGUNGEN UND INTERESSEN). . 791

ABSCHLUSS

BIBLIOGRAPHIE

I. ALLGEMEINES . . . . . . . . . . . . . . . . . . 801

A. Sammelwerke und Zeitschriften . . . . . . . . . . . 801

1. Sammelwerke, Wörterbücher, Bibliographieen . . . . 801

2. Zeitschriften des deutschen Sprachgebiets. . . . . . 801

3. Amerikanische Zeitschriften . . . . . . . . . . . 802

4. Zeitschriften des übrigen Auslandes . . . . . . . . 802

B. Gesamtdarstellungen der Psychologie ihrer Sondergebiete und ihrer Geschichte. Grundsätzliche Fragen . . . . . 803 
II. SINNESWAHRNEHMUNG . . . . . . . . . . . . . . . . 807

III. GEDÄCHTNIS UND VORSTELLUNGEN . . . . . . . . . . 809

IV. Denken Und Phantasie. . . . . . . . . . . . . . . . 811

V. STREBEN, HANDELN, LEISTEN . . . . . . . . . . . . . 814

VI. GEFÜHL. . . . . . . . . . . . . . . . . . . . . . . 815

VII. CHARAKTEROLOGie. TYPENLEhREN (Ergänzungen zu den Teilen Ib, V, VI.) . . . . . . . . . . . . . . 817

SACHREGISTER

NAMENREGISTER 


\section{VORWORT}

Ein Buch, das die "Allgemeine Psychologie" grundsätzlich und umfassend behandelt, ist seit langem in deutscher Sprache nicht geschrieben worden. Verschiedene Gründe spielten hierbei mit. Teils nahm die Spezialarbeit auf den vielen, sich schnell entwickelnden, Einzelgebieten die Kräfte in Anspruch. Teils hatte die theoretische Besinnung zu Einstellungen gefïhrt, die gegensätzlich oder unvereinbar zu einander waren und eine Zusammenschau verhinderten. Von jedem der verschiedenen Standpunkte aus erschien das Seelenleben unter einer bestimmten Perspektive, die den anderen Perspektiven nicht gerecht werden konnte. So hatten wir lauter Psychologieen: Elementen- und Gestalt-Psychologie, verstehende und erklärende Psychologie, Tiefen-, Bewusstseins-, Verhaltens-Psychologie u.s.w. - aber nicht die allgemeine Psychologie.

Nun kann jedoch keine Wissenschaft bestehen und fortschreiten, wenn sie nicht von Zeit zu Zeit den Versuch einer solchen Gesamtdarstellung macht. Diese darf freilich nicht nur eine Verknüpfung der verschiedenen Methoden, Ergebnisse und Standpunkte enthalten; sie muss auf einer, das Ganze tragenden, einheitlichen Grundlage ruhen.

Das vorliegende Buch stellt sich die Aufgabe einer solchen Gesamtdarstellung. Die geforderte Grundlage wird durch die perso nal ist $i$ sche Theorie gegeben, die hier zum ersten Male ihre Tragfähigkeit zur Begründung und Sinndeutung einer empirischen Einzelwissenschaft zu erweisen hat. Es wird sich zeigen, dass die personalistischen Voraussetzungen die anderen Theorieen und Gesichtspunkte (abgesehen von den rein mechanistischen) nicht ausschliessen, sondern zn ihnen in fruchtbaren Beziehungen stehen, sodass trotz der Einheitlichkeit der Theorie doch die obєn erwähnte Einseitigkeit vermieden ist.

Wenn sich die neue Theorie auch auf allen Teilgebieten der Psychologie auswirkt, so werden doch manche Probleme und Bereiche im 
stärkerem Mafse durch sie beeinflusst als andere. Es sei in dieser Hinsicht vor allem auf die veränderte Auffassung und Darstellung des Gefühlsproblems, ferner auf die Behandlung des Denkens und des Wollens hingewiesen.

Psychologie wird definiert als "die Wissenschaft von der erlebenden und erlebnisfähigen Person" (S. 99). Das unmittelbare Objekt der Psychologie, das Erleben, soll also dadurch erkannt und gedeutet werden, dass es bezogen wird aut seinen Träger, die sinnhaltige, einheitliche, lebendige Person. Das Leben der Person in jener Unmittelbarkeit, die noch vor jeder Scheidung von Physischem und Psychischem liegt, ist nicht eigentliches Thema der Psychologie, sondern einer ihr vorgeordneten Wissenschaft: der Personwissenschaft oder "Personalistik". Wie sich aus ihr die Kategorieen und Probleme der Psychologie ergeben, ist im IV. Kapitel dieses Buches dargestellt, wobei freilich der begrenzte Raum eine grosse Knappheit auferlegte. Als Ergänzung des Kapitels mögen daher andere personalistische Schriften, insbesondere die "Studien zur Personwissenschaft" Band $I$ "Personalistik als Wissenschaft" (I930) herangezogen werden $\left.{ }^{1}\right)$.

Unbeschadet dieser Formulierung, die ins Philosophische reicht, stellt das Buch doch die Psychologiealseine empirische Spezialwissenschaft dar. Da es sich aber um allgemeine Psychologie handelt, werden Probleme der Nachbarwissenschaften und Sondergebiete $\left.{ }^{2}\right)$ nur gestreift, soweit es das eigentliche Thema erfordert. Sind ja auch diese Gebiete in den letzten Jahren intensiv gepflegt und zusammenfassend behandelt worden.

Auch innerhalb des Rahmens der allgemeinen Psychologie war eine allseitige Berücksichtigung der Literatur aus inneren und äusseren Gründen unmöglich. Das Buch war von vorn herein nicht als ein Kompendium gedacht, sondern als neue Grundlegung unserer Wissenschaft. Diese Bestimmung wäre gefährdet worden, wenn die ganze Fülle der Einzelbefunde, Gesichtspunkte und methodischen Details zu ihrem Recht gekommen wäre. Ich musste mich begnügen, eine Auslese dessen zu geben, was mir für entscheidende Probleme

1) Der ursprïnglich bcabsichtigte Band II diescr "Studien" wird intolge der veränder. ten Verhaltnisse nicht mehr geschrieben werden. An seine Stelle tritt das vorliegende Buch.

Verieiesen sei auch auf das Buch "Die menschliche Persönlichkeit". Doch muss beachtet werden, dass seit seiner Abfassung $\left(19 x_{7}\right)$ die Theorie der Person manche inderungen und Erweiterungen erfahren hat.

2) Z.B. Physiologie, Anatomie, Soziologie. - Kindes- und Völker-Psychologie; differentielle, angewandte Psychologie. Psychodiagnostik. 
der allgemeinen Psychologie wesentlich zu sein schien. Diese Auslese erfuhr dann noch eine weitere Verschärfung durch Umstände, die mich von der Basis der erforderlichen Materialbeschaffung trennten.

Dennoch versuchte ich, soweit irgend möglich, dem Buch den Charakter einer Gesamtorientierung zu wahren. Ganz und gar dienen dieser Aufgabe die ersten drei Kapitel, die in referierender Form eine Ubersicht über Gebiete, Aufgaben und Methoden geben. Im weiteren Text habe ich Theorieen und Ergebnisse sehr verschiedenartiger Herkunft einzubeziehen gesucht; wo ein näheres Eingehen sich verbot, sollen kürzere Hindeutungen und bibliographische Angaben dem Leser den Weg zeigen.

Gelegentlich beschäftigt sich das Buch auch mit früheren Entwicklungen unserer Wissenschaft. Seit den letzten Jahrzehnten des 19. Jahrhunderts hat sich die Psychologie völlig geändert. Aber nun besteht die Gefahr, dass mit dem Abrücken von den Betrachtungsweisen jener Zeit auch die wertvollen Errungenschaften, die wir ihr zu danken haben, übersehen und vergessen werden. Hier hat gerade ein älterer Psychologe, dessen Anfänge noch unter dem unmittelbaren Eindruck jener Epoche gestanden hatten, die Pflicht, für die wïnschenswerte Kontinuität zu sorgen, und Lebensfähiges aus ihr in die weitere Entwicklung der Wissenschaft überzuleiten. Freilich ist dies, wie das Buch beweisen wird, nur möglich durch Einordnung der älteren Einsichten in ganz andere Zusammenhänge und durch teilzeise Um-Interpretation ihres Sinnes.

Die dem Buch beigegebene Bibliographie erhebt keinerlei Anspruch auf Vollständigkeit, nicht einmal auf durchgeführte Systematik der Auswahl. Die oben angedeuteten äusseren Erschwerungen der Arbeit haben sich gerade hier als besonders störend erwiesen; und wenn sie wenigstens teilweise überwunden werden konnten, so ist es auf die wertvolle und mühsame Mitarbeit von Dr. Betty Katzenstein (Hamburg) zurückzuführen, der an dieser Stelle herzlich gedankt sei. In erster Linie enthält die Bibliographie diejenigen Veröffentlichungen, auf welche im Text direkt Bezug genommen wird; dadurch konnte der Text selber von ausführlichen Zitationen trei gehalten werden. Ferner wurden Werke von führender Bedeutung, historisch wichtige Veröffentlichungen, Sammelwerke und Gesamtdarstellungen, Bibliographieen u.s.w. vorzugsweise berïcksichtigt.

Die Nichterwähnung eines Verfassers oder Werkes, im Text oder 
in der Bibliographie, bedeutet nach allem Gesagten in keiner Weise ein Werturteil.

Zwei Verleger haben Anteil an dem Zustandekommen des Buches. Der eine hatte die Notwendigkeit einer allgemeinen Psychologie früh erkannt und mich durch seine Aufforderung zur Inangriffnahme des Buches bewogen. Dem anderen Verleger, Martinus Nijhoff, spreche ich meinen herzlichen Dank dafür aus, dass er das - inzwischen heimatlos gewordene - Buch übernommen und dadurch die Fertigstellung und das Erscheinen möglich gemacht hat.

Hamburg,

z.Z. Duke University, Durham N.C.

WILLIAM STERN 20.XI.I934. 


\section{ERSTER HAUPTTEIL}

GRUNDRISS 
Das vorliegende Buch ruht auf zwei Stützen.

Die eine besteht in der ps y chologis chen Facharb e it der letzten Jahrzehnte. Diese wird nicht immer explizit zur Darstellung kommen; aber sie ist an jedem Kapitel, an jedem Satz direkt oder indirekt beteiligt. Die Psychologie steht heute da als ein wissenschaftliches $\mathrm{F} \mathrm{a} \mathrm{k} \mathrm{t} \mathrm{u} \mathrm{m}$, das sich jedem, der dazu gehört, mit sachlicher Wucht auferlegt, und als eine lebendige Arbeitsg e $\mathrm{m}$ e in $\mathrm{s} \mathrm{ch}$ a $\mathrm{ft}$, in welche sich jeder einzufügen hat, der einen individuellen Beitrag geben will. Auch dort, wo unser Buch kritisch oder ablehnend zu Gesichtspunkten, Theorieen und Methoden der modernen Psychologie Stellung nimmt, weiss es sich ihrer Arbeit aufs Stärkste verpflichtet.

Aber diese Einordnung in das grosse Gefüge des Faches darf nicht verhindern, dass das Buch einen ganz bestimmten $\mathrm{n}$ e $\mathbf{u}$ e $\mathrm{n}$ Standpunkt gegenüber der Gesamtheit der psychologischen Problematik einzunehmen sucht. Es ist der per s o n a lis $\mathrm{t}$ is $\mathrm{ch}$ e Standpunkt.

Die personalistische Theorie also bildet die $\mathrm{z}$ w e it e Voraussetzung dieses Buches. Sie ist ursprünglich als philosophisches Gedankensystem (des sogenannten „Personalismus”) entwickelt worden, hat aber allmählich auch den Charakter einer Spezialwissenschaft von der menschlichen Person gewonnen (,Personalistik"), die nun hier zum ersten Mal ihre Eignung erweisen soll, die Grundlage der allgemeinen Psychologie zu bilden.

Wohl ist - vom Verfasser und von Anderen - bei zahlreichen Spezialproblemen schon vielfach personalistische Betrachtungsweise mit Erfolg durchgeführt worden. Auch sind eine Reihe verwandter Strömungen in der Psychologie der Gegenwart wirksam. Aber es war bisher nur bei Ansätzen und Einzelarbeiten geblieben; auch fehlte noch grossenteils das Bewusstsein gemeinschaftlicher Zielsetzungen bei den personalistisch eingestellten Psychologen. Bemerkenswerter Weise waren es gewisse Sonderdisziplinen der Psychologie, welche schon in höherem 
Masse personalistische Einstellung gewonnen haben: so Kinderpsychologie, Charakterologie, Psychopathologie; - aber gerade die allgemeine Ps y chologie (ohne welche jene Sondergebiete in der Luft schweben) entbehrte noch dieser Neuorientierung. Hier soll sie nun versucht werden.

Der erste Hauptteil ist dazu bestimmt, über die beiden eben angedeuteten Voraussetzungen - die psychologische Facharbeit (Kap. I. - III) und die personalistische Theorie (Kap. IV) - eine Ubersicht zu geben. Er soll lediglich zur Vorbereitung dienen und muss sich auf knappe Umrisslinien beschränken. 


\title{
ERSTES KAPITEL
}

\author{
A LLGEMEINE PSYCHOLOGIE
}

\section{DER WEITESTE SINN VON „PSYCHOLOGIE”}

Gegenstand dieses Buches ist Psychologie a ls Wis e n$\mathrm{sc}$ h a f $\mathrm{t}$.

Eine solche Formulierung schliesst die Voraussetzung ein, dass es auch andere als wissenschaftliche Psychologieen geben müsse. Das ist in der Tat der Fall.

Man nennt oft einen Richter einen guten Psychologen, einen Dichter einen grossen Seelenkünder; man spricht von der Psychologie in der Oedipussage - und drückt mit alledem einen weiteren Sinn des Wortes „Psychologie” aus, den wir etwa umschreiben können als: Inbegriff aller Uberzeugungen, Erkenntnisse und Verhaltungsweisen, die sich auf Seelenwesen und Seelenleben be$z$ i e h e n.

\section{Das Schema}

Es wird nötig sein, diesen w e it e r e n Umfang von Psychologie kurz zu überschauen, um dann der wis se n s chaftli ch e n Psychologie - die uns späterhin allein beschäftigen wird - den rechten Platz anzuweisen. Hierzu diene uns ein Schema, das durch Kreuzung zweier Gliederungen entsteht.

Die oben gebrauchte Doppelbezeichnung des G e ge n s t a nde s aller Psychologie: „Seelenleben und Seelenwesen” gibt die Grundscheidung. Man kann sich beschäftigen mit Seelischem, sowie es uns in den Erfahrungen des Lebens begegnet, oder mit jenem hypothetischen Sein, das solchen Erfahrungen zu Grunde liegen, sie ermöglichen, ihnen Sinn geben soll. Es ist der bekannte 
Gegensatz zwischen einer e $\mathrm{m}$ piris $\mathrm{ch}$ e $\mathrm{n}$ und einer $\mathrm{meta-}$ physisch-weltanschaulichen Betrachtung.

Freilich sind grade im Psychologischen Erfahrung und Weltanschauung nie ganz zu trennen; immer wieder hat das Suchen nach den letzten Dingen die Probleme der Seele bevorzugt und weltanschauliche Úberzeugungen auf die Ordnung und Deutung der Erfahrung angewandt; immer wieder hat eine erfahrungsmässige Bearbeitung seelischer Tatbestände über sich selbst hinausgewiesen auf die Fragen nach Wesen und Sinn der Seele. Deshalb wird stets nur von einer vorwiegenden, nicht aber von einer alleinigen, nur-metaphysischen oder nur-empirischen Psychologie gesprochen werden können.

Die zweite Scheidung bezieht sich auf die $\mathrm{E}$ in s te 11 u n g e n, in welchen der Mensch an die metaphysischen und empirischen Gegenstände der Psychologie herantritt. Diese Einstellung kann naiv, künstlerisch oder wissenschaftlich sein. Die naive Psychologie bildet die allgemeine und unentbehrliche Grundlage; die beiden anderen Einstellungen führen zu differenzierten hohen Entwicklungen, die nicht etwa in ein einfaches Rangverhältnis zu einander gebracht werden dürfen.

Beruht die naive Psychologie auf Meinen und Glauben, so die künstlerische auf Schauen und Darstellen, die wissenschaftliche auf Forschen und Denken.

Durch Kreuzung der beiden Gliederungen ergeben sich nun sechs Hauptarten der Psychologie im weitesten Sinne, wie sie das Schema anzeigt.

Gegenstand der Psychologie:

\begin{tabular}{|c|c|c|c|}
\hline & & $\begin{array}{c}\text { a. } \\
\text { Seelenwesen } \\
\text { (metaphysische Ps.) }\end{array}$ & $\begin{array}{c}\text { b. } \\
\text { Seelenleben } \\
\text { (empirische Ps.) }\end{array}$ \\
\hline \multirow{3}{*}{$\begin{array}{l}\text { Ein- } \\
\text { stellung }\end{array}$} & Naiv. & $\begin{array}{l}11 \text { a) } \\
\text { Mythisch-religiöse } \\
\text { Seelenauffassung. }\end{array}$ & $\begin{array}{l}\quad 1 \mathrm{~b}) \\
\text { Natiirliche } \\
\text { Menschenkenntnis. }\end{array}$ \\
\hline & Kinstlerisch & $\begin{array}{l}\text { 2a) } \\
\text { Kunstlerische } 13 e- \\
\text { serlung der Welt u. } \\
\text { der Dinge. }\end{array}$ & $\begin{array}{l}\text { Kiinstlerische Seelen- } \\
\text { dentung und Seelen- } \\
\text { darstellung. }\end{array}$ \\
\hline & $\begin{array}{l}\text { Wissa- } \\
\text { shaftioh. }\end{array}$ & $\begin{array}{l}\quad 3 \text { a) } \\
\text { Philosophische } \\
\text { I'sychologie }\end{array}$ & $\begin{array}{l}\quad 3 \mathrm{~b}) \\
\text { Psychologie als } \\
\text { Erfahrungswissenschaft. }\end{array}$ \\
\hline
\end{tabular}


2. Naive und künstlerische Psychologie

Für den $\mathrm{n}$ a ive $\mathrm{n}$ M e $\mathrm{n} \mathrm{s} \mathrm{ch}$ e $\mathrm{n}$ aller Zeiten und Völker ist kennzeichnend, dass sein auf ungeklärter Erfahrung beruhendes Meinen und sein auf die letzten Gründe zielendes Glauben noch ungeschieden ineinander fliessen.

(Schemafeld 1a). Die allgemeinen Vorstellungen, die sich der Mensch vom W e s e $n$ der Seele, ihrer Materie, ihrem Wert, ihrem Sitz, ihrer Macht, ihrem Leben nach dem Tode bildet, gehören zu den wichtigsten Bestandteilen aller Mythen u n d R e l i g i o n e n, durchsetzen Aberglauben und magisches Denken; leben ebenso in uralten animistischen Kulten wie in modernen spiritistischen Sitzungen. Uberall herrscht dabei die von jeder Kritik unberührte Úberzeugung, dass das Recht jener Glaubenssätze durch die „Erfahrung” bestätigt werde.

Die moderne Wissenschaft kann diesen behaupteten Beziehungen $z$ wischen naiver Metaphysik und psychologischer Erfahrung zwar keinerlei direkten Erkenntniswert beimessen. Aber indirekt können solche Zusammenhänge doch Bedeutung für sie gewinnen; man beginnt einzusehen, dass in den Mythen und religiösen Dogmen eine unbewusste Urweisheit der Menschheit steckt, die in symbolisch verhüllter Form Grunderlebnisse und Grundtriebe zum Ausdruck bringt.

(Schemafeld 1b). Auf die unmittelbare Beherrschung des alltäglichen Lebens und der praktischen Beziehungen zwischen Mensch und Mensch geht eine andere Art naiver Psychologie, die wir als "natürliche Menschenkenntnis" zu bezeichnen pflegen. Sie ist stets differenzierend eingestellt: seelische B e s o n d e r heit eines Einzelnen oder einer Gruppe wird intuitiv erfasst und mit intuitiver Selbstverständlichkeit behandelt. Jeder Mensch bedarf ihrer, und jeder Mensch besitzt sie auch in irgend einem Grade. Sie ist weitgehend unabhängig von Kulturniveau, Bildungsstand und psychologischem Fachwissen. Bald ist sie vornehmlich auf das eigene Ich bezogen: „Selbsterkenntnis". Bald erwächst sie aus der Innigkeit der Beziehungen zu bestimmten Merıschen: so ist eine Mutter oft hellseherisch für die seelischen Regungen in ihrem Kinde, während sie sonst vielleicht eine schlechte Menschenkennerin sein nirag. In anderen Fällen kann dieser psychologische Blick auf einer aus- 
gesprochenen Sonderbegabung beruhen: Politische Führer, Erzieher, Ärzte, Richter, auch Häuptlinge und Medizinmänner der Primitiven erweisen sich oft als ,geborene Psychologen", sowohl in dem Verständnis für einzelne Individuen, wie in der seelischen Behandlung von Massen. Solche Hochformen natürlicher Menschenkenntnis sind freilich selten. Bei den meisten Menschen ist diese Fähigkeit zur Erfassung fremden Seelenlebens recht kümmerlich entwickelt; auch erfolgt ihre Anwendung gewöhnlich ohne Selbstkritik und ohne Sicherungen gegen die so häufigen Fehlurteile.

Wenn sich die naive Psychologie zu innerer Schau und äusserer Gestaltung von schöpferischer Kraft erhebt - was immer nur in einzelnen aus der Masse hervorstechenden Individuen möglich ist - sprechen wir von $\mathrm{k}$ ü n t $\mathrm{l}$ e r i s cher Psychologie.

(Schemafeld 2a). Das Weltbild des Künstlers steht dem mythischen Weltbild nahe, insbesondere darin, dass der Künstler nicht fähig ist, die Welt im Ganzen und ihre Dinge im einzelnen als leblose Sachsysteme zu begreifen; er leiht ihnen Seele und Leben. Er le ih t sie ihnen - undhierin liegt der Unterschied zum naiven Mythos, dem die Beseelung der Welt vollste Realität ist. Für den Künstler, der Baum und Fels beseelt, der die „Stimmung” der Landschaft und das „Streben” der Naturkräfte in seinen Werken zum Ausdruck bringt, ist die Realität dieser Beseeltheit nicht von unmittelbarer Bedeutung; in jenem Zwischenreich zwischen Sein und Schein, in dem er beheimatet ist, herrschen Bild und Symbol, aus denen die allgemeine Bedeutung des Seelischen hervorleuchtet, unabhängig von der Wirklichkeitsfrage im Einzelfalle.

(Schemafeld 2b). Die Erfahrungspsychologie des Künstlers tritt auf als tiefdringende $\mathrm{S}$ e e $\mathrm{len}$ de $\mathrm{ut} \mathrm{u} \mathrm{ng}$ und geformte Se elendarstellung. So waren etwa Dostojewsky oder Rembrandt oder Eleonore Duse künstlerische Psychologen höchsten Ranges, ebensowohl durch ihre Gabe, selbst Seelisches intensiv zu erleben, wie durch die Fähigkeit, Seelenbilder für Anschauung und Einfühlung anderer fassbar zu gestalten, deren Wesentlichkeit und tiefe Bedeutsamkeit wiederum ganz unabhängig von dem Wirklichkeitsbezug ist.

Die gelegentlich zu hörende Frage, ob diese Hochformen genia- 
ler Psychologie der wissenschaftlichen Psychologie über- oder unterzuordnen seien, erscheint müssig; Kunst und Wissenschaft sind zwei aus gemeinsamem Ursprung stammende Manifestationen des Menschengeistes, deren jede in ihrer Art zu unüberbietbaren Gipfelleistungen zu führen vermag. Keinesfalls darf der wissenschaftliche Psychologe die Seelenschau und Seelendarstellung künstlerischer Art deshalb gleichgültig beiseite schieben, weil sie einer anderen Region des Lebens angehöre. Er wird oft genug das, was ein Dichter vorwegnehmend geschaut hat, in die Sprache seiner Theorie übersetzen und mit den Mitteln seiner Methoden klären können; und er wird bei Künstlern oft die treffendsten Anschauungsbeispiele für die wissenschaftlichen Sätze finden, die er auf anderem Wege erarbeitet hat.

Auch eigentümliche Übergangsformen gibt es hier; so sind etwa Rousseau und Nietzsche weder reine Künstler, noch reine Wissenschaftler gewesen, aber gerade durch die einzigartige Verschmelzung von Künstlertum und abstrakter Geistigkeit zu Wegbereitern in psychologischen Gebieten geworden.

Die unter 3 ( $a$ und $b$ ) unseres Schemas angedeuteten w i s s e n$\mathrm{sch}$ aftlichen Behandlungsweisen der Psychologie verlangen nun eine ausführlichere Besprechung.

\section{PHILOSOPHISCHE PSYCHOLOGIE}

\section{Vorbemerkung}

Die Psychologie gehört heut zu der grossen Schar der Spezialwissenschaften, die ihre selbständigen Problemstellungen, Methoden, Ergebnisse und Anwendungsweisen besitzen; sie steht aber zugleich mit der Philos ophie in Zusammenhang. Dieser Zusammenhang ist uralt; war doch Philosophie das urspriingliche gemeinsame Mutterland für alle Bereiche wissenschaftlichen Denkens und Arbeitens überhaupt, aus dem sich dann erst fortschreitend die Sonderwissenschaften herauszulösen begannen und schliesslich verselbständigten. Gerade für die Psychologie hat die bedingungslose Zugehörigkeit zur Philosophie sehr lange gedauert. Die Absonderung kiundigte sich erst im 18. Jahrhundert an, als der deutsche Aufklärungsphilosoph Christian 
Wolff die „rationale” und die „empirische” Psychologie unterschied; und zur wirklichen Konstituierung einer selbständigen psychologischen Spezialwissenschaft ist es erst in der zweiten Hälfte des 19. Jahrhunderts gekommen.

Dabei ist aber der Zusammenhang mit der Philosophie nie verloren gegangen; er hat sogar grade in der jüngsten Zeit wieder an Stärke zugenommen. Die Scheidung von zwei unabhängigen Betrachtungsweisen - einer metaphysischen und einer empirischen - ist eben innerhalb der $\mathrm{w}$ is s e $\mathrm{n} \mathrm{s} \mathrm{ch} \mathrm{a} \mathrm{f} \mathrm{t-}$ $1 \mathrm{i} \mathrm{ch} \mathrm{e} \mathrm{n} \mathrm{Psychologie} \mathrm{genau} \mathrm{so} \mathrm{wenig} \mathrm{möglich} \mathrm{wie} \mathrm{in} \mathrm{der} \mathrm{naiven}$ oder in der künstlerischen Psychologie; vielmehr ist Wechselwirkung von philosophischer Besinnung und methodischer Erfahrung unumgänglich notwendig. Die - auch jetzt noch weit verbreitete - Überzeugung, dass die Psychologie eine völlig philosophiefremde Einzeldisziplin werden könne oder solle, droht entweder zu einer „Entseelung”' der Psychologie zu führen, oder hat zur Folge, dass man u n be w us $\mathrm{t}$ weltanschauliche und erkenntnistheoretische Voraussetzungen der, scheinbar voraussetzungslosen, wissenschaftlichen Arbeit zugrunde legt.

\section{2. Übersicht}

Wir geben im folgenden eine rein referierende Ưberschau über die philosophischen Grundprobleme der Psychologie und eine Aufzählung der hauptsächlichen Lösungsversuche, ohne hier schon Stellung zu nehmen und Entscheidungen zu treffen.

a) D a s W e se n d e r S e e l e. Die Frage lautet: W a s ist die Seele? (bezw. das Seelische?) Darauf antwortet der Substanzstandpunkt (der dem naiven, insbesondere religiösen Glauben am nächsten steht): die Seele ist ein selbständig für sich existierendes, vom Körper loslösbares Einzelding. - Der Elementenstandpunkt: Die Seele ist ein Gefüge (Aggregat) von letzten seelischen Elementen. - Der Aktualitätsstandpunkt: Das Seelische ist ein Abfluss von Prozessen und Tätigkeiten. - Der Attributstandpunkt: Das Seelische ist eine Eigenschaft (Erscheinungsweise) einer Substanz.

b) Die Frage nach dem U m k reis des Seelischen steht in engem Zusammenhang mit den oben angedeuteten Fragen. W o überall gibt es "Seele" und „Seclisches"? Nur an menschlichen Individuen? Oder auch an Tieren? Vielleicht gar bei Pflanzen und anorganischen Gebilden? (, Kristallscelen", „Atomseelen”.) Und ebenso über das menschliche Individuum hinaus: Haben wir ein Recht, von Volksseele oder 
Volksgeist, von Massenpsyche, Gesamtwillen u.s.w. zu sprechen ? Oder vielleicht gar von einer metaphysischen Menschheitsseele? von Gestirnseelen?

Es besteht hier also eine Stufenleiter philosophischer Denkmöglichkeiten: von solchen Erweiterungen des Seelenbegriffs, die noch im Rahmen nüchterner Forschung durchaus diskutierbar sind (Tierseele, Volksseele) bis zu metaphysischen Spekulationen erfahrungsfernster Art.

Die folgenden Punkte beziehen sich durchweg auf die Seele im menschlichen Individuum.

c) Die Beschaffenheit des Seelischen. Die Frage lautet: W i e ist das Seelische? Grundlegend ist hier die Scheidung zwischen dem reinen Bewusstseinsstandpunkt: das wesentliche, nie fehlende Merkmal des Seelischen sei das Bewusstsein - und der Philosophie des „Unbewussten”, die Seelisches annimmt, welches dem Träger dieser Seelenvorgänge selber verborgen bleibt.

Fragt man nach den Qualitäten des Seelischen, so stellt die „Vermögenslehre" eine begrenzte Zahl von getrennten Einzelkräften (z.B. Denken, Fühlen, Wollen) auf. Dem gegenüber versucht aber philosophischer Einheitsdrang in immer wieder anderen Formen, eine einzige Kategorie seelischer Qualitäten als grundständige nachzuweisen, auf die alle anderen zurückführbar seien. So gibt es eine intellektualistische Psychologie des Vorstellungsmechanismus, eine voluntaristische Psychologie (,,alles Seelische ist Willensakt"), eine "sensualistische" Empfindungspsychologie, eine Triebpsychologie, eine „emotionalistische" Gefühlspsychologie u.s.w.

d) Das Verhältnis von Seele und Leib. Schon die Gegenüberstellung dieser beiden Begriffe ist der Ausdruck einer ganz $\mathrm{b}$ e $\mathrm{s} \mathrm{t}$ i $\mathrm{m} \mathrm{m}$ t e $\mathrm{n}$ philosophischen Haltung; diese ist allerdings infolge der Geistesentwicklung der letzten drei Jahrhunderte so tief eingewurzelt, dass sie für viele Denker auch jetzt noch der unaufgebbare Ausgangspunkt aller psychologischen Gedankengänge ist.

Am schroffsten ist die begriffliche Trennung beim substanziellen "Dualismus": nach ihm sind Leib und Seele zwei völlig von einander verschiedene und geschiedene $\mathrm{S} u \mathrm{~b}$ t a $\mathrm{n} \mathrm{z} \mathrm{n}$, die entweder garnichts mit einander zu tun haben oder aber in einer nur äusserlichen Wechselwirkung stehen.

Aber auch der landläufige „Monisnus" kommt von der begrifflichen Gegensätzlichkeit Leib und Seele nicht los. Diese sind zwar nicht mehr selbständige Substanzen, sondern nur zwei , A t t r i b u t e" an dem einheitlichen Sein; aber als Attribute stehen sie doch schroff, ohne Ubergänge, ohne inneren Sinnzusammenhang, einander gegenüber; und ihr paralleles Vorhandensein liefert das einzige Kennzeichen der Substanz, an der sie hangen (,Parallelismus').

Ferner gibt es monistische Richtungen, die nicht einmal die Gleich- 
ordnung beider Attribute zugestehen, sondern das menschliche Sein ganz und gar in dem einen oder in dem anderen Merkmal aufgehen lassen. So kommt man entweder zum "Materialismus": alles Seiende ist stofflich, das Psychische nur Funktion der Materie - oder zum "Spiritualismus": es gibt nur Seelen und deren Bewusstseinsinhalte; auch die Materie und somit der eigene Leib ist nur da als Vorstellungsinhalt der Seele.

Diesen älteren Theorien gegenüber beginnt sich jetzt eine Auffassung zu entwickeln, die dem begrifflichen Gegensatz Leib/Seele überhaupt die Ursprünglichkeit abspricht. Die beiden Begriffe bilden nicht die Grundkategorieen, aus deren Beziehung zueinander die Welt und der Mensch zu erklären seien. Der Begriff „P e r s o n”, der nun die Führung übernimmt, steht noch v or jenem Gegensatz, ist „psychophysisch neutral'. - Dieser ,,personalistische" Standpunkt findet im vierten Kapitel unseres Buches ausführlichere Behandlung.

e) Das Schicksal der Seele. Hier handelt es sich um Herkunft und Zukunft der Seele, um ihre Stellung zur Welt und ihre Aufgabe in der Welt - ,Welt" hier gemeint als Inbegriff von allem, was nicht die Seele selbst ist: der eigene Leib, die Dinge, die Kultur, die anderen Individuen und Menschen, der Kosmos, die Gottheit. Da tauchen die grossen Kampfthemen auf: Anteil von Vererbung und Umwelt am Werden der Seele, Verhältnis von Freiheit und Determiniertheit; Charakter, Tat und Werk; Sinnhaltigkeit oder Widersinn des Daseins; Tod und Unsterblichkeit. Wieder berühren sich hier eng die philosophischen Fragen mit den ganz grossen Lebensrätseln und Sinndeutungen der Menschheit, die jenseits der blossen Wissenschaft stehen. -

e) Im Gegensatz zu den bisher besprochenen Themen, die von der Philosophie nicht geschaffen, sondern nur ins Denkerische erhoben und systematisiert worden sind, hat die Philosophie auch Probleme entwickelt, die ihr allein eigentümlich sind. Sie erstrecken sich auf die Möglichkeit und Gültigkeit des psychologischen Erkennens überhaupt und damit auf den Charakter der Psychologie als einer Wissenschaft, sind also nicht metaphysischer, sondern erkenntnistheoretischer und wissenschaftstheoretischer $\mathrm{N}$ at ur.

Erkenntnistheoretisch wird untersucht, mit welchen geistigen Werkzeugen der Mensch Psychologie treibe, ob eine spezifisch ",psychologische Erfahrung" als innere Erfahrung der äusseren Erfahrung gegenübergestellt werden müsse, ob das Recht bestehe, über das Erfahrbare hinauszugehen durch Spekulation, Hypothese und Deutung; wie die Methoden des Erklärens und des Verstehens an der Bearbeitung der psychologischen Befunde beteiligt seien, ob den psychologischen Einsichten Allgemeinheit, Notwendigkeit, Zeitlosigkeit zukomme, 
wie die einzelnen psychologischen Kategorieen (z.B. Bewusstsein, Vermögen, Typus, Individualität) logisch konstituiert seien u.s.w.

Diese wissenschaftstheoretische Untersuchung führt dann mit Notwendigkeit über die Grenzen der Psychologie selbst hinaus; denn es muss der wisse $\mathrm{nsch}$ a $\mathrm{t} 1$ i che $\mathrm{Ort}$ dieser Disziplin innerhalb der verschiedenen philosophischen Forschungszweige, ferner ihre Stellung zwischen Natur- und Geisteswissenschaften, endlich ihr Verhältnis zu verwandten Einzelwissenschaften, etwa der Biologie, der Biographik u.s.w. geklärt werden. -

Die obige Übersicht konnte und wollte keineswegs vollständig sein. Sie sollte nur den Satz veranschaulichen, der unserer ganzen weiteren Arbeit zu Grunde liegt: D i e philos o phis che n $\mathrm{Fragen}$ der Ps y chologi e bilden nicht einen abseitigen Bereich, um den sich der empirische Psychologe nicht zu kümmern brauche; sie greifen vielmehr von allen Seiten hinein in das Gewebe psychologischer Erfahrungswissenschaft, bringen in deren Befunde Ordnung und System, Sinn und Deutung. Andrerseits erfährt die philosophische Psychologie von der fortschreitenden Spezialforschung her eine Begrenzung, Konkretisierung und Kontrolle, die vor den früheren Abwegigkeiten einer bloss spekulativen wirklichkeitsfernen Psychologie schützt.

Unser Buch selbst ist seinem eigentlichen Thema nach der Psychologie als Erfahrung s wis se n s c haf t gewidmet; aber wir werden uns nicht scheuen, philosophische Voraussetzungen und philosophische Ausblicke dort, wo der Gegenstand sie fordert oder nahelegt, wenigstens andeutend mitzubehandeln.

III. PSYCHOLOGIE ALS ERFAHRUNGSIVISSENSCHAFT

\section{Vorbemerkung}

„Erfahrungen” über Seelisches macht jeder Mensch fortwährend. Aus diesen naiven Erfahrungskenntnissen wird eine Erfahrungswissenschaft dann, wenn 1) der $\mathrm{Gew}$ in n von Erfahrungen auf einem bestimmten Gebiet zum selbständigen Ziel geistiger Arbeit erhoben wird, und wenn 2) die $\mathrm{B}$ e a rbeitung der Erfahrungen unter methodischen und kritischen Gesichtspunkten vor sich geht.

Wenn man bedenkt, wie jung die Psychologie als solche Erfahrungswissenschaft ist, so versteht man es, dass sie noch nicht 
die innere Festigung und äussere Sicherheit gewinnen konnte, die vielen älteren Erfahrungswissenschaften zukommt. In ihr ist mancherlei Unfertigkeit, und ihre Fortschritte müssen zuweilen durch heftige Krisen hindurch erkämpft werden. Dennoch ist die Gesamtleistung, die in wenigen Jahrzehnten vollbracht wurde, ausserordentlich eindrucksvoll. Das Bild, das wir jetzt schon vom menschlichen Seelenleben haben, ist unvergleichlich reicher an Linien und Farben, als etwa das dürftige Schema in Herbarts Tagen; es hat aber auch eine ganz andere Tiefe und Plastik mit Untergründen und Hintergründen, von denen man früher nichts ahnte. Ferner hat sich das abstrakte Schema „der" Menschenseele zerlegt in eine Fülle von Bildern verschiedener Seelentypen und Seelenstufen. Zugleich verfügen wir heut über ein System von Begriffskategorieen, mit denen wir die psychischen Tatsachen unter immer wieder neuen Gesichtspunkten zu meistern vermögen. Aber über die theoretischen Befunde und Erkenntniskategorieen hinaus hat die gegenwärtige Erfahrungspsychologie noch zwei weitere Verdienste: sie gewährt allen Menschen, die es beruflich mit dem Seelenleben anderer zu tun haben, eine vertiefte Einstellung auf Seelisches; und sie erlaubt eine Reihe tiefgreifender A n w e n d u n ge n auf viele Gebiete der geistigen und praktischen Kultur.

Suchen wir in Kürze den Umkreis der Aufgaben zu überblicken, die eine psychologische Fachwissenschaft sich heute stellt. Dabei beschränken wir uns zunächst auf das, was man „r e i n e” oder ,allgemeine” Psychologie zu nennen pflegt, um dann erst später ihre Nebenzweige und Anwendungsgebiete zu skizzieren.

Wir haben vorhin "Gew in n" und „B earbeitu ng" psychologischer Erfahrungen als die beiden Grundaufgaben der empirischen Psychologie unterschieden. Der Unterschied sei an einigen, mit Absicht extrem gefassten, Beispielen veranschaulicht.

a) Ein Psychologe sammelt Träume, verzeichnet seine eigenen, lässt sich die Träume anderer berichten, stellt Traumberichte aus der Literatur zusammen (Erfahrungsgewinn). Fin andrer Psychologe sucht aus diesem Material solche Träume heraus, die ihm offenkundige oder verkappte Wunschträume zu sein scheinen, und analysiert und deutet 
sie mit Hilfe bestimmter - etwa psychoanalytischer - Theorieen (Erfahrungsbearbeitung).

b) Vermittels experimenteller Prüfungen werden gewisse Intelligenzleistungen von vielen Kindern verschiedener Altersstufen festgestellt (Erfahrungsgewinn). Das so gefundene Material kann in sehr verschiedenem Sinne „,bearbeitet” werden: man erforscht die Abhängigkeit des Intelligenzfortschritts vom Alter oder von der sozialen Schicht, die Varietätenbildungen der Intelligenz innerhalb einer Altersstufe, das Verhältnis der Intelligenzzleistungen zu den Schulleistungen u.s.w. Auch hier deutliche Scheidung der beiden Schritte, die sogar von verschiedenen Personen getan werden können.

In der wirklichen psychologischen Arbeit wird sich nun freilich diese Trennung oft verwischen. Denn schon irgend eine Materialsammlung ist ja nie völlig wahllos und ungeistig, sondern steht unter gewissen Leitgesichtspunkten, durch welche das Chaos der Eindrücke in psychologische Erfahrung verwandelt (also „bearbeitet") wird. Und jegliche Bearbeitung offenbart doch zugleich an dem Rohstoff, den man bearbeitet, neue psychologische Tatbestände. So wird man nur von einem Mehr oder Minder der beiden Arbeitsarten sprechen und - je nach der Zielsetzung eine Stufenreihe aufstellen können.

\section{A u f g b e n}

a) Bes chreibung. - Die „deskriptive” Psychologie ist ganz vorwiegend auf $\mathrm{Ge}$ win $\mathrm{n}$ von Erfahrungen gerichtet. Seelisches Geschehen soll eingefangen werden in eingehende und für andere verständliche Darstellung.

Es ist dies schon eine durchaus wissenschaftliche Aufgabe. So wenig wie etwa ein Ferientourist in der Lage wäre, die Flora des Gebirges, das er durchwandert, auch nur zu beschreiben, so unvollkommen wäre die Leistung eines Nicht-Psychologen, wenn er etwa die Vorstellungs- und Gefühlsprozesse beschreiben wollte, die in ihm während eines eben abgelaufenen Affekts vorhanden waren; oder wenn er die seelischen Äusserungen registrieren wollte, die ein Kind während eines länger dauernden Spiels bekundet.

Beschreibende Psychologie ist nötig, um überhaupt erst einmal die Fülle der Erscheinungen, die sich ja für den Laien meist auf eine dürftige Anzahl auffälliger Züge reduziert, vor uns auszubreiten und in ihren feineren Schattierungen sichtbar zu machen. Sie 
ist auch nötig, um zu verhindern, dass wertvolles psychologisches $M$ a t e r i a 1 durch voreilige Deutung nach Analogie der eigenen Psyche oder im Sinne einer vorgefassten Theorie ver f ä l s c h t wird. Sind doch z. B. die Berichte vieler Reisender über Naturvölker für psychologische $Z$ wecke deshalb wenig brauchbar, weil schon ihre Materialdarstellung durch die unkontrollierte Interpretation des europäischen Kulturmenschen hindurchgegangen ist.

Es gibt aber nicht nur eine Beschreibung seelischer Einzelvorgänge, wie sie von bestimmten Individuen in bestimmten Situationen vollzogen werden; vielmehr hat sich auch eine deskriptive Methode herausgearbeitet, die auf das Wesentliche und Allgemeingültige psychischer Tatbestände geht; diese „p h änomenologische Deskription", die aus der Philosophie stammt, (Husserl, Scheler, Heidegger u. a.) hat auf die Psychologie der letzten Jahrzehnte in hohem Malse anregend gewirkt. Man spricht etwa von einer „Phänomenologie des Raumbewusstseins”, einer „Phänomenologie der Gesinnungen” u.s.w.

b) Klassifikation und Bezeichnung. - Das deskriptiv gewonnene Material muss nun geordnet werden; umgekehrt ermöglicht die Ordnung und die mit ihr verknüpfte terminologische Klärung erst weitere Beschreibung.

Die Terminologie ist gerade in unserer Wissenschaft deshalb von grösster Bedeutung, weil ihre Gegenstände ja auch in der Alltagssprache fortwährend benannt werden. Hier tritt die wissenschaftliche Psychologie zur naiven Psychologie in eine doppelte Beziehung. Auf der einen Seite muss sie die Verschwommenheit und Ungleichmässigkeit des laienhaften Sprachgebrauchs beseitigen, damit die Worte wieder einen festen Sinn erhalten. Ausdrücke wie „Bewusstsein”, „Gefühl”, „Empfindung”, „Begabung”, ,Charakter" und viele andere bedürfen einer genauen begrifflichen Bestimmung, um wissenschaftlich verwertbar $\mathrm{zu}$ werden. Andrerseits aber hat der unbewusst schaffende Sprachgeist der Völker für manche seelischen Tatbestände Ausdrücke und Bilder von wunderbarer Treffsicherheit geprägt, die der Psychologe nicht unbenutzt lassen darf.

Bei der Schaffung von psychologischen Klassen-Begriffen und Ausdrücken sollte man sich stets darüber klar sein, dass solche 
ordnende Arbeit eine gewisse Vergewaltigung ihres Gegenstandes mit sich führt.

Ein Beispiel: wir erwähnten oben die alte Dreiteilung der seelischen Tatbestände in „De n k e n”, „F üh le n”, „W olle n”. Die Unterbringung alles dessen, was wir in der Seele vorfinden, unter diese drei Rubriken, und die scharfe Grenzziehung zwischen den dreien erfordert Isolierungen und Vereinfachungen, die dem stetigen Fluss des seelischen Geschehens und der Vieldeutigkeit jedes einzelnen seelischen Geschehnisses nicht angemessen sind.

Wir stehen hier vor einer wesentlichen Antinomie aller psychologischen Arbeit. Indem wir etwas benennen und damit einer bestimmten psychologischen Kategorie als Fall unterordnen, is t es schon nicht mehr dasselbe, das es zuvor gewesen war; es gewinnt eine eigentümliche Härte und Bewegungslosigkeit, die dem seelischen Leben selbst nicht zukommen kann. ${ }^{1}$ )

Die wissenschaftliche Psychologie muss versuchen, diese Unzulänglichkeit, die nicht zu beseitigen ist, in ständig fortschreitender Arbeit wenigstens zu mindern. Durch Auflockerung und Bereicherung der Gliederungen, durch Kreuzung verschiedener Gliederungssysteme bekämpft man die Starre der Klassifikation; durch Stellung eines und desselben seelischen Tatbestandes unter verschiedene Perspektiven sucht man seiner Vieldeutigkeit näher zu kommen; durch Ausbildung einer immer nüancenreicheren Sprache, durch Schaffung von Zwischen- und Ubergangsbegriffen (z.B. „Unterbewusst”, ,Anschauungsbild”, „Ernstspiel", „Ambivalenz”, „Ungestalt”) ist man bestrebt, das Unsagbare in immer angemesseneren Formen doch wenigstens einzukreisen. Wie grob erscheint uns heut jene gradlinige Dreiteilung in „Denken, Fühlen, Wollen” gegenüber den Gliederungen verschiedenster Richtung, die wir in Durchkreuzung und Verschmelzung heut anwenden. Eine wie vielfach bereicherte und verfeinerte Terminologie steht uns jetzt zur Verfügung, wenn es gilt, einen Menschen charakterologisch zu beschreiben.

Immerhin ist und bleibt die Gefahr gross, dass man den Versuchungen einer neugefundenen Klassifikation unterliege.

\footnotetext{
1) Künstlerischen Seelendeutern ist diese Unzulänglichkeit sehr stark zum Bewusetsein gekommen: „Spricht die Seele, so spricht, ach, schon die Se ele nicht mehr" (Schiller). "Welche Sachen schreiben und malen wir denn ab, wir Mandarinen mit chinesischem Pinsel, wir Verewiger der l)inge eben wolk werden will und anfängt, sich zu verriechen! Ach immer nur abzichende und erschöpfte Gewitter und gelbe späte Gefuhle..." (Nictsche).
} 
In früheren Jahrhunderten galt z.B. die bekannte Vierzahl der Temperamente als unbezweifelbares Einteilungsprinzip. Heut finden wir in modernen Typenlehren Ähnliches; da werden bald zwei, bald vier, bald sechs Typen scharf gegenübergestellt; und man glaubt, die Menschen durch Zuweisung zu dem einen oder andern Typ psychologisch hinreichend erfassen zu können. - Oder es wird innerhalb jedes Individuums die Scheidung von „Geist” und „Seele" scharf durchgeführt u.s.w.

c) Analyse und Ganzheitsbezug. - Ein seelischer Tatbestand, wie er uns in blosser Beschreibung entgegentritt, ist $\mathrm{k}$ om plex, d.h. er enthält eine Mannigfaltigkeit in sich. Daraus erwächst die wissenschaftliche Aufgabe, die im Komplex vorhandenen Bestandteile herauszusondern: ,Analyse”.

Nehmen wir als Beispiel das banale seelische Erlebnis, das ich mit den Worten ,ich will jetzt essen" ausspreche. Die Analyse findet hier etwa ein in meinem Körperinneren unbestimmt lokalisiertes Hungergefühl, ein daraus erwachsendes Bedürfnis, Abgelenktheit der Aufmerksamkeit von der bisherigen Beschäftigung, die mehr oder minder anschauliche Vorstellung von Speisen, die Erinnerung an frühere Beschäftigung mit Speisen, die gefühlsbetonte Vorstellung der zu erstrebenden Sättigung, einen willensmässigen Impuls zur Ausführung bestimmter Bewegungen, vielleicht auch eine zwischen verschiedenen Möglichkeiten hin und her gehende C̈berlegung, die dann in einer Entscheidung und Wahlhandlung ihr Ende findet.

Ein anderes Beispiel psychologischer Analyse: der Laie spricht von ",musikalischer Begabung”, als ob diese eine einfache, nicht weiter auflösungsbedürftige Eigenschaft wäre. Der Psychologe darf sich nicht damit begnügen. Er findet innerhalb jener Fähigkeit eine grosse Anzahl von Teilfähigkeiten, so Empfindlichkeit des Gehörs für Tonreinheit und Tonunterschiede, Ton- und Melodie-Gedächtnis, rhythmische Begabung harmonische Begabung, Verständnis für musikalische Zusammenhänge, Affekterregbarkeit, Fähigkeit zur Wiedergabe, Fähigkeit zur Neuschöpfung musikalischer Gebilde u.s.w.

Es ist vielleicht nicht unnötig hervorzuheben, dass psychologische Analyse zu jeder wissenschaftlichen Betätigung auf psychologischem Gebiete gehört, also nicht etwa jener Richtung allein eigen ist, die in ihren Namen das Wort „Analyse” aufgenommen hat. Die "Psychoanalyse" ist vielmehr nur durch eine besondere A rt der analytischen Tätigkeit gekennzeichnet, von der später zu sprechen sein wird.

Die fortschreitende Fähigkeit des Psychologen zur Zergliede- 
rung, die auch durch mannigfache Sondermethoden (z.B. experimentelle) unterstützt worden ist, hatte zum Teil ähnliche Wirkungen, wie sie das Mikroskop in den Naturwissenschaften zeitigte: auch scheinbar Einfaches löste sich immer wieder in ein Gefüge noch einfacherer Bestandteile auf, bis man glaubte, endlich bei den seelischen „E le me n t e n” angekommen zu sein.

Aber eben damit war ein Begriff von stärkster Problematik in die Psychologie hineingeworfen worden. Die eben erwähnte Analogisierung zu den naturwissenschaftlichen „Elementen” führte zu Auffassungen, welche die sogenannte „E l e m e n t e np s y c h o lo g i e" konstituierten. Dieser - von der modernen Psychologie bekämpfte - Standpunkt sei hier kurz charakterisiert.

„Elemente" sind einfache, für sich existierende Letztbestandteile. Wenn man annimmt, dass das Psychische aus Elementen bestehe, muss man zwei Fragen stellen: 1) Wie sind die Elemente beschaffen? 2) Wie verknüpfen sie sich miteinander? Auch die Beantwortung dieser Fragen erfolgte nach Analogie der Naturwissenschaften (und zwar mehr der exakten als der organischen Naturwissenschaften).

$\mathrm{Zu}$ 1). Fast stets führte die Annahme seelischer Letzt-Teile dazu, dass man diese (etwa entsprechend den Uratomen oder Elektronen der Physik) als gleichartig annahm. Jede Verschiedenartigkeit der durch Analyse gefundenen Qualitäten wurde dann als Zeichen dafür aufgefasst, dass man noch nicht am eigentlichen Ziel der Zerlegung angekommen sei: denn das menschliche Einheitsbedürfnis verlange, dass es nur e in e Art von „Elementen” gebe, und dass alle Mannigfaltigkeit nur aus der Verbindungsweise solcher Elemente resultiere.

Man erkennt, wie stark philosophische Voraussetzungen in diese elementenpsychologische Grundhaltung hineinspielen. (Vgl. die analogen Gedankengänge S. 11). - Die bekannteste Ausprägung solch einförmiger Elementenpsychologie bildet Herbart's Lehre: dass alles Scelenleben aus "Vorstellungen" bestehe, und dass Wille und Gefühl in Wahrheit Vorstellungsbeziehungen seien.

$\mathrm{Zu}$ 2). Es gehört ferner zum Wesen der „Elementenpsychologie", dass sie das, was in der Seele geschieht, ganz vo n de n ilementen her $z$ u erklären sucht. Alle seelischen 
Tatbestände sind hiernach Ag g r e g a t e (mechanische Gefüge) der Elemente und nichts anderes. Wie die materiellen LetztTeilchen, so werden auch die psychischen Elemente als Träger elementarer Kräfte angesehen, durch welche sie sich gegenseitig beeinflussen: anziehen und abstossen, fördern und hemmen und sich miteinander verknüpfen zu Ketten und Komplexen verschiedener Grössenordnung, deren oberster dann die Seele oder das Ich ist. Der Hume'sche Satz „Das Ich ist ein Bündel von Vorstellungen" war der erste, und ist noch heut der klassische, Ausdruck für diese Aggregatauffassung des Seelischen.

Die Elementenpsychologie entfernt sich weit von dem Boden direkter psychologischer $\mathrm{Erfahrung}$; diese wird vielmehr in ein System ganz bestimmter Voraussetzungen hineingepresst. Denn weder einfache Elemente, noch rein mechanische Gefüge von Elementen sind in dem Erfahrungsbestand, den wir über seelisches Leben haben, unmittelbar gegeben. Dennoch ist die Bedeutung elementen-psychologischer Forschung für die psychologische Erfahrungswissenschaft nicht gering anzuschlagen. Die vereinfachende Arbeitshypothese, a ls ob innerhalb des Menschen seelische „Elemente” unter einander in Verknüpfungen stehen, hat dazu geführt, dass man $\mathrm{R}$ e g e $\mathrm{ln}$ solcher Zusammenhänge gesucht und weitgehend gefunden hat, die unsere Erkenntnis wesentlich gefördert haben. Es wäre daher auch durchaus unangebracht, die Betrachtungsweisen und Untersuchungsmethoden, die im Zusammenhang mit jener Einstellung entwickelt worden sind, nun aus der Psychologie ganz ausschalten zu wollen, weil die theoretische Grundeinstellung selbst unzulänglich sei. Vielmehr werden wir vieles von den Befunden und Verfahrungsweisen jener ,exakten” Psychologie in die - nun freilich weit umfassendere und von $\mathrm{g}$ a $\mathrm{n} z$ a $\mathrm{n}$ dere $\mathrm{n}$ theoretischen Voraussetzungen ausgehende - neue Psychologie aufnehmen können und müssen.

Der Grundbegriff, der in dieser neuen Psychologie allenthalben dem Begriff des Elementes gegenübertritt, ist der der „G a n zh e i t"; und die Methode, die als Gegenspiel und notwendige Ergänzung der Analyse zur Anwendung gelangt, ist die des „G a n zhe it sbezuge s".

Es können hier noch nicht die mannigfachen Ganzheitsbegriffe 
der verschiedenen psychologischen Richtungen entwickelt werden, sondern nur der gemeinsame Grundgedanke. Nach diesem ist alles Seelische entweder selbst eine Ganzheit (d.h. eine in sich sinnvolle, mehr oder minder deutlich begrenzte Einheit) oder einer Ganzheit zugehörig. Ganzheit schliesst nicht innere Mannigfaltigkeit von Bestandteilen und Gliedern aus: aber diese haben nicht mehr den Charakter selbständiger, für sich existenzfähiger und aus sich wirkungsfähiger Elemente, sondern sinken zu unselbständigen „M o m e n t e n” innerhalb des Ganzen hinab und werden in ihrer Bedeutung und Funktion erst durch ihren ,Ganzheitsbezug" verständlich.

Beispiele: In einer gehörten Melodie ist der einzelne Ton nicht als elementare Tonempfindung seelisch gegeben, sondern a Is "Tonika” oder als "Leitton" oder als „Höhepunkt” u.s.w. i n n e r h a 1 b der Melodiegestalt. - In einer Willenshandlung ist eine Zielvorstellung nicht isoliert vorhanden; sondern sie hat in ihrer Spannung zu andern Motiven, in ihrem Antriebscharakter für eine auszuführende Bewegung u.s.w. einen Stellenwert, der von dem Gesamtakt her bedingt ist. Eine Begabung ist nicht eine Summation der Teileigenschaften, welche die Analyse in ihr findet. Bei einem musikalischen Menschen z.B. führen die Fähigkeiten des Tongedächtnisses, der Gehörschärfe, der Affekterregbarkeit durch Musik u.s.w. (vgl. die Aufzählung S. 18) keine Sonderexistenz für sich, sondern sie sind eingebettet in jene seelische Gesamtstruktur, die wir "Musikalität" nennen. - Aber auch scheinbar weit voneinander abliegende seelische Eigenschaften wie: Temperament, Phantasie, Triebhaftigkeit, Intelligenz stehen nicht als „Vermögen" getrennt nebeneinander, sondern sind nur eng zusammengehörige Teilstrahlen der einheitlichen „Person”.

Man kann diese Reihe von Beispielen für den „Ganzheitsbezug" sogar noch über das Einzelindividuum hinaus fortsetzen zu den seelischen Ganzheiten des Gemeinschaftslebens hin. Man kann weiter darauf verweisen, dass es Ganzheiten gibt, in denen „Momente" ursprünglich überhaupt nicht aufweisbar sind, sondern erst durch nachträgliche und abstrahierende Tätigkeit des Psychologen hineininterpretiert werden (z.B. in die Totalität einer vagen Stimmung).

Die Ganzheitsbegriffe der heutigen Psychologie sind die Kategorieen „Gestalt”, ,Struktur”, ,,Komplexqualität”, ,,Bewusstseinseinheit" und andere. Man beschränkt den Begriff auch nicht auf das rein Seelische des Menschen, sondern wendet ihn auf die leiblich-seelische Einheit des Menschen an und kommt damit zu 
Begriffen wie „Konstitution”, psychophysische Neutralität” „Person", u.s.w. Durchweg gilt die methodische Forderung, dass die Psychologie stets den korrelativen $\mathrm{Zus}$ a m m e $\mathrm{nh}$ ang von Moment und Ganzheit, von Abhebung und Einbettung, von Analyse und Ganzheitsbezug wahren muss.

Dieser hiermit gebotene Doppelaspekt alles Psy$\mathrm{ch}$ i s $\mathrm{ch}$ e $\mathrm{n}$ wird sich geradezu als eines der Leitmotive unseres Buches erweisen. Gewiss muss eine Elementenpsychologie entschieden abgelehnt werden, die nur das kennt und anerkennt, was als letztes Ergebnis der Zerlegung übrig bleibt. Aber man darf auch nicht in das entgegengesetzte Extrem fallen: dass man, von der "Totalität" eines seelischen Gebildes oder Geschehens geblendet, die analytische Kleinarbeit missachtet, die den Aufbau und die Bewegung innerhalb der Ganzheit erst begreiflich macht. Ein solches Schwelgen in der Ganzheitsidee ist hier und da bemerkbar; es darf nicht zu einer Gefahr für den Fortschritt wissenschaftlichen Forschens werden.

d) Verknüpfen, Vera $11 \mathrm{~g}$ e mei nern, Erklären. - In eine neue Phase der wissenschaftlichen Arbeit rückt die Psychologie dort, wo sie den $Z$ u s a m menhängen zwischen den untersuchten Erscheinungen nachgeht (,,s y n $\mathrm{t} h$ e $\mathrm{t}$ s c h e Forschung"). Auch hier ist zunächst die Erfahrungsgrundlage zu schaffen für die Existenz und die grössere oder geringere Festigkeit solcher Zusammenhänge.

Um z.B. das Problem „Beziehung zwischen Triebleben und Phantasie" zu bearbeiten, muss man eine umfassende Übersicht über Triebund Phantasiephänomene vieler Menschen gewonnen haben; erst dann kann man sich vergewissern, ob bestimmte vermutete Zusammenhänge $z$ wischen den beiden Gebieten in der Tat bestehen und welche Qualität sie haben.

Derartige synthetische Untersuchungen müssen nun mit innerer Notwendigkeit den Umkreis der rein-psychologi$\mathrm{sch}$ e $\mathrm{n}$ Erfahrung überschreiten. Nicht immer sind, wie in obigem Beispiel, beide Glieder des untersuchten Zusammenhanges seelische Erscheinungen. Vielmehr, da der Mensch mit seiner Seele mitten in der Welt steht, haben seine seelischen Phänomene Beziehungen zu den verschiedensten, auch a us ser- 
seelischen Sphären: zum Leib, zu den äusseren Reizgebieten des Lichts, Schalls u.s.w., zu Klima und Wetter, zu den andern Menschen und Menschengemeinschaften, zu den grossen kulturellen Gebieten, geschichtlichen Zuständen, Wertbereichen.

Hierdurch muss sich die Aufgabe unserer Wissenschaft stark erweitern. Befunde und Gesichtspunkte ganz anderer Wissenschaftsgebiete: der Physiologie, Medizin, Sozialwissenschaft, Geschichte, Sprachwissenschaft, Kunstwissenschaft u.s.w. sind heranzuziehen, um mit psychologischen Befunden synthetisch verknüpft zu werden. Aus der Mannigfaltigkeit der möglichen Beziehungen entwickeln sich $\mathrm{U} n \mathrm{t}$ e r g e bie te der Ps y c ho$\log$ i e von relativer Selbständigkeit ${ }^{1}$ ).

Nun kann sich aber die Psychologie - wie überhaupt die Wissenschaft - nicht damit begnügen, das Zusammenvorkommen von zwei Erscheinungen oder Erscheinungsreihen lediglich empirisch festzustellen. Sie sucht sie auch zu ,e r k lär e n”.

„Erklären” heisst zunächst: Unterordnung der konkreten Einzelgeschehnisse unter abstrakte Beziehungsregeln.

Die Feststellung allgemeingültiger $G$ ese $t z e$ des G e$\mathrm{s} c \mathrm{~h}$ e h e $\mathrm{n}$ s ist bekanntlich die Hauptaufgabe der exakten Naturwissenschaft. Als die neue Wissenschaft der Psychologie sich an diesem älteren Vorbilde zu orientieren begann, hat sie zunächist ebenfalls das Finden psychologischer Gesetz$\mathrm{m}$ äs sigkeit e n als das wesentlichste - ja zeitweilig als das einzige - Ziel ihrer Arbeit angesehen.

Die Ausbeute solcher Bemühungen war sehr beträchtlich; wir werden später auf jedem psychischen Funktionsgebiet Befunde von allgemeiner Geltung zu besprechen haben. Freilich hat sich grade mit fortschreitender Arbeit ergeben, dass die Parallelisierung dieser Befunde zu den strengen Gesetzen der Physik oder Chemie irreführend ist. Es gibt für seelische Zusammenhänge nicht Formeln von ähnlicher Exaktheit und unverbrüchlicher Gültigkeit, wie sie das (iravitationsgesetz oder Gesetze der chemischen Synthese darstellen.

Die allgemeingültigen Formeln der Physik und Chemie setzen voraus, dass die in Beziehung gebrachten Tatbestände e in-

1) Vgl. Kap. II. 
d e u t i g einander zugeordnet sind. Das ist im Psychischen schon deshalb unmöglich, weil ja jeder Tatbestand durch seine Zugehörigkeit zu verschiedenen Ganzheiten (s. oben) in eine Lnendlichkeit von Zusammenhängen eingebettet ist, deren jeder die anderen mitbeeinflusst und färbt. Verallgemeinerungen sind deshalb im Bereich der Psychologie nur durchführbar vermittels der Fiktion, dass man bestimmte Erscheinungen herausgenommen denkt aus der Totalität ihrer Zusammenhänge und deren alleinige Beziehung zu best i $\mathrm{mm}$ te $\mathrm{n}$ anderen Gliedern beachtet. Die so gefundenen allgemeinen Sätze (z.B. das „Assoziationsgesetz”, das „Weber-Fechner' sche Gesetz”, „Gesetze” des Memorierens u.s.w.) haben daher nicht den Charakter von eigentlichen "Gesetzen” in naturwissenschaftlichem Sinne, sondern den von $\mathrm{R}$ e g e $\mathrm{ln}$; sie sind nicht unbedingt gültig, sondern nur plausibel; sie haben eine höhere oder geringere Wahrscheinlichkeit.

Es ist nicht zufällig, dass die $\mathrm{n}$ e u e r e $\mathbf{n}$ Versuche, exakte Methoden in der Psychologie anzuwenden, nicht mehr die Aufstellung allgemeiner Gesetze und Formeln als alleiniges Ziel betrachten; man erhebt auch die Abweichungen von der allgemeinen Regel selber zum Problem (Streuungsmalse); man bringt ferner die Festigkeit des angenommenen Zusammenhanges in einer Skala von Wahrscheinlichkeitsgraden zum Ausdruck (Korrelationsforschung).

Zum „Erklären” gehört dann weiter, dass die gefundene Regel des Geschehens einer gedanklichen Beziehungs-K a t e g o r i e unterstellt wird, Diese Kategorien liefern auf der einen Seite die objektiven Voraussetzungen für die Interpretation der Erfahrungstatsachen, auf der anderen Seite die subjektiven Arbeitshypothesen, die dem Forscher die Synthese des Stoffes ermöglichen.

Bei der Anwendung einer Arbeitshypothese liegt stets die (iefahr einer Vereinseitigung nahe: man beachtet lediglich eine einzige Art des Zusammenhanges, die zur Ordnung und Vereinfachung des Forschungsmaterials geeignet erscheint, und schiebt die anderen beiseite. Hier wird also die objektive Mannigfaltigkeit der Beziehungsweisen einer subjektiven Zweckmässigkeit zum Opfer gebracht. 
Eine umfassende Psychologie muss grade dieser Lockung widerstehen; sie muss sich den Blick für die verschiedenen Erklärungs ge sichts punkte offen halten und sie einem übergreifenden Zusammenhange unterstellen.

Nur zum Zweck vorläufiger Orientierung seien hier die drei wichtigsten Kategorien psychologischen Erklärens erwähnt.

$\mathrm{K}$ a u s le E r klärung: Beziehung von Ursache und Wirkung. - Beispiele: Sinnestäuschungen werden auf Veränderungen im Sinnesorgen, oder auf Erwartungsvorstellungen, oder auf suggrestive Beeinflussungen zurückgeführt. -- L̈berwertige Vorstellungskomplexe erwachsener Menschen werden aus einem, in der Kindheit erlebten, seelischen Chok erklärt. - Die bei einem Verbrechen wirksam gewesenen Motive werden aus Erbfaktoren, oder aus sozialer Not, oder aus Zugehörigkeit zu einer Bande abgeleitet u.s.w.

Fin a le (teleologische) E r k ä r u $\mathrm{g}$ : Beziehung von Mittel und Zweck. - Beispiele: das Schmerzgefühl wird als zweckmässiges Signal aufgefasst, indem es zur Beseitigung eines den Menschen gefährdenden Zustandes antreibt. - Die Intelligenz wird erkannt als das Mittel, durch welches sich der Mensch neuen und fremden Situationen des Lebens geistig anzupassen vermag. - Im Falle von Defekten können „Ersatzfunktionen” eintreten: so übernimmt beim Blinden der Tastsinn einen Teil der Aufgaben, die beim vollsinnigen Menschen der Gesichtssinn zu leisten hat.

Finale Beziehungen können auch negative Vorzeichen haben, d.h. Zweckwidrigkeit enthalten: man denke etwa an den Zusammenhang zwischen fehlenden seelischen Hemmungen und antisozialem Verhalten, oder zwischen gestörtem Familienleben und seelischer Zerrüttung.

Gre $\mathrm{n}$ e $\mathrm{t}$ i s che Erklä r u n g: Beziehung von Phasen innerhalb der Entwicklung. - Beispiele: die Entwicklung des kindlichen Sprechens aus vorsprachlichen Verhaltungsweisen des Lallens, des Nachahmens, der expressiven Geste. - Das Hervorgehen differenzierter und strukturierter seelischer Erscheinungen aus vageren und vieldeutigen Zuständen in Kindheits- und Menschheitsentwicklung. - Der Übergang aus den seelischen Zuständen der Vorpubertät in die Pubertät u.s.w.

c) Verstehe n und I) e u t e n. - (ieht das ,Erklären" auf die Regelhaftigkeit, so das "Verstehen" a uf die Sinnhaftigkeit ron $Z$ usammenhängen. Wir sprachen schon oben von dem notwendigen (ianzheitsbezug alles Seelischen: ist nun das (ianze ein Träger sinnvoller Bedeutung (eine menschliche Person, eine Gemeinschaft, ein Kulturwert), dann verstehen wir einen seelischen Tatbestand, sobald er in seinem inteil an diesem Sinnganzen erfasst wird. 
Wir ,verstehen" z.B. die Worte, die jemand spricht, als bedeutungshaltiges Mittel, mit ihm in Gemeinschaft zu treten; es ist ein in noch engerem Sinne psychologisches "Verstehen", wenn jene Worte uns des Sinn seiner Wünsche, Strebungen und Interessen enthüllen, wenn wir - durch seine Worte hindurch — ihn selber als personale Ganzheit erfassen.

Man hatte zeitweilig geglaubt, mit der Gegenüberstellung von „Erklären” und „Verstehen” z we i P s y c holog i e e n von wesenhafter Feindseligkeit postuliert zu haben; man hat den Gegensatz zugleich mit dem von ,naturwissenschaftlicher” und „,geisteswissenschaftlicher" Methodik und Problematik identifiziert. Nun ist es richtig, - unsere vorangehenden Ausführungen haben es schon angedeutet - dass die Psychologie längere Zeit hindurch unter dem einseitigen Einfluss naturwissenschaftlicher Gesichtspunkte stand und über den Elementen die Ganzheit, über der Gesetzmässigkeit die Sinnhaftigkeit ihres Gegenstandes vernachlässigt hatte. Es ist auch zuzugeben, das eine von dieser Einstellung beherrschte Psychologie für manche psychologischen Bedürfnisse der Geistes-, Kultur- und Geschichtswissenschaften nur Steine statt Brot bieten konnte. So begreift man die Versuche - sie erstrecken sich von Dilthey bis zu Spranger eine eigene Seelenkunde zu schaffen, die es mit den bedeutungshaltigen und wertbezogenen Subjekten der Geisteswissenschaft zu tun hat, die sogenannte ,verstehende" Psychologie.

Aber eine solche Trennung zweier Psychologieen ist höchstens als vorübergehende $Z$ wischenphase möglich und erträglich. Die letzten Jahrzehnte zeigen auch schon deutlich die Synthese. In dem Augenblick, da die Naturwissenschaften selber den engen Elementenstandpunkt verliessen, da insbesondere die organischen Naturwissenschaften immer entschiedener die Ganzheit der Organismen und die Bedeutungshaltigkeit aller Lebensprozesse betonten, war jener Scheidung schon viel von ihrer grundsïtzlichen Schärfe genommen - wie ja auch auf der andern Seite die Geisteswissenschaften mit ,naturwissenschaftlichen" Verfahrungsweisen und Gesichtspunkten (Statistik, Erbforschung, Trieblehre u.s.w.) arbeiteten, ohne ihr Wesen aufzugeben.

I) ie Psychologie aber ist berufen, das eigentliche Bindeglied herzustellen. Denn seelische Tatbestände können erst dort völlig verstanden werden, 
wo ebenso ihr organisch-naturaler wie ihr geistig-kultureller Sinnbezug erfasst wird; ja noch mehr: wo das Ineinander beider zum eigentlichen Gegenstand der Forschung wird. Wer ,naturwissenschaftlich" nur den organischen Aufbau der menschlichen Person, etwa ihr Trieb-und Instinktleben, ihre körperliche Gebundenheit, ihre Temperamentsbeschaffenheit, die Regelhaftigkeit der seelischen Abläufe beachtet, ist ihrem wahren Verständnis ebenso fern, wie derjenige, der ,geisteswissenschaftlich" nur den Oberbau - ihre Ideale, Wertrichtungen, kulturellen und geschichtlichen Bezüge-berücksichtigt. Trieb und Wert, Instinkt und Geist, Naturell und Charakter sind nicht jeweils zwei getrennten menschlichen Welten zugeteilt und völlig verschiedenen wissenschaftlichen Betrachtungen und Betrachtern zugeordnet. Sie sind vielmehr die unbedingt zusammengehörigen - wenn auch zum Teil unter stärksten Spannungen und Unstimmigkeiten zusammengehörigen - Momente in der Sinneinheit der menschlichen Person, und daher der $\mathrm{g}$ e me i $\mathrm{ns} \mathrm{ch}$ a f tliche Gegenstand der Wissenschaft von der menschlichen Person und ihrem seelischen Erleben.

Diese Einheit des Verstehens herbeizuführen, ist die besondere Aufgabe, die sich die ,personalistische" Psychologie setzt.

Nunmehr sind wir in der Lage, die letzte Aufgabe der wissenschaftlichen Psychologie zu umschreiben: das De uten.

Deuten ist vermitteltes Verstehen, in welchem zwei getrennte Tatbestände auf einander bezogen werden: derjenige, a u $\mathrm{d}$ e $\mathrm{m}$ heraus etwas verstanden wird, und derjenige, $d$ e $r$ verstanden wird. Der erste wird g e deutet und bildet die "Deutungsmaterie"; der zweite wird e r deutet und bildet das ,Deutungsziel”.

So werden Gesichtszüge oder Schriftzüge g c deutet auf gewisse Charaktereigenschaften; es werden Testleistungen g e deutet auf Intelligenzgrade und Berufseignungen. Andrersits werden geheime Wunschsysteme cines Menschen e r deutet aus seinen Träumen, tiefere Erlebnisschichten eines Künstlers e r deutet aus seinem Werk.

Betrachtet man diese verschiedenen Bispiele, so zeigt sich ein gemeinsamer Zug aller Deutung: sie ist T i e f e $\mathrm{n} s \mathrm{ch}$ a $\mathrm{u}$, sie geht von aussen nach innen. Die Deutungsmaterie ist stets 
das mehr Äusserliche, Vereinzelte, Abgehobene; das Deutungsziel stets das mehr Innerliche, mit der Totalität der Person inniger Verschmolzene. Diese Vertikalrichtung unterscheidet die Deutung von der „Erklärung”, die auf das „horizontale" Nebeneinander der zu verknüpfenden Erscheinungen geht. Aber eben diese Besonderheit macht die Deutung zu einer Aufgabe von ungewöhnlicher Schwierigkeit; denn der Weg in die Tiefe ist zugleich der Weg in das Unbestimmte, schwer Ausdrückbare, ist die Annäherung an das Ineffabile, den eigentlichen Sinn der Persönlichkeit.

Die Gefahr ist gross, dass dieser Weg zu leicht genommen wird. Man glaubt, jene personale Tiefe, auf welche die Deutung geht, ebenso eindeutig formulieren und hart aufteilen zu können, wie die äusserlichen Symptome, aus denen man die Deutung schöpft. Dann kommt es zu „,Persönlichkeitsdiagnosen”, die im Grunde nur aus einem Register nebeneinandergeordneter Eigenschaften bestehen; dann wird ein einziger Symptomkreis, z.B. die Handschrift, als Lniversalschlüssel zur Erkenntnis des Menschen benutzt und je ein Einzelsymptom zu je einer Einzeleigenschaft in Beziehung gesetzt (,Nonosymptomatik”).

Da nun ein starkes praktisches Bedürfnis des Laienpublikums nach solchen Seelenschilderungen und Charakterdeutungen besteht, hat sich eine weite volkstümliche Persönlichkeitsdiagnostik entwickelt, welche zuweilen zu einer bedenklichen „Deutungspfuscherei" ausartet; von ihr wird in anderem Zusammenhang noch einiges zu sagen sein (S62f).

Aber auch die wissenschaftlichen Methoden der Persönlichkeitsdeutung halten sich nicht immer von den oben genannten Fehlern frei; Neigung zur Monosymptomatik zeigt etwa die Psychoanalyse, welche nur die dem Willen entzogenen Seelenäusserungen als Symptome verwertet; oder auf anderer Seite die experimentelle Psychotechnik, wenn sie ihre Eignungsfeststellungen lediglich auf Testprüfungen stützt.

Um diesen Gefahren und Bedenken zu begegnen, steht vor der Psychologie die grosse Zukunftsaufgabe, eine wissenschaftlich einwandsfreie und praktisch zuverlässige $\mathrm{D}$ e u t u $\mathrm{ngs}$ t e chn ik zu erarbeiten. Diese hat zwei Forderungen zu erfüllen: 1) Die Ieutungsmethodik muss personalistisch sein, d.h. die cinzelnen Symptome in ihrem personalen (janzheitsbezug 
erkennen und verwerten. 2) die Methodik muss „p o l y-s y m pto matisch" sein, d.h. souverän über die verschiedenen Symptomgebiete verfügen und ihre Verbindung elastisch der jeweiligen psychodiagnostischen Aufgabe anpassen können. Hierbei sind - mit Vorsicht und Kritik - auch die positiven Einsichten und Verfahrungsweisen zu berücksichtigen, die von den monosymptomatischen Systemen volkstümlicher und wissenschaftlicher Art erarbeitet worden sind.

Von der Methode der „Deutung” her fällt noch einmal ein Licht auf die sogenannte ,verstehende” Psychologie. Wenn das Verstehen, wie wir sahen, nur zum kleinsten Teil unmittelbar (rein ,,intuitiv") vor sich geht, zum weitaus grösseren Teil mittelbar (,deutend') - dann bedarf auch die verstehende Psychologie einer breiten und tiefen $\mathrm{T}$ a $\mathrm{t} \mathrm{s}$ a $\mathrm{ch}$ e $\mathrm{n} \mathrm{b}$ a s i s, die sich ebenso auf die deutbaren Symptome wie auf die zu erdeutenden Persönlichkeitszüge, wie endlich auf die Zusammenhänge zwischen beiden erstrecken muss. Und durch diesen $Z$ w an $g$ z u r E mp i r i e, die ohne emsige Kleinarbeit nicht möglich ist, kommt die verstehende Psychologie wieder in enge Berührung mit jenen Forschungen wie sie von der mehr "naturwissenschaftlich" eingestellten Psychologie ausgeführt zu werden pflegen. So ist auch von dieser methodischen Seite her zu hoffen, dass di e e in e Psychologie jenseits jener Gegensätze im Entstehen begriffen ist. Innerhalb ihrer bleibt Raum für die verschiedensten Interessen, Richtungen und Ziele. 


\section{ZWEITES KAPITEL}

SONDERGEBIETE DER PS Y C H OLOGIE

Das vorige Kapitel hatte das eigentliche Kerngebiet unserer Wissenschaft, die "Allgemeine Psychologie” in ihren Aufgaben abgesteckt. Wir müssen nun aber auch einen Blick auf die zahlreichen Seiten-und Übergangsgebiete werfen.

Soweit sich diese the or et is c h e Aufgaben stellen, bilden sie zwei grosse Gruppen: Wissenschaften, die die seelischen Tatsachen nicht an sich, sondern in ihren $B$ e $z$ i e h ung en $z$ ur W e l t behandeln; solche, die das seelische Leben nicht in seinen allgemeinen Formen und Gesetzen, sondern in seinen D if f e r e n$z$ i e r u n g en zum Gegenstand haben.

Als dritte Gruppe tritt dann die der prakt is chen A nwendungsgebiete der Psychologie hinzu.

\section{SEELENLEBEN CND WELT}

Die "Welt”, mit der das Seelenleben wissenschaftlich in Beziehung gebracht wird, ist sowohl die Naturwelt wie die Kulturwelt. Der Umstand, dass es ganz verschiedene Sonderwissenschaften sind, welche die Natur bezw. die Kultur bearbeiten, hat auch auf die Psychologie zurückgewirkt.

\section{Seelenleben und Naturwelt}

Die Naturwissenschaften haben der Psychologie nicht nur vielfach als methodisches Vorbild gedient; sie sind auch $s$ t of $f$ l i c h mit ihr in direkte Verknüpfung getreten. Dies gilt vor allem von der Physik, der Physiologie, der Biologie. Schon die Namen der so entstehenden Disziplinen drücken diese Verbindung deutlich aus. In den sechziger und siebziger Jahren des 19. Jahr- 
hunderts wurden „Psychophysik” und „physiologische Psychologie" begründet. Für die ,,biologische Psychologie" gibt es zwar auch schon viele ältere Ansätze; ihre eigentliche Entfaltung gehört aber unserem Jahrhundert an.

a) Psychophysik. - Gustav Theodor Fechner, Physiker von Fach, - aber ein Mann, dessen Vielseitigkeit keine Fachgrenzen achtete ${ }^{1}$ ) - fasste die hochfliegende Konzeption einer Wissenschaft, die Physik und Psychologie umfassen sollte, etwa in folgendem Sinne: Die Physik handelt von den Elementarvorgängen des Lichts, des Schalls, des Massendrucks u.s.w., die - sofern sie auf den Menschen wirken - „Reize" genannt werden. Die Psychologie hat es mit den Bewusstseinsinhalten zu tun, die diesen Reizen entsprechen, also mit den „Empfindungen". Psychophysik ist demnach die Wissenschaft von den gesetzmässigen Beziehungen $z$ wischen Reizen und Empfindungen.

In welcher Weise kommen die Empfindungen den unendlichen $\mathrm{Ab}$ stufungen und Verschiedenartigkeiten der Reize nach? So lautet Fechner's Frage, die er nicht nur durch die wichtigen Begriffe der "Reizschwelle" und der „Unterschiedsschwelle" klärte, sondern auch durch die neue und damals ungeheures Aufsehen erregende Methode experimenteller "Empfindungsmessungen" zu beantworten suchte. Als Ergebnis dieses kühnen Lnternehmens glaubte er eine umfassende Weltgesetzlichkeit gefunden zu haben, die uns später als das „Weber-Fechner'sche Gesetz" noch näher beschäftigen wird. Um dieses Gesetz ist es heut still geworden, vielleicht stiller als gerechtfertigt ist. Das Gesetz hat zwar nicht Fechner's Hoffnungen erfüllt, d i e Generalformel für das Verhältnis der physischen zur psychischen Welt zu bilden; doch hat es immerhin als Leitgesichtspunkt zur Erklärung und zum Verständnis wichtiger seelischer Zusammenhänge bleibende Bedeutung.

b) Physiologische Psychologie.- Die Physiologie, als Wissenschaft von den Funktionen des Organismus, hatte natürlich schon immer die Zusammenhänge bemerkt, die zwischen ihrem eigentlichen Forschungsobjekt (Nervenprozessen, Blutzirkulation, Stoffwechsel) und seelischen Vorgängen bestanden. Aber sie hatte diese Beziehungen doch nur beachtet,

1) Er war einer der ganz wenigen (ieister, die in einter Epoche der Enphimaphit. (im zweiten Drittel der 19. Jahrhunderts) motaphysischen (itanken nachzugehti wagten. 
soweit sie zum Verständnis der eigentlich physiologischen Vorgänge erforderlich waren. Durch Wilhelm Wundt, der selber früher Physiologe gewesen war, wurde nun die Problematik u m ge kehrt. Er wollte unter Heranziehung der physiologischen Tatbestände Ps y c h o l o g i e treiben. Sinneswahrnehmung, Aufmerksamkeit, Reaktionszeit, Bewusstseinsumfang, Gefühlsausdruck waren einige der Hauptthemen, die er unter ständiger Bezugnahme auf die körperlichen Begleitvorgänge und unter vielseitiger Anwendung der experimentellen Methode bearbeitete. Seine dreibändige „Physiologische Psychologie” war Jahrzehnte hindurch das Standwerk der modernen Psychologie; sein in Leipzig gegründetes psychologisches Laboratorium wurde zum Nuster für zahllose psychologische Institute in aller Welt. Neben Wundt ist aus jener älteren Zeit noch $\mathrm{H}$. von Helmholtz zu nennen, der zwar nicht Psychologe in eigentlichem Sinne war, aber durch seine fundamentalen Arbeiten über physiologische Optik und über Tonwahrnehmungen unserer Wissenschaft stärkste Impulse gab.

Die physiologische Psychologie bearbeitet drei Hauptgebiete: die Sinneswahrnehmungen, die Gehirnprozesse, die Bewegungsvorgänge. Was auf diesen Forschungsgebieten in dem halben Jahrhundert seit Wundt geleistet worden ist, ist fast unübersehbar.

Zum Teil waren es wieder Mediziner, Physiologen, Anatomen, die durch ihre neuen Funde die Psychologie bereicherten - so sei hier nur daran erinnert, wie sehr die Forschungen über die Lokalisation bestimmter Leistungen im Gehirn die psychologische Auffassung der Bewusstseinserscheinungen beeinflussten. Andrerseits sind aber auch die Psychologen bei ihren Untersuchungen über Tonsinn, Tast- und Vibrations-Sinn, Lichtsinn, Gestaltauffassung, Ausdrucksbewegungen, u.s.w. weit ins Physiologische vorgestossen und haben viele neue Erfahrungen und Theorieen erarbeitet.

1)iese Bewegung schreitet auch heut noch vorwärts; es hat sich aber ihr Schwerpunkt etwas verlagert, indem mehr und mehr div ganzheitliche Betrachtung des Organismus in den Vordergrund trat und so die Bahn bereitete für die

c) Biologische Psychologi e. - Seelenleben ist ein stick , I.elen", ist dem (iesamtleben des Individuums unlösbu: eingeschmolzen. Barum sind die Betrachtungsweisen, welche 
die Biologie zur Erklärung des organischen Lebens überhaupt entwickelt hat, auch auf die psychischen Lebensvorgänge anzuwenden.

So hat seinerzeit die aufkommende Entwicklungslehre (Spencer, Darwin) versucht, das Bewusstsein teils als Erzeugnis, teils als Motor der biologischen Prozesse des Daseinskampfes, der Anpassung, der fortschreitenden Differenziation und Integration zu erweisen. - Die beiden grossen Gruppen von B e ding u n g e $n$ organischen Werdens: Vererbung und Umwelt - zunächst nur beachtet in ihren Wirkungen auf körperliche Beschaffenheiten und Funktionen — wurden dann auch mehr und mehr für die Erklärung seelischer Eigenschaften und Vorgänge verwandt.

Der Umstand, dass sich die Biologie vorwiegend an der Erforschung untermenschlicher Lebewesen entwickelt hatte, machte sich auch bei ihrer Ubertragung auf die Psychologie geltend. Es ist ja ganz selbstverständlich, dass die T i e r p s y cholog i e stark biologisch orientiert sein muss; sofern beim Tier überhaupt p s y c h i s c h e Tatbestände auftreten, sind sie auf das Innigste eingebettet in die unmittelbaren Vitalbedürfnisse der Selbsterhaltung, Fortpflanzung u.s.w. und nur aus diesen Zusammenhängen verständlich. Auf der andern Seite wurde die Psychologie des Menschen hingelenkt auf die Beachtung derjenigen Seelenvorgänge, die bei Mensch und Tier identisch oder doch verwandt sind, also wiederum auf die vitalen Untergründe und somatischen Voraussetzungen des Seelischen.

Blicken wir auf den gegenwärtigen Stand dieser Bestrebungen, so finden wir, dass die heutige Psychologie in der Tat eine ganz andre Vit aln äh e zeigt, als die Psychologie früherer Zeiten. Charakteristisch dafür ist die starke Rolle, die heut die Kategorie des $\mathrm{Tr}$ i e b e s in gewissen psychologischen Schulen spielt, und der Versuch, auch die höchsten Formen des geistigen, moralischen, künstlerischen, religiösen Erlebens als Auswirkungen oder Umwandlungen primitiver Triebregungen zu erklären. I)as führt natürlich leicht zu einer allzu grossen Annäherung an das tierische Scelenleben; die Eigenbedeutung der spezifis ch menschlichen (sogenannten ,höheren”) Seelenfunktionen kommt dabei zu kurz. Aber als Reaktion auf eine recht abstrakte (ieistespsychologie war und ist doch diese Wendung dor Aufmerksamkeit zur erdgebundenen Verstricktheit des Seelenlebens von srïsster IIicht igkeit gewesen. 
Die Kategorie des „,Triebes” ist eigentlich keine rein psychologische, aber auch keine rein somatische; sie gehört vielmehr dem, noch garnicht in Physis und Psyche aufgeteilten, Urbereich des Lebens an. Hier berührt sich also die biologische Psychologie mit der Personalistik und ihrem Begriff der „psychophysischen Neutralität" der Person (vgl. Kap. IV). - Entsprechendes gilt bezüglich der neueren Lehre von der „Konstitution”, in welche ebenso Körperbau und Körperbewegung, wie die seelische Dynamik und Statik eingehen. Man beginnt sogar von einer „B i o 1 ogi e der Person” zu sprechen - wobei freilich die „Person" wiederum allzusehr zur blossen „Vitalperson” verengert wird. Auch die starke Verwertung des Begriffs des „Unbewussten” ist zum Teil aus biologischer Einstellung erklärlich.

Eine äusserste Konsequenz dieser Bewegung ist es, dass man am Menschen überhaupt nur noch das $\mathrm{P}$ h y s i s c h-Organische als Forschungsobjekt übrig lassen will, das Psychische dagegen ganz streicht. Dies geschieht in der ,Ver halte n s le h r e” (Behaviorismus), die vor allem in Amerika - in verwandter Form aber auch in Russland als , Reflexologie” - vertreten wird. Sie beschränkt sich bewusst darauf, das äus s e r li ch wahrnehmbare Verhalten von Mensch und Tier in bestimmt umschriebenen Situationen zu studieren; denn nur dieses sei objektiv aufweisbar und beliebig nachprüfbar; auch reiche dessen Darstellung völlig aus, um ein Individuum in all seinen Lebensfunktionen zu erkennen. Was bei diesem Verhalten innerlich passiert (d.h. im Bewusstsein erlebt wird), sei nie in einer Form zu erfassen, die wissenschaftlichen Objektivitätsansprüchen genüge, und sei deshalb aus der Wissenschaft auszuschalten.

Es ist zuzugestehen, dass dort, wo das Innenleben der untersuchten Individuen einerseits sehr dürftig, andrerseits sehr schwer erkennbar ist - z.B. bei Tieren, bei menschlichen Säuglingen schon die blosse Untersuchung des objektiven Verhaltens sehr wichtig sein kann; ferner, dass auch in höheren Entwicklungsformen das seelische Erleben erst durch seine Verbindung mit genau zu studierenden äusseren Verhaltensweisen verständlich wird. So ist die Verhaltensforschung als ein wertvolles Glied innerhalb der Psychologie zu begrülsen, aber die Meinung zurückzuweisen, als ob sie alles, was bisher Psychologie hiess, aufsaugen und überflüssig machen könne. - 
Bemerkenswert sind die Wandlungen, die die psychologische Beschäftigung mit den $\mathrm{Kausalfaktoren} \mathrm{des} \mathrm{Lebens:}$ Vererbung und Umwelt, in jüngster Zeit erfuhr. Die Fortschritte sind so bedeutend, dass man schon von einer eigenen $\mathrm{p} \mathrm{s}$ y ch ologischen Erbforschung und psychologi$\mathrm{schen} U \mathrm{~m}$ weltforschung sprechen kann. Hierbei zeigt es sich, dass man der rein biologischen Erb- und Umweltlehre zwar wichtige Leitgedanken e $\mathrm{n}$ t-nehmen muss, sie aber keineswegs unverändert ü be r-nehmen darf. Der $\mathrm{II}$ e $\mathrm{n} \mathrm{sch}$ ist in anderer Art und in geringerem Ausmass erbbestimmt als Pflanze und Tier, und das S e e l e $\mathbf{n}$ geschehen unterliegt anderen Erbbedingungen als rein körperliche Strukturen.

Psychische Eigenschaften vererben sich nicht als feste eindeutige Gegebenheiten, sondern nur als vieldeutige Möglichkeiten; es erscheint aussichtslos, die strengen Gesetzmässigkeiten der biologischen Erbbeziehungen hierauf anwenden zu wollen. Auch die Problemesind andere. $\mathrm{Zu} \mathrm{dem}$, was heut unter den Themen: erbliche Belastung und Entlastung, Familienpsychologie, Rassenpsychologie, Erblichkeit von Talent, Genie, Kriminalität, Psychopathie u.s.w. behandelt wird, gibt es doch nur sehr partielle oder garkeine Analogien in den Erbforschungen der Tier- und Pflanzenkunde. Viel näher sind die Zusammenhänge der Erb-Psychologie mit Betrachtungen der Nedizin auf der einen, der Geschichte auf der andern Seite; doch auch gegen diese beiden wird sie ihre spezifischen Fragestellungen und Verfahrensweisen abzugrenzen haben.

Ähnliches ist über die „U m we l t-Forschung” zu sagen. Die Umwelt des tierischen Individuums (wie sie z.B. von der Schule v. Uexkülls untersucht wird) ist starr und eng. Der Mensch hat eine labile, ewig wechselnde - vor allem mit sozialen, kulturellen und ideellen Momenten erfüllte - Lmwelt, die zu gänzlich neuen (beim Tier nicht erforderlichen und nicht möglichen) seelischen Reaktionen führen muss.

Besonders deutlich wird diese Wendung ins TransBiologische dort, wo die Beziehung beider Kausalfaktoren in Frage steht: Lassen sich nämlich bei Tier und Pflanze noch immerhin die Erbfaktoren einerseits, die Umweltfaktoren andrerseits ziemlich selbständig herauspräparieren und gesonderten Disziplinen zuweisen, so hört beim menschlichen Seelenleben diese Möglichkeit auf; nicht mehr Erbgut hier, Milieuwirkung dort - sondern das ständige Zusammenschmelzen beider 
in der Person und mit der Spontaneität der Person ist das eigentliche Problem. Es ist nur auf der Grundlage der Personalistik zu behandeln (Vg1. Kap. IV).

\section{Seelenleben und Kulturwelt}

Die Zusammenhänge, in denen menschliches Seelenleben zur $\mathrm{Kultur}$ steht, sind unter drei Hauptgesichtspunkten Gegenstände psychologischer Sondergebiete geworden. Die Gesichtspunkte sind: Gemeinschaft, Geschichte, Kultur-Sphaeren.

a) Gemeinschaftspsychologie. - Diese Bezeichnung ist hier nur ein Notbehelf; es gehört alles hinein, was unter dem Namen Völkerpsychologie, Sozialpsychologie, Massenpsychologie u.s.w. einhergeht. Den Ausgangspunkt bildet die Grunderkenntnis, dass es über-indıviduelle und $z$ wis ch e n-i n d i vid u e 11 e seelische Tatbestände gibt.

$Z$ war ist jeder individuelle Mensch unaufhebbar Subjekt seelischen Erlebens; aber Art und Inhalt dieses Erlebens erwachsen vom ersten Lebensmoment an aus dem stetigen Zusammenhang mit anderen Menschen; und dieses unablässige, in tausend Formen sich vollziehende Wechselspiel der Seelenvorgänge führt zu einer Reihe von Erscheinungen, die - gle i ch s a m losgelöst von den Individuen - ein eigenes Dasein führen und eigenen Gesetzen gehorchen. In dieser „Ent-Individualisierung" gibt es alle möglichen Stufen: von jenen sozialpsychischen Tatbeständen an, bei denen die individuellen Träger noch erkennbar bleiben und ihre besondere Tönung behalten (Erotik, Nachahmung, Führertum) - bis hin zu solchen, in denen das Individuum ganz in der Masse verschwindet und an den ïberindividuellen Phänomenen nur noch einen anonymen Anteil hat - man denke etwa an eine Revolutionsstimmung, eine Panik, an die Ausbildung eines psychischen Berufstypus, eines Volkscharakters.

Eine philosophische Betrachtung, die sich zuweilen an solche Feststellungen anknüpfte, sei hier nur kurz angedeutet. Die gewaltige Wucht der überindividuellen seelischen Phänomene bewog manche Denker, ihnen einen eigenen psychischen $\mathrm{T} r \ddot{a} g$ e $r$ unterzulegen, also von ,Volksgeist", ,Massenseele”, ,, Klassengeist” und Ähnlichem 
nicht nur in übertragenem, sondern in eigentlichem Sinne zu sprechen. Für die erfahrungswissenschaftliche Psychologie ist eine Stellungnahme zu solchen spekulativen Gedanken nicht notwendig; sie hat vor allem die Dynamik, die Beschaffenheit und die kausale Bedingtheit dieser Gemeinschaftsphänomene zu untersuchen.

Gemeinschaftspsychologische Forschungen traten in zwei recht verschiedenen Ausprägungen auf.

In den sechziger Jahren des 19. Jahrhunderts haben Lazarus und Steinthal Begriff und Gebiet der Völ k e r p s y c holog i e programmatisch umrissen; am Ende des Jahrhunderts erfuhr diese Disziplin in Wundts grossem Alterswerk eine Zusammenfassung. Es waren also die $\mathrm{Vol}$ k semeinschaften, die als Träger vongemeinschaftspsychischen Erscheinungen berücksichtigt wurden, und zwar vorzugsweise die primitiven Völker. An diesen untersuchte man die psychischen Vorgänge des Sprachgeschehens, der religiösen und mythischen Kulte und Uberzeugungen, der Bräuche und Rechtsformen. Da bei solchen Völkern die Wandlungen der Geschichtlichkeit keine wesentliche Rolle zu spielen schicnen, so glaubte man hier am ehesten zu wirklichen völkerpsychologischen Geset $z$ en allgemeiner Geltung vordringen zu können.

Die andre Strömung kam von jener Wissenschaft her, deren Zentralproblem die Gemeinschaft ist: von der Soziologie; es entstand eine "Sozialps y ch olog i e". Diese hatte es nicht so sehr mit den seelischen Inhalten be st i m m te $r$ Gemeinschaften (wie etwa des Volkes) zu tun, sondern mit den psychischen Vorgängen, welche Entstehung, Leben und Struktur von Ge meinschaften überhaupt begleiten. Es handelt sich hier also zum Teil um mehr formale und dynamische Kategorieen wie: Wetteifer, Suggestion, Klassenbildung, Mode, Angleichung und Differenzierung u.s.w. - immer im Hinblick auf die psychischen Crsachen, Ausdrucksformen und Folgen. - Ebenso wie bei der Völkerpsychologie, viclleicht noch ausgesprochener, ist hier das Verlangen erliennbar, zu allgemeinen, von jeweiliger historischer Situation unabhängigen, G e s e t zmässigkeiten zu kommen. Damit erstreben diese psychologischen Iisziplinen eine Annäherung an die Exaktheit und generelle betrachtungsart der Naturwissenschaften. Aber eben deshalb bedürfen sie der Ergänzung durch eine 
b) $\mathrm{H}$ is torische Psychologi e. - Denn Geschichtlichkeit ist ein so wesenhafter Faktor menschlicher Kultur, dass sie ihren Anspruch auf Beachtung auch in psychologischer Hinsicht erheben muss. Dies gilt ebenso bezüglich der geschichtlichen Einzel-Persönlichkeiten, wie der überindividuellen Geschichtsträger, der Völker, Staaten, Kulturen; sie alle haben ja — gerade in der E i n maligkeit ihrer geschichtlichen Struktur auch ihre geistig-seelische Eigenart; diese kann nicht mehr einfach durch Anwendung allgemeiner Gesetzmälsigkeiten erklärt, sondern sie muss in ihrem singulären So-Sein und So-Werden verstanden werden.

Die verstehende Psychologie ist nicht zufällig von einem Historiker begründet worden: Dilthey war der Biograph grosser Persönlichkeiten des Geisteslebens gewesen.

Seit Dilthey hat die psychologische Biographik manche Wandlungen und Erweiterungen erfahren. Neben die W e s e n s deskription der einzelnen Persönlichkeiten trat die Untersuchung ihrer historischen $\mathrm{B}$ e ding the it, wobei nicht selten auch Gesichtspunkte aus der biologischen Sphäre, z.B. erbgenealogische oder milieupsychologische, mit einbezogen wurden.

Die mannigfachen psychologischen Schulen versuchten - mit wechselndem Glück und sehr verschiedener historischer Begabung - ihre Theorieen ins Biographische zu wenden: so sei an die Biographieen aus der Feder der Psychoanalytiker, oder an die "Pathographieen", die Möbius von Denkern und Dichtern gab, erinnert; neuerdings sucht Ch. Bühler „Lebensläufe" psychologisch zu analysieren.

In der psychologischen Erforschung der $\mathrm{V}$ ö $1 \mathrm{k}$ e r musste der geschichtsfremde Standpunkt der älteren Völkerpsychologie um so unzulänglicher sein, je ausgesprochener ein Volk his t or i$\mathrm{sche} \mathrm{Nation}$ ist. Eine Psychologie der Kul$\mathrm{t} u \mathrm{rn}$ a tio ne $\mathrm{n}$ - die wir noch nicht haben, aber dringend brauchen - muss die unvergleichliche Besonderheit der Geistigkeit jedes Volkes gegenüber jedem andern verständnisvoll erfassen; sie muss aber dabei wiederum vermeiden, die Mentalität des einzelnen Volkes auf eine starre Formel zu bringen, die nun etwa für alle Phasen in der Geschichte des Volkes und für alle (ilieder des Volkes Gültigkeit haben sollte. Auch bei der Ursachfrage gibt es hier viele Klippen. Das seelisch-geistige Werden und Sein einer jeden Nation ist ja nur aus dem innigen Zusammenwir- 
ken von Erbgang u n d Schicksal zu verstehen; Rassen-Einheit oder -Mischung ist hieran ebenso beteiligt, wie Boden und Klima, Wirtschaft und politisches Erleben, Gemeinsamkeit von Sprache und Kultur - jede Theorie, die e in e n dieser Faktoren zur überragenden oder gar alleinigen Ursächlichkeit der Volkspsyche machen will, kann nur ein Zerrbild liefern. - Die Aufgabe einer Psychologie der Nationen ist so schwer, dass die bisherige $\mathrm{Zu}$ rückhaltung der Wissenschaft sehr wohl begreiflich, wenn auch bedauerlich ist.

c) Kulturpsychologie im engeren Sinne. Geschichtliche Kulturentwicklung bedeutet nun aber nicht nur die Herausdifferenzierung von Phasen und Stufen im Nacheinander, sondern auch die immer deutlichere Auseinanderfaltung zu bestimmten Kultursphären im Nebeneinand e r. Bei dieser Verselbständigung der Kulturgebietegehen praktische und theoretische Faktoren parallel. Je vielseitiger die kulturellen Verbundenheiten des Menschen sind, um so deutlicher formen sich einzelne Bereiche wie Religion, Kunst, Wissenschaft, Politik, Recht u.s.w. Diese Gebiete gewinnen allmählich ihre eigenen Objektivationsweisen, Gesetze und Ideale, ziehen die Menschen mit grosser Intensität - zuweilen mit despotischer Ausschliesslichkeit - in ihren Bann und führen endlich auch zur Ausbildung von Sonderwissenschaften (Kunstwissenschaft, Rechtswissenschaft, Erziehungswissenschaft u.s.w.).

Um das völlige Zerfallen der Kulturbetrachtung - und schliesslich der Kultur selbst - in Iauter Einzelgebiete zu verhindern, musste philosophische Selbstbesinnung einsetzen und synthetische Arbeit leisten. Es entstand eine $\mathrm{Kult} u \mathrm{rph}$ ilo sophie, die ihre erste grosse Ausbildung in Hegels Lehre vom ,objektiven Geiste" erfuhr, und die heut vornehmlich wertphilosophischen Charakter hat. Den einzelnen Kultursphären werden überindividuelle allgemeingültige Werte zugeordnet: Nutzen, Schönheit, Macht, Heiligkeit, Wahrheit, Gemeinschaft u.s.w.; diese Werte werden in Seins- und- Rangbeziehungen gebracht.

Von hier aus war nun der Schritt ins Kultur-P s y c h o l o g is c he nahe gelegt, wie er dann von Simmel, Scheler, Spranger, Litt, Jaspers und manchen andern getan wurde. ,Kulturpsychologie" betrachtet das menschliche Scelenleben in seiner Wertbezogenheit auf die objektiven Kultursphären. Nicht mehr die 
Beschaffenheit der im Bewusstsein vorkommenden Inhalte als solcher, sondern der $\mathrm{kulturelle}$ Sinn dieser Inhalte wird zum Gegenstand psychologischer Arbeit.

Natürlich kann die Sinnbezogenheit auch ein negatives Vorzeichen haben: so, wenn kriminelle Gesinnungen, antisoziale Strebungen u.s.w. als psychologische Forschungsobjekte auftreten. Primärer Gesichtspunkt der Kulturpsychologie ist aber doch die positive Sinnbeziehung von Seele und Kultur. Diese ist nicht nur das Ausleseprinzip, nach welchem die wissenschaftliche Arbeit gewisse seelische Tatbestände bevorzugt, andere vernachlässigt; sondern sie ist die verschwiegene Voraussetzung für die Auffassung des Seelischen überhaupt; es wird eine Art von prästabilierter Harmonie angenommen zwischen den Strukturformungen im Seelischen auf der einen, den objektiven Kulturbereichen auf der andern Seite.

So postuliert Spranger sechs „Lebensformen”, d.h. menschliche Idealtypen, die durch die vorzugsweise seelische Verwandtschaft mit einem der sechs Wertgebiete bestimmt sind. Es sind dies: der ökonomische, der intellektuelle, der politische, der ästhetische, der soziale, der religiöse Typ.

Nan erkennt, dass die Kulturpsychologie sehr stark von philosophischen Einstellungen determiniert wird. Das ist nun gewiss an sich kein Nachteil; es kann aber zu einer Gefahr werden, wenn sich die konstruktive Denkweise des Philosophen als Ersat $z$ für wirkliche Erfahrungspsychologie anbietet. So einfach, so durchsichtig, so sinnvoll wie die „Idealtypologieen” der Kulturpsychologie es glauben machen, ist das tatsächliche Seelenleben niemals; seine Vielschichtigkeit, seine Durchsetztheit mit Sinnwidrigkeit und Irrationalität, die innere Gespanntheit zwischen vitalen und kulturellen Kräften kommt in jenen Betrachtungsweisen nicht immer zur genügenden Geltung.

\section{DIFIERENZIERLNGEN DES SEELENLEBENS}

1. Differentielle Psychologie.

( h h a rakterologie

Kein liensch gleicht dem anderen; jeder hat seine individuelle Eigenart. - Dieser so banal klingende Satz birgt eine Fülle psy- 
chologischer Probleme in sich. Merkwürdigerweise war aber leren Behandlung bis vor kurzem ganz und gar dem gesunden Menschschenverstande ${ }^{1}$ ) und mehr oder weniger dilettierender Psychognostik überlassen geblieben.

Die zünftige Fachpsychologie bis zum Ende des 19. Jahrhunderts liess die differentielle Problematik entweder bei Seite liegen oder behandelte sie höchstens anhangsweise, und mit jener Zaghaftigkeit, welche abstrakte Wissenschaft oft bei notgedrungener Annäherung an die Fülle des Lebens zeigt. Vereinzelte Forscher des vorigen Jahrhunderts griffen wohl ernsthafter die Fragen der seelischen Verschiedenheiten an; sie blieben aber ohne dauernde Wirkung (Carus, Bahnsen, Galton u.a.). Geniale Persönlichkeiten, die - wie etwa Nietzsche an die Quellen menschlicher Eigenart herabstiessen, wurden nicht zu den Fachpsychologen im eigentlichen Sinne gezählt.

Das letzte Menschenalter hat Wandel geschaffen; und zwar lässt sich hier schon eine ältere und eine neuere Strömung unterscheiden.

Die erste kam von der experime n telle n Psychologie her. Bei experimenteller Erzeugung seelischer Leistungen zeigte sich nämlich deutlich, dass verschiedene lienschen auf gleiche Aufgaben verschieden reagierten. Zunächst hatte man in diesen Varietätenbildungen nur peinliche Einschränkungen der gesuchten allgemein-psychologischen Gesetzmässigkeiten gesehen; bald erkannte man aber, dass die Abweichungen selber auf (iemeinsamkeiten engerer Geltung beruhten, m.a.W., dass sich in ihnen typische Sonderformen des Seelenlebens oder bestimmte Grade psychischer Fähigkeiten bekundeten.

Nit dieser Einsicht war die ,d if f e r e n t i e 11 e P s y c holog i e" begründet ${ }^{2}$. Sie will nicht eigentlich Psychologie der "Individualitäten" sein, sondern die Wissenschaft von den wesentlichen Differenzierungen seelischer Funktionen und Eigenschaften - damit freilich eine B ü cke zwischen der allgemeinen Psychologie und der psychologischen Erfassung der Individualitäten.

Jedes seelische Funktionsgebiet erhiclt nun neben der generellpsychologischen seine differentiell-psychologische Behandlung; so trat neben die (generelle) Denkpsychologie die (differentielle) Intelli-

1) Virl. S.7.

2) bie bezcichneng ist von mir im Jahre $19^{-2}$ votgeschlagen worden 
genzforschung; neben die allgemeine Willenspsychologie die Lehre von den Willenstypen u.s.w. Auch methodisch verselbständigte sich die differentielle Psychologie: das Experiment wurde lebensnäher; dazu traten andere Verfahrensweisen: Beobachtung, Sammlung, Erhebung.

Eine bedeutende Rolle spielt in der differentiellen Psychologie die vergleichende Betrachtung. Menschengruppen, die durch bestimmte ausserpsychologische Gesichtspunkte gegeneinander abgegrenzt sind, werden in ihren verschiedenen psychischen Verhaltungsweisen und Reaktionen miteinander verglichen: so etwa die beiden Geschlechter; oder Angehörige verschiedener sozialer Schichten; oder Altersgruppen u.s.w.

Gemeinsam ist allen diesen differentiellpsychologischen Forschungen ein Zug: der Ausgang von der seelischen E in zelfu $\mathrm{nkt}$ i o n. Die Differenzierungen innerhalb jeder Funktion werden entweder auf gewisse Grundformen, „Typen”, gebracht (Vorstellungstypen; Aufmerksamkeitstypen u.s.w.) oder sie werden in ihrer quantitativen Abstufung erforscht; das bekannteste Beispiel hierfür ist die Gradmessung der Intelligenz. Die gefundenen Besonderheiten der Einzelfunktionen werden schliesslich in ihrer mehr oder minder engen Zusammengehörigkeit (,Korrela ti o n”) untersucht; die zahlenmässig bestimmbare Festigkeit dieses Zusammenhanges bildet das wesentlichste synthetische Prinzip innerhalb der differentiellen Psychologie.

Damit ist aber zugleich ihre $\mathrm{Gr}$ e $\mathrm{n} z$ e bezeichnet. Denn eine noch so enge Verknüpfung von Einzelmerkmalen liefert doch nie das Bild jener Ganzheit, als welche sich die Eigenart jeglicher Person darstellt. Die moderne Ganzheitslehre musste deshalb auch der differentiellen Psychologie eine Wendung geben. Sie nahm dafür einen Begriff auf, der schon immer in der Laienpsychologie die ,eigentliche" und dauernde Wesenheit der menschlichen Individualität bezeichnet hatte, aber von der Psychologie lange Zeit umgangen worden war: den Begriff „Charakter”; und sc erleben wir denn das Entstehen einer "C h a r a k te r o log i e" innerhalb unserer Wissenschaft (Klages, Ltitz und viele anclere).

Hierbei kann freiich die Psychologie nicht streng die zunftmiirsigen Grenzen innehaiten. Was praktische lienschenkennt- 
nis, Medizin, Ausdruckskunde, Graphologie u.s.w. an charakterologischen Einsichten gewonnen haben, muss sie berücksichtigen und verarbeiten; auf der anderen Seite hat sie sich der Gefahren zu erwehren, die von einem romantischen oder gar okkulten Dilettantismus drohen; gerade die Charakterologie ist ja das Feld für die schon erwähnte Deutungspfuscherei.

Theoretisch muss Ernst gemacht werden mit der These, dass die einzelnen Charaktereigenschaften nie beziehungslos nebeneinander stehen, sondern unselbständige Momente der einheitlichen (wenn auch in sich vielschichtigen und spannungsreichen) Charakter s t r u k t u r sind. Methodisch treten die Ausdrucksdeutungen jetzt in den Vordergrund; denn die A u s d r u ck s$\mathrm{w}$ e i s e $\mathrm{n}$ der Persönlichkeit sind unmittelbarer aus ihrem charakterlichen Wesenskern heraus geformt, als die $\mathrm{L}$ e is $\mathrm{t} u \mathrm{n} g \mathrm{~s}-$ weisen, mit denen es die differentielle Psychologie älteren Styls vorwiegend zu tun hatte.

Übrigens wäre es verfehlt zu glauben, dass nun die neue Charakterologie einfach an die Stelle der differentiellen Psychologie treten könnte. Denn auch sie sieht den Menschen und seine Eigenart nur unter gewissen Perspektiven, die ihre Ergänzung erfordern durch die Gesichtspunkte der anderen Art. Totalität u n d Vielfalt der Merkmale, Ausdruck un d Leistung gemeinsam müssen herangezogen werden zur Erkenntnis der individuellen und gruppenmässigen Seelenverschiedenheiten.

\section{Entwicklungspsychologie}

In Begriff der Entwicklung liegt nicht nur eine blosse Aufeinanderfolge von Zuständen und Phasen, sondern das A u s e ina nderhervorgehen, das Sich-Vorbereiten, Keimen, Wachsen, Reifen und Sich-Zurüickbilden als ein in sich zusammenhängender sinnvoller Prozess.

Der Entwicklungsgedanke beherrschte bekanntlich schon die Wissenschaft des 19. Jahrhunderts, namentlich die Biologie und die Cieschichte. Anwendungen auf die Psychologie wurden ebenfalls schon damals an verschiedenen Stellen erfolgreich versucht; aber doch ist "Entwicklungspsychologie” als eine selbständige, in sich geschlossene Betrachtungsweise erst ein Erzeugnis des 20. Jahrhunderts (Felix Krueger und seine Schule, 
Heinz Werner u.a.). Ihre Grundprobleme sind: die Einordnung jedes einzelnen seelischen Phaenomens in das seelische W e r$\mathrm{d}$ e $\mathrm{n}$, die Beschreibung und Sinndeutung jeder $\mathrm{Ph}$ a s e innerhalb des Gesamtablaufs der Entwicklung, die Erforschung der Gesetzmässigkeiten, Differenzierungen und Bedingtheiten in diesem seelischen Werden.

Dabei ist sie mit Erfolg bestrebt, die ver schi e de n s t e n F ormen seelischer Entwicklung zu berücksichtigen und zu vergleichen: die in d i vid u e lle Entwicklung vom Säugling bis zum Erwachsenen, die kulturelle Entwicklung vom primitiven Menschen bis zum Träger moderner Zivilisation, die ph y loge n e t is c h e Entwicklung von den niedersten Lebewesen über die höher und hochorganisierten Tiere bis zum Menschen, (schliesslich auch die R ückentwicklungen im (ireisenalter und in pathologischen Erscheinungen). Diese parallelen Entwicklungsbetrachtungen sollen nicht etwa zu einfacher (rleichsetzung der ontogenetischen und phylogenetischen Entwicklungsvorgänge dienen (wozu frühere Jahrzehnte in vorschneller Ubertragung von Häckels biogenetischem Grundgesetz auf die Psychologie neigten). Es wird damit vielmehr nur der Blick gerichtet auf gewisse analoge Girundformen und dynamische Eigentümlichkeiten aller seelischen Primitivität und a lles seelischen Reifens, wo auch immer sie uns begegnen - unbeschadet der Wesensunterschiede, die zwischen Kindheit, Tierheit Naturmenschheit bestehen.

Zugleich ist damit die Möglichkeit gegeben, für jedes einzelne der genannten Gebiete Richtlinien der Betrachtung, Erklärung und Deutung zu gewinnen, die vor naheliegenden methodischen Fehlern schützen. Der Psychologe selbst gehört ja als erwachscner Kulturmensch einer hohen Entwicklungsstufe an; deshalb drohen ihm, wenn er primitives Seelengeschehen zu erforschen sucht, die beiden Klippen: einer zu weit gehenden Vereinfachung hier, einer zu starken Annäherung an die eigene ausgereifte Lebensform dort. So wurde das kleine Kind bald als leere Tafel, bald als Erwachsener im Kleinen betrachtet, das Tier entweder als scelenlose Maschine oder als Träger menschenartiger Intelligenz, der Primitive bald als "Wilder", bald als völlig Wesensgleicher. IVir mussten erst auf allen diesen Gebieten e n $\mathrm{t} w$ i c k $1 \mathrm{ung} \mathrm{s}$ psychologisch sehen, denken und deuten 
l e r n e n, um über diese Mängel hinwegzukommen.

Im Folgenden werden einige der genannten Gebiete gesondert besprochen.

\section{K indes- und Jugendpsychologie}

Die psychologischen Forschungen über die Entwicklung des Einzelindividuums wandten sich zuerst den frühesten Lebensstadien zu und schritten allmählich zur Untersuchung der höheren Altersstufen fort.

Das Bild, das diese ausgebreitete kindespsychologische Arbeit bietet, ist von äusserster Buntheit, ja Buntscheckigkeit. Es liegt dies zu einem Teil daran, dass $\mathrm{prakt}$ is $\mathrm{ch}$ e Interessen von den verschiedensten Seiten her die Bearbeitung der einschlägigen Fragen forderten, und dass infolgedessen der Psychologe auf die Zusammenarbeit mit Kindergarten und Schule, Medizin und Hygiene. Rechts-und Wohlfahrtspflege angewiesen war. Ausserdem ist die The orie der modernen Kindes- und Jugendpsychologie im kleinen ein Abbild all der Strömungen und Richtungen, die für die Gesamtpsychologie unserer Tage kennzeichnend sind; es gibt keine Lehre und keine Methode, die man nicht auf das Seelenleben des heranwachsenden IIenschen anzuwenden versucht hätte - bald mit grösserem, baìd mit geringerem Erfolg, oft mit grosser Einscitigkeit - sodass nur eine, die Mannigfaltigkeit zusammenfassende, Schau dem tatsächlichen Ergebnis dieser Bemühungen gerecht werden kann.

Dies Ergebnis ist nun aber doch - bei aller Lnfertigkeit und Unsicherheit im Einzelnen - sehr bedeutend. Wir sind hellsichtig geworden für unzählige seelische Erlebnis-und Äusserungsweisen des Kindes, die dem erwachisenen IIenschen zwar immer ganz nahe gewesen, aber dennoch verborgen und unbekannt geblieben waren.

Wie primitiverscheinen uns etwa die Beobachtungen und wie simpel die Deutungen, die Preyer, der Vater der modernen Kindespsychologie, vor 50 Jahren am kileinkind vorzunehmen vermochte, vergrichen mit den heutigen Möglichkeiten, frühkindliches Verhalten und Erleben zu beschreiben, zu erklären und zu verstehen. Kaum geringer sind die Fortschritte in unseren Kenntnissen über die Schulkindheit, deren systematische, cxperimentell-psychologische Durchforschung (Meumann, Binet) erst um die Jahrhundertwende einsetzte; und über diss 
Jugendalter, das uns noch vor zwei Jahrzehnten ein Buch mit sieben Siegeln war.

Anfangs ist diese Forschung wesentlich $\mathrm{N}$ a t $\mathrm{u} \mathrm{r}$ wissenschaft von der kindlichen Seele gewesen; Physiologen und Mediziner waren die ersten Bearbeiter. Allmählich aber erweiterte sich die Betrachtung zu einer universal-kindespsychologischen, in der natur-und $\mathrm{k} \mathrm{ul} \mathrm{t} \mathrm{u} \mathrm{r}$-wissenschaftliche Gesichtspunkte vereinigt sind. Mit der Blickrichtung auf die Kulturverbundenheit und soziale Bedingtheit des Kindes hing manche Wandlung zusammen. Man ergänzte das Studium des kindlichen Einzelindividuums durch eine Ge meinschaftspsychologie des Kindes und Jugendlichen. Man beschränkte sich ferner nicht mehr, wie zu Anfang, darauf, das Kind der gebildeten Stände zu erforschen, sondern bahnte sich den Weg zum Seelenleben des proletarischen Kindes. Schliesslich musste sich der starke Glaube an die neu entdeckten „ewigen Naturgesetze” des kindlichen Werdens und Wachsens eine Erschütterung gefallen lassen; denn es stellte sich heraus, dass auch diese Entwicklungserscheinungen stark $\mathrm{v}$ a r i i e r e $\mathrm{n}$ mit der Verschiedenheit der Lebensumstände, der unbewussten Milieu- und bewussten Bildungs-Einflüsse.

Zwei Bcispiele hierfür: Die Bilder der Pubertätspsyche, die man um 1910 zur Höhezeit der deutschen "Jugendbewegung" entwarf und damáls für allgemeingültige Darstellungen hielt, sind heut zum Teil nicht mehr zutreffend. - Die Kindespsychologie, die in der Kultur- und Wirtschaftsordnung Westeuropas erarbeitet worden ist, ist nicht ohne Weiteres übertragbar auf das Kind in China oder Russland.

Es beginnt sich also neben der allgemeinen Kindes-und Jugendpsychologie eine ,kulturty pologis che” (Nartha Nuchow) und vergleichende Kindes-und Jugendpsychologie zu entwickeln - ein unerschöpfliches Thema für die Forschung kommender Jahrzehnte.

Auf der anderen Seite haben aber auch die $n$ a $t$ u r w is s e n$\mathrm{sch}$ a f t lich eingestellten Wissenschaften vom Kinde viel zum Fortschritt der Kindespsychologie beigetragen. Körperliche und seelische Vorgänge stehen ja während der ganzen Jugendentwicklung in engster Verbindung und unablässiger Wechselwirkung. So musste das, was die Physiologie und Pathologie des Kindes, was Sexualforschung und Erbforschung an neuen Ein- 
sichten lieferte, auch für das Verständnis der entwicklungsps y chisch en Tatsachen von grösster Bedeutung werden.

4. Psychopathologie.

a) Normalität und Abnormität. - Eine der einschneidendsten Differenzierungen innerhalb des menschlichen Lebens ist die zwischen "Gesund" und "Krank". Das gilt natürlich auch für das Seelische, bei dem der Gegensatz gewöhnlich durch die Ausdrücke „Normal" und „Abnorm” bezeichnet wird. Die Scheidung geht hier sogar so weit, dass sich zwei ganz verschiedene Wissenschaften mit den beiden seelischen Gruppen beschäftigen; die Psychologie mit dem normalen, die Psychopathologie (Psychiatrie, Neurologie) mit dem abnormen Seelenleben.

Allein die Trennung kann nicht endgültig sein; ja sie erweist sich umsomehr als nur provisorisch und künstlich, je weiter Forschung und Anwendung auf beiden Gebieten vorwärts schreiten. Immer stärker und zwingender stellt sich das AufeinanderAngewiesensein beider Forschungskreise heraus.

Schon der Begriff der "N or mal i t ä t” zeigt dies. Wo das Normwidrige beginne und aufhöre, kann nicht nur von den ausgesprochen normwidrigen Formen her bestimmt werden, die dem Psychopathologen vertraut sind; hier hat auch der Psychologe mitzusprechen, der das normale Seelenleben in seiner oft unterschätzten Breite und in der Mannigfaltigkeit seiner Gestalten kennt. Hinzu kommt, dass die Grenzen zwischen Abnorm und Normal an Schärfe verloren haben. Die „Grenzzustände” und Ubergangsphasen zwischen krankhaftem und gesundem Seelenleben machen sich um so eindrucksvoller geltend, je mehr man von beiden Seiten her dem imaginären Grenz-Strich nahe zu kommen sucht.

Die Wechselbeziehung beider Forschungszweige wird verstärkt durch die moderne Auffassung, dass "K $\mathrm{r}$ a n k he i t" nicht der isolierte Zustand eines einzigen Organs oder Teilfeldes der Persönlichkeit, sondern eine Gesamtänderung des personalen Daseins ist. Denn nun ist die seclische Störung irgend eines Individuums nur zu verstehen aus seiner ursprünglichen gesunden Seelenverfassung; im erkrankten Zustand verraten sich mit verschärfter Akzentuierung psychische Züge, die - in schwächerem 
Grade und der Totalität besser eingeordnet - zum wesentlichen Normal-Inventar der Persönlichkeit gehören. Andrerseits wissen wir heut, dass auch dort, wo ein Mensch im ganzen gesehen als „,gesund” oder ,normal” zu gelten hat, die Vielschichtigkeit seines Persönlichkeitsaufbaus Stellen geringeren Widerstands, Keime zu seelischen Abweichungen, also gleichsam potentielles seelisches Erkranken in sich trägt.

Solche allgemeinen Zusammenhänge wirken sich nun in unzähligen Einzelbeziehungen aus, die zwischen Psychologie und Psychopathologie hin und her gehen.

Jeder Psychiater, Neurologe und ärztliche Erzieher bedarf für die theoretische Bearbeitung seiner Probleme der Psychologie als Grundlage; und wenn man früher dazu neigte, sich einemanchmal etwas primitive - Psychologie für den eigenen medizinischen Hausgebrauch zusammenzuzimmern, so hat man doch heut längst den Kontakt mit der grossen fachpsychologischen Bewegung aufgenommen - zum grossen Vorteile beider.

Die moderne Lehre von den Sprachstörungen wäre ohne die Mitarbeit der Gestaltpsychologie, der Sprachpsychologie, der Kindersprachforschung nicht denkbar; - ebensowenig die Untersuchung Schwachsinniger ohne die fein ausgebaute Methodik der psychologischen Intelligenzprüfungen; die heilpädagogische Arbeit an Mindersinnigen (Blinden, Tauben, Taubblinden) nicht ohne die Wahrnehmungs- und Ausdrucks-Psychologie der letzten Jahrzehnte. Die Psychopathologie des Kindesalters und der Pubertätszeit hat nur im engen Anschluss an die Normalpsychologie dieser Entwicklungsphasen ihren grossen Aufschwung nehmen können u.s.w.

Uber solche Einzelheiten hinaus ist aber festzustellen, dass die Gesamtphysiognomie der modernen Psychopathologie von der Psychologie her stark mitbestimmt ist. Die heutige Auffassung und Darstellung psychopathischer Persönlichkeitstypen und Individualitäten, die subtile und vielseitige l'eschreibung von Krankheits-Bildern und -Verläufen wäre nicht denkbar ohne eine weitgehende Rezeption dessen, was Phänomenologie, Personalistik und Charakterologie inzwischen geleistet haben. Als ein besonders kennzeichnendes Beispiel sei Jaspers' "Psychopathologie" genannt.

Nicht minder wichtig ist der ungekehrte Einfluss. Am kranken Scelenleben werden manche Erscheinungen gerade durch ihre 
abnorme und auffällige Ausprägung nicht nur eher sichtbar, sondern auch leichter begrifflich formulierbar als beim normalen Menschen. Ist aber erst einmal an den pathologischen Fällen die grob makroskopische Struktur eines seelischen Tatbestandes bemerkt worden, dann vermag das nun geschärfte Auge in einer sozusagen mikroskopischen Schau die entsprechenden Vorgänge und Zustände auch innerhalb des normalen Seelenlebens zu erkennen.

Das galt schon für das uralte Leib-Seelen-Problem: Gehirn-Erkrankungen und-Verletzungen, Zirkulationsstörungen, Erkrankungen der Sinnesorgane mussten sich erst in ihren einschneidenden psychischen Folgen aufdrängen, damit dann die durchgängigen und normalen Beeinflussungen des Seelenlebens durch den Körper erforschbar wurden.

Vor einem halben Jahrhundert führte die Beschäftigung mit der Hypnose den Arzt zur Schaffung des Begriffs ,Suggestion", im Sinne von „abnormer Willensbeeinflussung”; bald aber sprengte der Begriff den engen pathologischen Rahmen; er wurde zu einer allgemeinen Kategorie erweitert, die auch in der normal-psychologischen Einzelarbeit längst unentbehrlich geworden ist.

Die moderne Psychiatrie hat zwei grosse Formenkreise der Geisteskrankheit herausgearbeitet: das manisch-depressive Irresein und die Schizophrenie. Durch Kretschmer u.a. wurde dann diese Unterscheidung ins Normalpsychologische übertragen und hier als Typenunterschied des zyklothymen und schizothymen Temperaments entwickelt.

Auch eine andere normalpsychologische Typologie, die heut viel gebraucht wird, stammt aus der Psychiatrie: Jung hat die Typen des nach aussen gewandten (,,extravertierten") und des nach innen gerichteten (,introvertierten") Menschen abgegrenzt und beschrieben.

Die allgemeine Psychologie hat gegenüber diesen Einflussströmen, die von der Psychopathologie herkommen, eine doppelte Aufgabe. Sie muss sich den vielen Anregungen und Einwirkungen of fen halten, muss die neuen (resichtspunkte dem Bestand ihres eigenen Wissens und den Tendenzen ihres eigenen Forschens einordnen. Sic muss aber andrerseits auch diejenigen U m-F or m u lier ungen und Um-Akzentuierungen vornehmen, die durch jene Einordnung und durch die ,Normalisierung" der Erscheinungen erforderlich werden. Der Psychiater oder Neurologe wird leicht - bei der Transposition seiner Einsichten ins Normalpsychologische - die pathologische Ubergewichtigkeit mit übertragen, die die Erscheinungen in se in e m spezifischen Erfahrungsmaterial, eben den krankhaften Entartungren, 
zeigen. So kann er sich allzusehr in seine, einleuchtende aber einseitige, Sondertheorie einspinnen. Darum wird sich der Normalpsychologe in allen solchen Fällen nicht auf eine einfache Ubernahme beschränken dürfen, sondern sehr viel eigene, kritische und $\mathrm{a} u \mathrm{fba}$ u e $\mathrm{nde}$ Arbeit leisten müssen, um den bedeutenden, aus der Pathologie stammenden Gedanken den richtigen Platz in der Gesamttheorie des normalen Seelenlebens anzuweisen.

b) Tiefenpsychologie. - Die eben erwähnte methodische Regel gilt vor allem jener stärksten Einflusswelle gegenüber, die von der Psychopathologie auf die Psychologie überströmte.

Der Ausdruck „Tiefenpsychologie” beginnt sich einzubürgern für alle jene Auffassungen, welche die Erscheinungen des bewussten Seelenlebens und des willentlichen Handelns aus unbewussten Tiefen der Persönlichkeit abzuleiten und zu deuten suchen. Es gibt heut schon sehr mannigfaltige, zum Teil sich widerstreitende Strömungen der Tiefenpsychologie; sie alle aber sind aus der Pat hologi e hervorgegangen; Psychiater und Nervenärzte sind durchweg ihre Schöpfer, grösstenteils ihre Träger.

Um die Jahrhundertwende begründete Siegmund Freud, beeinflusst durch Anregungen Breuers, die „Psychoanalyse”. Von den zahlreichen früheren und späteren Sezessionen haben manche eine durchaus selbständige Bedeutung erlangt, so die „Individualpsychologie" von Alfred Adler und die Psychologie Jungs. Es ist zwecklos, aus dieser ungeheuren internationalen Bewegung Einzelnamen zu nennen, zumal eine umfangreiche Spezialliteratur mit eigenen Zeitschriften, Gesellschafts- und Kongresspublikationen u.s.w. besteht.

Die Debatte, die in ne rhalb der Psychopathologie und Psychotherapie selbst über Wert und Unwert tiefenpsychologischer Theorieen und Methoden im Gange ist, muss hier ausser Betracht blieben; uns interessiert nur die Beziehung dieser Lehren zur Normalpsychologie. Der Anspruch, auch für die Normalpsychologie gültig zu sein, wird von allen Richtungen erhoben und auch in die Tat umgesetzt; so ist die Psychoanalyse tief in die Völkerpsychologie und in die Psychologie der Kunst, der I ichtung, der Religion eingedrungen; und die Anhänger der Individualpsychologie sehen in ihrer Theo- 
rie und Praxis das vornehmste psychologische Werkzeug aller Erziehung. Wie steht es mit dem Recht solcher - weit über die pathologischen Ursprünge hinausgehenden - Ansprüche?

Zweifellos hat die Normalpsychologie der Tiefenpsychologie sehr viel zu danken, vor allem im Hinblick auf die psychologische $\mathrm{T}$ h e o r i e. Versuchen wir, diese theoretischen frundgedanken auf gewisse allgemeine Formulierungen zu bringen.

Schon der Begriff der „Tiefe” mit allen daran hängenden Konsequenzen bedeutete eine psychologische Revolution: der Mensch ist mehr und anderes als das, was seine $\mathrm{O}$ be r fläche zeigt an körperlichen Handlungen und an Bewusstseinsinhalten; die Oberflächenerscheinungen sind nicht an sich verständlich und erschöpfen sich nicht in ihrem manifesten Sinn, sondern weisen hin auf Ursprünge und Ziele, die ohne Bewusstsein wirksam sind.

Daraus ergaben sich zwei, für die Psychologie ganz neue Aufgaben: 1) die Beziehung zwischen der Bewusstseinsoberfläche und der unbewussten Tiefe zu studieren; 2) das Yesen der unbewussten Tiefe selbst klar zu stellen.

ad 1). Die Beziehungen zwischen Bewusstsein und Lnbewusstem erwiesen sich als doppeldeutig: die Bewusstseins-Inhalte und-Vorgänge sind teils Kundgaben, teils Verhüllungen des Unbewussten. Als unmittelbarste $\mathrm{K}$ un $\mathrm{dg}$ e b ung tritt die ,adäquate" Bewusstmachung auf: so wenn ein unbewusster Trieb zu einer entsprechenden Wunschvorstellung führt. Die stärkste Verh ü 11 u ng ist die „Verdrängung”: so wenn ein, das Bewusstsein beunruhigender, Gedanke völlig ins Lnbewusste abgeschoben wird, in dem er dem Bewusstsein unerreichbar bleibt.

Zwischen diesen beiden Polen liegt nun jene Skala von „Bewusst"/,Lnbewusst"-Beziehungen, die das Hauptthema der Tiefenpsychologie bilden. Das Lnbewusste verbirgt sich nicht vollkommen, aber seine Kundgabe ist nicht unmittelbar und adäquat, sondern indirekt, umgebogen, bildhaft. So gewinnen die Bewusstseinsinhalte einen versteckt-verräteri$\mathrm{sch}$ e n Charakter, sie sind $S \mathrm{y} m$ bole des Lnbewussten, die gedeutet werden müssen, damit ihr wahrer Simn erscheine.

ad 2). Dieser "Sinn" ist aber nur dann erkennbar, wenn man weiss, was sich denn in den Bewusstseinserscheinungen svmbolisch darstelle; somit wird eine Theorie des $\mathrm{L} n \mathrm{~b}$ ew us t e n selbst nötig, die dann auch von jeder tiefenpsycho- 
logischen Richtung versucht wird. Gemeinsam ist ihnen allen, dass das Unbewusste als bewegende $\mathrm{Kraft}$ der Lebens-und Seelen-Vorgänge angesehen wird; und in dieser dy $\mathrm{nami-}$ schen Auffassung des Unbewussten ist ein weiteres Verdienst der Tiefenpsychologie zu sehen. Die Motoren dessen, was im Bewusstsein vor sich geht, liegen nicht allein im Bewusstsein selber - dieser Satz darf, zum mindesten in der gegebenen eingeschränkten Formulierung, als endgültige Einsicht verzeichnet werden.

Diese unbewussten Kräfte haben aber zugleich eine Richtung; in ihnen kommen bestimmte Te n de $\mathrm{n} z$ e $\mathrm{n}$ zur Geltung, die nun die Rolle des Bewusstseins bestimmen. In der Annahme, dass es solche Zweckmässigkeitsbeziehungen zwischen Unbewusstem und Bewusstem gebe, sind sich gleichfalls die verschiedenen Theorieen einig; ebenso darin, dass nach diesen Tendenzen die symbolischen Deutungen der Bewusstseinsinhalte $\mathrm{zu}$ orientieren seien; diese erscheinen dann als die Ergebnisse der Sublimierung, Abreaktion, Úberkompensation, als Schutz-, Abwehr- und FluchtMassnahmen oder als sonstige unbewusste Zielstrebungen.

Die angedeuteten Grundgedanken gehören schon heut zum unentbehrlichen Erkenntnisgut der Psychologie; sie müssen allerdings bei der Eingliederung in die allgemeine psychologische Theorie wesentliche Umbildungen erfahren; aber wegzudenken sind sie nicht mehr aus unserer Wissenschaft. (Kapitel IV wird zeigen, in welcher Wendung die „Personalistik” den tiefenpsychologischen Gesichtspunkten gerecht wird).

Aber zwischen den allgemeinen Grundgedanken und ihrer speziellen Verwendung und Ausgestaltung muss sehr unterschieden werden. In der $\mathrm{k}$ o $\mathrm{n} \mathrm{k}$ e te $\mathrm{n}$ Arbeit der tiefenpsychologischen Schulen werden jene Leitideen zum Teil überwuchert von ganz bestimmten Sondertheorieen und Praktiken, die den normalpsychologischen (iesamtertrag stark beeinträchtigen. Versuchen wir auch diese Mängel auf gewisse grundsätzliche Formulierungen zu bringen.

". Das Unbewusste" wird zu einer Art mythischer Urkraft erhoben, die eine (reheimdespotie im Individuum errichtet. I)icser Kraft wird dann zugleich eine ganz bestimmte Beschaffenheit zugeschrieten. Man begnügt sich nicht damit, ihren dyna- 
mischen Antriebscharakter durch die Bezeichnung "Trieb” ins rein Vitale zu verlegen, sondern es wird eine e in $z$ e l n e Triebart auf den Tron erhoben und menschliches Handeln und Erleben grösstenteils als Auswirkung und symbolische Umgestaltung des postulierten Triebes aufgefasst. Damit zerteilt man dic menschliche Person in Kern und Schale, in Urbestand und $\mathrm{Ab}-$ geleitetes - wobei der Urbestand ganz scharf und e in se it i $g$. abgegrenzt und definiert wird, während die grosse Mehrheit aller Lebens-und Seelen-Erscheinungen n u $r$ abgeleiteten Charakter und sekundären, uneigentlichen Sinn haben soll. Verstärkt wird dieser - aller Tiefenpsychologie immanente - D u a l is m u s dadurch, dass die Scheidung von Unbewusstem und Bewusstem nicht nur als Rangordnung (Kern/Schale) gilt, sondern geradezu als Gegensatz, als die Urfeindschaft innerhalb der Person.

Wie unzulänglich diese Lehre ist - die der Auffassung der Person als ,, unitas multiplex" zuwiderläuft — wird sofort daraus eikenntlich, dass der dominierende Triebkern von jeder tiefenpsychologischen Schule anders aufgefasst wird: von der Psychoanalyse als Sexualtrieb, von der Individualpsychologie als Geltungstrieb, von der Jung'schen Schule als der Bestand überindividueller (in der Gattungszugehörigkeit des Individuums verankerter) Tendenzen.

Die Einseitigkeit in der Ansetzung des Person-Kerns bestimmt nun natürlich auch die Prinzipien und die konkreten Durchführungen der Deutungsmethode. Irgend ein psychischer Tatbestand sieht natürlich ganz anders aus, wenn er als symbolische Kundgabe einer Minderwertigkeitstendenz, oder als sublimierte Sexualregung, oder als eine Art Atavismus gedeutet wird. Die Hartnäckigkeit und Monotonie, mit der die Anhänger dieser oder jener tiefenpsychologischen Schule einige wenige Deutungsgesichtspunkte ausnutzen, um alles Seelische: Krankhaftes wie Gesundes, Einzelmenschliches wic Kulturelles, zu erklären - macht es dem nicht darauf cingeschworenen Psychologen unmöglich, hierin noch eigentlich wissenschaftliches Tun zu sehen; vielmehr wird man - namentlich bei den Geistern zweiten Ranges und den Mitläufern - an den monomanen Wahrheitsanspruch einer Sekte erinnert. Dort, wo Zwecke der praktischen Menschenbehandlung verfolgt werden - in der Psychotherapie, auch in gewissen pädagogischen Situationen - mag 
der unbeirrte Glaube an die Richtigkeit und unbegrenzte Leistungsfähigkeit einiger weniger Dogmen beim Behandler und dem Behandelten wirksam sein, um die erforderliche Suggestionsatmosphäre zuschaffen. Für die psychologische Th e o r i e dürjen aber diese Rücksichten nicht mehr gelten; denn eine solch unkritische Verwendung der Deutungsmethode führt zu einer Verarmung, ja einer Fälschung des Bildes, das wir uns vom menschlichen Seelenleben machen.

\section{Tierpsychologie}

Der Tierforscher, der die zoologisch-biologische Problematik in ihrer ganzen Weite überschaut, stösst notwendig auf Erscheinungen des tierischen ,,Seelenlebens", vorsichtiger ausgedrückt: auf solche tierische Verhaltungsweisen, die auf Psychisches hinzudeuten scheinen. Diese Formulierung zeigt schon die Schwierigkeit der Aufgabe. Zwar sind die Lebensäusserungen der Tiere viel gleichförmiger und einfacher als die der Menschen; ihre äussere Feststellung ist daher mit exakten Mitteln des Experiments und der Beobachtung nicht allzu schwer zu bewirken. Aber die diesen Lebensäusserungen zu (irunde liegenden inneren Kräfte, Antricbe und etwaigen Erlebnisweisen sind von denen des Menschen so verschieden, dass die eigentlich psychologische Deutung hier vor Hindernissen steht, die in gleicher Stärke innerhalb der Menschenpsychologie nicht vorkommen.

So wird es verständlich, dass das Bedürfnis der modernen Tierforschung, eine möglichst einwandfreie und von Fehldeutungen unbelastete Erkenntnis zu gewinnen, gerade hier den ,V erh a $l t$ e n s'-Standpunkt nahe legte, der sich auf die Erforschung des objektiv sichtbaren Reagierens und Betragens der Tiere beschränkt. Der sogenannte Behaviorismus hat auf dem (iebiet des Tierstudiums seine bedeutendsten Erfolge zu verzeichnen.

Während Beobachtung und Film das ungezwungene Verhalten in Freiheit und Cefangenschaft registrieren, hat das Experiment das Verhalten unter bestimmten Bedingurigen studiert: etwa unter dem Einfluss von Emotionen (Schreck, Hunger), oder bei I) ressur auf gewisse erst zu erlernende Leistungen.

In letzter Hinsicht ist Amerika unbestritten tonangebend; hier sind in ungezählten Variationen Lernversuche an Affen, Ratten, Hunden, 
niederen Tieren gemacht worden, die nicht nur die Fähigkeit zur Aneignung neuer Leistungen (Dressierbarkeit) genauer erforschten, sondern auch in die Gesamtstruktur tierischen Reagierens Einblick gewährten.

Auch die Umweltforschung v. Uexküll's und seiner Schüler sei hier noch einmal erwähnt; ihr Thema ist -- ebenfalls unter Vermeidung „psychologischer" Deutungen — die Zusammengehörigkeit jeder Tierart mit ihrer spezifischen Umwelt und die Einwirkung dieser Umwelt auf das Tier.

Aber das wissenschaftliche Bedürfnis, auch in die $\mathrm{H}$ in $\mathrm{t}$ e $\mathrm{r}$ $\mathrm{g} \mathrm{r}$ ü $\mathrm{n}$ de des tierischen Verhaltens hineinzuleuchten, ist doch zu stark, als dass es sich dauernd zum Schweigen bringen liesse. Deshalb hat die europäische, insbes. die deutsche und holländische Tierpsychologie immer wieder versucht, aus dem Verhalten sowohl auf das Vorhandensein oder Nichtvorhandensein bestimmter seelischer Phä no me ne (Vorstellungen, Gefühle) wie auf das bestimmter seelischer $\mathrm{E}$ ig e $\mathrm{n} \mathrm{ch}$ a $\mathrm{ft}$ e $\mathrm{n}$ (Gedächtnis, Intelligenz, Temperament) zu schliessen.

So untersuchte etwa Köhler, ob es bei Affen „einsichtiges" Handeln als Kennzeichen einer keimhaften „Intelligenz” gebe; Katz machte Studien zur Sozialpsychologie und Charakterologie von Hühnern, Volkelt warf die Frage auf, ob man bei Spinnen von „Vorstellungen”, der Beute sprechen könne. Buytendijk erforschte das tierische Spiel u.s.w.

Eine streng wissenschaftliche Erforschung tierischen Seelenlebens ist um so notwendiger, als gerade hier we l t a n s c h a u1 i c h e Glaubenssätze und Vorurteile oft den unbefangenen Blick und die sachliche Auffassung trüben. Nicht nur der Laie pflegt das Tier nach der Stellung zu beurteilen, die ihm im Verhältnis zur Welt des. Menschen zugebilligt wird; auch in die wissenschaftliche Forschung selbst spielen noch diese aussertheoretischen Stellungnahmen hinein. Indessen ist hier doch der allmähliche Fortschritt zu objektiver Erkenntnis deutlich. Zwischen zwei Klippen muss die Tierpsychologic den Weg suchen: zwischen den Annahmen zu grosser Menschenferne und zu grosser Menschennähe. Wo der Mensch aller anderen Kreatur als etwas toto genere Verschiedenes gegenuibergestellt wird, wird man die Kluft auch im Seelischen wiederfinden. Man betont dann vor allem die Primitivität der seelischen Organisation im Tiere, die geringere Ausbildung der einzelnen seelischen Funktionen, den völlige dusfall 
gewisser bei Menschen vorhandener Fähigkeiten, den Gegensatz von tierischem „Instinkt” und menschlicher „Intelligenz”. In extremen Fällen finden wir dann sogar die alte Cartesianische Theorie erneuert, dass das Tier eine reine Reflexmaschinerie, also völlig seelenlos sei. - Dagegen wird der Standpunkt, der an die Kontinuität alles Lebendigen vom Protozoon bis hin zum Menschen glaubt, keine grundsätzlichen Unterschiede zwischen Tier und Mensch, sondern nur gleitende Übergänge und Verwandtschaften sehen wollen, daher leicht die Tiere vermenschlichen; so ist es noch nicht lange her, dass man allen Ernstes glaubte, man könnte in besonders begabten Pferden diejenige Intelligenz entwickeln, die zum richtigen Buchstabieren und zur Lösung verwickelter Rechenaufgaben gehört.

Die psychologische Tierforschung wird daher vor allem „,vergl e i che n d e" Wissenschaft sein (man findet den Namen „Komparative Psychologie” zuweilen geradezu als gleichbedeutend mit Tierpsychologie gebraucht). Die Vergleichungen müssen sich ebenso auf die verschiedenen Tierarten unter einander, wie auf Unterschiede und Ähnlichkeiten zwischen Tier und Nensch beziehen. Nur dadurch, dass man zugleich auf das Cbereinstimmende und das Abweichende achtet, wird sich der rechte Standpunkt zwischen den Einseitigkeiten, die wir eben schilderten, finden lassen.

III. PRAKTISCHE ANWENDLNGEN DER PSYCHOLOGIE

\section{Psychologie und Leben}

Unsere Cbersicht über die Gebiete der psychologischen Wissenschaft verfolgte einen Weg, der von einer sehr abstrakten und lebensfernen philosophischen Seelenlehre zur Erfahrungsseelenkunde, und innerhalb dieser zu immer lebensvolleren, konkreteren Formen führte. Die zuletzt besprochenen Nebenzweige, welche das Seclenleben in scinen Weltbeziehungen und Differenzierungen behandeln, sind der lebendigen Wirklichkeit schon recht nahe gerückt; ein weiterer Schritt musste nun $m$ it $t$ e $n$ in $s$ L e b e $n$ s elber hineinführen, und zwar in das Leben, das nicht nur Gegenstand ruhiger Betrachtung, sondern der bewegten und bewegenden $\mathrm{T}$ a $t$ ist. 
Die Durchdringung des Alltagslebens und der Kulturpraxis mit Wissenschaft ist uns ja längst selbstverständlich geworden; Technik, Gesundheits- und Krankenpflege, Wirtschaftsgestaltung sind weitgehend Leben-gewordene Wissenschaft. Aber deren Wirksamkeit hatte sich vorwiegend auf die äussere, materielle Seite der Kultur bezogen; erst sehr spät erwachte die Frage, ob nicht auch das psychische und geistige Geschehen, das ja ebenfalls jeden Kulturvorgang begleitet, einer solchen Verwissenschaftlichung fähig und bedürftig sei, im Interesse der beteiligten Menschen und der überpersönlichen Kulturwerte. I)ie Frage wurde bejaht $\left.{ }^{1}\right)$; und heut liegt ein Menschenalter sehr intensiver und viclseitiger praktisch-psychologischer Arbeit hinter uns. Trotzdem besteht auch jetzt noch nicht volle Klarheit über Notwendigkeit und Recht, Grenze und Art dieser Betätigung. Auf der einen Seite wird zuversichtlich die Uberzeugung vertreten, dass die Psychologie eine fundamentale Bedeutung für die verschiedensten Gebiete des praktischen Lebens besitze, auf der anderen die Meinung, dass der Einbruch der Wissenschaft in die Innenbezirke des persönlichen Dascins überflüssig oder gar grefährlich und verwerflich sei.

Ehe wir zu solchem Widerstreit Stellung nehmen, müssen wir eine kurze Orienticrung über Gegenstand und Problematik dieses Sondergebietes geben.

Man pflegt hout zwischen ,a n g e wa n d t e r" und ,p rakt is ch e r" Psychologie zu scheiden. Jene ist die Wis se n$\mathrm{s} \mathrm{ch}$ a f $\mathrm{t}$ von psychologischen Tatbeständen, die für praktische Anwendungen in Frage kommen, diese ist die $\mathrm{K}$ u n s t und die T e c h n i k des Anwendens selber.

Beispiel: Die angewandte Psychologie erforscht die Intelligenzunterschiede der Kinder und erarbeitet aus ihren Befunden die bestmöglichen Methoden der Intelligenzdiagnose; der praktische Psuchologe stellt an den Findern A, B, C mit gegebenen Methoden Intelligenzprüfungen an, um ihre Schullaufbahn zu bestimmen.

Die Unterscheidung ist deswegen nicht bedeutungslos, weil sich in neuerer Zeit ein eigener Perufsstand des ,.praktischen Psy-

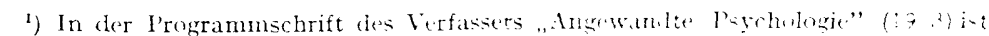
wohl Bezeichnung und begriff einer solchen wistenschaftli, hon I h-ziplin zuerst eing.fiuht worden. 
chologen" zu entwickeln beginnt, der sich nach Berufseignung und Berufsziel wesentlich von dem forschenden Psychologen unterscheidet ${ }^{\mathbf{1}}$ ).

Eine andere Einteilung bezieht sich auf die unmittelbare Arbeitsaufgabe des Psychologen: Menschen-Erkennung und Menschen-B e h a n d l u n g („Psychognostik” und „Psychopraktik") ${ }^{2}$ ). Oft beschränkt sich der Psychologe auf das erste: er gibt ein Testgutachten, eine graphologische Charakteristik, ein Eignungszeugnis, die Schilderung einer Gruppe - und überlässt es nun dem Besteller oder Empfänger der Diagnose, dâraus die ihm richtig scheinenden praktischen Folgerungen zu ziehen. In anderen Fällen besteht die Aufgabe des Psychologen gerade darin, unmittelbare Anweisungen für das Handeln zu geben : z.B. für die Art der Käuferwerbung, für gewisse pädagogische Nalsnahmen, für die Gestaltung des Strafvollzuges.

Sehr üblich ist die Einteilung der angewandten und praktischen Psychologie nach den $\mathrm{K}$ ult urge bi e t e n, denen sie Dienste leistet. Am meisten ausgebildet sind die pädagogische, die medizinische, die Kriminal-, die forensische, die Wirtschafts- ${ }^{3}$ ) Pschologie. Rasche Fortschritte machten in letzter Zeit die Wohlfahrts- und soziologische Psychologie; Ansätze sind vor handen für angewandte Psychologieen des Rechts, der Politik, des Krieges. Eine Sonderbetrachtung jedes dieser Gebiete liegt ausserhalb des Rahmens unseres Buches.

\section{Problemkreise}

Dagegen müssen wir die drei grossen Problemkreise besprechen, die in jedem Teilgebiet der angewandten Psychologie auftauchen: Individualitäten; Gruppen- und Sozialbeziehungen; objektive Bedingungen des menschlichen Kulturlebens.

So haten manche Städte drn Schulverwaltungen ,Schulpsychologen” angeglie$\therefore$ : bri bernfil, ratungsstellen, sowite in Cirossbetrieben der Industrie, des Handels

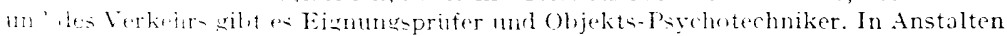

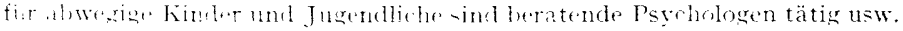

In dem oben krannten l'rogrammautsatz des Jahres 933 brauchte ich die Aus-

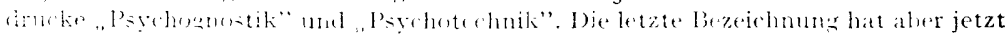

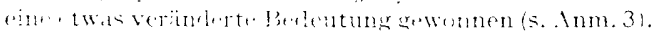

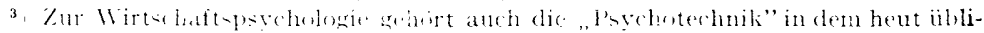

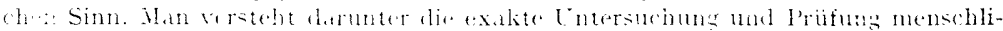

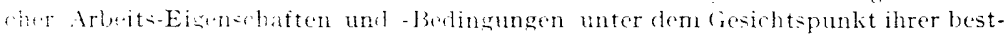

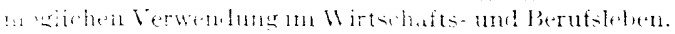


Die erste, individualisierende Aufgabe ist am meisten beachtet, gepflegt und umkämpft worden. Das, was sonst die „naive Menschenkenntnis” leistet, soll hier mit wissenschaftlichen Mitteln vollzogen werden: die Diagnose von Individualitäten (entweder in ihrerTotalbeschaffenheit oder in Bezug auf bestimmte, praktisch wichtige Fähigkeiten und (harakterzüge); die Prognose ihrer weiteren Entwicklung; und als deren Konsequenz: die Beeinflussung dieser weiteren Entwicklung durch Beratung, Erziehung, Therapie, Bestrafung.

In diesem Sinne wird praktische Psychologie angewandt bei dem Schüler, der auf Grund einer Befähigungsfeststellung in die Hilfsschule oder in eine gehobene Schule gesandt wird; bei dem Berufssuchenden, dessen Beratung im Berufsamt sich auf eine Eignungsprüung stützt; bei dem Verbrecher, dessen Charakteranlagen und Motivationen von dem Richter studiert werden, um die Beurteilung des Falles und die geeignete Strafzumessung abzuleiten; bei dem Zeugen, dessen Glaubwürdigkeit psychologisch analysiert wird; bei dem verwahrlosten Jugendlichen, dessen erzieherische Beeinflussung durch eingehendes und fortlaufendes ,case study" geregelt und kontrolliert wird.

IIan sieht, dass sich die Aufgaben des praktischen Psychologen mit denen des ärztlichen Peraters und Gutachters vielfach berühren, zum Teil sogar kreuzen. Aber be i de Kategorien von Sachverständigen sind nötig. Für krankhafte Seelenerscheinungen ist natürlich nur der Psychiater kompetent. Aber auch innerhalb der normalen Breite sind ja die psychischen Differenzierungen so gross und die seelischen Komplikationen oft so schwierig, dass ihre Erkennung und Behandlung im Einzelfalle nicht immer dem ,gesunden Menschenverstande" des Praktikers (Lehrers, Richters u.s.w.) allein überlassen bleiben darf, sondern einer fachmännischen Hilfe bedarf. Diese kann nur der geschulte Fachpsychologe gewähren. Sehr zu wünschen ist natürlich die enge Arbeitsgemeinschaft des praktischen Psychologen und des Arztes, wie sie weitgehend in den ,psychologischen Kliniken" Amerikas, in bescheidenerem Masse auch in anderen Ländern zu finden ist.

Die zweite Aufgabe bezicht sich auf die seelische Beschaffenheit menschlicher (iruppen und Gemeinschaften.

Der Erzieher etwa steht ja nicht nur einzelnen Zöglingein gegenüber, sondern den sichul- und Klassen-Gemeinschaften, den Bünlen und Flicken, den Freundschaften und Feindschaften; um mit diesen päda- 
gogisch fertig zu werden, muss er die psychische Struktur des Sozialgebildes (z.13. die Gliederung der Schulklasse in Führer, Mitläufer, Geführte, Einzelgänger) durchschauen; er muss ferner sozialpsychische Funktionsgesetze: dor Suggestion, Nachahmung, Eifersucht, Rivalität u.s.w. kennen und in ihren Auswirkungen einschätzen und verwerten. - Ebenso hat es der Kriminalist mit den Erscheinungen derVerbrecherfamilien, der Bandenbildung, der Gemeinschaftshaft zu tun; der Wirtschaftler mit der Frage der Gemeinschaftsarbeit, des Fabrikgeistes, des Standesbewusstseins, der Massenwirkung der Feklame u.s.w. - Auch ty pologis che Gruppierungen werden praktisch-psychologisch wichtig; so erfordert die Lehrplanschaffung für Knaben- und Mädchenschulen oder die verschiedene Einrichtung von Männer- und Frauengefängnissen eine differenzierende Berücksichtigung der Geschlechtertypik. - Wenn in jüngster Zeit die Rassenunterscheidungen tief in das praktische Leben einzugreifen beginnen, wird die Rassenbiologie durch eine angewandte Rassenpsychologie ergänzt werden müssen.

Schliesslich hat angewandte und praktische Psychologie auch o b jektive Tatbestände zu untersuchen und zu behandeln, die selber nicht psychologischer Art sind, aber mit dem psychischen Leben in enger Verbindung stehen.

Hierher gehören z. . die mannigfachen äusseren Bedingungen der menschlichen Arbeit in Schule und Beruf: Arbeits-Zeit und - Verteilung, Pausen und Ferien, Akkord- und Stundenlohn, Eintönigkeit oder Mannigfaltigkeit der Arbeit, Leistungsgrösse und Leistungsantrieb, Beschaffenheit der Arbeitsstätten, Geräte und Maschinen, (sogenannte „Objektspsychotechnik"); Unterrichts- und Anlernmethoden.

All diese sachlichen Dinge, Umstände und Malsnahmen sind ja nicht nur unmittelbar technisch, ökonomisch oder didaktisch bedeutsam, sondern sind verflochten mit menschlichen Reaktionen und Spontanaktionen; und ihre möglichst zweckmässige Gestaltung ist deshalb zum Teil von psychologischen Faktoren abhängig, die der Erforschung bedürftig und fähig sind.

In die gleiche Rubrik gehört auch die eigentliche $M$ i l i e uUntersuchung. Die Frage, wie Armut, Krise, Arbeitslosigkeit, gestörte Familie, wie Grossstadt, Kleinstadt und Land sich seelisch auf dic Menschen auswirken, müssen wir mit wissenschaftlichen Methoden erforschen, um die psychischen Schädigungen eines bestimmten Milieus verringern, die Vorteile eines anderen Milieus wirksamer machen zu können, und um bei Diagnose, Prognose und Behandlung von Einzelnen und Gruppen die Milieueinflüsse richtig einzuschätzen. 
3. E inw ände

Wir haben in dieser Ubersicht nur solche Themen genannt, die nicht als blosse Probleme interessieren, sondern für die es schon Ergebnisse und tägliche Berufspraxis gibt. Angewandte und praktische Psychologie bilden also heut bereits ein $\mathrm{F} \mathrm{a} \mathrm{k} \mathrm{t} \mathrm{u} \mathrm{m}$ unserer Gegenwartskultur, das genug Eigengewicht hat, um auch gegenüber Anfeindungen und Kritiken bestehen zu können. Aber es ist nötig, sich mit diesen gegnerischen Gesichtspunkten grundsätzlich zu beschäftigen und hieraus den Anlass zu etwa notwendiger Selbstbesinnung und Selbstkorrektur zu entnehmen.

Die geringste prinzipielle Bedeutung haben jene Aufcindungen, die lediglich aus der grossen Jugend der Psychologie und aus der Neuheit ihrer Ansprüche auf Lebensanwendung herrühren. Es ist das Schicksal je des Kulturfortschritts, dass die Vertreter der überlieferten Praxis den Wert des Neuen zunächst nicht einsehen können oder nicht zugeben wollen, weil sie es als einen Einbruch in ihre Kompetenz und als Bedrohung ihrer Routine empfinden. Man beruft sich dann darauf, dass man ja b i s h e $r$ in Erziehung und Unterricht, in der Verbrechensbehandlung, im Wirtschaftsleben u.s.w. ohne wissenschaftliche Psychologie ausgekommen sei; warum sollte es nicht so weiter gehen können?

Die Selbstgenügsamkeit des Praktikers fand und findet eine Stütze in dem Hinweis auf die „natürliche Ienschenkenntnis”, die teils auf angeborener Begabung, teils auf langer Erfahrung beruhe und der Wissenschaft nicht bedürfe; sie helfe, so meint man, in praktischen Situationen viel mehr als ausgekliggelte Theorie. Der Lehrer kenne seine Schüler, der Richter verstehe die Angreklagten, der Betriebschef durchschaue die Bewerber weit besser als der fremde Psychologe.

Die Berufung auf die naive Latenpsychologie ist an sich durchaus nicht unberechtigt; wir haben sogleich in der Anfangsbetrachtung dieses Buches auf ihre Lnentbehrlichkeit hingewiesen $\left.{ }^{1}\right)$. Allerdings musste auch dort schon betont werden, dass psychologischer , Blick" und pirchologische .Routine” für sich allein um so weniger ausreichen, je verwirkeiter die Kulturser-

\footnotetext{
1) S. 7 .
} 
hältnisse und je schwerer übersehbar demzufolge auch die personalen und psychischen Faktoren werden, die im praktischen Leben mitspielen. Daher wird wissenschaftliche Einsicht und wissenschaftlich gesicherte Methodik nötig als E r g än z ung, Kontrolle und Uberbau der natürlichen Menschenkenntnis; und so ergeben sich drei Forderungen: 1) die Bereitschaft des Praktikers, sich in geeigneten Fällen der Mitarbeit des Fachpsychologen zu bedienen; 2) die enge Zusammenarbeit des Fachpsychologen mit dem Praktiker; 3) die Notwendigkeit, dass der Fachpsychologe auch in si ch selbst beides verbindet.

Ein Psychotechniker, der das ihm abgehende Fingerspitzengefühl für die Eigenart anderer Menschen durch schematische Testprüfungen glaubt e r setze n zu können, verfehlt den Sinn seiner Aufgabe. Praktisch-psychologische Arbeit ist eben nicht nur eine Technik, sondern zugleich eine Kunstübung; wer zu dieser Kunst den Funken nicht in sich spürt, der lasse den Finger davon. Wo aber der Funken vorhanden ist, kann er durch wissenschaftlich psychologische Schulung angefacht werden; denn der „psychologische Blick”' ist nicht eine starre Grösse. Der praktische Psychologe muss also über den blossen Routinier hinausragen durch psychologische Erkenntnis, die ihm orga $\mathrm{n}$ is ch ge wor de n und dadurch in seine verstehende Menschenerkennung und Behandlung eingegangen ist.

Eine weitere Gegnerschaft erwächst dem praktischen Psychologen von einer ganz anderen Seite her: es ist der ständig zunehmende Kreis der „D e u t ung s f us cher”, die ohne psychologische Gesamtschulung aus einur einzelnen Sondermethode ein Gewerbe der Persönlichkeitsdiagnostik machen. Die Deutungspfuscher verhalten sich zum Psychologen ähnlich wie die Kurpfuscher zum Arzt. Die Einfachheit und Einseitigkeit ihrer Theorieen und die Ungehemmtheit ihrer Reklame locken ein weites Publikum an; die volkstümliche Ausdrucksweise und der dem Empfänger meist sehr sympathische - Inhalt ihrer Charaktergutachten erhöht den Zuspruch.

Fast immer ist für ihr Verfahren die II o nos y m p to mat i k kennzeichnend; jener stützt seine Charakteristiken nur auf Schriftanalysen, dieser auf Schädelform und Gesichtszüge, eindritter auf Handlinien und ein vierter gar auf Ausschläge des dem Schädel aufgesetzten Galvanometers (Methode Bissky). 
Die Tätigkeit dieser Psychognostiker hat in der neueren Zeit nicht nur an Umfang, sondern auch an praktischer Konsequenz - und damit an Bedenklichkeit - stark zugenommen. Früher begnügten sich die Kunden meistens mit dem prickelnden Ciefühl, ein mehr oder minder getroffenes Seelenkonterfei von sich zu besitzen. Heut aber werden solche (iutachten zu sehr lebenswichtigen Zwecken verlangt und gegeben; Wirtschaftsbetriebe stützen auf sie Anstellungen oder Ablehnungen von Stellungsuchenden; Eheberatungen und andere Beratungen machen von ihnen Gebrauch.

Man ersieht hieraus, wie stark heut das Bedürfnis nach praktischer Psychologie ist, zugleich aber auch, wic wenig noch die ungeheure Schwierigkeit und die hohe sittliche Verantwortung der Aufgabe ins allgemeine Bewusstsein übergegangen ist. Es ist die Sache des wissenschaftlich geschulten praktischen Psychologen, hier aufklärend zu wirken und die Schäden und (iefahren dilettantischer Charakterdeuterei und monosymptomatischer Einseitigkeit aufzudecken.

Allerdings darf man nicht im blossen Negieren des Bekämpften stecken bleiben. Denn auch darin ähnelt die psychologische Deutungspfuscherei der medizinischen Kurpfuscherei, dass sie der Fachwissenschaft gelegentlich starke positive Anregungen $\mathrm{zu}$ bringen vermag. Es gibt Charakterdeuter, bei denen eine ursprüngliche Intuition psychologische Wahrheiten zu Tage fördert, die nachher von der Wissenschaft gesichert oder vertieft werden können. Die Einseitigkeit, mit der ein spezielles Deutverfahren benutzt wird, vermag auch wohl eine Feintechnik zu entwickeln, die das Niveau und die Verwendbarkeit einer wissenschaftlichen Hilfsmethode erreicht. Auf dem Gebiet der (iraphologie ist das Hinüberwechseln aus der Sphaere des I)ilet tantismus in die der Wissenschaftlichkeit schon weit gediehen; Physiognomik und Mimik werden vielleicht bald einen ähnlichen Weg gehen.

Der praktische Fachpsychologe muss für diese Vorgänge offene Augen und Empfänglichkeit haben, ron sich aus auch an der Rezeption der Methoden und Cesichtspunkte, soweit sie wertwoll sind, mitwirken. Nur eines darf er nicht übernehmen: die Vionosymptomatik. Denn das Sich-Festbeissen auf e ine allein seligmachende Methode ist stets das Zeichen von Enge und Cnwissenschaftlichkeit. Polysymptomatik und Methodenelastizität, alio 


\section{DRITTES KAPITEL}

DAS MATERIAL DER PSYCHOLOGIE UN D DIE METHODEN SEINER GEW IN N U NG

Es gehört zum Wesen wissen s chaftlicher Arbeit, dass sie nicht nur ihren Erkenntnis z i e l e $n$ sich zu nähern sucht, sondern sich auch Rechenschaft gibt über die Wege, Möglichkeiten und Aussichten ihres Vorgehens. Eine solche Selbstbesinnung auf die Methoden ist der Psychologie vielleicht notwendiger als so mancher anderen Wissenschaft, weil ihre mannigfaltigen Verfahrungsweisen unter eigentümlichen Schwierigkeiten stehen. Gibt es doch kaum eine psychologische Methode, deren Recht und Brauchbarkeit nicht - grundsätzlich oder empirisch - umstritten wäre; auf der andern Seite ist die Neigung gross, irgend eine einzelne Methode zur allein seligmachenden zu erheben. Beides: Methoden-Verfehmung wie Methoden-Diktatur, ist in gleicher Weise schädlich für den Fortschritt der Wissenschaft.

Wenn man etwa nur auf e in e Methodik eingeschworen ist, kann es leicht kommen, dass man sich blind macht gegen andere Untersuchungsmöglichkeiten der vorliegenden Probleme, ja gegen ganze Problemgruppen überhaupt $\left.{ }^{1}\right)$.

Für den reinen Experimentalpsychologen sind dann solche Fragen nicht vorhanden, die sich experimenteller Bearbeitung entziehen. -I) Behaviorist verschliesst sich grundsätzlich allen Einsichten, die durch Sclbstbeobachtung zu finden sind. - Der psychoanalytische Methodenfanatiker bringt den Bewustsseinserscheinungen als solchen kein direktes Interesse mehr entgegen; sie sind ihm nur Material für scine Deutungsmethodik, die auf das Unbewusste zielt.

II ethoden sind nicht um ihrer selbst wil-

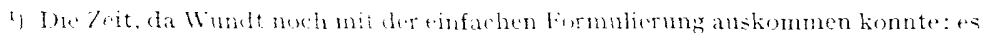

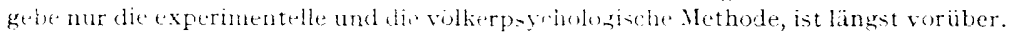


len da, sondern wachsen a us den Notwendigkeiten der Problemstellungen und aus den Möglichkeiten des II aterials heraus. Ihr Zusammenhang mit den Aufgaben und Fragestellungen ist bereits in den beiden ersten Kapiteln behandelt worden; dort war die Rede von der philosophischen und empiristischen Methode, von den Methoden der Analyse, des Ganzheitsbezugs, der Erklärung, der Deutung u.s.w.

Nunmehr haben wir die psychologischen Methoden vom II a t e ria 1 her zu betrachten; wir fragen nach den Hilfsmitteln, durch welche sich die Psychologie dasjenige Material an psychologischen Befunden verschafft, das sie zur Erfüllung ihrer wissenschaftlichen Aufgaben braucht.

\section{SELBSTERIASSCNG END FREMDERFASSLNG}

\section{Selbsterfassung}

W i e irgend ein Gefühl, z.B. der Trauer, der Angst, seelisch erlebt wird, weiss jeder Mensch $u \mathrm{n} \mathrm{mit}$ t e l b a r nur von sich selbst. Ebenso: wie etwa (redanken auftauchen und sich verketten, oder: wie die zur Willenshandlung führenden psychischen Tatbestände: Antrieb, Uberlegung, Zweifel, Kampf von Motiven, Lintscheidung u.s.w. a ls psychische Tatbestände aussehen. Nit anderen Worten: so weit es die Psychologie mit bewussten ErIebnis-Inhalten und-Abläufen zu tun hat, bedarf sie einer $n$ a $\mathrm{ch}$ in n e $\mathrm{n}$ gewandten Methode, weil nur diese den gesuchten Cegenstand in seinem direkten So-Sein trifft.

Nan hat für diese Methode früher den Ausdruck , Selbstbeobachtung" angewandt, der aber viel zu eng ist. Wenn wir von "Selbsterfassung" oder ,Introspektion" sprechen, sollen damit a 11 e auf das eigene Selbst gerichteten Verfahrungsweis'n gemeint sein.

Es gab psychologische Theorieen, welche in der Selbstbeobachtung die alleinige Methode der Psychologie sahen, weil eben l'sychologie keine andre Aufgabe habe, als das seelische in seine'r direkten (iegebenheit als Selbsterlebtes zu beschreiben. Lis gab andre lehren, welche die selbstbeohachtung vollig auschliessen wollten, weil es absurd sei, dass derselbe Mensch in gleichen 
Augenblick Beobachter und Beobachteter sein könne. Beide Anschauungen sind irrig.

Beginnen wir mit der zweiten Behauptung, die jene Spaltung für unmöglich erklärt.

J e d e s Beobachten ist ein zwiespältiger Prozess: Ich, der Beobachtende als tätige personale Ganzheit, richte mich auf ein abgehobenes Beobachtungsobjekt. Ein solches Objekt kann aber genau so gut „da draussen” oder ,in mir” sein; es gehört zuweilen nur eine kleine Aufmerksamkeitswendung dazu, um von dem einen zum andern überzugehen.

Ein Beispiel: Ich halte meine Taschenuhr ans Ohr und horche auf ihren Gang. Tue ich es, weil sie die Zeit schlecht zeigt und ich feststellen will, ob ihr Gang unregelmässig ist, dann treibe ich ,äussere Beobachtung”. Tue ich es aber, um festzustellen, ob ich sie in einer gewissen Entfernung vom Ohr nicht mehr höre, oder nur noch abwechselnd höre und nicht höre, dann ist die Beobachtung gerichtet auf meine Geräuschempfindlichkeit, auf meine Aufmerksamkeitsschwankungen. Versuche ich dann, in ihr Ticken bald einen 3/4, bald einen $4 / 4$ Takt hineinzuhören wobei ich dann jedesmal den ersten Taktschlag lauter zu hören meine als die anderen, so ist der (iegenstand der Beobachtung meine innere Rhythmik, deren Lmstellungsfähigheit, deren Wirkung aul die Wahrnehmungsperiodizität. In den letzten Fällen habe ich es also mit Selbsterfassung zu tun, und zwar mit Selbst-P e o b a c h t u $\mathrm{n} g$ im engsten Sinne; denn ich erfasse das Scelische, w äh r e nd es da ist und abläuft.

Nehmen wir nun aber ein zweites Beispiel.

Ich bin im Begriff, mich zu entscheiden, ob ich irgend eine Handlung vollziehen (z.B. eine Reise unternehmen) will oder nicht. Der Vorgang erstreckt sich über längere Zeit; es tauchen zu verschiedenen Zeitpunkten neue. Iotive dafür oder dawider auf; Augenblicke, in denen ich schon fest entschlossen bin, wechseln mit solchen neuen Schwankens u.s.w. Nun ist klar, dass ich in jenen Zeitpunkten, in welchen ich ganz mit dem inneren Erleben des Mollens beschäftigt bin, es nicht zugleich beobachten kann; denn meine Aktivitit ist dann voll beansprucht von jenen Wïnschen, Impulsen, Zweifeln und hat keinen Platz für kühle Beschaulichkeit. Aber ich verweile doch nicht dauernd auf solchen Kulminationspunkten. Der Vorgang hat seine Nachlässe 
und Zwischenphasen, in denen er zwar nicht ganz aus dem Bewusstsein schwindet, aber nicht dessen volle Energie beansprucht. In solchen Augenblicken kann man dann das, was in einem vorgeht, gleichsam ,e r tappen”, vorubergehend zum Objekt der Betrachtung machen. Es ist noch lebendig genug, um in seiner seelischen Eigentümlichkeit erfasst werden zu können, und zugleich passiv genug, um sich der beobachtenden 1 kitivität zur Verfügung zu stellen.

Ob man dies noch „Selbstbeobachtung” oder schon „Selbsterinnerung" nennen will, ist für die Sache selbst von geringer Pedeutung. Wir wissen ja heut, dass die psychische "Cegenwart" nicht nur einen Zeit-P unkt umfasst, sondern eine ZeitStrecke. Und deshalb kann etwas eben Dagewesenes noch mit der Anschaulichkeit des (iegenwärtigseins erfasst werden.

Einen kleinen Schritt weiter führt uns dic Selbsterfassung einer starken Emotion. Solange ich zornig bin oder in einem Kunstgenuss begeistert schwelge, bin ich zweifellos ansser Stande, diesen meinen Zorn oder Enthusiasmus zu beobachten. Dic sachliche Haltung des Beobachtens würde sofort den Affekt selbst ertöten. Es ist dies daher auch das beliebteste Beispicl für die grundsätzlichen fiegner der introspektiven Methode. Aber sic übersehen die fundamentale Bedeutung der primären Selbsterinnerung (,primär" deshalb geheisscn, weil sie sich ohne Zwischenpause an das Erlebnis anschliesst). Nachdem etwa ein Zorn eben verraucht ist, vermag man sich zu fratgen: was war denn das eben? was ging da in mir ror? Der Lmstand, dass man noch in dem Ausklang derselben Situation steht, macht diese Selbstbesinnung viel leichter; es sind die entsprechenden Gefühle, wenn auch in energielosen Rückständen, noch da; man hat die cben durchlebte Torsteliungseinengung, das Fehlen von C'berlegung, den inneren Impuls zu sinnlosen Bewegungen noch irgendwie lebendig gerade durch den Kontrast $z u$ der nun eingetretenen ruhigeren Verfassung.

In den weitaus meisten Fällen, in derien früher die Psychologie von "Selbstbeobachtung" sprach, haben wir es mit solchen primären Selbsterinnerungen zu tun.

Zwei weitere Beispiele:

Das Wissen über den Inhalt unserer T $\mathrm{r}$ ä u me stammt vorwiegend daher, dass wir unmittebar heim Erwachen aus cinem Traum 
noch gerade einen Zipfel seines davonflatternden Schleiers erhaschen können. Es ist meist recht wenig; wir haben sofort das Gefühl, dass wir viel mehr geträumt haben als wir noch wissen, und viel wirrer, als wir es sprachlich ausdrücken können. Aber immerhin: es sind doch die $\mathrm{r}$ e $\mathrm{l}$ a $\mathrm{t}$ i v besten Dokumente des Traumes - während vielleicht am Nachmittag des gleichen Tages nichts mehr da ist an echten Traumerinnerungen; was wir nun darüber berichten, ist höchstens eine sekundäre Rekapitulation der primären Traumerinnerung.

In die Psychologie des $\mathrm{D}$ e $\mathrm{n} \mathrm{k}$ e $\mathrm{n}$ s hat Külpe vor einigen Jahrzehnten ein Verfahren eingeführt, das er und seine (,Würzburger') Schule nicht ganz zutreffend die Methode der „Experimentellen Selbstbeobachtung" nannte. Den Versuchspersonen werden bestimmte Denkstoffe (Sentenzen, Rätsel u.s.w.) gegeben; sogleich $\mathrm{n}$ a c h de m die Denkaufgabe gelöst ist, haben sie anzugeben, welche Inhalte und Abläufe dabei in ihrem Bewusstsein gewesen waren.

Noch weiter von eigentlicher Selbstbeobachtung ist die nächste Stufe der Selbsterfassung entfernt; die s e k u n d ä r e S e l b s terinnerung. Sie bezieht sich auf seelische Erlebnisse und Zustände, die von der gegenwärtigen Zuständlichkeit und Situation des Ich zeitlich und qualitativ deutlich geschieden sind, ist also ein Wi e d e r-lebendigmachen (oder Wieder-lebendigwerden) von inzwischen Versunken-Gewesenem. Die Psychologie ist auch auf solche Erinnerungen angewiesen; denn ihre Untersuchungen haben oft seelische Situationen oder Bedingungen zum Thema, die nicht im Augenblick aktuell sind, aber in der Vergangenheit bedeutsam waren.

Beispiele solcher Themen: die seelische Wirkung ungewöhnlicher Ereignisse (eines Trauerfalles, einer schweren Erkrankung, einer Feuersbrunst, einer politischen Massenbewegung); Erst-Erlebnisse (die erste Lüge; Anfänge der Erotik; das Erwachen des religiösen Interesses).

Sicherlich ist eine solche weit zurückgreifende Introspektion möglich. Aber sie ist viel schwieriger und in ihrem Geltungswert problematischer als die früher erwähnten introspektiven Methoden. Denn die Erinnerung ist als Erkenntnismittel überhaupt sehr fragwürdig ${ }^{1}$ ); gilt dies schon für die Wiedervergegenwärtigung äusserer Tatbestände der Vergangenheit, wie viel mehr für die Erinnerung an deren seelis che Resonanz. In der Verwertung dieses Verfahrens muss also der Psychologe äusserste Vorsicht walten lassen.

"Vi. Kap. Xll. "Lrimerung". 
Die Schwierigkeit wächst, wenn sich die Selbsterinnerung auf längst überholt e Phasen des eigenen Lebens, z.B. auf die Kindheit richtet. Die Art, wie ein Mensch als Kind sich selbst und die Welt erlebt hat, ist so völlig bedingt gewesen durch seine personale Gesamtstruktur in jener Zeit, dass er in späteren Jahrzehnten wohl noch das eine oder andre seelische Erlebnisfragment oder eine Stimmungsfarbe erinnern kann, nicht aber mehr die Bedeutung, die jenes seelische Moment damals innerhalb der kindlichen Personalität gehabt hat. Hier muss recht viel neugestaltet und neugefärbt werden.

Diesen Gefahren ist z.B. die psychoanalytische Methode nicht immer entgangen, die besonders gern mit Kindheitserinnerungen Erwachsener operiert. Wenn ein 30-jähriger Neurotiker gewisse gegenwärtige Sexualregungęn als Rückstände von Infantil-Erlebnissen ansieht, so ist nicht mehr festzustellen, wieviel er aus seinem erwachsenen Seelenleben in jene, scheinbar ,erinnerten", Kindheitseindrücke hineinprojiziert.

Bezüglich aller bisher erörterter Formen der Selbsterfassung muss nun eine sehr wichtige methodische Grenze festgestellt werden: Es handelt sich stets um $\mathrm{B}$ e w us s t machung.

Entweder wird das, was im Originalerlebnis bewusst war, erfasst und registriert; oder es wird das, was ursprünglich unbewusst war, nachträglich ins Bewusstsein erhoben.

Im ersten Fall beschränkt sich also die Selbsterfassung v o n vorn he rein auf jene Ausschnitte des Seelischen, die in die helle Sphäre des Bewusstseins hineinreichen und genügend deutlich sind, um dann noch erhascht zu werden: das Ergebnis muss deshalb fragmentaris $\mathrm{ch}$ sein. Daraus folgt, dass negative Angaben höchstens lauten dürfen: „, das und das finde ich in meinen Bewusstsein nicht vor", n i ch t a ber: "das und das ist seelisch nicht wirksam gewesen". Denn zuweilen können sich die entscheidendsten Antriebe in einer nicht in Selbstschau fassbaren Schicht abspielen: beachtet man dies nicht, so sind grobe Täuschungen über die eigenen Motivationen möglich.

Im zweiten Falle wird der Versuch gemacht, solche unbewussten Momente nachträglich ins Bewusstsein zu heben, damit sie introspektiv erfassbar werden.

Das ist aber eine Operation, die nicht ohne eine V e r w a n dl u ng des Tatbestandes vor sich geht. Der bewusst gemachte 
Gedanke oder Affekt ist nicht mehr identisch mit jener Zuständlichkeit oder Einstellung, die ungeschieden in die tieferen Regionen der eigenen Person eingebettet war. Indem man das Leben künstlich in Er-leben verwandelt, nimmt man ihm viel von seiner Ursprünglichkeit. Diese Grenze der introspektiven Methode sollte man vor allem beachten bei tiefenpsychologischer Arbeit, deren Verfahren ja ausgesprochenermalsen in „Bewusstmachung des Unbewussten" besteht.

Der Rückgang zu dem, was hinter dem Bewusstsein liegt, kann nun aber in noch ganz anderer Form erfolgen bei der letzten Stufe der Selbsterfassung: der S e $1 \mathrm{bs} \mathrm{t} \mathrm{ch}$ a r a k t e r is t ik. Hier handelt es sich überhaupt nicht mehr um akute seelische Tatbestände, mögen sie gegenwärtig oder vergangen, bewusst oder unbewusst sein - sondern um chronische personale Wesenszüge, die den dauernden Hintergrund und Quellgrund für alle akuten Geschehnisse bilden. Eine solche Selbstbeurteilung meint der berühmte delphische Tempelspruch ,Erkenne Dich selbst”. Er meint ferner noch etwas anderes, was die Verwertung dieser Erkenntnisweise für wissenschaftlich psychologische Zwecke sehr erschwert: nämlich Selbstbesinnung im Hinblick auf Selbsterziehung.

Selbstcharakteristik ist fast nie ein blosses Feststellen, wie es die Wissenschaft verlangt, sondern ein stark von We $\mathrm{r}$ u $\mathrm{n}$ g e $\mathrm{n}$ bestimmtes Tun. Man sucht - und findet - in sich dicjenigen Züge, durch die man sich bejahen, vor sich und Anderen rechtfertigen, seine Zielsetzungen bestätigen will; oder aber man sucht - und findet - solche Eigenschaften, die man verwirft, um sie zu überwinden und um sich zu wandeln. Diese kaum lösbare Verbindung von Selbstcharakteristik, Selbstwerterleben und Selbitgestaltung bewirkt, dass das seelische Selbstbildnis jedes Menschen unter einer einseitigen Perspektive steht, nämlich ein Wunschbild oder ein Richterbild ist. Es gehört eine sehr seltene Kunst der Selbstoljektivation dazu, um zu verhindern, dass jene perspektivische Verschiebung zu einer Verzerrung wird. Ieshalb bildet die Selbstcharakteristik für die Psychologie viel mehr ein äusserst fesselndes Problem, als eine brauchbare Nethode zur lösung anderer Probleme. 
2. Die Erfassung des Fremdseelischen

Die Introspektion kann dem Psychologen schon deshalb nicht die einzige Methode sein, weil sie ihm nur einen s in $g$ ul ä re n Befund, das Seelenleben der eigenen Individualität, liefert. Wie weit die hier gewonnenen Einsichten nur-individueller oder typischer oder allgemein menschlicher Art sind, bleibt verborgen. Die Forschung des Psychologen ist aber auf allgemeine (ieset $z$ mäIsigkeiten, ferner auf die seelische Verfassung der von ihm sell st abweichenden Typen, Lebensformen, Altersstufen gerichtet; deshalb muss er auch zum Seelenleben anderer Wesen den Zugang finden.

Hier tritt nun wieder eine neue methodische Schwierigke it auf.

In welcher Weise ist uns denn fremdes Seelenleben $g e g e b$ e $n$ ? Die Antwort schein t zunächst recht entmutigend zul klingen: direkt gegeben ist es uns nie, vielmehr allein durch Vermittlung physischer Äusserungen, die wir wahrzunchmen vermögen. Träfe diese Antwort restlos zu, dann wäre uns das Seclische anderer Menschen nur auf dem Wege des Analogieschluss e s zugänglich in folgender Form: In mir selbst kenne ich beides: seelisches Erlebnis (z.B. ein Angstgefuill) und sichtbare Äusserungsformen (Zittern, Erblassen, Fluchtbewegung u.s.w.); bei dem Anderen sehe ich nur das eine cilied, den körperlichen Ausdruck, und schliesse daraus, dass diesem ebenso ein innere's Angstgefühl entspricht wie bei mir.

Unter dieser Voraussetzung wäre also das Seelische im Anderen immer nur etwas E rs chlosse nes, nie etwas Erfahrbares; und es wäre erschliessbar nur, so weit es mit meinem Scelenleben ü b e r e i n s t i m m t; denn es wäre ja lediglich eine Projettion meines Seelenlebens in die entsprechende Jusserunsivedise des Anderen. Im Grunde bliebe also jerler Mensch in (ler jerchologischen Erkenntnis auf sein scelenleben beschüulit,drehte sich psychisch im Kreise.

Glücklicher Weise sind diese Thesen nicht richtis.

1) Sie setzen voraus, dass in dem anderen Mensichen, den ich psychologisch erfassen will, zweigetren nte Momente enthalten seien, von denen ich das eine (kïrperliche) unnittelbai, das andere (seelische) mittelbar erfasse. Nun ist aber urspruinglich gar keine Zweiheit da, sondern die linheit des prichophy- 
sisch neutralen, persönlichen Lebens; und dem entspricht auch eine Erfassungsweise, die sich direkt auf dies ungeschiedene Ineinander von Ausdruck und Erlebnis bezieht, ein Verstehen jener personalen Haltung $\mathrm{m}$ i $\mathrm{t} \mathrm{s}$ a $\mathrm{m} \mathrm{t}$ dem darin steckenden Erlebnismoment. Gesichtsausdruck, Geste, Handlung, Wort eines X sind für mich, den Verstehenden, garnicht ursprünglich als bloss optische und akustische Wahrnehmungs-Gegenstände da, von denen ich dann „schliessend” zu der inneren Seelenkomponente des X übergehe - sondern: ich se he unmittelbar die Trauer durch das traurige Mienenspiel hindurch; ich höre die Erwartung aus dem Klang der Worte heraus; der seelische Anteil ist für mich in nicht geringerer Anschaulichkeit und Gegenwärtigkeit vorhanden als der körperliche.

Auf dieses in t u it i ve Erfassen des Fremdseelichen wurde schon an früheren Stellen hingedeutet ${ }^{1}$ ); es bildet die unentbehrliche Grundlage aller psychologischen Arbeit an anderen Menschen. Freilich kann es nie mehr als eben eine Gr undl a ge sein. Denn es erstreckt sich nur auf die ganz grossen und vagen Umrisslinien und die Gesamttönungen der Seelenverfassung; sobald man jedoch in die Einzeluntersuchung eintritt, reicht es nicht mehr aus, sondern muss stets durch deutendes und schliessendes Verfahren ergänzt werden. Beide Methoden stützen sich dauernd gegenseitig; das unmittelbare Verstehen braucht eine Sicherung, Kontrolle, unter Umständen auch Korrektur seiner Ėrgebnisse von der ,diskursiven” Arbeit her. Diese wiederum, die in physischen Äusserungen „Symptome” für Seelisches erkennen soll, muss die Vieldeutigkeit der Symptome von dem intuitiven Verständnis her einzukreisen suchen.

2) Wenn weiter gesagt wird, dass das Erschliessen und Erdeuten des Fremdseelischen nur nach Analogie des e ig e n e n I ch vor sich gehen kann, so darf man Analogie nicht mit Gleichheit verwechseln. Würde ich - der forschende Psychologe - nur denjenigen andren Menschen psychologisch erfassen können, der d a s s l b e Seelische erlebt wie ich und dies in cle r s e 1 b e n Weise - dann wäre mir der Zugang zum Fremdseelischen überhaupt versperrt; denn keiner gleicht dem Anderen. Aber einer ä h $\mathrm{n}$ e $1 \mathrm{t}$ dem Anderen in stärkerem oder

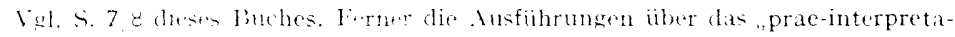

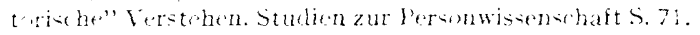


geringeren Grade; und eben diese Ähnlichkeit können wir erfassen.

Die menschliche Persönlichkeit ist ja nicht ein, nach allen Richtungen eindeutig festgelegtes, starres Gebilde, das in sein individuelles Sosein wie in einen Kerker eingeschlossen wäre; sie enthält vielmehr stets Vieldeutiges, Unterschichtiges, peripher Randmässiges. So ist in jedem Menschen der Umkreis seiner Möglichkeiten weit ausgreifender als seine jeweilige Wirklichkeit; diese Möglichkeiten muss er in sich zum Anklingen bringen, wenn er Fremdseelisches erfassen will. Wie könnte sonst der Seelenforscher hier Psychologie des Verbrechers, dort des Künstlers, dann des Kindes oder des Naturmenschen treiben, wenn nicht irgend etwas von alledem - spurenhaft und anlagemässig - in ihm steckte! Dem Nicht-Eidetiker ist die eidetische Erlebensweise, dem Nichtmusikalischen die seelische Reaktion auf Musik nicht völlig verschlossen. Jeder Mensch ist eben nicht nur ein Bruchstück der Welt, sondern ein Mikrokosmos, mit allem anderen verwandt ${ }^{\mathbf{1}}$ ).

Allerdings wird nun hier eine doppelte Grenze sichtbar; sie liegt sowohl im Psychologen, wie in dem zu untersuchenden anderen Menschen.

Die Fähigkeit, in der angedeuteten Weise die Schranken des engeren Ich zu sprengen, ist sehr verschieden abgestuft; wer sie nur in geringem Masse besitzt, taugt nicht zum Psychologen. Sehr viele Menschen - sie sind hauptsächlich, aber nicht ausschliesslich, unter psychologischen Laien zu finden - sehen ihr eng begrenztes Ich mit Selbstverständlichkeit als die „N or ma lp s y c h e" an; und von dieser Norm aus werden andre Menschen gedeutet - wobei Fremderes überhaupt nicht verstanden oder gewaltsam mittels eines angleichenden Schlusses umgedeutet wird. Eine solche Einstellung ist gewiss zu einem Teil eingeboren und unabänderlich, zu einem andern Teil aber auch nur das Ergebnis von psychologischer Ahnungslosigkeit und Cnbildung; hier kann psychologische Schulung stark aufklärend und horizonterweiternd wirken. Schon um dieses unersetzbaren Bildungswertes willen sollte Psychologie zur Berufsvorbereitung eines jeden Menschen gehören, der später - z.B. als

1) Vyl. Differentiellie Poycholugie. S. 557 . 
Lehrer, Richter, Arzt - Fremdseelisches zu verstehen und zu behandeln hat.

Die andere Grenze liegt in dem zu erforschenden Menschen; je geringer dessen Ähnlichkeit mit dem erkennenden Psychologen, um so schwerer ist es natürlich, ihn analogiemässig zu erfassen. Mit Recht nimmt man an, dass der männliche Psychologe wesentliche Züge der weiblichen Psyche deswegen nie ganz verstehen kann, weil er eben ein Mann ist. Und die Musikalität des andern Menschen kann ein musikalischer Psychologe sicherlich besser untersuchen als der unmusikalische. Schon früher wurde darauf hingewiesen, dass diese, aus der steigenden Fremdheit und Lnähnlichkeit hervorgehenden Schwierigkeiten sich häufen bei der psychologischen Erforschung des Kleinkindes, des Naturmenschen, des Tieres. Für die Psychologie gilt eben nicht jener methodische Leitgedanke, der wohl für alle anderen Wissenschaften zutrifft: „Das Einfachere ist leichter wissenschaftlich zu bewältigen als das Zusammengesetztere"; denn das einfachere Seelenleben ist uns besonders fern und fremd, weil wir selbst komplizicrte, ausgereifte Kulturmenschen sind.

Aber auch die durch Lnähnlichkeit gesetzte Grenze ist keine absolute; grade die Entwicklung der Kindes- und Tierpsychologie hat bewiesen, wie sich der Psychologe langsam und vorsichtig an die Rätsel dieser ihm so fernen Seelenwelten mit Erfolg heranzutasten vermag.

Die Erfassung des Fremdseelischen geht nun in sehr verschiedenen Verfahrungsweisen vor sich, die wir auf drei grosse Formkreise bringen können: Beobachtung des natürlichen Verhaltens; Experiment; Fernmethoden.

11. BEOBACHTLNG DES NATÜRLICHEN VERHALTENS

\section{Allgemeines}

Solange der psychologisch zu erforschende Mensch nicht um der Cntersuchung willen eigens beeinflusst und zu ,künstlichen” Reaktionen veranlasst wird (wie es im Experiment geschicht), nemnen wir sein Verhalten ,natirlich". Es ist ,reaktiv", wenn es als Antwortsverhalten auf bestimmte, dem natürlichen Lebenslauf angehörige, Einwirkungen anzusehen ist (Einflüsse der Fa- 
milie, der Schule, eines Unglückfalles, eines Kunsteindrucks, einer Bekanntschaft, eines geschichtlichen Ereignisses, u.s.w.); es ist „spontan", wenn es im wesentlichen von den im Inneren des Menschen wirkenden Kräften bestimmt ist (Spiel; Iufse-Beschäftigung; Erwachen von religiösen, künstlerischen, beruflichen Interessen u.s.w.) ${ }^{1}$ ).

Die natürlichen Reaktionen und Spontanaktionen sind in weitem Malse der Beobachtung durch andere zugänglich. Bis vor wenigen Jahrzehnten hat die Psvchologie, neben der Selbstbeobachtung, überhaupt keine andre Erkenntnisquelle gehabt, als die der kunstlosen Erfassung und psychologischen I)eutung von Alltagshandlungen und Geschehnissen, wie sie sich -- mehr oder weniger zufällig - in Haus und Schule, in der Offentlichkeit, in Anstalten u.s.w. dem Forscher darboten.

Als vor einem halben Jahrhundert das Experiment in die psychologische Methodik eingeführt wurde, glaubten viele, dass es jenes anspruchslosere Beobachtungsverfahren verdrängen werde. Sehr zu Unrecht. Denn die Beobachtung hat zwei Vorzüge, die ihr auch neben dem Experiment ihren dauernden Platz in der Wissenschaft sichern. Sie ist $l$ e be n $\mathrm{n}$ äh e $\mathrm{r}$ als das Experiment: die von ihr zu erfassenden seelischen Vorgänge sind weit organischer in das (iesamtleben der Persönlichkeit eingchaut als die Erzeugnisse einer experimentellen Versuchsanordnung. Ferner ist der Beobachtung das s po n t a ne Wirken persionlicher Kräfte zugänglich, während das Experiment seiner Bestimmung nach immer auf Reaktionen angewiesen ist. Wann und wie $z$.B. in einem heranwachsenden Menschen sich religiöse Interessen zu regen beginnen, kann man allenfalls beobachten, nie experimentell feststellen. Auch u n e $\mathrm{r}$ w a t e te seelische Ausicrungen, Wandlungen, u.s.w. sind allein einer wachen Beobachtung zugänglich, während das Experiment ja von vorn herein auf zuerwartende Reaktionen eingestellt sein muss. (ierade die letzten Jahrzehnte, die der Psychologie cine Hinwendung zu kulturpsychologischen Problemen gebracht haben, mussten auch wieder die Beobachtungsmethode in ihr altes Recht cinzetzen.

Dabei hat aber diese Nethode in sich selbst eine starke wissenschaftliche Ausgestaltung erfahren können. I ter Psicholo-

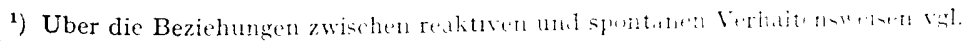
Kap. IV. 
ge hat auf Grund der Fortschritte seiner Wissenschaft allmählich ganz anders ,,sehen” gelernt; er tritt mit veränderten Einstellungen an sein Beobachtungsobjekt heran. Er sucht auch seine Beobachtungen zu systematisieren und vergleichb a $r$ zu machen. - Wie nennen einige Hauptformen.

2. Systematische Beobachtungsmethoden

a) Ps y c hographi e. - Die Gesichtspunkte, unter denen beobachtet werden soll, werden vorher ausgearbeitet und die Ergebnisse der Beobachtung dann in die einzelnen Rubriken eingetragen. Das vorbereitete Schema ist ein „Beobachtungsbogen". Die Ausfüllung für ein bestimmtes Individuum bildet dessen „Psychogramm”.

Der Beobachtungsbogen kann zunächst dem Beobachter selbst als ein sehr notwendiger Ariadnefaden durch das Chaos der sich aufdrängenden Beobachtungsmöglichkeiten dienen; ferner lassen sich an der Hand des Schemas die von vielen Beobachtern und an vielen Menschen gemachten Feststellungen mit einander vergleichen und zu allgemeineren Ergebnissen verarbeiten.

Beobachtungs-A $\mathrm{n}$ w e i s u $\mathrm{n}$ g e $\mathrm{n}$ sind insbesondere dort erforderlich, wo Menschen, die nicht im Hauptberuf Psychologen sind, dennoch eingehendes und für andere brauchbares Material sammeln müssen; daher spielen die psychologischen Personalbogen in Erziehungsanstalten, Schulen u.s.w. eine grosse Rolle.

Die psychographische Methode ist vielfach umstritten. Man weist - nicht ganz mit Lnrecht - auf die Gefahr hin, dass das „Psychogramm” das Individuum in ein Mosaik von äusserlich aneinandergereihten Einzelzügen aufzulösen drohe und dadurch den Einblick in die wesentliche Ganzheitsstruktur der beschriebenen Persönlichkeit versperre. Man verlangt deshalb oft an Stelle ausgefüllter Personalschemata sogenannte „freie Charakteristiken", in denen Lehrer und Erzieher die Eigenart jedes Zöglings von dessen besonderem Persönlichkeitszentrum her zu entwik$\mathrm{ke} \cdot \mathrm{ln}$ suchen sollen. Wenn nur eine solche Aufgabe nicht das Können der meisten Pädagogen weit übersticge! Neuerdings wird eine Synthese angestrebt: die Beobachtungsanweisungen werden so locker formuliert, dass sie zwar den Rahmen der beachtenswerten Gesichtspunkte abstecken, innerhalb dessen aber der freien Schilderung Spielraum gewähren. 
b) $\mathrm{K}$ a s u is t i $\mathrm{k}$ ist Darstellung, Sammlung und Verwertung von konkreten $\mathrm{F}$ älle n.

In der Ausbildung dieser Methode sind gewisse praktische Disziplinen, vor allem die Medizin, dann aber auch Kriminalistik, Pädagogik, Wohlfahrtspflege, der Psychologie weit voraus. Das ist ganz natürlich. Denn die Aufgaben der Praktiker beziehen sich ja primär auf Individualitäten: auf Kranke, Rechtsbrecher, Zöglinge; und die jeweils gebotene individuelle Behandlung fordert vor allem Einsicht in die besondere Beschaffenheit und Bedingtheit jedes einzelnen „Falles”. Meist geht dann der Weg von hier aus erst zu Verallgemeinerungen, Hypothesen und Theoricen.

Anders der Psychologe. Als Theoretiker war er von allgemeinen Proble me n ausgegangen; Fälle der Wirklichkeit kamen für deren Bearbeitung nur in Betracht als Anschauungsbeispiele oder Vergleichsmaterialien. Aber man scheute sich doch lange Zeit, stärkeren Gebrauch davon zu machen, weil die „Fälle” in ihrer Lebensnähe und Situationsgebundenheit zu komplex und unübersichtlich erschienen.

Unabweisbar wurde die Notwendigkeit kasuistischen Materials erst dort, wo der Psychologe selbst von der Theorie zur Praxis überging; denn nun gab es auch innerhalb seiner eigenen Arbeitssphaere wirkliche ,Fälle” - etwa die Kinder, für die er Erziehungs- und Schulbahnberatung zu treiben hatte, Verbrecher und Zeugen, die forensisch zu begutachten waren, Berufsuchende, deren Eignung festzustellen war u.s.w. Noch ist das verfügbare Arsenal an psychologischen Fallsammlungen relativ klein; seine Erweiterung ist dringend notwendig, damit der Psychologe bei jeder gebotenen Gelegenheit aus diesem kasuistischen Erfahrungsschatz schöpfen kann.

c) Beobachtung von Entwicklungsabläufon. Werden psychische Erscheinungen während einer gewisien lebensepoche ohne grössere Lnterbrechungen beobachtet und registriert, so ist man in der Lage, den inneren Zusammenhang in Zeitablauf aufzuweisen: seclisches Wachsen und Reifen, Entstehen und Vergehen gewisser Zustände, Plötzlichleit oder stetigkeit der Mandlungen.

Auch diese Art von Beobachtung ist ron der Medizin her bekdnnt. so wenn der l'sychiater den Ablauf einer geistigen Erkrankung hei oinem klinischen Patienten verfolgt and das, was er nicht direlit henh- 
achten kann, sogar durch Anamnese und Katamnese nach rückwärts und vorwärts ergänzt.

In der Psychologie hat die Methode ihre Hauptausbildung erfahren bei der Beobachtung $\mathrm{k}$ ind $\mathrm{lich}$ er Entwicklungen. Eltern oder Verwandte sind ja in der Lage, ein heranwachsendes Kind längere Zeit hindurch $z$ beobachten; so entstanden Tagebücher, welche seelische Entwicklungen über Jahre hin verfolgten. Neuerdings sind auch in Kindergärten und anderen Anstalten Beobachtungen von längeren Entwicklungsabläufen angestellt worden. Das Verfahren richtet sich bald auf die seelische Entwicklung überhaupt, sodass alles vermerkt wird, was ins psychologische Blickfeld gerät; bald beschränkt es sich auf bestimmte Teilprobleme: Entwicklung des Sprechens, oder des Spielens, oder des sozialen Verhaltens u.s.w.

Bei allen drei erwähnten systematischen Formen des Beobachtens können auch gelegentlich andere Methoden (Tests, Erhebungen) mit herangezogen werden; aber der leitende Gesichtspunkt bei diesem Verfahren bleibt doch, dass das n a t ür li c h e Verhalten nicht wesentlich durch die Arbeit des Psychologen beeinflusst und verändert wird.

Hierin liegt der eigentliche Unterschied zur Methode des Experiments.

III. EXAKTE METHODEN

\section{Experiment und Messung}

In der „Farbenlehre” (joethe's gibt es ein ausgesprochen psychologisches Kapitel "Cber die sinnlich-sittliche Wirkung der Farben". Dort erwähnt Goethe gleichsam im Vorbeigehen, wie man sich den seelischen Effekt einer farbigen Beleuchtung recht eindringlich verschaffen könne: man sehe durch ein farbiges Cilas; dann sei das gesante Ciesichtsfeld in diese eine Farbe getaucht, die nunmehr auch dic (jesamtstimmung der betrachtenden Person becinflusse.

Das Beispiel soll zeigen, dass es ,psychologische Experimente" schon gab, lange the eine ,experimentelle Psychologie" bestand. I)iese kam erst auf, als man s y tem a $t$ is $\mathrm{ch}$ die in 
Physik und Physiologie schon immer bewährte Methode des Experiments auf psychologische Probleme übertrug, mit Hilfe dieses Verfahrens M es sung en vornahm und schliesslich beides: Experiment und Messung, den besonderen Bedürfnissen und Aufgaben der Psychologie anpasste.

Fechner und Wundt waren die Pioniere; zwei Generationen von Psychologen aller Kulturländer - in besonderem Malse Deutschlands und Nordamerikas - haben die Methodik mächtig ausgehaut, die jetzt in einer kaum zu übersehenden Zathl von Instituten, Laboratorien, Kliniken, Prüfstellen u.s.w. geüht wird.

Der Umstand, dass heut andere Verfahrungsweisen neben dem Experiment ihr Eigenrecht teils wiedergewonnen, teils neu erworben haben, bedeutet nicht etwa einen Rückgang der experimentellen Methode; wir können vielmehr auch jetzt noch feststellen, dass sich der Umkreis der experimentell zu behandelnden psychologischen Aufgaben ständig erweitert, wobei die Wechselwirkung mit den andern Nethoden nur förderlich ist.

In jedem wissenschaftlichen Experiment wird der zu untersuchende Tatbestand absichtlich erzeugt, und $z$ war in einer Form, die der Untersuchung möglichst günstig is $t$. Der Forscher wartet also nicht $a b$, bis sich die ihn interessierende Erscheinung gelegentlich darbietet, sondern er ruft sie in dem $Z$ e i t p u $\mathrm{n} \mathrm{t}$ hervor, in dem er ihrer bedarf. Er nimmt sie ferner nicht in der Beschaffenheit hin, wie sie ihm der Zufall liefert, sondern er bereitet auch die Versuchsbedingunge $n$, die den problematischen Gegenstand scharf und einfach herausheben aus alledem, was im Augenblick nicht dazu gehört.

Diese für jedes Experiment geltenden lesichtspunkte sind nun ohne Weiteres auch auf psychologische Fragestellungen anwendbar. Wir wählen zur krläuterung eine in der Geschichte unserer 11 issenschaft klassisch geworlene Verfahrungsweise: die von Ebhinghaus ror 50 Jahren erdichte Nethode zur experimentellen Cntersuchung des mechanischen diedächtnisses.

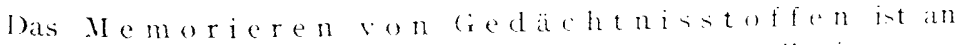
sich auch det kunstlosen Beobachtung zugängheh; es sibt ju wenus denschen - Schulkinder, P'rüfungskandidaten. Schauspicter - bed

iturn, l'sycholenie. 
denen uns Memorierleistungen begegnen. Welche Gründe geben Veranlassung, das Problem experimente 11 zu behandeln?

1) Beim natürlichen Memorieren ist das "mechanische" und das „verständnisvolle” Lernen nicht säuberlich zu trennen. Um das rein mechanische Einprägen von Gedächtnisstoffen möglichst zu gewährleisten, mussten diese eigens zubereitet werden in einer Form, die verständnisvolles Lernen auszuschliessen schien: Ebbinghaus stellte daher „, sinnlose” Silben auf, die er zu Lernreihen beliebig kombinieren konnte.

2) Aber auch solche Silben könnten sich, je nach ihrem Bau, verschieden schwer einprägen; diese Ungleichheit, welche die Ergebnisse undeutlich machen würde, erforderte Abhilfe. So wie der Chemiker nicht mit gewöhnlichem Leitungswasser arbeitet, das bald durch diese, bald durch jene Zusätze verunreinigt ist, sondern mit aqua destillata, so wurde hier der Lernstoff ,destilliert”, d.h. überall gleichwertig gemacht: Ebbinghaus baute seine Silben so, dass sie aus je drei Lauten bestanden: Konsonant - Vokal _ Konsonant; alle Silben, die an bekannte Wörter anklangen, wurden ausgeschieden.

3) Solch exaktes und gleichmässiges Material lässt sich nun genau $q u$ a $n$ i t a $t$ i v abstufen: die Länge der zu lernenden Reihen, die Zahl der Lesungen bis zum Erlernen, die zum Lernen nötige Zeit, die Zwischenzeit zwischen dem Erlernen und der Nachprǘung des Behaltens - dies und noch manches andere ist in Ziffern ausdrückbar, die unter einander in mannigfache Beziehung gesetzt werden können.

4) Um die unberechenbaren Einflüsse der Situation und der persönlichen Disposition auszuschliessen, wiederholt man die Versuche unter möglichst gleichen Situationsbedingungen: immer zur gleichen Tageszeit, nur bei voller Frische und Gesundheit der Versuchsperson u.s.w. (Das ändert sich natürlich, wenn die Situationsbedingung selber z.um Problem wird, also wenn z.B. untersucht werden soll, wie die Lernfähigkeit im Laufe des Tages variiert.)

5) Versuche, die in so genau abgezirkelter Form angestellt worden sind, lassen sich $z u$ anderen Zeiten und von anderen Untersuchern mit weitgehender Genauigkeit wi ed e r h o len. Damit entsteht eine Methodengemeinschaft innerhalb der Fachwelt, die sich $z u$ einer Problem- un $\mathrm{C}$ A $\mathrm{rbe}$ i $\mathrm{t} \mathrm{s}-\mathrm{G}$ e $\mathrm{me}$ in $\mathrm{s} \mathrm{ch}$ a $\mathrm{f}$ von früher ungeahnten Malsen ausweiten kann und die ausserdem eine Nachprüfung der von einem einzelnen Forscher gefundenen Ergebnisse gestattet, während früher die Selbstbeobachtung des Einzelnen eine inappellable Instanz bildete.

6) Bei Gelegenheit von Experimenten können Selbstbeoba c ht u $\mathrm{ngen}$ der Versuchsperson erzielt und $\mathrm{Beobacht} \mathbf{u}$ $g$ e $n$ uber die Art ihres Verhaltens gemacht werden, sodass hier das Experiment zum Hilfsverfahren für die anderen Methoden wird.

Was wir an dem einen, beliebig herausgegriffenen Beispiel veranschaulichten, gilt für psychologische Experimente überhaupt; 
nur dass die einzelnen Faktoren mit sehr verschiedenen Akzentuierungen auftreten können. Hier ist auch eine bedeutende Entwicklung seit den Tagen der klassischen Experimentalpsychologie (die im letzten Viertel des 19 . Jahrhunderts kulminierte) deutlich erkennbar. War damals das Vorbild der Physik bestimmend mit ihren Forderungen der eindeutigen, strengen und exakten Messbarkeit, so erkannte man in der Folgezeit, dass diese Ansprüche nur an leblosem Material erfüllbar seien, dass sie aber bei der Ubertragung von der sächlichen Welt ins personale Leben wesentlich gemildert werden müssen. Denn Organisches und insbesondere Seelisches ist eben nie in der isolierten Einfachheit und exakten Abstufbarkeit gegeben wie physikalische oder chemische Gegenstände; es ist und bleibt vieldeutig, labil und beweglich durch seine Zugehörigkeit zur Ganzheit der Person; dies um so mehr, je mehr der seelische Tatbestand eingebettet ist in jene Totalität. Maximale Exaktheit kann daher nur erkauft werden durch Entpersönlichung des Psychischen, das zur Lntersuchung steht, durch Abschneidung der Sinnbeziehung, durch welche es erst zu dem wird, was es ist.

Trotzdem wäre es durchaus verkehrt gewesen, aus solchen Gesichtspunkten auf die unermesslichen Leistungen des Experiments verzichten zu wollen. Es galt vielmehr, die Methode so durchzugestalten, dass jene Gefahren zurück- und diese Vorzüge hervortreten. Dies war auf verschiedenen Wegen möglich.

Zunächst war das Experiment aus seiner methodischen Isolierung $\mathrm{zu}$ befreien und als $\mathrm{H}$ il $\mathrm{fs} \mathrm{verf}$ a h $\mathrm{r}$ e $\mathrm{n}$ einer umfassenderen Methodik einzufügen (vgl. Punkt 6, S. 82). Jahrzehnte emsiger Spezialarbeit haben allmählich aus dem Experiment ein Werkzeug gemacht, das nicht den Psychologen beherrscht, sondern von ihm gemeistert wird. Es kann jetzt dort, wo es die Situation verlangt, und so, wie sie es verlangt, mit den anderen Verfahren kombiniert werden: hier, um die Selbstbeobachtung zu vertiefen oder die Selbsterinnerung auszulösen; dort, um eine Begabungs- oder Eignungsdiagnose zu stiitzen; dann, um eine theoretische Hypothese zu verifizieren; um frei gewonnene Beobachtungen durch spezielle Nachprüfungen zu ergänzen u.s.w.

Hierbei hat sich auch die Form des Experiments selbst allmählich gewandelt, namentlich bezüglich des - im Grunde psychologiefremden - „Ex a k the it s"-Merkmals. Je exakter 
ein Experiment angelegt ist, um so mehr liefert es eine b lo s s e „Reaktion" der Versuchsperson, eine Zwangsantwort auf einen Zwangsreiz. Da nun aber der Mensch, auch dort, wo er reagiert, doch zugleich spontane Persönlichkeit bleibt, musste versucht werden, auch die ,Spontaneität innerhalb der Reaktivität” im Experiment zu treffen. Daher ging man zu Aufgaben über, die einen grösseren Spielraum möglicher Reaktionen freilassen; die Versuchsperson muss dann die Vieldeutigkeit der Aufgabe durch spontan a uslesende Tat vereindeutigen. Hierbei kann „Auslese" ebensowohl bewusste Wahl wie auch völlig unbewusste Einstellung der inneren Kräfte bedeuten.

In der Freisetzung von Spontaneität gibt es viele Stufen: etwa von ästhetischen Farbenvergleichungen an, bei denen Wohlgefälligkeitsurteile abzugeben sind - bis hin zu Kombinationsexperimenten, in denen aus drei gegebenen Worten ein vom Prüfling selbst $z \mathfrak{u}$ findender sinnvoller Zusammenhang hergestellt werden soll - oder zu den Aufsatzversuchen, bei denen nur das Stichwort (z.B.: „Wie ich mir meinen künftigen Beruf denke") und die Notwendigkeit des Schreibens überhaupt von aussen aufgedrängt werden, während der Inhalt aus dem spontanen Innenleben der Versuchsperson geschöpft wird.

Damit hängt nun auch die veränderte Stellung der modernen Psychologie zur Frage der psychologischen II ess ung zusammen. Wir können uns heut kaum mehr in die ungeheure Aufregung zurückversetzen, die vor 70 Jahren die These Fechners, dass man Seelisches ,messen” könne, hervorgerufen hatte. İamals meinten Fechner und seine Nachfolger, physikalis che Mafsprinzipien unmittelbar auf das Seelenleben ubertragen und dieses dadurch der allgemeinen Naturgeset $z$ lichkeit einordnen $z u$ können. Andrerseits fürchteten die philosophischen und geisteswissenschaftlichen Kritiker, dass die Psyche unrettbar mechanisiert, ja vernichtet würde, sobald man Mals und Zahl auf sie anwendete.

Heut sehen wir die Frage viel nüchterner an. Zählbares und Abstufbares gibt es im Seelischen an den verschiedensten Stellen; und die Konstatierung und Verknüpfung dieser Nomente vernichtet die Eigenart des Seelenlebens ebensowenig, wie etwa Temperaturmessungen oder Zïhlungen von Blutkïrperchen die Einheit des Organismus, oder wie kriminal- und bevöikerungs-statistische Ziffern die lebendiglseit von staat und cesellschaft vernichten. Man darf nur die Ziffern nicht als Selbstzwecke, nicht 
als angemessene und erschöpfende Darstellungen des Seelischen betrachten - dann freilich würde die Psychologie ihrem eigentlichen Gegenstande Gewalt antun.

Gewiss gab es - und gibt es noch heut - solche lbergriffe des Zahlenkultus. - Ein Beispiel: Die Ziffer des „Intelligenzquotienten” mag als erste grobe Annäherung an das gesuchte geistige Niveau eines Menschen von heuristischem Wert sein; aber wer da glaubt, mit dieser Ziffer "die" Intelligenz eines Nenschen erfasst und eindeutig bestimmt zu haben, so dass er nun auf die eingehendere qualitative ('ntersuchung verzichten dürfte - der hört dort auf, wo Psychologie im engeren Sinne erst anfängt.

Die Anwendung mathematischer Hilfen in der Psychologie verschiebt sich in letzter Zeit mehr und mehr von den cigentlichen „Na Is"'-Werten zu den ,Rang”- und „Häufigkeits"-Werten hin.

„M a I s w e r t e" wollen das einzelne seelische Geschehen einem Punkt in einer stetigen Quantitätenreihe zuordnen und das Verhältnis mehrerer seelischer Geschehnisse auf eine eindeutige Formel bringen, die ihr Analogon in den Formeln für die Naturgesetzlichkeiten der Physik hat 1 .

"R a n g wer t c" gibt es in der Physik nicht, wohl aber im praktischen Kulturleben - man denke etwa an Zeugnisziffern, an Bewertung von Siortleistungen. Wenn die Psychologie also heute mit ,Intelligenz-Rangordnungen”, ,Rangordnungen der sozialen Schätzung" u.s.w. arbeitet, so ist sie bereits aus der naturwissenschaftlichen Nathematik herausgetreten.

Noch deutlicher wird es bei H äufigkeitswerten, für deren Benutzung die kulturwissenschaftliche Methode der Statistik das Vorbild ist. Die quantitativen Bestimmungen gelten hier nicht den Einzelpersonen, sondern der Verteilung psychischer Tatbestände auf Gruppen oder Massen. Fs wird z.lB. festgestellt, in welchen Häufigkeiten unter einer grossen Anzahl von Schulkindern die verschiedenen Intelligenzorade vorkommen: die Ergebnisse lassen sich in einer ," Verteilungskurve" darstellen. Oder es wird der Zusammenhang zwischen zwei solchen Verteilungsreihen untersucht (.,Korrelat i n”); sind z.lB.

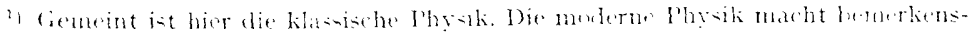

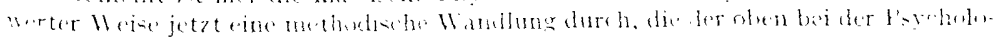

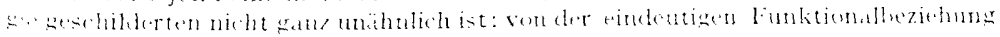

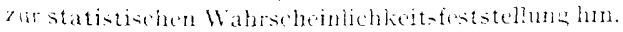


bei 1000 Individuen sowohl die Leistungen in theoretischen wie in praktischen Intelligenzaufgaben bestimmt worden, so lässt sich ein statistischer Wert für die mehr oder minder enge Zusammengehörigkeit beider Leistungsarten errechnen.

Werden dann sekundär solche Ziffernwerte auf einzelne Individuen bezogen, so bedeuten sie für diese lediglich eine bevorzugte Möglichkeit des seelischen Geschehens, nicht aber eine eindeutige Determination. Um bei obigem Beispiel zu bleiben: selbst wenn sich statistisch eine hohe Korrelation zwischen theoretischen und praktischen Intelligenzleistungen ergeben hat, ist damit noch nicht gesagt, dass in einem e in zelnen mitgeprïften Individuum die beiden Leistungsniveaus sehr ähnlich sein müssen. Statistische Ziffern sind ihrem Wesen nach immer nur Wahrscheinlichkeitswerte, innerhalb deren noch für Spontaneität und Individualisierung reicher Spielraum bleibt.

Mit der Wendung zum Statistischen hängt eng zusammen die Extensivier ung des psychologischen Experiments.

In der ersten Zeit der experimentellen Psychologie waren die Lntersuchungen vornehmlich auf Intensivierung bedacht. Sie wurden an einer relativ kleinen Anzahl von Versuchspersonen (meist waren es Studenten) vorgenommen, an diesen aber in wochenlangen, vielstündigen Sitzungen. Für viele, namentlich theoretische Probleme, wird das Intensiv-Verfahren stets notwendig bleiben. Andere Aufgaben aber verlangen eine starke V e rb r e it e rung der Untersuchungsbasis. Die eben erwähnten Häufigkeits- und Korrelations-Bestimmungen, ferner Typenuntersuchungen, Vergleichungen von Gruppen oder Altersstufen u.s.w. sind nur an grösseren Menschenmengen durchzuführen. solche extensiven Experimente können natürlich das Einzelindividuum nicht mit der früher üblichen Intensität beanspruchen; das würde ebenso die Kräfte des Psychologen, wie die verfügbare Zeit der zu untersuchenden Personen überschreiten.

Sis haben sich Kurz-Experiment e herausgebildet, die mit relativ einfachen, nicht ortlich gebundenen, Hilfsmitteln an vitle Individuen verschiedener Bevölkerungskreise herangebracht werden können. Thre Ergebnisse dienen als Stichproben, d.h. als Symptome für umfassendere seelische Tatbestände. Die stichprobenmethoden oder "Tests" haben - von Amerika 
ausgehend - eine ausserordentliche Verbreitung über die ganze Kulturwelt gefunden. Sie sind lebensnäher, leichter anwendbar und beweglicher als die Präzisionsexperimente der klassischen Psychologie. Aber ihre Bedeutung ist zweischneidig. Einerseits machen sie jene geforderte Extensität der Untersuchungen erst möglich; andererseits verleiten sie leicht zu dilettantischen Anwendungen und zu allzu weitgehenden Schlussfolgerungen, für die sie nicht tragfähig genug sind. So kam es bei dieser, an sich sehr wertvollen, ja unentbehrlichen Methode gelegentlich zu C'bertreibungen und Missbräuchen - die ihrerseits wieder eine über das Ziel schiessende Gegnerschaft wachriefen. Das ist nicht nur um der Sache selbst willen bedauerlich, sondern auch wegen der praktischen Folgen; denn der Test kann, vorsichtig und kritisch verwandt, im Interesse von Erziehungs-, Wirtschafts-, psychiatrischen, forensischen Aufgaben vielseitige Dienste leisten.

Zwei Anwendungsformen des Tests gibt es: als „F or s ch ung sexperime n t" hat er allgemeine und vergleichende Befunde an grösseren Menschenmassen zu erarbeiten; als ,P r ü f u n g se x p e r i m e n t" ist er ein Nittel der Individualdiagnostik. $\mathrm{Zu}$ verantwortungsvollen Individualprüfungen darf ein Test nur dann gebraucht werden, wenn vorher durch Forschungsexperimente Umfang und Zuverlässigkeit seines .,Symptomwertes" sichergestellt sind.

2. Hauptarten des psychologischen Expe$\mathrm{riments}$

Wir geben schliesslich eine Cbersicht über die $\mathrm{H}$ a u p $\mathrm{t}$ a $\mathrm{r}$ t e $\mathrm{n}$ der experimentellen Yethodik, mit stichwortartigen Angaben über Teilprobleme und über Anwendbarkeit ron Mafs und Zahl.

a) Reaktionsversuche im engeren sinne. - Ciegenstand der Lntersuchung ist der Ce'samtprozess, der von einem äusseren Reiz zu einer auf ihn bezogenen Bewegung führt.

Der Reiz kann bestehen in einfachen sinneseindrucken, in Bildern und Figuren, zugerufenen oder optisch gezeigten Worten - die Reaktion in einer einfachen Bewegung (z.B. Druck auf eine Taste), im Aussprechen eines Wortes, im Ausfüren einer Handlung. Man untersucht einfache und Wahlrealionen, misst die Reaktionszeiten, 
zählt die Häufigkeit der richtigen und Fehl-Reaktionen, analysiert die beim Reagieren mitspielenden Bewusstseinsvorgänge, studiert die Abhängigkeit der Reaktionsgeschwindigkeit und Reaktionsweise von verschiedenen äusseren und inneren Bedingungen.

Eng ist die Beziehung der Reaktionsexperimente zu verschiedenen anderen Gebieten der Wissenschaft und der Praxis.

Die, der Psychologie scheinbar so fern liegende, Astronomie gab vor fast 100 Jahren den ersten Anstoss zu Reaktionsuntersuchungen. Es fiel auf, dass bei der 7eitregistrierung von Sterndurchgängen verschiedene Beobachter merklich von einander differierten. Das Rätsel löste sich psychologisch: die Abweichungen beruhten auf dem verschiedenen indiriduellen Tempo, in welchem die Astronomen den im Fernrohr erscheinenden optischen Eindruck mit einer Registrierbewegung beantworteten (,persönliche Gleichung”).

Heut ist die Reaktionsuntersuchung integrierender Bestandteil zahlreicher Einnungsprüfungen; beim Bedienen von Fahrzeugen, Kränen, Maschinen ist ja die Schnelligkeit und Sicherheit des Reagierens auf wechselnde Eindrücke von entscheidender Wichtigkeit.

b) Ein drucksversuch e haben es mit dem Zustandekommen und der Beschaffenheit von Sinneswahrnehmungen zu tun.

Es war dies das Hauptthema der physiologischen Psychologie gewesen, als deren erste Vertreter wir schon frïher Joh. Wüller, Helmholtz, Fechner, Wundt nannten. Damals handelte es sich in erster Reihe um Zerlegrung der Wahrnchmungen in ihre seelischen Elemente, um Zusammensetzung ron komploxen Wahrnehmungsgebilden aus diesen Elementen und um die Zuorlnung von Wahrnehmungen zu physiologischen funktionen und physikalischen Reizgrissen.

Das moderne Wahrnehmungsexperiment sucht unmittelbar dem eigentlichen Erleb n i s-Charakter des Wahrnehmens nahe zu kommen und die im Erlebnis selbst liegenden Gesetzmässigkeiten und Differenzierungen zu studieren. Themen wie: Gestaltauffassung, eidetisches Anschaungsbild, Objektivationsstufen der Wahrnehmung u.s.w. sind ohne experimentelle Hilfsmittel nicht zu bearbeiten. Aber die älteren Probleme sind noch lange nicht ausgeschöpft und beschäftigen dauernd den experimentierenden Psychologen.

Det hauptsäbliche Mafswert der Wahrnehmungspsychologie war fribher die "Enterschiedsschwelle", d.h. derjenige Abstand zweier Reize, der als Interschied eben merklich wird. (Fechner, Wundt, (i, F. Nuller). Das Schwellenmals ist heut zu einem vielseitig verwendbaren Hilfsmittel hei verschiedensten whrnehmungspsychologischen Intersuchungen geworden; daneben gibt es noch andere Wöglichkeiten mathematischer Bearheitung, so Zählung cler Häufigkeit, mit der bestimmte Wahnehmunasurteile (gleich, verschieden, wohlgefälig, missfällig u.s.w.) vorkommen. 
c) A usdrucksmethoden. Die Fragestellung lautet: In welchen körperlichen Zuständen und Prozessen bekunden sich innere Erlebnisse und Erlebnisabläufe?

Das Experiment kann sich hier sowohl auf den psychischen wie den physischen Teilvorgang erstrecken. Man erzeugt künstlich bestimmte seelische Tatbestände: Schreck, Schmerz, aesthetisches Wohlgefallen, Aufmerksamkeitsspannung - und kontrolliert die gleichzeitigen Änderungen gewisser Körperfunlionen, wie Itmung, Herzschlag, Zitterbewegung, Schreibbewegung u.s.w. durch feine Registrierapparate. - In anderen Fällen werden die im zwanglosen Ahlauf des seelischen Geschehens auftretenden Ausdrucksformen mit experimentellen Hilfsmitteln erforscht; so wenn man an Handschriften studien äber Druckstärke, Schnelligkeit u.s.w. anstellt, oder wenn man die naturliche Mimik und Gestik durch Photographie und Film der Analyse unterwirft. Dem Mafs zugänglich sind hier u.à.: Ausschlagsstärke, Geschwindigkeit und Rhythmik der Bewegungen; Druckintensität; Proportion und Winkel in den Ausdrucksgestalten; und dann natürlich, wie überall, statistische Häufigkeiten.

d) Selbsterfassungsmethoden. -- Das Experiment dient hier lediglich als Anlass zur Erzeugung bestimmter seelischer Erlebnisse, um die Selbstbesinnung auf das Erlebte sowie dessen protokollarische festlegung zu erleichtern.

Hierher gehören die sogenannten "Gedankenexperimente", bei welchen der Psychologe seine eigene Versuchsperson ist, sich fiktiv in gewisse Situationen versetzt und sich von den begleitenden bewusstseinsvorgängen Rechenschaft zu geben sucht. - Bei anderen Versuchspersonen werden zu gleichen Zwecken Denkabläufe, Willenshandlungen, Gefühlsreaktionen experimentell hervorgerufen; aufgrund der primären Selbsterinnerung haben sie jedesmal sofort Auskunft darüber zu geben, was soeben durch ihr Bewusstsein gegangen war $)$. Quantitative Bestimmungen spiclen innerhalb der eigentlichen Erlebnisregistrierung nur eine ganz sekundare Rolle (eventucll wieder in der Form statistischer Zählungen).

e) Le is t ung smethoden. - Eine "Leistung" ist eine solche Handlung, die im Hinblick auf ein objektires Ziel cine positive Wertmarke erhält. Die Leistung ist abo nichts rein Psychisches mehr, wohl aber efwas Personales; denn durch sie ordnet sich die Person in die Forderungen und Ansprüche der objektiven Welt sinnvoll ein. Psychologisch ist eine Lntersuchung der

1) Cber die Cirenzen dieser introspektiven Ne the de val. S.71. 
Leistung dann, wenn man den Anteil psychischer Phänomene und Dispositionen an ihrem Zustandekommen zum Problem erhebt ${ }^{\mathbf{1}}$.

Man geht hierbei entweder aus von dem psychischen Bereich: so wenn man die Leistung des Gedächtnisses beim Auswendiglernen, die der Erinnerung bei der Zeugenaussage, die der Aufmerksamkeit bei Dauerarbeiten, die der Intelligenz bei Denkaufgaben untersucht. Oder man geht aus vom objektiven Leistungsgebiet: der Rechenleistung, der technischen, der künstlerischen Leistung - um nun analysierend die hierbei beteiligten Seelenvorgänge und Anlagen aufzudecken.

Messbar ist bei jeder Leistung Quantum und Quale. Das Leistungsquantum wird bestimmt durch das Verhältnis von Menge des Geleisteten zum Zeitaufwand, die Leistungsgüte durch den Grad der Annäherung an die Idealnorm einer Höchstleistung. Wo es möglich ist, die einzelnen Elemente der Leistung unter der Kategorie falsch/richtig $z u$ beurteilen, lässt sich eine Fehlerzählung zur Gütemessung benutzen; in anderen Fällen, z.B. bei Aufsätzen, wird man sich mit Schätzungen des Leistungswertes begnügen müssen.

\section{FERNMETHODEN}

Solange der Psychologe auf den unmittelbaren Kontakt mit dem Seelenleben anderer Menschen angewiesen ist, bleibt der Lmkreis der zugänglichen Personen notgedrungen beschränkt. Die Fxtensivierung der modernen Psychologie sprengte diese Schranken und machte auch solche Menschen der Forschung zugänglich, die räumlich oder zeitlich fern waren. Hierfür wurden vermit te $\ln$ de Methoden ausgebildet.

\section{Erhebung}

Dem Experiment nahe steht das Verfahren der E $\mathrm{r}$ h e b ung (Enquête). Der Psychologe entwirft eine Liste mit Fragen und mit Anweisungen über die Art der Beantwortung; die Liste wird clurch Druck oder Rundfunk verbreitet. Nur ein Bruchteil der aufgeforderten Personen pllegt zu antworten; die von ihnen ausgefillten Bogen bilden dann das Erhebungsmaterial, das der psichologischen Bearbeitung unterworfen wird.

"Zum Problem ler "Leitume" igl den Ennten Haupteril. 
Dies der allgemeine Rahmen; im einzelnen gibt es mannigfache Abwandlungen, die auch für die Brauchbarkeit der Methode entscheidend sind. Von den ersten, noch sehr groben und unvollkommenen $\mathrm{U}$ mfragen, wie sie seinerzeit von Amerika (Stanley Hall) ausgingen, bis zu den zum Teil sehr durchgefeilten Erhebungsuntersuchungen der modernen Psychologie ist ein weiter Weg zurückgelegt worden.

So pflegt man jetzt die Fragebögen nur bestimmten $k$ a $t$ e$\mathrm{g}$ o rie e $\mathrm{n}$ von Beantwortern vorzulegen; denn nur dann besteht eine Gewähr für jenes gemeinschaftliche Niveau der Bildung, der Interessen und der sprachlichen Ausdruckweise, das die Voraussetzung für vergleich ba re Antworten bildet.

Beispiele: Bei einer holländischen Erhebung (von Heymans) wurden $\ddot{A}$ r t e aufgefordert, in Familien, die ihnen genau bekannt waren, Eigenschaftslisten über die ältere und jüngere Generation auszufüllen; die Enquête diente der Erforschung psychischer Vererbung. In einer deutschen Enquête (von E. Knoblauch) wurden St u d e nt i n $\mathrm{n}$ e $\mathrm{n}$ befragt nach ihrer seelischen Stellung zu Studilim, Beruf und Ehe.

Sodann haben wir gelernt, uns besser in die Seelen derer zu versetzen, die zur Beantwortung aufgerufen werden. Eine psychologische Erhebung stellt ja an den Antwortenden zum Teil ganz ungewohnte Ansprüche. Er muss den Sinn der Fragen richtig verstehen; er muss die so natürliche Hemmung, sein Inneres zu enthüllen, überwinden; er muss den guten Willen, die Objektivität und die Ausdrucksfähigkeit besitzen, gewisse Tatbestände seines Seelenlebens angemessen darzustellen.

Darum erfordert schon die $\mathrm{V}$ o r b e r e it ung einer psychologischen Erhebung grosse Sorgfalt; die Fragen und Anweisungen sollen Vertrauen erwecken, unmissverständlich und suggestionsfrei sein und an geeignete Personen gesandt werden.

Gleiches gilt von der Ve ra r be it ung des Naterials: Antworter wie Antworten sind kritisch zu würdigen; bei der Ableitung allgemeinerer Befunde dürfen die Fehlerquellen nicht übersehen werden.

Eine solche Fehlerquelle, die auch der besten schriftlichen Erhebung anhaftet, drängt sich gerade einer personalistisch eingestellten Betrachtung auf. Man hat ron dem einzelnen Beantworter ja nur eine, aus seinem Leben hera usgerissene, Serie von tussagen in der Hand und vermag nicht einmal zu 
ahnen, welche Bedeutung diesen innerhalb des personalen Ganzheitsbezuges zukommt. Deshalb sucht man heute die rein extensiven Erhebungen zu ergänzen durch, ,Qual it ä t se rheb u $\mathrm{n}$ ge n', bei welchen der Psychologe seine Fragen direkt an eine kleinere Zahl von persönlich bekannten Menschen stellt und die Antworten eingehend mit ihnen durchspricht. Oft fällt von hier aus erst das rechte Licht auf Sinn und Bedeutung der Massenergebnisse.

\section{Sa m m lu ng}

Die Sammelmethode erstreckt sich auf Dokumente verschiedenster Art, in denen Seelisches auf irgend eine Weise dauernden Niederschlag gefunden hat.

Hierher gehören in erster Linie Erze ug n isse des Sch affens: Zeichnungen, Ciedichte, Tagebücher, Aufsätze, Plastiken, Handarbeiten, u.s.w.

Ein solches, unter psychologischen (iesichtspunkten angelegtes Archiv unterscheidet sich sehr deutlich von jenen sammlungen, die aus künstlerischen, pädagogischen, ethnologischen oder sonstigen psychologiefremden Motiven veranstaltet werden.

Bei der Sammlung von Kinderzeichnungen z.B. interessiert den Psychologen nicht der ästhetische Wert, die technische Korrektheit oder die an ihnen zu erweisende linterrichtsmethodik, sonclern das in ihnen sich äussernde Seelenleben; sie sind ihm bokumente kindlicher Kaum-und Farb-Wahrnehmung, Gestaltungsfähigkeit, Nachahmung oder Originalität; sie lassen Entwicklungsstufen und Typen des Darstellens, Interesseneinstellungen und Milieucinflïsse erkennen.

Je spontan e r und zwangloser die Erzeugnisse zu stande gckommen sind, um so deutlicher ist die psychologische Sprache, die sie sprechen, mögen sie im Ubrigen noch so dürftig, primitiv und .hässlich" sein. - Sammlungen von Selbstbekenntnissen, Tagebiichern, Memoiren sind ja eben darum so besonders ertragreich, weil hier die spontancität den höchsten, die direkte Beeinflusiung von ansien den geringsten cirad aufweist.

Eine andere (iruppe von Sammlungen verfolgt a u s d r u ck spsichologische Ziele. Hier ist die Spezialisierung sehr weit gediehen: jener sammelt nur Handschriften, ein anderer Porträts, ein dritter Hand-Abliklungen oder-Abdrücke u.s.w. 
Für alle diese Gegenstände des Sammeleifers gilt methodisch die gleiche Einschränkung, die wir soeben bei der Erhebung machten: eine psychologische Deutung ist um so schwieriger, je isolierter das blosse Dokument vor uns steht, je weniger wir im übrigen von der dahinter stehenden Person wissen.

Von sonstigen Materialien, die für psychologische $Z$ wecke verwertet worden sind, nennen wir noch einige, um die Mannigfaltigkeit der Sammelmethode zu veranschaulichen: Schulzeugnisse, Personalbögen, Kriminal- und Fürsorge-Akten, Vereinsprotokolle, Benutzungslisten von Volksbibliotheken, Warenmarken, Heiratsanzeigen. Die Liste der $\mathrm{d}$ e $\mathrm{n} \mathrm{k} \mathrm{b}$ a r e $\mathrm{n}$ Sammelobjekte liesse sich beliebig fortsetzen; denn in jedem Produkt menschlicher hultur haben schliesslich irgend welche seelischen Erlebnisse und Tendenzen ron Individuen, Gruppen, Nationen, Epochen, Niederschlag gefunden, die durch geschickte Bearbeitung wieder herauspräpariert und in psychologische Einsicht umgesetzt werden können.

\section{Historische Nethoden}

Schliesslich wird auch die zeitliche Ferne überbrückt: der Psychologe sucht seelische Tatbestände der Vergangenheit in seine Forschung einzubeziehen - sei es, um die besondere psychische Struktur einer Epoche oder einer geschichtlichen Persönlichkeit zu untersuchen (.,Psychologie des gothischen Menschen"); "Psychologie Napolíons"; sei es, um dort neues, sonst unzugängliches Material für allgemein-psychologische Problematik zu gewinnen.

So ist z. B. die Psychologie der Genialität ohne Zuhilfenahme historischer Quellen garnicht zu bearbeiten. Denn Genies laufon nicht in einer dem Psychologen greifbaren Form herum; vielmehr ist ihre Fxistenz und ihr Wesen erst fassbar aus ihren Werken, ihrer Gesamtgestaltung des Lebens und ibrer Mirkung anf die Ienschheit, d.h. erst dann, wenn sie geschichtlich geworden sind.

Damit wird die Biographik zum Hilfsmittel für die Psychologie des Individums, die Inhalte der grosien feschichte zum Material für völker-, entwicklungs- und sozial- pychologische For-

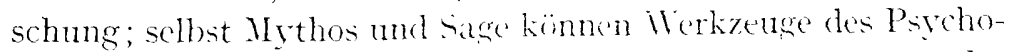
logen werden, wofü ja die kulturpuryhologischen beutungen der Psychoanalyse bekannte beispick liefern.

So zeigt denn der Cberblick über die verechiedenen it e tho- 
d e $n$ der Psychologie ein Bild ähnlich jenem, das wir aus der Betrachtung der Gebiete und Probleme gewonnen hatten. Die, zuerst vorwiegend der Naturwissenschaft entlehnte, Arbeitsweise (Experiment und Messung) hat in sich selbst eine Wandlung durchgemacht, die sie den Geisteswissenschaften nähert; sie hat zugleich eine Ergänzung erfahren durch andere Methoden, die in steigendem Malse denen der Kulturwissenschaften ähneln. Die Synthese der natur-und geistes-wissenschaftlichen Einstellung ist daher auch im Bereich der psychologischen Methodik das Kennzeichen der neuen jetzt im Werden begriffenen Epoche. 


\section{VIERTES KAPITEL}

PERSONALISTISCHE GR L NDLEGUNG DER PSYCHOLOGIE

Die drei bisherigen Einführungskapitel hatten vorwiegend rückschauenden Charakter; sie schilderten die fachwissenschaftliche Psychologie nach ihren bis heut hervorgetretenen Aufgaben, Gebieten und Methoden.

Dagegen wird das vorliegende Kapitel Vorscha u sein müssen, und zwar so sehr, dass erst die Spezialdarstellungen der späteren Hauptteile den Sinn und die Tragweite der personalistischen Grundthesen voll verständlich machen können.

Eine Wiederholung dessen, was vom Verfasser an anderen Stellen über die personalistische Theorie entwickelt worden ist, kommt hier natürlich nicht in Frage; es kann nur dasjenige angedeutet werden, was unmittelbar zur Neuorientierung der Ps yc holog i e erforderlich ist. Wer an dem allzu knappen Inhalt und an der allzu dogmatischen Form dieses Kapitels Anstoss nimmt, mag zu den anderen Büchern greifen, welche die systematische Ableitung und Begründung der Personalistik enthalten ${ }^{\mathbf{1}}$ ).

\section{DAS SUBSTRAT DES SEELISCHEN}

Auf den ersten Seiten dieses Buches war der Gegenstand a 11 e r Psychologie (nicht-wissenschaftlicher wie wissenschaftlicher) durch eine Doppelbestimmung ausgedrückt worden: Scelenwesen und Seelenleben. Oder allgemeiner: das $\mathrm{Substrat}$ und die $\mathrm{T}$ a t best än de des Seelischen. Es wurde auch dort schon vorbereitend darauf hingewiesen, dass die beiden Gegenstände nicht voneinander unabhängig erforscht werden können,

\footnotetext{
1) Insbesondere: Die menschliche Persönlichkeit; Studien zur l'ersonwisenschatt; Wertphilosophie.
} 
sondern sich gegenseitig bedingen. Denn die Art, wie man das Substrat des Seelischen auffasst, gibt erst dem Gange der psychologischen Erfahrungswissenschaft die Richtung und für die empirisch feststellbaren Erscheinungen die Möglichkeit der Erklärung und Deutung.

\section{Fragen}

Hat das Psychische iberhaupt ein ,Substrat”? Also ein Etwas, wo $\mathrm{r}$ a $\mathrm{n}$ es existiert und abläuft?

Die Frage muss bejaht werden. Psychisches ist nur Beschaffenheit und Merkmal, nicht selbst Substanz. (Darum wird auch mit Absicht die adjektivische Bezeichnung ,psychisch”, ,seelisch” gebraucht, um den anhangenden - ,inhaerenten" — Charakter auszudrücken).

Man hat oft versucht, ein Substrat des Psychischen zu lugnen oder zum mindesten aus jeder wissenschaftlichen Untersuchung auszuschliessen. Man musste dann das Psychische selbst gleichsam substanzialisieren, also Vorstellungen, Wollungen, Charaktereigenschaften, Stimmungen u.s.w. behandeln als etwas, das irgendwo und irgendwie für sich Bestand hätte und im Leeren flatterte.

Hicrbei ist unbeachtet geblieben, dass schon innerhalb der psychologischen Erfahrung - also noch unabhängig von philosophischen Hypothesen - die psychischen Erscheinungen, Vorgänge und Beschaffenheiten nur da sind a ls z u g e h ö r ig zu einem jeweiligen individuellen Ich, welches sie „hat”. Nicht die Existenz des Substrats, sondern nur seine Art kann in Frage stehen.

Ist das substiat, so formulieren wir diese weitere Frage, als substantielle ..Seele" zu denken? O).h.: Gehört das Substrat selber in die Kategorie des Psychischen? Besteht seine alleinige Wenonheit darm, seelisches zu erzeusen, zu besitzen, zu beherrshen? Ind steht es demmach dem substrat der nicht-seelischen Tathestande am Menschen, dem Leibe, als etwas Inderes, Fremdes erendiber? Diese frage wird rerneint.

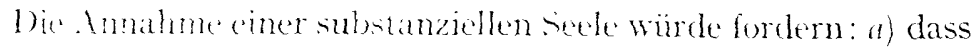

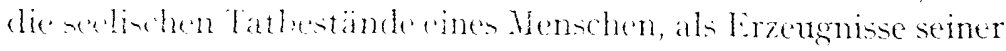

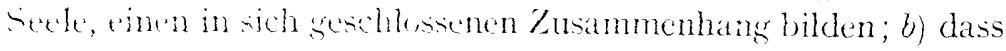


der Mensch eine substanzielle Zweiheit, Seele und Leib, darstelle; c) dass die Beziehungen $z w$ is $c$ he $n$ Seelischem und Leiblichem im Individuum sekundären Charakter haben, gegenüber den primären Zusammenhängen, die in n e $\mathrm{rh}$ a l b jeder der beiden Substanzen obwalten; $d$ ) dass sich alles, was am Menschen besteht und geschieht, ohne Rest in Seelisches einerseits, Körperliches andrerseits aufteilen lasse.

Die Unzulänglichkeit dieser Annahme für eine Wissenschaft vom Psychischen ${ }^{1)}$ kann erst durch den Inhalt des ganzen Buches nachgewiesen werden.

Der extreme Gegenstandpunkt gegen den eben genannten ist der materialistische: die einzige Wirklichkeit sei die Materie; das Substrat des sogenannten Seelischen könne daher nur der Leib sein; die Realität des Seelischen werde gebildet durch physiologische Vorgänge des Leibes.

Es ist nicht nötig, hier die hundertfach wiederholten Argumente der Philosophie gegen den Materialismus noch einmal vorzubringen. Die P s y c h o log i e verfügt über einen indirekten, aber lapidaren Gegenbeweis: ihre eigene Existenz. Es $\mathrm{g} \mathrm{i} \mathrm{b} \mathrm{t}$ eine Wissenschaft vom Psychischen; und diese Wissenschaft hat es mit etwas ganz anderem zu tun als mit physiologischen Vorgängen, die nur gleichsam in eine andere Sprache übersetzt wären. Sie hat es zu tun mit dem Erleben, den Erlebnissen, der Erlebensfähigkeit - also mit Kategorieen, die zu denen der rein physischen Welt disparat sind.

Bleibt also nur übrig:

Das Substrat des Seelischen muss etwas sein, d a s j e n s e i ts oder vor der Scheidung $z$ wischen Psychi$\mathrm{schem}$ und Physischem liegt und daher die ursprüngliche Einheit des menschlichen Individuums gewährleistet.

Diese Formel klingt „monistisch”; denn jeder Monismus bestreitet die substanzielle Zweiheit ron Physis und Psyche, sieht in beiden nur Merkmale eines einzigen Substrates. (Spinoza: „Denken und Ausdehnung sind Attribute der all-einen Substanz”.) Aber der landläufige Monismus ve r s a g $\mathrm{t}$ bei der Frage nach dem $W$ e s e n des Substrates; denn dies wird lediglich definiert

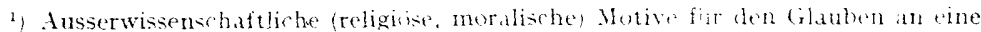

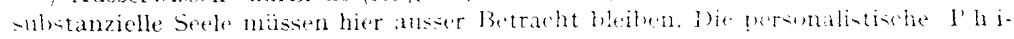
lus oph i e muss sich natirlich auch mit ihnen auseinanderstzen.
} 
als das „Zugleich Physische und Psychische”; andere Merkmale werden nicht angenommen oder gelten als unerkennbar. Damit bleibt der Monismus auf derselben Ebene stehen, die durch Leugnung der Zweiheit überwunden werden sollte; er muss sich damit begnügen, das durchgehende Zusammen-Dasein der beiden disparaten Attribute zu behaupten („Parallelismus”), ohne den $S$ in $n$ dieser Zuordnung begreifen zu können.

Es ist nun also die entscheidende Frage, ob jenes Substrat durch posit iv Merkmale bestimmt werden kann, die weder der rein-psychischen noch der rein-physischen Sphäre allein angehören ; mit anderen Worten: ob die Kategorieen "Physisch" und "Psychisch" selber zu sekundären gegenüber anderen, das Wesentliche treffenden, herabgedrückt werden können. Die Bejahung dieser Frage ist die Grundleistung der personalistischen Theorie. Die Person is t nicht nur - metaphysisch gesehen ein „psychophysisch neutrales" Wesen, sondern sie ist auch charakterisierbar und e m p ir is $\mathrm{ch}$ fassbar durch Merkmale, die jenseits der Scheidung von Physischem und Psychischem liegen.

\section{Definitionen}

Wir definieren die Person folgendermalsen:

Die Person ist eine individuelle, eigenartige Ganzheit, welche zielstrebig wirkt, selbstbezogen und weltoffen ist, lebt und erlebt.

Mit Ausnahme des Merkmals „Erleben”, das mit Absicht an den Schluss gestellt ist, sind die Bestimmungen durchweg p y c h ophysisch re utral Der Ganzheit der Person fügen sich ebenso ihre physischen wie psychischen Momente ein. Zielstrebige Aktivität bekundet sich ebenso in Atmung und Gliedbewegungen, wie im Denken und Streben. Selbstbezug und Weltaufgeschlossenheit kommt ebenso bei Körperfunktionen wie bei Bewusstseinserscheinungen vor. Gleiches gilt auch von den Unterbestimmungen jener Merkmale (wie sich sofort bei der Analyse des Merkmals "Leben" zeigen wird).

Das Nerkmal „Erleben” unterscheidet sich von allen anderen dadurch, dass es fa k u l t a t iv ist. Jede Person ist zwar immer 
und überall eine Ganzheit mit individueller Eigenart, zielstrebiger Selbsttätigkeit, mit Selbst- und Welt-Bezug, Lebendigkeit aber nicht immer mit Bewusstsein. Auch dann, wenn nichts ,erlebt" wird, existiert die Person, während der Fortfall eines der anderen Merkmale ihr Dasein aufheben würde.

Es gibt eine $\mathrm{W}$ is s e $\mathrm{n} \mathrm{s} \mathrm{ch}$ a $\mathrm{ft}$ von der menschlichen Person, welche sie in ihrer Totalität und ihrem psychophysisch neutralen Wesen untersucht: die Personwissenschaft oder „Personalistik". Sie liefert die gemeinsamen Voraussetzungen für alle Teilwissenschaften; die Biologie, Physiologie, Pathologie, Psychologie der Person.

Psychologie ist die Wissenschaft von der erlebenden und erlebensfähigen Person. Sie hat das personale Merkmal des Erlebens zu untersuchen: in den Bedingungen seines Auftretens, in seiner Art, Funktionsweise und Gesetzmässigkeit, in seiner Teilbedeutung für die Totalität des personalen Seins und Lebens.

\section{LEBEN LND ERLEBEN}

1. Die Modi des Lebens

Nur was lebt, kann auch er-leben.

„Leben” ist die Einheit von Sein und Geschehen in einem weltoffenen Ganzen. Ein lebendiges Wesen ist ein solches, das sein ganzheitliches $\mathrm{S}$ e in durch sein ganzheitliches $\mathrm{Funk}$ i o$\mathrm{n}$ i e r e $\mathrm{n}$ ständig verwirklicht, und das bei unablässigem Austausch mit der umgebenden Welt dennoch ein Ganzes bleibt.

Dies „Leben-haben” und „Leben-führen” ist der Crtatbestand, von dem jede Betrachtung der menschlichen Person auszugehen hat. Leben bildet die Grundlage, aus der alles Erleben erwächst, die alles Erleben trägt, in die alles Erleben einmündet. Leben ist total, Erleben ist ihm gegenüber partiell, vom Leben her und auf Leben hin verstehbar.

Es muss hier die Frage eingefügt werden, warum zur speziellen Kennzeichnung des Psychischen der Ausdruck „Erleben” und nicht der althergebrachte Terminus „B ew us tse in” be- 
vorzugt wird. Der Ausdruck „Bewusstsein" ist ursprünglich durchaus intellektualistisch gemeint gewesen; er bezeichnete den Zustand, in welchem der Mensch etwas w e is s (um die Dinge oder um sich weiss). Später wurde das Wort zwar mehr und mehr abgeschliffen (sodass man auch von einem dumpfen Gefühlsbewusstsein u.s.w. sprechen konnte); aber die ursprüngliche Einstellung schwang doch immer noch mit, wenn man es gebrauchte. Es ist entscheidend und verhängnisvoll für die gesamte neuere Auffassung des Psychischen geworden, dass man es von seiner spätesten und reflektiertesten Form, dem „Wissen" her, interpretierte und nach ihm orientierte. Im Zustande des Wissens ist ja der Mensch am weitesten von dem Zustande ungebrochener und selbstsicherer Lebendigkeit entfernt.

Aus der „Bewusstseins"-Orientierung heraus sind zwei sehr verschiedene Konsequenzen möglich, die aber beide in Sackgassen führen:

Entweder: man trennt das Bewusstsein schroff von allem, was nicht Bewusstsein ist, und beschränkt die Psychologie streng auf die Erforschung der „Bewusstseinserscheinungen”. Dann wird also der Zusammenhang des Erlebens mit den Untergründen des Lebens preisgegeben.

Oder: man erkennt diesen Zusammenhang an, bezeichnet aber die Voraussetzung alles Bewusstseins lediglich durch dessen Verneinung. Dann gewinnt das negative Neutrum „D a s U n b ew us t e" geradezu die Bedeutung einer geheimnisvollen Urkraft, die teils als Gegeninstanz, teils als Quellgrund des Bewusstseins angesehen wird.

Die Philosophie und Psychologie des "Unbewussten” — von Leibniz über Schelling und Eduard von Hartmann bis zur modernen Tiefenforschung - hat den fundamentalen Gedanken herausgearbeitet, dass die Bewusstseinserscheinungen nicht für sich allein verstehbar und erklärbar seien. Aber ihr Blick blieb vom Psychischen her nach rückwärts gerichtet und ihre Ausdrucksweise blieb vom Psychischen her bestimmt.

Die personalistische These: „Erleben wächst aus Leben heraus und in Leben hinein", kehrt nun die Blickrichtung um. Das Primäre wird nun wirklich als primäres, nämlich mit dem positiven Merkzeichen „Leben” erfasst ${ }^{1}$ ).

"Die Benutzung aer A us d r it cke "bewusst" and, "unluwust" wird sich frei- 
Was aber bedeutet hier „Leben”, bezogen auf die me n s c h$\mathrm{liche}$ Person? Es handelt sich hier $\mathrm{nich} \mathrm{t} \mathrm{nur}$ um jenes Leben, welches Gegenstand der Biologie ist. Vielmehr spielt sich das Leben des Menschen in drei $M$ odalit ät e n ab; und jedesmal gewinnt denn auch die personale Welt, der sich das Leben öffnet, einen neuen Aspekt.

Die erste Modalität ist die eben genannte b i o $10 \mathrm{~g}$ i $\mathrm{s} \mathrm{ch} \mathrm{e} \mathrm{im}$ engeren Sinne. Menschliches Leben hat mit pflanzlichem und tierischem gemeinsam jene Funktionen, durch welche sich das Individuum selbstverständlich und treffsicher ins Einvernehmen setzt mit seiner Welt. Selbstbehauptung und Selbststeuerung, Wachstum und Reifung, Fortpflanzung, Anpassung, Mneme sind solche „Vitalfunktionen”. Die "Welt" ist für diese Funktionen nur da als erweiterter Lebensbereich, als Reiz oder Material, als Gehäuse oder Bedrohung; sie bildet die Vitalwelt oder „Bi os ph a e r e" der Person.

Wir überspringen zunächst die zweite Nodalität und beschreiben den entgegengesetzten Pol: die reine $\mathrm{H}$ u m a n-Sphaere im Leben der Person. Bei Tier und Pflanze fehlt jede Spur von dieser Art Leben. Jetzt bildet jeder Mensch das selbstwertige, sinnhaltige Zentrum einer Welt, die ihrerseits aus selbständigen Wertsubstraten besteht, seien es Nebenmenschen, Gemeinschaften, kulturelle, historische, religiöse Tatbestände und ideale Forderungen. Soll es in dieser Welt ein individuelles „Leben” geben, so muss wieder im Sein und Funktionieren die personale Ganzheit angestrebt werden. Dies Ziel wäre nicht erreichbar, wenn das Individuum sich ganz a u f 1 ö s t e in die Welt als blosser Teil, als nur dienstbares Glied - es verlöre seine Personalität („Ent-Ichung”). Das Ziel wäre auch nicht erreichbar, wenn das Individuum sich auf sich selbst b e s c h rä n k te und die Welt nur seinen engen Eigenzwecken dienstbar zu machen suchte - es würde durch sein Verhalten die Selbstbedeutung aller objektiven Werte negieren (,Ver-Ichung”). Das Ziel des humanen Lebens ist also, dass der Mensch in seinem Tun und Sein die eigene Selbstbedeutung un $\mathrm{d}$ die objektiven Weltbedeutungen zugleich bejaht, dass er sich als

\footnotetext{
lich in psychologischen Erïterungen nicht mehr vermeiden lassen. Sie sind Scheidemünzen geworden, die nicht von einem Tag zum andern aus dem wissenschaftichen Verkehr gezogen werden künnen. Auch wir werden aus Griinden sprachlicher Vereinfachung der Termini nicht ganz entraten können. Aber nach den grundsätzlichen Erläuterungen dieses Kapitels sind Missdeutungen nicht mehr zu befüchten.
} 
Person verwirklicht durch Einschmelzung der objektiven Weltgehalte in seinen Selbstgehalt. Diese Einschmelzung oder Einverleibung bezeichnet die personalistische Theorie als "I $\mathrm{t}$ r o$z$ e p t i o n"; sie bildet die Aufgabe, die allem wahrhaft menschlichen Leben Richtung und Gestalt verleiht. Die einheitliche sinnvolle Lebensgestalt, der die Introzeption zustrebt, heisst „P e rsön li c h ke i t". (Während also der Person-Begriff im oben definierten Sinn auch auf jedes tierische Individuum anwendbar ist, ist „Persönlichkeit” eine nur-menschliche Kategorie).

Der Begriff der Introzeption ist psychophysisch neutral: er bezeichnet die Zielsetzung der Lebensfunktionen, nicht eine blosse Weise des Erlebens. Dies gilt auch für alle spezifischen Weisen der Introzeption: das Lieben, das Verstehen, das Schaffen, das Heiligen u.s.w. Wohl sind sie ohne Bewusstseinsphänomene wie gleich zu zeigen sein wird - nicht denkbar; aber ihr eigentliches Wesen besteht in personalen Verhaltungsweisen und Gestaltungsrichtungen, in Sinnverwirklichungen, welche ihrem letzten Endziel nach weit über alle „Bewusstheit" hinausragen. Deshalb gehört die Theorie der Introzeption nicht in die Psychologie, sondern in die Personalistik ${ }^{1}$ ).

$Z$ wischen dem ersten Lebensmodus der Vitalität und dem dritten der Introzeption steht nun jener, mit dem es die Ps y cholog i e direkt zu tun hat: der Er le b e n s m od us. Ebenso steht die „Welt”, die zu dieser Modalität gehört, zwischen der blossen Biosphaere und der Werte-Welt:als die Ge gen st a nds welt.

\section{Das Erleben}

a) Spa l t u n g. - Person ist Ganzheit; d.h. nicht Einfachheit, sondern unitas $\mathrm{multiplex.} \mathrm{Das} \mathrm{ist} \mathrm{durchaus} \mathrm{wörtlich}$ zu nehmen. All das Viele, das in der Person enthalten ist, an $\mathrm{Zu}-$ ständen, Geschehnissen, Teilen, Phasen, Schichten, g e hört zur (janzheit, ist ihr nicht nur äusserlich angeklebt, stützt und bedingt sich gegenseitig; dies $Z$ u sa m menklingen des Vielen zum personalen Ganzen, und der Person mit der Welt, macht das menschliche Leben möglich ${ }^{2}$ ).

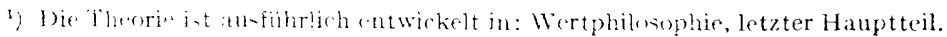

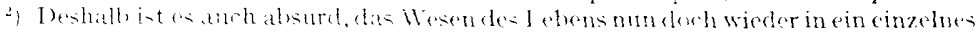
Thinmoment 211 projiseren, in ein besonde e e s Lebensprinzip, eine Lebenskraft,

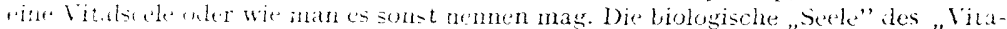


Aber dies Zusammenklingen ist nicht nur ein konsonanter Dauerakkord. Je reicher eine Lebensganzheit gegliedert ist, je mannigfaltiger das zu ihr gehörige Viele, je wechselnder andrerseits ihre Welt und ihre Beziehung zu dieser Welt, um so we n iger selbstverständ li ch ist das Leben. Cberall also, wo der reine Vitalzustand verlassen wird und der volle Introzeptionszustand nicht erreicht ist, gibt es im Leben Spannungen und Unstimmigkeiten, die dem unmittelbaren Eingeschmolzenwerden in die Ganzheit widerstreben - es setzt ein $Z$ e r-leben ein. Aber da sich auch diese Aufspaltungen auf dem unaufgebbaren Fundament der Ganzheit vollziehen, werden sie selber zu Lebensfunktionen: in der besonderen Form des E r-lebens.

Erleben also ist Leben in Spaltung und Spannung.

Spaltung und Spannung können niemals ruhende Zustände sein; sie sind Vorgänge von stärkster Bewegung. I) shalb findet an ihnen stets Zunahme oder tbnahme der Entzweiung statt. Alles Erleben hat also die Richtung auf "A b he bun g" aus der Ganzheit oder auf "E i n b e t t u n g" in die (ranzheit.

Genauer: in jedem Erleben sind stets beide Richtungen zugleich vorhanden, da ja röllige Abspaltung die Einheit der lebenden Person vernichten, völlige Einbettung das Aufhören der Spannungen und dadurch des Erlebens bewirken wirde. Aber die verschiedene Anteiligkeit von Abhebung und E in bet $t$ ung gibt jedem Erlebnis-Yorgang und-lnhalt seine besondere Charakteristik.

Zur vorläufigen Verauschaulichung dieses wichtigen Begriffspaares, dessen Anwendung sich durch das ganze Buch hindurchzichen wird, mögen die folgenden Beispiele dienen. Wenn ein zunächst dumpfes Gefühl einer Gefahr zu klaren Gedanken und zugeordncten Willensregungen führt, haben wir steigende. bhebung vor uns. - l hort, wo die deutlichen Frinnerungen an einen lieben Verstorbenern allmählich in eine allgemeine und rage Wehmut verfliessen, liegt steigende Einbettung vor.

Die moderne Gestaltpsychologic arbeitet mit dem Begriff .Gestalt" und „Umfeld”. Die Gestalt als Bew unstseinsinhalt steht am äussersten Pole der Abgehobenheit; das l'mfeld dagegen, sofern es überhaupt erlebt wird, geht ohne Grenze in den Totitzustand der P'erom diber, steht also am Eingebettetheits-Pol.

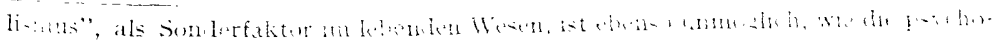

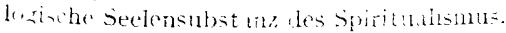


Der Spaltungscharakter des Erlebens drückt sich zunächst darin aus, dass es einen $G$ e g e n s t a n d hat. Der Mensch lebt - unbedingt und absolut; aber er er-lebt „E t w a s”. Erleben ist also stets transitiv; es geht über, zielt hin auf etwas, was nicht selbst Erleben ist.

W a s ist nun dieses Etwas, das erlebt wird? Neue Spaltung: es ist die Welt da draussen oder die Person selbst. Jene beiden Momente also, die in der Unmittelbarkeit der Vitalität und in der höheren Ganzheit der Introzeption Eines sind, werden hier auseinandergelebt. Der Mensch erlebt W e 1t: äussere Vorgänge, Objekte, Zustände, Gesetze, mögliche und wirkliche, vergangene, gegenwärtige, künftige, zeitlose - oder er erlebt $\mathrm{s}$ i c h s e $1 \mathrm{~b}$ s t: eigene Strebungen, Geltungen, Beschaffenheiten, Unstimmigkeiten, früheres Gewesensein, Zukunftsmöglichkeiten. - Von dem ersten Aufblitzen eines Tasteindruckes über Wahrnehmung, Vorstellung, Gedanken bis zur ausgestalteten Weltanschauung reicht die Skala der objektivierenden Erlebnisse. Vom dumpfen Lebensgefühl des Säuglings bis zum durchgebildeten Ichbewusstsein und Selbstwert-Erleben des Erwachsenen erstreckt sich die Stufenleiter der subjektivierenden Erlebnisse.

Niemals aber wird das eine oder andere Ziel des Erlebens ganz erreicht, weil die völlige Aufspaltung von Person und Welt das personale Leben - und damit das Erleben - ertöten müsste. Auch eine so hoch objektivierte Erlebensweise, wie sie die wissenschaftliche Erkenntnis ist, findet nie das ,,reine Objekt”, vermag die Welt nie ganz herauszulösen aus den personalen Verstrickungen. Und die höchste Entwicklungsstufe subjektivierenden Erlebens, die „Selbsterkenntnis”, spiegelt nicht etwa das Selbst in unverhüllter Wesentlichkeit wieder; denn dann würde ja Erlebendes und Erlebtes Eines sein und die Voraussetzung des Erlebens - die Spannung und Spaltung - vernichtet sein.

Objektivierendes und subjektivierendes Erleben sind also ewige En t deckungs reisen zur objektiven Welt und zum subjektiven Selbst hin; niemals kommt es zum endgültigen Haben des „I)inges an sich" und des „Ich an sich” im Erleben. Dieses Durchlaufen vieler Etappen in der Objektivation und Subjektivation des Erlebens bildet wiederum eines der Leitmotive unserer Buches. 
b) Ers ch e in e n. - Wenn nun aber zwischen dem Erleben und seinem Gegenstand stets eire Distanz bleibt, so besteht doch andrerseits zwischen beiden ein pos it iver Zusammenhang; denn jedes Erlebnis de u t e $t$ hin auf ein (aussenweltliches oder eigenpersonales) Sein. Iiese positive Beziehung wird gemeint mit den Ausdrücken: spiegeln, reflektieren, e r s c h e i n e n. (In einer Erinnerung z.B. erscheint gewesene Wirklichkeit. In einem Minderwertigkeitsgefühl spiegelt sich die personale Sichwäche des Subjekts wieder.) Im Erlebnis ist der Gegenstand noch einmal gegeben, aber nicht in realer Verdoppelung, sondern als ein Reflex, der dem, was er spiegelt, zugleich nahe und fern, zugleich ähnlich und unähnlich ist. Er ist $\mathrm{S} c \mathrm{~h}$ e i n, aber nicht wesenloser Schein; vielmehr Erschein ung von Wesenhaftem.

Unter diesem Doppelaspekt müssen also die Bewusstseinserscheinungen bald als Annäherungen an den Gegenstand, bald als „Täuschungen" betrachtet werden. Wichtig ist hier, dass es nicht nur Täuschungen des objektivierenden Erlebens: also Sinnestäuschungen, Erinnerungstäuschungen, Urteilstäuschungen u.s.w. gibt, sondern dass in entsprechender Weise auch Täuschungen des subjektivierenden Erlebens bestehen; auch das Bild, das jemand von sich selbst in seinem Erleben hat, mus täuschungsvoll sein. (An dieser Stelle ordnen sich Einsichten der modernen Tiefenpsychologie dem personalistischen Grundgedanken ein).

Erleben ist somit, an seinen Gegenständen gemessen, unvollständig und inkongruent; aber zugleich ist es doch Erscheinung und Spiegelung. So erhebt sich die Frage: Wa s b e d e u t e t d i ese Doppelsinnigkeit alles Erlebens für die Person?

Erleben ist p a r t i e 11. Nicht das ganze leben vermag sich in Erleben umzusetzen, und braucht es auch nicht. Aber für jene Teilgeschehnisse des Lebens, die spannungshaltis sind, ist nun das Erleben repräsen tat iv. Im Erleben spiegelt sich der erlebende Mensch, sofern er $\mathrm{Kämpfer}$ is $t$; sofern innere Widerstände, Hemmungen und Unsicherheiten den selbstrurständlichen Abfluss des Lebens unterbrechen. Lnd es spiegelt sich die erlebte Welt, sofern sie gegen-ständig ist, sofern sie als etwas Anderes, Fremdes, Problematisches sich dem Individuum und seinem Lebensablauf gegenüber stellt. 
Je schärfer die Spannungen, je vielgestaltiger die Reibungen, je wechselnder - und damit je ungewisser - die Weltsituationen, in denen das Individuum lebt, um so stärker ist die Bewusstheitsrepräsentation seines Lebens. Darum ist das Leben des Erwachsenen so viel bewusster als das des Kindes; darum hat der Kulturmensch so viel mehr Möglichkeiten des Erlebens als der Naturmensch. Darum sind Wandlungen und Katastrophen des Lebens, neue Eindrücke und neue Entfaltungsphasen ganz anders bewusstseinsbesetzt als ruhigere Zustände und konservative Stadien des Daseins.

Nun aber ist der Lebensmodus der Spannung und Un-Selbstverständlichkeit kein abgeschlossener Lebensbereich für sich, sondern stets in engster und unablässiger Verbindung mit jenen beiden anderen Lebensmodalitäten der Vitalität einerseits, der Introzeption andrerseits. Und darum gleitet auch das Erleben in tausend unmerklichen Schattierungen hinüber in jene Lebensmodi, die schliesslich des Bewusstseins nicht mehr bedürfen wie es umgekehrt aus ihnen immer wieder hervorgeht. Gerade jene Randzustände bilden ein besonders interessantes, aber auch schwieriges Objekt der Psychologie: denn in ihnen trägt das Erleben nicht mehr den leicht erfassbaren Charakter deutlich abgehobener Bewusstseinsgestalten, sondern bettet sich mehr und mehr dem Leben ein, bis es ganz in diesem verschwindet.

Es gibt dann freilich auch die anderen Fälle, in denen man den $\mathrm{Pu}$ u k angeben kann, an welchem eine innere Spannung oder äussere Störung zum Bewusstsein (oder zu einer bestimmten Bewusstseinserscheinung) führt. Dieser Punkt bildet dann die Erlebens-S c h w e 11 e. Der Schwellenbegriff reicht also in der personalistischen Psychologie viel weiter als in der Psychophysik, die ihn nur auf das Bewusstwerden der Sinneseindrücke beschränkt hatte.

Erleben ist partiell, aber die Partialität ist ke in e belieb i ge und simmose, sondern fügt sich durchaus dem Sinn- und Zivech-Zusammenhang des personalen Lebens ein. Denn im Erleben st a u $t$ sich das Le? en ; es wird Kraft gebraucht, die somit d.m anderen ummittelbaren Ganzheitsgeschehen entzogen wird. (Solange der ilensch z.B. im vollen Bewusstsein von Willensmotiven und Motivkämpfen steht, ist die Tattähigkeit gelähmt). I)eshalb ist die Sparanilecit des Erlebens ein wesentlicher Faktor im 
Krafthaushalt der Person; und wir werden später an vielen konkreten Beispielen zeigen können, wie Eintritt, Intensität und Art des Erlebens sich reguliert nach dem personalen Erlebensbedarf. Es herrscht hier weitgehend eine zweckmässige A u s les e, die die Erlebnisbesetzung von I.ebensvorgängen nach der perso$\mathrm{n}$ a l e $\mathrm{n} \mathrm{R}$ e le va $\mathrm{z}$ der Spannungen und Störungen richtet. Dies gilt für das subjektivierende wie für das objektivierende Erleben. Der Mensch wird sich selbst zum (iegenstande nur in jenen Teilzügen, zu denen er Distanz gewinnen muss; und ebenso wird ihm nur derjenigen kleine Ausschnitt seiner Welt zur Gegenstandswelt, der schon zu fern ist, um in seiner Biosphaere oder Introzeptionssphaere aufzugehen - aber noch nahe genug, um in seiner Abgespaltenheit und Fremdheit sich geltend zu machen.

Auch der Ausschluss aus dieser Auslese hat also einen personalen Sinn: das Vergessen, das Verdrängen, das Selbstverständlichwerden, die Automatismen - kurz all das, was sonst der geheimnisvoll wirkenden Instanz .des Unbewussten" zugeschrieben wurde, ordnet sich jetzt der einheitlichen Teleologie des personalen Lebensprozesses ein.

Entsprechendes gilt num auch für dic In k on gruenz. zwischen Erlebnisinhalt und Gegenstand. Wir hatten oben diese Lnstimmigkeiten als „Täuschungen” bezcichnet; aber damit wird man ihrer Rolle im Leben der Person nicht voll gerecht. Der abwertende Begriff ,Täuschung" ist ja eigentlich kein rein pirchologischer, sondern ein erkenntnistheoretischer; Täuschung ist das, was gültiger Erkenntnis zuwiderläuft. Für die Pšchologie aber erhebt sich eine ganz andere Frage: ist die Bedeutung der Erlebnisinhalte für die Person nur in ihrem Erkenntniswert ?11 sehen? Ist nicht vielmehr dic Erkenntnis (die auf mögrlichste Annäherung des Bewusstseininha!ts an den (itgenstand ziclt nur eine der Aufgaben, die der erlebenken Peron gectellt sind? Gibt es nicht andere Aufgaten, die jente Inkongruene fordern?

Da das Erleben auf der kïmpferichen sevite alles feldensteht,

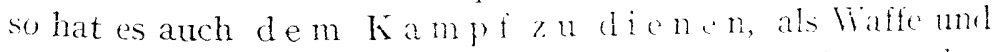
schutzmittel, als Prophylaxe und Therapie. Eben darum aber kann der Erlebnispiegel nicht der glatte und starre, gle ichmäsis klare Planspiegel sein, der selbst und tielt in indifferenter lie-

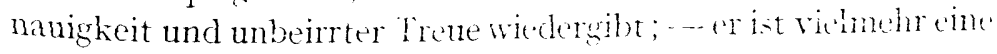


elastische, vielfach gewölbte Hülle um die Person, die mit ihren Buckeln und Vertiefungen, Mattierungen und Formveränderungen so reflektiert, wie es der personale Spannungszustand verlangt, sodass die Proportionen verändert, die Lichter verstärkt, abgeschwächt, ausgelöscht werden. Der Mensch erlebt s i ch so, dass er bestmöglich vor sich selbst existieren kann. Und er erlebt We $1 \mathrm{t}$ so, dass das Nahe grols, das Ferne klein, das Wichtige deutlich, das Nebensächliche verwaschen, das Geliebte liebenswert und das Leben lebenswert erscheint.

Freilich: auch diese Modellierung und Stylisierung der inneren und äusseren Wirklichkeit im Erleben ist nie ein Definitivum; denn die Inkongruenz von Bild und Realität erzeugt neue Spaltungen des Lebens, die neues Erleben mit sich bringen: und so ist die Entlarvung des naiveren Erlebens durch ein kritischeres Erleben, ist die ständig fortschreitende Korrektur der subjektiven und objektiven Bewusstseinstäuschungen selber eine der vornehmsten Aufgaben des Bewusstseins.

\section{DAS PSYCHISCHE}

Unsere Theorie muss nunmehr Anschluss gewinnen an den eigentlichen Zentralbegriff der psychologischen Wissenschaft. Was ist das "Psychische”? Welche Tatbestände sind „psychisch" zu nennen? Und in welchem Sinne werden sie zu Gegenständen psychologischer Problematik?

"ir definieren zunächst: "P s y chis ch" heisst alles das an der Person, was Erleben ist, oderzum Erleben in wesentlicher Beziehung steht.

Die Klärung dieses Satzes erfolgt auf einem Wege, der dem des vorangegangen Abschnitts entgegengesetzt ist: wir steigen $\mathrm{v}$ o $\mathrm{n}$ unte $\mathrm{n} \mathrm{n}$ a ch obe $\mathrm{n}$ auf, d.h. vom aktuellen, einzelnen Erleben über die Erlebensfähigkeit zur Person.

\section{Das aktuelle Erleben}

a) „E r l e b n i s”. - „Aktuelles” (d.h. tatsächliches, gegenwärtiges) Erleben kann sich in kontinuierlichem, strömendem Geschehen vollziehen - dann ist es ungestaltet, vage, dem Gesamtleben der Person tief eingebettet. Es kann aber auch 
Gestalt gewinnen, sich deutlich abgrenzen gegen andere Erlebensgestalten, oder gegen jenen stetigen Strom, oder gegen das erlebensfreie Leben: eine solche Einheit heisst ein „E r l e bn i s". Das Erlebnis stellt eine Teilganzheit des Lebens dar, hat Anfang, Anstieg, Höhepunkt, Abstieg und Abschluss, ist in sich gegliedert und geformt. So gibt es Denk-Erlebnisse und WillensErlebnisse, künstlerische, religiöse Erlebnisse u.s.w.

Das Verhältnis von Erleben zu Leben wiederholt sich natürlich auch beim einzelnen Erlebnis: jedes $E \mathrm{rl}$ eb $\mathrm{n}$ is ist die Partial-Erscheinung eines „L e b n is se s". Der Begriff „Lebnis" erweist sich als notwendig, da auch das Leben als solches sich in relativ abgegrenzten Teilganzheiten verwirklichen kann. Eine in sich geschlossene Willenshandlung ist ein Lebnis; im dazugehörigen Willens-Erlebnis sind nur einige Teile und Momente jenes Lebnisses repräsentiert.

b) Pha e nomene. - Der In halt aktuellen Erlebens, das, was die erlebende Person in sich vorfindet, heisst psychisches Phänomen (Bewusstseinserscheinung). Es ist das Psychische in seinem reinsten, aber auch engsten Sinne, ohne Beimischung von Nicht-Psychischem - darum aber auch in seiner Eingeschränktheit, ohne Beziehung zu dem, woran es hängt und was ihm Bedeutung verleiht.

Eine blosse Psychologie der Phänomene müsste in reiner Beschreibung versanden oder in Mechanistik ausmünden. Dennoch spielen die Phänomene in der Psychologie eine fundamentale Rolle; denn sie bilden gleichsam das Urmateria l, das der Psychologe beschreiben, zerlegen und ordnen muss, um es dann deuten und erklären zu können.

An den Phänomenen ist sowohl ihre Beschaffenheit in einzelnen (als Vorstellung, Gefühl, Gedanke, Willensruck u.s.w.), wie auch ihre Strukturierung (als Gestalt oder Lngestalt, Komplex, Kette, gerichteter Ablauf u.s.w.) Gegenstand der psychologischen Lntersuchung. A 11 e weiteren psychologischen Forschungsaufgaben aber führen aus der Ebene der Phänomene heraus. Denn nun handelt es sich um Tatbestände, die selber nicht mehr Inhalte des Erlebens sind, wohl aber zum Erleben in Beziehung stehen und deshalb im weit eren Sinne "psychisch" heissen können. 
„Phänomene, die nicht erlebt werden", sind ein Widerspruch in sich selbst. Die Bezeichnungen ,unbewusste Vorstellung", „unbewusstes Gefühl" sind bequem, aber absurd. Erlebnisinhalte sind keine Dinge, die man aus dem Erleben herausnehmen, woanders hin verstecken und später vielleicht wieder mit erhaltener Identität ins Erleben aufnehmen kann. Will man auf den Ausdruck „unbewusst” nicht verzichten, dann muss man ihn jedenfalls beschränken auf das Psychische in weiterem Sinne, also auf die personalen Zustände, Akte und Dispositionen.

c) Zustän d e und Akt e. - Das Verhältnis der Person zu ihren aktuellen Erlebnissen ist ein Haben und ein Tun. Der Mensch hat Erlebnisse, und er wirkt sich a us in seinem Erleben - stets beides zugleich; es gibt kein Erleben, in welchem nicht Zuständlichkeit und Funktion vereinigt wären. Aber die Gewichtsverteilung von beidem kann so verschieden sein, dass wir das Recht haben, manches Erleben wegen seiner überwiegenden Zuständlichkeit als passiv zu bezeichnen, anderes Erleben, in welches die Person dirigierend, gestaltend, auslesend, ordnend eingreift, als a $\mathrm{t} \mathrm{iv}^{1}$ ). Ausgesprochene Beispiele für passives Erleben sind: eine Behaglichkeitsstimmung, eine Tagträumerei; für aktives Erleben: ein energischer Denkvollzug, ein innerer Kampf zwischen Neigung und Pflicht.

Der A k t, der ein Erlebnis beherrscht, ist selbst nicht mehr Erlebnisinhalt, also nicht im engeren Sinne „psychisch”. Er kann wohl durch Phänomene im Bewusstsein repräsentiert sein, etwa durch ein Tätigkeitsgefühl, durch Spannungsempfindungen u.s.w.; aber solche Phänomene sind nur Spiegelungen (die unvollständig oder sogar täuschend sein können), nicht der Akt selbst. Dennoch ist die Bezeichnung ,psychischer Akt" im we i t er en Sinne verwendbar für einen Akt,d er auf psychische Phänomene gerichtet ist, oder s of e r n er auf solche gerichtet ist. Ein Denkakt ist also „psychisch”, weil die von thm erzeugten und dirigierten Denk-Inhalte und -ibläufe psychische Phänomene sind. Ein Willensakt ist ,psychisch", sofern er auch Willenserlebnisse (Bedürnis-, Motivations-, Wahl-, Entscheidungs-Phänomene) in sich schliesst. Aber dies zweite Beispiel

1) Die Ansirtiche ,aktives" und ,aktuelles" Erleben (s. oben) dirfen also nicht verwechiselt werien. 
zeigt schon, dass die Brauchbarkeit des Ausdrucks "psychisch" begrenzt ist. Denn der Willensakt im ganzen hat seinen Sinn in der zielstrebigen Einheit von psychischen Erlebnissen und körperlichen Handlungen; er ist ein psychophysisch neutraler, ein personale $\mathrm{Akt}$. Der Psychologe hat das Recht und die Pflicht, die darin enthaltenen psychischen . Momente herauszuanalysieren und für sich zu betrachten; aber wenn er hiernach das Ganze einen „psychischen” Akt nennt, so muss er stets dabei bedenken, dass er die Bezeichnung nur ron unselbständigen Teilerscheinungen her nimmt, und dass er gerade die sinnvolle G a $n z$ he it des Aktes dabei verfehlt. Auch hier zeigt sich witder, wie die unmittelbar personalen Kategorieen den rein psychischen wie den rein physischen überlegen sind.

\section{Dispositionen}

Aktuelles Erleben ist auf eine bestimmte Gegenwart begrenzt. Es beginnt und hört auf; Erleben ganz anderer Art oder auch Erlebnislosigkeit geht roraus und schliesst sich an. Wollen wir den Begriff des „Psychischen” nur auf das fragmentarische und chaotische Auftreten von Phänomenen, Zuständen und Akten beschränken? Der allgemeine Sprachgebrauch hat längst anders entschieden, und wir schliessen uns ihm an; demn wir haben in der personalistischen Theorie die Rechtfertigung zu dieser Erweiterung des Begriffes ,psychisch" auch auf das potentielle E r leben. Iie Person ist ja in ihrem Cesamtlebensrollzuge eine sinnvolle Einheit; die ihr innewohnende Zielstrebigkeit zwingt uns, alles Einzelne in den pers o n a l-h is t or is $\mathrm{ch}$ en Zusammenhang einzuordnen, und in diesem Zusammenhang gleichsam den potentiellen Cntergrund: die Toraussetzung, Piereitschaft, Gerichtetheit-kurz, die .. Dis p os it i o n" für clus Eintreten aktueller Tatbestände zu sehen.

Die Psychologie war, nachdem die Lehre von den ., Seelenvermögen" Schiffbruch erlitten hatte, lange Zeit der Veinung gewesen, ganz ohne „dispositionelle" Kategorieen auskommen zu können. Wir wissen heut, dass dies nicht möglich ist. In Pegriffen wie Gedächtnis, Phantasie, Intelligenz, Temperament, Charaktereigenschaft, Suggestibilität u.s.w. liegt mehr als die blosse Zusammenfassung für viele Einzeltatbestände, in denen der 
Nensch Vorstellungen hat, Gefühle äussert, Handlungen vollzieht - sie bedeuten zugleich die da u e r n d e Fähigkeit und Tendenz der Person, solche Tatbestände bei gegebener Gelegenheit in bestimmter Weise $\mathrm{zu}$ aktualisieren.

Freilich werden die Iispositionsbegriffe in der modernen Psychologie wissenschaftlich nur brauchbar durch folgende Merkmale, welche sie von dem alten Begriff der Seelenvermögen unterscheiden.

a) Dispositionen stehen nicht als starre und abgegrenzte Seelenkräfte nebeneinander, sondern sie sind unselbständige Teilstrahlen der einen persönlichen Entelechie. Man kann wohl in theoretischer Abstraktion die Sinnhaftigkeit des personalen Lebens als ein gegliedertes $Z$ wecksystem darstellen und den einzelnen Teilzwecken Dispositionen zu ihrer Verwirklichung zuordnen; aber diese Aufteilung hat keine ontische Bedeutung. Es gibt nicht realiter: ein Gedächtnis für sich, das dem Ziel diente, frühere Lebnisse weiter wirken zu lassen; eine Intelligenz für sich, mit dem Ziele, neuen Anforderungen durch Denkvollzüge gerecht zu werden u.s.w.; vielmehr sind das alles nur Momente, Seiten, Perspektiven des personalen Ganzheitslebens. Aber die Wissenschaft muss sich diese in der Struktur der Person selbst vorgebildeten Perspektiven $z u$ eigen machen und wird daher jeweilig die eine oder andere Disposition in den Vordergrund stellen müssen - ohne je zu vergessen, dass an jedem einzelnen $\mathrm{konkreten} \mathrm{Erleben}$ verschiedene Dispositionsweisen beteiligt sind. (So ist für Denkvollzüge zwar in erster Linie eine Denkdisposition - die Intelligenz - anzusetzen, aber zugleich sind auch mnemische und voluntative Dispositionen an ihrem Zustandekommen beteiligt).

b) Dispositionen sind $\mathrm{M}$ ög lichkeiten mit Spielr a u m breite, nicht eindeutig wirkende Kräfte und also nicht alleinige Voraussetzungen für das, was aktuell in der Person geschieht. Nit ihnen k o nvergiert vielmehr immer und überall jene andere Faktorengruppe, die aus der Welt da draussen stammt. Es gibt kein Lebnis, kein Erlebnis, keine Beschaffenheit und Verhaltungsweise der Person, die ausschliesslich aus Dispositionen ableitbar wäre, sowie es keine gibt, die ein- 
deutig vom Milieu her bestimmt wäre. Milieu wird nur wirksam dadurch, dass in Dispositionen die $\mathrm{Empfänglichkeit}$ für seine Einflüsse vorbereitet ist. Dispositionen ihrerseits sind ergänzungsbedürftig; sie vermögen sich aus der Potentialität und Vieldeutigkeit nur dadurch in Aktualität und Eindeutigkeit umzusetzen, dass die Limweltsituation ihnen Anstoss oder Material dazu bietet.

Diese „Ko n vergen $z$ th e ori e” ermöglicht die Uberwindung der beiden einseitigen Standpunkte des Nativismus und des Empirismus. Weder darf man den Menschen erklären wollen allein aus dem, was er von vorn herein an ,angeborenen" und eindeutig wirksamen Eigenschaften besitzt; noch darf man in ihm lediglich einen passiven Empfangsapparat für beliebige Ausseneinflüsse sehen. ${ }^{1}$ )

c) Dispositionen sind, teleologisch gesehen, Möglichkeiten in doppeltem Sinne: nämlich als Hilfsmittel und als Richtungsweisungen des personalen Funktionierens.

Beispiel: Eine mnemische Disposition enthält in sich sowohl die F ähigkeit, Nachwirkungen früherer Lebnisse zu verwerten, wie die $B$ e reitschaft, sich jener Nachwirkungen in bestimmter Weise zu bedienen (z.B. sein Vorstellungsleben vornehmlich mit visuellen Bildern $z u$ bereichern).

In jeder Disposition steckt also zugleich P o t e $\mathrm{n} z$ und $\mathrm{T}$ e $\mathrm{n}$ d e $\mathrm{n}$ z. Aber die Betrachtungsperspektive kann nun vorwiegend das Potenzmerkmal oder das Tendenzmerkmal zum Kennzeichen einer Disposition machen; danach sondern sich , $\mathrm{R}$ ü s $\mathrm{t}$ u $\mathrm{n} \mathrm{g}$ s"und „Richtungs"-Dispositionen. So ist die Intellige n $z$ Rüstungsdisposition; denn hier kommt es auf die ins t r u m ent a l e Bedeutung an, die sie für die verschiedensten personalen Sonderzwecke besitzt. Dagegen ist das In ter es se eine Richtungsdisposition; denn in ihm ist das dauernde Tendieren der Person auf bestimmte $Z$ i e $l e$ enthalten.

d) Dispositionen sind rariabel nach Zeit, Potenz und Tendenz.

Wohl sind Dispositionen ch ro n is che Möglichkeiten; das bedeutet aber nicht, dass sie das ga nze Leben der Person von

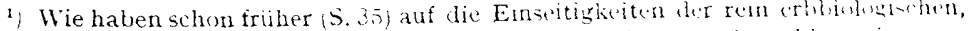
wie der rein soziologischen Ableitung menschlicher Lebensworghnge hingewienen.

Stern, Psychologie
} 
der Geburt bis zum Grabe begleiten müssten. Es gibt vielmehr Dispositionen von ganz verschiedener Dauer und Zeitstruktur.

Die seelische Labilität und Unausgeglichenheit vieler Menschen während der Pubertätszeit ist zweifellos dispositioneller Natur; denn diese Beschaffenheit bildet durch einige Jahre die gemeinsame potentielle Ursächlichkeit für die einzelnen Handlungen und Erlebnisse. Aber sie hat Anfang und Ende mitten im Lebensablauf des Individuums; und wenn die Pubertätszeit durchgemacht ist, braucht nicht mehr eine Spur jener ,,epochalen" Disposition vorhanden zu sein.

Es können auch Dispositionen mit ganz bestimmten Lebenssituationen zusammenhängen; während einer Krankheit, oder vor einem Examen, ist der Mensch körperlich und seelisch ganz anders ,disponiert" als ausserhalb dieser Zeit. Wir werden derartige halbchronische Dispositionen später als personale „Lagen”, „Haltungen”, „Einstellungen” zu behandeln haben.

Aber auch die voll-chronischen Dispositionen, jene Dauerbeschaffenheiten, die aus dem personalen Leben überhaupt nicht fortgedacht werden können - sind doch nicht immer in gleichförmiger Weise vorhanden. Triebhaftigkeit, mnemische Fähigkeit, Denkfähigkeit u.s.w. gehören zum Wesen jedes Menschen; aber sie machen im Laufe des Lebens mannigfache Veränderungen durch. Aus völliger Latenz entwickeln sie sich früher oder später zu wirklichen Bereitschaften; hierbei gewinnt ihre Potenz an Kraft, ihre Tendenz an Bestimmtheit. Was ursprünglich nur vage, sehr vieldeutige „Anlage” war, verfestigt sich allmählich zur „Eigenschaft" 1). Auch die R i cht u n g ihrer Bereitschaft kann im Laufe der Zeit Umbiegungen erfahren; Charakterzüge, Interessenrichtungen können sich innerhalb gewisser Grenzen verändern. Endlich unterliegt auch der $\mathrm{Grad}$ ihrer Bereitschaft periodischen oder unperiodischen Schwankungen; eine Disposition kann so energiegeladen sein, dass der geringste Anstoss genügt, um sie in Aktualität zu versetzen; in anderen Epochen ist sie schwer ansprechbar oder völlig latent.

Diese Variabilität der Einzeldispositionen zwingt dazu, noch einmal die Ursachfrage zu stellen. Sie sind eben nicht, wie die Vermögenslehre meinte, konstante Urkräfte, welche - selber

1) Daher gilt für alle praktische Psychologie der Leitsatz: „Auf Anlagen kann man wirken; mit Eigenschaften muss man rechnen". 
unableitbar - die Ursächlichkeiten für das aktuelle Leben und Erleben bilden; sondern sie sind ihrerseits von Ursachfaktoren abhängig; und zwar wiederum von der Konvergenz des Aussenund des Innen-Faktors. Die eben angedeuteten Ä n d e r u n g e n der personalen Dispositionen sind zu einem Teil von Milieubedingungen der Natur und Kultur (von Kklima, Erziehung, (jemeinschaftswirkungen u.s.w.) beeinflusst; zum anderen Teil von der Ganzheit und der einheitlichen Lebendigkeit der Person, deren Teilstrahlen sie sind.

e) Der Ausdruck „p s y ch is ch" ist auf J)ispositionen nur in weiterem Sinne anwendbar. Sie erscheinen ja nicht selber im Bewusstsein; die Intelligenz als I)isposition z.B. ist nicht ein Denkphänomen, sondern die Voraussetzung der Möglichkeit von Denkphänomenen. Immerhin ist hier die Bezeichnung ,psychisch" auch für die Disposition noch relativ unmissverständlich: weil nämlich ihre Betätigung lediglich auf psychische Phaenomene (Denkinhalte und Denkabläufe) gerichtet ist.

Anders dort, wo die Bekundungsart der Disposition selber nicht mehr eindeutig psychisch oder physisch, sondern psychophysisch neutral ist. Was wir oben von den personalen Akten sagten, gilt sinnentsprechend auch von den Dispositionen zum Vollzuge solcher Akte.

Man denke etwa an die Eigenschaften des Temperaments und des Charakters. Te m perame $\mathrm{nt}$ ist die Bereitschaft zu einer bestimmten Art der personalen Dynamik; diese Dynamik bekundet sich in Tempo, Fülle, Weltoffenheit oder Gehemmtheit des personalen Geschehens überhaupt, may es sich um körperliche $Z$ weck- und Ausdrucks-Bewegungen, oder um Erlebnisse der Gemüts- und Strebungs-Sphaere handeln. - Eine $\mathrm{Ch}$ a raktereig e $\mathrm{nsch}$ a $\mathrm{ft}$ bedeutet dauernde Eingestelltheit auf Willenshandlungen gewisser Art; Willenshandlungen sind aber - siehe oben -- personale Akte mit unselbständigen Erlebnismomenten, nicht etwa rein psychische Phänomene und Akte. - Auch die mnemischen Dispositionen: Cbung, Gedächtnis, sind nicht mehr rein psychischer Natur; sprachliches Gedächtnis z.B. erstreckt sich ebenso auf die Sprechbewegungen wie auf die Wortvorstellungen.

\section{Person und Persönlichkeit}

Der Weg von Unten nach Oben hatte uns von den aktuellen 
Einzelphänomenen $\mathrm{zu}$ den sie übergreifenden, aber ebenfalls noch aktuellen Zuständen und Akten geführt, von diesen zu den halbchronischen und ganz chronischen Dispositionen. Aber auch diese bedurften, da ihre Vielheit und ihr Nebeneinander nichts Endgültiges sein konnte, der übergreifenden Einheit: das ist die Person.

In welchem Sinne ist die Bezeichnung „psychisch” auf die Person selbst anzuwenden?

Zuvor nur wenige Worte über das $T$ i e $r$, weil dadurch die auf den Menschen bezogene Problematik an Deutlichkeit gewinnt.

Das tierische Individuum ist zwar nach unserer Definition ebenfalls „Person” - aber fast ausschliesslich „Vitalperson” (Organismus). Sein Leben erschöpft sich so gut wie ganz in dem untersten Lebensmodus der "Vitalität”. Infolgedessen hat beim Tier die Erlebens-Modalität eine - mit dem Menschen verglichen - nur spurenhafte Bedeutung. Bewusstsein ist lediglich anzusetzen als gelegentliche Staungserscheinung bei gehemmten und gespannten Vitalfunktionen. Da der Introzeptionsmodus ganz fehlt, entfällt auch jede auf Introzeption hindeutende und vorbereitende Funktion des Bewusstseins. (Desgleichen ist auch die $W$ e $1 \mathrm{t}$ des Tieres fast nur Biosphaere; eine Gegenstandswelt ist höchstens in kargen Spuren vorhanden).

Diese Struktur des tierischen Individuums bringt es mit sich, dass die Wissenschaft vom tierischen Leben im wesentlichen Biologie ist und bleiben muss. Eine Tierps ychologie kann es niemals in derjenigen Selbständigkeit und systematischen Geschlossenheit geben, wie es eine Menschenpsychologie gibt; und es ist kein Zufall, dass sich gerade an Tieruntersuchungen der Behaviorismus entwickelt hat, der sich auf das Studium der vitalen Verhaltensweisen und deren Beziehung zur Biosphaere beschränkt.

Beim Me n s che n spielt der Modus des Er-lebens eine gänzlich andere Rolle; und darum ist die menschliche Person in ganz anderem Malse und Sinn „psychisch” als das tierische Individuum.

Charakteristisch für den Menschen ist nämlich die $\mathrm{M}$ it t e lstellung des Erlebcns $z$ wischen Vitalität und Introzeption. Das Psychische ist hier zugleich ¿berbau über dem Fundament des ,unbewussten" Vitalgeschehens, wie Unterbau für die introzeptive Krönung des Lebens. Der Mensch muss sich der Selbstverständlichkeit seiner bloss biologischen Natur entfremden und damit Welt und sich zum Gegenstande erheben; und er ist ständig von dem Stre- 
ben beherrscht, diese Entfremdung zu überwinden auf dem höheren Niveau eines werterfüllten Lebens in einer Welt der Werte. Dieser Doppelsinn seines Lebens ist nur $\mathrm{durch} \mathrm{Erleben}$ $\mathrm{h}$ indurch zu erfüllen. So ist das Bewusstsein einmal die sublimierte - verfeinerte, beherrschte, nüanzierte - Vitalität; andrerseits die im Gange befindliche Auseinandersetzung mit den eigenen und den Fremd-Werten des Daseins.

Hier nur zwei vorläufige Beispiele für diese Mittlungrs-Funktion des Bewusstseins: Aus der rein vitalen Sensibilität erwächst die bewusste Wahrnehmung, die zur Erfassung einer Gegenstandswelt und schliesslich $z$ deren Introzeption in einer Weit-und Lebensanschaumer führt. - Der rein vitalen Sexualfunktion überlagern sich die Gefuhlserlebnisse der Sehnsucht und des Verlangens, die dann als Liebeserlebnisse die Introzeption des anderen Ich in die eigene Persönlichkeit vorbereiten.

Die Fähigkeit des Erlebens wandelt also den M e n s c he 11 aus einer bloss animaiischen Vitalperson in die humane, introzipierende Persönlichkeit; sie wandelt die $\mathrm{W}$ elt des Menschen aus blossem Lebensbereich in ein System von Gegenständen, die sich der Introzeption darbieten.

Darum ist das Psychische in der menschlichen Person von allerwesentlichster Dienst-und Strahl-Bedeutung: es dient in breit angelegter Vermittlungsfunktion der personalen Lebensaufgabe; es repräsentiert - veranschaulicht, versinnbildlicht - jene Stellung des Menschen zwischen Vitalität und Wert.

Aber Dienst-Bedeutung und Strahl-Bedeutung, so umfassend sie sein mögen, sind doch immer nur abgeleitete Bedeutungen. Und damit schliesst sich der Kreis unserer Betrachtung: Selbstbedeutung, letzter unableitbarer Sinn kommt dem "Psychischen” $\mathrm{n}$ i c h t zu. Die menschliche Persönlichkeit kann nicht schlechthin dadurch charakterisiert werden, dass sie psychisch sei - weil umgekehrt das Psychische charakterisiert werden muss durch das, was es in der menschlichen Persönlichke it und für sic bedeutet.

4. Das Verhältnis des Psychischen zum Physischen

Das alte "Leib-Seelen-Problem" erhält in personalistischer Auffassung eine neue Wendung; es verliert aber zugleich sehr riel von seiner friiheren Bedeutung. 
Der Mensch ist nicht hier Leib und dort Seele, sondern erlebensfähige Person. Er ist ein Stück Welt, das - obzwar nach aussen abgegrenzt - dennoch in ständigem Austausch der Sub$\operatorname{stanz}$ und der Funktion mit allen anderen Weltstücken steht: das ist seine Leiblichkeit. Und er ist zugleich fähig, sich und die Welt innerlich zu spiegeln: das ist sein Psychisches. Das personale Leben schliesst beides in sich; es $g$ ib t $\mathrm{dem} \mathrm{nach} \mathrm{ke}$ in Erleben und keine Erlebensfähigkeit, die nicht an leibliche Lebenssphären und Funkt i o nen geknüpft wäre.

Wie ist nun aber die Verknüpfung im Einzelnen zu denken?

Keinesfalls als „Wechselwirkung” im Sinne des Cartesianismus. Denn hier wird ja das Vorhandensein von zwei Substanzen im Menschen vorausgesetzt, die aufeinander wirken sollen. Mit der Ablehnung der substanziellen Seele entfällt auch diese Hypothese.

Aber auch nicht als ,Parallelismus der Elemente”. Diese Theorie behauptet eine durchgängige, eindeutige und konstante Zuordnung von psychischen zu physischen Tatbeständen. Jedem seelischen Elementar-Phänomen entspricht hiernach ein bestimmter physiologischer Erregungsverlauf, jeder Verkettung von Seelenerscheinungen eine Verkettung von Erregungen, jeder psychischen Disposition eine Körperregion, in der sie ihren Sitz habe (Lokalisationslehre) u.s.w.

Diese Auffassung ist schon wegen ihrer elemententheoretischen Voraussetzungen unannehmbar. Es gibt ja innerhalb der personalen Ganzheit gar keine Einzeltatbestände psychischer und physischer Art, die so isolierbar und zugleich so stabil wären, dass sie u $\mathrm{n}$ te $\mathrm{r}$ e in a $\mathrm{nder}$ in ein direktes - gleichsam person-unabhängiges - Verhältnis treten könnten. Jeder Zusammenhang von Physischem und Psychischem geht immer durch die Pers o n hindurch, wird von deren Totalfunktionen und von deren Totalzielen überhaupt erst geschaffen und ständig gesteuert; auch ob die Zuordnung eine konstante oder variable sei, hängt ab von ihrer Bedeutung innerhalb der personalen Entelechie.

Beispiel: Nicht eine bestimmte Gehirnzelle ,erlebt” eine bestimmte Vorstellung, wenn sie in Erregung gerät; sondern die Person beantwortet eine bestimmte Reizsituation mit einer Totalreaktion, die sich leiblich vor allem auf bestimmte Gehirnbahnen konzentriert und sich psychisch in einem Vorstellungserlebnis auswirkt. 
Man betrachte es nicht als Spitzfindigkeit, dass zwischen den physiologischen und den psychischen Vorgang die "Totalperson" eingeschoben wird; und man sage nicht, es sei ja eine, der besonderen Betonung nicht bedürftige, Selbstverständlichkeit, dass sich Physiologisches und Psychisches an der identischen Person abspielen. Denn die Person ist hier nicht als blosses „Zwischenglied" oder passiver Schauplatz des psycho-physischen Geschehens gemeint, sondern als dessen eigentlicher Erzeuger und Träger, Beherrscher und Regulator.

Der gemeinsame Bezug von Physischem und Psychischem auf die Person erlaubt, die psychophysische Beziehung als $S$ in $n-$ $z$ u s a $m \mathrm{~m}$ e $\mathrm{h}$ a $\mathrm{n} g$ zu begreifen, während der landläufige $\mathrm{Pa-}$ rallelismus dabei stehen bleiben musste, die sonderbare Koppelung zweier zu einander völlig disparater Reihen zu konstatieren. Wenn wir oben hervorhoben, dass alles, was zur Person gehört, $\mathrm{D}$ i e n s t-Bedeutung und $\mathrm{S} t \mathrm{r}$ a h l-Bedeutung für sie habe, so gilt dies natürlich auch für die Sinnbeziehungen der le iblic h e n Tatbestände zur e rle be nden Person.

Dienstbedeutung: Die Person bedient sich ihres Körpers als $\mathrm{H}$ il f s mit tels für ihr Erleben. Hier besteht eine sehr weitgehende teleologische Zuordnung, die aber etwas ganz anderes ist als der Parallelismus der Elemente. Das Gesamt-Telos der Person bringt es mit sich, dass für die stark a b g e h o b e$\mathrm{n}$ e $\mathrm{n}$, fein abgestuften und durchgestalteten Erlebensweisen ein Organsystem verfügbar ist, welches seinerseits hoch differenziert ist und relativ abgegrenzte und abgestufte Teilfunktionen erlaubt: das Zentralnervensystem. Dagegen stehen die e in g e b e t t et e r e n, diffuseren Erlebensweisen und die dispositionellen psychischen Beschaffenheiten in Verbindung mit den Funktionen der Blutzirkulation, des Stoffwechsels, der inneren Sekretion u.s.w. - also solchen, die den Organismus in seiner Totalität durchwirken.

Ferner ist Stabilität und Variabilität der Körperfunktionen den besonderen Aufgaben angepasst, die sie für das Lrleben zu erfüllen haben. Jene Erlebnisse, die der Vitalität noch sehr nahe stehen, sind von relativ konstanter Natur, phylogenetisch wie ontogenetisch; so können auch die leiblichen Aquivalente weitgehend fixiert sein, in der (attung wie im Individuum. I)aher hat die Zuordnung im Gebiet der Instinkte und (iewöhnungen einen 
stark stereotypen Charakter. Dagegen ist es den höheren Erlebensformen eigen, dass sie fortwährend wechselnden Aufgaben des Lebens mit wechselnder Betätigung gerecht werden, und dass sie zu immer wieder neuen Gestalten sich verbinden. So bedürfen sie organischer Hilfsmittel, die beweglich, umstellungsfähig, kombinationsfähig sind.

Dies gilt ebenso für die peripheren wie für die zentralen Körpergebiete. Man vergleiche Füsse und Hände; den relativ einförmigen Betätigungen der Füsse, die ausserdem zumeist ohne Bewusstsein erfolgen, steht eine gewaltige Spielraumbreite möglicher Handbetätigungen gegenüber, die als „Handlungen” durch Erleben vorbereitet und mit Erlebnissen durchsetzt sind. - Das Entsprechende innerhalb des zentralen Nervensystems: Im Rückenmark ist die motorische Beantwortung bestimmter Sinnesreize an genau fixierte und erblich unveränderliche Stellen gebunden; dies Organ steht daher im Dienst solcher stets wiederkehrender Vitalaufgaben, die des Erlebens nicht bedürfen. Das Grosshirn ist dagegen das Universalwerkzeug für die e r l e b e n d e Person, daher mit vielseitigster Verwendbarkeit und nie erschöpfbarer Plastizität begabt.

Warum ist die menschliche Hand zum Klavierspielen geschickt? Weil $\mathrm{n} \mathrm{i} \mathrm{cht} \mathrm{jeder} \mathrm{Finger} \mathrm{einer} \mathrm{bestimmten} \mathrm{Taste,} \mathrm{einem} \mathrm{be-}$ stimmten Ton, einem einzigen Bewegungsimpuls zugeordnet, sondern zu immer neuen Koordinationen bereit ist.

Aus gleichem Grunde ist das Grosshirn das geeignete Hilfsmittel für das Aufnehmen immer neuer Erfahrungen, für das Erzeugen immer neuer Kombinationen des Denkens und Phantasierens, für ein Schaffen und Handeln, das nicht durch Vergangenheit streng gebunden, sondern auf Zukunft eingestellt ist - es $\mathrm{k}$ a $\mathrm{n} \mathrm{n}$ dies Hilfsmittel darum sein, weil seinen Teilen und Teilfunktionen $\mathrm{nich}$ t eine eindeutige Zuordnung zu bestimmten Erlebnisinhalten, Akten und Fähigkeiten zukommt.

Was wir hier noch, behufs vorläufiger Vereinfachung der Betrachtung, als Ciegensätze schroff gegenüberstellten, ist nun freilich in Wirklichkeit nicht als Dualismus zu verstehen. Alle körperlichen Organe und Funktionen der Person haben Anteil ebensowohl an der Stabilität, wie an der Labilität des Lebens. Es gibt in ihnen allen erbliche Tendenzen und individuelle Gewöhnungen an gewisse Bereiche des Tuns und des Erlebens, wie es andrer- 
seits in ihnen allen eine gewisse Bildsamkeit und Anpassungsfähigkeit gibt. Aber wie nun dieses und jenes sich ve r b i n d e t zu der personalen Teilaufgabe des einzelnen leiblichen Organs oder der Funktion, das ist grundverschieden nach der Art des Dienstes.

Darum ist es eine voll berechtigte und höchst fruchtbare psychophysiologische Fragestellung, die nach relativ generellen und konstanten Zuordnungen zwischen psychischen und physischen Einzeltatbeständen sucht; nur muss sie sich stets mit der anderen Frage durchdringen: nach der Vieldeutigkeit, der Umbildbarkeit, der Neubildbarkeit, der Individualisierbarkeit solcher Zuordnungen.

Es ist wissenschaftsgeschichtlich sehr lehrreich zu verfolgen, wie sich in der Nerven- und Gehirn-Forschung der letzten $1 \frac{1}{2}$ Jahrhunderte diese beiden Betrachtungsweisen periodisch ablösten. Bald stellte man eingehende Hypothesen auf im Sinne ,spezifischer Energieen"; d.h.: jedem einzelnen Ort und Vorgang im Nervensystem wurde eine ganz bestimmte, eine einzig mögliche, Erlebensweise (Empfindung, Vorstellung, Wollung) zugeordnet. Und ebenso wurden auch die psychischen Dispositionen an feste Stellen des Grosshirns gebunden gedacht (Phrenologie des 18. Jahrhunderts, Lehre von den Sinneszentren, Assoziationszentren, Sprach- und Handlungszentren im 19. Jahrhundert). Aber immer wieder wurde ein solcher Parallelismus der Teile abgelöst durch eine Ganzheitsbetrachtung, welche die Spezifikation der psychischen Leistungen auf einzelne Gehirn-Gebiete und -Elemente ablehnte und die Vielseitigkeit und Plastizität des zerebralen Apparats in seinem Zusammenhang mit dem personalen Gesamt-Telos betonte.

In der Gegenwart erlebt diese letztere Betrachtungsweise wieder einen entschiedenen Aufstieg (Lashley, Goldstein und andere). Indessen vermeidet sie doch die Einseitigkeit und sucht analog der oben angedeuteten personalistischen Theorie - die Dop pela ufgabe des Nervensystems dadurch zu verstehen, dass ihm Stereotypie und Plastizität zugleich zuseschrieben wird. So wird die Existenz von .Zentren" innerhalb des Grosshirns nicht bestritten - wie wäre das auch möglich angesichts der zahllosen Beweise aus Anatomie, Physiologie, Pathologie und Klinik -; aber man sieht in diesen Zentren nicht mehr feste Teil-Organe, die allein und unabänderlich die Bestimmung hätten, bestimmte psychische Tatbestände aufzuspe'ichern, zu verknüpfen und weiter wirken zu lassen - sondern es sind nur Stellen mit bevorzugter B e r e it $s \mathrm{ch}$ a f $\mathrm{zu}$ bestimm- 
ten Sonderleistungen, zu denen sie auf Grund der Strukturverhältnisse des Organismus und einer gewissen Abgestimmtheit praedisponiert (nicht jedoch praedestiniert) sind.

Wie sehr die Mehrdeutigkeit der psycho-physischen Zuordnung vom personalen Gesamt-Telos aus reguliert wird, zeigen besonders eindrucksvoll die Vertretungserscheinungen (,S u bs t it u t i o n e n"). Auch sie bestehen peripher und zentral. Ein Mensch, dessen rechte Hand verletzt ist, schreibt (wenn auch unvollkommen) mit der linken. Der Erblindete kann zwar mit der tastenden Hand nicht ,sehen", wohl aber psychische Erkennungsleistungen vollziehen, die sonst der optischen Eingangspforte bedurften. Und auch die Funktionsuntüchtigkeit eines Gehirnzentrums muss nicht endgültigen Ausfall der daran geknüpften psychischen Erscheinungen zur Folge haben; es kann eine, freilich begrenzte, Wiedergewinnung der Leistung vermittels anderer Gehirnpartieen eintreten. - Taubstumm-blinde Menschen können sprechen lernen (vermittels einer Tastsprache). Ihr "Sprachzentrum" muss demnach eine ganz andere Struktur und Lage haben als das vollsinniger Menschen; denn es erhält seine Funktionsfähigkeit nicht, wie bei diesen, durch vorzugsweise nervöse Verbindungen mit dem Ohr und den Mundorganen, sondern durch solche mit der tastenden und Tasteindrücke empfangenden Hand.

Das Körperliche hat aber nicht nur Dienstbedeutung, sondern auch $\mathrm{Strah} 1$ bedeut ung für die Person, d.h. es re prä$\mathrm{s}$ e $\mathrm{n} t \mathrm{i}$ e $\mathrm{r} \mathrm{t}$ das Wesen der Person, stellt diese nach aussen dar. Da nun auch das Psychische solche repräsentative Bedeutung hat (s..S. 105), so verein ig t sich beides zum psychophysisch-neutralen A u s d r u ck der Person.

Hier wird also nochmals der Elementenparallelismus überwunden. Es sind nicht, aus irgend welchen unerkennbaren Gründen, gewisse Gefühle mit gewissen Mienenbewegungen, Herzschlagbeschleunigungen u.s.w. aneinandergekoppelt, sondern be i d e s in Einem ist die Art, wie die Person sich darlebt nach innen und a ussen. Ein Anstieg der personalen Lebenswelle z.B. drückt sich zugleich aus in Tempobeschleunigung der Vorstellungen wie der Bewegungen, in Expansion der Gefühle wie im Recken des Körpers und im Ausbreiten der Arme. Das Gefühl wäre garnicht erlebbar, wenn es nicht zugleich in dergelebten Bewegung seinen A usdruck fände. - Ebenso haben psychische Dauerdispositionen ihre körperliche Ausdrucksrepräsentation in Dauerfunktionen und Zuständen der Physiognomie, der Gestikulation, des Körperbaus, der Haltung. 
Die Person als „weltoffene” Ganzheit hat in ihrem Leben und Erleben unablässige Beziehung zur Welt. Zu ih rer Welt. Denn da wir hier nicht Kosmologie treiben, so kann es sich nicht um die Welt überhaupt, sondern um das Stück Welt handeln, das für das Leben der Person bedeutsam ist - und für jene Beschaffenheit dieses Weltausschnitts, in der er für die Person bedeutsam ist.

D a her hat jede Person ihre person-relevante Welt - kurz: ihre „person a le Wel t". (Man könnte auch von der ,subjektiven” Welt der Person sprechen, wenn dieser Ausdruck nicht, wie gleich zu zeigen sein wird, Missverständnisse nahelegte).

Für das Wesen und den Aufbau dieser personalen Welt jeder Person gibt es eine Reihe von allgemeinen Bestimmungen, welche die personale Welt von den anderen "Welten" (der mathematischen, der physikalisch-kosmischen, der soziologisch-historischen) grundsätzlich unterscheiden.

\section{Die Modiderpersonalen Welt}

Die personale Welt ist - im Gegensatz zur kosmischen Welt - zentriert: jede Person ist das Zentrum ihrer We $1 \mathrm{t}$.

Dieses Zentrum ist nun aber nicht - wie der Nullpunkt in einem mathematischen Koordinatensystem - ein ausdehnungsund qualitätsloser Punkt, sondern, als Person, selbst gestaltet und inhaltserfüllt. Indem die Gestaltetheit und Sinnhaltigkeit des personalen Zentrums mit der Qualitätenfülle und dem Bedeutungsreichtum der Welt zusammentrifft, ergeben sich alle weiteren Merkmale der personalen Welt.

Den drei Modis des personalen Lebens entsprechend stellt sich auch die personale Welt in drei (schon früher kurz erwähnten) Modalitäten dar: als B i os ph a e r e = Bereich für die Vitalfunktionen; als Gegenstandswelt $=$ Ziel objektivierenden Erlebens; als introzeptible Welt = Kosmos von transpersonalen Eigenbedeutungen, Wertträgern und Forderungen, die nun doch auf das Zentrum der Person bezogen, ihr eingeeignet werden. 
Die personale Welt ist also nicht etwa identisch mit jenem Erlebnisganzen, das wir „Weltbild”, Weltanschauung”, „Weltbewusstsein" nennen. Diese ,e r l e b t e We l t" ist nur ein Teilstück der ,gelebten Welt" (genau wie in der Person das Erleben nur ein Teilstück des Lebens ist). Nennt man also die personale Welt ,,subjektiv", so darf das jedenfalls nicht nur heissen: die Welt, so wie sie sich im B e w u s s t s e i n eines Subjekts spiegelt. Das wäre viel zu eng. Die Möglichkeit, in das Erleben der Person aufgenommen zu werden, besteht für die personale Welt nur in dem mittleren der Ringe, mit denen sie sich um das Zentrum der Person lagert. Vor und hinter diesem liegt die Welt der S e l b stvers tänd 1 i c h k e it, der ursprünglichen (biosphaerischen) und der auf höherem Niveau wiedergewonnenen (introzeptiven) Selbstverständlichkeit.

Für die Psychologie ergibt sich hieraus eine wichtige Konsequenz bezüglich aller Untersuchungen, welche die Beziehung der Bewusstseinstatsachen zu bestimmten Bezirken und Tatbeständen der Welt zum Problem haben. Objektive Tatbestände können nur dadurch zur e r-lebten Welt einer Person werden dass sie sich einfügen in deren g e-lebte Welt. Die zu erforschende Bezichung ist also nicht zweigliedrig (objektive Welt, subjektives Welt-Erlebnis), sondern dreigliedrig (transpersonale Welt, gelebte personale Welt, erlebte Welt). Zwischen dem physikalischen Reiz und dem Wahrnehmungserlebnis steht die einheitliche Reizsituation, in der die Person lebt. Zwischen dem soziologischen (iebilde ,Familie” und dem FamilienErlebnis des Individuums steht der vitale und introzeptive $\mathrm{Zu}$ sammenhang des Individuums mit der Familie. Zwischen dem objektiven Raum der Nathematik und dem Raum-Bewusstsein steht der personale Lebensraum (Dies letzte Beispiel wird im folgenden Abschnitt näher ausgeführt.)

Noch in einer anderen Hinsicht geht die personale Welt über die blosse ,Subjektivität” hinaus. Wenn diese Welt auch um das Zentrum der Person gelagert ist, bleibt sie doch erfüllt von objektiven Wertgchalten; und es ist ja die Aufgabe der In t r o$z$ e p t i o n, deren Einklang mit der im Zentrum stehenden Person herzustellen. So ist die personale Welt objektiv und subjektiv zugleich; sie enthält (Objekte der Erkenntnis und des Handelns; sie enthält Gemeinsamkeiten mit den personalen Welten anderer 
Personen - nämlich die soziologischen und kosmologischen Tatbestände. Aber sie enthält nun doch wieder diese Objekte in der eigenen Perspektive zum Zentrum: entweder in ihrer positiven Bedeutsamkeit für die Person, oder aber in ihrer ausdrücklichen Emanzipation von der eng-personalen Bindung. Für den erkennenden Menschen gehört auch sein Erkenntnisinhalt - und dessen höchste Stufe, die IIissenschaft - zur personalen Welt; indem der Mensch das bloss Subjektive zu überwinden trachtet, betätigt er sich ja als Person, als Zentrum seiner Welt.

\section{Die Beziehung Person/Welt}

a) We ch s e l be st i m m ung. - Im ständigen Austausch des Geschehens zwischen Person und Welt for $\mathrm{m} t \mathrm{~s}$ i $\mathrm{ch}$ nicht nur die Person, sondern auch d e re n We $1 \mathrm{t}$. Die „Umwelt" eines Menschen ist nicht jenes Stück objektiver Welt, das sich zufällig in der Nähe befindet und deshalb auf den Menschen einwirkt; Umwelt ist vielmehr das Stück Welt, das der Mensch sich nahe b r ing t, weil er dafür Empfänglichkeit oder Reizbarkeit besitzt, und dem er zugleich diejenige Form zu g e b e n s u c h t, die seinem Wesen gemäls ist. Zwei Personen, die dauernd in der gleichen Landschaft, in der gleichen Gemeinschaft, ja im gleichen Zimmer leben, haben dennoch nicht gleiche Umwelt; denn die Auslese und Modellierung, die jede Person an den Dingen, Geschehnissen und Umständen rornimmt, ist verschieden; und verschieden deshalb auch die Gesamtgestalt und Gesamtatmosphaere der beiden personalen Umwelten.

Das Ineinander jener Wechselwirkung von Person und Welt ist so innig, dass eine rein $\mathrm{k}$ a u s a le Betrachtung nicht im stande ist, im einzelnen Falle herauszusondern, was Ursache, was Wirkung sei. Wohl aber kann man in $\mathrm{f}$ in a le $\mathrm{r}$ Hinsicht zwei Richtungen des Person-Welt-Geschehens unterscheiden: eine zentripetale (Welt $\rightarrow$ Person) und cine zentrifugale (Person $\rightarrow$ Welt $)$ Dort steht die Person der Welt segenüber als Empfangende und Antwortende. Hier als Suchende und Gebende. Das personale Leben vollzieht sich also dort in $\mathrm{R} e-\mathrm{a} \mathrm{k}$ t $\mathrm{i}$ o $\mathrm{n} \mathrm{e} \mathrm{n}$, hier in- $\mathrm{S}$ p o $\mathrm{n}$ t a n-a kt i o n e $n$; die personale Welt hat lort, ,A u f f or d erungscharakter" ${ }^{1}$ ) hier ... I a terialcharakter".

\footnotetext{
1) Dieser Terminus ist von kurt Lewin eingefuhet worden.
} 
Mit dieser Feststellung werden die blossen „Reaktionstheorieen" überwunden, welche alles Geschehen an der Person somit auch das psychische Geschehen - lediglich als Antwortsprozesse auf Welteinwirkungen ansehen. Mag solche Auffassung noch für die Tierbiologie weitgehend brauchbar sein (obzwar sie auch hier nicht allein ausreicht), so ist sie beim Menschen jedenfalls ganz unzulänglich. Gerade jene spezifisch menschlichen Lebensvollzüge, die in höherem Malse von Erleben begleitet sind, erschöpfen sich niemals in blossen Antworts-Taten; in ihnen wirkt vielmehr die Person von sich aus bestimmend auf die Welt, erweitert und vervielfältigt ihre Beziehungen zur Welt aus ihren spontanen Entwicklungstendenzen, aus ihren Denk- und WillensBedürfnissen. Welt ist für diese Spontanaktion der Angriffspunkt, der Rohstoff — freilich auch sofort der Widerstand und die Abgrenzung, sodass nun rückwirkend das spontane Tun mit reaktivem durchwirkt und dadurch vereindeutigt wird. Die Souveränität des reinen Schöpfertums ist ebenso wie das völlig passive Ausgeliefertsein an die Welt ein unvollziehbarer Grenzbegriff; in Wirklichkeit gibt es nur ein ewiges Oszillieren zwischen Spontaneität und Reaktivität. Di e pers on a 1 e Welt ist stets zugleich Schicksal und Werk der Person.

b) Qualität der P erson/Welt-Bezi e hung. Der Qualität nach ist diese Beziehung bald ,homogen”, bald „,heterogen" - - und zwar in jeder der beiden oben besprochenen Sinnrichtungen.

Homogeneität in zentripetaler Richtung: „Teilnahme”. Auf Grund ihrer Zugehörigkeit zur Welt und ihrer Hingegebenheit an die Welt nimmt die Person teil an den Beschaffenheiten, Funktionsweisen und Tendenzen jener transpersonalen Gebilde, die ihre Welt ausmachen. So verwirklicht sie in sich Eigenschaften der Crattung und der Sippe, der Nation und der Rasse; so übernimmt sie aus ihrer Umwelt Sitten und Gebräuche, Wertungen und Uberzeugungen, Handlungs- und Verhaltungsweisen.

Dies Angleichungsgeschehen ist an sich durchaus psychophysisch neutral; sind ihm doch Körperformen und Bewegungsweisen ebenso unterworfen wie Vorstellungsinhalte und Gesinnungen. Es ist ferner sowohl phylogenetisch wie ontogenetisch 
wirksam: Erb-Anlagen machen die Einzelperson zum homogenen Glied der Geschlechterreihe ; Nachahmung, Kulturrezeption, Suggestionsempfänglichkeit gleichen sie an die Mitwelt an.

Homogeneität in zentrifugaler Richtung: „Prägung". Aus seinem spontanen Innengeschehen heraus prägt jeder Mensch seiner personalen Welt einen Widerschein seines Wesens auf. Er setzt seine innerpersonalen Ideen in transpersonale Werke um; er wirkt - bewusst und unbewusst - als Vorbild und Suggestor; er erweitert gleichsam die Sphaere seiner Persönlichkeit in die ihn umgebende Atmosphaere hinein und bildet so die Gemeinschaft, das Heim; bestimmt den Geist, die Form, ja die Substanz des von ihm beeinflussten Gebietes $\mathrm{n}$ a $\mathrm{ch} \mathrm{s}$ i $\mathrm{ch}$. Und auch die $Z$ uk unft. Denn die bedeutendsten Angleichungswirkungen sind ja jene, die die individuelle Ursprungsperson überleben, die ihre Unsterblichkeit ausmachen: das Weiterleben der personalen Art in Kindern und Kindeskindern, der personalen Ideen und Werke in der menschlichen Kultur.

Freilich: die „Angleichung” führt zentripetal wie zentrifugal nie zum Gleichwerden; sie kann dem wirklichen Effekt nach nur

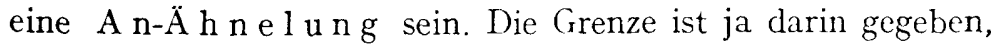
dass bei aller Gemeinschaft von Person und Welt der Eigenrhythmus und die Eigenmelodie des einen und des anderen Faktors nie ganz verstummen kann. So stark die Gewalt sein mag, mit der die Welt den Menschen zur Teilnahme an ihrer Wesensart veranlasst: - er bleibt doch auch hier „Person” und kann auf jene Einflüsse nur in seinem personalen Sinn reagieren, dabei auch die Beschaffenheit des Einflusses in sich abwandelnd und abbiegend. Und umgekehrt: so überschwänglich neu und eindringlich der prägende Einfluss sein mag, durch den z.B. die geniale Persönlichkeit eines Künstlers, eines Religionsgründers, eines Politikers der Welt ein neues Gesicht gibt: - da die empfangende Welt selbst nicht genial ist, wie der Schaffende, vermag sie nur in abgeschwächter, vereinfachter Form jenes Neue zu rezipieren; und da sie zugleich ihren eigenen Gesetzen folgt und noch anderen Einflüssen unterliegt, muss sie auch fortlaufend das Übernommene abwandeln.

So ist schon in $\mathrm{n}$ e $\mathrm{r}$ h a $1 \mathrm{~b}$ jeder homogenen Beziehung von Person und Welt ein Anteil ron $\mathrm{H}$ e terogeneität. Aber letztere hat eine noch viel weitere Bedeutung. 
Denn der Sin $\mathrm{n} z$ u sa $\mathrm{mm}$ e $\mathrm{nh}$ a $\mathrm{ng}$ zwischen Person und Welt ist ja zugleich ein sinn-t e i l i g e r: und der Gesamtsinn kann nur dadurch realisiert werden, dass jeder Faktor einen a $\mathrm{n}$ de re $\mathrm{n}$ Teilsinn vertritt und damit auch eine andere Beschaffenheit hat. Zur Herrschaft der einen Seite gehört Gefolgschaft der anderen; auf Bedrohung wird reagiert mit Abwehr oder Flucht. Das Entsprechende in die Zukunft projiziert: jetziges Säen des Bauern dient zukünftiger Ernte; jetzige Geschäftsbeschlüsse des Kaufmanns dem künftigen Gewinn. Überall greifen die beiden Glieder gerade dadurch sinnvoll ineinander, dass sie, an verschiedenen Stellen des Zusammenhanges stehend, auch unter sich vers chi eden sind: als Reiz und Reaktion, als Nittel und Zweck, als Ursache und Wirkung, als Bedürfnis und Erfüllung, als Motiv und Handlung. Uberall ist das eine Glied als solches unvollständig; das andere liefert dann die Ergä nz u n g dazu. Dass solche heterogenen Sinnzusammenhänge wieder in den beiden Richtungen, von der Welt zur Person und von der Person zur Welt, vorkommen, bedarf nicht erst der Veranschaulichung durch Beispiele.

Am schärfsten heterogen scheinen die beiden Glieder dort zu sein, wo sie einen G e gens a t $z$ bilden. Aber gerade der Gegensatz konstituiert einen besonders starken Sinnzusammenhang. Es ist die Dialektik im Verhältnis von Person/Welt, dass d a s, was sich gegenseitig negiert, sich zugleich gegenseitig zu ergänzen vermag. Die Person sucht in der Welt das, was ihr $\mathrm{fehlt}$; und sie reagiert auf die Welt im Sinn einer G e g e $n$ w i r k u n g, wenn sie ihr Selbstsein gegenüber dem Angeglichenwerden behaupten muss.

Eine weitere Art der Person/Nelt-Beziehung, die dime nsi o n a le, findet im folgenden Abschnitt eine eigene Besprechung.

\section{DIE PERSONALEN DIMENSIONEN}

„Raum" und „Zeit” sind Kategorieen, die von den verschiedensten Wissenschaften in Anspruch genommen, von jeder aber in einer besonderen Weise bearbeitet werden. Diesen verschiedenen Dimensionslehren muss eine personalist is che angereiht werden. 
Die „Personalistik der Dimensionen” steht zwischen den objektivierenden Wissenschaften, welche Raum und Zeit als Gegenstände der Erkenntnistheorie, der Mathematik, Physik, Geschichte u.s.w. behandeln - und der Psychologie, welche vom Raumbewusstsein und Zeitbewusstsein spricht. Ihr Gegenstand sind die personalen Dimensionen, d. h. diejenigen richtungsbestimm ten Erstreckungen, in denen jede Person sich selbst und ihre personale Welt verwirklicht. Im Gegensatz etwa zu den „Dimensionen” der Mathematik sind die personalen Dimensionen nicht reine Formalprinzipien, vielmehr von grossem Qualitätenreichtum und belebt von einer ständigen inneren Entwicklung. Das personale Leben in bestimmten Dimensionen setzt sich partiell in Erleben um, mit dem es dann die Psychologie des Raumes und der Zeit zu tun hat.

\section{Die Aussen/Innen-Dimension}

a) A ussen/Innen. - Die mathematisch-physikalische Welt ist ohne Mitte - denn jeder beliebige Punkt kann als Koordinatennullpunkt angesetzt und wieder mit einem anderen vertauscht werden. Die personale Welt hat eine na$\mathrm{t}$ ü $\mathrm{r} \mathbf{l}$ i che $\mathrm{M}$ i t $\mathrm{t}$ e, von der aus und zu der hin sich alles an ihr erstreckt: die Person selbst, um die sie sich lagert (s. S. 123). Diese Mitte ist wesentlich und unaufgebbar - solange die Person und ihre Welt existieren.

Die Nullpunkte der mathematischen Dimensionssysteme sind „Punkte”, also nichts als blosse Ausgangsstellen ohne jeden Eigengehalt und ohne Eigengestalt. Die $\mathrm{Mit}$ t e der pers on ale $\mathrm{n} W$ e $1 \mathrm{t}$, die Person, ist ein endliches, gestaltetes Ganzes, damit selbst schon Erstreckungen in sich ent$\mathrm{h}$ a l t e nd. Wir werden daher später die personalen Eigendimensionen und die personalen Weltdimensionen zu unterscheiden haben.

Das Verhältnis Person Welt ist also das Verhältnis $z$ we i e r Dimensionssysteme - welches Verhältnis selbst wieder dimensionsmälsig ausgedrückt werden kann als: I n n e nidus se n. Dies ist die dimensionale Grund-Polarität innerhalb des Personalen; in der unpersönlichen Welt fehlt zur Imnen Aussen-I)imen-

Stern, Psychologie 
sion jedes Analogon. (Ein mathematischer Nullpunkt hat kein „Innen" mehr; im Verhältnis zu ihm ist alles ,aussen”).

Die P o l a rit ät Innen/Aussen hat zur Voraussetzung, dass sich Person und Welt als zwei Substrate $g$ e $g$ e $n$ ü b e r-stehen. Wo sie eins sind - also in der ersten und dritten Modalität des Person/Welt-Verhältnisses --, f e hlt auch die dimensionale Polarität. Im primitiven Zustand des Säuglings, der noch ganz biosphaerisch existiert, gibt es kein Innen und Aussen. Ebensowenig im sublimen Zustand der Introzeption: für den Liebenden ist der geliebte Mensch, für den Frommen die Gottheit nicht mehr etwas „Äusseres”, das seinem „Inneren” gegenüberstände. Die Pole Innen/Aussen treten also nur in der mittleren Modalität auf, dort wo die Welt gegenständlich wird. Die Dinge und Vorgänge meiner Welt, die mir gegenüberstehenden anderen Menschen mitsamt ihren Lebnissen und Erlebnissen, sind „draussen”, dagegen mein Herz und meine Lunge, meine Gedanken und Gefühle ,drinnen”.

Man ersieht aus diesen Aufzählungen, dass die Innen/AussenDimension psychophysisch neutral ist. „Drinnen” wie „draussen” kann sowohl Physisches wie Psychisches sein.

b) Gege nwart. - Da die Polarität des Innen/Aussen nicht immer existent ist, brauchen wir einen Terminus für den, vor oder hinter dem Gegensatz liegenden, dimensionalen Grundtatbestand: er heisse "Gegenwart”, genauer ,p e r s o n ale G e ge nwart”, oder "Praes en $z$ ". Damit sind wir bei der Urzelle des ganzen personalen Dimensionssystems angelangt.

In der personalen Gegenwart ist das akute Le b n is (der Person) und die akute $\mathrm{S}$ it u a $\mathrm{t}$ i o $\mathrm{n}$ (der personalen Welt) durchaus in Eins verschmolzen. In diesem Augenblick z.B. gehört zu $m$ e in e $r$ Gegenwart der sich formende Gedanke und der Impuls zur Federführung ebenso wie das Objekt „Feder" und der objektiv auf dem Papier entstehende Schriftzug.

Die personale Gegenwart ist raum-zeitlich neutra 1; sie ist das ungetrennte "Jetzt-Hier". Dadurch ist der Begriff unterschieden von dem rein zeitlichen Gegenwartsbegriff der objektivierenden Wissenschaften.

Die personale Gegenwart ist nicht punktuell, 
sondern a usgedehnt und strukturiert. Eine Melodie, die ich höre, oder die Schreibhandlung, die ich ausführe, ist mir in einem $\mathrm{J}$ e $\mathrm{z} \mathrm{z}$ gegeben, ohne dass dadurch die Zeitgestalt der Melodie (der Handlung) verloren ginge. Zugleich geht die Schreibhandlung hi e r vor sich; für dieses "Hier" ist kein Punkt angebbar; nicht nur mein Körper, sondern auch die räumlich ausgedehnten Gegenstände: Papier, Schreibtisch, gehören zum Hier. Die jeweilige Struktur der Gegenwart hängt von der personalen Relevanz der in Lebnis und Situation enthaltenen Momente ab.

Es gibt eine Superposition der personalen Ge ge n w a r t e n. „Hier” ist der Schreibtisch, aber auch das Zimmer, in dem er steht, ja auch die Stadt, in der ich mich aufhalte - wiederum je nach der personalen Perspektive. So habe ich ein jetzt notwendiges Buch „hier”; d.h. ich brauche nicht fortzugehen, um es mir zu kaufen oder zu leihen. Es ist aber doch nicht „hier” (von meinem augenblicklichen Platz aus erreichbar), sondern es ist ,dort" auf dem Regal, zu dem ich hingehen muss. - Ebenso im Zeitlichen: "Jetzt" bin ich mit diesem Schriftzug beschäftigt, aber ich bin auch ,,jetzt" bei der Niederschrift des Kapitels „Dimensionen”; ja, ich schreibe ,jetzt" an einer ,allgemeinen Psychologie” (im Gegensatz zu meiner vergangenen und künftigen Beschäftigung mit anderen Themen).

c) D i e $z$ we i $\mathrm{A}$ s t e - Von der personalen Gegenwart gehen die beiden $\AA$ ste der Aussen-Innen-Dimensionalität aus: nach „,innen” in die Person hinein und von der Welt fort; nach ,,aussen” in die Welt hinein und von der Person fort. Die Äste sind verschieden in ihren dimensionalen Eigenschaften. I $\mathrm{n} n$ e $\mathrm{r}$ b a $1 \mathrm{~b}$ jedes Astes gibt es sowohl Abstufungen wie qualitative Abtönungen.

$\mathrm{Di}$ e Richtung $\mathrm{n}$ a ch in $\mathrm{nen}$ führt zuerst zu den gegenwartsnächsten Gebieten der Person; diese bilden - sofern sie zwar schon von der Welt losgelöst, aber ihr noch zugekehrt sind - die personale „O be r f l äch e”. Weiter nach innen führt der Weg in die personalen „T i e f e n”, d.h. zu jenen Momenten der Person, die nicht mehr unmittelbar Bezug haben zu der akuten Aussensituation, sondern in spezifischer Weise das Insichselbstsein der Person vertreten. Das Weiterschreiten auf dem 
Wege nach Innen bedeutet zugleich ein Übergehen von eindeutiger Bestimmtheit zu vager Vieldeutigkeit, Hintergründigkeit, Potentialität. Am fiktiven Ende dieses Weges in die personale Tiefe steht dann die völlige Unbestimmtheit, die innere Unendlichkeit der Person.

Die Richtung nach a us sen durchläuft die Weltzonen der Nähe und Ferne. Auch hier fortschreitend vom Bestimmten zum Vieldeutigen, vom Wirklichen zum Möglichen um sich schliesslich fiktiv im gänzlich Inhaltslosen, der äusseren Unendlichkeit, $z$ verlaufen.

"P e r s o n a le $\mathrm{N}$ äh e" haben diejenigen Tatbestände des Draussen, die stetigen Sinnbezug zur personalen Gegenwart besitzen; sie lagert sich um diese wie eine Aura. Das Nahe hat noch unmittelbar personale Relevanz, ist Kontaktnachklang oder Kontaktbereitschaft. ,Nah” ist das Hegende oder Drohende, der Bereich, dem die Person ausdruckshaft ihr Wesen aufprägt, das Ziel gegenwärtiger Strebung, die Handlung, in deren Konsequenz man noch steht.

„Personal fern" ist entweder das, was u n t e r halb d e r S c h w e 11 e personaler Relevanz liegt, oder das, was sich von Gegenwart und Nähe durch seine Gegensätzlichkeit a bs p a l t e t. Im ersten Sinne ,fern" ist dem Strassenbahnpassagier der unbekannte Nachbar. Im zweiten Sinne „fern” ist dem von plötzlichem Unglück betroffenen Menschen der gestrige Tag, an dem er noch glücklich war.

Es ergibt sich also das folgende

Schema der Aussen/Innen-Dimension:

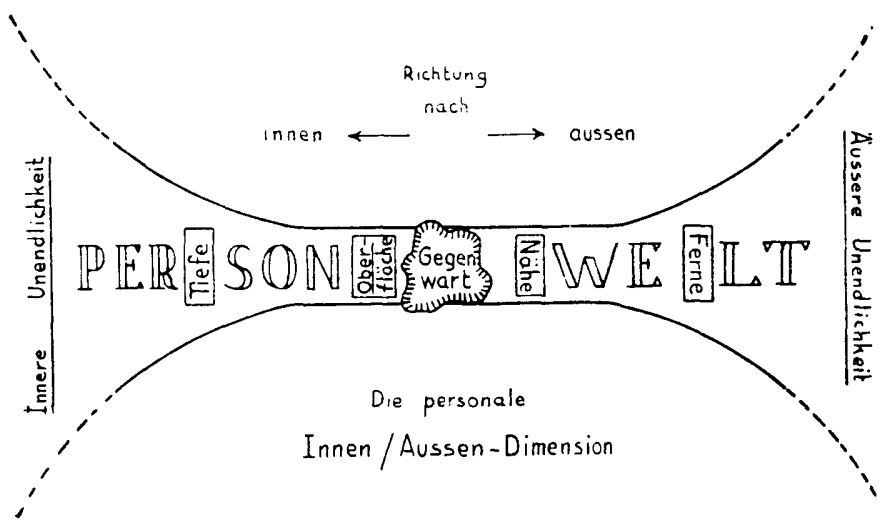


Alle oben besprochenen Merkmale der Aussen/Innen-Dimension sind $\mathrm{rau}$-zeit $\mathrm{lich}$ ne utral. So wenig wie "Gegenwart" einen bloss zeitlichen Sinn hat, haben „Oberfläche”, „Tiefe”, „Nähe”, ,Ferne” rein räumliche Bedeutung. (Von den soeben genannten Beispielen für Ferne ist das eine räumlich, das andere zeitlich).

Die beiden Beispiele zeigen zugleich, dass die A b s t u f u n$\mathrm{g}$ e $\mathrm{n}$ in jenen Dimensionen nicht mit den objektiven Raumoder Zeit-Malsen konform zu gehen brauchen. Der Nebenmann in der Strassenbahn ist mir fern, während der Freund, zu dem ich fahre, mir schon nahe ist - im Gegensatz zu meinem messbaren Abstand von beiden; entscheidend ist allein die personale Relevanz für mein gegenwärtiges Leben.

Die Merkmale der Aussen/Innen-Dimension sind an sich auch w e r t-n e u t r a 1. „Oberfläche” ist nur unter ganz bestimmten personalen Leitmotiven minderwertig; unter anderen Gesichtspunkten kann gerade der unmittelbare Kontakt mit der Welt personal gefordert und darum positivwertig sein. Ebenso kann "Tiefe" sowohl das im Menschen bedeuten, was in ihm aus rückständigen Primitivphasen noch wirksam ist - wie das, was sein eigenstes Selbst unverfälscht durch Äusserlichkeiten und fremde Einflüsse ausmacht.

\section{Eigenpersonale Dimensionen}

a) A 11 g e me in e s. - Aus den Hauptmerkmalen der Person ergeben sich auch die Hauptmerkmale ihrer Dimensionierung.

Die Person ist individuelle Ganzheit. Das heisst dimensional: ihre Erstreckungen sind begrenzt. Jede Person hat i hr e $n$ Raum und i h re Zeit.

Die Person ist unitas multiplex. Das bedeutet dimensional: ihre stetigen Erstreckungen enthalten zugleich ein A u s$s$ e r-einander der Momente.

Die Person ist Leben; Lebensgeschehen ist gerichtet. Die Richtung des Geschehens kann aber $\mathrm{umkeh} \mathrm{rb}$ a $\mathrm{m}$ oder $\mathrm{u} \mathrm{n} \mathrm{u} \mathrm{m-}$ $\mathrm{ke} \mathrm{hrbar}$ sein. Dort besteht Leben in ständiger Wiederherstellung des Seins, hier in ständigem Erzeugen neuen Seins. Konservative Zuständlichkeit hier, progressives Werden dort, 
drücken sich dimensional aus als $\mathrm{R}$ ä umlichkeit und $Z$ e it li ch ke it der Person.

Die strenge Scheidung beider Dimensionsweisen ist freilich nur in der Abstraktion möglich, die Lebensrealität der Person besteht immer in einem Mehr oder Weniger von Stabilität und Labilität, von Selbsterhaltung und Selbstentfaltung. Darum gibt es in der Person zeitgeladene Räumlichkeit, raumartige Zeitlichkeit, Gemeinsamkeiten und Analogieen zwischen räumlichen und zeitlichen Nerkmalen.

Die oben erwähnte Doppelbestimmung jeder personalen Dimension-Stetigkeit und Aussereinander-bedeutet $\mathrm{r}$ ä u m li ch: die Person $f$ ü $11 \mathrm{t}$ ihren Eigenraum allseitig und kontinuierlich, enthält aber zugleich ein $\mathrm{N}$ e be nein a n der der Bestandteile. Sie bedeutet zeitlich: die Person da u e $t$ durch ihre Eigenzeit stetig, enthält aber zugleich das $\mathrm{N}$ a c h e i n a n d e r der Momente.

b) Der Eigenraum der Person. - Räumlich erstreckt sich die Person allseitig, aber nicht gleichförmig. Aussere Abgrenzung und innere Strukturierung heben vielmehr drei räumliche Hauptrichtungen der Erstreckung heraus. Aber eben dadurch, dass diese personale Dreidimensionali$t$ ä $t$ an die Wesensbeschaffenheit der Person geknüpft ist, hat sie einen ganz anderen Charakter als die qualität-entleerte Dreidimensionalität des Raumes der Euklidischen Geometrie. Die drei personalen Hauptdimensionen Oben/Unten, Vorn/Hinten, Links/Rechts sind durch und durch qualität-erfüllt und unter einander unverwechselbar; auch innerhalb j e d e r Dimension unterscheiden sich die zwei Pole nicht nur durch das Vorzeichen, sondern eigenschafts- und rangmälsig.

Die $\mathrm{Oben} / \mathrm{U}$ te $\mathrm{n}$-Dimension ist die personale Hauptachse (aufrechter Gang). „Oben” ist das spezifisch Menschliche lokalisiert: das Denken, die Sprache; ,Oben-sein” ist das Symbol fürllacht und Sieg. Die Vorn/H in t en-Dimension ist noch stark mit zeitlicher Dynamik geladen; ,vorn” ist das den personalen Zielen Zugewandte; aus der Vorderfront handelt der Mensch, in der Vorderfront gibt er sich cxpressiv der Welt. Die Re ch t s/ L i n k s-Limension schafft die Grunderscheinung der Symmetrie; hier gibt es noch eine Vertauschbarkeit der Pole. 
c) D i e Eig enzeit d e r P er s o n. - Diese ist zunächst L e bn is z e it. Denn schon jedes einzelne Lebnis enthält innerhalb seiner Praesenz sowohl Dauer wie Sukzession: man denke nur an den unmittelbar gelebten Rhythmus einer Tanzbewegung, oder an eine in sich zusammenhängende, aber gegliederte Willenshandlung.

Die personale Zeit ist $\mathrm{nicht}$ schlechthin eindimensio nal, wie die mathematische Zeitlinie. Sie wäre es, wenn ihr Wesen in Dauer allein bestünde. Dann gäbe es innerhalb ihrer nur die Verschiedenheit der Länge. In Wirklichkeit aber gibt es (bei gleicher Zeitdauer) die verschiedensten Zeit g c s t a lt e n: z.B. eine unendliche Zahl von Rhythmen, von Melodieen u.s.w. Das ist nur bei Mehrdimensionalität möglich. Und in der Tat hat die personale Zeit auch ihre Breitendimension: die G leichzeitigkeit. Die abgehobenen Teilinhalte eines zeitlichen Lebnisses - z.B. die Töne einer Melodie - treten ja nicht an die Stelle der stetigen Dauer, sondern sind dieser Linie a $\mathrm{u} f \mathrm{~g}$ e $\mathrm{t} \mathrm{r}$ a g e $\mathrm{n}$, die gleichzeitig im Untergrunde des Geschehens weiter läuft. Wird nun gar die Melodie gebildet nicht von einzelnen Tönen, sondern von vollen Akkorden (deren jeder ein reiches „Gleichzeitig” bedeutet), dann erhält der Zeitstrom dieses Lebnisses regelrechte Voluminosität.

Die Nicht-Umkehrbarkeit im Ablaufssinn eines Lebnisses gibt den einzelnen Sukzessionsgliedern den dimensionalen Stempel „Früher und Später”, und in ihrem Verhältnis zueinander die Positionsmarken „Vor” und „Nach”. Nur dadurch, dass alle diese wesentlichen Zeitmerkmale schon innerhalb des e in ze l n e n Lebnisses vorkommen, ist dann ihre Ausweitung auf umfassendere personale Zeitabläufe und schliesslich auf die Lebenszeit möglich. Die Dauer fliesst über jedes einzelne Lebnis hinaus weiter und nimmt immer neue Lebnisse in sich auf, lässt die früheren I.ebnisse hinter sich.

So entsteht eine eigentümliche Doppelbewegung, welche die personale Zeit nochmals grundsätzlich von der mathematischen Zeit scheidet. Diese hat eindeutig und alleinig die Richtung nach vorn. Für die personale Zeit aber ist wesentlich, dass sie eine (instabile) II it te hat, die zeitliche Gegenwart, und dass diese an der ununterbrochenen Leitstange der Latuer unablässig vorw är t s gleitet, während ihre konkreten Grehalte die ungekehr- 
ten Bewegungen vollziehen, also $\mathrm{r} \ddot{\mathrm{u}} \mathrm{ck} \mathrm{k}$ ä $\mathrm{r} \mathrm{t} \mathrm{s}$ - und immer mehr nach rückwärts rutschen. $Z \mathrm{uk} \mathrm{unft}$ und $\mathrm{Vergan-}$ $\mathrm{g}$ e $\mathrm{n}$ h e it sind daher, personalistisch gesehen, werdende Gegenwärtigkeit (,Entwicklung”) und gewesene Gegenwärtigkeit (,Geschichte”). Sie bilden so, mitsamt der jeweilig aktuellen Gegenwart, die unteilbare Einheit des personalen Lebensablaufs.

All dies liegt wieder jenseits des rein Psychologischen. Die Person hat Zukunft als den zu erfüllenden Lebenssinn, auch ohne darum zu wissen; und sie hat Vergangenheit als Noch-Wirksamkeit des schon Gelebten (,Mneme”), auch ohne dass eine Erinnerung vorhanden sein müsste.

Da die Richtung der Zeit unumkehrbar ist, ist alles rein Zeitliche im Leben der Person e i $\mathrm{m}$ a lig und $\mathrm{u} n \mathrm{w}$ ider r uf$\mathrm{l}$ i c h. Einmalig und unwiderruflich auch die B e g re $\mathrm{nzung}$ der personalen Zeit: Geburt und Tod. In dieser Einmaligkeit liegt das spezifisch $\mathrm{H}$ is t oris $\mathrm{ch}$ e jedes personalen Lebens, die unvergleichliche Würde jedes Lebensaugenblicks. Aber gegen die Absolutheit des Einmaligen bäumt sich das Leben selbst auf, weil es stets zugleich nach Wiederherstellung und Stabilität strebt. So enthält die personale Zeit Merkmale, die ihrem unablässigen Weiterfliessen Widerstand bieten - und damit dem abstrakten Zeitbegriff $\mathrm{zu}$ widersprechen scheinen: ein In-sichselbst-Zurückkehren durch Rhythmisierungen der Lebensvollzüge, durch ständige Wiederholungen von Gebräuchen und Gewöhnungen. Und schliesslich wird auch die unwiderrufliche Einmaligkeit der Grenze negiert, sowohl durch die Tat (Wirken auf die Zukunft, in der man nicht mehr lebt; Machtstabilisierung durch testamentarische Verfügungen u.s.w.), wie durch den Glauben (an ,ewige Wiederkehr”, Seelenwanderung, Unsterblichkeit).

3. Dimensionale Wechselbestimmung von Person und Welt

Da die raum-zeitliche Person in einer raum-zeitlichen Welt steht und lebt, ergeben sich dimensionale Wechselwirkungen verschiedener Art.

a) Die eigenpersonale Dimensionalität wird auf die Welt homogen e rwe i t e r t. Das eben erwähnte Beispiel der „letztwilli- 
gen" Verfügung gehört bereits hierher; denn diese setzt voraus, dass „meine" Zeit nach meinem Tode gleichartig weiter läuft. Dasselbe im Räumlichen: die drei personalen Raumdimensionen werden über die Leibesgrenze hinaus verlängert. „Oben” ist nicht nur mein Kopf, sondern der Hut auf ihm und die Zimmerdecke über ihm; ,hinten” ist nicht nur mein Rücken, sondern auch die ihm nächst liegende Zimmerwand.

b) Aber die Gegenstände der Welt sind ja nicht nur in Bezug auf ,mich” als Zentrum da, sondern haben ihre Eigenbedeutung - und ihre Eigendimensionalität. Hier kann nun eine personifizierende $\mathrm{U} m \mathrm{z}$ en $\mathrm{tr}$ i e r u $\mathrm{ng}$ der Dimensionen erfolgen. Der Gegenstand (lebender oder unbelebter) hat von se in e $m$ e ig e n e n $Z$ e n t r u m aus sein Vorn und Hinten, seine Vergangenheit und Zukunft u.s.w. - Beispiele: Der Schrank, der, von mir aus orientiert, dort "hinten" steht, hat dennoch sein eigenes Vorn und Hinten, das von meiner Stellung zu ihm unabhängig ist. - Von meinen hypothetischen Ur-Lr-Ur-Enkeln kann ich sagen: ,,Sie werden die Erschütterungen des 20. Jahrhunderts längst überwunden haben", d.h. für das, in m e in e Zukunft gelegte, n e u e Beziehungszentrum "Nachkommen” ist dasjenige, was für mich Gegenwart ist, ferne Vergangenheit.

c) Es genügt jedoch nicht, dass die Person den ausser ihr befindlichen Objekten und Menschen ihre Dimension le ih t: sie muss sich auch mit den Dimensionen der Welt a u s e in a nderset z e n, sich ihnen anpassen. Damit tritt eine Entwicklung nach zwei Richtungen ein: gewisse eigenpersonale Erstrekkungen werden als $\mathrm{n}$ u r eigenpersonal entlarvt und damit $\mathrm{su}$ b$\mathrm{je} \mathrm{k} \mathrm{t} \mathrm{i} \mathrm{vi} \mathrm{e} \mathrm{r} \mathrm{t,} \mathrm{andere} \mathrm{in} \mathrm{ihrer} \mathrm{Gemeinsamkeit} \mathrm{mit} \mathrm{anderen} \mathrm{er-}$ kannt und damit objektiviert. Sitzen vier Personen um einen viereckigen Tisch, so ist der an der Wand stehende Schrank für den einen rechts, für den zweiten vorn, für den dritten links, für den vierten hinten; diese dimensionalen Bestimmungen sind also ganz an die Subjekte und ihre augenblickliche Lage gebunden. Dagegen ist die Zimmerdecke für alle ,oben”; diese Bestimmung ist also viel objektiver. Man bedenke, dass für den naiven Menschen das "Oben" sogar kos mis c he Objektivität hat; der Himmel ist nicht nur für ihn als Einzelsubjekt, sondern er ist für alle, er ist ,wirklich” oben - während seine objektive Welt kein „Rechts” und „Links" hat. Im kosmologischen System der 
Nissenschaft ist auch die Objektivität des „Oben” verschwunten. Hier sind überhaupt die qualitativen Unterschiede, die wir ei den personalen Dimensionen fanden, der Objektivierung zum Jpfer gefallen. Der Raum der Euklidischen Geometrie hat ebenalls alle Qualitäten der personalen Dimensionen als „nur subektiv" gestrichen; aber er hat ihre Dreizahl und ihr AufeinanJer-Senkrecht-Stehen noch objektiviert; und er hat die - aus der versonalen Rechts/Links-Dimension stammende - Symmetrie :uf alle drei Dimensionen übertragen. Die Nicht-Euklidische Geonetrie hat endlich auch die Dreizahl ins nur Subjektive verwiesen; hr Raum ist völlig entpersönlicht.

Eine entsprechende Entpersönlichung zeigt sich bei den quanitativen Dimensionsbestimmungen. „Nähe” und „Ferne”, ,gross" und „klein" u.s.w. sind im eigenpersonalen Dimensionsystem durchaus von der personalen Relevanz her bestimmt. Das _eben in einer objektiven Welt verlangt aber Identifizierung, rergleichung und Messung - und damit Entsubjektivierung der Juantitäten.

Für die personalistische Betrachtung ist nun das Entscheidende, dass diese objektivierten Dimensionsweisen und Mafse wieder $\mathrm{ntrozipiert}$ werden in das eigenpersonale Dimensionenystem.

Der „L e be nsra u m" des reifen erwachsenen Menschen st nicht mehr so unobjektiv wie der Vitalraum des Säuglings; ber er ist auch nicht so unpersönlich wie der fiktive, mittelrunkts-und qualitätslose Raum der Mathematik. „Mein Heim” st als räumliche Struktur durchaus um mich zentriert, ist ausdrucksvolle Erweiterung meiner Persönlichkeit, ist eingestellt uf meine $Z$ wecke, bereitet mir Zwang oder Schutz. Zugleich st es jedoch eingegliedert in den soziologischen Raum (durch zigentumsabgrenzung und Gemeinsamkeit); in den terrestrichen und kosmischen Raum (,meine" Wohnung in dieser jtrasse, dieser Stadt, diesem Lande u.s.w. ; Projektion des Eigenrts auf die objektive Landkarte u.s.w.); in den mathematischen raum (durch Anlegung von Malsen, die "meinen” Raum mit edem anderen ,vergleichbar" machen). - Indem aber der engee Person-Raum und -Ort jenen transpersonalen Raumgebilden -ingeordnet wird, sind umgekehrt auch jene Sphaeren in den - 
nun erweiterten und verfeinerten - Personraum introzipiert: er bleibt, mit all diesen Beziehungen zur Objektivität, dennoch der gelebte Raum dieser Person.

Entsprechend gehören auch die objektiven $Z$ e i t-Perioden der Jahreszeiten, des Kalenders, der Feste, ebenso die einschneidenden Zeitgliederungen durch politische Weltereignisse (die alle Zeitgenossen gemeinsam betreffen) - in die personale Struktur meiner personalen Lebenszeit hinein.

\section{Zur Psychologieder Dimensionen}

Aus der Personalistik der Dimensionen wird der Ubergang zur Psychologie der Dimensionen durch die Frage gegeben: wie e rlebt der Mensch Raum und Zeit?

Zwar ist das, was wir bisher als dimensionale Merkmale des persönlichen Lebens und der personalen Weltgestaltung schilderten, seinem Umkreis und seiner Wirkungsweise nach viel weiter, als das menschliche Bewusstsein reicht; aber grundsätzlich $\mathrm{k}$ a $\mathrm{n} n$ doch jede dieser Beziehungen zum Inhalt jeweiligen Erlebens werden.

Eine erste Antwort auf obige Frage muss negativ lauten: es gibt keine $\mathrm{s} p$ e $\mathrm{z}$ if is $\mathrm{ch}$ e scelische Funktion, vermittels deren der Mensch seine Dimensionen erlebt, also keinen besonderen „Raumsinn”, oder „Zeitsinn”.

Dasselbe positiv ausgedrückt: der Mensch vermag die Dimensionalität seiner selbst und seiner Welt mit allen psychischen Funktionen zu erleben. Es gibt Raumgefühl, Raumwahrnehmung, Raumvorstellung, Raumdenken, Raumphantasie, Raumstreben - und ebenso bei der Zeit. R a u m und $Z$ eit sind psychologisch in terfunktionell. Selbstverständlich behalten dabei die Probleme: wie denn nun jede dieser besonderen Erlebnisweisen beschaffen sei, ihre psychologische Bedeutung. Nur darf man nicht glauben, dass man es jeweilig mit selbständigen psychischen bezirken zu tun habe, wenn man die Raumwahrnehmung für sich, die Ramphantasie für sich u.s.w. betrachtet; denn es handelt sich immer um denstlben personalen Raum, dieselbe personale Zeit, nur jedesmal in anderer Erkbnisprojektion; und es bestehen tausenderlei Zwischenformen und čbergänge zwischen den verschiedenen Erlebnisweisen. 
Diese Warnung vor Zerstückelung muss besonders scharf ausgesprochen werden bei einem spezielleren Problem, das die Psychologen am ein gehendsten beschäftigt: bei der W a h r n e hm u n g der Dimensionen. Der Umstand nämlich, dass die Sinneswahrnehmung durch verschiedene „Modalitäten” zustande kommt, hat dazu geführt, dass man auch die Dimensionsforschung hierauf zuschnitt und die psychischen Erscheinungen des Gesichtsraumes, des Tastraumes, des Gehörsraumes u.s.w. für sich behandelte. Diese besonderen psychischen Räume sind künstliche Fiktionen, ja noch mehr, sie sind Verfälschungen des eigentlichen psychischen Sachverhalts. Soweit der Mensch überhaupt Raum erlebt, ist es der e in e Raum seiner personalen Existenz und Welt; zu dieser erlebten Raumstruktur tragen sinnesspezifische Teilerlebnisse des Gesichts, Getasts u.s.w. wesentlich bei, bleiben ihr aber unaufhebbar und als unselbständige Momente eingetragen. Entsprechendes gilt wieder von der Zeit. $R$ a u m nd Zeit sind alsopsychologischintersensoriell.

Ein zweiter Gesichtspunkt für alle psychologische Dimensionsforschung ist dadurch gegeben, dass es sich stets um die beiden Dimensionssysteme Person und Welt handelt. Ich kann meine eigene Räumlichkeit und Zeitlichkeit ,subjektivierend", und ich kann die der Welt ,objektivierend" erleben. Ich kann hier wie dort die Totalität der raum-zeitlichen Struktur, oder eine dimensionale Einzelheit, eine Gestalt, eine Richtung, eine Grösse erleben. Und ich kann vor allem das Verhältnis beider Systeme zu einander als Bewusstseinsinhalt haben, so z.B., wenn ich die Lage irgend eines äusseren Gegenstandes zu meiner augenblicklichen Eigenposition wahrnehme, vorstelle oder denke.

Spezielleres über Psychologie von Raum und Zeit kann erst in den späteren Hauptteilen an geeigneten Stellen zur Sprache kommen ${ }^{1}$ ).

1) Vgl, insbes. Achtes Kap., Teil I. 
Bevor wir nun in die Spezialerörterung der einzelnen psychologischen Tatsachen eintreten, sind noch die Gesichtspunkte anzugeben, nach denen Einteilung und Anordnung des Stoffes erfolgt.

Hier steht gerade eine personalistisch orientierte Psychologie vor einer besonderen Schwierigkeit. Denn für sie gibt es nicht eine $\mathrm{n}$ a t ü r lich e Reihenfolge, wie für jene Psychologieen, die aus e in e $r$ bestimmten psychischen Grundfunktion alle anderen ableiten. Die Personalistik kennt keine solche Grundfunktion innerhalb des Psychischen; denn der „Grund” alles Erlebens liegt für sie jenseits der Erlebensphäre. Da alle einzelnen Erlebensgebiete nur aus dem Ganzheitsbezug zur Person verstanden werden können, sind sie untereinander derart verbunden und verschmolzen, dass jede $\mathrm{Re}$ ihe $\mathrm{n}$ folge der Betrachtung eine Will$\mathrm{k}$ ü $\mathrm{r}$ bleibt.

Wir wählten als Ordnungsgesichtspunkt das P e r s o n ' W e 1 t$V$ er hä $I t n$ is.

Die Darstellung beginnt mit jenen psychischen Gebieten, in denen die Abhängigkeit der Person von ihrer Welt am stärksten ist. Die Bindung an die unmittelbare g e g e n w är t i g e Wcltsituation führt erlebnismälsig zur Wa hrnehmung, die Abhängigkeit von gewesen en Tatbeständen der Welt zum Ge dächt n is.

Die weiteren psychische Funktionen sind durch stärhere Verselbständigung der Person gegenüber der Welt gekennzeichnet. Dies äussert sich in ihrer veränderten $z$ e it lich en l)imensionalität. Nicht der wuchtende Druck der Gegenwart, nicht die festgelegte Vergangenheit bestimmen Inhalt und Ablauf, wondern die vieldeutige Zukunft oder eine zeitlich indifferente, gleichsam überzeitliche Sphäre.

Auf Zukunftsziele richtet sich das $\mathrm{I}$ ) e nke $\mathrm{n}$; in zeitlicher Freiheit bewegt sich das $P$ han tasieren, das ebenso vorwärts wie rückwärts gerichtet, wie richtungslos sein kann.

Denken und Phantasie tasten den Bestand der realen Welt noch nicht an; sie bilden daher eine Zwischenstufe in dem Emanzipationsprozess. Die stärkste Cberwindung der Weltabhängig- 
keit liegt erst dort vor, wo die Person von sich aus in die Welt verändernd einzugreifen tendiert: W o 11 e n - und wo sie sich von der Welt ganz auf sich selbst und ihr Erleben zurückzieht: F ü h l e n.

Das Wollen ist eindeutig zukunftsgerichtet. Das Gefühl kann in allen Zeitmodalitäten auftreten (es gibt Gegenwarts-, Vergangenheits-, Zukunfts- und zeitindifferente Gefühlserlebnisse).

Es sei hier zum lezten Male wiederholt, dass die so abgegrenzten psychischen Funktionsbereiche in keiner Weise als gesonderte Seelenvermögen oder Fächer betrachtet werden dürfen; sie sind nur die verschiedenen Weisen, in denen die erlebende Person ihr Verhältnis zur Welt orientiert.

Ein formaler Vorzug der von uns gewählten Reihenfolge darf darin gesehen werden, dass sie den Einteilungen sehr ähnelt, die seit Jahrzehnten für Darstellungen der allgemeinen Psychologie üblich sind. Der Zugang zu der neuen theoretischen Grundeinstellung, welche die personalistische Psychologie verlangt, wird dadurch vielleicht etwas erleichtert, dass die Gliederung des Stoffes nicht allzu fremdartig anmutet. 
ZWEITER HAUPTTEIL

SINNESWAHRNEHMUNG 


\section{FUNFTES KAPITEL}

GRUNDBEGRIFFE UNDGRUNDTATSACHEN

\section{WAHRNEHMUNG UND EMPFINDUNG}

In der ursprünglichen Gegenwärtigkeit eines Lebnisses ist Gegenwart der Person und Gegenwart der Welt ungeschieden (s.S. 130). Findet nun ein solches Lebnis einen Bewusstseinsniederschlag, dann ist die Spaltung da: die gegenwärtige Person erlebt ein gegenwärtiges Etwas, das ihr gegenübersteht. Dies Erleben heisst $\mathrm{W}$ a h $\mathrm{r}$ e h m e $\mathrm{n}$.

Aber freilich ist in jedem Wahrnehmungsakt die Spaltung nur begonnen, nicht durchgeführt. Die Tendenz ist zwar - wie der Name zeigt - etwas ,als w a h r" zu nehmen, d.h. in seiner, vom Subjekt losgelösten, Wesenheit zu erfassen. In Wirklichkeit aber ist der Inhalt des Erlebnisses ebenso von der gegenwärtigen Beschaffenheit der Person wie von der des Objektes abhängig; und die Tendenz zur Isolierung beider Faktoren wird fortwährend durchkreuzt durch die andere: die Verschmelzung zwischen Erlebendem und Erlebtem wieder herzustellen.

Die psychologische Wahrnehmungstheorie hat zu untersuchen, welche Aspekte die verschiedenen Stufen dieses unablässigen Trennungs- und Annäherungs-Prozesses darbieten ${ }^{\mathbf{1}}$ ).

Jenes „Etwas”, das in der Wahrnehmung erfasst wird, kann entweder "Ich selbst" in meinem gegenwärtigen Zustand, bezw. ein an mir jetzt vorhandener Teilzustand sein: Selbstwahrnehmung; innere Wahrnehmung. Oder es kamn etwas ausser mir Befindliches sein: äussere Wahrnehmung oder Sin nes w a h $\mathrm{r}$ $\mathrm{n}$ e h $\mathrm{m} \mathrm{u} \mathrm{n}$ g. Nur diese ist das eigentliche Thema des vorlicgen-

1) Die Psychologie begegnet sich hier an manchen Stellen mit der Erkentnistheo-

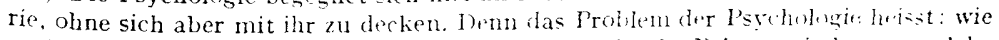
e r le b t der Mensch gegenwärtige Tatbestände? - das der Erkemintistheoru: Weiche objektive Gelt ung hat die Wahrnehmung gegenwärtiger Tathestinde?

stern, Psychologie 
den Hauptteils; aber jene andere wird im Hintergrunde der Betrachtung zuweilen mitschwingen müssen.

Betont man an der Wahrnehmung die Unmit te l bar$\mathrm{ke}$ i t des konkreten Gegenwärtigseins, das: „Auf einmal und einmalig und eindeutig Gegebensein", so heisst sie „A ns c h a u u ng." Anschauung bildet also einen Gegensatz (freilich keinen absoluten) zu jenen Bewusstseinsbeständen, die nur durch Vermittlung und in Einzelschritten erarbeitet werden, und die infolge ihrer Vieldeutigkeit auf Vieles anwendbar sind ${ }^{1}$ ).

Weitere Grundeinsichten gewinnen wir, indem wir die methodische Doppelkategorie $\mathrm{A} \mathrm{b}$ e b u $\mathrm{ng} / \mathrm{E}$ in b e $\mathrm{t} \mathrm{ung}$ auf die Wahrnehmung und auch auf ihr objektives Korrelat anwenden.

Analysiert man eine objektive Situation, in der eine Wahrnehmung stattfindet, so trifft man auf Situationserstreckungen (dort, hier, vorn, hinten), auf Situationsbereiche (Licht, Masse, Duftendes, Schwingendes u.s.w.), auf Situationsgebilde (Gegenstände, Geschehnisse), schliesslich auf letzte, physika$\mathrm{l}$ i s ch-ch e $\mathrm{mis} \mathrm{ch}$ bestimmbare Elemente dieser Bereiche: (einen einzelnen Lichtvorgang, einen Massendruck, einen Duftstoff, die Schwingungen einer Saite). Man pflegt ein abgehobenes Situationsglied, sofern es am Zustandekommen einer Wahrnehmung beteiligt ist, als „R e i z" zu bezeichnen. Seit Fechner ist dieser Ausdruck vorzugsweise verwandt worden für die physikalischen Elementarprozesse, auf welche die Objektanalyse führt, und die, wie schon bemerkt, in einem physikalischen Mafswert eindeutig ausdriickbar sind.

Bei diesem Physikalismus wird nicht genügend geschieden dazwischer, ob das objektive Geschehnis sich tats ächlich als geschlossenes Gebilde aus der diffusen Gesamtsituation heraushebt, oder obes lediglich durch die $\mathrm{Abs} \mathrm{trak}$ tion des Theoretikers aus seiner Situationsgebettetheit abgehoben gedacht wird. Nur im ersten Fall sollte man von einem ,Reiz" sprechen, im zweiten höchstens von einem ,L e i z m o m e n t" oder „Reizglied”.Ein Akkord, der voll angeschlagen die Stille unterbricht, ist ein Reiz; der cinzelne darin enthaltene Ton nur ein Reizmoment.

\footnotetext{
1) Sehen wir den gleichen Tathestand erkentnistheoretisch an, also in Bezug auf das, wa sich der Ansehaunng auflr.̈ngt, so sprechen wir von "Evidenz". Das Wort meint eber diese Cnentrinnbarkeit des "Da ist etwas", nit der ein Seiendes im Erleben scinen Seiuscharakter durchsetzt.
} 
Das Entsprechende finden wir auch auf der psychologischen Seite. Die einzelne Wahrnehmung ist zunächst als $\mathrm{E}$ i n h e it im Bewusstsein da: indem ich einen Apfel ergreife und meinem Gesicht nähere, ist die Wahrnehmung „da ist ein Apfel" ein Gesamterlebnis. Schon die naive Selbstbeobachtung lässt daran eine Reihe von Erlebnis-Momenten erkennen: hart, rund, duftend, gelbgrün. Der Psychologe vermag durch künstliche Abhebung noch weiter zu analysieren: er kann z.B. feststellen, dass das Wahrnehmungsmoment ,hart" nicht nur Berührungserlebnisse meiner Hautoberfläche, sondern auch Widerstandserlebnisse meiner Handmuskulatur beim Umschliessen des Apfels in sich fasst, dass in dem Farbeneindruck so und so viel unterscheidbare Stufen enthalten sind u.s.w.

Wir stehen hier an der Stelle, wo die ,elementenpsychologische" Betrachtungsweise lange Zeit ihre grössten Triumphe gefeicrt hat: sie glaubte in den letzten Ergebnissen solcher Zerlegung der Wahrnehmung die eigentlichen psychischen "Atome” gefasst $z u$ haben, für die nun der Ausdruck „Em p f i n d u n g e n" verwandt wurde.

„Empfindungen sind die einfachen Bauelemente der Wahrnehmungsgebilde" - das ist die begriffliche Prägung, welche die, von der Physiologie und Psychophysik herkommende, klassische Periode unserer Wissenschaft diesem so vielgestaltigen Wort verliehen hat, und die dann Jahrzehnte lang mit Selbstrerständlichkeit angewandt worden ist. (Eine ganz andere, „romantische” Begriffsprägung des Wortes „Empfindung” wird nachher zu besprechen sein).

Wenn auch die elementenpsychologische Voraussetzung dieser Begriffsbestimmung heut nicht mehr aufrecht erhalten wird, so ist es doch notwendig, ihre Konsequenzen kurz zu skizzieren. Denn erstens arbeitete fast die gesamte psychologische Literatur der letzten hundert Jahre mit diesem Empfindungshegriff, sodass jeder, der Psychologie treibt, damit vertraut sein mus;; zweitens aber behalten zahlreiche wisemschaftiche Ergehnisie, die aus der subtilen Zerlegung der Sinneswahrnehmung gewonnen sind, bleibende Bedeutung; sie werden durch dic veränderte theoretische Auffassung nicht einfach über den Haufen geworfen, sondern erfordern nur eine Lmdeutung und eine Ergänzung durch neue, anders eingestellte Intersuchungen und Betrachtungen. 
Zunächst war der genannte Empfindungsbegriff sehr brauchbar, um die elementaren Beziehungen der psychischen Sinneserlebnisse zu den physiologischen und physikalischen Vorgängen durch geeignete Arbeitshypothesen zu bewältigen. $\mathrm{Zu}$ jeder Empfindung besonderer Art wurde ein physiologischer Prozess besonderer Art gesucht, der ihr zu entsprechen hätte; es wurde zugleich der verursachende physikalische Reiz nach seiner messbaren Grösse festgestellt. Ohne diese - wenn auch noch so vereinfachende - Voraussetzung wären die Leistungen eines Helmholtz, Fechner, Wundt und anderer nicht möglich gewesen.

Sodann wurde, im Rahmen des Psychischen selbst, der innere Reichtum unseres Wahrnehmens erst durch diese subtile Zerlegung komplexer Gebilde evident gemacht, auch manches früher unbekannte Gebiet der Sinneswahrnehmung entdeckt (z.B. Lageempfindungen, Gleichgewichtsempfindungen, Vibrationsempfindungen).

Ihre Grenze erreichte jene Auffassung freilich in dem Augenblick, da sie glaubte, aus den Empfindungs-,,Bausteinen” nun die Wahrnehmungen wirklich a u f b a e n zu können. Der Umstand, dass man in der Wahrnehmung „Apfel” (vgl. unser obiges Beispiel) eine Reihe von Empfindungsmomenten: Härte, Farbe, Gestalt, Duft aufweisen konnte, wurde für identisch damit gehalten, dass die Wahrnehmung „Apfel" a u s jenen Empfindungen $\mathrm{b}$ e s $\mathrm{t}$ e h e, nur eine Summierung, ein Gefüge von ihnen sei. Diese Wahrnehmungstheorie musste gegnerische Stimmen herausfordern, welche den einheitlichen Ganzheitscharakter jeder Wahrnehmung betonten.

Einen ersten Schritt in dieser Richtung tat schon Wundt, ob-

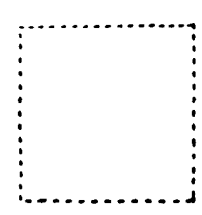

Fig. 1 . wohl er im Wesentlichen elementenpsychologisch dachte. Er nahm noch an, dass die einfachen Elemente die eigentlichen seelichen Grundphänomene seien, stellte aber die These auf, dass das Bewusstsein sie nicht einfach aneinanderfüge, sondern eine „schöpferische Synthese” mit ihnen vornehme: das Erzeugnis der Verbindung sei etwas anderes und Neues gegenüber dem blossen Beisammen der Teile. So bilden bei der nebenstehenden Figur die von den einzelnen schwarzen Punkten erzeugten Empfindungen zwar das seelische Rohmaterial für die Wahrnehmung; aber dass wir nun nicht bloss ein Punktgewim- 
mel, sondern die Gestalt "Viereck" sehen, ist ein Ergebnis schöpferischer Synthese (sowie in der Chemie sich zwei Wasserstoffatome und ein Sauerstoftatom zu einem Molekül "Wasser" mit ganz neuen, in den Elementen nirgends angedeuteten, Eigenschaften verknüpfen).

Immerhin war in der Theorie von der schöpferischen Synthese die Ursprünglichkeit der Empfindungselemente noch nicht in Frage gestellt; das geschah erst in der Gestalt theorie.

\section{GESTALT UND UNGESTALT}

Im Begriff der „Gestalt” treffen wir auf die vielleicht wichtigste Kategorie der Wahrnehmungslehre der letzten Jahrzehnte. Der Begriff ist von der ,gestaltpsychologischen Schule" (Wertheimer, Köhler, Koffka u.a.) nicht erst gefunden worden; denn andere Forscher waren vorangegangen und gehen nebenher, so Ehrenfels (schon sehr früh), Bühler, der Leipziger Kreis um Krueger, der Verfasser dieses Buches. Aber freilich hat jene Berliner Schule durch die unbcirrbare Konsequenz, mit der sie von diesem Begriff her zunächst die Wahrnehmungspsychologie, dann die Psychologie überhaupt (schliesslich sogar Physik, Biologie und andere Wissenschaften) um ein neues theoretisches Zentrum zu gruppieren suchte, einen starken Einfluss auf die wissenschaftliche Bewegung unserer Tage ausgeübt. Dadurch wurde möglich gemacht, dass sich andere Psychologen über die Tragweite und Leistungsfähigkeit, aber auch iber die Einseitigkeit und Begrenztheit des Gestaltsbegriffes Rechenschaft geben konnten ${ }^{1}$ ).

Uns geht hier lediglich seine Anwendung auf die W a h $\mathrm{r} n$ e h$\mathrm{m}$ u $\mathrm{n} \mathrm{g} \mathrm{s} \mathrm{le} \mathrm{h} \mathrm{re} \mathrm{an;} \mathrm{wir} \mathrm{bringen} \mathrm{das,} \mathrm{was} \mathrm{in} \mathrm{diesem} \mathrm{Gebiet} \mathrm{heut}$ als Allgemeingut unserer Erkenntnis gelten kann, auf kurze Sätze.

Wahrnehmungsgebilde treten als "Gestalten" auf, d.h. als Ganzheiten, die nach innen strukturiert, nach aussen gegen ihre Umgebung abgegrenzt sind.

Diese Ganzheiten sind u $\mathrm{r}$ p r ï $\mathrm{ng}$ li ch, also nicht erst durch Summierung oder Synthese von Elementen erzeugt.

1) Eine systematische Gesamtdarstellung der Gestaltpsyhologie ist von ihren Vertretern bisher leider nicht g(-gelen worden. Dagegen stanmen von anderen Seiten Veroffentichungen, die zugleich zusammentassende Orientiernng und hritik bieten. In erster Reihe ist hier das buch ron Martin schecrer zu nennen, ferner die Arbeiten von letermann und Brunswick. 
Es gibt Wahrnehmungsgestalten, in denen psychisch überhaupt keine Teilstücke vorhanden sind: ein weisses Viereck auf schwarzem Feld; der Klang eines Geigentones. Mag auch eine Analyse $\mathrm{n}$ a ch t räglich in solchen Wahrnehmungsgestalten Elemente ausfindig machen (eine Reihe von Weiss- und Schwarz-Empfindungen beim Viereck, einen Grundton und mehrere einfache Obertöne beim Violinklang) - so ist deren Aufzählung doch keine angemessene Beschreibung der Gestalterlebnisse „Viereck”, ,Geigenklang”, sondern im Gegenteil deren Ersetzung durch eine Serie andersartiger psychischer Tatbestände.

Es gibt ferner Wahrnehmungsgestalten, in denen schon mit und in der Ganzwahrnehmung auch Bestandteile gegeben sind, so dass hier der Versuch einer Auflösung in Elemente noch näher liegt: etwa ein aus Punkten bestehendes Viereck (s.S.148), oder eine als Tonfolge erlebte Melodie, oder der Tasteindruck eines aus Punkten bestehenden Buchstabens der Blindenschrift. Aber gerade hier bewährt sich die Ursprünglichkeit des Gestalterlebnisses. Denn jene Bestandstücke sind eben nicht da als „Elemente" (d.h. selbständige, isolierte Bewusstseinsgebilde), sondern nur als Glieder innerhalb der Gestalt. Ihre psychische Bedeutung erhalten sie erst von der Gestaltganzheit her, die dem einzelnen Gliede eine bestimmte Stellung, Funktion, Akzentuierung erteilt. So wird „Ein und derselbe” objektive Ton (der einer bestimmten physikalischen Schwingungszahl entspricht) seelisch jedesmal ganz anders erlebt, wenn er als Tonika in der einen Melodie, als Leitton in einer zweiten, als blosser Vorhalt in einer dritten auftritt. So stark kann sich dies Bestimmtsein von der melodischen Gesamtgestalt her geltend machen, dass selbst bei schärfster Aufmerksamkeit ein Gleichklingen der drei physikalisch gleichen Töne nicht erlebbar ist. Ebenso ist in dem Punktviereck S. 148 der eine schwarze Punkt für die Wahrnehmung nur da ,als" Eckpunkt, ein anderer ,als" Seitenmitte u.s.w. Kurz: selbst die in einer Gestalt abhebbaren Einzelmomente sind dies nur in ihrem ,Als"-Charakter, der sich aus ihrer Rolle innerhalb der Titalstruktur ergibt.

Diese Hegemonie der Wahrnehmungsgestalt gegenüber den Gliedern tritt noch deutlicher hervor in der völligen $\mathrm{U} n \mathrm{n}$ bhängigkeit von dem spezifischen Empfindungsmaterial. In der Musik ist dies Phänomen be- 
kannt als „Transponierbarkeit”: eine Melodie bleibt „dieselbe”, wenn sie aus C-Dur nach Cis-Dur transponiert wird. Im zweiten Fall sind also lauter andere Einzeltöne da; keine elementare „Empfindung” ist den vorher vorhandenen gleich -- und doch bleibt die melodische Gestalt hiervon unberührt.

Die Erscheinung hat aber einen viel weiteren Bereich. Die Wahrnehmungsgestalt eines gleichseitigen Ireiecks mit allen ihren Eigenschaften bleibt dieselbe: ob der Lehrer las Dreieck mit weisser Kreide auf die schwarze Tafel, der Schüler es mit schwarzer Tinte auf weisses Papier zeichnet oder aus brauner Pappe ausschneidet; die spezifischen Helligkeits-, Farb- und Grösseneindrücke sind also für den Gestaltcharakter irrelevant. Ja, die Transponierbarkeit überschreitet sogar die Grenze des einzelnen Sinnesgebiets: ich kann die Gestalt „Kugel” optisch und taktil, die rhythmische Bewegungsgestalt eines fahrenden Eisenbahnzuges mit meinen Körperempfindungen und mit meinem Ohr aufnehmen ${ }^{1}$ ).

Selbst f ehlende Empfindungsmaterie braucht die Gestaltwahrnehmung nicht zu hindern; von der Gesamtgestalt her werden Lücken ohne weiteres ausgefüllt. Wir ahnen meist garnicht, wie unvollständig unserer Perzeptionen sind, wieviel von der Aufforderung der sinnvollen Wahrnehmungsgestalt her hinzugefügt wird. Eine künstlerische Skizze von wenigen Strichen gibt uns mit zwingender Notwendigkeit die Gestalt eines Pferdes; und in der Silhouette Fig. 2 wird der $\mathrm{K}$ r a g e $\mathrm{n}$ mit voller sinnlicher Deutlichkeit gesehen, obgleich keine Spur von seitlicher Abgrenzung gegen den weissen Grund vorhanden ist. - Die Geräusche, die das Telephon uns vermittelt, formen sich sofort zu Worten und Satzgestalten; erst wenn unvermutet ein nicht bekannter Eigenname oder eine fremdländische Ortsbezeichnung dazwischen kommt, geht uns die I ürftigkeit des rein akustische Empfindungsitoffes anf, weil jetzt die Gestaltbildung nicht gelingt.

Verwandt mit diesem Prinzip der ,Vollstän-

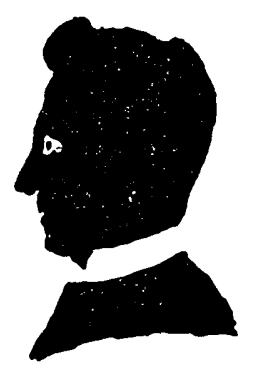

I.1. 2 . digkeit der Gestalt” ist dann das der "Präsnanz der ('estalt”: in der Art, wie eine Wahrnehmungsogestalt die ihr charakteristichen

a) Vgl. hierzu kap. VIII. 
Strukturmerkmale scharf ausprägt, geht sie recht souverän mit der Empfindungsmaterie um. Eine mit freier Hand gezogene Linie kann ich ,als” gerade Linie sehen, unbeschadet der Hockrigkeit. - Wenn ich eine tickende Taschenuhr ans Ohr halte, und ihr Ticken ,als” Dreitakt oder ,als" Viertakt höre, dann gewinnt der jeweilig erste von drei, bezw. vier Takten eine verstärkte Intensität als hauptbetonter Taktteil.

Bietet man die Figur 3 a einem Prüfling dar mit dem Auftrag: „Betrachte di e s e n B o ge $n$ und zeichne ihn dann aus der Erinnerung

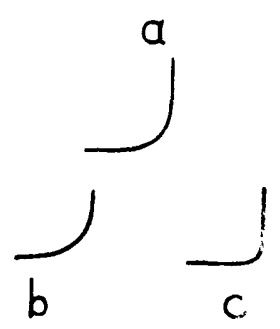
nach", so entsteht eine viel mehr abgerundete Gestalt (b) ; lautet die Weisung: ,zeichne di e s e n W i n k e l nach", so wird die Gestalt mehr zugespitzt (c). Jedesmal hat der aufgezwungene Gestaltgesichtspunkt die Sehweise und damit auch die Nachgestaltung beeinflusst. (Versuch von Nartha Nuchow).

Fig. 3.

Die umfassende Bedeutung des Gestaltbegriffs für die Wahrnehmungspsychologie steht nach dem Gesagten fest. Aber ist dieser Begriff erschöpfend? Kann man ihn - wozu manche Vertreter der „Gestaltpsychologie” neigen — zum Grundprinzip für die Erklärung aller Wahrnehmungsphänomene erheben? Wenn im Folgenden ein solcher Anspruch bestritten wird, so soll dies nicht vorwiegend in Form einer Kritik geschehen, sondern dadurch, dass diejenigen Wahrnehmungstatsachen aufgezeigt werden, die sich einer Unterordnung unter die Gestaltkategorie entziehen, und dass andere Kategorieen eingeführt werden, die ergänzend $\mathrm{Z}$. der der Gestalt hinzutreten müssen.

Werden die „Gestalten” zu den eigentlichen Grunderscheinungen der Wahrnehmung gemacht, die ihre Selbstgesetzlichkeit in sich tragen, so entsteht die Gefahr, dass wir - nur auf einer andern Ebene - wieder in den Elementenstandpunkt verfallen, der gerade durch den Gestaltbegriff überwunden werden sollte. Es werden dann eben die "Gestalten” als solche El e m e n t e angesehen, aus denen sich alles seelische Leben zusammensetze, so wie man es früher von den Empfindungen angenommen hatte. Deshalb ist hier gleich die erste Ergänzung erforderlich. Die Wahrnehmungsgestalten sind wohl autonom nach unten hin: sie g eb e $\mathrm{n}$ der in ihnen gestalteten Empfindungsmaterie ihre Gesetze 
der Prägnanz, der Vollständigkeit, der Transponierbarkeit. Aber sie sind nicht autonom nach oben hin; vielmehr e $\mathrm{m} p \mathrm{f}$ a $\mathrm{n} g$ e $\mathrm{n}$ sie ihre Gesetze, ja ihre Existenz von einem übergeordneten Prinzip: der Person. „Ke in e Gestalt ohne Gestalt er". Die Wahrnehmungen treten in Gestalten auf, weil die Person als ganze die Welt auch nur in Ganzheiten kleinerer Ordnung gesondert zu erfassen vermag. Dabei kann im Einzelfalle die Wahrnehmungsgestalt eine solche Eindringlichkeit besitzen, dass der wahrnehmende Mensch sie einfach akzeptieren muss. Iie Lrsache hierfür liegt vornehmlich in der objektiven Reizsituation, in welcher bestimmte Abgrenzungen - der Einzeldinge, der Einzelvorgänge - vorgegeben sind; die Gestaltwahrnehmung bedeutet dann die lebensnotwendige An passung der Person an die Gegliedertheit ihrer Welt.

Wertheimer bringt einmal das drastische Beispiel, das für sich selber spricht: sehe ich zum Fenster hinaus, dann ,, sehe" ich nicht Tausende von Farbflecken und Liniengrewirren, sondern ich sehe: Häuser, Bäume, Menschen, Tiere u.s.w., also lauter Gestalten.

In anderen Fällen - schon einige unserer Beispiele zeigten dies - ist die mitwirkende Spontaneität der Person sowohl beim Zustandekommen der einzelnen Wahrnehmungsgestalt wie beim Wechsel der Gestalten trotz identisch bleibenden Reizes deutlich erkennbar. Es hängt von mi $\mathrm{r}$ b, ob ich das Ticken meiner Taschenuhr als Dreivierteltakt oder als Viervierteltakt strukturiere. Oder: der Detektiv sieht auf Grund seiner b e r u f l i c h en Einstellung etwas als „Fingerspur”, also als abgehobene Gestalt, was sich für andere Menschen überhaupt nicht irgend merklich von der Fleckigkeit der Umgebung absondert.

Ist nun aber das Zustandekommen der Gestaltwahrnehmung nicht nur durch den Reiz, sondern auch durch die Person bedingt, so entsteht die weitere Frage: wie sie sich der Totalität der Person einfüge. Und da stellt es sich heraus, dass innerhalb der Sphäre des Wahrnehmens die "Gestalt" nur den einen äussersten P o l einer Reihe von Zuständen darstellt, an deren andern Pol die ungeteilte Einheit der Person steht. Es ist di e Reihe, die von maximaler Abgehobenheit $z u$ ma$\mathrm{ximaler}$ Einbettung führt. "Gestalten" sind lediglich die am meisten abgehobenen Phacnomene der Wahrnehmung. 
Dass es beim Wahrnehmen noch etwas anderes als „Gestalten” gibt, hat die Gestaltpsychologie selbst natürlich erkannt, aber doch meist so zu formulieren gesucht, dass die Vorherrschaft der „Gestalt" möglichst unberührt blieb. Sie nennt solche Wahrnehmungsgebilde, die nur schwer und widerstrebend gestaltmälsig erlebbar sind, „schlechte Gestalten”; sie nennt ferner dasjenige Wahrnehmungsgebiet, das die Gestalten von aussen umschliesst, das „Umfeld" und betont immer wieder die korrelative Verknüpfung von Figur und Feld ${ }^{1}$ ). Wir müssen nun die hiermit angedeuteten Tatbestände von den - verschwiegenen oder ausgesprochenen - Wertungsmalsstäben frei zu machen suchen. Ein unbestimmter rötlicher Schein am Himmel; das Geräusch der Stadt, wie es aus einer gewissen Ferne in mein Zimmer dringt; ein mich leise umfliessender Wind; der Blumenduft in dem Raum, den ich betrete - alles dies sind ebenso zweifellos Gegenstände der Sinneswahrnehmung, wie sie zweifellos nicht „Gestalten" sind; denn es fehlt ihnen Abgrenzung nach aussen wie Gliederung nach innen. Solche „Ungestalt”-Wahrnehmungensind - wie unsere Beispiele zeigen - durchaus nicht nur als „Lmfelder”, als blosse Hintergründe für Gestalten vorhanden, sondern auch als eigent 1 ich e Erlebnisgehalt e. Sie können freilich zum Umfeld w e r d e $\mathrm{n}$ : wenn sich etwa von dem rötlichen Schein am Himmel nun schwarzer Qualm abhebt, oder wenn aus dem diffusen Strassengeräusch die Schallgestalt eines näherkommenden Wagens heraustritt.

Dass es hier alle möglichen $Z$ wischenstufen gibt, sei noch durch B e is p i e l e erläutert.

1) Eine Reihe von Akkorden trägt - wenn sie sich abhebt gegen die Stille vorher und nachher und wenn sich die einzelnen Akkorde abheben gegen einander - deutlich den Charakter der Gestaltetheit. Werden die Akkorde aber zur Begleitung einer Melodie, so verlieren sie an Gestaltetheit und gewinnen an Untergründigkeit. Die Linie der Nelodie erscheint klar, eindeutig, ja scharf gegenüber den rauschenderl, sie tragenden Harmonieen, die den Raum diffus zu füllen scheinen.

2) Sehe ich vom Berge aus eine Landschaft, so ist der Teil, der auf meine Stelle des deutlichsten Sehens fällt, weitgehend strukturiert und nüanziert. Seitlich davon wird das Wahrgenommene immer undeutlicher, umfeldmäfsiger - um schliesslich ganz zu verfliessen ins Nicht-Begrenzte; denn ich kann zwar durch nachträgliche Kontrolle (z.B. durch Kopfbewegung) feststellen, dass dies und das vorher nicht

1) Vyl. insbes. Rubin. 
im Sehfeld gewesen sei, habe aber während einer bestimmten Kopfstellung keine Grenzen oder Ränder des Sehfeldes als Wahrnehmungstatsachen.

Nun darf aber die Skala, die von der gestalteten zur ungestalteten Wahrnehmung führt, nicht lediglich als eine solche abnehmender Deutlichkeit und damit abnehmender Wertigkeit angesehen werden. Die positive Bedeutung des „Ungestalteten” geht daraus hervor, dass es am Pole der $\mathrm{max}$ i male $\mathrm{n}$ Ei n geb e $t$ t e t h e it steht. Gerade weil hier die Wahrnehmung nicht abgehoben ist, strömt sie ein in die Totalität der Persönlichkeit, durchdringt sie, wird ein Stück ihrer selbst. Die schroffe Scheidung zwischen äusserer und innerer Wahrnehmung wird mit steigender Auflösung der Gestaltetheit mehr und mehr verwischt. Wenden wir das auf unsere Beispiele an: der Wind, der mich umweht, das Wasser, in dem ich schwimme, der Blumenduft in meinem Aufenthaltsraum, - - all dies ist nicht nur das fremde Etwas, das abgehoben mir gegenübersteht, sondern ist mein Lebensbereich, gehört zu meiner „Biosphäre”, setzt sich um in seelische Gesamtstimmung und körperliche Gesamthaltung. Die rauschenden Akkorde umspielen nicht nur die Melodie, sondern auch mich; der von ihnen diffus erfüllte Raum ist zugleich mein personaler Raum, dessen Rhythmus mich mit ergreift. Das unklare Sehfeld, in dem die Landschaft verläuft, ist nur deshalb nicht umgrenzt, weil es ein unablösbarer Bestandteil meines augenblicklichen Existenzfeldes ist.

Hier stossen wir nun auf jenen $z$ we it e n ..Empfindungs"-Begriff, der schon früh - bei Herder und den deutschen Romantikern geprägt und neuerdings von Heinz Werner und anderen wieder aufgegriffen worden ist. „Empfindung" ist hiernach die personal eingebettete Wahrnehmung, die subjektive Gesamtresonanz der Verson auf einen Sinneseindruck. Wenn man etwa den romantischen Terminus "Empfindsamkeit" neben die "Lnterschiedsempfindlichkeit" der Psychophysik stellt, wird der Interschied der beiden Empfindungshegriffe klar.

$O b$ es freilich möglich ist, sich durch Wiedereinfuhrung des äteren Begriffs der Empfindung über den, in cincm haben Jahrhmulert inblich gewordenen und durch vicle noue Erkenntnisse gesicherten. Sprachgebrauch der wissenschaftlichen Psychologie und Jhysologie hinwegzusetzen, erscheint sehr fraglich; ja, es ist sogar zu bezweifeln, ob a wänschenswert wäre. I)enn da der klassische sprachgebrameh des Wortes „Empfindung" sicherlich nicht mehr auszuncrzan soin wird. 
würde das Neben- und Durch-Einander zweier so verschiedener Bedeutungen bedenkliche Verwirrung stiften. Wir werden deshalb in diesem Buch den Ausdruck „Empfindung” nur zur Bezeichnung der atomisiert gedachten Wahrnehmungsmaterie verwenden.

Wovon hängt es ab, ob eine Wahrnehmung mehr dem Gestaltpol oder dem U n ge st a $1 \mathrm{t}$-Pol nahe steht? Es begegnen uns hier dieselben beiden Gruppen von Bedingungen, die wir oben für das Zustandekommen von Gestalten heranziehen mussten.

Die objektive Beschaffenheit des Reizes kann selber mehr oder weniger strukturiert und damit mehr gestalt- oder ungestalt-wirksam sein. Die gasförmigen Geruchsreize sind unbegrenzt und ungeformt, optische Reize deutlich konturiert; infolgedessen ist die Geruchswahrnehmung ihrem Wesen nach viel mehr subjektivierend und eingebettet als die Gesichtswahrnehmung. Auch innerhalb ein es Sinnesgebiets sind entsprechende Unterschiede der Reizbedingungen möglich, wie unsere obigen Beispiele von der Melodie und der untergründigen Harmonik, von der Rauchsäule und dem hintergründigen roten Schein zeigten.

Bei identischem Aussenreiz aber können nun pers o n a le Bedingungen bald diese, bald jene Wahrnehmungsweise erzeugen. Das Farbenspiel eines Sonnenuntergangs, von dem sich der eine Betrachter ganz diffus erfüllen lässt, wird von einem anderen - z.B. dem Landwirt - - als ein abgehobenes und durchgegliedertes Zeichen für das morgen zu erwartende Wetter angesehen. - Wechselnde Dispositionen spielen mit: im Zustande der Abspannung können Geräusche im Hause lediglich als eine Beeinträchtigung des persönlichen Befindens erlebt werden, die man bei anderer Verfassung in ihrem objektiven Bedeutungsgehalt abgehoben erfasst. - Auch konstitutionell und $\mathrm{ch}$ a$\mathrm{rakte}$ r ologisch kann die Bevorzugung der einen oder anderen Wahrnehmungsweise verankert sein; es entstehen dann T y p e n, deren nähere Erörterung einem späteren Kapitel vorbehalten bleiben muss.

Experimentell lässt sich der Einstellungswechsel auf folgende Weise prüfen: Man bietet der Versuchsperson das gleiche Reizobjekt mit wechselnden Instruktionen, die bald eine kühl-sachliche, distanzierte Auffassung des Gegenstandes, bald ein Mitschwingen-lassen des ganzen körperlich-seelischen Ichs nahelegen (Wohlwill). 


\section{VERSCHIEDENHEIT UND GEMEINSCHAFT DER SINNE}

\section{Sinnesmodalitäten}

a) Die Vie i heit. - Uralt ist die Meinung, dass der Mensch „fünf Sinne” habe. Darin liegt ausgesprochen, 1) dass sich die Sinneswahrnehmungen a u t e il e n auf Bereiche, die von einander gänzlich verschieden seien; 2) dass es $\mathrm{f} \ddot{u} \mathrm{n} f$ solcher Bereiche gebe.

Die heutige Wissenschaft kann keinen dieser zwei Sätze einfach übernehmen. Den ersten muss sie wesentlich ergänzen, den zweiten korrigieren.

Der populäre Ausdruck „Sinne” legt die Deutung nahe, dass es sich um lauter selbständige und getrennte Vermögen handle. Der wissenschaftliche Terminus „S i n n e s m o d a li t ä t e n” will dagegen besagen, dass sich die einheitliche personale Funktion des Wahrnehmens auf verschiedene $W$ e i s e $n$ betätige, und dass diese Modi sich zwar stark von einander abheben, dennoch aber mannigfache Zusammenhänge und Verwandtschaften unter einander zeigen. Man hat sogar gradezu von der „Einheit der Sinne" gesprochen (H. Plessner) ${ }^{1}$ ).

Wir behandeln zunächst die $V$ i e lhe it der Sinnesmodalitäten. Diese Vielheit ist unter verschiedenen Gesichtspunkten aufzuweisen: physikalis ch wirken verschiedene Arten von Reizen; physiologisch gibt es verschiedene Eingangspforten (die Sinnesorgane); ps y chologisch handelt es sich um verschiedene (,,sinnesspezifische") Erlebensweisen.

b) D i e R e i z e. - Derjenige physikalische Gegenstand, von dem Energieen ausgehen, welche im Menschen Sinneseindrücke hervorrufen, heisst „Reizquelle”. Die Reizquelle tritt entweder in direkte Berührung mit der Körperoberfläche des Wahrnehmenden oder entsendet aus einer gewissen Ent fernung Energieströme bis zu den Sinnesorganen. Zu der ersten Crruppe der "K o nt a $k$ t-R e i $z$ e" gehören die einen I)ruck ausübenden Gegenstände, die den Tastsinn erregen, ferner die Flüssigkeiten, die auf Zungenschleimhaut Geschmacksempfindungen hervorrufen. Ausgesprochene „F er n-R e i ze” gehen von den optischen und

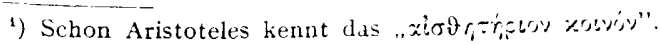


akustischen Reizquellen aus; denn die leuchtenden, bezw. tönenden Körper befinden sich in weiter Entfernung vom wahrnehmenden Menschen; nicht sie selbst, sondern nur die, von ihnen erzeugten, periodischen Schwingungsvorgänge, die sich durch eine vermittelnde Schicht (ein „Medium”) fortpflanzen, sind die Erreger des Auges und Ohres. Eine Mittelstellung nimmt der Geruchssinn ein. Der riechende Gegenstand kann zwar einen gewissen Abstand vom Wahrnehmenden haben; aber er muss stoffliche Partikel (in gasförmigem Aggregatzustande) aussenden, die erst bei unmittelbarem Kontakt mit der Nasenschleimhaut Geruchsempfindungen erwecken.

In doppelter Form können wirken: 1) Temperaturreize; denn Wärmeempfindungen können ebenso herrühren von Gegenständen, die unsere Haut berühren, wie von solchen, die aus der Ferne Wärme ausstrahlen (Ofen, Sonne). 2) Vibrationsreize; wir vermögen ebenso das Vibrieren des Autos, in dem wir sitzen, wie das eines fernen Eisenbahnzuges (durch Vermittlung von Luftoder Erdbodenschwingungen) wahrzunehmen.

c) Di e Sin n e s org a n e. - Physiologisch-anatomisch betrachtet ist die Trennung der Sinne besonders deutlich, mindestens für die vier Modalitäten des Sehens, Hörens, Riechens und Schmeckens; denn für jede gibt es bestimmte, eng umgrenzte Stellen des Körpers, welche die entsprechenden Reize entgegennehmen und verarbeiten. Physikalische Lichtschwingungen treffen den Körper zwar an den verschiedensten Stellen; aber nur diejenigen, die zum Auge gelangen, führen Gesichtsempfindungen herbei; entsprechendes gilt für das Ohr, die Nase, die innere Mundpartie. Diese Sinnesorgane sind jeweilig mit spezifis c h e n Aufnahmegebilden (sog. „Rezeptoren”) ausgerüstet, die bestimmten Reizarten in besonderer Weise angepasst sind. So enthält die Netzhaut chemische Stoffe, die äusserst empfindlich gegen Belichtung sind; im inneren Ohr gibt es mikroskopische Gebilde, die wie Resonatoren die Schallschwingungen der Luft aufnehmen und weitergeben, u.s.w..

I $m$ besonderen gliedern sich die Sinnesorgane in solche Bestandteile, welche die $Z$ u le it u $\mathrm{n} g$ des Reizes zum Sinnesnerven besorgen und fremde Reize fermhalten, und in die eigentlichen Per ze pt i o $n$ s-Gebilde nervöser Natur, welche zugleich die äusseren Pole der 
S i n n e s n e r ve n darstellen. Diese leiten den physiologischen Erregungsprozess (über gewisse $Z$ wischenstationen) den verschiedenen Gebieten des Zentralnervensystems (Zentralstrang, Gehirn) zu. - So haben beim Auge als Zuleitungsgebilde zu gelten: das Pupillenloch, welches die Menge der einzulassenden Strahlen dosiert, die Linse, welche die Bilder auf die Hinterwand des Auges entwirft, der Glaskörper, die chemischen Substanzen der Netzhaut, die mit äusserster Feinheit auf jede Änderung der Belichtung reagieren. Die so ausgelesenen und vorbereiteten physiologischen Vorgänge teilen sich nun dem eigentlichen Perzeptionsorgan, d.h. den feinsten in der Netzhaut ausgebreiteten Verästelungen des nervus opticus mit und werden von diesem als Nervenerregungen weiter geleitet. - Fbenso sind im Ohr Trommelfell und Gehörknöchelchen Zuführungsorgane, welche die Luftschwingungen zum inneren Ohr weiter leiten, wo eine elastische Membran (die quer gefaserte „membrana basilaris" der Schnecke) als sehr fein organisierter Resonator die Schwingungsvorgänge in Erregungen des nervus acusticus umwandelt). - Die Rezeptoren für Geschmacksreize werden von den sogenannten ,Geschmacksknospen” gebildet, die sich an den Wärzchen der Zunge befinden. - Das eigentliche Geruchsorgan besteht in kleinen Bezirken der inneren Nasenschleimhaut.

Nicht so eindeutig sind die körperlichen Grundlagen für jene Wahrnehmungen, die der populäre Sprachgebrauch dem „,fünften” Sinn, dem sogen. „Gefühlssinn” zuschreibt. Denn hier gibt es nicht mehr einen Körper-T e i l, der wie in einem Brennpunkt die Eindrücke sammelt; vielmehr ist der Gesamtkörper an ihrer Aufnahme beteiligt, in erster Linie die Körperoberfläche, sodann aber auch innere Organe. Und nicht nur, dass wir llärme, Druck, Berührung, Vibration, Bewegung an den verschied ens t e n Stellen des Körpers spüren können, - es gibt hier Sinneswahrnehmungen, bei denen wir überhaupt nicht mehr genau lokalisieren können, sondern den Körper in seiner diffusen Totalität als Sinnesorgan ansehen müssen. Die Frage z.B.: mit welcher Körperstelle wir die Verminderung des Luftdrucks im Hochgebirge, die strahlende Wärme der Sonne, das Lmspültwerden rom Wasser beim Bade, die Vibration beim Fahren im Auto spouren, ist sinnlos.

Nur scheinbar steht es hierzu im Widerspruch, wenn die Physiologie dennoch spezifische "()rgane” für Berührung, Wärme, Kälte, u.s.w. gefunden hat. Man hat nämlich festgestellt, dass bei langsamer Abtastung der Haut mit einem punktförmigen leichten Gegenstand (z.B. der Spitze eines Pferdehaares) nur an bestimmten Hautstellen eine Berührungswahrmehmung aufblitzte, 
während man an den dazwischen liegenden Stellen nichts merkte. Jene bevorzugten Hautstellen heissen „Druckpunkte”. Der gleiche Versuch, ausgeführt mit einer kalten Metallspitze, ergab „,Kältepunkte”, mit einer erwärmten Spitze „Wärmepunkte”, so dass die gesamte Hautoberfläche des Menschen eine Art Punktm o s a i k von drei Gruppen solcher elementaren Sinnesorgane darstellen würde. Hier braucht nun aber nur an die früher erwähnte Tatsache erinnert zu werden, dass Berührung, Kälte, Wärme sowohl als Gestaltwahrnehmung, wie als Ungestaltwahrnehmung auftreten kann. Wenn ich also die Angabe mache: ich taste einen harten, kalten Gegenstand, dann ist diese a bgehobene Berührungs- bezw. Temperaturwahrnehmung nur möglich vermittels jener Stellen mit ausgezeichneter Empfindlichkeit für Berührung oder Kälte. Aber es sind eben nur die Stellen mit ausgezeichneter, nicht mit alleiniger Empfindlichkeit. Die Kälte einer Metallspitze bemerke ich - nicht deshalb, weil nur der Kontaktpunkt im Gegensatz zu seiner Umgebung temperaturempfindlich ist, sondern weil sich diese spezifische und lokale Temperaturwahrnehmung hera ushebt aus dem vagen Total meines Temperaturerlebens. Und ebenso bei Berührung und Wärme ${ }^{1}$ ).

Aber der „fünfte Sinn” alten Styls enthält noch weitere Wahrnehmungsweisen, die uns hier zunächst nur bezüglich ihrer physiologischen Grundlage interessieren. Jetzt handelt es sich nicht mehr darum, dass von aussen her Reize an den - passiv gedachten - Körper des Wahrnehmenden herankommen und von dessen Oberfläche akzeptiert werden, sondern dass der Mensch sich selbst aktiv zu seiner Umgebung verhält, durch Veränderung oderBehauptung seines körperlichensVerhaltens. Hier besteht also eine ganz enge Verbindung von Sensorium und M o t o ri u m. Denn die Eigenbewegungen der Glieder oder des Gesamtkörpers werden nicht nur v o $1 \mathrm{l} z$ og e n, sondern auch e m p f u n d e n. Es entstehen: „Bewegungsempfindungen”, wenn eine tatsäch-

1) Dicse Auffassung wird vermutlich von physiologischer Seite Widerspruch erfahren. Aber wir stehen hicr an einer Stelie, an der die Psychologie nicht zu Gunsten einer physiologischen Hypothese, die ganz auf dem „elemententheoretischen" Mosaikprinzip aufgebaut ist, grundlegende Tatsachen personaler Ganzheitsbildung unter den Tisch fallen lassen darf. Das Temperat ure r leben is t ke in Mosaikerleben: diesem psychologischen Faktum muss auch die physiologische Sensibilitätstheorie gerecht werden, eventuell unter Änderung ihrer Hypothesen. 
liche Bewegung erfolgt; „Lageempfindungen” oder „Spannungsempfindungen", wenn eine bestimmte Lage des Körpers oder einzelner Glieder aktiv aufrechterhalten wird. Beide Gruppen sind nicht eindeutig von einander $z u$ scheiden; der vielbenutzte Ausdruck, "ki na est he tische Empfindungen" gilt für den ganzen Bereich. Die Organe dieser Empfindungen sind vermutlich sensible Nervenendigungen in den Muskeln und Gelenken ${ }^{1}$ ).

Hierzu kommt aber für die Wahrnehmung der Lage und Bewegung des eigenen Körpers im Raum noch eine spezifische Organfunktion, von der wir erst seit wenigen Jahrzehnten Näheres wissen. Das innere Ohr des Menschen ist nämlich nicht nur Gehörsorgan; es besteht aus zwei deutlich getrennten Gebilden, deren eines, die sogenannte Schnecke, dem Hören dient, während das andere eine Art Gleich gewich tsapparat darstellt. Dieser wird gebildet aus drei auf einander senkrecht stehenden halbkreisförmigen Kanälen, den „Bogengängen”; die in diesen enthaltene Flüssigkeit spielt um Nervenendigungen, deren Reizung von der Kopflage abhängt. Da nun die Kopflage weitgehend mit der Lage, bezw. der Bewegung des Gesamtkörpers konform geht, können die Reizungen der Bogengänge als Signale für Änderungen der körperlichen Gleichgewichtslage dienen. Physiologisch wichtig ist, dass hier ein elementarer Reflexmechanismus vorliegt: die Reizung des in einer bestimmten Ebene liegenden Bogenganges ruft diejenigen Gliedbewegungen oder Rumpfverlagerungen hervor, die zur Wiederherstellung des bedrohten Gleichgewichts nötig sind. Solche Regulierbewegungen sind ohne Weiteres erkennbar beim Gehen auf stark schwankendem Schiff, oder bei Irehschwindel. Werden bei Erkrankungen des inneren Ohres die Bogengänge in Mitleidenschaft gezogen, so treten Defekte dieser Regulierfähigkeit auf. Tierversuche haben entsprechendes festgestellt: wurde z.B. bei Tauben ein Bogengang durchschnitten, dann erfolgten schwerste Gleichgewichtsitörungen.

\footnotetext{
1) Erwähnt sei die physiolugische. Theorie, dass dit: Kind--hetiwhen Empfindun-

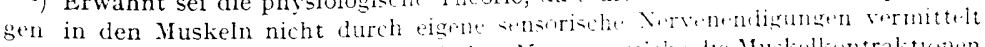
werden, sondern dass dieselhen motorischen Nerven, wo he do Muskelkutraktwhen

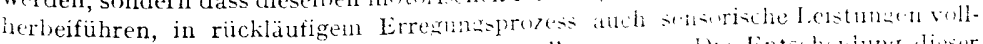

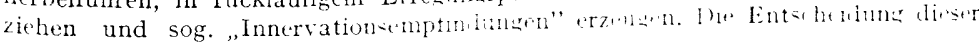
lirage geht allein den Physiologen an.
} 
d) Die spezifischen Erlebnisbereiche.-Wir kommen nun erst zu der eigentlich psychologischen Frage: ob auch die Art, wie wir die verschiedenen Reize mittels der verschiedenen Organe e r l e b e n, das Recht gibt, von einer Vielzahl von Sinnen zu sprechen.

Diese Frage ist zweifellos zu bejahen. Es gehört mit zu den eindruckvollsten Tatbeständen unseres Seelenlebens, dass wir die Welt auf ganz verschiedene sinnliche Weisen „haben”, dass es Bereiche der Wahrnehmung gibt, die sich gegeneinander scharf abheben, während die zu e i n e m Bereich gehörenden Eindrücke eine unmittelbare innere Zusammengehörigkeit besitzen.

Ein Ton hat erlebnismässig eine ganz andere Beschaffenheit, als eine Farbe oder ein Geruch; die Disparatheit der drei Wahrnehmungen würde unserem Bewusstsein auch dann nicht geringer erscheinen, wenn wir nicht wüssten, dass sie durch drei verschiedene Sinnesorgane vermittelt werden. Auch "hart" und „warm” sind als Bewusstseinsphänomene qualitativ verschieden, obwohl sie mit dem gleichen Körperteil - etwa der Hand wahrgenommen werden und der naive Mensch nichts davon weiss, dass hierbei das eine Mal die Druckpunkte, das andre Mal die Wärmepunkte der Haut als spezifische Organe wirksam sind.

Betrachten wir nun aber jede einzelne Wahrnehmungsmodalität in s i ch, dann zeigt sich ein anderes Bild. Zwei Farbeneindrücke können zwar psychisch stark von einander abweichen - aber diese Verschiedenheit hat einen anderen Charakter als der Unterschied zwischen Farbe und Ton. Ein leuchtendes sattes Rot und ein schmutzig-blasses Graugrün mögen sogar gegensätzlich wirken; dennoch haben sie eine nahe seelische Gemeinschaft eben durch ihr „Farbesein”, d.h. durch ihre gemeinsame Zugehörigkeit zu einem in sich stetigen Erlebnisbereich. Denn ich kann den einen Farb-Eindruck durch allmähliche Veränderung in den anderen überführen; nirgends gibt es hierbei den Sprung in eine andere Wahrnehmungswelt.

Diese psychische Einheitlichkeit jeder Sinnesmodalität gab der Wahrnehmungspsychologie Anlass, sich lange Zeit fast ausschliesslich mit den „s in nesspezifischen Erschein u n g e n" zu beschäftigen, d.h. mit denjenigen Erlebnisinhalten, die $n$ u $r$ innerhalb einer einzigen Modalität vorkommen 
und diese entscheidend charakterisieren (Über die, zum Teil sehr wichtigen Ergebnisse solcher Untersuchungen berichtet das sechste Kapitel).

\section{Der spezifische Objektbezug und die "spezifische Sinnesenergie"}

Jede Sinneswahrnehmung steht in wesentlicher Beziehung zu dem Objekt, das in ihr gemeint ist. Diese Beziehung aber unterliegt jenen Prinzipien, die wir früher (S. 105 ff.) für a ll es Erleben feststellten: in der Wahrnehmung erschein t das Objekt, aber es erscheint nicht vollständig und adäquat.

Aus dieser unzulänglichen Entsprechung ergeben sich für die Wahrnehmungspsychologie zwei Problemgebiete. Wo das Objekt der Wahrnehmung anders erscheint als es ist, sprechen wir von S innestäuschungen; wo die Fülle und Verschiedenartigkeit des objektives Seins nur teilweise und vergröbert in die Wahrnehmung eingeht, haben wir es mit den Grenze $n$ und S chwelle n der Wahrnehmung zu tun. Diese beiden Themen werden ausführlich im Kap. IX behandelt.

Dagegen muss hier schon einer allgemeinen Theorie gedacht werden, welche die Spezifizität der einzelnen Sinnesmodalität verabsolutiert und infolgedessen jede Entsprechung zwischen Wahrnehmungsinhalt und wahrgenommener Welt überhaupt leugnet. Es ist die Lehre von der "Spezifischen Sinnesenergie” 1).

Diese, früher sehr einflussreiche und stark diskutierte, Theorie ist von Joh. Müller aufgestellt, von Helmholtz und vielen anderen ausgebaut worden. Sie geht von der Tatsache aus, dass jede Sinnesmodalität einem bestimmten Sinnesorgan, und nur diesem, zugeordnet ist: Farbeneindrücke nur dem Auge, Schalleindrücke nur dem Ohr u.s.w. Diese Zuordnung wird interpretiert als eindeutige $\mathrm{Abhängigkeit} \mathrm{des} \mathrm{psychischen} \mathrm{Erlebnisses}$ vom funktionierenden Organ, und infolgedessen: als Unabhängigkeit des Erlebnisses vom objekt i ve n R e i z I)er Sehnerv hat hiernach die ,spezifische Energie", dem Bewusstsein Licht- und Farbenteindrücke zu vermittehn, gleichgültig, durch welche Art Reiz er in Erregung versetzt wird. Er reagiert mit optischen Erlebnissen nicht nur, wenn objektive

1) Vgl. die Monographieen von Weinmann und Löwy. 
Lichtstrahlen ihn treffen, sondern auch, wenn ein Druck auf ihn ausgeübt wird, ein elektrischer Strom durch ihn geleitet wird u.s.w. - Der gleiche elektrische Strom weckt, durchs Ohr geleitet, Schallerlebnisse, durch die Zunge geleitet, Geschmackseindrücke. Uns ere Sinnese m p find ungen ge be n uns also keine Kunde von der Beschaffen heit der Reize, sondern nur von derspe$z$ ifischen Reaktionsweise des einzelnen $\mathrm{Sin}$ nesorgan s!

Wäre diese Theorie eine richtige und erschöpfende Interpretation der Tatsachen, dann würde sie in der Tat zu unabsehbaren Folgen führen. Die Sinneswahrnehmung verlöre ihren eigentliche Sinn: nämlich uns ein Bild von der o b j ektiven Welt zu geben, und erzeugte statt dessen eine gespenstige Scheinwelt, die lediglich von der Organisation der Sinnesorgane abhinge ja, noch schlimmer: nicht e i n e Scheinwelt, sondern so $\mathrm{v}$ i e l e Scheinwelten, als es Sinnesorgane mit spezifischen Energieen gäbe; denn die farbige Welt des nervus opticus hätte mit der schallenden Welt des nervus acusticus u.s.w. nichts zu tun ${ }^{1}$ ).

An dieser Stelle muss es genügen, in kurzen Thesen anzudeuten, was an der Theorie zutrifft, und in welchen Punkten sie unzulänglich oder geradezu irreführend ist. Wir können hier um so kürzer sein, als alle Betrachtungen der nächsten Kapitel über die Sinneswahrnehmungen die Argumente gegen die Müller'sche Theorie mit enthalten.

Zwei Ausgangstatsachen sind unbestreitbar.

1) Jedes ausgebildete Sinnesorgan eines erwachsenen Menschen hat seine „spezifische" Energie, d.h. es kann Empfindungserlebnisse liefern, die nur ihm zukommen. (Wir können niemals mit dem Ohr sehen, mit dem Auge riechen u.s.w.).

2) Jedes Sinnesorgan reagiert in seiner ,spezifischen” Weise auf Reize verschiedener Art, s o f e r $n$ diese Reize es überhaupt in Erregung versetzen.

\footnotetext{
1) Die rein erkenntnistheoretische Frage: ob und inwiefern die I ehre von der spezifischen Sinnesenergic Zusammenhang mit der Kantischen Lebre von der Apriorität der Anschaumgsformen habe, kann hier nicht näher erörtert werden. J. Miiller hatte seiner Zeit geglaubt, durch sein Gesetz geradezu den physiologischen Beweis für die fantische Theorie erbracht zu haben; andere haben nit kecht diese Folgerungen abgelehnt.
} 
Hier sind aber weitere Betrachtungen anzuknüpfen, die uns von der Müller'schen Hypothese weit abführen.

3) Das "Sofern" in These 2 ist entscheidend. Denn normaler Weise sind die spezifischen Organe nur auf spezifische Reize abgestimmt, das Auge nur auf Lichtschwingungen, das Gehörsorgan nur auf Schallschwingungen u.s.w. Wir müssen also scheiden zwischen "a da equaten" und ,nicht-a d a equaten" Reizen, was in Müllers Theorie versäumt ist. Gewiss: we $n n$ einmal - in einer abnormen Situation oder bei einem sehr künstlichen Laboratoriumsversuch - die Netzhaut nicht durch objektive Lichtschwingungen, sondern durch Schlag oder elektrischen Strom gereizt wird, dann reagiert sie mit dem ihr spezifischen Lichterlebnis. Aber das s sie von einem solchen Reiz getroffen wird, ist - im Vergleich zu den ihr adaequaten Reizen - eine seltene Ausnahme; denn den adaequaten Reizen öfnet sich das Auge, und gegen nicht-adaequate Reize ist es normalerweise durch verschiedene Schutzmassnahmen des Organismus gesperrt. Daher kann das Auge denn auch auf die adaequaten Reize mit einem feinst abgestuften und geordneten System von Eindrücken reagieren, auf den nichtadaequaten Reiz nur mit einem dumpfen chocartigen Lichterlebnis.

4) Es bestehen also normaler Weise Zuordnungen zwischen bestimmten Reizgebieten und bestimmten sinnesorganen - Zusammenhänge, die offenbar nur so verständlich werden, dass jedes Sinnesorgan auf gewisse Torgangsweisen der objektiven Welt e inge ste $11 \mathrm{t}$ ist. Eine Gleichgültigkeit der sinneserlebnisse gegen die objektive Wirklichkeit ist keineswegs vorhanden. Allerdings ist die spezifische Finstellung der Sinnesorgane stark fixiert, sodass sie in gleicher Weise funktioniert, auch wenn sie einmal unspezifisch - durch einen nicht-adaequaten Reiz..ausgelöst wird. Der Umstand also, dass das Auge auch auf einen nicht-optischen Reiz (Druck, elektrischen Strom) mit "Lichterlebnissen" reagiert, ist als eine, durch unzählige (ienerationen herangezüchtete, Funktionsgewöhnung und Funktionsvererbung zu verstehen, deren Festigkeit sich auch nicht durch abnorme Auslösungsweisen beirren lässt, deren eigentlicher Sinn aber in der feinen Angepasstheit an die normalen Reize besteht.

5) Die enge und vielfach differenzierte Bezichung der Simneswahrnehmungen zur Welt der objektiven Reize (die ja von den 
Theoretikern der „spezifischen Sinnesenergie” ganz geleugnet wird) erhält ihre volle Klärung erst durch eine e n t wi c kl ungspsychologische Betrachtung; diese zeigt, wie Sinnesorgane und Sinneserlebnisse in stetigem Kontakt mit den lebensrelevanten Weltsituationen und Reizen ihre'Funktionsweise und Modalität allmählich erworben haben. Es ist wirklich so, dass „sich das Auge dem Licht entgegen-entwickelt" hat u.s.w. (vgl. hierzu das folgende Kapitel).

6) Schliesslich ist die Voraussetzung jener Theorie irrig, als ob die Sinneswahrnehmungen des Menschen endgültig und eindeutig in die verschiedenen Sinnesmodalitäten $\mathrm{z}$ e $\mathrm{r}$ f a $1 \mathrm{l}$ e n.

\section{We chselbeziehungen der Sinne}

Wäre das Nebeneinander vieler, qualitativ verschiedenartiger, Sinne das letzte Wort, so würde damit nicht nur die Einheit der Person, welche Wahrnehmungen hat, sondern auch die Einheit der Welt, die wahrgenommen wird, unwiderruflich zerrissen sein. Es wäre jedesmal ein anderer Mensch, der Gesichtserlebnisse, Gehörserlebnisse, Geruchserlebnisse u.s.w. hätte; und die sichtbare Welt hätte mit der hörbaren, diese mit der tastbaren u.s.w. überhaupt nichts zu tun.

Aber der Mensch ist - unbeschadet der Mannigfaltigkeit seiner Erlebnisbereiche - e in e r; und seine Welt ist - unbeschadet der Verschiedenheit der Perspektiven und Auschnitte, in der sie sich ihm bietet - ein einheitliches Gebilde.

Dieses Ganzheitsprinzip macht sich nun auch in der menschlichen Wahrnehmung in mannigfacher Weise geltend.

Zunächst erweist sich, dass die Verschiedenheit der Sinne das Ergebnis einer Entwicklung aus einem noch nicht sinnesspezifischen Zustand ist; diese Entwicklung ist sowohl phylogenetisch wie ontogenetisch wirksam. In ihrem Ablauf wird die $u$ n t e rs p e $z$ if is c h e Urform des Wahrnehmens nicht etwa abgelöst und ersetzt durch die differenzierten Sinnesmodalitäten; sie bleibt vielmehr als deren vitaler Untergrund stets bestehen und kann mehr oder weniger vordringlich werden.

Des weiteren treten die sinnesspezifischen Erlebnismomente in engste Wechselwirkung zueinander, so dass in terse nsorielle Wahrnehmungsgebilde entstehen. Diese beherr- 
schen vor allem die Gebiete des räumlichen und zeitlichen Wahrnehmens.

Es gibt ferner - als höchstentwickelte Form des Wahrnehmens - eine über-s pe z if i s c he Wahrnehmung, bei der das, was die einzelnen Sinne an Eindrücken liefern, in seiner ungeteilten Einheit von der ungeteilten Person introzipiert wird: sie wird uns als "physiognomische" Wahrnehmung beschäftigen.

Endlich stellt sich heraus, dass die Sinnesmodalitäten auch dort, wo ihre Besonderheit deutlich ausgeprägt ist, nicht gänzlich disparat zu einander sind (wie noch S. 162 fiktiv angenommen wurde). Vielmehr zeigen die Erlebnisse der verschiedenen Sinne eine eigentümliche $\mathrm{V}$ erwand $\mathrm{s} \mathrm{ch}$ aft, die unter besonderen Umständen bis zur Verschmelzung oder Verwechslung führen kann.

Wechselbeziehung und Verwandtschaft ermöglichen in besonderen Bedarfsfällen auch die teilweise Vertretung eines Sinnes durch einen anderen.

Diese hier nur in Stichworten angegebenen Zusammenhänge werden in den Kapiteln VI und VIII ausführlich behandelt. 


\section{SECHSTES KAPITEL}

DIE EN T W I K L U N G DER SIN NE

Die Fähigkeit, auf äussere Reize zu reagieren, kommt schon den primitivsten Formen des Lebens zu, auch den Pflanzen ${ }^{1}$ ). Innerhalb dieser, allem Lebendigen gemeinsamen, Disposition gibt es aber eine ungeheure Entwicklung, in der zwei Stufen deutlich unterscheidbar sind.

Auf der unteren Stufe sind die Sinnesfunktionen noch durchaus den vit a le n Funktionen des Organismus eingeordnet, durch welche dieser seine Beziehung zur umgebenden Welt unmittelbar reguliert. Auf der höheren Stufe dienen sie der g e g e n s $t$ ä n dlichen und introzeptiven Erfassung der jeweilig gegenwärtigen Situation. Während die „niederen” Sinnesleistungen dem Tiere und dem Menschen im wesentlichen gemeinsam sind, finden die ,höheren" Sinnesleistungen ihre entscheidende Auswirkung erst auf der menschlichen Stufe.

Die Anwendung wertender Ausdrücke (,höher” und „nieder”) ist von der wissenschaftlichen Psychologie meist vermieden worden. Aber da die Ausdrücke hier e n t w i c k l u n g s p s y c holog i s c h gemeint sind, haben sie durchaus ihr Recht. Denn die Vitalstufe ist nicht nur in Gattung und Individuum die zeitlich frühere, sondern sie bildet auch dauernd den Untergrund, aus der sich dann später die andere Stufe als differenzierter Oberbau erhebt.

\section{SENSIBILITÄT}

Im Anfang organischer Entwicklung ist noch keinerlei Vielheit der Sinne vorhanden, nicht einmal eine Reiz-E m p f ä n g l i c hke i t (,Sensibilität)" als selbständiger Funktionsbereich. Es

1) Die wir aber aus unserer Betrach tung ausscheiden. 
gibt nur S e n s u-M o til it ä t, d.h. eine diffuse Fähigkeit zur Beantwortung von Reizen durch Bewegungen. Bei den tiefststehenden einzelligen Organismen ist diese Fähigkeit noch ungeschieden dem Gesamtkörper eigen: die Protoplasmamasse ist im ganzen z u g l e i ch Sinnes- und Bewegungsorgan. Ob bei diesen primitiven Reaktionen überhaupt schon ein eigentlich ,psychologisches" Faktum vorliegt, nämlich Bewusstsein in irgend einer, wenn auch noch so dumpfen Form, entzicht sich jeder Feststellungsmöglichkeit.

Alle weitere Entwicklung bringt nun eine Differenzierung der Funktionen, lässt Beteiligung des Erlebens entstehen und wachsen und verselbständigt eigentliche Wahrnehmungserlebnisse.

Die ursprüngliche Einheit von Sensibilität und Motilität wird in dieser Entwicklung einerseits verfeinert, andrerseits gelockert.

Die Verfeinerung der Sensumotilität bekundet sich zunächst darin, dass auf allen Entwicklungsstufen gewisse Organe zu bevorzugten Trägern für b e i d e Funktionen zugleich werden. So findet man schon bei niederen Lebewesen die Ausbildung von Wimperzellen, Flimmerhaaren und ähnlichen Organen, die durch ihre besondere B e w e g i i c h k e it zum Kontakt mit der Lmwelt, also auch zum R e i z e mp fang in höherem Malse geeignet sind als die trägere Masse des Körpers. Ein Beispiel aus höherer Stufe bilden die Fühler der Insekten, die durch ihre Länge und Wendigkeit den Umkreis dessen, was der Berührung zugänglich ist, für das Tier beträchlich erweitern. Beim Menschen ist zwar die Haut des Gesamtkörpers für Berührung empfindlich, aber zur Eit a st ung der Dinge werden die Berührungsempfindungen nur von den besonders beweglichen oberen Extremitäten - und vor allen von ihren feinsten dusläufern, den Präzisionsapparaten der Finger - benutzt. Das Tasten ist so die erste sensumotorische spe$\mathrm{z}$ i a $\mathrm{lf} \mathrm{unk}$ t i o $\mathrm{n}$, die sich aus der eingangs geschilderten sensumotorischen Totalfunktion des Körpers herausarbeitet. Es ist gleichsam die grundständige Leistungsform, durch welche sich das Lebewesen durch eigene Aktivität die allernächste Melt zu erobern beginnt.

Die hohe Bedeutung dieser Leistungsform zeigt sich auch in der Entwicklung jedes Einzelindividuums. Noch ehe das Menschenkind das erste Jahr vollendet, hat es dis Greifen aus- 
gebildet als ein zwar primitives und grobes, aber doch sehr eindringliches, eben,, handgreifliches", Mittel sensumotorischer Weltorientierung.

Die Verbindung hoher Sensibilität und Motilität bleibt übrigens nicht auf das Tasten beschränkt. Auch die Leistungen des Auges sind nicht nur der feinen Struktur der Netzhaut zu danken, sondern auch der vielgestaltigen Bewegungsfähigkeit der Augäpfel (vgl. hierzu S. 201).

Die angedeuteten sensumotorischen Verknüpfungen setzen aber nun noch eine andre Entwicklungstatsache voraus: die Entstehung eines eigenen verknüpfenden Organsystems. Von gewissen Stufen der Tierreihe an übernimmt das $\mathrm{N}$ e r v e n s y s t e m die Aufgabe, sensorische Erregungen in motorische Impulse umzusetzen. Nicht mehr der Gesamtkörper in seiner Diffusität, aber auch nicht das Einzelorgan, das zugleich Reize empfängt und Bewegungen vollführt, kann Verwalter dieser Koordinationen sein, sobald diese etwas verwickelter werden. Denn die motorischen Rückwirkungen eines sensorischen Reizes bleiben ja nicht auf das Empfangsorgan beschränkt (Beispiel: auf Lichtreize hin bewegt sich nicht nur das Auge, sondern auch der Kopf, der Rumpf, der Arm u.s.w.); und dennoch muss die motorische Antwort zweckmässig gegliedert, gestaltet und abgestuft sein. Dies wird möglich durch einen, aus massenhaften Verbindungsgliedern bestehenden, $z$ e $n \mathrm{t} r$ a le $n$ Vermittlungs- und Schaltungs-Apparat zwischen den motorischen und sensorischen Nervenfasern. Ein solcher tritt zuerst auf in der einfacheren Form eines Nervenknotens oder Nervenstranges, zu dem die sensorischen Leitungen hin- und von dem die motorischen Leitungen ab-führen; später in einer, diesem Zentralstrang sich überlagernden, obersten Instanz, dem G e h i r n. Die höchsten Formen der Tierwelt zeigen vor allem eine Steigerung der relativen Bedeutung des Gehirns, das endlich beim Menschen seine gewaltigste Ausformung erhält.

Auch am menschlichen Gehirn selbst kann man noch entwicklungsgeschichtlich ältere und jüngere Teile unterscheiden $\langle\mathrm{Pa}-$ laeenkephalon und Neenkephalon. Edinger).

Diese Entwicklung hat nun für das Verhältnis von Sensibilität zu Motilität einen zwiefachen Sinn. Einerseits ermöglicht sie feinste Koordinationen und Regulationen im $\mathrm{Z}$ us a m m e n- 
w i r k e n beider; andrerseits aber richtet das Zentralnervensystem zwischen beiden eine Art Schranke auf und ermöglicht dadurch deren Trennung und Verselbständi$\mathrm{g}$ u n $\mathrm{g}$.

Erst dort, wo ein Zentralnervensystem auftritt, gibt es daher eine von der Motilität a b h eb a re Sensibilität, gibt es ein Hinausgehen über die sensumotorische Einheit des Tastens, die Entwicklung eigener Gebiete der Reizempfänglichkeit und damit des eigentlichen, kontemplativen „Wahrnehmens".

Auch diese Entwicklung der einzelnen Sinne nimmt aber jedesmal den Weg von einer diffusen Gesamtsensation zur spezialisierten Sonderwahrnehmung, so wie wir es schon beim Tasten gefunden hatten. Wir verfolgen dies an drei parallelen Entwicklungsgängen.

Die Objekte, die es mit der Ernährung zu tun haben, üben auf den Organismus eine chem $1 \mathrm{sch}$ e Wirkung aus; deshalb ist eine besondere Reizbarkeit durch chemische Reize nötig für diejenigen Stellen, die sich allmählich zu spezifischen Signal- und Aufnahmestationen ausbilden. Iiese Organe machen die so lebensnotwendige A u sles e der Nährobjekte möglich: zunächst ein Suchen und Meiden, noch ehe der Nährstoff in Kontakt tritt mit dem Organismus: G e r u c h; -- sodann ein Annehmen oder Ausstossen, wenn der Reiz schon die erste Zone des Ernährungstraktes erreicht hat: $\mathrm{Gesch} \mathrm{m}$ a ck. Beide Formen sind wohl aus einer diffusen Sensibilität für chemische Einwirkungen hervorgegangen. Auch beim Menschen haben sie eine besonders enge Verwandtschaft untereinander (vgl. S. 199); aber es ist doch insofern eine Differenzierung eingetreten, als der Geschmack, ein reiner Kontaktsinn, seine fast ausschliessliche Beziehung zur Aufnahme von Nahrungs- und Genussmitteln beibehalten hat - während der Geruch, der schon in eine gewisse Ferne reicht, vieldeutiger ist: ausser der Beziehung zur Ernährung hat er eine solche zur Erkennung von Spuren (Wittern), zur Sexualität und anderen Gebieten.

Mechanische Vorgänge spielen sich in der L'mgebung der Organismen nicht nur in der groben Form ab, dass Objekte aller Aggregatzustände ${ }^{1}$ ) mit der Oberfläche in Tastkontakt gebracht

\footnotetext{
den.

1) Auch bewegte Luft (Wind) kann durch den Berihrungssinn wabrgenommen wer.
} 
werden; auch mikro-m e chan is ch e Vorgänge, schnellste und kleinste Schwingungsbewegungen, die sich durch bestimmte Medien fortpflanzen, treffen den Organismus. Der lebende Körper ist zunächst befähigt, d i f f u s diese Vibrationen zu perzipieren (Vgl. die S. 180 besprochenen „Vibrationsempfindungen"). Es bilden sich dann aber entwicklungsgeschichtlich Spezialorgane aus, die auf Luftschwingungen bestimmter Periodik besondere Resonanz zeigen, also bis in feinste Abstufungen mitzuschwingen vermögen: die Gehörsorgane, denen ja auch spezifische „Gehörs”-Empfindungen zugeordnet sind.

Andersartige Mikro-Schwingungen affizieren den Organismus chemisch: es sind die Strahlungen (Licht, Wärme). Auch hier steht am Anfang der Entwicklung eine ganz diffuse Beeinflussung des Gesamtorganismus durch die strahlende Reizquelle, die zu inneren chemischen Zustandsänderungen und zu gewissen Bewegungen führen kann, ohne dass überhaugt Bewusstsein mitspielt. Schon Pflanzen zeigen ja „Heliotropismus”, d.h. Hinwendung zur Sonne; das "Suchen des Lichts" ist in der Tierwelt ein ausserordentlich verbreiteter Zug, von den tiefsten bis zu den höchsten Formen (dem Laien am auffälligsten bei den Insekten). Dieses Suchen kann übrigens in bestimmten biosphärischen Situationen auch ein negatives Vorzeichen bekommen; es tritt dann Meiden des Lichts, Suchen der Dunkelheit auf.

Auch beim Menschen gibt es diese diffuse Urform der Strahlungswirkung mitsamt den reflektorischen Funktionen des Suchens und Meidens. Sofern sie ihm bewusst wird, hat sie viel mehr den Charakter der Selbstwahrnehmung als der äusseren Wahrnehmung. Nach langem Regenwetter empfinden wir das Wiederhervortreten der Sonne als eine allgemeine Hebung des Lebensgefühls; auch der wärmende Ofen oder die Bestrahlung durch künstliche Höhensonne ändern den Gesamtzustand.

Aus den diffusen Strahlungswirkungen differenzieren sich nun die spezifischen Sinnesbereiche für strahlende Energieen heraus: gewisse Hautstellen unterscheiden sich von ihren Nachbarn durch besonders gute Wärmeleitung und werden dadurch zu fein reagierenden Aufnahmestationen für Wärmereize, also zu „Wärmepunkten". Sie ermöglichen das Erkennen von Objekten, deren Temperatur sich von der ler Lingebung abhebt. Andrerseits ent- 
wickeln sich in der Körperoberfläche der Organismen Pigmentflecke, Farbstoffanhäufungen, die durch Licht leichter photochemisch affizierbar sind als ihre Nachbargebiete: von diesen sehr primitiven Organansätzen bis hin zur fein entwickelten Netzhaut der Säugetiere und Menschen führt eine Stufenleiter von Lichtsinnorganen.

\section{GEGENSTÄNDLICHE UND INTROZEPTIVE WAHRNEHMUNG}

Die bisher behandelte Entwicklung der Sinne hatte sich wesentlich im Biologischen bewegt, erörterte das $\mathrm{H}$ e r v o r wachsen der einzelnen Sinne aus der ihnen allen gemeinsamen Vitalsphäre des Individuums.

Nunmehr aber müssen wir die Entwicklung in einer andren Höhenlage, der spezifisch m e n s h lich e n, verfolgen, dort, wo die Sinnesfunktion über die unmittelbare Vitalfunktion $h$ in . a u s wächst, wo ihre Leistung im Vollsinne zur „Wahr”-nehmung wird.

Wir wiesen schon früher auf die verbreitete Unterscheidung zwischen „niederen" und „höheren" Sinnen hin. Man rechnet zur zweiten Gruppe nur Gesicht und Gehör, räumt dem Tastsinn eine gewisse Mittelstellung ein und nennt alle anderen Modalitäten „nieder”. Bei den höheren Sinnen wird die bloss vitale Bedeutung der Sensibilität durch die gegenständliche Verwertung überwunden. Der auslösende Reiz ist nun nicht nur Erreger eines Lebensvorgangs, sondern Gegenstand einer Erlebnis-Intention. Das Objekt wird distanziert vom erlebenden Subjekt als ein für sich bestehendes Etwas. Uns geht hier die erkenntnistheoretische Seite dieser Wandlung nicht an, wohl aber die psychologische Voraussetzung, durch welche sie möglich wird.

Das Funktionieren der niederen Sinne geht entweder ganz ohne Beteiligung des Bewusstseins vor sich; oder aber es zeigt einen Bewusstseinsaspekt, in dem sich eigentlich sensorischen Momente verschmelzen mit jenen Erlebnissen, die den Zustand des eigenen Selbst betreffen, also mit Trieben und Gefühlen. So sind z.P. Geruchseindrücke fast ausnahmslos positiv oder negativ gefühlsbetont; ich erlebe in ihnen viel mehr die Art, wie der Geruchsträger fördernd oder störend, in meine Lebenssphäre eingreift, als die 
Art, wie das Objekt, abgesehen von „mir”, beschaffen ist. Gewiss, auch Gesichts- und Gehörs-Eindrücke treten mit verschiedensten Gefühltsbetontheiten auf; Farben, Formen und deren Kombinationen, Tonfolgen und Harmonieen, menschliche Stimmen gefallen oder missfallen mir, können mein Gemüt bis zur Begeisterung oder bis zur Unerträglichkeit erregen - aber sie müssen es nicht. Bei den höheren Sinnen gibt es zwischen den stark gefühlsbetonten Polen ein breites Zwischengebiet der gefühlsmäIsigen Unbetontheit (was nicht völlige Gefühlsleere zu bedeuten braucht). In diesem Zwischengebiet ist die eigentliche $\mathrm{Er}$ $\mathrm{k}$ e $\mathrm{n} n \mathrm{t} n \mathrm{i}$ s-Funktion heimisch, und die allmähliche Erweiterung dieser gefühlsärmeren Sphäre bildet wiederum eine der wichtigsten Entwicklungstatsachen - nicht nur von Tier zu Mensch, sondern auch i n n e $\mathrm{r}$ h a $1 \mathrm{~b}$ der Menschheit von der Kindheit zur Erwachsenheit oder vom primitiven zum kultivierten Menschen.

Wenn ich ein Buch lese, oder im Mikroskop ein Objekt beobachte, so will ich das Gegebene nur ,wahr"-nehmen; ob die Seh-Erlebnisse meiner Vitalsphäre zuträglich oder abträglich sind, ob sie meiner Gefühlssphäre angenehm oder peinvoll sind, kommt nicht in Betracht. Ist jemand beim Lesen in den „Gegenstand" ganz vertieft, dann müssen Änderungen der optischen Reize - z.B. allmählich zunehmende Abenddämmerung schon ein hohes Mafs erreichen, damit diese Vitalstörung überhaupt zum Bewusstsein kommt. - Das Gleiche gilt bezüglich der mit dem Gehör aufzunehmenden Sprachreize. Ihre wesentliche Bedeutung ist, dass der Sinn der gehörten Worte verstanden, also ihr objektiver Gehalt bewältigt wird. In dem Augenblick, in welchem etwa ein Gesprächspartner sich dem einschmeichelnden Wohllaut der Sprache des anderen hingibt, also vital reagiert, ist die Intention auf Sinnverständnis gefährdet.

Freilich ist diese Loslösung der Objektfunktion von der Vitalfunktion zugleich eine Verarmung, eine Entseelung der Wahrnehmung. Sie ist aber auch nicht die höchste Stufe der Entwicklung. Diese wird erst dort erreicht, wo das erkannte Objekt selbst in seinem Eigen l eben wahrgenommen wird. Was ich nun erlebe, an Farbigkeit und Formung, an Tongestalt und Sprachklang, ist nicht nur $\mathrm{d}$ a als fremdes Ding, sondern ist A u sd r u c k, Wesensbekundung. Ich sehe, ich höre dem I)inge an, wie es ist, - weil ich es nämlich nicht lediglich mit meinen Augen, 
meinen Ohren wahrnehme, sondern weil ich mit me in e r ganzen Person, durch Vermittlung des Optischen, bezw. Akustischen, s e i n e ganze Existenz erfasse.

In dieser „physiognomischen" Wahrnehmung ${ }^{1}$ ) wird also jene bloss gegenständliche Abhebung der Gesichts- oder GehörsPhaenomene wieder rückgängig gemacht durch eine neue Einbettung in die Person. Es ist aber nicht mehr die Einbettung auf bloss vitaler Stufe, die wir oben schilderten, sondern , i n t r oz e p t i v e" Einbettung, das Einverleiben des im wahrgenommenen Objekt zugleich wahrgenommenen Sinn- und Wert-Gehaltes. Hier treten auch wieder Gefühlsreaktionen auf, aber es sind andere, als die oben besprochenen Vitalgefühle; denn sie lassen den Gegenstand in seinem Eigense in unangetastet. Insbesondere gehören hierher die ästhetischen Wahrnehmungen, deren Gefühlsbetontheit ja schon Kant als „uninteressiertes” Wohlgefallen bezeichnet hatte.

Das „U n a n ge t a s t e t b l e i b e n” des Gegenstandes ist in der Tat ein wesentliches Kennzeichen der höheren Sinne. Die niederen Sinne erkennen dem Gegenstande kein Eigenrecht auf Eigendasein zu; denn sie suchen ihn selber einzuverleiben. Das ist am deutlichsten beim Geschmackssinn, der das Objekt beim Vollzug der Wahrnehmung sogar zerstören muss. Auch der Geruch wird „,in die Nase eingezogen”. Das Tasten ist eine Art Besitzergreifen; es ist eine Kontaktfunktion, nicht nur für den Tastenden, sondern auch für (oder besser gegen) das getastete Ding, dessen Oberfläche, dessen Widerstandsfähigkeit (bei Druck) dem Wahrnehmenden preisgegeben ist. Aber immerhin: der Gegenstand wird hierbei nur gestört, nicht zerstört; so zeigt sich auch hier die Mittelstellung des Tastens.

In die Rangordnung Höher/Nieder müssen wir nun auch die mehrfach erwähnte Verschiedenheit der R e ich we it e bringen. Gehör und Gesicht sind die einzigen spezifischen Sinne, die uns systematisch und umfassend die Ferne öffnen $\left.{ }^{2}\right)$. Ist das Cehör noch angewiesen auf die Schwingungen der erdgebundenen Luft, so durchbricht der optische Sinn alle irdische Begrenzung und erschliesst uns den Kosmos. Aber nicht nur die Grösse und

\footnotetext{
1) Die Bezeichnung stammt von Heinz Werner. Naheres hierzu S. 219.

$\Rightarrow$ Abgesehen von den Vibrationsemptindungen, deren Bedeutung für die Fern. wahrnehmung aber bei Vollsinnigen sehr gering ist. Vgl. S. 180.
} 
We i t e der Welt ist es, die durch das Hören und Sehen in die Ferne erschlossen wird, sondern auch die $\mathrm{O}$ b j e k t i v i t ä t der Welt. Denn was fern ist, ist noch nicht eindeutiger, aktionfordernder Einbruch in mein Leben, sondern ist - in Bezug auf mich noch vieldeutig, unaktuell und eben darum der kühleren Betrachtung, dem unbewegten Schauen und Lauschen zugänglich.

Der Gegenstandscharakter der höheren Sinne findet dann weiter seinen Ausdruck in ihrer inneren G e or d n e t h e i t. Wenn wir im nächsten Kapitel die Systematik der einzelnen Sinnesmodalitäten erörtern, wird sich ergeben, dass die niedrigen Sinne über dürftige Ansätze für eine Ordnung ihrer spezifischen Erlebnisinhalte nicht hinauskommen. Dagegen gibt es bei Gesicht und Gehör mehrdimensionale Ordnungen von so übersichtlichem Bau, dass weitgehend eine Plat $z$ a $n$ we is un $\mathrm{g}$ für die einzelnen Erlebnismomente möglich wird. Eine solche Einordnung aber ist Vorbedingung der Objektivierung; denn nur durch sie vermag man die zwischenindividuelle Verständigung über Wahrnehmungen und die überindividuelle Festlegung ihrer Gesetzmälsigkeiten zu bewerkstelligen. Das Notensystem etwa, in welchem die Tonhöhen und Tondauern eines Musikstückes eingefangen sind, ermöglicht es, immer wieder identische Musikwahrnehmungen bei beliebig vielen Menschen zu beliebigen Zeiten herbeizuführen.

Endlich ist die Kategorie der G e s $t$ a $1 \mathrm{t}$ ganz wesentlich eine solche der höheren Sinne. Bei den niederen Sinnen bedeutet die starke Eingebettetheit in die Vitalsphaere der Person zugleich weitgehend Ungestalt der Erlebnisse. Der Tastsinn steht wiederum in der Mitte. Er kann Gestalten verschiedener Art erfassen, aber doch nur in einer etwas groben Simplizität, und vor allem nicht in hierarchischer Úberordnung. Gesicht und Gehör dagegen erleben Gestalten im unendlichen, feinst differenzierten Nebeneinander: man denke nur an die Fülle der Wortgestalten einer Sprache, die hörbar und lesbar sind; an die unbegrenzten Möglichkeiten künstlerischer Style und künstlerischer Werke, deren jedes eine Gestalt für sich darstellt. Auch Gestalt-H i e ra $r c h$ i e ist nur bei Gesichts- und Gehörs-Eindrücken ausgeprägt. Eine engere Gestaltganzheit ist Glied einer umfassenderen, diese einer noch umfassenderen Gestalt u.s.w. - und doch bleibt die unmittelbare Inschaulichkeit der Wahrnehmung gewahrt. 
Beispiele solcher hierarchischen Ordnungen: das Gemälde als Gesamtgestalt enthält viele Menschenbilder als untergeordnete Gestalten, jede Menschendarstellung die Teilgestalt des Gesichts, diese die Teilgestalten des Auges, der Nase u.s.w. Ähnlich im Akustischen: Gedicht, Strophe, Satz, Wort. - Sonate, Satz, Melodie, Motiv.

Welche Kluft gerade in dieser Beziehung zwischen höheren und niederen Sinnen besteht, wird sofort klar, wenn man nach der Möglichkeit einer Geruchssonate, eines Geschmacksgemäldes, eines Tastgedichtes fragt.

Jedes Werk - sei es künstlerischer, wissenschaftlicher, technischer oder sonstiger Art - ist ein hierarchisch gestaltetes Gebilde. Darum sind We rke in ihrem eigentlichen Sinn und Wesen normalerweise nur dem Auge oder dem Ohr zugänglich.

Fassen wir zusammen: Die menschliche Sinneswahrnehmung steht als Mittlerin zwischen den beiden Polen der unmittelbaren Vitalität und des geistigen - erkennenden und künstlerischen Erlebens. Je nach der grösseren Nähe zu jenem oder diesem Pol kann man dem spezifischen Wahrnehmungsbereich und der einzelnen Wahrnehmung einen Rangplatz beilegen. Aber jede Wahrnehmung weist, wenn auch mit verschiedenem Akzent, nach beiden Richtungen; es gibt keine, noch so vital gebundene, in der nicht ein Funke von Erkenntnis - keine noch so sachlich kühle, in der nicht ein vitaler Untergrund lebte. I)ie Höchstform der Entwicklung stellt die introzeptive oder physiognomische Wahrnehmung dar, in welcher der spezifische Sinneseindruck, von der Ganzheit der wahrnehmenden Person getragen, zugleich Ausdruck für die innere Wesenheit des Objekts ist. 


\section{SIEBENTES KAPITEL}

DIESINNESSPEZIFISCHEN ERSCHEINUNGEN U N D I H R E Y S T M A TIK ${ }^{1}$ )

Bei den psychologischen Analysen der einzelnen Sinnesmodalitäten sind zwei Problemrichtungen deutlich zu unterscheiden. Eine ältere - der Psychophysik und Physiologie nahestehende Betrachtungsweise setzt sich als Ziel eine Systematik der elemantaren psychischen Beschaffenheiten, die gewöhnlich als „E m p fin d u n g e n” bezeichnet werden; das psychologische System wird dann zu den Systemen der physikalischen Elementarreize und der physiologischen Elementarerregungen in Beziehung gebracht. Der anderen Untersuchung ist es um die Phänomenologie des Gebiets zu tun; sie will die „Erscheinungsweisen" der Wahrnehmungsinhalte in ihrer unmittelbaren Bewusstseinseigenart aufweisen und beschreiben; sie bringt nicht die Vielgestaltigkeit dieser Erscheinungen vorzeitig einem hypothetischen Ordnungsprinzip zum Opfer.

\section{DIE MODALITÄTEN DES „FÜNFTEN” SINNES}

Wir beginnen mit jenen Sinnesmodalitäten, die an die Stelle des „fünften” Sinnes alten Styls (des sogenannten „Gefühlssinnes") getreten sind. Zwei dieser Modalitäten, Temperatur und Berührung, sind zu allen Zeiten bekannt gewesen; hinzu getreten sind als „neue" Sinne die Modalitäten der kinästhetischen, Vibrations- und Gleichgewichts-Empfindungen.

1) In frïheren Kompendien der Psychologie wurde gewöhnlich den Untersuchungen über die Erscheinungen der Einzelsinne ein ausserordentlich grosser Raum gewidmet. Wir müssen hier, um den Rahmen einer allgemeinen Psychologie nicht zu sprengen, äusserste Zurückhaltung üben. Unsere Betrachtung beschränkt sich auf die Erwähnung solcher Tatbestände, die zu den prinzipiellen Fragen der Wahrnehmungspsychologie enge Beziehung haben. 
Der T e m perat u rsin n liefert das einleuchtendste Beispiel einer einfachen psychologischen Systematik. Denn alle ihm zugehörigen Sinneserlebnisse lassen sich anscheinend linear ordnen; von dem Eindruck ",heiss" gelangen wir stetig durch „warm” und „lau” zur Temperatur-Indifferenzzone und dann weiter durch ,kühl” und „,kalt” zu ,eisig”. Die Beziehung zur physikalischen Skala, etwa des Thermometers, ist offenbar. Aber auch hier dürfen wir nicht einem Physikalismus verfallen. Personale Dimensionen können sich, zum Lnterschied von denen der Physik und Mathematik, nie in einer blossen Gradabstufung erschöpfen, sondern sind zugleich qualitativ getönt. Schon die Sprache zeigt das. „Heiss" ist für unser Erleben nicht nur ein gesteigertes "warm”, oder , kühl”" ein gemindertes „kalt"; sondern ein Erlebnisinhalt von anderer Art. "Lau” bedeutet eine ganz besondere Erscheinungsweise; nicht jeder Zwischenzustand zwischen ,warm" und ,indifferent" wird als "lau" wahrgenommen, sondern nur ein solcher Zustand, in den auch ein Feuchtigkeitsmoment eingeht. (Wasser und Witterung kömnen „lau” sein, nicht aber ein Stück Holz oder ein trockenes Tuch.) - Endlich weicht die psychologische Temperaturlinie in ihrem Endver-

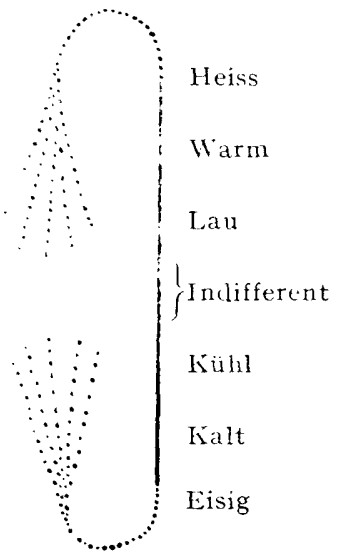

Fig. 4.

Die psychologische Temperaturlinie. lauf entscheidend von der gradlinigen physikalischen Wärmeskala $\mathrm{ab}$; exzessive Hitze und exzessive Eisigkeit sind erlebnismälsig nicht am weitesten von einander entfernt, sondern sehr nahe; sie können geradezu mit einander verwechselt werden. (Siehe Figur 4).

Vor einer eigentümlichen Schwierigkeit steht die psychologische Beschreibung bei dem Berührungssinn. Eine „Sinnesspezifizität” ist hier deswegen sehr schwach ausgebildet, weil dieser Sinn fast nie für sich allein funktioniert, sondern in Verbindung mit Körperbewegungen aufzutreten pflegt, die wieder ihre besonderen Erscheinungsweisen haben. Das Wort „Tast$\mathrm{S}$ i n n" ist irreführend; denn im Tasten sind stets mehrere Sinne aktiv (vgl. S. 169). Man müsste also die Erscheinungsweisen 
suchen, die bei fehlenden Körperbewegungen auftreten. Es scheint, dass wir hier nur eine dürftige Dreiheit aufweisen können: Berührung, Druck, Zug. Eine andere Einteilung spricht von drei Gegensatzpaaren: hart/weich, spitz/stumpf, nass/trokken; doch sind diese schon nicht mehr in engster Bedeutung sinnesspezifisch, sondern der intersensoriellen Tastwahrnehmung zugehörig. Denn in ihnen sind räumliche und zeitliche Merkmale enthalten, die ohne Eigenbewegungen nicht erfassbar sind.

Die ,neuen Sinne” sind dem naiven Bewusstsein als gesonderte Modalitäten überhaupt nicht bekannt. Die Wissenschaft weiss von ihrer Existenz erst seit relativ kurzer Zeit. Es ist dies ein Zeichen dafür, dass ihre sinnesspezifische Erlebbarkeit sehr gering sein muss. In der Tat sind diese Eindrücke normaler Weise eingeschmolzen in komplexere Gebilde; und nur unter ungewöhnlichen Umständen oder durch experimentelle Hilfsmittel wird ihre Existenz erkennbar.

$\mathrm{Vibrat}$ i o n se m p fin d u n gen. - Ist jemand in einem Fabrikraum, in dem sich schnell rotierende oder schwingende Maschinen befinden, so wird er im allgemeinen den Eindruck des Vibrierens nicht loslösen von den akustischen Geräuschen des Summens und Schwirrens und von den Tasteindrücken, die er vom Fussboden, der Luftbewegung im Raum u.s.w. hat. Man kann aber bei eigens darauf gerichteter Aufmerksamkeit doch das besondere Vibrationserlebnis erfassen, das in ganz anderem Sinne von der Oberfläche ins Innere des Körpers dringt, als der Schall und die Berührung.

Die Sonderstellung der Vibrationsempfindung ist zuerst von Katz erkannt worden, der ihre Gesetzmälsigkeiten auch experimentell untersuchte.

Es ergab sich, dass die Feinheit der Vibrationsempfindlichkeit von einer Grössenordnung ist, mit der sich die Empfindlichkeit des Tastens auch nicht in Entferntesten messen kann.

Ferner ist - wie schon früher erwähnt - cas Tasten auf Kontakt mit der Reizquelle angewiesen, während der Vibrationssinn uns ebenso Nähe wis frune vermitteln kann. Menschen, die die beirlen eigentlichen Fernsinne, das Gesicht und das Gehör, entbehren - also die Taubblinden - vermögen nur durch Vibrationsemplindungen (und Geruch) über die unerträgliche Enge einer blossen Kontaktweit hinauszukommen. - Selhst die Schallschwingungen der Musik sind auf vibratorischem Wege dem Gehörlosen nicht völlig verschlossen (vgl. S. 221). 
Auch die durch motorische Betätigung der eigenen Körperteile erregten $\mathrm{B}$ e w e g u $\mathrm{g}$ s e $\mathrm{m}$ p f in $\mathrm{d} u \mathrm{n} g$ e $\mathrm{n}$ treten eigentlich niemals isoliert auf, sondern sind stets mit anderen Wahrnehmungsmomenten verschmolzen. Und zwar stellen sie ein eigentümliches Bindeglied dar zwischen äusserer und innerer Wahrnehmung. Denn jede Bewegung, die ich vollziehe, verschiebt die Relation zwischen mir und der Welt; und da die kinästhetischen Empfindungen von dieser Verschi e bung Kunde geben, kann der Akzent bald auf dem, sich gegen mich bewegenden, $G$ ege n s t a nd, bald auf dem, sich gegen die Welt bewegenden, I $\mathrm{c}$ h liegen.

Zum Zweck objektivierender Erkenntnis ordnen sich die kinaesthetischen Erlebrismomente in die von anderen Modalitäten getragenen Wahrnehmungen $\mathrm{ein}$; die grosse Rolle, die sie beim Blicken, Lauschen, Tasten spielen, wird später zu erörtern sein (S. 200 ff.). - Beim Vollzug von $\mathrm{H}$ a $\mathrm{n} \mathrm{d} \mathrm{l}$ u $\mathrm{n} g \mathrm{~g}$ e dagegen sind die kinaesthetischen Empfindungen an der Selbstwah rne hm ung beteiligt; sie keben dem Menschen Kunde von Grösse, Richtung, Kraftaufwand und Gesamtstruktur seiner Sclbsttätigkeit, dienen der Sellsstkontrolle und Selbstregulierung. Wenn ich mich endlich in einen wahrgenommenen Gegenstand ('infühle - etwa beim Anblick cines hohen Baums oder eines gotischen Domes mich innerlich strecke, beim Höreì eines Tanzrhythmus ihn mitklopfe - dann tragen die begleitenden Bewegungsempfindungen dazu bei, die Identifikation von $\mathrm{O} b$ je kt und Subjekt zu fördern.

Am allerschwersten ist es, sich crlebnismälsig Rechenschaft zu geben von jenen Gleichgewichtsempfindungen, die durch die Erregung der Bogengänge im inneren Ohr zustande kommen. Ja, man könnte bezweifeln, ob sie bei den normalen Gleichgewichtsfunktionen des Körpers überhaupt als $\mathrm{B} \mathrm{e-}$ w u s s t s e in s-Momente in dem Gesamtbewusstseinszustand enthalten sind, oder ob es sich hier nur um einen rein physiologischen - jenseits des Bewusstseins funktionierenden - Regulationsapparat handelt. Immerhin scheint doch zum mindesten bei chokartigen Eingriffen in das Gleichgewichtsbewusstsein so bei Seekrankheit und Luftkrankheit, beim Drehschwindel, beim Schaukeln - die nervöse Erregung in den Bogengängen auch das Erleben mit zu beeinflusien. 


\section{GESCHMACK UND GERUCH}

Die Bewusstseinsinhalte der beiden chemischen Sinne sind durch eine unübersehbare Anzahl von Qualitäten und durch fehlende (oder nur spurenhaft vorhandene) Systematik gekennzeichnet. Jede Speise, die unsere hochausgebildete Kochkunst herstellt, jeder Jahrgang jeder Weinmarke - ebenso der Duft jeder Blumengattung und jeder künstliche Riechstoff besitzt eine Erlebnisbeschaffenheit für sich, unvergleichlich mit jeder anderen, psychologischer Analyse widerstrebend. Daher kommt es auch, dass eine phänomenologische Beschreibung der Geruchsund Geschmack-Qualitäten bisher nur in geringen Ansätzen existiert.

Im Gegensatz $z u$ dieser Qualitätenfülle hat beim G e$\mathrm{s} \mathrm{ch} \mathrm{m} \mathrm{a} \mathrm{c} \mathrm{k} \mathrm{s} \mathrm{s} \mathrm{i} \mathrm{n} \mathrm{n}$ die Suche nach elementaren Empfindungsarten zu nur vier Urformen geführt: „süss”, „, sauer”, „bitter”, „salzig” (einige Forscher fügen noch die Geschmäcke „,metallisch" und ,alkalisch" hinzu). Irgend eine Ordnung oder Reihenbildung dieser einfachen Geschmacksempfindungen ist nicht auffindbar - mit einer Ausnahme: dem „Süss” kommt erlebnismälsig eine Gegensätzlichkeit gegenüber den drei anderen Qualitäten zu.

Wie unmöglich es ist, die einheitliche Eigenart der Erscheinungsweisen elementenpsychologisch zu erklären, zeigt sich besonders eindringlich auf dem Gebiet des Geschmacks. Man mache den Versuch, das Geschmackserlebnis "Brot" oder "Kirsche" in eine bestimmte prozentuelle Verteilung und Verbindung von ,Sauer"-, ,, Süss"'-, ,Bitter"- und ,Salzig"'-Empfindungen zu verwandeln — man wird kläglich scheitern.

Beim $\mathrm{G}$ e r u c h s s in $\mathrm{n}$ hat das naive Bewusstsein augenscheinlich keinen Anlass gefunden, eine Mehrheit von Urqualitäten aus der Fülle der Erscheinungsweisen herauszuheben; das zeigt sich schon in dem Versagen der $\mathrm{S}$ p r a c h e. Im Deutschen gibt es keine geruchsspezifische Qualitätsbezeichnung. Denn die Ausdrücke „Duft” und „Gestank” gehen auf die G ef ü h l s wirkung der Geruchseindrücke, nicht auf deren sensorielle Beschaffenheit als solche. In anderen Sprachen wird es sich wohl ähnlich verhalten. Wollen wir Gerüche benennen, so müssen wir Anleihen machen bei anderen Sinnen (vgl. S. 215) oder bei 
den Gegenständen, an denen sie zu haften pflegen (Teergeruch, Rosenduft, u.s.w.).

Damit stimmt es zusammen, dass die bisher versuchten Systemaufstellungen für Gerüche bis auf eine Ausnahme durch nichtpsychologische Gesichtspunkte (chemische, botanische) bestimmt waren. Eine rein psychologische Systematik versucht Hans Henning. Er unterscheidet sechs geruchliche Urerlebnisse, die sogenannten „Grundgerüche”: „würzig”, ,,blumig”, „fruchtig”, „harzig”, ,brenzlich", „faulig" und ordnet sie in ein "Geruchsprisma"; dieses bildet das Koordinatensystem, in welchem alle erlebbaren Gerüche ihren Platz finden sollen. Die Brauchbarkeit des Schemas

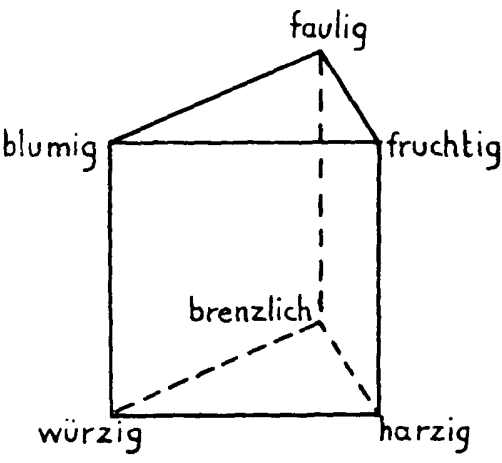

Fig. 5

Das psychologische Geruchsprisma (nach Henning).

bedarf der Nachprüfung; es hat jedenfalls nicht den unmittelbar einleuchtenden Charakter wie die sonst bekannten psychologischen Empfindungssysteme. (Vgl. Fig. 5).

In ganz anderem Malse als die bisher besprochenen Modalitäten sind die beiden sogenannten ,höheren” Sinne, Gehör und Gesicht, der psychologischen Analyse zugänglich gemacht worden; bei ihnen müssen wir etwas ausführlicher sein.

\section{GEHÖR}

\section{Ger äusche}

Beim Gehörssinn drängen sich zwei Grundarten von Erscheinungsweisen ohne weiteres auf: Ge räusche und Klänge (bezw. T ö n e). Physikalisch ist der Lnterschied eindeutig: Geräusche werden durch unperiodische, Klänge durch periodische Luftschwingungen erzeugt. Aber auch wer hiervon nichts ahnt, erlebt unmittelbar einen qualitativen Unterschied zwischen jenen Gehörseindrücken, die wir Pochen, Donnern, Poltern, Knallen, 
Klirren, Knirschen, Brüllen u.s.w. nennen - und den Instrumentalklängen der Geige und Pfeife, den Vokalklängen menschlichen Singens und des Vogelgesangs.

Ge räu schwahrnehmungen spielen im menschlichen Leben eine ungeheure Rolle. Alle menschlichen Betätigungen und alle technischen Vorgänge sind durch spezifische Geräusche gekennzeichnet; und die ganze gesprochene Sprache ist, rein akustisch genommen, eine Abfolge von Geräuschen. $\mathrm{Zu}$ dieser Bedeutung steht in seltsamem Widerspruch, dass die Psychologie den Geräuschen nur ein geringes Eigeninteresse entgegengebracht hat. $\mathrm{Zu}$ einer eigentlichen Phänomenologie der Geräusche ist es bisher nicht gekommen; soweit man sich mit ihnen beschäftigte, hat man sie fast immer in Elemente der anderen akustischen Erscheinungsweise aufzulösen versucht. Physika1 is c h kann man nämlich durch gleichzeitiges Darbieten vieler periodischer Schallreize eine aperiodische Resultante erzielen, was dann psychisch auch als „Geräusch” erlebt wird. (Einfachstes Beispiel: gleichzeitiges Anschlagen vieler Klaviertasten durch Auflegen des ganzen Armes.) Daraus wurde von Helmholtz der Schluss gezogen, dass auch psychisch ein Geräusch nichts anderes als ein wirrer Komplex von viclen einzelnen Tonempfindungen sei, sodass damit die Töne als einzige Urqualitäten des Gel:örssinnes gerettet schienen.

Nun sind sicher in vielen (reräuschen auch tonale Momente enthalten (die in malender Musik sogar nachgeahmt werden); ja, man kann durch Aneinanderreihen von Geräuschen (z.B. durch Klopfen auf Hölzer) eine regelrechte Tonleiter erzeugen. Dennoch ist und bleibt die Geräuschartigkeit als Erscheinungsweise unserer Wahrnehmung etwas anderes als die mitbeteiligten Töne. Dies gilt auch von der Sprache trotz der in ihr enthaltenen sogenannten "Sprachmelodi e"; die Darstellung dieser gleitenden Tonänderungen durch musikalische Noten tut ihnen reichlich Gewalt an; und erlebnismälsig haben sie eine ganz andere Natur als die gesungene Melodie.

Wundt bezeichnet Geräusche der eben genannten Art als Klangguräusche. Ihnen reiht er zwei weitere Erscheinungsweisen der Geräusche an : die intermittierenden Dauergeräusche (Schnarren, Zischen, Rollen u.s.w.) und die Momentangeräusche (Knallund Schlag-Geräusche, Explosivlaute der Sprache). Weiter ist 
die psychologische Systematik der Geräusche bisher noch nicht gediehen.

\section{Töne und Klänge}

Warum hat wohl die psychologische Theorie innerhalb der Gehörserscheinungen die Tön e so bevorzugt? Zweifellos zum grossen Teil deshalb, weil sie - gegenüber dem Chaos der Geräusche - ein geradezu ideales Ordn ung s y s t e m darbieten. Sowohl die eindrucksvolle Systematik der Musik, wie die physikalische Ordnung der Luftschwingungen, deren Frequenzen $^{\mathbf{1}}$ ) genau feststellbar und bis ins Kleinste variierbar sind, legte das Suchen nach einer ebenso einfachen, quantitativ ausdrückbaren und eindeutig abstufbaren, Systematik der entsprechenden psychischen „Elemente” nahe. Dieser zweifellos sehr fruchtbare Gedanke ist vor allem von Helmholtz zur Grundlage der Tonpsychologie gemacht worden, dann von Stumpf weiter geführt, freilich auch im Sinne feinerer psychologischer Beobachtung aufgelockert worden.

Man kann diese Theorie auf folgende Grundthesen bringen.

a) Die alleinigen psychischen Urbestandteile aller Gehörswahrnehmungen sind e infache Töne. Das sind solche, deren physikalischer keiz in einfachen Sinusschwingungen besteht, und in denen ps y chologis ch bei noch so starker analysierender Aufmerksamkeit keine weiteren Teiltöne gefunden werden können.

b) Die einfachen Töne ordnen sich (abgesehen von ihrer Intersität) in ein eindeutiges und stetiges 1 in e a r e $s .5 \mathrm{y}$ t e $\mathrm{m}$, in welchem die tberführung eines Tones in einen anderen nur auf e i n e $m$ Wege, durch die zwischenliegenden Töne, möglich ist: das System der To n höh e n, welches der Zunahme der physikalischen Schwingungsfrequenzen entspricht. Durch diese Beziehung hat jeder Ton einen festen Platz in der Skala. 1)a die Tonlinie s te $\mathrm{t}$ ig ist, stellen die diskreten Tonhöhen, mit denen die Iusik arbeitet, nur eine karge Auslese ans der Lnzahl der dem Wahrnehmen zugänglichen Tonhöhen dar.

\footnotetext{
1) "Schwingungsfrequenz" ist die Anzahl ler innerhab riner Sekunde aufeinander folgenden periodischen Verdichtungen und Verdiunumgen der den Schall leitenden I.uft.
} 
c) Alle weiteren Eigenschaften der Gehörserlebnisse müssen daher aus dem Zusammensein und den Beziehungen einfacher Töne und ihrer Tonhöhen erklärt werden.

Iie Durchführung des Punktesc) auf verschiedensten Problemgebieteri ist die eigentliche Leistung von Helmholtz gewesen. Er hat te sehr wohl gemerkt, dass es noch andere Erscheinungsweisen im Tonreich gibt ausser der Tonhöhe; aber er suchte sie weniger phänomenologisch zu beschreiben, als in die hypothetischen Empfindungselemente aufzulösen. Die Anwendung dieses Prinzips auf die „Geräusche” wurde schon erwähnt. Der gleiche Versuch wurde bezüglich der Vokale gemacht. Am wichtigsten aber ist die Anwendung auf die musikalischen Klänge und ihre spezifischen Qualitäten, die Klang f a r be n.

Ein „K 1 a n g” ist der durch eine einzige Reizquelle hervorgerufene tonale Eindruck, der als solcher dem unbefangenen Hörer einheitlich erscheint. Diese Einheit ist nach Helmholtz eine Täuschung. Die Klänge fast aller Instrumente ${ }^{1}$ ) wie auch der menschlichen Singstimme sind zusammengesetzt. Das heisst p h y s i k a li s c h: die Luftschwingungen sind zerlegbar in eine Anzahl gleichzeitiger Schwingungsfrequenzen, die in einfachen Zahlenverhältnissen zu einander stehen. (Wird die Grundfrequenz $=1$ gesetzt, so gelten für die anderen Frequenzen die Ziffern 2, 3, 4, u.s.w.). Es heisst p s y chologi s c h: in dem Klangerlebnis sind die Tonempfindungen, die den verschiedenen Frequenzen entsprechen, enthalten; denn sie sind bei spezieller Aufmerksamkeitsrichtung oder mit Hilfe von Resonatoren heraushörbar. Der Ton mit der geringsten Frequenz heisst „G $\mathrm{r} \mathrm{u} \mathrm{n}$ dt o n”, die anderen Töne "O b e r $t$ ö n e”. Da nun bei jedem Instrument aus physikalischen Gründen die Obertonbesetzung und die Stärkeverteilung der Obertöne verschieden ist, ist der Gesamteffekt des Zusammenklingens von Grund- und Ober-Tönen jedesmal ein anderer; deshalb haben die verschiedenen Instrumeinte auch bei gleichem Grundton verschiedene „Klangfarben”.

Auch auf die Zusammenklänge (Intervalle) wandte Helmholtz diese Theorie an: konsonant sind solche Intervalle, die identische Obertöne haben. Dissonant wirken solche Zusammenklänge, deren Obertöne mit einander interferieren, Schwebungen und Rau-

1) Nur Stinumabeln und angeblasene Flaschen licfern fast einfache Töne. 
higkeiten erzeugen und sich damit den aperiodischen Geräuschen nähern.

Diese Theorie ist einer der genialsten Versuche, mit Hilfe eines psychologischen Atomismus die Qualitätenfülle eines reichen Erlebnisgebiets zu erklären. Nur dass die Qualitäten zum Teil dabei weg-erklärt werden! Hier musste die phä nome n o$1 \mathrm{og}$ is ch e Gegenbewegung einsetzen, die durch Carl Stumpf eröffnet wurde.

So stark Stumpf noch unter dem Helmholtz'schen Einfluss steht, so muss er doch eines ablehnen: beim Ertönen eines Klanges oder eines Zusammenklanges hören wir nicht ein blosses Nebeneinander von Grund- und Ober-Tönen, sondern eine mehr oder minder differenzierte Einheit. Die einfachen Töne machen nicht als psychische Atomsumme den Klang aus, sondern sie „verschmelze n” miteinander. Im Maximalfalle kann die Verschmelzung (Einheitsbildung) sogar absolut werden: die beiden einfachen Töne, die eine Oktave miteinander bilden, werden bei Gleichzeitigkeit von den meisten Nenschen unbedingt als e i n Ton gehört. Die Intervalle in der Reihenfolge abnehmender Konsonanz: von der Oktave über Quinte, Quarte u.s.w. bis zur Septime, werden von Stumpf als Zusammenklänge abnehmenden Verschmelzungsgrades aufgewiesen.

Allerdings enthält auch der Verschmelzungsbegriff noch die Voraussetzung, dass das Verschmelzungsprodukt ein sekundäres Erzeugnis sei; primär werden also auch hier lediglich die einfachen Töne als Urqualitäten und die Tonhöhe als deren einziges Wesensmerkmal angesehen. Die moderne Tonpsychologie befreit sich auch von diesen Voraussetzungen. Lnd zwar sind es nun drei, bisher vernachlässigte, Erscheinungsweisen der Töne, denen jetzt ihr psychologisches Recht wird.

a) Schon von älteren Psychologen, insbesondere auch von Stumpf, war darauf hingewiesen worden, dass den Tönen der Skala nicht nur jene rein graduelle Beschaffenheit zukomme, die wir mit den Ausdrücken "höher" und ,tiefer" bezeichnen, sondern dass damit zwei andere Eigenschaft:änderungen einhergehen: der Helligkeit und der $\mathrm{Vl}$ assigkeit ( $\mathrm{Vo}$ I u minosität). Was mit den Bezeichmungen ,dunkle" und 
„helle” Töne, „spitze” und „,volle” („runde”, ,raumfüllende”) Töne gemeint ist, lässt sich nicht eigentlich beschreiben; aber jeder Hörende versteht sie und findet die phänomenologische Unterscheidung durchaus einleuchtend. Nun hatte man früher in diesen Merkmalen lediglich Nebenerscheinungen der Tonhöhe gesehen; jetzt werden sie mehr und mehr in ihrer selbständigen Bedeutung erkannt; denn der Unterschied von tonaler Helligkeit und Dunkelheit, ebenso die V'eränderung der tonalen Voluminosität kommt auch unabhängig von Tonhöhenänderung vor. Ja, es sind Eigenschaften, die auch bei Geräuschen erlebt werden und damit für das ganze Gehörsreich, nicht nur für die Welt der Töne, gelten.

b) Die rein gradlinige Darstellung des Tonsystems würde bedeuten, dass die Töne sich auch erlebnismälsig um so mehr von einander entfernen, je weiter ihr Abstand auf der Skala ist. Dies trifft aber nicht zu; denn die $\mathrm{Ok}$ t a ve fügt sich nicht diesem Schema. Verfolgt man von irgend cinem Ausgangston an die Tonreihe, so geht der Weg nicht stetig weiter fort von dem Ausgang, sondern in der Oktave ist man wieder bei einem - zwar nicht identischen, aber sehr ähnlichen — Punkt angekommen; sogar Verwechslungen beider Töne sind möglich.

G. Révész wies nun nach, dass die Sonderstellung der Oktave auch für e in f a c he Töne gilt, sodass die Zurückführung der Oktavenbeziehung auf die (remeinsambeit von (Obertönen (Helmholtz, Stumpf) nicht angängig sei. Es handelt sich vielmehr um eine primäre Eigenschaft der Töne. Révész stellt folgende Theorie auf: Die einfachen Töne haben nach ihm $z$ we i Grundmerkmale: Tonhöhe und ,Tonqualität”. In Bezug auf die „Qualität” sind alle Töne mit der gleichen Oktavenbezeichnung identisch; dass sie nicht einfach zusammenfallen, wird durch die Verschiedenheit des Höhenmerkmals bewirkt.

c) Dáss die Vok a le der menschlichen Stimme irgendwie dem Tonreich einzuordnen seien, wurde schon längst als Postulat aufgestellt. Helmholtz, I. Hermann u.a. suchten Vokalklänge durch Zusimmensetzung einfacher Töne zu erzeugen; strittig war, ob hicrbei Töne aus festen Schwingungsbereichen (sog. „Formanten") eine mafsgebende Rolle spielen. Eine Wendung enthielt dies Problem durch die Feststellung Wolfgang Köhlers, dass auch ganz e infachen Tönen Vokalcharakter zukomme. 
Nach geringer Übung konnten seine Versuchspersonen hören, dass gewisse Töne ausgesprochenen U-Klang hatten, andere (mit fortschreitender Höhe) O-Klang, A-Klang, E-Klang, I-Klang. Die dazwischen liegenden Töne hatten den Charakter der Übergangsvokale.

Weiter fand Köhler, dass sich die reinen Ausprägungen der (etwo 40000 ) Obere Tongrenze

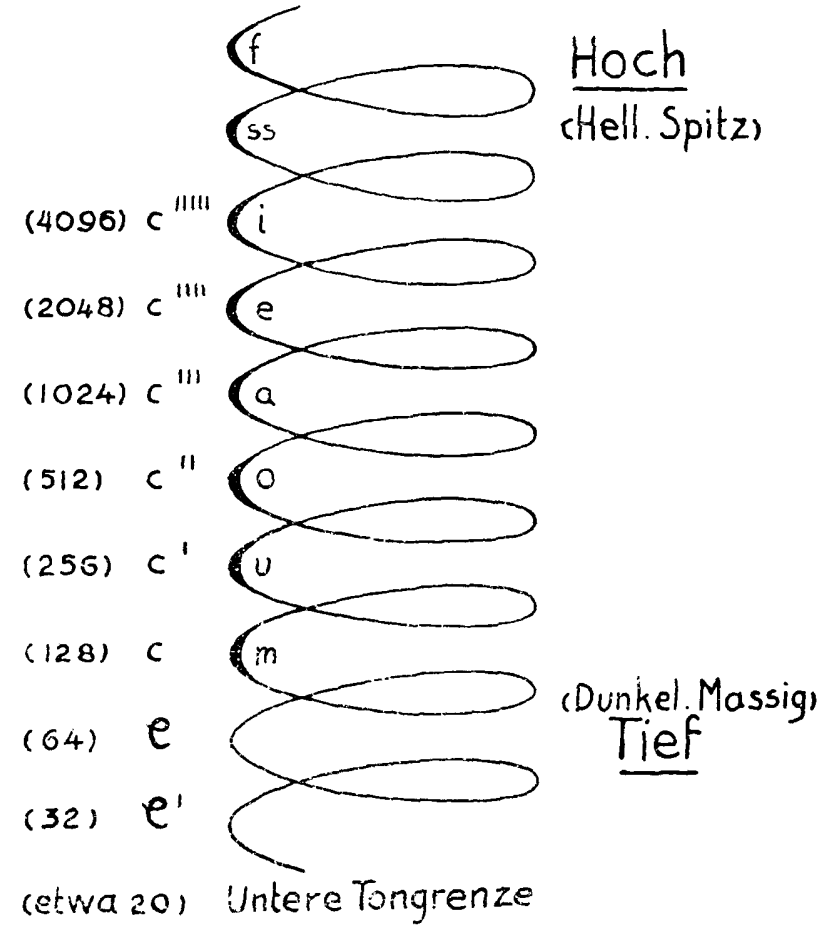

Iis. 6

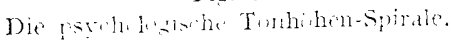

Vokalität an ziemlich eng umgreizte Stellen der Tonlinie heften, welche für alle seine Versuchspersolen (mabhängig vom D)inlekt) fast identisch waren. Dience rokalisch answezeichneten stellen der Tonlinie stehen merkmüriger licine in (ok tavenAbständen, und zwar ungrefält in den Höhen der C des musikaliwhen systems.

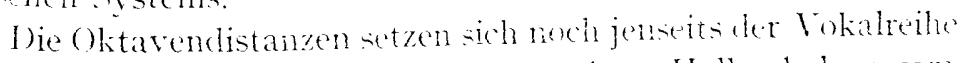
in die Tiefe und in die Höke fort za gewissen Halbrokalen: rom 
U-Klang zur Tiefe hin zeigen die Töne M-Klang, vom I zur Höhe hin erst SS-Klang, dann F-Klang.

Verbindet man die Aufstellungen von Révész und Köhler, so ergibt sich beide Mal als wesentliches Merkmal der Tonreihe (auch der einfachen Töne) die Ok t a ve ng l i e d e r ung. Während Révész die Ähnlichkeit der Töne verschiedener Oktaven betont, hebt Köhler, die qualitative Oktaven-Differe nzi e r ung der Tonreihe hervor; denn jede Oktave hat nach ihm einen anderen Vokalitäts-Charakter.

Das umstehende Spiral-Schema ${ }^{1}$ ) sucht alle genannten Eigenschaften des Tonreichs zu veranschaulichen. Die (dreidimensional zu denkende) Schraubenlinie steigt stetig an, entsprechend dem stetigen Steigen der $\mathrm{T}$ on hö he. Jede Windung umschliesst eine $\mathrm{Ok} \mathrm{tave}$, sodass jede senkrechte Tangente die Töne gleicher musikalischer Benennung (nach Révész: die Töne identischer "Qualität”) berührt. Die durch reine Vokalität (nach Köhler) ausgezeichneten Stellen der Schraublinie sind durch verstärkten Druck markiert: innen ist der dazugehörige Vokalklang (oder Semivokalklang) eingezeichnet. Aussen stehen die musikalischen Oktavenbezeichnungen mit ihren (eingeklammerten) physikalischen Schwingungsfrequenzen.

\section{GESICHT}

Bei den Untersuchungen über den Gesichtssinn ist die Entwicklung von einer zerlegenden Elementenpsychologie zu einer phänomenologischen Betrachtungsweise am deutlichsten zu verfolgen.

\section{Das System derFarben}

Die klassische psychophysiologische Optik, deren Hauptbegründer Helmholtz war ${ }^{2}$ ), sah ihre Aufgabe darin, die elementaren Gesichts-,,Empfindungen” aufzuweisen und durch deren Verknüpfung alle optischen Phänomene zu erklären.

1) Das Symbol der Schraubenlinie für die Tonreihe geht schon auf Drobiscb zurück.

$\left.{ }^{2}\right)$ Wundt ist im wesentlichen hierher zu rechnen, E. Hering nur zum Teil. Als später Abschluss dieser Epoche darf das Alterswerk von G. E. Müller gelten. 
Für die einfachen Grundbestandteile jeglicher Gesichtswahrnehmung ist (wenigstens in der deutschen Sprache) der Ausdruck „F a r b e n e m p findungen” üblich geworden, es werden deshalb auch die Eindrücke „schwarz”, ,grau”, , weiss" als Farberlebnisse bezeichnet; man spricht dann von "tonfreien" oder „unbunten” Farben. Ihnen stehen die „bunten” (,tonigen”, „eigentlichen”) Farben gegenüber.

Die tonfreien Farben ordnen sich zwanglos in eine grade Linie, die vom tiefsten Schwarz durch dunkleres, mittleres, helleres Grau stetig zum reinen Weiss hinaufführt. Die bunten Farben bilden dagegen einen in sich geschlossenen Ring (Fig. 7); denn wenn wir die bekannten physikalischen Spektralfarben: rot, orange, gelb, grün, blau, violett in ihrer erlebnismälsigen Beschaffenheit verfolgen, so ist psychologisch etwa im Blaugrün die weiteste Entfernung vom

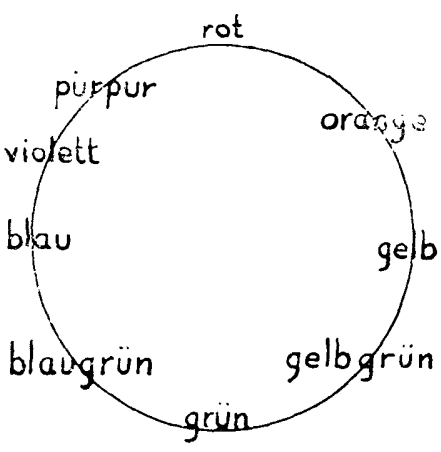

Fig. 7

Der Ring der bunten Farben. Ausgangspunkt Rot erreicht, während von da an wieder eine Annäherung stattfindet. Zwischen Violett und Rot ist nur noch ein geringer psychischer Sprung, der durch die (im Spektrum nicht vertretene) Farbe Purpur überwunden wird.

Werden nun diese beiden Teilsysteme mit einander verbunden, so entsteht der „Farbenkörper", in welchem die SchwarzweissLinie die senkrechte Achse und der Ring der bunten Farben eine Art Aequator bildet. In einem solchen dreidimensionalen System erhält nun jede erlebbare Elementarqualität ihren eindeutigen Platz. Der Aequator repräsentiert die bunten Farbt ö ne in reinster Ausprägung, jeder Parallelkreis en thält sie ebenfalls sämtlich, aber je nach ihrer näheren Lage zum Weisspol oder zum Schwarzpol in grösserer H e ll i g k e i t oder Dunkelheit. Im Inneren liegen die Farben, die dem Mittelpunkt des Globus, dem Grau, näher liegen, also ihren Farbenton in geringerer $\mathrm{S}$ ä $\mathrm{t} \mathrm{t}$ i g u n g enthalten.

Eine solche Systematik der Farben bietet einen mehrfachen Vorteil. Sie ermöglicht erstens, die Zusammenhänge zu studieren, die zwischen den psychischen „Elementen" und den physikali- 
schen Reizen wie auch den physiologischen Erregungen bestehen. Sie erlaubt zweitens eine Festlegung jeder denkbaren Farbennüanze, sodass sie im wissenschaftlichen wie im sozialen Verkehr in stets identischer Weise verwertet werden kann ${ }^{1}$ ). Aber auch hier bestand wieder die Gefahr, dass man um der Elementaranalyse und der einfachen physikalisch-physiologischen Entsprechungen willen die unbefangene Beobachtung und Würdigung der tatsächlichen optischen Erlebnismannigfaltigkeit preisgab. Nur das, was in jenem dreidimensionalen Ordnungssystem Platz hat, galt als unmittelbares sensorisches Erlebnis, als „Empfindung"; alle anderen Phänomene mussten deshalb aus der eigentlichen Sinnessphäre abgeschoben und einer sekundären Sphäre: des Denkens, Vorstellens, Urteilens, zugewiesen werden.

So unterschied Fechner zwischen dem ,direkten” und ,assoziativen" Faktor bei der ästhetisch-optischen Wahrnehmung; Helmholtz hat zur Erklärung von Phänomenen wie Kontrast, Beleuchtung, Farbenkonstanz eine Theorie der ,unbewussten Schlüsse" entwickelt. In kausaler Betrachtungsweise führte dieser sinnespsychologische Dualismus dazu, dass man als ,angeborene" Faktoren nur die Elementarempfindungen gelten liess und alle anderen Wahrnehmungsleistungen dem „Erwerb” oder der "Erfahrung” zuschrieb. Deshalb ist Helmholtz weitgehend „Empirist".

Anders Ewald Hering. Zwar kam es ihm, dem Physiologen, ebenfalls darauf an, die nervösen Vorgälige im Schapparat zu erklären. Aber er war überzengt, dass solche Erklärungen erst versucht werden dürften, wenin man sich unbefangen über die Erlebnishaltigkeit des Sehens Rechenschaft gegeben habe. Wo eine solche Untersuchung unmittelbar sinnliche Erlebnisweisen aufzeige, dürfe man sie nicht zu sekundären Erfahrungserwerbungen degradieren; sie seien dann eben "angeboren”. Hering vertritt also den ,Nativismus".

I ie richtigste pliänomenologische Feststellung Herings war clie, dass die geschlossene Linie der Buntfarben nicht kreisfömig, sondern viereckig dargestellt werden müsse. Erlebni-mälsig ist nicht jede tonige Farbe jeder anderen gleichwertig

1) Diese Zinde vertolat vor alkm das exakt geeichte, ausserst minutiöse Farbensytem von llith. Ostwall. 
und sind nicht alle Ubergänge zwischen den Farben in gleicher Weise gleitend (was durch eine Kreislinie symbolisiert würde); vielmehr gibt es in der Reihe der Farben ausgezeichnete Punkte, gleichsam Ecken, in denen sich die Richtung des Erlebens sprunghaft ändert. An diesen Ecken liegen die vier tonigen ,H a u p tf a r b e n" Rot, Gelb, Grün, Blau, die eine ganz andere Unmittelbarkeit und Ursprünglichkeit des Erlebens zeigen als die zwischen ihnen liegenden Farbtöne. So hat z.B. „Orange”, verglichen mit der in sich selbst ruhenden Einfachheit von "Rot" und "Gelb”, einen ausgesprochenen Zwischencharakter, ebenso „Violett" gegenüber dem „Urblau” und „Urrot”. - Gleiches behauptet Hering bezüglich der tonfreien Farben: nur "Schwarz" und "Weiss” seien Hauptfarben, alle Stufen des „Grau” Zwischenfarben.

Man kann dieser Aufstellung von sechs phänomenologischen Hauptfarben zustimmen, allerdings mit zwei Einschränkungen. Das Sechsfarbensystem trifft zu für die heutige europäisch-amerikanische Kulturmenschheit; ihre Gültigkeit für alle Zeiten und Kulturen ist dagegen äusserst problematisch. Das Farbenerlebnis ist so eng mit Erlebnissen aus ganz anderen Schichten verknüpft, hängt so stark mit der Farbigkeit des Milieus und mit symbolischen Bedeutungen zusammen, dass auch die erlebnismälsige Unterscheidung von „Haupt”- und „Neben"-Farben hiervon betroffen werden kann. Deshalb ist es auch bedenklich, die Cnterscheidungen gradewegs ins Netzhaut-Physiologische zu übersetzen und dadurch zu einer für alle Menschen aller Zeiten gültigen machen zu wollen ${ }^{1}$ ). - Ferner darf die Bezeichnung "Zwischenfarbe” nicht verwechselt werden mit „Mischfarbe”. Orange mag physikalisch und maltechnisch durch Mischung von Rot und (ielb erzielt werden, psychologisch aber wird in Orange nicht ein Gemisch von Rot und Gelb erlebt; der Eindruck ist durchaus einheitlich, hat nur eine nach zwei Seiten gerichtete Änlichkeit, sodass es mit Recht als „Zwischen” Rot und Gelb stehend bezeichnet werden kann.

\footnotetext{
1) Nach Hering bestehen in jedem Jetzhautcientent dreisubtanzen nebeneinander, deren jede durch chemische Prozese entgegengesetzter Rl hitur (1)issinilation und Assimilation) ein Paar von Empfindunger hervorrafe: di. cine liefert de Emptin. hungen Schwarz und Weiss, die zweite de Empfindmin R.t and Grund de'dritte the Empfindungen Gelb und Blau: alle anderen Farbemprimlunaten fntetän len durch gleichzeitige Funktion von mehreren dieser Substanzen.
}

Stern, Psychologie 
Der „Farbkörper” gewann durch die Hering'sche Korrektur die Form eines $\mathrm{Okta}$ e ders (Fig. 8). Die sechs Ecken repräsentieren die Hauptfarben Schwarz, Weiss; Grün, Rot; Blau,

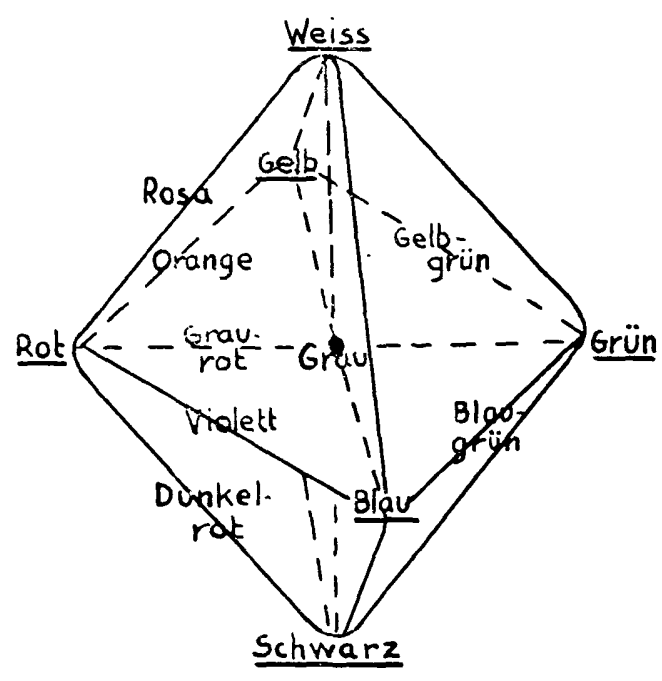

Fig. 8

Das psychologische Farben-Oktaeder (nach Ebbinghaus) Gelb. Alle anderen Orte des Farbkörpers sind von $Z$ wischenfarben verschiedener Tonigkeit,Helligkeit und Sättigung besetzt.

Die an entgegengesetzten Ecken liegenden Farben stehen $z u$ einander im Verhältnis des $\mathrm{K}$ on trastes und des $\mathrm{K}$ om plementarismus. Treten zwei solche Farben $z$.B. nebeneinander oder nacheinander auf, dann ist ihre Gegensätzlichkeit unmittelbar evident;

auch steigern sie sich gegenseitig in ihrer spezifischen Besonderheit. Eine neutrale Farbe wird beim Zusammentreffen mit einer bunten Farbe in der Richtung zur Kontrastfarbe hin verfärbt. Komplementarismus heisst: wirken beide Farben zugleich auf dieselbe Stelle des Sinnesorgans, dann hemmen sie sich gegenseitig; bei geeigneter Dosierung der beiden Komponenten entsteht ein neutrales Grau.

\section{Erscheinungsweisen der Farben}

Hering bildet das Zwischenglied zwischen der älteren, physiologisch orientierten, und der neuen $\mathrm{ph}$ ä n o m e n o lo g i s ch gerichteten Psychologie der Gesichtswahrnehmungen. Nunmehr sind es Ps y c h o log e n - vor allem Katz, ferner Gelb, Bühler und andere - die (unter einstweiliger Zurückstellung systematischer und physiologischer Ziele) die innere Mannigfaltigkeit des farbigen Erlebens als solchen zu beschreiben und seine Ge- 
setzmärsigkeiten $\mathrm{zu}$ ergründen suchen. Die „E E s chein ungsweisen der Farben" (Katz) werden jetzt zum Problem. Im wirklichen Bewusstseinsbereich des Menschen gibt es ja nie rote, grüne, graue u.s.w. Farbelemente, die sich zu optischen Gebilden addieren, sondern es gibt farbige Dinge in bestimmter Beleuchtung; es gibt Farbiges nur in gewissen räumlichen Strukturen, aus denen es nicht herausgenommen werden kann, ohne seine psychische Wesenheit aufzugeben. 1)as, was die älteren Theorieen als eigentliche Beschaffenheiten der „Empfindungen" hingestellt hatten, Farbenton, Helligkeit, Sättigung bildet nach Katz nur die „Farbmaterie” für die verschiedenen psychischen Erscheinungsweisen. So pflegt man jetzt nach Katz zu unterscheiden: „Flächenfarben" (z.l3. die spektralen Farben im Farbenmischapparat); „Oberflächenfarben” (die den Aussenseiten der Dinge anhaften); ,durchsichtige Flächenfarben” (z.B. von buntem Glas); "Raumfarben” (von farbigen Flüssigkeiten im Gefäss, von farbigen Dämpfen). Die Besonderheiten dieser Erscheinungsweisen sind - wie immer wieder hervorgehoben wird - unmittelbare Qualitäten des sinnlichen Eindrucks als solchen, nicht etwa erst Ergänzungen auf assoziativem oder logischem Wege. Das Gleiche gilt von den Erscheinungweisen des Leuchtens, Glühens, Glänzens, der Spiegelung und der Durchsichtigkeit.

Die bisher genannten Erscheinungsweisen der Farben kommen durchweg Einzelgebilden zu; über diese hinaus aber greift eine optische Erscheinungsweise, deren Wesen darin beruht, ungestaltet und ganzheitlich zu sein. Die "B e l e u ch t u ng", in welcher ein Zimmer bei diffusem Tageslicht, eine Landschaft vor einem Gewitter erscheint, ist alles andere als eine Summe der Farbtöne und Helligkeiten der einzelnen sichtbaren Dinge. Sie ist, psychologisch gesehen, unserem Erleben viel tiefer eingebettet als alle Gegenstände; sie liefert die ,E i n d r ing $\mathrm{l}$ i c hk e i t" (Katz), mit der sich das ganze Gesichtsfeld - oder grosse Teile des Gesichtsfeldes -- dem Menschen aufdrängen. Beleuchtung haftet nicht an den Gegenständen, sondern durchdringt den Raum und teilt sich allem Einzelnen mit.

Der Mensch kann sich einer Beleuchtung so ganz und gar hingeben, dass die einzelnen Dinge erlebnismälsig ganz zurücktreten. Er kann aber andrerseits, bei seelischer Einstellung auf ein Ein- 
zelding, die spezielle Beleuchtungssituation, in welcher es steht, unbeachtet lassen. Und hier erhebt sich noch ein letztes farbenpsychologisches Problem, dessen Bedeutung schon von Hering bemerkt, aber erst von der modernen Psychologie eingehender untersucht wurde: das der „F a r b e n k o n s t a n $z "{ }^{1}$ ).

Ein und derselbe farbige Gegenstand, z.B. ein grünes Blatt, wirft ganz verschiedene Strahlen auf die menschliche Netzhaut, je nachdem es in direkter Sonnenbeleuchtung, in der Dämmerung, in der künstlichen Beleuchtung von Bogenlicht oder Gasglühlicht gesehen wird. Bestände also eindeutige Entsprechung zwischen Reiz und Wahrnehmung, dann müsste der Gegenstand jeweils in ganz anderer Farbigkeit erscheinen. In Wirklichkeit aber bleibt das Blatt für den Betrachter nicht nur derselbe Gregenstand, sondern auch seine Farbigkeit erscheint konstant - solange die Beleuchtungsverhältnisse nicht ganz abnorm werden.

Noch paradoxer ist der folgende Fall. Stellt man eine weisse und eine schwarze Scheibe so auf, dass die weisse im Schatten eines Schirmes, die schwarze im hellen Tageslicht steht, dann wird jeder Beobachter, der beide zugleich betrachtet, sie trotz der verschiedenen Beleuchtung als weiss und schwarz sehen, wenn auch das Weiss weniger "eindringlich" als sonst erscheint. Weiss bleibt also für die Gesichtswahrnehmung "weiss", obgleich die von der beschatteten Weissscheibe ausgestrahlte physikalis che Helligkeitsmenge geringer ist, als die von der hell beleuchteten Schwarzscheibe ausgehende. - Der Eindruck ändert sich aber sofort, wenn man die Beleuchtungsquellen für den Beobachter unsichtbar macht. Schiebt man nämlich vor die beiden verschieden beleuchteten Scheiben einen Lochschirm, sodass der Beobachter durch zwei Löcher nichts als Teile jeder Scheibe ohne jedes Umfeld sieht dann erblickt der Beobachter zwei Grau, von denen das von der ,weissen" Scheibe stammende dunkler erscheint als das andere. Also nur im ,beleuchtungsfreien Zustand" werden die Helligkeiten ihren physikalischen Grössen entsprechend gesehen. Sonst herrscht weitgehend Helligkeits-, bezw. Farbenkonstanz.

Die Erscheinung der Farbenkonstanz gehört mit zu den eindrucksvollsten Beispielen für die personale Verankerung der Wahrnehmung ${ }^{2}$ ). Der Mensch kann nur in einer Welt existieren, in welcher konstante Gegenstände vorhanden sind. Wahrnehmung liefert ihm diese Gegenstände in ihrer gegenwärtigen Situation -

1) Einc zusammenfassende Darstellung gab A. Gelb.

$\left.{ }^{2}\right)$ Über analoge Konstanzph inomene vgl. S. 203. 
löst sie aber nicht auf in bloss augenblickliche Beschaffenheiten (sodass sie im anderen Zeitpunkt bei anderer Beleuchtung nicht mehr dieselben wären); vielmehr erhält sie zugleich die notwendige Konstanz ihres Erscheinens aufrecht. In der Art des optischen Wahrnehmens kommt nicht nur die augenblickliche Reizung bestimmter Netzhautstellen durch bestimmte physikalische Reize, sondern das Gesamtverhältnis Person/Ding innerhalb des Sichtbaren zur Geltung. 


\title{
ACHTES KAPITEL
}

\author{
ZUSA M M N H ̈ N GE DER SIN N E
}

I. INTERSENSORIELLE WAHRNEHMUNG

INSBES. DES RAUMES UND DER ZEIT

\section{Allgemeines}

Wenn an einem einzelnen Wahrnehmungserlebnis Eindrücke verschiedener Sinnesmodalitäten beteiligt sind, nennen wir es ,,intersensoriell".

Dadurch, dass die Psychologie lange Zeit die sinnesspezifischen Erscheinungen bevorzugt hatte, war ihr die grosse, ja fast unbegrenzte Bedeutung des intersensoriellen Wahrnehmens nicht ganz zum Bewusstsein gekommen. In Wirklichkeit sind die weitaus meisten menschlichen Wahrnehmungserlebnisse durch das mehr oder minder enge Ineinandergreifen mehrerer Sinnesmodalitäten bedingt, wenn auch gewöhnlich eine Modalität vorzuherrschen pflegt.

Die wichtigsten Belege hierfür werden uns alsbald aus dem Gebiet der Raum- und Zeit-Wahrnehmung begegnen; hier seien zur vorläufigen V'eranschaulichung zwei andere Beispiele gegeben.

Das Wahrnehmungserlebnis an unserer Hautoberfläche, das wir mit ,nass" bezeichnen, entsteht nur dann, wenn ein ausgebreiteter und diffuser $\mathrm{B}$ e $\mathrm{r}$ ü $\mathrm{rungseindruck}$ zugleich die T e m per a t u r marke „kühl" enthält. Warmes Wasser wird in dem Augenblick, da ich die Hände hineinstecke, nicht als nass empfunden; erst wenn die wieder herausgenommenen Hände an der Luft stark abkühlen, wird mir bewusst, dass sie ,nass” sind.

Wie stark bei unseren Gesch mackswahrnehmungen auch Geruchsempfindungen mitspielen, bemerkt man erst, wenn ein heftiger Schnupfen diesen Faktor ausschaltet; dann haben die 
sonst sehr schmackhaften Speisen „keinen Geschmack mehr”. Auch andere Sinne wirken beim Geschmack mit. So beruht der zusammenziehende oder brennende Geschmack bestimmter Würzen auf Tast- oder Temperatur-Empfindungen. Knusprige Genussmittel (Radieschen, Backwerk) verlieren beim Weichwerden ihre geschmackliche Eigenart durch den Ausfall der sonst beim Beissen entstehenden Widerstands- und Bewegungsempfindungen.

In diesen Beispielen haben wir die Wahrnehmungserlebnisse a nal y si e r e n d besprochen und darum auch den Ausdruck „Empfindungen” gewählt für die Beiträge, welche die verschiedenen Modalitäten $z u$ der Totalwahrnehmung liefern. Um so entschiedener muss aber nun betont werden, dass diese Darstellung nicht elementenpsychologisch verstanden werden darf. Rein erlebnismäfsig genommen ist die intersensorielle Wahrnehmung "nass" oder ,knusprig” genau ebenso einheitlich wie die sinnesspezifische Wahrnehmung ,rot" oder "Geigenklang”. Beim Eindruck „nass" ist keine Rede von irgend einer bewussten „Summierung” oder „Assoziation” oder „Synthese” eines Berührungs- und eines Temperatur-Eindrucks; ja, wenn ich mir diese beiden Bestandteile bewusst zu machen suche, verliere ich geradezu die eigentliche Qualität „nass” aus meinem Erleben.

Es gibt also intersensorielle Erscheinungsweisen der Wahrnehmungen vongleicher Ursprünglichkeit und Einheit lichkeit wie es sinnesspezifische Erscheinungsweisen $\mathrm{g}$ i b t.

Oder vielleicht gar von noch stärkerer Ursprünglichkeit? Erinnern wir uns der entwicklungsps ychologischen Betrachtung des sechsten Kapitels. Dort wurde gezeigt, dass sich die spezifischen Sinnesorgane und Sinneserlebnisse erst allmählich aus einer diffusen, ,unterspezifischen" Ursensibilität entwickeln. Da diese in den höheren Entwicklungsstadien nicht einfach dahinschwindet, so haben wir ein Recht, in den intersensoriellen Wahrnehmungsphänomenen, soweit sie ursprünglichen Charakter haben, ein Weiterwirken jener Gesamtsensibilität zu sehen.

Das Verhältnis der sinnesspezifischen zu den intersensoriellen Wahrnehmungsphänomenen enthüllt sich also als ein doppelseitiges. Einerseits sind die intersensoriellen Wahrnehmungen die 
ursprünglicheren, aus denen sich die sinnesspezifischen herausdifferenzieren; andrerseits können sich im Laufe der Erfahrung sinnesspezifische Einzelwahrnehmungen zu neuen intersensoriellen Wahrnehmungen verbinden.

Hatte die Elementenpsychologie die intersensoriellen Wahrnehmungen durch "Assoziation" der verschiedenen spezifischen Empfindungen $\mathrm{zu}$ erklären versucht, so muss nach personalistischer Auffassung eine „Dissoziation” vorangegangen sein, die aus der unspezifischen, der Person tief eingebetteten Totalwahrnehmung erst die Anteile der einzelnen Sinne heraussonderte. $\mathrm{D}$ a n n erst können die verselbständigten Ergebnisse dieser Dissoziation, also die spezifischen Erlebnisse, zu neuen intersensoriellen Wahrnehmungen verknüpft werden.

\section{Raumwahrnehmung}

a) Der intersensorielle Charakter. - Dass der Mensch Räumliches „wahrnehmen” d.h. in seiner gegenwärtigen Gegebenheit unmittelbar erfassen könne, steht ausser Frage. Wir sind auch ohne Schwierigkeit im stande, die räumlichen Hauptqualitäten zu benennen, die auf solchem Wege, also a n$\mathrm{sch}$ a u li ch (nicht nur vorstellungsmälsig oder gedanklich) erlebbar sind: Ausdehnung, Gestalt, Grösse, Richtung, Lage, Ort, Entfernung, Bewegung.

Aber ins Problematische geraten wir sofort, wenn wir nach der Art dieser Wahrnehmung fragen.

Es stellt sich nämlich heraus, dass jedes räumliche Gebilde und jede räumliche Qualität durch mehrere Sinnesmodalitäten wahrgenommen werden kann. A u s d e h n u n g kommt erlebnismälsig ebenso dem Tisch zu, den ich vor mir sehe, wie dem Stuhl, auf dem ich sitze, und der mir nur durch Berührungseindrücke gegeben ist; sie kommt auch der Musik zu, die soeben in breiten Strömen mein Ohr trifft. - Die verschiedene En t$\mathrm{f}$ e $\mathrm{r} n \mathrm{u} \mathrm{n} \mathrm{g}$ zweier auf dem Tisch liegender Bücher von mir kann ich durch das Auge und durch Greifbewegungen, also kinaesthetisch, feststellen. -- Die runde $G$ es $t$ a $1 \mathrm{t}$ eines Balles wird mir durch Gesicht oder durch Getast oder durch beides vermittelt. Die R ichtung, aus der ein Wagen kommt, kann ich sehen und hören. 
Die psychischen Raumqualitäten sind also ihrem Wesen nach intersensoriell. Sie sind es auch dann, wenn im konkreten Einzelfalle nur e in e Sinnesmodalität funktioniert. So ist die Kugeligkeit des Balles auch in dem Augenblick, da ich den Ball nicht anfasse, sondern nur optisch wahrnehme, dennoch nicht in gleichem Sinne seh-spezifisch wie etwa die Farbe des Balles. Denn diese verschwindet beim C'bergang in eine andere Sinnesmodalität; die räumliche Gestaltbeschaffenheit aber bleibt hierbei bestehen.

Selbstverständlich behalten trotz dieser Feststellungen alle jene Untersuchungen ihre hohe Bedeutung, welche sich mit dem Anteil der Einzelsinne an der Raumwahrnehmung beschäftigen; aber ihre theoretische Deutung muss zum Teil verändert werden. Es sei dies exemplifiziert an den beiden Hauptarten der Raumwahrnehmung, dem Sehen und Tasten.

b) Raumwahrnehmung durch das Auge. Eine besondere Pflege haben in der modernen Psychologie die optischen Raumphänomene erfahren; in der Tat übertrifft das Auge alle anderen Sinne sowohl an Qualitätenfülle wie an Feinheit des räumlichen Wahrnehmens. Allein angewiesen auf das Auge ist die Wahrnehmung flächiger Gestalten, und damit das weite Reich von Bild und Schrift; ebenso die Erscheinungen der Ferne. Aber auch bei jenen Raumphänomenen, die nicht nur optisch, sondern auch mit anderen Sinnen erlebt werden können, ist die Unterscheidungsfähigkeit des Auges meist der der andern Organe überlegen.

Die sogen. „Sehschärfe” wird gemessen durch den kleinsten Unterschied räumlicher Gegebenheiten, der bei ruhendem Auge optisch bemerkt werden kann. Man hat sie untersucht für Punktdistanzen, I.inien, Winkel, Figuren, Bewegungen, an den verschiedensten Stellen des Auges und unter verschiedenen Beleuchtungsbedingungen. Die Sehschärfe ist in den mittleren Partieen der Netzhaut von erstaunlicher Feinheit; unter günstigen Umständen genügt hier ein Abstand $z$ weier Punkte um eine Winkelminute, damit sie als getrennte gesehen werden. Gegen die Seitenteile der Netzhaut hin nimmt die Sehschärfe rapide $a b$.

Aber selbst in n e r h a l b der Raumwahrnehmung durch das Auge lässt sich der intersensorielle Charakter des räumlichen Wahrnehmens nicht ausschalten. Denn das Auge ist kein nur- 
optischer, sondern zugleich ein $\mathrm{B}$ e w e g u n g s a p p a r a t und zwar ein recht komplizierter; und alle diese Augenbewegungen führen zu kinaesthetischen Eindrücken, die in das Erlebnis des räumlichen Sehens mit eingehen.

Innerhalb des e i n z e l n e n Augapfels gibt es die Dickenregulierung der Linse, durch welche Bilder von Objekten verschiedener Entfernung deutlich auf die Netzhaut entworfen werden können (,Akkomodation'), und die Funktion des Ringmuskels, der das Pupillenloch vergrössert oder verkleinert. Von aussen greifen an jedem Augapfel sechs Muskeln an, welche ihm verschiedene Dreh- und Roll-Bewegungen erteilen können. Endlich stehen die Bewegungen beider Augäpfel in so enger Koordination, dass man von e i n e m Doppelorgan zu sprechen pflegt. Die Sehlinien beider Augen werden normaler Weise so eingestellt, dass sie sich in dem fixierten Gegenstande schneiden (,Konvergenz”). Dieser Konvergenzwinkel ist um so spitzer, je weiter das Objekt vom Betrachter entfernt ist. Ausserdem kann das Doppelauge gleichsinnig nach oben, nach unten, nach rechts, nach links gedreht werden.

Diese muskulären Funktionen sind beim Sehen geradezu allgegenwärtig. Selbst wenn wir mit $\mathrm{ruh}$ e n d e m Auge etwas fixieren, müssen die Augenmuskeln, um die richtige Konvergenz inne zu halten und Doppeltsehen zu vermeiden, in einem bestimmten Spannungszustand gehalten werden; dass dieser $\mathrm{Zu}$ stand nicht ohne psychischen Niederschlag ist, erkennt man z.B. an der Ermüdung, die man nach längerer Fixation in den Augenmuskeln spürt. Sobald nun aber die Augen bewegt werden: bei allem eigentlichen „Blicken”, beim Verfolgen mit den Augen, beim optischen Abtasten von Konturen, beim Lesen, beim Umstellen der Konvergenz aus der Ferne auf die Nähe und umgekehrt - durchdringen sich rein optische und kinaesthetische Momente im Raumerlebnis so innig, dass jede Analyse nur ein künstliches Verfahren ist.

Wir müssen uns hier damit begnügen, an e i n e $r$ Erscheinungsweise des räumlichen Sehens, der T i e f e n w a h $\mathrm{r} n$ e h$\mathrm{m} \mathrm{ung}$, diesen Sachverhalt zu veranschaulichen; wir betonen aber sogleich, dass analoge Betrachtungen für die anderen Erscheinungsweisen anzustellen sind. 
In welcher Weise und mit welchen Mitteln sieht der Mensch die Tiefe des Raumes, d.h. die Erstreckung in die Ferne, das Hintereinander, die Plastik der Dinge? Das Problem war deshalb so fesselnd, weil ein Widerspruch zu bestehen schien zwischen dieser Sehleistung und der räumlichen Beschaffenheit des Aufnahmeorgans; denn die Netzhaut ist ja eine Fläche, und die auf ihr hervorgerufenen Eindrücke stehen nebeneinander, liefern nur flächenhafte Bilder. Woher stammt dennoch das optische Tiefenerlebnis?

Subtile Analysen ergaben eine grosse Mannigfaltigkeit von Leistungen der Netzhaut wie der Augenmuskulatur, die alle zum Tiefensehen beitragen. Es sind im Wesentlichen die folgenden.

I. Rein optisch: a) Die sogen. "Querdisparation": infolge der Tiefenerstreckung der angeschauten Welt sind die Netzhautbilder beider Augen nicht völlig gleich. (Das Stereoskop isoliert diesen Faktor und vermittelt dann künstliches Tiefensehen).

b) Die perspektivischen Verschiebungen (z.B. der Winkel und Kanten an dem vor mir stehenden Tisch).

c) Die Verkleinerung der Objektbilder auf der Netzhaut bei zunehmender Entfernung.

d) Die Úberschneidung, infolge deren die weiter zurückliegenden Gegenstände von den näher gelegenen teilweise verdeckt werden.

e) Die Luftperspektive, welche die sichtbaren Gegenstände um so verschwommener erscheinen lässt, je weiter sie vom Beschauer entfernt sind.

II. $\mathrm{K}$ in a e st he tis ch: a) die Empfindungen, welche die wechselnde Akkomodation der Linse auf die verschieden entfernten Gegenstände begleiten.

b) Die Empfindungen, welche die wechselnde Konvergenz des Doppelauges auf die verschieden entfernten Gegenstände begleiten. (Versucht man die Augen auf den ganz dicht vor die Nase gehaltenen Finger zu fixieren, so hat man ein unmittelbares II kelerlebnis der ungewöhnlich starken Konvergenzeinstellung).

Man kann alle diese Faktoren durch geschickte experimentelle inordnung gesondert untersuchen; auch Naturexperimente, z. B. Augenmuskellähmung, Einäugigkeit, bieten lehrreiche Aufschlüsse über den Anteil dieses oder jenes Moments. Insbesondere sind solche Forschungen in leistungspsychologischer Hinsicht wichtig; so hat man z.13. 
festgestellt, dass die Konvergenzbewegung des Doppelauges viel feineren Tiefenunterschieden gewachsen ist, als die Akkomodation.

Phänomenologisch aber ist von dieser Vielfältigkeit nichts zu spüren. Die Erschein u $\mathrm{g} s \mathrm{w}$ e i s e „T i e f e” ist für den unbefangenen Betrachter eine durchaus ursprüngliche und einheitliche; wir haben es mit einer primären intersensoriellen Wahrnehmung zu tun.

Aber unsere Beschreibung des Tiefensehens war noch nicht vollständig. Denn die Wahrnehmung erschöpft sich nicht in den, vom Auge herrührenden, optischen und kinaesthetischen Eindrücken. A ndere $\mathrm{K}$ ör perteile beteiligen sich gleichfalls daran, und zwar gerade in den primitivsten Entwicklungsstadien am meisten. Beim Kleinkind beschränkt sich die wahrnehmbare Tiefe auf eine sehr enge und nahe Sphaere, innerhalb deren die optischen Eindrücke angeborenermalsen zu Greifimpulsen führen; die kinaesthetischen Greiferlebnisse sind somit notwendige Konstituenten des Gesamteindrucks „näher" oder „,ferner”. Wenn später der Mensch sich selber zu den entfernten Gegenständen hinzubewegen vermag, wird nun wiederum das Bewusstsein dieser Eigenbewegungen zu einem Index der Entfernung - kurz: der Mensch, ,s i e h t" T i efe nicht nur mit der Netzhaut, nicht nur vermittels der Augenbewegungen, sondern vermittels seiner ganzen Person, von der jeweilig diejenigen Organe in Funktion gesetzt werden, welche dem Wahrnehmungsziel am zweckmälsigsten dienen. Und wenn wir den ganzen Vorgang "Sehen” nennen, so deshalb, weil der Impuls zu dieser Totalreaktion vom Auge ausgeht, und weil auch die rein optischen Eindrücke der Gesamtwahrnehmung das Gepräge geben - nicht aber weil es sich um eine ausschliesslich sinnesspezifische Leistung der Netzhaut handelte.

Verfolgt man das Tiefensehen in seiner Entwicklung innerhalb des einzelnen Individuums, so zeigt sich deutlich, wie sich aus der ursprünglichen intersensoriellen Wahrnehmung durch Dissoziation sinnesspezifische Faktoren verselbständigen (sodass dann der rein optische Faktor der perspektivischen Verkürzung und der Querdisparition für sich allein den Tiefeneindruck zu erwecken vermag), und wie dann auf höherer Stufe immer wieder neue intersensorielle Strukturen entstehen. Man hatte lange gestritten, ob man die optische Tiefe nativistisch oder empiristisch 
zu erklären habe; unsere Darlegung zeigt, dass sowohl Ursprüngliches, wie Erworbenes an ihr beteiligt ist.

c) Raumwahrnehmung durchden Tastsinn - Neben dem Auge ist die ta ste nde Hand ein Hauptorgan für die Vermittlung räumlicher Wahrnehmungen. Welcher Art sind nun diese Tasterlebnisse? Wir mussten schon mehrfach hervorheben, dass der sogen. „Tastsinn" keine spezifische Sinnesmodalität darstelle, sondern dass er Berührung und Bewegung (und demnach haptische und $\mathrm{k}$ in a est het ische Erlebnismomente) unlösbar vereinigt in sich schliesse. Der blosse Kontakt eines Gegenstandes mit der ruhenden Handoberfläche erweckt zwar Berührungsempfindungen; aber über die räumliche Beschaffenheit des Objektes entsteht bei diesem „Ruhetasten" nur eine äusserst dürftige Wahrnehmung; wir erhalten ein diffuses Bild seiner Ausgedehntheit, ohne irgendwie deutliche Gestalts- und Proportions-Merkmale. (Man kann bei Auflegen auf die unbewegte Hand nicht ein 5-eckiges Pappstück von einem 6-eckigen unterscheiden). Es muss erst das a $\mathrm{kt}$ i ve Tasten einsetzen, um einigermalsen gestaltete Raumeindrücke zu vermitteln. Dies tritt in zwei Formen auf.

Beim „Gr e if t a s t e n" wird der Gegenstand vom tastenden Organ umschlossen; die an mannigfachen Stellen der Hand gleichzeitig einsetzenden Druckempfindungen verschmelzen mit den Lage- und Spannungs-Empfindungen in Nuskeln und Gelenken zu der einheitlichen intersensoriellen Wahrnehmung des Gegenstandes. Greiftasten kann einhändig sein, so wenn ich im Dunkeln einen Schlüssel, eine Streichholzschachtel ertaste. Es kann zweihändig sein; so ist beim Lmgreifen eines mittelgrossen Balles das Händepaar in ähnlichem Sinne ein einheitliches 1)oppelorgan, wie wir es oben vom Augenpaar erwähnten. Wir erleben hierbei nicht etwa rechts und links je eine Kugelkalotte, sondern durchaus einheitlich die (iesamtkugel. Auch mit anderen Organen gibt es umgreifendes Tasten: der Blinde umfasst z.B. mit seinen Armen einen Schrank, um desien Umfang wahrzunehmen.

Beim "A b tast en" wird ein und dieselbe Körperstelle sukzessiv über die Konturen oder Oberflächen des wahrzunehmendeil Gegenstandes geführt. Da hier also die Berührungsemptin- 
dung kaum variiert, muss die eigentliche Qualität des Wahrnehmungsinhalts durch die wechselnden Widerstands- und Bewegungsempfindungen in Gelenken und Muskeln erzeugt werden. So tasten wir im Dunkeln mit der Hand die Kanten eines Tisches $\mathrm{ab}$, oder mit den Füssen, bezw. mit einem Stock, die Stufen einer unbeleuchteten Treppe.

Gerade das letzte Beispiel ist lehrreich. Die Berührungs- und DruckEmpfindungen, die der Stockgriff in meinem Handinnern erzeugt, sind sehr dürftig und eintönig; dennoch erhalte ich eine gute Wahrnehmung der Stufen durch Nitwirkung jener kinästhetischen Empfindungen, beim Manipulieren mit dem Stock. - Aber wiederum muss betont werden: unsere Wahrnehmung der Treppe enthält nicht ein Mosaik von Druckempfindungen des Fusses, Druckempfindungen der Hand, kinästhetischen Empfindungen in der Bein-, Arm-, und HandMuskulatur, sondern ein einheitliches Erlebnis des Objektes Treppe.

d) Der Wahrne h m ung s a u m. - Einen wichtigen Schritt weiter zum Verständnis des räumlichen Wahrnehmens führt uns nun die folgende Erwägung.

Wir nehmen ja niemals isolierte räumliche Objekte oder räumliche Qualitäten (Gestalt, Ausdehnung, Richtung) für sich, sondern immer nur rä um lich e G e bilde im Raum wahr. Und dieser Raum, so wie er als gemeinsamer Träger der einzelnen Raumdata zu meiner Wahrnehmung gehört, ist ebenfalls nur i n t e r s e n s ori e 11 vorhanden. Es ist irreführend, wenn man von einem „Gesichtsraum”, „Tastraum”, „Gehörsraum” spricht. Es gibt nicht Sonderräume der einzelnen Sinnesmodalitäten, vielmehr nur den einen personalen Raum, in dem jeder Mensch lebt und den er teilweise erlebt. Wenn ich den Ort und die Voluminosität eines musikalischen Klanges wahrnehme, so sind dies zwar Raumerlebnisse von vornehmlich akustischer Natur; aber der Raum, i n dem sich diese Eindrücke für mein Erleben befinden, ist nicht ein besonderer Schallraum, sondern mein Raum, derselbe Raum, der auch der gemeinsame Grund für meine optischen und taktilen Raumerlebnisse ist.

Ebensowenig gibt es einen reinen Gesichtsraum. Man könnte vielleicht dagegen einwenden, dass ja die räumlichen Eindrücke der Ferne - z.B. der weiten Gebirgslandschaft oder des Himmels - nur sinnesspezifisch durch das Auge erlebbar sind und daher in ihrer Gesamtheit einen „Raum” eigener Art bilden, der 
dem Blinden völlig fehle. Aber dieser Einwand ist nicht zutreffend. Gewiss besteht ein sehr wesentlicher Unterschied zwischen personaler Nähe und Ferne, aber es gibt wahrnehmungsmälsig keine Kluft zwischen ihnen, sondern kontinuierliches Übergehen. Von den blauen Bergen dort hinten bis zu dem Hause vor mir, das ich mit wenigen Schritten erreichen kann, und bis zu dem Strauch neben mir, dessen Zweige ich greife, bildet die Landschaft e in en Raum mit mir selbst als Mittelpunkt. - Und wie steht es mit der Raumwahrnehmung des Blinden? Gewiss ist sein Erkennen der Einzeldinge ganz überwiegend auf den Tastsinn angewiesen; dennoch ist sein Raum kein blosser Tastraum; es ist derselbe Raum wie der des Sehenden, nur dürftiger an Inhalten, enger an Aktionsmöglichkeiten. Aber auch für den Blinden erstreckt sich der Raum kontinuierlich aus der Nähe in die Ferne, aus der ihm der Ruf und der Donner, das Telephon, der Wind, die strahlende Sonnenwärme Kunde mit Hilfe verschiedener Sinnesmodalitäten bringt.

Wir müssen deshalb auch endgültig brechen mit allen Versuchen, welche einem einzigen Sinn ein M o nopol auf Raumerlebnisse zuschreiben wollen. Derartige Versuche führten zu höchst seltsamen Konstruktionen und taten dem wirklichen psychischen Erleben mehr oder minder grosse Gewalt an.

So wurde oft behauptet, dass nur der Gesichtssinn unmittelbar räumliche Eindrücke verschaffe, während die Eindrücke der anderen Sinnesmodalitäten indirekt als Symptome für Räumliches gedeutet werden müssten. Ging doch diese Meinung zum Teil so weit, dem Blinden eigentliches Raumerleben überhaupt abzusprechen. Es ist gegenüber solcher Verstiegenheit kaum nötig, darauf hinzuweisen, dass es unter Blindgeborenen bedeutende Raumwissenschaftler (Geometer) und Raumkünstler (Plastiker) gab und gibt; j e d e r Blinde erweist durch sein alltägliches Verhalten und Tun und Aussagen, dass Raum durchaus anschaulich für ihn vorhanden ist.

Eine entgegengesetzte Theorie erkennt nur den kinacsthetischen Empfindungen unmittelbar räumlichen Charakter zu und erklärt die quasi-räumliche Wahrnehmung der anderen sinne nur durch ihre assoziative Beziehung zu Bewegungsempfindungen.

Das bekannteste Beispiel hierfür ist die ..Lokalzeichen"-Theorie Lotze's für die optische Raumwahrnehmung: Trifft ein optischer 
Reiz irgend eine Stelle der Netzhaut, so weckt er den Impuls zu einer Augenbewegung, bis der Lichtreiz auf die Mitte der Netzhaut, die Stelle des deutlichsten Sehens fällt. Diese Einstellungsbewegung ist für jede Netzhautstelle eine andere; es entstehen daher spezifische Assoziationen $z$ wischen den optischen Empfindungen bestimmter Netzhautstellen und bestimmten kinästhetischen Empfindungen. So werden für den wahrnehmenden Menschen die Bewegungsempfindungen zu Zeichen für die Örter im Raume, aus denen die Lichtreize kommen.

e) Räumliche Konstanz der Objekte. Schliesslich macht die hier dargestellte psychologische Raumtheorie ein Phänomen verständlich, das unlösbar bleibt, solange man die Raumwahrnehmung als rein sinnesspezifisch ansieht: die räumliche Konstanz der gesehenen Gegens t ä n d e. Sie tritt in zwei Hauptformen auf: als Grössenkonstanz und als Gestaltkonstanz.

Grössenkonstanz. Zwei Gegenstände von gleicher Grösse, aber verschiedenem Abstand vom Auge, entwerfen auf meiner Netzhaut Bilder ganz verschiedenen Umfangs. Ist z.B. ein Baum 5 Meter von mir entfernt, ein anderer 10 Meter, so füllt das Bild des ersten die vierfach so grosse Fläche auf der Netzhaut wie das Bild des zweiten. Diesen gewaltigen Grössenunterschied „sehe” ich aber normaler Weise nich t. Man frage einen Lehrer, ob er die Schüler auf der zweiten Bank kleiner „sieht” als die auf der ersten Bank; er wird die Frage verneinen. Nähert sich mir ein Mensch, so nimmt die Grösse seines Netzhautbildes ständig zu; trotzdem erscheint er mir dauernd in seiner konstanten Grösse. Diese Erscheinungen gelten für einen recht weiten Spielraum von Entfernungen; nur bei ungewöhnlicher Nähe oder ungewöhnlicher Ferne drängt sich das Erlebnis der besonderen Grösse oder Kleinheit auf. (Vom hohen Kirchturm oder Berg aus erscheinen einem die Menschen, Häuser, Wagen tief unten wie aus einer Liliputwelt).

$\mathrm{G}$ es $\mathrm{t}$ a l $\mathrm{t}$ k o n s t a n $\mathrm{z}$. Bei unbefangenem Betrachten sehe ich den Tisch, an dem ich schreibe, und die Bücher, die auf ihm liegen, in ihrer ,richtigen” Form, nämlich als Rechtecke, den auf dem Nebentisch stehenden Teller als Kreis. Die Netzhautbikier dieser Objekte sind aber - wenn ich nicht gerade genau setikrecht von oben auf sie blicke - niemals rechteckig oder kreisförmig, sondern lkhomben mit verschiedensten spitzen und stimnpfen Winkeln, bezw. Ellipsen verschiedener Dicke oder 
Schlankheit. Mit jeder Verschiebung des Tellers auf mich zu oder von mir fort ändert sich die Ellipsenform: ich merke es nicht, er bleibt kreisrund. Erst bei zeimlich weiter Entfernung wird mir klar, dass ich ihn „eigentlich" nicht als Kreis sehe, sondern als Ellipse.

Dieses - von den Netzhautbildern so abweichende -- Konstanz-Sehen ist nicht etwa eine erst spät erlernte Fähigkeit des Menschen, sondern im Gegenteil eine ganz ursprüngliche Art der Wahrnehmung. Wenn primitive Menschen Anlass haben, Tische oder Teller darzustellen, dann werden sie sie nie anders denn als Rechtecke und Kreise zeichnen - gerade als ob sie niemals Bilder von Rhomben und Ellipsen in ihrem Auge gehabt hätten. Dagegen ist langes Lernen nötig für Schau und Darstellung der rein optischen Erscheinung als solcher, mit all den Verzerrungen der Perspektive und der Proportionen, welche durch die Stellung des Objekts zur Netzhaut bedingt sind. Die Gesetze der Perspektive mussten bekanntlich von der Kunst erst mühselig erarbeitet werden; und es gibt ganze Völker, die sie nicht entdeckt haben.

Man mache sich klar, wie paradox diese Erscheinungen sind, so lange man lediglich eine sinnesspezifische Raumwahrnehmung anerkennen will. Unter den unzähligen Bildern, die ein Teller je nach seiner Stellung zu mir - auf meine Netzhaut entwirft, ist nur ein einziges kreisförmig, alle anderen sind elliptisch: wie komme ich dazu, dies eine, ganz selten verwirklichte, Bild so auszuzeichnen und als die ,wirkliche" Form des Tellers nicht nur denkend anzuerkennen, sondern auch anschaulich zu sehen und in die anderen Formen hineinzusehen: Lnd wie komme ich dazu, diesem Teller, der in jedem Abstand ron mir eine andere Bildgrösse hat, dennoch eine konstante Grösse zuzusprechen? Die spezifische Optik für sich allein würde mir nie dazu verhelfen können. Sie versagt hier - gerade wegen der Fülle und Variabilität ihrer Eindrücke, also wegen jener Eigenschaften, die wir oben als ihren besonderen Vorzug rühmten.

In Wirklichkeit sehen wir aber ja nicht Netzhautbilder, sondern Objekte; und diese sehen wir - es muss immer von neuem gesagt werden - mit der ganzen Person. Der Teller ist als Aktionsobjekt für mich ein identischer Gegenstand von identisch bleibender Form und Grösse. Für meinen Tastsinn ist ebenfalls 
Grösse und Form immer dieselbe, da gibt es nicht jene Verzerrungen, Schrumpfungen u.s.w., wie auf der Netzhaut. Wenn der Teller dann lediglich mit dem Auge wahrgenommen wird, so spielt jenes potentielle Wahrnehmen mit den anderen Sinnen mit hinein und ich sehe ihn a $1 \mathrm{~s}$ dieses Objekt, in seiner Grösse und Form.

Aber nun offenbaren jene Abweichungen des Netzhautbildes wiederum ihre positive Bedeutung: sie ändern zwar nicht die Objektwahrnehmung, bestimmen aber die Stellung des Objekts i n meinem personalen $\mathrm{R}$ a u m. Wahrnehmen heisst ja: die gegenwärtige Situation eines Objekts erfassen; zu dieser gehört aber vor allem die relative Lage und Entfernung des Objektes zu $\mathrm{m}$ i r. Das elliptische Bild bestimmter Grösse, das der Teller auf meiner Netzhaut entwirft, bewirkt nicht, dass ich ein elliptisches Objekt, sondern dass ich ein kreisrundes Objekt in bestimmter Entfernung und schiefer Lage zu mir sehe. Es ist ein einheitliches Wahrnehmungsgeschehen, das mir das konstante Objekt zugleich in diesem seinem augenblicklichen Raumbezug zu mir darbietet.

Mit diesem Bezug zu "mir" als räumlichem Zentrum kommt noch einmal ein intersensorieller Faktor in das Raumsehen hinein. Denn die Lagequalitäten oben/unten, rechts/links u.s.w. sind ja zunächst Merkmale meines personalen Eigenraums, und hier in einer Selbstwahrnehmung gegeben, die noch unabhängig von allem Optischen wirksam ist. Erst dardurch, dass die Eigendimensionen auf die Objektwelt übertragen werden (s.S. 137), erhalten auch die Seherlebnisse ihr Oben und Unten. Ich sehe die Zimmerdecke „oben", d.h. als das, was meinem personalen Oben nahe und durch Eigenbewegung nach oben erreichbar ist, den Fussboden ,unten” als das, was mit meinen unteren Extremitäten in Kontakt steht.

Das Oben und Unten des Gegenstandsbildes auf der Netzhaut hat also mit dem Oben/Unten-E r leb n is garnichts zu tun; und alle jene Grübeleien darüber: wieso der Mensch die Dinge aufrecht sehe, da sie sich ja auf der Netzhaut verkehrt abbildensind müssig gewesen.

Empirisch wird unsere Auffassung dadurch bestätigt, dass zwischen der Bildlage auf der Netzhaut und der Art, wie die Lage gesehen wird, keine optisch zwangsläufige Beziehung besteht. Folgende zwei Befunde gehören hierher: 
1) Die „R a u m ver la g e r u n g”. Auf primitiven Stufen seelicher Entwicklung werden räumliche Gestalten erkannt und dargestellt unabhängig von ihrer Lage zum Beschauer. Kinder sehen sich Bilder an, die auf dem Kopf stehen, und zeichnen oft Figuren, Zahlen, Buchstaben verkehrt oder in Spiegelschrift; dabei wird die Vertauschung von oben und unten, rechts und links nicht einmal bemerkt.

2) Das Um ler n e n des Lagesehens. Das Mikroskop dreht bekanntlich das Bild der Objekte um $180 \%$. Der geübte Mikroskopiker hat sich hieran so gewöhnt, dass er die Dinge trotz der Verdrehung in ihrer richtigen Lage ,sieht".

Berühmt geworden ist das Experiment von Stratton, der eine ganze Woche lang ununterbrochen eine Brille trug, welche die sichtbare Welt um 180\% drehte. Anfangs war er völlig desorientiert, da ihm tatsächlich alle Dinge auf dem Kopf zu stehen schienen; der Fussboden wurde oben und die Möbel von ihm herunterhängend gesehen u.s.w.. Aber nach wenigen Tagen begann er sich an die neue Konstellation zu gewöhnen und gegen Ende des Experiments waren ihm diejenigen optischen Eindrücke ,oben”, die er durch aufwärts gerichtete Bewegungen erreichen konnte, und umgekehrt; es war also ein neues intersensorielles Wahrnehmungserlebnis oben/unten entstanden.

\section{Zeitwahrnehmung}

Bei der Zeit ist das Wahrnehmungsproblem etwas anders gelagert als beim Raum. Denn Wahrnehmung ist auf Gegenwärtiges gerichtet; solange man aber Gegenwart in mathematisierender Weise als Zeit p u $\mathrm{kt}$ ansah, war es unmöglich, in diesen „Punkt" das Erlebnis einer Sukzession oder einer Dauer hineinzupressen. Man musste sich dann mit Theorieen etwa in der Form helfen: im späteren Zeitpunkt wirkt die frühere Wahrnehmung noch als Vorstellung nach, die nun mit der jetzt fälligen Wahrnehmung verbunden oder verglichen werden kann.

Nun gibt es gewiss temporale Erlebnisse dieser Art, z.B. beim Sehen von Bewegungen. Wenn ich den Stundenzeiger der Lhr mehrmals beobachte, so zeigt er bei jedem einzelnen Wahrnehmungsakt eine scheinbare Ruhelage. Aber in dem zweiten Wahrnehmungsakte kann ich mich der früheren anderen Stellung erinnern und daraus den Schluss ziehen: der Zeiger hat sich in der $Z$ wischenzeit bewegt. Hierbei wird also das Zeitgeschehen nur 
vorstellungsmälsig oder denkmälsig erlebt. Ist dies aber die einzige Erlebnisweise? Ja, würde ich das Zusammentreffen einer Wahrnehmung mit einer Erinnerung, wie es mir im zweiten Beobachtungsakt gegeben ist, überhaupt als Zeichen für ein da$\mathrm{z}$ wischen liegendes Zeitgeschehen auffassen können, wenn mir solches Geschehen nicht aus einem viel direkteren Erleben bekannt wäre?

Ich betrachte jetzt den Sekundenzeiger der Uhr - und habe ein ganz anderes Erlebnis. Ich „sehe”, dass er sich bewegt, sehe es mit derselben Anschaulichkeit, wie ich seine Färbung und seine Grösse sehe.

Ein anderes Beispiel: ich höre das Wort ,trálala”. Dann ist mir die Sukzession der drei Silben und der daktylische Rhythmus in der einheitlichen und unmittelbaren Wahrnehmung gegenwärtig. Und zwar a ls Folge und Zeitgestalt gegenwärtig. Es ist nicht so, dass die Eindrücke der ersten zwei Silben in den dritten hineinkriechen, so dass ich im letzten Zeitpunkt die „Empfindung” der dritten und zugleich die Vorstellungen der beiden ersten Silben hätte - dieser „letzte Zeit p u n k t” ist überhaupt für mein Wahrnehmen garnicht isoliert da, weil es die ganze Zeit s t r e kk e umfasst.

Es gibt also Wahrnehmungen, die - ohne ihre Einheitlichkeit und Anschaulichkeit zu verlieren - eine gewisse Zeitspanne a usfüllen und den zeitlichen Inhalt dieser Spanne zum Gegenstand haben könn e n. Diese Zeitspanne, innerhalb deren direkte Zeitwahrnehmung möglich ist, bezeichnete ich als „Pra e s e n $z \mathrm{z}$ e i t".

Die Paradoxie, die in dieser ,ausgedehnten Gegenwart” zu stecken scheint, ist heut dadurch überwunden, dass wir die mathematisierende Betrachtung nicht mehr als malsgebend für personales Leben ansehen können. Die gelebte Gegenwart der Person ist ausgedehnt und geformt, wie wir früher (s.S. 131) ausführlich entwickelten; die e r le bt e Gegenwart - also die unmittelbare Wahrnehmung zeitlicher I)auer und Sukzession - ist nur ein Niederschlag jenes viel allgemeineren und fundamentaleren Tatbestandes.

Freilich ist die psychische Präsenzzeit eng begrenzt; darum kann ich die Lageveränderungen des Stundenzeigers nicht in 
einem einzigen Anschauungsakt erfassen und bin hier auf Vergleichen und Denken angewiesen.

Klopfe ich einen Dreitakt in Walzertempo, so höre ich den Rhythmus; lasse ich dagegen zwischen je zwei Klopftönen drei Sekunden vergehen, so geht das Rhythmuserleben völlig verloren; ich mache drei getrennte Wahrnehmungen, die zwar auf einander beziehbar sind, aber sich nicht mehr zum unmittelbaren Erlebnis einer rhythmischen Zeitgestalt strukturieren.

$\mathrm{Zu}$ welcher Sinnesmodalität gehören die Zeitwahrnehmungen? Unsere Beispiele zeigen schon, dass auch hier kein Monopol besteht. Zeitwahrnehmung ist ausgesprochenermalsen in t e rs e n s o r i e 11. - D a u e r nehme ich wahr, wenn ich den Bach rauschen höre, einen Vogel schweben sehe, die Schwere eines zu tragenden Koffers lasten $f \ddot{u h} l$ e. - Die zeitliche Grundgliederung, der $\mathrm{Rhy} t \mathrm{hm} \mathrm{us}$, ist durchaus nicht eine nur-akustische Erscheirungsweise, als welche er manchmal angesehen worden ist. Bewegungen einer Tänzerin, die ich im stummen Film sehe, kann ich durchaus rhythmisch erleben; es gibt auch einen reinen Berührungsrhythmus: wenn jemand leise mit dem Finger einen Takt auf meinen Handrücken klopft.

Allerdings nimmt der Crehörssinn eine bevorzugte Stelling bei der Wahrnehmung von Zeitgestalten ein; er spielt hier eine ähnliche Rolle im Sinne des Leistungsvorsprungs, wie der Gesichtssinn bei der Raumwahrnehmung. Der Gehörssinn ist wenig auf das Nebeneinander des Gleichzeitigen eingestellt (worin gerade die Stärke des Gesichtssinnes liegt), umsomehr auf die Sukzession. Im akustischen Wahrnehmen von Sprache und Musik gibt es eine so grosse Qualitätenfülle und Abstufung zeitlicher Wahrnehmungsgestalten wie in keiner anderen sinnesmodalität. Völlig gehörsfreie Wahrnehmungen von Zeitgestalten sind zwar, wie unsere obigen Beispiele zeigen, möglich, aber doch selten. Zum mindesten wird akustische Begleit $1 \mathrm{ng}$ gesucht, wenn Zeitliches recht eindrucksvoll für die Wahrnehmung gegliedert und akzentuiert werden soll. Daher Marschmusik und Arbeitsgesänge; beim Tanz ist das Mitwirken akustischer Rhythmen fast obligatorisch.

Die volle Eigenart der Zeitwahrnehmung wird aber erst dann offenbar, wemn man nicht nur an die zeitlichen Geschehnisse in der Aussenwelt denkt. Bei der Raumwahrnehmung ist noch eine 
relative Scheidung zwischen Aussenraum und Eigenraum möglich; bei der Zeit, soweit sie in psychischer Präsenz gegeben ist, lässt sich Aussenzeit und Eigenzeit nicht mehr trennen ${ }^{1}$ ). Jedes Zeitgeschehen, das ich draussen wahrnehme, ist zugleich ein Stück meines eigenen Lebensgeschehens, das ich innen wahrnehme. Die Dauer des Bachrauschens, dem ich lausche, ist zugleich die Dauer meines Lauschens. Der Rhythmus der Tanzenden, denen ich zusehe, rhythmisiert auch meine Bewegungsimpulse und meine personale Gesamtverfassung.

Deshalb sind aus der Zeitwahrnehmung die $\mathrm{k}$ in a e $\mathrm{s} \mathrm{th}$ et i s c h e n Beiträge, die mein Körper liefert, nirgends auszuschalten; Eigenbewegungen gliedern nicht nur zeitlich alle Handlungen, die ich vollziehe, sondern treten als Begleitbewegungen beim Wahrnehmen äusserer Zeitgestalten auf.

Aber wir müssen in noch tiefer eingebettete Erlebnisbestände zurückgehen, die überhaupt in keine Sinnesmodalität mehr einzuordnen sind. Das allerursprünglichste Zeiterleben hat der Mensch in einem diffusen Zeitgefühl, welches ihm seine personale Gesamtverfassung und deren Veränderungen vergegenwärtigt, das sich nun aber auch der Wahrnehmung äusserer Zeitgeschehnisse mitteilt. Das Zeitgefühl der Langenweile bewirkt nicht nur, dass „mir" die Zeit lang wird, sondern dass auch der Vortrag, den ich anhören muss, ausserordentlich lang erscheint.

Die Zeitwahrnehmung ist also nicht nur intersensoriell, sondern ist stets beladen mit einem prae-sensoriellen Anteil. Erst im Zeitvorstellen und Zeitdenken - die sich aus der Stufe der Zeitwahrnehmung entwickeln - ist jene hier noch fehlende Objektivierung der Zeiterlebnisse möglich.

\section{VERWANDTSCHAFT DER SINNE}

Trat uns bisher der Zusammenhang der Sinne entgegen als eine Leistungsgemeinschaft, als Zusammenwirken, so haben wir nun ihre $Q$ u a li t ä t s gemeinschaft, ihr Zusammenstimmen zu besprechen. Wir hatten zwar an früherer Stelle (S. 162) die Disparatheit der Sinnesmodalitäten betont. Aber damit hatten wir, wie sich nun zeigt, nur einen Teilaspekt gegeben; denn es beste-

1) Deshalb hatte Kant das Zeitbewusstsein als den „inneren Sinn” dem „äusseren Sinn" des Raumbew'usstseins gegenübergestellt. 
hen - trotz aller Verschiedenartigkeit - ursprüngliche Ähnlichkeiten zwischen den Sinnesmodalitäten.

Einen ersten Zugang hierzu liefert uns die menschliche $\mathrm{S}$ p r a c h e ${ }^{1}$ ). Diese benutzt nämlich zur Bezeichnung von Qualitäten e in es Sinnes weitgehend Ausdrücke, die einem a nd e r e n Sinne entlehnt sind.

So hat selbst ein so hoch entwickeltes System wie das der F a rbenwahrnehmung im Deutschen spezifische Eigenbezeichnungen nur für die sechs Hauptfarben und für Grau und Braun. Aber reich ist die Sprache an Bezeichnungen wie: „satte”, "schreiende”, „stumpfe” Farben. Wenn der Maler von „kalten, harten Tönen" spricht, meint er mit dieser, aus Temperatur-, Tast- und Gehörsausdrücken gemischten, Charakteristik optische Wirkungen! - Das a ku st i s c h e Gegenstück zu „Farbton” ist das Wort "Klangfarbe"; hier begegnen wir dann weiter den „hellen" und „dunklen”, ,,hohen” und „tiefen", ,spitzen” und „runden” Tönen. - Das Sinnesgebiet des Geruchs, das keinerlei eigenständige Qualitätsbezeichnungen besitzt, muss Anleihen machen bei Geschmacks- und Tast-Benennungen: „süsser", „saurer" - „weichlicher”, „stechender" Geruch.

Ferner gehören hierher die übertragenen Schallma le re i en: Namen für nicht-akustische Sinneseindrücke, die durch den akustischen Sprachklang nachgebildet werden. Beim Hören der Wörter „Flimmern”, „Glitzern”, empfinden wir unmittelbar die Ähnlichkeit zwischen der akustischen Bezeichnung und dem optischen Bezeichneten. Im Gehörseindruck des Wortes "Spitz" klingt charakteristisch das taktile Erlebnis des scharf Punktförmigen an.

Das unmittelbare (nicht auf Sprache angewiesene) Erlebnis des Zueinandergehörens von Empfindungen verschiedener Sinnesgebiete bezeichnet man als $S$ y $n$ a e $\mathrm{t}$ h h e si e. Hier muss man zwischen generellen und differentiellen Tatbeständen unterschieden.

Wenn Goethe die Farbentöne um Blau als ,kalt”, die um Rot als "warm" erlebt, so kann das wohl jeder normal farbenempfindliche Mensch mehr oder weniger deutlich nachwollziehen;

\footnotetext{
1) Unsere Beispiele entstammen nur der deutschen sprache, doch gibt es wohl in jeder Sprache die Analoga dazu.
} 
ebenso wenn er sagt: durch ein Purpurglas sähe die Landschaft so aus, als ob die Posaune des jüngsten Gerichts ertönte. Dass musikalische Töne in der Tiefe „dunkler" sind als in der Höhe, besitzt kaum geringere sinnliche Evidenz, als wenn wir, rein im Akustischen bleibend, gewisse Töne lauter finden als andere; wir h ö r e n eben die „Dunkelheit" des Basstones, oder — um wieder in ein anderes Sinnesgebiet überzuspringen — die „Süssigkeit” des Geigenklanges.

Im engeren Sinne versteht man aber unter Synästhesie eine Intensivierung und Zuspitzung dieser Beziehungen, wie sie nur bei einer kleinen Anzahl von Menschen zu finden ist. Hier wird dann die Verkoppelung gewisser Phänomene des einen Sinnesgebiets mit denen des anderen geradezu zwanghaft; es gibt keine monästhetische Wahrnehmung mehr. Die gehörte Musik ist dann zugleich eine Folge von Farben, Formen, Lichtern; die einzelnen Vokale oder Wort-Klänge sind in ganz bestimmte Farben getaucht u.s.w.

Die in diesen Beispielen angedeutete Art der Synästhesie, bei der von wirklichen Schalleindrücken her optische Schein-Empfindungen (,Photismen') mit geweckt werden, ist die häufigste; es kommen aber auch andere Formen vor. Merkwürdig ist bei solchen Zwangs-Synästhesieen die starke individuelle Verschiedenheit. Es gibt nicht zwei mit Synästhesie behaftete Menschen, die der Reihe der Vokale dieselben Farben zuordnen; ebenso launisch und jeder Verallgemeinerung spottend sind die Photismen, die sich bei musikalischen Gebilden: Einzeltönen, Akkorden, Motiven, ganzen Stücken - einstellen. Von zahlreichen Forschern ist hier im Laufe der letzten Jahrzehnte sehr interessantes Material gesammelt worden ${ }^{1}$ ); aber die Ausbeute an Regelmälsigkeiten und festen Beziehungen ist noch recht dürftig. Dabei ist für den einzelnen Synästhetiker der Zusammenhang nichts weniger als willkürlich oder gelegentlich, sondern konstant und unbezweifelbar, ja oft so selbstverständlich, dass er höchlichst überrascht ist, wenn andre Menschen nichts dergleichen in sich finden können.

Die psychologische Deutung dieser intersensoriellen Verwandt-

1) Veuerdings insbesondere von Anschiitz und seinen Sohilern; vgl. auch die Untersurhumgen von Argelander und Bos. 
schaften bietet manche, heut noch nicht ganz gelöste Schwierigkeiten.

Am nächsten liegt der Versuch, erfahrungsbedingte Assoziationen zur Erklärung heranzuziehen. So mag der Vokalklang O, weil er im Wort ,rot” dominiert, ein rotes Photisma nach sich ziehen. Eine getragene Musik - etwa eines Trauermarsches wird von Photismen in dunklen, schwarzen, grauen Farbtönen begleitet, weil erfahrungsmälsig für uns Abendländer Trauermusik und schwarze Farbe in Kleidung und Dekoration zusammengehören. Töne der Hirtenflöte erscheinen grün, weil die Gesamtsituation Wald und Feld mitassoziiert wird.

Aber selbst angenommen, dass solche Ableitungen gelegentlich zutreffen, so könnten sie höchstens den äusseren Anlass für das Zustandekommen bestimmter Synästhesieen bilden, nicht aber deren Existenz überhaupt verständlich machen. Denn erlebnismälsig handelt es sich eben nicht darum, dass mit akustischen Wahrnehmungen gewisse optische Vorstellungen ,verknüpft" sind, sondern um etwas viel Tieferes, um eine Art I d e n $\mathrm{t}$ i f $\mathrm{k}$ a $\mathrm{t}$ i o $\mathrm{n}$, um ein Verschmolzensein der Erlebnisse beider Sinnessphären. Will man also Erfahrungsmomente überhaupt zur Erklärung heranziehen, so muss man fragen, welche besonderen Motive die blosse Assoziation in jene Verschmelzung verwandeln. Hier gibt es zwei Möglichkeiten. Die eine wird durch unser Beispiel: Trauermusik/schwarze Farbe vertreten. Die Erfahrung des Beieinander (bei Leichenbegängnissen und Trauerfeiern) stösst auf eine starke synästhetische Bereitschaft des Wahrnehmenden für das $Z$ us a m m e $\mathrm{p}$ as s en gerade dieser akustischen und optischen Teilerlebnisse. I) a s man ebendiese beiden Bekundungsformen für "Trauer" gewählt hat, wird als selbstverständlich empfunden, weil man die gemeinsame Ausdruckshaltigkeit der zwei Eindrucksbereiche spürt. - I)ie zweite Möglichkeit: Es können in der Tat „zufällig” die Eindrücke zweier Sinnesgebiete zusammentreffen, aber bei einem Ereignis, welches katastrophenhafte Bedeutung für den Erlebenden hat, sodass das Gesamterlebnis mit allen dazugehörigen Merkmalen als unauflösliches Ganzes der Seele eingebrannt ist und (als sogen. "Trauma”) weiter wirkt. Wer eine nächtliche Feuersbrunst unter erregenden Umständen miterlebt hat, für den können Hornsignale für alle Zukunft eine intensive Rotfärbung besitzen (die et- 
was ganz anderes ist als die blols assoziativ angeschlossene Vorstellung der roten Flamme).

Es liegt dann also eine Art Rückfall in jene primitiven Formen des Wahrnehmens vor, in welcher nicht sowahl einzelne objektivierte Wahrnehmungsgestalten, sondern eine Totalreaktion der Person auf die diffuse Totalsituation vorhanden ist.

Und eben damit rühren wir an den eigentlichen Grund aller intersensoriellen Verwandtschaft. Es handelt sich nicht mehr um das Beziehungspaar Einzelempfindung/Einzelreiz, sondern um das ganz anders gelagerte: $\mathrm{T}$ o $\mathrm{t}$ a $\mathrm{l}$ e in d r u c k/T o t a l a u s$\mathrm{d} r \mathrm{uck}$. Wenn der Mensch mit seinem ganzen Ich eintaucht in eine bestimmte Reizsituation, so hört diese auf, sinnesspezifisch (z.B. nur-akustisch) für ihn zu sein. Es erfolgen Gesamtumstimmungen seiner personalen Haltung; sein Erleben weilt in Regionen, die tiefer als die Scheidung in Klang, Farbe, Berührung usw. liegen.

Dies ist von Werner, Zietz und anderen e $\mathrm{x}$ p e r i m e $\mathrm{n} t$ e $1 \mathrm{l}$ nachgewiesen worden.

Man erzeugt Pfeifentöne bestimmter Höhe in einem Raume bestimmter Beleuchtung und verändert dann: bald nur die Beleuchtungsstärke oder Farbe bei objektiver Konstanz des Tones, bald die Tonhöhe bei objektiver Konstanz der Beleuchtung. Bei einem gewissen Typus von Versuchspersonen ruft dann die objektive Änderung des einen Reizgebiets eine Änderung der Eindrücke des anderen Gebiets hervor: der (konstantbleibende) Ton klingt höher bei Erhellung des Raumes u.s.w. Aber noch mehr: Beide Änderungen können so zur Einheit verschmelzen, dass die Versuchsperson unklar darüber wird, mit welchem Sinn sie eigentlich die eingetretene Veränderung wahrnimmt; der Ton selbst scheint sich (bei Eintreten von roter Beleuchtung) rot zu färben; der stärker beleuchtete Raum selbst scheint höher zu klingen.

Bemerkenswert sind hier zwei weitere Folgen.

Nicht nur die Grenzen der Sinne gegeneinander können verfliessen, sondern auch die Trennung von Sensibilität und Motilität. Mit dem Totaleindruck verbindet sich eine Totalbewegtheit oder Körperhaltung, in der die Person sich gerade diesem so gearteten Eindruck erst ganz eröffnet, ihm in irgendwie geheimnisvoller Weise korrespondiert, ihn schliesslich wieder nach aussen als eigenen A usdruck projiziert. So kann es zu einer Art "Synkinesie” kommen. Die seelische Aneignung geometrischer 
Formen oder architektonischer Gebilde wird nur dadurch vollziehbar, dass man in sich die Spannungen und Kräftelagerungen des Gebildes nachahmt; zum vollen Erleben eines gehörten Rhythmus ist nötig, dass man ihn in eigener Motorik mitmacht.

Ottomar Rutz hat für die Wiedergabe musikalischer Werke aus diesen Zusammenhängen ein System gemacht: die Werke jedes Komponisten verlangen nach ihm eine besondere Körperhaltung, um angemessen gespielt, bezw. gesungen zu werden.

Endgültig aber tritt die Erscheinung aus der blossen Vitalsphäre dadurch heraus, dass es sich nicht nur um den Eindruck und Ausdruck bei der wahrnehmenden Person handelt, sondern zugleich um den Ausdruck beim wahrgenommenen Objekt. Farbe und Schall, Härte und Wärme sind dann nicht mehr nur sinnlich gegebene Einzelmerkmale des Dinges, sondern die Schleier, durch die hindurch sich uns der Sinngehalt, das innere Kraftgefüge des $\mathrm{G}$ e g e n s t a n d e s darbietet. Wenn wir einen grossen Schauspieler auf der Bühne sehen: wissen wir da noch, wieviel von dem Totalausdruck, den wir erleben, auf den akustisch wahrgenommenen Klang seiner Stimme, wieviel auf das optische Bild seiner Gesten zurückgeht? Aber selbst wenn wir zeitweilig die Augen schliessen und ihn nur noch hören, so ist uns dies Gehörte auch nicht da a ls Klang, sondern als der Zugang zu jenem Totalausdruck. Diese Art der Objektwahrnehmung bezeichnet H. Werner als ,physiognomische Wahrnehmung"'). In der Fähigkeit hierzu gibt es grosse individuelle Differenzen; der eine hört ein $\mathrm{Mu}$ sikstück lediglich als formale Struktur von Tongebilden, der andere „expressionistisch" als Kraft- und Seelenausdruck, sodass das rein Akustische fast sekundär wird. Der eine erlebt optische Formen als geometrische Gebilde, der andere sieht durch sie hindurch auf dynamische Spannungen, Widerstände und Harmonieen.

\section{DIE VERTRETUNG DER SINNE}

Wechselwirkung und Verwandtschaft der Sinne ermöglichen es, dass dort, wo die Funktion eines Sinnesorgans vorübergehend oder dauernd ausgeschaltet ist, ein anderes Simnesorgan aushilfsweise eintritt (,Sinnesvikariat").

1) Vgl. S. 175. 
Gelegentliche Vertretungsleistungen der Sinne kennen wir alle; so tritt im Stockdunklen plötzlich das Tasten in den Vordergrund und verschafft uns Erkenntnisse, die sonst nur das Auge vermittelt. Im ohrenbetäubenden Lärm eines Orkans oder einer Fabrik, der die akustische Verständigung ausschaltet, greifen wir zu Gesten, also optischen Zeichen u.s.w.

In ganz grossem Malsstab aber wird das Sinnesvikariat bei den Mindersinnigen wirksam. Die Wahrnehmungswelt des Blinden wäre nicht zu verstehen, wenn man einfach von der Welt des Vollsinnigen alles optisch Erkennbare subtrahieren wollte; denn vieles, was wi $r$ durch Sicht aufzunehmen pflegen, wird vom Blinden ertastet oder erlauscht. - Für den Gehörlosen ist die Welt der gesprochenen Sprache, der Geräusche, der Musik nicht durchaus ausgelöscht; er liest von den Lippen ab; er wird feinfühlig für Erschütterungen gröberer und für Vibrationen feinerer Art, die wir wohl auch erleben können, aber nicht zu beachten und bewusst $z u$ verwerten pflegen.

Gewiss, diese Vertretung ist nie ein Ersatz. Auch die geübtesten Finger des Blinden können die spezifische Qualität von Farbe und Helligkeit niemals vermitteln. Trotz alledem bleibt es erstaunlich genug, dass es eine so weit gehende Hilfsfunktion eines Sinnes für den ausfallenden anderen gibt.

Bei den sensoriellen Vertretungen ist ein $\mathrm{E} \mathrm{r} \mathrm{le} \mathrm{b} \mathrm{n} \mathrm{i} \mathrm{s-} \mathrm{V} \mathrm{i} \mathrm{ka-}$ $\mathrm{r}$ i a $\mathrm{t}$ und ein $\mathrm{L}$ e is $\mathrm{tung} \mathrm{s}-\mathrm{Vik}$ a riat $\mathrm{zu}$ unterscheiden.

Erlebnismäfsig treten diejenigen Züge des Eindrucks hervor, die intersensoriell g emein sam sind; jener personale Urgrund, in dem es noch garnicht die spezifische Sonderung der Einzelsinne gibt, macht sich geltend.

So ist z.B. die allgemeine Vitalwirkung der Musik die den ganzen Organismus mitvibrieren lässt, auch dem Gehörlosen zugänglich; unter Umständen kann sogar durch ¿bung das rein vibratorische Erlebnis eine Verfeinerung und Differenzierung bis zur einfacheren ästhetischen Gestalterfassung hin erfahren.

Die Raumwahrnehmung des Blinden ist stark verwurzelt in den Erlebnissen der eigenräumlichen Zuständlichkeit und Bewegtheit; von dieser (für alle Menschen gemeinsamen) Grundlage aus erobert sich der Blinde den Aussenraum vornehmlich durch den Tastsinn. Sein erlebter Raum ist zwar in der Aktions- und 
Erlebnis-W e i t e gegenüber dem Raum des Sehenden sehr eingeschränkt; aber in ihm sind doch alle wesentlichen RaumE i g e n s c h a f t e n der Dinge, wie Gestalt, Lage, Richtung, Grösse, Proportionen, zugänglich (Vgl. S. 207).

Das Erlebnisvikariat ist, wie schon angedeutet, $\ddot{\mathrm{u}} \mathrm{b}$ b a $\mathrm{r}$, und damit auch der erziehlichen Beeinflussung zugänglich. Es liegt durchaus nicht ausserhalb des Bereiches pädagogischer Möglichkeit, beim Taubtsummen eine ästhetische Vibrationsfreude an einfachen Musikdarbietungen oder eigens für diesen Zweck zu schaffenden Vibrationswerken zu erzeugen; oder dem Blinden die Formenfülle und Schönheit von Plastiken durch Abtastenlassen zugänglich $\mathrm{zu}$ machen. I)abei darf man sich freilich nicht den Schwierigkeiten und Bedenklichkeiten solcher kunstpädagogischen Bestrebungen verschliessen.

Helen Keller, die bekanntlich sowohl blind wie taub ist, hat die C̈berzeugung, an Klavierstücken (deren Rhythmik und Vibration sie durch Auflegen der Hand auf das Instrument spürt) und an betasteten Plastiken Freude zu empfinden. - Der taube Schweizer Schriftsteller Sutermeister ist in reifen Jahren geradezu cin Musikenthusiast und unermüdlicher Konzertbesucher geworden, nachdem er einmal erlebt hatte, wie stark die ihn umspülenden Schallvibrationen ihn ästhetisch erfreuten. - Natürlich wird in diesen und verwandten Fällen die Möglichkeit der Autosuggestion und das wohlverständliche Verlangen, eine sonst nur dem Vollsinnigen zugängliche Erlebnissphäre in sich zu realisieren, mit in Betracht gezogen werden müssen; doch wäre es nicht berechtigt, nun alles auf solche ,Selbsttäuschungen" zurückführen zu wollen. - Dagegen wird man mit sehr starken individuellen Verschiedenheiten rechnen müssen. Nur bei einer Minderzahl von Blinden und Tauben würde es wohl denkbar sein, das Erlebnisvikariat bis $z u$ aesthetischer Genussfähigkeit zu entwickeln.

Viel weniger problematisch ist die pädagogische Wirkungsmörlichkeit auf dem Gebiet des Leist ung s-Tikariats. Hier kommt es nicht mehr auf die spezifische Art des Erlebens an; es soll nur die andersartige Wahmehung in den Dienst derjenigen Aufgaben gestellt werden, welche die Vollsimigen durch das Auge, bezw. durch das Ohr bewältigen. Wenn sich auch jeder Blinde und Taube ganz aus eigenem Antrieb heraus alle möglichen Ersatzmittel des Erkennens schafft, so vermag planmälsige Herstellung solcher Ersatzmittel und systematische Erziehung in ihrem Gebrauch die persönliche und soziale Leistungsfähigkeit des Mindersinnigen in ausserordentlichem Mafse zu steigern. 
Wir müssen uns hier begnügen, nur einige hervorstechende Beispiele zu nennen: das Lesen der Blindenschrift, die aus tastbaren Punktfiguren besteht; die Übung der blinden Textilarbeiter im Erkennen von Fadendicken, Stoffarten u.s.w. durch das Tasten; die Erziehung der Taubstummen zum "Ablesen" gesprochener Worte von den Lippen. Gegenwärtig werden hier und da sogar Versuche gemacht, Apparate zu erfinden, die das gesprochene Wort vibratorisch auf die Finger der Taubstummen übertragen.

Die grossartigsten Erfolge eines systematisch ausgebauten Leistungsvikariats sind bisher bei den Taubblinden erzielt worden, bei denen ja Tast- und Vibrations-Sinn fast allein die Auffassung der Dinge und der Sprache zu leisten haben. Die Schriften von Helen Keller sind sprechende Dokumente für die doppelte Wahrheit: 1) dals es nicht so sehr auf die sinnliche Materie (Licht, Schall, Druck) ankommt, sondern darauf, was die selbsttätige Persönlichkeit aus dem - wenn auch noch so dürftigen und eingeschränkten - sinnlichen Rohmaterial zu machen vermag; 2) dass der Erzieher die Möglichkeit hat, von den verschiedensten sensoriellen Zugangsstellen aus den gemeinsamen personalen Untergrund aller Sinneswahrnehmung, und von hier aus des geistigen Lebens überhaupt, in Funktion zu setzen ${ }^{1}$ ).

1) Vgl. auch meine Monographie iiber Helen Keller. 


\section{NEUNTES KAPITEI.}

T A USCHUNGEN, GRENZENGND SCHWELLEN DER WAHRNEHMUNG

\section{SINNESTÄUSCHUNGEN}

„Eine Sinnestäuschung ist eine Sinneswahrnehmung, deren naiver Objektbezug durch kritischen Objektbezug eine Korrektur oder Widerlegung erfährt".

Das ist an sich eine erkenntnistheoretische, keine psychologische Definition. Dennoch bieten die Sinnestäuschungen auch zahlreiche psychologische Probleme, die sich auf ihre Entstehung und Beschaffenheit wie auf die Irrtumseinsicht beziehen.

\section{Kriterien}

Wie können wir überhaupt merken, dass eine Sinneswahrnehmung irrig sei? Die „objektivierenden” Kriterien, an denen ich die Richtigkeit oder Unrichtigkeit meiner Sinneswahrnehmung prüfen kann, sind sehr verschiedener Natur. Ein Hauptkriterium ist schon in $\mathrm{m}$ ir selbst gegeben. Die einzelne $\mathrm{m}$ o m e $\mathrm{n} \mathrm{t}$ a $\mathrm{n}$ e Sinneswahrnehmung gehört ja in einen grösseren Bedeutungszusammenhang, dessen Glieder miteinander harmonieren sollen; tritt hier plötzlich statt der erwarteten Einstimmigkeit eine Cnstimmigkeit auf, so wird die Unrichtigkeit der Wahrnehmung wahrscheinlich.

Beispiel: Ich sehe vor mir einen Gegenstand, will ihn greifen, und fasse - ins Leere; jetzt merke ich, dass durch Spiegelung das Bild des Gegenstandes an eine Raumstelle vor mir projiziert worden war; ich war einer „optischen Täuschung" erlegen.

Unser Beispiel lehrt noch etwas andres. Es wäre ja theoretisch 
ebenso berechtigt, die Unstimmigkeit zwischen Sicht und Griff so zu deuten, dass die Sicht richtig, aber der Griff täuschend war. Warum geschieht das nicht? Weil das Greiferlebnis in viel evidenterer Weise $\mathrm{Ex}$ is t e $\mathrm{n} \mathrm{z}$ vermittelt. Dem Tasten kommt also auch hier eine Sonderstellung innerhalb der Wahrnehmung zu. Was sich greifen lässt, was dem tastenden Menschen Widerstand leistet, ist nicht wegdisputierbar, steht jenseits jeder Täuschmöglichkeit. So kommt es, dass der Tastsinn das bevorzugte Kontrollorgan für die anderen, täuschbaren, Sinne ist und bleibt. Beim Kinde ist dies ja ganz deutlich; nach allem, was es sieht oder hört, sucht es auch zu greifen, um es sich in seiner vollen Wirklichkeit zu sichern. Aber auch der reife Erwachsene sucht sich bei allem Vagen und Fraglichen der andern Sinne durch Zugreifen und Betasten zu vergewissern; zuverlässiger als die An-Schauung ist die An-Fassung.

Allerdings gilt dies nur, solange es sich um die bare Existenzfeststellung oder um ganz spezifische Tasteigenschaften der Dinge (Härte, Dicke, Rauhigkeit u.s.w.) handelt. Sobald feinere qualitative und quantitative - Merkmale der Objekte erkannt werden sollen, ist der Tastsinn oft den anderen Sinnen unterlegen. Es gibt daher auch ,haptische Täuschungen" ${ }^{1}$ ).

Ein anderes Kontrollmittel ist $\mathrm{s}$ o $\mathrm{z}$ i a l e $\mathrm{r}$ Natur. In einem gemeinsamen Erlebnisraum erscheint eine Wahrnehmung als Täuschung, wenn sie von den anderen nicht gemacht wird. „Ging nicht eben eine Tür?" Kein anderer der Anwesenden hat es gehört. „Dann werde ich mich getäuscht haben”. Das Kriterium ist natürlich nicht von absoluter Zuverlässigkeit. Vielleicht habe ich grössere Hörschärfe, bin leichter durch Geräusche ablenkbar, als die anderen. Dennoch wird im Allgemeinen der consensus der Vielen, insbesondere wenn es Menschen mit ,normalen” Sinnen sind, gegenüber der Wahrnehmung des Einzelnen Recht behalten.

Iies gilt auch in der Wissenschaft. So mancher Naturforscher hat bei einem bestimmten Experiment irgend welche schwellennahen Veränderungen etwa in der Form oder der Farbe cines Objektes zu beobachten geglaubt; kann kein anderer Fachgenosse die gleiche Wahrnehmung machen, so wird bei dem ersten eine Sinnestäuschung an genommen.

1) Sie sind systematisch von G. Révész untersucht worden. 
Das dritte objektive Kriterium ist die $\mathrm{M}$ ess u $\mathrm{ng}$. In den beiden nebenstehenden Figuren ,sehe" ich die Wagerechten verschieden lang; behauptet ein andrer, sie seien gleich, so glaube ich ihm nicht - bis mich ein angelegter Malsstab überzeugt, dass ich einer Sinnestäuschung unterlag. Denn es ist das

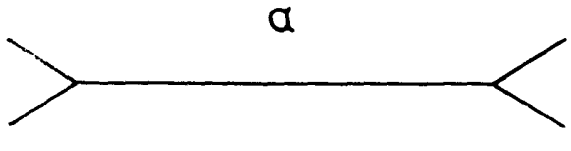
Wesen des Malsstabes, dass er, unabhängig von den Schwankungen und Grenzen der Wahrnehmung, Gleichheit und Verschiedenheit und den Grad der Verschiedenheit objektiv erweisen kann.

Das letzte Kriterium endlich ist der Tot a $1 \mathrm{z}$ u s a m m e nh a $\mathrm{n} g$ der Dinge, wie er in einer wissenschaftlichen Theorie gedacht ist. Es ist die aufdringlichste Wahrnehmung, dass sich die Sonne um die Erde und nicht die Erde um die Sonne bewegt ; erkenne ich aber die Kopernikanische Theorie als richtig an, dann muss ich damit zugleich meine Wahrnehmung als Täuschung anerkennen.

\section{Arten derTäuschung}

Dem Ge ge n s t a n d e nach lassen sich die Sinnestäuschungen gliedern in: Halluzinationen, Qualitäts-Illusionen, Quantitäts-Illusionen.

H a 11 u z in a t i o n e n sind "Existenztäuschungen”, d.h. es wird in der äusseren Welt etwas wahrgenommen, ohne dass überhaupt draussen ein Etwas da wäre, das die Vahrnehmung hervorgerufen hätte. Lady Macbeth halluziniert fortwährend lilut an ihren Händen; der Alkoholiker sieht ,weisse Mäuse”, der religiöse Ekstatiker hört Stimmen, die ihm bestimmte Verkündigungen oder Aufträge geben. Auch Geruchshalluzinationen (Leichengeruch, Blutgeruch) kommen vor. (brisens beschränken sicin Halluzinationen nicht auf solche patholegischen oder aussergewöhnlichen Fälle; es gribt auch gelegentliches Halluzinieren 
innerhalb des normalen Seelenlebens, namentlich bei solchen Menschen, die ,eidetisch" veranlagt sind ${ }^{\mathbf{1}}$ ).

I 11 u sion en sind „Beschaffenheitstäuschungen”. Es ist wirklich ein äusserer Reiz da, der die Wahrnehmung auslöst; aber die $\mathrm{Besch}$ af $\mathrm{fe} \mathrm{nh}$ eit des Wahrgenommenen wird verfehlt. Hierher gehören die weitaus meisten Irrungen der Alltagswahrnehmung, alles Verhören und Verlesen, alle Verfärbungen der Dinge durch Affekte (Beispiel: Der einsame ängstliche Abendwanderer hält einen undeutlichen Baumstumpf für einen sich duckenden Räuber.).

Eine Unterart der Illusionen sind die ,Q u a n t i t ä t s t ä us c h u n g e n"; sie erstrecken sich auf Grösse, Intensität, Entfernung, Anzahl der Wahrnehmungsobjekte. Der Mond sieht beim Aufgehen weit grösser aus als im Zenith. Menschenstimmen klingen in der Bergeinsamkeit besonders laut und erscheinen dadurch näher. Senkrecht gestreifte Kleidung lässt den Träger grösser erscheinen.

Besonders bearbeitet ist das weite Gebiet der geometrisch-optischen Täuschungen, bei denen Linienlängen, Winkelgrössen, Figurenmalse durch bestimmte experimentelle Hilfsmittel in mehr oder minder täuschendem Grade verändert werden können (Beispiele s.S. 225 und S. 228) ${ }^{2}$ ).

$\mathrm{Zu}$ den Quantitätstäuschungen gehören ferner die Kontrastphänomene: ein Mensch mittlerer Grösse erscheint klein unter den grossen, gross unter den kleinen Menschen. Zwei Papierstücke von gleichem mittleren Grau rufen auf schwarzem und auf weissem Hintergrund einen so verschiedenen Eindruck hervor (auf Schwarz einen helleren, auf Weiss einen dunkleren), dass der naive Beschauer absolut nicht an die objektive Gleichheit der Helligkeit glauben mag.

\section{Ursachen}

In die eigentlich psychologische Problematik stossen wir aber erst vor, wenn wir nach den $\mathrm{U}$ rs a che n des Zustandekommens der Täuschungen fragen. Alle Sinneswahrnehmung beruht ja auf drei Faktoren: der äusseren Reizsituation, der spezifischen

1) V'gl. S. 272 .

2) Die erste grundlegende Untersuchung stammte von Theodor Lipps. 
Erregung des Sinnesorgans und der gesamtpersonalen Reaktion. Nach dem Uberwiegen eines der drei Faktoren ergibt sich nochmals eine Dreigliederung der Täuschungen, aber auf einer anderen Ebene; in physikalische, periphere (rein sensorielle), zentrale (besser: personale) Täuschungen.

a) Eine physikalische Täuschung entsteht durch bestimmte Art oder Konstellation der äus ser en Reizbedingungen.

Beisviele: Verzerrung des Gesichts im gewölbten Spiegel; scheinbarer Brach eines geraden Stabes, wenn er ins Wasser gesteckt wird (weil der Lichtbrechungskoeffizient des Wassers ein anderer ist als der der Luft); die durch besondere Luftverhältnisse hervorgerufene Spiegelung der ,fata morgana”. Auf akustischem Gebjet gehört hierher das Echo; akustisch-cptisch ist die Täuschung, dass Donner und Blitz zeitlich verschieden sind (infolge der geringeren Fortpflanzungsgeschwindigkeit der Schalls).

P s y c hologis ch gesehen sind diese Täuschungen an sich ohre Interesse; aber sie dienen erstens dazu, die beiden andern Täuschungsarten deutlicher abzugrenzen; dann aber können sie sich auch mit jenen andern kombinieren. Solche Kombinationen sind vor allem experimentell wichtig: man erzeugt absichtlich bestimmte physikalisch bedingte Täuschungen, um die psychischen Reizwirkungen daran zu studieren.

So ermöglicht das Spiegelstereoskop, die psychologischen Bedingungen der Tiefenwahrnehmung zu untersuchen. Der Kinematograph gibt Aufschluss über das Zustandekommen des subjektiven Bewegungseindrucks, u.s.w.

b) Die peripheren (oder rein sensoriellen) Täuschungen beruhen auf Vorgängen im Sirnesorgan selbst. Charakteristisch für sie ist, dass die Einsicht in die Täuschung den simnlichen Eindruck selbst nicht zu verändern vermag. Ein Beispiel: An einem kalten Wintertage ist meine rechte Hand, die unbehandschuht in der Luft war, kalt, die linke durch gefütterten Handschuh warm. Nun stecke ich beide Hände in laues Wasser. Dies wird von der rechten Hand "warm", von der linken ,kalt" empfunden; und das Erlebnis eines starken Temperaturunterschiedes bleibt, trotzdem ich weiss, dass das Wasser an den beiden stellen, an denen es meine Hände umspült, identische Temperatur hat. Erklärung: 
der kälteren Hand wird vom Wasser Wärme zugeführt, der wärmeren Hand dagegen Wärme entzogen; diese verschiedenen Erregungsprozesse in der Haut bedingen Temperaturwahrnehmungen entgegengesetzten Vorzeichens.

Zweites Beispiel: in unterstehender Figur erscheint das weisse
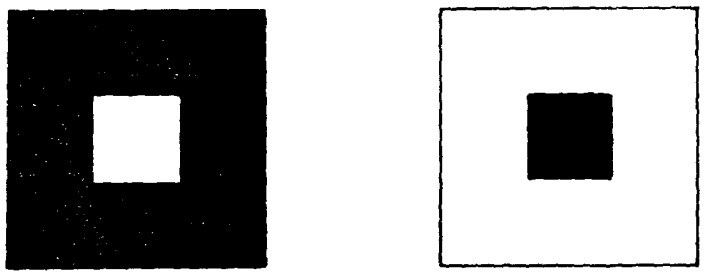

Fig. 10.

Quadrat auf schwarzem Grunde grösser als das schwarze auf weissem Grunde. Die beiden Quadrate sind in Wirklichkeit gleich gross. Erklärung: der starke Helligkeitsreiz des weissen Quadrates beschränkt sich in seinen Wirkungen nicht auf diejenigen Netzhautstellen, die unmittelbar von seinem Bilde getroffen werden; die Erregung breitet sich vielmehr etwas über den Rand hinaus, greift auf benachbarte Netzhautstellen über (sogen. I r r a d i at i o n). Dem so erweiterten Erregungsfeld entspricht dann der Eindruck „Grösser”. Umgekehrt irradiiert bei der zweiten Figur die intensivere Helligkeit des Umfeldes und verengert dadurch das innere schwarze Feld.

Auch die zeitliche Ausbreitung der Erregung kann Täuschungen bewirken infolge der ,Trägh e it” des Sinnesorgans. Die Erregung der gereizten Sinnesstelle hört nicht genau in demselben Zeitpunkt auf, in welchem der Reiz abbricht, sondern klingt mehr oder minder langsam ab; infolgedessen bleibt auch noch die Empfindung bestehen. Hören wir einen langsam abnehmenden Schalleindruck (ausschwingende Glocke, sich entfernenden Eisenbahnzug), dann sind wir gegen Ende ganz unklar darüber, ob das, was wir noch eben hören, auf den noch vorhandenen schwachen Schallschwingungen der uns umgebenden Luft beruht, oder aber auf der Trägheit des (sehörsorgans, in dem die Erregung noch nicht zum Stillstand gekommen ist. - Drückt man jemandem eine Nünze gegen die Stirnhaut, hält mit dem Druck einige Zeit an und nimmt dann leise das Geldstück fort, 
so kann die Täuschung, dass es noch an der Stirn klebe, vollkommen sein.

Am bekanntesten und mannigfaltigsten sind diese Trägheitserscheinungen im Optischen, wo sie "N a c h b i l d e r" heissen. Bewege ich im Dunklen schnell einen glühenden Punkt (z. B. einen Streichholzkopf) im Kreise, dann sehe ich nicht einen sich fortbewegenden Punkt, sondern einen ruhenden Lichtkreis.... Im Kino folgen sich die einzelnen Bildreize so schnell, dass die durch jedes Bild erzeugte Erregung über die Zwischenzeit bis zum nächsten Bild hinweg dauert und dadurch Kontinuität des gesehenen Vorgangs vortäuscht. - Fixiere ich längere Zeit das kleine weilse Quadrat (Fig. 10), und blicke ich dann auf eine gleichförmiggraue Fläche, dann erscheint auf dieser sehr bald ein dunkles (Ouadrat auf hellem Grunde. Hier hat die Trägkeit der Netzhaut eine besondere, „komplementäre” Form angenommen. Der Erregungsvorgang bleibt nicht in der ursprunglichen Form bestehen, sondern schlägt in sein Gegenteil um, ehe er ganz zur Ruhe kommt. (Sogen. negatives oder komplementäres Nachbild).

In den genannten und in zahlreichen weiteren Fällen ist der periphere Ursprung der Täuschung eindeutig und unzweifelhaft. Bei vielen anderen Täuschungen aber besteht diese Eindeutigkeit nicht. Denn es gibt auch Täuschungsquellen, die abseits des gereizten Sinnesorgans entspringen, oder sich mit peripheren Täuschungsanlässen in schwer zu entwirrender Weise verbinden. Man versteht es daher, dass in der Theorie der Sinnestäuschungen, die ein sehr beliebtes und vielfältig bearbeitetes Thema darstellt, recht kontroverse Erklärungen für bestimmte Täuschungen gegeben wurden und werden.

c) Personale (zentrale) Täuschungen. - Jie nicht peripher bedingten Täuschungen sind psychologisch die interessantesten. Man stellte sie früher als „Lrteils"'-Täuschungen den eigentlichen „Sinnes”-Täuschungen gegenüber. Hieran ist soviel richtig, dass jede Täuschung in der Form eines falschen Lrteils a u ge sproch en werden kann, z.B.: "Dort hinten in der dunklen Ecke kauert eine menschliche Gestalt" (während der undeutlich gesehene Gegenstand vielleicht ein Sack ist). Aber im tatsächlichen Erleben wird eine solche Täuschung nur selten auf einem Versagen oder Fehlgehen der Lrteilstätigkeit beruhen; 
sie kann ganz andre Quellen - affektmälsiger, willensmälsiger, sozialpsychischer Natur - haben; sie kann auch aus einer personalen Einstellung zur Situation fliessen, bei der einzelne isolierte Ursachmomente garnicht mehr unterscheidbar sind. Ist ein Mensch - sei es konstitutionell oder momentan - in einem besonders erregten Zustand, in sehr labilem Gleichgewicht, dann werden Sinnesreize ganz anders aufgenommen und verarbeitet. Erwartung, Furcht, Wunsch, Masseneinflüsse verwandeln das Gesehene und Gehörte im Sinne des personal Bedeutsamen. Niemals gab es so viele Wahrnehmungstäuschungen wie etwa in den ersten Tagen des grossen Krieges, als verkleidete Spione, Goldautos, verdächtige Gespräche u.s.w. überall bemerkt worden sein sollten.

Auch die Suggest i o $\mathrm{n}$ muss in diesem Zusammenhang erwähnt werden. Man stelle sich an eine belebte Strassenecke und starre in den Himmel; auf Fragen der neugierigen Passanten sage man, dort oben sei, ganz klein und kaum erkennbar, ein merkwürdig geformtes Flugzeug zu sehen - und bald werden auch andre dies nicht vorhandene Objekt zu sehen meinen.

Alfred Binet hat einmal in einer Vorlesung folgendes Experiment gemacht: Er sagte den Hörern, er wolle Versuche über ihre Geruchsempfindlichkeit anstellen, indem er Flaschen öffnen werde, welche schlecht riechende Fliissigkeiten in äusserster Verdünnung enthielten. Damit hatte er eine bestimmte Erwartungscinstellung geschaffen. Nun entkorkte er die Flaschen, und die Anwesenden bemerkten nicht nur mit Widerwillen die angekündigten schlimmen Gerüche, sondern reagierten mit Hüsteln, Abwenden, ja mit Ausdrucksbewegungen des Ekels - auf aqua destillata!

Erwartungsspannungen und abgelenkte Aufmerksamkeit spielen auch eine entscheidende Rolle bei der Wahrnehmung von Taschenspielerkunststücken und okkultistischen Vorführungen. In beiden Fällen wird durch Schaffung einer, zugleich aufreizenden und einlullenden, Gesamtatmosphaere, - durch Hokuspokus, Halbdunkel, langes Wartenlassen, geheimnisvolles Gebahren, die Empfänglichkeit für die Täuschungen aufs höchste gesteigert. Wenn man sich erst einmal klar macht, wie wenig der Mensch auch unter ganz alltäglichen Umständen und bei hellem Licht des Tages gegen Sinnestäuschungen gefeit ist, dann sollte man nicht mehr erstaunt und vor allem nicht kritiklos gläubig sein ge- 
genüber dem, was die Teilnehmer an spiritistischen Séancen ,,mit ihren eigenen Sinnen" gesehen, gehört und sogar getastet haben wollen.

Menschen, die von Natur zu kühler, sachlicher Beobachtung neigen, werden viel seltener zentralen Wahrnehmungstäuschungen unterliegen als die Menschen des subjektiven Typs, bei denen jede Wahrnehmung ungeschieden eingebettet ist in die gesamte Affekt- und Wunsch-Struktur der Persönlichkeit. Insbesondere aber können ungewöhnliche und abnorme seelische Zustände und Beschaffenheiten die Empfänglichkeit für Sinnestäuschungen ins Ungemessene steigern. Hochgradige Eidetiker verwechseln gelegentlich ihre Anschauungsbilder mit echten Wahrnehmungen. In Zuständen religiöser Verzückung treten Visionen und Stimmen auf, die mit der vollen Evidenz äusserer Wirklichkeit hingenommen werden. Und in verschiedenen Formen der Geistes- und Gemüts-Krankheiten sind Halluzinationen und Illusionen von geradezu konstitutiver Bedeutung.

In allen diesen Fällen liegt der eigentliche Ursprung der Sinnestäuschung im Zentralen und nicht in der Peripherie. Gewiss mag auch eine gesteigerte oder gestörte Funktion der Sinnesorgane selbst mitspielen. Aber Ohrensausen oder Augenflimmern haben viele Menschen, ohne dass es zu „Täuschungen” käme; - akustische oder optische inneren Reizungen werden eben nur dort irrig objektiviert (als ,Stimmen”, als ,weisse Mäuse”), wo die krankhafte Totalbeschaffenheit der Person eine solche fehlgreifende $V$ e r a r b e it u n $g$ der Sinneseindrücke begünstigt.

Gelegentlich kommen auch „Urteils-Täuschungen” im eigentlichen Sinne vor, nämlich dann, wenn die Bedeutung einer Wahrnehmung erst durch urteilsmälsige Interpretation gefunden wird. Bekannte Beispiele bilden gewisse Kontrasttäuschungen. Sehe ich einen Menschen mittlerer Grösse in einem Kreise ungewöhnlich grosser Menschen, so erscheint er mir nicht nur "kleiner”, sondern schlechthin ,klein". Der unmittelbar sinnlich erfasste Grössen-U n t e r s c h i e d führt zu einem Crteil über die a bs o l u t e Grösse. Mache ich mir die irrige I)enkworaussetzung klar, so „sehe" ich den Menschen nicht mehr als ,klein”, sondern in seiner natürlichen, ,mittleren" (irösse. Ein solches L'm-Mahrnehmen bei Einsicht in die Täuschungsursache ist — so stellten wir schon oben fest - bei den peripheren Täuschungen nicht möglich. 
Dieser methodische Gesichtspunkt erweist zugleich, dass die Meinung mancher Theoretiker, a lle Kontrasttäuschungen seien „Urteils"'-Täuschungen, unhaltbar ist. Der Farbenkontrast z.B. ist wahrnehmungsmärsig unaufhebbar und darum nicht (wie noch Helmholtz glaubte) auf Urteilstäuschungen zurückführbar. Betrachte ich eine, unter durchscheinendem Papier liegende, neutral-graue Scheibe auf grünem Grunde, dann wird die Scheibe rötlich; d.h. ihr Ton verschiebt sich in Richtung auf die dem Grün entgegengesetzte Farbe. Mein $W$ i s s e $n$, dass jene Scheibe in Wirklichkeit farblos grau ist, ändert nicht das Geringste an der sinnlichen Evidenz des Rot-Eindrucks. Die Ursache muss daher in einer veränderten Reizung der Netzhaut liegen.

d) Abschliessend sei an einem Beispiel gezeigt, wie eine und dieselbe Täuschung durch sehr verschiedene Theorieen erklärt werden kann. Die „Müller-Lyer'sche Figur” (s.S. 225) zeigt zwei objektiv gleich lange wagerechte Linien, die durch angesetzte Winkel in ihrem Längeneindruck aufs stärkste differenziert werden.

Frklärungsmöglichkeiten: 1) Optisch-gestaltpsychologische Frklärung: ich kann die wagerechten Linien überhaupt nicht isoliert sehen, sondern nur als tragende Momente der Gesamtfiguren. Der wagerechte Ausdehnungsunterschied der Gesamtfiguren wird nun in die wagerechte Tcillinie hineingesehen. 2) Kinästhetische Erklärung: Verfolge ich die wagerechten Linienzüge durch Augenbewegung, so wird bei b diese Bewegung schroff durch die abschliessenden Winkel gehemmt, während die nach aussen gerichteten Winkel von a die Augenbewegung langsam auslaufen lassen. Da aber das Ausmals der Bewegung interpretiert wird als Malsstab für die Länge der mit dem Auge abgetasteten Linie, so erscheint die obere Linie länger. 3) Einfühlungspsychologische Erklärung (Lipps): Die Figuren werden nicht statisch als ruhende Liniengefüge, sondern dynamisch als Kraftäusserungen gesehen, mit denen ich mich irgendwie personal identifiziere. Die obere Linie zieht sich in sich zusammen, ,verkürzt sich", die untere reckt sich nach aussen, ,verlängert sich”. Wir sind sogar geneigt, diese Tendenz durch entsprechende Ausdrucksbewegungen unseres eigenen Körpers zu akzentuieren.

Von diesen Erklärungsversuchen ist der mittlere am wenigsten befriedigend, da die Täuschung auch bei unbewegten Augen besteht. Die beiden anderen Erklärungen entsprechen den beiden Arten der Wahrnehmung, die wir als ,abhebende" und als ,einbettende" bezeichneten. Dort wird der optische Gestalteindruck als solcher isoliert; hier erlebt man den Eindruck nicht nur mit dem Auge, sondern mit der ganzen Person. Ia bei jeder tatsächlichen Wahrnehmung beides, nur in verschiedener Verteilung, wirksam ist, werden auch beide Täuschungsmotive Geltung haben. Es gibt Menschen und es gibt Situa- 
tionen, bei denen mehr das statische Gestaltsmotiv, und andere, bei denen mehr das dynamische Einfühlungsmotiv vorherrscht. Eine generelle Ableitung der Täuschung aus einem der beiden Motive erscheint verfehlt.

\section{GRENZEN UND SCHWELIEN DER WAHRNEHMUNG}

Die Physik lehrt, dass die objektiven Reizvorgänge abstufbar und in ihren Abstufungen messbar sind. Die Psychologie kann Ähnliches auch bezüglich der Wahrnehmungsinhalte aufweisen. Die zwischen den Reizstufen und den Wahrnehmungsstufen bestehenden Beziehungen bilden das Problemgebiet der „Psychophysik" (vgl. S. 31).

\section{Der Reihencharakter der Wahrnehmungen}

Beschränken wir uns zunächst auf die Erlebnisinhalte als solche, so kann man die Wahrnehmungen unter verschiedenen Gesichtspunkten graduell vergleichen, d.h. ihre erlebte Verschiedenheit durch ein ,Mehr oder Minder" ausdrücken.

Wahrnehmungen zeigen Unterschiede der In t ensität, d.h. der Gewalt, mit der sich ihr Inhalt sinnlich geltend macht: Eine Lampe leuchtet heller als eine andre, das Geräusch eines sich nähernden Eisenbahnzuges schwillt an; eine Rose duftet stark, eine andre schwach u.s.w. - Dann Lnterschiede der Ext e n sität: Man kann ein mehr oder minder Lang, Hoch, Breit u.s.w. sehen und tasten; ein mehr oder minder Fern sehen und hören. - Endlich Lnterschiede der A n $\mathrm{z}$ a h l: eine gesehene Punktreihe enthält mehr Punkte als eine andre u.s.w.

Für alle genannten Differenzen gilt der $R \mathrm{e} i \mathrm{~h}$ e n charakter. Habe ich drei oder mehr Eindrücke a, b, c.... verschiedener Helligkeit (Länge, Anzahl), dann ist erlebnismäfsig c in höherem Malse von a verschieden als b; b liegt eindeutig zwischen a und $c$.

Extensität und Numeralität können psychologisch gemessen werden; d.h. die einzelnen Eindrücke sind als vielfache einer Einheit ausdrückbar. Man kann z.B. -- noch ohne Rücksicht auf den objektiven Reizwert -- sagen: diese Linie erscheint mir dreimal so lang wie jene. Oder die Anzahl dieser Punkte (in einer Punktgruppe) erscheint mir doppelt so gross wie die Anzahl jenter. 
Bei den Intensitäten ist eine entsprechende Angabe nicht möglich. Vergleiche ich die Helligkeit zweier Lampen a und b, so finde ich a stärker (etwas stärker, viel stärker) als b; aber die Angabe: der von a erzeugte Eindruck sei dreifach so stark wie der von b erzeugte, wäre absurd ${ }^{\mathbf{1}}$ ).

Will man eine rein psychologische Messung auch auf Intensitäten anwenden, dann ist es nur dadurch möglich, dass man sie in Extensitäten einbaut, d.h. die zwischen je zwei Intensitäten bestehenden $\mathrm{A} b \mathrm{~s} \mathrm{t}$ ä $\mathrm{n}$ e als Einheiten wählt.

Beispiel: ich habe vier graue Papiere von verschiedener Helligkeit a, b, c, d. Nun kann ich den Helligkeits-U n t e r s c h i e d zwischen a und $b$ vergleichen mit dem $z$ wischen $b$ und $c$ und dem $z$ wischen $c$ und d, und alle drei Distanzen unter Umständen als gleich erleben. Danach wäre dann der Helligkeitsabstand a bis c doppelt so gross wie der von c zu d.

Die Reihen, in welche sich quantitative Abstufungen der Wahrnehmung ordnen lassen, sind nicht unendlich; man kann den Grad einer Wahrnehmung nicht beliebig ins Ungemessene steigern oder verringern. Aber ihre Grenzen an den beiden Enden haben einen ganz verschiedenen Charakter. Die untere Grenze nämlich ist stets die Null: das Verschwinden der Wahrnehmung überhaupt. Wird ein Ton leiser und leiser, so hört er schliesslich ganz auf, als Erlebnis für mich da zu sein. Und ebenso in aller andern Fällen. Die obere Grenze dagegen ist die Sättigung und Ubersättigung: ein Höchstmals noch eben zu bewältigender Stärke oder Weite des Eindrucks, jenseits dessen nicht mehr eine weitere Abstufung des Wahrnehmungsgrades, sondern eine gesamtpersonale, diffuse Störungsreaktion erfolgt: Betäubung bei zu starken Schalleindrücken, Blendung bei zu heftigen Lichteinwirkungen, Unmöglichkeit, die ungeheure Weite des Ozeans zu fassen u.s.w.

Eine andere Stellung nehmen die schon früher besprochenen Systeme der Farben und Tonhöhen ein. Sie bilden ebenfalls R e i h e $n$, sodass ein bestimmter Wahrnehmungsinhalt als zwischen zwei anderen liegend erlebt wird; auch die Abstände zwischen je zwei Inhalten können verschieden gross erscheinen.

1) Werden dennoch solche Angaben gemacht, so wird nicht mehr das Erlebnis, sondern die vermutete o b je $\mathrm{kt}$ i v e Helligkeit des Reizes damit gemeint. 
Aber die Reihenbildung wird durch andere Faktoren kompliziert, ist deshalb nicht gradlinig darstellbar (vgl. den „Ring” der bunten Farben, die "Spirale” der Tonhöhen). Auch sind die Abschlüsse der Reihen anders beschaffen. Die Farbenreihe hat überhaupt keine Abgrenzung, da sie in sich selbst zurückläuft; die Tonhöhenreihe ist an b e i d e n Seiten durch den Nullzustand (Fehlen jedes Tonerlebnisses) begrenzt.

\section{Die Schwellen}

und das We ber-Fechner'sche Geset $z$

a) Äusere und innere Schwellen. - Die psychologischen Abstufungsarten sind nun bestimmten, physikalisch zu charakterisierenden, Merkmalen der Reize zugeordnet. So entsprechen: den Wahrnehmungs in t e n s i t ä t e n des Gesichts- und Gehörssinns die Schwingungs w e it e n der Lichtund Schall-Schwingungen, - den Eindrücken verschiedener S c h w e r e die physikalischen G e w i ch t e der Reize, - den verschiedenen $\mathrm{E} x \mathrm{t}$ en sit ät serlebnissen messbare physikalische Längen-, Flächen-, Volumen-, Zeit-Quanta. - Auch zu den beiden zuletzt genannten psychologischen Stufensystemen: den Tonhöhen und den Farbtönen, gibt es korrelative Reizmafse, nämlich die A n z a h 1 der Licht- und Schall- Schwingungen in der Sekunde (oder auch die zu dieser Anzahl in umgekehrter Proportionalität stehenden Wellenlängen).

Aber diese Entsprechung ist nichts weniger als vollkommen. Die Welt der objektiven Reizgrade ist von einer ganzanderen Weite und II annigfaltigkeit als die Welt der erlebbaren Wahrnehmungsstufen. Sieht man selbst ab von der Tatsache, dass es ganze physikalische (rebiete (z.B. die der magnetischen Vorgänge) gibt, die überhaupt nicht der Sinneswahrnehmung unmittelbar zugänglich sind - selbst in den wahrnchmbaren Gebieten ist das physikalische Stufensystem dem psychologischen unendlich ïberlegen. Das gilt ebenso für die äussere Grenzsetzung, wie für die innere Abstufung.

Aus jeder Abstufungsart physikalischer Vorgänge wird durch die Sensibilität ein enger Bereich herausgeschnitten, innerhalb des-

1) s.S. 189 u. 191. 
sen die Reize durch Wahrnehmungen beantwortet werden können. Diejenigen Reizmalse, die jenen Ausschnitt begrenzen, bezeichnet man alsdie ,ä u s s e r e n S c h w e 1 l e n”. Eine solche heisst ,untere Schwelle" dort, wo die Wahrnehmung eben die Null überschreitet; „Reizhöhe” dort, wo Steigerung des Reizfaktors die spezifische Wahrnehmungsintensität nicht mehr weiter steigert, sondern eine gesamtpersonale Wirkung (Blendung, Betäubung u.s.w.) herbeiführt; „obere Schwelle” dort, wo bei Steigerung des Reizfaktors die Wahrnehmung wieder erlischt.

Auch innerha $1 \mathrm{~b}$ des durch äussere Schwellen eingeschlossenen Reizgebiets besteht keinerlei Parallelität zwischen Wahrnehmungsreihe und Reizreihe. Die physikalische Zunahme oder Abnahme der Reizstärke durchläuft zwischen zwei gegebenen Grenzen unendlich viele Mafswerte (man kann z.B. eine objektive Helligkeit s t e $\mathrm{t}$ ig in eine höhere oder geringere verändern); die Wahrnehmung dagegen vermag nur eine engbegrenzte Zahl von Stufen zu unterscheiden.

Als „innere Schwelle” oder „Unterschied ss ch w e 11 e" bezeichnet man denjenigen Unterschied zweier Reize, der s o e b e n einen Unterschied in der Wahrnehmung zu erzeugen vermag. Halte ich in der Hand ein mit Wasser halb gefülltes Gefäss, so habe ich eine bestimmte Schwerewahrnehmung. Wird jetzt weiteres Wasser in ganz dünnem Strahl hinzugefügt, so nimmt das physikalische Gewicht stetig zu, aber die SchwereWahrnehmung ändert sich nicht sofort; der Reizunterschied bleibt zunächst noch ,u n t e r s c h w e 11 i g”. Erst bei einer bestimmten Zusatzmenge entsteht der Eindruck „schwerer"; der Unterschied ist „eben merklich" oder ,s c h w e 1 li g", geworden, die Unterschiedsschwelle erreicht.

Die Fähigkeit des Menschen, Reizunterschiede eben zu bemerken, wird seit Fechner als ,U n t e r s c h i e d s e m p fin dl i chkeit" bezeichnet; ihre Feinheit ist umgekehrt proportional dem Mafswert der Unterschiedsschwelle. Wer das Schwererwerden eines Gewichts (vgl. obiges Beispiel) schon bei Zusatz von 10 Gramm bemerkt, hat eine kleinere Unterschiedsschwelle, somit eine höhere Unterschiedsempfindlichkeit, als derjenige, der (bei gleichem Grundgewicht) erst nach Zusatz von 20 Gramm die Gewichtsänderung wahrnimmt. 
Wird die Unterschiedsschwelle ausgedrückt in festen physikalischen Malsen (z.B. in Grammen, in Längen, in photometrischen Einheiten u.s.w.), so heisst sie a b s o 1 u t e $\mathrm{C} n \mathrm{ter}$ e h i e d s$\mathrm{sch}$ w elle. Diese Schwelle ist im allgemeinen $\mathrm{n} i \mathrm{ch} \mathrm{t}$ konstant. Sie ist nicht nur verschieden bei verschiedenen Menschen oder in verschiedenen Wahrnehmungssituationen, sondern sie ist, unter sonst gleichen Bedingungen, verschieden, sobald der Grundreiz wechselt.

Wenn in unserem Beispiel 10 (rramm nötig waren, um an dem mit Wasser halb gefüllten Gefäss eine Lnterschiedswahrnehmung $\mathrm{zu}$ erzeugen, so sind, wenn ich ein doppelt so schweres (refäss nehme, nicht 10, sondern etwa 20 (rramm Zusatz nötig, damit die Schwelle erreicht wird, bei einem vier mal so schweren (xefäss 40 Gramm u.s.w.: Es kommt also hier nicht auf die Differenz zwischen Grundreiz und zweitem Reiz an, sondern auf das Verhältnis des Zusatzreizes zum Grundreiz; dieses Verhältnis - die „r e 1 ative Unterschiedsschwelle" — ist (innerhalb später zu besprechender Einschränkungen) k o n s t a $\mathrm{n} t$.

Bezeichnen wir den Grundreiz als r, den zur Ebenmerklichkeit nötigen Zusatzreiz als dr, dann ergibt sich aus obigem die Formel:

$$
\frac{\mathrm{d} r}{\mathrm{r}}=\text { Konst }
$$

Dies ist das berühmte „Psychophysische Grundgesetz", heut allgemein "W e ber-Fech her's ches Gese t $z$ " genannt. Ernst Heinrich Weber hatte nämlich vor einem Jahrhundert (1834) diese eigentümlichen Mafsverhältnisse bei Grewichtswahrnehmungen entdeckt; Fechner hat dann dic Formel auf vielen andern Empfindungsgebieten zu erweisen versucht.

b) Experimentelle Lntersuchungen $74 \mathrm{~m}$

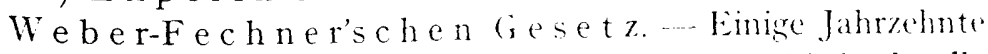
lang haben psychophysische Hessungen der Lnterschiedschwelle geradezu im Vittelpunkt der experimentellpsychologischen Arbeit gestanden. Alle Sinnesgebiete wurden durchgeprüft, die verschiedensten Versuchs- und Berechmugsmethoden aussearbeitet.

Bei den ,Beurteilungsmethoden" werden keizpare dargeboten, deren Glieder mit tinander zu rersleichen smd: dic Versuchsperson (Vp.) hat anzugeben, ob der Reiz b dem Reiz a slejch seit. oder nach oben oder nach unten won ihm abzuwichen scheine. Murch 
Verwendung sehr verschiedener Grundreize, wechselnder Reizabstände $z$ wischen $a$ und $b$ und häufig wiederholter Darbietung der einzelnen Reizpaare gelangt man schliesslich zu denjenigen Reizpaaren, bei denen sich die Urteile ,gleich" und ,verschieden" ungefähr die Wage halten; zeigen diese so ausgezeichneten Reizpaare, trotzdem sie sehr verschiedenen Intensitätsgebieten angehören, dennoch annähernd gleiches Stärke-V e r h ä $1 \mathrm{t} n$ i s, so ist dies ein Zeichen für die Gültigkeit des obigen Gesetzes.

Anders die „B es $\mathrm{t}$ i m m u n g s m e th od e n”. Hier hat die Versuchsperson selber das Reizpaar zu bestimmen, welches einer gegebenen Anforderung entspricht. So wird etwa neben einer Fläche von konstanter Helligkeit eine andere gezeigt, deren Helligkeit allmählich verringert oder erhöht wird; die Vp. gibt den Moment an, in welchem die Vergleichshelligkeit eben anfängt oder aufhört, sich von der ersten Helligkeit $z u$ u n e r s cheiden. Man kann die Forderung auch auf möglichst genaue Herstellung subjektiver $\mathrm{Gle}$ ich h e it beziehen, z.B. auf Zeichnung einer Linie, die eben so lang ist wie eine gegebene; oder auf Abstimmung einer Saite, so dass ihr Ton dieselbe Höhe hat wie ein eben gehörter anderer Ton. Da nämlich ideale Gleichheit nie erreicht wird, lässt sich in solchen Fällen der begangene F e h l er messen; es zeigt sich, dass auch dieser Exaktheitsfehler, d.h. also derBereich, innerhalb dessen Verschiedenheiten unbemerkt bleiben, im allgemeinen ein konstantes Verhältnis zu dem Grundreiz hat.

So wie ins Unterschwellige kann die Bestimmungsmethode auch ins C bers ch we $11 \mathrm{ig} \mathrm{e}^{1}$ ) hin erweitert werden; wir haben es dann mit Wahrnehmungsunterschieden zu tun, die weit über die Unterschiedsschwelle hinausreichen. Hier kann man sich nämlich der I n t e n s i tätsa b s $\mathrm{t}$ ä $\mathrm{n}$ d e bedienen, von denen schon oben (S. 234) die Rede war.

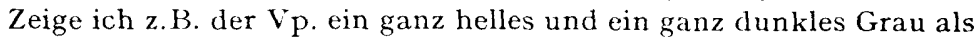
feste Grenzpunkte, ferner eine Reihe dazwischen liegender Graupapiere, mit der Aufforderung, dasjenige herauszusuchen, das $\mathrm{d} i \mathrm{e}$ II it e zwischen jenen Grenzhelligkeiten $z u$ bilden scheint, dann ergibt sich folgendes:

Die physikalische Helligkeit (welche photometrisch zu bestimmen ist) sei bei dem hellen Grau durch den Wert 8, beim dunklen Grau durch 2 dargestellt. Dann wird die Wahl für die subjektive ,Mitte" nicht auf die Helligkeit 5 fallen (die den gleichen objektiven Abstand, nämlich drei Einheiten, von den beiden Grenzhelligkeiten hat), sondern auf die Helligkeit 4 , welche in gleichem $V$ er hält $n$ is zu jenen steht: $2: 4==4: 8$.

Fassen wir alle diese Befunde zusammen, die mit sehr verschie-

1) Lechner hatte fiir die drei Arten von Reizunterschieden die Bezeichnungen ,eben merkliche", „untermerkliche”, ,tibrmerkliche" Lnterschiede eingefiihrt. Der dritte Ausdruck ist aber sprachlich $z u$ beantanden, da es sich um voll merkliche, (nicht "über"-merkliche) Differenzen handelt. I ie oben gebrauchten Termini "schwellig", ,.unterschwellig” "überschwellig" sind angemessener. 
denen Methoden erzielt worden sind, so können wir das Ergebnis so formulieren: Um schwellige oder um gleich grosse überschwellige Wahrnehmungsunterschiede zu erzielen, müssen die Reize nicht einen konstanten Abstand, sondern ein konstantes Verhältnis zu einander besitzen. Fechner, der die schwelligen, unterschwelligen und überschwelligen Unterschiede zusammenfasste, formulierte das Gesetz ganz allgemein: Wenn die Empfindungen in arithmetischer Reihewachsen sollen, müssen die Reize in geometrischer Reihe wachsen. Noch kürzer: $\mathrm{E}=\log \mathrm{R}^{1}$ ).

Was die e mpirische Bestät igung des Gesetzes an langt, so haben die massenhaften, auf Fechner folgenden Experimental-Untersuchungen den Optimismus wesentlich gedämpft. Wir wissen heut, dass es sich nicht um eine „Weltgesetzlichkeit' handelt, die von gleichem Rang wäre, wie die allgemeinen, mathematisch formulierbaren Naturgesetze der Physik und Chemie; vielmehr nur um eine Bezichung, die für eine Anzahl von Reizgebieten mit einer gewissen Annäherung gilt, in diesen aber nie für das ganze Gebict, sondern nur für eine mittlere Breite. Es sei dies zunächst durch einige Zahlenwerte belegt.

Die relativ deutlichste und umfassendste Ausprägung zeigt das Gesetz bei Helligkeitsstärken. Hier gilt es, wie unsere Beispiele zeigten, nicht nur für schwellige und unterschwellige, sondern auch für stark überschwellige Lnterschiede; und $z$ war innerhalb eines recht weiten Bereiches. König und Brodhun ') haben seinerzeit Helligkeiten benutzt $z$ wischen den objektiven Masswerten 1 (Belichtung eines Papiers durch eine Kerze aus a m. Entfernung) und 200000 (Belichtung durch eine starke Bogenlampe aus wenigen Zentimetern Entfernung). Wir greifen nun einige charakteristische Ziffern heraus:

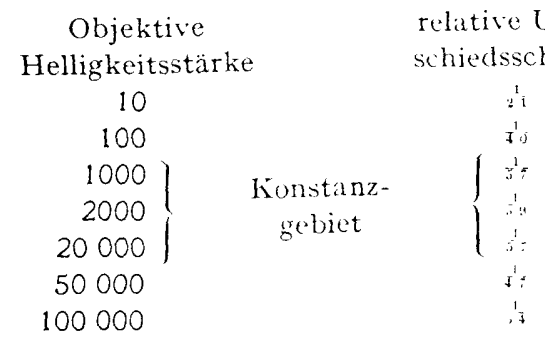

\footnotetext{
1) Die mathematische Ableitung dieser vielumitritten'n formel kann hier nicht gegeben werden; man vergleiche hiteru die Darstellungen bei Ebbinghaus, Winkt, Fröbes und anderen.

2) Nach Ebbingbaus I $\$ .5 .23$.
} 
Bei sämtlichen Helligkeiten zwischen 1000 und 20000 genügt also zicmlich gleichmässig eine Steigerung der Reizstärke um nicht ganz $2 \%$, damit eine psychische Unterschiedswirkung entstehe.

Der Wert 2\% für die relative Unterschiedsschwelle ist übrigens von den besonderen Versuchsbedingungen abhängig, die in obigem Experiment nicht sehr günstig waren. Andere Experimentatoren haben bei Vergleichung von Helligkeiten in verschiedenen Intensitätsgebieten eine viel feinere Schwelle (um 1\%) gefunden. Andrerseits werden die Schwellen gröber, wenn man nicht zwei Helligkeiten vergltichen, sondern den rückweisen Übergang einer Helligkeit in eine andre beobachten lässt. Meine eigenen Untersuchungen über solche Helligkeitsveränderungen ergaben dann - bei Gültigkeit des Weber-Fechner'schen Gesetzes - Schwellen von etwa $3 \%$.

Bei Gewich $\mathrm{tsh}$ ebungen - deren Untersuchung durch Ernst Heinrich Weber den Ausgangspunkt dieserganzen Problematik bildete - zeigen die Experimente eine Konstanz der relativen Schwelle zwischen den Grundreizen 2000-6000 Gramm. Im ganzen ist hier die Schwelle weit gröber als bei den Helligkeiten; sie beträgt unter günstigen Versuchsbedingungen $10^{\circ}$. Jenseits der genannten frenzen wird die relative Unterschiedsempfindlichkeit nach unten hin stumpfer, nach oben hin dagegen überraschender Weise feiner.

Auch bei passiver Gewichtswahrnehmung - wenn auf eine ruhende Korperstelle ein Druck ausgeübt wird - gilt das Prinzip. So hat der Zeigefinger innerhalb der Reizgrenzen 50--2000 Gramm eine Unterschiedsschwelle von ungefähr $5 \%$.

Weiter gehört hierher die Unterschiedsempfindlichkeit für extens i re Reize, ror allem für solche, die vermittels der Augen und ihrer Bewegungen aufgefasst werden (sogen. "A ug e n maf s"). Lässt man Iinien nach ihrer Länge, Flächen nach ihrem Inhalt miteinander vergleichen, so genügt - bei verschiedenen absoluten Mafsen - ein Lnterschied von etwa 20, um die Verschiedenheit merklich zu machen. - Auch für Strecken, die durch Armbewegungen abgeschätzt werden, scheint das Weber-Fechner' sche Gesetz in gewissem Lmfang zu gelten.

Der Ge hörssın n bietet ein etwas buntscheckiges Bild.

Die Prüfung ron Ton- und Geräusch-Stä $\mathrm{r} k \mathrm{k}$ ist dadurch erschwert, dass es hier noch an sicheren physikalischen Mafswerten fehlt; indessen scheint bei Tonen mittlerer Höhe im mittleren Stärkeberich eine relative sehwellenkonstanz zu bestehen, die bestenfalls 12" "beträgt. Hine noch wrobere Schwelle, die aber ziemlich konstant ist. Lat matu für (xeränschstïrken berechnet (etwa $33_{0}^{\circ}$ ).

Auf dasinenauestemessbar sind lagegen die den $\mathrm{T}$ o $\mathrm{n}$ h ö he $\mathrm{n}$ entsprebenden Robabstufungen, nämlich die schwingungszanlen der tonenden borper (je sekunke). Die ausseren Schwellen liegen hier etwa ber 20 schwingumgen und bei $20000-40000$ schwingungen; jenatits dieser Grenzen der tiefsten bezw höchsten lone sind schallsehwingungen akustisch unwirksam. Untersuchungen der Unter- 
s c hieds s c h w e 1 l e zeigten keine Spur des Weber-Fechner'schen Prinzips, dagegen innerhalb eines weiten mittleren Tonbereichs die Konstanz der a bs ol ute n Unterschiedsempfindlichkeit. In der Region von 100-1000 Schwingungen, also durch mehr als drei Oktaven, genügt bei sehr geübten Hörern eine $\mathrm{D}$ if $\mathrm{fer}$ e $\mathrm{n}$ von etwa Schwingung, um den Eindruck einer Höhenverschiedenheit zu erzeugen. Vom Ton 100 (Schwingungen) wird also der Ton 100,25, vom Ton 500 der Ton 500,25 eben unterschieden.

Diese Ziffern zeigen, dass die Gehörsempfindlichkeit für Tonhöhen eine ganz ausserordentliche Feinheit erlangen kann. Sind doch in $\mathrm{nerhalb}$ eines $\mathrm{Halbt}$ a n chrittes der musikalischen Mittellage (z.B.: es $1 / \mathrm{e}^{1}$, Schwingungszahlen $300 / 320$ ) bei maximaler Übung noch 80 verschiedene Tonstufen erkennbar. Die eingestrichene Oktave würde hiernach 5000, der ganze musikalische Tonbereich 50000 unterscheidbare Töne enthalten!

Aus dieser unermesslichen Fülle hat die Musik also nur eine ganz karge Auslese getroffen, die eben nicht durch die Unterschiedsempfindlichkeit, sondern durch die einfachen Beziehungen der Konsonanz und Dissonanz bedingt ist. Und nun ergibt sich das Merkwürdige, dass für diese, eigentlich $\mathrm{musik}$ a $\mathrm{s}$ is $\mathrm{ch}$ e $\mathrm{n}$, Beziehungen wieder das Weber-Fechner'sche Malsprinzip gilt! Wenn eine Melodie transponiert wird, z.B. in eine höhere Oktave, dann bleibt sie "dieselbe" Melodie, und alle Intervalle bleiben ,dieselben" Intervalle. Nun wird z.B. die Quinte $c^{1} / \mathrm{g}^{1}$ durch die Schwingungszahlen 256/384 erzeugt, die Quinte $\mathrm{c}^{2} / \mathrm{g}^{2}$ durch die Schwingungszahlen 512/768. Der physikalische Abstand ist also im zweiten Fall doppelt so gross (256 Schwingungen) wie im ersten (128 Schwingungen). Aber das $V$ e $r$ ä $1 \mathrm{t} n$ is ist gleich geblieben, nämlich hier wie dort $2: 3$, und dem entspricht der Eindruck eines psychologisch gleichen $Z$ wischenraumes: Quinte = Quinte. Hier haben wir also ein Reizgebiet vor uns, auf dem überschwellige Intervalle und schwellige Unterschiede nicht dem gleichen Gesetz unterliegen.

c) Erklärungsversuche. - Unter dem Eindruck einer solchen Mannigfaltigkeit der Befunde muss man zu dem Schluss kommen, dass es ein aussichtsloses Unternehmen ist, mit einer einheitlichen und allgemeingültigen Hypothese das WeberFechner'sche Prinzip e r k 1 ä r e n zu wollen. Der Versuch hierzu ist oft wiederholt worden; die drei Haupthypothesen seien in kurzen Stichworten angedeutet, da sie uns dann eine neue Stellungnahme erleichtern.

Vier Faktoren sind an dem Gesamtgeschehen beteiligt: der physikalische (Reiz), der physiologische (Nervenprozess), der psychologische (Wahrnehmung), der personale (Reaktion des Menschen auf die Welt).

Stern, Psychologie 
Die psychophysische Erklärung (nur von Fechner vertreten) fasst die physikalischen und physiologischen Vorgänge als die der Körperwelt zusammen und stellt sie den psychologischen, den „Empfindungen”, gegenüber. Während alle früher bekannten Naturgesetze sich entweder nur auf die Körperwelt (z.B. Gravitationsgesetz), oder nur auf das Seelische (z.B. Assoziationsgesetz) bezogen, glaubte Fechner hier ein noch viel umfassenderes Gesetz gefunden zu haben, das nämlich die generelle Beziehung zwischen beide $\mathrm{n}$ Seiten der Welt herstelle und sich in eine mathematische Formel kleiden lasse. Die metaphysische Kühnheit dieser Konzeption ist bewundernswert aber die empirische Basis für sie ist viel zu schmal und unsicher. Fechner selbst hatte noch geglaubt, die Abweichungen vom Gesetz bagatellisieren und durch Hilfsannahmen erklären zu können. Wir wissen heute, dass das von ihm aufgestellte Prinzip überhaupt nirgends exakt gilt, und dass es auch annäherungsweise nur für gewisse, mehr oder minder eng begrenzte Gebiete zutrifft.

Die physiologis che Erklärung (G. E. Müller, Ebbinghaus u.a.) sieht nicht in Reiz/Empfindung, sondern in $\mathrm{R}$ e i $\mathrm{z} / \mathrm{N}$ erven p r o z es s die eigentlichen Beziehungsglieder der Gesetzes. Die Wirkung des physikalischen Reizes auf die physiologische Erregung geht nach dieser Auffassung nicht in parallelem Ablauf vor sich, bei dem jeder Steigerung des Reizes auch eine gleiche Steigerung der Erregung entspräche (so hatte noch Fechner gemeint); vielmehr bilden sich im arbeitenden Nerven Trägkeits- und Hemmungsmechanismen aus, sodass ein körperlicher Erregungszustand höheren Grades einer weiteren Reizsteigerung stärkere Widerstände entgegensetzt als ein minderer Erregungszustand. Es bedarf daher beim ersten Zustand des Nervenprozesses eines stärkeren neuen Reizschubs, um ihn $z u$ ändern, als im zweiten Fall.

Das psychologische Faktum der Empfindung soll sich dann in einfacher Proportionalität zum Nervenprozess ändern, auf Grund der ,parallelistischen" Hypothese.

Es ist durchaus denkbar, dass sich im physiologischen Geschehen Vorgänge dieser Art abspielen; hat man doch sogar bei Organismen, bei denen Wahrnehmungserlebnisse nicht anzunehmen sind (bei Pflanzen, bei enthirnten Tieren) Reaktionen be- 
obachtet, die mit steigender Reizgrösse steigende Hemmungen zeigten. Das menschliche Wahrnehmen aber ist viel zu kompliziert, als dass dieser eine Faktor allein die Erklärung tragen könnte. Auch wird wiederum nicht verständlich, warum er dann nur in jenen begrenzten Revieren wirksam sein sollte. Unerklärt bleibt ferner, warum jene Hemmungszunahme nun gerade proportional zur Reizgrösse vor sich gehen sollte, wie es das WeberFechner'sche Gesetz fordert. Endlich ist jener Parallelismus der Elemente, wie er zwischen Empfindungen und nervösen Erregungen angesetzt wird, jetzt allseitig als unbrauchbare Hilfshypothese erkannt worden.

Die psychologis che Erklärung (Wundt) sieht in dem Gesetz nur einen Sonderfall eines allgemeinen ,Relativitätsprinzips" der Bewusstseinszustände. Nicht die Empfindungen, wie wir sie an und für sich "haben”, unterliegen jenem Gesetz, sondern die Empfindungen, sofern wir sie „vergleich en”. Nun hat aber unser Bewusstsein stets nur ein rela tives Mals für die Intensität der in ihm vorhandenen Zustände und jeder einzelne Inhalt wird daher nur in Relation zu anderen apperzipiert. Die Empfindungen selbst also mögen in genauer Proportionalität zu den Reizen zu- und abnehmen; aber unsere A uffassung dieser Empfindungen geht nur in Verhältniswerten vor sich.

Der - wie sich gleich zeigen wird - berechtigte Grundgedanke dieser Auffassung wird leider dadurch getrübt, ja unbrauchbar gemacht, dass über die „Empfindungen”, die man hat, aber nicht apperzipiert, Aussagen gemacht werden, als ob es sich um reale Gegebenheiten mit realen Grössenwerten handelte. Eine Relativität liegt tatsächlich zu Grunde; aber es handelt sich nicht um die Relation einzelner Bewusstseinszustände zu einander, sondern um deren aller Relation zu der erlebenden Person.

Den drei angedeuteten Erklärungsversuchen wird nun eine personalistische Deutung gegenüber gestellt.

\section{Personalistische Deutung der $\mathrm{Sch}$ w ellenerscheinungen}

Die Malsbezichungen zwischen der menschlichen Person und ihrer Umwelt sind bestimmt durch den Umstand, dass der Un- 
endlichkeit der Welt und ihrer Reize die e n d lich e Person mit begrenzten Kräften gegenübersteht. Diese Kräfte und Möglichkeiten haben nun $\mathrm{zu}$ den ebenfalls begrenzten Lebensaufgaben eine sinnvolle Beziehung, d.h. sie schneiden aus der Welt diejenigen Teilgebiete und diejenigen inneren Abstufungen der Teilgebiete heraus, die für die Person b e d e u $\mathrm{t} \mathrm{s}$ a $\mathrm{m}$ sind. Wir kommen hier zu einem Begriff der Schwelle, der viel weiter ist als in der ganzen bisherigen Betrachtung dieses Kapitels, da er nicht etwa nur auf die Begrenztheit der Wahrnehmung bezogen ist, sondern auf alle personale Begrenztheit überhaupt. Der Begriff ist psychophysisch neutral. Schwellen sind die Bedeutsamkeitsgrenzen der Welt für die Person, sofern diese Grenzen $z$ iffernmä(sig feststellbar $\operatorname{sind}^{1}$ ).

So kann etwa eine kleine Minderung des Luftdrucks nicht nur unbemerkt, sondern auch unwirksam bleiben für das Gesamtbefinden eines Menschen; nimmt nun der Luftdruck weiter ab (z.B. durch Ubersiedlung in höhere Regionen), so beginnt der Unterschied biologisch wirksam zu werden, ohne dass er sich schon psychisch bemerkbar machen müsste. Er hat dann die Schwelle der vitalen, aber noch nicht die der Bewusstseins-Bedeutsamkeit überschritten. Hierzu muss die Änderung einen noch höheren Grad erreicht haben.

Somit gibt es für ein bestimmtes Reizgebiet so viele verschiedene Weisen des Schwelligwerdens, als es verschiedene Weisen seiner Bedeutungshaltigkeit für die Person gibt. Diese verschiedenen Schwellen superponieren sich; die Wahrnehmungsschwelle stellt nur ein e von den vielen Schwellenarten dar. Ja, jene Wahrnehmungsschwelle, von der die Untersuchungen der Psychophysik handeln, hat eine noch engere Bedeutung; sie ist lediglich die $\mathrm{B}$ e obachtung sschwelle, d.h. die Grenze derjenigen Wahrnehmung, die mit voller Aufmerksamkeit eigens auf die Feststellung von Reizunterschieden gerichtet ist. Die unaufmerksame Wahrnehmung, oder eine Wahrnehmung, welche auf andre Ziele als Reizunterschiede gerichtet ist, hat viel gröbere Schwellen; umgekehrt kann eine Wahrnehmung, von deren Feinheit Reaktionen von grösster Existenzwichtigkeit abhängen (z.B. Lauschen auf verdächtige

1) Vgl. S. 105 und: Die menschliche Persönlichkeit S. 190-222. 
Geräusche), für viel kleinere Unterschiede empfänglich werden, als beim psychophysischen Experiment.

Nun ist freilich eine solche Verfeinerung der Schwellen (wie im letzten Beispiel) nicht ins Unendliche fortsetzbar; die j ew e iI ig e Anpassung der Schwelle an die Bedeutung der Aufgabe findet nämlich in k o n s t it u t io nell en Eigenschaften der Person schliesslich Schranken, die absolut unübersteiglich sind. Die Gewichtszunahme, z.B. die ein Kilogramm durch Hinzufügung e in es Sandkörnchens erfährt, wird s t e t s unter der Wahrnehmungsschwelle bleiben; die Feinheit der Geruchsunterscheidung, wie sie der Hund hat, ist dem Menschen ein für alle Mal unzugänglich. Hier steht auch die Schwelle in unmittelbarer Beziehung zum Bau und zur Funktionstüchtigkeit des Sinnesorgans.

Man mag immerhin diese letzte Grenze als die eigent liche „Empfindungs"-Schwelle bezeichnen und von den Schwellen der Wahrnehmung, der Beobachtung, der Aufmerksamkeit, der Apperzeption, der Lust- oder Unlust u.s.w. scheiden - aber man muss sich klar sein, dass wir es hier lediglich mit einem Grenzbegriff zu tun haben, der nie empirisch erreichbar und daher auch nicht ziffernmälsig festlegbar ist. Denn nachte „Empfindungen" sind als Bewusstseinsinhalte niemals aufweisbar; und alle Schwellen, die wir erfahrungswissenschaftlich studieren, stehen nicht nur unter den generellen Bedingungen der Konstitution, sondern auch unter den speziellen der personalen Einstellung auf den Reiz und der personalen Bedeutung der Reizsituation für das jeweilige Telos der Person. Von hier aus wird es auch verständlich, dass von verschiedenen Forschern für das gleiche Reizgebiet sehr verschiedene Schwellen gefunden wurden. Die besonderen Bedingungen des Versuchs sind eben nicht bloss mehr oder weniger brauchbare Zugänge zu den „Empfindungs”Schwellen, sondern liefern selbst Bedeutsamkeitsperspektiven, von denen das Schwelligwerden der Reize mit abhängt.

Was nun aber jene $k$ on st it u t i n ellen Bedingungen des Schwelligwerdens selbst betrifft, so müssen auch sie in ihrem personalen Bedeutungsgehalt verstanden werden. Denn die menschliche psychophysische Konstitution, welche nur eine endliche Zahl von Reizen und Reizstufen aus der Unendlichkeit der Welt überhaupt zu verarbeiten vermag, ist ja nicht zufällig und willkürlich gerade mit diesen Reizen verknüpft, sondern ist 
selbst so geworden in der dauernden Wechselwirkung mit ihrer Welt und in ständigem Sicheinpassen in diese Welt.

Daher bezeichnen die Schwellen die personal bedeutsame A u slese. Die äusseren Schwellen (s.S. 235) begrenzen dasjenige Reizgebiet, innerhalb dessen abgestufte Reaktionen der Person möglich sind. Es ist dies zugleich das Reizgebiet, in dem sich das Leben der Person we sentlich bewegt und mit dem es in realem Kontakt des Empfangens und Gebens, des Sichwehrens und Sicheinfügens steht. Die $Z$ weckentsprechung, die hier obwaltet, ist äusserst weitgehend - was besonders deutlich wird, wenn man die reaktionsweckenden Reizgebiete des Menschen mit denen bestimmter Tiere, und die Reizgebiete der Tiergattungen unter einander vergleicht. Jeweilig bezieht und beschränkt sich der Umkreis der, einer Gattung sensorisch $\mathrm{z}$ ugä ngli che n, Reize im wesentlichen auf die, für die Gattung generell lebensbedeutsamen, Reize. Für einen Tiefsee-Organismus der unter ungeheurem Wasserdruck lebt, ist die Skala der Druckreize, auf die er zu reagieren vermag, ganz anders gelagert als beim Menschen, der unter atmosphärischem Druck lebt; und sofern jenes Tiefseewesen noch Sehorgane besitzt, sind sie jener Dunkelheit adaptiert, die für den Menschen jenseits jeder Unterscheidbarkeit von Helligkeitsstufen liegt. Und umgekehrt.

Die in n e r e n oder Unterschiedsschwellen haben eine doppelte personale Bedeutung. Die eine ist der Bedeutung der äusseren Schwellenanalog: E n e r g i e-E r s p a r u n g und-K on$z$ e $\mathrm{n}$ r a t i o n. Wären die unzähligen physikalischen Abstufungen innerhalb des reaktionsweckenden Reizgebiets sämtlich dem Menschen zugänglich, - er würde überschüttet werden von einem unablässigen Wechsel, von nie zur Ruhe kommenden Nüanzierungen, von irrelevanten Unterschieden; die Zusammenraffung der personalen Kraft auf das Lebensbedeutsame und Wesentliche wäre unmöglich. Hier schafft wiederum die Schwelle die erforderliche Auslese. Nur die wenigsten Unterschiede, die die physikalische Welt enthält, sind für den Menschen, sein Wahrnehmen, Auffassen, Reagieren, vorhanden; aber indem die meisten ausgeschaltet werden, steht $\mathrm{f} \ddot{u} \mathrm{r}$ die $\mathrm{B}$ ewältigung der übrigbleibenden (und lebenswichtigsten) die erforderliche Energie zur Verfügung. 
Die gen erelle Zweckmälsigkeit, die den äusseren und inneren Schwellen im Sinn der Kraftsparung und Konzentration zukommt, kann natürlich unter speziellen Bedingungen in Unzweckmärsigkeit umschlagen; irgend eine bes ondere Lebensaufgabe der Person könnte die Empfänglichkeit gerade für jene Reize oder Reizunterschiede erfordern, die durch die Schwellen ausgeschaltet sind. Ein solcher Fall ist bei Tieren selten, da diese eine weitgehend konstante Umwelt haben, welcher ihr Reaktionssystem mitsamt dessen Schwellen in hohem Malse angepasst ist. Anders der Mensch, dessen Lebensweite und Entwicklungstendenz immer wieder neuartige Situationen erzeugt, für welche die konstitutionell festgelegten Grenzen der Reizempfänglichkeit nicht ausreichen. Und so ist es verständlich, dass gerade der Mensch - und n u r der Mensch - eine T e c h$\mathrm{n}$ i k erzeugte, welche zu einem grossen Teil nichts anderes als eine künstliche $\mathrm{Sch}$ welle $\mathrm{nverfeinerung}$ in gewaltigem Malsstabe ist. Sie erweitert die äusseren Grenzen unserer Wahrnehmung, macht uns physikalische Gebiete zugänglich, die nicht sensorielle Reizbereiche sind, und vervielfältigt innerhalb der einzelnen Reizgebiete die Zahl der wahrnehmbaren Stufen.

Aber weit über die kraftsparende Bedeutung der Unterschiedsschwelle hinaus reicht ihre e $\mathrm{rk}$ e $\mathrm{n} \mathrm{n} \mathrm{t} \mathrm{n}$ i s s c hö p f e r i s c h e Bedeutung. Indem sie Unterschiede und Veränderungen verschwinden lässt, $\mathrm{s} c \mathrm{~h}$ a $\mathrm{fft}$ ' $\mathrm{s}$ i $\mathrm{Gle}$ i $\mathrm{ch}$ heit $\mathrm{und} \mathrm{K}$ on$\mathrm{stanz}$ in der Wahrnehmung. In der objektiven physikalischen Welt ist Gleichheit zweier Vorgänge oder das Konstantbleiben eines Vorgangs ein Fall von verschwindend geringer Wahrscheinlichkeit; in der personalen Welt des Menschen dagegen sind die Bedeutungen der Kategorieen "Gleichheit" und „Verschiedenheit" e b e n bü r ti g; ebenso die der Kategorieen „Konstanz" und ,Veränderung".

Die Farbe meines Schreibpapiers wäre nicht gleichförmig weiss, die Linien auf ihm wären keine graden, wenn nicht unzählige kleinste Helligkeits- und Farbunterschiede hier, Richtungs- und Dicke-Unterschiede dort unterschwellig blieben. Kein Ton könnte rein klingen, kein Lnisono von Instrumenten wäre möglich, wenn alle physikalisch vorhandenen Abweichungen und Schwankungen in der Schwingungsperiodik auch unserem Hören zugänglich wären. Jene Konstanz des Erlebens, die nötig ist, 
damit wirfeste Gegenstän de und dauernde $Z$ us tände als solche wahrnehmen, wird dadurch erleichtert, dass die Schwellen einen wohltätigen Schleier über die innere physikalische Unruhe legen, die auch im scheinbar stabilsten Objekt wirkt.

Mit dieser, Gegenstand erzeugenden, Bedeutung der Unterschiedsschwelle hängt auch das Weber-Fechner'sche Prinzip zusammen; doch eine andere Betrachtung muss noch zwischengeschoben werden.

Das durch die äusseren Schwellen herausgeschnittene Reizstoffgebiet ist - personal gesehen - in sich nicht homogen, sondern strukturiert, nach Mitte und Grenzphasen. Die Rei z$\mathrm{m}$ i t $\mathrm{t} \mathrm{e}$ ist nicht ein Punkt, sondern ein Gebiet von beträchtlicher Breite, in welchem die Anpassung an die generellen Lebensbedingungen und Bedürfnisse der Person kulminiert. Die Reizmitte ist der ,personalen Mitte” zugeordnet, d.h. den in der Person selbst wirkenden Energiemalsen, die ihrer normalen Lebensfunktion entsprechen. Die Reizmitten der verschiedenen Reizgebiete stellen gleichsam die ,p h y i kalis c h e H e i ma t" der Person dar, jenes Gebiet, mit dem man vertraut ist, das man in den Einzelheiten kennt, auf das man selbstverständlich, zweckmälsig und fein nüanziert reagiert.

Die Gren z p h a s e n sind zwar ebenfalls der Person noch zugänglich, aber doch schon eher als "physikalische Fremde”. Man vergleiche etwa mit dem diffusen Tageslicht, das die günstigste optische Voraussetzung für die meisten normalen Verrichtungen des Menschen ist, die grelle direkte Sonnenbelichtung oder die weit fortgeschrittene Dämmerung: „sehen” kann man hier und dort wohl noch, man kann auch noch Unterschiede bemerken; aber es sind ganz andere Energieaufwendungen nötig, und der Erfolg im Erkennen feinerer optischer Abstufungen ist viel geringer.

Die experimentellen Schwellenuntersuchungen hatten ergeben, dass nach den Grenzgebieten der Reizskalen hin die Unterschiedsschwellen im allgemeinen stumpfer werden; jetzt sehen wir, dass es sich hierbei nicht um eine unerklärliche Abweichung von einem unverbrüchlichen Gesetz, sondern um die personal bedingte Strukturierung der Reizskala handelt.

Dass aber das Weber-Fechner'sche Prinzip seine Gültigkeit immer nur auf eine $\mathrm{m}$ i t $\mathrm{t} l$ e r e Reizbreite beschränkt, bekommt 
nunmehr erst einen verständlichen Sinn. Denn in dieser engeren Optimalsphäre unseres Auffassens, Erkennens, Geniessens und Handelns sind für den Menschen nicht absolute Reizgrössen und Reizdifferenzen von Bedeutung, sondern ganz vorwiegend Reizverhältnisse. Wir haben es ja hier nicht mit Einzeleindrücken, ja auch nur ganz selten mit einem blossen Paar von Eindrücken zu tun, sondern mit $\mathrm{R}$ e izg a $\mathrm{n} z$ heit e $n$, mit Gegenständen, mit Handlungsabläufen, mit ästhetischen Gebilden u.s.w. Diese gestalteten Ganzheiten haben eine Festigkeit, die in ihrer Identität auch erfassbar bleiben muss, wenn etwa die absoluten Intensitäten, die an ihnen wirksam sind, sich ändern. Sehe ich einen Würfel einmal in starker, ein andres Mal in schwacher Beleuchtung, so sind nicht nur die Helligkeiten der einzelnen Seiten, sondern auch die Differenzen der Helligkeiten viel kleiner geworden. Und dennoch kann ich ihn als ,,denselben” Würfel erkennen, weil die Relationen der Seitenhelligkeiten die gleichen geblieben sind. - Ertönt in einem Konzertsaal ein Crescendo, das von pp. bis $\mathrm{zu}$ ff. fortschreitet, so ist der Eindruck kaum merklich ein anderer, wenn man in der vierten oder in der zwanzigsten Reihe sitzt ; dabei ist die absolute Intensität des ff. für den hinten Sitzenden „empfindungsmälsig" vielleicht nur so stark wie für den vorn Sitzenden ein mittelstarker Ton. Aber das Stärke-V e r h ä l t$n$ is und die Zahl der durchlaufenen Ebenmerklichkeitsstufen ist dieselbe geblieben. - Hat ein Uhrmacher es mit einem feinen Mechanismus zu tun, so würde ein Schätzungsfehler von $\frac{1}{2} \mathrm{~mm}$ schon das ganze Gefüge der Uhr und ihre Funktionen stören; beim Grobschmied oder gar beim Strassenbaumeister wird, entsprechend der gröberen Gesamtstruktur des Werkes, auch der Grössenbereich, innerhalb dessen noch Ungleichheiten unbemerkt und bedeutungslos bleiben, entsprechend wachsen. - In allen diesen Fällen erweist sich also die relative Unterschiedsschwelle als personal bedeutsam.

Nun wird auch die Paradoxie gelöst, die sich bei den T on hö he n zeigte, indem hier das Weber-Fechner'sche Gesetz nur bei üherschwelligen Unterschieden, nicht aber bei schwelligen galt. Zwei Töne, die sich nur eben von einander unterscheiden, gehören nämlich keiner gestalteten Ganzheit an, sie bleiben isoliert; im praktischen Leben wird das Problem ja eigentlich nur akut, wenn zu entscheiden ist, ob bei einem Finzelton eine Abweichung von der Reinheit vorliegt. Die überschwelligen Tonunterschiede (Intervalle) dagegen fügen sich $z u$ Akkorden und zu 
Melodieen, also zu Ge st a 1 te n, die wiederum ihren, von den absoluten Höhen unabhängigen Bestand wahren, solange die gegenseitigen Verhältnisse der Glieder konstant bleiben.

Das Faktum der Unterschiedsschwelle ermöglicht also in doppelter Weise die Wahrnehmung konstanter Gegenständlichkeit: einmal indem sie die Unruhe der kleinsten Unterschiede unterdrückt, dann indem sie die Konstanz der Relationen unabhängig von den wechselnden absoluten Mafsen aufrecht erhält. 
DRITTER HAUPTTEIL

GEDÄCHTNIS 
Für die Psychologie des 18. und 19. Jahrhunderts bezog sich der Terminus „Gedächtnis" lediglich auf die Fähigkeit des Menschen, frühere Eindrücke später als Vorstellungen wieder zu vergegenwärtigen. Dieser Begriff is viel zu eng; er wird auch der spezifisch personalen Bedeutung des Gedächtnisses nicht gerecht.

Unsere Definition lautet: Ged ächt $n$ is ist Vergangenheitsbeding theit des Erlebens.

Damit ordnet sich das Gedächtnis einem weit umfassenderen Faktum ein: der Vergangenheitsbedingtheit alles Lebens, der sogen. „Mneme”. Sofern sich die Mneme im psych is chen Leben auswirkt, haben wir es mit Gedächtnis zu tun.

Vergangenes kann psychisch nachwirken, ohne dass es zu „Vorstellungen” käme, so in den „gebundenen” Gedächtniserscheinungen der Ubung, des Wiedererkennens, der Verwertung. Erst auf den höchsten Entwicklungsstufen gibt es "freie" Gedächtniswirkungen: die Vergangenheit schlägt sich nieder in eigenen psychischen Repräsentationen, den Gedächtnisvorstellungen, die sich dann, ihrer personalen Funktion nach, nochmals gliedern in Kenntnisse und Erinnerungen.

Die hier angedeutete Stufenleiter führt zugleich das Gedächtnis durch die drei Modalitäten des Lebens hindurch: sind die primitivsten Vorgänge noch wesentlich biologisch verwurzelt, so gewinnt in den höheren Erscheinungen das Gedächtnis mehr und mehr überbiologische, nämlich gegenständliche und introzeptive Bedeutung. 


\title{
ZEHNTES KAPITEL
}

\author{
M N E M E
}

\section{MNEMISCHE ERSCHEINUNGEN IM ALLGEMEINEN}

Vergangenheitsabhängigkeit (,Mneme”) ist ein Grundprinzip alles organischen Lebens ${ }^{1}$ ). Das Prinzip ist doppelt ausdrückbar, je nachdem man von der Gegenwart oder von der Vergangenheit den Ausgang nimmt: 1) Was g e g e n w ä r t i g an einem Lebewesen vorhanden ist und vor sich geht, steht unter den Nachwirkungen früheren Seins und Geschehens. 2) Was fr üh er e in $\mathrm{m} \mathrm{a} \mathrm{l}$ an einem Lebewesen war oder geschah, braucht mit dem damaligen Gewesensein nicht abgetan und erledigt zu sein; es kann nach Abschluss seiner ursprünglichen Gegenwart sich geltend machen in ferneren Gegenwarten.

Dieser Tatbestand ist von weitester Allgemeinheit; darum enthalten die obigen Sätze noch keine nähere Bestimmung darüber, w a s nachwirkt und wie es nachwirkt. Insbesondere beschränkt sich jene „historische Bedingtheit” alles Lebenden nicht auf das Psychische; ja, die primitivsten Erscheinungsweisen liegen noch weit vor aller Bewusstheit im rein BiologischPhysiologischen.

Die Beschaffenheit einer Pflanze im gegenwärtigen Augenblick, ihre jetzige Widerstandsfähigkeit gegen Witterungseinflüsse u.s.w. ist mitbedingt durch die Gesamtheit der Einwirkungen, die in früheren Stadien ihrer Entwicklung von Humus, Sonne, Bewässerung u.s.w. auf sie ausgeübt wurden. Selbst weit zurückliegende und von den gegenwärtigen Umweltbedingungen sehr abweichende Einflussfaktoren haben dennoch ihren Nachhall in Art und Stärke der augenblicklichen pflanzlichen Lebensfunktionen.

Die Dressur, die ein Tier in ganz jungen Jahren empfangen hat,

1) Obigen Gedanken hat zuerst Ewald Hering grundsätzlich formuliert. Den Ausdruck ,Mneme” hat Semon eingeführt. 
mag, wenn es dann frei geworden ist, scheinbar völlig verloren gegangen sein; wird aber das Tier wieder gefangen und neu dressiert, so wird es schneller und mit geringerer Mühe die alten Fertigkeiten wiedererlernen.

Die Mneme bleibt sogar nicht auf das Einzelindividuum beschränkt; es gibt eine "Gattungsmneme", die Vererbung; denn was im Zeugungs- und Schwangerschaftsprozess der älteren Generation dem werdenden Individuum an Erbanlagen mitgegeben wurde, wirkt sich erst viel später im postnatalen Leben aus ${ }^{1}$ ).

Auch das Leben des $\mathrm{M}$ e $\mathrm{n} \mathrm{s} \mathrm{h}$ e $\mathrm{n}$ ist allenthalben von mnemischen Wirkungen durchsetzt. Die Ausdrücke "Anpassung", „Gewöhnung”, „Ubung”, „Fertigkeit”, „Abhärtung”, „Abstumpfung" bezeichnen verschiedene Abtönungen dieses Nachwirkens. Hat ein Mensch längere Zeił unter dem Einfluss eines bestimmten Milieus gestanden (z.B. eines bürgerlichen, eines bäuerlichen, eines proletarischen), dann wirkt diese vergangene Situation unaufhebbar nach, nicht etwa nur in der Art seines Denkens und Fühlens, in Charakter- und Begabungs-Zügen, sondern in den Funktionen und Zuständen seines Körpers, in Ernährungs- und Stoffwechselprozessen, in Gang und Haltung, und ebenso in Verhaltungsweisen, die physisch und psychisch zugleich sind: in Manieren, Ausdruck, Sprechweise, Fertigkeiten. Die Mneme ist also nicht ein rein physiologischer, nicht ein rein psychologischer, sondern ein personaler Tatbestand.

Alles mnemische Geschehen verläuft zwischen zwei ursächlich verknüpften Phasen. Das Primärgeschehen liefert den „m n emischen Reiz", im Sekundärgeschehen erfolgt die „mne mische Wirkung".

Der mnemische Reiz kann entweder bestehen in einer, längere Zeit anhaltenden, Zuständlichkeit (vgl. obiges Milieu-Beispiel) oder in einem einzelnen Lebnis rezeptiver oder aktiver Natur; sowohl Eindrücke, die man empfängt, wie Handlungen, die man vollzieht, vermögen sich mnemisch auszuwirken ${ }^{2}$ ).

Die gleiche Einteilung gilt für das Sekundärgeschehen. Denn auch mnemische Wirkungen bekunden sich sowohl in veränder-

\footnotetext{
1) Zum Thema ,Gattungsmneme” vgl.: Die menschliche Persönlichkeit S. 104 ff. - Im vorliegenden Buch werden nur diejenigen mnemischen Vorgänge behandelt, die in nerhalb des Einzellebens zustande kommen.

2) Im Gegensatz zum sensorischen Reiz besteht also der mnemische Reiz nicht in ienem physikalischen Aussenvorgang, sondern in einem personalen Innengeschehen.
} 
ten Zustandsbildern der Person, wie in aktuellen Kenntnissen und Fertigkeiten.

Grundsätzlich ist keinem Lebnis die Möglichkeit abzusprechen, mnemischer Reiz zu werden. Tatsächlich aber findet eine scharfe Auslese und zugleich eine Abstufung statt. Die meisten primären Lebnisse bleiben unterhalb der mnemischen Reizschwelle; sie wirken nicht merkbar nach. Diejenigen, die überschwellig werden, können die verschiedensten Grade mnemischer Wirksamkeit, nach Intensität und Dauer, zeigen. Dieser Wirkungsgrad ist nicht allein von der objektiven Stärke des primären Geschehens abhängig, sondern von einem personalen Faktor: der mnemischen Empfänglichkeit.

Man ist oft erstaunt, dass ein Ereignis katastrophaler Art in einem Kinde keinerlei erkennbare Nachwirkungen hinterlässt, so lebhaft die Reaktion des Kindes im Augenblick des Erlebens gewesen sein mag; umgekehrt kann ein objektiv geringfügiges und in seiner primären Wirkung unbedeutendes Geschehen auf lange hin oder erst nach langer Latenzzeit seine Nachwirkung ausüben.

Das Sekundärgeschehen ist dem Primärgeschehen niemals völlig gleich; denn es steht an einer anderen Stelle im gesamten Lebensprozess, der einen unablässigen Wandel zeigt. Aber es gibt Stufen der Abweichung. Deshalb scheiden wir zwischen einer solchen Nachwirkung, die dem Primärgeschehen ähnlich (,h o m o g e n") ist, und einer solchen, die besonders stark von dem ursprünglichen Lebnis abweicht, also „h e t e rog e n" ist.

Beispiel aus der körperlichen Mneme: die Ćbungsarbeit für eine bestimmte Leistungsform (z.B. Schlittschuhlaufen, Maschineschreiben, Fussballspielen) bewirkt zunächst, dass e be n d i e s e Leistung immer besser gekonnt wird: homogene Wirkung. Zugleich aber wird dadurch körperliche Gewandtheit und Kraft, oder Fingergeschicklichkeit im allgemeinen, also auch die Eignung für Leistungen anderer Art, gesteigert: heterogene Wirkung.

Beispiel aus dem psychischen Gedächtnis: Wahrnehmungen, die ich während einer Reise gemacht habe, kehren später als entsprechende Erinnerungen wieder (homogene Nachwirkung). Aber jene Reiseeindrücke können ihre Nachhaltigkeit auch anders bewähren:indem ich späterhin das, was ich über jenes Land höre und lese, mit ganz anderem Verständnis aufnehme als früher (heterogene Nachwirkung) ${ }^{2}$ ).

1) Der Luterschied ist auch typologisch wichtig: es gibt Menschen mit vorwiegend ", bewahrendem", andere mit vorwiegend ,verarbeitendem” Gedächtnis. (Jonas Cohn. Erich Stern-Aachen. Rombach). 
Am stärksten heterogen ist die Beziehung zwischen Primärund Sekundärgeschehen dort, wo der mnemische R e i z ganz im Unbewussten verläuft, während die mnemische Wirkung in Bewusstseinserscheinungen, also in „Gedächtnis"-Form hervortritt.

Wenn jemand eine schwere Krankheit im Zustand vollster Bewusstlosigkeit durchgemacht hat, können doch spätere Bewusstseinszustände unter ihrem Einfluss stehen. Er erinnert sich nicht daran; dennoch wirkt die Krankheit weiter in Angstzuständen, in Abneigungen und Protesteinstellungen, deren Sinn ihm ganz unklar bleibt. Die psychiatrische und insbesondere psychoanalytische Literatur bringt zahlreiche Beispiele für solche nachträgliche Umsetzung nicht-psychischer Ursachen in psychische Folgen.

Fragen wir nach dem Sinn der Mneme im menschlichen Individualleben, so stossen wir auf eine charakteristische Doppelbedeutung. Sie ist konservativ und fortschrittlich zugleich; denn sie dient der Konservierung des Fort$\mathrm{sch}$ ritts. Das mnemische Sekundärgeschehen hat ja durchaus erhaltende Aufgaben; in ihm ist der Bestand von Kenntnissen, Fertigkeiten, Lebensformen, der schon von früher her stammt, auch für Gegenwart und Zukunft gewährleistet. Aber dieser mnemisch gesicherte Besitz musste doch erst e r w orb e n werden; es ist die Aufgabe des Primärgeschehens, diesen Erwerb einzuleiten. Die mnemische Empfänglichkeit ermöglicht es also dem Menschen, dass er Neues in sein Leben aufnimmt, dass er mit Änderungen der Umwelt mitgeht. So erhält die Mneme eine mittlere Stellung zwischen dem Instinkt, der konservativer Art ist, und der Intelligenz, die progressiv gerichtet ist.

In $z$ eit licher Hinsicht kann man ,unmittelbare" und „vermittelte" Mnemewirkung unterscheiden. Bei jener wächst aus dem Primärgeschehen ohne fremde Zwischenglieder das Sekundärgeschehen hervor; bei dieser liegt zwischen beiden Polen eine zeitliche Pause, die von ganz andersartigen Lebnissen ausgefüllt ist: die "L a te n $z$."

In der Fähigkeit, Latenzen zu überbrücken, erweist sich der Mensch so recht als unitas multiplex. Die bunte Mannigfaltigkeit seiner Lebnisse und Erlebnisse bewirkt, dass jedes einzelne schnell durch ganz andere abgelöst wird; und da auch zugleich 
die Lebenssituationen fortwährend wechseln, so mag die Gelegenheit zur Wiederaktualisierung eines früheren Lebnisses erst sehr spät eintreten. Dass aber dann, selbst nach recht langen $Z$ wischenzeiten, solche Wiederbelebung $\mathrm{m}$ ö $\mathrm{gl} \mathrm{ich}$ ist, ist ein eindruckvolles Zeichen der persönlichen unitas, die den nie unterbrochenen Hintergrund für die sich abrollenden Ereignisse und ihre Nachwirkungen darstellt. Die Latenzzeit, die durch mnemische Phänomene überbrückbar ist (mnemische "Spanne”), kann unter Umständen nur um weniges kürzer als die ganze Lebenszeit eines Menschen sein: Eindrücke der frühesten Kindheit, „die längst ich vergessen geglaubt”, tauchen im Greisenalter mit unerwarteter Plastik wieder auf.

Die Länge der mnemischen Spanne ist eine entwicklungspsychologisch bedeutsame Grösse. Beim Tiere sind eigentliche Gedächtnisleistungen (sofern es sich also nicht um bloss biologische Mneme handelt) nur über ganz kurze Zeiträume hin möglich. Die Kuh, der das neugeborene Kälbchen fortgenommen wurde, bekundet noch einige Tage durch suchende Ausdrucksbewegungen und klagende Laute, dass sie das Junge vermisst; aber bald ist Vergessen eingetreten. - Vermutlich wird die Gedächtnissspanne beim Naturmenschen auch geringer sein als beim Kulturmenschen. - Kindespsychologische Feststellungen ergeben, dass in den ersten Lebensjahren die Gedächtnisspannen ganz beträchtlich zunehmen und zwar für schwierigere Leistungen langsamer als für primitivere. So ist beim zweijährigen Kinde schon häufig ein Wiedererkennen von Menschen und Örtlichkeiten zu bemerken, die es mehrere Monate lang nicht gesehen hatte, während spontane Erinnerungen von solcher Reichweite noch garnicht oder nur ausnahmsweise vorkommen.

\section{ZUR THEORIE DER MNEMISCHEN ERSCHEINUNGEN}

Von dem Faktum der Latenz aus lässt sich am besten die t h e or e t is c he Problematik aufrollen. Denn da das, was in die Latenz fällt, irgend einer direkten Erfahrung nicht zugänglich sein kann, so muss die Hypothesenbildung vorherrschen; hierbei trennen sich deutlich mechanistische und personalistische Theorieenbildungen.

Gemeinsam ist allen Theorieen die Überzeugung vom $\mathrm{Zu}$ $\mathrm{s}$ a $\mathrm{m}$ m e $\mathrm{nh}$ a $\mathrm{ng}$ zwischen Primär- und Sekundär-Geschehen über die Latenz hinweg. Es muss eine Brücke von einem zum andern führen; das fordert der Mechanist, da er eine zeitliche 
Fernwirkung zwischen zwei Elementen ohne ein verknüpfendes Medium nicht denken kann; das fordert der Personalist, weil die stetige Einheit des personalen Lebens den gemeinsamen Hintergrund bildet, von dem sich beide Pole des mnemischen Prozesses abheben. Aber bezüglich des $\mathrm{W}$ i e der Lückenausfüllung trennen sich die Meinungen.

Die nächstliegende Lösung ist die Annahme einer I $n$ h a $1 \mathrm{t} \mathrm{s}$ beharrung des mnemischen Reizes bis zum Augenblick seiner Erneuerung im Sekundärprozess. Es wird also dem primären Vorgang eine Art von $\mathrm{T} r$ äg h e it zugeschrieben. Die „Spur”, die er hinterlässt, führt eine zwar verborgene, aber im Wesen unverändert bleibende Weiterexistenz und kann daher auch, sobald der Anlass gegeben ist, zur Erneuerung des früheren Lebnisses führen. Statt von "Spuren” spricht die Trägheitstheorie auch von „Residuen” oder „Resten"; in der Physiologie ist die Rede von ,ausgefahrenen Nervenbahnen", in der Biologie von „Engrammen” (nach Semon). Innerhalb der eigentlichen Psychologie begegnet uns der gleiche Gedanke in der Wendung, dass die früheren Eindrücke als Vorstellungen im Unbewussten beharren, bis sie wieder hervorgeholt werden.

Nun gibt es zweifellos solche in halt lich e n Perseverationen im Physischen und Psychischen, aber sie stellen lediglich die äussersten - und unwichtigsten - Wirkungsweisen der Mneme dar. Sie sind nur möglich bei Lebensprozessen, die weitgehend isoliert und abgegrenzt, ja gleichsam „petrefiziert" sind und eben nur durch ihre geringe Verankerung im Ganzen der Persönlichkeit diese Erstarrung und Beharrung zeigen können.

Die überwältigend grosse Mehrzahl mnemischer Wirkungen zeigt aber einen ganz anderen Typus. Wir erwähnten schon oben, dass die Sekundärprozesse den Primärprozessen nie völlig gleich sind, ja dass zuweilen gar keine Ähnlichkeit zwischen ihnen besteht. Alle diese heterogenen Mnemewirkungen würden also dem Trägheitsprinzip nicht unterzuordnen sein; nimmt man überhaupt eine ununterbrochene Weiterexistenz des mnemischen Reizinhaltes an, so müsste dieser während der Latenz in unbekannten Tiefen der Person die mannigfaltigsten Wandlungen durchmachen, um dann später als etwas ganz anderes wieder zum Vorschein zu kommen. Um solche, dem Beharrungsprinzip widersprechenden, Änderungen begreifbar zu machen, wären wie- 
der Hilfshypothesen sehr gewagter Art nötig. Denn im Grunde ist das versteckte Eigen-L e b e n der "Residuen” mit einer elemententheoretischen Grundauffassung überhaupt nicht zu vereinbaren - um so weniger, als jene Veränderungen ganz offenbar mit Bedürfnissen und Entwicklungen der Person, in der sie sich abspielen, zusammenhängen.

Das führt uns zur personalist ischen Auffassung. Nach dieser bleiben die mnemischen Reize während der Latenz nicht irgendwie dinghaft in ihrer inhaltlichen Beschaffenheit bestehen; sondern: so wie sie von der personalen Empfänglichkeit ergriffen waren, tauchen sie auch in die Totalzuständlichkeit der Person unter und beeinflussen deren $\mathrm{d}$ is posit i o n elle Beschaffenheit. Nur in diesem Sinne sind sie selber - solange die Latenz dauert - als „Dispositionen” zu bezeichnen. Werden sie aber später im Sekundärprozess aktuell, dann sind sie nicht mehr „dieselben” Inhalte oder Vorgänge wie damals; sondern sie sind abgehobene Momente der $\mathrm{j}$ e $\mathrm{t} \mathrm{z}$ i g e $\mathrm{n}$ Person, daher auch durchtränkt von dem Leben und den Wandlungen, die die tragende Person inzwischen durchgemacht hat.

Der personalistische Begriff der „Disposition” ist viel bescheidener - und zugleich viel besser geeignet, den zu erklärenden Tatbeständen gerecht zu werden - als der mechanische Begriff der "Spur", wenn dieser auch dem Anschauungsbedürfnis bequemer sein mag. Dispositionen sind ih re m $\mathrm{W}$ e se $\mathrm{n} \mathrm{n}$ a $\mathrm{ch}$ latent, denn sie bedeuten nur Möglichkeiten, Bereitschaften, Gerichtetheiten; und es müssen noch auslösende Ursachen dazu kommen, um die Umsetzung ihrer Potentialität in Aktualität zu bewirken. Dispositionen sind ferner nur unselbständige Teilstrahlen der dispositionellen Gesamtbeschaffenheit der Person; und so bleibt auch beim Begriff der mnemischen Disposition der Zusammenhang mit dem personalen Ganzen gewahrt.

Wie diese mnemischen Dispositionen ,aussehen”, ist eine müssige Frage; eine Potentialität „sieht nicht aus"; müssig ist sogar die Frage, ob denn nun diese Dispositionen psychischer oder physischer Natur seien. Eine Möglichkeit oder Bereitschaft der Person kann zwar darauf ge richtet sein, psychische oder physische Nachwirkungen zu aktualisieren; sie ist aber selbst weder das eine noch das andre, sondern ungeschieden „personal”. 


\section{WIEDERHOLUNGSWIRKUNGEN}

Die wichtigste Bedingung für das Zustandekommen mnemischer Wirkungen ist die Wi e d e $\mathrm{rh}$ ol $\mathrm{ung}$.

Viele Lebnisse, die bei nur einmaligem Auftreten keine merkbaren Folgen hinterlassen, werden durch Wiederholung zu mnemischen Reizen; und je häufiger sie sich wiederholen, um so intensiver und nachhaltiger wird ihre mnemische Wirksamkeit.

Allerdings sind nicht alle mnemischen Reize der Wiederholung bedürftig oder fähig. Manche sind so leicht eingängig und treffen auf eine so starke mnemische Empfänglichkeit, dass schon ihr einmaliges Auftreten genügt, um ihre künftige mnemische Verwendung zu sichern. Andere sind als Eindrücke unwiederholbar, weil ihre personale Bedeutung gerade in der Einmaligkeit des primären Lebnisses und der besonderen Situation des Damals liegt. Dies gilt z.B. für viele „Erinnerungen” (s. Kap. XIV).

Wiederholungswirkungen kommen also nur in Betracht bei solchen mnemischen Reizen, von denen später eine allg em e in e V e rwe r t b a r k e it zu erwarten ist, und die durch einmaliges Auftreten nicht genügende Gewähr für eine solche künftige Bereitschaft bieten.

In drei Haupterscheinungsweisen treten mnemische Wiederholungswirkungen auf.

Steht das Individuum einem primären Zustand oder Geschehen ursprünglich fremd und unangepasst gegenüber, so kann durch ständige Wiederholung die unstimmige Beziehung von Individuum und Welt in eine einstimmige verwandelt werden. Der Vorgang heisst „G e w öhnu n g” (in anderen Nüancen: Abhärtung, Abstumpfung), das Ergebnis „Gewohnheit” (Vertrautheit, Selbstverständlichkeit, Gleichgültigkeit). Dies mnemische Geschehen ist psychophysisch neutral: bei einem Aufenthaltswechsel z.B. gewöhnt man sich körperlich an das veränderte Klima, seelisch an die andere Lebensweise, Umgebung und Beschäftigung.

Wird ein mnemischer Wiederholungsprozess rein auf die D y$\mathrm{n}$ a $\mathrm{m} \mathrm{i} \mathrm{k} \mathrm{der} \mathrm{körperlichen} \mathrm{oder} \mathrm{geistigen} \mathrm{L} \mathrm{e} \mathrm{i} \mathrm{s} \mathrm{t} \mathrm{u} \mathrm{ng}$ bezogen, dann sprechen wir von „U b u n g." Durch Übung wird Güte und Höhe der Leistung selbst gesteigert, der Aufwand an Zeit, Kraft und Bewusstheit vermindert und damit im ganzen der 
Nutzeffekt (d. h. die mit bestimmtem Aufwand zu erzielende Leistung) erhöht.

Wird ein Wiederholungsprozess unter dem in hal $\mathrm{t} l \mathrm{i}$ c h e $\mathrm{n}$ Gesichtspunkt betrachtet, dass er einen gesteigerten personalen Besitzstand (an körperlichen Fertigkeiten oder an psychischen Kenntnissen) sichern soll, dann heisst er "L e r n e n”. Es gehört zum Lernen demnach $\mathrm{n}$ ic $\mathrm{h} t$ notwendig die Willenseinstellung auf das Ziel des mnemischen Besitzes, sondern lediglich der Effekt einer nur durch Wiederholung erzielbaren Vermehrung des Könnens und Kennens.

Im folgenden besprechen wir kurz einige $G$ e s e $t z \mathrm{~m}$ ä $\int \mathrm{s}$ ig$\mathrm{k}$ e i t e $\mathrm{n}$ der mnemischen Wiederholung, die sich auf alle eben genannten Erscheinungsweisen, und zwar ebenso auf die physischen, wie die psychischen Mnemevorgänge erstrecken. (Speziellere Anwendungen dieser Gesetze kommen erst in späteren Kapiteln zur Sprache).

Der sich wiederholende Vorgang ist vom zweiten Auftreten an zugleich mnemische Wirkung und mnemischer Reiz. Denn er steht in der Art seines Ablaufs schon unter den Nachwirkungen des vorangegangenen gleichartigen Geschehens, er trägt aber seinerseits bei zum Effekt der weiteren Wiederholungen und mit ihnen allen zum mnemischen Endergebnis.

Man findet diesen Tatbestand oft bezeichnet als „Summationswirkung der Reize". Aber dieser Ausdruck ist missverständlich. Denn würde es sich nur um eine „Summe” von Einzelwirkungen handeln,dann müsste jede Wiederholung den gleichen Beitrag zur mnemischen Verfestigung liefern wie jede andere; es müssten etwa die ersten drei Wiederholungen - beim Auswendiglernen eines Gedichtes oder beim Einüben einer Fertigkeit - die gleiche Wirkung haben, wie die 4.-6. Wiederholung oder wie die 7.-9. Wiederholung. Aber diese Voraussetzung trifft nicht zu, wie die Alltagserfahrung und genauer das Experiment lehrt. Die mnemische Wirksamkeit des Gliedes einer Wiederholungsreihe hängt nicht von seiner isolierten Wucht, sondern von seiner Stelle in der Reihe ab. Und zwar nimmt im allgemeinen die Wirksamkeit der sich wiederholenden mnemischen Reize mit steigender Ordnungszahl ab. Der zusätzliche Effekt, der von der 20. Wiederholung ausgeht, ist geringer als jener, der von der 10 . Wieder- 
holung ausging. Wird die Zahl der Wiederholungen immer weiter fortgesetzt, so wird schliesslich der Effekt überhaupt nicht mehr merklich gesteigert, unter Umständen sogar wieder herabgesetzt.

Die grosse biologische und personale Bedeutung dieses mnemischen Wiederholungsgesetzes wird durch folgende Erwägung klar. Die Mannigfaltigkeit der Funktionen, welche ein Lebewesen zu vollziehen hat, bedingt, dass die ihm zur Verfügung stehenden Energieen nicht dauernd in gleicher Weise e in e $r$ Aufgabe gewidmet werden können. Es besteht also eine Spannung zwischen der zweckmälsigen Kräfteverteilung im Ganzen und den Ansprüchen, die ein einzelner Reiz durch ständige Wiederholung an die Person stellt. Die Abnahme der Wiederholungswirkung mit steigender Wiederholungszahl ist deshalb eine Art Selbstschutzvorrichtung des Individuums gegen die Vereinseitigung seines Kraftverbrauchs.

Die mnemische Wiederholungswirkung ist entweder $\mathrm{spe} z \mathrm{i}-$ f i s ch oder a us trahlend. Dort bleibt sie beschränkt auf das ursprüngliche Gebiet des mnemischen Reizes; hier greift sie über auf andere Bereiche der Person. Hierfür sind drei Regeln aufzustellen. 1) Je weniger eng die Bindung des mnemischen Prozesses an den totalen Lebensvollzug des Individuums ist, um so mehr bleibt die Wiederholungswirkung auf den Ursprungsbereich beschränkt. Das Hauptbeispiel hierfür ist die tierische Dressur. Man kann durch unablässige Wiederholung einem gelehrigen Tier die seltsamsten Verrichtungen beibringen, die kaum etwas mit seinen biologischen Lebenszielen zu tun haben. Freilich bleiben die so errungenen Fertigkeiten Fremderscheinungen, sind abgekapselt gegen das übrige Leben des Tieres. Es fehlt aber auch nicht an Analogieen hierzu beim Menschen (Drillpädagogik; mechanisches Memorieren). 2) Die Ausstrahlung der mnemischen Wirkung stuft sich ab nach dem Verwandtschaftsgrade zwischen induzierender und induzierter Sphäre. So kann ein Mensch, der seine rechte Hand und nur diese im Schreiben geübt hat, zur Not auch mit anderen Körperteilen schreiben, am besten mit der linken Hand. 3) Je spezifischer (und damit starrer) eine Wiederholungswirkung geblieben ist, um so schwerer ist sie durch andere mnemische Wiederholungswirkungen zu ersetzen. Wo dagegen der ursprüngliche mnemische Prozess 
seine Wirkung auf weitere Bereiche der Person ausgebreitet hat, ist eine grössere Elastizität im Übergang zu neuen mnemischen Anforderungen vorhanden: d.h. das Umlernen und Umgewöhnen geht leichter von statten.

\section{IV. ÜBER TIERISCHE MNEME}

Wir haben oben (S. 257) festgestellt, dass die Mneme eine mittlere Stellung zwischen Instinkt und Intelligenz einnimmt. Dadurch wird die entwicklungspsychologische Frage nach den mnemischen Fähigkeiten des Tieres nahe gelegt. Denn die Bedeutung des Instinkts im tierischen Leben steht ebenso fest, wie der geringe Anteil von Intelligenz an den tierischen Lebensvollzügen. Dagegen ist die Bedeutung des Zwischengliedes zwischen diesen beiden Entwicklungsstufen, also der Mneme, nicht ohne Weiteres klar. In der Tat stellt sich auch heraus, dass man über ,die" tierische Mneme nicht allgemein sprechen kann. Der Anteil mnemischer Vorgänge am tierischen Leben ist nämlich bei verschiedenen Tierarten und Tierindividuen äusserst verschieden, und eben wegen dieser Verschiedenheit geradezu ein Index für die Entwicklungshöhe.

Das Leben der niederen Tiere ist fast ausschliesslich von der Gattungsmneme beherrscht; eine Umgewöhnung, eine Steigerung oder Änderung bestimmter Fertigkeiten durch individuelle mnemische Wirkungen ist, wenn überhaupt, nur in minimalen Ausmalsen möglich; das einzelne Tierindividuum hat nur geringe „Plastizität”. (Eine Fliege mag hunderte Male gegen die durchsichtige Fensterscheibe stossen, sie „lernt" nie, dass hier ein unbesiegbares Hindernis vorliegt.)

Die einfachsten Formen tierischer Individual-Mneme treten auf als $\mathrm{Umgew}$ öh n u gen. Wenn biologisch relevante Wandlungen in der Umwelt des Tieres eintreten, so wird die unablässige Einwirkung der neuen Reize (z.B. veränderter Ernährungsbedingungen) eine in Minimalschritten vor sich gehende und sich schliesslich fixierende Änderung des tierischen Verhaltens mit sich führen. Allerdings sind die hier möglichen Variationen innerhalb des Einzellebens meist verschwindend gering gegenüber dem Bestand erblich festgelegter und nicht umstellbarer Verhaltungsweisen. 
Der nächste Entwicklungsschritt führt zur mnemischen Auszeichnung gewisser Umweltgebilde, also zur Differenzierung des Verhaltens gegen Vertra tes und Frem des. Auf dieser Stufe ist das Tier in seinem Aufenthaltsrevier gut orientiert, „kennt" sein Heim (den Bau, das Nest u.s.w.), ist an einen bestimmten Geschlechtspartner gebunden und findet den eigenen Nachwuchs unter allen jungen Tieren der gleichen Art heraus.

Weit höhere mnemische Fertigkeiten sind erforderlich bei jenen Tieren, welche gezähmt oder dressiert werden können.

Beides ist durchaus nicht identisch. Zähmung bedeutet eine Totalwandlung des tierischen Charakters, Dressur dagegen die Beibringung scharf umschriebener Einzelfertigkeiten.

$\mathrm{Zäh} \mathrm{mung}$ setzt vor allem eine gewisse Bildsamkeit der Triebstruktur voraus; nur dadurch können die Tiere an bestimmte Verhaltungsweisen, die ihnen im freien Zustand ganz fremd waren, gewöhnt werden. Manche Tiere besitzen diese Bildsamkeit nur während einer kurzen Jugendperiode, wodurch der Schein der Zähmbarkeit erweckt wird. Nach vollkommener Triebreifung setzt sich dann aber die Dynamik der Gattungsmneme vollständig durch, und die mnemischen Erwerbungen der individuellen Jugendperiode erweisen sich als ganz oberflächlich und vergänglich: das Tier fällt wieder in die "Wildheit” zurück. - Eine weitere Voraussetzung für mögliche Zähmung ist sodann eine bedeutende Gewöhnungs- und Umgewöhnungsfähigkeit in Bezug auf die personelle und gegenständliche Umwelt. Das Vertrautheitsverhältnis des Hundes oder Pferdes zum Herrn, zum Heim, zum Stall ist mnemisch bedingt. Es gibt ja viele Beispiele für die besondere Nachhaltigkeit dieser Beziehungen. Andrerseits findet bei Wechsel des Herrn oder des Heims nach einiger Zeit auch die völlige Umstrukturierung der Umweltbezüge statt; die neuen Eindrücke und Handlungsabläufe gewinnen durch Wiederholung Vertrautheit und Selbstverständlichkeit und verdrängen die alten mnemischen Bindungen.

Bei der Dress u r müssen wir zwei Formen unterscheiden: die artistische und die experimentelle.

Dressur als $\mathrm{K} \mathrm{unst}$ wird geübt von dem beruflichen Tierbändiger oder von dem Liebhaber, der seinem Hunde verschiedene Kunststücke beibringt. Die Fertigkeiten, die das Tier er- 
wirbt, liegen ausserhalb seiner eigentlichen Biosphäre; diese ist nur indirekt beteiligt, einmal durch die enge Bindung des Tieres an die Person des Abrichters, sodann durch die, je nach Leistung winkende, Belohnung und Bestrafung. Diese beiden Motivgruppen genügen, um nun auch den wesensfremden, für das Tier an sich sinnlosen, Verrichtungen einen gewissen Sinn zu verleihen und damit den steten Wiederholungen eine steigende biologische Resonanz zu verschaffen. Man darf den Anteil des personalen Moments hier nicht gering schätzen: zwischen dem Herrn und dem abzurichtenden Tier besteht eine Gefühlsatmosphäre ganz spezifischer Art; fehlt diese, so kann selbst die genaueste Kopie aller Dressurmafsnahmen durch einen Fremden völlig erfolglos bleiben.

Im Gegensatz hierzu wird bei der ex p e r i m e n t e l l-p s ychologischen Dressur der personale Einfluss völlig ausgeschaltet und die $\mathrm{mech}$ a $\mathrm{n}$ is che $\mathrm{Wucht}$ der Wi e$\mathrm{d}$ e $\mathrm{r}$ h o l u n g e $\mathrm{n}$ zum alleinigen Dressurmittel gemacht. Damit ist die Bedeutung, aber auch zugleich die enge Begrenzung der tierpsychologischen Lernexperimente gekennzeichnet, wie sie namentlich in Amerika in grossem Umfang gepflegt werden.

Der einfachste Versuch hat etwa folgendes Schema: Drei gleich aussehende Kästen stehen nebeneinander, der rechts stehende enthält, für das Tier nicht erkennbar, das Futter, die anderen sind leer. Bei jedem Versuch wird diese Anordnung wiederholt. Das futtersuchende Tier wird anfänglich wahllos bald rechts, bald in der Mitte, bald links suchen; allmählich $l$ e r n t es, gleich auf das rechte Gefäss zuzugehen. Es lässt sich genau messen, nach wievielen Versuchen die Dressur auf "rechts" perfekt ist. Wird nun das futterhaltende Gefäss nach links verlegt, so muss das Tier „umlernen”, d.h. von dem eben mit Mühe gewonnemen Lerneffekt wieder abkommen; auch hier lässt sich exakt feststellen, welcher Wiederholungsaufwand dazu gehört. Die Versuche sind beliebig variierbar: durch Vermehrung der Gefässe; durch Dressur auf andere Merkmale als „rechts” „links”, z.B. auf Farbe, Form, Grösse der Gefässe, durch Einfügung von Hindernissen, von Vexierversuchen u.s.w.

Sehr beliebt sind die Versuchsanordnungen der "mazes"; das sind Labyrinthe mit verschlungenen Wegen, Blindgängen u.s.w.; Will das Tier aus ihnen herauskommen, oder das irgendwo befindliche Futter erreichen, dann muss es lernen, seine Bewegungen in bestimmter Weise zu organisieren (z.B.: immer den linken von zwei sich abzweigenden Wegen einzuschlagen). 
Über Methodik und Ergebnisse solcher Versuche muss hier einiges Grundsätzliche genügen.

Die Aufgabe besteht darin, dass ein biologisch relevantes Ziel auf einem, biologisch nicht vorgebildeten, Wege erreicht werden soll. Der mnemische Prozess muss also mindestens bezüglich des Zieles im Vitalen verankert und durch ein echtes Bedürfnis gestützt sein, sonst kommt er überhaupt nicht zustande. Nur die Stärke dieses Bedürfnisses treibt das Tier dazu, den Versuch zur Erreichung immer von neuem zu wiederholen und hierbei verschiedene, zunächst fremde Wege einzuschlagen, deren Beziehungen zum Ziel ihm nicht einsichtig sind. Die Weg-oder Mittelwahl ist zunächst ganz beliebig; es gibt einige Zufallstreffer neben vielen Fehlleistungen. Nun findet aber allmählich eine Auszeichnung des richtigen Weges dadurch statt, dass er zur Bedürfniserfüllung führt. Aus der Sukzession: Bedürfnis, Weg, Erfüllung, bildet sich eine assoziative Kette von ganz anderer Festigkeit als aus jenen Suchakten, bei denen die Aktion ins Leere verpufft. Jene Kette wird durch ständige Wiederholung schliesslich zu einer festen Lebnisgestalt, die dann automatisch abläuft, sobald die Reizund Bedürfnis-Situation gegeben ist.

Mit dieser relativ einfachen Erklärung sind die Umrisslinien dieses primitiven Lernvorganges gegeben, wie er durch die Besonderheit der Aufgabe bedingt ist. Es ist ein Lernen, das dem Vorgang der "Gewöhnung" noch sehr nahe steht, dagegen von den höheren Lernvorgängen sehr verschieden ist. Diese Feststellung ist deshalb wichtig, weil zuweilen die rein automatische Wiederholungsdressur solcher Versuche als die typische Grundform alles Lernens, des tierischen wie des menschlichen, angesehen worden ist. Davon $\mathrm{kann} k$ eine $\mathrm{Rede}$ sein. Auf die artistische Dressur mit ihrer stark personalen Bindung wiesen wir schon oben hin. Wichtiger aber ist, dass schon die, bei höheren Tieren vorkommenden, natürlichen Lernvorgänge durch den Einschlag der Einsich t in die zu erwerbenden Zusammenhänge eine andere Struktur erhalten, und dass die menschliche Lernhandlung als echte Intelligenz- und Willenshandlung unter durchaus veränderten psychologischen Bedingungen zustande kommt. Die mnemischen Wirkungen der Wiederholung gehen in diese höheren Lernvorgänge nur noch als Teilfaktoren ein; sie bilden gleichsam das Rohmaterial, mit denen das Denken und Wollen des lernenden Menschen arbeitet. 
Dagegen ist hier noch auf die Brauchbarkeit der psychologischen Dressurmethoden für exakte vergle i ch ende Feststellungen hinzuweisen. Quantität und Qualität des experimentellen Dressurerfolges ist direkt aus der Zahl der, zur Erzielung der mnemischen Sicherheit nötigen, Wiederholungen und aus dem Verhältnis von Treffern zu Fehlleistungen abzulesen. So lassen sich bei Aufgaben bestimmter Schwierigkeit verschiedene Tierarten und Tierindividuen in Bezug auf ihre Lernfähigkeit miteinander vergleichen. Andrerseits kann man durch Variation der Aufgaben erforschen, wo für bestimmte Tiere die obere Grenze des Lernens überhaupt liege, und welchen Einfluss bestimmte Teilbedingungen auf die Lernfähigkeit haben.

Hier stossen wir noch einmal auf die Verankerung dieser Fähigkeit in den vitalen Bedürfnissen. Je „unnatürlicher”, d.h. je mehr den angeborenen Verhaltungsweisen des Tieres widersprechend der Weg ist, den das Tier lernen muss, um ein Bedürfnis zu befriedigen, um so schwieriger ist der Lernprozess. Selbst das intensivste Bedürfnis reicht dann unter Umständen nicht aus, um das Tier zur Erwerbung einer Fertigkeit zu befähigen, sofern diese zu stark von der angeborenen Handlungsstruktur des Tieres abweicht.

Die oben erwähnte Stubenfliege, die immer wieder vergeblich gegen das geschlossene Fenster prallt, mag einmal oder auch mehrmals durch Zufall an den benachbarten, geöffneten Fensterflügel geraten und dadurch ins Freie gekommen sein. Dennoch lernt das Tier nie, diesen Umweg zu suchen; es wird vielmehr bei seinen fruchtlosen Wiederholungen des direkten Weges schliesslich zu Grunde gehen.

Hier waltet ein sehr allgemeines tierisches Bewegungsprinzip: die Bedürfniserfüllung wird in möglichst gradliniger Annäherung an das Bedürfnisziel gesucht. Die Fähigkeit, dies Prinzip aufzulockern und d e n ,U m w e g" $\mathrm{z} u \mathrm{l}$ e $\mathrm{r} \mathrm{n}$ e $\mathrm{n}$, ist ausserordentlich charakteristisch für die Entwicklungshöhe des Tieres. Ein Huhn, das zu den, vor dem Gitter liegenden Körnern nur durch eine, in der Hinterwand des Käfigs befindliche Offnung gelangen kann, lernt diesen Umweg nie, weil es sich hierbei vorübergehend von dem Ziel entfernen muss. Der Hund hat dagegen nach wenigen Wiederholungen den Umweg herausgefunden und benutzt ihn nun ständig. 


\section{ELFTES KAPITEL}

PRIMITIV FORMEN DES GED ÄCHTNISSES

\section{DAS UNMITTELBARE GEDÄCHTNIS}

\section{Zeithof und Anschaungsbild}

Ein unmittelbarer Gedächtnisvorgang ist der seelische Weiterklang und Ausklang eines Erlebnisses nach dem Aufhören des äusseren Reizes. Hier steht das Gedächtnisphänomen dem Wahrnehmungsphänomen am nächsten; die Grenzen können so fliessend werden, dass es zweifelhaft ist, ob man noch unter der $\mathrm{G}$ e g e $\mathrm{n}$ w a $\mathrm{r} \mathrm{t} \mathrm{s}$ wirkung eines sensorischen Reizes oder schon unter den ersten $\mathrm{N}$ a c h wirkungen steht.

Wenn ich in einem Vortrag auf dieses Thema komme, pflege ich zu sagen: „Ich werde nach dem Satz, den ich jetzt gerade spreche, eine Pause machen, damit Sie die Erscheinung des unmittelbaren Gedächtnisses an sich beobachten können." Es folgt ein kurzes Schweigen, das den Hörern Zeit lässt, die zuletzt gehörten Worte und ihren Sinnes ungestört im Bewusstsein ausschwingen zu lassen. Sie finden dann den eben durchlebten Eindruck, obwohl er nun ,vergangen" ist, doch noch immer in starker Plastik in sich, viel lebendiger als andre vergangene Erlebnisse, von denen sie Intervalle trennen. - Man mache den entsprechenden Versuch etwa mit einem Bild, nach dessen Betrachtung man das Auge schliesst: dann steht es noch längere Zeit „vor dem inneren Auge”, sodass man im Zweifel sein kann, ob man es noch ,sieht”, oder schon ,,vorstellt". - Bekannt ist, dass man die Schläge einer Uhr, die man während des Schlagens nicht beachtet hatte, unmittelbar darauf gedächtnismälsig nachzählen kann; Die gesamte Schlagfolge bis zu 12 Schlägen kann dann im Bewusstsein mit seltsam sinnlicher Lebhaftigkeit wieder zum Abrollen gebracht werden. 
Das Phaenomen besteht auch dort, wo es nicht - wie in obigen Beispielen - Gegenstand eigens darauf gerichteter Beobachtung ist. Jedes primäre Erlebnis, dem volle Entwicklungsmöglichkeit gegeben ist, hat einen solchen "Z e ith of," in dem es ausschwingt.

Die personale Bedeutung des unmittel$\mathrm{b}$ a re $\mathrm{n} \mathrm{G}$ ed ächt $\mathrm{n}$ is s e s besteht vor allem darin, dass es die tiefere seelische Verankerung irgend eines Eindrucks, einer Erfahrung, eines Gefühls ermöglicht. Jeder neue seelische Inhalt gewinnt durch dieses Nachschwingen und Sich-Ausleben-können zugleich eine starke mnemische Durchschlagsmöglichkeit und Wirkungsbereitschaft für spätere Zukunft.

Jemand macht eine Reise in fremde Länder. Gönnt er jedem einzelnen Eindruck genügend Zeit, um sich in primärer Nachwirkung „zu setzen”, dann besteht grosse Wahrscheinlichkeit, damit einen dauernden geistigen Besitz gewonnen zu haben. Diese Aussicht ist viel geringer, wenn sich die Eindrücke ohne Zeithöfe mit kaleidoskopischer Geschwindigkeit ablösen - mag auch jedes einzelne Erlebnis noch so lebhaft sein.

Man sollte deshalb dort, wo es um absichtsvolle Gewinnung von Gedächtnisinhalten geht, von dieser Hilfe des unmittelbaren Gedächtnisses Gebrauch machen. Wer irgend etwas neues lernt, sorge dafür, dass beim erstmaligen Empfangen des neuen Inhalts die Wahrnehmungen ihre Auslebezeit erhalten. Úberstürzt man die Sukzessionsgeschwindigkeit der Neuaufnahme (z.B. bei Vokabelreihen, Regeln u.s.w.), dann leidet die dauernde Gedächtniswirkung unter der Unmöglichkeit, den Einzeleindruck im unmittelbaren Gedächtnis zu verfestigen. - Filme für Unterrichtszwecke sind diesem psychologischen Gesichtspunkt oft sehr wenig angepasst.

Das Faktum des unmittelbaren Gedächtnisses verlangt auch eine entwicklungspsychologische Betrachtung; diese ergänzt zugleich unsere Erörterungen über die Sinneswahrnehmung.

Wir hatten früher gezeigt, dass die G e ge n wa rt, auf welche sich jede Wahrnehmung bezieht, ausgedehnt ist. Jetzt müssen wir hinzufügen, dass die Grenzen dieser Gegenwart flüssig sind. Zum augenblicklichen Erleben gehört schon das Ausklingen- 
können (also ein Stück Zukunft) mit hinzu; und innerhalb des „Zeithofes" reicht soeben Vergangenes noch in die Gegenwart hinein. In einem solchen ursprünglichen Erlebnis ist also die scharfe Differenzierung von Wahrnehmungs- und Gedächtnisinhalt noch gar nicht erfolgt; es stellt vielmehr den gemeinsamen Urgrund dar, aus dem sich dann erst die Trennung von Gegenwarts- und Vergangenheits-Bezug, also von Sinneseindruck und Gedächtnisvorstellung allmählich herausarbeitet.

Diese entwicklungspsychologische Auffassung, so wie die nun zu besprechende Stufentheorie steht in Zusammenhang mit der Lehre von E. Jaensch (Marburg).

Den fliessenden Übergang zwischen Wahrnehmung und Gedächtnisvorstellung hat man nämlich wissenschaftlich dadurch zu bewältigen gesucht, dass man einige Zwischenstufen heraushob.

Die erste dieser Stufen ist altbekannt: das $\mathrm{N} \mathrm{a} \mathrm{c} \mathrm{h} \mathrm{b} \mathrm{i} \mathrm{l} \mathrm{d.} \mathrm{Von}$ ihm war schon früher die Rede (s.S. 229). Der Ausdruck „Nachbild" stammt zwar aus dem Optischen, wird aber auf die unmittelbare Nachwirkung aller Empfindungsinhalte angewandt, sofern diese noch durch Weiterfunktionieren der Erregung i $\mathrm{m}$ gereizten Sinnesorgan selbst bedingt sind. Nachbilder sind also $\mathrm{S}$ i n $\mathrm{n}$ e s phänomene genau wie die Wahrnehmungen selber, überdauern auch nur ganz kurze Zeit den Abschluss des äusseren Reizes.

Eine zweite $Z$ wischenstufe bildet das von Jaensch sogenannte „A n schau u g sbild". Dies ist schon stärker abgelöst vom ursprünglichen Reiz; der Eindruck ist mehr ,innerlich” geworden, stärker personal eingebettet. Aber er hat noch lange nicht die reine Innerlichkeit - und damit die Blässe und mangelnde Sinnfälligkeit - der blossen Vorstellung erreicht. Menschen, die über solche Anschauungsbilder Rechenschaft geben können, charakterisieren ihr Erlebnis so, dass sie den Gegenstand (der nicht mehr gegenwärtig ist) „sehen”; auch gewisse Gesetzmälsigkeiten dieser Anschauungsbilder und die erstaunliche Fülle von Einzelheiten, die in ihnen erlebt werden, beweisen, dass sie der eigentlichen Wahrnehmung noch sehr nahe stehen. Immerhin geht diese Erscheinung normaler Weise nicht so weit, dass sir zu Halluzinationen führt; das Bewusstsein, dass in W i r klich$\mathrm{k}$ e i $\mathrm{t}$ der Gegenstand nicht mehr da ist, fehlt selten. 
Im bisher besprochenen Sinne ist das Anschauungsbild ein Begriff der allgemeinen Psychologie; denn es stellt jene Zwischenform zwischen Wahrnehmung und Vorstellung dar, wie sie im Zeithof auftritt; und der Zeithof ist, wie schon bemerkt, eine generelle psychische Erscheinung.

Hiervon muss man die differentiell-psychologische Bedeutung des „Anschauungsbildes” unterscheiden; es ist diejenige, die für Jaensch und seine Schule den Ausgangspunkt der Untersuchung bildete. Die Tendenz zu Anschauungsbildern variiert nämlich nach Stärke und Umfang ausserordentlich; gewisse Altersstufen und Menschentypen neigen zu besonders lebhaften Anschauungsbildern. Bei diesen sog. „E i d e t i kern” sind Anschauungsbilder nicht nur vorhanden als schnell verschwimmende und verschwindende Übergangsformen im unmittelbaren Gedächtnis; sie verselbständigen sich vielmehr, werden der Selbstbeobachtung gesondert zugänglich und treten auch nach längeren Zwischenpausen (also im „mittelbaren” Gredächtnis) mit grolser Lebhaftigkeit wieder auf.

Untertypen des eidetischen Typus werden dann noch danach geschieden, ob die Anschauungsbilder mehr den Nachbildern ähneln, indem sie starr und unbeeinflussbar sind und sich der Person, selbst gegen ihren Willen, als seelische Fremdkörper aufdrängen (,tetanoider” oder T-Typus nach Jaensch) — oderob die Einbettung in die Totalität der Person überwiegt, so dass der Eidetiker Anschauungsbilder seinen Interessen und Neigungen entsprechend hervorrufen, verwerten und verändern kann (,,basedowider” oder „B.-Typus”.).

Nach Überzeugung Erich Jaensch's (sowie seines Bruders, des Mediziners $W$. Jaensch), beschränkt sich der genannte Typenunterschied nicht auf das spezielle Funktionsgebiet der Eidetik, sondern hat gesamtpersonale Bedeutung. Insbesondere werden den beiden eidetischen Typen bestimmte Eigentümlichkeiten des Körperbaus, der Gesichtsstruktur u.s.w. zugeordnet, auch die Verwandtschaft mit den Krankheitsbildern des Tetanus- und des Basedow-Kranken behauptet (daher die erwähnte Namengebung). Da sich bei Statistiken über die Häufigkeit des eidetischen Typus sehrstarke örtliche Unterschiede herausstellten, wurde die Vermutung aufgestellt, dass die Bodenbeschaffenheit (insbesondere die Kalkhaltigkeit) ursächliche Bedeutung habe. Alle diese Punkte sind noch strittig.

Die vielseitigen experimentellen Untersuchungen der Marburger Schule und anderer haben dazu geführt, dass man 5 Stärke- 
grade in der Ausprägung des eidetischen Typus aufstellte. - Die Häufigkeitskulmination scheint in dem Lebensalter kurz vor der Pubertät zu liegen; viele Menschen, die als Jugendliche Eidetiker waren, verlieren später diese Eigenart.

Die $Z$ wischenstellung des Anschauungsbildes $z$ wischen Wahrnehmung und Vorstellung wurde dadurch experimentell erhärtet, dass die Anschauungsbilder manche gesetzmärsigen Erscheinungen zeigen, die sonst nur bei echten Wahrnehmungen bekannt waren.

Umstritten ist die Beziehung der Eidetik zur Intelligenz. Während manche Forscher glaubten, bei Schwachbegabten eine Häufung der eidetischen Anlage zu finden, haben eingehende Untersuchungen von Bonte wahrscheinlich gemacht, dass diese Anlage vom Intelligenzgrad unabhängig sei.

In den letzten Jahren hat $E$. Jaensch die Lehre von den eidetischen Typen auszugestalten gesucht $z u$ einer umfassenden $c h$ a rakte$\mathrm{r} o \mathrm{log}$ is che $\mathrm{n}$ Typologie, über die an anderer Stelle berichtet wird ${ }^{1}$ ).

\section{Merkfähigkeit}

Es gibt Lebensaufgaben, für deren Erfüllung schon das unmittelbare Gedächtnis in sich selbst genügt, wenn es unter die Herrschaft des Willens gestellt wird. Es ist dies das „u n m i t t e l b a r e M e r k e n." Ein Kind, das einen Auftrag der Mutter in der Küche ausrichten oder einen Einkauf in Nachbarladen machen soll, vermag dies nur, weil die eben gehörte Rede der Mutter noch ohne Störung und Unterbrechung in ihm weiter wirkt. Jeder Telephonierende weiss, dass die soeben nachgesehene Nummer während der verschiedenen Teilhandlungen bis zum Erreichen des endgültigen Anschlusses in einer besonderen Lebendigkeit noch optisch und akustisch für ihn da ist; es ist nicht einmal immer die leise sprachliche Wiederholung erforderlich.

Der Umfang dieser unmittelbaren $\mathrm{Me} \mathrm{rkfähigkeit} \mathrm{ist}$ messbar, indem man Eindrucksreihen bestimmter Art und variierbarer Länge (Ziffernreihen, Wortreihen, Sätze) einmal darbietet und sofort wiederholen lässt. An dem Prüfergebnis sind allerdings zwei Teilfähigkeiten ununterscheidbar beteiligt: erstens die Aufmerksamkeitsspanne, die es ermöglicht, eine Reihe bestimmten Umfangs als Ganzes zu ergreifen, dann das unmittel-

1) Vgl. Kapitel „Charakter”.

Stern, Psychologie 
bare Gedächtnis, welches sofort hinterher die ganze Reihe noch festzuhalten vermag. Die Merkfähigkeit weist sehr starke $\mathrm{Zu}$ nahme mit steigendem Alter auf; sie ist auch von Individuum zu Individuum sehr verschieden; besonders niedrige Leistungswerte können Symptome geistiger Defekte sein.

Mit wachsender L ä n ge der zu merkenden Reihe nimmt die Merkschwierigkeit unverhältnismälsig rasch zu. In den Vorlesungen pflege ich diese Regel durch einen einfachen Massenversuch zu veranschaulichen.

Ich nenne in e intöniger Aussprache Ziffern im Halb-Sekunden-Abstand und lasse nach jeder Reihe das Behaltene niederschreiben. Also:

$6,9,2,8,3,7$. (Niederschreiben!) . . .

$9,4,1,3,8,5,7,2$. (Niederschreiben!) ...

$3,0,9,4,6,1,7,8,2,5$. (Niederschreiben!)

Während die sechsgliedrige Reihe von allen Hörern ohne weiteres richtig niedergeschrieben wird, machen sich schon bei der achtgliedrigen Reihe Ausdrucksbewegungen des Staunens und Unwillens bemerkbar wegen der unverhältnismälsigen Erschwerung durch zwei weitere Glieder; nur ein Bruchteil der Versuchspersonen ist noch zu richtiger Wiedergabe fähig. Bei der zehngliedrigen Reihe gibt es fast Aufruhr und im Ergebnis weitgehendes Versagen. Die Einprägung der nicht einmal doppelt so langen Reihe wird als eine Aufgabe völlig anderer Art erlebt als die kinderleichte Aufgabe mit 6 Gliedern.

Bemerkenswert ist hierbei die Feststellung, dass bei der Aufgabe mit 10 Gliedern nicht etwa eine Teilreihe von 6 Gliedern (wie in der ersten Aufgabe) behalten worden ist, und nur das Merken der 4 weiteren Glieder die Fähigkeit überschritt; vielmehr ist die Zahl der gemerkten Glieder geringer als im ersten Versuch.

Nach assoziationspsychologischer Ausdrucksweise liegt hier „rückwirkende Hemmung" vor: die Assoziation, die zwischen den ersten Gliedern schon beim einmaligen Hören gestiftet war, wird durch die folgenden Elemente wieder zerstört. - In Wirklichkeit geht der Prozess aber nicht von den „Elementen” aus, sondern von der, dem Merk-Ganzen zuzuwendenden, Energie. Diese ist eng begrenzt; bei längerer Reihe können den einzelnen Gliedern und ihren Verbindungen nur geringere und ungleichmälsigere Teilbeträge zugewandt werden; daher der geringere Totalerfolg. 
Zwei Faktoren, welche die unmittelbare Merkfähigkeit günstig beeinflussen, seien kurz erwähnt ${ }^{\mathbf{l}}$ ).

Da ist zunächst die $\mathrm{Rhy} t \mathrm{hm}$ is i e r u $\mathrm{g}$ des Merkstoffes. In dem oben erwähnten Vorlesungsversuch lasse ich den drei Ziffernreihen, die monoton hergesagt waren, eine vierte folgen mit scharfer Rhythmisierung im Dreiertakt:

$$
5,8, i-4,0,2-3,8, \mathfrak{7}-5
$$

Das Ergebnis ist dann stets verblüffend, insbesondere wenn gerade die andere katastrophale Zehnerreihe vorangegangen war; denn die rhythmische Zehnerreihe wird von allen mit Leichtigkeit richtig reproduziert $\left.{ }^{2}\right)$.

Der zweite Faktor ist der S in $\mathrm{n} g$ e halt. Die obigen Beispiele enthielten unzusammenhängende Einzelglieder. Bildet aber der Merkstoff ein Sinnganzes (z.B. einen zusammenhängenden Satz, einen Auftrag u.s.w.), und wird dieser Sinn ver st a nd e n, dann erfährt das Merken eine bedeutende Erleichterung; und Merkstoffe von ganz anderer Längenordnung können nun durch einmaliges Hören bewältigt werden.

Von grossem theoretischen Interesse ist es, dass sich in einem solchen Merkprozess der Sinngehalt loslösen kann von der eigentlichen Wortmaterie und in ganz anderem Wortlaut zur Wiedergabe gelangt - ohne dass der Sprechende etwas von dieser Unterschiebung anderer Wörter ahnt.

Zwei Beispiele.

1) Herr $X$ trägt seinem Diener folgende Bestellung auf: "Gehen Sie zu Herrn $Y$ und sagen Sie ihm: „Ich fühle mich nicht gesund und bedaure daher, an der Sitzung nicht teilnehmen zu können". Der Bote richtet Herrn Y aus: „Herrn X tut es sehr leid; er kann nicht zu der Versammlung kommen, weil er nicht ganz wohl ist'. Der Bote hat $\mathrm{ke}$ in e in $z$ ige s Wort des Auftrages behalten; jeder Ausdruck ist durch einen anderen ersetzt; sogar die Reihenfolge der einzelnen Teile des Auftrages ist verändert - und doch hat der Bote gute Merkfähigkeit gezeigt, weil er den Sinn richtig wiedergab.

2) Der französische Sprachforscher Ronjat hat eine deutsche Frau. Der Sohn des Ehepaares wuchs von Anfang an zweisprachig auf; der Vater sprach mit ihm stets französisch, die Mutter und das Kindermädchen deutsch. Den 21-jährigen Knaben schickte einmal der Vater aus seinem zu kalten Zimmer zum Kindermädchen mit der Begrün-

\footnotetext{
1) Näheres dariber im Abschnitt iiber Lernen als Willenshandlung.

2) Die leichtere Einprägsamkeit von Versen gegenüber gleichlangen Prosatexten ist grossenteils durch den Rhythmusfaktor bedingt.
} 
dung: „, ne reste pas ici, il fait trop froid”". Der Knabe lief zum Mädchen und bestellte: "Papas Zimmer ist zu kalt". Er hat nicht etwas den gehörten Wortlaut übersetzt; vielmehr sind die Worte als solche garnicht bemerkt und gemerkt worden. Der allein behaltene Sin n fand ganz automatisch denjenigen Ausdruck, der für den anderen Gesprächspartner angemessen war.

Durch solche Erscheinungen wird die "Spuren"-Theorie der mnemischen Vorgänge aufs bündigste widerlegt. Von den gehörten Worten sind keinerlei "Spuren" in der Form entsprechender und wieder hervorholbarer Wortvorstellungen hinterlassen worden; dennoch ist eine starke und durchaus zweckentsprechende mnemische Gesamtwirkung vorhanden.

\section{Perseverationen}

Eine Zwischenstellung zwischen den Erscheinungen des unmittelbaren und des mittelbaren Gedächtnisses nehmen die „P e r s everati o n e n" ein. Sie sind zwar noch kurzfristig, reichen aber immerhin zeitlich viel weiter als der blosse Zeithof.

In solchen Fällen bleibt die Wirkung des mnemischen Reizes hintergründig bestehen, ohne das Bewusstsein voll in Anspruch zu nehmen - als eine D is position von grösster Bereitschaft, um bei jedem Nachlassen der inzwischen eingetretenen anderen Lebnisse wieder aktuell zu werden. So kann z.B. der mnemische Reiz nur als motoris cher Wiederholungsimpuls perseverieren und sich in stereotyp gewordenen Redeformeln äussern. Oder er kann als Gefühls- und Affekt-'Tönung weiter wirken, aus der dann mit Leichtigkeit auch der dazu gehörige Vorstellungsinhalt wieder hervorwachsen kann.

Zwei Beispiele:

1) Ich hatte morgens in der Zeitung von einer Aufführung der ,Fledermaus" gelesen; im Anschluss daran war mir die Melodie des Fledermauswalzers einen Augenblick bewusst durch den Kopf gegangen. Ich machte mich sodann an Arbeiten, die mich völlig in Anspruch nahmen. Nach einer Stunde ertappte ich mich zu meinem eigenen Erstaunen dabei, dass ich noch immer von der Walzermelodie besessen war; und ich hatte das Gefühl, dass ich sie in der Zwischenzeit innerlich nie ganz verloren, vielleicht sogar fortwährend vor mich hergesummt hatte.

2) Man hat eine wichtige Nachricht bekommen und sie zunächst im Zeithof innerlich auswirken lassen. Nun ist man gezwungen, den All- 
tagspflichten obzuliegen, die zeitweilig alle Aufmerksamkeit in Anspruch nehmen, sodass jene Nachricht währenddessen als Bewusstseinsinhalt nicht vorhanden ist. Aber zwischendurch - bei jedem Nachlassen der Arbeitsenergie, - schnappt das Bewusstsein jener Nachricht mit solcher Selbstverständlichkeit und Stärke ein, dass man sich sagt: man hat sie dauernd in Form eines untergründigen Gefühls gehabt, und es bedurfte nur der geringsten anderweitigen Entspannung, um auch die Vorstellungsgeladenheit dieses Gefühls wieder lebendig zu machen.

\section{DAS GEBUNDENE GEDÄCHTNIS}

Jene „mittelbaren” Gedächtnisvorgänge, die - mit vollständigen und oft langfristigen Latenzen - immer wieder ihre Wirksamkeit erweisen, zerfallen nochmals in zwei Hauptformen. Die einfachere und auch entwicklungspsychologisch frühere ist die gebundene Gedächtniswirkung, die noch nicht zu einer selbständigen und freien Gedächtnisvorstellung führt. Es ist ein neuer Primärprozess nötig, innerhalb dessen Einflüsse des früheren mnemischen Reizes zur Aktualisierung gelangen.

\section{Das Vertrautheitserlebnis}

Wir haben schon früher die mnemische Wirkung von Wiederholungen besprochen und hierbei auch auf die Phänomene der Ge wöhnung hingedeutet. Diese sind jetzt in ihrer spezifisch psychischen Auswirkung zu erörtern.

Ein Eindruck, der der üblichen Welt eines Menschen nicht angehört, gleitet entweder völlig von ihm ab, oder befremdet ihn, oder ruft sein Staunen hervor. Wiederholt sich der Eindruck, so ändert sich das Bild. Was unbemerkt geblieben war, fängt an, bemerkt zu werden; was fremd oder verwunderlich erschien, wird allmählich vertra ut.

Das Vertrautwerden - als erste Stufe der Gewöhnung - ist an sich ein psychophysisch neutraler Vorgang, dessen äusserer Aspekt als „Vertrautheitshaltung” bezeichnet sei. Der Mensch (auch schon das Tier) be n i m $\mathrm{m} t$ sich anders zu vertrauten Gegenständen und in wiederholt dagewesenen Situationen als bei Reizen, die ihm erstmalig gegenübertreten. Beim kleinsten Kind und beim Tier ist es sogar noch durchaus fraglich, ob diesen Vertrautheitshaltungen irgend welche psychischen Begleiterlebnisse zur Seite stehen. 
In ihren entwickelteren Formen aber haben die Vertrautheitswirkungen einen offenbar psychischen Einschlag, der uns hier allein interessiert: das Vertrautheits-Erlebnis. Entweder ist es mit der Totalität der personalen Umwelt verknüpft: so tritt es auf als Geborgenheitsstimmung des kleinen Kindes gegenüber seiner engen Umgebung, als Heimatsgefühl des Erwachsenen, als Pietät gegen altgewohnten Hausrat, als Heilighaltung von Volkssitten und Kultgebräuchen. Oder es hebt einen einzelnen Gegenstand (Mensch oder Sache) aus der Gesamtheit der übrigen - gleichgültigen oder gar fremden - Gegenstände heraus: Anhänglichkeit des Kindes an seine alte Puppe; Wiedersehensfreude mit alten Freunden. Wesentlich für diese Wiederholungswirkung ist also die stark gefühlsmälsige Reaktion auf einen, jet $z \mathrm{t}$ in die Wahrnehmung tretenden Gegenstand, während die gesonderte Vorstellung der $\mathrm{fr} \ddot{\mathrm{u} h \mathrm{~h}} \mathrm{r}$ en Eindrücke, auf Grund deren uns der jetzige vertraut vorkommt, nicht notwendig dazugehört. Jeder hat es schon einmal erlebt, dass ihm ein begegnender Mensch „,bekannt vorkomme," ohne dass er imstande war, ihn zu identifizieren und sich der Gelegenheit des früheren Treffens zu entsinnen. Die gegenwärtige Wahrnehmung erscheint nur in eine andersartige Gefühlsatmosphäre getaucht, als wenn sie eine erstmalige wäre; mehr ist im Bewusstsein nicht vorhanden als dieses Vertrautheitserlebnis in Reinkultur.

Höffding hat als erster diesen Tatbestand psychologisch beschrieben; ein Sinneseindruck - so formuliert er es etwa - erhalte durch wiederholtes Dagewesensein eine neue Eigenschaft, die „B e k a n n th e i t s q u a lit ä $t$ ". Uns erscheint es angemessener, nicht sowohl die Beschaffenheit der Gegenstandswahrnehmung, als die veränderte Stellung des Subjekts gegenüber dem wiederholt Dagewesenen zu betonen, daher die, auf die Person bezogenen, Ausdrücke „Vertrautheitshaltung" und "Vertrautheitserlebnis".

Sehr deutlich ist beim Kleinkind die allmähliche Entwicklung dieser Erlebnisweise gegenüber Einzelgegenständen zu beobachten. Beim sogenannten ersten „Wiedererkennen” ist von einem "Erkennen” im eigentlichen Sinne noch keine Rede. Das halbjährige Kind, das beim Anblick der Mutter lächelt, während es bei anderen Gesichtern gleichgültig bleibt oder ,fremdelt" - hat nicht etwa die Erkenntnis: „das ist derselbe Mensch, den ich 
gestern und immer gesehen habe." Denn es weiss nichts von gestern und früher, da es ganz in der Gegenwart lebt; es ist auch noch absolut nicht zu einer Vergleichung zweier Eindrücke fähig. Vielmehr liegt lediglich jene oben beschriebene Vertrautheitshaltung und-Stimmung vor; erst späterer wächst daraus - in vielen Etappen - das Erinnerungsbild der Mutter.

Auf dem Gebiet des Wiedererkennens gibt es nun eine sehr merkwürdige Täuschung: das Vertrautheitserlebnis kann sich auch einstellen, ohne dass es sich um einen wiederkehrenden Eindruck handelt, also bei erstmaligen Begegnissen. Man findet in der Literatur für diese "B e k a n n t h e it st ä u s c h u n g" folgende Bezeichnungen: „fausse reconnaissance”, „Paramnesie”, „le phénomène du déjà vu."

Zunächst einige Aufzeichnungen, die mir von Studenten geliefert wurden.

$A$ ) „Seit etwa 6 Jahren habe ich bei mir häufig die eigentümliche Erscheinung des Vertrautseins bei objektiv Neuem beobachten können. Diese Erscheinung bezieht sich bei mir hauptsächlich auf Personen und gewisse Situationen, seltener auf landschaftliche Eindrücke. Begegne ich z.B. in einer fremden Stadt einer Person, überkommt mich plötzlich ein Angstgefühl, und mich bedrängt der Gedanke: den Menschen kennst du doch, o, wo ist mir der nur schon einmal begegnet. Dieses Gefühl dauert etwa $\frac{1}{2}$ bis höchstens 10 Minuten. Nach dieser Zeit beschäftigt mich das Erlebnis nicht mehr.

Die "fausse reconnaissance" ist bei mir nicht die Folge einer Erregung, ich bin meist in vollkommen ruhigem $Z$ ustande.

Zum ersten Mal konnte ich die Erscheinung im Alter von 16 Jahren beobachten. Ich war damals in Untersekunda, und $z$ war etwa erst 4 Wochen, in der Realschule einer kleinen Stadt. Ich sass in einer Schülerratssitzung auf der Platte der ersten Bank mit dem Rücken nach dem Katheder hin. Mir gegenüber sassen 3 Buben. Wir sprachen über das Programm unserer Einjährigenfeier. Ich erinnere mich noch sehr genau daran, dass ich, nachdem ich eine kurze Bemerkung gemacht hatte, plötzlich schwieg, schweigen musste, ängstlich wurde und der Gedanke mich quälte: das alles war schon einmal genau so, das habe ich alles schon einmal Wort für Wort gesagt.

(Objektiv nachweisbar: unmöglich.)

Diese erstmalige Erscheinung wirkte während der ganzen Besprechung auf mich (1 Stunde etwa). Ich wurde schweigsam und hatte ständig ein unsicheres Gefühl".

B) „....Als das Merkwürdigste dieses ebenso seltenen wie rätselhaften Phänomens erscheint mir sein gleichsam providentieller Charakter. Man hat nicht nur das Gefühl, schon einmal erlebt zu haben, 
was jetzt eben geschieht, sondern auch, was jetzt geschehen wir d. Man e $r$ w a $r$ e $t$ es geradezu und findet seine Erwartung unmittelbar darauf bestätigt. Das Erlebnis ist sehr kurz und gewöhnlich in dem Augenblick, wo man sich davon Rechenschaft gibt, schon zu Ende. Das Seelenleben befindet sich dabei in einem unreflektorischen, stimmungsmälsig träumerischen Zustand. Auch hat das Phänomen gewöhnlich nur ein enges Blickfeld, erfasst aber in diesem alle Einzelund Feinheiten. Es bezieht sich zumeist darauf, was jetzt eben in einer Gesellschaft gesprochen wird, wie sich die Anwesenden verhalten, oder was jemand vorträgt, was man gerade in einem Buche liest, oder auf irgendwelche ganz gleichgültigen Situationen auf der Strasse oder Ausschnitte einer Landschaft".

C) „Ich lese ein Buch, ein ganz neues, welches ich zuvor noch nicht in Händen gehabt habe. Da finde ich plötzlich eine Stelle, von der ich $z u$ wissen glaube, sie vor kurzem einmal gesehen oder gehört zu haben. Diese Stelle kann ein einzelnes Wort, ein sogenannter Ausdruck oder auch ein ganzer Satz sein. Aber zu dieser scheinbaren Wiedererkennung gesellt sich ein eigenartiges Gefühl. Während ich nämlich diese betreffende Stelle lese, fühle ich mich gewissermalsen erleichtert. Endlich habe ich nun die Stelle gefunden, die ich so lange gesucht habe Und von einem Fall her weiss ich noch, dass mir diese betreffende Wortkonstellation im Traum ein paar Tage vorher erschienen ist. Dies ist ein ganz vereinzelter Fall, der schon längere Zeit zurückliegt'”.

Eine befriedigende Erklärung dieser Erscheinungen ist bisher noch nicht möglich gewesen; aber soviel darf als sicher gelten - und lässt sich auch aus obigen Schilderungen erkennen dass die Grundlage in ei n e $\mathrm{V}$ eränderung der personalen Gefühlslage zu suchen ist. Es ist wohl nicht so, dass der o b je k t i ve n Reizsituation als solcher etwas anhaften müsste, was einem früheren Reiz ähnelt und nun fälschlich mit diesem identifiziert wird; vielmehr fühlt sich der Mensch in eine seelis che Situation versetzt, die das, was nun an Sinneswahrnehmungen auf ihn einströmt, mit dem Bekanntheitsgefühl durchtränkt. Nur so wird auch der „providentielle Charakter" verständlich, den unser Berichterstatter B der Erscheinung zuspricht: der Mensch, der dies paradoxe Vertrautheitsgefühl in sich aufsteigen fühlt, e r w a r t e t, dass, was im nächsten Augenblick auch kommen mag, ihm bekannt erscheinen wird.

Allerdings gelingt diese Gefühlsübertragung nicht immer glatt; das reine Vertrautheitserlebriis, das ja lustvoll ist, wird 
durchsetzt von dem Gegengefühl: dass mit dieser Vertrautheit etwas nicht in Ordnung sei; und so kommt es manchmal zu jenen „Unsicherheiten” und Angstgefühlen, von denen die Berichte sprechen.

Uber die besonderen Bedingungen konstitutioneller und dispositioneller Art, die das Auftreten des paradoxen Bekanntheitsgefühls herbeiführen, weiss man nichts Bestimmtes. Unberechtigt wäre es, in ihm etwas schlechthin Pathologisches zu sehen; denn solch gelegentliches Aufblitzen, wie es unsere Beispiele schildern, kommt bei durchaus normalen Individuen und in normalen Zuständen vor. Wenn sich freilich die Erscheinungen häufen, und wenn die Kritik gegenüber dem illusionären Charakter des Wiedererkennens versagt, so muss man wohl schon von einer pathologischen Desorientiertheit sprechen ${ }^{1}$ ).

Besonders starke Phänomene des paradoxen Bekanntheitsgefühls können sogar unter Umständen ins $\mathrm{W}$ el t a n s c h a u$1 \mathrm{i} \mathrm{ch} \mathrm{e} \mathrm{hinüberwirken.} \mathrm{Ist} \mathrm{der} \mathrm{Eindruck} \mathrm{des} \mathrm{"Schon-einmal-}$ Erlebthabens" unwiderstehlich trotz des Wissens, dass man es als dieses Individuum $\mathrm{X}$ nie erlebt haben $\mathrm{k}$ a $\mathrm{n} \mathrm{n}$ - dann bietet sich der Ausweg an: man müsse es eben in einem anderen Leben primär erfahren haben! Wir stehen hier an einer der psychologischen Quellen, aus denen die Lehren von der Präexistenz, der Seelenwanderung, der ewigen Wiederkehr ihre Kraft schöpfen ${ }^{2}$ ).

Platon fühlte sich im Reich der Ideen heimisch; da diese aber nicht aus den Erfahrungen seiner sinnlichen Existenz ableitbar waren, so schuf er den Mythos von der "Anamnesis": während einer vorgeburtlichen Existenz in der rein geistigen Welt habe die Seele die Ideen primär geschaut, sodass sie sich im irdischen Leben an sie „wiedererinnern" könne. - In Nietzsche's Lehre von der ewigen Wiederkehr, die er in der letzten Periode seines Schaffens verkündete, finden sich Ausdrücke, die wörtlich an Berichte über fausse reconnaissance anklingen.

1) Sie ist ein Gegenstück $z u$ jener anderen Desorientiertheit der „Entfremdung”, in welcher gewohnte Situationen und bekannte Menschen plötzlich fremdartig und unheimlich erscheinen. Auch dies paradoxe Unbekanntbeitsgetühl ist durchaus nicht immer pathologisch; es kann vielmehr, genau wie das paradoxe Bekanntheitsgefiihl, auch gesunde Menschen gelegentlich überfallen. Eine gem ein $\mathrm{s}$ a me Cuntersuchung dieser beiden Arten von Orientierungstäuschungen würde gewiss manche Dunkelheiten klären.

$\left.{ }^{2}\right)$ Interessante I'roben hierzu bringt Ottokar Fischer. 


\section{Verwertung s wirkungen}

Die unterirdische (gebundene) Nachwirkung von mnemischen Reizen äussert sich aber nicht nur bei Gelegenheit von Wiederholungen, sondern an Vorgängen und Inhalten gänzlich anderer Art ${ }^{1}$ ); es werden dann jene älteren Erlebnisse in neuen Primärprozessen ve rw e r t e t. Die mnemischen Reize tragen bei zur Bildung des Hintergrunds, auf dem das Neue aufgetragen ist; sie gehen ein in die Gesamtstruktur und Färbung des Neuen, sind vielleicht sogar entscheidend an seinem Aufbau beteiligt - ohne dass es hierbei zu einer Reproduktion des früheren Bewusstseinsinhalts kommen müsste.

Der mnemische Effekt besteht also nicht in der Erzeugung von Vorstellungen, sondern von $\mathrm{E}$ in s te $1 \mathrm{lu}$ u gen (Richtungsdispositionen).

a) Solche Verwertungswirkungen treten uns in drei Hauptformen entgegen.

Die G e fü h $1 \mathrm{~s}$-Betonung des Primärvorgangs wirkt in ihrer Färbung und Dynamik weiter. So kann eine einmal erlebte seeliche Gleichgewichtserschütterung (ein „Trauma”) eine lang dauernde Disposition zu schweren Verstimmungen nach sich ziehen; die inhaltliche Erinnerung an den Anlass ist dann zuweilen nur unter grösster Schwierigkeit oder auch garnicht zu wecken. (Sogenannte „Verdrängung”). Die mnemisch bedingte Gefühlseinstellung hat sich inzwischen ganz anderer Inhalte bemächtigt.

Der ge istige Gehalt des mnemischen Reizes bleibt wirksam, jedoch nicht als abgehobener Bewusstseinsbestandteil, sondern als B il d u n g s-Ferment. Denn „Bildung” ist ja nicht in erster Linie eine Summe isolierbarer Kenntnisse und Erinnerungen, vielmehr ein Inbegriff von dispositionellen geistigen Haltungen und Bereitschaften. Was der Mensch im Laufe seines Lebens erfährt und lernt, erzeugt die Disposition, neue Primärprozesse in einer ganz bestimmten Weise zu gestalten. Man „sieht" ein Gemälde mit „gebildeten” Augen; man beteiligt sich an der Unterhaltung, man versteht politische Ereignisse u.s.w. aus einem mnemischen Fundus heraus, der gerade darum solche starke Dy-

\footnotetext{
1) Es handelt sich also um ,heterogene" Gedächtniswirkungen in dem S. 256 er wähnten Sinne.
} 
namik hat, weil er ganz ein Stück der Person geworden ist oder, negativ ausgedrückt: weil er sich nicht ohne weiteres in mnemische Einzelelemente auflösen lässt.

Beispiel: Ein Mensch, der über mittelalterliche Geschichte vielleicht nur wenig aufweisbare „Kenntnisse” besitzt, kann doch von dem, was er über Mittelalter früher las, hörte und sah, psychisch stark bereichert und beeinflusst sein. Ihm wird der Anblick eines gotischen Domes oder die Lektüre eines alten Mystikers etwas ganz Anderes sagen und bedeuten - nicht nur als jenem, in dessen vergangenem Leben Eindrücke und Erfahrungen über ,Mittelalter" überhaupt nicht eingegangen waren - sondern auch Anderes als einem Dritten, der vielleicht sehr viel mehr abhebbares Wissen über das Mittelalter hat, es aber nie in die tieferen Schichten seines personalen Daseins einzubetten vermochte.

Endlich tragen solche Verwertungswirkungen bei zur Schaffung personaler Gesamthaltungen. Innere Tendenzen des Menschen bemächtigen sich eines gewissen Bereichs von Inhalten nnd verfestige $\mathbf{n}$ diese mnemisch zu Interessen, Gesinnungen, Grundsätzen und schliesslich Charakterzügen. Man hat zuweilen den Charakter als „Willensgedächtnis" bezeichnet; hieran ist richtig, dass primäre Willensakte zu mnemischen Reizen von dauernder Wirksamkeit werden müssen, damit Charakter entstehe. Unzweckmälsig aber ist der Ausdruck „Willensgedächtnis” deswegen, weil die Nachwirkung selbst nicht mehr jedesmal als abgehobene Willensentscheidung aufzutreten braucht, da ein neues Wählen und Uberlegen eben wegen der mnemischen Verfestigung unnötig ist.

Fassen wir zusammen: Di e personale $B$ ed e ut ung des gebundenen Gedächtnisses ist vor allem eine personal-his torische: jede seelische Gegenwart eines Individuums ist erfüllt von seiner ganzen seelischen Vergangenheit. Und zwar gehört zu dieser historischen Verankerung noch nicht das $W$ is se $n$ um diese Vergangenheit; bewusstseinsmäfsig kann der Mensch ganz dem gegenwärtigen Lebnis hingegeben sein, das aus den verschiedensten Schichten und Epochen seines früheren Lebens Kraft und Farbe zieht.

b) Wir müssen hier kurz auf psychologische Th e or i e en eingehen, welche das gebundene Gedächtnis ohne Zuhilfenahme personalistischer Begriffe vermittels der Spuren-Theorie zu erklären 
suchen. Während wir uns damit begnügen zu sagen, dass die mnemischen Reize eine dispositionelle Bereitschaft und Einstellung bestimmter Art schaffen, wird dort die Inhaltsbeharrung der mnemischen Reize in der Form von „Vorstellungen” angenommen; da aber diese Vorstellungen nicht als solche ins Bewusstsein kommen, werden sie als „unbewusst” bezeichnet. Vorstellungen, die aus irgend einem Anlass besonders eng miteinander verbunden sind, bilden einen „Vorstellungskomplex”; - jeder Mensch trägt viele solcher, aus seinen verschiedenen Lebensepochen und Lebensgebieten stammenden, Vorstellungskomplexe in sich, und diese sind es, die dann in späteren Zeitpunkten das seelische Geschehen beeinflussen.

Zweimal und in zwei sehr verschiedenen Formen hat die Lehre von den unbewussten „Vorstellungskomplex e n" grossen Einfluss auf die Psychologie ausgeübt, im Herbartianismus und in der Psychoanalyse.

$\mathrm{H}$ e r barts Absicht war es vor allem, den ge is tige n Gehalt der mnemischen Reize - also den Bildungsbestand durch seine Theorie verständlich zu machen. Jede Gruppe menschlicher Erfahrungen schlägt sich ii der Seele nieder als mehr oder minder umfangreicher, mehr oder minder festgeballter Komplex von Vorstellungen; dies gilt ebenso von ganz weiten Erfahrungsbereichen: Elternhaus, Beruf, Vaterland - wie von ganz engen: von dem jeweiligen Unterrichtsstoff in einem Schulfach, von den Erlebnissen einer Reise, von einer geschäftlichen, einer familiären Situation u.s.w. Diese Vorstellungskomplexe nun sind die eigentlichen Träger des geistigen Lebens; denn was auch neu dem Menschen begegnen mag, wird sein psychisches Eigentum nur dadurch, dass es irgend einem der schon vorhandenen Komplexe eingegliedert wird. Den Prozess der Eingliederung nennt die Herbartische Schule „Apperzeption”, den aufnehmenden Vorstellungskomplex die "Apperzeptionsmasse”, oder auch „das Apperzeptionsorgan" (in Analogie zu den körperlichen Greiforganen) ${ }^{1}$ ).

1) Der Ausdruck "Apperzeption" wird in der deutschen Psychologie und Philosophie leider in mehreren, völig verschiedenen Bedeutungen gebraucht. Lassen wir die älteren Begriffsbestimmungen von Leihniz unil Kant bei Seite, so sind aus dem 19. Jahrhundert noch die beiden Verwendungen des Ausdrucks bei Herbart und bei Wund zu beriicksichtigen. Der Herbart'sche wird oben erläutert, der Wundt'sche an einer späteren Stelle dieses Kapitels. - Wer sich heut des Ausdrucks „.Apperzeption” bedient, tut gut hinzuzufügen, in we s s e $n$ Sinn er gemeint ist. Bei der nun einmal 
Andere Ziele verfolgt die psychoanalytische Komplextheorie; sie will die mnemischen Nachwirkungen verständlich machen, die im Gemüts-, Trieb- und Willensleben gebunden sind. Die hier gemeinten Komplexe stammen gewöhnlich nicht aus beliebigen, häufig gemachten Erfahrungen, sondern aus ungewöhnlichen, aufwühlenden Erlebnissen oder Erlebnisfolgen (vgl. Punkt a unserer Aufzählung S. 282), die durch ihre D y$\mathrm{n}$ a $\mathrm{mik}$ nachwirken und Unheil anrichten. Ein solcher Komplex ist daher nicht - wie eine Herbart'sche Apperzeptionsmasse - die selbstverständliche Orientierungsstelle für Gegenwart und Zukunft, sondern ein in der Tiefe lauernder Feind des ungebrochenen Weiterlebens. Sind die in der Herbartischen „Apperzeptionsmasse" enthaltenen Vorstellungen zwar unbewusst, aber bei jedem Anlass bereit, bewusst zu werden, so sind die Inhalte eines psychoanalytischen Komplexes nicht nur unbewusst, sondern sie setzen sogar der Bewusstmachung die heftigsten Widerstände entgegen.

Trotz dieser Unterschiede haben aber doch die beiden Komplextheorieen sehr wesentliche Gemeinsamkeiten, und zwar wenn man nun ihre historische Bedeutung für die Psychologie einschätzt - sowohl im Positiven wie im Negativen.

Sie stellen - das ist ihr grosser positiver Wert - konsequente Versuche dar, die personal-historische Bedeutung des Mnemischen in Theorie zu fassen. Sie ergänzen sich dadurch, dass sowohl die personal-historische Bedeutung der Alltagserfahrung (Herbart), wie die der ungewöhnlichen Erlebnisse (Psychoanalyse), sowohl die Bedeutung der bewusstseinsnahen Nachwirkungen (Herbart), wie die der bewusstseinsfeindlichen mnemischen Kräfte (Freud) nachgewiesen wird.

Abzulehnen ist dagegen der mechan is t ische Zug, welcher beiden Theorien - freilich der Herbart'schen noch prinzipieller als der Freud'schen ${ }^{1}$ ) - anhaftet. Die Vorstellungskomplexe wer-

eingetretenen Verwirrung wäre es vielleicht am empfehlenswertesten, wenn ihn die wissenschaftiche Fachsprache ganz vermiede. Er ist in der Tat entbehrlich.

1) Die Psychoanalyse hat allerdings - durch die starke Betonung des dynamischen Moments, durch die Lehre von der C bertragung, durch die Behauptung vonSpannungszuständen zwischen bewussten und unbewussten Schichten-virl eher als der Herbartianismus die Mijglichkeit, eine fruchthare Beziehung zu personalistischen Gesichtspunkten herzustellen. Es ist in ihr auch -- wenn man die Entwicklung über ein Menschenalter hin verfolgt - langsam aber deutlich eine $A b$ wendung von der Mechanistik der ersten Freud'schen Thesen und eine Annäherung an personalistische Auffassungen erkennbar. 
den ja hier aufgefasst als kleine mechanische Wirksysteme im Menschen, die von sich a u die weiteren seelischen Prozesse bestimmen - sodass der Mensch selber, in dem sie vorhanden sind, als personal tätige Ganzheit ausgeschaltet ist.

Abzulehnen ist auch die Lehre von den ,unbewussten Vorstellungen". Es ist ja unzweifelhaft, dass die gebundenen mnemischen Nachwirkungen „unbewusst” sind insofern, als während der Latenzzeit kein Bewusstsein von ihnen besteht und sie sogar bei ihrer Aktualisierung nicht zu selbstständigen gedächtnismärsigen Bewusstseinsinhalten zu führen brauchen. Aber eben w e i 1 die Nachwirkungen ,unbewusst" sind, sind sie auch nicht als „Vorstellungen” da. Hier hat das Dogma mitgespielt (s.S. 259), dass mnemische Wirkungen nur in der Form der Inhaltsbeharrung möglich seien. Dann freilich musste auch während der Latenz der früher aufgenommene Inhalt dauernd - als „Vorstellung", aber doch nicht als bewusste Vorstellung - vorhanden sein, eine Behauptung, die nicht nur durch keine Erfahrung je bestätigt werden kann, sondern die auch gedanklich nicht vollziehbar ist. Unbewusstes gibt es in der Person immer nur in dispositioneller Form, als Bereitschaft und Einstellung, nicht aber in substanzieller Form, als psychischen Inhalt ${ }^{1}$ ). Denkt man personalistisch, dann $\mathrm{g}$ e $\mathrm{n} \ddot{\mathrm{u}} \mathrm{gt}$ aber auch die Annahme einer mnemischen Bereitschaft als ursächlichen Faktors für die gebundene Nachwirkung, und der abenteuerliche Begriff unbewusster Vorstellungskomplexe wird überflüssig.

Erst nachdem wir den Begriff der „Vorstellung” aus der gebundenen Gedächtniswirkung ausgeschaltet haben, können wir seine wahre Bedeutung als das Bewusstseinserzeugnis der f r e i e n Gedächtniswirkung verständlich machen.

1) Vgl. S. 110. 


\title{
ZWOLFTES KAPITEL
}

\author{
DAS FREIE GEDACH T IS
}

\section{DIE GEDÄCHTNISVORSTELLUNG}

1. Vorstellung und Wahrnehmung

Die Nachwirkung eines mnemischen Reizes wird „frei”, wenn sie sich von der Gebundenheit an einen gegenwärtigen Primärprozess emanzipiert und sich als Sekundärprozess verselbständigt.

Während ich hier am Schreibtisch sitze und als ge ge nw ä r t i g Schreibpapier, Federhalter und Schriftzüge, Geräusch der Strasse, Aussicht aus dem Fenster u.s.w. wahrnehme, kann ich $\mathrm{z} \mathrm{u} \mathrm{g} \mathrm{l} \mathrm{e} \mathrm{i} \mathrm{c} \mathrm{h} \mathrm{—} \mathrm{und} \mathrm{doch} \mathrm{einer} \mathrm{anderen} \mathrm{Sphäre} \mathrm{angehörig} \mathrm{-}$ ein Bild der Einfahrt in den New Yorker Hafen, den ich vor Jahren sah, im Bewusstsein haben, oder mir die Melodie eines Liedes oder das Gesicht eines Bekannten vergegenwärtigen.

Damit wird das B e w us st se in aus seiner dimensionalen Enge blosser Gegenwärtigkeit befreit; es wird mehrschichtig. „Hier und jetzt erlebe ich das $\mathrm{Nicht-Hier}$ und $\mathrm{N}$ i ch t-J e t $\mathrm{z}$ t": dies Grundfaktum eröffnet dem Menschen seelisch die Ferne nach a 11 e n Richtungen, ins Räumliche und Zeitliche, ins Raumlose und Zeitlose, nach vorwärts und nach rückwärts. Sofern das „Nicht-Hier” und „Nicht-Jetzt” in konkreter Form erlebt wird, nennen wir den seelischen Inhalt "Vorstellu ng".

Uns geht augenblicklich nur die Richtung zum zeitlichen $\mathrm{R} \ddot{\mathrm{u}} \mathrm{ckwärts}$, und damit die Gedächtnisvorstell ung an ${ }^{1}$ ). In dieser wird ein Gegenstand erlebt, der früher

1) Andere dimensionale Gerichtetheiten, und damit auch andere Arten der Vorstellung: Phantasievorstellung, Erwartungsvorstellung, Zielvorstellung - werden uns erst später beschäftigen. 
durch eine Wahrnehmung erlebt worden war; es ist derselbe Hafen von New York, den ich damals sah und heut erinnere.

Diese Identität des $\mathrm{Geg}$ e $\mathrm{nstandes}$ ist nun von vielen psychologischen Theorieen naiver Weise als Gleichheit des phänomenalen Bewusstseinsinhaltes ausgelegt worden: die Vorstellung soll in ihrem Erlebnischarakter mit der ursprünglichen Wahrnehmung übereinstimmen. Eine solche Auffassung wurde bestärkt durch die mechanistische Spurentheorie, nach welcher die Gedächtnisvorstellung nichts anderes als die, inzwischen deponiert gewesene und nun wieder hervorgeholte, Wahrnehmung sein sollte. Der Satz Hume's „Die Vorstellungen sind Kopieen von Impressionen" ist seitdem in mannigfachen Varianten wiederholt worden. In Deutschland war vor 100 Jahren Herbart, in neuerer Zeit Ziehen Hauptvertreter dieser Anschauung.

Prüfen wir diesen Satz durch eine Vergle ichung de s phänomenalen Gehalts von Wahrnehmung und Vorstellung. Dass sie sich nicht absolut gleichen können, muss auch der Mechanist zugeben; denn sonst müssten wir sie ja verwechseln und in jeder Vorstellung etwas Gegenwärtiges wahrzunehmen meinen. Der - also nicht zu bestreitende - Unterschied wird von jener Lehre zu einem blossen Gradunterschied gemacht; die Vorstellungen seien a b g e b l a s s t e Impressionen.

Nun gibt es aber Gradunterschiede auch schon innerhalb der Wahrnehmung selbst, z.B. zwischen mehr oder weniger Hell, zwischen Laut und Leise u.s.w. Ist der Unterschied von Wahrnehmung und Vorstellung gleicher Art? Ist z.B. ein vorges t e 11 t e s Fortissimo so leise wie ein g e hör t e s Pianissimo? oder lauter? oder leiser ? Die Frage ist absurd; man bemerkt sofort, dass der besondere Charakter der Vorstellung mit jenen Gradunterschieden der Wahrnehmung nichts zu tun hat. Auch das hauchzarteste Pianissimo, wenn es eben g e hört wird, ist auf Grund seines sinnlichen Charakters des "Gehörtwerdens” durch eine weite Kluft von dem noch so intensiv vorgestellten Fortissimo getrennt.

Was der Vorstellung im Vergleich mit der Wahrnehmung $\mathrm{f} \mathrm{e} \mathrm{h} 1 \mathrm{t}$, ist also nicht ein bestimmter Stärkegrad, sondern jenes besondere Merkmal, das wir bei der Wahrnehmung als "Anschaulichkeit” oder "Evidenz” beschrieben haben (s.S. 145/6), das 
eindeutige Ausgeliefertsein an die unentrinnbare Gegenwärtigkeit des Objekts. Selbst die lebhaftesten Vorstellungen sind solcher Sinnfälligkeit gegenüber un-sinnlich, verwaschen und vieldeutig.

Man versuche, sich ,rote Erdbeeren zwischen grünen Blättern” vorzustellen. Wenn man diese Wörter hört oder liest, weiss man, was gemeint ist. Man hat auch innerlich irgendwie ein Bild. Aber: Wie gross sind die Erdbeeren? Wie sind die Blätter geformt? Von welchem Hintergrund heben sie sich ab? An welcher Stelle des Raumes sind sie? In welchen Nüancen ist das Rot oder Grün im Erlebnis da? - Eine andere Probe: man stelle sich einen nahen Angehörigen, mit dem man täglich zusammen ist, vor. Man wird auch hier diese Undeutlichkeit bemerken, zugleich ein Schwanken zwischen verschiedenen Möglichkeiten der Stellung, der Kleidung, der Sehrichtung, aus der man ihn vorstellt u.s.w. - Ich kann, innerlich mit der Lösung einer geometrischen Aufgabe beschäftigt, die Vorstellung eines rechtwinkligen Dreiecks haben, in ihm vorstellungsmälsig Hilfslinien ziehen u.s.w., ohne dass Grösse, spezielle Form, Farbe der Striche und der Fläche irgendwie fixiert wären. - Selbstverständlich gilt Entsprechendes auch für Vorstellungen, die ganz oder teilweise aus anderen Sinnessphären als der optischen stammen.

Diese mangelnde Eindeutigkeit der Vorstellungen ist von ganz anderer Art als die Undeutlichkeit, die der wirklichen Sinneswahrnehmung eines sehr fernen oder durch Nebel oder Halbdunkel verhüllten Gegenstandes zukommt. Bei der Sinneswahrnehmung liegt ein Mangel vor, der durch Änderung der Wahrnehmungsbedingungen beseitigt werden kann; bei der Vorstellung handelt es sich dagegen um eine wesentliche Eigenschaft. Denn jene Unbestimmtheit ist das Korrelat eines weiteren, sehr positiven Merkmals der Vorstellung: ihrer I $n$ n e $r$ li c h$\mathrm{k}$ e i t. Die Vorstellung ist in anderem Sinne als die streng situationsgebundene Wahrnehmung $\mathrm{m}$ i $\mathrm{r}$ zugehörig; sie hebt sich nicht so schroff $a b$ von den anderen personalen Inhalten und Vorgängen, sondern ist in diese mehr oder weniger stark eingebettet und kann eben durch ihre Vieldeutigkeit ganz anders an dem vielgestaltigen und ständig wechselnden Leben der Person beteiligt werden.

Hier muss ein früher gegebenes $\mathrm{R}$ e i h e $\mathrm{n} \mathrm{s} \mathrm{ch}$ e m a noch einmal aufgenommen und erweitert werden. Wir hatten (s.S. 271) eine Reihe abnehmender Sinnfälligkeit aufgestellt, welche lautete: Wahrnehmung, Nachbild, Anschauungsbild, Vorstellung. In Wirklichkeit geht aber die Reihe noch weiter; denn die Vor- 
stellung ist selber ein ausgesprochen Mittleres zwischen den sinnfälligeren Stufen der Gegenstandserfassung (Wahrnehmung, Nachbild, Anschauungsbild) einerseits, der noch blasseren Stufe des $\mathrm{G}$ e d a n k e n s andererseits. Als dieses Mittlere ist sie zugleich ein vermittelndes Glied $z$ wischen An$\mathrm{sch}$ a u en und Denken, zwischen Konkretion und Abstraktion. Ihr haftet von beidem etwas an; sie ist noch nicht ganz abstrakt, wie der Gedanke, aber auch nicht mehr ganz konkret, wie die Sinnesanschauung; sie ermöglicht, dass das Wahrnehmen sich vergeistigen und das Denken sich der Wirklichkeit nähern kann ${ }^{1}$ ).

Natürlich besitzt dieses Mittelgebiet, in dem die Vorstellung lebt, selbst noch eine grosse Breite; es gibt Vorstellungen, die mehr anschauungsnah, und damit farbiger, satter, aber auch starrer sind - und solche, die mehr gedankennah, und damit beweglicher, vieldeutiger, aber auch unanschaulicher sind. - Entsprechend gibt es Personen, deren Vorstellungsleben im ganzen mehr den Charakter der Anschauungsnähe bezw. der Gedankennähe hat. Das führt zu einer t y p ologi s chen Scheidung. Künstler bezw. Gelehrte sind oft ausgeprägte Vertreter des konkreten bezw. abstrakten Vorstellungstypus.

\section{Vorstellungsty pen}

Noch eine speziellere Typenbildung ist aufgestellt worden, je nach der Vorherrschaft besonders anschauungsnaher Vorstellungen in einzelnen Sinnesgebieten. Danach wird ein visueller, ein auditiver und ein motorischer Typus unterschieden.

Der stark Vis u elle ist ein „Augenmensch", nicht nur in dem Sinn, dass er das Bedürfnis nach reichen und mannigfachen Eindrücken des Auges hat; auch seine Vorstellungen stammen vorzugsweise aus der optischen Sphäre und haben eine sinnfälligere Färbung und Formung als die der nicht-visuellen Menschen. Bei besonders starker Ausprägung gleitet der visuelle Typ in den des Eidetikers über, der, wie wir sahen, über die noch wahrnehmungsnäheren „Anschauungsbilder" verfügt ${ }^{2}$ ).

Für den ausgesprochen a u d it iv e n Menschen ist die Welt vornehmlich zentriert um Klang und Schall. Geräusche, der aku-

1) Näheres hierüber in XV. Kap. Teil II, wo auch das Reihenschema ausgeführt wird.

2) Vgl. S. 271. 
tische Gehalt der Sprache, vor allem Musik bilden das bevorzugte und reich differenzierte Material seines Vorstellungslebens.

Zum m o t or is c h e n (oder kinästhetischen) Typus rechnet man solche Menschen, deren Vorstellungen sich stark auf die Erlebnisse eigener Körperbewegungen gründen.

Diese Einteilung ist übersichtlich und einfach - aber wohl zu einfach, um der Wirklichkeit auch nur annähernd gerecht zu werden. Klare Vertreter der drei Typen findet man nur selten, und zwar dann ganz vorwiegend bei schaffenden Künstlern.

Es gab und gibt visuelle Maler, deren personale Welt sich ganz in Farbigkeit und Licht aufzulösen scheint, und die in sich optische Vorstellungsbilder von solcher Stärke und Anschaulichkeit tragen, dass sie nach diesen malen können, ohne der Gegenwart des Modells oder des Naturausschnittes zu bedürfen. - So mancher grosse Musiker verschloss sich gegen alles, was nicht Melodie und Harmonie war, lebte nur in Tönen, die er nicht mehr leiblich zu hören brauchte, weil er sie vorstellungsmälsig in sich trug. Hat doch der ertaubte Beethoven aus seiner auditiven Vorstellungsfähigkeit heraus die neunte Symphonie komponieren können. - Bei Angehörigen der gymnastischen, tänzerischen und sportlichen Künste ist nicht nur das jeweils gegenwärtige Erleben des eigenen Körpers intensiv ausgeprägt, sondern auch das Vorstellungsleben stark mit Nacherlebnissen motorischer Art durchsetzt.

Aber für die ganz grosse Masse der Menschen trifft eine solche Konzentration auf e i n Sinnesgebiet und die dazu gehörigen Vorstellungen absolut nicht zu; sie gehören dem ,type mixte” an.

Soll also jene Typenscheidung ihre psychologische Bedeutung nicht verlieren, so muss man sie in gemälsigterem Sinne verstehen. Deshalb nennt man denn auch einen Menschen schon visuell, wenn seine Gesichtsvorstellungen lebhafter und farbiger sind als die der Durchschnittsmenschen, ohne dass aber die optische Sphäre in seinem Seelenleben jene oben beschriebene Vorherrschaft ausüben müsste.

Endlich hat die Vorstellungstypik eine noch engere, nämlich g e dächtn is te chn is che Bedeutung gewonnen. Es gibt gewisse Gedächtnisinhalte, die durch mehrere Sinnessphären in die menschliche Psyche eingehen können. Hierzu gehören vor allem sprachliche Stoffe. Denn Sprache kann akustisch durch Hören der von anderen gesprochenen Worte, optisch durch Lesen, kinästhetisch durch die Bewegung der eigenen Sprech- 
und Schreiborgane angeeignet werden. Die Sprachvorstellungen des Menschen enthalten daher Komponenten aller drei Sinnesgebiete; aber die Gewichtsverteilung dieser Bestandteile kann eine verschiedene sein. Die meisten Menschen sind im Sprachlichen vorwiegend auditiv-motorisch eingestellt, bedienen sich zur Hilfe des Lernens und Reproduzierens von Sprachstoffen der Klangvorstellungen und der Vorstellungen der eigenen Sprechbewegung. Es gibt aber auch sprachlich Visuelle, die die sprachlichen Gebilde geschrieben und gedruckt vor ihrem inneren Auge sehen und dadurch Erleichterungen des Gedächtnisses haben.

Die verschiedenen - heut grösstenteils als überholt anzusehenden experimentellen Prüfmethoden zur Festellung des Vorstellungstypus, sowie die, früher sehr überschätzten, pädagogischen Folgerungen, die man aus dieser Typenscheidung glaubte ziehen zu dürfen, können im Rahmen einer allgemeinen Psychologie nicht näher besprochen werden.

3. Kenntnisseund Erinnerungen

Zwei Hauptaufgaben haben die Gedächtnisvorstellungen im Leben der Person zu übernehmen. Als „Kenntnisse” sind sie die bewusstwerdenden Teil-Inhalte des erworbenen Bildungsbestandes, als „Erinnerungen” sind sie die Bewusstseinsspiegelungen der personalen Lebensgeschichte.

Beide Arten von Vorstellungen stammen aus der Vergangenheit der Person; aber diese mnemische $\mathrm{Herkunft}$ ist für die Kenntnisse gleichgültig, für die Erinnerungen entscheidend. Der personale Sinn sprachlicher, erdkundlicher, literarischer, technischer oder andrer Kenntnisse ist nicht abhängig davon, wann und wie sie erworben sind; wichtig ist nur der Effekt jenes Erwerbs: dass sie jetzt nach Bedarf zur Verfügung stehen, und dass man auch für künftige personale Aufgaben ihre Verfügbarkeit erwarten kann. Der personale Sinn der Erinnerung aber liegt gerade darin, dass das Bewusstsein des Menschen auf jenen primären Prozess des ursprünglichen Erlebnisses zurückgreifen und damit in der Gegenwart die eigene Vergangenheit wieder lebendig machen kann.

Selbstverständlich sind die beiden Funktionen der Gedächtnisvorstellung nicht streng geschieden. Wenn ich die $\mathrm{K} \mathrm{e} \mathrm{n} \mathrm{n} \mathrm{t-}$ $n$ i s einer früher erlernten Fremdsprache verwerte, kann auch die 
eigentümliche Situation, in der ich sie damals - etwa als Kind, oder als einsamer Mensch in fremdem Lande - erlernt habe, erinnerungsmälsig mitschwingen. - Umgekehrt mögen E ri n n e r u n ge $n$ an Reisen, die ich gemacht, an welthistorische Ereignisse, die ich miterlebt habe, zugleich Dauerbereicherungen meines Kenntnisschatzes bedeuten.

Auf der anderen Seite gibt es auch schroffe Gegensätzlichkeiten zwischen beiden. Der Mensch hat zahlreiche Kenn t$n$ is se, die völlig erinnerungsfrei sind. Dies gilt z.B. für den weitaus grössten Teil des muttersprachlichen Wortschatzes. Nur ganz wenige Ausdrücke und Wendungen sind für unser Bewusstsein irgendwie personal-historisch verankert; die frühesten Sprachkenntnisse stammen sogar aus einer Zeit, an die es Erinnerung uberhaupt nicht gibt. - Und ebenso hat jeder Mensch E r i n$\mathrm{n}$ e $\mathrm{r}$ u n g e n, die so individuell gefärbt und so ganz und gar an die unwiederholbare Situation des Damals geknüpft sind, dass sie als Hilfsmittel für andersartige personale Aufgaben der Gegenwart oder Zukunft, also als Kenntnisse, nicht in Betracht kommen.

Der Erwerb von Kenntnissen wird im XIII. Kapitel, die Psychologie der Erinnerungen im XIV. Kapitel ausführlich behandelt.

\section{ASSOZIATION UND EINSTELLUNG}

Eine „einzelne”, isolierte Vorstellung gibt es nicht. Jeder Inhalt des Vorstellens ist nur als Glied engerer und weiterer $\mathrm{Zu}$ sammenhänge da, wächst aus diesen heraus und sinkt wieder in sie zurück, geht in andere Inhalte über; eine Vielheit von Vorstellungen führt zu Verknüpfungen und Verschmelzungen, zu kettenartigen Abläufen, zu Scheidungen und Verdrängungen u.s.w.

Dieses unablässige Geschehen, das sogen. „Vorstellungsleben”, ist dem Psychologen schon früh zum Problem geworden und hat zu jahrhundertelangen, auch heut noch nicht abgeschlossenen Auseinandersetzungen geführt, die in dem Streitbegriff „A s s oz i a t i o n" ihren Brennpunkt fanden. Auch die heutige Psychologie muss - so weit ihre Wege von der alten Assoziationspsychologie fortgeführt haben mögen - mit diesem Begriff ver- 
traut sein und sich darüber Rechenschaft geben, wie sich die in ihm ausgedrückten Tatbestände und Hypothesen ihrer veränderten Grundauffassung einfügen.

\section{Der empirische Begriff der Assoziation}

Zunächst ist festzustellen, dass für zahlreiche e m p i r i s c h e Tatbestände der Ausdruck „Assoziation” durchaus brauchbar erscheint. Es g i b t Vorstellungsinhalte, die besonders eng miteinander zusammenhängen, derart, dass das Vorhandensein des einen im Bewusstsein eine Wahrscheinlichkeit für das Bewusstwerden des anderen bedeutet. Lese ich "pain", so kann die Wortvorstellung „Brot" sofort in mir auftauchen, vielleicht auch die Gegenstandsvorstellung eines Brotes. Sehe ich einen sehr giftgrünen Apfel, so entsteht in mir fast zwangsläufig die Geschmacksvorstellung der Säure, die Tastvorstellung der Härte, vielleicht auch die Vorstellungen von Eigenbewegungen des Würgens, des Spuckens u.s.w. Geht mir die Melodie „Freude, schöner Götterfunken” durch den Kopf, so ist es sehr wahrscheinlich, dass auch Vorstellungen eintreten, die es mit „9. Symphonie”, Beethoven” "Schiller" zu tun haben ${ }^{1}$ ).

Solche Zusammenhänge von Vorstellungen sind auch ex perime n tell nachweisbar: man ruft durch Nennung eines Wortes, durch Zeigen eines Bildes u.s.w. eine bestimmte Vorstellung hervor und lässt diejenige weitere Vorstellung bezeichnen, die sich im Anschluss an den Reiz eingestellt hat (sogen. „Assoziationsexperiment). Auch die zwischen Darbietung und Antwort verlaufende Zeit (,Assoziationszeit”) ist durch Stoppuhr oder Chronoskop messbar.

Empirisch nachweisbar ist ferner für viele solche Vorstellungsassoziationen ihre gemeinsame mnemische $\mathrm{Her}$ $\mathrm{k} \mathrm{u} \mathrm{f} \mathrm{t}$. Sind in e i n e m Primärprozess mehrere Eindrücke in zeitlicher Verbindung dagewesen, so ist hierdurch eine Anwartschaft für ihr gemeinsames Wiederauftreten bezw. für gegenseitiges Sichherbeiziehen gegeben. Man spricht dann von Assoziation durch „K o n tiguit ä t" (Berührung).

1) Für mich persönlich ist mit obigem Beispiel eine sehr konkrete Assoziation unauflöslich verbunden: vor meinem innern Auge taucht $\mathrm{Hans}$ von Bülow als Dirigent der neunten Symphonie mit seinen charakteristischen Bewegungen auf, wie ich ihn als mitsingender Chorist vor mehr als 40 Jahren gesehen habe. 
Je häufiger die zeitliche Verbindung realisiert war, um so stärker ist die Bereitschaft zu ihrer assoziativen Erneuerung. Diese "Assoziationsfestigkeit" ist also wiederum eine mnemische Wiederholungswirkung, ähnlich jener, die wir bei der experimentellen Dressur von Tieren feststellten. Nur dass dort der mnemische Reiz durch Wiederholung mit einer Bewegung assoziiert wurde, während hier eine Verknüpfung zwischen Vorstellungen entsteht. Auch diese ist eingehend experimentell studiert worden in den, seit Ebbinghaus (1885) allerorten angestellten, psychologischen Lern experimente $n$ an Menschen, über welche später zu berichten sein wird.

An den, auf gemeinsamem mnemischen Reiz beruhenden, Assoziationen muss man nun noch $U$ n terscheid ungen vornehmen.

Zeitliche Gemeinsamkeit des Reizes kann Gleichzeitigkeit oder unmittelbare Folge bedeuten; so entstehen zwei Formen:

Simultane Assoziationen: Bei dem giftgrünen Apfel ist die Vorstellung ,sauer" und "hart" zugleich mit dem Anblick der Farbe da. - Stelle ich mir ein geläufiges Wort der Muttersprache (z.B. „Tisch") vor, so ist im selben Noment auch die Bedeutung, vielleicht auch eine Gesichtsvorstellung des Gegenstandes gegeben.

$\mathrm{Sukzessive} \mathrm{Assoziationen:} \mathrm{Wer} \mathrm{eine} \mathrm{Fremdsprache} \mathrm{zu}$ erlernen a $\mathrm{n} f$ ä $\mathrm{ng} t$, hat die Wortvorstellung der fremden Vokabel und die muttersprachliche Ubersetzung zunächst in deutlichem Nacheinander. Mit steigender UUbung rücken sie immer näher zusammen, bis schliesslich bei grosser Sprachfertigkeit Simultaneität eingetreten ist. - Es gibt andere Sukzessivassoziationen, in deren Wesen es liegt, dass ihre Glieder nie simultan werden: die Worte eines gelernten Gedichtes; die Töne einer Melodie.

Psychologisch wichtiger, aber bisher weniger beachtet, ist die Scheidung von Intra- und Inter-Assoziationen.

Intra-Assoziation ist die Gliedbeziehung in ner$\mathrm{h}$ a $1 \mathrm{~b}$ einer ursprünglichen Erlebnis-Ganzheit. Ist der mnemische Reiz eine psychische Gestalt, die eine Vielheit von Momenten in sich schliesst, so braucht die Verbindung dieser Momente nicht erst gestiftet zu werden; sie ist ursprünglich da und kann 
sich später im Sinn assoziativer Wirkung bekunden. Ich habe z.B. eine einfache Melodie stets nur in ihrem Gesamtablauf gehört und als diese einheitliche musikalische Form mir eingeprägt. Werden jetzt die ersten 2 oder 3 Töne angegeben, dann laufen die weiteren in meiner Vorstellung von selbst ab. Man sieht, dass es sich bei der Intra-Assoziation im wesentlichen um das gleiche Prinzip handelt, das wir früher (S. 151) als das der Vollständigkeit der Gestalt besprachen, nur dass wir es jetzt von u $\mathrm{n}$ t e $\mathbf{n}$ (d.h. von den in der Gestalt enthaltenen Momenten und deren gegenseitigen Beziehungen) her betrachten.

Bei den „I n t e r-A s s o z i a t i n e n" oder „Koppelungen" handelt es sich um ursprünglich geschiedene, selbständige Inhalte, die erst durch ihr zeitliches Zusammentreffen zu einer nicht in ihnen selbst liegenden Verknüpfung kommen, und nun diese Verknüpfung aufrecht erhalten. - Für den eine Fremdsprache erlernenden Schüler sind das deutsche und das französische Wort für denselben Gegenstand zunächst zwei gegeneinander fremde Vorstellungen, die erst zusammengekoppelt werden müssen. - Habe ich auf einer Reise die Bekanntschaft eines Herrn X gemacht, so mag der ganze Eindruckskomplex, der mit diesem Herrn zusammenhängt, die mit ihm geführte Unterhaltung u.s.w. an sich nichts mit der Reise zu tun zu haben, - aber der Umstand, dass Reiseeindrücke und Bekanntschaft zeitlich simultan waren, bewirkt doch später, dass, wenn ich $\mathrm{X}$ vorstelle, auch Vorstellungen jener Reise auftauchen - und umgekehrt.

Aus den bisherigen Feststellungen lässt sich die folgende empirische Begriffsbestimmung ableiten: Assoziation ist eine Verbundenheit von psychischen Inhalten, die sich darin kund gibt, dass das Auftreten des einen Inhalts eine hohe Bereitschaft zum Auftreten des andern mit sich bringt. In diesem Sinn ist der Assoziationsbegriff in der modernen Psychologie nicht nur berechtigt, sondern geradezu unentbehrlich; und es besteht kein Grund, ihn - wie es manche heutige Forscher wollen - ganz aus der Fachsprache zu entfernen. 
2. Mechanistische Assoziationstheorieen

Zum eigentlichen Streitobjekt wird der Assoziationsbegriff erst dort, wo sich die theoretische $\mathrm{H}$ y pothese $\mathrm{n}$ bildung seiner bemächtigt. Die mechanistische Auffassung des Seelischen erhebt nämlich gerade diesen Begriff zum alleingültigen Erklärungsprinzip für das gesamte psychische Leben. Die Assoziation soll hier etwa die gleiche Rolle spielen, wie die Gravitation in der physischen Welt: als di e Gesetzmässigkeit, welche die Beziehung zwischen den seelischen Elementen erschöpfend regelt. Nit diesem Begriff der Assoziation ist für die heutige Psychologie freilich ein Paktieren nicht denkbar. Er beruht auf zwei Voraussetzungen, die unhaltbar sind.

Erste Voraussetzung: Das assoziative Geschehen ist nach die-

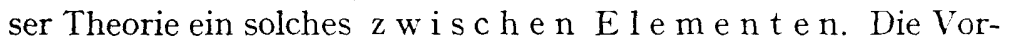
stellungen als die seelischen Atome werden durch eine Kohaesion an einander geknüpft, die durch ihr zeitliches Zusammen entsteht. Das Naturgesetz dieser Kohaesion allein bestimmt, welche Vorstellungen kommen oder gehen, wie sie sich zusammenfinden oder trennen, nach Reihen oder Komplexen ordnen.

Bei den assoziativen Verknüpfungen wäre also nach dieser Theorie irgend ein beherrschendes personales Ganzheitsprinzip und irgend eine sinnhafte Zielstrebigkeit des Geschehens ausgeschlossen. Das widerspricht absolut der Überzeugung, dass die Vorstellungen nicht selbständige „Elemente”, sondern Zustände der erlebenden Person sind, und dass auch ihre Verknüpfungen in die Sinn-Ganzheit der Person eingeordnet und von dieser kausal abhängig sein müssen.

Zweite Voraussetzung: das seelische Leben soll e r s c hö pf e n d durch das Assoziationsprinzip erklärbar sein. Es wird also auch die Möglichkeit bestritten, dass es neben assoziativen Verknüpfungen solche anderer Art geben könnte. Hieraus wird die Forderung abgeleitet, dass auch diejenigen seelischen Vorgänge, die zunächst andersartigen Prinzipien zu unterstehen $\mathrm{s} c \mathrm{~h}$ e i$\mathrm{n}$ e n, insbesondere die des Gefühls-, Denk- und Willenslebens, letzthin als nur assoziative Phänomene aufgewiesen werden müssen.

An dieser Stelle hat die a u $\mathrm{f}$ b a e n d e Kritik einzusetzen, 
welche uns innerhalb der psychologischen Theorie die angemessene Stellung des Assoziationsbegriffs zu finden ermöglicht.

Betrachtet man diejenigen Vorstellungsabläufe näher, die von der mechanistischen Assoziationspsychologie in erster Reihe als Anschauungsbeispiele für ihre Lehre herangezogen werden, so findet man, dass sie fast alle eine negative Gemeinsamkeit haben: es sind Abläufe, die $\mathrm{n}$ i c ht durch eine ak u t e Zielsetzung der Person, also nicht durch eine Denkaufgabe, ein Schaffensziel, eine Handlungsabsicht -- gelenkt werden. Solche typischen Assoziationsabläufe sind: Träume (und zwar ebenso Schlaf- wie Wach-Träume), ideenflüchtige Phantasieen und Fabulationen; dann wieder stereotyp abrollende Vorstellungsketten (etwa eines mechanisch gelernten Textes); ferner Einfälle, die sich ungewollt aufdrängen; endlich in $\mathrm{n}$ e $\mathrm{h} \mathrm{h} \mathrm{l} \mathrm{b} \mathrm{zielgerich-}$ teter Handlungen gewisse, nicht zum Ziel passende, Abwegigkeiten, Seitensprünge, Entgleisungen, Fehlhandlungen.

Diese Feststellung ist wichtig, weil sie uns noch einmal ins Empirische zurückführt: es gibt $z$ ahllose Fälle, in denen Vorstellungsreihen ohne Beteiligung einer eigens auf sie gerichteten personale $\mathrm{n} \mathrm{T} \mathrm{a} \mathrm{t} \mathrm{a} \mathrm{bla} \mathrm{u} \mathrm{f} \mathrm{e} \mathrm{n.} \mathrm{Ja,} \mathrm{wir} \mathrm{können} \mathrm{sogar} \mathrm{noch} \mathrm{weiter} \mathrm{ge-}$ hen: es gibt Fälle, in denen sich Assoziationen g e g e $n$ eine, auf ihre Verhinderung gerichtete, personale Tat durchsetzen. (Der Wille, etwas zu vergessen oder andern gegenüber zu verheimlichen, kann gerade dazu führen, dass die entsprechenden Vorstellungsabläufe nun erst recht mit Hartnäckigkeit unser Bewusstsein erfüllen und sich sogar durch Ausdrucksbewegungen oder Fehlhandlungen nach aussen verraten).

Die Assoziationspsychologen haben nun diesen Typus von seelischen Vorgängen verallgemeinert und das Assoziationsprinzip, das sich relativ leicht auf jene Beispiele anwenden liess, auch auf die zielgerichteten personalen $\mathrm{T}$ a t e $\mathrm{n}$ des Denkens und Wollens zu übertragen gesucht. Diese seien in Wirklichkeit nicht Akte einer Person, sondern ebenfalls passive Verknüpfungen von Elementen, nur verwickelter und schwerer durchschaubar. Auf die Bestrebungen, alle menschlichen Denk- und Willensprozesse in assoziationspsychologischen Begriffen erschöpfend darzustellen, ist eine Fülle von Scharfsinn verwendet worden; hierbei sind auch manche assoziative Züge entdeckt worden, die bei je- 
nen personalen Akten mitspielen, und die man früher nicht beachtet hatte. Aber das eigentliche Ziel konnte nicht erreicht werden; denn niemals lässt sich Tat in blosses Geschehenlassen, lässt sich Zielgerichtetheit in mechanisches Geschiebe von Elementen verwandeln.

Hier wird die historische Bedeutung des Kampfes klar, den Wundt gegen Herbart führte. Herbart hatte versucht, die „Mechanik und Statik der Vorstellungen" zum alleinigen Prinzip des Seelenlebens überhaupt zu machen. Wundt betonte dem gegenüber, dass man schon innerhalb des Vorstellungslebens zwischen assoziativen und nicht-assoziativen Verbindungen scheiden müsse, welch letztere er "a p p e r z e p t i v e" Verbindungen nannte. Apperzeption ist nämlich nach Wundt eine innere zielstrebige Tätigkeit, die sich ebenso bei den geistigen Prozessen der Aufmerksamkeit und des Denkens, wie bei den Vorgängen des Willens bekundet ${ }^{1}$ ).

Damit war die Alleinherrschaft der Assoziation beseitigt. Aber war dafür nicht ein bedenklicher Dualismus geschaffen? Zerfiel nun nicht das Vorstellungsleben in personal bedingte (,,apperzeptive") und impersonale (mechanisch bedingte, assoziative) Abläufe? Dass Wundt dieser Schwierigkeit nicht entschieden und klar zu Leibe gegangen ist, darf man vielleicht als die Hauptschwäche seiner Lehre ansehen.

3. Personalistische Deutung der Assoziationen. Empfänglichkeit und Einstellung

Eine Verschiedenheit der beiden Ablaufsweisen ist unbestreitbar, aber sie liegt in $\mathrm{n}$ e $\mathrm{rh} \mathrm{a} \mathrm{l} \mathrm{b}$ der personalen (also hypermechanischen) Kausalität. Bei Denk-und Willenshandlungen äussert sich diese Kausalität in der akuten, zielgerichteten $T$ a t der Person, bei den Assoziationen dagegen in der $\mathrm{B}$ e re it $\mathrm{s} \mathrm{ch}$ a $\mathrm{ft}$ personaler D is position en. Dies ist für die Assoziationsstiftung wie für die Assoziationsauslösung nachzuweisen.

a) Stiftung von Assoziationen. - Zum Stiften von $K$ ontiguitätsassoziation en gehört, so sahen wir, zeitliches Beisammen im mnemischen Reiz. Aber nicht alles, was einmal - oder auch oftmals - zeitlich zusammen erlebt

1) Zum Begriff der Apperzeption vgl. S. 284, Anm. 
wird, ist dadurch so aneinander gekoppelt, dass es sich später als assoziative Verbindung erneuern müsste.

Was wir oben für mnemische Einzelreize feststellten, gilt auch für ihre Koppelungen; es findet eine scharfe A u s l e s e statt, die verschwindend wenige Paare und Gruppen der, in zeitlicher Kontiguität stehenden, primären Erlebnisse mnemisch auszeichnet und so zu Assoziationen verfestigt. Diese Auslese ist auf eine entgegenkommende Bereitschaft der Person zurückzuführen; auf ihre Empfänglichkeit für mnemische Reize.

Die mechanistische Assoziationslehre durfte diese Auslese nicht beachten, weil sie sonst ihr Prinzip hätte preisgeben müssen. Denn sie konnte ja die Assoziationsfestigkeit nur von dem rein f or m a le n Merkmal der Dauer und Häufigkeit des zeitlichen Beisammen abhängig sein lassen, während irgend welche Bedeutungsbezüge keine Rolle spielen durften. In Wirklichkeit aber gibt es keine Assoziationsstiftung im Menschen ohne personalen Bedeutungsbezug. Die Person ist mnemisch empfänglich für solche Erlebniskontiguitäten, die für sie nicht belanglos und gleichgültig sind.

Man muss freilich dem Begriff der „personalen Bedeutsamkeit" die genügende begriffliche Weite geben. Vielfach liegt der Sinn klar zu Tage, wie in folgenden drei Gruppen von Fällen.

1) Die Intra-Assoziation zwischen den Einzelmomenten e i n e r Gestalt ist unmittelbar daraus verständlich, dass die Gestalt als ganze eine Sinneinheit für die Person besitzt.

2) Situationen und Ereignisse, die aus dem Einerlei des Alltagslebens herausfallen und dadurch die Anwartschaft darauf haben, zu ausgezeichneten Erinnerungsetappen der Lebensgeschichte der Person zu werden, erhalten eine mnemische Wirksamkeit besonderer Art eben wegen dieser ihrer personal-h is t o$\mathrm{r}$ is ch en Bedeutung. Die mnemische Wirksamkeit erstreckt sich dann nicht nur auf die isolierten Einzelerlebnisse, sondern auch auf ihre zeitliche Gemeinschaft, die sich dann später in festen Assoziationen auswirkt.

3) Zahlreiche Assoziationen werden sogar mit voller Absicht und mit Willensanstrengung gestiftet, um dem Menschen später die selbstverständliche Verfügung über personal wichtige Verknüpfungen zu sichern; jede L e r n tätigkeit gehört hierher.

Aber durchaus nicht alle vorkommenden Assoziationen verra- 
ten so unmittelbar ihren Sinn; ja es gibt viele, die ausgesprochen sinnlos oder gar sinnwidrig erscheinen. Doch auch diese bilden kein Argument gegen die These, dass alle Assoziationsstiftung personale Bedeutung habe.

Es ist ja möglich, dass der personale Bezug, der s e in e r$z$ e it (beim Primärprozess) zur Stiftung der Assoziation führte, in dem späteren Zeitpunkt, in dem sich die Assoziation erneuert, nicht mehr aktuell zu sein braucht und daher nicht mehr verstanden wird. So geht es uns allen mit zahlreichen Assoziationen, die wir noch von unserer Kindheit her mit uns herumtragen. Warum mag sich mit irgend einem sprachlichen Ausdruck damals gerade dieses optische Bild, warum mit der Vorstellung eines bestimmten Menschen irgend eine gleichgültige Handlung oder Haltung dieses Menschen so fest assoziiert haben, dass auch nach Jahrzehnten noch die eine Vorstellung sofort die andere nach sich zieht? Man versteht den Zusammenhang nicht mehr, weil aus der Zeit des primären Erlebens weder die eigene Beschaffenheit noch die personale Gesamtsituation vergegenwärtigt werden kann. Aber es wird damals schon ein personaler Anlass gewesen sein, der gerade diese Verbindung aus allen anderen gleichzeitigen Erlebnissen heraushob und mit mnemischem Akzent versah.

Was aber noch wichtiger zur Deutung der scheinbar ,sinnlosen" Assoziationen ist: "persona le B edeut sam ke it" ist nicht identisch mit positiver rationale r $\mathrm{Z}$ we ckh a f t igkeit. Denn das für die Person bedeutsame Geschehen läuft ja nur zum geringsten Teil in der Schicht logisch einsichtiger Zweckbeziehungen ab. Regungen des Trieblebens, Entwicklungsanlagen, die nur keimhaft und dumpf sich ankündigen, Spannungszustände der Gefühlswelt können dazu führen, dass bestimmte Vorstellungsverknüpfungen eine personale Betontheit besonderer Art erhalten - vielleicht gerade deshalb, weil sie „sinnwidrig" sind, weil in ihnen das personale Gleichgewicht durchbrochen, die personale Oberfläche aufgerührt wird. „Sinnwidrigkeit" ist nicht sinnfremde Mechanik; auch sie ist personale (nämlich negat iv personale) Bedeutsamkeit.

Wir begegnen hier also innerhalb der assoziativen Ursprungsbestimmung einer ähnlichen Doppeltheit der personalen Bedeutung, wie wir sie oben bei der Kritik der Komplextheorien von Herbart und Freud gefunden haben (S. 284). Beides hängt 
eng zusammen und kann in dem Satz zusammengefasst werden: Besondere mnemische Empfänglichkei bringt die Person solchen mnemischen Reizen und Reiz-Verknüpfungen entgegen, die personal bedeutsam für sie sind. Die personale Bedeutsamkeit kann positivesoder negatives Vorzeichen haben, d.h. ebenso in direkter $Z$ weckdienlichkeit wie in einer Störung des personalen $Z$ wecksystems best e he n.

b) Wie kommt dann ferner die Wi ederauslösung früher gestifteter Assoziationen zustande?

Nehmen wir an, zwischen den Vorstellungen a und b sei einmal eine Assoziation geknüpft. Ist dann das Wiederauftreten der Vorstellung a an sich schon die zureichende Ursache dafür, dass b mit ins Bewusstsein gezogen wird? Die Antwort muss offenbar verneinend lauten. Für den, der Französisch gelernt hat, sind die Wortvorstellungen „Brot” und „pain” sehr eng miteinander assoziiert. Dennoch ist keine Rede davon, dass mir jedesmal, wenn mir das Wort „Brot” begegnet, zugleich „pain” einfällt. Der Vorstellungsprozess kann ganz andere Wege gehen, vielleicht von „Brot" zu „Brotpreis”, „Agrarzoll”, „Politik”; oder von „Brot” zu „Fleisch" „Obst” und anderen Nahrungsmitteln, u.s.w. u.s.w. Oder vielleicht wird von „Brot” überhaupt nicht weiter assoziiert, weil sofort eine andere Vorstellungsgruppe von meinem Bewusstsein Besitz ergreift. Um also eine bestimmte Assoziation zu aktualisieren, muss wiederum ein Ausleseprinzip wirksam sein. Worin besteht dies?

Das Ausleseprinzip ist ganz eindeutig personaler Natur dort, wo die Assoziation nur im D i e $\mathbf{n} \mathbf{s}$ t bewusst gerichteter seelischer Aktivität - also des Denkens oder Wollens - steht. Denn dann werden eben durch das akute Zielstreben gewisse Vorstellungen, die assoziativ erreichbar sind, gesucht und herbeigeholt, andere, die sich vielleicht aufdrängen, gehemmt. Aber davon kann erst in den Kapiteln über Denken und Wollen die Rede sein.

Hier geht uns allein die dis position elle Bedingtheit der Assoziationsauslösung an. Die Person muss einem Erlebnis, 
das zu einer $\mathrm{f} r \ddot{\mathrm{u}} \mathrm{h}$ e $\mathrm{r}$ gestifteten Assoziation gehört, jetzt eine inhaltlich gerichtete Bereitschaft entgegenbringen, damit die Assoziation zur mnemischen Erneuerung gelangen kann. Solche inhaltlich gerichtete Bereitschaft nennen wir (s.S. 114) „E i ns t e 11 u ng".

Der assoziative Ablauf der Vorstellungen, sofern er nicht durch unmittelbare Eingriffe von Willens- und Denktaten reguliert wird, ist von den jeweiligen Einstellungen der Person anhängig. Hierbei sei noch einmal darauf hingewiesen, dass „Einstellung” eine personale Bereitschaft ist, die zwar einem Inhalts b e r e i $c h$ im Ganzen zuneigt, aber - als Disposition - noch vieldeutig und potentiell ist. Um einen einzelnen umgrenzten Inhalt aus jenem Bereich zu aktivieren, bedarf es einer akuten A u s lösu n g, die durch einen Sinneseindruck oder durch eine anderswoher auftauchende Vorstellung hervorgerufen werden kann. Dann schnappt die Assoziation im Sinn der Einstellung ein.

Dieser überaus wichtige Tatbestand muss durch eine Reihe von Beispielen belegt werden.

a) In der Schulstunde „Französisch” ist der Schüler eingestellt auf den Aufgabenkreis, französisches Sprachmaterial in Beziehung zum deutschen (und umgekehrt) aufzufassen. Diese Rahmeneinstellung bewirkt, dass nunmehr das Wort "Brot" wirklich zu der Wortvorstellung "pain" hinüberleitet und nicht zu irgend einer der unzähligen anderen, mit „Brot" assoziierbaren, Wortund Sach-Vorstellungen. Hat er in der nächsten Stunde Englisch, so führt die veränderte Einstellung ohne Nachdenken dazu, dass mit „Brot” „bread” assoziiert wird.

b) Die musikalischen Notenzeichen sind bekanntlich mehrdeutig, je nach dem vorgezeichneten Schlüssel. Steht am Anfang des Musikstücks der Violinschlüssel, so schafft dessen Wahrnehmung eine allgemeine Einstellung für die Lesung aller folgenden Noten, welcher Art sie auch seien; mit dem optischen Bild der Note im dritten $Z$ wischenraum wird selbstverständlich der Notenname c, ein bestimmtes Tastenbild und die auf diese Taste zielende Bewegung assoziiert. Mitten im Stück taucht plötzlich der Bassschlüssel auf - und nun ist der Spieler gleichsam in eine andre Region umgeschaltet; die veränderte Einstellung lässt mit dem 
identischen Notenbild ganz andere Notennamen und Tasten assoziieren. Die bisherigen, eben noch so dominierenden, aber jetzt nicht mehr einstellungsgemäIsen Vorstellungen tauchen normaler Weise garnicht erst auf.

c) Auf einer Zeitungsanzeige fällt zunächst nur die fettgedruckte Überschrift auf: „Vortrag über Wurzelausziehen”. Der Botaniker ,assoziiert" diese Worte im Sinne von Pflanzenwurzeln, der Mathematiker im Sinne von Quadratwurzeln, der Dentist im Sinne von Zahnwurzeln. Die vorwiegende berufliche Einstellung eines jeden bestimmt also, welcher Sinngehalt mit der gelesenen Überschrift verknüpft wird.

d) Es hat jemand ein Delikt begangen und befindet sich seitdem in der dauernden Einstellung, gesucht und erkannt zu werden. Diese Einstellung bestimmt nicht nur sein Benehmen und die Richtung seiner Aufmerksamkeit, sondern auch seine Assoziationen. Kreuzt zufällig sein Blick den eines Begegnenden, hört er undeutliche Gesprächsfetzen u.s.w., so führen diese Eindrücke sein Vorstellen weiter auf seine Tat, deren Begleitumstände und die angeknüpften Besorgnisse.

e) In einem psychologischen Experiment werden phonographisch aufgenommene sinnlose Silben vorgeführt. Die Hörer sollen angeben, wie sie jenes Klangmaterial hören. Fast stets werden sinnvolle Wörter hineingehört, aber ganz verschiedene, je nach Einstellung. Ein junger Mann assoziiert mit den gehörten Silben lauter Mädchennamen - und mag damit seine stark erotische Einstellung verraten.

Die Einstellungen, die den Vorstellungsabläufen zu Grunde liegen, haben doppelten Ursprung. Erwähnten wir früher vor allem die mnemisch erworbenen Einstellungen, in denen sich die Lebenserfahrungen der vergangenen Zeit niedergeschlagen haben, so müssen wir nun noch die konstitutionell bedingten Einstellungen hinzufügen. Während z.B. die Berufseinstellung in unserem Beispiel c) vorwiegend auf erworbenen Grundlagen ruht, ist die erotische Einstellung des jungen Mannes in e) aus der angeborenen Besonderheit seiner Persönlichkeitsstruktur heraus zu erklären. Aber freilich gibt es keine reine Einstellung der einen oder anderen Art. Die Berufseinstellungen (c) sind zwar geladen mit zahllosen empirischen Nachwirkungen aus Berufserlebnissen, aber die angeborenen Neigungen und Fähigkeiten besonderer Art 
haben ebenfalls zur Konsolidierung dieser Einstellungen beigetragen. Umgekehrt ist zwar die überwertige erotische Tendenz in e) innenbedingt, aber die vielen Mädchennamen, die in so starker Bereitschaft lagen, waren mnemisch gewordenes Erfahrungsgut.

Die Trennung der beiden Kausalfaktoren der Einstellung ist deshalb wichtig, weil dadurch ein neuer Gegensatz zur Herbart'schen Apperzeptionslehre konstituiert wird. Nach Herbart sind es $n \mathbf{u} r$ die E r f a h r u n e n die sich zu Apperzeptionsmassen verdichten und durch diese alles Assoziieren bestimmen. Da Vorstellungen nicht angeboren sind und Herbart nur in „Vorstellungen" $z u$ denken vermag, ist für ihn die Anerkennung konstitutioneller Einstellungen und der durch sie bestimmten Assoziationen nicht möglich.

Jede Person verfügt als unitas multiplex über unzählige Einstellungsmöglichkeiten. Sie besitzt Einstellungen von langer Dauer (Berufseinstellung, Einstellung zur Familie), und ganz vorübergehende (vgl. unsere Beispiele a) Schulfächer und c) Notenschlüssel). Es gibt solche von immer wacher Aktualisierungsbereitschaft, andere, die eines starken Anreizes oder sogar eines Zwanges bedürfen, um leistungsfähig zu werden. Dieser Vielheit von Einstellungen gegenüber muss man sich nun aber vor dem naheliegenden Fehler hüten, eine Einstellungs-M e $\mathrm{ch}$ a $\mathrm{n} \mathrm{i} \mathrm{k}$ an die Stelle der früheren Vorstellungsmechanik zu setzen. Die Entscheidung, w e $1 \mathrm{ch}$ e Einstellung in irgend einem Zeitpunkt vorherrscht und den Vorstellungsablauf spezifisch bestimmt, ferner, wie die Einstellungen sich ablösen u.s.w. - geht nicht hervor aus Kraftgrössen, die den einzelnen Einstellungen als solchen zukommen, sondern aus der Dynamik der Gesamtperson. Die Struktureinheit und Lebenslinie der Person, ihre dauernden und wechselnden Ziele, ihre immanenten Rhythmen und Spannungen verleihen den verschiedenen Einstellungen Wirksamkeitsstärke und bestimmen den Zeitpunkt des Aktuellwerdens.

\section{Assoziationsexperimente}

Die empirische Untersuchung der Asso$z$ i a $t$ i o n e $n$ hat sowohl die experimentelle Psychologie wie die Tiefenpsychologie eingehend beschäftigt. Man bediente sich hierzu entweder des paarigen Experiments oder des Kettenversuchs.

Im $\mathrm{p}$ a a rige $\mathrm{n}$ Experiment werden viele Reize nacheinan-

Stern, Psychologie 
der dargeboten (Wörter, oder Figuren, oder Bilder); die Versuchsperson hat auf jeden Einzelreiz mit der ersten Vorstellung zu antworten, die sich assoziativ darbietet. Die Antworten und die für die einzelnen Assoziationen nötigen Zeiten werden registriert.

a) Allgemeinpsychologische Probleme. Die ursprüngliche Absicht dieser Versuche war, die GesetzmäIsigkeiten zu erfassen, nach welchen sich im menschlichen Bewusstseinsleben Assoziationen vollziehen. Man stellte fest, in welchem Verhältnis die assoziierten Vorstellungen zu den assoziierenden ständen, fand hier Beziehungen der Åhnlichkeit, des Gegensatzes, oder des räumlichen und zeitlichen Beieinander, der Uber- und Unterordnung u.s.w., und glaubte damit die Pri n $z$ i $p$ i e $n$ des assoziativen Geschehens festgestellt zu haben. Das Recht zu dieser Schlussfolgerung leitete man daraus ab, dass bei den Versuchspersonen $\mathrm{nach}$ der Instruktion das Nachdenken und die absichtliche Auswahl der Antwort ausgeschlossen war; es wurde ein passives Hingegebensein an die Reize und die sich anschliessenden Vorstellungen gefordert, also eine Haltung, welche rein assoziative Abläufe zu begünstigen schien.

Aber diese Voraussetzung ist unzutreffend. Die Versuchspersonen sind durchaus nicht in einer denk- und willensfreien Situation, sondern in einer sehr paradoxen Denk- und Willens-Situation: sie sollen sich absichtlich einstellen auf absichtsloses Tun, sollen den Sinn der Aufgabe im Vermeiden sinnvoller Denkvollzüge sehen, sollen jeden Denkansatz, der sich vielleicht bei $\mathrm{Ge}$ legenheit eines Reizes bildet, sofort abbrechen und dem folgenden Reiz wieder ganz voraussetzungslos gegenüberstehen. In einer so künstlichen, ja geradezu widernatürlichen Lage ist ein freies Assoziieren, eine lässige Hingegebenheit an den das Bewusstsein durchströmienden Vorstellungsfluss nicht möglich. Das beweisen schon die Zeitmalse; denn wenn im paarigen Experiment die „Assoziationszeit", also der Ubergang von der assoziierenden zur assoziierten Vorstellung durchschnittlich eine halbe Sekunde dauert, dann ist darin kein Abbild der grossen Geschwindigkeit zu sehen, mit der sich im wirklichen Leben ungehemmte Vorstellungsabläufe vollziehen. - Die eigentlich positive Bedeutung der "Assoziationsexperimente" liegt auf zwei ganz anderen Gebieten: einmal auf dem der Denkpsychologie (darüber später), sodann auf dem der personalen Deutungstechnik. 
b) Diagnostische Probleme. - Da nämlich, wie wir sahen, allen Assoziationen eine personale Bedeutung zukommt, so müssen sie auch $\mathrm{d}$ e $\mathrm{u} \mathrm{t} \mathrm{b}$ a $\mathrm{r}$ sein, d.h. auch für andere Züge der assoziierenden Person symptomatischen Wert besitzen. Man kann also durch die Art des Assoziierens hindurch zu tiefer liegenden Einstellungen des Menschen vordringen.

Unter diesem Gesichtspunkt ist neben dem paarigen Experiment (Jung) dann die andere Methode des $\mathrm{K}$ e $\mathrm{t}$ t e $\mathrm{n}$ e $\mathrm{x}$ p e r i$m$ e $n t s$ ausgebildet worden, die der Versuchsperson weit grössere Freiheit lässt (Freud und andere).

Der Assoziationsablauf wird dann nämlich vom Experimentator oder Psychodiagnostiker nur durch einen oder einige wenige Reize eingeleitet; im Obrigen aber wird die Versuchsperson der in ihr spontan sich abwickelnden Vorstellungskette überlassen, die sie allerdings möglichst vollständig in Worte umsetzen muss, damit eine Kontrolle erfolgen kann. Dies Verfahren hat namentlich in der Tiefenpsychologie Verwendung gefunden. Dort ist es in der Richtung entwickelt worden, dass der Experimentator nur selten und behutsam in den Ablauf der Kette eingreift. Vor allemwird dafür gesorgt, dass die seelische Gesamtatmosphäre, in welcher die Versuchsperson (der Patient) sich befindet, jenes Sichgehenlassen und die Ausschaltung von Denk- und Willenshemmungen begünstigt.

Man kann den Gegensatz der älteren und der neueren Ziele der Assoziationsexperimente auch so ausdrücken: früher hatte man gemeint, Assoziationen erfassen zu können, die mit Denken und Wollen nichts zu tun haben und gleichsam den ,reinen" Vorstellungsablauf bedingen. Heut sucht man durch Assoziationen jene Seiten der Person zu erfassen, die zu bewusstem und absichtsvollem Denken und Wollen i $m$ G e ge n sa $t z$ stehen; man will durch Ausschaltung der Zweckbewusstheit die, sonst von ihr überdeckte, unbewusste Zweckgerichtetheit, also die im Menschen wirksamen Ein st e ll ung e n blosslegen. Der seinen Assoziationen hingegebene Mensch treibt durch die Art seines Assoziierens einen unfreiwilligen „personalen Selbstverrat”.

Diese symptomatologische Verwertung des Assoziationsexperiments tritt in vier Hauptformen auf.

1) Personale $D$ a uereigenschaften kommen in den Assoziationen zum Durchbruch. So kann sich Enge oder Weite des geistigen Horizonts in der Eintönigkeit oder Mannigfaltigkeit der Assoziationen, langsames persönliches Tempo oder Gehemmt- 
heit in sehr langen Assoziationszeiten zeigen. Originelle, phantasievolle und auch originalitätssüchtige Menschen werden durch häufige Wahl ungewöhnlicher Assoziationen auffallen. Vorherrschende Trieb- und Interesse-Richtungen führen dazu, dass die Assoziationen vorwiegend bestimmten Gebieten entnommen sind.

2) Personale $Z$ u st a n d s bilder spiegeln sich in der Art der Assoziationen wieder. Dies gilt namentlich für pathologische Zustände. Krankhafte Perseveration sowie ihr Gegenstück, die "Ideenflucht”, treten namentlich bei Kettenassoziationen sehr deutlich hervor; Gemütsdepressionen, Selbstvorwürfe, Phobieen, Erschöpfungszustände, ebenso aber auch Grössenwahn und andere Wahngebilde sind aus dem Inhalt der Assoziationen ablesbar.

3) Verdrängte Erlebn is se traumatischer Art können auf assoziativem Wege ins Bewusstsein gehoben und dadurch abreagiert werden.

Wir hatten oben (S. 257) erwähnt, dass stark erregende Eindrücke als solche ganz aus dem Bewusstsein schwinden können und dennoch nicht mnemisch erledigt sind. Sie wirken indirekt nach in einer veränderten Gemütsverfassung, die sich wiederum neuer Vorstellungsgebiete bemächtigt. Die Psychoanalyse hat nun die Theorie entwickelt, dass diese schädigenden Nachwirkungen nur dann zum Schwinden zu bringen sind, wenn es gelingt, die ursprünglichen Erreger wieder ins Bewusstsein zu heben und dadurch den ganzen mnemischen Prozess endgültig abzuschliessen. Dieses Wiederbewusstmachen geschieht durch freie Assoziationen. Darum wird versucht, möglichst jenen Zustand der Passivität zu erzeugen, in dem der Patient sich dem Spiel seiner Vorstellungsverkettungen hingeben kann. Die allgemeine Dämpfung des Willens schwächt auch jene Hemmungsmechanismen, die bisher eine Wiedervergegenwärtigung des früheren Erlebnisses unmöglich machten; in der bunten Bilderreihe der vorbeiziehenden Vorstellungen kommen Einstellungen aus den verschiedensten Vergangenheitsphasen zum Vorschein; allmählich tauchen auch solche Vorstellungen auf, die dem Ursprung des Traumas näher stehen, bis schliesslich der Quellpunkt selber aus der Verschüttung befreit wird und erneut Bewusstsein und Ausdruck gewinnt.

Uns geht hier nicht die therapeutische Frage an, ob diese Me- 
thode zu wirklichem „Ab-Reagieren”, also zu endgültiger Befreiung von dem Trauma führt. Aber die allgemein-p s y c h o l o$\mathrm{g}$ i s $\mathrm{ch}$ e Voraussetzung: dass die Hingabe an die Assoziationen zur Beseitigung innerer Hemmungen und damit zur unwillkürlichen Preisgabe verborgener Erlebnisnachwirkungen zu führen v e r m a g, ist sicherlich zutreffend. Sie liegt auch der folgenden Anwendung des Assoziationsexperiments zu Grunde.

4) Bewusste Verheimlichungsabsichten, die sich auf personal bedeutsame Erlebnisse beziehen, können auf assoziativem Wege überrumpelt werden (sogen. „Tatbestandsdiagnostik" oder "Spuren-Symptomatologie"). Die Eingestelltheit eines Delinquenten auf sein Verbrechen (s. unser Beispiel d) steht in dauerndem Gegensatz zu der bewussten Absicht, die äussere und innere Beteiligung an jener Tat zu verschleiern. Die Aufgabe des paarigen Experiments, auf jedes zugerufene Reizwort die erstbeste Vorstellung zu nennen, wird nun - namentlich bei „kritischen” Reizwörtern - auch Vorstellungen aus der in starker Bereitschaft liegenden Sphäre des Deliktes ins Bewusstsein und vielleicht sogar über dieLippen bringen. Erweist sich aber der Verheimlichungswille als stark genug, um das Aussprechen verräterischer Assoziationen zu hemmen, dann braucht der Prüfling Zeit, um ein anderes „harmloses" Wort zu finden; und so kann indirekt die verlängerte Reaktionszeit bei kritischen Reizwörtern als Symptom der „Einstellung auf Delikt” wirken ${ }^{\mathbf{1}}$ ).

1) Derartige tatbestandsdiagnostische Experimente sind in erster Reihe $t \mathbf{b}$ e or e $t$ i s c h wichtig, weil sie den Nachweis führen, wie innerhalb der Person die Energieen mit einander in Konflikt geraten, die einerseits akuten Zielsetzungen, andrerseits dispositionellen Einstellungen zuerteilt werden; in jeder verräterischen Assoziation siegt der dumpfe Antrieb eines tiefer eingebetteten personalen Zustandes über die Leistungsfähigkeit der abgehobenen Willenstat. - Zu einer Anwendung des Assoziationsexperiments für die oben fingierten $\mathrm{prakt}$ is c he $\mathbf{n}$ Aufgaben der Verbrecherüberfuibrung ist es bisher nur in ganz vereinzelten Fällen gekommen; es stehen solchen Anwendungen auch gewichtige moralische Bedenken entgegen.

Die ersten experimentellen Untersuchungen dieser Art sind von Wertheimer und Klein augeführt worden.

Die gesamte psychologische Literatur über "Spuren-Symptomatologie” ist zusammengestellt von Otto Lipmann. 


\section{DREIZEHNTES KAPITEL}

ER W R B U N D BESITZ VON KEN T NISSEN

\section{ALLGEMEINES}

1. Gebundene und freie Bildungsinhalte

Bei Besprechung des gebundenen Gedächtnisses hatten wir die Verwertungswirkungen erwähnt, die man „Bildung” und „Lebenserfahrung" nennt; jene mnemisch gewonnenen Ei n$\mathrm{s}$ t e $1 \mathrm{l}$ u n g e n, mit deren Hilfe der Mensch geistig mit den wechselnden Aufgaben des Lebens fertig wird und sich auseinandersetzt. Aber dieser personale Besitzstand ist nicht immer und nur "gebunden"; vielmehr steht er mit freien selbständigen Gedächtnisvorstellungen in dem dreifachen Zusammenhang: dass er erstens aus ihnen entstehen, zweitens sie aus sich heraus wieder produzieren (also „re-produzieren”), drittens sie immer wieder sich einverleiben kann. Die Gedächtnisvorstellungen, die in diesem personalen Aufgabenzusammenhang stehen, sind die „Kenntnisse”.

Es handelt sich hierbei freilich schon um eine sehr komplizierte und hochorganisierte Form mnemischen Geschehens, das im wesentlichen dem $\mathbf{M}$ e $\mathbf{n} \mathbf{s} \mathbf{c}$ h e $\mathbf{n}$ vorbehalten ist. Das Tier vermag zwar Erfahrungen mannigfacher Art zu machen und zu verwerten; aber f a $11 \mathrm{~s}$ damit überhaupt freie Gedächtnisvorstellungen verbunden sein sollten, so ist doch ihr Umfang und ihre Lebensbedeutung verschwindend gegenüber alledem, was vermittels gebundener mnemischer Wirkungen geleistet werden kann. Auch i n n e r h a $1 \mathrm{~b}$ des menschlichen Bereichs ist das Wachsen der Kenntnisse eines der wichtigsten entwicklungspsychologischen Merkmale, sowohl im Lebensgange jedes Individuums, wie in der steigenden Kultur der Menschheit.

Niemals aber fehlt der Zusammenhang zwischen beiden mne- 
mischen Sphären; ja, Sinn und Bedeutung der freien Gedächtnisvorstellung wird überhaupt erst aus diesem Zusammenhang mit der mnemischen Unterschicht verständlich. Diese Einsicht steht in diametralem Gegensatz $z u$ jenen früheren Versuchen einer mechanistischen Psychologie, die das Lernen, Behalten und Vergessen rein aus den Gesetzmärsigkeiten der Vorstellungsprozesse selbst ableiten zu können glaubte.

Eine eigentümliche Spannung erhält die Beziehung von mnemischen Einstellungen und aktuellen Kenntnissen dadurch, dass die Kenntnisse zugleich von jenen Einstellungen a b g e h o b e $n$ und in sie e ingebet $t$ e $t$ sind.

Auf den einen Seite besteht nämlich der entwicklungsmäfsige Fortschritt darin, dass Gedächtnisvorstellungen als s e l bs t ä n d i g e Gebilde hervortreten; so kann früher Erworbenes in vielen Einzelheiten, Klarheitsgraden und Verknüpfungen dem Bewusstsein gegenwärtig gehalten und schliesslich als gesonderte Leistung - konkretes Spezialwissen, gestaltetes Werk - nach aussen projiziert und verwertet werden. Die verwickelteren Lebensbedingungen und höheren Kulturaufgaben des Menschen erfordern unbedingt eine solche Verselbständigung, Spezialisierung und Bewusstmachung erworbener Erfahrungen; sie wären aus dem blossen Fonds selbstverständlich gewordener mnemischer Einstellungen heraus nicht zu bewältigen.

Auf der anderen Seite ist stets die Gefahr vorhanden, dass die Abhebung zu einer $\mathrm{Abschn}$ ür ung führt; die Kenntnisse drohen $z u$ selbstgenügsamen Gebilden zu erstarren und die Beziehung zu dem Gesamtleben der Person zu verlieren, wenn sie sich nicht immer wieder einbetten in jene Unterschicht und aus ihr lebendigen Sinn, Beweglichkeit und vielseitige Verwendbarkeit ziehen.

Diese Ambivalenz von Abhebung und Einbettung liefert die wissenschaftliche Erklärung für eine, der Laienpsychologie längst geläufige Einsicht, dass Kenntnisse $\mathrm{zugleich} B$ esitz u n d B a ll a s t bedeuten können, und dass sie in sehr verschiedenen Graden in der Tiefe der Person verankert sind. Die höchste Stufe mnemischer Entwicklung nach dieser Richtung ist dort erreicht, wo der Mensch über eine Fülle abhebbarer, zugleich aber völlig organisch gewordener und deshalb immer wieder einbettbarer Kenntnisse verfügt. Zwei einseitige Entwicklungswege 
führen einmal zu jenem Menschen, bei dem die Abhebung und damit die Entpersönlichung der Kenntnisse überwiegt: dem Polyhistor, dem, der viel ,auswendig' kann, - in der anderen Richtung $\mathrm{zu}$ jenem, der sich eine tiefe und vielseitige Bildung und Lebenserfahrung erworben hat, aber nur sehr unzulänglich im stande ist, aus dieser im speziellen Fall die erforderlichen Inhalte an Einzelwissen herauszulösen. Zweifellos gibt es hier psychologische Typenunterschiede von grosser Bedeutung, die bisher merkwürdigerweise noch wenig wissenschaftlich untersucht sind.

Dabei hat z.B. jeder Examinator, der ein wenig Menschenkenner ist, reiche Gelegenheit, unter seinen Prüfungskandidaten ausgesprochene Vertreter beider Typen zu finden. Ausserdem gibt es den Prüflingstypus, der weder abhebbares noch eingebettetes Wissen besitzt, und - leider nur sehr selten - jenen Idealtypus, in dem Abhebung und Einbettung zur vollen Harmonie gekommen sind. - Gerade weil es im Wesen der Exameninstitution als solcher liegt, dass a u f z e i g$b$ a r e s Wissen leicht über Gebühr bewertet und beachtet wird, ist es um so notwendiger, dass man die eben geschilderten psychologischen Verhältnisse kennt und berücksichtigt.

\section{Der Erwerb von.Kenntnissen}

Der Erwerb von Ken n $\mathrm{n}$ is se $\mathrm{n}$ erfolgt entweder durch einen einmaligen oder durch einen wiederholten mnemischen Reiz; dort nennen wir es "Sich-Merken", hier "Lernen”.

a) $\mathrm{D}$ a s "S i c h-M e r k e n." - Man merkt sich eine Telephonnummer eines Bekannten, einen seltsamen Namen, einen besonderen Ausdruck einer Fremdsprache wohl gelegentlich auf einmaliges Hören oder Lesen, also ohne sie „lernen” zu müssen. Meist sind die auf solchem Wege erworbenen Kenntnisse zeitlich kurz befris t e $\mathrm{t}^{1}$ ): es handelt sich dann um Gedächtnismaterial, das man nur innerhalb bestimmter Situationen braucht und nachher wieder verlieren kann; für solch oberflächliche Haften genügt die einmalige Aufnahme.

Ein bezeichnendes Beispiel hierfür ist etwa das Gedächtnis für die Zimmernummer in einem Hotel, in dem man eine Reihe von Tagen wohnt. Man behält die Nummer nach dem ersten Hören, aber nur solange man ihrer bedarf; bald nach der Abreise ist sie völlig vergessen.

1) Über die experimentelle Untersuchung der ganz kurzfristigen, „unmittelbaren” Merkfähigkeit vgl. S. 273 ff. 
Dauernde und tiefer verankerte Kenntnisse werden nur in Ausnahmefällen durch einmaliges Sichmerken erworben, und zwar nur dann, wenn gerade diesem Stoff eine besonders starke Empfänglichkeit der Person entgegenkommt: so kann z.B. ein mathematisch stark begabter und interessierter Mensch durch einmaliges Rezipieren eines mathematischen Lehrsatzes oder einer Formel einen Besitz fürs Leben gewinnen.

b) „Lerne n” ist Kenntniserwerb durch wiederholte Darbietungen.

Ein allgemeinerer, biologischer, Begriff des Lernens begegnete uns schon früher (S. 262); dort war vornehmlich von der Aneignung neuer Fertigkeit en durch Wiederholung die Rede; und es wurde betont, dass hierzu nicht notwendig eine Willenseinstellung auf mnemischen Erwerb gehöre. Auch Aneignung von Kenntnissen kann durch un willkürliches Ler$\mathrm{n}$ e $\mathrm{n}$ erfolgen. Diejenigen Einwirkungen, denen ein Mensch in häufigen Wiederholungen ausgesetzt ist, schaffen in ihm, ohne dass er es bewusst erstrebt, Dauerdispositionen, die sich dann bei geeigneten Anlässen in Kenntnissen aktualisieren. Gerade in frühen Entwicklungsperioden (der Menschheit und des Einzelnen), in denen die Vorbelastung mit Kenntnissen gering, die Empfänglichkeit für neue Eindrücke fast grenzenlos ist, schafft dieses ungewollte Lernen die Grundschicht von Kenntnissen, die noch ganz unsystematisch, zum Teil auch recht vage und unklar sein mögen, in ihrer Gesamtheit aber das erste Umrissbild der Welt liefern, in der der Mensch zu Hause sein muss.

Das eindruckvollste Beispiel für die schlafwandlerische Sicherheit und staunenswerte Leichtigkeit dieses primitiven Lernens ist wohl der Erwerb der Muttersprache durch das 1-3 jährige Kind. Hier fehlt jede Spur von Lernabsicht und von Kraftaufwand für Lernzwecke - und doch dieser Erfolg, der unvergleichlich grösser ist, als der spätere Effekt eines vieljährigen willentlichen Lernens einer Fremdsprache. Das Gleiche gilt aber in diesem Alter von allen anderen Lerneffekten; sie kommen zustande nicht als gewollte Erfolge, sondern als Nebenwirkungen anderer seelischer Betätigungen ${ }^{\mathbf{1}}$ ).

1) „Das Kind lässt sich Verschen vorsingen, nicht um sie zu lernen, sondern um sie zu hören, und sich immer wieder an ihnen zu freuen - aber es lernt sie schliesslich. Es horcht auf das Sprachchaos, das es umgibt, versucht zu verstehen und nachzuah- 
Aber auch später, wenn es längst ein willensbestimmtes Lernen gibt, ist doch die Rolle jenes ungewollten Lernens keineswegs ausgespielt. Unzählige Auswanderer, die die Sprache ihrer neuen Heimat nicht kannten, haben diese dort gelernt, ohne irgendwelche ausdrückliche Lernbemühung, lediglich dadurch, dass sie ihren anderweitigen Lebenszielen in dem steten Milieu dieser Sprache nachgingen. Und sie haben unzählige sonstige Kenntnisse über Land und Leute, Sitten und Gebräuche in gleich unwillkürlicher Weise miterworben. Ferner: Wieviel lernt man auf einer Reise, was man garnicht lernen will, was man vielleicht während der Reise garnicht beachtet hat - und nachher zur eigenen Uberraschung als neue Kenntnis in sich vorfindet.

Das Zustandekommen dieser Lernerfolge ist aus einer doppelten Ursächlichkeit abzuleiten. Die eine Ursache liegt im Aussenreiz und dessen steter Wiederholung. Eindrücke, die u n e n t$\mathrm{r}$ i $\mathrm{n} \mathrm{n} \mathrm{b}$ a $\mathrm{r}$ sind, und die sich unablässig erneuern, haben eine besonders starke Anwartschaft darauf, sich schliesslich mnemisch geltend zu machen - auch ohne Wissen und Willen der Person. Dennoch kann man hier nicht von einem eindeutigen Zwang sprechen. Es ist nicht wie in dem Sprüchwort, nach welchem j ed e $r$ Tropfen den Stein höhlt, wenn er nur stetig an immer dieselbe Stelle fällt. Vielmehr kommt nun als die andere Ursächlichkeit die innere $\mathrm{Em} \mathrm{p}$ fä $\mathrm{nglichkeit} \mathrm{der} \mathrm{Person} \mathrm{dazu,}$ die für gewisse sich wiederholende Eindrücke eine viel stärkere mnemische Bereitschaft zeigt als für andere.

Wir stossen hier also wiederum auf jene unbewusste mnemische A u s l e s e; durch sie hebt sich das unwillkürliche Lernen entscheidend vom willentlichen $a b$, das auf Vollständigkeit zielt. Die persönliche Disposition greift aus der Fülle der sich wiederholenden Umweltreize die ihr besonders gemäfsen heraus, um sie sich anzueignen und schliesslich in Kenntnisse umzusetzen. Der

men, nicht in der Absicht, sich die Worte einzuprägen und sie zu behalten, sondern um in seelischem Zusammenhang mit seiner Umgebung zu stehen - aber es lernt hierbei spielend sprechen. Es bliebt beim Spaziergang vor jedem Schaufenster stehen und lässt sich die Herrlichkeiten darin zeigen und erklären, nicht um es morgen oder in einem Jahr, sondern nur, um es im Augenblick zu wissen - aber es erwirbt sich dabei dauernde Kenntnisse über Aussehen, Bedeutung und Zweck der Dinge. Es ahmt spielerisch die Hantierung der Mutter nach - und lernt dabei, wozu dies und jenes Werkzeug gut sei, wie diese oder jene Verrichtung vollzogen werde. Im Bewusstsein des Kindes nichts als Augenblicksfreuden und Gegenwartsinteressen - aber jenseits aller Absicht nachhaltige Zukunftswirkungen durch Vermehrung des Wissensschatzes". (Psychologie der frühen Kindheit S. 188). 
lernmögliche Stoff ist also hier um ein Vielfaches grösser als der tatsächlich angeeignete - während beim willentlichen Lernen sich die Umfänge beider Stoffe annähernd decken ${ }^{1}$ ). Die persönliche Empfänglichkeit kann von Geschlecht, Alter, Typik abhängen; sie kann auf der einmaligen Besonderheit eben dieses Individuums beruhen - jedes Mal bestimmt sie, welches $\mathrm{S}$ t ü ck We lt zur mnemischen Wirkung gewählt wird.

Auf derselben Strasse spielen Tag für Tag verschiedene Kinder; dieselben alltäglichen Vorgänge laufen fortwährend um sie alle herum ab; und doch zieht die unbewusste Lernauslese der Knaben hieraus ganz andere Kenntnisse als die der Mädchen; das 4-jährige Kind lernt dort anderes, als das 8-jährige, das technisch interessierte Kind andere als das sozial interessierte ${ }^{2}$ ).

Auch a $\mathrm{k} \mathrm{t} \mathrm{i} \mathrm{v} \mathrm{kann} \mathrm{der} \mathrm{Mensch} \mathrm{diese} \mathrm{seine} \mathrm{Lernauslese} \mathrm{unter-}$ stützen, ohne Lernabsicht: er sucht, von seinen Trieben oder Interessen gedrängt, bestimmte Weltausschnitte auf, gibt sich ihnen hin und lernt eben dadurch.

Als Beispiel diene der S a m m e l t $\mathrm{r}$ i e b. Fast nie macht sich ein Mensch aus Lernwillen an das Sammeln von Bildern, von Marken, von Münzen u.s.w., sondern er wird von einem unmittelbaren, oft leidenschaftlichen, Interesse an den Dingen selbst und ihrem Besitz getrieben. Aber stets hat das Sammeln zugleich den didaktischen $\mathrm{N}$ e b e ne $f$ f e $k t$, die Kenntnisse auf jenem Fachgebiet bedeutend zu erweitern und zu vertiefen.

\section{DAS WILLENTLICHE LERNEN}

Es bedeutet einen der grössten entwicklungspsychologischen Fortschritte, wenn der Mensch reif wird, vom willenlosen zum willentlichen Lernen überzugehen. Die Menschheit macht den Schritt, wenn sie aus dem Dahinleben des Naturvolkes aufsteigt zu der Scheidung von Arbeit und Musse, zur Einführung des Unterrichts, zur Schaffung von Berufen, welche be-

1) Nur hingewiesen sei auf die pädagogische Folgerung: überall dort, wo die unbewusste Lernauslese wirksam werden soll, (und schliesslich gibt es kaum eine pädagogische Situation, in der sie nicht zum mindesten $\mathbf{n}$ e b e $\mathbf{n}$ dem willentlichen Lernen ihr Recht hätte), muss man dem Lernenden $\mathrm{m} \mathrm{e} \mathrm{h} \mathrm{r}$ an Eindrücken zur Verfügung stellen, als eingeprägt werden soll; nur so kann jedes Individuum die ihm gemälse unwillkürliche Lernauslese treffen. - Vgl. über dies „Prinzip der Mehrdarbietung”: Psychol. d. frühen Kindheit S. 189.

2) Besonder wichtig sind die Untersuchungen von Martha Muchow über den Lebensraum des Grolsstadtkindes. 
stimmter Kenntnisse bedürfen, zur Festlegung einer religiösen, völkischen und kulturellen Überlieferung, in welche jede neue Generation hineingebildet werden muss. Das E in zelindivid u u m erreicht die neue Stufe mit der sogen. "Schulreife”; denn erst jetzt wird ein Lernen nötig, das mehr als unbeabsichtigter Nebeneffekt ist, jetzt wird durch Aufgaben und Termine das Lernen systematisiert.

In der Gewinnung dieser Leistungsstufe liegt nicht etwa nur ein Fortschritt des Gedächtnisses als solchen - wie man überhaupt dem Thema „Lernen" nicht gerecht wird, wenn man es allein als ein Problem der Gedächtnispsychologie ansieht. Gewiss ist ein Gedächtniserfolg das $\mathrm{Z}$ i e l: was gelernt wird, soll behalten werden und reproduzierbar sein. Auch die hierfür ins Spiel zu setzenden Mittel sind $z$ u m $\mathrm{T}$ e i l gedächtnismälsiger Art: Klarheit, Anschaulichkeit, einreihige oder vielseitige Verknüpfung von Vorstellungen, allmähliche Festigung der mnemischen Wirkungen durth Wiederholung. Aber um das Ziel zu erreichen, und um jene Mittel verwertbar zu machen, werden nun die verschiedensten anderen seelischen Funktionen des Menschen mobilisiert, ja recht eigentlich die ganze Person in ihren Willens-, Interesse-, Gefühls- und Intelligenz-Funktionen beteiligt - dies alles in einer weitgehend geordneten und durchstrukturierten Form, sodass es sich in der Tat um eine recht hochstehende personale Leistung handelt.

\section{Psychische Faktoren des Lernens}

Dieses Ineinandergreifen eigentlicher Gedächtnisphänomene und anderer seelischer Bereiche muss näher betrachtet werden, unbeschadet dessen, dass diese anderen Gebiete erst später ihre Sonderbetrachtung erhalten können ${ }^{1}$ ).

a) Le rnwille. - Während die einfacheren Formen des $\mathrm{W}$ i 11 e $\mathrm{ns}$, wie wir sie schon beim Kleinkinde finden, durch ein ganz gegenwartsnahes Ziel charakterisiert sind, setzt sich der L e r n w i 11 e ein Ziel, das nicht im ersten Anlauf, nicht in einem einzigen Akt innerhalb der Präsenz erreicht werden kann. Immer wiederholtes Neuansetzen gehört vielmehr zum Wesen des Ler-

1) Hier zeigt sich wieder, wie künstlich im Grunde alle Zerteilung des Menschen in eine Vielzabl seelischer Funk tionsgebiete ist. 
nens; nur dem, der Wiederholung zu wollen vermag, winkt das in der Zukunft liegende Ziel, das „K ö $\mathrm{n} n$ e n”. Es ist also ein vielgliedriges, durchhaltendes Wollen nötig. Freilich steht dies nicht so hoch, wie das produktive Wollen, das - etwa zur Schaffung eines Werkes - ve r s c h i e d e n e Zwischenziele wollen und diese miteinander verknüpfen muss. Die Vielgliedrigkeit ist bei der Lernhandlung vielmehr eine relativ e i n t ö n i g e; man muss ja immer wieder denselben Stoff vornehmen, bis die Wiederholung zur Einprägung führt.

Aber eben diese Eintönigkeit ist auch die stärkste Hemmung des Lernwillens. Denn obwohl es eine natürliche Wiederholungsfreude gibt - namentlich in kindlichen Entwicklungsstadien so schlägt diese doch leicht in Überdruss um, wenn die Häufigkeit des Wiederholens nicht mehr im Belieben des handelnden Menschen, sondern im Dienst einer objektiven Aufgabe steht. Bei unentwickelter oder konstitutionell schwächlicher Willensbeschaffenheit kann daher derErmüdungspunkt oder der Sättigungspunkt, der eine Fortsetzung der Wiederholung unmöglich macht, schon erreicht sein, ehe der angestrebte Lernerfolg da ist.

Aber nicht nur die Häufung, sondern auch die Orga $\mathrm{n}$ i s a$\mathrm{t}$ i o $\mathrm{n}$ der Wiederholungen stellt starke Ansprüche an den Willen. Das willentliche Lernen ist fast immer an Termine und Pensen gebunden, ganz eindeutig in der Schule, wo man von heut auf morgen eine vorgeschriebene Vokabelmenge, ein Gedicht, eine Reihe mathematischer Lehrsätze ,,auf hat"; aber auch in der freieren Lerntätigkeit des Erwachsenen, der sich selber sein Totalziel (Beherrschung einer Fremdsprache, Können einer Rolle auf der Bühne, Sicherung der in einem Examen verlangten Kenntnisse) in zahlreiche Teilziele aufgliedern muss, um schliesslich des Ganzen Herr zu werden ${ }^{1}$ ).

In jedem Falle ist das Ziel nur zu erreichen, wenn der Wille zu einer bestimmten Zeit für bestimmte Stoffe ein Höchstmals personaler Energie bereit stellt, die sonst vielleicht ganz andere Wege gegangen wäre.

b) In t e r e s s e. - Deshalb ist es von grosser Bedeutung für das Lernen, dass die, auf alle Fälle unumgängliche, Selbstdiszi-

1) Hier hat also der Lernwille schon grössere Ähnlichkeit mit dem oben erwähnten „produktiven Wollen”. 
plin und Selbstüberwindung erleichtert wird durch Gleichschaltung des Lernwillens mit anderen Richtungsdispositionen. Das Lernen auf Gebieten, für welche lebhaftes Interesse besteht, oder die in starken Triebrichtungen des Menschen verankert sind, ist leichter und erfolgreicher, als das Lernen auf gleichgültigen oder unsympathischen Gebieten ").

Das in teressevolle Lernen verbindet die Vorzüge des unwillkürlichen Lernens mit denen eines systematischen Lernwillens; es ist die erstrebenswerteste Form alles Lernens. Am stärksten macht sich dies in jenen - allerdings seltenen Fällen geltend, in denen die innere Verbundenheit mit dem Stoff eine so unbedingte ist, dass es $\mathrm{zu}$ einer völligen I $\mathrm{n} \mathrm{t} \mathrm{r}$ o $\mathrm{zep}$ $\mathrm{t}$ i o $\mathrm{n}$ kommt. Was hier der Lernwille zu leisten hat, ist dann nicht mehr das Heranholen eines fremden, sondern das SichVersenken in einen personnahen Stoff, ein weitgehendes SichIdentifizierenwollen mit dem Gehalt, der zu eigen gemacht werden soll. Ein solches "Inwendiglernen” - wie man es nennen könnte - ist der extreme Gegensatz zu dem mechanischen „Auswendiglernen", von dem später noch zu sprechen sein wird. Wir finden jene seltene Lernweise vornehmlich bei grossen $\mathrm{re}$ produktiven $K$ ünstlern, bei denen sie zuweilen zu fast wunderbar anmutenden Gedächtnisleistungen führt; so vermögen manche Kapellmeister lange Konzertstücke völlig aus dem Kopf zu dirigieren. Das wäre durch blosses „Memorieren" der Partitur nie zu erreichen gewesen, sondern nur durch das "Leben in" der Partitur.

Ein bekannter Regisseur und Schauspieler, den ich einmal über die Art des Rollenlernens befragte, antwortete mir mit einem Paradoxon: „Der echte Schauspieler lernt seine Rolle überhaupt nicht. Er versenkt sich in sie - und kann sie dann eben". Natürlich ist der Satz in dieser Allgemeinheit nicht richtig. Die weitaus meisten Schauspieler sind gezwungen, regelrecht zu memorieren; und selbst für die Grössten wird jenes geistige Besitzergreifen durch Identifikation nur bei gewissen, ihnen besonders „liegenden" Rollen möglich sein.

Von ganz anderer Art als dies gegenständliche Interesse ist das for $\mathrm{m}$ a $1 \mathrm{e}$ Interesse, das den Lernwillen befeuern und den Lernerfolg steigern kann. Allem Lernen wohnt nämlich ein

1) Die Volkspsychologie kennt das Wort „Gedächtnis ist Interesse”, das zum Mindesten eine Teilwahrheit enthält. 
s portähnlich er Z u g inne: das durch Willenseinsatz zu erzielende Können wird als Erhöhung des Geltungsbewusstseins genossen; zugleich ist durch genaue Messung eine weitgehende Vergleichung mit Mitbewerbern sowohl bezüglich der Lernzeiten wie der Lernmengen möglich und damit dem Wetteifer und dem Wettkampf Tür und Tor geöffnet. Ebenfalls an den Sport erinnert der Umstand, dass die Betonung des dynamischen Moments den Lernenden schliesslich gegen den gegenständlichen Gehalt des Lernstoffes gleichgültig macht. Darin liegt ein Vorteil; denn die psychische Sättigung, die den, nun einmal lernnotwendigen, Stoffen gegenüber leicht eintritt, kann übertönt werden durch das sportliche Interesse. Aber auch nachteilige Wirkungen sind möglich: das mangelnde Interesse am Gegenstand kann leicht beharren, nachdem man den Stoff eingeprägt hat, sodass dieser seinen geistigen Gehalt überhaupt nicht geltend machen kann.

Für die pädagogische Anwendung ergibt sich: In erster Linie muss das Lernen durch Erweckung des ge ge n s tändlichen Interesses unterstützt werden. Das formal-s portlich e Interesse durch Wetteifer und Ehrgeiz sollte nur dort gelegentlich zum Einsatz kommen, wo das gegenständliche Interesse nicht allein ausreicht, um den Lernwillen anzutreiben; aber dann muss mindestens nachträglich das Interesse auch für den Gehalt des gelernten Stoffes entwickelt werden.

Wetteifer bedarf übrigens nicht unbedingt anderer Mitbewerber; denn auch mit sich selbst kann man konkurrieren, indem man die zunächst geringeren Leistungen durch bessere zu übertreffen sucht. Man findet gerade bei schlechten Lernern nicht selten diese verbissene Tendenz, nun erst recht mit dem spröden Stoff fertig zu werden und sich dadurch $z u$ beweisen, dass man erfolgreich Selbstüberwindung zu üben vermag. Eine solche Uberkompensation einer Minderwertigkeit kann mitunter zu bedeutenden Lernerfolgen führen.

c) In t ellige n z. - Auch die Beteiligung der Intelligenz am Lernen ist in formaler wie inhaltlicher Hinsicht von Bedeutung.

Formales (organisatorisches) Denken muss die Lernstoffe zweckmärsig gliedern und verknüpfen, die Wiederholungen geeignet verteilen, die Tageszeiten geschickt auswählen. Im allgemeinen wird auf diese Erfordernisse viel zu wenig Denken verwandt und sonderbarer Weise auch wenig Anleitung gegeben, wie sie zu erfüllen seien. 
Die Schule z.B. (die ja auch in ihren fortgeschrittensten Formen auf das häusliche Lernen der Schüler nie wird verzichten können) pflegt sich kaum darum zu kümmern, wi e es eigentlich die Schüler anstellen, sich daheim die aufgegebenen Vokabeln, Jahreszahlen, Regeln, Lehrsätze, u.s.w. einzuprägen. Von selbst aber kommen die Kinder nicht immer darauf, dass es sich hier um ein $d u r c h ~ D e n k e n$ $t$ e $\mathrm{c} \mathrm{h}$ n i s i e r b a r e s Tun handelt, bei dem eine geschickte Ökonomie Kräfte sparen und Leistungen steigern kann. So mag die Verwertung des Vorstellungstypus, zu dem der Schüler gehört, die Einprägungsarbeit erleichstern. Andere lerntechnische und lernökonomische Gesichtspunkte werden uns weiter unten begegnen. (Vgl. z.B. 326-330).

Ältere und reifere Lerner - Schüler der Oberklassen und Studenten, junge Menschen, die in der Berufsausbildung sind, u.s.w. - vermögen natürlich in höherem Malse, als es Kinder können, ihre Lernarbeit durch Denken zu organisieren.

Viel wichtiger aber ist die i $\mathrm{nhal}$ t li che Beteiligung des Denkens am Lernen. Es handelt sich darum, ob der Lernstoff rein in seiner anschaulichen Gegebenheit und seiner assoziativen Verbundenheit eingeprägt wird, oder ob auch der ihm innewohnende ge d a n kli c h e Gehalt beim Lernen mitergriffen wird. Der hier berührte Unterschied ist früher von psychologischer und pädagogischer Seite durch die Ausdrücke "m e chanis ch e s" und ,j u d i z i ö s e s" Gedächtnis bezeichnet worden. Es wird sich später zeigen, dass es Ưbergänge gibt; hier sei erst einmal der Gegensatz besprochen.

Von geringen Ausnahmen abgesehen, haben die einzuprägenden Lernstoffe nicht nur Materie, Gestalt und Gruppierung, sondern auch einen $\mathrm{S}$ i $\mathrm{n} \mathrm{n}$; sie bedeuten, sie meinen etwas; und gerade darin, dass man diesen Sinne versteht und beherrscht, liegt der Hauptbildungswert der durch Lernen erworbenen Kenntnisse. In vielen Fällen lässt sich der Sinn von der Gegebenheit des Stoffes gar nicht trennen; seine Erfassung bedarf keiner besonderen Denkleistungen. Wenn ein erwachsener Deutscher aus irgend einem Grunde einen einfachen deutschen Vierzeiler zu lernen hat, dann ist es ihm garnicht möglich, sich die Worte unabhängig von dem Sinn einzuprägen; der sprachliche Text ist überhaupt nur als Sinnträger für ihn da.

In anderen Fällen aber muss die Scheidung doch gemacht werden. Dann wird das Lernen durch das Fehlen der Sinnerfassung erschwert. 
Beispiele.

1) Ein deutsches Gedichtchen von 60 Silben lernt ein Deutscher ganz schnell in drei bis vier Lesungen. Für ein gleich langes ungarisches Gedicht von gleichem Rhythmus, dessen Sinn aber nicht verstanden wird, braucht der deutsche Leser ein Vielfaches (nach Ebbinghaus etwa das 10 fache) an Wiederholungszahl und Zeitaufwand.

2) Ein Schüler, der einen geometrischen Lehrsatz v e r s t e ht, wird ihn viel leichter lernen und sinngemäls reproduzieren können, als jener, der in Ermangelung tieferen Sinnverständnisses den wörtlichen Text als solchen memorieren muss.

3) Es gibt einen Test zur Intelligenzprüfung, der eine Lernleistung voraussetzt ${ }^{1}$ ). Er besteht aus 10 Wortzusammenstellungen $z u$ je drei Gliedern, z.B.:

Gewinn-Neid-Junge

Regen-Frost-Glatteis

Diebstahl-Gefängnis-Verachtung

u.s.w.

Die Reihe wird mehrmals dargeboten, mit dem Auftrag, sie einzuprägen. Der Versuchsleiter prüft den Lerneffekt, indem er die Anfangswörter jeder Dreiergruppe zuruft; der Prüfling hat die beiden dazugehörigen Wörter zu nennen.

Das Ergebnis ist deutlich: Diejenigen Prüflinge, die beim ersten Hören sofort den Sinnzusammenhang innerhalb der einzelnen Gruppen bemerkten und sich merkten, können nachher weit mehr Gruppen richtig wiedergeben als jene, die sich beim Einprägen wesentlich auf die assoziative Verknüpfung der Wörter verlassen mussten, weil sie die Bedeutungsbeziehung nicht erkannt hatten.

Der „Sinn” ist also nicht ein zur Lernmaterie neu hinzukommendes weiteres Lernelement, das mit jenem assoziiert würde (wäre dies der Fall, dann müsste ja Wortlaut plus Sinn einen Lernstoff von grösserem Umfang darstellen, als der Wortlaut allein, und daher schwerer einzuprägen sein); er ist vielmehr ein die Lernmaterie organisierendes und gestaltendes Prinzip. Er vermag auch in ganz anderer Weise den Lernstoff in der P e r s o n zu verankern, die - selber ein Sinnganzes - nach sinnvollem Tun verlangt und gegen die Aufnahme bloss chaotischen Stoffes und bedeutungsloser Komplexe stärkste Hemmungen hat.

Freilich setzt ein sinnhaftes Lernen eine gewisse Höhe der Intelligenz voraus, die entweder den Stoff von vorn herein als sinnerfüllten ergreift oder aber durch bewusste Denkarbeit bemüht ist, den Sinn zu finden.

1) Der Test ist vom Leipziger Lehrerverein herausgegeben worden. Auch abgedruckt in Stern-Wiegmann, Methodensammlung S. 31 .

Stern, Psychologie 
Wenig untersucht ist bisher noch der zweite Fall: die a $11-$ mähliche Erarbeitung des Sinnverständ$\mathrm{n}$ i s s e s während des Lernens (z.B. eines schwierigen Gedichtes, eines mathematischen Zusammenhanges). Oft steht am Anfang nur eine ganz vage Sinnerfassung; die Wiederholung dient dann nicht nur der immer festeren Einprägung des Textes, sondern auch der fortschreitenden Klärung des Sinnes. Gerade aus dem sicherer beherrschten Stoff heraus findet das Denken neue Ansätze zu Sinndeutungen und Sinnverknüpfungen, die bisher nicht bemerkt worden waren. So bildet der Lernprozess für den judiziös Lernenden auch nicht jene eintönige Aneinanderfügung immer derselben Abläufe, sondern er macht eine Reihe qualitativ sehr ungleicher Phasen durch, in denen bald mehr das Bewusstsein steigender Sicherung der Stoffbeherrschung, bald das vertiefte Zueigenmachen des Sinngehalts vorherrscht.

Von hier aus muss man Bedenken gegen die schroffe Scheidung von „mechanischem" und „judiziösem" Lernen, namentlich in entwicklungspsychologischer Hinsicht, erheben. Denn für gewisse Entwicklungsstufen ist eine ganz vage Sinnerfassung die angemessene und vielleicht allein mögliche Verhaltungsweise; sie ist daher durchaus nicht so personfremd, wie das Beiwort „mechanisch" anzudeuten scheint.

Beispiel: Unsere vierjährige Tochter hatte mit der älteren schulreifen Schwester das Gedicht „Es braust ein Ruf wie Donnerhall” absichtslos mitgelernt, dessen Bedeutungsgehalt natürlich weit über den Horizont des Kindes ging. Dennoch hatte das Gedicht für das jüngere Kind einen Sinn, wenn auch einen andern, mehr vitalen, weniger geistigen, als für höhere Entwicklungsstufen. Die Freude an den Klanggestalten und Rhythmen, gewisse unklar verstandene Einzelwörter und Stellen, um die sich dann ein Hof vagerer Klänge lagert, die soziale Freude am Mitmachenkönnen: das war zunächst für dieses Kind der "Sinn" des Gedichts.

Man sollte also nicht gleichsam einen idealen Sinngehalt des Lernstoffes voraussetzen, dessen Nichtbeachtung dasLernen schon als „mechanisch" charakterisierte. Vielmehr darf das Lernen nur auf denjenigen Sinngehalt bezogen werden, der dem Lernenden $\mathrm{z} u$ g e m u t e $\mathrm{t}$ werden kann. Wo auch dieser nicht aktiviert wird, und wo deshalb das Lernen rein in der äusserlichen Aneignung des Stoffes und seiner assoziativen Verknüpfungen stecken bliebt, da ist die Bezeichnung "m e c h a n i s c h" am Platze. 
Mechanisch lernt also derjenige Mensch, der zwar intelligent genug wäre, um die für das Sinnverstehen nötigen Denkwege zu gehen, der aber zu wenig geistig interessiert ist, um hierauf Mühe und Kraft zu verwenden. Mechanisch lernt ferner derjenige, dem von aussen her Lernstoffe aufgedrängt werden, die auf keinerlei Resonanz in der Sinnstruktur seiner Persönlichkeit stossen. Endlich kann die - etwa vom Unterricht gestellte - Forderung wörtlich e r Texteinprägung zu mechanischem Lernen Anlass geben, da die Beachtung des Sinnes leicht die strenge Bindung an den festgelegten Wortlaut lockert.

In den obigen Zusammenhang gehört auch die sogenannte „M $\mathrm{n}$ em o t e c h n i k". Sie besteht in einem System von Kunstgriffen, um sinnfremde Lernstoffe - vor allem Ziffern, ferner schwierige geographische und sonstige Fremdnamen - mit einem indirekten Sinnbezug zu behaften und dadurch einprägsamer zu machen. So sind z.B. historische Jahreszahlen, Hausnummern, Telephonnummern schwer zu behalten und leicht zu verwechseln; werden nun die einzelnen $Z$ iffern, z. B. einer Telephonnummer, durch Konsonanten ersetzt, und wird dann aus den Konsonanten (unter Einschiebung von Vokalen) ein Wort gebildet, das auf irgend welchen Umwegen zu dem Inhaber jener Rufnummer in Sinnbeziehung gebracht werden kann, so haftet das Stichwort - und durch Rückübersetzung die Telephonnummer - viel leichter.

Der praktische Wert solcher Gedächtnistricks ist nur gering einzuschätzen. Bei pädagogischen Stoffen sind sie sogar sehr bedenklich; denn wer eine Jahreszahl auf diesem gekünstelten Wege einprägt, der unterlässt es, das Ereignis in Beziehung zu den Zeitverhältnissen zu denken, durch welche es erst seinen wahren Sinn innerhalb der Chronologie erhält.

Der Hauptschauplatz mnemotechnischer Kunststücke wird wohl immer das Variété bleiben, in dem Rechen- und Gedächtnis-Künstler durch das Behalten grosser Mengen sinnfremden Stoffes Erstaunen erregen.

2. Experimentelle Untersuchungen

a) A u f g a b e n und M e thode n. - Nunmehr ist der Boden für eine Behandlung derjenigen Ergebnisse bereitet, die von der experimentellen Psychologie, inbes. von Ebbinghaus, G. E. Müller und ihren Schülern, gerade auf dem Gebiet des mechanischen Lernens gefunden worden sind.

Es war kein Zufall, dass die Gedächtnispsychologie an dieser 
Stelle, und nicht an dem Lernen sinnvoller Stoffe, ihre exakte Arbeit begann. Gewiss spielte hier das methodische Motiv mit: sinnfremde Stoffe konnten (in der Form sinnloser Silben von bestimmtem Bau) besonders leicht untereinander vergleichbar gemacht und mengenmälsig dosiert werden (vgl. hierzu S. 81f). Aber ein anderes stillschweigendes Motiv lag tiefer: hier glaubte man diejenigen Bedingungen der Lernens rein erfassen zu können, die in der Beschaffenheit des Stoffes als solchen und in dem Assoziationsprinzip begründet sind. Die Person als aktiv mitwirkender und sinngebender Faktor schien ausgeschaltet zu sein. Es war also im Grunde eine Umformung der Assoziationstheorie der Engländer und Herbarts ins Empirisch-experimentelle.

Für uns erhalten jene Untersuchungen ein anderes Gesicht, werden aber darum nicht wertlos.

Ein völlig person-unabhängiges Lernen, dessen Mechanismus seinen eigenen Gesetzen folgen würde, ist nicht denkbar. Da es aber sehr verschiedene Grade der Einbettung des Lernprozesses in die Person gibt, so bieten die am wenigsten eingebetteten $\mathrm{Ar}$ ten des Lernens die beste Möglichkeit, den relativen Anteil der nicht-personalen Bedingungen des Lernens zu ergründen. Aus der Konvergenz dieser nichtpersonalen mit den eben ausführlich besprochenen personalen Bedingungen des Lernens geht dann der tatsächliche Lernprozess hervor.

Die meisten dieser Experimentaluntersuchungen benutzten als Lernstoffe Serien sinnloser Silben; gelegentlich kamen auch Reihen von Ziffern, von unzusammenhängenden Wörtern, von Bildern zur Anwendung.

Die Verfahrungsweisen gliedern sich folgendermalsen. Bei der „Lernmethode" hat die Versuchsperson die zu erlernende Reihe so oft durchzulesen, bis sie sie „kann”. Die „Ersparnismethode” lässt eine früher gelernte, aber wieder vergessene Reihe nach einiger Zeit wiederlernen; je geringer die $Z a h l$ der nun wieder nötigen Wiederholungen, um so grösser die Nachwirkung des ersten Erlernens. Die "Treffermethode” unterbricht den Lernprozess, ehe die Reihe voll beherrscht wird, und stellt den bisherigen Teilerfolg des Lernens dadurch fest, dass zu zugerufenen Gliedern der Reihe das folgende Glied genannt werden soll. Die „Hilfemethode" schiebt in den unvollendeten Lernprozess eine Reih mit Hilfegebung ein; die Zahl der nötigen Hilfen zeigt, wieviel noch am vollen Lernerfolg fehlt. 
b) Der Umfang des Lernst of fes. - Richtet man (unter Absehung vom Bedeutungsgehalt) das Augenmerk lediglich auf die Menge der einzuprägenden Glieder, so wächst natürlich die Lernarbeit mit der Länge der Reihe, aber nicht proportional, sondern in zunehmendem Grade ${ }^{1}$ ). Wenn z.B. zur Einprägung einer Reihe von 6 Gliedern für den erwachsenen gesunden Menschen eine einzige Lesung genügt, so verlangt eine 12gliedrige Reihe nicht etwa zwei Wiederholungen, sondern deren 10-12, eine 24-gliedrige Reihe wieder weit mehr als den doppelten Aufwand, der für 12 Glieder nötig ist, nämlich 44 Lesungen. Schnell ist hier eine obere Grenze erreicht; sehr lange Lernstoffe sind überhaupt nicht mehr durch wiederholte Gesamt-Durchlesung zu bewältigen, mag die Zahl der Lesungen noch so sehr gesteigert werden. In solchen Fällen ist dann „Fraktionierung” nötig, d.h. Zerlegung des Lernstoffes in Bruchstücke, die gesondert eingeprägt werden müssen. (Vgl. hierzu S. 326).

Der Umfang des Lernstoffes hängt natürlich auch von dem Umfang der einzelnen Glieder ab; aber bemerkenswerter Weise hat dieser innerhalb bestimmter Grenzen keinen wesentlichen Einfluss auf die Lernschwierigkeit. Eine achtgliedrige Reihe, die aus unzusammenhängenden Wörtern besteht, bereitet kaum grössere Mühe, als eine Reihe aus acht ungeordneten Einzelbuchstaben oder Ziffern, obgleich die erste einen Stoff von vielfacher Länge darstellt. Es kommt also nicht auf die objektive Menge der „Elemente", sondern auf die Lern-E i n h e it e n an, die sich als natürliche Gliedgestalten der Reihe darbieten.

Solche Einheitsbildungen, die das Lernen wesentlich erleichtern, sind nun auch bei gänzlich sinnlosen Lernstoffen möglich, ja sogar kaum zu umgehen, selbst wenn die äussere Darbietung des Stoffes sie zu vermeiden sucht. Für den Aufnehmenden schliessen sich nämlich benachbarte Einzelglieder leicht zu "Komplexen" zusammen, die als einheitliche klanglich-rhythmische Gestalten eingeprägt und wiedergegeben werden. Die Art der Darbietung kann solche Komplexbildung natürlich sehr fördern ${ }^{2}$ ).

Auf die vielen anderen Gesichtspunkte der Komplexbildung

1) Uber das entsprechende Gesetz bei der unmittelbaren Merkfähigkeit vgl. S. 274.

2) Bezüglich der Rhythmisierung des Lernstoffes gilt hier das Gleiche wie für die unmittelbare Merkfähigkeit. Vgl. hierzu S. 275. 
(wie sie namentlich von G. E. Müller entwickelt worden sind) kann hier nicht näher eingegangen werden. Nur darauf sei hingewiesen, dass auch die zu erlernende Ges a $\mathrm{mtr}$ e i h e eine solche komplexe Gestalt bildet, deren verschiedene Glieder, j e $\mathrm{nach}$ ihrer $\mathrm{Stelle}$ in der $\mathrm{Reihe}$, eine geringere oder grössere Bevorzugung beim Erlernen erfahren. So werden im allgemeinen Anfangs- und End-Glieder einer Reihe viel früher beherrscht als die mittleren Glieder.

c) „F r a k t i o n i e r u n g” kommt nicht nur bei überlangen Lernstoffen vor, sondern auch bei Memorieraufgaben, die innerhalb e i n e s Lernpensums bewältigt werden können. Ist z.B. ein längeres Gedicht von einem Tage zum anderen einzuprägen, so gibt es zwei Möglichkeiten. Der Lernende liest entweder den ganzen Lernstoff von $A$ bis $Z$ immer wieder durch, bis er ihn kann (,Ganzmethode”). Oder er fraktioniert ihn: er lernt etwa zunächst die ersten vier Zeilen für sich durch mehrfache Wiederholung, dann die nächsten vier Zeilen u.s.w., um schliesslich alles Gelernte zum ganzen Gedicht zusammenzusetzen. („Teilmethode"). Schüler, denen man die Art des häuslichen Memorierens ganz überlässt, pflegen fast durchgehends die Teilmethode zu benutzen.

Die experimentelle Prüfung hat nun gefunden, dass das fraktionierte Lernen unökonomisch ist und zwar bei sinnvollen wie bei sinnlosen Lernstoffen, bei der Einprägung ebenso wie bei der Reproduktion. Nach der Ganzmethode konnten die Lerner einen Stoff schneller memorieren als einen gleich langen und schweren Stoff, den sie nach der Teilmethode lernten. Waren nach einiger Zeit beide Lernstoffe vergessen, so erforderte die Wiedereinprägung des „Ganzgelernten" weniger Wiederholungen als die des fraktioniert Gelernten.

Zur Erklärung dieses Tatbestandes liegt zunächst ein a s s o$z$ i a $t$ i o n s-psychologischer Gesichtspunkt nahe. Lernt man ein Gedicht fraktioniert und beginnt mit mehrfach wiederholter Lesung der ersten vier Zeilen, so folgt jedesmal auf das letzte Wort der vier ten Zeile daserste Wort der er s ten Zeile; so bildet sich hier eine Assoziation, die $\mathrm{f} \mathrm{a} 1 \mathrm{~s} \mathrm{c} \mathrm{h}$ ist, sie muss später gelöst und durch die Assoziierung des letzten Wortes der vierten Zeile mit dem ersten der fünften Zeile ersetzt werden. Und ebenso an den 
weiteren Bruchstellen. Es wird also zum Teil unfruchtbare und wieder rückgängig $\mathrm{zu}$ machende Lernarbeit geleistet. Bei der Ganzmethode wird dagegen jedes Glied des Gedichtes von vorn herein nur in der richtigen Reihenfolge mit den Nachbargliedern assoziiert. - Wichtiger aber ist der $\mathrm{G}$ a $\mathrm{n} \mathrm{h}$ e i $\mathrm{t} \mathrm{s}$ g e s i c h t s$\mathrm{punkt}$ als Erklärungsmotiv. Die Fraktionierung zerreisst die natürliche Einheit des Lernstoffes und schwächt daher jene Lernhilfen, die von der klanglich-rhythmischen Gesamtgestalt und vom ununterbrochenen Sinnzusammenhang ausgehen ${ }^{1}$ ).

Ist nun aber dies experimentelle Ergebnis geeignet, ohne weiteres auf die Praxis, etwa des häuslichen Memorierens der Schulkinder, übertragen zu werden? Zwei psychologische Bedenken erheben sich hier.

Erstens steht der Schüler unter gewissen pe r s o n a l e n Bedingungen des Lernens, welche die vom Lernstoff her kommenden durchkreuzen können.

Sieht sich der Schüler bei Beginn des Lernens vor der Total-Aufgabe, ein Gedicht von 40 Zeilen zu lernen, so schreckt er vor diesem Umfang zurück. Deshalb dosiert er sich sein Pensum und gelangt schneller zu Teilerfolgen, die zu weiteren Fortschritten Mut machen. („Die erste Strophe ist nun glücklich bewältigt".) Auch ist es abwechslungsreicher, in den ersten 10 Lernminuten den Anfang, in den zweiten 10 Minuten die Mitte, in den dritten den Schluss des Gedichtes zu lernen, als die ganze Lernzeit hindurch immer dasselbe, nämlich das ganze Gedicht, vorzunehmen.

Zweitens enthält jeder Lernstoff - sinnvoller in viel höherem Malse als sinnloser - Stellen ver s chie de ner Schwierigkeit. Die besonders schwer eingängigen Stellen b e dü $r \mathrm{f}$ e $n$ spezieller Lernanstrengung; es wäre daher sehr unpraktisch, wegen einiger noch nicht bewältigter Verse oder (in einem Musikstück) Passagen jedesmal den ganzen Stoff einschliesslich der schon beherrschten Stellen abrollen zu lassen.

Man wird also - worauf schon Meumann aufmerksam gemacht hat - folgendes Verfahren als das zweckmälsigste anzusehen haben: Der neue Lernstoff wird zunächst im ganzen an-gelernt. Hierbei wird eine gewisse allgemeine Vertrautheit erworben, der einheitliche Rahmen der Gedichtgestalt und des Sinnzusammenhanges gesichert. Zugleich machen sich hierbei schon die spröden Stellen spürbar, die nun im Teillernen gesondert eingeprägt werden. Dann wird wieder in mehrfachen Ganzlesungen das Teil-gelernte jenem Rahmen eingefügt, sodass das blosse Aneinanderstücken der isoliert gelernten Teile vermieden wird.

1) Das so häufige „Stocken” beim Aufsagen von Gedichten wird in der Tat am båufigsten an solchen Bruch- und Lötstellen stattfinden, wo der glatte Verlauf eine Unterbrechung erfährt. 
d) Verteilung der Wiederholungen. - Wir hatten an früherer Stelle (S. 262) das allgemeine mnemische Gesetz besprochen, dass bei Durchführung einer längeren Serie von Wiederholungen des gleichen Lernstoffes die mnemische Empfänglichkeit allmählich abnimmt; schliesslich kommt den weiteren Wiederholungen überhaupt kein zusätzlicher Einprägungswert mehr zu. Diese Abnahme des Wiederholungseffekts stellt so fanden wir - eine Art Selbstschutz der Person gegen die Überlastung mit einer einseitigen Lernaufgabe dar; das hartnäckige pausenlose „Büffeln” desselben Lernstoffs erweist sich schliesslich als sinnlos.

Nun haben aber experimentelle Untersuchungen ergeben, dass dies Gesetz nur bei sehr dichter Abfolge der Wiederholungen gilt. Einer bestimmten Anzahl von Wiederholungen entspricht überhaupt nicht eine konstante mnemische Gesamtwirkung; vielmehr ist die Wirkung um so grösser, je weiter die mnemischen Reize zeitlich verteilt sind (sogen. "Jost'sches Gesetz"). Lerne ich ein Gedicht dadurch, dass ich es $30 \mathrm{Mal}$ hintereinander durchlese, so ist der Einprägungswert ungleich geringer, als wenn ich an 6 aufeinander folgenden Tagen das Gedicht je 5 Mal durchgelesen hätte.

Selbstverständlich gilt das Jost'sche Gesetz nicht unbegrenzt: wenn ich nur einmal im Monat das Gedicht je einmal durchlese, würde ich es auch nach 30 Monaten noch nicht „können". Es ist daher korrekter, das Gesetz so zu formulieren: $F$ ü r j e d e, einer Lernaufgabe $z u$ widmende, Wiederholungsanzahl gibt es ein Optimum der Wirkung, das von der BreitederVerteilung $\mathrm{a} b \mathrm{~h}$ ä $\mathrm{ng}$ i $\mathrm{i}$ s t. Offenbar ist jeweilig diejenige Verteilung die optimale, bei welcher die, der Sonderaufgabe zuzuwendende, Energie dem gesamten energetischen Geschehen der Person am besten eingeordnet ist.

Das Jostsche Gesetz ist von grosser p r a $\mathbf{k}$ t i s c h e r Bedeutung: denn es besagt, dass die für irgend eine Lern- oder U'bungsaufgabe verfügbare Kraft und Zeit in mehr oder weniger ökonomischer Weise verwendet werden kann. Deshalb sollte man auf allen Gebieten, die es mit repetierende m Lernen und Uben zu tun haben, - in der Schule, beim beruflichen Anlernen, im Sport, bei Examensvorbereitung - sowohl die gruppenmälsig günstigste Verteilung der Repeti- 
tionen und der Pausen, wie den für das Einzelindividuum geltenden optimalen Wert der Verteilung beachten.

e) L e r n t e m p o. - Man kann einen Lernstoff in langsamem, mittlerem oder schnellem Tempo durchlesen. Ebbinghaus, der an sich selbst die verschiedenen Tempi beim Lernen von Gedichten verglich, fand, dass das schnellste noch mögliche Lesetempo (200 Jamben in der Minute) den besten Erfolg hatte, sowohl für die Gesamtzeit des Lernens wie für die Nachhaltigkeit der Einprägung nach acht Tagen.

Aber auch hier wird man zwischen der möglichen Maximalleistung und dem o p $t$ i m a 1 e $n$ Verhalten scheiden müssen. Es gibt allerdings Situationen, in denen es auf schnellstes Lernen ankommt (Ebbinghaus erinnert an den Schüler, der in den Minuten der Zwischenpause noch eiligst das zuhause Versäumte nachholt); es erweist sich aus dem Experiment, dass solches Notverhalten ganz gute Erfolge zeitigen kann. Aber nicht nur wegen der sehr zweifelhaften Dauerwirkung des Erfolgs (siehe unten), sondern auch wegen der personalen Inadaequatheit solch gehetzten Tuns darf man aus dem Experimentalergebnis keine Empfehlung machen. Die übergrosse Schnelligkeit muss entweder zu einer sehr lockeren Einprägung führen - es wird nur gerade die äusserste seelische Haut von dem Lernstoff geritzt - oder sie verlangt eine unnatürliche Kraftanspannung des Lernenden, die höchstens in Ausnahmefällen zu rechtfertigen ist. Gerade die Wahl des Lerntempos wird man weitgehend dem Lerner überlassen können und müssen. Denn dies Tempo hängt eng zusammen mit seinem personalen Tempo überhaupt; daher findet jeder Mensch mit grosser Treffsicherheit die für ihn optimale Lerngeschwindigkeit.

Ubrigens handelt es sich bei diesem individuellen Lerntempo nicht nur um die Geschwindigkeit des Lesens, sondern auch um den Anspruch, den der Lernende an sich selbst stellt, um sich mit dem Erfolg zufrieden zu geben. „K ö n n e n” u n d „K ö nnen" sind zwei sehr verschiedene Dinge. Der eine hört mit dem Memorieren auf, sobald es ihm gelingt, soeben und notdürftig den Lernstoff, ohne ins Buch zu blicken, herzusagen; der andre knüpft hieran erst eine Reihe vonWiederholungen zum Zweck der Sicherung und der Kontrolle (mit gelegentlichen Blicken auf das Buch, ob der von ihm rezitierte Wortlaut auch mit dem Text übereinstimmt). Der langsame Lerner ist also zu- 
gleich der gründlichere und kritischere - manchmal vielleicht auch pedantischere - Lerner als der Schnell-Lerner; der Unterschied ist zum Teil charakterologischer Art.

Mag der Schnell-Lerner für kurzfristiges Behalten den andern übertreffen - auf lange Sicht ist meist die Lernarbeit des langsamen Lerners aussichtsvoller ${ }^{1}$ ).

\section{BEHALTEN UND VERGESSEN VON KENNTNISSEN}

\section{Der Lernverlust}

Der Mensch lernt nicht, um zu lernen, sondern um den gewonnenen Kenntnisbesitz d a u e r n d zu haben und um all$\mathrm{g}$ e $\mathrm{m}$ e i $\mathrm{n}$ über ihn verfügen zu können. Aber zwischen Wunsch und Erfüllung klafft eine grosse Unstimmigkeit. Fast mit gleicher Wucht wie die positive Bedeutung des Lernens drängt sich der entgegengesetzte Tatbestand auf: alsbald nach Abschluss der Einprägung setzt ein $r$ ü c k lä u fi ge r Prozess ein, der den eben erreichten Erfolg abschwächt und schliesslich fast bis auf den Nullpunkt reduziert.

Dieser "Lernverlust” äussert sich in verschiedenen Symptomen. Die einzelnen Glieder des Lernstoffes werden blasser, vager, schwankender (Klarheitsverlust). Die Zusammenhänge zwischen den Gliedern werden gelockert, bis sie zu reissen beginnen und schliesslich den Stoff überhaupt nicht mehr zusammenhalten können (Festigkeitsverlust). Die durch den primären Lernakt geschaffene dynamische Disposition wird geschwächt, sodass später die Wiedererlernung des halb Vergessenen immer grössere Neuaufwendung von Zeit und Kraft erfordert (Ubungsverlust). Die Wiederhervorholung des Gelernten macht eine zunehmende Willensanstrengung des Sich-Besinnens notwendig (Sicherheitsverlust). Endlich ist auch die unterirdische Wirkung, die vom Gelernten ausgeht, sein Niederschlag in Bildung und Lebenserfahrung einer allmählichen Abschwächung ausgesetzt („Verwertungsverlust”).

Die Laienpsychologie fasst alle diese sehr verschiedenartigen Verlusterscheinungen unter der Bezeichnung des „V e r g e s-

\footnotetext{
1) Sehr plastisch sind die beiden Lernertypen gegenübergestellt in Külpe's „Vorlesungen über Psychologie". S. 208 ff.
} 
s e n s" zusammen; aber es ist nötig, dass man die einzelnen Momente auseinanderhält. Im allgemeinen beachtet man nur die beiden ersten Phänomene, welche die freie Reproduzierb a rke it des Gelernten schädigen, und hält das Vergessen für vollständig, wenn Inhalt und Zusammenhang des Gelernten nicht mehr in Form von Gedächtnisvorstellungen und Vorstellungsketten vergegenwärtigt werden können. Hierbei wird zweierlei übersehen: dass selbst die absolute Unmöglichkeit, in einer bestimmten Lebensepoche oder Situation zu reproduzieren, die spätere Reproduzierbarkeit nicht ausschliesst; und dass die gebundenen, eingebetteten Wirkungen noch erhalten sein können, wenn längst das freie Reproduzieren vorbei ist.

Von diesen letzten Wirkungen war zum Teil schon früher die Rede. (s.S. 282) ; dort wurde der Hauptwert der „Bildung" gerade darin gesehen, dass das früher Gelernte $\mathrm{n}$ i $\mathrm{c} \mathrm{h}$ t verloren ist, obgleich es nicht mehr für sich reproduziert werden kann. In der Tat, der Satz: „non scholae discimus, sed vitae” würde nichts als ein ungeheurer Irrtum sein, wenn er die Forderung einschlösse, dass alles Gelernte zeitlebens „reproduzierbar” sein sollte. Nur dann, wenn wir auch jene ,eingebetteten” Wirkungen mit einrechnen, ist der Satz sinnvoll. Der Umstand, dass jemand als Schüler ganze Bücher der Odyssee, Balladen und Monologe der Klassiker, die griechischen unregelmäfsigen Verben u.s.w. gelernt hatte, ist nicht einfach aus seinem Dasein verschwunden, weil er davon nach Jahrzehnten nichts mehr „kann”; denn das frühere Können hat mit beigetragen zur Formung seiner geistigen Persönlichkeit; und wenn selbst auch diese gebundene Wirksamkeit allmählich nachlässt (s. oben „Verwertungsverlust”), so doch sicher sehr viel langsamer als die freie Reproduktionsfähigkeit, und wohl nie bis zum Nullpunkt.

Die personale Bedeutung des Vergessens scheint zunächst eine rein negative zu sein, was ja schon der Ausdruck „Verlust” bekundet. Der Mensch empfindet immer wieder die „Vergesslichkeit" als ein besonders ärgerliches, ja tragisches Symptom seiner Unvollkommenheit; gesteigert wird dies Unzulänglichkeitsgefühl noch durch den Gedanken an den gewaltigen Kraftaufwand, welcher der Lernarbeit nun "ganz umsonst" in den schönsten Entwicklungsjahren gewidmet worden war. 
Dass das „Umsonst” nicht in vollem Sinne zutrifft, haben wir schon oben gesehen. Aber es gibt auch einen unmittelbar positiven Wert des Vergessens ${ }^{1}$ ): Kenntnisverlust kann Entl astung bedeuten. Die verschiedenen Lebensepochen und Lebenssituationen e r forder $\mathrm{n}$ immer wieder andere Kenntnisse, und die ja stets begrenzte Energie muss daher jeweils diejenigen Kenntnismassen unberücksichtigt lassen, die zur Lebensaufgabe nicht in Beziehung stehen. Wir erwähnten schon früher einmal den typischen Polyhistor, der nicht „vergessen” kann und dadurch weder sein Wissen in die tiefere Schicht echter Bildung einzubetten, noch seine Energieen für über-mnemische (z.B. schaffende) Aufgaben freizumachen vermag.

Natürlich will eine solche Betrachtung die schmerzhaften Erscheinungen des Vergessens nicht bagatellisieren. Aber es musste betont werden, dass dem Vergessen eine a m bival e $\mathrm{nte} B$ deutung zukommt.

\section{Experimentelle Untersuchungen}

Experimente über den zeitlichen Ablauf des Lernverlustes haben eine G r u n d rege 1 ergeben -, freilich auch speziellere Regeln, die jene zum Teil durchkreuzen.

Die Grundregel lautet: Je länger die seit der Einprägung verflossene Latenzzeit ist, um so stärker ist das Vergessen; und zwar steigt die Vergessenskurve in der ersten Zeit nach der Einprägung besonders schnell, späterhin allmählich langsamer, und verläuft schliesslich asymptotisch.

Ebbinghaus hat das Gesetz am Ubungsverlust nachgewiesen; es war eines der frühesten Ergebnisse experimenteller Gedächtnispsychologie überhaupt. Wir geben seinen Befunden des leichteren Verständnisses halber eine etwas veränderte Fassung.

Für die Einprägung einer sinnlosen Silbenreihe bestimmter Länge seien beim erstmaligen Lernen - so nehmen wir an - 30 Wiederholungen nötig gewesen. Wird nun eine so gelernte (und sofort wieder vergessene) Reihe nach einer halben Stunde erneut gelernt, so sind jetzt noch einmal 15 Lesungen nötig. Wird ein

1) Das Gleichnis von der versöhnenden Milde des Letheflusses bezieht sich freilich nicht auf Kenntnisverluste, sondern auf das Verlieren der Erinnerungen (Vgl. hierzu Kapitel XIV). 
gleicher Doppelversuch gemacht mit einer anderen, ebenso langen Reihe, aber mit einer Pause von 24 Stunden, so erfordert das Wiedererlernen 20 Wiederholungen u.s.w. Bei jedem Versuch kann der "Ubungsverlust” daran ermessen werden, welcher Bruchteil der ersten Lernarbeit beim Wiedererlernen neu aufgewandt werden musste.

Silbenreihen, die beim erstmaligen Lernen 30 Lesungen erfordern, brauchen beim Wiederlernen

nach . . . . . . 20 Min. 1 Stunde 9 Stunden 24 Std. 6 Tagen 1 Mon $\begin{array}{lllllll}\text { Lesungen: } & 12 & 17 & 19 & 20 & 23 & 24\end{array}$

Neuer Lernaufwand in

$\%$ des ersten (=

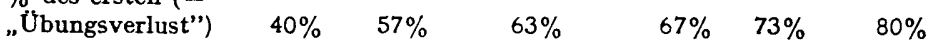

Dass 100\%iger Verlust, also völliges Erlöschen aller Nachwirkungen, selbst bei ganz grossen Latenzzeiten nicht eintritt, zeigt ein anderer Versuch Ebbinghaus'. Er hatte als junger Forscher eine Reihe Byron'scher Stanzen gelernt, und in der Folgezeit nicht wieder angesehen, noch je an sie gedacht. Als er sie $\mathrm{n}$ a c h $22 \mathrm{~J}$ a h r e n zum Wiederlernen vornahm, erschienen sie ihm völlig fremd; es fehlte jede Erinnerung, ja auch irgend ein Wiedererkennen. Aber eine U bung swirkung in Höhe von $7 \%$ war dennoch gegenüber anderen, gleich schweren, jedoch früher nicht gelernten Stanzen vorhanden.

Den Grad des Absinkens der Reprod u zier barkeit bei einer Latenzzeit von einem Jahr hat Wessely an Schülern verschiedenę Alters geprüft. Gewählt wurden Gedichte, die ein Jahr vorher gelernt und seitdem nicht mehr wiederholt worden waren; die Schüler hatten alles, was sie vom Wortlaut der Gedichte noch im Gedächtnis hatten, auch kleinste Bruchstücke, niederzuschreiben. Das Ergebnis war für den oben erwähnten Satz des „Vitae discere” sehr enttäuschend. Denn die gelernten Gedichte erwiesen sich nicht nur nicht als ein „Schatz fürs Leben"; sie waren nicht einmal ein Schatz für ein Jahr gewesen. Am geringsten war der Gedächtnisverlust bei Schülern des siebenten Schuljahres, die noch im Durchschnitt $85 \%$ ihres Gedichtes reproduzieren konnten; beim fünften Schuljahr betrug die behaltene Menge nur $42 \%$, beim zehnten Schuljahr gar nur 37\%. Man ersieht hieraus zugleich die entwicklungspsychologische Tatsache, dass um das Alter 12-13 Jahr ein Höhepunkt des Lerng e dä c ht n is s e s liegt. Bei den Jüngeren ist diese Fähigkeit noch nicht voll entfaltet, bei den Älteren tritt sie hinter anderen Funktionsgebieten, vor allem den Fähigkeiten denkender Stoffverarbeitung, zurück. 


\section{A uslösung der Reproduktionen}

Wie kommt die Reproduktion früher erworbener Kenntnisse in einem gegebenen Zeitpunkt zustande?

a) Freisteigende Vorstellungen. - Die mnemische Disposition, die von einer früheren Einprägung her im Menschen vorhanden ist, kann in sich selbst wachsen und schliesslich eine solche innere Verstärkung erfahren, dass sie sich spontan aktualisiert: aus der blossen Einstellung entwickelt sich die Vorstellung. Jeder kennt diese sogenannten „freist eigenden Vorstellungen”, jene Bilder, Verse, Melodien, die einen plötzlich überfallen, ohne dass ein assoziativer Anlass oder eine aktives Suchen vorangegangen wäre. In der Tat ist in nerhalb des Bewusstseins keine hinreichende Ursache für dies Aktuellwerden älteren Wissens aufweisbar. Die Assoziationspsychologie musste daher zu der Hilfskonstruktion greifen, dass zwischen den früheren und den jetzigen bewussten Vorstellungen unbewusste Zwischenvorstellungen die Vermittlung bewirkt hätten.

b) Einlinige und vielseitige Auslösung. Bei sehr fest eingeprägten Vorstellungsreihen genügt ein einziger Anstoss (die Nennung eines Gliedes), um die ganze Kette zum lückenlosen und fehlerfreien Abrollen zu bringen. Es gilt dann nur, das Stichwort aufzufangen (z.B.: a, b, c,.... oder: $1 \mathrm{mal} 7=7 .$. . ; oder: „Fest gemauert....”). Die folgenden Reproduktionen stellen sich dann von selber (rein ,assoziativ") ein.

Sind freilich solche Reihen stark mechanisiert, so hat ihre grosse Reproduktionsbereitschaft eine Kehrseite: die Reihen sind $\mathrm{n} \mathrm{u} \mathrm{r} \mathrm{e} \mathrm{i} \mathrm{n} \mathrm{li} \mathrm{n} \mathrm{i} \mathrm{g,} \mathrm{vom} \mathrm{Anfangsglied} \mathrm{her,} \mathrm{reproduzierbar.}$ Es fehlt die freie Verfügbarkeit über die Kenntnisse, ihre Einordnungsmöglichkeit in Zusammenhänge verschiedener Art, ihre Verwertbarkeit unter wechselnden Gesichtspunkten. Das kann soweit gehen, dass ein Schüler auf die Frage: „5 mal 7 ?” erst antworten kann, nachdem er die ganze Kette von „1 mal 7” an leise für sich reproduziert hat.

Der einlinigen ist die vi else it i g e R e produktionsbereitschaft gegenüberzustellen. Sie beruht zum Teil darauf, dass schon beim Lernen die einzelne Kenntnis in vieler- 
^ei Zusammenhängen eingeübt worden ist (z.B. das Einmaleins ausser der Reihe), sodann darauf, dass die Kenntnisse tiefer in die geistigen Bildungszusammenhänge der Person eingebettet worden sind. Sie können dann in späteren Einzelfällen von immer neuen Seiten her zum Anklingen gebracht werden.

c) D a s S i c h-B e si n n e n. - Ein ganz anderes psychologisches Bild ergibt sich, wenn die Reproduktionsbereitschaft des Stoffes selbst nicht den Forderungen der Situation genügt. Es wird die Aktualisierung eines Wissens verlangt (z.B. in der Schule, bei Prüfungen u.s.w.); aber die Vorstellung kommt weder auf mechanischem Wege, noch aus einer Einstellung heraus von selbst ins Bewusstsein. Sie muss erst reproduktionsreif gemacht werden; dies geschieht durch a kt ives Eingreifen in das mnemische Geschehen. Der Mensch „sucht”, „denkt nach", „besinnt sich."

Dies "S i c h-b e s i n n e n" ist ein Tun, das erst auf relativ hoher menschlicher Entwicklungsstufe möglich ist. Es setzt sowohl geraffte Willenseinstellung auf das Ziel, wie auch Verfügung über Denkhilfsmittel voraus, welche die gesuchte Vorstellung immer enger einkreisen, bis man sie "hat." Wer s ic h besinnen soll, muss sowohl wollen wie denken k ö n n e n; darum wird es manchem so unsäglich schwer, seine Kenntnisse im Moment, wo es erforderlich ist, zu realisieren.

Es genügt auch nicht, in solchen Fällen dem Schüler, der auf ein Vokabel oder Regel nicht kommt, zu befehlen: „Besinne Dich doch!" Das möchte er schon von selbst; er weiss nur nicht, wie er es machen soll! Hier kann, namentlich bezüglich der einzuschlagenden Wege des Nachdenkens, aber auch bezüglich des nicht zu schnellen Nachlassens des Suchwillens, sehr wohl pädagogische Anleitung g e ge be n und damit eine UUbung im Sichbesinnen erzielt werden.

Als eine eigentümliche Komplikation tritt zuweilen eine $\mathrm{V}$ e rk ra m p f u n g der Besinnungsarbeit auf. Die Willensanspannung führt zwar schon nahe an die gesuchte Vorstellung heran („das Wort schwebt mir auf der Zunge”), hemmt aber zugleich die Mitbeteiligung anderer spontaner Einstellungen, und verhindert dadurch den Enderfolg. Zuweilen geschieht es dann, dass einige Zeit später, wenn der Mensch sich anderen Themen zugewandt hat, plötzlich der vorher vergebens gesuchte Name, 
die vergessene Formel u.s.w. einschiesst. Nachdem die hemmende Wirkung des Besinnungswillens aufgehört hat, rentiert sich noch nachträglich die von ihm geleistete Vorbereitungsarbeit.

Ganz anderer Art ist die $\mathrm{R} \mathrm{e} \mathrm{p} \mathrm{r} \mathrm{od} \mathrm{u} \mathrm{k} \mathrm{t} \mathrm{i} \mathrm{o} \mathrm{n} \mathrm{sh} \mathrm{e} \mathrm{m} \mathrm{m} \mathrm{u} \mathrm{ng}$, die aus der tiefen Verankerung der Kenntnisse in der geistigen Gesamteinstellung der Persönlichkeit entsteht. Gerade Menschen von echten Bildung können zuweilen ihre einzelnen Wissensinhalte nicht so leicht frei machen und isolieren, wie Menschen, denen die Kenntnisse oberflächenhaft angeklebt sind. Es sei hier noch einmal der typische Polyhistor erwähnt, oder jener in geistiger Geselligkeit mit vielseitigstem Wissen brillierende Mensch; bei ihnen sitzen die Kenntnisse merkwürdig locker und können bei jedem leisen Reiz anspringen. In solchen Situationen wird der wirklich wissende Mensch oft ganz versagen - nicht etwa aus Hochmut, sondern weil die tiefere Schicht, in der bei ihm die Kenntnisse sitzen, gesperrt ist.- Eine ähnliche, nur tiefenpsychologisch zu verstehende, Hemmung kann gelegentlich auch dann eintreten, wenn die Kundgebung von Wissen gefordert wird, z.B. bei Schul- und Examens-Befragungen. Hier kann -nebender üblichen Prüfungsangst - auch eine unbewusste Protesthaltung dagegen wirksam werden, dass die, als organische $\mathrm{Be}-$ standteile der Person erlebten, Bildungsbestände zu toten, isolierten Dingen gemacht und als solche auf Kommando hervor geholt und kundgegeben werden sollen. 


\section{VIERZEHNTES KAPITEL}

E R I N N E R U N G

\section{ALLGEMEINES}

\section{Wesender Erinnerung}

Der Ausdruck „Erinnerung” wird in zwiefachem Sinne gebraucht. Einmal wird darunter ein abgehobenes Vorstellungsganzes bestimmter Art verstanden. „Die Begegnung mit X hat eine lebhafte Erinnerung in mir hinterlassen". Das Wort is dann auch in der Mehrzahl verwendbar: „Ich habe noch viele Erinnerungen an mein Elternhaus". Zwei Merkmale charakterisieren diese Gedächtnisvorstellungen: der bewusste Vergangenheitsbezug und die konkrete Einmaligkeit. In jeder Erinnerungsvorstellung wird ein individuelles Stück Vergangenheit a ls Vergangenheit vergegenwärtigt.

Andrerseits bedeutet Erinnerung eine totale Richtungsdisposition der Person (das Wort ist dann nur in der Einzahl anwendbar): „Die Erinnerung verklärt”. „Der alte Mann lebt ganz in der Erinnerung”. ,Nur der Mensch hat Erinnerung; dem Tiere fehlt sie." In diesem Sinne lautet die Definition: "Erinnerung ist die personal-historische Bewusstseinseinstellung."

Wenn sich früher die Psychologie mit dem Erinnerungsthema beschäftigte, hat sie sich fast stets auf die Erinnerungs-Vorstellungen beschränkt; diese wurden in ihrer immanenten Beschaffenheit und in ihrer (adaequaten oder inadaequaten) Beziehung zu den erinnerten Tatbeständen studiert.

Unsere Untersuchung nimmt ihren Ausgang von der anderen Seite; wir fragen, was es b e d e u t e t, dass der Mensch sich zu erinnern vermag und zu erinnern versucht ${ }^{1}$ ); erst aus diesem per-

1) Monographisch behandelt ist dies Problem in meiner Abhandlung „Personalistik der Brinnerung". 
sonalen Sinn von Erinnerung überhaupt wird Wesen und Leistung der einzelnen konkreten Erinnerungsvorstellung verständlich zu machen sein.

Von allen anderen mnemischen Erscheinungen unterscheidet sich die Erinnerung dadurch, dass sie nicht nur eine Nachwirkung von Vergangenem auf die Gegenwart, sondern ein $\mathrm{R}$ ü c kgreif e n a f Vergangenes aus der Gegenwart heraus darstellt. In ihr kehrt sich also der personale Zeitverlauf geradezu um; das Leben fliesst nicht restlos weiter nach vorwärts, sondern wendet sich nach rückwärts in sein eigenes Gewesensein; die Erinnerung hat daher für das Individuum eine ähnliche Bedeutung wie das geschichtliche Bewusstsein für ein Volk. Das Subjekt (Einzelmensch wie Nation) erlebt sich als ein stetig G e w ord e n e s, erlebt Vergangenes als zu diesem stetigen Ablauf, und damit zum eigenen Selbst, Gehöriges.

Die Gegenwart ist nicht mehr der einzige Erlebensbereich (wie beim Tier); Vergangenheit ist nicht nur das Kraftreservoir, aus dem die jeweilige Gegenwart mnemisch gespeist wird, sondern eine eigene Lebensphase, die neben der Gegenwart anerkannt und immer wieder von Neuem erlebt wird.

Das Erleben der stetigen Lebenslinie geht natürlich von der Gegenwart aus nicht nur nach rückwärts, sondern auch nach vorwärts; und so ist die Zukunftsbewusstheit (in Lebensplänen und in Vorsätzen, in Wünschen, Hoffnungen, Sorgen und Ängsten) das Korrelat zur Vergangenheitsbewusstheit der Erinnerung, die uns aber hier zunächst allein angeht.

Der personale Sinn der Erinnerung wird nun durch eine doppelte Polarität bestimmt: Person/Welt und Vergangenheit/ Gegenwart.

Erinnerung ist erlebbare Geschichte der Person. Die Geschichte der Person läuft aber in engster Wechselwirkung mit der Geschichte der sie umspielenden Welt $\mathrm{ab}$; das eigene Werden und Wandeln und die Ereignisse und Situationen da draussen verbinden sich, um dem Lebensablauf der Person seine konkrete Form, und um der Erinnerung an diesen Ablauf den Inhalt zu geben. In jeder naiven Erinnerung ist daher Selbst-Erinnerung und Welt-Erinnerung ungeschieden enthalten; und auch der Versuch derScheidung im kritischen Sichbesinnen führt nie zu völlig reiner 
Vergegenwärtigung der Objekt-Vergangenheit oder der IchVergangenheit. Tempora mutantur et nos mutamur cum illis. Dennoch ist die vorwaltende Te nde nz auf "Wel t" oder „I c h" entscheidend für die Aufgabe, die im konkreten Falle der Erinnerungsfunktion zukommt. Daher wird die objektivierende und die subjektivierende Erinnerung weiterhin in gesonderten Abschnitten zu behandeln sein.

Die andere Polarität besteht zwischen den beiden beteiligten Zeitphasen.

Ich erinnere mich ,jetzt” an das „Damals"; die Vergangenheit wird also in die Gegenwart hinübergenommen, „ver-gegenwärtigt". Das ist nur möglich, weil beides zur ununterbrochenen Lebenslinie der identischen Person gehört, also in kontinuierlicher Beziehung zu einander steht. Ich bin der selbe, der das damals Erlebte jetzt erinnert. (,Mnemische $\mathrm{K}$ o n t in u i$\mathrm{tä} \mathrm{t).} \mathrm{Zugleich} \mathrm{aber} \mathrm{ist} \mathrm{das} \mathrm{„Damals”} \mathrm{etwas} \mathrm{A} \mathrm{nderes} \mathrm{als}$ das "Jetzt", nicht nur, weil es zeitlich einer anderen Lebensepoche angehört, sondern auch, weil es inhaltlich von dem, was jetzt mein Leben erfüllt, mehr oder minder stark abweicht, ja, weil ich selber mich gewandelt habe.

Diese Andersartigkeit kann zur offenbaren Unstimmigkeit werden, und sich schliesslich geradezu versteifen zu gespenstiger Fremdheit: „Man kann es kaum mehr fassen, dass man noch derselbe ist, der dies damals erlebt hat". („Mnemische S p a lt u n g'). Diese beiden Merkmale der Stetigkeit und der Spaltung sind sehr verschiedener Ausprägung fähig und verleihen dann jeweilig den Erinnerungen auch ganz verschiedene personale Bedeutung. - Auch inhaltlich-phänomenal besteht zwischen Vergangenheit und Gegenwart Polarität. Das vergangene Primärgeschehen war eine Wahrnehmung gewesen (Selbstwahrnehmung oder Objektwahrnehmung), in der Erinnerung wird das einstmals Wahrgenommene als Vorstellung lebendig; wie verhält sich Beides zu einander? Wir haben die "Spurentheorie", nach welcher die Erinnerung eine regelrechte Wiederhervorholung der ursprünglichen Wahrnehmung wäre, schon früher zurückgewiesen ${ }^{1}$ ). Jedes Erinnerungsbild ist ein neuer seelischer Inhalt, gehört der Person an, wie sie j e t $\mathrm{z}$ t (im

1) S. 259. 
Augenblick des Erinnerns) ist, und wird von diesem, ihrem jetzigen Gesamtzustande bestimmt und gefärbt. In ihr wird zwar „d a s s e lb e" Geschehen oder Objekt ge me in t, welches damals die Wahrnehmung hervorgerufen hatte; sie ist aber nicht dieser Wahrnehmung gleich, und repräsentiert daher das vergangene Objekt nicht in der gleichen Weise, wie es seiner Zeit die Wahrnehmung getan hatte.

Hieraus ergibt sich die weitgehende Möglichkeit von Eri nn e r u n g t ä u s chungen. Sie spielen eine noch grössere Rolle als die früher besprochenen Sinnestäuschungen. Denn während man diese in der Mehrzahl der Fälle durch verschiedene Kontrollmittel aufdecken und korrigieren kann, werden Erinnerungstäuschungen eigentlich nur in Ausnahmefällen entlarvt und führen im Allgemeinen ein geheimes, aber höchst wirkungsvolles Dasein.

Jede Erinnerung ist „t e m p or a 1 i s i e r t”, d.h. auf irgend eine $\mathrm{Stelle}$ der personalen Vergangenheit bezogen. Dieser "Irgendwann-Index" 1) kann allerdings in sehr verschiedener Schärfe auftreten; er pendelt zwischen dem ganz vagen „es war einmal" und dem ganz bestimmten „es war damals". Manche Erinnerungen werden lediglich erlebt als einer nebelhaft fernen Vergangenheit zugehörig, ohne dass die Möglichkeit oder auch nur das Bedürfnis bestände, sie auf einen genaueren Zeitpunkt zu beziehen. Ähnlich dem ,es war einmal” des Märchens oder der Sage fehlt jede chronologische Eindeutigkeit. Andere Erinnerungen sind innerhalb der personalen Eigenzeit deutlich temporalisiert: „Den Pianisten X habe ich bei meinem Aufenthalt in München spielen hören." Endlich kann diese Eigenvergangenheit in die objektive Zeit und deren Mafse und Merkzeichen projiziert werden: „Ich erinnere mich an den Aufenthalt in N. im Frühjahr 1899." Oder: „Vorgestern Nachmittag um 4 Uhr habe ich meinen Freund M. auf der Strasse getroffen."

Wenn der Mensch solcher scharfen Temporalisation fähig wird, ist er aus seiner personalen Märchenepoche in die Phase wirklicher personaler Geschichtlichkeit und in die Teilhabe an der überpersonalen Zeitgeschichte eingetreten.

1) Die Analogie zu Raumerlebnissen drängt sich hier auf; diese haben stets einen Irgendwo-Index. In Analogie zu dem Ausdruck „Lokalisation” nemen wir die zeitliche Platz-Anweisung: „Temporalisation”. 
2. Zur Entwicklungspsychologieder Erinnerung

Eine entwicklungspsychologische Betrachtung muss bei dem Zustand der Erin n e u n s losigkeit („Amnesie”) einsetzen.

Es gibt eine durchaus normale Früh-Amnesie; denn von allen mnemischen Leistungsarten entwickelt sich die Erinnerungsfähigkeit am spätesten. Ein Kind von 5/4 Jahren, das bereits wiedererkennt, Gewohnheiten angenommen hat, gewisse Kenntnisse besitzt und anwendet (also vielfach mnemisch funktioniert), w $e$ is s noch nichts von seiner Vergangenheit und vermag deshalb Gedächtnisvorstellungen, die ihm etwa kommen mögen, nicht auf frühere Erlebnisse bewusst zu beziehen. Die ersten Spuren wirklicher Erinnerung sind etwa bei der Altersstufe $1 \frac{1}{2}$ Jahr anzusetzen; aber auch dann handelt es sich zunächst nur um ganz vereinzelte, unbestimmt aufflackernde und schnell wieder erlöschende, Lichtfunken in dem - sonst noch ganz undifferenzierten, ohne zeitliche Tiefe hinter dem Kinde liegenden Vergangenheitsnebel. Es dauert lange, ehe sich ein reichhaltigeres Erinnerungsleben entwickelt, und noch beträchtlich länger, bis der Mensch fähig ist, sein bisheriges Leben als kontinuierliches sich bewusst zu machen ${ }^{1}$ ).

Es gibt aber auch Spät-Amnesien, die zum normalen Seelenleben gehören. Sie unterscheiden sich von jener Früh-Amnesie dadurch, dass nun das abstrakte $\mathrm{W}$ is s e $\mathrm{n}$ um das Vorhandengewesensein jenes Zeitabschnittes besteht, von dessen Inhalt kein Bewusstsein (weder in der Form von Stimmungen noch von Vorstellungen) mehr aufzubringen ist. Ganz generell gilt dies für den Rückblick auf die früheste Lebenszeit. Jeder Mensch w e is s, d a s s er einmal Säugling war; er vermag sich aber nicht mehr an jene Zeit zu erinnern ${ }^{2}$ ). Ein ähnliches blasses Wissen um Vergangenheit ist untergründig auch bezüglich anderer Lebensepochen vorhanden, wenn sie nicht gerade zum Gegenstand bestimmten Erinnerns gemacht werden; geschieht dies, dann kann sich jene Erlebnisweise in höhere Stufen, also in Erinnerungs-

1) Zahlreiche Beispiele und theoretische Ausführungen zur Frühentwicklung der Erinnerungsfähigkeit in: C. und W. Stern, Monographie II.

2) Über früheste Kindheitserinnerungen des Erwachsenen vgl. Reichardt. 
gefühle oder Erinnerungsvorstellungen verwandeln. Oft aber gelingt auch dies nicht, trotz aller Bemühungen. Es weiss jemand etwa, dass er vor Jahrzehnten einige Monate an einem bestimmten Ort zugebracht habe, kann auch Einzelheiten aus indirekten Quellen: Briefen Tagebuchnotizen, Aussagen von Verwandten, feststellen; aber selbst diese Hilfen vermögen jenen Aufenthalt nicht zum stimmungs- oder anschauungsmälsigen Wie-deranklingen $\mathrm{zu}$ bringen. Er verhält sich zu diesem Stück seines eigenen Lebens nicht anders als zu den Schicksalen eines fremden Menschen, die er aus historischen Quellen rekonstruiert.

Freilich darf solche Amnesie nie als endgültig bezeichnet werden; denn sie ist abhängig von der jeweiligen personalen Situation, Disposition und Lebensphase, aus der heraus die Erinnerung gesucht wird. So gibt es im reifen Mannesalter ganz normaler Weise weitgehende Kindheits-Amnesie; wird aber der Mensch älter, nähert sich die personale Struktur des vergreisenden Menschen wieder mehr der Kindlichkeit an, dann wird auch die Kindheit wieder erinnerbar und unter Umständen geradezu aufdringlich (vgl. S. 258).

$\mathrm{P}$ a $\mathrm{t} \mathrm{h}$ o $\mathrm{log}$ i s c h e Amnesieen, die in Verbindung mit einer allgemeinen geistigen Erkrankung oder einem Unfall eintreten, unterscheiden sich von den bisher erwähnten deutlich; sie pflegen sich nämlich gerade auf solche Lebensabschnitte und Ereignisse zu erstrecken, die normaler Weise der Erinnerung besonders zugänglich sind, also auf sehr kurz zurückliegende und sehr lebenswichtige Tatbestände. Oft fehlt auch das leere Wissen um den unerinnerbaren Zeitabschnitt. So kann sich eine geistig gestörte Witwe an die zehn Jahre ihrer Witwenschaft nicht mehr erinnern und glaubt ihren Mann noch am Leben. - Sehr merkwürdig ist die, nach schweren Unfällen eintretende "retrograde Amnesie”, die sich auf die dem Ereignis unmittelbar vorangehenden Geschehnisse bezieht. Ein alter Mann ist auf dem Rückwege vom Geschäft nach Hause überfahren und erheblich verletzt worden. Als er aus der Bewusstlosigkeit erwacht, kann er sich noch an den Aufenthalt im Geschäft erinnern, nicht aber an das Fortgehen und seinen Weg durch die Strassen. Auch später bleibt diese $Z$ wischenzeit verschwunden. Der Choc macht also dem eben Erlebten jenes ruhige Ausklingen unmöglich, durch welches es unter normalen Umständen zum mnemischen Reize verfestigt wird und mnemische Dispositionen hinterlassen kann ').

\footnotetext{
1) Es ist dies ein indirekter Beweis für die grosse Bedeutung des „Zeithofes”. Vgl. S. $269 \mathrm{f}$.
} 
Amnesie ist Erinnerungslosigkeit, nicht aber mnemische Wirkungslosigkeit. Denn die mnemischen Reize haben ja andere Wirkungsmöglichkeiten, die nicht abgeschnitten zu sein brauchen, selbst wenn Erinnerung nicht mehr weckbar ist. Ein geisteskranker Schriftsteller, den ich vor Jahrzehnten in einer Anstalt sah, hatte völlige Amnesie für die unmittelbar vorangegangenen Jahre; er sprach von Bismarck, der seit langem nicht mehr im Amt war, als von dem amtierenden Kanzler u.s.w. Aber jene Jahre waren dennoch nicht einfach aus seiner Mneme weggelöscht erkonnte nämlich die innerhalb jener kritischen Zeit erlernte Stenographie mit unverminderter Fertigkeit schreiben.

Úber das bloss abstrakte Wissen um vergangene Existenz erhebt sich als zweite Stufe das g e f ü h $1 \mathrm{~s}$ m ä $\int \mathrm{s}$ i g e Haben der Vergangenheit. Wir werden von diesen „rückgreifenden” Gefühlen der Wehmut, der Pietät u.s.w. im Abschnitt über das Gefühlsleben sprechen. Hier sei nur betont, dass diese Gefühle wegen ihrer Flüssigkeit und unscharfen Begrenztheit geeignet sind, uns die $\mathrm{K}$ on $\mathrm{t}$ in u it ä $\mathrm{t}$ des früheren Lebens zum Bewusstsein zu bringen. Wenn wir uns unsere Spielkindheit, die Pubertätszeit, die Studentenzeit stimmungsmälsig wieder vergegenwärtigen, zerfällt unsere Erinnerung nicht in Einzelbilder, sondern hat den Charakter einer unbestimmten Erstreckung, die ebensowenig innerlich gegliedert wie äusserlich scharf abgegrenzt ist. Und dies Kontinuum bleibt auch als Hintergrund bestehen, wenn sich jetzt einzelne Geschehnisse aus jener Zeit als $E \mathrm{r}$ i n n e r u n g svorstellungen abheben. Damit ist die höchste Stufe dieser Entwicklung erreicht.

Erinnerungsvorstellungen bilden stets nur eine karge Auslese aus der ungeheuren Fülle primärer Erlebnisse, die früher aufgenommen waren. In ihnen verdichten sich einerseits Höhepunkte, Merksteine, Besonderheiten der Vergangenheit, andrerseits stets wiederkehrende Geschehnisse einer früheren Epoche, die damals zu vertrauten Bestandteilen des selbstverständlichen Lebensablaufs geworden waren.

Man versuche sich seine Schulzeit zu vergegenwärtigen. Der erste und der letzte Schultag, Schulfeste, Prüfungserlebnisse u.s.w. tauchen da auf - aber dann wieder ein geliebter oder gehasster Lehrer mit seinen typischen Bewegungen und Redensarten; die stetige Angst vor dem Ausfall der schriftlichen Arbeiten, die geistige Atmosphäre einer bestimmten Schulklasse. Vorstellungen der zweiten Art sind noch tiefer in die primitivere 
Form rein stimmungsmärsiger Erinnerung eingebettet als jene scharf abgehobenen einmaligen Ereignisse; dafür aber ist ihre Temporalisation und überhaupt ihre anschauliche Bildhaftigkeit weniger scharf.

\section{DER SUBJEKTBEZUG DER ERINNERUNG}

Die Vergangenheiten, die ein Mensch als Abschnitte und Merkpunkte seines Lebens erinnert, sind für ihn niemals blosse Gewesenheiten, sondern Faktoren seines gegenwärtigen Selbstbewusstseins und seines in die Zukunft hinaustendierenden Strebens. Infolgedessen ist das, was ein Mensch als seine „Vergangenheit" hat, nicht ein für allemal mit sich gleich und feststehend; es wandelt sich mit dem fortschreitenden Leben und den sich ändernden Befürfnissen und Strebungen unablässig. So spielt etwa die Kindheit für den eben in die Pubertät Eingetretenen eine ganz andere personalgeschichtliche Rolle (sie wird geringschätzig abgelehnt), als für den Mann (sie ist weitgehend indifferent) und für den Greis (sie wird wieder nahe, gewinnt eine erneute sentimentale Lebendigkeit). D i e V e r gange $\mathrm{nheit}$ is t also - personalgeschichtlich gesehen - $\mathrm{pl}$ a s $\mathrm{t}$ i $\mathrm{s} \mathrm{h}$; und davon werden nun auch die Erinnerungen selbst im einzelnen be stimmt: in ihrer Auslese, ihrer Strukturierung und ihrer inhaltlichen Modellierung.

\section{Kontinuität und Spaltung}

Gewisse Phasen der Vergangenheit erlebt man als durchaus noch organisch zu Gegenwart und naher Zukunft gehörig; in diesen Erinnerungen wird eine breitere Gegenwärtigkeit des Daseins geschaffen, die weit über das bloss momentane Jetzt hinausgreift. Es sind vornehmlich die letztvergangenen Ereignisse, das „Vorhin" und das „Gestern”, die auch bewusstseinsmälsig das Heut aus sich hervorbringen, und das Morgen vorbereiten. Aber auch weiter Zurückliegendes kann mit diesem $S$ t e t i g$\mathrm{k}$ e i t s a k z e n t versehen sein, während Dazwischenliegendes fremd, ja geradezu gegensätzlich zum Jetzt anmutet. Die personale Zeit ist eben viel krauser und irrationaler als das gradlinige Schema der objektiven Zeitlichkeit; und so kann ein Lebens- 
abschnitt, der zehn Jahre zurückliegt, mir subjektiv viel näher sein, als die Epoche vor zwei Jahren. Umgekehrt: eine Tat, die ich gestern tat, kann mir heut schon unfasslich erscheinen, als Fremdkörper in der sonst kontinuierlich abfliessenden Vergangenheit.

Während die mnemische Kontinuität das gleichförmige Alltagsleben mit seinen kleinen unbedeutenden Ereignissen bevorzugt, gewinnt erst in der Erinnerungsspalt ung das Eigenleben wirklich geschichtlichen Charakter, weil es nun a $1 \mathrm{~s}$ e in Identischbleiben trotz ständigen Anderswerdens, ja trotz grundsätzlicher Wendungen und Katastrophen, bewusst wird. In pathologischen Fällen kann das Bewusstsein von der Fremdheit der eigenen Vergangenheit so stark werden, dass eine Brücke zur Gegenwart überhaupt nicht mehr geschlagen werden kann; dann geht ein Riss durch die sinnhafte stetige Lebensbahn der Persönlichkeit ${ }^{1}$ ). Im normalen Leben aber spielt die mnemische Spaltung eine sehr bedeutsame p os i t i v e Rolle. Denn das Bewusstsein der Icheinheit, das ja als Untergrund bestehen bleibt, gewinnt jetzt eine ganz andere, spannungsreiche Fülle. Freilich kann sich dann der erinnernde Mensch nicht damit begnügen, das Anderssein des Gewesenen gegenüber dem Jetzigen einfach festzustellen und hinzunehmen. Er muss damit als gegenwärtiger Mensch $f$ e $r$ t i g w e $r d e n$, es seiner Gegenwart irgendwie einzuverleiben suchen.

Wir schildern einige typische Hauptformen, in denen eine solche Introzeption abgespaltener Erinnerunge n auftritt.

Dort, wo die Gegenwart relativ leer an unmittelbarem Erleben und an Wirkungsmöglichkeiten ist, wird die Erinnerung an die frühere - bessere und unwiderbringlich verschwundene - Zeit zu einem L e b e n s s u r r o g a t. Für alte und unheilbar kranke Menschen, für zur Ruhe gesetzte Berufsmenschen und für gescheiterte Existenzen wird das Weiterleben auf diese Weise überhaupt erst möglich. Wenn der bejahrte, leidende Seemann seiner früheren abenteuerlichen Fahrten gedenkt, wenn der gestürzte Staatsmann seine Memoiren schreibt, wenn der lebens länglich Gefangene seine unbeschwerte Kindheit in allen Einzel-

1) Vgl. hierzu K. Oesterreich. 
heiten auszumalen sucht, - überall wird dem Leben, das inhaltslos zu werden droht, ein neuer Inhalt gegeben. Freilich ein Inhalt, der nur noch Nacherleben, nicht mehr Leben selbst ist. Aber das Bewusstsein, früheres Gelebthaben noch irgendwie innerlich $z u$ besitzen, die Fülle gewonnener Erfahrungen, die Höhe der Warte, von der aus man seine eigene lange Vergangenheit überblickt, (während der unmittelbar Tätige in der Kampfebene des Lebens steht und nur das Nächste sieht) - all dies kann nicht nur genussvoll sein, sondern auch das Geltungsbewusstsein mit neuen Impulsen füllen. Gesteigert wird diese Wirksamkeit der Erinnerungen dann, wenn man nicht nur selbst in ihnen lebt, sondern auch ein Publikum für die erzählten oder geschriebenen Memoiren findet; denn jetzt gewinnt das Leben sogar wieder ein direktes Strebeziel: neue soziale Resonanz.

Anders wirkt die Erinnerungsspaltung dort, wo die Vergangenheit sich nicht durch Helligkeit, sondern durch $D$ u n k e 1 h e it von der Gegenwart abhebt,

Oft findet sich ja die Person mit solchen Schattenstellen ihres früheren Lebens dadurch $a b$, dass sie ihr überhaupt keine Erinnerung widmet; sie werden entweder vergessen oder verdrängt. Doch dabei bleibt es nicht. Jene Ereignisse können ja aus der Vergessenheit wieder auftauchen, können aus dem verdrängten Zustand mit Hilfe künstlicher Methoden (Psychoanalyse) oder durch eigenen Willen wieder bewusst gemacht werden. In vielen Fällen sind sie aber auch von vorn herein als bewusste Erinnerungsbestandteile haften geblieben. Die personale Wirksamkeit solcher "Minus-Erinnerungen" beruht auf dem Kontrast. Kontrast ist etwas anderes als blosse Spaltung, ist das gegenseitige Sichsteigern von zwei polaren Momenten, dadurch dass sie in einer gemeinsamen höheren Einheit enthalten sind. So vermag die Erinnerung an eine überstandene Gefahr das Gegenwartsgefühl sicheren Geborgenseins zu vertiefen. Der Selfmademan pflegt mit besonderer Zärtlichkeit die Erinnerung an die armseligen Anfänge seiner Laufbahn, weil er dadurch sein jetziges Glück um so intensiver geniesst. Und schon das fünfjährige Kind spricht mit Geringschätzung von der Zeit, ,als ich noch ein Baby war"', und erinnert sich voller Genugtuung seiner damaligen Unfertigkeiten.

Solche Kontrastwirkungen gewinnen eine grössere Komplika- 
tion und greifen weit tiefer in die personale Struktur ein, wenn es sich um Erinnerungen an sittliche Verstösse handelt. Das $\mathrm{S}$ ü n$\mathrm{d}$ e $\mathrm{n}$ be w u s t s e in kann ja alle Stufen von gelegentlichen Gewissensbissen bis zu habitueller Selbstanklage durchlaufen, beschränkt sich nicht nur auf wirklich ausgeführte Handlungen, sondern kann sich mit den Erinnerungen an versuchte, bloss gedachte, ja nur dumpf gefühlte Verfehlungen abquälen. Sofern der Mensch sich hier lediglich in seiner personalen Kontinuität erlebt - als jetzt noch d e r s e l b e, der jenes gedacht, gewollt oder getan hat - untergräbt er den Boden, auf dem seine personale Existenz ruht; die Pein der Sündenerinnerung kann ja unter Umständen bis zum Selbstmord treiben. Normaler Weise aber erlebt der Mensch zugleich die $D$ is t a n $z$ von jener Vergangenheit; er blickt von einem ausserhalb belegenen Standpunkt aus auf das Vergehen zurück, gibt sich von ihm Rechenschaft, macht sich innerlich von ihm und der mit ihm zusammenhängenden Willenseinstellung frei, oder erzeugt wenigstens in sich den Wunsch nach einer solchen Selbstbefreiung. So wird in Gewissensbissen und Reuegefühlen die Spaltung zwischen dem Einst und Jetzt zugleich voll ausgeschöpft und überwunden. Und auch hier fehlt nicht der Kontrasteinfluss auf das gegenwärtige Geltungsbewusstsein; denn nicht nur vor Gott, sondern auch vor sich selber ist der Mensch als reuiger Sünder höherwertig als einer von tausend Gerechten.

2. Erinnerungswandel und Erinnerungsmythos

Die Aufgabe der Erinnerung: dem Individuum seine Vergangenheit in der ihm gemälsen Form zu garantieren muss nun bewirken, dass sich auch in $\mathrm{h}$ a $1 \mathrm{tl}$ i c h die Erinnerung vom ursprünglichen Erlebnis mehr oder weniger entfernt. Gleichgültiges wird abgestossen, Unliebsames verändert, Unklares und Verwickeltes $\mathrm{zu}$ scharfen Linien vereinfacht, Banales zum Ungewöhnlichen emporgesteigert; schliesslich formt sich so ein neues Gesamtbild, ohne dass der sich erinnernde Mensch irgend ein Bewusstsein dieser Abweichungen vom primären Erlebnis, oder gar den Willen zu absichtlicher Fälschung haben müsste. 
Diese subjektivierende Umgestaltung der Erinnerung geht auf zwei Wegen vor sich: der Labilisierung und der Stabilisierung.

Da die personalen Bedürfnisse, denen die Erinnerung dient, vielfach wechseln, so kann auch irgend ein Erinnerungsobjekt an diesem Wechsel teilnehmen. So wird es 1 a bil.

Ein Beispiel. $\mathrm{X}$ und $\mathrm{Y}$ waren Freunde. Die Erinnerungen des $\mathrm{X}$ an gemeinsame Erlebnisse und an Handlungen und Äusserungen des $\mathbf{Y}$ waren während dieser Freundschaftszeit gefärbt durch starke Sympathiegefühle; sie nahmen bestimmte Formen an, welche den Freund in hellerem Licht erscheinen liessen und die Freundschaft gleichsam rückschauend rechtfertigten. - Nun geht die Freundschaft in die Brüche. Das neue Feindseligkeitsgefühl lässt jetzt den $X$ nicht nur mit Bitterkeit an jene gemeinsamen Erlebnisse zurückdenken, sondern beeinflusst den Inhalt der Erinnerung selbst. Licht und Schatten werden jetzt anders verteilt; die erinnerten Worte erhalten einen anderen Sinn, die Handlungen eine andere Motivation; früher Verdrängtes wird jetzt wichtig, früher Betontes wird verdrängt - und schliesslich hat jenes Stück Vergangenheit eine Form und Farbe angenommen, welche der gegensätzlichen Einstellung des X zu Y entspricht.

Aber unterhalb dieser wechselnden Bedürfnisse, welche die Erinnerungen so labil machen, gibt es noch eine andere Tendenz in jedem Menschen: das Verlangen nach einem festen Vergangenheitsfundament, welches tragfähig sein soll für alle weiteren Wechselfälle des Lebens. Es ist ebenfalls Aufgabe der Erinnerung, ein solches zu schaffen. Die Stabilisier ung, die sie vornimmt, betrifft auch die Veränderungen, die an den ursprünglichen Erlebnissen vorgenommen worden sind; die flüssige Masse, in welche sich real Erfahrenes mit den Erzeugnissen der personalen Tendenzen legiert, erstarrt allmählich zu einer festen Form „Elternhaus”, „Schulzeit”, „Ehe”; die Erinnerung wird zum personalen $\mathrm{Mythos}{ }^{\mathbf{1}}$ ).

Besonders eindrucksvoll erweist sich diese mythenbildende Tendenz bei der Erinnerung an liebe Verstorbene. Die Unmöglichkeit, die Erinnerung durch neue Erfahrungen zu modifizieren, und die Unwiderbringlichkeit des Verlustes tragen dazu bei, dass sich das Gedenken zu festen Formen stylisiert.

1) Hier begegnet uns eine weitere Analogie zwischen Erinnerung und grosser Geschichte. Denn auch die Geschichte der Völker hat Mythen nicht nur als Vorbereitung, sondern wird fortwährend von my thenbildenden Kräften geformt. 
Eine Frau, die in jungen Jahren nach wenigen Monaten glücklicher Ehe ihren Mann verloren hat, lebt vielleicht ein weiteres halbes Jahrhundert lang nur in und von den Erinnerungen an jene kurze Frist; ihre ganze Existenz wird gehalten von jenen Bildern, die für sie persönlich echteste Erinnerungen sind, mag auch schliesslich kaum mehr irgend ein Zug des Bildes Ähnlichkeit haben mit dem, was damals wirklich gewesen und geschehen ist.

Hier gewinnen nun auch die Kindheitserinnerungen der Erwachsenen einen neuen Sinn. Im Erinnerungsmythos von Elternhaus, Eltern und Ahnen wird für jeden Menschen bewusstseinsmälsig jener Urzusammenhang symbolisiert, der das Individuum - über die Enge seiner Einzelexistenz hinaus - in die Kette der Generationenfolge einfügt. Zwischen Kindheitserinnerung und Ahnenkult ist die Grenze flüssig.

\section{DER OBJEKTBEZUG DER ERINNERUNG}

1. Erinnerungstreue und ihre Untersuchung

Solange die Erinnerung lediglich der subjektiven Vergangen-

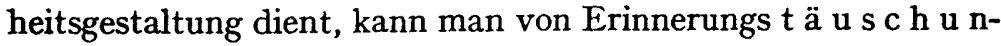
g e $\mathbf{n}$ in eigentlichen Sinne nicht sprechen. Denn auch die zuletzt erörterten Wandlungen und Mythenbildungen erfüllen für das $\mathrm{S} \mathrm{u} \mathrm{b} \mathrm{j} \mathrm{e} \mathrm{k} \mathrm{t,} \mathrm{das} \mathrm{an} \mathrm{ihre} \mathrm{Realität} \mathrm{glaubt,} \mathrm{durchaus} \mathrm{ihre} \mathrm{positive}$ Aufgabe.

Unter ganz anderem Aspekt steht dagegen die Erinnerung, wenn ihre objektivierende Funktion berücksichtigt wird. Die in ihr repräsentierte Vergangenheit ist ja nicht nur die des Subjekts, sondern auch der Welt, zu der das Subjekt gehört; diese Welt ist transpersonal, ihre Tatbestände haben oder hatten eine Handfestigkeit und Eindeutigkeit und Wirklichkeit, die das Individuum anzuerkennen und $\mathrm{zu}$ berücksichtigen hat. Die Tatsachen fordern Ehrfurcht, auch we n n sie vergangen s ind; denn auf sie gründet sich das gegenwärtige praktische Handeln, das in die Welt eingreift; und sie bilden den $\mathrm{g}$ e $\mathrm{m}$ e in $\mathrm{s}$ a m e $\mathrm{n}$ Vergangenheitsfundus, auf den sich alles soziale Miteinanderleben und alle eigentliche historische Erkenntnis stützt. Der tätige Mensch muss imstande sein, sich angemessen an die Aufgaben, die er übernommen hat a und an die Fähigkeiten, die er besitzt, zu erinnern; ein fesselloser 
personaler Mythos, den er über sich selbst schafft, macht ihn zum untauglichen Gliede der menschlichen Gesellschaft ${ }^{1}$ ).

Vom Memoirenschreiber verlangen wir, dass durch die subjektive Färbung seiner Darstellung dennoch der reale Sachverhalt erkennbar hindurchschimmere. - Der Zeuge vor Gericht soll das von ihm miterlebte Ereignis darstellen, „wie es wirklich gewesen ist", unabhängig von den individuellen Wünschen, Parteieinstellungen, Abwehraffekten u.s.w., die den Inhalt der Erinnerungen und Aussagen zu verfärben drohen.

So erhebt sich hier die psychologische Frage nach Art und Grad der Übereinstimmung von Erinnerung und Wirklichkeit, also nach der Erinnerungstre u e - und nach den Abweichungen von dieser Übereinstimmung, also nach den Erinnerung s tä u sch u n ge n ${ }^{2}$ ).

Dieser Problematik hat die moderne Psychologie starke Beachtung und umfangreiche - experimentelle, kasuistische und theoretische - Arbeit gewidmet; die Ergebnisse haben auch vielfach zu praktischen Anwendungen geführt, insbesondere in der Rechtspflege. Für den ganzen Untersuchungszweig ist die Bezeichnung "Psychologie der Aussage" üblich geworden.

Aussage-Experimente sind in zwei Hauptformen ausgebildet worden.

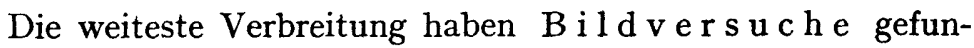
den. Dem Prüfling wird ein Bild vorgelegt, über dessen Inhalt er unmittelbar nach der Betrachtung oder nach längerer Zwischenzeit aus der Erinnerung Auskunft zu geben hat. Der Experimentator kann dann die Aussage mit dem Bilde Punkt für Punkt vergleichen und dadurch Auslassungen, Zusätze und Umwandlungen exakt feststellen ${ }^{3}$ ).

1) Ibsen hat dies Sich-Einhüllen in ein rein subjektives Erinnerungsgespinst als "Lebenslige" bezeichnet und in einigen Dramen geschildert. Der Ausdruck "Lüge" ist allerdings insofern nicht ganz zutreffend, als die Täuschungsabsicht durchaus fehlen kann.

$\left.{ }^{2}\right)$ Die Beschränkung auf eigentliche Erinnerungstäuschungen bringt es mit sich, dass b e a b i c b tig t e Fälschungen erinnerter Tatbestände - also die Erscheinungen der Lüge, der bewussten Heuchelei, des Meineides - an dieser Stelle ausser Betracht bleiben.

3) Ein, von mir vor 30 Jahren zuerst benutztes, farbiges Bild einer Bauernstube hat trotz mancher Mängel für solche Versuche an Kindern und Erwachsenen immer wieder Anwendung gefunden, daneben viele andere Bilder. 
Bilder bieten den Vorteil, stets für die Konfrontation mit der Aussage verfügbar zu bleiben, aber den Nachteil, dass die Versuchsbedingungen sich sehr weit vom natürlichen Leben entfernen; denn dieses hat es meist mit Geschehnissen zu tun, die schnell in der Zeit ablaufen. Darum hat man auch Vorgang sexperimente ausgebildet („Wirklichkeitsversuche”). Bei solchen wird irgend ein Vorfall inszeniert : z.B. ein Streit mit Wortwechsel und körperlichen Aggressionen; jedes Wort, jeder Handlungsteil und die Aufeinanderfolge sind genau festgelegt und vorher einstudiert. Die Zuschauer wissen meist nicht, dass es sich um einen fingierten Vorfall handelt, und erleben daher reale Affekte, die natürlich auf die Art ihrer dann geforderten Aussagen Einfluss haben ${ }^{1}$ ).

Bei Bild- wie bei Wirklichkeits-Versuchen wird dann gewöhnlich noch geschieden zwischen „B e rich t” und „Verhör”. Im Bericht hat der Prüfling zusammenhängend anzugeben, was in ihm spontan als Erinnerung auftaucht; im Verhör wird der Erinnerung durch Befragung nach Einzelheiten nachgeholfen. Auch der Wortlaut dieser Fragen ist vorher ausgearbeitet; eine besondere Rolle spielen in diesen Verhörslisten die $\mathrm{Sug}$ g e s$t$ i v f r a g e $n$, das sind solche, die durch Wortlaut oder Betonung eine bestimmte Antwort nahelegen, z.B.: „Hatte der Mann nicht ein Messer in der Hand?"

Solche Versuche erlauben auch zahlenmälsige Feststellungen über: den Umfang der Aussage (Anzahl der Einzelangaben), die Verteilung der Aussage auf verschiedene Kategorieen (Wesentliches und Unwesentliches, Gegenstände, Wortlaute, Handlungen, Farben- und Raum-Bestimmungen u.s.w.), die Aussagetreue (Verhältnis der richtigen Angaben zu allen Angaben), die Verhörstreue (Verhältnis der richtig beantworteten $\mathrm{zu}$ allen beantworteten Verhörsfragen), die Suggestibilität (Prozentsatz der Suggestivfragen, bei denen Suggestionswirkung erfolgte) u.a.m. Vermittels dieser Zahlen können Gruppen und Individuen verglichen werden. Uber die rein quantitativen Bestimmungen hinaus aber geben Aussageversuche Gelegenheit zu sehr wertvollen Beobachtungen über das Verhalten der Versuchspersonen in den psychologi-

1) Auch der Film hat für Vorgangsexperimente gelegentlich Verwendung gefunden. 
schen Situationen der Erinnerungspflicht und des Verhörszwangs.

Neben der experimentellen Methode (die etwa bis 1920 die Aussagepsychologie ganz vorwiegend beherrschte), hat in neuerer Zeit mehr und mehr das $\mathbf{k}$ a s $u$ is $t$ is $\mathbf{c} h$ e Verfahren an Raum gewonnen. In Rechtspflege, Krankenbehandlung und Schulbetrieb ereignen sich ja fortwährend Vorfälle mit bemerkenswerten Aussagephänomenen, deren genauere Darstellung unter psychologischen Gesichtspunkten wichtiges Erkenntnismaterial liefert ${ }^{1}$ ).

\section{Ergebnisse der Aussageuntersuchungen}

a) Grenzen der Erinnerungstre ue. - Als erstes Ergebnis aller dieser Untersuchungen ist zu vermerken, dass es eine $100 \%$-ige Erinnerungstreue nicht gibt.

Wohl kann unter günstigen Bedingungen die Erinnerung und die auf sie gestützte Aussage eine weitgehend angemessene Wiedergabe des Tatbestands darbieten; aber auch hier besteht nicht die Gewähr für vollständige Ưbereinstimmung. Sobald ungünstige Bedingungen - deren $\mathrm{Zahl}$ gross ist - mitspielen, kann der $\mathrm{Zu}$ verlässigkeitswert der Aussage erheblich sinken.

Maximal günstige Bedingungen lagen z.B. vor bei einem von mir angestellten Bildversuch mit erwachsenen gebildeten Versuchspersonen. Diese konnten die leicht verständlichen Bilder in Musse betrachten; sie wussten während der Betrachtung, dass sie über den Inhalt nachher Auskunft geben sollten, und erfüllten diese Aufgabe unmittelbar nach der Darbietung. Ihre Niederschrift sollte nur Angaben über diejenigen Bildinhalte liefern, deren sie sich noch mit Sicherheit erinnerten. Es bestand der feste Wille zu richtigen Angaben; es fehlten affektive Hemmungen oder Verlockungen. Dennoch enthielten diese Berichte noch durchschnittlich 5\% irriger Angaben, die sich nicht immer nur auf Unwesentliches bezogen.

Überblicken wir nun die $\mathrm{F}$ a k t or e n, welche auf die Erinnerungstreue schädigend wirken können.

b) Wahrnehmung und A ufmerksamkeit. Einige Fälschungsquellen finden sich schon im Prim ä r-E rle be n, also bei der ursprünglichen Wahrnehmung. Sinnestäuschungen, infolge deren etwas falsch gesehen oder gehört wurde, falsche Auffassung des Tatbestandes auf Grund mangeln-

1) Fallsammlungen haben u.a. veröffentlicht: Marbe, Plaut, W. Stern. 
den Verständnisses, oder Befangenheit durch affektive Anteilnahme an dem Erlebnis verleihen diesem von vor $\mathrm{n}$ h e re i n eine Prägung, die weit von der Objektivität abweichen kann und sich natürlich auch in jede Erinnerung einschleicht. Nachträgliche Korrekturen sind in solchen Fällen schwierig und selten.

Ein Gefangenenwärter führte aufgeregt beim Direktor Klage, dass der Gefangene $\mathrm{X}$ in einem Wutanfall mit dem Messer auf ihn losgegangen sei. Nun stellte sich heraus, dass X gar kein Messer zur Verfügung gehabt, dass er aber den Hering, der ihm gerade vorgesetzt worden war, in seiner Wut ergriffen und gegen den Wärter geschwungen hatte.

Eine sehr wichtige Rolle spielt der Grad der A u f m e r ks a m k e i t, mit welcher der Tatbestand im Primär-Erleben bedacht worden war. Was man intensiv bea $\mathrm{cht}$ e $t$, hat viel mehr Wahrscheinlichkeit, richtig erinnert zu werden, als das, was nur am Rande des Aufmerksamkeitsfeldes zur Wahrnehmung gelangt. In extremen Fällen kann Unaufmerksamkeit bewirken, dass Eindrücke zwar die Sinnesorgane treffen, aber völlig unbemerkt bleiben; es besteht für sie dann „partieller Schlaf” 1). Der Durchschnittszeuge weiss nichts von dieser Tragweite seiner Unaufmerksamkeit; daher kommt es, dass er entweder die Existenz des Nichtbeachteten rundweg leugnet (er sagt: „der $\mathrm{Y}$ ist nicht dabei gewesen", statt zu sagen: „, ich haben ihn nicht bemerkt, weil ich auf anderes achtete") - oder dass er die Lücke der Erinnerung durch Konfabulationen ausfüllt.

Als Beispiel diene ein von mir veranstalteter Wirklichkeitsversuch.

Während einer Seminarübung mit Studenten betrat ein fremder Herr den Seminarraum, bat um die Erlaubnis, in ein Buch der Bibliothek Einblick zu nehmen, verweilte einige Zeit lesend im Zimmer und ging dann wieder fort un er $M$ it $n$ a h m e des Buches (obwohl dies streng verboten war). Inzwischen hatten die Seminarbesprechungen ihren Fortgang genommen, sodass die Studenten dem Herrn und seinem Tun keine Beachtung geschenkt hatten. Eine Woche später wurden sie überrascht durch die Aufforderung, über den Vorgang und das Aussehen des Mannes Aussagen zu machen.

Man hätte erwarten sollen, dass sich die Versuchspersonen auf ihre abgelenkte Aufmerksamkeit berufen und nur sehr wenig Angaben machen würden. Überraschender Weise aber liessen sie diese Vorsicht durchaus vermissen; sie machten zahlreiche Angaben, die nun natür-

1) Vgl. hierzu das XXVI. Kapitel über Aufmerksamkeit.

Stern, Psychologie 
lich zu einem beträchlichen Teil falsch waren. Aus den widersprechenden Angaben über Kleidung und Aussehen des Herrn, über die Frage, ob er ein Augenglas hatte oder nicht, würde sich kein Richter ein angemessenes Bild haben machen können. Und die Hauptfrage: „Was geschah mit dem Buch, als er es gelesen hatte?" wurde nur von einer kleinen Minderheit richtig beantwortet; einige andere enthielten sich der Antwort; die meisten aber erklärten ohne Bedenken: „er stellte es wieder in den Bücherschrank zurück".

Ähnlich wie die Aufmerksamkeit wirkt auch der $Z$ e it f a kt o r. Liegt zwischen dem primären Erleben und der Reproduktion eine längere $Z$ wischenzeit, so macht sich nicht nur fortschreitendes Vergessen bemerkbar, sondern meist auch zunehmende Verfälschung der Aussage. (Es kommen sogar paradoxe Fälle vor, in denen die späteren Aussagen mehr Angaben enthalten als die früheren. Aber es handelt sicht fast stets nur um eine scheinbare Verbesserung der Erinnerung; denn qualitativ ist die spätere Aussage gewöhnlich viel schlechter, der Fehlerprozentsatz viel höher).

Bei dem oben (S. 352) geschilderten Bildversuch fand nach einigen Wochen eine Wiederholung statt; die Versuchspersonen mussten die damals betrachteten Bilder, ohne sie wiederzusehen, aus der Erinnerung noch einmal beschreiben. Die Berichte waren umfangsmälsig nur um weniges geringer. Die Fehlerhaftigkeit aber hatte sich verdoppelt (von durchschnittlich $5 \%$ auf $10 \%$ ).

c) Verhörs-und Suggestions-Wirkungen.Einen starken Einfluss haben die ä us sere n Einflüsse, unter denen die Aussage zustande kommt.

Hier besteht der Hauptunterschied zwischen freie $\mathrm{r}$ und g e f o r d e r t e r Aussage. Solange der Zeuge (bezw. der Prüfling im Experiment) zusammenhängend seine Erinnerungen darstellen kann, ist die Irrungsgefahr viel geringer, als wenn er unter der Bindung eines Verhörs steht. Die Experimente beweisen dies schlagend. In Bildversuchen z.B., die zuerst einen zusammenhängenden „Bericht” forderten und im Anschluss daran ein ergänzendes Verhör anstellten, betrugen die Fehlersätzedort $5 \%$ bis $10 \%$, hier $20 \%-25 \%$.

Dies Ergebnis ist durchaus verständlich. Dort, wo der Aussagende in der Lage ist, s p o $\mathrm{ntan}$ zu berichten, steht es in seiner Macht, auszuwählen und wegzulassen. Er wird sich daher auf diejenigen Momente des Ereignisses beschränken, die er vornehm- 
lich beachtet hatte, die ihn interessierten, die gleichsam den hell beleuchteten Kern seiner Erinnerungen bilden. - Ganz anders ist die Situation beim Verhör. Jetzt werden Angaben g e f o rder t über Einzelheiten, die nicht im Bericht vorgekommen waren. Sie gehören zum grösseren Teil dem dunklen und verschwommenen Randgebiet der Erinnerung an - wenn sie überhaupt in dieser noch einen Platz hatten. Was höchstens ganz vage, schemenhaft und vieldeutig vorgestellt wird, soll num in die harte Form eindeutiger Verlautbarung gepresst werden. Gewiss kann man diesem Zwange widerstehen oder ausweichen, die Antwort „ich weiss es nicht” steht ja immer zur Verfügung. Aber es ist merkwürdig, in wie verschiedenem Malse davon Gebrauch gemacht wird.

„Ich weiss nicht" ist die vorläufige Ausflucht des Trägen, der sich nicht anstrengen will, um seine Erinnerungen wieder zu wecken, oder des Schüchternen, der nicht auszusprechen wagt, was ihm undeutlich innerlich vorschwebt. In solchen Fällen ist es möglich, durch Antrieb $\mathrm{zu}$ energischerem Sichbesinnen noch wichtige und richtige Angaben zu erzielen. - "Ich weiss nicht" kann aber auch die Antwort des innerlich selbständigen Menschen sein, der sich dem Fragezwang dort nicht fügen will, wo das Erinnerungsbild garnicht oder mit unzulänglicher Deutlichkeit vorhanden ist. Eine so motivierte Ablehnung der Antwort ist aber durchaus nicht häufig. Es gibt Menschen, auf welche die Frage des Verhörenden als ein Imperativ wirkt: „Du sollst antworten”; in ihren Verhörsangaben ist dann die Antwort ",ich weiss nicht" nur ganz spärlich zu finden.

Wenn schon der Fragezwang im allgemeinen die Aussage beeinflusst, so noch viel mehr, sobald er suggestive Form annimmt. Es war eine der wichtigsten Feststellungen der Aussageexperimente, dass $S u g g$ est ivfrag e n eine geradezu verhängnisvolle Wirksamkeit ausüben können ${ }^{\mathbf{1}}$ ). Ist der Erwartungston der Frage recht eindringlich (z.B. : „Erinnern Sie sich denn nicht, dass der Mann einen Stock in der Hand gehabt hat?") und besitzt der Befragte nicht eine starke Selbständigkeit und innere Widerstandsfähigkeit, dann kann es kommen, dass der Verhörende viel mehr seine Vermutungen in den Zeugen hineinfragt, als dass er dessen tatsächliche Erinnerungen aus ihm herausfragt.

1) Vgl. hierzu auch Kap. XXIV „Suggestion”. 
Bei den Versuchen mit dem Bauernstubenbild, die an Kindern und Jugendlichen angestellt wurden, betrug der Suggestibilitätskoeffizient im Durchschnitt $25 \%$; d.h. jede vierte Suggestivfrage wurde falsch beantwortet. Dabei bezogen sich diese, in ein längeres Verhör eingestreuten, Fragen auf Gegenstände, die auf dem soeben gesehenen Bild überhaupt nicht vorhanden gewesen waren. Die blosse Frageform: „War nicht ein Schrank auf dem Bild zu sehen?” „Hatte der Knabe nicht eine zerrissene Jacke an ?" u.s.w. genügte, um in vielen Fällen die Antwort ,ja” zu erzielen.

Gewiss mag manches „Ja" nicht mit der vollen inneren Überzeugung von der Richtigkeit der Angabe ausgesprochen worden sein, sondern mehr, um den dringenden Frager zufrieden zu stellen; bewusste Lügen wird es hier ebenso geben, wie ein Halbund-halb-daran-Glauben (etwa mit der Motivation: wenn die fragende Autoritätsperson glaubt, dass es so war, dann wird es wohl so gewesen sein).

Aber ist erst einmal das "Ja" ausgesprochen und damit eine ganz bestimmte Vorstellung fixiert, dann wird der Weg bis zur vollen Richtigkeitsüberzeugung schnell durchlaufen. Man hat sich nun einmal darauf festgelegt, darum werden Zweifel und Bedenken möglichst zurückgedrängt, damit man sich nicht desavouiere. Schliesslich ist dann die suggerierte Vorstellung in die Gesamterinnerung so eingeschmolzen, dass ihr dieselbe Gewissheit zukommt wie den zutreffenden Vorstellungen.

Diese Stabilisierung einer Suggestionswirkung hat zwei schwerwiegende Folgen.

1) Bei künftigen Aussagen über denselben Tatbestand werden die früher suggerierten Vorstellungen vielfach s p o n t a n geäussert. Der Verhörende kann ihnen dann den Ursprung aus einer früheren Suggestion nicht anmerken und schliesst von der Spontaneität der Äusserung auf besondere Glaubwürdigkeit.

2) Die suggerierte Vorstellung wird zum Ausgangspunkt von "A n s c h l u s s f r a g e n", die in ihrem Gesamteffekt zu einer unbegrenzten Verfälschung des Tatbestandes führen können.

In dem Verhör über das Bauernstubenbild hatte ein 12jähriges Mädchen die Suggestivfrage „War nicht ein Schrank auf dem Bilde?” b e ja h t. An diesen nicht existierenden Schrank knüpfte sich nun folgendes Frage- und Antwort-Spiel:

Wo stand der Schrank? - „In der rechten Ecke”.

Welche Farbe hatte er? - „braun”. 
War er eintürig oder zweitürig? — „zweitürig”.

Konnte man sehen, was drin war? - „,ja, Kleider”.

Was stand auf dem Schrank? - „ein Blumentopf”.

Dies Wechselgespräch hätte noch beliebig weiter geführt werden können. Das Kind wollte offenbar nicht lügen, war aber so phantastisch und zu gleicher Zeit so suggestibel, dass es jeder Anregung des Fragers nachgab und die geweckten Vorstellungen sofort mit Wirklichkeitsakzent versah.

Es ist dies ein extremer und seltener Fall; aber auch weit geringere Grade der Suggestivwirkung können genügen, um den Wert einer Aussage stark zu beeinträchtigen.

Erinnerungssuggestionen werden übrigens nicht nur durch das Verhör ausgeübt, sie können auch von anderen äusseren Faktoren ausgehen, von der Presse, von Gerüchten, Aussagen anderer, Abbildungen u.s.w.. Hat sich z.B. in einer Schule das Gerücht entwickelt, dass ein Lehrer sich unangemessen zu manchen Schülerinnen verhalte, so „erinnern” sich bald andere Schülerinnen, dass er sich früher einmal ebenso zu ihnen benommen habe. - Die Darstellung der Zeitungen über den mutmafslichen Verlauf eines Verbrechens beeinflusst manchen Leser in der Richtung, dass er dies oder das gesehen haben will u.s.w. - In Zeiten starker Massenerregung: bei Kriegsausbruch, Revolution, Katastrophen, üben solche Suggestionen eine Wirkung aus, die völlig anonym bleibt, aber eben deshalb auch völlig verantwortungslos und fessellos um sich greift: plötzlich ,steht es fest", dass irgendwo ein verkleideter Spion gesehen worden ist, und Hunderte bestätigen es aus angeblich eigenem Augenschein.

d) Te m pora 1 is a t i o n. - Eine wichtige Rolle spielt bei jeder Aussage die richtige $\mathrm{T}$ e $\mathrm{m}$ p or a $\mathrm{l}$ is a $\mathrm{t}$ i o $\mathrm{n}$; denn es sollen ja nur diejenigen Erinnerungen zum Einsatz kommen, die sich auf einen bestim m t e $\mathrm{n}$ Zeitpunkt der Vergangenheit beziehen. Nicht darauf kommt es an, ob der Zeuge den Verdächtigen überhaupt einmal an einer bestimmten Strassenecke gesehen hat, sondern ob dies auch gerade am 24. März nachmittags 3 Uhr gewesen war. Nun kann ein, im übrigen sehr inhaltsreiches und anschauliches, Gedächtnis dennoch mit einem ganz unzuverlässigen Zeitbewusstsein verbunden sein. Das Gedächtnisbild jener Begegnung steht lebhaft vor dem inneren 
Auge des Zeugen - aber die Einordnung in den Zeitverlauf ist nicht von vorn herein miterinnert und kann daher leicht durch die vom Verhörenden angebotene Zeitangabe suggestiv fixiert werden. Es gibt unzählige Menschen, in deren Bewusstsein die Vergangenheit $\mathrm{z}$ e i $\mathrm{t} l \mathrm{i} \mathrm{ch}$ sehr wenig gegliedert ist.

Jüngere Kinder haben durchweg ein äusserst unbestimmtes chronologisches Bewusstsein; zwingt man ihnen eine Zeitangabe auf, etwa durch die Frage: „Hast Du gestern das und das getan?" - dann wird bereitwillig ja gesagt, weil der Tatbestand als solcher erinnert wird und die Temporalisation auf den Vortag noch jenseits des kindlichen Verständnisses liegt.

Aber auch bei Erwachsenen sind die so bedingten Täuschungen nicht selten. Bei einem meiner Bildversuche gab ein Prüfling einige Wochen nach Betrachtung des Bildes eine Schilderung, die nach einigen richtigen Punkten lauter völlig abwegige Abgaben enthielt. Der Aussagende war in die Erinnerung an ein anderes Bild hineingeraten. das er zu einem ganz anderen Zeitpunkt gesehen hatte.

e) Alltäglichkeit und Ungewöhnlichkeit. - Besonders schwierig wird die spezielle Temporalisation, wenn es sich um häufig wiederholte und vertraut gewordene Eindrücke handelt. Abweichungen vom Gewohnten, die nicht beachtet worden waren, werden dann später von der Erinnerung leicht im Sinn des Gewohnten umgedeutet. Möbel sind im Allgemeinen braun. Wird nun gefragt, welche Farbe ein bes t i m m t es Möbelstück gehabt habe, das man bei einer bestimmten Gelegenheit gesehen habe, so liegt die Antwort „braun" nahe - falls einem nicht schon bei der Wahrnehmung die Abweichung aufgefallen ist.

So erklärt sich folgendes sonderbare Teilergebnis beim Bauernstubenbild. Auf dem sehr bunten Bild befand sich unter anderem eine Kinderwiege von sehr auffällig $\mathrm{b} l \mathrm{a}$ u e $\mathrm{r}$ Farbe. Der Prozentsatz der Versuchspersonen, die diese auffällige Färbung sofort bemerkt und nachher spontan angegeben hatten, war gering. Die Verhörsfrage nach der Farbe der Wiege erzielte in $\frac{2}{3}$ aller Fälle die Antworten ",braun" oder "gelb". (Dieser Befund beweist auch, dass man sich selbst auf die Angaben der Zeugen me h $\mathrm{r}$ heit nicht ohne weiteres verlassen kann).

Ein Beispiel aus dem praktischen Leben: Ein Lehrer vermisste ein Medaillon, das stets an seiner Uhrkette hing. Bei Umfrage in den Klassen, in denen er am gleichen Tage unterrichtet hatte, ergab sich, dass die meisten Schüler das Medaillon noch an di e s e m Tage an der 
Kette gesehen haben wollten. Später fand es sich in einem Wirtshaus, in dem der Lehrer am vor he r g e h e n d e $n$ Tage gewesen war. Die Schüler hatten also den gewohnten Anblick des Medaillons fälschlich auf den Tag der Befragung projiziert. Verständlich ist, dass der Prozentsatz der Schüler, die irrtümlich temporalisierten, in den jüngeren Jahrgängen grösser war als in den älteren.

Man sollte hiernach glauben, dass $\mathrm{u} n \mathrm{ge} \mathrm{w}$ ö $\mathrm{h} \mathrm{n} \mathrm{lich}$ e und auffällige Eindrücke, sofern nur ihre Abweichung vom Ublichen beachtet worden war, die beste Gewähr böten, gut erinnert zu werden. Hier gibt es indessen eine neue Klippe. Wenn sich nämlich etwas wegen seiner B e s o n d e r h e it der Aufmerksamkeit aufgedrängt hat, dann besteht die Tendenz, in der Erinnerung diese Besonderheit noch zu potenzieren. War ein Mensch wegen seiner Grösse aufgefallen, so wird er in der Erinnerung zum Riesen. War man beeindruckt von der grossen Zahl von Menschen, die sich bei einem Ereignis angesammelt hatten, so wird die geschätzte Ziffer mit der Zeit immer weiter wachsen u.s.w. Besonders gilt dies von solchen Erlebnissen, deren Besonderheit stark auf den A f e k t gewirkt hatte. Eine durchlebte Gefahr wird in der Erinnerung vergrössert; die Vorstellung einer guten Tat, die man mit ansah, wird mit fortschreitender Zeit idealisiert.

Hier macht sich also wieder stark jener Subjektbezug der Erinnerung geltend, der vergangene Erlebnisse im Sinn subjektiver Bedürfnisse stylisiert. So wichtig dieser Zug sein mag zur Bildung des Erinnerungsmythos ${ }^{1}$ ), so bedenklich ist er dort, wo es sich um objektive Wiedergabe von Tatbeständen handelt. Am drastischsten wirkt dieser Fälschungsfaktor bei Kettenaussagen, den sogen. „G e r ü c h t e n". Denn jeder einzelne, der ein Gerücht weiter trägt, lässt das fort, was seinem Interesse oder Verstännis ferner liegt; aber dafür unterstreicht und potenziert er das, was ihm als wichtig und ungewöhnlich auffiel; und so kann nach einer nur kleinen Anzahl von Zwischenträgern der Tatbestand bis zur Unkenntlichkeit verzerrt und vergröbert sein.

f) Gestaltungstendenzen. - Nicht unbeträchtlich sind die Einflüsse, die die logischen, ästhetischen und sprach-

1) Vgl. das Beispiel von der Witwe, S. 349. 
lichen Gesta $1 \mathrm{tung}$ ste ndenzen des Aussagenden auf die Aussagetreue ausüben.

Das Gewoge der mehr oder minder deutlichen, oft lückenhaften und ungeordneten Erinnerungsbilder muss, um überhaupt aussagbar zu werden, umgewandelt werden in einen einleuchtenden, dem Aussagenden und dem Verhörenden verständlichen Zusammenhang. Bei dieser $\mathrm{L}$ o g i f i z i e r u $\mathrm{n} g$ spielen Ergänzungen, Vermutungen und Deutungen eine, dem Aussagenden selbst meist unbewusste Rolle ${ }^{1}$ ).

In einem meiner Aussageexperimente war die Abbildung eines Umzugs verwendet worden. Ein offener Wagen war mit Möbeln voll bepackt; vorn stand als Kutschbock ein Sopha, quer gestellt, auf dem eine Frau sass. - Ein Student, der nach einigen Wochen den Bildinhalt reproduzieren sollte, erinnerte sich der sitzenden Frau, nicht aber mehr des Gegenstandes, auf dem sie sass. Da sie aber auf irgend etwas gesessen haben musste, so wurde ihr statt des Sofas eine Kiste untergeschoben. Der Aussagende ahnte nicht, dass die Kiste nur eine Konjunktur, keine reale Erinnerung war.

Besonders bedenklich sind solche Ergänzungen dann, wenn sie nicht die äusseren Gegenstände und Geschehnisse, sondern deren Ursachen, die zu Grunde liegenden Absichten und Motive u.s.w. betreffen. Das logische Bedürfnis nach kausalem Verständnis mischt sich hier oft mit sehr subjektiven Affekten. Wenn ein Zeuge $z$.B. aussagen soll, ob die von ihm beobachtete Handlung des Angeklagten vorsätzlich oder im Affekt oder fahrlässig ausgeführt worden sei, so wird die Deutung, die er seinen, vielleicht recht spärlichen Erinnerungen gibt, stark mitbestimmt sein durch seine Stellung im Streit der Parteien.

Das ästhetische Bedürfnis nach darstellerischer Abrundung und Ausschmückung wirkt ähnlich. Erzählungen von Selbsterlebtem, die zugleich „Dichtung und Wahrheit” sind, können erfreuend für den Erzähler und die Hörer sein, solange es sich nur um künstlerischen Genuss handelt. Anders, wenn sich ein Zeuge vor Gericht an seiner eigenen Darstellung berauscht und die Forderung nach objektiver Richtigkeit weniger beachtet. Kinder, Künstlernaturen, Phantasten sind zuweilen ganz ausser stande, diese Verschmelzung von Erinnerung und Konfabulation zu lösen und dem Objektbezug der Aussage gerecht zu werden.

1) Über die spezielle Auswirkung solcher logifizierenden Tendenzen bei $\mathrm{T} \mathrm{ra} \mathrm{u} \mathrm{m-}$ e rinnerungen vgl. Kap. XIX. 
Endlich ist die Fassung der Erinnerung in sprachli$\mathrm{c}$ h e $\mathrm{n}$ Ausdruck zu beachten.

Worte sind $\mathrm{h}$ a $\mathrm{rt}$ im Vergleich $\mathrm{zu}$ dem wallenden und beweglichen Vorstellungsgewebe, das sie wiedergeben sollen; so erhält das Erinnerungsbild durch die Pressung in Worte eine gewaltsame Vereinfachung und Versteifung. Soll nun in einem späteren Zeitpunkt (z.B. bei einem zweiten Verhör) der Tatbestand wieder hervorgeholt werden, so erinnert man sich oft viel deutlicher an die A u sd r ü cke, die man bei der ersten Beschreibung verwandt hat, als an die Gegenstände und Vorgänge selbst. Bei mehrfacher Aussage über dasselbe Ereignis wird dann allmählich der Wortlaut s t e r e o t y p: das beste Zeichen, dass an die Stelle bildhafter Gegenstands- und VorgangsErinnerungen mehr und mehr sprachliche Erinnerungen getreten sind.

Sprache ist aber andrerseits vi e l d e u t i g: und wenn man nur noch Worte reproduziert, dann kann es kommen, dass man beim zweiten oder dritten Male andere Gegenstandsbilder damit verbindet als zur Zeit der ersten sprachlichen Prägung der Aussage.

Bei dem eben erwähnten Versuch mit dem Umzugsbild hatte eine Versuchsperson den poetischen Ausdruck gebraucht: „Ein Maler zieht zum Tore hinaus". Nach einigen Wochen war noch das W o $t$ "Tor" haften geblieben, aber die damalige nur symbolische Wortbedeutung vergessen. So erfolgte jetzt die Angabe: „Ein Möbelwagen fährt durch ein enges Tor'. Von einem solchen Tor war keine Spur auf dem Bilde vorhanden.

g) Charakterologische und biologische F a k t or e n. - Wenn wir im Obigen Punkt für Punkt die psychologischen Bedingungen besprachen, von denen die grössere oder geringere Erinnerungstreue und Aussagerichtigkeit abhängt, so muss zum Schluss doch wieder betont werden, dass die Wirksamkeit aller Einzelbedingungen abhängt von der personalen Empfänglichkeit des Aussagenden für diese Einflussfaktoren.

Hier werden nun $\mathrm{charakterolog}$ ische Züge bedeutsam. Denn ob man die zuströmenden Vorstellungen, die sich als Erinnerungen anbieten, durchlässt oder einer mehr oder minder scharfen Zensur und Siebung unterwirft, ist stets zugleich 
Sache der Gewissenhaftigkeit und der Selbstkritik. Auch innerhalb des Wahrheitswillens gibt es noch eine sehr grosse Spielraumbreite für die Strenge, mit der man seine Erinnerungen und Worte behandelt. Hierher gehört ferner, dass Menschen des „objektiven Typus" von vorn herein bessere Gewähr für korrekte Aussagen bieten, als Subjektivisten, dass Menschen von selbständigem und starkem Willen den Suggestionen des Verhörs und der Gerüchte besser widerstehen als Willensschwache.

Bei alledem darf man die "Perspektivik des Charakters" 1) nicht übersehen. Auch der, im allgemeinen sehr nüchterne und objektive, Gelehrte kann ein ganz subjektiver Zeuge sein, wenn Interessen seiner Person oder die naher Angehöriger auf dem Spiel stehen. Und ein junger Mensch, der im allgemeinen wenig suggestibel sein mag, kann doch durch einen Freund oder Verführer, dem er hörig ist, in so starkem suggestiven Bann gehalten sein, dass er die zu bekundenden Tatbestände nur in dem, von diesem gewünschten, Lichte sieht und darstellt. -

Auch die Abhängigkeit der Aussagetreue von den b i o log i$\mathrm{s} c \mathrm{~h}$ e $\mathrm{n}$ Bedingungen des Alters und des Geschlechts ist vielfach untersucht worden.

Sehr deutlich zeigt sich innerhalb der $\mathrm{K}$ in $\mathrm{d}$ he it mit zunehmenden Jahren eine Abnahme der Suggestibilität: bei Bildversuchen sind 7-jährige Kinder der Hälfte aller an sie gestellten Suggestivfragen erlegen, ältere Kinder nur jeder fünften Frage. $\mathrm{Zu}$ Beginn der Pubertät scheint es noch einmal einen neuen Suggestibilitätsschub zu geben; diese stärkere Beeinflussbarkeit in Verbindung mit der sehr lebhaften Phantastik jener Altersstufe und dem Einfluss des erwachenden Trieblebens macht die Aussagen jugendlicher Zeugen besonders problematisch. Es ist dies auch das Gebiet, auf dem vorzugsweise die Mitwirkung psychologischer Sachverständiger in Anspruch genommen wird.

Uber den Unterschied beider Geschle $\mathrm{chter}$ bestehen widersprechende Meinungen. Die Ergebnisse experimenteller Aussageuntersuchungen sind nicht eindeutig; wenn auch in der Mehrzahl der Fälle die Aussagen von Frauen einen höheren Fehlerprozentsatz aufweisen, so gibt es doch auch gelegentlich entgegengesetzte Befunde. Allerdings ist ja bei solchen Experimen-

1) Vgl. zu diesem Begriff das Kapitel XXIII „Charakter”. 
ten die innere Anteilnahme der Versuchspersonen gering und daher objektive Haltung leichter möglich. In den Ernstfällen des Lebens dagegen wird sich die Frau im allgemeinen schwerer als der Mann von den subjektiven Affektbindungen und den dadurch bedingten Fälschungen der Aussage frei machen können.

\section{Thesen über praktische Anwendungen}

Die praktischen Anwendungen dieser psychologischen Einsichten können im Rahmen des vorliegenden Buches nicht mit solcher Ausführlichkeit behandelt werden, wie es der Wichtigkeit der Aufgabe und der Schwierigkeit der Probleme entspräche. Wir begnügen uns damit, thesenartig die wichtigsten Punkte aufzuzählen.

I) Es gibt eine Psychotechnik und eine Psychognostik der Aussage. Jene liefert die psychologischen Gesichtspunkte für die Erzielung und Lenkung, diese für die Beurteilung und Bewertung der Aussage.

Ia) Die Psychotechnik der A us sage besteht in einer psychologisch sinnvollen Art der V e r n e h m u n g. Dazu gehört u.a.: Herstellung eines seelischen Kontaktes zwischen Verhörendem und Aussagendem; Anpassung der Vernehmungsweise an Eigenart, Bildungsstand, Altersstufe des Zeugen; verständnisvolle Verwertung der sprachlichen und mimischen Ausdrucksphänomene. - Richtige Verteilung von Bericht und Verhör; sparsamste Anwendung von Suggestivfragen; Berücksichtigung der möglichen Wirkung von Suggestionen, sofern diese unvermeidlich sind. - Protokollführung, die nicht nur den sachlichen Inhalt der Aussage zusammenfasst, sondern auch die Art des Fragens und Antwortens erkennen lässt.

Ib) Zur Psychognostik der Aussage gehört: Persönlichkeitsdiagnose des Aussagenden ${ }^{1}$ ); Feststellung der Milieufaktoren und ihrer Wirkungen; Analyse der einzelnen psychologischen Bedingungen der Aussage; Rekonstruktion der Geschichte der Aussage (vom Aufkommen der ersten Gerüchte

1) Hierbei sind natürlich auch manche, in den vorbergehenden Seiten nicht behandelte Persönlichkeitsmerkmale, pathologische Züge, absichtliches Täuschungsverhalten u.s.w. zu berücksichtigen. - Gelegentlich werden auch experimentelle Prüfmethoden anwendbar sein. 
durch die verschiedenen Verhöre hindurch bis zur Verhandlung); Gesamturteil über die Glaubwürdigkeit der Aussage.

II. Alle Praktiker, welche Aussagen zu behandeln haben: Justiz- und Polizeibeamte, Mediziner und Pädagogen müssen mit der Psychologie der Aussage gründlich vertraut sein, um obigen Aufgaben gerecht zu werden.

III. In schwierigeren Fällen sind $\mathrm{Fach}$ p s y c h o logen a $1 \mathrm{~s} \mathrm{~S} \mathrm{a} \mathrm{c} \mathrm{h} \mathrm{vers} \mathrm{t} \mathrm{ä} \mathrm{n} \mathrm{di} \mathrm{g} \mathrm{e} \mathrm{hinzuzuziehen,} \mathrm{und} \mathrm{zwar} \mathrm{in} \mathrm{mög-}$ lichst frühen Stadien des Verfahrens. Der psychologische Gutachter muss neben theoretischer und experimenteller Schulung auch umfassende forensische Erfahrungen haben. Sein eigentliches Kompetenzgebiet sind solche Fälle, die noch innerhalb der Normalitätsbreite liegen, aber psychologische Komplikationen zeigen. Zusammenarbeit mit den medizinischen Sachverständigen ist erforderlich. 


\section{VIERTER HAUPTTEIL}

DENKEN UND PHANTASIE 


\section{FƯNFZEHNTES KAPITEL}

D A S D E N K E N

\section{DENKPSYCHOLOGIE}

\section{Allgemeines}

Denken ist - neben der Erfahrung — das wichtigste Werkzeug aller Wissenschaft; kein Wunder, dass sich die Wissenschaft von alters her mit diesem ihrem eigensten Thema beschäftigt hat. Aber das wissenschaftliche Denken über das Denken war bis vor kurzem fast durchweg nicht-psychologischer Natur, vielmehr o bj e k t i vi e r e n d eingestellt: auf das, was gedacht wird, und auf die Formen, in denen gedacht wird, auf die Forderungen, denen das Denken entsprechen muss, um gültige Ergebnisse zu erzielen, und auf die Grenzen dieser Gültigkeit. Logik, Erkenntnistheorie, Methodenlehre, schliesslich auch Metaphysik behandelten das Denken.

Das Interesse am Denken, wie es sein soll, hat lange die Beschäftigung mit dem De n k e n, wie es is t und wird, in den Hintergrund gedrängt. Das wird jetzt anders. Das keimhafte, werdende, naive, verworrene, falsche Denken, das Denken in seinen vielfachen Verbindungen mit nicht-intellektuellen Faktoren, das praktische Denken, das magische Denken - alle diese Themen fangen erst soeben an, in den Gesichtskreis der Forschung zu treten, seitdem man eine Psychologie des Denkens aufzubauen beginnt.

Gehemmt wurde deren Entwicklung aber auch von psychologischer Seite selbst; denn grosse und führende Psychologenschulen sahen im Denken nicht eine psychische Funktion von eigenwertiger Bedeutung, sondern eine Spezialerscheinung des Vorstellungslebens. Man machte bezüglich der Denkinhalte keinen grundsätz- 
lichen Unterschied zwischen "Gedanken” und „Vorstellungen”, bezüglich des Denkgeschehens keinen Unterschied zwischen eigentlichen Denkakten und assoziativen Verknüpfungen.

Es bedurfte - am Anfang unseres Jahrhunderts - erst der Abkehr der Psychologie von einer elemententheoretischen und mechanistischen Auffassung und erneuter Anstösse von philosophischer Seite her, um den Grund zu einer wirklichen Psychologie des Denkens zu legen. Besonders fruchtbar waren die Anregungen, die von der Phänomenologie Edmund Husserls ausgingen; sie wirkten auch hinüber auf die experimentalpsychologische Arbeit. Diese fand ihre erste systematische Anwendung auf Denkprobleme in dem Kreis um Oswald Külpe (sog. „Würzburger Schule"). Von den zahlreichen hierhergehörigen Forschern seien genannt: Ach, Karl und Charlotte Bühler, Lindworsky, Marbe, Messer, Selz, Watt; speziell für religionspsychologische Probleme: Girgensohn.

In der Folgezeit blieb die Denkpsychologie nicht auf diese Schule beschränkt; andere Methoden und andere Gesichtspunkte wurden erschlossen. Kinder-, Tier- und Völkerpsychologie brachten wertvolle Beiträge zum Denkproblem. Auch mit den p h i l os o phis chen Bearbeitungen des Denk-Themas wurden nun weitere Verbindungen hergestellt (es sei hier auf Cassirer's „Philosophie der symbolischen Formen" hingewiesen); ja von philosophischer Seite wurde sogar der Versuch gemacht, den eigentlichen Kern a ll e r Psychologie in einer - sehr stark erkenntnistheoretisch unterbauten - Denkpsychologie zu finden (Hönigswald).

Die psychologischen Problematik des Denkens wurde auch noch von einer anderen, wel t a n s ch a u li c h e n, Seite her kompliziert, nämlich durch den Gegensatz von Rationalem und Irrationalem. Der rationalen Welt entspricht psychologisch das Denken, der irrationalen Welt einerseits Trieb und Anschauung, andrerseits Gemüt und "Seele". Ist nun, auch psychologisch gesehen, der denkende "Geist" etwas toto genere anderes als der Trieb hier, die Gemütssphäre dort? Besteht daher zwischen dem trieb- und sinnes-gebundenen Tiere und dem homo sapiens eine absolute Kluft oder nur ein Uunterschied des Entwicklungsgrades? Ist der "Geist" der „Widersacher der Seele" und nichts anderes, wie es Klages behauptet? - Man sieht, dass solche Fragen 
tief in dogmatischen Wertvoraussetzungen verankert sind, dass sie aber doch mit ihren Folgerungen hinüberreichen in Sphären, die der wissenschaftlichen Prüfung fähig und der Kritik bedürftig sind.

Eine personalistisch orientierte Denkpsychologie wird das Doppelprinzip der Abhebung und Einbettung auch hier anzuwenden haben.

Sie wird also auf der einen Seite das b e s o n d e r e Wesen des Denkens herausstellen und anderen seelischen Sphären, dem Trieb, dem Vorstellen, dem Fühlen u.s.w. gegenüberstellen; dies ist um so mehr gefordert, als es gerade für das Denken charakteristisch ist, weithin a b g e hobene Erlebnisganzheiten und durchgestaltete Abläufe zu zeigen. Auf der anderen Seite ist und bleibt aber auch das Denken eine tief in die Personganzheit e i n$\mathrm{g}$ e b e $\mathrm{t} t \mathrm{e} t \mathrm{e}$ Funktion und ist deshalb eng von seelischen Tatbeständen anderer Art durchsetzt, ja mit ihnen verschmolzen. Dadurch wird es innerlich viel reicher, zugleich viel weniger ,rational", als wenn es die isolierte Betätigung eines selbständigen logischen Vermögens wäre. Auch entwicklungspsychologisch wird sich ergeben, dass das Denken organisch aus praelogischen Vorstufen hervorwächst, um dann über sie hinauszuwachsen. So ist es zugleich Sublimierung wie Überwindung der Trieb- und Anschauung-Sphäre und - nach der anderen Richtung - zugleich Widersacher wie Bundesgenosse der Gemütssphäre.

\section{Erscheinungsweisen des Denkens}

Wir geben im folgenden vier Beispiele von Denkprozessen, auf welche wir später mehrfach zurückgreifen werden. Sie repräsentieren vier wesentliche $\mathrm{Ersch}$ e in u $\mathrm{ng}$ s e is en des Denkens und sind so gewählt, dass sie von ganz konkreten Formen zu immer abstrakteren führen. Zugleich geht aus ihnen deutlich hervor, dass das Denken inhaltlich und funktionell etwas anderes ist als das Vorstellen, so vielfach auch die, zwischen beiden psychischen Sphären bestehenden, Verbindungen sein mögen.

In den ersten drei Erscheinungsweisen ist das Denken wesentlich statisch: ein $\mathrm{Haben}$ von ge gebenen Gedan$\mathrm{ken}$. Die vierte Erscheinungsweise ist dynamisch: e in Suchen von a ufgegebenen Gedanken. 
a) „D e n ke n a n E t w a s.”- Ich denke an den „Hamburger Hafen". Verschiedene Vorstellungen tauchen in mir auf: das Bild des Hafens von einem Punkt des erhöhten Ufers aus; die wechselnden Szenerieen bei einer Hafenrundfahrt; eine abendliche Ankunft mit einem überfüllten Vergnügungsdampfer; der Anblick eines Stapellaufes; ferner die Klangvorstellungen heulender Sirenen und stampfender Maschinen; eine kürzlich gelesene Statistik über den Schiffsverkehr u.s.w. Daneben her läuft dauernd die Wortvorstellung „Hamburger Hafen”. - Aber all dies is t nicht der Gedanke an den Hamburger Hafen, sondern nur Rankenwerk, vielleicht Stützgerüst für ihn. Indem ich jenen Gedanken habe, meine ich nicht das optische Bild des Hafens von einer bestimmten Seite in einer bestimmten Beleuchtung, oder die Hafengeräusche und Hafengerüche, die ich vorstelle - sondern ich meine d e n Hafen, wie er garnicht Inhalt einer einzigen Vorstellung sein kann. Ich meine ihn vielleicht jeweilig unter einer anderen Perspektive, einmal als Mittelpunkt des Weltverkehrs, ein anderes Mal als bauliche Anlage, dann wieder als Sehenswürdigkeit für den Fremden - aber trotz solcher "Als"-Perspektiven ist es immer d e r s e 1 b e Hafen. Beide Erlebnismomente: Dasselbigkeit und „Als"-Gesichtspunkte sind nicht anschaubar, nicht in einzelnen konkreten Vorstellungen zu vollziehen, sondern rein gedanklicher Natur.

b) Das," Wis s e n u m...." - Mehrere Personen unterhalten sich über das bevorstehende Wetter. A.: „Es ist möglich, dass es heute noch Regen gibt." B.: „Ich halte es sogar für sehr wahrscheinlich." C. : „Aus der meteorologischen Lage geht hervor, dass rs heut noch zu Regen kommen muss." - Alle Drei sprechen von Regen und mögen dabei mehr oder weniger deutlich irgend welche Sprach- und Gegenstands-Vorstellungen von "Regen" haben. Aber diese Vorstellungen sind bei jedem in eine andre gedankliche M o d a li t ä t gesetzt: Möglichkeit, Wahrscheinlichkeit, Notwendigkeit - für diese Denkerlebnisse fehlt es an vorstellungsmälsiger Repräsentanz. Jeder von den Unterrednern w e is s trotzdem genau, was jene modalen Ausdrücke bedeuten; die Unanschaulichkeit dieses Wissens um Möglichkeit u.s.w. beeinträchtigt in keiner Weise die Klarheit des Gedankens.

Die Rede des C. verlangt aber noch eine andere Analyse. Die 
Notwendigkeit, die er denkt, gilt nicht sowohl dem Regen an sich, sondern der $\mathrm{B}$ e $\mathrm{z}$ i e $\mathrm{h}$ u $\mathrm{n} g$ zwischen der meteorologischen Lage und dem Regen. Die beiden Glieder der Beziehung mögen noch vorstellungsmäfsig unterbaut sein, etwa durch innere Bilder des Barometerstandes und des zu erwartenden Regengusses. Aber die $\mathrm{z}$ wis $\mathrm{ch}$ e $\mathrm{n}$ beiden bestehende Beziehung ist selbst nicht mehr vorstellungsmälsig da, sondern sie ist $\mathrm{ge} \mathrm{da} \mathrm{cht}$, und zwar ist sie nicht nur vage als irgend eine Zusammengehörigkeit überhaupt, sondern als Beziehung einer bestimmten Kategorie „Ursächlichkeit” gedacht. Wir stossen hier also auf ein durchaus unanschauliches, aber durchaus klares Wissen um eine kategoriale Beziehung.

c) Das Verstehen des Abstrakten. - Den mathematischen Satz: „Die Winkelsumme im ebenen Dreieck beträgt zwei Rechte" vers t e h e ich. Was bedeutet das bewusstseinsmälsig? Halten wir uns zunächst an die einzelnen Bestandstücke (obwohl wir dadurch dem Bewusstseinsgehalt eine gewisse Gewalt antun). Von den drei Gliedern: Winkelsumme, ebenes Dreieck, zwei Rechte ist offenbar das letzte am stärksten vorstellungshaltig; jeder, der irgendwann Geometrie getrieben hat, wird beim Hören der Worte „zwei Rechte” eine Vorstellung dieser Art in sich finden: $\perp$ Anders ist es schon mit „Winkelsumme"; mag mir hierbei auch ganz vage vorschweben, wie sich Winkel um einen gemeinsamen Scheitelpunkt zusammenfügen; so ist doch schon die Grösse der einzelnen Winkel völlig beliebig. Dasselbe gilt von dem Gedankenmoment „ebenes Dreieck”. Ein etwa anschaulich vorgestelltes Dreieck gewisser Grösse, Form und Färbung kann ohne weiteres durch irgend ein anderes vorgestelltes Dreieck ersetzt werden, ohne dass dadurch der gedankliche Inhalt im mindesten berührt würde. Wesentlich ist nur das „Dreieck-Sein” und „Eben-Sein”; alle andern Merkmale, welche vorgestellten Dreiecken zukommen und diese voneinander unterscheiden, sind für den Gedanken gleichgültig. Sofern überhaupt irgend eine Dreieckvorstellung da ist, hat sie lediglich als beliebiger $\mathrm{R}$ e p r ä$\mathrm{s}$ e $\mathrm{n} t$ a $\mathrm{n} t$ des Gedankens zu dienen.

Verlassen wir nun aber die künstliche Vereinzelung der drei Glieder; in meinem Bewusstsein sind ja nicht drei nebeneinander bestehende Gedanken vorhanden, sondern ein $\mathrm{G}$ es a $\mathrm{m} \mathrm{tg}$ e- 
d a n ke, der sprachlich die Form des Satzes, logisch die Form des Urteils angenommen hat. P s y c h o l o g i s c h können wir diesen Gesamtgedanken am besten einen S in n-Gedanken nennen: der Satz im ganzen hat einen einheitlichen, geschlossenen Bedeutungsgehalt, der mehr und anderes ist, als der Bedeutungsgehalt der einzelnen gedanklichen Erlebnismomente und ihrer Beziehungen. Was wir im Denkgebiet „Verstehen" nennen, ist immer auf den Gesamtsinn einer geschlossenen gedanklichen Einheit bezogen.

d) Das $\mathrm{Nachdenken} \mathrm{über} \mathrm{Etwas.} \mathrm{-} \mathrm{Ein} \mathrm{junger}$ Psychologe erbittet meinen Rat bezüglich der Wahl eines Themas für seine erste selbständige Arbeit. Ich kenne ungefähr seine Interessenrichtungen und lasse sie mir durch seine Angaben noch präzisieren; ich kenne ungefähr Grad und Art seiner Begabung und seine Arbeitstüchtigkeit - und nun ,denke ich nach". Dabei geht etwas sehr Merkwürdiges in mir vor. Ich denke an etwas, was noch garnicht da ist, nämlich das Thema; mein Gedankeninhalt ist vorläufig nur „Thema-S u c h e", ein Eingestelltsein auf ein Loch, das erst gestopft werden soll. Aber gerade dies noch Fehlende beschäftigt mich ganz und ist auch bestimmend dafür, wie nun inhaltlich erfüllte Gedanken in meinem Kopf kreisen, bis irgend einer dieser Inhalte dem Suchen entgegenkommt und „als" Lösung der Schwierigkeit erlebt wird. - Wenn ich nun dem Frager einen Vorschlag mache, dann beginnt bei ihm ein ähnlicher Prozess; auch er denkt nach, ob das gehörte Thema, das zunächst für ihn auch nur ein unerfülltes $\mathrm{X}$ ist, mit seinen Gedanken über seine Wünsche und Fähigkeiten u.s.w. übereinstimmt.

\section{GEDANKE UND VORSTELLUNG ${ }^{1}$ )}

1. Unterschiede und Beziehungen

In der Bezeich nung der spezifischen Denkinhalte besteht noch keine Einheitlichkeit.

Die ältere Psychologie pflegte den Ausdruck „Vorstellung” so

1) Spezielle Literatur über das Thema ist zusammengestellt in I. Meyersons „L'Image". 
weit auszudehnen, dass auch die Erlebnisinhalte des Denkens dazu gehörten. Sie rubrizierte diese dann als „Allgemeinvorstellungen”, abstrakte Vorstellungen, „Obervorstellungen” (Liepmann), "Gesamtvorstellungen" (Moskiewicz) - und schied sie von den „konkreten Vorstellungen” oder „Einzelvorstellungen”. Eine solche Bezeichnung scheint deshalb nicht glücklich, weil dann immer - wissentlich oder unwissentlich - konkrete, wahrnehmungsnahe Vorstellungen und ihre Verknüpfungsweisen als die $\mathbf{M}$ od e 11 e gelten, nach denen dann auch die Denkinhalte und Denkabläufe gedeutet werden.

Aus diesem Grunde hat auch die neuere Denkpsychologie, als sie auf $\mathrm{un}$ a $\mathrm{n} \mathrm{s} \mathrm{h} \mathrm{a} \mathrm{u} \mathrm{lich} \mathrm{e} \mathrm{Bewusstseinsinhalte} \mathrm{stiess,} \mathrm{dafür}$ eigene Ausdrücke einzuführen gesucht. Von diesen haben die Termini „Bewusstheit”, „Bewusstseinslage” sich nicht behaupten können. Am geeignetsten scheint die seinerzeit von Karl Bühler aus dem natürlichen Sprachgebrauch übernommene und in die wissenschaftliche Sprache eingeführte Bezeichnung „G e d a n k e”.

Der erlebensmäfsige Unterschied von „Vorstellungen” und „Gedanken" ist nun aber durch die Merkmale ,anschaulich"/,unanschaulich" nur zu einem Teil gekennzeichnet; ja diese Verscheidenheit enthält erst ihren tieferen Sinn durch eine andere. Die Vorstellung is $\mathrm{t}$ e in $\mathrm{f} \mathrm{a} \mathrm{ch}$ da in ihrer immanenten bildartigen So-Beschaffenheit; der Gedanke weist über sich hinaus, er m e i n t etwas, was nicht er selber ist (einen Gegenstand, eine Gattung, eine Beziehung, einen Sinn, eine Problemlösung). Diese ihm zukommende "I n t e n t i o n" ${ }^{1}$ ) verleiht dem Gedanken eine spezifische Erlebnistönung.

Ebenso wichtig aber wie der Unterschied ist die positive Beziehung von Vorstellungen und Gedanken. Beide gehören zusammen; sie sind eigentlich - von wenigen Grenzzuständen abgesehen - stets zusammen da, auf einander angewiesen, mit einander verschmolzen. Es handelt sich also wiederum nicht um verschiedene „Elemente”, sondern um M o m e n t e eines einheitlichen geistigen Bewusstseinsbestandes.

Die Grenzzustän de selbst sind kaum mehr beschreibbar. Dem rein vorstellungsmälsigen, „gedankenlosen” Erleben

1) Der Begriff der „Intention” bildet eines der Zentralstücke der Phänomenologie Edmund Husserl's. 
kommt wohl am nächsten die seelische Verfassung des Wachtraums, wenn sich im Bewusstsein Bilder drängen und ablösen, selbstgenügsam, ohne etwas ausserhalb ihrer selbst $\mathrm{zu}$ meinen oder zu bedeuten. Auch beim Kleinstkind, beim „ideenflüchtigen" Irren, dürfen wir ähnliche Zustände annehmen. Auf der anderen Seite finden sich ganz anschauungs- und vorstellungsarme, annähernd „reine” Gedankenerlebnisse nur bei Vertretern höchster wissenschaftlicher Abstraktionen, etwa bei Erkenntnistheoretikern, Mathematikern, Begriffsjuristen — und auch bei diesen nur auf seltenen Höhepunkten ihrer Denkbetätigung, nicht etwa als die Normalform ihres Denkens überhaupt.

Die ganze Fülle des dazwischen liegenden geistigen Erlebens ist stets zugleich konkret und abstrakt, mit Vorstellungen erfüllt und von Gedanken bestimmt. Aber der Anteil von beiden kann sehr verschieden sein. Es ist $\mathrm{s} c \mathrm{~h}$ on Denken beteiligt, wenn der Mensch einen individuellen Gegenstand als Gegenstand, der ausserhalb seiner Person Existenz hat, anspricht (vgl. unser Beispiel a „Hamburger Hafen”); es sind andrerseits n o c h Vorstellungen beteiligt, wenn der Mensch einen so abstrakten Satz wie den von der Winkelsumme im ebenen Dreieck denkt und seinen Sinn versteht (Beispiel c). Aber im letzten Falle ist die Emanzipation des Gedankens von den Vorstellungen schon viel weiter gediehen als im ersten.

So wird jetzt eine Bedeutung der Vorstellung klar, auf die wir an früherer Stelle (S. 290) nur vorläufig hinweisen konnten: ihre Vermittlungsfunktion zwischen Wahrnehme n und Denken. Grade weil sie - verglichen mit der vollsaftigen, aber situationsgebundenen Anschaulichkeit der Wahrnehmung - eigentümlich vage, dürftig, vieldeutig erscheint, kann sie als halbabstraktes $\mathrm{S} c \mathrm{~h}$ e $\mathrm{m}$ a ein Stützgerüst für gedankliche Operationen bilden.

Die Logik bezeichnet als „Abstraktion” jenen gedanklichen Prozess, durch welchen das einmalig Anschauliche der Einzelfälle ausgeschieden und das Dauernde und Allgemeine gewonnen wird. Psychologisch ist es vorteilhafter, dafür den - logisch nicht belasteten - Ausdruck „Ent a n s ha u lich u n g” zu verwenden. Es zeigt sich jetzt nämlich, dass die eigentlich logische Abstraktion, die sich auf Vergleichung und Isolierung gemeinsamer Merkmale stützt, nur die seltene Höchstform eines viel um- 
fassenderen Geschehens ist, in welchem die Anschaulichkeit schrittweise iiberwunden wird.

Bildung und Verwertung schematischer Vorstellungen ist eine der wichtigsten Etappen in dieser Entwicklung.

Würde meine Vorstellung eines Dreieckes alle Farbtöne und Höckerigkeiten mit enthalten, die ich früher einmal an irgend einem gezeichneten Dreieck wahrgenommen habe, dann würde eine solche Dreieckvorstellung mir nicht als der beliebig auswechselbare Repräsentant für den Gedanken des Dreiecks überhaupt dienen können, der im Satz von der Winkelsumme gedacht wird. Nur dadurch, dass die Vorstellung an besonderem Inhalt schon weitgehend reduziert ist, kann sie zu weiterer Reduktion beitragen.

Dem En t s ch a u lichung s-Prozess entspricht in umgekehrter Richtung der Veranschaulichung s-Prozess, bei dem ein abstrakter Gedanke nach einem greifbaren Halt und nach Vereindeutigung strebt: so beim Sichbesinnen, beim Lösen einer Aufgabe, beim Anwenden einer Regel auf einen Spezialfall. Ein erster Schritt führt hin zu einem vorgestellten Schema, das schon anschaulich genug ist, um dem Denken einen Angriffspunkt zu bieten, aber offen genug, um weiterer Denkarbeit Anreiz und Spielraum zu geben - bis dann das Resultat als relativ anschaulicher Gedanke gewonnen ist.

\section{Zeichen und Symbole}

Es gibt nun gewisse Gruppen von Vorstellungen, denen der $\mathrm{s} \mathrm{ch} \mathrm{e} \mathrm{m}$ a $\mathrm{t}$ i s c h e Charakter und damit die Hilfsdienststellung für das Denken in besonderem Malse zukommt, dadurch dass sie sehr einfach und übersichtlich, leicht für den Einzelnen reproduzierbar und verwendbar und leicht für den Verkehr zwischen den Individuen sozialisierbar und fixierbar sind: es sind die, vornehmlich dem optischen und akustischen Gebiet angehörigen, bez e i c h n e n d e n (,semantischen") Vorstellungen.

Jetzt wird die Bedeutung der S p r a c h e für das Denken klar. Die Sprache selbst - als Inbegriff klanglich-graphisch-motorischer Wahrnehmungen und Vorstellungen - ist zwar keineswegs mit dem Denken identisch; es gibt ebenso gedankenfreie SprachErlebnisse und -Ãusserungen, wie es sprachloses, „unformulier- 
tes" Denken gibt. Aber die Gedanken bleiben solange völlig gleitend und ungreifbar, mit sich selbst nicht identifizierbar und unter den Menschen nicht austauschbar, solange ihnen die Umsetzung in einen Bereich des Anschaulichen fehlt; darum sind sie fixierbar nur durch Heftung an Vorstellungen, die immer wieder in gleichem Sinn und zu gleichem Zweck zur Verfügung stehen. Diese Vorstellungen $\mathrm{m}$ ü s s e $\mathrm{n}$ schematisch sein; denn zu weit gehende Konkretion bedeutet Fesselung und Einzwängung der Gedanken in all $\mathrm{zu}$ individuelle und nicht mehr vergleichsfähige Situationen. Am reinsten wird also der obige Zweck erreicht durch solche Vorstellungen, die nichts weiter beanspruchen, als eben jene Fixierung zu besorgen: es sind die reinen "Z e i c h e n". Das Zeichen + hat keine andere Funktion als anschaulich den Gedanken der Zusammenfügung zweier Zahlengrössen zu repräsentieren, sodass dasselbe Individuum immer wieder den identischen Gedanken daran knüpfen kann und viele Individuen sich über diesen identischen Gedanken verständigen können. Chemische Zeichen, Verkehrszeichen, Schriftzeichen, die Worte des Esperanto sind andere Beispiele für diese nur bezeichnende Funktion schematischer Vorstellungsgegenstände.

Aber gerade diese Beispiele lehren etwas weiteres: sie entstammen künstlich $\mathrm{g} \mathrm{e} \mathrm{ma} \mathrm{ch}$ te $\mathrm{n}$ Zeichensystemen und entsprechen daher einem Denken, das sich bereits ausserordentlich weit von der Basis der Anschaulichkeit entfernt hat. In der natürlich g e w a c h s e n e n S p r a c he ist es anders. Die zu ihr gehörigen Wortvorstellungen haben gewiss a u c h Zeichencharakter; und dieser muss um so mehr hervortreten, je mehr die Sprache dem Ausdruck des rein Gedanklichen dient - also z.B. in der Sprache der Wissenschaft, bei der sachlichen Berichterstattung über objektive Vorgänge u.s.w. Aber zugleich sind doch die Wortvorstellungen auch in ih re $\mathrm{r} A \mathrm{~s} \mathrm{chaulichkeit} \mathrm{sel-}$ be r b e de u t u n g s v o 11; ihr klanglicher, motorischer, auch optischer Gehalt (im Schriftbild) wird nicht völlig gleichgültig, sondern greift über in das mit ihm Gedachte, verleiht dem Gedanken selber Anschauungsnähe und bettet ihn damit zugleich tiefer in das personale und soziale Totalerleben ein. Der Gedanke, der sich an das Wort „Haus" knüpft, i s t nicht derselbe, wie derjenige, der durch „maison" getragen wird, obwohl der objektive Gegenstand beider Gedanken identisch sein mag. Und wenn 
es sich gar um einen ganzen Satz oder um eine längere sprachliche Auslassung handelt, so ist eine Úbersetzung in eine andere Sprache im Sinn identischer gedanklicher Bezeichnungen erst recht unmöglich. Denn durch die anschauliche Wortvorstellu ng hin d u r c h wurzeln die Gedanken im Mutterboden vorgedanklicher - personal- und volkshistorischer Voraussetzungen des Denkenden.

Dieser Zusammenhang von Vorstellung und Gedanke wirkt sich aber auch umgekehrt aus: die Vorstellung selbst ist gedanklich gefärbt; sie weist nicht nur als beliebiges Zeichen auf den Gedanken hin, sondern drückt ihn in der Sphäre des Anschaulichen aus. Man vergleiche nur mit dem eben erwähnten mathematischen Additionszeichen + das fast ebenso aussehende Kreuz auf christlichen Kultgegenständen: das hat nicht nur hinweisenden, sondern geradezu darstellenden Charakter; es gehört ganz anders i n n e r l i c h zum Gedanken des Christentums, als das Pluszeichen zum Gedanken der arithmetischen Addition.

Solche Schema-Vorstellungen, die nicht nur als Zeichen f ü r, sondern als ausdruckshaltige Darstellungen v o n Gedanken erlebt werden, heissen S y m b o l-Vorstellungen; die Gedanken erhalten durch sie über das blosse Gedachtsein hinaus einen "physiognomischen" Zug.

An dem Verhältnis von Symbolzum Z eichen kann man wieder die beiden korrelativen Vorgänge der Entanschaulichung und Veranschaulichung nachweisen, und zwar ebenso im Einzelindividuum, wie in der Gattung.

Das primitive Denken, das noch ganz im einzelnen Gegenständlichen steckt, scheidet überhaupt noch nicht zwischen dem Gedanken und den, ihn tragenden, Vorstellungen. Im Schema ist ein Haus sowohl a b g e bild e t wie be zei c h n e $t$; der Klang ticktack is $t$ ein Moment des Uhrerlebnisses selbst und $m$ e in $t$ zugleich Uhr; in einer stechend roten Farbe $1 \mathrm{e} \mathrm{b} \mathrm{t} \mathrm{zugleich} \mathrm{Blut}$ oder Feuer, und wird Blut oder Feuer g e m e i n t. Wenn dann allmählich das Denken sich zu der Einsicht hin entwickelt, dass es für die Gedanken Zeichen gibt, so klammert sich diese Einsicht zunächst noch an solche ,natürlichen" Symbole; und erst allmählich findet eine A useinanderentwicklung beider statt, indem die Symbole immer schematischer und damit fähiger 
zur Bezeichnung unanschaulicher Gedanken werden - und die Gedanken immer unanschaulicher und daher auch weniger symbolisierbar, nur noch bezeichenbar werden.

Im frühkindlichen Sprachschatz wimmelt es noch von solchen natürlichen Symbolen, die entweder malender oder interjektionaler Art sind (wauwau, puffpuff - wehweh, mammam). Später wird "wauwau" durch „Hund" „wehweh" durch "Schmerz", kurz das anschauliche Symbol durch das konventionelle Zeichen ersetzt ${ }^{\mathbf{1}}$ ).

Auch die $\mathrm{Sch}$ rif $\mathrm{t}$ besteht ursprünglich aus Bildern in der Art des obigen Hausbeispiels; je mannigfacher die graphisch darzustellenden Gedanken, um so mehr müssen sich die Schemata zugleich vereinfachen wie verallgemeinern, bis schliesslich jede darstellerische Beziehung zwischen Schriftbild und Gedachtem verschwunden ist; das Schema ist - wie etwa in der chinesischen Schrift - zum blossen Zeichen des Gegenstandes geworden. Ein weiterer Schritt führt dann dazu, dass das vereinfachte Schriftbild nur noch einen Teil des dazugehörigen Lautbildes wiedergibt, dafür aber identische Bestandteile vieler Lautbilder zu decken vermag: aus der Bilderschrift ist dann die Schrift der Buchstabenzeichen geworden.

Endlich sei auch auf die Entwicklung des $\mathrm{Z}$ e i $\mathrm{ch}$ n e n s hingewiesen. Solange etwa das Kind auf der Stufe der Schemazeichnung steht, ist ihm auch noch nicht der Unterschied zwischen konkreter Darstellung und abstrakter Hindeutung auf den Gegenstand aufgegangen. So kann es kommen, dass es ohne irgend welche Skrupeln „,einen” Hund oder ,einen” Mann zeichnet, der zugleich „der" Hund oder „der" Mann ist - d.h. einerseits anschauliche Liniengestalt, andrerseits allgemeingültiges Zeichen für Hund oder Mann ${ }^{2}$ ). Später scheiden sich die Wege. Es wird etwa ein Haus entweder gezeichnet als anschaulich vorstellbares $\mathrm{Ge}$ bilde, das von einem bestimmten Augenpunkt aus mit bestimmten perspektivischen Verschiebungen und Verkürzungen gesehen ist - oder aber es wird bewusst schematisiert zum Grundriss oder Aufriss, d.h. in einer gedanklichen Isolierung, die mit der konkreten Hausvorstellung kaum mehr etwas zu tun hat. Und in der technischen Zeichnung des Architekten ist - im Gegensatz zu

1) Vgl. C. und W. Stern, Die Kindersprache.

2) Mir ist es sogar einmal begegnet, dass ein Kind ein Säugetierschema zeichnete und auf Befragen, welches Tier es sei, ziemlich ratlos antwortete: „nun eben ein Tier”. Es hatte die allgemeine „Idee des Tieres” ins sichtbare Schema übersetzt! 
dem Hausdarstellung eines Malers - die Entanschaulichung bis zur willkürlichen reinen Zeichengebung für Mauerwerk, Glas, Eisen u.s.w. fortgeschritten.

Die geistesgeschichtliche Parallele hierzu ist etwa an der Entwicklung der Landkarte zu verfolgen. Alte Landkarten enthalten noch so manche konkreten Bilderchen, in denen Bauwerke oder Produkte bestimmter Gegenden dargestellt sind; auch haben die Berge eine gewisse Perspektive u.s.w. Von alledem sind in der modernen, völlig schematisierten Landkarte nur noch letzte „symbolische" Spuren geblieben; etwa die Blaufärbung des Wassers, die Schraffierung der Berge, die verschieden grossen Kreise für verschieden grosse Städte.

Aber dieser Entanschaulichungsprozess ist glücklicher Weise nicht der einzige. Gewiss verlangt die ständige Vergeistigung des Gedanklichen, dass das Zeichensystem der Vorstellungen ihr immer gefügig bleiben muss; aber für sich allein würde daraus eine Entseelung der Gedankensphäre drohen, die ja in ihrer Abstraktheit keine eigene Existenz besitzt, sondern im Ganzen des Seelenlebens irgendwie verankert bleiben muss. Dieser personalen For-

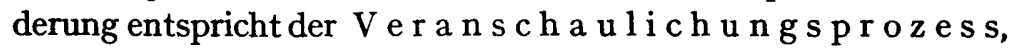
der dem blossen, kahlen Zeichen immer wieder einen lebensnäheren Symbolcharakter zu verleihen sucht.

Wie diese Tendenz sogar in die bewusste Schaffung künstlicher Zeichensysteme hineinwirkt, sei an dem Beispiel der Verke hrszeic h e n illustriert. Unter dem Gesichtspunkt blosser Zeichengebung wäre es durchaus denkbar, dass - statt der heut üblichen Farbensignale - Grünlicht für „Gefahr" und Rotlicht für ,freie Bahn” benutzt würden. Solche Bezeichnungen würden aber - nicht etwa nur in Folge der anderen Gewöhnung - als irgendwie sinnwidrig empfunden werden. Die uralte, vital verankerte, aufrüttelnde und erregende Wirkung des Rot ist vielmehr zum a dä qu a t e $\mathbf{n}$ Symbol der Bedeutung: Warnung, Vorsicht, Halt! vergeistigt worden. - Oder man denke daran, wie die $\mathrm{R}$ i cht u $\mathrm{ng}$ s e is u $\mathrm{n}$ symbolisiert wird durch die unmittelbare Symbolik des zeigenden Fingers auf Wegweisern oder noch mehr vereinfacht - des Pfeils, bei dem schon sehr atavistische Schichten des Menschen angerufen werden.

Aber viel wichtiger als dieses bewusste Zurückgreifen in die Anschauungssphäre ist es, dass eine solche Tendenz sich sogar von selbst mit innerer Notwendigkeit geltend macht, wo immer gedankliche Gehalte nicht in isolierter Lebensferne, sondern in Wechselwirkung mit der personalen Gesamtlebendigkeit durch das Be- 
wusstsein ziehen. Am eindringlichsten zeigt sich dies bei der $\mathrm{k}$ ü $\mathrm{n}$ s $\mathrm{t}$ l e r i s c h e n Gestaltung von Gedanken. Mag ein Schriftsteller noch so abstrakte Gedankengänge durchleben 'und äussern: die sprachliche Einkleidung ist ihm mehr als das, an sich gleichgültige, Zeichensystem für die Fixierung und Mitteilung dieser Gedanken, es ist zugleich ihre physiognomische Durchseelung ; und das gilt nicht etwa nur für die konkreten Bilder und Gleichnisse, in die er das abstrakt Gedachte kleidet, sondern auch für die Weckung formal-sprachlicher Vorstellungen; Rhythmus und Klang, Periodenbildung, Wiederholung, Schallmalerei u.s.w. werden zu natürlichen Symbolen der gedanklichen Intentionen. Wie stark wirkt z.B. dieser Veranschaulichungsprozess mit bei den Gedanken Nietzsches!

Der gleiche Vorgang aber, wenn auch nicht in dieser ausgesprochenen Deutlichkeit, wohnt dem Denken der Menschen überhaupt inne. Selbst jene Schemavorstellungen, die zunächst nur als blosse Zeichen bestimmten Gedanken zugeordnet werden, können nicht dauernd diesen unpersönlichen Charakter behalten; indem sie sich mit dem Gedanken immer enger zur Einheit verbinden und mit diesem gemeinsam dem Totalleben der Person einbetten, um so mehr gewinnen sie symbolischen Charakter. Wenn wir vorhin sagten, dass die Wortvorstellung „Hund”, verglichen mit dem kindgemäIsen Wortsymbol „wauwau”, nur ein konventionelles Zeichen sei, so hat doch für jeden, der in der deutschen Sprache lebt, jene Wortvorstellung Hund ihren nur zufälligen und willkürlichen Charakter längst verloren; der Wortklang hat „Physiognomie” gewonnen, ist zu einem integrierenden Bestandteil des G e d a n$\mathrm{k}$ e n s Hund geworden.

Dort, wo neue anschauliche Zeichen geschaffen werden - z.B. für einen neugegründeten Staat, für einen Bund, eine Partei - ist deutlich zu verfolgen, wie das Zeichen mehr und mehr zum Symbol wird und so dazu beiträgt, den neuen Gedanken in immer tieferen Schichten der Person zu verankern. Das Symbol und das in ihm Gemeinte, die Vorstellung und der Gedanke, befruchten und tragen sich gegenseitig.

Die hier besprochenen psychologischen Tatbestände haben eine grosse pä d a g o g i s c h e Bedeutung. Wenn die Pädagogik seit 150 Jahren das Anschauungsprinzip so stark betont, so handelt es sich nicht nur darum, das Kind im Gebrauch der Sinne zu üben und sein 
Interesse für die unendliche Mannigfaltigkeit des Wahrnehmbaren zu erschliessen; vielmehr hat man die Anschauung auch als $W$ e $\mathbf{r}$ ze ug u d Motor des Denkens erkannt und gepflegt. An konkreten Gegenstandsvorstellungen - z.B. den Kugeln einer Rechenmaschine, oder den Fingern der Hand - erarbeitet das Kind die Zahlengedanken; aus der Anschauung konkreter Maschinen oder beobachteter Pflanzen und Tiere werden die allgemeinen Erkenntnisse der Physik, der Biologie u.s.w. entwickelt. Vielleicht ist hierbei die Reformpädagogik von einer gewissen Einseitigkeit nicht ganz freizusprechen, indem sie den Veranscha u lich ung sprozess zwar aufs Stärkste betonte, aber die ebenso notwendige Gegenbewegung, den E $n t$ a $n \mathrm{~s} h$ a $u$ li c h u n g s prozess, nicht genügend beachtete. Der heranwachsende Mensch muss nicht nur lernen, die abstrakten Gedanken durch Rückgang auf Anschauung mit Leben zu erfüllen, sondern auch die $F$ e s s e $1 \mathrm{n}$, die eine sehr lebhafte Anschauung der Weite und Allgemeinheit des Denkens auferlegt, allmählich zu lockern und abzustreifen. Wer stets in der Zahlenlehre auf irgendwelche anschaulichen zählbaren Gegenstände angewiesen bleibt, wird nie den eigentlichen Sinn abstrakt mathematischer Gesetzmälsigkeiten erfassen können - und entsprechend auf anderen Gebieten. Je höhere Schulstufen in Betracht kommen, je mehr die geistige Reifung in die Sphäre abstrakten Denkens hineinführt, um so mehr muss der Veranschaulichungspädagogik auch die Entanschaulichungspädagogik an die Seite treten.

Die Spannung zwischen anschaulicher Vorstellung und abstrakten Gedanken wird in gewissen Spezialfällen zum Widerstreit. So ist künstlerischen Naturen durch ihr Angewiesensein auf ein Leben in der Anschauung oft der Zugang zu abstrakteren Denkgebieten geradezu versperrt. - Eidetiker ${ }^{1}$ ) sind zuweilen durch die Aufdringlichkeit ihrer sinnlich eindeutigen Anschauungsbilder an der Erzeugung gedanklicher Abstraktionen behindert.

Abschliessend sind wir nun im Stande, eine $\mathrm{S} \mathrm{k}$ a $\mathrm{l}$ a von seelischen Erlebnisinhalten aufzustellen, die die Hauptetappen auf dem Wege von der Unmittelbarkeit konkreter Anschauung bis zur Allgemeinheit des abstrakten Gedankens bilden. Dabei handelt es sich, psychologisch gesehen, nur um Markierung gewisser b e t o n t e r Stellen in einer durchaus g l e i t e nden Reihe; gerade hierdurch wird der Unterschied zwischen der psychologischen und einer logischen oder erkenntnistheoretischen Behandlung unseres Problems deutlich. Die Erkenntnistheorie hatte seit Jahrtausenden die wesenhafte Vers chiedenheit der bei-

1) s. S. 272 . 
den Grenzphasen „Sinnlichkeit” und „Vernunft” so stark in den Vordergrund gestellt, dass sie dann später, um die zwischen ihnen bestehenden Zusammenhänge verständlich zu machen, besonderer Verknüpfungsprinzipien bedurfte. Die Psychologie dagegen sieht von vorn herein sowohl die Verschiedenheiten wie die $\mathrm{Zu}$ sammenhänge; sie erkennt schon in den Wahrnehmungen die ersten Andeutungen von Gedachtem, in den abstrakten Gedanken die Unentbehrlichkeit anschaulicher Symbole und Zeichen; sie hat immer mehr Zwischen- und Ubergangsformen entdeckt und beschrieben (das „Anschauungsbild” zwischen Wahrnehmung und Vorstellung; die schematische Vorstellung zwischen der Gegenstandsvorstellung und dem abstrakten Gedanken). Die Reihe lässt sich - in Erweiterung des schon auf S. 290, im Anschluss an Jaensch, aufgestellten Schemas - folgendermalsen darstellen:

$\mathrm{S}$ in n e s e r l e b-
$\mathrm{n}$ is s e $\quad\left\{\begin{array}{l}\text { Vitale Sensibilität } \\ \text { Gegenstands-Wahrnehmung } \\ \text { Introzeptive Wahrnehmung }\end{array}\right.$

$\mathrm{Nach}$ bilder

A n s cha u u g s-

bild e r

$\left\{\begin{array}{l}\text { nachbild-nahe } \\ \text { vorstellungs-nahe }\end{array}\right.$

( Gegenständliche Vorstellungen Gedächtnis- $\}$ Vorstellungen

Vorstellunge n

Ge da n ken

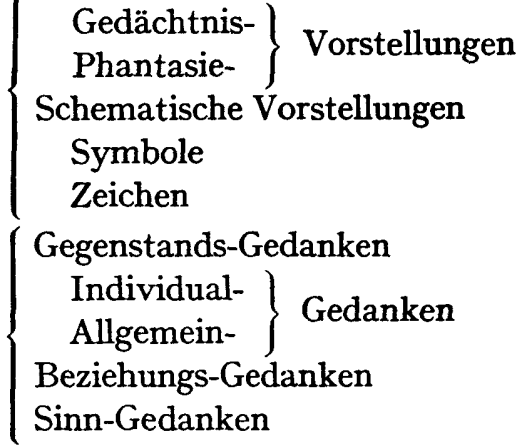

III. DER DENKVOLLZUG

Am aktuellen Vollzug des Denkens drängt sich zunächst die starke $\mathrm{A} b \mathrm{~g}$ e h o b e $\mathrm{n}$ h e it auf. Das einzelne Denkgeschehen füllt fast stets eine deutlich abgegrenzte Zeitstrecke, die innerlich g es t a l t e $t$ ist: es wird eingeleitet von einem Denkantrieb, ver- 
läuft in Richtung auf ein Ziel und endet mit dem Erreichen, Verfehlen oder Offenlassen des Zieles. In dieser Hinsicht hat der Denkablauf eine enge Verwandtschaft mit der Ablauf einer Willenshandlung; ja, er is t eine solche, nur dass als Ziel nicht eine Anderung der Aussenwelt, sondern ein gedanklicher Effekt gesetzt ist (innere Willenshandlung).

\section{Denkantriebe}

Das Denken wird in Bewegung gesetzt durch äussere Reize und innere Einstellungen und Bedürfnisse. Je nach dem Überwiegen des einen oder anderen Faktors bezeichnet man den Denkprozess als „reaktiv" oder als „spontan”. Aber die Scheidung beider Antriebsformen bleibt stets nur eine relative. Es gibt kein rein von aussen erzeugtes Denken ohne den Anteil innerer Denkfähigkeit im allgemeinen und augenblicklicher Denkbereitschaft im speziellen. Und es gibt kein rein spontanes Denken, das gänzlich von äusseren Umständen und Situationsgegebenheiten unabhängig wäre. Nur Abstufungen in der Anteiligkeit der äusseren und inneren Antriebsfaktoren sind zu unterscheiden.

a) $\mathrm{N}$ iedere und höhere Denkantriebe.-Bei den primitivsten Denkvorgängen sind die beiden Antriebsfaktoren aufs engste verknüpft: ein inneres Bedürfnis wird durch äussere Störungen an direkter Befriedigung gehindert.

Das Kleinkind und das Tier ${ }^{1}$ ) ,denken” erstmalig, wenn rein vitale Strebungen auf Hindernisse stossen, die nun umgangen oder beseitigt werden sollen. Der Schimpanse, der die zu weit vor dem Gitter liegende, lockende Banane nicht mit seinem gewohnten Instinktwerkzeug, der Greifhand, erreichen kann, holt sich einen zufällig im Käfig stehenden Stock, ja kann - wenn er sehr intelligent ist — von selbst darauf kommen, zwei Stöcke in einander zu stecken, um das angelnde Werkzeug zu verlängern. Niemals würde die blosse äussere Sinneskonstellation: Anblick eines vor dem Käfig liegenden Objektes und der Stöcke - zum Denkantrieb geworden sein, wenn nicht die starke innere Bedürfniseinstellung auf die begehrte Nahrung eine Bereitschaft zur denkenden Bewältigung jener Umweltgegenstände geschaffen hätte.

1) Näheres über das tierische Denken auf S. 438 ff. - Die Frühentwicklung des kindlichen Denkens behandeln u.a.: K. Bühler, Piaget, Werner, der Verfasser. 
Ein entsprechendes Beispiel vom Kleinkind: Ein einjähriger Knabe war, als er seine Flasche ziemlich leer getrunken hatte, noch nicht satt. $\mathrm{Da}$ er durch den Lutschpropfen keine Milch mehr erhielt, aber am Boden der Flasche noch Milch sah, drehte er selbständig die Flasche um, und steckte den Boden in den Mund. War es auch ein Versuch mit untauglichen Mitteln, so ist doch unverkennbar, dass hier ein primitiver Denkakt durch das Bestreben angeregt war, eine direkt versagte Trieberfüllung auf einem Umweg zu erreichen.

Solche Urprozesse des Denkens sind deshalb von besonderer psychologischer Wichtigkeit, weil sie - bei Tier und Kleinkind zunächst noch als einzelne seltene Intelligenz-Lichtblitze hervorspringen aus einem sonst denkfremden Primitivzustand. Solange die vitale Existenz ungestört abläuft, gibt es auf dieser Stufe noch kein Denken; und man könnte glauben, dass eine bestimmte Kindheitsstufe, oder eine bestimmte Tiergattung, überhaupt noch nicht denkfähig sei - bis plötzlich eine Bedürfnis- oder StörungsSituation eintritt, die nur durch eine Umweghandlung bewältigt werden kann. Eine solche Handlung aber ist - als aussergewöhnliche - nicht im Instinkt selber vorgebildet; sie erfordert und erweckt Denken. Das primitive Denken bezieht also seine A nt r i e b s e n e r g i e unmittelbar aus der Sphäre der Vitalkräfte und ist eben hierdurch aufs stärkste personal verankert.

Auf entwickelteren Denkstufen ist der Denkantrieb nicht mehr an rein biologische Bedürfnisse gebunden, aber die personale Verankerung bleibt ungebrochen Ein Wanderer hat sich im Walde verirrt. Er mag ein im allgemeinen recht denkträger Mensch sein - jetzt aber weckt das Gefühl der Desorientiertheit und der Gefährdung latente psychische Energieen, die zum Denkantrieb werden : er überlegt die Möglichkeit der Orientierung, macht Pläne für den Fall, dass er im Walde übernachten muss u.s.w. Gewiss, auch hier ist das Denken noch vornehmlich reaktiv, denn ohne den äusseren Anlass der Situation wäre dieser Mensch nicht zum Denken gekommen. Aber die Situation hat doch nur deshalb „Aufforderungscharakter" für sein Denken, weil sie an sehr wesentliche Momente seines persönlichen Wohles und Wehes rührt.

Je höher das Entwicklungsniveau des Menschen liegt, um so mehr können stillere und feinere Einstellungen der Persönlichkeit schon genügen, um Denkakte auszulösen.

F orma le Denkantriebe erwachsen aus persönlichen Geltungsbedürfnissen : man will seinen gegenwärtigen, unbefriedigen- 
den Zustand überwinden, anderen den Rang ablaufen, etwas verdienen, Macht oder den Schein der Macht gewinnen u.s.w. I n$\mathrm{h}$ a $\mathrm{lt} l \mathrm{i} \mathrm{ch}$ e Denkziele werden gesetzt von Dauerinteressen und Idealen: so wird das Gebiet des Berufs für zahllose Menschen das Hauptbetätigungsfeld selbständigen Denkens, während sie im übrigen weitgehend auf denkende Stellungnahmen verzichten. Ebenso gehört hierher die Unterscheidung von „praktischem", „religiösem", „sozialem”, „theoretischem” u.s.w. Denken. Der Handwerker, der Techniker, der Kaufmann wird zum Denken angeregt durch Aufgaben, die die Welt verändern sollen; der religiöse und metaphysische Denker fühlt sich getrieben, durch Denken seine Stellung zu den letzten Dingen zu klären; der soziale Denker nimmt denkend zu den Werten der Gemeinschaft Stellung. Für sie alle ist demnach das Denken ein Mittel im Dienst anderweitiger, denkfremder, Einstellungen. Nur das "theoretische" Denken sucht das Denkergebnis um seiner selbst willen; das bedeutet aber nicht eine Entpersönlichung des Denkantriebes, sondern umgekehrt: die Erhebung des gedanklichen Gehalts zu einem eigenen personalen Antriebsmoment. Hier hat die Spontaneität des Denkens ihre höchste Stufe erreicht.

b) Situationsbedingtheit und Denkschwel1 e. - Mit den erwähnten inneren Antriebsfaktoren müssen nun gewisse Situationsbedingungen konvergieren, damit Denken entstehe. Ihre (schon bei den Beispielen vom Schimpansen und vom Kleinkind angedeuteten) Merkmale sind: die personale Bedeutsamkeit und die Neuheit.

Sowie überhaupt Reaktionen des Individuums nur auf solche Reize erfolgen, die für die Person irgend welche Relevanz haben, so auch Denkreaktionen. Die äussere Situation muss erst eine gewisse personale $\mathrm{W} \mathrm{u} \mathrm{cht} \mathrm{gewinnen,} \mathrm{um} \mathrm{das} \mathrm{Denken} \mathrm{in} \mathrm{Bewegung}$ zu setzen. Man kann hier geradezu den Begriff der „D e n ks c h w e 11 e" einführen. So muss in unserem Beispiel vom verirrten Wanderer die Unüberschaubarkeit der örtlichen Verhältnisse erst eine ziemliche Eindringlichkeit gewonnen haben, um über die „Denkschwelle” zu treten, d.h. bei dem sonst denkträgen Mann Nachdenken zu erzwingen.

Ferner muss die äussere Situation für das Individumu „n e u” sein. Mit bekannten Lebensbedingungen wird der Mensch im all- 
gemeinen auf Grund anderer Funktionen fertig, mittels der Instinkte, wenn es sich um phylogenetisch alte Reize, mittels des Gedächtnisses und der Gewöhnung, wenn es sich um ontogenetisch vertraut gewordene Reize handelt. Dort aber, wo diese ererbten oder mnemischen Reaktionsweisen nicht ausreichen---oder jedenfalls nicht die zweckmäIsigsten Reaktionsweisen darstellen setzt das Denken ein.

Nun sind natürlich zwei Situationen niemals völlig gleich; irgend etwas Besonderes und Neues gegenüber früheren Umständen gibt es stets. Trotzdem regt nicht jede Situation zum Denken an und braucht es auch nicht. Vielmehr muss das B e s o n d e r e der gegenwärtigen Situation wiederum pers on relevant sein, damit es die Denkschwelle überschreiten kann. Es darf andrerseits nicht so erschütternd sein, dass die Reaktion des Menschen sich völlig in einer affektiven Gleichgewichtsstörung erschöpft, also in Verzweiflung oder Lähmung ausmündet; es muss unterhalb der "Choc-Schwelle" liegen. Innerhalb dieses breiten $Z$ wischengebiets ist die Person fähig, sich dem Neuen zweckmälsig anzupassen; und hierzu dient eben das Denken.

Die folgende Beobachtung ist gerade wegen des negativen Ausgangs geeignet, die Faktoren zu veranschaulichen, von denen die Denkantriebe abhängen und die Denkschwelle bestimmt wird.

Eine Hausangestellte ist gewöhnt, Tag für Tag einen Papierkorb in einen Müllkasten auszuschütten. Das Gewicht des gefüllten Papierkorbes wechselt natürlich von Tag zu Tag; aber diese Gewichtsverschiedenheit hat im allgemeinen keine objektive und für die Angestellte keine personale Bedeutung; die Gewohnheit des Ausschüttens kann ohne Denkeinschlag funktionieren. Eines Tages war die Gewichtsabweichung besonders gross - es war nämlich durch ein Versehen ein ziemlich schwerer, mit wertvollem Inhalt gefüllter, Kasten in den Papierkorb geraten, dann aber durch darüber liegendes Papier unsichtbar geworden. Die Hausangestellte hatte sogar - wie sie später berichtete - die ungewöhnliche Schwere bemerkt; aber dies Bewusstsein blieb in einem unklaren, schnell wieder abklingenden Gefühl stecken, überschritt nicht die Denkschwelle - und der Korbinhalt wurde, wie gewohnt, ausgeschüttet. Bei einem intelligenten Menschen hätte die Fremdartigkeit des Gewichts als Denkantrieb gewirkt und die Kontrolle des Inhalts herbeigeführt.

c) Problem bew ustsein. - Schon Plato hatte die Verwunderung das eigentlich ,philosophische" Gefühl genannt. In der Tat: nur wo wir und weil wir uns wundern, wer- 
den wir zum suchenden Denken angeregt. Freilich das Wundern allein - als blosses Gefühl - genügt noch nicht; es muss das B. ed ü $\mathbf{r} \mathbf{f} \mathbf{n}$ is des Erlöstwerdens aus dem Wundern, und der En ts chlus s, diese Lösung zu suchen, hinzukommen. Diejenige Beschaffenheit einer Situation, die für eine bestimmte Person solche Wirkung hat, bezeichnen wir als „Problematik”.

Es sind nur die entwickelteren und verwickelteren Denkabläufe, die durch Proble m e in Bewegung gesetzt werden. In einfacheren Fällen pflegen die als Denkanreize wirkenden Fragen oder Aufgaben sofort die gedankliche Erfüllung zu bringen, sodass vōn Denkbeginn bis Denkabschluss ein einheitliches Erlebnisganzes vorliegt; dabei ist nichts problematisch. Von Problemen sprechen wir erst, wo sich jener Denkanreiz zu einem selbständigen G e d a n k e n verdichtet, der die eigentümliche Form der Offenheit, der Unfertigkeit, des Weitertreibens in sich schliesst.

Hier wird noch einmal der Unterschied zwischen „Vorstellung” und „Gedanken" so recht klar. Vorstellungen haben einen konkreten Inhalt; die Problemgedanken sind aber gerade durch ihre inhaltliche $U$ nerf ülltheit charakterisiert, zugleich durch die starke I $\mathrm{n} t$ e $\mathrm{n} \mathbf{t}$ i o $\mathrm{n}$ auf den erst $\mathrm{zu}$ erarbeitenden Inhalt. Es ist von sekundärer Bedeutung, in welcher Form das „Problem" zum Denkantrieb wird: ob als Zweifel, als Frage, als Geheimnis, als Aufgabe, als Auftrag, als mathematisches X, als philosophischer Streitpunkt - ihnen allen sind doch jene eben angedeuteten Wesenszüge der Problematik gemeinsam.

Die Ungelöstheit des Problems ist zugleich eine Unerlöstheit der Person. Es gibt wirklich ein „Leiden am Problem”; aus dieser personalen Verankerung, aus dieser beunruhigenden Fragwürdigkeit zieht jedes echte Problem seine Dynamik. Zugleich aber gibt es auch eine Problemfreudigkeit, eine Lust am Suchen der Lösung und am Uberwinden der Schwierigkeit, eine geistige Abenteuerlust. So ist jedes Problemerleben gefühlsmälsig ambivalent.

d. De n k-I m perative. - Eine besondere Behandlung erfordern diejenigen Denkantriebe, die von aussen her als direkte I m p e r a t i ve an den Menschen herantreten.

Hier ist es also nicht mehr die Situation in ihrer Totalität, aus der der Mensch die Aufforderung zum Denken herausholen soll; 
sondern die Denkaufgabe wird ihm von anderen vor-formuliert und inhalts- wie termin-mälsig fixiert: „Jetzt sollst Du über dies und das denken.” Solches „Denken auf Kommando” spielt im Leben des Menschen, insbesondere des Kulturmenschen, eine ungeheure Rolle. So gehört es ja zum Wesen der Schule, dass sie Aufgaben stellt, die mit Denkmitteln bearbeitet und gelöst werden sollen, und dass im Frage-Antwort-Verkehr von Lehrer und Schülern augenblicklich zu erfüllende Denkansprüche gestellt werden. Für das Kind im Schulalter darf wohl die ganz überwiegende Mehrheit der Denkverläufe zu diesem provozierten Denken gerechnet werden; aber auch beim Erwachsenen spielt es eine recht grosse Rolle. Nicht nur, dass der Erwachsenenunterricht, dass Studium, Berufsvorbereitung, Examina unter ähnlichen Denkaufforderungen stehen wie die Schule - auch das soziale Leben stellt fortwährend formulierte Denkaufgaben: man soll an einer Unterhaltung teilnehmen, Witze verstehen, Rätsel raten; man wird um Rat gefragt und soll denkend entscheiden. Es gibt ferner gewisse Berufe, deren Hauptaufgabe im „Beraten” und damit in der denkenden Verarbeitung eines von aussen herantretenden Falles (eines Rechsstreits, einer Krankheit, einer geschäftlichen oder Berufswahl-Entscheidung) besteht.

Diese Art des Denkens ist also am ausgesprochensten r e a k$t$ i v; hier hat sich der denkende Mensch als Glied der Gemeinschaft und Bestandteil einer objektiven Welt zu bewähren. Je höher diese transpersonalen Bereiche organisiert sind, um so mehr treten ihre Anforderungen als formulierte Denkaufgaben an die Person heran, sodass diese sich ihre Denkproblematik nicht erst selbst zu erarbeiten braucht. Zweifellos ist dies im Sinne der sozialen Einordnung und Leistung notwendig; sowohl die Übernahme überlieferten Denkgutes durch die nachwachsende Generation, wie auch die Erhebung des Denkens zu einem Gemeinschaftstun ist nur auf diesem Wege möglich. Aber das provozierte Denken hat auch seine Kehrseite: je ausgesprochener die Denkakte auf äussere Imperative hin erfolgen, um so grösser ist die Gefahr, dass sie äusserlich bleiben, dass sie mit den spontanen Denkbedürfnissen und der selbstgewachsenen Problematik nichts $\mathrm{zu}$ tun haben. Das rein reaktive Denken kann daher recht personfrem sein.

Aus dieser Einsicht ergeben sich wichtige Folgerungen. 
Eine erste ist pä da g o g i s c h e r Art. Da spontanes und reaktives Denken verbunden aufzutreten pflegen, so ist es weitgehend möglich, die Denkimperative so darzubieten, dass sie zugleich Resonanz im spontanen Denken finden. Es ist z.B. die zentrale Aufgabe jedes Unterrichts und jeder Prüfung, mit ihren Denkfragen den spontanen Denkeinstellungen (Interesse, Aufmerksamkeit, Disponiertheit) entgegenzukommen.

Ps y c hodiag nost is ch darf aus der Art, wie jemand auf äussere Denkreize reaktiv eingeht, kein einseitiger Schluss auf seine spezifische Denkfähigkeit im ganzen gezogen werden. Jedem sind Menschen bekannt, die vortreffliche Schüler, auch gut d e nk e n d e Schüler waren, sofern es sich um das Reagieren auf die Denkforderungen der Schule handelte - und die dann später, als dieser äussere Zwang zum Denken aufhörte, enttäuschten; sie erwiesen sich nicht nur als denkträge, sondern auch als weitgehend denkunfähig - nämlich unfähig zum spontanen Denken. Umgekehrt gibt es Menschen, deren, vielleicht recht starkes Denken schon sehr früh seine spontanen und eigenwilligen Wege geht, und sich eben deshalb recht spröde gegen den Einbruch äusserer Denkimperative verhält. Sie sind dann z.B. „keine Examensmenschen".

Welche Bedeutung diese Betrachtung für den Begriff der Intelligenz und für die Praxis der Intelligenzprüfungen hat, wird sich sehr bald erweisen.

Wissenschaftsmethodisch ergibt sich eine Begrenzung des Wertes der experimentellen Denkpsychologie. Da die Methodik der Würzburger Schule ${ }^{1}$ ) sich eben auf Denkexperimente und die dabei gemachten Selbstbeobachtungen stützt, hat sie es ausschliesslich mit dem reaktiven Denken zu tun. Ja das „Denken auf Kommando" tritt hier in noch reinerer Form auf als anderwärts, weil die experimentelle Situation lediglich „Denken überhaupt" fordert, aber in keiner Weise Gebiet und spezifischen Inhalt der Denkaufgaben aus der lebendigen Person/Welt-Beziehung zu rechtfertigen vermag. Die Denkimperative sind also und bleiben - äusserlich und personfremd; keine der spontanen Einstellungen, Interessen und Bedürfnisse, die sonst Denkantriebe für bestimmte Themen liefern, sind hier wirksam. Der bleibende Wert der Methode ist darin zu sehen, dass sie uns ermöglicht, ge-

1) s. S. 70 und 368. 
wisse $\mathrm{f}$ o $\mathrm{r} \mathrm{m}$ a $\mathrm{l}$ e Züge der Denkabläufe genau zu studieren. Irrig aber ist die Meinung, dass mit diesem Verfahren jemals „d a s Denken" in seiner entscheidenden Wesensart erfasst werden könnte.

\section{Denkhandlung und Denkbereitschaft}

Jeder Ablauf eines Denkprozesses ist durch das Zusammenwirken zweier personaler Faktoren bestimmt: des aktuellen Tätigkeitsfaktors und des dispositionellen Bereitschaftsfaktors.

a.) De n k e n a ls T ät i g e i t. - Dass zum Denken Tätigkeit wesentlich gehöre, ist ein fundamentaler Satz der Denkpsychologie. Dieser aktive Charakter des Denkens ist sowohl phänomenal durch Selbstwahrnehmung, wie funktionell durch die Art des Denkgeschehens gesichert.

Jeder Mensch e r l e b t es in stärkster Evidenz, dass er beim Nachdenken, beim Sich-Besinnen, beim Verstehen schwieriger Zusammenhänge u.s.w. in ausgesprochenem Malse selbsttätig ist. Nur mit Verwunderung kann man auf jene künstlichen Konstruktionen mechanistischer Psychologen zurückblicken, die die Denkabläufe rein passivistisch aus dem Kommen und Gehen, Sich-Verbinden und Trennen von Elementen erklären wollten. Eine Wachträumerei und die energische Beschäftigung mit einem schweren mathematischen Problem zeigen psychologische Unterschiede, die allein durch die Merkmale: wesentlich passives Hingegebensein dort, wesentlich aktives Sicheinsetzen der ganzen Person hier, beschrieben und durch keine, noch so geistvollen, psychomechanischen Theorieen wegdisputiert werden können ${ }^{\mathbf{1}}$ ). - Nur das Wollen ist von gleich starkem Tätigkeitsbewusstsein begleitet.

In diesem Erlebnis spiegelt sich der personale Tätigkeitscharakter des Denkens, der drei Momente enthält.

Das d y n a m i s c h e Moment: Denken erfordert intensiven Kraftaufwand, zu dem sich die Person während einer begrenzten Zeitspanne zusammenrafft. Die Einzelerscheinungen dieser Denkdynamik (Konzentration, Rhythmisierung, Ermüdung u.s.w.) können uns erst später beschäftigen.

1) Dieses ganz ursprüngliche Bewusstsein, welches das denkende Ich von seiner Aktivität besitzt, hat sich sehr eindrucksvoll in $\mathrm{ph}$ il os o p h i s c he n Lehren aller Zeiten niedergeschlagen; ja, es hat dazu geführt, die Denktat geradezu als den Ursprung aller geistigen Existenz anzusehen. Es sei hier nur an die Aristotelischscholastische Lehre vom Geist als „actus purus”, an Descartes' „cogito, ergo sum”, an Fichte's: „Das Ich ist keine Tatsache, sondern eine Tathandlung” erinnert. 
Das t e l e o log i s c h e Moment: Denken funktioniert zielstrebig. Jedem einzelnen Denkvollzug ist eine $\mathrm{Z}$ e it g e s t a $1 \mathrm{t}$ eigen, deren Hauptakzent auf dem letzten Teil des Prozesses, dem Denkergebnis, liegt. Auf dieses drängt alles Ubrige hin; ihm sind dem Range nach die anderen Momente des Ablaufs untergeordnet: als Denkwerkzeuge und Denkhilfen, als Signale für Fehlwege, als Verknüpfungen und Trennungen, als Teilziele, die zu Stufen des weiteren Anstiegs werden, und die zugleich vorübergehende Ruhepunkte bilden. Diese intellektuelle Gestalt des Denkvollzugs ist ferner getragen von wechselnden Gefühls- und Strebeanteilen: am Anfang besteht die Spannung der Aufgabe und das Leiden am Problem, zugleich die Unsicherheit des Weges und die Fraglichkeit des Erfolgs; weiterhin die Teilgefühle der Förderung und des plötzlichen Weiterkommens, der Hemmungen, Sperrungen und Ermüdungen - die steigende Vereindeutigung bis hin zu dem Abschlussgefühl der Erfüllung oder des Versagens. Hinter alledem aber steht als treibender Motor die W i 11 e $\mathrm{n} \mathrm{s}$ h a n dl u $\mathrm{n} \mathrm{g}$ : denn das erst in der Zukunft liegende Ziel wirkt $\mathrm{k}$ a us a 1 auf den Denkprozess, determiniert die Wahl der Hilfsmittel, sorgt für Ausscheidung der nicht passenden Elemente, verhindert das Abgleiten in denkfremde psychische Vorgänge.

Hier wird also der grundsätzliche Unterschied zwischen Denkvollzug und Assoziationspiel erkennbar: im Denken waltet eine vom Ziel her bestimmte Ordnung; das Ziel übt, wie es Ach ausgedrückt hat, eine "d e t e r m in i e r e n d e T e n d e n z" aus. Die Assoziationspsychologie, die natürlich diese entscheidende Eigenschaft des Denkens nicht übersehen konnte, hat immer wieder versucht, sie dennoch mit ihren Kategorieen zu bewältigen. So sprach z.B. Hugo Liepmann von der „Obervorstellung”, die dauernd im Bewusstsein ist und dadurch den Ablauf der anderen Vorstellungen beeinflusst ${ }^{1}$ ). Aber mit dieser Konstatierung von zwei ganz verschiedenen Arten von Vorstellungen, von denen die eine teleologisch - nämlich richtunggebend und ordnend auf den Verlauf der anderen wirkt, ist ja bereits die mechanistische Assoziationslehre gesprengt; und es ist nur folgerichtig, wenn

\footnotetext{
1) Für dievornehmlich psychatrischen Problemstellungen, mit denen es H.Liepmann zu tun hatte, erwies sich sein Gedanke, ungeach tet der unzulänglichen theoretischen Formulierung, als sehr wich tig und fruch tbar; so konnte er die Erscheinung der "Ideenflucht" dadurch verständlich machen. dass er zeigte, wie hier die "Obervorstellungen" (also die determinierenden und ordnenden Denkantriebe) unwirksam geworden sind.
} 
man jetzt auch darauf verzichtet, dasjenige Moment, das diese zielstrebige Funktion ausübt, ,,Vorstellung” zu nennen. Denn für den Denkvollzug ist ja gerade dies wesentlich, dass das zu erreichende Ziel noch $\mathrm{nicht}$ als konkrete Bewusstseins g e g e$\mathrm{b}$ e $\mathrm{n} \mathrm{h}$ e i t da ist (wäre es so, dann wäre ja die Erarbeitung des Ergebnisses durch Denken überflüssig), sondern als $A$ u f g e g eb e $\mathrm{n}$ h e i t, als ein Vakuum - das aber doch schon die Tendenz zu seiner Selbstaufhebung enthält. Die Art, wie das Ziel vor seiner Erreichung b e w u s s t ist, kann sehr verschieden sein: es kann erlebt werden als selbständiger „Problemgedanke”, als mehr unselbständiger, dem Gesamtverlauf eingebetteter, Aufgabegedanke, als vage Schemavorstellung, als blosses Spannungsgefühl; es kann aber auch überhaupt ohne eigene Bewusstseinsrepräsentation sein und dennoch dem Denkvollzug seine Richtung geben. Es ist ein personaler Wirkungsfaktor, der den Ablauf des Bewusstseins beeinflusst, aber selbst mit psychologischen Bewusstseinskategorieen nicht eindeutig zu beschreiben ist.

Das $\mathrm{t} h \mathrm{e} t \mathrm{t}$ s $\mathrm{ch}$ e Moment: In jeder Tat (des Wollens wie des Denkens) st e $11 \mathrm{t} \mathrm{s} \mathrm{i} \mathrm{ch}$ die Person als Aktionszentrum irgendwie zu ihrer Welt. Bei der Denktat verbleibt dies Stellungnehmen rein im Innern der Person; sie ist $\mathrm{g}$ e is $\mathrm{t}$ i g e Stellungnahme. Diese wird im Denken entweder tatsächlich voll z o g e n: Bejahung und Verneinung - oder g e s u c h t: Frage, Zweifel, Problematik. Jedesmal aber handelt es sich um ein nicht weiter beschreibbares Einsetzen der ganzen Person für oder wider einen Gedanken, eine Aussage, eine Entscheidung. Nur derjenige $\mathrm{d}$ e $\mathrm{n} \mathrm{k \textrm {t }}$ wirklich, der innerlich zu dem Gedachten Ja oder Nein sagen, es anerkennen oder verwerfen kann - und der solche Stellungnahme anstrebt und in sich selber erzeugt. Diese Fähigkeit ist - entwicklungspersonalistisch gesehen - eine sehr späte; auf primitiveren Stufen nämlich ist Stellungnehmen noch das u ng e s c h i e d e n e äussere und innere Sichstellen zur Welt, also zugleich weltändernde Tat: „äussere Willenshandlung”. Erst auf höheren Stufen verselbständigt sich das innere Stellungnehmen, ohne übergreifen zu müssen in das äussere Gefüge der Dinge; und so wird erst hier das reine Denken, die praxisfreie Theorie möglich.

b) Grenzen der Aktivität. Denkbereit$\mathrm{s} \mathrm{c} \mathrm{h} \mathrm{a} \mathrm{f} \mathrm{t.} \mathrm{-} \mathrm{Ist} \mathrm{nach} \mathrm{allem} \mathrm{Gesagten} \mathrm{der} \mathrm{Tatcharakter} \mathrm{des} \mathrm{Den-}$ 
kens gegenüber einer rein mechanistisch-passivistischen Ableitung der Denkvollzüge gesichert, so müssen wir nun aber fragen: e r s c hö p f t sich das Denken in solch konzentriertem Tun? Diese Frage ist zu verneinen. Wir haben ja nicht nur personale Aktivität und mechanische Passivität zu unterscheiden, sondern auch: personale Aktivität und personale $D$ is p o s i t i o $\mathbf{n}$. Hier muss die These von der schlechthin geltenden Aktivität des Denkens wirklich revidiert werden. Auch für den einzelnen Denkvollzug gilt, was wir früher vom Denken überhaupt sagten: es findet ein fortwährendes Ineinandergreifen und Wechseln von aktueller Tat und dispositioneller Bereit$\mathrm{s} \mathbf{c h}$ a f $\mathrm{t}$ statt. Das denkende Tun ist nur zum geringeren Teil direkt in der Lage, bis zum Denkziel hin ununterbrochen den Verlauf zu steuern; seine andere Aufgabe besteht darin, personale Einstellungssphären in Bereitschaft zu setzen, sodass nun aus diesen heraus - ohne neue Inanspruchnahme personaler Denktat - ein bestimmter Denkfortschritt vollzogen oder sogar das gesuchte Endresultat gewonnen wird.

Besonders deutlich wird dieses Wechselspiel in dem sogenannten „A h a”-E r l e b n i s (Bühler). Es gibt Denkabläufe, bei denen das Denkziel sehr energisch gesucht wird, ohne dass doch diese Bemühungen direkt zum Erfolge führen. Beispiele : man hört einen Witz erzählen und erfasst die Pointe nicht sofort; man bemüht sich, in einem Vexierbild die aufgegebene Figur herauszufinden; man beschäftigt sich mit einem mathematischen Lehrsatz, dessen Gesamtsinn nicht gleich einleuchtet; man steht vor einer rätselhaften Situation, die man nicht sofort durchschaut. In solchen Fällen stösst das aktive Weiterdenken auf Schranken : es geht nicht voran; die Anstrengung ist fruchtlos - und plö t zl i c h, oft für den Denkenden selbst ganz überraschend, schiesst dann doch das Ergebnis hervor: „Aha, so ist's!" Das Vexierbild „sieht auf einmal ganz anders aus"; der Sinn der mathematischen Aufgabe leuchtet vollkommen ein; die plötzlich verstandene Pointe des Witzes löst erst jetzt die adäquate Reaktion des Lachens aus u.s.w. In allen diesen Fällen hat die eigentliche $\mathrm{D}$ e $\mathrm{n} \mathrm{k}-\mathrm{A} \mathrm{r}$ b e i t nur den Boden bereitet und aufgelockert für das organisch aus personalen Tiefen herauswachsende Denkergebnis; sie hat die Bereitschaft innerer Einstellung geschaffen und gesteigert. Daher denn auch der oft so starke Einschlag von Irrationalität im Aha- 
Erlebnis; es erscheint unbegreiflich, dass man vorher bei aller aktiven Denkbemühung das Resultat nicht gefunden hatte, das jetzt so selbstverständlich anmutet.

Zuweilen können die beiden Faktoren des Denkablaufs geradezu g e g e $n$ einander wirken, so etwa beim Sichbesinnen auf Namen: alles aktive Nachdenken erweist sich als vergeblich, obgleich der Name „uns auf der Zunge schwebt” (d.h. wir spüren, dass sich die Bereitschaft durch die Denkbemühung verstärkt); aber die Bereitschaft bedarf, um sich zu aktualisieren, einer gewissen passiven Lockerheit und diese ist während des Denkaktes unerreichbar. Gibt man nun aber die Bemühung zeitweilig auf, beschäftigt man sich mit anderen Dingen, dann kann sich jene Disposition auswirken - und der Name springt unerwartet hervor und mitten in ganz abseitige Denkabläufe hinein. (Vgl. hierzu S. 335).

Je stärker das Denken personal verankert ist, um so treffsicherer funktioniert im Denkvollzug das Wechselspiel von Denkbereitschaft und Denkaktivität - darum viel besser im spontanen Denken als im reaktiven. Bei den höchsten Formen des Spontandenkens, so beim geistigen Schaffensprozess des Forschers, sind die spezifischen Denk a $\mathrm{k}$ t e oft nur die obersten Instanzen, die den Denkdispositionen Antrieb und allgemeine Richtung verleihen, über ihre Erzeugnisse Kontrolle üben, sie einer Zensur unterziehen und schliesslich die systematische Gesamtordnung der Ergebnisse sichern; aber die eigentliche Substanz der Gedanken stammt doch weitgehend aus jener unwillkürlichen Denkbereitschaft. Dagegen ist bei den extremen Formen reaktiven Denkens - also beim „Denken auf Kommando" - die aktive Denkbemühung, bis zur gewaltsamen Anstrengung hin, von nöten; denn sie muss ja all das leisten, was anderwärts dem spontanen Bereitschaftsdenken überlassen werden kann.

Es gibt kurzfristige Denkabläufe, bei denen eine aktive Konzentration des Tuns ganz in den Hintergrund tritt, und alles Wesentliche der Selbstauslösung von Denkbereitschaften überlassen bleibt: die sogenannten „E in f ä $11 \mathrm{e}$ ”. Ein Witzbold, ein geistreicher Schriftsteller ist geladen mit Einfällen: d.h. ihm strömen die Gedanken und gedanklichen Verknüpfungen zu, ohne dass er i m M o m e n t bestimmte Denkziele bewusst intendieren, die dahin führenden Wege aktiv wählen und durchlaufen und 
anstrengende Konzentration auf den Ablauf verwenden müsste. Dass freilich intensive Denkarbeit von Jahren vorausgegangen sein mag, um allmählich jene Bereitschaft zu erzeugen, steht dazu nicht im Widerspruch.

Diese zeitliche Trennung ist auch sonst von Bedeutung. Oft hört man von produktiven Menschen (Schriftstellern, Gelehrten, Staatsmännern u.s.w.), dass sie w e c h s e ln müssen zwischen jener Vorbereitungsarbeit, in denen die Denkbemühungen (das aktive Planen, Erwägen, Nachdenken, Kombinieren, Kritisieren) im Vordergrunde stehen - und den Ausführungen, in denen die nunmehr geschaffenen Bereitschaften sich aus ihrer potentiellen Vieldeutigkeit gleichsam von selbst in aktuelle Eindeutigkeit umsetzen. Hier ist das Denken nicht mehr in gleichem Sinne aktiv, wie vorher - oder sofern es aktiv ist, wendet es sich anderen Seiten des Problems zu: der Nüanzierung gewisser Gedanken, der bestmöglichen sprachlichen Formulierung, u.s.w. ${ }^{1}$ ).

\footnotetext{
1) Aus eigenen Erfahrungen über meine Art wissenschaftlichen Arbeitens kann ich hierzu folgendes beitragen.

Das stille Nachdenken über eine Problematik führt mich bis zu einigen Grundgedanken allgemeinerer Art, liefert Gesichtspunkte, Schemata und Umrissskizzen dessen, was ich suche. Die Vagheit, die alledem zukommt, ist aber nicht ein blosses Manko; denn nur sie ermöglicht die nötige Einkreisung und Vertiefung des Gedankengefüges. In einer gewissen Phase dieses Prozesses entsteht das Bedürfnis und die Bereitschaft, nun an die schriftliche Formulierung zu gehen. Erst $w$ ä h $r$ e $n d$ dieser erfolgt die Vereindeutigung und detaillierte Durchführung der Gedanken, natürlich zum Teil in denkender Anstrengung, zum grössten Teil aber als das, sich von selbst einstellende, Ergebnis früheren Denkens, gelegentlicb auch als, mich selbst überraschendes, „Aha"-Erlebnis. Zwischen die ursprünglichen Denk a k te und die jetzige Schreibtätigkeit hat sich also eine Schicht von Denk be r e i t s c h a f $t$ und Denk e in $\mathrm{s}$ e $11 \mathrm{u} \mathrm{n}$ gelagert, aus der beraus ich jetzt schaffen kann.
} 


\section{SECHSZEHNTES KAPITEL}

DIE HAUPTARTEN DER GEDA N K N

Allen Gedanken wohnt eine I $n t e n t$ i o $n$ inne; deren Ziel kann sein: ein Gegenstand, eine Beziehung, ein Gesamtsinn. Hiernach gliedern sich auch psychologisch die Hauptarten der Gedanken.

\section{GEGENSTANDSGEDANKEN}

Der Beginn gegenständlichen Denkens ist noch ganz in die Sinneswahrnehmung eingeschmolzen. Rein in der Gegenwart erlebt der Mensch ein : „da ist etwas”; die Denkintention geht auf einen flüchtigen „Augenblicksgegenstand". Erst von hier aus scheiden sich dann allmählich die beiden Wege des Objektdenkens: zum individuellen und zum allgemeinen Gegenstand hin. Beide setzen schon gewisse Entanschaulichungsprozesse voraus.

1. Das Denken individueller Gegenstände

Die Auffassung des selbständig existierenden $\mathrm{E}$ i n $\mathrm{z}$ e $1 \mathrm{~d}$ i nge s verlangt Identifikation durch Bezug beliebiger Vorstellungen auf ein, mit sich selbst über die Zeit hin identisch bleibendes, Etwas. Die reine Gegenwartsbindung reicht also nicht aus, ebenso wenig das Erlebnis irgend einer einzelnen konkreten Vorstellung. Wir haben dies früher an dem Beispiel „Hamburger Hafen" aufgezeigt (S. 370). Beim Kleinkind kann man das Denken individueller Gegenstände im Entstehen beobachten, z.B. dort, wo aus dem blossen Vertrautheitsgefühl beim Sehen des mütterlichen Gesichts oder des Püppchens ein regelrechtes „Wiedererkennen", also ein Identifizieren wird. Die fortschreitende „Vergegenständlichung" der Einzeldinge ist ein sehr langsamer, 
nie ganz zum Abschluss kommender Prozess; es ist immer nur ein kleiner Bruchteil der personalen Welt eines Menschen, innerhalb dessen jene Herauslösungen, Abgrenzungen, Gegenüberstellungen und Identifikationen erstrebt werden und gelingen, die zum Gegenstandsgedanken führen.

Ein Beispiel: für naive Menschen ist die Luft, die sie atmen, so innig dem Vitalprozess eingeschmolzen und so unklar gegen anderes abgegrenzt, dass sie psychologisch nicht den vollen und klaren Gegenstandscharakter gewonnen hat.

Wie sehr der Identitätsgedanke, bezogen auf einen individuellen Gegenstand, schon über die blosse konkrete Vorstellung hinausgeht, ersieht man am besten an dem Unterschied zwischen unbelebten und belebten Gegenständen. Auch einem unbelebten Gegenstand „Puppe”, „Berg” entsprechen vi e l e Vorstellungen. Aber deren Verschiedenheit wird nicht dem Objekt zugeschrieben, sondern nur der jeweilig wechselnden Stellung des Subjekts zu ihm; hier ist dem Identitätsgedanken der Gedanke der Gleichheit (genauer des Mit-sich-Gleichbleibens) zugesellt. Anders beim lebendigen Gegenstand. Eine Pflanze wächst und blüht und welkt, ruft in mir im Zeitablauf verschiedene Wahrnehmungen hervor, die sich in verschiedenen Vorstellungen niederschlagen; diese werden objektiviert, d.h. auf jeweilig wechselnde $Z$ ustände des Objekts bezogen - aber das Objekt selbst wird als identisch gedacht, ungeachtet der an ihm mitgedachten Veränderungen. Und zwar ist diese Fähigkeit zur gedanklichen Identifikation veränderlicher Gegenstände nicht etwa ein spätes Phänomen; sie ist vielmehr ganz primitiv, ja sie ist gerade auf primitiven Denkstufen besonders fessellos; denn diese Stufen denken magisch: jedes Ding, jedes Geschöpf kann sich in ein völlig anderes verwandeln - ohne dass seine „Dasselbigkeit” dadurch irgendwie berührt würde; in Märchen, Mythos und Zauberei gibt es ja unbeschränkte Metamorphosen der Personen und Sachen.

Natürlich kommt auch dieser primitive Identitätsgedanke nicht ohne anschauliche Hilfen zustande, die teils der äusseren Wahrnehmung, teils der Selbstwahrnehmung angehören. An den G e g e n s $t$ ä n d e n wird der Zeitablauf ihrer Zustandsänderungen als ein stetiger erlebt; nirgends erfolgt der Bruch, der die Abhebung eines neuen Objekts gegen das alte rechtfertigen würde. 
Zugleich erlebt das $\mathrm{S} \mathrm{u} \mathrm{b} \mathrm{j} \mathrm{e} \mathrm{k} \mathrm{t} \mathrm{sich} \mathrm{selbst} \mathrm{als} \mathrm{identisch} \mathrm{mit} \mathrm{sei-}$ nem früheren Dasein. „Ich" habe Erinnerungen an frühere $\mathrm{Zu}$ stände als „meine”; „Ich” habe das Bewusstsein, dass die Linie meines Lebens nirgends eine Zerreissung erfuhr und auch weiterhin auf lange nicht erfahren wird, sodass die verschiedensten $\mathrm{Zu}$ stände verschiedener Zeiten der Vergangenheit und Zukunft demselben, „meinem”, Leben angehören. Der Identitätsgedanke kann sich hier also auf den unmittelbar vitalen Untergrund der Person stützen; nach Analogie zum eigenen Ich erhalten dann auch die anderen Gegenstände eine Art personaler Identität.

An dieser Stelle wird der Unterschied zwischen psychologischer und logischer Behandlung desselben Themas deutlich. Der "Satz von der Identität" wird von der Logik ausgesprochen in der Formel „A $\mathbf{A}=\mathbf{A}$ " oder ,jedes Ding ist sich selbst gleich". Psychologisch ist die auf Gl e i c h h eit gestützte Identität die späteste und abstrakteste Form dieses Gedankens; viel primitiver sind die beiden Kriterien der Identität, die sich in die Sätze fassen lassen: ,Jedes Seiende existiert s t e t i g zu sich selbst" und "Ich bin Ich; Dein Ich ist Dein Ich". Von hier aus führt ein langer Weg zu jener versä $c h$ li $c h t e n$ Identität, in der das „Mit-sich-g l e i c h-sein” — und damit die Starrheit, Unveränderlichkeit - zum Kriterium des Gegenstandes wird. Seine abstrakteste Form hat dieser Identitätsgedanke gewonnen in den philosophischen Kategorieen der Substanz, der leblosen Materie, des "Seins" schlechthin, aus dem alles Leben und alle Veränderung fortgedacht ist.

2. Das Denken allgemeiner Gegenstände

Aber der Mensch denkt nicht nur individuelle, sondern auch a $11 \mathrm{~g} \mathrm{e} \mathrm{m} \mathrm{e} \mathrm{i} \mathrm{n} \mathrm{e} \mathrm{Gegen} \mathrm{s} \mathrm{tän} \mathrm{de} \mathrm{(vgl.} \mathrm{Beispiel} \mathrm{c} \mathrm{S.} 371$ von der Winkelsumme im Dreieck); und hier ist nun allerdings die G le i chheitskat egorie als Denkstütze von wesentlicher Bedeutung. Denn das Denken des Allgemeinen setzt voraus, dass an einer Mehrzahl individueller Gegenstände Übereinstimmendes erkannt, und dass dann dies Übereinstimmende von den Einzelgegenständen losgelöst (abgezogen, ,abs-trahiert”) und zu selbständigem Gedankeninhalt erhoben wird. Diese Verselbständigung verlangt dann eine Fixierung, die im sprachlich formulierten Allgemeinbegriff (,Dreieck”, „Mensch”, „Affekt”) erfolgt. Vergleichung, Abstraktion und Fixation sind also die gedanklichen Akte, ohne welche allgemeine Gegenstände nicht gedacht 
werden können. Eine solche Leistung setzt schon einen ziemlich hohen Grad geistiger Entwicklung voraus; man muss sich deshalb hüten, überall dort schon echte Allgemeingedanken anzunehmen, wo das äussere Symptom - ein für verschiedene Gegenstände gebrauchtes gleiches Wort - auftritt.

Hier hat es namentlich in früheren Stadien der Kindespsychologie Irrungen gegeben, indem man den psychischen Vorgang zu stark logifizierte. Wenn ein Kind von 5/4 Jahren nicht nur verschiedene Vögel, sondern auch Insekten, fliegende Papierstücke u.s.w. „pipip” nannte, so hatte es nicht etwa den sehr allgemeinen Gedanken des „Fliegenden überhaupt"' gewonnen; vielmehr bewirkte nur die Vagheit des Erlebens und der Wortmangel, dass in irgend einem Augenblick dem Eindruck eines in der Luft bewegten Objekts ein geläufiges Wort zugesellt wurde. $\mathrm{Ob}$ es "derselbe Gegenstand" sei, wie früher, wenn etwas „pipip" genannt wurde, ob es ein anderer, aber jenem früheren Gegenstand ähnlicher oder gleicher sei - diese Gedankenoperationen liegen noch ganz jenseits des frühkindlichen Bereichs; nur ein "Momentgegenstand" wird gedacht und benannt.

Auch das primitive oder flüchtige Denken des Erwachsenen täuscht zuweilen einen besonders hohen Grad der Abstraktion vor durch Verwendung sehr allgemeiner Sprachsymbole, wie „Ding”, "Tier", „Mensch" - wo in Wirklichkeit überhaupt nicht Abstraktion, sondern blosse Unbestimmtheit des Denkens, geringe Anschaulichkeit und grosse Wortarmut vorherrscht.

Auch nach der anderen Seite hin darf man nicht in eine falsche Logisierung des Problems verfallen, indem man etwa sagt: der Gedanke eines Allgemeingegenstandes setze j e d e s m a l voraus, dass ein Prozess der Vergleichung, Abstraktion und Fixierung, also ein regelrechtes Induktionsverfahren, vorangegangen sei. Träfe dies zu, dann wäre der mögliche Vorrat an Allgemeingedanken beim Einzelindividuum unsäglich dürftig. In Wirklichkeit bedarf der Mensch, um überhaupt zu erfassen, was Allgemeingedanken seien, einer relativ kleinen Anzahl von Modellen, an denen die Intention auf das Allgemeine entwickelt wird; ist sie aber einmal gewonnen, so ist nicht mehr die jedesmalige Ableitung aus einer Vielheit individueller Gegenstände oder die tatsächliche Anwendung auf sie nötig; es genügt das abstrakte Wissen, dass sich der Gedanke auf das Úbereinstimmende vieler Einzelobjekte bezieht. Wenn man einem Menschen erstmalig einen ihm bisher unbekannten Begriff - z.B. „Komet” oder „Infusorium” — nahe 
bringt, so versteht er $\mathrm{u} \mathrm{n} \mathrm{m}$ i t $\mathrm{t} \mathrm{e} \mathbf{l b}$ a r, dass damit nicht ein Einzelgegenstand, sondern eine Gattung - der Inbegriff der Gemeinsamkeiten vieler Einzelgegenstände - gemeint ist, ohne dass er auch nur einen einzigen individuellen Repräsentanten wahrgenommen oder mehrere verglichen haben müsste.

Aber freilich - um den Allgemeingedanken zu kl ä re n, um die ihm zukommenden und nicht zukommenden, die wesentlichen und unwesentlichen Merkmale zu unterscheiden, ist das immer wiederholte Zurückgreifen auf Anschauung und Vorstellung, auf Schema und Einzelgegenstände („Beispiele”, „Fälle”) von grösster Bedeutung. Solche Veranschaulichungsschritte des Denkens wechseln dann immer wieder mit Entanschaulichungsschritten, um den abstrakten Gleichheitsgedanken der Idealform des logischen „Begriffes” anzunähern.

In diesem $\mathrm{Hin}$ und $\mathrm{Her}$ von Allgemeindenken und Anschauungshilfen gibt es die krausesten psychologischen Verquickungen und Zwischenstufen.

Die Frühentwicklung des kindlichen Sprechdenkens liefert hierfür besonders instruktive Beispiele, von denen wir an dieser Stelle nur einige wenige herausgreifen können ${ }^{\mathbf{1}}$ ).

Der erste, deutlich erkennbare Allgemeingedanke des Kindes ist vielleicht der, dass „jedes Ding einen Namen habe”. Einige Monate nach den ersten Spracherwerbungen, die noch wie zufällige Verknüpfungen von Lauten mit Momentangeschehnissen oder Individualgegenständen anmuten, beginnt das Kind plötzlich zu bemerken, dass Dinge allgemein benennbar sind; es zeigt auf verschiedene, ihm sprachlich unbekannte Objekte und verla $\mathrm{n} g \mathrm{t}$, ihren Namen zu erfahren, durch fragende Mienen oder fragende Worte (,isn das?" = was ist denn das ?).

Immerhin ist diese Entdeckung der Nennfunktion zunächst noch ein Gedanke von beschränkter Allgemeinheit, da das Kind ihn nur auf wahrnehmbare Gegenstände (also nicht auf Tätigkeiten, Eigenschaften u.s.w.) erstreckt und innerhalb dieser auf solche Gegenstände, die das Inventar seiner engen Umwelt ausmachen.

Unterstützt werden diese primitiven Abstraktionen sehr stark durch $\mathrm{Re}$ ih e $\mathrm{nbildung}$, da in einer Reihe die zu vergleichenden Einzelgegenstände a $\mathrm{s} \mathrm{ch}$ a $\mathrm{u}$ li ch neben- oder hintereinander gegeben sind. Die Wahrnehmung von Úbereinstim-

1) Vgl. C. u. W. Stern, Die Kindersprache. 3. Aufl. - W. Stern, Psychol. d. fr. Kindheit, III. und VIII. Abschn. 
mungen erleichtert es wesentlich, einen Gattungsgedanken als Substrat des gemeinsamen Merkmals zu denken.

Ein Kind von $1 \%$ Jahren läuft im Zimmer umher, berührt jeden Stuhl mit jedesmaliger Wiederholung der Frage "das Tul?" (= „Ist das ein Stuhl?"). Und wenn es etwa an eine anders aussehende Sitzgelegenheit, einen gepolsterten Sessel oder einen Schemel, kommt, so wird der sprachliche Ausdruck der Frage noch zweifelnder und zögernder; die Unterordnung dieses Gegenstandes von geringerer Ähnlichkeit unter den Allgemeingedanken "Stuhl" wird eben nicht ohne weiteres vollzogen. ${ }^{1}$ )

Was wir in einer solchen Einzelbeobachtung ertappen, ist nur der Momentausschnitt aus einem Prozess, der sich bezüglich aller Allgemeingedanken fortwährend vollzieht; ihre Klärung, Verengung, Erweiterung, Verschiebung geht das ganze Leben hindurch; neue Erfahrungen, Korrekturen aus der Wahrnehmung, aus anderen Denkvorgängen, aus dem sozialen Kontakt bewirken, dass der Erlebnisgehalt eines Allgemeingedankens nicht stabil ist, sondern stark wechselt. Auch die Allgemeingedanken sind also unselbständige Momente des personalen Lebens selbst und ändern sich mit diesem. (Wieder sehen wir den Unterschied zwischen dem "psychologischen" Gedanken und dem „logischen" Begriff, der zeitlos und von dem denkenden Subjekt unabhängig ist.)

Die Reihenbildung spielt eine besonders interessante Rolle bei einer sehr wichtigen Kategorie allgemeiner Gedanken, den $\mathrm{Z}$ a h $\mathrm{lg}$ ed a n k e n.

Beim Kleinkind entwickelt sich der erste sinnvolle Gebrauch von Zahlen stets an $\mathrm{g} l \mathrm{e}$ i $\mathrm{c}$ h a $\mathrm{r} \mathrm{t}$ i g e $\mathrm{n}$, neben-oder nacheinander gereihten Gegenständen. Sind solche in ihrer Zusammengehörigkeit durch e i n e n Anschauungsakt zu erfassen, dann gelangt das Kind zu den ersten „Anschauungszahlen": zwei Äpfel, zwei Hände, drei Männer.

Für die höheren Ziffern sind Zwischenstadien nötig. Das Kind legt lauter Kastanien hintereinander und „zählt": eins, noch eins, noch eins; auf einer nächsten Stufe werden die einzelnen Glieder einer solchen Reihe schon mit den gelernten Zahlwörtern verbunden: eins, zwei, drei, vier. Diese Sprachsymbole bedeuten also

1) Vgl. hierzu die viel primitivere Verhaltungsweise des Tieres in analogen Fällen S. 440 . 
zunächst nur den Platz in der Reihe, stellen „Ordnungszahlen” dar; und es ist noch ein weiterer Entwicklungsschritt nötig bis zu dem Gedanken, dass die letztgenannte Zahl zugleich die A nz a h 1 aller Reihenglieder - also die Kardinalzahl - angibt ${ }^{\mathbf{1}}$ ). Der Gedanke der „Anzahl” wird nicht sogleich in seiner abstrakten Allgemeinheit gewonnen; er bleibt zunächst auf gewisse, personal wichtige Gegenstandsgruppen beschränkt. So können Kinder schon die ,Zweiheit” bei Äpfeln und Händen verstehen und sinnvoll aussprechen, ohne dass sie diese Zahlennamen auf Häuser oder Berge anwenden können. Ganz entsprechende Erscheinungen zeigen die Zahlsysteme primitiver Völker; doch auch die der Kulturmenschheit sind nicht frei davon. Es gibt in den Kultursprachen halb-abstrakte Anzahlbezeichnungen, wie „Paar”, „,Dutzend", „Schock”, die nur auf bestimmte Gegenstandsgruppen anwendbar sind; und es gibt $\mathrm{m}$ a $\mathrm{g}$ i s $\mathrm{c}$ h e Zahlen wie 3, 7, 13, die nicht einen indifferenten Mengenwert darstellen, sondern personalen Symbolcharakter haben.

Es ist hier nicht der Ort, den gewaltigen Entanschaulichungsprozess zu verfolgen, den das Zahlendenken der Menschheit im Laufe der Zeiten durchmessen hat. Nur gewisse Haupttypen seien genannt.

Am Anfang stehen, wie wir eben sahen, die „ausgewählten” und "magischen" Zahlen — bei denen überhaupt nur wenige unter den möglichen Anzahlen erfasst und auch diese nur in Bezug auf wenige Gegenstandsgebiete angewandt werden. In weiteren Denkschritten werden gewonnen: die ,, benannten" Zahlen, die noch an Gegenständen kleben, aber schon auf beliebige Gegenstände anwendbar sind, die ,unbenannten" ganzen Zahlen, bei denen bereits die gedanklichen Operationen in Unabhängigkeit von irgend welchen Gegenständen vollzogen werden. Durch eine Kluft getrennt von diesen sind jene weiteren Zahlabstraktionen, die erst durch wissenschaftliches Denken erarbeitet werden konnten: die negativen, die irrationalen, die imaginären, die infinitesimalen Zahlen - bis hin zu den, in keiner gegenständlichen Anschauung mehr verifizierbaren, nur noch in abstrakt-begrifflichen Zeichen fassbaren Zahlgedanken der modernen Zahlentheorie.

\section{BEZIEHUNGSGEDANKEN}

Die letzte Betrachtung hatte schon mehrfach Beziehungsgedanken behandelt (Identität, Gleichheit, Anzahl), aber doch nur so-

1) So kann es kommen, dass Kinder zwar die Finger einer ihnen dargebotenen Hand richtig zählen, aber die Frage: wieviel Finger sind das also? noch nicht beantworten können. 
weit, als sie zur Erzeugung von Gegenstandsgedanken erforderlich sind. Nun können aber die Beziehungsgedanken auch selbständig auftreten als zwischengegenständliche und übergegenständliche Erlebnisinhalte. Die Gedanken „Kausalität” oder „Ähnlichkeit” sind zwischengegenständlich, sofern sie zwischen mehreren Gegenständen eine Brücke schlagen, übergegenständlich, sofern sie in identischer Weise auf beliebige Gegenstandsarten anwendbar sind.

Logik und Erkenntnistheorie nennen diejenige Beziehungen, die unter dem Gesichtspunkt der Erkenntnis als letzte, irreduzible Voraussetzungen für die Verknüpfung und Ordnung von Gegenständen anzusehen sind, „Kategorieen”. Die Psychologie hat, unabhängig von der Geltungsfrage, jene Beziehungsgedanken in ihrem psychischen Gehalt zu beschreiben und ihre Genese im Einzelindividuum wie in der Menschheit zu verfolgen.

\section{Praekategoriale Beziehungen}

Hierbei stösst sie auf einen Tatbestand, der noch einmal deutlich die Verschiedenheit logischer und psychologischer Blickrichtung zeigt: das ursprünglichste Beziehungsdenken erweist sich als p raekategorial. Auf jenem geistigen Niveau, auf welchem der Mensch beginnt, Gegenstände aus dem Chaos seiner Vitalwelt heraus $\mathrm{zu}$ analysieren, ist es ihm noch gar nicht möglich, den abgegrenzten Einzelgegenstand zu jrgend einem anderen abgegrenzten Gegenstand in eine scharf charakterisierte Einzelbeziehung zu setzen; jeder Gegenstand ist noch eingebettet in das Total der Welt und gehört mit allem anderen, das ebenfalls vergegenständlicht wird, auf das innigste zusammen. Die Urbeziehung, welche gedacht wird, ist also garnicht die Zweierbeziehung (wie sie Ursache und Wirkung, Mittel und Zweck, die zwei Glieder einer „Ähnlichkeit” u.s.w. verbindet), sondern eine A 11 b e $z$ i e h u n g, ein Miteinander-zu-tun-haben von Jedem mit Jedem - oder, besser: ein noch garnicht völlig Abgesondertsein des einzelnen Gegenstandes aus der unbestimmten Ganzheit der personalen Welt. Unbestimmt aber bleibt zugleich die kategoriale A r t dieser Beziehung. Ein Gegenstand wird als einem anderen ähnlich und zugleich als mit ihm identisch gedacht. Zwei Phasen eines Vorgangs werden noch ungeschieden gedacht als: eine Wir- 
kung, die aus einer Ursache herrührt; ein Zweck, dem ein Mittel dient; ein Zeichen für ein Bezeichnetes. Wie bei allen psychischen Entwicklungserscheinungen, so steht also auch beim Beziehungsdenken ein Zustand der Diffusität und Vieldeutigkeit am Anfang; und erst allmählich werden dann durch Ausgliederung die $\mathrm{s}$ p e $\mathrm{z}$ if i s c h en Beziehungsgedanken gewonnen.

In die chaotische, praekategoriale Urbeziehung wird aber auch die denkende Person miteinbezogen; ja, es handelt sich u rs p r üngli ch um die Beziehung I ch/Welt, erst in zweiter Linie um die Beziehung von Weltstück zu Weltstück. Alles, was an Einzelgegenständen, Zuständen und Vorgängen in der Welt abhebbar ist, hat etwas zu tun mit "m i r"; und i c h habe zu tun mit allem, was da draussen passiert. Ein Komet erscheint am Himmel, oder eine Katze läuft über den Weg: diese Begegnung wird irgendwie in Zusammenhang gedacht mit dem Schicksal des Denkenden - wobei es noch ganz diffus bleiben kann, ob jene Gegenstände Ursache oder Zeichen kommenden Unglücks, oder Strafen für vergangene Taten, oder gar Identifikationen mit „mir” seien. In umgekehrter Richtung ist eine Tat meiner selbst - z.B. eine Kulthandlung, eine Beschwörung - für die W e $1 \mathrm{t}$ bestimmend; sie kann das Wetter ändern, den Feind schädigen, einen Erfolg herbeiführen; wobei wiederum Beobachtung natürlicher Ursachbeziehung und kritische Nachprüfung der Richtigkeit der Annahme noch völlig fehlen können.

Wir haben damit die Grundformen des $m$ y s $t$ is c h-m a gis che n B e zieh ung s de n ken s entwickelt ${ }^{1}$ ). „Mystisch" heisst dies Denken, wenn man die praekategoriale Allbeziehung betont; ",magisch", wenn man den aktiven Anteil des eigenen Ich hervorhebt. Diese Denkweisen führen auf primitiven Stufen: bei Naturvölkern, bei kleinen Kindern, durchaus die Vorherrschaft. Aber auch auf höherem Denkniveau fehlen sie nie ganz. Sie bilden beim Kulturmenschen, ja sogar beim Wissenschaftler, zum mindesten eine Unterschicht, die das darüber gelagerte, rationale und kategoriale Denken oft genug in verschwiegener Weise färbt, zuweilen aber durchbricht und sich in ausgesprochen mystischmagischem Denkgehalt bekundet.

Dabei wäre es falsch, praekategoriales und rationales Denken einfach mit den Wertausdrücken „nieder" und „höher” rangieren

1) Literatur bei $\mathrm{H}$. Werner und Zeininger. 
zu wollen. Denn das rein rationale Denken für sich bringt die Gefahr einer Entpersönlichung mit sich, die der Mensch immer wieder durch eine Rückkehr zu den personalen Untergründen des Denkens bekämpfen muss. Die umfassendsten Denksysteme, die die Menschheit überhaupt produzierte, die der „Weltanschauungen" im weitesten Sinne, sind deshalb stets Synthesen beider Denkweisen. Mythen, Religionen, künstlerische Weltbilder und - auf wissenschaftlicher Stufe - metaphysische Systeme sind aus den beiden Quellen des ganzheitlich-totalen und des abstraktkategorialen Beziehungsdenkens gespeist und reichen dadurch sowohl in den Wurzelboden der personalen Existenz wie in die Höhen der Spekulation hinein.

Daneben stehen dann solche Verquickungen beider Denkweisen, bei welchen das rationale Denken eigentlich nur dazu benutzt wird, dem mystisch-magischen Denken als Werkzeug der Begriffs- und Systembildung zu dienen. Mystizismus, Spiritismus, Theosophie, Aberglaube, Sektenbildungen verschiedener Art sind mehr oder minder trübe Erzeugnisse solcher Denkarbeit.

Das Beziehungsdenken ist also ebenfalls von einer Doppelbewegung bestimmt (ähnlich jener, die wir beim Gegenstandsdenken als Entanschaulichung und Veranschaulichung beschrieben hatten). Zwischen Fntpersönlichung und Verpersönlichung geht der Weg hin und her; und jeder einzelne Beziehungsgedanke steht an einer bestimmten Stelle dieses Weges, ist zugleich personal verankert und kategorial abstrahiert.

Es sei dies an einigen Beispielen erläutert, die hier nur als Hinweise dienen können für eine anzustrebende Phänomenologie aller wesentlichen Beziehungsgedanken.

2. Gleichheit, Verschiedenheit, Ahnlichkeit

Eine Gruppe von Beziehungsgedanken baut sich auf Denkakten des V e r g l e i c h e n s auf: so die Kategorieen: Identität, Gleichheit, Verschiedenheit, Ähnlichkeit, Steigerung.

Schon oben konnten wir nachweisen, wie der Gedanke der I d e n $\mathrm{t}$ i t ä $\mathrm{t}$ seinen Ursprung in der Selbstgewissheit von der 
Stetigkeit des Ich, also durchaus im Personalen habe, und dass die abstrakte Identität zweier Begriffe, oder die mechanische Identität der trägen und unveränderlichen Substanz erst am Ende eines langen Prozesses der Versächlichung steht.

Der Gedanke der "Gleichheit" bedeutet ursprünglich Gleichwertigkeit für mich, Vertauschbarkeit und Vertretbarkeit im Dienste personaler Zwecke, Bedeutungslosigkeit (Unterschwelligkeit) der Verschiedenheiten, immer im Hinblick auf irgend welche sinnvolle Zielsetzung. Erst sehr allmählich wird dies personale Ziel zum sachlichen Gesichtspunkt rationalisiert, zum sogenannten "tertium comparationis" - ganz zurück tritt es endlich im abstrakten, mathematischen Gleichheitsgedanken, sodass hier Gleichheit zn einer rein unpersönlichen Mafsbeziehung wird.

"Vers ch i e d e n h e i t" und "Anderssein". - Zu Grunde liegt ein Urerlebnis der Durchbrechung der personalen Situation: das Fremdheitsgefühl, die Desorientiertheit, der Choc - oder auch die Entbehrung, das Bedürfnis, der Wunsch. Hier wird also „Anderssein", ,Anders-werden" noch erlebt ohne Vergleichungsakte, ohne Zweigliedrigkeit der Denkbeziehung. Im leidenschaftlichen Ausruf: „Das muss anders werden!”, in der Konstatierung „Ich fühle mich heut ganz anders”, oder „Du siehst heut so verändert aus" braucht der - vergangene oder zukünftige - Zustand, v o n dem der gegenwärtige verschieden ist, garnicht als zweites Denkglied im Bewusstsein zu sein. Die scheinbare Paradoxie einer eingliedrigen Beziehung löst sich dadurch, dass ich im Grunde die Beziehung des Gegenstandes zu $\mathrm{m}$ i r, nicht zu einem anderen Gegenstande denke. Aber auch, wenn das zweite Vergleichsglied mitgedacht wird, werden doch „Verschiedenheit” und „Veränderung" zunächst noch stark als Wechsel innerhalb der personalen Welt, als Bedeutsamkeit für "mich" erlebt - um erst allmählich (ganz entsprechend, wie wir es vorhin von der Gleichheit ausführten) entpersönlicht und formalisiert zu werden.

Sehr deutlich ist der personale Anteil beim Beziehungsgedanken der quantit a t i ve n Verschiedenheit: in den Gedanken der Zunahme und Abnahme, des „Mehr und Minder”, „Grösser und Kleiner" u.s.w. lässt das naive Denken ganz unverhüllt ein Urerlebnis der personalen Geltungssteigerung und-Minderung mitklingen.

Beim Ä h n l i c h k e i t s-Gedanken gibt es eine, nunmehr ver- 
ständlich werdende, Seltsamkeit. Während für die Logik „Ahnlichkeit" eine durchaus reziproke Beziehung ist ( $a$ ist dem b ebenso ähnlich, wie b dem a), gilt dies psychologisch durchaus nicht. Im wirklichen Leben wird die Ähnlichkeitsbeziehung einseitig nach dem mir personal näher stehenden, bedeutsameren Gliede orientiert. Ich kann daher sagen: dieser (fremde, mir zufällig begegnende) Mann sieht meinem Bruder ähnlich, ohne dass ich umgekehrt sagen könnte: mein Bruder sieht diesem fremden Manne ähnlich. Je mehr die Vergleichsglieder der Person entfremdet, versachlicht werden, um so mehr kann sich die rein abstrakte Ähnlichkeit als reziproke Beziehung im Denken durchsetzen; in der mathematischen Lehre von den ,ähnlichen Dreiecken” etwa ist die volle Gleichordnung beider Glieder erreicht.

\section{Ka us alität und Finalität}

Eine andere Gruppe von Beziehungsgedanken hat es mit Gliedern zu tun, die in zeitlicher Abfolge stehen. Aus der mystischmagischen Allbeziehung, die ebenso Gleichzeitiges wie Sukzessives umfasst, sondert der Mensch allmählich gewisse Sukzessionsglieder heraus und setzt zwischen ihnen eine sinnhafte Beziehung an, sei es als Ursache/Wirkungs-Zusammenhang, sei es als Mittel/Zweck-Zusammenhang. Wie sind diese Beziehungsgedanken psychologisch zu beschreiben?

Dass der Gedanke ,propter hoc" mehr und anderes ist als der Gedanke ,post hoc", ist eine unmittelbar einleuchtende, psychologische Erfahrungstatsache. Dennoch hat man zuweilen eine einfache Reduktion versucht. Das bekannteste Beispiel hierfür ist Hume's psychologische Ableitung des Kausalitätsgedankens aus blosser Assoziation: Sind zwei Vorgänge häufig nacheinander ins Bewusstsein getreten, so hat sich allmählich eine sehr feste Assoziation zwischen beiden gestiftet; diese Gewöhnung bewirkt, dass bei Wiedereintritt des einen Gliedes das zweite e r wartet wird. In solchen Fällen sagen wir: der eine Vorgang verursache den anderen.

Die erkenntnistheoretische Bedeutung dieser Theorie geht uns hier nichts an. Psychologisch ist sie aber durchaus unzureichend. Sie könnte vielleicht verständlich machen, warum wir den Kausalitätsgedanken, w e n n e r e i n m a 1 d a is $t$, nun gerade auf 
die (häufig in Verbindung erlebten) Vorgänge $a$ und b, nicht aber auf die Vorgänge a und c anwenden. Aber völlig unerklärt bleibt, $\mathrm{w}$ a $\mathrm{r} \mathrm{u} \mathrm{m}$ wir jene häufig vorkommende Verbindung unter einem ganz anderen, viel gehaltvolleren Beziehungsgedanken („Kausalität') denken, als es der Gedanke der wiederholten Sukzession ist. An sich hat die Gewöhnung an Wiederholung nichts mit dem Ursachgedanken zu tun. Wenn ein Mensch Tag für Tag und Jahr für Jahr beim Aufstehen erst den linken Strumpf und gleich darauf den rechten Strumpf anzuziehen pflegt, wird hieraus dennoch nie der Kausalgedanke entstehen: das Strumpfanziehen links sei die Ursache, deren Wirkung in dem Strumpfanziehen rechts hervortrete. Und ebenso wenig hat die immer wieder erlebte Sukzession von Abenddämmerung und Nachtdunkel, und die sehr feste Erwartung, dass der Dämmerung das Dunkel auch in Zukunft folgen werde - jemals dazu geführt, dass die Dunkelheit der Nacht als eine „Wirkung” der Dämmerung aufzufassen sei.

Es wird hier also wiederum die Unzulänglichkeit einer rein assoziationspsychologischen Theorie des Denkens offenbar.

Fragen wir weiter, w e $1 \mathrm{c}$ h e Art von Erlebnissen es sind, an denen sich diese ersten Kausalgedanken entwickeln, so muss die Antwort wiederum der Hume'schen These von Gewohnheit und Erwartung entgegengesetzt sein. Denn für die alltägliche, im Gleichtrott des Lebens wiederkehrende, Åhnlichkeit von Verknüpfungen $\mathrm{b}$ e d a r f der Mensch keiner besonderen gedanklichen Kategorie; die wiederholten Verbindungen werden hingenommen mit dem blossen Vertrautheitsgefühl; sie ordnen sich von selbst der personalen Welt und ihrem magischen Totalzusammenhang ein; sie werden erwartet mit Selbstverständlichkeit, d.h. ohne Denkarbeit. (Deshalb gibt es auch für das Tier - dessen Welt viel gleichförmiger und dessen Leben viel konservativer ist - keinen Zwang zum Kausaldenken.) Die Frage nach der Ursache entzündet sich vielmehr an $\mathrm{N}$ e u e m und Unge w o h n t em, an dem, was plötzlich in die vertraute Selbstverständlichkeit einbricht, und eben deshalb für sich da steht, fremd, drohend, beängstigend oder mindestens staunen-erregend. Reicht für die Bewältigung des Neuen nicht mehr die rein vitale Reaktion (Abwehr, Flucht, Neuanpassung) aus, dann tritt das $\mathrm{D}$ e $\mathrm{n} \mathrm{k}$ e $\mathrm{n}$ in Funktion und sucht nach der speziellen Beziehung, durch welche sich das Befremdliche in Ver- 
trautes einordnet: es wird als Wirkung einer bekannten Ursache gedacht. Daher setzt das kausale Denken der Primitiven ein bei Naturereignissen, die die Existenz bedrohen, wie Gewitter, Sturm, Erdbeben, Hungersnot, Feuer, Krankheit; bei den hervorstechenden Wendepunkten des Lebens, wie Geburt, Mannbarkeit, Tod; bei schweren Schicksalsentscheidungen des Individuums und bei den, das Alltagsleben unterbrechenden, Gemeinschaftsphänomenen, wie Krieg und Aufruhr. Auch die ersten Kausalfragen des Kindes beziehen sich nicht auf das Alltägliche, sondern auf das Ungewohnte.

„Macht die Sonne die Fingerle blutig ?" fragte ein 2; 8 alter Knabe, als er zum e rs t e $\mathrm{n} \mathrm{Mal} \mathrm{in} \mathrm{seinem} \mathrm{Leben} \mathrm{bemerkte,} \mathrm{wie} \mathrm{die} \mathrm{gegen} \mathrm{die}$ Sonne gehaltenen Finger rosig durchleuchtet wurden. Wie hätte dieser Knabe „auf Grund von Gewohnheit und Erwartung" jemals darauf kommen können, dass Sonne und Aussehen der Finger kausal zusammenhängen?

Ganz langsam erst lockert sich mit fortschreitender Abstraktionsfähigkeit diese Gebundenheit des Kausalgedankens an das für die Person Neue und Relevante; immer weitere Kreise des Seins werden ihm unterworfen, bis die höchste Abstraktion erreicht ist in dem wis se $\mathrm{n} \mathrm{s}$ chaf $\mathrm{t} l \mathrm{i}$ ch e $\mathrm{n}$ Kausalprinzip, nach welchem jedes Geschehen und jedes Sein unentrinnbar in die Kette der Weltverknüpfungen eingereiht ist.

Auch dem gedanklichen $\mathrm{G}$ e h a $1 \mathrm{t}$ nach durchläuft die Entpersönlichung des Kausalgedankens zahlreiche Entwicklungsschritte.

Aus der diffusen Totalbeziehung von Jedem mit Jedem hebt sich als erste Sonderbeziehung zweier Sukzessionsglieder heraus der Zusammenhang zwischen $\mathrm{m}$ e in e $r$ 'Tat und ihrem unmittelbaren Effekt: das Erlebnis des „M a chen s”. Diese ursprüngliche Ein he it von Macher und Gema ch te m bildet das Schema, an dem der Kausalgedanke sich zu entwickeln vermag. Es ist eine Erlebniseinheit der Anschauung, aber zugleich auch eine solche der personalen Geltung; die „Mach"-Beziehung ist zugleich „Macht"-Beziehung.

Schon das einjährige Kind hat, wenn es den von der Mutter gebauten Turm mit Begeisterung einwirft, das Bewusstsein: ich hab's gemacht, Gleichzeitig erlebt es solchen Zusammenhang in 
umgekehrter Richtung: die Mutter macht, dass ich jetzt Nahrung bekomme; die Tischkante macht, dass ich plötzlich einen Stoss an der Stirn erhalte. Die letzten Beispiele zeigen schon jene Verallgemeinerung des "Machens”, in der wir den ersten Abstraktionsschritt des Kausaldenkens sehen können: A 11 e V e r ä nderungen, die mich (aktivoder passiv) ange he n, sind, "ge m a ch t".

Noch auf lange hinaus kann Kausalität überhaupt nicht anders denn als „Machbeziehung” gedacht werden. Für diese primitive Denkstufe legen die Schöpfungsgeschichten und Mythologieen der Völker Zeugnis ab, nach denen Wetter, Einzelschicksale, Stammesgeschichte, ja die ganze Welt von göttlichen Kräften, Dämonen, Zauberern ,gemacht" sind - ebenso das Kausalinteresse des Kindes, das danach fragt, wie und von wem die Bäume, die Tiere, die Häuser, die Krankheiten u.s.w. „gemacht” werden. Zugleich steigert und erweitert sich die eigene Erfahrung des Selber$\mathrm{machenkönnens;} \mathrm{und} \mathrm{so} \mathrm{kommt} \mathrm{es,} \mathrm{dass} \mathrm{die} \mathrm{t}$ e $\mathrm{chn} \mathbf{n}$ s c he $n$ und $\mathrm{k} \ddot{\mathrm{u}} \mathrm{n}$ s t le ris chen Kausalbeziehungen zu Modellen für naives Kausalitätsdenken überhaupt werden. Denn das Hervorbringen von Artefakten zeigt ja am klarsten die Zueinandergehörigkeit von tätigem Ich und gemachtem Erzeugnis.

Kennzeichnend für diese Abstraktionsstufe desKausaldenkens ist aber auch die Undifferenziertheit des dynamischen und des teleologischen Moments. Ist doch die tätige $\mathrm{K} \mathrm{r}$ a f $\mathbf{t}$ im allgemeinen auf das $\mathrm{zu}$ erreichende $Z$ i e 1 eingestellt; ja, noch mehr, das Ziel wird als „Aufgabe” bereits im Bewusstsein vorweggenommen.

Der naive Kausalgedanke enthält also zugleich und diffus die „causa efficiens" und die „causa finalis". Die gedachte Ursache ist kraftgeladene Zielstrebigkeit, die gedachte Wirkung angestrebte Kraftverwendung.

Ein weiterer Abstraktionsschritt führt nun zur $\mathrm{D}$ if $\mathrm{f}$ e r e nz i e r u g dieser beiden Momente. Zeigt schon das primitive personale Erleben gelegentlich ein „Machen”, das nicht zielgemäls ausläuft (z.B. das Zerstören - Kaputt-,,machen” - bei einem Wutanfall), so werden mit Erweiterung der Erfahrung immer mehr Fälle von Kraftentladung des eigenen Ich und anderer Kraftquellen sichtbar, bei denen der Effekt zum mindesten nicht eindeutig auf entsprechende Zielsetzung zurückgeführt wer- 
den kann: die „b li n d e” K r a f t wird als Ursachprinzip erkannt. Auf der anderen Seite führt das wachsende Vorausschauen des Menschen dazu, dass er von gedanklich gesetzten, aber noch nicht verwirklichten Zukunftseffekten her die ,gerichteten" Kräfte $\mathrm{zu}$ denken sucht, die das Ergebnis herbeiführen können: die Beziehung "Mit t e $1 / \mathrm{Z}_{\mathrm{we} \mathrm{c}} \mathrm{k}$ " löst sich aus der vagen Urkausalität heraus.

Es wäre sehr reizvoll zu verfolgen, wie sich nun diese beiden Typen kausalen Denkens teils auseinanderentwickeln, teils gegenseitig zu beeinflussen suchen. An dieser Stelle müssen wenige Andeutungen genügen.

Der Beziehungsgedanke der „,blinden Kräfte” findet innerhalb des naiven Denkens seine umfassendste Abstraktion im Gedanken des blindwaltenden $\mathrm{Schicks}$ als. In der Wissenschaft ist dem Gedanken der „,m e c h a n is c h e n Kausalität” eine starke und vielseitige Entfaltung beschieden gewesen - bis zur Selbstaufhebung.

Die Mechanik machte den Anfang; von hier wurde der Begriff der um Ziel und Zweck unbekümmerten „Naturkräfte” auf die anderen Gebiete der Physik, ferner auf Chemie nnd Biologie übertragen und auch die Erweiterung auf Soziologie, Psychologie und Geisteswissenschaften zum mindesten versucht - bis auch hier die höchste Abstraktionsstufe in einem Fatumbegriff (allgemeine Naturgesetzlichkeit, Prinzip der Erhaltung der $\mathrm{Kraft}$ ) erreicht war. Aber als man so weit vorgedrungen war, erkannte man, dass im Kraftbegriff selbst noch ein letzter Rest jenes personalen Ursprungs, der "Mach-Beziehung” enthalten war; und man ersetzte ihn durch den Begriff der gesetzmälsigen $\mathrm{Zu}$ ordnung zweier Geschehnisse. Damit war die Entanschaulichung und Entpersönlichung des Kausalgedankens vollkommen geworden aber dieser Gedanke selbst preisgegeben. Blosse Funktionalbeziehung ist keine „Kausalität” mehr.

Die Gedanken der zi elg eri ch te te n Kausalität (die Mittel/Zweck-Gedanken) haben sich auf vier grossen Denkgebieten in jeweilig besonderer Weise entwickelt.

Der Bereich des eigentlichen „Machens”, den wir schon kennen, breitete sich ungemessen aus. Wirtschaft, Technik, Geldwesen, Krankenheilung, Erziehung u.s.w. existieren ja nur dadurch, dass für Zwecke, die zum Teil erst in ferner Zukunft liegen, die Mittel, und für deren Verwirklichung wieder die Mittelsmittel gesucht, geordnet und ins Spiel gesetzt werden müssen. Die natürliche 
Lebenspraxis des Alltags ebenso wie alle praktischen Wissenschaften stehen dauernd unter dem Mittel/Zweck-Gedanken; und wenn dieser Gedanke im Einzelfalle (z.B. beim Kauf eines Brotes, oder bei der Heilung eines Kranken) noch durchaus in der Anschaulichkeit der Situation verankert ist, so ist doch selbst diese individuelle Anwendung nur möglich, weil der Mensch zum D e nke $n$ a bstrakterer $M$ it t e $1 / Z$ w e c k- $Z$ us a m men$\mathrm{h}$ ä ng e fähig ist, die als Lebensregeln, Erfahrungsmaximen, sittliche Grundsätze, Rechtsnormen, Heil- und ErziehungsMethoden auftreten. Gemeinsam ist allen diesen Mittel/ZweckGedanken die $Z$ weiheit von Macher und Gemachtem; es ist eine von aussen wirkende Teleologie.

Im Gegensatz hierzu entwickelt sich auf dem Erfahrungsgebiet des or g a n is c h e n Lebens der Gedanke der „inneren” (immanenten) Teleologie. In aller organischen Selbsterhaltung, Entwicklung, Selbststeuerung, Selbstheilung werden Mittel ins Spiel gesetzt, die ihren Zielen nicht als etwas Fremdes, Zweites gegenüberstehen, sondern mit ihnen zusammen einer identischen Ganzheit angehören. Dieses „Sich-selber-Machen” erlebt ja der Mensch fortwährend an seinem eigenen Lebensgeschehen, an seinem Wachsen und Reifen, seiner Atmung und Ernährung, seiner Erkrankung und Gesundung. Aber gerade wegen dieser alltäglichen Selbstverständlichkeit ist der Anstoss zur g e d a n k li c h e n Heraussonderung dieser Beziehungsform nicht so stark wie etwa für die Ausgliederung des „Mach”-Gedankens; auch erfordert der organische Zweckgedanke eine Selbstreflexion, die stets später einsetzt als das, auf das Verhältnis Ich/Welt gerichtete, Nachdenken. So ist es verständlich, dass der spezifische Gedanke einer immanent-organischen Teleologie innerhalb der naiven Denkstufen über Ansätze und Andeutungen nicht hinaus gelangte und erst als wissenschaftlicher Gegen-Gedanke gegen die Gedanken der blinden Kausalität und der äusseren Teleologie seine volle Entwicklung erlebt.

Die Geschichte der Biologie, von Aristoteles' Entelechie-Begriff bis zum modernen Vitalismus und Personalismus, liefert die Belege hierfür. Von jenen - heut unentbehrlich gewordenen - Teilgedanken, die diesem Bereich des Mittel/Zweck-Gedankens angehören, seien hier nur die Beziehungsbegriffe der Zielstrebigkeit, der Erblichkeit, der Anlage, der Disposition, der Selbstregulierung genannt. 
Die Selbstreflexion des Menschen hat nun aber einen, der eigenen Person zukommenden, Bereich des Mittel/Zweck-Gedankens gefunden und herausgearbeitet, der weit über das Nur-Organische hinausreicht. Es ist die Stellung der Person $\mathrm{z} u \mathrm{~d}$ e $\mathrm{n} \mathrm{W}$ e rt e $n$. Die Werte bilden eine gedankliche Welt von, in sich bedeutsamen, Sinngehalten, in die sich einzuordnen und denen nachzuleben, nun für den Menschen zur Aufgabe wird. „A u f g a b e u n d Erf üll u n g" ist also die hier neu auftretende Gestalt des Mittel/Zweck-Gedankens.

Dabei ist eine mehrfache Entwicklung. des Denkens zu verfolgen. Die Werte werden aus der konkret anschaulichen Fassung (Gott, die eigene Nation, die eigene Ehre u.s.w.) ins Abstrakte vergeistigt (,das Wahre”, ,das Gute”, ,das Schöne”, ,das Heilige"); und eine äussere Teleologie (Befolgung des göttlichen Gesetzes, Treue gegen die Autorität) wird durch eine innere abgelöst (die Kantische Idee der sittlichen Autonomie). In den Bereich dieser so spezifisch p e r s o n a le n Kausalitätsgedanken gehören dann die Beziehungsgedanken der Motivation, der Entscheidung, der Pflicht, der Freiheit, der Verantwortlichkeit, der $\mathrm{Zu}$ rechnung.

Endlich wird das Gebiet der objektiven Wertverwirklichung, auch unabhängig von den daran beteiligten Einzelpersonen, zum Gegenstand des Mittel/Zweck-Gedankens. Man versucht für den „o b j e k t i ve n Ge i s t” d.h. die Gesamtkultur und Gesamtgeschichtlichkeit der Menschheit, Kausalgedanken zu erarbeiten. Sie sind teils dynamischer Natur, indem sie „treibende Faktoren" des Kulturgeschehens ausdrücken, teils sind sie mehr teleologisch gerichtet, indem sie das „Ziel der Geschichte” vorwegnehmen und von diesem, erst zu verwirklichenden, Ziel her das Vergangene zu verstehen, das Gegenwärtige zu würdigen und das Kommende zu beeinflussen suchen.

Von den naiven Formen der Schöpfungs- und Heilsgeschichte bis hin zu den ausgebauten kulturphilosophischen Systemen und abstrakten geschichtsphilosophischen Utopieen der Gegenwart ist auch hier eine gewaltige Denkentwicklung zu verzeichnen; die einzelnen gedanklichen Stufen sind zwar von genialen Individuen - religiösen Heroen, Staatsmännern, Philosophen und Propheten - erstmalig gedacht, dann aber vom Denken der Massen übernommen und in Ideale, Uberzeugungen und Taten umgewandelt worden. 


\section{SINNGEDANKEN}

Die einzelnen Beziehungsgedanken, wie wir sie soeben isolierend betrachteten, stehen im wirklichen Denkleben niemals selbständig nebeneinander; sie sind eingebettet in e i n e $\mathrm{ge}$ schlossene Denkgestalt, die wir als „Sinn” bezeichnen.

Ich lese etwa den Satz Nietzsche's: „Nicht nur fort sollst Du Dich pflanzen, sondern hinauf." Dann denke ich dabei vielerlei Beziehungen: räumliche Gerichtetheit nach vorwärts und nach oben; Symbolik dieser beiden Raumrichtungen, Gegensätzlichkeit, Ergänzung, Steigerungsverhältnis zwischen beiden Teilgedanken, die Normbeziehung, die im „Du sollst” liegt - aber alle diese Gedanken in ihrer Summierung machen noch nicht den „Sinn" jenes Satzes aus; ja es wäre möglich, dass ich einem anderen jede einzelne Teilbeziehung verständlich machen könnte, ohne dass er doch jenen Gesamtsinn erfasste.

Das Eigentümliche eines solchen „Gesamtsinnes” lässt sich nicht mehr durch bestimmte logische Kategorieen determinieren, auch nicht angemessen in Worten ausdrücken - genau so wenig, wie sich die individuelle Gestalt eines Kunstwerks adäquat beschreiben lässt.

Mit dem Terminus „Gestalt” kann man wohl den f o r m a l e n Aspekt des Sinngedankens umschreiben, aber nicht mehr. Gewiss sind in dem "Sinn" des obigen Satzes (oder in dem "Sinn" des Faustdramas u.s.w.) die zahlreichen einzelnen Gegenstands- und Beziehungs-Gedanken zu einer besonderen Denkstruktur zusammengeschlossen, in welcher das Gewicht und die Bedeutung der einzelnen Gedanken vom Ganzen her bestimmt sind. Es gibt dominierende und unterstützende Teilgedanken; es gibt zwischen den gedanklichen Momenten Spannungen und Verschränkungen und Differenzierungen - all dies sind Phänomene gestaltpsychologischer Art.

Aber dem eigentlichen Sinn des „Sinns" kommt man doch erst dann nah, wenn man die $\mathrm{T}$ i e f e n dimension einbezieht. So wie die Person "Tiefe” hat, so auch die Welt für die Person ${ }^{1}$ ). Diejenigen Erlebnisse, die aus dem unmittelbaren Kontakt von Person und Welt entstehen, haben Oberflächencharakter, aber

1) Vgl. S. 131. 
sie weisen hin auf anderes, dahinter Liegendes; und das Bestreben, in dieses Andere vorzustossen, heisst den "Sinn" von Person und Welt suchen. Gegenüber dem gesuchten tieferen "Sinne” ist nicht nur die „Sinnlichkeit" oberflächenhaft, sondern auch das Vorstellen und Denken, sofern es sich auf Einzelgegenstände und Einzelbeziehungen erstreckt.

Diese Bedeutung des „,Sinndenkens” gilt also ebenso für die Tiefe der Person, wie für die der Welt: man sucht d e n $\mathrm{S}$ i n n $\mathrm{d}$ e r e i g e n e n Ex is t e n z, des eigenen Schicksals zu ergründen, aber ebenso d e $\mathrm{n}$ S in $\mathrm{n}$ d e r W e $1 \mathrm{t}$, den Sinn der Natur, den Sinn der Geschichte, den Sinn der Nationen. Ferner kann das Sinndenken auf Grösstes und Kleinstes gerichtet sein: man bemüht sich um den Sinn des Goethe'schen Faust im ganzen, und um den Sinn eines einzelnen Zitats aus dem Faust; um den Sinn der Mathematik, und um den Sinn des Pythagoräischen Lehrsatzes; um den Sinn des eigenen Lebens, und um den Sinn einer einzelnen Handlung, die man getan hat.

Der Akt, in dem sich dieses Sinndenken erfüllt, bezeichnet man als "V ersteh en". Damit wird auch ps y chologis ch der Unterschied jener beiden Denkakte deutlich, die als „Erklären" und „Verstehen" in der modernen Wissenschaftstheorie eine gegensätzliche Rolle spielen ${ }^{1}$ ). „Erklären” ist die Anwendung des Kausaldenkens auf einen bestimmten Denkgegenstand - wobei es gleichgültig ist, we $1 \mathrm{ch}$ e der verschiedenen Formen des Kausalgedankens verwertet sind; genug, wenn das Fremde und Einzelne dadurch einem bekannten Zusammenhang eingeordnet wird. "Verstehen" aber ist das Erfassen des Sinnes; die Fremdheit des oberflächenhaften Eindrucks soll nicht durch Ausgreifen in die Weite, sondern durch Eindringen in die Tiefe überwunden werden. Wer Napoleon ,erklären” will, muss auf anderes ausserhalb Napoleon's Bezug nehmen: auf seine Vorfahren, seine Umgebung, die geschichtlichen Ereignisse, in die er hineingestellt war. Wer Napoleon ,verstehen” will, kann sich ganz auf ihn selbst beschränken, aber muss sich alles einzelne, das er von Napoleon weiss, gleichsam transparent machen, um in die Substanz seines Lebens vorzudringen. Und es kann jemand, der Napoleon sehr gründlich erklärt hat, unter Umständen doch nur ein sehr geringes Verständnis für den Sinn des Phänomens Napoleon haben.

) Vgl. S. 25 f. 
Wenden wir nun noch einmal die so gewonnen Merkmale des „Sinndenkens" auf engere Sinnzusammenhänge, etwa einzelne Sentenzen, Lehrsätze, Handlungen an.

Was wir oben (S. 414) bei dem Nietzsche-Satz hypothetisch andeuteten, ist oft genug Wirklichkeit : die einzelnen Gegenstandsund Beziehungs-Gedanken eines Sinnzusammenhanges werden durchaus begriffen, ohne dass doch der Sinnzusammenhang des ganzen Denkgebildes verstanden würde. So kann etwa ein Schüler die einzelnen Denkschritte eines mathematischen Lehrsatzes erfasst haben; er sieht ein, dass aus der Voraussetzung a die Folgerung $b$, aus dieser der weitere Satz $c$ abgeleitet werden kann oder muss - aber warum im ganzen gerade diese Denkwege begangen werden, welche Bedeutung dem einzelnen Denkschritt in diesem Gefüge zukommt, kurz die „Plausibilität” des gesamten Sinnzusammenhanges kann ihm trotzdem verschlossen bleiben. Âhnliches gilt auch bei einem literarischen Werk, etwa einem Gedicht, an dem die einzelnen Gedanken, auch vielleicht der Oberflächenzusammenhang des Gedankenfortschritts, durchaus erfasst sind, während der ,tiefere Sinn” noch gänzlich unter der Schwelle des Verstehens bleibt.

Sehr bekannt ist die entsprechende Erscheinung bei $\mathrm{W}$ i t $\mathbf{z}$ e $\mathbf{n}$ und bei $R$ ätseln. Es gibt sehr intelligente Menschen, die Witze nicht verstehen. Sie begreifen durchaus alle Teilgedanken und ihre Verknüpfungen, bringen aber kein Verständnis auf für die „Pointe”, jenen nicht weiter definierbaren Überraschungssinn, der dem G a n z e n zukommt. Ebenso gehört beim Rätselraten eine besondere Gabe dazu, in einer Art von Intuition jenen gemeinsamen Punkt zu schauen, zu dem die verschiedenen, im Rätseltext angelegten, Fäden konvergieren.

Es gibt aber auch das Umgekehrte: Sinnverständnis, ohne dass die Einzelheiten gedanklich bewältigt würden. Ein Kind lacht zuweilen herzlich über einen Witz, dessen von uns gemeinte Pointe es garnicht verstanden haben kann, weil die Voraussetzungen zum Verständnis der einzelnen dazugehörigen Denkschritte fehlen. Es legt eben irgendwie s e i n e $\mathrm{n}$ - von jenen Voraussetzungen unabhängigen - Sinn in den Witz hinein. Oder es können die Einzelheiten eines Denkgebildes nur halb und unklar begriffen sein aber der dahinter liegende Totalsinn offenbart sich doch. Ist dieser Tatbestand erst einmal an gewissen markanten Beispielen ein- 
sichtig geworden, dann bemerkt man, dass er viel allgemeinerer Natur ist: Sinnverständnis greift nicht nur über die gedankliche Erfassung der Einzelmomente hinaus, sondern ist nicht auf sie angewiesen, eilt ihr voraus, kann sich aus Spuren und dumpfen Ansätzen aufbauen, um dann von sich aus die Einzelheiten gedanklich zu klären. So sind z.B. alle V e rmutungen und $\mathrm{H}$ y $\mathrm{p}$ ot h e s e n nur dadurch möglich, dass ein problematischer Totalsinn die $\mathrm{zu}$ findenden Einzelbeziehungen antezipiert.

Aus der Tiefendimension des Sinnes ergibt sich noch eine letzte wichtige Folgerung. Der Sinn kann in verschiedenen Tiefen gelagert sein; ein und derselbe Denkgegenstand kann mannigfache "Sinngehalte" in verschiedener Tiefenlage besitzen; ein und derselbe Mensch kann denselben Denkgegenstand $\mathrm{zu}$ verschiedenen Zeiten mit verschiedenen Sinngehalten erfüllen; verschiedene Menschen können den Sinn eines Denkgegenstandes aus ganz verschiedenen Tiefen - und auch sehr verschiedenen Richtungen - hervorholen.

Wer zum ersten Male den Faust liest, mag schon irgendwie den Totalsinn (besser: e i n e n Totalsinn) zu verstehen meinen; und doch: wieviel an Einzelheiten ist unverstanden geblieben; wieviel wird bei zweiter Lesung erst gedanklich geklärt von jenem früher erfassten Totalsinn aus! Und wenn die zweite Lektüre beendet ist - hat man wieder einen anderen - tieferen - Totalsinn gewonnen. 


\section{SIEBZEHNTES KAPITEL}

DENKDISPOSITIONEN BEI MENSCH UND TIER

\section{INTELLEKT UND INTELLIGENZ BEIM MENSCHEN}

\section{Terminologis ches}

Wird das Disponiertsein zum Denken als eine Beschaffenheit angesehen, die dem Menschen dauernd eigen ist, so spricht man von Intellekt und Intelligenz.

Es erscheint um der Sauberkeit der Terminologie willen besser, wenn man in rein psychologischen Erörterungen Ausdrücke vermeidet, die nicht nur mit den Überbleibseln veralteter psychologischer Theorieen belastet, sondern ursprünglich überhaupt aus nicht-psychologischen Gesichtspunkten (vielmehr aus solchen der Logik) geschaffen und definiert worden sind.

Dies gilt besonders von den Bezeichnungen "Verstand" und „Vernunft". Sie stammen, wenigstens innerhalb des d e u t s c h en wissenschaftlichen und ausserwissenschaftlichen Sprachgebrauchs, noch aus der Vermögenslehre des 18. Jahrhunderts. Dort galten Verstand und Vernunft als starre und selbständige Seelenkräfte, die den Menschen vom Tier unterschieden, die jeder Mensch fertig von seinen Vorfahren erhielt, und die als hinreichende Ursachen für alle tatsächlichen Denkvollzüge angesehen wurden. Speziell wurde dann „Verstand” als das Vermögen begrifflicher Scheidung und Ordnung, "Vernunft" als das Vermögen der Prinzipien, d.h. des Zusammenfassens alles Einzelnen unter letzten allgemeinsten Gesichtspunkten definiert. Kant, dem wir vornehmlich die Festlegung und Verbreitung dieser Begriffe verdanken, hat dann dem Verstand und der Vernunft die „Urteilskraft" angereiht, als das Vermögen, die allgemeinen Kategorieen auf die konkreten Einzelfälle richtig anzuwenden.

In der heutigen Psychologie ist an die Stelle des Vermögensbegriffs der der Disposition getreten, mit jenen Unterscheidungs- 
merkmalen, die wir früher (S. 112) genau bestimmten. Dies gilt auch für das Denken. Potentialität zum Denken ist ein Wesenszug menschlichen Daseins; es ist daher nicht nur möglich, sondern sogar notwendig, von einer $\mathrm{D}$ e $\mathbf{n ~} \mathrm{k}$ d i s p o s i t i o $\mathrm{n}$ zu sprechen.

In jeder Disposition steckt Richtung und Rüstung zugleich. Betont man in der Denkdisposition den Richtungsfaktor, so heisst sie Intellekt, betont man den Rüstungsfaktor: Intelligenz. I ntellekt is t das Eingestelltsein a u Denkvoll$z \ddot{u} g e$, I ntelligenz das Befähigtsein zu solchen.

Dieser sprachlichen Abgrenzung hängt noch eine gewisse Willkür an; aber dass der Sprachgebrauch nach einer solchen Scheidung tendiert, dafür sind die abgeleiteten Eigenschaftswörter ein Beweis. Der „i n t e ll e k t u e ll e" Mensch ist der auf geistige Dinge gerichtete, der vornehmlich in geistigen Sphären lebende unabhängig vom Grade seiner geistigen Begabung. Der ,i n t e 1lige n t e" Mensch ist der für Denkleistungen gut gerüstete, also der denkbegabte Mensch - gleichgültig, ob seine Interessensphären dem Geistigen fern oder nahe liegen.

Zugleich eignet sich der Ausdruck „Intellekt” besser zur Bezeichnung der g e n e r ell e n Tatsache: dass jedem Menschen die Gerichtetheit auf Denken zukom me - während sich das Wort Intelligenz im internationalen Sprachgebrauch für den dif f er e $\mathrm{n}$ t i e 1 l e $\mathrm{n}$ Tatbestand eingebürgert hat, d.h. zur Bezeichnung der verschiedenen Grade und Arten der Denkfähigkeit.

2. Personale Bedeutung des Intellekts

a) Dienstbede u t u ng. - Denken ist das Mittel, um mit dem Nichtselbstverständlichen fertig zu werden. Soweit also das Verhältnis Person/Welt im Selbstverständlichen verweilt sei es im gattungsmälsig Selbstverständlichen (Vererbung), sei es im individuell Selbstverständlich-Gewordenen (Mneme) - bedarf der Mensch nicht des Denkens. Aber der Mensch lebt in einer sehr weitgehend nicht-selbstverständlichen Welt; fortwährend wechseln Zustände und Situationen, fortwährend sieht er sich neuen Anforderungen, Gefahren und Problemen gegenüber, bei denen die rein konservativen Kräfte des Instinkts, der Tradition und der Gewöhnung versagen; um trotzdem der Welt gewachsen zu bleiben, bedarf der Mensch des Denkens. 
Es wäre jedoch nicht richtig, diese Beziehung als eine rein reaktive aufzufassen und demnach das Denken als diejenige Form des "Kampfes ums D a s e i n" anzusehen, die durch die Unsicherheit und Labilität der Umwelt notwendig wird. Das fortwährende Problematisch-Werden des Verhältnisses Person/Welt geht ja nicht nur von der Welt aus, sondern auch von der Person selber, die, über die blosse Selbstbehauptung hinaus, auch die Tendenz zur Selbstentfalt ung in sich trägt. Der spontane Entwicklungsdrang aber kann sich mit keiner bestehenden und gewohnten Person/Welt-Relation zufrieden geben, sondern sucht andere zu erreichen; so entsteht eine Unselbstverständlichkeit ganz anderer Art, ein Nichtruhenkönnen im erreichten (und vielleicht sogar gesicherten) Dasein, ein Kämpfen um Entfaltung, dem wiederum das Denken zu dienen hat.

In Betrachtungen über den menschlichen Intellekt, die vornehmlich bi o lo g i s $\mathrm{ch}$ bestimmt sind, findet man fast immer nur jene Ableitung aus der blossen Selbsterhaltung; das Denken wird dann in der Reihe der Anpassungsmechanismen als der komplizierteste betrachtet, aber immerhin lediglich als Mittel im Daseinskampf.

Schon Schopenhauer gibt eine solche Theorie: Der Wille zum Dasein, ursprünglich blind und dumpf (also das, was man heut "Selbsterhaltungstrieb" nennen würde), bedarf in der besonderen Situation menschlicher Weltverstricktheit der Einsicht; er "steckt sich die Fackel der Intelligenz an". - Die biologische Entwicklungstheorie seit Darwin und Spencer lässt den Intellekt als Ergebnis natürlicher Auslese aus dem Kampf ums Dasein und dem Uberleben der Angepassten allmählich entstehen.

In unserer Zeit sondern sich zwei Wurzeln dieser Auffassung deutlicher. Eine objektivistisch-biologische Betrachtungsweise sieht alles Verhalten des Menschen, so auch die Denkleistung, rein als Kette von Selbsterhaltungsreaktionen an (Reflexologie, Behaviorismus und ähnliche Theorieen). Eine subjektivistisch-triebpsychologische Lehre erblickt im Denken nur eine Sublimierung von Urtrieben, sodass der Intellekt - wenn auch auf Umwegen - lediglich denselben Zwecken dient, auf die das Triebsystem eingestellt ist.

Solche Theorieen sind brauchbar, soweit es sich um das Verständnis der primitiven Einstellungen des Denkens han- 
delt; denn diese sind stark in den natürlichen Vitalbedürfnissen verankert. Das praktische Ur-Denken als Umweg der Instinktbefriedigung, das magische Ur-Denken als eine Sicherung des Ich gegenüber der Unheimlichkeit der Welt, die biologisch orientierte Auslese der ersten Denkgebiete und Denkformen, die noch ungeschiedene Verquickung des primitiven Denkens mit Wünschen, Angsten und Hoffnungen - all dies wird aus jener biologischen Ableitung verständlich. Ebenso, dass das Denken zeitliche Vorausschau möglich macht; denn zur Lebenssicherung gehört auch Vorwegnahme künftiger Situationen. (Freilich reicht hier schon die rein biologische Erklärung aus der Selbsterhaltung nicht weit, höchstens in die sehr enge personale "Nähe" des unmittelbar Bevorstehenden und zu Erwartenden hinein).

Sobald aber die entwi ckelt e re n Leistungen des Intellekts in Betracht kommen, genügt diese Ableitung aus der rein reaktiven Selbstbehauptungssphäre nicht mehr. Der Mensch ist mehr als ein Anpassungswesen im passiven Sinn; er ist nicht nur bestrebt, sich der Welt - sondern auch die Welt sich anzupassen; sich, d.h. seiner ständig wachsenden, reifenden und sich entfaltenden personalen Sphäre. Selbst wenn die Welt konstant bleibt, die Situationen sich wiederholen, reichen für den Menschen die rein mnemischen Funktionen nicht aus (die für das Tier genügen mögen); denn e r s e l bs t ist jedesmal ein anderer; und so muss er sich immer wieder mit der gewandelten Relation Person/ Welt $\mathrm{d}$ e $\mathrm{n} \mathrm{k}$ en $\mathrm{d}$ auseinandersetzen.

Dies gilt zunächst schon für die Alltagspraxis. Das Streben nach gesteigerter Geltung und Macht, nach Beherrschung immer weiterer Weltbereiche und nach Hinauswirken auf immer weitere $\mathrm{Zu}$ kunftsstrecken setzt den Intellekt viel stärker in Bewegung, als es die blosse Selbsterhaltungstendenz vermöchte. Die höchsten Formen des Intellekts aber entspringen aus der spontanen „Introzeptionstendenz" des Menschen, d.h. aus dem Streben, die objektiven Wertgehalte der Welt sich einzuverleiben und so den eigenen Selbstwert dauernd zu steigern. Daraus (und $\mathrm{n} u \mathrm{r}$ daraus, nicht aus irgend welchen biologischen Motivationen) wird die Leistung des Intellekts im Dienste künstlerischer, moralischer, religiöser und wissenschaftlicher Ziele verständlich - insbesondere auch die volle Verselbständigung der Denkerzeugnisse zu Erkenntnissen, die um ihrer selbst willen gesucht und erlebt werden. 
b) Stra h l bede u t u n g. - So ist der Intellekt weit mehr als ein blosses Werkzeug; er wird zum Strahlwert und zum charakteristischen Ausdruck eines Wesens, das einer unsicher gewordenen Welt das eigene Selbstentfaltungsstreben gegenüber stellt.

Der Mensch als denkender ist nicht einfach der Unheimlichkeit und Problematik der Welt und seiner selbst preisgegeben; er hat sich ihr aber auch niemals endgültig angepasst - sondern steht in immer wieder erneutem Kampf mit ihr. Der Mensch als denkender wurzelt in dem animalisch-vitalen Urboden, dessen Erschütterung die ersten Denkfunken weckt; aber er reicht hinein in die Bereiche objektiver Geltung bis zu den abstraktesten und lebensfernsten hin. Sein Denkleben führt immer wieder von der Praxis zur Theorie und umgekehrt, ist zugleich Selbstbehauptung und Selbstentfaltung, pendelt zwischen Veranschaulichung und Entanschaulichung, zwischen Verpersönlichung und Entpersönlichung. Erscheint der Intellekt auf den Stufen stärkster Abstraktion und Vergeistigung als „Widersacher der Seele”, so ist er mit der anderen Wurzel eingebettet in jene personalen Schichten, die man - im Gegensatz zum „Geist" - mit Vorliebe als „Seele” bezeichnet. Darin, dass der Mensch als denkender sowohl homo sentiens, wie auch homo sapiens ist - gerade darin liegt die eigentliche Strahlbedeutung des menschlichen Intellekts.

\section{GRADE UND ARTEN DER MENSCHLICHEN INTELLIGENZ}

\section{Bedeutung der Intelligenzprüfungen}

Die Verschiedenheit en der menschlichen Denkfähigkeit sind ein Thema der d if f e re n t i e ll en Psychologie, nicht der allgemeinen, die uns hier beschäftigt. Dennoch muss das Thema wenigstens kurz gestreift werden. Denn die Untersuchungen der Intelligenzunterschiede haben in methodischer und praktischer Hinsicht einen so breiten Raum in der psychologischen Arbeit der letzten Jahrzehnte eingenommen, dass auch die allgemeinpsychologischen Theorieen davon nicht unberührt bleiben konnten.

Den Ausgang nahmen diese Untersuchungen in Frankreich um die Jahrhundertwende, als Binet (in Gemeinschaft mit Simon) sein Prüfungssystem zur psychologischen Auslese von Hilfsschul- 
kindern entwarf. Dies System wurde dann auch anderen Zwecken dienstbar gemacht und fand in allen Kulturländern Anwendung. Weiterhin wurde das Intelligenzthema hauptsächlich in Deutschland und Amerika bearbeitet. Die von mir geleiteten Institute in Breslau und Hamburg und das Laboratorium von Terman in Berkeley bildeten Brennpunkte dieser Untersuchungen und Prüfungen; aber auch andere Forscher und Institute vieler Länder beteiligten sich daran. Insbesondere hat die Intelligenzprüfung mit verschiedenen Standardmethoden in Amerika einen grossen Umfang angenommen.

Da zum grossen Teil Interessen des praktischen Erziehungsund Schullebens diese Forschungen leiteten, so sind sie vor allem kindes- und jugend-psychologisch orientiert ${ }^{\mathbf{1}}$ ).

Für Kleinkinder sind besondere Prüfungsserien ausgearbeitet worden von Descoeudres, Gesell, Bühler-Hetzer und anderen.

Methoden zur Intelligenzuntersuchung Erwachsener sind hauptsächlich von Psychiatern für ihre speziellen diagnostischen Zwecke ausgebildet worden; sie können hier nicht erwähnt werden $\left.{ }^{2}\right)$. Übrigens werden die für Kinder und Jugendliche erdachten Verfahrungsweisen auch oft auf Erwachsene angewandt. Besonders zu erwähnen sind die umfangreichen Prüfsysteme für Erwachsene (auch für Analphabeten), die in Amerika während des Krieges benutzt worden sind.

Was die praktische Verwendung angeht, so gibt es kein psychologisches Verfahren, das in solchem Umfange und solcher Mannigfaltigkeit für die verschiedensten Kulturaufgaben nutzbar gemacht worden ist, wie das der Intelligenzprüfung. Viele Tausende von Kindern und Erwachsenen sind solchen Prüfungen unterzogen worden, ganz besonders häufig in Amerika.

Die praktischen $Z$ we $\mathrm{ck}$ e, für welche diese Prüfungen verwandt wurden, können hier nur aufgezählt werden: Untersuchungen der $R$ e if e von Kindern für Kindergarten, Schuleintritt, verschiedene Schul-Arten und -Grade. A u s s onder u ng für die Hilfsschule und andere Spezialanstalten. $\mathrm{D}$ i a $\mathrm{g} \mathrm{n}$ os $\mathrm{t}$ i s $\mathrm{ch}$ e Feststellung der Intelligenzunterschiede der Kinder einer Schulklasse. Ständige $\mathrm{K}$ o n-

1) Zur Ubersicht über die Intelligenzpsychologie der Kinder und Jugendlichen, sowie uber die Untersuchungsmethodik kann auf die Monographie des Verfassers und auf die Methodensammlung Stern-Wiegmann hingewiesen werden. Die Bïcher enthalten auch umfangreiche Bibliographieen, die bis zum Jahre 1928 reichen. - Eine Bibliographie amerikanischer Testsysteme gibt Hildreth.

2) Zusammengestellt in Lipmanns Handbuch. 
t r o 11 e des geistigen Status von Kindern und Erwachsenen in Irrenhäusern und Schwachsinnigenanstalten. Beurteilung von verwahrlosten, kriminellen, gefährdeten Kindern, Jugendlichen und Erwachsenen. Feststellung des Intelligenzgrades zum $Z$ weck der $B$ e r u f sberatung und Berufsauslese. Musterung für den Militärdienst. Forensis che Beurteilung der Intelligenz von Angeklagten und Zeugen.

Der allzu grosse Enthusiasmus, mit welchem zuerst diese Methoden angewandt wurden, hat jetzt einer zurückhaltenderen und ruhigeren Betrachtung Platz gemacht. Das ist nur zu begrüssen. Man hat zeitweilig im Intelligenztest eine Allerweltsmethode gesehen, die alles leisten und alle anderen Beurteilungsmethoden in Pädagogik, Psychiatrie, Berufsauslese zurückdrängen könnte. Das war ein Irrtum, der sogar der legitimen Anwendung dieser Verfahrungsweisen Hemmungen bereitete. Heute weiss man die grosse Bedeutung zu schätzen, welche die Intelligenzprüfungen besitzen, wenn sie als elastische Teilmethoden in vielseitige diagnostische Untersuchungen eingebaut und zugleich als Hilfsmittel für eingehende psychologische Beobachtungen verwandt werden.

2. Begriffsbestimmungder Intelligenz

„Intelligenz ist die personale Fähigkeit, sich unter zweckmälsiger Verfügung über Denkmittel auf neue Forderungen einzustellen' 1). - Diese Definition, die zwar vielfach bekämpft wurde, hat sich doch als die angemessenste bewährt. Sie bedarf nur kurzer Erläuterungen, da sie ja lediglich das zusammenfasst, was in den vorhergehenden Betrachtungen dieses Buches über das Denken dargelegt worden war. Die Aufgabe der Intelligenz ist es (im Gegensatz zum Gedächtnis), mit n e u e n Forderungen, die das Leben stellt, fertig zu werden, und zwar dadurch, dass von den vorhandenen Denkmitteln ein zweckmäIsiger Gebrauch gemacht wird. Also Denken-können an sich ist noch nicht Intelligenz; sondern die Verwendung der Denkhilfen am rechten Ort und in der rechten Weise. „Unintelligent ist nicht nur, wer zu wenig denkt, dort, wo mit mehr Denken Besseres erreicht werden könnte, sondern auch, wer zu viel denkt, dort, wo mit weniger Denk-

1) Intelligenzprüfung S. 344. 
aufwand Gleiches oder gar Besseres erreicht werden könnte $\left.{ }^{1}\right) . "$

Viel umstritten ist die Frage, ob die Intelligenz eine $\mathrm{e}$ i $\mathrm{n} \mathrm{h} \mathrm{e}$ i tli c h e Funktion oder eine Summe von vielen Einzelfunktionen sei. Manche, analytisch eingestellte Psychologen (z.B. Theodor Ziehen) wiesen daraufhin, dass die verschiedenen Prüftests bei einem und demselben Individuum sehr verschiedene Ergebnisse liefern, also zu gleicher Zeit etwa eine gute Abstraktionsfähigkeit, eine mittlere Kombinationsfähigkeit und eine geringe Kritikfähigkeit anzeigen könnten; die Intelligenz sei daher keine dispositionelle Einheit. Otto Lipmann forderte sogar, dass man nur von „Intelligenzen" einer Person sprechen dürfte.

Von anderen Seiten wurde dem gegenüber der Ganzheitsstandpunkt vertreten. Spearman wies auf die Ergebnisse von Korrelationsbestimmungen hin: Untersucht man eine grössere Anzahl von Individuen mit einer Reihe von Intelligenztests, so ergibt sich eine merkliche Korrelation; diese lässt nach Spearman darauf schliessen, dass neben gewissen Sonderfähigkeiten ein "general factor" existiere, der dem Intelligenzgrad jedes Individuums das Gepräge gebe.

Ich selbst verband diese experimentellen Befunde mit personalistischen Erwägungen. Jede Person hat - in ihrer Totalität gesehen - zweifellos ein gewisses ge is tige s $\mathrm{N}$ i ve a u. Die Volkspsychologie hat das ganz richtig eingesehen, wenn sie die Bezeichnungen „klug” und „dumm” als Kennzeichen dieses geistigen Gesamtzustandes verwendete. Das Niveau ist freilich keine ebene Fläche, sodass alle Teilfunktionen die gleiche Höhe haben müssten. Es ist vielmehr mannigfach profiliert; und die in ihm vorhandenen Erhebungen und Vertiefungen bewirken sehr verschiedenartigen Ausfall verschiedener Teiltests. Die P r o f i l i er u $\mathbf{~} \mathbf{g}$ ist dadurch bedingt, dass die „Intelligenz” als angeborene Disposition ja nicht für sich allein funktioniert, sondern durch Interessen und Charaktereigenschaften, durch Gewöhnung und Ausseneinflüsse gefärbt und mitbestimmt ist. Dadurch aber wird doch nicht verhindert, dass man die mittlere Höhe des Gesamtniveaus als eine für die Person charakteristische Grösse ansehen kann. Nur freilich darf man nicht glauben, dass zwei Menschen von gleichem Intelligenzniveau nun auch durchweg in ihren einzelnen In-

1) Intelligenzprüfung S. 345 . 
telligenzleistungen gleich sein müssten; dem steht eben die verschiedene Profilierung entgegen.

\section{Erforschung und Prüfung der Intelli- genzgrade}

Zur Prüfung des Intelligenzgrades sind „starre” und „elastische” Prüfreihen geschaffen worden.

In den starren Systemen sind Prüfaufgaben und Bewertungsmalsstäbe ein für alle Mal festgelegt. Das Prinzip, nach welchem das System gebildet ist, ist in den meisten Fällen das der Altersstaffelung; es ist auch das Prinzip der Binet-Simon-Methode. Andere Prinzipien können hier nicht besprochen werden ${ }^{\mathbf{1}}$ ).

In den Systemen mit Altersstaffelung sind für jeden Jahrgang der Kindheit Aufgaben aufgestellt, die der normalen Leistungsfähigkeit dieses Alters entsprechen. Wird nun ein Kind mit dieser Serie geprüft, dann kann man die Leistungsstufe, die es erreicht, (sein sogen. „Intelligenzalter” = IA) mit seinem Lebensalter (LA) vergleichen. Binet wählte als Intelligenzmals die Differenz zwischen IA und LA; heut wird nach meinem Vorschlag allgemein das Verhältnis beider Werte berechnet, der sogen. In telligenzquotient IQ $=\frac{I A}{\text { LA. }}$ Beim normalen Kind ist dieserWert $=1$.

Beispiel : Ein achtjähriges Kind löst die Tests der Sechsjährigen, versagt aber bei den Aufgaben für normale 7-8jährige. Dann ist $L A=8$, $\mathrm{IA}=6$, der Intelligenzrückstand (nach Binet) IA $-\mathrm{LA}=-2$, der Intelligenzquotient $I Q=\%=0,75$. Das Kind hat, grob ausgedrückt, „Dreiviertels-Intelligenz”.

Der IQ-Wert eines Kindes besitzt durch eine Reihe von Jahren eine gewisse Konstanz und kann daher als Niveaubestimmung benutzt werden. Allerdings liefert er nur eine sehr grobe Charakteristik, denn die nackte Niveauziffer lässt ja alle Profilierung der Intelligenz unter den Tisch fallen. Der IQ kann nur als die erste Annäherung an die kindliche Individualität angesehen werden; er gewinnt erst rechten Wert, wenn seine bloss quantitative Angabe durch qualitative Diagnose ergänzt wird. Irgend welche praktisch-

1) Genannt seien: Die von Rossolimo erdachte „Profilmethode"; die von Yerkes vorgeschlagene „Punktskalamethode”, die amerikanische „Testheft-Methode” (in Deutschland durch Bobertag und Hylla eingefuihrt). 
erzieherischen Malsnahmen (z.B. die Uberweisung zur Hilfsschule) allein auf den IQ zu gründen, ist nicht zu verantworten.

Wertvoll ist die IQ-Messung für massenstatistische $Z$ wecke. Die einfache Handhabung der Methode erlaubt es, sehr grosse Zahlen von Kindern verschiedenen Alters und auch von Erwachsenen zu prüfen und nun die Gruppenergebnisse zu vergleichen.

Von den so gewonnenen Befunden zählen wir hier einige auf:

Prüft man eine grosse, ungesiebte Anzahl von Kindern und ordnet sie nach dem IQ, so entsteht eine $\mathrm{H}$ ä u f i g k e i t s k u rv e, die der normalen Gauss'schen Verteilungskurve entspricht. D.h.: Der IQ $=1$ und die ihm benachbarten Werte nach oben und nach unten sind am häufigsten vertreten; weiterhin fällt die Kurve nach beiden Seiten erst langsam, dann schneller ab; die höchsten und tiefsten Stufen der Intelligenz sind ganz selten.

Vergleicht man die Intelligenzquotienten mit medizinisc h e n Diagnosen, so reicht die volle Normalität bis etwa zum IQ $=0,90$ herunter. Zwischen 0,90 und 0,80 liegen die Grenzfälle zur Unternormalität. Die Debilen gruppieren sich um den IQ 0,75; sie haben „Dreiviertels-Intelligenz"; die Imbezillität streut zwischen 0,60 und 0,70 (,Zweidrittels-Intelligenz").

Vergleicht man beide $\mathrm{G}$ e s ch le ch t er unter sonst gleichen Bedingungen des Alters, des Milieus, der Schule u.s.w., dann zeigen sich keine bemerkenswerten Unterschiede im Intelligenzdurchschnitt. (Dies Ergebnis zeigt deutlich, wie unzulänglich die blosse Niveauziffer ist; denn in derProfilierung der weiblichen und männlichen Intelligenz gibt es Unterschiede, die auch schon imKindesalter bemerkbar sind, aber bei dieser Berechnungsart verloren gehen.)

Vergleichungen von Kindern verschiedener rassischer und nationaler $\mathrm{H}$ er k u f $\mathrm{t}$ haben bedeutende statistische Unterschiede gezeigt. Das Völkergemisch Amerikas bot hier günstige Untersuchungsmöglichkeiten. (So ist z.B. der Intelligenzdurchschnitt weisser Kinder und Erwachsener höher als der der Farbigen.)

Ähnliches ergab sich bei Kindern verschiedener sozialer Schichten. Das geringere Intelligenzniveau der sozial schlecht gestellten Schichten tritt z.B. deutlich hervor, wenn man Volksschulen aus verschiedenen Stadtteilen vergleicht; die Armenviertel fallen stark ab gegen die Bezirke der Wohlhabenderen. 
Zur richtigen Interpretation dieser Ergebnisse sind aber zwei wichtige Bemerkungen zu machen.

1.) Sie haben $\mathrm{nur}$ massenstatistische Bedeutung, besagen also nichts über einzelne Individuen. Die Streuung ist in allen Gruppen sehr gross; deshalb gibt es innerhalb der ungünstigen Gruppen stets eine Anzahl von Individuen, die in die günstigere Gruppe hinein-, ja, über deren Mittelwert hinaus-ragen. So findet man z.B. stets einige Kinder aus dürftigem Milieu, deren Intelligenz die der gutbegabten wohlsituierten Kinder erreicht oder übertrifft; es ist eine der vornehmsten Aufgaben der Intelligenzprüfung, an der Auffindung solcher hochbegabten Kinder mitzuwirken.

2.) Der experimentelle Befund liefert zwar das Faktum der geistigen Niveauunterschiede verschiedener Gruppen, besagt aber nichts über die eigentliche U r s a ch e dieser Erscheinung. Der Test prüft ja nicht die nackte angeborene Begabung, sondern diejenige Fertigkeit, die aus der Verbindung der Begabung mit den äusseren Einflüssen hervorgegangen ist. Wenn auch die einzelnen Aufgaben möglichst so gewählt wurden, dass sie nicht direktes Schulwissen treffen, sondern eigene Denkarbeit fordern, so sind doch die unablässigen Einwirkungen von Haus, Schule und Strasse nicht ohne Bedeutung für die Art, wie ein Kind die Aufgaben löst. Man wird deshalb vermuten, dass die Gruppenrückständigkeit weder ein reines Produkt angeborener Minderwertigkeit, noch eine blosse Wirkung der geringeren geistigen Anregung und Schulung ist, sondern dass beides zusammenwirkt.

Während die Staffelsysteme die Leistung jedes Prüflings an einem absoluten Malsstab messen, der ein für alle Mal festliegt, begnügen sich andere Prüfmethoden mit r e l a $t$ i v e n Malsstäben, d.h. mit einer Vergleichung der geprüften Kinder untereinander. Hier besteht dann grössere Freiheit in der Wahl der Aufgaben. So ist in Hamburg viele Jahre hindurch die Intelligenzprüfung als Hilfsmittel zur Auslese der begabten Schüler für die höheren Schulen mit herangezogen worden; jedes Jahr wurde für diesen $Z$ weck andere Aufgaben ausgesucht und zu Testserien kombiniert. Die Punktzahlen, welche die einzelnen Prüflinge erreichten, konnten mit einander verglichen werden; die Schüler mit den höchsten Punktzahlen wurden der Schulbehörde für die Auslese 
empfohlen. Durch Verwendung solcher freier Prüfserien wird die Arbeit des Psychologen viel elastischer; er kann sich der jeweiligen Aufgabe besser anpassen.

\section{Intelligenzty pen ${ }^{1}$ )}

Die verschiedene Profilierung der Intelligenz führt dazu, dass sich $\mathrm{t} y \mathrm{p}$ i $\mathrm{s} \mathrm{ch}$ e Formen des intelligenten Verhaltens herausbilden. Vier Typenpaare sind deutlich unterscheidbar.

a) Der reaktive und der spontane Intellig e $\mathrm{nz}$ t y p us. - Es gibt Menschen, deren Intelligenz (selbst wenn sie dem Grade nach ziemlich hoch ist) eine gewisse Trägheit besitzt und daher zu jeder Betätigung eines Anstosses von aussen bedarf. Diese Menschen lassen die Anforderungen an sich herankommen und finden sich dann zweckmälsig mit ihnen ab. Sie können ihr Bestes geben in gebundenen und geregelten Lebensverhältnissen. - Die Menschen mit spontaner Intelligenz warten nicht erst die Gelegenheit zum Denken ab, sondern setzen es von sich aus in Aktion. Sie erleben Probleme und ringen mit ihnen, stellen Fragen, nehmen künftige Ziele planend vorweg. Selbst dort, wo die Denkanregung von aussen kommt, begnügen sie sich nicht mit der einfachen Reaktion, sondern spinnen den Faden selbständig weiter. Der spontan Intelligente bewährt sich vor allem da, wo die Bindungen gelockert sind und freier Selbsttätigkeit Spielraum geboten ist.

b) Der objektive und subjektive Typus. Das fundamentale Verhältnis Person/Welt macht sich in der Typisierung der Intelligenz geltend. Die objektivierende Intelligenz nimmt die Tatsächlichkeiten und Gesetzmälsigkeiten der Objekte zur Richtschnur des eigenen Denkens und Handelns; die subjektivierende Intelligenz vollzieht an den Gegenständen diejenigen Umformungen, Auslesen und Deutungen, die dem Bedürfnis der Person entsprechen. Freilich ist dies subjektivierende Verhalten nur dann „intelligent”, wenn dabei die zwe ckmä Isige Beziehung zwischen Objekt und Subjekt gewahrt bleibt. Die Unterscheidung hat Verwandtschaft mit der charakterologischen Typik des extravertierten und introvertierten Menschen ${ }^{2}$ ).

1) Vgl. Intelligenzprüfung $S .18 \mathrm{f}$.

2) Vgl. XXIII. Kap. 
c) Der analytische und dersynthetische T y p u s. - Es gibt Menschen, welche ihre Intelligenz vornehmlich im Zerlegen bekunden. Sie stellen Ganzheiten unter bestimmte isolierte Gesichtspunkte, suchen die einzelnen Teile, Teilbegriffe, Teilvorgänge aufzuweisen, bemerken Fehler und Mängel im einzelnen und sind daher die eigentlich kritischen Naturen. Ihnen stehen die Synthetiker gegenüber, welche in das Chaos der Einzelheiten logische Ordnung und Einheit zu bringen bestrebt sind. Zuweilen können die Synthetiker im Schematismus stecken bleiben. Andererseits ist ein hoher Mals konstruktiver Intelligenz zu jeder schöpferischen Leistung nötig.

d) Der theoretische (gnostische) und der p ra k t is c h e T y p u s. - Eine der wichtigsten Tatsachen der Intelligenzdifferenzierung ist von der Psychologie lange übersehen worden, weil die Psychologen selber Wissenschaftler sind und daher dem $t$ h e o r e $t$ is c h e $n$ Typus angehören pflegen. So kam es, dass sie nur an jene Art der Intelligenz dachten, welche es direkt mit logischen Operationen und deren sprachlicher Bewältigung zu tun hat, also mit den Leistungen des Erkennens, Verstehens, gedanklichen Kombinierens und Unterscheidens, Urteilens und Schliessens u.s.w. Erst als die Intelligenzprüfung mehr und mehr in den Dienst praktischer Lebensaufgaben gestellt wurde, erkannte man, dass die weitaus grösste Zahl der Menschen in ihrer Intelligenzbetätigung einem anderen Typus angehört. Die p r a k t i s c h e Intelligenz ${ }^{1}$ ) bekundet sich darin, dass die Denkmittel unmittelbar dem Handeln untergeordnet und dienstbar gemacht werden. Die intelligente Hausfrau, der intelligente Handwerker mögen recht unbeholfen sein, wenn reine Erkenntnisleistungen, Definitionen, kombinierte Schlussfolgerungen von ihnen erwartet werden - aber wenn sie vor einer neuen praktischen Situation stehen, die durch die gewohnten Hausfrauenoder Berufs-Erfahrungen nicht einfach zu meistern ist, dann wird das Denken mobil gemacht, in der ganz konkreten Form, die der Augenblick verlangt. 


\section{Die einzelnen Intelligenzfunktionen}

Eine ausserordentlich umfangreiche und fruch tbareArbeit ist auf die Erfindung und Eichung von Prüfmitteln für die einzelnen Teilfunktionen der Intelligenz gewandt worden. Seitdem Ebbinghaus im Jahre 1897 seine, noch heut vielfach gebrauchte, Methode der Ergänzung lückenhafter Texte einführte, um die „Kombinationsfähigkeit" zu prüfen, sind unzählige Tests für die verschiedensten Arten von Denk- und verwandten Leistungen erdacht worden ${ }^{1}$ ).

Zum Teil haben die Aufgaben freilich nur indirekt mit der Intelligenz zu tun, so wenn sie die Raumanschauung, die Merkfähigkeit, die Sprachfähigkeit, die Aufmerksamkeit u.s.w. prüfen. Andere aber fordern ausgesprochene Denkarbeit: so muss der Inhalt von Bildern oder Bilderreihen erfasst und wiedergegeben werden; eine angefangene Geschichte muss fortgeführt werden; durcheinander gewürfelte Wörter oder Sätze oder Bilder müssen richtig geordnet werden; der Sinn von Fabeln oder Sprüchwörtern muss angegeben werden u.s.w.

Weitere Beispiele für einige der gebräuchlichsten Tests $\left.{ }^{2}\right)$ :

1.) B indewort-Ergänz ung s-Test (nach Minkus und Otto Lipmann). Die fehlenden Wörter sind vom Prüfling einzufügen. „Als wir am Sonntag morgen aufwachten, fragte ich gleich meinen Vater, ob die Sonne scheint - ob es regnet. - das Wetter sehr schön war, und es - regnete - schneite, so wollten wir einen Ausflug machen...."

2.) A n a l o g i e t e s t: $Z$ u drei Wörtern ist das passende vierte $z u$ finden (das vom Prüfling zu findende Wort steht hier in Klammern)

Sturm - Ruhe ......... Krieg - (Frieden)

Arm - Ellenbogen....... Bein - (Knie)

Apfel - Schale ........ Hase - (Fell)

3.) „M a s s l 1 on-T e s t” (Dreiwortmethode): Aus je drei gegebenen Wörtern sind sinnvolle Sätze zu bilden:

Regen, Kälte, zerbrochener Krug.

Pferd, Biene, heruntergefallener Reiter.

Eisenbahnunglück, stehengebliebene Uhr, Freude.

4.) Kritiktest. Aus einem Text sind die widersinnigen Stellen herauszufinden und zu kritisieren.

(Nach Binet:) „Ich habe drei Brüder, Paul, Ernst und ich."

1) Die Methodensammlung Stern-Wiegmann enthält nicht weniger als 451 verschiedene Tests.

2) S. auch S. 321 . 
(Nach W. Stern :) „Ein Herr sagt zu einem anderen : , Ich hörte erzählen, dass Sie von einem Rittergeschlecht aus der Zeit der Kreuzzüge abstammen. Ist das wahr?"' Der Andere antwortete: ,Nein das stimmt nicht, es liegt eine Verwechselung mit meinem Vater vor."

„Der Kirchturm des Dorfes war vor einem Jahr völlig niedergebrannt. Zur Erinnerung hatte man an der Stelle, wo die Turmspitze gewesen war, eine Gedenktafel anbringen lassen."

5.) Der B o ge n's $c h$ e Kä fig (nach Hellmuth Bogen, s. Fig. $11 \mathrm{~S} .432$ ) erlaubt, die praktische Intelligenz zu prüfen, ohne dass irgend welche sprachlichen Leistungen nötig werden. Ein Gestell aus zwei Holzkästen enthält mehrere in Verbindung stehende Abteilungen und schräge Ebenen. Eine Holzkugel ist in der ersten Abteilung, für die Versuchsperson seitlich durch ein Glasfenster und von vorn durch ein Gitter sichtbar. Aufgabe: die Kugel ist von aussen vermittels geeigneter Stäbe so durch das Labyrinth zu leiten, dass sie schliesslich aus der Öffnung der letzten Abteilung (links unten )herauskommt. Neben dem Gestell liegen verschiedene Stäbe zur freien Wahl. Der Test ist sehr geeignet zur Untersuchung Schwachsinniger, Taubstummer, Sprachgestörter.

Man darf nun freilich niemals glauben, mit einem jeden dieser Tests eine bestimmte, eng umschriebene, Teilfähigkeit des Denkens prüfen zu können. Stets sind noch weitere Fähigkeiten beteiligt. So beruht die richtige Bindewortergänzung in Nr. 1 nicht nur auf dem Verständnis für die logischen Verknüpfungen zwischen den Satzteilen, sondern auch auf dem verfügbaren Wortschatz. Bei Nr. 3 ist neben der logischen Kombination auch die Phantasie mehr oder weniger stark beteiligt. Mit Test 4 wird nicht nur die „Kritikfähigkeit” im engsten Sinn, sondern auch das Sprachverständnis, die Ausdruckfähigkeit, die geistige Selbständigkeit (die nicht jedes gedruckte Wort für eine unantastbare Wahrheit hält) und anderes geprüft.

Aber hierin ist keineswegs ein Mangel dieser Tests zu sehen. Sie bieten im Gegenteil eine vorzügliche Gelegenheit, die Denkarbeit in ihrer Komplikation zu beobachten und das Ineinandergreifen der verschiedenen Teilfunktionen zu studieren. Freilich darf man sich dann nicht damit begnügen, für jede Leistung eine Bewertungsziffer aufzustellen. Sehr oft kann eine Testlösung, welche nach dem Bewertungsschema als Fehlleistung oder mangelhafte Leistung zensiert wird, darauf beruhen, dass a n d e r e Denkwege als die erwarteten eingeschlagen werden, die aber in Hinblick auf die Altersstufe oder die besondere Geistesart des Prüflings positive Bedeutung haben können. 


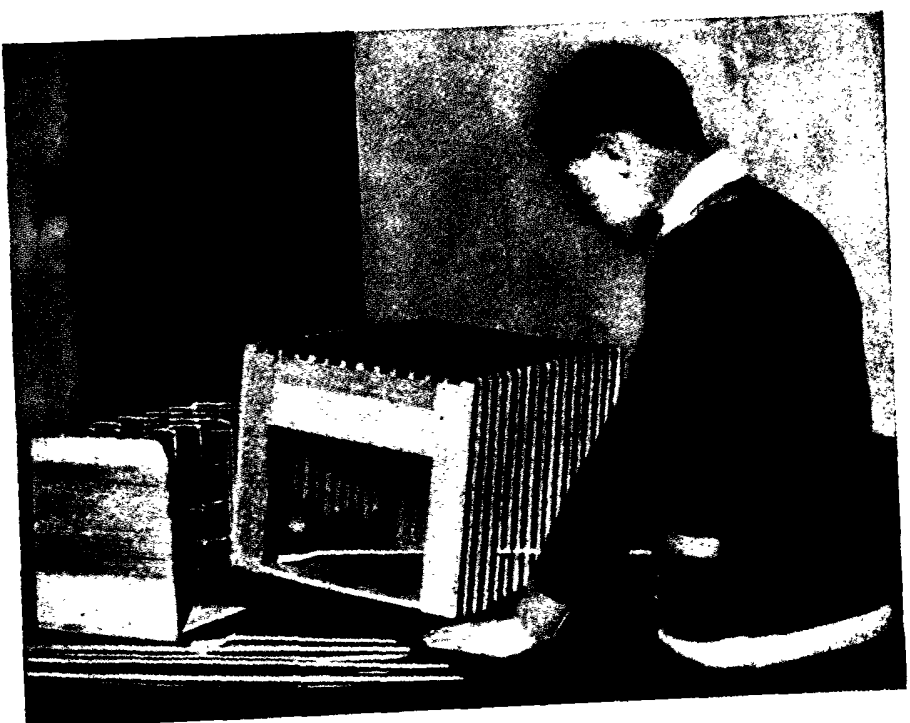

Fig. II. Prüfung der praktischen Intelligenz am „Bogen'schen Käfig”. 
So liefern z.B. Kinder bei dem Analogietest (Nr. 2) oft unerwartete Lösungen; sie bringen Worte, die zu den drei anderen durchaus nicht in dem geforderten $\mathrm{log}$ i s $\mathrm{ch}$ e $\mathrm{n}$ Verhältnis stehen. Aber dann stellt sich zuweilen heraus, dass die drei gegebenen Wörter im Kinde überhaupt nicht einen diskursiven Denkprozess, sondern ein ganz konkretes $\mathrm{Ph}$ a $\mathrm{n}$ a sie bild einer Situation erzeugt hatten, und dass nun mit innerer Folgerichtigkeit ein zu dieser Situation gehöriges Wort genannt wird.

Sehr instruktiv und reizvoll ist es, Kinder am Bogen'schen Käfig (Test 5) zu beobachten. Das eine Kind starrt nur auf die Kugel, macht den sinnlosen Versuch, sie direkt mit den Fingern durch das Gitter zu holen und bleibt dann ratlos stehen. Ein anderes Kind überschaut zunächst die Gesamtsituation; man kann an seinen Augen- und Kopf-Bewegungen erkennen, wie es im Geiste die einzelnen Teilaktionen vorwegnimmt, ehe es zur Ausführung schreitet. Auch in der Wahl der Werkzeuge bekunden sich grosse Intelligenzunterschiede; bald wird wahllos irgend ein Stab ergriffen und trotz seiner Ungeeignetheit beibehalten; bald wird sorgfältig ausgesucht oder nach einem ersten Misserfolg das Werkzeug gewechselt.

So kann gerade die sorgsame Beobachtung während der Arbeit und die eingehende Analyse der Testergebnisse den Einblick in die geistigen Fähigkeiten von Jugendlichen und Erwachsenen wesentlich vertiefen.

\section{T a le nte}

a) W e s e n d e s T a l e $\mathrm{n} t \mathrm{~s}$. - Neben der Intelligenz und ihren typischen Ausprägungen gibt es noch eine andere Gruppe von geistigen Begabungen, die Talente. Während die Intelligenz das Gesamtverhalten des Menschen bestimmt, ist das Talent i n$\mathrm{h}$ altlich begrenzt; es erstreckt sich nur auf eine Teilsphaere der Person. So hat der eine sprachliches Talent, ein anderer musikalisches, ein dritter technisches Talent u.s.w. Ein und derselbe Mensch kann sogar mehrere Talente haben, z.B. zugleich mathematisches und musikalisches Talent.

Das Talent ist also in seinem Wirkungskreis beschränkter als die Intelligenz, dafür aber tiefer in der Person verankert, weil es nicht nur eine Rüstungsdisposition, sondern zugleich eine Rich- 
tungsdisposition ist. Im Talent drückt sich das besonders enge Verhältnis einer Person zu einer Kultursphaere aus, ein Verhältnis, in welchem Liebe zum Gegenstand und Fähigkeit zu seiner Bemeisterung normaler Weise unscheidbar verschmolzen sind. Daher ist es fast nie mehr auseinanderzuhalten, ob die Neigung (zur Musik, zum Malen, zum Bauen, zur Rhetorik u.s.w.) die entsprechenden Fähigkeiten angeregt und gesteigert hat, oder ob umgekehrt die besondere Begabung für bestimmte Leistungsweisen und der erfolgreiche Fortschritt in ihnen die Liebe zu dem Gebiet entzündet hat.

Nur in gewissen aussergewöhnlichen Fällen ist die Verbindung zwischen Neigung und Eignung gelockert oder sogar gelöst. So mancher Mensch lässt eine starke Sonderbegabung ungenutzt, weil ihn keinerlei Interesse zu eingehender Beschäftigung mit dem Gebiet seiner Fähigkeit treibt. Umgekehrt gibt es die „unglückliche Liebe" eines Menschen zu einem Gebiet, für das er nun einmal keine Fähigkeiten besitzt; er mag es noch so sehr umwerben, mag noch so leidenschaftlich musizieren oder malen, sein Bemühen führt zu keiner nennenswerten Fertigkeit.

Zuweilen aber hat dieses Werben doch Erfolg; dann kommt es zu jener Erscheinung, welche die Individualpsychologie als „Überkompensation einer Minderwertigkeit" bezeichnet. Gerade ein M a n g e 1, der ein bestimmtes Können zunächst erschwert, spornt dann alle Kräfte an, um ihn zu überwinden; Ehrgeiz, Fleiss und Trainung führen schliesslich zu beträchtlichen Leistungen. So findet man unter Sportsmännern zuweilen Menschen von ursprünglich schwächlicher Konstitution, deren grosser Erfolg ohne den verbissenen, nie erlahmenden Kampf gegen ihre Schwäche nicht möglich wäre. Auch im Geistigen mag es gelegentlich Ähnliches geben.

Aber in allen diesen Fällen ist doch die individualpsychologische Behauptung anzuzweifeln, als ob die ursprüngliche Minderwertigkeit geradezu die U r s a c h e der späteren Hochleistung sein könnte. Vielmehr wird der Kampf gegen die Schwäche nur dann mit solcher Intensität aufgenommen, wenn andere Dispositionen zu jener (durch die Schwäche erschwerten) Betätigung d r ä n g e n. Jener Sportmann, von dem wir oben sprachen, kann sehr wohl eine ursprüngliche sportliche Begabung und Neigung haben; aus dieser heraus wird er nun freilich bedeutende Kräfte 
aufwenden, um das Hindernis der schwächlichen Konstitution zu überwinden.

Auch das immer wieder zitierte Beispiel von Demosthenes ist ähnlich zu interpretieren. Demosthenes hatte bekanntlich einen schweren Sprachfehler; aus der Hartnäckigkeit, ihn durch Redeübungen zu überwinden, soll dann seine glänzende Rednergabe entstanden sein. Wahrscheinlich wird es wohl umgekehrt gewesen sein: das, als D i sp os it i o n vorhandene, Rednertalent machte die gewaltigen Energieen frei, die zur Überwindung äusserer Hemmungen nötig waren.

Die Unterschätzung der ursprünglichen Anlagen ist ein charakteristischer Zug der Individualpsychologie, die alles wesentliche Können des Menschen auf Trainung bezw. Ermutigung zurückführen möchte. In Wirklichkeit tragen stets beide Faktoren gemeinsam bei zur Entwicklung der menschlichen Fertigkeiten.

b) Häufigkeitsverteilung der Talente. Auch dieses Problem wird kompliziert durch die Spannung zwischen inneren Anlagen und äusseren Einflüssen. Wie gross der Prozentsatz der musikalischen Menschen (oder der zeichnerischen Begabungen u.s.w.) sei, ist deshalb kaum angebbar, weil wir nicht wissen, wieviele wertvolle Anlagen durch mangelnde Ausbildung oder gar durch Unterdrückung unverwirklicht bleiben. Sehr charakteristisch für diese Problematik ist die Entwicklung des Schreibenkönnens. In früheren Jahrzehnten und bei primitiven Völkern galten und gelten die Schreibkundigen nicht nur als besonders geschult und gelehrt; sondern man schreibt ihnen auch eine besondere $\mathrm{G}$ a b e $\mathrm{zu}$, gleichsam ein Maltalent für die geheimnisvollen Zeichen. Heut wissen wir, dass es dazu keiner Sonderfähigkeit bedarf, die nur einem Bruchteil der Menschen vorbehalten wäre, sondern dass jeder normale Mensch das Schreiben lernen kann.

Auch das eigentliche zeichnerische Talent ist lange Zeit stark vernachlässigt worden. Als Kerschensteiner vor drei Jahrzehnten die zeichnerische Begabung sämtlicher Münchener Volksschulkinder mit Aufgaben untersuchte, die von den damals üblichen, sehr unvollkommenen Methoden des Zeichenunterrichts abwichen, entdeckte er eine Reihe von starken Talenten, die der Schule entgangen waren. Diese psychologischen Untersuchungen haben seiner Zeit mit dazu beigetragen, den Zeichenunterricht in den deutschen Schulen zu reformieren. Seitdem ist nicht nur die Freude am Zeichnen mächtig gestiegen; sondern es ergab sich auch, dass 
zahlreiche, früher als unbegabt geltende, Kinder merkliche zeichnerische Begabung besassen.

Natürlich bedeutet das nicht, dass man aus allen Kindern durch Schulung kleine Raffaels machen könnte. Möglich ist die Hebung des Gesamtniveaus und die Freisetzung jener, früher vernachlässigten, Fähigkeiten, die in allen Menschen ruhen. Die höheren und höchsten Grade des zeichnerischen, ebenso wie jedes anderen Talents werden aber stets nur einer Minderheit von Menschen zukommen; und dies kann auch durch eine noch so umfassende und psychologisch adäquate Schulung nicht geändert werden.

Unter diesem Gesichtspunkt ist auch die Formel, die man zuweilen von begeisterten Reformern der Musikpädagogik hört, zu beurteilen: es gebe eigentlich keine „unmusikalischen” Menschen, alles komme nur auf die musikalische Erziehung an. In Wirklichkeit gibt es eine - allerdings kleine - Anzahl von Menschen, die hoffnungslos für alle Musik unempfänglich und für Musizieren absolut untauglich sind; ihre "Amusie" ist unheilbar. Dann gibt es aber sehr zahlreiche Menschen, welche eine gewisse Freude an Musik haben und es auch zu einer gewissen Fertigkeit im Singen und im Spielen eines Instrumentes bringen können; in dieser Gruppe hat Erziehung eine weitgehende Bedeutung. Die eigentliche $\mathrm{Musikalit}$ ä $\mathrm{t}$ aber ist nun doch wieder der besondere Besitz einer Minderheit. Ihr Wesen besteht gerade in dem, was $\mathrm{n}$ i c h t erlernbar ist; sie ist auch keine blosse Fähigkeit, sondern ein Leben in Musik, ein Nichtlebenkönnen ohne Musik. Das musikalische „Talent” im engeren Sinne geht nur als Teildisposition in diese personale Gesamteinstellung ein.

Entsprechende Betrachtungen lassen sich über jedes andere Talent anstellen.

c) A nalyse der Ta le n t e. — Wenn auch jedes Talent die einheitliche Gesamthaltung einer Person zu einem Kulturgebiet bedeutet, ist innerhalb seiner doch eine grosse Mannigfaltigkeit von Teilfähigkeiten und Tendenzen zu unterscheiden. Auchdie Talente sind also p r of i l i e r t; zwei Menschen, die ein Talent in ungefähr gleich hohem $\mathrm{Gr}$ a d e besitzen, können dennoch in ganz verschiedener $\mathrm{W}$ e i s e talentiert sein.

Die Einzelfähigkeiten eines Talentes sind zum Teil einer Gradmessung fähig. 
Man betrachte z.B. die Aufzählung der Teilfähigkeiten des musikalischen Talents, die S. 18 gegeben worden ist: von diesen sind Unterschiedsempfindlichkeit und Tongedächtnis mit bekannten Methoden messbar. Für die Prüfung rhythmischer und melodischer Begabung sind in neuerer Zeit ebenfalls exakte Verfahrungsweisen mit Erfolg angewandt worden $\left.{ }^{1}\right)$.

Ein interessantes Teilergebnis sei erwähnt. Es erwies sich, dass die rhythmische Begabung viel stärker im Angeborenen verankert und daher viel weniger durch Erziehungs- und Entwicklungseinflüsse zu steigern ist. Während daher die Fähigkeiten der Kinder im Wiedererkennen und richtigen Hervorbringen von Melodieen mit steigendem Alter deutlich zunahmen, zeigte sich bei den $\mathrm{rhythmischen} \mathrm{Leis-}$ tungen kein nennenswerter Altersfortschritt. Manche sehr kleine Kinder überragten infolge ihrer angeborenen rhyth mischen Fähigkeit weit den Durchschnitt von höheren Altersstufen.

Bei den Teilfunktionen höherer Art, wie Affekterregbarkeit, Musikverständnis, kompositorische Begabung, versagt freilich das Messen, und man ist auf Schätzung und auf qualitative Beurteilung angewiesen. Dies gilt erst recht von der Beurteilung der Begabung im ganzen. Die Ziffer, mit der bei der Aufnahme in eine Musikschule die Begabung eines Kandidaten im ganzen bewertet wird, ist psychologisch als eine sehr zweifelhafte Grösse anzusehen. Denn das Gesamtbild der Begabung ist nun einmal nicht durch blosse Summierung der Teilleistungen als Mosaik zu gewinnen; vielmehr hängt die Rolle, die eine Teilfähigkeit innerhalb des Talentes spielt, von der Struktur des Talentes und seiner Verankerung in der Person ab.

Gewiss fordert das Leben zuweilen solche Totalziffern für den Grad eines Talentes (so z.B. auch bei Berufseignungsprüfungen). Man muss sich dann aber immer davon Rechenschaft geben, wie unvollkommen, psychologisch gesehen, ein solcher diagnostischer Index ist.

Die verschiedene Profilierung führt wieder innerhalb jedes Talents zu $\mathrm{t}$ y $\mathrm{p}$ is $\mathrm{ch}$ e $\mathrm{n}$ Differenzierungen.

Wir wählen hier als Beispiel die Begabung für die optischen Künste. Den Hauptkunstgebieten: Malerei, Zeichnung, Plastik,

1) Es sei u.a. auf die Untersuchungen und Methoden von Seashore, Révész, Rupp hingewiesen. Aus unserer Hamburger Arbeit nenne ich die Arbeit von Prager uiber rhythmische Begabung und die umfassende Untersuchung Brehmers über melodische Begabung im Kindesalter. 
Architektur, Kunstgewerbe entsprechen sehr verschiedene Begabungsrichtungen; und es kann ein Künstler selbst als Maler vornehmlich dem zeichnerischen, als Zeichner dem malerischen Typus angehören. Nach anderen Gesichtspunkten kann man (ähnlich wie bei der Intelligenz) den Subjektivisten und den Objektivisten, den Analytiker und den Synthetiker unterscheiden. Im Verhältnis zur sichtbaren Welt gibt es alle Abstufungen: den reinen Kopisten, den Naturalisten, den Phantasten, den Expressionisten. - Gewiss sind auch solche Talenttypen zum Teil von Strömungen und Moden abhängig; so schien in einer gewissen Epoche die Mehrzahl aller Maler zum expressionistischen Typ zu gehören. Aber auch jenseits dieser Einflüsse gibt es eine angeborene Tendenz zur Betätigung des Talentes in dieser oder jener Weise.

Im Grossen und Ganzen betrachtet, besteht die Psychologie der Talente zur Zeit noch weit mehr in Problemen als in Ergebnissen. Hier ist in der Zukunft noch viel zu tun.

\section{TIERISCHE INTELLIGENZ}

\section{Das Problem}

Ist der Intellekt eine nur-menschliche Eigenschaft? Vermag a llein der Mensch zu denken, nicht aber das Ti e r? Diese Frage lässt sich nach dem Stande der heutigen Psychologie nicht mehr so glatt mit Ja oder Nein beantworten, wie es frühere Zeiten wagten. Es waren weniger psychologische als weltanschauliche Interessen ${ }^{\mathbf{1}}$ ), welche dem Tier das Denken bald völlig absprachen, bald in einer ganz menschenähnlichen, höchstens graduell geringeren Weise zusprachen.

Erst die letzten Jahrzehnte haben in unbefangener Forschung die Frage geklärt; man kann heut schon mit Sicherheit sagen, dass beide eben erwähnten Dogmen fehl gehen. Zwar gibt es eine intellektuelle Grenze zwischen Mensch und Tier; aber diese liegt nicht zwischen Denkenkönnen und Nicht-Denkenkönnen, sondern in ner halb der Denkfähigkeit selb e r: zwischen vitalem, konkret-praktischem, unformuliertem, gegenwartsgebundenem Reaktions-Denken - und dem überbio-

1) Vgl. S. 55. 
logischen, abstrakt-logischen, sprachlich formulierbaren, zeitüberlegenen Spontandenken.

Freilich sind selbst jene vormenschlichen Urformen primitiven Denkens mit Sicherheit nur bei wenigen sehr hoch organisierten Tierarten und Tierindividuen, und auch bei diesen nur als relativ seltene psychische Spitzenleistungen nachgewiesen worden, über die gleich zu berichten sein wird. Was sonst als tierisches „Denken" angesehen wird, beruht zum Teil auf vagen Vermutungen, zu einem anderen Teil auf offenkundigen Fehldeutungen tierischer Verhaltungsweisen. Zeigen diese nämlich eine äussere Ähnlichkeit mit solchen Handlungen des $\mathrm{M}$ en s c he n, die nur unter starkem Denkaufwand vollziehbar sind, dann liegt es nahe, auch beim Tier eine entsprechende „Intelligenz" anzunehmen.

Weite Reise machen, Häuser bauen kann der Mensch nur auf Grund eingehender Planung, Vorüberlegung, denkender Entscheidung. Wenn nun Zugvögel weiteste Reisen mit Rückkehr an den Ausgangspunkt vollbringen, wenn Bienen ihre Waben, Vögel ihre Nester auf das $Z$ weckmäIsigste bauen - sind das nicht dann ebenfalls Denkleistungen, und zwar um so imposantere, als die sonst für solche Denkvollzüge nötigen Voraussetzungen (Sammeln von Erfahrungen, kulturelle Úberlieferung, sprachliche Verständigungsmöglichkeit) völlig fehlen?

Wir werden uns mit dieser geheimnisvollen Leistung anderwärts zu beschäftigen haben, (beim Kapitel In s t i n k te); in das Reich der Intelligenz gehören sie $\mathrm{n}$ i $\mathrm{ch}$ t. Denn es handelt sich hier nicht um das Fertigwerden mit Neuem, sondern im Gegenteil um ein selbstverständliches Eingespieltsein auf konstant bleibende Lebensbedingungen, um ein inneres Funktionieren, dessen Zielstrebigkeit des individuellen Denkens nicht bedarf, weil es in tiefen Erbschichten jedes Individuums gattungsmärsig verankert ist. Die bemerkenswerten Untersuchungen J. v. Uexkülls und anderer über die tierische Umwelt haben gezeigt, wie weit dieser Einklang der tierischen Individuen mit ihrer „Merk- und Wirk-Welt" reicht. Ein Lebewesen, das über eine solche E i nGepasstheit in eine ausserordentlich einförmige und durch die Generationen stabile Welt verfügt, hat nicht die A n-Passung an neue Weltkonstellationen durch eigene Denkakte nötig. 


\section{Einsicht}

Schwieriger wird das Problem tierischer Intelligenz bei jenen Tierarten, die bereits des Le rn ens fähig sind. Wer „lernt", gewinnt allmählich Fertigkeiten, die er früher nicht besass; hier bricht also schon „Neues” in das Leben des Individuums ein. Aber die Einförmigkeit dieses äusseren Sachverhalts darf nicht die grosse Mannigfaltigkeit der Formen verdecken, die sich im tierischen Lernen finden. Die Hauptstufen der mnemischen Leistungen von Tieren: Umgewöhnung, Vertrautheitshaltung, Zähmung und Dressur, haben wir bereits an anderer Stelle besprochen; dort wurde auch (S. 267) der Punkt erwähnt, bei dem die eigentliche Intelligenzproblematik einsetzt: die Möglichkeit, dass bei höheren Tieren diese Lernvorgänge "durch den Einschlag der E i ns i c h $t$.... eine andere Struktur erhalten".

Mit dieser aufblitzenden Einsicht ist in der Tat ein Sprung in den tierischen Lernleistungen festzustellen. Ein sorgsamer Beobachter kann es sehr wohl dem äusseren Verhalten eines in Dressur befindlichen Tieres anmerken, ob es lediglich von einer werdenden Gewohnheit getrieben wird (die auch sinnlose Teilhandlungen enthalten kann, und zuweilen durch völlig fehlgehende Handlungen unterbrochen wird), oder ob das Tier nun „,heraus hat, worauf es ankommt" und nicht nur objektiv zielgemäls, sondern s u b j e kt iv zielstrebig handelt. Auch Tiere können zweifellos „Aha"-Erlebnisse haben und nun plötzlich die Art des Handlungsvollzugs aus blindem Automatismus in sinnvolle Zuordnung von Mittel und Zweck verwandeln. Wir sind wohl gezwungen, hier allererste Anfänge von denkartigen $\mathrm{A}$ b 1 ä u f e $n$ anzusetzen, so wenig wir auch etwas aussagen können über den tatsächlichen Bestand von psychischen Bewusstseins-I $n$ h a 1 t e $n$ gedankenmäfsiger Natur.

Der Denkanteil bei andressierten Handlungen kann sich auch darin zeigen, dass eine gewisse $\mathrm{Spi}$ elra u mbreit e des $\mathrm{H}$ a n d e $\mathrm{ln} \mathrm{s}$ erworben wird, sodass auch bei Änderungen der Situationsbedingungen dennoch sinngemälser Vollzug möglich bleibt. So hatte Sarris einen Hund darauf dressiert, auf die Worte "geh auf Stuhl", auf einen Stuhl zu springen und sich dort niederzusetzen. Das Tier konnte nun diesen Befehl auch ausführen, wenn der Stuhl durch Einhüllung in Papier merklich verändert 
wurde, wenn er ganz unter einen Tisch gerückt war, sodass ein anderes optisches Gesamtbild vorlag, wenn der Stuhl durch einen lehnenlosen Schemel ersetzt war; ja, als weder Stuhl, noch Schemel im Sichtbereich war, benutzte das Tier in Ausführung des Befehls die untere Etage eines Regals. Da hierbei zwischen Hören des Wortes und der Ausführung des Befehls ganz offensichtlich Intervalle des $\mathrm{S} u \mathrm{ch}$ e $\mathrm{n} \mathrm{s}$ eingestreut waren, so wird man annehmen müssen, dass sich im Tier die reflektorische Verbindung: Befehlsworte/Stuhl sublimiert hatte zu der Ein sich t: Aufforderung, Sitzgelegenheit zu suchen.

Aber mit dem sinnvollen Lernen und der Auflockerung der Dressur ist noch nicht die Möglichkeit tierischer Intelligenzleistung erschöpft. Bei aller Dressur wird immerhin der Zusammenhang von Mittel und Zweck dem Tiere von aussen d a r g e b ot e $n$ und erst nachträglich von diesem vers t a nden. Ein Tier kann aber unter Umständen einen solchen Zusammenhang selber $\mathrm{finden}$; es kann von sich aus wi rkliche $\mathrm{Neu-}$ h a n d l u n g e $n$ sinnvoller Art ausführen.

Solche Feststellungen sind vor allem bei Affen und Hunden gemacht worden.

Bahnbrechend waren hier die Versuche, die Wolfgang Köhler an Schimpansen anstellte. Den Tieren wurden beliebte Genussmittel (Bananen) unter sehr erschwerten Bedingungen dargeboten, sodass sie mit ihren instinktiven Mitteln (Greifen, Klettern) nicht an sie herankommen konnten - sie fanden dann von sich aus neue und zweckmälsige Wege zur Erreichung des Ziels und benutzten sogar dafür verfügbare Gegenstände als Werkzeuge. So wurde ein Bambusstock herangeholt, um als Angel nach der weit vor dem Käfig liegenden Banane zu dienen; und als e i n Stock nicht reichte, kam ein besonders intelligenter Affe ganz von selbst sogar darauf, das Werkzeug durch Ineinanderstecken zweier Stäbe zu verlängern. - Um das an der Decke hängende Ziel zu erreichen, wurde eine Kiste unter die Banane geschoben, dann sogar noch eine zweite darauf gesetzt u.s.w.

Sarris hat vor den Augen seiner Hunde ein Stück Fleisch unter einen umgestülpten Blechtopf gelegt, der oben mit Steinen beschwert war. Während die weniger intelligenten Hunde nicht über den immer wiederholten, vergeblichen Versuch hinauskamen, den Topf direkt an dem unteren Rande, wo sie das Fleisch rochen, 
umzuwerfen, haben einige Hunde von selbst die Steine als Behinderung erkannt und erst diese einzeln hinuntergeworfen (mit jedesmaligem Versuch, ob der Topf jetzt beweglich sei) und schliesslich so ihr Ziel erreicht.

In allen diesen Fällen wurden Dressur und Gewöhnung auf das Ängstlichste vermieden. Wohl ist es möglich, dass dem Tiere in seinen unablässigen und zunächst ungeordneten Bestrebungen, das Ziel zu erreichen, einmal z u f ä $1 \mathrm{li} g$ die zweckmälsige Bewegung giückte; aber selbst in solchen Fällen war es bemerkenswert, dass dann sofort das Aha-Erlebnis einschnappte und nun das weitere Tun offensichtlich einsichtsvoll vor sich ging.

Für die Probleme der mens chlichen Intelligenz sind diese Höchstformen tierischer Denkleistungen aus zwei Gründen von grosser Bedeutung.

Entwicklungspsychologisch zeigt sich eine grosse Ähnlichkeit mit den primitivsten Formen menschlicher Intelligenz, wie wir sie namentlich beim Kleinkind beobachten können. Auch hier das allmähliche E i n i c h t i g w e r d e n solcher Vollzüge, die zunächst nur angelernte sinnlose Dressurkunststücke gewesen waren; auch hier erste Versuche, eine Bedürfnisbefriedigung, die auf direktem Wege nicht glückt, auf indirektem Wege mit Hilfe eigener $\mathrm{Erfind} \mathrm{u} g$ zu erreichen. Auch hier jene enge B eg r e n z the it der Denkvollzüge, die uns zum folgenden Gesichtspunkt überleitet.

4. Die Grenzen des tierischen Intelligenz

Da wir nunmehr wissen, was tierisches Denken be st e nf a 11 s leisten kann, sind auch die Gre n z e n gegen die vollentwickelte menschliche Intelligenz deutlich zu ziehen. Es ergeben sich folgende Hauptunterscheidungspunkte:

1) Eigentliche Denkleistungen sind beim Tier nur A u s n a h$\mathrm{m} \mathrm{e} \mathrm{h} \mathrm{a} \mathrm{n} \mathrm{d} \mathrm{l} \mathrm{u} \mathrm{n} \mathrm{g} \mathrm{e} n$, seltene Einbrüche in eine sonst denkfreie Lebensführung. Sie spielen daher in der Gesamtstruktur des tierischen Individuums nicht annähernd die Rolle, wie im Gefüge der menschlichen Person.

2) Denkvollzüge treten beim Tier nur in engstem Zusammenhang mit biologisch stark betonten Bedürf$\mathrm{n}$ i s s e n auf, und zwar immer erst dann, wenn sich das Bedürfnis 
nicht auf unmittelbarem Wege befriedigen lässt. Nur aus der Stärke des, zunächst gestauten, Bedürfnisses erwächst dem Tiere der Kraftaufwand, der für einen Denkakt nötig ist. Wir hatten im Gegensatz hierzu gesehen, dass der menschliche Intellekt sehr bald die Grenze vitaler Gebundenheit überschreitet, objektive Ziele sich setzt und verfolgt und schliesslich im theoretischen Denken einen selbständigen Eigenbereich seiner Betätigung schafft. Von alledem ist beim Tier auch nicht die geringste Spur vorhanden.

Eine seltsame Verirrung hat dazu geführt, tierische Intelligenz gerade auf Gebieten zu suchen, die garnichts mit der biologischen Bedürfnissphäre des Tieres zu tun haben. So haben "sprechende" und „rechnende" Pferde und Hunde längere Zeit eine gewisse Berühmtheit erlangen können. Diese Tiere hatten angeblich gelernt, durch Klopfen mit dem Hufe (bezw. der Pfote) eine Zahl als Ergebnis einer optisch gestellten Rechenaufgabe, oder die Ordnungszahl eines Buchstabens im ABC anzugeben und durch solche "Buchstabiermethode” Worte zusammenzusetzen. Sogar das Ausziehen von Kubikwurzeln, die Wiedergabe fremder, dem Tier einmal gesagter Namen und Ähnliches sollte auf diesem Wege möglich sein. Alle ernsthaften Psychologen sind davon überzeugt, dass es sich hier nur um Dressurleistungen handeln konnte, indem die Tiere gelernt hatten, auf die unwillkürlichen Spannungs- und Erwartungshaltungen des „Lehrers” beim Eintreten des kritischen Fussschlages weiteres Klopfen zu unterlassen. Gerade wenn man es für möglich hält, dass Pferde und Hunde zu gewissen Denkleistungen in $\mathrm{n}$ e $\mathrm{r}$ a $1 \mathrm{~b}$ ihrer Biosphäre fähig sind, wird man die Absurdität doppelt empfinden, dass sich ihr Denken auf solche ganz abseitigen, zu ilırem tierischen Dasein ganz disparaten Gebiete wie Rechnen und Buchstabieren erstrecken sollte, und dass sie - was bei echtem Denken zu erwarten wäre - ihr unerhörtes Können in keiner Weise zur Umgestaltung ihres Daseins verwerteten. Niemals hat eines dieser Tiere die Klopfsprache zu wirklichen spontanen Sprachäusserungen, etwa zum Stellen einer Forderung oder Frage, zum Ausdruck eines Wunsches oder Affektes, benutzt!

Vielleicht, dass die Dressur soweit zugleich zu „Einsichten” geführt hatte, dass das Tier nun wusste: mit diesen und diesen Bewegungen oder Bewegungshemmungen ist der Herr zufrieden zu stellen und ist von ihm eine Belohnung zu erwarten. Dann wäre das Fussklopfen für das Tier aus blosser Gewöhnung zu einer sinnvollen Handlung geworden; aber der ,Sinn" war ein ganz anderer, viel primitiverer, und hatte nichts mit „Rechnen" oder „Buchstabieren" zu tun ${ }^{1}$ ).

1) Aus der umfangreichen Literatur erwähnen wir das Buch von Herrn v. Osten über den „, Klugen Hans”, die Publikationem von Krall und seiner Anhänger über die "Elberfelder Pferde" und die gründliche, auf eingehenden Experimenten beruhende Widerlegung durch $O$. Pfungst. 
3) Tierische Denkvollzüge sind durchaus a n s c h a u li c h e r Natur: in einer konkreten Situation wird eine konkrete Lösung gesucht. Wenn wir oben von einer gewissen „Verallgemeinerung” sprachen (bei dem Hund, der auf die Aufforderung ,geh auf Stuhl" verschiedenartige Objekte als Stuhl behandelte), so liegt in keiner Weise jene Abstraktion vor, die zu dem „allgemeinen” Begriff Stuhl geführt hätte, sondern lediglich eine gewisse Spielraumbreite des praktischen Tuns, das aber in jedem einzelnen Falle durchaus konkret bleibt. Kein Hund kommt zu dem „Gedanken": Stuhl ist eine (von der jeweiligen Form unabhängige) Sitzgelegenheit. Diese Unfähigkeit ist identisch mit der Unfähigkeit zur Sprache; sahen wir doch oben, dass eine Voraussetzung alles Sprechens darin besteht, Zeichen zu besitzen für fixierte, verselbständigte und von den Zufällen des Augenblicks abstrahierte Gedanken.

4) Tierisches Denken ist G e g e n w a r t s denken. Denn Anschaulichkeit (siehe Punkte 3) ist ja nur in der Gegenwart, im Hier und Jetzt möglich. Dass „Gegenwart” kein Punkt, sondern die Zeitspanne eines in sich zusammenhängenden einheitlichen Lebnisses ist, haben wir früher besprochen. Nur innerhalb einer solchen recht engen Frist kann sich ein Tier Denkziele setzen und Denkakte vollziehen. So bleibt dem Affen, der die Banane nicht direkt erreichen kann, diese Banane noch „gegenwärtig” (nämlich Bedürfnisziel), wenn er sich auch momentan von ihr abwendet, um sich nach einem Werkzeug umzusehen, mit dem er nach ihr angeln kann. Aber er vermag z.B. nicht mehr - wenn er sehr durstig ist und es zu regnen anfängt - auf den Gedanken zu kommen, eine Kokosschale in den Regen zu stellen, mit dem Ziel, darin so viel Wasser zu sammeln, dass er $\mathrm{n}$ a $\mathrm{ch}$ einiger Zeit trinken kann.

Gewiss, auch Tiere sorgen vor (z.B. durch Vorratsammeln für den Winter, durch Bauen von Waben für die kommende Brut u.s.w.); auch Tiere beginnen Handlungen auf weite Sicht (Zug der Zugvögel nach dem Süden). Aber gerade diese Zukunftseinstellungen sind beim Tier durchweg und restlos instinktiver Natur, also $\mathrm{n}$ i $\mathrm{c}$ h $\mathrm{t}$ von Einsicht in das späte Ziel und von Planung und Disponierung begleitet.

Wenn man bedenkt, dass die entwickelteren menschlichen Denkvollzuge fast durchweg über die Gegenwart hinausreichen, 
dass der Mensch durch planendes, vorwegnehmendes, vorsorgendes Denken weit hinausgreift in die personale und transpersonale Zukunft, dass dieses „Zukunft-Denken-Können und-Wollen” ihn erst als personalgeschichtliches Wesen konstituiert - dann kann man erst die Weite der Kluft ermessen, die zwischen tierischem und menschlichem Denken besteht. 


\section{ACHTZEHNTES KAPITEL}

P H A N T A S I E

\section{WESEN DER PHANTASIE}

1. Bewusstseinspsychologische

Betracht ung

Die Abgrenzung der Phantasiefunktion gegen die anderen Bereiche des Seelenlebens stösst auf eine eigentümliche Schwierigkeit.

Solange man sich nämlich darauf beschränkt, die B e w u s stse in s - Inhalte und -Abläufe des Phantasielebens zu beschreiben, findet man lediglich Merkmale, die auch in anderen seelischen Provinzen vorkommen. Erst bei der Erweiterung der Betrachtung ins $\mathrm{Pers}$ on ale und $\mathrm{Tr}$ a $\mathrm{nspers}$ on a le treten die eigentlichen Unterscheidungskriterien hervor.

Dem psychischen I $\mathrm{n}$ h a $1 \mathrm{t}$ nach gehören Phantasieerlebnisse vornehmlich in die Kategorie der Vorste 11 u ngen: sie haben k onkreten Gegenstandscharakter, stehen in Gegensatz zur Abstraktheit rein gedanklicher Inhalte. Aber hierin sind Phantasievorstellungen psychisch nicht grundsätzlich anders beschaffen als Gedächtnisvorstellungen oder Erwartungsvorstellungen. Nehmen wir so ausgesprochene Phantasiegebilde wie „Fee" oder „Flügelross”, so ist im Vorstellungsbestand selbst kein Merkmal anzugeben, wodurch sie sich von den Vorstellungen einer wirklichen Frau, eines früher einmal gesehenen Pferdes unterscheiden müssten.

Gewiss können psychologische Unterschiede in der Art der Wirklichkeitsintention bestehen. Es gibt viele Phantasievorstellungen, bei denen zugleich das Bewusstsein vorhanden ist, dass ihnen keine objektive Realität entspreche, dass sie einer Scheinwelt angehören. Dieser - in der Tat sehr wesent- 
liche - Tatbestand muss später ausführlich erörtert werden; aber er liefert nicht das jetzt zu suchende Merkmal, welches Phantasievorstellungen allgemein gegen andere Vorstellungen abgrenzt. Denn das Bewusstsein der Unwirklichke it fehlt of $t$ genug: so bei Erinnerungen, die durch überwuchernde Phantastik gefälscht werden, bei den Wahngebilden der Irren, bei Luftschlössern von Phantasten, bei Traumphantasieen, vielfach auch beim Phantasiespiel des Kindes ohne dass der „Phantasie”-Charakter der Vorstellungen durch die sen Wirklichkeitsglauben aufgehoben würde.

Oder gibt es vielleicht eine psychologisch charakteristische Art des A uftretens, die der Phantasie und nur ihr zukommt?

Man pflegt bei geistigen Prozessen bekanntlich ,intuitive" und „diskursive" Abläufe zu unterscheiden. Bei jenen drängen sich die einzelnen Gestaltungen mit einer Evidenz auf, die keiner Begründung fähig und bedürftig ist: sie sind auf einmal da, bewusstseinsmälsig unvorbereitet und sogleich fertig in geformter Anschaulichkeit, die zuweilen fast die Lebhaftigkeit echter Wahrnehmungen gewinnen kann. Beim diskursiven Ablauf dagegen wird langsam und schrittweise jedes Moment aus den vorhergehenden Momenten entwickelt, das Ganze rational aus den Teilen aufgebaut. Nun sind zweifellos Phantasiegeschehnisse vorwiegend intuitiv, und im Gegensatz dazu Denkgeschehnisse sehr stark diskursiver Natur. Aber schon früher (S. 393/4) hatte sich gezeigt, dass es auch beim Denken nicht ohne Intuition abgeht, die sogar - als „Einfall” - eine selbständige Bedeutung gewinnen kann. Andererseits sind Phantasieabläufe, namentlich solche umfassenderer Art, ohne diskursive Einschläge garnicht möglich. Ferner gibt es auch noch in anderen Seelenbereichen, z.B. beim Gedächtnis, Vorstellungen, die ohne Bewusstseinsvorbereitung (also „intuitiv") auftreten: die sog. freisteigenden Vorstellungen. - Somit ist auch dieser Gesichtspunkt als A b g r e n z u n g skriterium für „Phantasie überhaupt” nicht brauchbar.

\section{Personalistische Betrachtung}

a) Unstimmigkeit zur Objektwelt. - Der eigentliche Sinn des Begriffs „Phantasie" enthüllt sich erst einer personalistischen Betrachtung; denn er betrifft d a s V e r häl t- 
$\mathrm{n}$ is Person/W e $1 \mathrm{t}$. Dort wo die Gegenstandsintention menschlicher Vorstellungen der objektiven Gegebenheit als etwas anderes und Fremdes gegenübersteht, spricht man von Phantasie. Es ist dies zunächst eine Bestimmung von aussen her und zugleich eine negative Abgrenzung: $P h$ a $t$ a si e is $t d a s$ e bie der zur objektiven Welt unstimmigen Vorstellungen eines Menschen. Zur objektiven Welt: das kann bald die praktische Realität sein, in der die harten, von allen anzuerkennenden Gesetze der Tatsächlichkeit gelten; es kann die Welt der sozialen Gemeinschaft sein, deren Úberzeugungen und Wertungen von jedem Glied übernommen werden sollen; es kann die Welt der wissenschaftlichen Erkenntnis sein, die um so reiner ist, je mehr sie entsubjektiviert ist. Sofern sich die konkrete Vorstellung eines Menschen mit solchen Objektivitätsansprüchen nicht deckt, ist sie ein „Ph a n t a s m a”; und die aus solchen Phantasmen sich aufbauende personale Welt ist eine „Phantasiewelt", eine unobjektive Welt. ${ }^{1}$ )

Während also (s. S. 447) für den phantasierenden Menschen selbst die $\mathrm{E}$ in s i ch t in den mangelnden Objektivitätscharakter seiner Vorstellungen nicht notwendig ist, sehen wir jetzt, dass für seine E ingli ed e r ung in die Welt des Handelns, der Gemeinschaft und der Wissenschaft die Nichtobjektivität seiner Phantasievorstellungen wesentlich ist.

Dieser Zug führt leicht zur A b w e r $\mathbf{t} u \mathbf{n g} \mathrm{d}$ e r $\mathrm{P}$ h a n t asi e, nämlich überall dort, wo allein Bewertungsmalstäbe der praktischen, sozialen oder theoretischen Objektivität vorherrschen.

Es gibt $\mathrm{S}$ i t u a t i o n e $n$, in denen die Phantasie gefährlich werden kann, weil alles auf Einstimmigkeit der Bewusstseinsinhalte mit der Realität ankommt; so bei Aussagen über vergangene Tatbestände, bei Entscheidungen über bevorstehende Handlungen, bei Verifikation wissenschaftlicher Hypothesen. Der phantasierende Zeuge, der phantasierende Spekulant, der phantasierende Forscher können mit ihren Phantasieen grossen Schaden anrichten.

Es gibt ferner $\mathrm{M}$ e nschen von so realistischer Grundbeschaffenheit, dass sie an der Phantasie nur jene Unstimmigkeit

\footnotetext{
1) Von einer anderen Art der Objektivität, zu der die Phantasiebetätigung eine sehr positive Beziehung hat, wird erst später zu sprechen sein.
} 
zur Realität und zu allgemeinen Geltungen sehen und sie deshalb geringschätzen: es sind dies die Tatsachenmenschen, die nüchternen Beobachter, die reinen Zwecknaturen, Philister, Pedanten einerseits, - die Prinzipienmenschen, Moralisten, reinen Theoretiker, Logizisten andrerseits.

Allein diese negative Bewertung der Phantasie ist nur so lange möglich, als man das Grundverhältnis Person/Welt lediglich von der Objektseite her - also äusserlich - beachtet. Jetzt aber erheben sich erst die personalistischen Fragestellungen im engsten Sinne: Wie ist es möglich, dass jede Person eine Vorstellungswelt hat, die zur objektiven Welt unstimmig ist? (Ursachfrage). Und: was bedeutet diese nicht-objektive Bewusstseinswelt für die Person selber? (Sinnfrage).

b. S p o n $t$ a n e it ä $t$. - Die Antwort auf die Ursachfrage lautet: Phantasiegebilde sind konkrete Eigenerzeugnisse der Person, welche die Erfahr ungen übers chreit e n. Hier wird also der Unterschied zu den Wahrnehmungen, Gedächtnis- und Erwartungs-Vorstellungen deutlich, welche sämtlich auf Erfahrung - d.h. lebendigem Kontakt der Person mit der ausserpersonalen Welt beruhen. Man verstehe diese Beziehung zur „Erfahrung” nicht falsch. Auch Wahrnehmungen und Gedächtnisvorstellungen sind nicht - das haben ja frühere Kapitel eingehend gezeigt - blosse, passiv empfangene Impressionen und deren Nachwirkungen; in aller „Erfahrung" sind die Reize bereits personal verarbeitet. Aber auch noch diese geformte Erfahrung wird überschritten in der Phantasie. Uberschritten - nicht etwa negiert. Vielmehr werden in der Uberschreitung Erfahrungsmomente fortwährend benutzt, um in neue Gebilde umgegossen zu werden. Diese Beziehung von „alt" und „neu” in der Phantasieschöpfung bedarf einer näheren Betrachtung.

Mechanistisch eingestellte Psychologieen haben früher gerade darauf den Nachdruck gelegt, dass es doch immer wieder Erfahrungs-,Elemente” seien, die nur in neue Kombinationen gebracht würden; eine „Urschöpfung” wirklich neuer Phantasiegebilde sei unmöglich.

Für eine solche Auffassung gibt es zahlreiche Belege. Die schon einmal erwähnte Phantasievorstellung „Pegasus” ist, so scheint 
es, nur eine Addition zweier allbekannter Erfahrungselemente: „Flügel” und „Pferd”; und Homer kann das berühmte Ungeheuer „Chimaere" nicht anders beschreiben als: vorn ein Löwe, hinten eine Schlange, in der Mitte eine Ziege.

Das phantastischste Gedicht besteht aus Worten, die aus der Erfahrung bekannt sein müssen; und selbst sprachliche Neubildungen in diesem sind wiederum nur Zusammensetzungen und Ableitungen aus erfahrungsgegebenen Wörtern. Das phantastischste Märchen arbeitet letzten Endes mit lauter bekannten Elementen, die nur gesteigert oder verkleinert, und vor allem in ganz neue Verknüpfungen gebracht werden. Genau ebenso kann man bei der $Z$ e r le g u n g von Träumen, Luftschlössern, Kunstwerken, Mythen, Hirngespinsten schliesslich überall auf empirisch bekannte Elemente stossen.

Das alles mag zutreffen; aber es ist für die Psychologie der Phantasie sehr wenig belangvoll. Denn es kommt beim Phantasiegebilde nicht sowohl darauf an, w o $r$ a u s es erzeugt sei, sondern wi e aus beliebigem Rohmaterial - mag es noch so bekannt, und mag es noch so dürftig sein - etwas durchaus anderes, Einmaliges, gestalthaft Einheitliches erzeugt wird. Beethovens Sonaten sind darum nicht weniger „neu" und nicht weniger aus ,,Spontaneität"' geboren, weil nur eine kleine Anzahl bekannter musikalischer Töne zur Verwendung gekommen sind. Und was hier vom Phantasie-Werke gilt, gilt gleichermalsen von der $P$ h a n t a s i e-V or s t e 11 u n g. Würde es bei dieser nur darauf ankommen, die aus früheren Erfahrungen stammenden Bewusstseinselemente in eine andere Verknüpfung zu bringen, dann gäbe es ungezählte Möglichkeiten der Gruppierung, und einer jeden würde eine Phantasievorstellung entsprechen. In Wirklichkeit ist es aber das Eigentümliche der Phantasie, dass sie in ihre Gebilde nur solche „Elemente” hineinlässt, die hineinpassen, die von der anschaulichen Ganzheit der Gestalt gefordert, angezogen und aufgesogen werden. Auch sind es ja in Wirklichkeit gar keine „Elemente”, d.h. stabile Steinchen eines psychischen Mosaiks; denn sie werden beim Eingehen in ein Phantasiegebilde etwas anderes, als sie in einem früheren Strukturzusammenhang gewesen waren. Beliebige Flügel, an einer beliebigen Stelle einem Pferd aufgesetzt, ergeben noch lange keinen Pegasus; und noch so viele Erfahrungen, die aus alten Chroniken über den Magier Faust 
zusammengetragen und dann mosaikartig zusammengesetzt werden, ergeben noch lange keinen Goethe'schen Faust als einheitliche Phantasiegestalt.

Es ist also gerade das souveräne Schalten und Waltenkönnen mit dem Rohmaterial der Erfahrung, in dem sich der p r o d u kt i v e Charakter jeder Phantasieleistung bekundet. Der Mensch ist viel zu innig der objektiven Welt zugänglich und verbunden, als dass er sich den aus ihr stammenden Erfahrungen einfach verschliessen könnte; genug, dass er über sie hinauszugehen und sie völlig unzuwandeln vermag, und dass er spontan solche Bewusstseinsgebilde erzeugen kann, die keine geringere Anschaulichkeit, Evidenz und Gestaltetheit besitzen, als die erfahrungsgebundenen Inhalte.

c. S y m p t o m a t i k u n d S y m bolik. - Nunmehr wird gerade das, was vorher als Manko der Phantasie erschien, zu ihrem positiven Merkmal: die Schwäche der Nicht-Objektivität

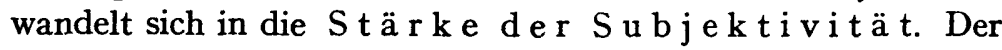
phantasierende Mensch errichtet sich in seinem Bewusstsein eine Eigenwelt, die - gerade weil er sie mit keinem anderen teilt als eine Erweiterung dèr individuellen Persönlichkeit und zugleich als deren Schutzhülle erlebt wird; denn ohne sie wäre er nackt und unvermittelt der Härte der gegebenen, geforderten und fordernden Objektwelt ausgeliefert. Gerade diese personale Bedeutung der Phantasie wird uns das Verständnis für ihre Einzelerscheinungen wesentlich erleichtern. Denn wir erkennen jetzt, dass es sich nicht um eine, neben allen anderen Personbereichen stehende, Sonderkraft handelt, die ein Zufallsspiel mit allerlei Vorstellungen ermöglicht, sondern um eine Erlebnisweise, die aus den Tiefen personalen Totalstrebens herauswächst und formal wie inhaltlich aus diesen Tiefen gespeist wird. W i e e i n Mensch phantasiert, so ist er - so ist er zum mindesten unter einer bestimmten Perspektive, nämlich als Wunsch- und Angst-Wesen, als Gestalter seiner binnenseelischen Welt im Sinne seiner Lebensbedürfnisse, Triebrichtungen und Ideale.

Diese, in die Tiefe der Person weisende Gerichtetheit der Phantasie verleiht ihrem Inhalt nun eine $\mathrm{s} \mathrm{y} \mathrm{m} \mathrm{bolis} \mathrm{che} \mathrm{Bedeu-}$ tung. Jedes Phantasma erhält damit einen Doppelcharakter: es 
ist nicht nur eine konkrete Vorstellung, die einen scheinrealen $\mathrm{G}$ e g e n s t a n d meint, sondern zugleich auch eine Projektion einer personalen $Z$ uständlichkeit in die Sphäre bildhaften Vorstellens. Uber ihren konkreten Inhalt hinaus weist die Phantasievorstellung auf etwas, das nicht in gleicher Weise dem Erlebenden bewusst und für andere Menschen beobachtbar ist. Eine und dieselbe Phantasievorstellung vermag ganz verschiedene Tiefenvorgänge zu repräsentieren; so können etwa jene schreckenerregenden Dämonengestalten, die im Mythos, im Traum, im Kinderspiel begegnen, zugleich mit Machtwünschen, Ängsten, wollüstigem Grauen, sadistischen oder masochistischen Triebregungen zu tun haben. Andrerseits kann dieselbe personale Regung sich in verschiedenen Phantasmen darstellen : ein starkes, im Wachzustand unterdrücktes, Geltungsbedürfnis lebt sich aus in Phantasmen der eigenen Machtentfaltung, oder in märchenhaften Phantasievorstellungen von Riesen, Zauberern, Prinzen; oder in räumlichen Symbolen des Obenseins, des Fliegens; u.s.w. Und zwar wirkt hierbei oft ein eigentümliches V e r h ü $11 \mathrm{u} \mathrm{ng} \mathrm{s-}$ p r in z i p mit: diejenige Vorstellung, welche am direktesten zu der personalen Regung gehört, wird nicht selber phantasiemälsig realisiert, an ihre Stelle tritt eine andere, irgendwie mit jener verwandte Vorstellung.

Es ist ausserordentlich schwer, in die hierbei vor sich gehenden Úbertragungen und Verschiebungen einen Einblick zu gewinnen, der vor wissenschaftlicher Kritik standhält; es ist andrerseits verständlich, dass der symbolische Charakter der Phantasiegebilde unerschöpfliche Möglichkeiten für die entlegensten, ja wildesten D e u t e r e i e n darbietet - Möglichkeiten, die dann auch reichlich ausgenutzt worden sind. Denn bei der Vieldeutigkeit der $\mathrm{Zu}$ sammenhänge zwischen personalen Tendenzen und Phantasiegebilden kann ja schliesslich aus jedem Traum- oder Spiel- oder sonstigen Phantasma alles Mögliche heraus und in das Phantasma alles Mögliche hineininterpretiert werden. Einzelbeispiele werden uns später begegnen; hier können nur gewisse Grundsätze formuliert werden, die bei allen solchen Deutungen zu beachten sind.

1) Die Neigung zu symbolischer Deutung darf nicht dazu führen, jene oben erwähnten direkten Beziehungen zu übersehen, die zwischen personaler Regung und Phantasiebild bestehen können und eine komplizierte Ableitung überflüssig machen. Eine Umdeu- 
tung des unmittelbaren Phantasmas sollte immer erst dann versucht werden, wenn eine direkte sinnvolle Beziehung des Phantasmas zur Person nicht auffindbar ist, und wenn die personale Struktur auch sonst Symptome zeigt, welche Sperrungen oder Verhüllungen direkter Erlebnis- und Audrucks-Möglichkeiten vermuten lassen. Völlig abwegig ist die Verwendung eines Deutungs-S $\mathrm{c}$ h e$\mathrm{m}$ a s mit stereotypen Symbolisierungen, wonach etwa jeder längliche Phantasiegegenstand den Deutungsindex „männliches Geschlechtsorgan" erhielte, oder jedes zerstörende Spiel eines Kindes eine verhüllte Tötung des gehassten Vaters bedeutete u.s.w. Aus einer einzelnen Phantasievorstellung als solcher ist nie etwas über ihre symbolische Bedeutung zu entnehmen; sie erhält diese immer nur aus dem Zusammenhang mit der gesamtpersonalen Beschaffenheit des phantasierenden Menschen.

2.) Gerade weil eine Unendlichkeit der Deutungsmöglichkeiten besteht, liegt die Gefahr nahe, durch eine vorgef as ste T h e or i e diese Möglichkeiten e i n z u e n g en. Die unübersehbare Vielgestalt der Phantasmen wird dann einem einzigen Bereich oder einigen wenigen Bereichen seelischer Regungen symbolisch zugeordnet, mit anderen Worten: die unitas multiplex der Person wird vereinfacht zu einem Schema, das ein oder zwei Urrichtungen des Trieblebens enthält. So kann es kommen, dass ein und dasselbe Phantasma von Psychoanalytikern so lange umgedeutet wird, bis es als Sexualsymbol entlarvt ist, während die Individualpsychologie in ihm das Symptom für die Ubberkompensation eines Minderwertigkeitserlebens erblickt. Die Gefahr solcher Simplifikationen erschöpft sich nicht darin, dass in ihnen eine unzulängliche Theorie dogmatisch festgelegt ist; sie machen blind gegen die ungeheure Vielgestaltigkeit seelischen Lebens und führen zu völlig einseitigen praktischen Konsequenzen, indem auch bei Beurteilung und Behandlung der Persönlichkeiten in Therapie und Pädagogik aus der Gesamtheit der Seelenäusserungen nur das herausgelesen wird, was als symbolischer Hinweis auf die vorausgesetzten Urtriebe gedeutet werden kann.

Aus der personalen Bedeutung der Phantasiegebilde wird dann auch Grad und Art des begleitenden Realitätsbew u s s t s e i n s verständlich. Wir deuteten schon oben an, dass die Wirklichkeitsintention alle Stufen durchlaufen kann von völ- 
ist nicht nur eine konkrete Vorstellung, die einen scheinrealen $\mathrm{G}$ e ge $\mathrm{n} \mathrm{s}$ a nd meint, sondern zugleich auch eine Projektion einer personalen $Z$ uständlichkeit in die Sphäre bildhaften Vorstellens. Über ihren konkreten Inhalt hinaus weist die Phantasievorstellung auf etwas, das nicht in gleicher Weise dem Erlebenden bewusst und für andere Menschen beobachtbar ist. Eine und dieselbe Phantasievorstellung vermag ganz verschiedene Tiefenvorgänge zu repräsentieren; so können etwa jene schreckenerregenden Dämonengestalten, die im Mythos, im Traum, im Kinderspiel begegnen, zugleich mit Machtwünschen, Ängsten, wollüstigem Grauen, sadistischen oder masochistischen Triebregungen zu tun haben. Andrerseits kann dieselbe personale Regung sich in verschiedenen Phantasmen darstellen: ein starkes, im Wachzustand unterdrücktes, Geltungsbedürfnis lebt sich aus in Phantasmen der eigenen Machtentfaltung, oder in märchenhaften Phantasievorstellungen von Riesen, Zauberern, Prinzen; oder in räumlichen Symbolen des Obenseins, des Fliegens; u.s.w. Und zwar wirkt hierbei oft ein eigentümliches $V$ e r h üllu ng sp r in $\mathrm{z}$ i p mit: diejenige Vorstellung, welche am direktesten zu der personalen Regung gehört, wird nicht selber phantasiemälsig realisiert, an ihre Stelle tritt eine andere, irgendwie mit jener verwandte Vorstellung.

Es ist ausserordentlich schwer, in die hierbei vor sich gehenden Ubertragungen und Verschiebungen einen Einblick zu gewinnen, der vor wissenschaftlicher Kritik standhält; es ist andrerseits verständlich, dass der symbolische Charakter der Phantasiegebilde unerschöpfliche Möglichkeiten für die entlegensten, ja wildesten $\mathrm{D}$ e u $\mathrm{t}$ e r e i e n darbietet - Möglichkeiten, die dann auch reichlich ausgenutzt worden sind. Denn bei der Vieldeutigkeit der $\mathbf{Z u}$ sammenhänge zwischen personalen Tendenzen und Phantasiegebilden kann ja schliesslich aus jedem Traum- oder Spiel- oder sonstigen Phantasma alles Mögliche heraus und in das Phantasma alles Mögliche hineininterpretiert werden. Einzelbeispiele werden uns später begegnen; hier können nur gewisse Grundsätze formuliert werden, die bei allen solchen Deutungen $z u$ beachten sind.

1) Die Neigung zu symbolischer Deutung darf nicht dazu führen, jene oben erwähnten direkten Beziehungen zu übersehen, die zwischen personaler Regung und Phantasiebild bestehen können und eine komplizierte Ableitung überflüssig machen. Eine Umdeu- 
tung des unmittelbaren Phantasmas sollte immer erst dann versucht werden, wenn eine direkte sinnvolle Beziehung des Phantasmas zur Person nicht auffindbar ist, und wenn die personale Struktur auch sonst Symptome zeigt, welche Sperrungen oder Verhüllungen direkter Erlebnis- und Audrucks-Möglichkeiten vermuten lassen. Völlig abwegig ist die Verwendung eines Deutungs-S c h emas mit stereotypen Symbolisierungen, wonach etwa jeder längliche Phantasiegegenstand den Deutungsindex „männliches Geschlechtsorgan" erhielte, oder jedes zerstörende Spiel eines Kindes eine verhüllte Tötung des gehassten Vaters bedeutete u.s.w. Aus einer einzelnen Phantasievorstellung als solcher ist nie etwas über ihre symbolische Bedeutung zu entnehmen; sie erhält diese immer nur aus dem Zusammenhang mit der gesamtpersonalen Beschaffenheit des phantasierenden Menschen.

2.) Gerade weil eine Unendlichkeit der Deutungsmöglichkeiten besteht, liegt die Gefahr nahe, durch eine vorgefas te Th e or i e diese Möglichkeiten e in z u engen. Die unübersehbare Vielgestalt der Phantasmen wird dann einem einzigen Bereich oder einigen wenigen Bereichen seelischer Regungen symbolisch zugeordnet, mit anderen Worten: die unitas multiplex der Person wird vereinfacht zu einem Schema, das ein oder zwei Urrichtungen des Trieblebens enthält. So kann es kommen, dass ein und dasselbe Phantasma von Psychoanalytikern so lange umgedeutet wird, bis es als Sexualsymbol entlarvt ist, während die Individualpsychologie in ihm das Symptom für die Ưberkompensation eines Minderwertigkeitserlebens erblickt. Die Gefahr solcher Simplifikationen erschöpft sich nicht darin, dass in ihnen eine unzulängliche Theorie dogmatisch festgelegt ist; sie machen blind gegen die ungeheure Vielgestaltigkeit seelischen Lebens und führen zu völlig einseitigen praktischen Konsequenzen, indem auch bei Beurteilung und Behandlung der Persönlichkeiten in Therapie und Pädagogik aus der Gesamtheit der Seelenäusserungen nur das herausgelesen wird, was als symbolischer Hinweis auf die vorausgesetzten Urtriebe gedeutet werden kann.

Aus der personalen Bedeutung der Phantasiegebilde wird dann auch Grad und Art des begleitenden Realitäts bew us s $\mathrm{s}$ e in s verständlich. Wir deuteten schon oben an, dass die Wirklichkeitsintention alle Stufen durchlaufen kann von völ- 
ligem Realitätsglauben bis zu völliger Illusionseinsicht. Diese Intentionalität hängt nicht von der Beschaffenheit des Stoffes als solchen ab: dasselbe Märchen wird von der erwachsenen Erzählerin als Unwirklichkeit, vom zuhörenden Kinde als Wirklichkeit erlebt. Wohl aber zeigt sich hier die S p o n t a neität des Phantasierens in einem neuen Licht: Der Mensch bedient sich der selbsterzeugten Phantasiegebilde zum Aufbau seiner personalen Welt, und er kann dieser Welt (oder verschiedenen Schichten dieser Welt) verschiedene Realitätscharaktere verleihen! Vermittels der Phantasie vermag er die harte und enge Realität der Sinne und des unmittelbaren Handelns in eine Welt hineinzusetzen, die erlebnismälsig gleich "wirklich" ist, ohne doch „wirkend" und konsequenzenhaltig zu sein wie jene. Er vermag beide Welten ganz in Eins zu verschmelzen (dies namentlich in primitiven Entwicklungsstadien, im magisch-mythischen $\mathrm{Zu}$ stand); er kann auch gerade das Wechseln und Schweben zwischen ihnen geniessen (sehr häufig zu beobachten beim kindlichen Spiel) ; er kann endlich die beiden Welten schroff gegenüberstellen und sich in die Scheinwelt flüchten, um der realen Seinswelt wenigstens zeitweilig entrückt zu sein (dies gilt namentlich oft für den Kuntsgenuss).

Man erkennt jetzt, wi e unzulänglich jene oben erwähnte Auffassung ist, als ob es für den Menschen nur e i n e handfeste, endgültige Wirklichkeit gäbe, der gegenüber alles übrige Vorstellbare nichts als Lug und Trug, Irrealität und Irrwahn wäre. Die personale Wirklichkeit ist vielschichtig; und auch die (ganz oder partiell) scheinhafte Wirklichkeit hat in diesem Schichtengebilde ihre positive Bedeutung. Oft sind es gerade die Übergänge und Schwebezustände zwischen den klaren Seinswelten und den Scheinwelten, die das Menschenleben zum typisch m en s c h1 i c h e n machen. (Im tierischen Leben fehlt die Differenzierung zwischen Seins- und Schein-Welt, und daher auch der Reichtum der Spannungen und Verknüpfungen.)

d. S c h ö p f u n g.-Die Beziehung der Phantasie zur Realität hatte sich bisher in zwei Formen dargestellt. Wir stiessen erstens auf das Merkmal der Nicht-Objektivität: Phantasie steht im Gegensatz zu der Objekt-Welt der Gegebe $\mathrm{n}$ he i t e n . und der GeIt ungen. Wir fanden zweitens das Merkmal der 
S c h e i n-Objektivität: Phantasie schafft im Erleben des Subjekts eine neue Wirklichkeit, die aber binnenseelisch bleibt. Wir haben nun noch eine dritte Stufe festzutsellen: Phantasie schafft $\mathrm{n}$ e u e Objektivation a ls Werk. Dadurch erweist sie sich als eine psychophysisch neutrale Funktion: was sie erzeugt, bleibt nicht im Bewusstsein des Subjekts stecken, sondern ä n dert di e Wirklichkeit, wird zur "Schöpfung”.

Als eine solche ist bereits jene Mitwirkung anzusehen, welche die Phantasie dauernd am Aufbau der Eigenpersönlichkeit leistet. Der schon erwähnte Schutz- und Wunsch-Charakter des Phantasielebens bewirkt, dass der Mensch sich selbst u mge$s t$ a 1 t e $t$ und seiner Beziehung zur Welt eine Neuprägung gibt. Don Quijote, der sich phantastisch zum ,letzten irrenden Ritter" um-erlebt, $h$ a n d e $1 \mathrm{t}$ auch entsprechend und greift damit in den objektiven Lauf der Dinge ein. Ähnliches gilt natürlich dort, wo der Mensch nicht in wahnhafter, sondern in durchaus normaler Weise sein Leben und Tun durch Phantasie ergänzt und umformt.

Aber der phantasierende Mensch hat auch ein direktes Bedürfnis nach $\mathrm{transpersonaler}$ Entäusserung seines binnenseelischen Erlebens; er tendiert danach, die blosse Vorstellung in Bewegung, Ausdruck und Erzeugnis umzusetzen. Die Vorstellung selbst wird dadurch erst ganz lebendig und anschaulich, dass sie sich vermittels ihrer Äusserung formt und konkretisiert; aber sie wird zugleich als Nur-Seelisches überflüssig, weil sie äussere Gestalt geworden ist. Hier gibt es eine fortschreitende Ablösung des Phantasieerzeugnisses vom Erzeuger; die Hauptfunktionen in diesem Prozess sind Darstellen und Werkschaffen, die Hauptgebiete der Phantasieobjektivierung sind Spiel, Kunst und Mythos.

$\mathrm{S}$ p i e $\mathrm{l}$ und $\mathrm{Kuns} \mathrm{t}$ sind oft zusammen genannt und behandelt worden; sie sind in der Tat darin nahe verwandt, dass sie durch Objektivation von Phantasieerlebnissen eine Welt neuer Tatbestände und Geschehnisse in die vorhandene und geltende Welt hineinsetzen. Aber Art und Bedeutung der Objektivation sind doch hier und dort von ganz verschiedener Art. Beim Spiel bleiben die aussenweltlichen Hervorbringungen nur so lange objektiv, als es dem Erzeuger beliebt, und sie haben auch keine über die Person des Erzeugers hinausgehende Bedeutung. Gerade hier- 
in aber besteht dasWesen der Kunst. EinePhantasieäusserung wird zu einem Kunstwerk erst dort,wo sie mehr ist als Selbstgestaltungsund Ausdrucksmittel des Erzeugers, wo sie vielmehr transpersonal wird als neuer objektiver Bedeutungsträger in der bisherigen Welt der Gegenstände. Eine Zwischenstufe bilden jene Phantasiegestaltungen, die noch an die Persönlichkeit des Erzeugenden gebunden bleiben, wie Tanz und Schauspiel; doch auch hier kann man doch deutlich unterscheiden zwischen dem bloss spielhaften Tun etwa eines Kindes, das seinem Bedürfnis nach Herumtanzen und Darstellen folgt - und der künstlerischen Tänzerin oder Schauspielerin, welche objektiv Wertvolles zu geben bestrebt ist. Vollständig aber wird der Unterschied dort, wo das Phantasieerzeugnis selbst entlassen wird aus der Lebenssphäre des Erzeugers und nun als „K u n st w e r k” ein eigenes und selbständiges Stück Welt konstituiert. Gerade das ist das Kennzeichen der eigentlich schöpferischen Phantasie (im Gegensatz zur bloss erlebenden und auch zur bloss hervorbringenden wie beim kindlichen Spiel): dass ihre Objektivationen ganz aus dem Innersten und Eigensten des Erzeugers hervorgehen, dann aber sich von diesem emanzipieren und der Welt des Gegebenen einen Wertzuwachs bringen.

e) Gebundene Phantasiewirkungen.-DieBetätigung der Phantasie erschöpft sich nun aber nicht in der Erzeugung abgehobener Phantasievorstellungen und ihrer Objektivationen; vielmehr gibt es auch zahllose phantasiemälsige Einschläge und Momente innerhalb andersartiger Erlebnis- und Verhaltens-Weisen. Sie mögen "gebundene Phantasiew i r k u n e n" heissen. Und zwar ist es überhaupt erst durch nachträgliche Ursachanalyse solcher Erlebnis- und VerhaltensWeisen nachweisbar, wie weit in ihnen Erfahrungen einerseits, Erfahrungsüberschreitungen (also Phantasiemomente) andererseits wirksam sind; das personale Lebnis oder Erlebnis selbst ist aber durchaus nicht etwa ein Summationsprodukt von Wahmehmung plus Phantasma, oder von Erinnerung plus Phantasma, oder von Denk-oder Willens-Vollzug plus Phantasma, sondern eine einheit liche Gestalt. Hier wird also nochmals die Unzulänglichkeit einer vermögenspsychologischen Auffassung klar, welche „d i e Einbildungskraft" als Sondervermögen neben Sensibilität, Gedächtnis, Intelligenz, Willen stellt; es wird ferner verständlich, 
dass erst die analytisch geschulte Psychologie der letzten Jahrzehnte diese gebundenen Phantasieeinschläge in den sensorischen, mnemischen und prospektiven Bereichen bemerkt und gewürdigt hat.

\section{PHANTASIE IM ALLTAGSLEBEN}

Der Bereich der zuletzt erwähnten, gebundenen Phantasiewirkungen ist weit umfassender als der der selbständig abgehobenen Phantasmen 1). Denn es gibt kein Lebens- und Erlebens-Gebiet des Menschen, das er nicht mit Eigenschöpfungen durchsetzte, selbst wenn die Intention auf die gegebene und geltende Objektivität der Welt gerichtet ist. Es gibt auch keinen Menschen, er mag noch so phantasielos und sogar (wie S. 448/9 angedeutet) phantasiefeindlich sein, der nicht doch zum mindesten in gebundener, verdeckter Form phantasierte. Es ist eben ein gewaltiger Irrtum, zu meinen, dasss Phantasie sich nur im Traum, Spiel, Mythos und Kunstschaffen offenbarte und betätigte, während die praktische Alltagswirklichkeit, der Ernst des Lebens nichts mit ihr zu tun habe. Wohl gibt es hier sehr starke Gradunterschiede; aber nie fehlt Phantasie gänzlich. Diese A 11 g e g e $n$ wa rt mitwirkender Phantasie ist geradezu eines von den Wesensmerkmalen des Menschen ${ }^{2}$ ).

Wir gliedern diese Alltagsphantasieen nach $z$ e i $t$ l i c h e n Gesichtspunkten.

\section{Gegenwarts- und Vergangenheits-} $P h$ ant asieen

a) G e g e n w a r t . - Nirgends scheint der Zwang der äusseren Verhältnisse eindeutiger das Erleben zu bestimmen, als dort, wo die Welt sich g e g e n wä r $\mathbf{t}$ i g der Wahrnehmung gibt. In Wirklichkeit bleibt auch hier immer noch Spielraum zur Eigenschöpfung, der weitgehend ausgenutzt wird. Die „Illusionen", die im Kapitel Sinneswahrnehmung beschrieben wurden (S. 226), be-

1) Es liegt hier Āhnliches vor wie bei den mnemischen Funktionen; auch dort erwiesen sich die gebundenen Gedächtniswirkungen als das breite Fundament, dem erst die selbständigen Gedächtnisvorstellungen entwuchsen.

2) In einer seiner frühesten Schriften hat Freud, allerdings unter rein psychoanalytischen Gesichtspunkten, die Durchsetzung des Alltagslebens mit Phantasmen behandelt. 
ruhen nicht etwa nur auf sensorischen Mängeln, sondern auch auf Bereicherung und Erweiterung der unvollständigen Reizsituation aus dem Inneren der wahrnehmenden Person heraus. Ja es gibt Sinnesreize, die lediglich oder vorwiegend die Aufgabe haben, solche Eigenschöpfungen auszulösen, also als „P h a n t a si e$r$ e i $z$ e" zu wirken: so etwa die groben Klexe der Kulissen, dürftige Umrisszeichnungen oder andeutende Worte auf Plakaten. Je undeutlicher oder je vieldeutiger die Sinnesreize selber sind, um so stärker ist der Antrieb, sie phantasiemälsig zu umkleiden und zu vervollständigen; in Stimmengewirr, Wolkenbilder, verschwimmende Gestalten wird alles Mögliche hinein-gesehen, -gehört, -phantasiert. Das herausgerissene Wort aus einem Gespräch, ein unverstandener Satz in einem Brief, - sie können garnicht in ihrer nackten nur-sensorischen Beschaffenheit aufgefasst werden; sie werden hineingestellt in Sinnzusammenhänge, die mit Phantasiemitteln ausgemalt werden; und wenn nun jenes Wort für den Hörenden oder Lesenden eine ganz bestimmte Bedeutung erhält, dann ahnt er nicht, wieviel er aus eigenem dazu beigetragen hat.

Entsprechendes gilt aber, wenn auch in geringerem Grade, von jeder Lektüre, von jedem Gespräch. Lese ich etwa ein Drama, oder eine Zeitungsnotiz über ein Eisenbahnunglück, so habe ich nicht nur die Wortverstellungen und die mit ihnen verbundenen allgemeinen Bedeutungsgedanken, sondern ich konkreti$\mathrm{s}$ i e r e den Inhalt in einer, über den gebotenen Text hinausgehenden Weise; die Menschen, von denen die Rede ist, „sehen irgendwie aus", auch wenn mit keinem Worte des Textes ihr Aussehen angedeutet ist ; die räumliche Umgebung, das Zueinander, die Bewegungen und Ausdrucksformen werden irgendwie bildhaft; vielleicht klingt mir auch die Stimme der handelnden Personen irgendwie, obwohl ich ihre Worte nur schweigend lese. Diese eigenen Phantasiezutaten verschmelzen normaler Weise mit den Wahrnehmungen der gedruckten Worte und mit den durch sie ausgelösten Gedanken so sehr zu einer Totalität, dass sie dem Leser unbemerkt bleiben - bis er seine Vorstellung mit einer echten Wahrnehmung konfrontieren muss. Dann ist er verblüfft, dass der auf der Bühne dargestellte Held ganz anders aussieht, spricht und agiert, als er sich ihn nach der Lektüre vorgestellt hatte. Irgend eine Landschaft, die man zum ersten 
Male erblickt, will garnicht stimmen zu dem Bilde, das man sich nach Beschreibungen und Photographieen gemacht hatte. Solche Uberraschungen bedeuten zuweilen grosse Enttäuschungen - ein Zeichen, wie stark ein Mensch mit seinem Phantasieerzeugnis verwachsen sein kann. Es gibt sogar Fälle, in denen jene Korrektur durch echte Wahrnehmung das Phantasiebild nicht zu verdrängen vermag; man will die Wirklichkeit nicht wahr haben, weil man sich in seine Scheinwirklichkeit verliebt und hineingelebt hat.

Solange es sich um rein rezeptive Wahrnehmungsvorgänge handelt (wie beim Lesen von Dramen, Landschaftsbeschreibungen u.s.w.), ist der Phantasieeinschlag relativ harmlos, ja er ist notwendig, um etwa den ästhetischen Genuss der Lektüre vollständig zu machen. Anders ist es, wenn es nicht bei blosser Rezeption bleibt, sondern aktive Folgerungen daraus abgeleitet werden.

Ein sehr banales, aber durch seine Verbreitung besonders wichtiges Beispiel ist der $\mathrm{Klat} s \mathrm{ch}$. Man hört dies und das erzählen, begnügt sich nicht mit dem durch den Wortlaut festgelegten Sachverhalt, sondern schmückt aus, steigert, ergänzt aus der Phantasie - u n d g i b t e s s o w e it e r. Jeder Beteiligte glaubt, sich an das objektiv Ubernommene zu halten; jeder aber hat in Wirklichkeit anderes daraus gemacht, eine neue Schein-Objektivität geschaffen, die beansprucht, Voll-Objektivität zu sein. Wenn wir finden, dass bei Klatschweibern beiderlei Geschlechts sehr oft blühende Phantasie mit geringem Verantwortungsbewusstsein und mangelndem Mitgefühl gepaart ist, dann können wir daraus nur wieder entnehmen, dass Phantasie nicht für sich allein steht, sondern personal tief verankert ist.

b) V e r g a n g e n h e i t. - Die phantasiemälsige Durchdringung $\mathrm{m} \mathrm{ne} \mathrm{m}$ is $\mathrm{ch}$ e $\mathrm{r}$ Funktionen zeigt sich besonders deutlich bei der Wiedergabe vergangener Erlebnisse. Wir haben in dem Abschnitt über Personalistik der Erinnerung bereits darauf hingewiesen ${ }^{1}$ ), dass Erinnerungen nicht einfach festgewordene Spuren früherer Erfahrungen sind, sondern dass in ihnen ein früherer Lebensabschnitt in der Perspektive der gegenwärtigen personalen Bedürfnisse gesehen wird. Erinnerung ist also stets in gewissem Sinne Neuerzeugung ; und der hierdurch geforderte Phantasieeinschlag wird um so stärker sein, je tiefer das erinnerte Stück Leben in den totalen Lebenssinn der Person eingebettet ist.

1) Vgl. insbes. S. 348 u. 360. 
Personal indifferente Erinnerungen sind daher viel weniger in ihrem sachlichen Objektivitätscharakter bedroht, als die uns nahegehenden. Gesteigert wird nun aber noch der Anteil der Phantasie, wenn die sprachliche Darstellung der Erinnerung zu einem selbständigen Ziel wird. Wie überall, so wird auch hier das Phantasiebild erst dadurch abgerundet und ausgestaltet, dass es in eine, auch anderen zugängliche und auf sie wirkende Ausdrucksform gegossen wird. Sei es mehr die ästhetische Erzählerfreude, sei es Aufschneiderei und Renommiersucht, sei es Selbstschutz und Scham, sei es Freude am Schlüpfrigen oder Grausigen - die verschiedensten Triebgebiete der Person können daran beteiligt sein, aus einer mnemischen Darstellung von Erlebtem ein phantasiegefärbtes Erleben des Darstellens und des Dargestellten zu machen.

Auch hier gibt es ausgesprochene „Phantasiereize”; so kann bei einem Zeugen vor Gericht die Suggestion der Verhörsfragen bewirken, dass nun Situationen ausgemalt werden, die ohne jene Befragung garnicht in den Kreis des Vorstellens getreten wären.

Werden im geselligen Kreise Geschichten über Selbsterlebtes erzählt, so kann die Dämmerstunde mit ihrer Verwischung scharfer Gegenständlichkeit, oder die Konkurrenz anderer Erzähler die Phantasie in stärkstem Malse entfesseln ${ }^{\mathbf{1}}$ ).

\section{Zukunftsphantasieen}

a. Vorweg n h m e. - Am stärksten - weil am wenigstens kontrollierbar - können sich Phantasievollzüge einschleichen in jene seelischen Funktionen, die es mit der eigenen $Z \mathrm{u}$ $\mathrm{k} u \mathrm{n} f \mathrm{t}$ zu tun haben. Es liegt ja im Wesen alles prospektiven Verhaltens, dass seine Inhalte nicht eindeutig bestimmt sind. Das Morgen und Ubermorgen ist selbst bei den einfachsten und konservativsten Lebensformen dennoch irgendwie unsicher; und gar das weitere Lebensschicksal, Erfolg und Misserfolg, Berufs- und Familien-Geschicke, insbesondere auch ausserordentliche Einzelereignisse, Prüfungen, Reisen, Berufswahl und -Wechsel, Verlust und Zuwachs in der Familie u.s.w. - all dies trägt für den Menschen ein Gepräge der Unbestimmtheit und Ungestaltetheit, bei dem er sich nicht immer zu beruhigen vermag.

\footnotetext{
1) Goethe schildert, wie er als Knabe, durch die Gläubigkeit seiner Zuhörer verführt, das Märchen vom "neuen Paris" erdachte und als selbsterlebtes Abenteuer vor-
trug.
} 
Es gibt nun allerdings Menschen, die ihr bewusstes Interesse konzentrieren auf diejenigen Gebiete, die auf Grund der Erfahrung und eigener Denktätigkeit mit relativer Sicherheit voraussehbar sind. Ihre Fürchte und Hoffnungen halten sich in den Schranken, die eine begründete Erwartung zieht; die von ihnen selbst zu beeinflussenden Lebensvollzüge werden unter die klare Beleuchtung des Vordenkens und Planens und unter den Motor des bewussten Willens gesetzt, im übrigen aber nicht psychisch vorweggenommen. Damit ist freilich nur eine Grenzform angedeutet, die in dieser Reinheit nie vorkommt, weil ein völlig phantasiefreies Leben nach vorwärts für den Menschen nicht möglich ist. Denn die Unklarheit und Vieldeutigkeit der Zukunft gibt nicht nur die $\mathrm{M}$ ö $\mathrm{g} l \mathrm{i}$ c h k e i t einer Ausfüllung und Konkretisierung der vagen Vorstellungen, sondern $\mathrm{d} r a ̈ n g t$ geradezu zu einer

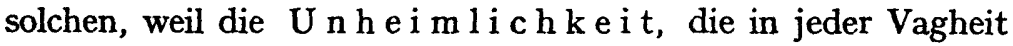
liegt, unerträglich werden kann.

Endlich haben phantastische Zukunftsbilder nie jene sofortige Desavouierung ihrer Realitätsgeltung zu fürchten, die bei Gegenwarts- und Vergangenheits-Phantasieen immerhin eine starke Hemmung bedeutet. So kommt es, dass nach Stärke und nach inhaltlicher Ungebundenheit die $Z \mathrm{u} \mathrm{k} \mathrm{u} \mathrm{f} \mathrm{t} \mathrm{s}$-Phantasieen auch des Alltagsmenschen weit lebhafter und schweifender sind als die anderen Formen. Da baut jemand Luftschlösser für den Fall, dass er einmal zu unerwarteten Reichtümern kommen sollte. Das junge Mädchen malt sich den Mann aus, den sie einmal heiraten möchte. Jemand, der eine grosse Reise vorhat, lebt schon lange vorher in den Eindrücken, Abenteuern, Begegnissen, die ihm der Aufenthalt in den fremden Ländern bringen soll. Vor Prüfungen, schicksalsschweren Unterredungen, erstem Auftreten in der Offentlichkeit, wird oft eine Phantasie-Generalprobe gehalten, in der auch die Worte und Handlungen des Partners oder des Publikums in höchst konkreter Form vor-erlebt werden.

In unseren Beispielen handelt es sich durchweg um personal sehr relevante Zukunftsereignisse, die in der Phantasie antezipiert werden, und zwar ebensowohl um positiv wie negativ bedeutsame. Es sind teils Wunsch-, Hoffnungs-, Geltungs-Phantasieen, teils Furcht-, Angst-, Vernichtungs-Phantasieen. 
b) W u n s h. - Dass sich Wün s che, offene wie verschwiegene, in Phantasmen umsetzen, ist leicht verständlich. Gibt doch das Phantasiebild schon etwas Bestimmtes, anschaulich Gegenwärtiges, gaukelt daher dem Wunsch schon die E r f ü ll u n g vor, die in der Realität noch nicht erreicht, vielleicht überhaupt nicht erreichbar ist. So wiegt sich der unbekannte hungernde Künstler in Ruhmesphantasieen, der Kranke in Bildern alles dessen, was er nach seiner Gesundung leisten und geniessen kann; der Schwächling ersetzt seine wirkliche Machtlosigkeit durch phantasierte Macht-Situationen und -Funktionen. Wunscherfüllungsphantasieen können also, wie schon diese Beispiele zeigen, eine $\mathrm{k}$ o m pen s a $\mathrm{t}$ or i s $\mathrm{c}$ e Aufgabe innerhalb des personalen Kräfte- oder Geltungs-Haushalts erfüllen, und zwar in doppeltem Sinne. Der Zustand eines personalen Defizits wird ersetzt durch einen fingierten Überschuss: so überdeckt der PhantasieG e n us die Realitäts-U n 1 us t. Und die aktive Bemühung um Erreichung eines Zieles wird ersetzt durch das Phantasma des schon erreichten Zieles: so überdeckt die Phantasie-L e i c h t i gke it die Willens- und Denk-S chwierigkeit. Von der tiefenpsychologischen Bedeutung der Wunschphantasieen wird später (beim Traum, Spiel, Mythos) noch eingehender zu sprechen sein.

c) F u r c h t. - Rätselhafter als die Wunscherfüllungs-Phantasieen erscheinen die Furchterfüllungs-Phanta$\mathrm{s}$ i e e $\mathrm{n}$. Denn auch bezüglich möglicher Misserfolge, Unglücksfälle und Leiden wirkt ja die vorgreifende Phantasie als Konkretisierung und Vereindeutigung. Was veranlasst den Menschen, Schlimmes, das ihn vi ell e i c ht, - vielleicht auch nicht treffen wird, schon als wirklich vorzustellen und bildhaft auszumalen? Hier scheinen zwei verschiedene Motivgruppen mitzuwirken.

Einmal kann das Unbestimmte, Ungreifbare dann besonders unerträglich werden, wenn es ein negatives Vorzeichen hat; so rettet sich der Mensch vor der Unheimlichkeit des gestaltlos Drohenden $\mathrm{n}$ a $\mathrm{ch}$ vorn ins gestaltete Furchtbare hinein, wenn auch nur in der Phantasie ${ }^{1}$ ). Dadurch, dass es konkret vorgestellt 1) Bekanntlich gilt es dieses „Fliehen nach vorn” auch im realen Handeln, so im
Krieg, bei Feuersbrünsten, Schiffsunfällen. 
wird, wird es doch irgendwie bewältigt, der Person zu eigen gemacht; es wird ihm der Fremdheits- und Uberraschungs-Charakter genommen. Nicht ganz selten kann man in solchen Fällen hören, dass das Unglück, wenn es dann später wirklich eintraf, „nicht so schlimm war, wie man es sich vorgestellt hatte." Es liegt hier wohl eine unbewusste Umkehrung vor; $\mathrm{d} u \mathrm{r} \mathrm{ch}$ die phantasiemälsige Vorwegnahme wurde die Choc-Wirkung des Realerlebnisses abgeschwächt.

Aber auch eine Rettung $n$ a $c h$ hinten kann das Furchtphantasma bedeuten, nämlich dort, wo es sich um Vermeiden eigener Aktivität handelt. Ein Mensch fühlt sich der Aufforderung zu Entschluss und Tat, die von aussen oder innen an ihn herantritt, nicht gewachsen: dann malt er sich den negativen Ausgang des geforderten Tuns als wahrscheinlich oder sogar unabwendbar in allen Einzelheiten aus, um seine Inaktivität dadurch für sich und andere zu rechtfertigen. „Es hat ja doch keinen Zweck”; „ich bestehe die Prüfung ja doch nicht” ; „ich bekomme ja doch einen Korb" - solche und ähnliche Gedanken werden dann nicht nur gedacht und in ihrem Für und Wider durchdacht, sondern sie werden wiederum anschaulich phantasiert und mit Zukunftsrealität ausgestattet. Damit werden die Schreckbilder erlebnismälsig in Ursachen des Nicht-W o 11 e n s umgebogen, während sie in Wirklichkeit die Folgen des Nicht-wollen-Kö nn e n s sind.

Die Hemmungswirkung von Furchtphantasmen kann aber auch eine sehr positive, nämlich Abschreckungsbedeutung besitzen; sie führt dann zur $\mathrm{V}$ o r b e u g u $\mathrm{n} g$ gegenüber drohenden Situationen, oder zur Unterlassung gefährdender Handlungen.

Zwei Beispiele:

1.) Der G e d a n k e: „Unvorsichtiges Umgehen mit Benzin kann Brand und Tod verursachen" mag noch so klar gedacht werden - er braucht als bloss abstrakter Gedanke darum noch keine starke Motivationskraft zu besitzen. Wer aber damit zugleich das konkrete $\mathrm{Phan}$ tasie-B il d verbindet, in welchem er sich selbst beim Hantieren mit Benzin in Flammen aufgehend sieht und wo möglich furchtbare Einzelheiten des Verbrennungsleidens vorwegnimmt, der wird in viel stärkerem Malse zur Vorsicht veranlasst werden.

2.) Jemand will auswandern in ein Land anderen Klimas und geringerer Kultur. Er hat sich genau informiert und we is $s$ theoretisch, dass es dort Hitzetemperaturen gibt, die er bisher noch nicht hat erdulden müssen, dass er auf die zivilisierte Lebensführung verzichten 
muss, die ihm bisher selbstverständlich war. Er weiss dies und ist ebenso theoretisch - überzeugt, dass sein Körper und sein Willen diesen Schwierigkeiten gewachsen sein werden. Aber dies „Wissen” kann eine grosse Täuschung bedeuten, weil er sich die leiblich-seelischen Anforderungen nicht konkret hat vorstellen können, weil er sich $\mathbf{k}$ e i n $\mathrm{B}$ i l d $z$ u ge st a lte n vermochte, wie nun tatsächlich sein Leben ablaufen würde, auf welche unzähligen Unentbehrlichkeiten er verzichten, welche unzähligen neuen Unannehmlichkeiten, Unangepasstheiten er durch machen müsste. Kurz: er war - bei aller Intelligenz - zu $\mathrm{ph}$ a $\mathrm{t}$ a s i e a $\mathrm{m}$ gewesen, um das Kommende angemessen antezipieren $z u$ können.

Bekanntlich spielt das Abschreckungsprinzip in der Kriminalistik eine grosseRolle; aber eine eigentlich psychologische Durchforschung fehlt hier noch. Offenbar kann man von Strafandrohungen dann Abschreckungswirkungen erwarten, wenn in die Erwägung vor einer geplanten Tat auch die konkrete und ichbezogene Vorstellung der möglichen Straffolgen mit eingeht. Wie viel Verbrechen durch diesen Phantasieeinschlag $\mathrm{n}$ i c h t zustande gekommen sind, lässt sich natürlich niemals feststellen. Wohl aber wäre der Forschung die Frage zugänglich, welchen Anteil Phantasielosigkeit oder wenigstens Phantasiearmut am positiven $\mathrm{Zu}$ standekommen von Verbrechen hat. Er dürfte nicht ganz gering sein.

Freilich kann auch Phantasiereichtum Verbrechen begünstigen. Denn da Wunsch- und Furcht-Phantasieen nicht säuberlich zu trennen sind, so kann die vorwegnehmende Vorstellung einer kriminellen Tat (z.B. einer Erpressung, eines Sexualdelikts) sowohl die intensive Vorstellung erfüllter Triebe und Wünsche, wie auch diejenigen der möglichen Folgen enthalten; überwiegen die ersteren, - und bei der engen Verbindung von Triebregung und Triebhandlung ist dies oft der Fall — dann reichen die Furchtphantasmen zur Hemmung nicht aus.

d) Objektivierende Vorwegnahme. - Die aus Wunsch oder Furcht geborenen Phantasmen, die wir bisher besprachen, sind ganz im Subjektiven verankert. Es wäre aber sehr falsch zu meinen, dass prospektive Phantasie nur als Verfälschung oder Hemmung des objektgerichteten Denkens und Wollens aufträte; sie kann auch deren wertvollste Helferin werden. Bei Denkund Willens-Vollzügen ist ja durchaus nicht in allen Phasen nur 
aktuelles Denken bezw. Wollen vorhanden; vielmehr sind die eigentlichen Akte einem Untergrund von Einstellungen und Vorstellungen, von Bedürfnissen und Affekten aufgesetzt. Hier haben auch Phantasieeinschläge ihren Platz.

Der „phantasievolle Kaufmann” braucht nicht der „phantastische Spekulant" zu sein, welcher unkontrollierte Phantasmen a n d i e St e ll e begründeter Denkergebnisse setzt; er kann seine konkreten Zukunftsbilder einbauen in sein Denken, lässt nur die plausiblen Bilder passieren, weil die stets wache Denkkritik Entgleisungen abschneidet; er kann aber auch eine Art intuitiven Fingerspitzengefühls für das Plausible haben und hierdurch zu Vorwegnahmen kommen, die - zunächst irrational erscheinend - nachträglich durch Erfahrung oder rationale Begründung gerechtfertigt werden. So sieht er bereits Zusammenhänge zwischen scheinbar Disparatem; er ahnt Entwicklungen, deren Keime noch unter der Schwelle rationaler Behandlung liegen.

In diesem Sinne ist vorwegnehmende Phantasie erforderlich für jede weiter ausgreifende Tat, sei es die des Politikers oder Strategen, des Erziehers oder Wirtschaftsmannes, des Künstlers oder Wissenschaftlers. Aber freilich : die Grenzen zwischen ihrer legitimen Betätigung und ausschweifender, kritikloser Phantastik sind fliessend; und ihre Auswirkungen werden stets - da irrational auch der Möglichkeit des Misserfolgs ausgesetzt sein. Gerade ein auf intuitiver Phantasie beruhender Fehler kann weit verhängnisvoller sein als ein Denkfehler, der schliesslich durch Denken wieder korrigierbar ist. Hier rühren wir an die Tragik mancher grossen Persönlichkeiten der Geschichte, die, gerade weil sie Grosses weit ausschauend vorbereiten und durchführen mussten, auch weit gehend auf vorwegnehmende Phantasie angewiesen waren.

\section{Da u r phantasieen}

Da $u$ e r pha $\mathrm{n}$ t a sie e $\mathrm{n}$ sind solche, die nicht auf ein bestimmtes Zeitstück bezogen sind, sondern von dem phantasierenden Menschen als ein integrierendes Moment seines Daseins erlebt werden. Sie bestimmen das Jetzt des Menschen, organisieren aber auch kommende und frühere Lebens-Abschnitte, sofern diese mit dem Jetzt in organischer Verbindung stehen; sie geben den Erin- 
nerungen ebenso wie den Wünschen und Fürchten ihre Farbe. Ihre objektive Dauer kann sehr verschieden sein; ein Geisteskranker, der an Grössenwahn leidet, lebt in seinen Kaiser- oder GottPhantasmen bis an sein Lebensende; ein Jugendlicher, der sich während einer Pubertätskrise eine Phantasiewelt aufbaut, kann nach wenigen Monaten die kritische Periode und damit sein Phantasmasystem überwunden haben. Aber es ist eben mehr oder minder ein Syst e $\mathrm{m}$ und dadurch, solange es andauert, von ganz anderer personaler Bedeutung als ein einzelnes Gegenwarts-, Vergangenheits- oder Zukunfts-Phantasma. Die Dauerphantasie ähnelt hierin dem Spiel und der Kunst, in welchen Bereichen ja ebenfalls die phantastische Scheinwelt eine gewisse Verfestigung und Durchgestaltung erfährt; sie unterscheidet sich aber von ihnen durch ihren Realbezug. Denn der Mensch, der sich in eine solche „Lebenslüge” einspinnt, verändert damit von sich aus die Wirklichkeit, in der er lebt ; unscheidbar fliessen praktische Realität und Phantasiewelt ineinander, und so drohen fortwährend Konflikte mit den harten Tatsachen der Aussenwelt und den Ansprüchen der Gemeinschaft.

Möglich sind solche Dauerphantasieen daher nur dort, wo das objektivierende Realitätsbewusstsein noch nicht zur vollen Ausbildung gelangt ist, wie beim Kinde und Jugendlichen, oder wo es in krankhafter Weise gelockert ist, wie bei manchem Neurotiker und Geisteskranken. Ein solcher Mensch wird dann ,autistisch", d.h. für ihn existiert die Welt nur, so weit sie seine Person angeht; und alles in der Welt wird umgedeutet, umgesehen, umgehört in personale Wunsch- und Furcht-Erfülltheiten und Triebverwirklichungen. Oder aber seine Persönlichkeit wird „gespalten"; neben dem Normalleben in der Realwelt, das unverändert weiterläuft, wird ein zweites Leben in der Scheinwelt nicht nur phantasiert, sondern auch verwirklicht, zuweilen begleitet von Dämmerzuständen, infolge deren das eine Leben um das andere nichts weiss.

Die Grenzen zwischen Normalität und seelischer Krankheit sind hier nicht immer leicht zu ziehen. Beim nichterwachsenen Menschen z.B. wäre es durchaus unberechtigt, das Auftreten solcher Dauerphantasieen sofort als krankhaft zu deuten. Zum mindesten in zwei Epochen - der sogenannten „Kindheitspubertät” (erstes Trotzalter, etwa viertes Lebensjahr) und der Jugendpubertät (um 
das 14. Lebensjahr) - ist das Brüchigwerden des vorher selbstverständlichen Verhältnisses Ich/Welt geradezu eine normale Entwicklungserscheinung; und die Unstimmigkeit, die sich zwischen eigenem Geltungsstreben und Selbstwerterleben einerseits, der Fesselung durch eine Welt der Verbote und Gebote und eigene Leistungsschwäche andererseits einstellt, kann dann oft nur durch zeitweilige Flucht in die Wunschwelt einer Dauerphantasie überwunden werden.

Die unerwartete Verbreitung solcher Dauerphantasieen bei Kindern des 4. Jahres konnte in einer Untersuchung von $\mathrm{C}$. und W. Stern nachgewiesen werden. Meist handelt es sich dabei um frei geschaffene Phantasie-,,Gefährten": Geschwister, welche die tatsächliche Vereinsamung des Kindes vergessen machen sollen; unsichtbare Geister, welche gebraucht werden als Spielgenossen und Helfer, als Sündenböcke für eigene kleine Vergehen, als Befehlsgeber dort, wo der Trotz dem Kind verbietet, die Anweisung als eine von den Eltern empfangene zu befolgen. Alle beobachteten Kinder waren und blieben seelisch gesund und gaben auch ihr Phantasmensystem von selbst auf, als die kritische Epoche vorüber war. Pädagogische Gewaltsmafsnahmen, Verbote, Strafen sind in solchen Fällen durchaus verfehlt. Ablenkung und womöglich Beseitigung der Anlässe (der Vereinsamung, der Eingeengtheit) unterstützen das allmähliche Abklingen.

Uber die entsprechenden Erscheinungen bei Pubertätskrisen enthält die jugendpsychologische Literatur reichliches Material.

Auch bei Erwachsenen kommen solche Dauerphantasieen vor, ohne notwendig Krankheitssymptome sein zu müssen, freilich nur dann, wenn sie bi n n e $\mathrm{n}$ s e e 1 i s $\mathrm{ch}$ bleiben. Rationales T'enken und organisierender Wille sind dann stark genug, um den Realbezug des Lebens in Ordnung zu halten; nur im Wachtraum, in Zuständen verantwortungsfreien Sichselbstüberlassenseins spielt man dann mit einem Leben in jener Scheinwelt der Wünsche. (Hier sind wir schon ganz in die Nähe von Traum, Spiel und Kunst geraten.)

Ist in den oben besprochenen Erscheinungen des realen Alltagslebens die Phantasie doch immer nur als E in s ch 1 a g wirksam, so haben wir jetzt jene besonderen Bereiche personalen Daseins zu besprechen, in denen es zu selbständigen Phantasiebetätigungen und Abläufen kommt, oder bei denen die Phantasie zum mindesten eine herrschende Rolle spielt. 
Die drei zu besprechenden Gebiete bilden zugleich eine Stufenleiter fortschreitender Objektivation. Die $\mathrm{t} r$ ä u m e n d e Phantasie bleibt rein binnenseelisch, die spielende Phantasie führt zu momentanen, die schöpferische Phantasie zu dauernden Objektivationen. 


\section{NEUNZEHNTES KAPITEL}

SONDER EUNKTIONEN DER PHANTASIE

(TR A U M N. S P I E I N. S C A F F E N)

\section{DAS TRÄUMEN}

Im Traum ist jeder Mensch ein Phantast; er erlebt in sich Bilder, deren Inhalte und Abläufe alles real Erfahrene überschreiten, so sehr auch ihr Rohmaterial in Erfahrungen bestehen mag; er erlebt sie mit vollem naiven Realitätsbewusstsein, da ja Kritik, Kontrolle und Widerlegung durch praktische Konsequenzen fehlen; und er hat, beim Erwachen, in aller Stärke das $Z$ w e i w e l t e ng e f ü hl, nämlich das Gefühl des Nichtzueinandergehörens der Scheinwelt, aus der er kommt, und der Seinswelt, in die hinein er aufwacht. Auch das schnelle Entschwinden der Traumerinnerungen und das Bewusstsein, dass selbst die in der Erinnerung zurückbleibenden Traumfetzen nur ein ganz schwaches und noch dazu verschobenes Bild von dem geben, was im Traum tatsächlich erlebt worden war - trägt zu jenem Zweiweltengefühl bei.

Allerdings enthält jenes Gefühl auch den starken Anreiz, nach einer Uberwindung der Zerspaltenheit zu streben; und alles, was die Menschheit von alters her bis zu unserer Zeit, von dem biblischen Josef bis zum modernen Freud, an Traumerklärungen und Traumdeutungen versucht hat, steht unter diesem gemeinsamen Ziel, die Bilder und Geschehnisse der Traumwelt den Gegenständen und Vorgängen der Wachwelt irgendwie einzuordnen.

Hierbei hat man die Traumproblematik bald vom Objekt her, bald vom Subjekt her zu fassen gesucht. Im ersten Falle wird angenommen, dass objektive Gegenstände und Zustände, Geister und Dämonen, Seelen Lebender und Toter in die Welt des Schlafenden einbrechen; im zweiten Falle ist das Träumen ein, in das personale Totalleben eingebettetes und mit ihm sinnvoll ver- 
knüpftes Geschehen, das daher auch aus dem Wachleben her auf die eine oder andere Weise verständlich gemacht werden muss.

Die moderne psychologische Traumtheorie hat beide Gesichtspunkte zu berücksichtigen.

\section{Traumreize}

Die $\mathrm{Objektbedingtheit} \mathrm{der} \mathrm{Träume} \mathrm{ist} \mathrm{sowohl} \mathrm{eine}$ sensorische, wie eine mnemische; gegenwärtige Sinnesreize und früher gemachte Erfahrungen entfalten ihre Wirkung.

a. Se n s oris ch e R e i z e. - Die Zugänglichkeit des Menschen gegenüber $S$ in $n$ e $s$ r e i z e $n$ ist im Schlafe zwar herabgesetzt, aber keineswegs aufgehoben. Gewiss ist Zahl und Mannigfaltigkeit der den Körper treffenden Reize weit geringer als im Wachzustand; Ruhelage, Schluss der Augenlider, Dunkelheit, Stille der Nacht bedeuten Ausschaltung unzähliger Reize der taktilen und kinästhetischen, der optischen und akustischen Sphäre. Aber auch der schlafende Mensch bewegt sich und erzeugt dadurch neue Tast- und Bewegungsreize; Veränderungen der Lage der Decke modifizieren die Temperatur; grelle Lichtreize dringen auch durch das geschlossene Auge, und das Ohr hat überhaupt keinen besonderen physiologischen Schlafschutz gegen Geräusche und Stimmen.

Nur dadurch, dass der Schlaf zugleich eine bedeutende Herabsetzung der sensorischen $\mathrm{Empfänglichkeit} \mathrm{mit} \mathrm{sich}$ bringt, ist es möglich, dass diese nie fehlenden Reize unwirksam bleiben. Je geringer die Durchschlagskraft äusserer Reize, um so "tiefer" ist der Schlaf. Das menschliche Restitutionsbedürfnis, dem der Schlaf dient, schafft normaler Weise auch die nötigen Hemmvorrichtungen gegen Störungen; und das Hauptmittel ist die starke Erhöhung der sensorischen Schwelle.

Diejenigen Reize nun, welche die Schwelle überschreiten, können zwei verschiedene Arten der Wirkung ausüben: bei grosser Eindringlichkeit We ckung 1 ), bei geringerer Traumbeeinflussung.

„Eindringlichkeit” bedeutet hier nicht etwa lediglich die rein

\footnotetext{
1) Kraepelin hat eine experimentelle Messmethode der Schlaftiefe entwickelt, indem er feststellte, welche Reizintensität (z.B. eines Schalles) nötig ist, um den Schlaf zu unterbrechen. Die obigen Beispiele zeigen aber, dass ein rein sensorisches Mals
unzureichend ist.
} 
sensorische Intensität. Das zeigen schon die „Weckreize”. Soldaten im Schützengraben schliefen hinweg über das stärkste Artilleriefeuer, wenn sie daran gewöhnt waren; aber auf das, akustisch viel leisere, Kommandowort hin wurden sie sofort wach. Es handelt sich also augenscheinlich um die personale $\mathrm{Rele-}$ v a $\mathbf{n}$ z des Reizes, welche dessen Weckschwelle sofort stark herabsetzt. Andere Beispiele hierfür: Eine junge Mutter, die über stärksten Strassenlärm hinwegschläft, wacht vom leisen Wimmern des Kindes auf. Das Klingeln der Weckeruhr weckt Menschen, die durch viel lauteres Klingeln der elektrischen Bahn oder durch Glockenläuten nicht geweckt werden u.s.w.

Ganz Entsprechendes gibt es offenbar bei den „T $\mathrm{r}$ a u $\mathrm{m}$ r e iz e n", nur dass hier der Nachweis viel schwerer ist. Die traumhafte Verarbeitung eines Reizes bedeutet zunächst eine Art Selbstschutz der Person gegen den Erweckungs-Choc. Die Erregung, die -durch den Reiz gesetzt ist, fliesst ab in einer Richtung, in der der Schlaf zwar gelockert und abgeflacht, aber nicht unterbrochen wird. Ist der Reiz traummäIsig verarbeitet, so ebbt seine Wirkkraft ab, und der Schlaf kann fortgesetzt werden. Der Vorgang kann aber auch so ablaufen, dass die Weckung nicht verhindert, sondern nur verlangsamt wird; die Traumwirkung des Reizes ist dann eine Art Ubergangs- und Vorbereitungs-Erscheinung. Jeder kennt aus eigener Erfahrung solche Fälle, in denen das Klingeln der Weckeruhr, das Klopfen an die Schlafzimmertür, der sprachliche und handgreifliche Ermunterungsappell eines Anderen zunächst traumartig erlebt und verarbeitet wurde, dann aber doch zu allmählichem Aufwachen führte. So wird auch verständlich, weshalb man so oft das Gefühl hat, sich nur des Traumes zu erinnern, den man unmittelbar vor dem Erwachen hatte; es ist dann eben derjenige Traum, der schon in den Erwachensvorgang selber hineingehört.

In den letztgenannten Fällen wird der Traumreiz oft adäquat wirken (d.h. solche Traumwahrnehmungen erzeugen, wie sie den Wachwahrnehmungen gleichen Reizes entsprechen); man träumt dann also etwa, dass der Wecker klingelt, dass angeklopft wird u.s.w. Aber auch hier gibt es schon öfter jene eigentümliche Umgestaltung der Wahrnehmungen, die dann bei den, nicht zur Weckung führenden, Traumreizen geradezu die Regel bildet. 
Es wird etwa ein Schlafender durch eine herabfallende leichte Stange am Nacken gestreift: er träumt, ohne aufzuwachen, eine ihm bevorstehende Hinrichtung durch die Guillotine. - Die Bettdecke fällt herab und die plötzliche Kälte wirkt als Traumreiz; der Schlafende träumt, er sei plötzlich in Polargegenden versetzt. - Das Klingeln des Weckers wird zum heftigen Läuten der Feuerwehr, ein Türschlagen zu einem Kanonenschuss u.s.w. - Auch innere Reize, z.B. des Verdauungstraktes oder des Zirkulationsapparats, können sich im Traum in ganz andersartige Körpererlebnisse, des Fliegens, Fallens, Alpdrückens umsetzen.

b. Mnemische Reize. - Wie alle Phantasiegebilde sind auch die Träume auf ein Rohmaterial von Erfahrungen angewiesen, die der Träumende in früheren Wachzuständen gesammelt hatte. Aber nicht nur einzelne Traumbruchstücke sind mnemisch bedingt; es gibt auch die Wiederkehr ganzer, in sich zusammenhängender Erlebnis-Gestalten und -Abläufe: Schulträume, Examensträume, Reiseträume. Nächstes und Fernstes, Vorgänge des eben abgelaufenen Tages und Szenen aus der fernen Kindheit stehen im Traum wieder auf.

Die A u s les e dieser mnemischen Traumarbeit ist von der der wachen Erinnerung sehr verschieden. Oft genug gibt es Verwunderung, warum man wohl gerade von irgend einer unwesentlichen Einzelheit, von irgend einem gleichgültigen, längst vergessenen Menschen oder Ereignis geträumt habe. Auch objektive Anlässe werden nur selten aufweisbar sein: so etwa, wenn man auf Reisen in einem Zimmer besonderer Art schläft und nun von einem ähnlichen früheren Aufenthalt träumt. Es weist also auch hier alles darauf hin, dass die Auswahl vom $\mathrm{S} \mathrm{u} \mathrm{b} \mathrm{j} \mathrm{e} \mathrm{k} \mathrm{t}$ her erklärt werden muss, sofern überhaupt eine Erklärung möglich sein soll. Hierbei wird man zwei Arten mnemischer Traumwirkungen unterscheiden müssen, die einem, bei den Wacherinnerungen gemachten Unterschied entsprechen, nämlich $\mathrm{K}$ on $\mathrm{t}$ in u it ä t sund $\mathrm{S}$ pa l t u n g s-Erscheinungen ${ }^{1}$ ).

Die Kontinuitätserscheinungen sind relativ einfach zu beschreiben. Sowie das Träumen die Vorbereitung des Erwachens ist, ist es beim Einschlafen auch der $\mathrm{Nachklang}$ des $\mathrm{Wach}$ $\mathrm{s}$ e in s. Stetig geht hier der Lebensprozess aus dem, durch Denken und Willen disziplinierten Tun in lässiges Wachträumen, in 
Halbwachtraum und Schlaftraum über, bis er in traumlosen Schlaf einmündet. Dass in solchen Ubergangszuständen das vorangegangene Wachleben tatsächlich "nachklingt", ist nun verständlich; was uns am Abend lebhaft beschäftigte, vielleicht erregte und noch nicht ganz abreagiert war, erlebt dann im Traum jene Periode des Ausschwingens und seelischen Erledigtwerdens, die uns aus der Psychologie des Gedächtnisses als „primäres Gedächtnis" und „Zeithof" bekannt ist (s. S. 268 f.).

Aber diese mnemische Kontinuitätswirkung ist durchaus nicht allgemein; oft $\mathrm{m}$ e i d e $t$ der Traum sogar grade die eindrucksvollsten Ereignisse des Vortages - so ist bekannt, dass nach einem Todesfalle die Hinterbliebenen fast niemals sofort von dem Verstorbenen träumen. Stattdessen werden nun im Traum jene unerwarteten Erinnerungen an ganz verschollene Erlebnisse lebendig. Hier also haben wir es mit Spaltungserscheinungen zu tun; der Traum ist, wie es scheint, nicht der Fortsetzer, sondern der Ge ge n s pieler des Wachlebens und seiner Interessen und Betätigungen.

Die negative Seite dieser Erscheinung - also das Nicht-weiterarbeiten der Wachinteressen - kann als eine Art personaler Umschaltefunktion zu Erholungszwecken angesehen werden. Der Schlaf soll ja, neben der körperlichen Entspannung, auch die Gefahr einer Uberreizung und Uberbeanspruchung seelischer Bereiche beseitigen. Solche Erholungstendenzen aber verwirklichen sich nicht nur in absolutem Nicht-Funktionieren, sondern auch im Uberwechseln aus ernsteren, aktiveren, verantwortungsvolleren Betätigungen in leichtere, freiere, unernstere - kurz $\mathrm{p} \mathrm{h}$ a n$\mathbf{t}$ a si e $\mathbf{m}$ ä $\mathbf{s}$ i g e re Verhaltungsweisen. Dies führt im Wachleben zum Spiel nach des Tages Mühe, im Schlafleben zum Traumspiel. Die völlige Andersartigkeit der seelischen Gebiete des Traumlebens, die Unbeherrschtheit und Ungehemmtheit der Traumabläufe hat also regenerative Bedeutung.

2. Traumphantasieen

Nach welchen Gesichtspunkten erfolgt nun die Auslese, die das Traumleben aus den Erfahrungen des Wachlebens vornimmt? Und was macht der Träumende mit diesen Vorstellungen - sodass sich schliesslich jene irrationalen, erfahrungsfremden Phantasmen ergeben? 
Diese Probleme sind so schwierig, dass wir uns ihnen nur schrittweise nähern können.

a. Dimension a le Verwandlungen. - Beginnen wir damit, dass im träumenden Menschen die pers o n a le n $\mathrm{D}$ i m e n sion en merkwürdig verändert sind. Man träumt eigentlich immer nur „Gegenwart”, räumlich und zeitlich. Im Traum ist alles „hier" und „jetzt" - in diese Präsenz ist Fernes und Nahes, Vergangenes und Künftiges wahllos hineingezogen (denn selbst Bevorstehendes wird geträumt nur als unmittelbar Drohendes oder Winkendes, also der weiteren seelischen Gegenwart Zugehöriges). So verliert sich hier die objektive, raum-zeitliche Ordnung; das phantastischste Zaubermärchen kann nicht groteskeres Versetztwerden aus einem Ort an einen anderen, und wildere Vermischungen von Vorgängen verschiedenster Zeiten ersinnen, als es der Traum vermag. Eben darum sind weit zurtickliegende Erlebnisse, sofern sie überhaupt noch reproduzierbar sind, für den Träumenden von keiner geringeren Bedeutung als die Ereignisse des gestrigen Tages. Wenn ein Erwachsener von Schulängsten träumt, so ängstigt er sich j e t $\mathbf{z} \mathbf{t}$ - wobei wiederum der Traum nicht so konsequent zu sein braucht, dass der Träumende sich noch als „Schulkind" sehen müsste.

Es ist hier die bisher noch kaum erörterte Frage aufzuwerfen: ob nicht das, was der Traum noch an objektiver Geordnetheit der Dimensionen zu enthalten scheint, zum grössten Teil erst in der $\mathrm{nachträglichen} \mathrm{Traum-Erinnerung} \mathrm{und} \mathrm{-Aussage} \mathrm{ent-}$ standen ist. Das Wissen um Träume und die nachträglichen Berichte über ihren Inhalt setzen den Wachzustand voraus, also eine völlig andere seelische Situation als jene, in welcher der Traum stattfand. Vor allem steht die wache Erinnerung und Darstellung zwangsläufig unter L o g i f i z i e r u n g s-Bedingungen. Das völlig Krause und Wilde lässt sich nachträglich nicht als solches rekonstruieren, geschweige denn in, für andere verständliche, Worte fassen. Schon der Umstand, dass die Aussage ü b e r einen Traum in zeitlicher Folge ablaufen muss, kann zu der Täuschung führen, dass die geschilderten Vorstellungen auch in dieser Sukzession auf einander gefolgt sein müssten - was keineswegs bewiesen ist. Ja, es gibt indirekte Anhaltspunkte, die den Zweifel hieran sehr bestärken. Bei Reizträumen nämlich, die schliesslich 
zum Erwachen führen, kann man die geträumte Zeit gelegentlich mit der objektiven Zeitdauer vergleichen, die zwischen Reiz und Wachwerden verging; und da gibt es die seltsamsten Unstimmigkeiten.

Oben (S. 472) wurde als Beispiel für Reiztrăume ein Hinrichtungstraum erwähnt, der durch Fallen einer Stange auf den Hals des Schlafenden ausgelöst war. Im gleichen Bericht (sein Ort ist mir nicht mehr erinnerlich) war nun erwähnt, dass $f$ a s $t$ u $m$ it $t$ el bar nach jener Schlafstörung Erwachen eintrat. Die Traumerzählung aber berichtete von einem längeren Zusammenhang von Feinden, Verfolgungen, Gefangennahme, Todesurteil - und im Moment vor der Exekution sei der Traum durch das Erwachen unterbrochen worden. Es muss hier also durch den Reiz ein Gewirr von Vorstellungen, die mit Kopfabschneiden etwas zu tun hatten, in Gleichzeitigkeit oder in stärkster zeitlicher Verkürzung ausgelöst worden sein; erst Erinnerung und Erzählung brachten eine logische Zeitordnung hinein.

Ich selbst hatte einmal folgendes Traumerlebnis. (Zur Erläuterung sei vorausgeschickt, dass damals meine kurze Nachmittagssiesta normaler Weise durch Ankunft des Postboten abgeschlossen wurde; die angekommenen Briefschaften pflegten mir in das Zimmer, in dem ich auf dem Sopha lag, gebracht zu werden.) Einmal drang zwar das Läuten des Briefträgers in meinen Nachmittagsschlaf hinein, weckte mich aber nicht, sondern wirkte als Trau mreiz; nach meiner eigenen Traumerinnerung hatte ich sehr logisch geträumt: ich höre den Briefträger klingeln, die Hausangestellte mit der empfangenen Post eintreten, nehme einen Brief entgegen, öffne ihn, lese ihn - es war ein längerer, mich sehr interessierender Brief von 4 Seiten - und als ich damit fertig bin, werde ich durch das tatsächlich nun eintretende Dienstmädchen geweckt, die ohne Verzug nach Empfang der Briefe in mein Zimmer gekommen war. Die objektive Zeitspanne zwischen dem Läuten des Briefträgers und dem Eintritt des Mädchens war viel zu kurz, als dass sie im Wachleben zu jener langen Brieflektüre ausgereicht hätte.

b. Verändertes I c h-E r l e be n. - Die Auflockerung der personalen Dimensionen im Traume ist nur ein Symptom für einen tiefer liegenden Tatbestand: die A uflocker ung des I c h-E r l e b e n s. Das Zusammenschrumpfen des träumenden Ich zu einem blossen „Gegenwarts Selbst” bedeutet ja viel mehr als etwas bloss Zeitliches und Räumliches: es geht diejenige höhere Selbstorganisierung der Pers o n verloren, durch die sie ihre Lebenskontinuität in die Ordnung der objektiven Welt einfügt. Im Traum fehlt mit der Erinnerung an die eigene Vergangenheit auch die bewusste Verantwortung für sie, und mit der Vorausschau in eine weitere Zukunft 
auch die bewusste Anerkennung von Aufgaben und Verpflichtungen; ebenso fehlt mit der Auflösung der räumlichen Ordnung auch der feste Punkt, von dem aus das Ich seine Stellung zur transpersonalen Welt fixiert. Anders ausgedrückt: im Traum schläft zwar nicht das Bewusstsein, wohl aber jene konzentrative Aktivität, die - als Aufmerksamkeit, Denken und Wollen - die Bewusstseinsphänomene zielmälsig richtet, hemmt, ordnet und unter Forderungen stellt. Die - entwicklungspsychologisch spätere Oberschicht der Persönlichkeit wird im Traum eingenebelt und funktionsunfähig gemacht; es bleibt nur die vitale und intuitive Unterschicht, die nun ihrem eigenen Schwergewicht folgen kann.

Dieser Tatbestand bedeutet zunächst: Erholung von dem Kraftaufwand des Wachzustandes. Alle Aktivität strengt an, geistige nicht weniger als körperliche. Der Kraftverbrauch bedarf der Regeneration; Denken und Wollen müssen sich für neue Taten ausruhen.

Weit wichtiger aber ist der p o s i t i v e Sinn der Erscheinung. Die aktiven Leistungsgebiete des bewussten und geordneten Geisteslebens (des Denkens und Wollens) stehen ja in einem, nun schon oft berührten, S p a n n ungsverhält $n$ is zu dem intuitiv-selbstherrlichen Phantasieleben und zum triebhaft dumpfen Streben. Aus dieser Spannung ergibt sich in der Helle des Wachbewusstseins eine weitgehende Eindämmung jener Bereiche. Sie werden nur zugelassen, sofern sie sich den weiterreichenden Aufgaben und Ansprüchen objektiver Gültigkeit fügen; und sie werden bei diesem Prozess vielfach unterdrückt, abgeschwächt und umgemodelt. Aber diese Hemmung der personalen Wunsch-, Bedürfnis- und Phantasie-Sphären ist niemals eine vollständige, führt nie zu ihrer Abtc̈tung; und in dem Augenblick, in welchem die Denk- und Willens-Aktivität ruht, brechen nun die aufgestauten Kräfte jäh und ungeordnet hervor.

Geschähe dies innerhalb des Wachlebens selbst, dann würde damit das normale Verhältnis der Person zur objektiven Welt vernichtet und die Sinnstruktur der Person selbst zerstört sein. Dies ist der Fall bei Geistes- und Gemüts-Krankheiten, in denen Denken und Wollen die Gewalt über Trieb und Phantasie verloren haben.

Im Leben des gesunden Menschen aber geschieht das Wunder: Triebregungen, Wünsche und phantasiemälsige Vorstellungs- 
spiele emanzipieren sich im Traum vom Denken und Wollen; sie lassen ihre unterdrückten Kräfte ausströmen, a b e r o h n e dass dadurch das normale Ich/Welt-Verhält$n$ is gef ä hrdet wird. Der Traum wird zum Tummelplatz sonst gefesselter seelischer Tendenzen, aber dieses Geschehen bleibt durchaus in nerpsy chisch, bildet lediglich eine vorübergehende Scheinwelt dieses individuellen Menschen und greift nicht unmittelbar ein in die objektive und soziale Welt, der er angehört.

Um so wichtiger aber sind diese Vorgänge für die Person, die dieses Seelenbinnenleben in sich erzeugt. Denn es handelt sich ja in Wirklichkeit nicht um verschiedene selbständige Vermögen, die isoliert oder feindselig im Menschen vorhanden sind, sondern um ihn selbst, in dessen Totalstruktur sich Wille und Trieb, Denken und Phantasie zur mehr oder weniger spannungshaltigen Einheit binden. Deshalb haben die im Traum auftretenden Phantasiephänomene personale B ed e u t ung; sie sind kein beliebiges Vorstellungsgemenge aus heterogenen Elementen, keine rein mechanischen Assoziationsketten ohne Sinn, sondern ein Stück personalen Lebens und darum diesem sinnvoll verbunden.

c. Tr a u m d e u t u n g. - Es ist als das bleibende Verdienst von Freud anzuerkennen, dass er das Prinzip der Sinnlosigkeit aus der Traumpsychologie ausgemerzt hat. Indem er nachzuweisen suchte, dass Träume B ede u t ung haben, folgerte er auch, dass sie $\mathrm{d}$ e $\mathrm{u} \mathrm{t} \mathrm{b}$ a $\mathrm{r}$ seien; und damit wurde zum ersten Mal die Traumdeutung, die bis dahin blosser Gegenstand von Aberglaube und Mystik war (und grossenteils noch heute ist) als wissenschaftliches Problem dargetan.

Aberglaube muss freilich die Traumdeutung bleiben, sofern sie es wagt, $\mathrm{Objektives,} \mathrm{insbesondere} \mathrm{k} u ̈ \mathrm{n} f \mathrm{t}$ ige Realgeschehnisse aus dem Traum vorauszusagen. Der alleinige Gegenstand der Traumdeutung kann vielmehr nur der $\mathrm{T} r$ ä u m e n d e s e l b s t sein - mit denjenigen Schichten seiner Persönlichkeit, die im Wachzustande gebunden und versperrt sind, aber als geheime Untergründe auch die höheren Tätigkeitsgebiete und die personale Gesamtstruktur mit beeinflussen. Solche subjektivierende Traumdeutung hat Freud und haben Unzählige nach ihm 
geübt; und unsere ganze bisherige Untersuchung des Traumes ergibt die Berechtigung dieses Gedankens. Damit ist nun freilich noch nichts über Art und Inhalt der Deutung gesagt; und hier muss eine personalistische Betrachtung die Enge der psychoanalytischen Traumdeutung zu überwinden suchen.

Freud erleichtert sich seine Aufgabe zunächst dadurch, dass er Tra u m-B ericht gleich Tra u m set $z \mathrm{t}$. Wir zeigten nun schon oben, dass der Bericht über einen erinnerten Traum als Tätigkeit des wachen Menschen stark von Wachfunktionen der Logifikation mitbestimmt sein muss; und dass er sich daher viel sinnvoller anhört, als der Traum vermutlich selber war. Je sinnvoller die Deutungsmaterie, um so leichter die Deutung. Nur wissen wir dann leider nicht, wie weit der Traumdeuter den Traum, und wie weit er die unbewusste Interpretation des Traumes durch den Erzähler zum Gegenstand seiner Analyse macht.

War dies Bedenken methodischer Art, so trifft das folgende die Sache selbst. Da der Traum eine Art seelischen Ventils für sonst gehemmte Regungen ist, so glaubt die Psychoanalyse, dass sich die Einzelheiten des Traum-I nhalts auch dem Inhalt jener Regungen zuordnen lassen müssen. Damit würden dann sämtliche Phantasmen des Traumes deutbar werden entweder als direkte Wiedergaben oder als symbolische Verhüllungen jener innerpersonalen Richtungen und Strebungen.

Diese These ist deshalb so gefährlich, weil sie eine Legitimation für restlose Deuterei gibt; der Traum erscheint so lange sinnlos, als nicht für jedes $\mathrm{m}$ a $\mathrm{n}$ if e s te $\mathrm{Tr}$ a u $\mathrm{m} \mathbf{s} \mathbf{t} \ddot{\mathrm{u}} \mathrm{ck}$. der tiefere Sinn enthüllt ist. Das ist viel zu sehr elementenpsychologisch gedacht. In Wirklichkeit aber ist der Traum eine teilweise recht ungestaltete Erlebniseinheit, das Träumen der Ausdruck einer jeweiligen Gesamtverfassung des Schlafenden; und nun kann sehr wohl Traum und Träumen als diese T ot a lität personal bedeutsam sein, ohne dass zu jedem einzelnen Element in ihm ein Bedeutungskorrelativ bestände. Die Psychoanalyse übersieht z.B., dass das Spielenkönnen mit Vorstellungen als solches einem tief eingewurzelten menschlichen Bedürfnis entspricht, dass die Möglichkeit, sich solchem freien Spiel hinzugeben, ohne von der Brutalität der Wirklichkeit dauernd zurechtgewiesen zu werden, unabhängig vom Spezialinhalt dem Traum einen personalen Bezug verleiht. Es ist ferner zu bedenken, dass es Gefühls- 
lagen gibt, die rein die vitale Beschaffenheit des Menschen angehen, ohne inhaltlich differenziert zu sein. Es gibt Zustände der Beklommenheit, der Ängstlichkeit, der gehobenen Stimmung, der inneren Unrast u.sw. - die nicht ursprünglich durch konkrete Vorstellungen, sondern etwa durch rein somatische Veränderungen bedingt sein mögen. Schlägt sich nun eine solche Seelenverfassung im Traum phantasiemälsig nieder (z.B. Ängstlichkeit oder Beklommenheit in einem Angsttraum), so darf man nicht durchaus nach dem „ursprünglichen Angsterlebnis" suchen, das nun in dem Traum seine symbolisch verhüllte Darstellung gefunden habe.

Selbstverständlich bleiben daneben immer noch Möglichkeiten zu berechtigter inhaltlicher Interpretation von Traum und Traumstücken übrig. Aber man kann darauf verzichten, Einzeldeuterei um jeden Preis zu treiben, und sich auf solche Deutungen beschränken, die nicht nur für Anhänger einer bestimmten Schule, sondern für jeden Psychologen plausibel sind.

Die einfachsten Fälle sind diejenigen, bei denen Deutungsmaterie und Deutungsziel zusammenfallen und gleichsam nur die Modalität geändert ist. Was im wachen Leben gewünscht oder gefürchtet wird, verwandelt sich im Traum in Gegenwart und damit in Erfüllung. Eine erhoffte Reise wird im Traum schon gemacht; ein bevorstehendes Examen wird im Traum bereits bestanden oder auch verfehlt; ein ferner Mensch, nach dem man sich sehnt, ein Verstorbener, den man geliebt hat - sie besuchen uns im Traum; wir geniessen ihre Gemeinschaft als selbstverständlich. In noch tiefere Schichten der Persönlichkeit leuchtet der Traum dann hinein, wenn es sich um Wünsche und Fürchte handelt, von denen man sich im wachen Leben keine bewusste Rechenschaft gibt - sei es, weil solche Strebungen vor dem $D$ e $n k$ e $n$ nicht bestehen könnten (utopische Wünsche, unbegründete Ängste), sei es, weil aus der Sphäre des W i 11 e n s Verbote und Hemmungen kommen, die das Bewusstwerden verbieten (sündhafte, verbrecherische, sozial verfehmte Wünsche). Es ist also der Tiefenpsychologie darin zuzustimmen, dass der Mensch in seinen Träumen jene Untergründe seiner Seele verraten kann, die er im wachen Leben nicht nur den anderen, sondern auch sich selbst vorenthält.

Einseitig ist aber wiederum jene Meinung der Psychoanalyse - 
die nun material ihre ganze Deutungspraxis bedingt - dass es sich hierbei fast stets um Sexualregungen handle. Gewiss ist das weite Gebiet des Erotischen und Geschlechtlichen schon deswegen besonders disponiert, das Traumventil der Wunscherfüllung zu benutzen, weil es wie kein anderes Gebiet im Wachleben unter einem Tabu steht, und weil andrerseits die Triebstärke hier so gross sein kann, dass jene Wachhemmungen an irgend einer Stelle zur Lösung drängen. Indessen wäre damit höchstens ein starker Anteil, nicht aber die Alleinherrschaft der Sexualsphäre im Traum zu begründen. Der Mensch ist auch im Traum die unitas multiplex seiner Regungen und Strebungen. Innerhalb der Triebsphäre können sich daher auch andere Gebiete als die Geschlechtlichkeit geltend machen; so gaukelt z.B. der Hunger exzessive Wunscherfüllungsträume, Teilnahme an schwelgerischen Mahlzeiten und ähnliches vor. Ausserdem aber besteht, o b e r h a $1 \mathrm{~b}$ der vitalen Triebe, eine Mannigfaltigkeit von Interessen, Wünschen und Bestrebungen, die ebenfalls im Wachleben mannigfachen Einschränkungen und Verdrängungen unterliegen und nun im Traum ihre Erfüllung suchen. Wenn Jemand einen bestimmten Menschen als sterbend oder gestorben träumt - muss dabei dann immer die geschlechtliche Eifersucht, oder der unbewusste Tötungswunsch des Odipuskomplexes Gevatter gestanden haben? Kann hier nicht auch eine Konkurrenz anderer Art, z.B. um ein Amt, oder ein sonst wie motivierter untergründiger Hass beteiligt gewesen sein? - Geltungsstreben und Ruhmsucht, Begeisterung für politische, künstlerische, religiöse Ideale, auch soziale Gefühle, die mit Erotik nicht das Mindeste zu tun haben - sie flüchten sich oft genug in die Träume, wenn sie sich im Ernstleben nicht voll auswirken und befriedigen können. Da träumt sich der allseitig geduckte kleine Angestellte als Chef eines gewaltigen Unternehmens; der Kriegsmann, der in seinem realen Tun nicht weich werden darf, träumt von zartem, mitleidigem Verhalten zum Nebenmenschen und reagiert im Traum seinen, in der Tiefe lebenden Abscheu gegen das Tötenmüssen ab. Der, mit dem unfertigen Werk hart ringende Künstler schaut im Traum das fertige, ideal gelungene Gebilde. Wir haben weder einen Grund noch ein Recht zu der Behauptung, dass solche Träume keine unmittelbare Beziehung hätten zu unerfüllten Wünschen und unterdrückten Strebungen, und dass sie solange umgedeutet werden müssten, bis ihr 
"eigentlicher" (nämlich sexueller) Wunschgehalt hervorträte. Der Mensch ist ja seelisch viel reicher, als eine solch einseitige Theorie es wahr haben will.

\section{DAS SPIELEN}

Da das Spiel überwiegend ein Kindheitsverhalten ist, so erklärt es sich, dass die Theorie des Spiels hauptsächlich von den modernen $\mathrm{K}$ in $\mathrm{d}$ e s psychologen behandelt worden ist; für viele Einzelheiten kann auf diese eingehenden und vielfältigen Untersuchungen verwiesen werden ${ }^{1}$ ).

Es bleiben aber dennoch einige Erscheinungen und Fragestellungen übrig, die in das Gebiet der a $11 \mathrm{~g} \mathrm{e} \mathrm{m}$ e i n e n Psychologie gehören und daher hier zu besprechen sind.

Ja es ist sogar notwendig, die rein kindespsychologische Einstellung einmal zurücktreten zu lassen, weil sonst das Bild und die Theorie leicht einseitig werden. Denn die Tatsache, dass nicht nur Kinder spielen, sondern dass auch Erwachsene sicht oft mit grosser Leidenschaft dem Spiel hingeben (Karten, Schach, Fussball, Billard u.s.w.), ja, dass es unter ihnen den charakterologischen Typ des „Spielers” gibt, verlangt eine umfassendere Behandlung des Spielproblems.

\section{Das Spiel in den verschiedenen Lebens- stufen}

Vergleichen wir das Spielen von Kindern und Erwachsenen, dann zeigt sich eine grundsätzliche Gemeinsamkeit: eine Scheinwirklichkeit wird mitten in der Welt der praktischen Realität erzeugt. Das Billardspiel der Grossen ist ebenso wie das Soldatenspiel der Knaben ein Scheinkampf zwischen Menschen, die in Wirklichkeit keine Feindschaft gegeneinander haben; die Rolle des Schauspielers ist ebenso eine Fiktion, wie die Mutterrolle des mit der Puppe spielenden Mädchens. Es entspricht hier wie dort dieser Scheinhaftigkeit, dass für das B e w u s s t s e in der Spie-

1) Der eigentliche Begründer der Psychologie des Spiels war K. Groos, der vor einigen Jahrzehnten grundlegende Monographieen verfasst hat. Neuere Monographieen stammen von Hetzer, Buytendyk und anderen. Im Ubrigen finden sich Untersuchungen zur Theorie und Empirie des Spiel eingefügt in die kindespsychologischen Bücher von Groos, Claparède, W. Stern und anderen. Eine Gesamtübersicht iber Spieltheorieen gab in jüngster Zeit Noack. 
lenden der Sinn des Spiels sich in der G e g e n w a r $\mathbf{t}$ erschöpft; es soll nicht - wie etwa Arbeiten oder Kunstschaffen - über sich hinaus auf ein dahinter liegendes Ziel hin tendieren; es hat keine Konsequenzen, es ist unernst, so ernst auch die Spielenden das Spiel während seines Ablaufs nehmen mögen ${ }^{1}$ ).

Die Unterschiede zwischen dem Spielen von Jung und Alt werden deutlich, wenn man gewisse Entwicklungs linien aufdeckt, die dem steigenden Alter parallel gehen.

In den ersten Lebensjahren, etwa bis zum Eintritt in die Schule, ist das Spiel geradezu zentral für das kindliche Verhalten (man nennt diese Zeit deshalb auch das "Spielalter"). Hier fehlt auch noch die scharfe Sonderung von Spielwelt und Ernstwelt; alle Gegenstände der Umgebung und alle Handlungen des Kindes, auch die „ernsthaften”, wie Essen, Sich-Anziehen u.s.w., werden ins Spiel einbezogen, mit Spiel durchsetzt; auch im Grade des „Ernstnehmens" besteht keine scharfe Grenze zwischen den beiden Lebensbereichen des Scheins und des Seins. Ob das Kind der Mutter beim Ankleiden des Babys durch Zureichen der Kleidungsstücke hilft, oder ob es seine Puppe ankleidet,macht erlebnismäIsig kaum einen Unterschied. - Das Schulalter schafft grundlegende Änderungen, indem das Kind die beiden, nun deutlich getrennten, Sphären der Arbeit und des Spiels n e b e n einander durchlebt und erlebt; von da an beginnt eine immer stärkere Entwicklung der Ernsttätigkeit und eine Zurückdrängung des Spielverhaltens, nach Zeitdauer und nach Lebensbedeutung. - Im Jugendalter treten dann $\mathrm{Z}$ wischenformen und Mischformen auf : Zwischenformen sind die Betätigungen des Sports, der durch sein Prinzip ständiger Leistungssteigerung nicht mehr rein in der Gegenwart sich befriedigt wie das Spiel, sondern Zukunftsziele des Fortschritts und des Rekords setzt; ferner das Sammeln, das Basteln und andere, schon auf Erzeugung dauernder Objekte gerichtete "Beschäftigungen". Eine Mischform ist das „Erns ts p i e l", d.h. ein Verhalten, welches bei subjektivem Ernstnehmen doch objektiv noch die Freiheit und Konsequenzlosigkeit des Spiels hat ${ }^{2}$ ).

In der Erwachsenheit wird nun Spiel, Sport und spielähnliche

\footnotetext{
1) Wo die Absicht des Spiels dennoch auf Konsequenzen zielt, die uiber die Gegenwart hinausreichen, ist der eigentliche Spielcharakter schon nicht mehr vorhanden.

Dies gilt z.B. für Hazardspiele, durch die sich der Spieler bereichern will.
2) Vgl. S. 496 .
} 
Beschäftigung immer deutlicher eine blosse $\mathrm{N}$ e b e $\mathbf{n} \mathrm{sph}$ ä $\mathrm{re}$ des Lebens, eine Zugabe und Ergänzung, zugleich aber auch eine Entgegensetzung zu dem strengen Ernst des Berufs und den verantwortungsvollen und konsequenzhaltigen Handlungen des familiären und öffentlichen Lebens.

Noch eine zweite Entwicklung läuft nebenher; sie betrifft Anteil und Art der $\mathrm{Ph}$ a $\mathrm{n}$ t a s i e. In der frühen Kindheit ist diese sehr frei und spontan, beliebig, unorganisiert und springend. Aus allem kann im Spiel alles gemacht werden; der Spielende selbst und die Spielgegenstände können jegliche „Rolle” übernehmen; es gibt keine Grenze, keine Bindung; das Kind ist in seiner Spielwelt Alleinherrscher ${ }^{1}$.

Wenn dann Gemeinschaftsspiele stärker hervortreten, muss sich die Phantasie des Einzelnen schon gewisse Zügelungen durch Rücksicht auf die Anderen gefallen lassen; auch die Spielaufgabe, das Spielmaterial und endlich die Spielregel liefern Bindungen und Richtlinien, die das Walten der Phantasie nicht zu ertöten brauchen, es aber disziplinieren und organisieren. Beim Sport ist dann dieses Bindungsprinzip noch viel strenger; hier ist jede Teilhandlung vorgeschrieben und festgelegt; freie Phantasie hat wenig Platz. Diese erhält dann noch einmal einen neuen Antrieb im Ernstspiel des Jugendlichen, in welchem Triebregungen, Wünsche, Ängste in stark phantastischer Weise ausgebaut werden.

Dagegen sind die Spiele der Erwachsenen fast durchweg phantasiearm; spielmäIsige Einzelbeschäftigungen, wie Sammeln und Basteln, erhalten von der sachlichen Aufgabe und dem Stoff her mehr oder minder strenge Marschrouten. Die Gemeinschaftsspielen (Karten-, Brett-, Bewegungsspiele) sind in ein solches Netz fester Spielregeln gehüllt, dass der kombinierenden Phantasie nur eine recht begrenzte Betätigungsfreiheit bleibt.

Man sieht, es handelt sich nicht nur um Akzentverschiebungen, sondern um grundlegende qualitative Wandlungen; das Spiel des Erwachsenen ist und bedeutet anderes als das Spiel des Kindes. Und doch - alle diese Verschiedenheiten haben den einen gemeinsamen Untergrund: die Fähigkeit des Menschen zum Spielen

1) Vgl. auch S. 489. 
überhaupt; und die Theorie des Spiels muss dieses Grundfaktum in erster Reihe verständlich machen, um von ihm aus dann die besonderen Funktionen des Spielens in den verschiedenen menschlichen Entwicklungsphasen und Lebenssituationen zu erklären.

\section{Theorieen des Spiels}

a) Der personalistische Grundgedanke. Die Zahl der Theorieen, die man zur Erklärung des Spiels erdacht hat, ist gross; vielleicht hat grade die scheinbare $Z$ wecklosigkeit der Spieltätigkeit das Denken angespornt, den wahren Zweck zu enthüllen. Das Irrationale sollte rationalisiert werden. Aber eben hierdurch haben diese Theorieen sich als unzulänglich erwiesen. Sie fragten nach dem eigentlichen Zweck des Spiels, nach seinem Nutzen, nach seiner biologischen Funktion. Die Frage ist voll berechtigt, aber sie ist nicht die einzige und nicht die erste. Gerade unter personalistischem Gesichtpunkt müssen wir an den Anfang den Satz stellen: Das Spielen hat für den Menschen nicht nur Dienstbedeutung, sondern auch, ja vor allem, $S \mathrm{t} r$ a $\mathrm{h} l \mathrm{~b}$ e d e $\mathrm{u}$ t u n g. Der Nicht-Ernst des Spiels darf nicht dadurch wegerklärt werden, dass er auf einen tiefer liegenden Ernst als seinen „eigentlichen" Sinn zurückgeführt wird; vielmehr besteht einer der wesentlichsten Züge des Menschen darin, dass er unernsthaft sein (also spielen) $\mathrm{k}$ a $\mathrm{n} \mathrm{n}$ und $\mathrm{m}$ us s.

Im Spiel bewährt der Mensch-bei aller Weltoffenheit und Weltverflochtenheit - ein Stück Souveränität der Welt gegenüber; er schafft sich eine Sphäre des Daseins, die ihm gehört und die er von sich aus gestaltet. Diese Souveränität aber ist nicht göttliches Schöpfertum, das der Welt überhaupt nicht bedarf; sie ist von der menschlichen Weltoffenheit mitbestimmt, darum wird „Welt" in das Spiel übernommen, in ihm nachgebildet, in Schein verwandelt, umgeformt. Der spielende Mensch spielt immer zugleich "sich" und „Welt": Kämpfer und Kampf, Schöpfer und Werk, Mutter und Kind. Die Welt, die er in seiner Spiel-F r e i h e it verneint, bejaht er zugleich in seinem Spiel-I $n$ h a $1 \mathrm{t}$.

Wir greifen damit auf eine Theorie zurück, die von den modernen Spieltheorieen zu Unrecht in den Hintergrund gedrängt worden war. Der Satz: „Der Mensch ist nur dort ganz Mensch, wo er spielt" stammt von Schiller; und Schiller entwickelt auch den 
Gedanken ${ }^{1}$ ), dass das Spiel eben darum so spezifisch menschlich sei, weil es zwischen der animalischen Weltabhängigkeit ("Gebeugt vom Joche der Notdurft') und der göttlichen Weltüberwindung (dem reinen Pflichtverhalten im Kantischen Sinne) stehe. Schiller bezeichnet dies, im menschlichen Wesen so tief verankerte, Spielen-Können und-Müssen als "Spieltrieb”; und wenn der Ausdruck vielleicht mit der heutigen Fassung des „Trieb"-Begriffes nicht gut vereinbar ist, so hat er doch in der Sache durchaus Recht.

Nun erst sind wir im stande, auch den anderen Spieltheorieen gerecht zu werden, und zwar ihnen a 11 e n, während jede von ihnen mit dem unberechtigten Anspruch aufgetreten war, "die" Spieltheorie zu sein. Denn jede dieser Theorieen suchte e in e bestimmte Beziehung des spielenden Verhaltens zum Lebensernst herauszustellen; solcher Beziehungen aber gibt es unbestimmt viele, und nur einige Grundtypen lassen sich theoretisch formulieren.

Als zweckmälsig erweist sich auch hier die Einteilung in Gegenwarts-, Vergangenheits- und Zukunfts-Theorieen. ${ }^{2}$ )

b) Gege nwartst he orie e n sind solche, die das Spiel in gegenwärtige Strebungen des Menschen einordnen. Es kann dies rein dynamisch oder auch inhaltlich gemeint sein.

Dort, wo der jeweilig verfügbare Kräftevorrat nicht vollständig von den Ernstforderungen des Lebens verbraucht wurde, müssen sich die überschüssigen Energieen einen Ausweg suchen; sie entladen sich daher in Betätigungen, die nicht auf reale Ziele gehen, also in Spielen. Herbert Spencer, der diese Theorie aufgestellt hat, weist darauf hin, dass das Menschenkind in viel höherem Malse als das Tierjunge überschüssige Kräfte hat und sie deshalb im „Spiel" ausgeben kann - und zwar deshalb, weil dem Menschen in seiner langen Jugend viele Lebensaufgaben durch die Erzieher abgenommen werden, die das Tier sehr bald allein zu verrichten hat.

Nach dieser Auffassung ist das Spielen eigentlich nur ein Aus-

1) In seinen, heut viel $z u$ wenig gelesenen „Briefen über die ästhetische Erziehung des Menschen".

2) Ich übernehme hier die Einteilung aus meiner "Psychologie der frühen Kindheit." S. 265 ff. Die entsprechende Einteilung leitete uns auch oben bei den Phantasieen des Alltagslebens, s. S. 457 ff. 
brechen unverbrauchter Vitalspannungen; zwischen dem blossen Zappeln und Johlen auf der einen Seite, dem werkschaffenden oder Rollenspiel auf der andern Seite besteht kein grundlegender Unterschied. Da ja der Mensch - so lehrt Spencer - die nach Äusserung drängenden Kräfte in i r g e n d e i n e r Weise betätigen muss, so greift er zum Nächstliegenden, nämlich zu den Tätigkeiten, die er bei anderen sieht: inhaltlich ist also das Spiel rein durch Nachahmung bestimmt.

Diese Theorie hebt richtig eine $\mathrm{V}$ or a $\mathbf{u}$ s e $\mathbf{t} \mathbf{z} \mathbf{u} \mathbf{g}$ alles Spielens hervor: den überschüssigen Kraftvorrat. In der Tat: wo alle Kräfte eines Menschen vom Ernst des Lebens absorbiert werden, z.B. bei schwerer Überbürdung durch Schularbeit oder Berufsfron, da kann in der kargen Freizeit auch nicht einmal mehr gespielt werden. Ebenso hängt z.B. die Spielintensität des Kindes deutlich von seiner körperlich-geistigen Frische ab; sie kann dort, wo etwa eine Krankheit die vorhandenen Energieen ganz in den Kampf um die Lebenserhaltung stellt, auf Null sinken.

Damit ist aber auch schon die Leistungsfähigkeit dieser Theorie erschöpft. Die Zurückführung alles Spielinhalts auf beliebige und zufällige Nachahmung ist, wie sich gleich zeigen wird, völlig unzulänglich.

Schon etwas tiefer dringt die zweite dynamische Theorie, die "Erholungstheorie" (zuerst von M. Lazarus formuliert). Sie geht, im Gegensatz zur Idee Spencers, von dem starken Kraft ve r$\mathrm{b} \mathrm{r}$ a $\mathrm{u} \mathrm{ch}$ aus, den das Ernstleben vom Menschen fordert, und der eine Kompensation, eine Erholung, notwendig macht. Erholung kommt aber nicht nur zustande durch Abstellung der Kraftbetätigung überhaupt (Ausruhen, Schlafen), sondern auch durch andersartige, und vor allem verantwortungslose Kraftbetätigung: Spiel. Es ist erstaunlich, über welche Energiereserven selbst ein ermüdeter Mensch noch verfügt, sofern nur keine ernsthafte und konsequenzhaltige Tätigkeit mehr von ihm gefordert wird. Selbst starke Aufmerksamkeitskonzentration (z.B. beim Schachspiel, beim Kartenspiel) strengt nicht so an, weil sie unernsten Aufgaben gilt.

Diese Theorie ist, wie man sieht, in erster Reihe auf das Spielen der $\mathrm{E} r \mathrm{w}$ a $\mathrm{c}$ h s e $\mathrm{n}$ e $\mathrm{n}$ zugeschnitten. Für diese ist ja in der Tat das Spielen die $Z$ wischenbeschäftigung zwischen Beruf und vollem Ausruhen. Der Mensch, der eben noch ganz eingespannt war 
in seinen Pflichtenkreis, ist nicht immer sogleich imstande, ohne Ubergang sofort ins dolce far niente einzutreten; er sucht sich allmählich zu ,entspannen" ; und hierfür ist die Vertauschung der realen Welt mit einer Scheinwelt vorzüglich geeignet. Verantwortungslosigkeit erholt.

Auf den unerwachsenen Menschen ist die Erholungstheorie dort anwendbar, wo bereits die Scheidung zwischen "Arbeit" und "Spiel" besteht - also beim Schulkind. Besonders wenn die Schularbeit vom Kinde als eine äussere, noch nicht organisch gewordene Bindung erlebt wird, bereitet das Überwechselnkönnen zum Spiel nicht nur intensiven Genuss, sondern auch Auffrischung der Kräfte.

Im spezifischen ,Spielalter' dagegen gibt es ja noch gar keine andersartige anstrengende Beschäftigung, von der das Kleinkind sich durch Spiel dann wieder erholen müsste; hier versagt die Theorie.

Alle anderen Gegenwartstheorieen haben es mit dem Spielin $\mathrm{h}$ a $1 \mathrm{t}$ zu tun, den sie aus den im Kinde lebendigen Trieben, Interessen und Willensrichtungen zu erklären suchen.

Dass hierbei der $\mathrm{Nach}$ a h m ung t rie b mit in erster Reihe steht, ist unbestreitbar. Die Weltoffenheit des Menschen, insbesondere die des Kindes, erschöpft sich nicht darin, dass der Mensch die tausendfältigen Eindrücke rein rezeptiv in sich einsaugt; gerade in primitiven Stadien und in Zuständen ungehemmter Lebensentfaltung herrscht die Ungeschiedenheit des sensumotorischen Verhaltens vor, in dem das Wahrgenommene zugleich in Aktion umgesetzt wird. Solche Nachahmungstätigkeit kann sich jedes wahrgenommenen Vorgangs der Aussenwelt bemächtigen und macht deshalb nicht Halt bei jenen Tätigkeiten, die dem Kind zum $Z$ w e $\mathrm{k}$ des Erlernens vorgemacht werden; die verschiedensten Vorgänge des häuslichen Lebens und der Strasse, Zeitereignisse und Sensationen, Betätigungen der verschiedenen Berufe, der Tiere und Verkehrsmittel werden ins Spiel übernommen. Auch die Reize der Sozialspiele liegen zu einem grossen Teil in dem Mitmachen und Nachmachen der Handlungen der Vor- und Mit-Spieler (man denke z.B. an Reigenspiele).

Trotzdem wäre es falsch, mit Spencer (s. oben) zu meinen, dass das spielende Kind nur deshalb nachahme, weil die überquellenden Kräfte sich an irgend einem Stoff betätigen müssen. Denn das 
$\mathrm{Nachahmen} \mathrm{selbst} \mathrm{ist} \mathrm{ein} \mathrm{innerlich} \mathrm{gelei-}$ te tes $\mathrm{Tun}$. Aus den unendlichen nachahmungsmöglichen Eindrücken der Aussenwelt greift der spielende Mensch immer nur dasjenige heraus, das ihm innerlich gemäls ist, und er formt sein Nachahmungsprodukt so, w i e es ihm innerlich gemäls ist. Ein einfaches Beispiel möge dies erläutern.

Ein Knabe und ein Mädchen spielen am Strande, äusserlich betrachtet, „dasselbe": sie errichten einen Sandberg und graben einen wagerechten Stollen hinein. Diese identische Spielhandlung bedeutet aber für den Knaben: „ich habe einen Eisenbahntunnel gemacht”, für das Mädchen: „ich habe einen Backofen gemacht". Beide haben Tunnels und Backöfen gesehen; aber das Mädchen denkt nicht daran, im Spiel den Tunnel, der Knabe denkt nicht daran, den Backofen nachzuahmen.

Zuweilen gehen Auslese und Umformung bei der Nachahmung so weit, dass die Aussenbestimmtheit des Spielinhalts ganz zurücktritt hinter diesen inneren Antrieben; aber selbst bei ausgesprochen imitativen Menschen ist das Spiel dennoch niemals eine blosse Kopie, sondern stets von den personalen Innenfaktoren mitgefärbt.

Hier stossen wir auf einen eigentümlichen Doppelaspekt. Der Mensch projiziert nämlich sein Wesen in sein Spielen sowohl direkt wie indirekt.

Es gibt gewisse Persönlichkeitszüge, die solche Durchschlagskraft haben, dass sie sich in allen Betätigungen, ernsten wie spielhaften, bekunden müssen - in den spielhaften vielleicht noch stärker, weil sich hier der Mensch spontan gibt. So wird Art und Inhalt des Spiels zu einem unverhüllten Persönlichkeitsausdruck. Charaktereigenschaften wie: Willensstärke, launisches oder laues Verhalten, Despotismus, Anschmiegsamkeit, Rohheit und Zartgefühl, Pedanterie, soziale oder asoziale Tendenzen verraten sich dann im Spiel nicht minder als im Arbeits-, Berufs- und Familienleben; Gleiches gilt von geistigen Eigenschaften wie: Originalität, Witz, Kombinationsfähigkeit, Unselbständigkeit und Beschränktheit u.s.w. Spezielle Interessenrichtungen und Talente technischer pflegerischer, organisatorischer, kämpferischer, geistiger Art bestimmen den Spielinhalt ebenso wie die ernsthafte Lebensführung.

Aber nicht immer ist die Umsetzung von Persönlichkeitstendenzen in Spielausdruck so einfach und gradlinig. 
Da der Mensch beim Spielen in $f r$ e i e $r$ Tätigkeit sein e i g en e s Scheinreich errichtet, können hier grade solche inneren Regungen zur Auswirkung kommen, die in der harten Wirklichkeit des Ernstlebens schweigen müssen. In solchen Fällen steht also der Spielinhalt in einer gewissen $\mathrm{G}$ e g e $\mathrm{n} \mathrm{s}$ ä $\mathrm{z} \mathrm{l} \mathrm{i} \mathrm{c} \mathrm{h} \mathrm{k} \mathrm{e} \mathrm{i} \mathrm{t} \mathrm{zur}$ realen Lebensformung - entsprechend jenem Gegensatz, den wir oben zwischen Traum und Wirklichkeit schilderten. In der Tat kommt dem Spiel ebenfalls die Funktion zu, s o n s $t$ u n t e rdrückte Persönlichkeitstendenzen an harmlosem Material abzureagieren.

Zunächst bedeutet ja jedes Spiel Sprengung der realen Lebense $\mathbf{n}$ g e, bei Kindern wie bei Erwachsenen. Wenn das Kind „Rollen" spielt: Briefträger oder Kutscher, Puppenmutter oder Kaufmann u.s.w., so ist schon die bloss fiktive Vertauschung des eigenen Ich mit einem anderen Ich, dies Sichhineinversetzen in ein Individuum anderer Art und anderer Betätigung - eine unendliche Erweiterung und Bereicherung. Wenn der Erwachsene nach aufreibend eintöniger Tätigkeit in Büro oder Fabrik abends Karten oder Billard spielt, so erlebt er, wenn auch noch so verdünnt, die Erregungen des Kämpfens, des Wetteiferns, des Siegens und Unterliegens; und wenn er gar in einem Liehhabertheater mitspielt, dann sind die grossen Leidenschaften und hohen Ideen der dargestellten Helden wenigstens zeitweilig seine eigenen.

Aber nicht nur durch phantasiemälsige Erweiterung kann die reale Ichenge negiert werden, sondern durch volle Umkehrung, die sogenannte "Uberkompensation einer Mind e rwertigk e i t". Dieser Gesichtspunkt bildet den Leitgedanken der in dividual p s y cholog is chen Spieltheorie, wie sie von Alfred Adler und seinen Schülern vertreten wird. Die Scheinwelt des Spiels soll dann all das gewähren, was die Realwelt des Ernstes versagt; und je drückender die Enge der Wirklichkeit und die eigene Unfertigkeit empfunden werden, um so exzessiver wird nun Macht und Glanz, unbegrenztes Können und Herrschen g e s pi elt. Gerade das Kind, das an hundert Gebote, Verbote und Abhängigkeiten gebunden ist, strebt danach, im Spiel sich überlegen zu fühlen; es geht recht willkürlich um mit der Materie beim Bauen; es tyrannisiert andere (fingierte oder wirkliche) Individuen beim Spielen mit Haustieren und Puppen, beim Kutscher- und Lehrer-Spielen, bevorzugt in Märchen- 
und Rollen-Spiel Zauberer und Feen, Prinzen und Riesen. Auch so mancher Jugendliche und Erwachsene mag im Spiel mit betonter Energie und Rechthabereipose auftrumpfen, gerade weil er im wirklichen Leben so viel Geltungsminderung ohne Gegenwehr herunterschlucken muss.

Es wäre aber unberechtigt, diese kompensatorische Deutung des Spiels als eine allgemeingültige anzusetzen. Die direkten Persönlichkeitsäusserungen sind im Spiel sicherlich viel häufiger als diese indirekten und paradoxen; und feinere psychologische Beobachtung wird auch sehr wohl den Unterschied bemerken. Energisches oder originelles Spiel sieht doch anders aus, wenn es unmittelbar aus energischem oder originellem W e s e n entspringt, als wenn es eine Überkompensation von Schwäche oder das Erzeugnis blosser Originalitätssucht ist.

In diesen Zusammenhang gehört endlich die ps y c ho a n a$1 \mathrm{y} \mathrm{t}$ is c h e Spieltheorie. Auch hier wird das Spielen als Ventil für unterdrückte Triebe gedeutet; nur sind diese Triebe stets als solche der Sexualsphäre angesetzt. In den seltensten Fällen handelt es sich hierbei um offenkundige Sexualspiele (z.B. spielendes Manipulieren an den Geschlechtsorganen) und um Liebesspiele; meist wird von der Psychoanalyse ein, an sich sexualfremder,Spielinhalt umgedeutet, sodass er als Symbol für Sexualvorstellungen und -Strebungen erscheint. So soll sich hinter dem Spielgebrauch der Peitsche beim Kutscher- und Pferd-Spielen eine sadistische Regung verbergen; ein Spiel „Schweineschlachten”, bei welchem Holzklötze gestochen werden, soll den "Odipuskomplex", d.h. den eifersuchtsgeleiteten Tötungswunsch des Sohnes gegen den Vater verraten u.s.w.

Dass gelegentlich Triebrichtungen solcher Art mitwirken, ist beim Spiel ebenso und aus gleichen Gründen möglich wie beim Traum ${ }^{1}$ ). In pathologischen Fällen mögen sich oft recht weitgehende Sexualisierungen des Spiels finden. Eine allgemeinpsychologische Spieltheorie aber kann in der Sexualmotivation nur eine unter vielen Motivgruppen sehen, die den Inhalt des Spiels bestimmen, und sicherlich nicht die wichtigste. Es gibt eben nicht e in e n Trieb, der die spezifische Eignung hätte, „Spieltrieb" zu werden; vielmehr ist die Spielwelt der Menschen ein orbis pictus a 11 e $\mathrm{r}$ menschlicher Regungen und Wunschrich-

1) S. S. 480 . 
tungen, Trieb- und Interessen-Gebiete, die hier teils in farbgleicher, wenn auch abgeschwächter Kopie, teils im photographischem $\mathrm{Ne}$ gativ, teils in Verzerrung und farbiger Abwandlung auftreten.

Ja noch mehr: in dieses mikrokosmische Bilderbuch ist nicht nur die Gegenwart des spielenden Menschen projiziert; es enthält auch Chronik des Vergangenen und Prophezeiung des Kommenden. Mit anderen Worten: Das Spiel muss auch e $\mathrm{n} t \mathrm{wick}$ $\mathrm{l} \mathrm{ung} \mathrm{s} \mathrm{p} \mathrm{y} \mathrm{ch} \mathrm{olog} \mathrm{is} \mathrm{ch}$ betrachtet werden.

c) Vergangenheitstheorie. - Spielneigung und Spielrichtung sind, wie wir sahen, in den menschlichen Anlagen verankert; Anlagen aber sind wenigstens zum Teil e r b b ed in $g$ t. So lag es nahe, erbbiologische Gedanken auch auf das Spiel zu übertragen. Dies tat zuerst der amerikanische Kindespsychologe Stanley Hall, der das bekannte „b i o g e n e tis c h e Grundgesetz" Häckels auf seelische Vorgänge anzuwenden suchte. Wenn nach diesem Gesetz jedes heranwachsende menschliche Individuum die Entwicklung der Gattung in gekürzter Form wiederholt, dann müssen wir im Kinde Erscheinungen finden, die früheren, heut längst überwundenen, Entwicklungsstadien der Menschheit irgendwie ähneln. Dies sind die Spiele. In den Kinderspielen werden primitive Formen menschlichen Seins noch einmal lebendig: die einfachsten Grundbeziehungen der Gemeinschaftsbildung und des Kampfes, animistische Belebung toter Gegenstände (Fetisch, Menschen- und Tier-Puppe), Benutzung verschollener Waffen (Pfeil, Schleuder), magisches und Zauberwesen, Indianer- und Räuber-Romantik. Dieses Wiedererwachen atavistischer Regungen erfolgt aber nun nicht mehr in der Ernstform ihres ursprünglichen Auftretens, sondern $\mathrm{n} u \mathrm{r}$ als Spiel, d.h. in einer verantwortungsfreien und schnell verrauschenden Scheinform. Gerade darin sieht diese Theorie die positive Zweckbedeutung des Spiels, dass der Mensch die erblich überkommenen (aber der Gegenwartskultur nicht mehr angepassten) Urstrebungen betätigen und damit a b r e a $\mathrm{g}$ i e r e $\mathrm{n}$ kann in harmloser und unschädlicher Weise.

Nähme man die Theorie wörtlich, dann würde das kindliche Spielen nichts mehr mit eigentätiger und gestaltender $\mathrm{Ph}$ a nt a si e zu tun haben, sondern nur mit (unbewusster) Erinnerung. Schon hieraus ergibt sich ihre Unzulänglichkeit. Auch der 
abenteuerliche Glaube, dass das Kind die psychischen Stadien der Vorfahren in gleicher Reihenfolge repetiere, hilft uns wissenschaftlich nicht weiter. Aber man kann doch den Gedanken des „Vergangenheitsbezugs" des Spiels aus der erbbiologischen Fassung befreien und den entwicklungspsychologischen Gehalt herausschälen; dann ergibt sich auch, dass nicht nur das Spielen des Kindes, sondern alles Spielen unter einen neuen Gesichtspunkt gestellt werden kann.

Jede Person ist ge schich tet; sie trägt in sich Dispositionen und Einstellungsbereiche, die in verschiedener personaler Tiefe schweben und jeweilig dann aktualisiert werden, wenn die personale Gesamtsituation es nahe legt. Einige dieser Schichten sind durch ihre zeitliche Zusammengehörigkeit gekennzeichnet. Sie stammen teils aus dem Erbgut (,archaische" oder „atavistische" Schichten), teils aus der individuellen Vergangenheit (,infantile", "puberale" Schichten). Dem Durchbruch solcher Schichten ist nun besonders die personale Situation des Un-Ernstes günstig. Dort, wo der Mensch überhaupt noch nicht eingespannt ist in das Joch der praktischen Realität mit ihren Konsequenzen (Kindheit), und dort, wo der Mensch zeitweilig heraustritt aus der Ernstbindung der Schularbeit, des Berufs u.s.w. (Freizeit der Schüler und Erwachsenen) - dort kann er sich solchen Tendenzen hingeben, die in ihm von früher her schlummern, aber nicht erstorben sind. Sie sind bereit, hervorzutreten, aber auch wieder zurückzutreten, je nach dem „Spiel"-Raum, der ihnen von den Ernstaufgaben des Menschen gelassen ist. Dabei handelt es sich sogar vorwiegend nicht (wie es die Hall'sche Theorie nahe legt) um feste I $\mathrm{nh}$ a $\mathrm{lt} \mathrm{e}$, die aus der Vergangenheit her mnemisch erneuert werden, sondern um E in s te $11 \mathrm{ung}$ s f or men, Gerichtetheiten allgemeiner Art, naivere Gefühlsfärbungen. Deshalb bleibt auch innerhalb der Wiederbelebung vergangener Phasen eine weite Wirkungsmöglichkeit für Neuschöpfung durch gestaltende Phantasie.

In diesem eingeschränkten Sinne ist es fraglos, dass jeder Mensch, Kind wie Erwachsener, primitiver ist, wenn er spielt, als wenn er ernsthaft handelt. Grössere Kinder können im Spiel wieder "Babies" werden; und Erwachsene, die in freier $\mathrm{Na}$ tur ihre Ferien verleben, verfallen hier in einen sehr gesunden, erfreuenden und erholsamen Infantilismus. 
d) Z u k u n $\mathrm{t} \mathbf{s} \mathrm{th}$ e orie en. - Aber zu diesem Vergangenheitsbezug gibt es das Gegenstück: die $\mathbf{Z} \mathbf{u} \mathbf{k} \mathbf{u} \mathrm{n} \mathbf{t} \mathrm{s}$ be de ut u n g d e s S p i e ls. Der spielende Mensch spielt sich nicht nur rückwärts, sondern auch vorwärts. Die „Zukunftstheorie”, vor einem Menschenalter insbesondere durch Karl Groos ausgebaut, muss nun in personalistischem Sinne erweitert und mit den anderen Theorieen verknüpft werden.

In jedem menschlichen Gegenwartsaugenblick lebt Zukunft nicht nur dadurch, dass sie b e w u s s t vorausgesehen, erwartet, geplant, gewollt wird. Die personale Entelechie und die Zielgerichtetheit ihrer einzelnen Anlagen ist vielmehr vorbereitend wirksam, lange vor dem „Fälligkeitstermin" ihrer eigentlichen Zielverwirklichung, und lange bevor sie sich in zieladäquatem Bewusstsein darstellt. Als solche $\mathrm{k}$ e i $\mathrm{m} h$ a $\mathrm{f} t \mathrm{e} n \mathrm{~V}$ or-F or m e $\mathrm{n}$ von Emst-Funktionen sind die Spiel-Funktionen anzusehen. Anlagen, Triebe, Wünsche, Entwicklungsphasen, deren Zeit noch nicht gekommen ist, können doch schon eine so starke innere Quellkraft haben, dass sie nicht mehr in der vollen Latenz zu verbleiben vermögen; sie suchen nach Äusserungsmöglichkeiten, sind aber andrerseits noch nicht stark und in sich gefestigt genug, um schon reale Tat zu vollziehen - und so bemächtigen sie sich der Scheinwelt des Spiels. Dies geschieht durchaus $\mathrm{u} n \mathrm{~b}$ ew u s s t; der spielende Mensch lebt bewusstseinsmälsig ganz in der Spielfreude des Augenblicks und ahnt nicht, dass sich in seinem Spiel Kommendes vorbereitet.

Man könnte an diesem Faktum zunächst das Negative feststellen: die Un s t i m mig k e it zwischen dem verfrühten Durchbruch irgend einer Tendenz und der viel späteren sinnhaftenAnwendung. In der Tat führt diese Unstimmigkeit auch oft zu grosser Unvollkommenheit der Spielleistung. Da wird der Bau eines kleinen Jungen schief und fällt hundertmal zusammen, weil weder die konstruktive Begabung noch das Verständnis für statische Gesetze schon so gereift sind, um einen ordentlichen Bau zu ermöglichen. Da behandelt das kleine Mädchen ihre Puppe beim Anziehen, Baden u.s.w. so unzweckmälsig, dass ein lebendiges Kind darunter Schaden nehmen würde; ihre pflegerischen Fähigkeiten sind eben noch unentwickelt. Philiströse Gegner des Spiels greifen mit Vorliebe diese Mängel auf und schliessen daraus, dass solche Beschäftigungen noch lange nichts für das Kind seien; sie übersehen 
eben, dass ihnen ein ganz anderer Sinn zukommt, als der der Gegenwartsangemessenheit.

Die personale Bedeutung, die in diesem Vor-Charakter des Spiels steckt, ist eine dreifache: Vorübung, Vorausdruck, Vortastung.

Die Spieltheorie von Groos stellt die $\mathrm{V}$ or $\ddot{\mathbf{u}} \mathbf{b} \mathbf{u} \mathbf{n} \mathbf{g}$ in den Mittelpunkt. Im Gegensatz zum Tier kommt der Mensch sehr unfertig zur Welt; das hohe Entwicklungsniveau, das er schliesslich erreichen soll, und das - ebenfalls im Gegensatz zum Tier - das Niveau der Vorfahren überbieten soll, erfordert eine lange Vorbereitungszeit: die Jugend - und eine ununterbrochene Vorbereitungstätigkeit: das Spiel. Denn das absichtsvolle Lernen und Uben würde bei weitem nicht ausreichen, um so weniger, als es von aussen auferlegt wird, während die Spieltätigkeit einen dauernden, spontanen und ungezwungenen Selbstunterricht des Kindes darstellt, einen Ubungsprozess ohne Wissen und Willen. Gerade die Unvollkommenheiten der Spielleistungen haben einen grossen Ubungswert; eindringlicher kann dem bauenden Knaben die Statik der festen Dinge garnicht beigebracht werden, als dass er an seinen, immer wieder zusammenfallenden, Bauten bemerkt, wie es $\mathrm{n}$ i c h $\mathrm{t}$ gemacht werden muss, um bessere Erfolge zu erreichen. Auch durch $\mathrm{S}$ p i el schaden wird man klug.

Dieser Ubungswert des Spiels ist ganz allgemein: Körperbewegung, Werkschaffen, Sozialität, Intellekt - alles wird spielend geschult. Das spielende Strampeln, Handbewegen und Lallen des Säuglings ist Vorübung für das künftige Laufen, Greifen und Sprechen. Das ältere Kind lernt an konstruktiven Spielen das zielgerechte geschickte Hantieren, das sachgerechte Umgehen mit dem Material, die zweckmälsige Verwendung der Naturkräfte. Das spielende Zeichnen und Kneten übt Raumvorstellung, Raumbeherrschung, ästhetischen Sinn; das Puppenspiel des Mädchens ist gerade wegen seiner Unermüdlichkeit und Vielseitigkeit ein durch nichts ersetzbarer Vorbereitungskurs für die spätere Ernsttätigkeit als Mutter, Pflegerin, Hausfrau. In den Sozialspielen lernt das Kind befehlen und gehorchen, organisieren und wetteifern; bei Spielen mit Spielregeln geht dem Kinde die Notwendigkeit auf, sich unter die Geltung eines abstrakten Gesetzes zu stellen eine Vorbereitung für die künftige Anerkennung sittlicher Forderungen.

Aber der Zukunftssinn des Spieles erschöpft sich nicht in dieser 
utilitarischen Wirkung der Ubbung; er ist noch tiefer in der Person verankert. Denn das Spiel, als keimhafte Äusserung künftig fälligen Ernstverhaltens, stellt auch eine $V$ or v e r $k$ ü $n d u n g$ dieser kommenden Lebensphase dar, es hat progn os t is c h e n A u sdru ckswert. Es ergibt sich also die Paradoxie, dass das spielende Kind entwickelter, reifer ist, als dasselbe Kind, sofern er der Realwelt angehört.

Es sei hier ein Selbstzitat erlaubt. „Wer kleine Mădchen je beim Puppenspiel genauer beobachtet hat, ist gerührt und erschüttert zugleich, wie hier die künftige Mütterlichkeit ihre Schatten vorauswirft. Vielleicht erst $z$ wei Jahrzehnte später wird sie zu einer wirklichen gegenwärtigen Lebensform der Persönlichkeit werden; aber als Ausdrucksform ist sie schon mit solcher Intensität, mit solcher Inbrunst vorhanden, dass man geradezu gespensterhaft die ferne Zukunft vorspuken sieht. Aber es ist kein Spuk, sondern es ist nichts als einer der eindringlichsten Beweise für die Einheit persönlichen Lebens, die auch nicht durch die Gliederung in zeitliche Abschnitte zerrissen werden kann." (Wertphilosophie S. 155.)

Die Grenze dieses prophetischen Vorausdrucks liegt allerdings dort, wo die Vieldeutigkeit und Unbestimmtheit der Veranlagung beginnt. Das zukünftige Sein der Person ist ja nicht so eindeutig festgelegt, dass alle ihre Züge schon lange vorher in Vorzeichen erkennbar sein könnten; die Entwicklung besteht ja zum grossen Teil in einem langsamen Sichherantasten an die gemälseste Lebensform, in allmählicher Vereindeutigung unklarer Tendenzen. Es gibt auch bestimmte Epochen, in denen diese Unsicherheit vorwiegt und daher die gradlinige prognostische Beziehung des Spielverhaltens zur Zukunftsgestaltung fehlen muss. Eine solche Epoche ist vor allem die Pubertät.

Aber gerade dieses, seiner selbst unklare, Suchen nach den personalen Zukunftsmöglichkeiten gibt dem Spiel die neue Funktion der "Vort a s t u n g”; es wird zum Organ eines unbewussten Durchprobens verschiedener Möglichkeiten. Man kann schon beim jüngeren Kinde zuweilen bemerken, wie es hin und her laviert zwischen verschiedenen Spielinteressen, die zum Teil nur durch sehr äusserliche Anlässe: Vorbilder und Suggestionen, Empfang bestimmter Spielzeuggeschenke, Materialbestand eines Kindergartens u.s.w. geweckt sein mögen; erst in der Betätigung erweist sich dann, welches Interesse am nachhaltigsten ist. Weit wichtiger aber wird diese Erscheinung in der Pubertätszeit. Denn 
hier beginnt der junge Mensch abzurücken von dem naiven spielenden Verhalten der Kindheit; er nimmt das, was er erstrebt und tut, solange es ihn erfüllt, $\mathrm{s} \mathrm{u} \mathrm{b} \mathrm{j} \mathrm{e} \mathrm{k} \mathrm{t} \mathrm{i} \mathrm{v} \mathrm{ausserordentlich} \mathrm{ernst}$ und er würde entrüstet die Bezeichnung dieses Tuns als "Spiel" zurückweisen. Aber dennoch hat das Tun - glücklicher Weise nicht den Tiefgang und die Konsequenzhaltigkeit echten Ernstes; denn dem Streben entspricht noch kein adaequates Können und keine Zielsicherheit. So ist die Handlung des Jugendlichen in Wirklichkeit nur ein Glied in einer Reihe von Vortastungen, obwohl er sich jeweilig ganz mit ihr identifiziert. Ich bezeichne diese eigentümlich ambivalente Verhaltungsweise als „Ernsts p i e l". Notwendig ist hier die Illusion des Ernstes, weil bei einer Tätigkeit, die von vorn herein als Spiel durchschaut wird, nicht derjenige Gefühls- und Willens-Aufwand zustande kommen würde, der zur Erprobung auf Wesens-Gemälsheit oder -Ungemälsheit nötig ist; aber die schnelle Abschüttelung dieser affektiven Akzente, sobald zu einem anderen Lebensexperiment übergegangen wird, zeigt doch den Spielcharakter. Am charakteristischen offenbart sich dies Vortasten bei den Liebes-Ernstspielen der Pubertätszeit, ähnlich aber auch bei Bundesgründungen, bei Inangriffnahme künstlerischer oder technischer Pläne (Drama, Perpetuum mobile), in der Begeisterung für Lebensreformen u.s.w. Wichtig ist, dass man die komplementäre Beziehung von Vortastung und Vorausdruck im Auge behält: je mehr der junge Mensch im Stadium jenes vorbereitenden Tastens ist, um so weniger besteht das Recht, irgend ein bestimmtes ernstspielhaftes Verhalten als Vorausdruck und damit als prognostisch verwertbares Symptom endgültiger Persönlichkeitsstruktur anzusehen.

\section{DAS SCHAFFEN}

(INSBES. DAS KÜNSTLERISCHE SCHAFFEN ${ }^{1}$ )

\section{Phantasma und Werk}

Wir sprechen von schaffender Phantasie dort, wo aus der Phantasie neue objektive Gebilde und Vorgänge erwachsen, die nun

1) In diesem Abschnitt können nur einige wenige Themen und Gesichtspunkte aus dem grossen Gebiet der Psychologie des künstlerischen Schaffens und Geniessens zur Behandlung kommen. Im übrigen muss verwiesen werden auf die Bücher über Psychologie der Kunst, auf die psychologischen Teile der Werke über Ästhetik: von Dessoir, Miller-Freienfels, Utitz u.a, und auf die „Personalistische Aesthetik" von F. Kainz. 
über den phantasierenden Menschen hinweg selbständige Existenz erhalten und behalten, and zwar sowohl im Materiellen wie im Geistigen. Ein Kunstwerk (z.B. ein Gemälde) ist zugleich ein körperlicher Gegenstand und Träger geistiger Werte; ein Heroenkult ist zugleich „Kult” (also sichtbare auf die Welt einwirkende Handlung) und Mythos (also ein, dem Volk heiliger, geistiger Gehalt).

Ebenso ist bei dem schaffenden Menschen selbst beides vorhanden: im Seelischen treiben Phantasie-Inhalte und -Abläufe ihr Spiel; im Leiblichen werden die zu ihrer Gestaltung notwendigen Handlungen vollzogen.

Aber diese so entstehende Vierteilung von Merkmalen des Phantasieschaffens hat doch nur ein Recht in der Abstraktion; in der Wirklichkeit bilden sie eine spannungsreiche Vieleinheit, wie die Person selbst, die das Schaffen vollbringt.

Die rein binnenseelischen Phantasiegestalten des $\mathrm{K}$ ü $\mathrm{n}$ tle rs sind nicht etwa vor dem materiellen Schaffensprozess selber schon fertig vorhanden und bleiben während jenes Prozesses $\mathrm{n}$ e b e $\mathrm{n}$ ihm bestehen; vielmehr ist das Schaffen ein p s ychophysisch neutrales Geschehen von fortwăhrend wechselnden Sichten. Der Phantasiebeginn, der als „Konzeption" eimen neuen Schaffensakt einleitet, ist weniger "Bild" als "Antrieb": ein vages Bewusstsein dessen was werden soll, verbunden mit stärkstem Tätigkeitsdrang (also ein Analogon zu dem, was wir in der Denksphäre als "Problematik" bezeichneten). In diesem Tun nun konkretisiert, klärt und wandelt sich das Phantasma, wirkt wieder auf die weiteren Schaffensakte, emanzipiert sich zeitweilig von diesen, wird mit dem Ergebnis konfrontiert. Hierbei kann es zum Bejahen der Harmonie von Phantasma und Werk, aber auch zu starken seelischen Gkeichgewichtserschütterungen kommen. Der Schaffende wird bald überrascht von der, alles Vorgestellte überbietenden, Wirklichkeit des Erzeugnisses, bald wird er gepackt von schmerzhaftem Unzulänglichkeitsgefühl, weil es nicht gelang, das Uberschwängliche der inneren Schau in äussere Gestalt zu giessen.

Ebensowenig ist im geschaffenen $\mathrm{O} b \mathrm{j} \mathrm{e} \mathrm{kt}$ Materielles und Geistiges scharf zu trennen. Weder für den schaffenden Menschen noch für diejenigen Menschen, die das Geschaffene empfangen, geniessen und weiter geben (Publikum, Vermittler von Kunst und 
Kult u.s.w.) ist erlebnismäfsig der materielle Gegenstand geschieden von dem geistigen Gehalt; vielmehr wird ein Gegenstand überhaupt nur dadurch zum Kunstwerk oder zum Kultobjekt, dass in seiner sinnenfälligen Gestalt der geistige Gehalt zugleich Ausdruck findet.

\section{Individuelles und kollektives $\mathrm{Sch}$ affen}

a) Kunstwerk und Mythos. - Macht man die schöpferische Phantasieleistung in der h e u ti g e $\mathrm{n} \mathrm{Kultur-}$ $\mathrm{m}$ e $\mathrm{n} \mathrm{s} \mathrm{ch}$ h e it zum alleinigen Gegenstand der Betrachtung, so erscheint sie als das Werk einer individuellen Persönlichkeit, ja sogar als eine $\mathrm{H}$ ö h stform individuellen Tuns, da sich hier der einzelne Mensch als Künstler zutraut, im Gegensatz zu der ganzen gegebenen und geltenden Objektwelt, von sich aus neue Objektivität zu erzeugen. Aber das Bild ändert sich sehr, wenn man die Basis im Allgemein-Menschlichen nimmt. Dann zeigt es sich nämlich, dass die durchindividualisierten Phantasieerzeugnisse nur ganz seltene und historisch eng umgrenzte Phänomene darstellen, ja, dass diese auch in der gegenwärtigen Kulturepoche immer noch stark in einem $\mathrm{kolle} \mathrm{kt}$ i v e $\mathrm{n} \mathrm{P} \mathrm{h}$ a $\mathrm{t}$ a$\mathrm{s}$ i e b o d e $\mathrm{n}$ verankert bleiben.

Um sich das hier Gemeinte klar zu machen, braucht man nur die soeben genannten Hauttypen schöpferischer Phantasieleistung, $\mathrm{Kunst}$ werk und $\mathrm{Mythos}$, gegenüberzustellen. Sie sind in Wirklichkeit nur zwei Pole eines gewaltigen, immer von neuem sich wiederholenden, Entwicklungsprozesses. Dass der Mythos ein Erzeugnis schöpferischer Phantasie ist, ist ebenso sicher, wie dass er nicht von einer Einzelperson geschaffen ist. Er ist vielmehr die typische und ewige Form kollektiver Phantasiearbeit. Soweit er dies ist, gehört seine Besprechung nicht in die Psychologie der Einzelperson, mit der wir es hier zu tun haben, sondern in die Völker- und Kultur-Psychologie. Wohl aber müssen wir hier auf die Beziehung des kollektiven $\mathrm{zum}$ personalen $\mathrm{M}$ om ent hinweisen.

Die mythenbildende Phantasie in ihrer unauflöslichen Verbindung mit Kult und Magie schafft aus der fremden Welt des Vorhandenen die Heimatswelt der Sippe, der Horde, des Stammes, des 
Volkes $\left.{ }^{1}\right)$. Dieser kollektivpsychische Prozess ist nicht etwa irgendwann einmal in vorgeschichtlicher Vergangenheit durchlaufen worden und dann zum Stillstand gekommen, sodass wir auf die mythische Phantasie als eine heut längst überwundene Entwicklungsphase der Menschheit zurückblicken könnten; vielmehr gehört er notwendig zu jedem menschlichen Gemeinschaftsleben; und so kann man auch das fortwährende Entstehen neuer Mythen beobachten.

Selbstverständlich ist die Ausgestaltung des Mythos nur dadurch möglich, dass die einzelnen Individuen der Mythen-tragenden Gemeinschaft daran mittun; aber der Anteil des Einzelnen ist durchaus anonym; zwischen $r$ e $z$ e $p t$ i v e r Phantasie, die das Gehörte übernimmt, reproduktiver Phantasie, die es wiederholt, weiter gibt, äusserlich gestaltet (z.B. in der Kulthandlung, im magischen Tanz u.s.w.) und $\mathrm{produkt}$ ive $\mathrm{r}$ Phantasie, die umformt und neue Einzelheiten hinzufügt, besteht in dem kollektivpsychischen Geschehen noch keine Sonderung. Das Individuum funktioniert und erlebt sich hierbei durchaus als Träger eines Uberindividuellen und weiss nichts davon, dass in seinem Mitmachen eine individuelle Schöpferkraft tätig ist.

Damit hängt zusammen, dass es in dieser kollektiven Urphantasie auch noch nicht die Absonderung verschiedener $\mathrm{B}$ e $\mathrm{r}$ e ic h e der Phantasiebetätigung gibt; der kultische Mythos ist der gemeinsame Mutterboden, aus dem sich erst sehr allmählich Religion, Kunst, Wissenschaft, Sittlichkeit u.s.w. herauslösen. Dies ist besonders wichtig für das Phänomen der Kunst und des Künstlers. "K u n s t” als autonomes Gebiet, und „d e r K ü n s t1 e r" als individueller Schöpfer einmaliger, eigenwilliger und einzigartiger Werke - das sind ganz späte Entwicklungserscheinungen; und bei aller heute vorhandenen Differenzierung müssen die Künstler doch immer wieder durch ein Eintauchen in jenen mütterlichen Urboden des kollektiven Mythos ihre Kräfte erneuern und ihren Anspruch auf „Originalität" rechtfertigen. Die Homerischen Epen sind noch nicht reine Werke der Kunst, sondern umgeformter Mythos; Homer selbst kein individueller Dichter, sondern eine mythische Verkörperung jener mythenformenden Kräfte. Mittel-

1) Wie weit infolge dessen alles Geschich ts bew us t s e in zugleich Mythik sein muss, mag hier unerörtett bleiben; vgl. hierzu unter anderem: Wertphilosophie S. 277. 
alterliche Madonnenbilder, Goethe's Faust, Wagner'sche Musikdramen u.s.w. sind wiederum mehr und anderes als blosse souveräne Erzeugnisse genialer Individuen; sie sind schon wieder ein Stück Mythos geworden, weil sie aus den, mehr als nur ästhetischen, Quellen des kollektiven Lebens gespeist sind.

b. Die Individualisierung des Schaffens. - Freilich darf man nun deshalb die andere Seite nicht unterwerten. Die Verselbständigung der Kunst und die damit Hand in Hand gehende Ver-Persönlichung des schaffenden Künstlers ist einer der eindruckvollsten Entwicklungsprozesse des menschlichen Geistes; und dieser Prozess bedeutet nun, psychologisch betrachtet, die personaleVerselbständigung der $\mathrm{sch}$ öpferischen Phantasie. Darin liegt ein Doppeltes: die enge Beziehung der schaffenden Persönlichkeit zum geschaffenen Werk, und die Umwandlung des objektiven Seins in ästhetischen Schein.

Es wäre eine psychologisch sehr fruchtbare Aufgabe, die Bedeutung der A n on y mit ä $t$ im künstlerischen Schaffen zu untersuchen. Durchaus $\mathrm{n}$ a i v ist die Anonymität bei demjenigen, der sich lediglich als ausführendes Organ kollektiver.Kräfte fühlt und daher garnicht auf den Gedanken kommt, seinen besonderen Anteil an dem Werk zu betonen, ja der in der Abweichung vom Geltenden (also in dem eigentlich „Produktiven”) eher eine Verfehlung seiner transpersonalen Aufgabe sieht ${ }^{1}$ ). Selbstverständlich anonym geblieben sind daher die Schöpfer der Volkskunst: der Volkslieder, Volksepen, Volkstänze, der kultischen Dramen, der Tempelbauten, der Volkstrachten, der kunstgewerblichen Techniken u.s.w., u.s.w. Im Mittelalter ist die Scheidung des Malers vom Handwerker, dessen Name relativ gleichgültig ist, noch nicht vollzogen. Dem Bildhauer, der eine Heiligenfigur zum Schmuck der Münsterfassade anfertigte, lag es völlig fern, durch seine Leistung seine persönliche innere Schau verwirklichen zu wollen, oder gar seinen persönlichen Namen berühmt zu machen: er diente der überindividuellen Förderung des Kults und sah nicht einmal eine Sinnwidrigkeit darin, dass seine Schöpfung so hoch oben angebracht wurde, dass kein Menschenauge sich an

1) Eine zweite Form der Anonymität wird uns später bescbäftigen. 
ihrer Schönheit erfreuen konnte. Es wäre völlig abwegig, in dieses Künstlertum psychische Vorgänge hineinzuprojizieren, die man heut leicht als allgemeingültige Erlebensweisen ästhetischen Schaffens ansieht.

In unserer Zeit ist für den Maler, den Bildhauer, den Dichter und Schriftsteller die Zuordnung des Werkes zur Person und damit die Bewertung der personalen Eigenart der Leistung selbstverständlich geworden; aber beim Architekten z.B. stehen auch wir noch an der Grenze; für das grosse Publikum sind Bauwerke noch immer anonyme Erzeugnisse des kollektiven Geistes. Ebenso lassen sich bei den reproduktiven Künstlern diese Übergangserscheinungen zwischen anonymem und personalem Schaffen deutlich erkennen; während die Orchestermitglieder und die Bühnenstatisten anonym bleiben, ist der Dirigent und sind die Träger der Hauptrollen individuelle, „namhafte” Künstler.

\section{Originalität und Verantwortung}

Die Bindung der Phantasieschöpfungen an Einzelpersonen und Namen verleiht nun der schöpferischen Phantasie eine ganz besondere Rolle in dem Doppelsinne der orig in a 1 e $n$ L e istung und der individuellen Verantwortung.

Das Bewusstsein, v o n s i c h a u s in die Welt des Gegebenen ein Neues, und zwar ein werthaltiges Neues hineinzubringen, gehört wohl zu den stärksten Geltungserlebnissen des Menschen überhaupt. „Originell” sein heisst ja U r s p r u n g (origo) sein; and Ursprünglichkeit kann sich immer nur im Kampf gegen geltendes Alltägliches durchsetzen. So kommt es hier leicht zu einer Uberschätzung und Selbstverherrlichung der künstlerischen Individualität, für die ja der Geniekult der Romantik ein eindrucksvolles Beispiel ist. Ihre Zuspitzung finden wir in dem zuweilen mafslosen Geltungstrieb und der Eitelkeit mancher Künstler; und zwar sind diese Eigenschaften charakteristischer Weise um so stärker persongebunden, je enger die Leistung an die momentane Existenz geknüpft ist. So ist für den Schauspieler die gegenwärtige Anerkennung für sein Schaffen ungleich wichtiger als für den Werkschöpfer, der den späteren Ruf und den Nachruhm mit einer gewissen Gelassenheit dem Eigengewicht seines Werkes anheim stellen kann. Durch das Bedürfnis nach Publikum und nach Ruhm 
wird übrigens wieder das scheinbar so individualistische Tun des schaffenden Künstlers stark im Kollektiv verankert. Andrerseits aber kann ihn das Verlangen, original zu sein, zu der Meinung verführen, dass das Andersartige, das Abweichende, schon a n s i c h einen neuen „Wert” repräsentiere. Dann wird die Schöpfung zu einer blossen Aussenprojektion einer Persönlichkeit, mit den besonderen Zügen dieser Persönlichkeit, oder sogar mit künstlichen Einschlägen einer Originalitätshascherei - ohne dass damit irgend etwas über die transpersonale Bedeutsamkeit dieses „Neuen” ausgemacht wäre.

So muss denn hier immer wieder als Kontrolle die in dividu elle Verantwortlichkeit eingreifen. In dem Augenblick, in welchem der Künstler über das bloss binnenseelische Phantasieren hinaus ein Werk schafft, hat er es mit der W e l t zu tun, die für ihn zugleich eine überindividuelle Forderung bedeutet. Gerade weil er mit jedem Werk „Neues” schafft, ist seine Verantwortung um ein Vielfaches grösser als die des namenlosen Künstlers früherer Zeiten oder als die des heutigen Handwerkers, die ihre Erzeugnisse mit Selbstverständlichkeit der bestehenden und geltenden Welt eingliedern können. Diese Verantwortlichkeit kann als voll bew us t e auftreten, etwa als Uberzeugung von einer inneren Sendung, von einer prophetischen Sehergabe; einem solchen Künstler kommt es dann weniger auf das individuell „Neuartige" seines Werkes an, als darauf, dass er aus einer neuen Perspektive $\mathrm{Objektives,} \mathrm{das} \mathrm{noch} \mathrm{ungestaltet} \mathrm{war} \mathrm{und}$ nach Gestaltung drängte, eben dieser Gestaltung zuführt. Aber auch wo dies Bewusstsein einer Berufung nicht lebendig oder nicht vordringlich ist, kann die Verantwortlichkeit als Verhaltensmotiv eine starke Rolle spielen. Schon das Hinausgehen über ein bloss spielerisches Leben in Phantasmen, also der Wille $\mathrm{z} \mathrm{u} \mathrm{m} \mathrm{W} \mathrm{e} \mathrm{r} \mathrm{k} \mathrm{ist} \mathrm{hiervon} \mathrm{mitbedingt:} \mathrm{denn} \mathrm{erst} \mathrm{durch} \mathrm{das} \mathrm{Werk}$ wird ja der Künstler zum Glied der Gemeinschaft und zum Teilhaber der Kultur.

Hier kann es nun zwischen dem originalen Schöpferdrang und jenem Bewusstsein transpersonaler Verantwortlichkeit zu Spannungen kommen, die bei dem anonymen Kollektivkünstler (siehe oben) nicht möglich wären. Zwei besondere Auswirkungen dieses innerpersonalen Konfliktes sind: die Konzession und die reflektierte Anonymität. 
K o n z e s s i o n: der Künstler gibt die innere Gesetzlichkeit seiner schöpferischen Phantasie weitgehend den Rücksichten preis, die aus der objektiven Welt durch Aufträge, Gönnertum, Publikumsresonanz und Tendenz von ihm verlangt oder doch erwartet werden. Hier gibt es die merkwürdigsten Verwicklungen: werden doch in unzähligen Fällen künstlerische Schöpfungen höchster Art überhaupt erst durch Aufträge ermöglicht; und ist doch die „Tendenz" eines Kunstwerkes um so natürlicher, je mehr es als organischer Bestandteil der Gesamtkultur erlebt wird. Nur ein dekadenter „L'art pour l'art"'-Standpunkt wird in einem, von allem sonstigen Kulturbezug (und damit auch von „Tendenz”) losgelösten Kunstwerk den Gipfel der Kunst erblicken. Aber freilich: die Grenze, wo Auftrag oder Tendenz die schöpferische Phantasie nicht nur anregen, sondern knechten, ist flüssig. Allzuleicht kann durch die vorgeschlagene Gestalt der Aufgabe die gestalterische Originalität der Phantasie und damit auch die tiefere Verantwortung des Schöpfers unterdrückt werden. Nicht jeder beauftragte Künstler hat die Kraft - wie Michelangelo in den Malereien der Sixtinischen Kapelle - innerhalb des vorgeschriebenen Rahmens seine ungebrochene Originalität zu entfalten; und nicht jeder Tendenzdichter vermag - wie Lessing, in seinem „Nathan” - aus seinem Bekenntnis zugleich ein schöpferisches Werk zu gestalten.

Dort aber, wo man nicht Konzessionen machen will und doch auch nicht die volle Verantwortung für das originale Werk tragen kann, da gibt es ein Ausweichen: die r ef le ktie r te A n o$\mathrm{n}$ y $\mathrm{m}$ i $\mathrm{t}$ ä $\mathrm{t}$. Sie ist von ganz anderer Art als jene naive Anonymität, die aus dem selbstverständlichen Aufgehen im Kollektivgeiste entspringt. Wo der moderne Künstler anonym ist, da w i 11 er sich verbergen, da lehnt er die individuelle Verantwortung ab. Dies kann eine notwendige Zuflucht sein, um aller jener Rücksichten und Konzessionen enthoben zu sein, zu denen er gezwungen wäre, sobald die Welt ihn als Einzelperson mit seinem Erzeugnis identifizieren würde. Es kann aber auch eine innerpersonale Zerspaltenheit bedeuten: der Schaffende vermag sich nicht mit seinem Namen - und also mit seiner ganzen Person - hinter das Werk zu stellen, weil dieses nur e i n e $r$ Seite, e in e $r$ Schicht, e i n e $r$ Phase eben dieser Person entspricht und von anderen 
Schichten oder zu anderen Zeiten von der identischen Person verleugnet werden müsste ${ }^{1}$ ).

Hier haben wir die allersubjektivste Form schöpferischer $\mathbf{P h a} \mathbf{n}$ tasie vor uns, in der die Originalität ungebrochen, ja fessellos bis zur Laune sich entfalten kann, aber zugleich die Verantwortung gegenüber den transpersonalen Aufgaben der Phantasieschöpfung auf ein Mindestmals herabzusinken vermag.

\section{Die Welt des Scheins}

Handelt es sich bei Konzessionen und Ausweichungen um Verhaltungsweisen ausserkünstlerischer Natur, so gibt es aber auch beim schaffenden Künstler noch eine imman en te Möglichkeit, jene Verantwortung tragbar zu machen, ohne den schöpferischen Akt und Inhalt als solchen zu beeinträchtigen: das ist die $\mathrm{S} \mathrm{c}$ h e i n-Prägung des Phantasieerzeugnisses.

Zwischen der fessellosen Subjektivität des Künstlers und der vollen Objektivität des Lebens gibt es eine $Z$ wischenschicht: eine Realität des Scheins, in der recht eigentlich das Kunstwerk ruht. Hier wird, ähnlich wie beim Spiel, mitten in der geschlossenen konsequenzhaltigen Wirklichkeit eine andere, in sich genügsame und in sich sinnvolle Wirklichkeit errichtet. Sie ist nicht ohne Bezug auf jene; denn sie ist ihre Wiederspiegelung, Symbolisierung, Ausdrucksform, ihre Vorahnung oder ihr Nachklang. Aber sie hat eine Objektivität geringeren Grades, denn sie erlaubt das konsequenzenlose Eintauchen und Wiederhinaustreten des Individuums; und gerade diese Souveränität des Wechselnkönnens bedeutet für den Künstler ein Hauptingrediens seines schöpferischen Freiheitsbewusstseins, für den Kunstgeniesser eine Hauptquelle der ästhetischen Lust. Und nicht nur der Wechsel zwischen Schein- und Seins-Welt ist möglich, man kann auch innerhalb der Scheinwelt die verschiedensten Annäherungen z u, und Entfernungen $\mathrm{v}$ on der Vollwirklichkeit in sich aktualisieren. Das Kunstwerk kann, als traumhafte, als gespenstige, als spielhafte, als Ernstspiel-Welt, in verschiedensten Nüancen erlebt werden.

\footnotetext{
1) Es gibt ein Musterbeispiel für diese Art der Anonymităt: Kjerkegaard, der unter den verschiedensten Decknarnen schrieb, weil er sich auf keine seiner Ansich ten mit seiner Gesamtexistenz festzulegen vermochte. - Vgl. zu diesem Thema das Buch von Fritz Fischer.
} 
Es gibt manche Ästhetiker, welche in diesem s c h w e b e nden Illusion ismus das ästhetische Grundertebnis schlechthin sehen (vgl. Konrad Lange's Theorie). Dies ist schon deshalb nicht zutreffend, weil das Phänomen beschränkt ist auf jene hochdifferenzierten Formen der Kunst, in welchen das Werk auf das schaffende Künstlerindividuum bezogen ist. Es fehlt dagegen (oder ist höchstens in keimhaften Ansätzen vorhanden) dort, wo die schöpferische Phantasie noch kollektiv gebunden ist; denn in diesen primitiven Stufen ist die ganze Wirklichkeit $\mathrm{z}$ ugl e i ch praktisch und magisch, spielhaft and ernsthaft; Kunst ist nicht aus Gesamtkultur, und entsprechend auch Schein nicht aus dem Sein herausgelöst.

Das Spielen mit der Illusion erweist damit seinen p e r s o n al e n Sinn: es ist die notwendige Form, in der die individuelle Originalität der Person sich von der überindividuellen Verantwortung gegenüber der seienden Welt entlastet, ohne sie verleugnen zu müssen. Darum ist auch die „Schein”-Prägung der schaffenden Phantasie um so deutlicher, je individualistischer der Künstler sein Schaffen erlebt und je stärker sich die Kunst als Eigenbereich aus der Gesamtkultur abhebt.

\section{Wissenschaftliche Phantasie}

Zum Schluss sei noch kurz darauf hingewiesen, dass sich die individuelle schöpferische Phantasie in ihrem Werkschaffen durchaus nicht auf das Gebiet der Kunst beschränkt. Insbesondere kann sie beim wis e $\mathrm{n} \mathrm{s} \mathrm{ch}$ a $\mathrm{ft} \mathrm{l}$ i c h e $\mathrm{n}$ Werk eine mehr oder weniger bedeutende Rolle spielen.

In den $\mathrm{N}$ a $\mathrm{t} \mathrm{ur}$ w is se $\mathrm{n} \mathrm{ch}$ a t t e n vermag sie Einsichten zu antezipieren, die dann nachträglich durch die spezifisch wissenschaftlichen Methoden nachgeprüft und bearbeitet werden können.

Wenn z.B. Newton das Pendeln eines Kronleuchters und den Fall eines Apfels „zusa mmenschaute" $z$ u einem, ihnen gemeinsa men, Bewegungsprinzip und sich damit den Weg zur Entdeckung des Gravitationsgesetzes eröffnete, so handelt es sich nicht um ein rein im Logischen ablaufendes Geschehen. Ähnlich ist die Kant-Laplace'sche Theorie von dem Entstehen unserer Welt aus einem Urnebel, ist die Darwin'sche Hypothese von dem Selelctionsprozess, der die Stufenleiter aller Lebewesen erzeugt und bestimmt, nur vermittels der Beteiligung schöpferischer Intuition möglich geworden. 
Der phantasievolle Forscher überschreitet die Grenzen der Wissenschaft erst dann, wenn er das Phantasma als solches schon für einen objektiv wissenschaftlichen Befund ansieht und daher seine Kontrolle durch die eigentlich wissenschaftlichen Methoden der Logik und des Experiments für überflüssig hält.

Etwas anders liegt es bei den $\mathrm{g}$ e $\mathrm{s} \mathrm{c} h \mathrm{~h} \mathrm{c} \mathrm{h} \mathrm{t} \mathrm{l}$ i c h e $\mathrm{n}$ Wissenschaften; denn hier gehört die Phantasie noch viel wesentlicher zu den Voraussetzungen der wissenschaftlichen Arbeit. Sobald der Historiker das blosse Sammeln von Material und die gestaltlose chronikartige Berichterstattung hinter sich lässt, steht er vor der Aufgabe, einmalig Gewesenes neu zu gestalten. Hier ist das Experiment unanwendbar, und die Logik, die nur allgemeine Begriffe liefert, unzureichend; er muss sich ein anschauliches $\mathrm{G}$ es a $\mathrm{m} \mathrm{t}$ b i l d schaffen, in dem alle jene Rohmaterialien der Quellen u.s.w. zur Einheit zusammenschmelzen - dazu bedarf er der Phantasie. Er muss ferner - hierin dem Künstler ähnlich - dies innerpsychische Gesamtbild nach aussen in eine Darst e 1l u n $\mathrm{g}$ projizieren, die auch anderen erlaubt, jene Vergegenwärtigung von Vergangenem nachzuvollziehen. So steckt im Historiker notwendig etwas vom schauenden und gestaltenden Künstler er unterscheidet sich von diesem nur darin, dass er die kritische Uberprüfung mit streng wissenschaftlichen Methoden als Kontrollinstanz über sein Werk anerkennt und selbst anwendet.

Man wird vielleicht die Bezeichnung ,schöpferische Phantasie” für diese seelische Funktion beanstanden. In der Tat ist sie ja der Absicht nach re-produktiv; etwas objektiv Dagewesenes soll noch einmal im Bilde erstehen. Aber „Gewesenes" ist ja nicht durch sein blosses Einmal-Existierthaben schon ein "historischer" Tatbestand ; es wird dazu erst durch seinen Bedeutungszusammenhang mit sinnvollen „geschichthaften" Totalitäten ${ }^{1}$ ), mögen dies Völker, Staaten, Kulturgebiete, Einzelpersonen sein; und solche Zusammenhänge können nur intuitiv bewältigt werden. So ist der Spielraum, innerhalb dessen der Historiker sich der schöpferischen Phantasie bedienen kann, ein recht bedeutender.

Auch hier gibt es natürlich alle möglichen Stufen: von dem strengen Fachspezialisten, der die nackten Tatsachen in seinen Darstellungen nur um das unvermeidbare Minimum eigenen Hinzutuns überschreitet

1) Über den Begriff der „Geschichthaftigkeit” vgl. Wertphilosohpie S. 271. 
- bis zu einem Mommsen, der römisches Leben in ein, unserer Anschauung zugängliches, Gesamtbild giesst.

Schon an der Grenze eigentlicher Wissenschaft stehen jene stilisierten $\mathrm{B}$ i o g r a p h i e e $n$, welche alle Lebensdetails einer Persönlichkeit in eine intuitiv erfasste Grundform einzuschmelzen suchen; in ihnen scheint sich ein neues Zwischengebiet zwischen Forschung und Kunst - und somit zwischen Denk- und Phantasieleistung - zu entwickeln, ebenso wie in den durchgestalteten $\mathrm{Selbs} t \mathrm{biogra-}$ ph i e e n, die ja nicht nur bei Goethe "Wahrheit und Dichtung" sind. 


\section{FƯNFTER HAUPTTEIL}

STREBEN. HANDELN. IEISTEN 
In den beiden Hauptteilen, die nun folgen, muss die Betrachtung gleichsam noch einmal v o $n$ v o r $n$ a $n$ f a $n g$ e $n$. Hatten die vorangegangenen Teile diejenigen Seiten des personalen Lebens behandelt, welche man gewöhnlich als ge is tige zusammenzufassen pflegt, so hat uns jetzt der Mensch als fühlender, als handelnder und leistender zu beschäftigen. Freilich: auch das geistige Leben war nur verständlich zu machen dadurch, dass wir es aus personalen Urgründen hervorwachsen sahen, in denen noch ungebrochenes Gefühl und unmittelbares Streben vorhanden sind; wir konnten bei Wahrnehmung, Gedächtnis, Denken und Schaffen diese allmählige $\mathrm{E} \mathrm{m}$ a $\mathrm{n} z$ i p a t i o $\mathrm{n}$ des Geistigen aus dem Vitalen verfolgen. So wird umgekehrt das Gemüts- und Willens-Leben des Menschen nur dadurch erfassbar, dass wir es als fortschreitende $\mathrm{Vergeistigung}$ vitaler Grundfunktionen betrachten. Damit ist nicht eine Rationalisierung gemeint, welche die Dynamik des Trieblebens und die Unmittelbarkeit des Gemüts je überwinden oder ersetzen könnte, sondern eine Bereicherung und Überbauung derjenigen Funktionen, die Menschen und Tieren gemeinsam sind, durch rein humane Entfaltungsformen.

Die Themen der beiden Hauptteile, das Streben und das Fühlen, stehen in so engem Zusammenhang mit einander, dass ihre getrennte Besprechung nicht ohne Gewaltsamkeit möglich ist. So werden wir oft vorwärts und rückwärts verweisen müssen.

Der fünfte Hauptteil behandelt den Menschen in seiner $t$ ä $t$ ig e $n$ Beziehung zur Welt. Einige terminologische Vorbemerkungen sind erforderlich.

Derjenige in sich geschlossene Tätigkeitsvollzug einer Person, der eine sinnvolle Veränderung der Welt bewirkt, ist eine „Handlung". Wird der Aufwand von personaler Kraft in Beziehung gesetzt zum Ergebnis der Tat, so ist sie eine „Leistung". Handlung und Leistung sind demnach nicht psychologische, sondern 
psychophysisch neutrale Begriffe. Dagegen ist „Streben" ein rein psychologischer Begriff; er bezeichnet das auf mögliche Handlung gerichtete Erleben im weitesten Sinne. Zum Bewusstsein des Strebens gehört also ein Hindrängen in die Zukunft, aber zugleich die Unerfülltheit dieses Dranges; alle Strebungen sind daher ihrem Wesen nach unvollständig und "offen" im Gegensatz zur Handlung selbst, die im Abschluss geradezu kulminiert.

Auf den primitivsten $\left.{ }^{1}\right)$ Stufen setzt sich eine Strebung noch ohne Zwischenglieder in Tat um; die Strebung selbst bleibt ganz in dumpfer Gefühlsartigkeit stecken: T r i e b- und I ns tink r-Handlung. Sobald aber die Strebung sich verselbständigt und - noch vor Realisierung der Handlung - deren Ziel im Bewusstsein vorwegnimmt, entsteht die Erlebnisform des B e d ürf $\mathrm{n}$ is s e s. Wird die Dualität von Strebung und erfüllender Tat so gross, dass der Übergang von der einen zur anderen nicht gefunden wird, dann bleibt das Bedürfnis im binnenseelischen $W$ u $\mathrm{s} c \mathrm{~h}$ stecken. Wird aber jene $Z$ weiheit überwunden durch einen besonderen Akt der Umsetzung, dann haben wir den Tatbestand des W ill e n s vor uns. Der menschliche Willen, seine Merkmale, Stufen, Ablaufsweisen, sowie die, ihn tragenden, personalen Dispositionen bilden das eigentliche Kernstück dieses Hauptteils.

1) Vorangeht diejenige Betätigungsweise, bei der eine Strebung iberhaupt nicht vorhanden ist, der Reflex. 


\section{ZWANZIGSTES KAPITEL}

PRIMITIVFORMEN DES TUNS UND STREBENS

Die Grundlage alles menschlichen Tuns wird durch jene Urzusammenhänge hergestellt, die das Individuum mit seiner Vorwelt und seiner Umwelt verknüpfen. So selbstverständlich gehört jedes Einzelwesen in die Reihe der sich folgenden Generationen und in die Gegenwärtigkeit seines Lebensbereichs, dass auch seine Aktivität weitgehend darin eingebettet ist - mit einer Unbedingtheit und Treffsicherheit, die noch vor aller Bewusstheit liegt. Für dieses primitive "Sich im Leben halten" bedarf es nicht einer Objektivierung der Handlungsziele, bedarf es keiner Erfahrung, aus der man lernen müsste, und keiner Vorausschau, auf deren Inhalt man sich einstellen müsste. Diese Urhandlungen sind es, in denen der Mensch den untermenschlichen Lebewesen am ähnlichsten ist; sie sind es, die in der Entwicklung jedes einzelnen Menschen schon ganz frühe auftreten, noch ehe eine Spur von Willens- und Denk-Handlungen möglich ist; sie bleiben aber als Grundschicht auch bestehen, wenn sich allmählich darüber die Handlungsmöglichkeiten in der Gegenstands- und der Wert-Sphäre erheben - empfangen freilich von diesen spezifisch menschlichen Strebungen und Handlungen wesentliche Beeinflussung und Umformung.

Schon bei den primitivsten Tätigkeitsweisen lassen sich die beiden Grundrichtungen menschlichen Tuns unterscheiden: das Re-agieren und das Spontan-agieren $\left.{ }^{1}\right)$. Jenes überwiegt beim Reflex, dieses bei den Trieb- und Instinkthandlungen.

1) Vgl. S. 125. 


\section{REFLEXE}

\section{Angeborene Reflexe}

Im Reflex bilden Reizung und Reizbeantwortung eine unmit telbare Einheit. Ist die Einheit zugleich ursprünglich (also nicht erst während des Individuallebens entstanden), dann heisst der Reflex „angeboren”. Die Zuordnung von Reiz zu Bewegung kann das Individuum im ganzen, oder bestimmte Körperteile bezw. Funktionsgebiete im einzelnen betreffen.

Ein Totalreflex tritt z.B. ein, wenn ein Mensch ins Wasser fällt; Blutkreislauf und Atmung funktionieren plötzlich anders; und Zappelbewegungen der Glieder stellen sich ein, noch ehe irgend welche zweckvollen Bewegungen bewusst intendiert werden können.

Beispiele für spezielle erbliche Reflexe: Wird einem ebengeborenen Kind ein Finger in das Händchen gelegt, dann schliessen sich die Kinderfinger um den Finger des Erwachsenen so fest, dass man das Kind daran emporheben kann. - Fällt starkes Licht ins Auge, so kontrahieren sich die Pupillarmuskeln und verkleinern die Einfallsstelle des Lichts, nämlich das Pupillenloch. - Gerät ein Krümchen in die Luftröhre, so erfolgt eine Hustenbewegung, die es wieder ausstösst.

Experimentelle Untersuchungen haben hier noch viel engere Zuordnungen ergeben: Punktuelle Reizung einer Körperstelle kann die reflektorische Reaktion eines Einzelmuskels oder einer kleinen Muskelgruppe herbeiführen u.s.w.

Man sieht aus diesen Beispielen, dass der angeborene Reflex a $1 \mathrm{~s} \mathrm{~s} \mathrm{o} \mathrm{l} \mathrm{c} \mathrm{h} \mathrm{e} \mathrm{r}$ eigentlich gar kein direktes Thema der Psychologie ist; denn er verläuft - oder kann wenigstens verlaufen ganz ohne Beteiligung von Psychischem ${ }^{1}$ ). Möglich, dass ein dumpfes Gefühl den Vollzug begleiten mag, Einfluss auf den Ablauf hat es nicht. Es ist deshalb eine fast groteske Umkehrung aller Verhältnisse, wenn man hier und da den Versuch macht, die

1) Dem entspricht im Physiologischen, dass die Reflexe ohne Beteiligung des Grosshirns vor sich gehen. Die Umsetzung der sensorischen in motorische Nervenerregung erfolgt im Rückenmark und anderen subkortikalen Zentren. 
Psychologie durch eine „Reflexologie” zu ersetzen, also am Menschen nur dasjenige zu untersuchen, was als Reflex oder Kette von Reflexen gedeutet werden kann.

Immerhin gehört die Besprechung der Reflexe auch in die Psychologie hinein; denn die Fäden, die die reflektorische Betätigung mit den überreflektorischen - und damit bewusstseinsbesetzten - Handlungen des Menschen verbinden, sind überaus mannigfach. Sie verlaufen nach beiden Richtungen, von den Reflexen zu den Willenshandlungen und umgekehrt, wie sich später erweisen wird.

Die Reflexe werden oft als "mechanische" Reaktionen bezeichnet. Man kann aber diesen Ausdruck nur gelten lassen, wenn man ihn in Gegensatz bringt $z u$ bewusster Uberlegung und Entscheidung. Auch die weitgehende $Z$ w a ng s lä u fig ke it in der Verbindung Reiz/Bewegung erinnert an das Funktionieren einer Maschine; sowie bei dieser ein Uberdruck des Dampfes stets das Ventil in Tätigkeit treten lässt, so ruft beim menschlichen Auge starkes Licht normaler Weise s $t$ e $t \mathrm{~s}$ die Verkleinerung des Pupillenlochs hervor. - Wenn man aber das Wort "mechanisch" als gleichbedeutend mit „,sinnfremd”, ,zwecklos” auffasst, dann passt es nicht auf die Reflexe. Völlig Sinnfremdes gibt es im Funktionieren lebendiger Wesen überhaupt nicht; höchstens. dass der Sinn nicht zu voller Verwirklichung kommt, weil die Sinngerichtetheit des Tuns zu vage ist, oder weil andere Sinnbezüge störend dazwischen treten.

Wenn man die obigen Beispiele für erbliche Reflexe daraufhin betrachtet, so wird man durchweg finden, dass der Reiz $\mathrm{n} \mathrm{i} \mathrm{ch} \mathrm{t}$ irg end e i n e be li e bi ge, sondern eine, für den Organismus oder das Organ $\mathrm{zwe}$ ckmä $\mathrm{l}$ sige Beantwortung findet $\left.{ }^{1}\right)$. Ja, es ist sogar Stärke und Ausbreitung der Reflexbewegung weitgehend von der personalen Bedeutung des Reizes abhängig. Ein Schläfer, dem eine Fliege über die Stirn kriecht, wird vielleicht nur mit reflektorischem Zucken des Kopfes reagieren. Sticht ihn dort eine Mücke, so greift der Reflexbogen schon auf Arm und Hand über; der Schläfer macht wischende Handbewegungen nach der Stirn. Und beisst ihn ein Skorpion, so kommt es zu ungleich stärkeren und ausladenderen Abwehr-

1) Eine neue Theorie der Reflexe vom Ganzheitsstandpunkt aus hat soeben Kurt Goldstein in seinem Buch „Der Aufbau des Organismus” aufgestellt. 
bewegungen, vielleicht sogar zu einem Totalreflex: Zusammenzucken des ganzen Körpers, Erwachen, Flucht.

Aber man darf auch nicht die Gre n z e n der Zweckmälsigkeit angeborener Reflexbewegungen übersehen. Sie erschöpfen sich im Reagieren auf a u genblicklich Gegebenes ihnen fehlt also alles Prospektive, das nicht nur den Willenshandlungen, sondern auch den Instinkten eigen ist. Und sie haben nur eine konservative Zweckmälsigkeit - sie stiften keine neuen Mittel/Zweck-Zusammenhänge, sondern Erneuerungen der alten. Dies letztere gilt phylogenetisch wie ontogenetisch.

Die Reflexe sind in erster Reihe Werkzeuge, welche das Individuum von seinen Vorfahren übernimmt, um den, der Gattung a $11 \mathrm{~g} \mathrm{e} \mathrm{m} \mathrm{e} \mathrm{in} \mathrm{zukommenden,} \mathrm{Lebensnotwendigkeiten} \mathrm{zu} \mathrm{ent-}$ sprechen. Sie stellen die Eingepasstheit in die konstanten und immer wiederkehrenden Umweltbedingungen dar. Tritt Neuartiges in die Lebenssphäre des Individuums, so bestehen drei Möglichkeiten:

1) Der Unterschied des Neuen vom Alten bleibt unterschwellig: es erfolgt ein unangepasster Reflex (so ruft etwa ein weisses, in Konsistenz oder Geschmack dem Zucker ähnliches Pulver, auf die Zunge gebracht, den Schluckreflex hervor, obgleich es nicht die Nährfunktion des Zuckers hat). 2) Es erfolgt ein vager Totalreflex: das Neue wird nicht in seiner Spezifizität, sondern nur in seinem allgemeinen Charakter: als Störung und Gefahr, oder als Aufforderung und Einladung, beantwortet (Choc-Wirkung; Flucht; Abwendungs- oder Hinwendungs-Bewegung). 3) Es erfolgt Reflexhemmung; das Neue wird psychisch verarbeitet und $\mathrm{zu}$ bewusster Willenstat übergeleitet: hiervon später.

\section{Erworbene Reflexe}

Neben diesen erblich bestimmten Reflexen hat man in neuerer Zeit starke Beachtung jenen Reflexen zugewandt, die erst innerhalb des individuellen Lebens entstehen (e r w orbene Reflexe, b e d in g t e Reflexe). Sie beruhen stets auf Erfahrungen, und zwar auf häufigen gleichartigen Erfahrungen und stellen die Vereinfachung komplizierterer Handlungsformen dar. Der Chauffeur, der gelernt hat, dass man entgegenkommenden 
Hindernissen nach rechts auszuweichen habe, macht schliesslich bei jedem plötzlich vor ihm auftauchenden Hindernis die richtige Drehbewegung am Steuer - und zwar in normalen Fällen rein reflektorisch: er braucht weder den Reiz bewusst aufzufassen, noch die Bewegung bewusst zu intendieren. Die sehr verwickelten Willenshandlungen, die anfangs hierfür nötig waren, und bei denen zwischen Reizeinwirkung und Bewegung ein umfangreiches psychisches Zwischenstück - mit Beachtung und Erkennung des Reizes, Ưberlegung und Entscheidung, Vornahme von Bewegungen bestimmter Art und Stärke - noch eingeschoben war, - haben im Laufe der Úbung immer mehr diese seelischen Einschaltungen verloren, bis nur die beiden Grenzphasen in kurzschlussartiger Verbindung übrig blieben.

Diese „M e c h a n is a t i o n" oder „Automatisierung" stellt für die davon betroffene Verrichtung eine Niveausenkung, eine Entgeistigung dar. Aber im Rahmen des gesamtpersonalen Geschehens hat sie eine sehr bedeutungsvolle Funktion. Denn normaler Weise tritt sie ja nur ein für solche Vorgänge, bei denen eine Bewusstseinsbeteiligung überflüssig oder sogar schädlich wäre. Bei jenen, sich immer wiederholenden Alltagsverrichtungen, in denen zwischen einer, in der Situation enthaltenen, Anforderung und ihrer personalen Beantwortung eine eindeutige und ebenfalls immer wiederkehrende Beziehung besteht, ist das reflektorische Verhalten das schnellste, sicherste und sparsamste. Noch mehr: die Kraftersparung, die mit der fortschreitenden Automatisierung geübter und gewohnter Tätigkeiten verbunden ist, macht die früher hierfür erforderliche Mehr-Energie frei für neue Leistungen, die der Bewusstheit, der Uberlegung und Entscheidung bedürfen. Vor allem aber ist der Mensch fähig, bei Durchbrechung der gewohnten Situationen - also in Fällen, in denen der blosse Reflex versagen müsste sein Handeln wieder auf das höhere Niveau der Bewusstheit und wollenden Entscheidung zu heben.

Als Beispiel diene der $\mathrm{mens} \mathrm{ch} \mathbf{l}$ i ch e Ga ng. Während beim laufenlernenden Kinde noch viel Bewusstheit auf die ersten tappenden Schritte verwandt werden muss, wird das Gehen allmählich derart automatisiert, dass man auf die fortwährenden kleineren Unebenheiten des Weges, auf Stufen, auf schlüpfrige Stellen u.s.w. reflektorisch mit den nötigen Änderungen der Schrittimpulse und dẹ Gleichgewichtsregulierung antwortet. Dies alles läuft $a b$, ohne dass man sich 
in völlig anders gerichteten Bewusstseinseinstellungen (z.B. in einem Gespräch) zu unterbrechen brauchte. Nun aber herrsche einmal Glatteis: sofort wird das reflektorische Gehen ebenso gestoppt wie alle anderweitige Bewusstseinsbesetzung: man "passt auf” und „sieht sich vor" bei jedem Schritt; d.h. sowohl die Beachtung des Reizes wie die Innervation der Bewegung ist plötzlich zum Hauptinhalt bewussten Tuns geworden ${ }^{1}$ ).

Die enge Beziehung der erworbenen Reflexe zur personalen Gesamtteleologie ist in gewissen neueren Forschungsrichtungen dadurch verschleiert worden, dass man i m $L$ a b o r a t o r i u m neue Reflexe zu erzeugen versuchte, die anscheinend zweckfremd waren und nur auf der künstlichen, assoziativen Zuordnung zweier disparater Glieder beruhten. Richtunggebend waren hierfür die Experimente Pawlows am Hunde. Der ererbte Reflex des Hundes: dass er bei Annäherung an Fleisch Speichel absondert, konnte so umgebogen werden, dass er auf den Eindruck eines bestimmten Tones (ohne dass Fleisch in der Nähe war) speichelte; Voraussetzung war nur, dass in längerer Einübung Fleisch und Ton immer wieder gleichzeitig dargeboten worden waren. Auch hier konnte also allmählich - wie in unserm obigen Chauffeurbeispiel - das Zwischenglied (Fleisch) ausgeschaltet werden; der Unterschied besteht darin, dass die übrigbleibende reflektorische Verbindung - Ton/Speicheln - völlig sinnlos zu sein scheint. So glauben sich die Reflexologen (und ähnlich viele Vertreter der behavioristischen Theorie) zu der These berechtigt, dass alles Lernen und damit alle geistige Entwicklung auf der assoziativen Herstellung solcher bedingten Reflexe beruhe.

Hierzu ist zu sagen: es gibt in der Tat eine gewisse Art des Lernens, für welche der geschilderte Versuch das einfachste Modell darstellt: es ist das D r e s s u r lernen, das bei gelehrigen Tieren zuweilen eine grosse, beim Menschen aber nur eine untergeordnete Rolle spielt (vgl. hierzu S. 266). Der Hund Pawlows ist ,dressiert" worden, auf einen bestimmten Ton hin zu speicheln, ähnlich wie ein Affe darauf dressiert werden kann, auf bestimmte Worte des Dresseurs den Zylinderhut abzunehmen, obgleich ihm der ,Sinn" dieser Geste unbekannt ist.

Aber selbst bei diesen andressierten Reflexen fehlt nicht jede

1) Vgl. eine andere Verwertung desselben Beispiels S. 763. 
Bedeutung im Sinn der Lebensaufgaben des Individuums; und hier liegt der hauptsächlichste positive Ertrag der reflexologischen Versuche. Wenn wir nämlich oben sagten, dass die Reflexe ganz im G e g e n wärtigen sich erschöpfen, so darf dies nicht punktuell verstanden werden. Die biologische Gegenwart ist kein Zeit-,,Punkt”; sie hat eine gewisse - beim Tier freilich sehr kurze - Ausdehnung, und so können auch die, den Hauptreiz begleitenden, ja ihm unmittelbar vorangehenden Umstände in den Reflexvorgang mit einbezogen werden. Hierher gehört ja schon der angeborene Reflex: dass der Hund bereits speichelt, wenn er das Fleisch nur sieht, also vor dem ersten tatsächlichen Zubeissen. Mit anderen Worten: Die Fleischsicht hat in dem Reflexgeschehen die Bedeutung eines vo r b e reite nden Signals. Das darf nicht "psychologisch" verstanden werden; denn der Hund braucht keinerlei Bewusstsein von dem Signalcharakter des Fleischanblicks zu haben. Dadurch aber wird der biologische Signalsinn jenes Bestandteils des Reflexprozesses nicht berührt. Wird nun auch noch ein Ton eingeschaltet, so wird dieser durch gewohnheitsmärsige Einfügung in die Einheit des reflektorischen Prozesses ebenfalls Signalbedeutung gewinnen und zu dem motorischen Geschehen überleiten selbst wenn in dem Einzelfall der spezifische Sinn des Reflexes (die Nahrung gehörig anzuspeicheln) nicht erfüllt wird. Auch der erworbene Reflex hat also, ebenso wie der ererbte (s. S. 516), eine nur generelle Zweckmälsigkeit, die im Sonderfalle tatsächlich zu sinnloser Stereotypie werden kann. (Die Parallele hierzu würde etwa ein Chauffeur bilden, dem der Signalcharakter des roten Lichts so stereotyp geworden ist, dass er bei jedem plötzlich auftauchenden Rotlicht, auch wenn er garnicht auf dem Auto sitzt, die Bremsbewegung innerviert). Es ist ja aber eine Paradoxie, eine solche Reflex-E $n \mathrm{tg} l$ e is u $\mathrm{n} g$ zum Typus aller Lernfunktionen des Tieres wie des Menschen und gar zur Grundlage der Wissenschaft vom Menschen überhaupt machen zu wollen. Die tierische Dressur auch ausserhalb des reflexologischen Laboratoriums beruht weitgehend darauf, bestimmte Reize, deren ,eigentlicher" Sinn dem Tiere nicht zugänglich ist, dadurch zu Reflexauslösern zu machen, dass ihnen durch Gewöhnung, Belohnung u.s.w. ein künstlicher Sinn, nämlich Signalcharakter, verliehen wird. 


\section{TRIEBE}

Nur ein Bruchteil der Urbetätigungen des Menschen hat die Form von starren (bezw. erstarrten) Antworten auf Aussenreize, also von Reflexen. Es gibt andere, die so stark von in n er e n Bedingungen des Individuums abhängen, dass ein relativer Spielraum im Fertigwerden mit äusseren Anlässen besteht. Solche Betätigungen-z.B. eine Nahrungsaufnahme, ein Geschlechtsakt, eine Nachahmung - treten nur dann als aktuelle Handlungen auf, wenn jene inneren Bedingungen von sich aus

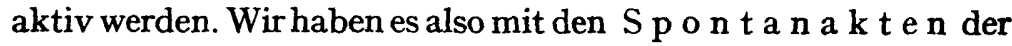
Vitalsphäre zu tun. Es sind die Trieb- und Instinkt-Handlungen.

\section{Triebe als Richtungsdispositionen}

Wir behalten uns die Besprechung des Instinkt-Begriffs für später vor und versuchen zuwächst, die $T$ r i e b h a n d l u n g von der eben erörterten Reflexbewegung zu unterscheiden. Dazu diene wieder das Beispiel der Nahrungsaufnahme. Es wurde erwähnt, dass die Speichelabsonderung des Hundes bei Annäherung eines Nahrungsmittels ein Reflex ist; denn wenn ein, zur Ernährung bestimmtes, Objekt dem Maul des Hundes genähert wird, findet immer jene Absonderung statt. Aber ein und dasselbe Objekt is $t$ nicht immer ,ein zur Ernährung bestimmtes"! Wenn einem völlig gesättigten Tier ein Stück Fleisch gezeigt wird, dann unterbleibt der Speichelreflex, weil das Fleisch in der Biosphäre jetzt garnicht die Bedeutung eines „Ernährungs"-Objektes hat. Der Organismus bringt dem Fleisch nicht jene spontane Aktivität entgegen, die es erst zum „Nahrungsmittel” macht. Der komplexe Akt des Fressens kommt überhaupt nicht zustande. Wir nennen ihn eine „Triebhandlung", weil er von der inneren Bedingtheit, dem „Trieb" (hier dem Nahrungstrieb) abhängig ist.

"Trie b" ist also eine, a u $\mathrm{Verwirk}$ lichung personaler $Z$ iele eingestellte, angeborene Richtungsdisposition, deren Umsetzung in aktuelle Handlung vornehmlich vonder inneren Dynamik der Person bedingt ist.

Diese Definition bedarf nach mehreren Seiten der Erläuterung. 
1) Trieb ist eine $D$ i s p o s it i o n, d. h. eine potentielle Dauerbeschaffenheit. Wir können die Person überhaupt nicht anders denken, als im Besitz solcher Gerichtetheiten auf die Erfüllung ihrer Urziele; und diese Gerichtetheiten müssen in der Form potentieller Energieen auch dann als existent angesetzt werden, wenn sie in keiner gegenwärtigen Handlung hervortreten. Die Sprache sucht solche Latenz auszudrücken durch Bezeichnungen wie: der Trieb schlummert, ruht, ist gesättigt, ist verdrängt. Voraussetzung für diese Annahme latenter Triebe ist freilich, dass im gegebenen Falle, d.h. wenn die äusseren und in nere n Bedingungen vorliegen, der Trieb aktiviert werden kann, dass er ,erwacht”, „,nach Erfüllung drängt”.

Nur dann, wenn jede weitere Aktivierungsmöglichkeit aus gewissen Symptomen heraus ausgeschlossen erscheint, kann dem Trieb die dispositionelle Existenz abgesprochen werden: „der Trieb ist abgestorben”. Aber gerade hier sind bekanntlich schwere Irrtümer möglich; so kann etwa der scheinbar völlig verdorrte Sexualtrieb wieder $\mathrm{zu}$ neuem Leben erwachen.

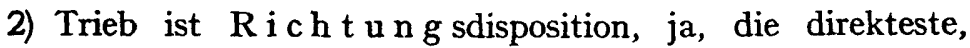
aber zugleich auch vageste, ungegliedertste Richtungsdisposition, die im Menschen lebt; die jeweilige Aktualisierung ist nicht so sehr durch sachgemälse Mittelwahl, Setzung von Teilzielen u.s.w. bestimmt und geordnet, als durch die Stärke des inneren Dranges und die äussere Gelegenheit der Befriedigung.

3) Jeder Trieb ist e in e solche Richtungsdisposition; demnach muss es im Menschen viele Triebe geben, da es viele immanente Richtungen der personalen Lebensbetätigung gibt.

Aber freilich, sobald man versucht, ein "Inventar" der Triebe aufzunehmen, stösst man auf eine grundsätzliche Schranke. Die Zielsetzungen der Person und die ihnen zugewandten personalen Dispositionen stehen nicht hart und gesondert, in bestimmter Anzahl, nebeneinander - sondern sind ja im Grunde nur die fortwährend aus der personalen Gesamt-Entelechie herausquellenden, Gestalt und Abgrenzung wechselnden, Einzelstrahlen der Strebigkeit. Man muss sich hier sehr hüten $\mathrm{zu}$ glauben, dass man mit den Unterscheidungen, die für die Gesichtspunkte analysierender Betrachtung erforderlich sind, existenzielle Sonderkräfte erfasst habe. Sonst droht Rückfall in die alte „Vermögens"-Psychologie. 
$\mathrm{Da}$ wird etwa der S e x u a $\mathbf{t} \mathbf{r}$ i e b in einen „Kontrektationstrieb" und einen „Detumeszenztrieb" (Annäherungs- und Entladungstrieb) untergeteilt; unter anderen Gesichtspunkten wieder in einen autosexuellen und heterosexuellen; oder unter nochmals anderer Orientierung in einen Oral-, Anal-, Genital-Trieb - alle diese Scheidungen sind nötig, weil in gewissen Entwicklungsphasen oder unter abnormen Verhältnissen das eine oder andere dieser Sonderziele sich relativ verselbständigen oder eine Hegemonie gewinnen kann; und dennoch wäre es widersinnig, daraus so und so viele zählbare Elementartriebe zu machen, die in ihrer Summierung erst die Gesamtdisposition "Sexualtrieb" bildeten. - Ebenso bedeutungslos wäre die Frage, ob etwa neben dem „Gesellungstrieb" noch „Nachahmungstrieb" "Mitteilungstrieb", „Pflegetrieb" selbständige Existenz haben, oder ob sie Teile von ihm seien, sich mit ihm kreuzen, und ähnliches.

Von Trieben in der Mehrzahl zu sprechen, hat zwar keine vermögenspsychologische Bedeutung; es ist aber nötig aus s t r u k t u r p s y c h o log is c h e n Gründen. Denn die totale Richtungsdisponiertheit der Person (ihre „Entelechie”) erhält ihre S t r u k t u r durch die Vordringlichkeit oder das Zurücktreten, durch Uber- und Unterordnung, durch Zueinander- oder Gegeneinanderstreben der in ihr enthaltenen Teilgerichtetheiten oder ,Triebe”.

So ist vor allem $\mathrm{zu}$ betonen, dass in die personale Triebstruktur a 11 e personimmanenten Richtungseinstellungen gehören. Also sowohl die rein vitalen - die der Mensch mit dem Tier gemeinsam hat - wie auch die spezifisch humanen, die dem Menschen allein zukommen.

Gewöhnlich denkt man ja, wenn man von „Trieb" spricht, vornehmlich an die erste Gruppe. Innerhalb ihrer können wir noch eine Untergliederung nach drei Gesichtspunkten machen: Elementare S e l b s t e $r$ h a 1 t u n g s $t$ r i e b e: z.B. Nahrungs-, Schutz-, Verteidigungs-, Flucht-Triebe; elementare Selbstentf a 1 t ung s $t$ ri e b e: z.B. Geltungs-, Macht-, Schmuck-, Angriffs-, Wachstums-, Entwicklungs-Triebe; - elementare Sozi a l-T rie be: Gattungs-, Herden-, Pflege-, Kampf-, Nachahmungs-Triebe.

2. Humantriebe

Es besteht aber kein Grund und keinerlei Recht dazu, bei 
der menschlichen Person sich auf diese Elementartriebe zu beschränken; denn im Menschen gibt es Gerichtetheiten noch ganz anderer Art, die ihm durchaus wesensimmanent sind und die spontan die personale Energie in Bewegung setzen, mithin Triebcharakter haben. Es sind die Triebe, die auf geis tige, ideelle und kulturelle Zielsetzungen gerichtet sind: Sprach-, Denk-, Erkenntnis-Trieb, Darstellungsund Schaffenstrieb, metaphysischer, religiöser, sittlicher, politischer, technischer Trieb.

Weshalb hat man sich solange gescheut, die zuletzt genannten Dispositionen als „Triebe” zu bezeichnen? Aus zwei Gründen.

Entwicklungstheoretisch betrachtet, sind die humanen Triebe jünger als die Elementartriebe. Dies zeigt sich schon innerhalb der Tierreihe, in der gewisse Ansätze des Mitteilungstriebs und des Wissenstriebs (Neugier) sich nur bei wenigen, hoch organisierten Tierarten vorfinden. Es zeigt sich innerhalb der Menschheit bei Vergleichung primitiver mit kultivierten Stufen, da hier die Elementartriebe relativ konstant bleiben, während die humanen Triebe sich allmählich immer stärker bemerkbar machen. Endlich zeigt es sich auch in der Entwicklung des Einzelindividuums: im Neugeborenen führen die Vitaltriebe eine fast unumschränkte Vorherrschaft; erst sehr allmählich treten die Bekundungen der humanen Triebe auf.

Das zweite Argument besteht darin, dass die höheren Gerichtetheiten nicht in der nackten Form des Nur-Triebmärsigen auftreten können, weil sowohl die Ziele wie die Mittel zu ihrer Verwirklichung eine höhere personale Reife, eine Fülle von Erfahrungen und eine starke Beteiligung des Willens voraussetzen. Ein Mensch, der intensiv nach Vermehrung seines Wissens strebt, müsse - so wird dann argumentiert - schon eine Wissensgrundlage besitzen, müsse Probleme haben, müsse den weiteren Wissenserwerb planen und in Voraus organisieren können. Von jenem dumpfen Drang, der sich unmittelbar im Tun entlädt wie beim Sexualtrieb, beim Fluchttrieb - sei hier nicht mehr die Rede. Darum erscheine die Bezeichnung „Wissenstrieb” unzweckmälsig.

Beide Gründe sind nicht stichhaltig. Zum Wesen des ,Triebes" gehört weder, dass seine Bekundungen schon ganz $f \mathrm{r} \ddot{u} \mathrm{~h}$, noch, dass sie in n a c k t e r Form auftreten müssen. Ein "Trieb" als 
$D$ is p os it i o n, nämlich als personimmanente und dauernde Richtungsdynamik, ist auch dort anzusetzen, wo er nur der Möglichkeit nach besteht; er wäre nur zu leugnen, wenn die, irgend wann einmal auftretenden, Zielerfüllungen aus anderen Faktoren erschöpfend abgeleitet werden können, z.B. aus anderen Trieben oder aus äuIseren Einflüssen.

Bleiben wir bei unserem obigen Beispiel. Wenn wir einen Menschen antreffen, der sein Wissen zu vermehren trachtet, so ist es möglich, dass er dies aus Geltungsstreben tut, oder weil er es für seinen Beruf braucht, oder weil es in seinem Kreise üblich ist, etwas zu lernen, und er sich dem Zwange fügt. Gelingt es, sein Wissensstreben auf solche Beweggründe restlos zurückzuführen, dann besteht kein Grund, ausserdem noch einen ,Wissenstrieb" anzusetzen. Aber es gibt viele Fälle, in denen das Wissensstreben durch diese und andere ausserhalb liegende Faktoren nicht zu erklären ist: dann müssen wir dem Menschen jene u n m it t elbare innere Gerichtetheit auf Wissen zuschreiben, die nur als ,"Wissenstrieb" bezeichnet werden kann. Dieser Trieb liefert den - oder einen - M o t o r für die Handlung des Lernens und Forschens, gleichgültig, wie weit diese Handlung in den Einzelheiten von anderen, nicht-triebartigen Momenten: Erfahrung, Planung, Uberlegung, bestimmt wird.

Entwicklungspsychologisch betrachtet besteht also der Unterschied zwischen niederen und höheren Organismen bezw. Stufen nicht darin, dass auf dem höheren Niveau an die Stelle der Triebe andere Strebungsweisen treten, die mit Trieben überhaupt nichts zu tun hätten - sondern darin, dass auf den niederen Stufen die Triebe hauptsächlich vitaler Natur sind und sich vornehmlich in spezifischen Triebhandlungen auswirken, während auf den höheren Stufen vitale wie humane Triebe zu mitwirkenden Faktoren in komplexeren Handlungsformen werden.

Diese Auffassung verbietet auch, die eigentlich humanen Triebe als bloss sekundäre Erze ug $\mathrm{n}$ is s e der Elementartriebe anzusehen. Solche Theorieen begegnen uns ja fortwährend. Bald ist es der Selbsterhalt ung s-Trie b, der als einziger „Ur"-Trieb anerkannt wird; alle, auf andere Individuen, auf Gemeinschaften oder auf Ideale gehenden, personalen Gerichtetheiten - bis zu den Liebesbeziehungen, den Staatenbildungen und den moralischen Pflichten hin - werden dann als 
verkappte Formen des Egoismus dargestellt. - Bald ist es der Sexualtrieb, der nicht etwa nur in unmittelbaren Sexualhandlungen wirksam sein soll, sondern als die ,eigentliche” Triebkraft für Spiel- und Ernst-Handlungen verschiedenster Art, für mythische und künstlerische Schöpfungen u.s.w. hingestelt wird; für die Psychoanalyse sind deshalb Wissenstriebe, Darstellungstriebe u.s.w. nur verfeinerte - „sublimierte" - Sexualtriebe.

Der Begriff der „S u bli mie r u n g" ist aber doch nicht überflüssig. Er bedeutet nämlich, dass die, für das personale Triebgeschehen verfügbare Gesamtenergie dann, wenn ihr die Entladung auf einem bestimmten Triebgebiet verwehtt ist, eine andere Entladungsbahn sucht - oder richtiger: auf eine solche gewiesen wird. Es ist also nicht so, dass ein $\mathrm{T} \mathrm{rie} \mathrm{b}, \mathrm{sich}$ sublimiert" $z u$ einem anderen hin, sondern dass die P e r s o $n$ ihre Totaltriebkraft anders akzentuiert, umleitet in eine Wirkungssebene höheren Niveau. In der Nähe besehen ist also die „Sublimierung" nicht etwa ein Beweis für den sekundären, nur abgeleiteten Charakter der humanen Triebe, sondern für das Gegenteil: nur weil die starke innere Bereitschaft und Gerichtetheit auf geistige Tat im Menschen lebt, kann sie die freigewordenen Energieen zu spontaner Aktivität erwecken. ${ }^{1}$ )

Wenn also z.B. der junge Goethe sein Wetzlarer Liebeserlebnis zu dem Kunstwerk „Werthers Leiden” "sublimiert” hat, dann bedeutet das nicht, dass sein Drang nach künstlerischer Darstellung "nur" eine Sublimierung seines erotischen Triebes sei, sondern es bedeutet, dass der höhere, aber darum nicht minder eingeborene, Darstellungsund Gestaltungs-Trieb jetzt jene Energieen sich unterwirft und nutzbar macht, die bisher durch den erotischen Trieb gebunden gewesen waren.

\section{Drang und Hemmung}

Wir haben nun zu fragen, wie aus den Dispositionen, die wir "Triebe" nennen, die einzelnen Triebäusserungen hervorgehen.

Wenn eine triebhafte Disposition aus dem Zustand der Latenz erwacht, muss es nicht sofort zur Handlung kommen; gewöhnlich schieben sich Zwischenphasen ein, die nun auch psychologisch

1) Der Ausdruck "Libido", der für jene personale Ge s a m $t \mathrm{kr}$ a $\mathrm{ft}$ oft in psy choanalytischen Darstellungen zu finden ist, scheint deshalb bedenklich, weil er wiederum aus der Sexualpsychologie entnommen ist. 
in ihrer Gefühlsbeschaffenheit beschrieben werden können. Vom Dy a m is chen her gesehen, fühlt der Mensch Unrast und Spannung, dumpfen Drang, das Verlangen zu irgend welcher Ånderung seiner Situation. Dies Fortdrängen aus dem bisherigen Zustand kann zunächst noch ganz vage sein (ist also noch kein Hindrängen auf ein Ziel); aber es kann, bei aller Unbestimmtheit, sich doch bis zur Unerträglichkeit steigern und schliesslich so aufstauen, dass ir g e $\mathrm{n} d$ e in e Entladung erfolgen muss - gleichgültig, ob diese überhaupt im Sinne personaler Ziele liegt oder nicht. So kann z.B. in einem Menschen, der sich in einem Versteck vor Feinden verborgen hält, und bei dem alles darauf ankommt, dass er sich nicht rührt, der Bewegungsdrang schliesslich so unwiderstehlich werden, dass er seine Lage ändert, ohne Rücksicht auf die Folgen. - Bei Schiffbrüchigen, die dem Verhungern nahe sind, entlädt sich der Nahrungstrieb im Zerkauen und Verschlingen der unmöglichsten Gegenstände.

Solche kurzschlussartigen Entladungsakte zeigen die Triebhandlung in ihrer nacktesten Form. Fast ist das Wort „Handlung" hierfür schon zu hoch; denn zur Handlung gehört Zielgemälsheit, und hier ist nichts als Dammbruch und sinnloses Uberfluten aller Ziele durch die ungebändigte Dynamik.

Aber unsere Beispiele zeigen auch, dass Triebakte dieser primitiven Art für den Menschen keine n or m a le Betätigung darstellen. Wir mussten auf abnorme Situationen verweisen, in denen durchweg erst Hemmungen errichtet und lange gehalten worden waren, ehe jene Triebkatastrophe erfolgte. Lebenszustände, bei denen solche Hemmungen überhaupt noch garnicht vorhanden sind, finden sich beim Menschen nur in der frühesten Kindheit; und hier können wir in der Tat solche ganz diffusen Ausserungen der Kraftentladung: Zappeln, Schreien, Zerstören u.s.w. bemerken. Sehr bald aber beginnt das menschliche Triebleben unter die Herrschaft der Doppeldynamik zu treten: dem Entladungs d r a n g tritt ein, sich immer weiter ausbreitendes und verstärkendes, System von $\mathrm{H} \mathrm{e} \mathrm{m}$ m u n g e n entgegen, die aus dem Denken, dem Wollen, der Gewöhnung und der Gesinnung stammen, und die zwar niemals die Kräfte der Triebsphäre einfach auslöschen können, wohl aber sie zu regulieren, zu verteilen und zu sublimieren vermögen. Dadurch erhält dann auch der einzelne Triebablauf eine andere Form. 
Es gibt noch andere Lebensbereiche, in denen jene wahl- und besinnungslosen Entladungsakte vorkommen; aber auch sie stellen „abnorme Situationen” dar. Zu ihnen gehört: der kurzfristige, aber despotische Affekt (Wut, Verzweiflung), die Wirkung von Rausch- und verwandten Mitteln, schliefslich auch verschiedene Formen der Geistes- und Gemüts-Krankheiten und der psychopathischen Anlagen. Bildet doch der ,Hemmungslose" einen bestimmten psychopathischen Typus.

Freilich, auch innerhalb der. Normalität kann das Verhältnis der beiden Dynamismen Entladungsdrang/Hemmung die verschiedensten Formen zeigen; und man braucht nur an die bekannten T y p e n-bezeichnungen des "Triebmenschen" und des „Verstandesmenschen" zu denken, um die Spannweite der hier obwaltenden Verschiedenheiten zu erkennen.

Uberall dort, wo der Triebdisposition Zeit und Möglichkeit bleibt, sich a $1 \mathrm{~lm}$ ä h l i c h zu aktualisieren, wandelt sich auch das begleitende Erleben. Aus dem blossen „Fortdrängen von” wird ein "H indräng e n z u”; nicht bloss Änderung der Gegenwartssituation überhaupt wird ersehnt, sondern Änderung in gewisser Richtung. Ein solches Gefühl, das aus gegenwärtiger Entbehrung heraus auf künftige Erfüllung tendiert, heisst „Be dü $r \mathrm{f} n$ i s". Damit gewinnen wir den zentralen Begriff der Psychologie des menschlichen Trieblebens ${ }^{1}$ ).

\section{BEDÜRFNISSE}

1. Dynamik der Bedürfnisse

Der Mensch hat in ganz anderem Sinne und Ausmalse Bedürfnisse als das Tier - nicht nur, weil sein Leben unter einer viel grösseren Mannigfaltigkeit von Zielsetzungen steht, sondern auch, weil seine Triebe sich viel weniger unmittelbar entladen. Bedürfnisse gibt es erst dann, wenn ein Trieb sich nicht direkt durch Tat $\mathrm{zu}$ entspannen vermag, sondern durch äussere oder innere Hemmungen hingehalten und $\mathrm{z} u \mathrm{n}$ ä $\mathrm{chs} t$ auf $\mathrm{b}$ in $\mathrm{n}$ e nseelische Auswirkungen beschränkt wird.

1) Szymansky hat den Versuch gemacht, das Bedürfnis zum Zentralbegriff der Psychologie überhaupt zu erbeben. - Spezielle Literatur aus neuerer Zeit zur psychologischen Theorie der Beduirfnisse: Lewin, Katz, Mc Dougall. Dazu die psychoanalytische und individualpsychologische Literatur. 
Aber auf der anderen Seite nennen wir einen solchen inneren Gefühlszustand nur dann ein Bedürfnis, wenn er mit T r i e bd y $n$ a $m$ i $k$ verknüpft ist, also die personale Aktivität in der Richtung auf das Ziel in Gang zu setzen geeignet ist. Hierin unterscheidet sich das Bedürfnis vom Wunsch, von der Sehnsucht und anderen Gefühlszuständen, deren Wesen im Binnenseelischen beschlossen bleibt. Man vergleiche etwa die beiden Aussprüche eines überarbeiteten Menschen: „Ich habe den Wunsch, auszuspannen" und "Ich habe das Bedürfnis nach Ausspannung". Nur im letzten Fall erwarten wir eine Tat.

Ein Bedürfnis hat - falls es nicht wieder abstirbt - eine Art Selbststeigerungsmotor in sich. Selbst wenn es zeitweilig durch Gefühle anderer Art und Richtung in den Hintergrund gedrängt werden mag, entzündet es sich immer wieder an seinem Nichterfülltsein. Je länger der Vorgang dauert, um so schwieriger wird es dem Menschen, sich auf anderweitige Beschäftigung zu konzentrieren; endlich ist der Spannungsgrad ein so hoher geworden, dass das Bedürfnis sich ganz spontan in Tätigkeit umsetzt, oder auf einem unverhältnismälsig geringfügigen Anlass mit der, auf Erfüllung gerichteten, Handlung einschnappt. Und zwar wird diese Handlung sich um so mehr dem Typus der reinen Triebhandlung nähern, je mehr das Bedürfnis aufgestaut war; $z w$ ischen Bed ür $\mathbf{n}$ isintensität und Organisationshöhe der Erfüllungshandlung besteht eine Art umgekehrter Proportionali$t$ ä t. „Hunger ist der beste Koch"; d.h. ein stark angestiegenes Nahrungsbedürfnis ist nicht wählerisch, sobald nur irgend eine Gelegenheit zur Befriedigung gegeben ist.

2. Innere und äulsere Bedingungen der $\mathrm{Bed}$ ürfnisse

Bei den Bedürfnissen muss (ähnlich wie bei den Reflexen und Trieben) unterschieden werden zwischen denjenigen Zieleinstellungen, die erblich angelegt, und jenen, die empirisch gewonnen sind ${ }^{1}$ ).

Ein Beispiel: Der Selbsterhaltungstrieb jedes lebenden Wesens

1) Eine „Zweikomponenten”-Theorie der Bedürfnisse hat neuerdings D. Katz au gestellt und speziell am Nahrungsbedürfnis nachgewiesen. 
führt dazu, dass, wenn seit der letzten Flüssigkeitsaufnahme längere Zeit verflossen ist, ein zuerst dumpfes, dann immer stärker fühlbares, schliesslich quälendes Flüssigkeitsbedürfnis, „Durst”, auftritt. Dies Bedürfnis bedarf keiner Erfahrung; es kann - wie beim eben geborenen Kind, das nicht gleich an die Brust der Mutter gelegt werden kann - in starken Ausdruckserscheinungen seine Intensität, und in der sofortigen richtigen Mittelwahl (Saugbewegung, sobald es dann angelegt wird) seine Ursprünglichkeit bekunden. Wenn dagegen ein erwachsener Mann nach getaner Arbeit das Bedürfnis verspürt, ein Glas Bier zu trinken, so ist dieser "Durst" von ganz anderer Art: er ist ge g e n s t a nd s g e la de n, und der Gegenstand konnte nur durch Erfahrung bekannt werden. Nicht Flüssigkeitsaufnahme schlechthin, sondern die Aufnahme einer Flüssigkeit ganz bestimmter Art wird angestrebt.

Das Verhältnis der beiden bedürfniserzeugenden Faktoren ist sehr kompliziert und wissenschaftlich noch wenig geklärt. Durch die Aulseneinflüsse wird ein Bedürfnis zunächst weitgehend spezifiziert und differenziert: so nimmt in Ländern, die Bier nicht oder wenig kennen, auch der spezifizierte Durst eine andere Richtung. - Oder: Der, jedem Menschen innewohnende, Allgemeintrieb nach Erweiterung seines geistigen Besitzes wird bei dem einen als Bedürfnis nach Lektüre, bei dem andern als Reise- und Wander-Bedürfnis, bei einem dritten als Experimentierbedürfnis u.s.w. Gestalt gewinnen. Hierzu aber müssen die verschiedenen Menschen erst die Erfahrung gemacht haben, dass es so etwas wie Lesestoff, Reisemöglichkeit, Maschinen und Apparate gibt.

Es ist eine „Erfahrung” ganz besonders tiefer Art, auf die wir hier stossen. Nicht das blosse Aufnehmen von Eindrücken durch die Sinne, nicht das blosse Verfügen über Kenntnisse, auch nicht das blosse Besitzen retrospektiver Erinnerungen - sondern die prospektive Einstellung der Triebdynamik auf gegenständliche Ziele ist das Werk dieser Erfahrung. Die Erfahrung ist aus der rein sensorisch-intellektuellen Schicht hinuntergesickert in die Schicht der zielgerichteten personalen Aktivität und bewirkt eine Vermannigfaltigung, Verfeinerung, Wandelbarkeit der Bedürfnisse, durch die sich der Mensch nun turmhoch über das Tier erhebt. Sie erst ermöglicht Zivilisation und Kultur, freilich 
auch deren Schattenseiten. Denn Raffiniertheit der Bedürfnisse, Gier nach immer neuen Bedürfnissen (also gleichsam Bedürfnis in zweiter Potenz), selbstzerstörerische Bedürfnisse (sogenannte „Süchte”) gibt es nur beim Menschen.

Die enge Verbundenheit von Bedürfnis und Welt kann nun auch von der $\mathrm{G}$ e g e n s t a n d s s e it e her betrachtet werden. Die personale Welt eines Menschen ist nicht nur der Inbegriff der Dinge und Vorgänge, die er wahrnimmt und denkt, sondern auch die Welt möglicher Bedürfnisziele und -Erfüllungen. Ja, sie ist diese Welt in einem viel ursprünglicheren Sinne als jene. Irgend ein Gegenstand gehört zur personalen Welt des naiven Menschen nicht, sofern er diese oder jene Form, Grösse, Farbe, diese oder jene sachliche oder logische Bedeutung hat - sondern sofern er Bedürfnisse anzureizen und zu befriedigen vermag. Es ist das Verdienst von Kurt Lewin, diesen wesentlichen Zug der personalen Dingwelt deutlich herausgestellt $\mathrm{zu}$ haben. Er bezeichnet jene Bedürfnisrelation der Dinge als ihren ,A $\mathrm{u}$ f f or d e $\mathrm{r}$ u $\mathrm{n}$ gsch a r a k ter". Mannigfaltigkeit und Abstufungen der Aufforderungscharaktere seien mit Lewins eigenen Worten dargestellt: ${ }^{1}$ )

„Das schöne Wetter, eine bestimmte Landschaft locken zum Spazierengehen. Eine Treppenstufe reizt das zweijährige Kind zum Heraufklettern und Herunterspringen; Türen reizen es zum Auf- und $\mathrm{Zu}$ schlagen, kleine Krümchen zum Auflesen, ein Hund zum Streicheln; der Baukasten reizt zum Spielen; die Schokolade, das Stück Kuchen. will gegessen werden u.s.w." ....

„Die $\mathrm{S} t$ ä $\mathrm{r} k \mathrm{e}$, mit der die von einem Dinge oder Ereignisse ausgehende Forderung uns begegnet, ist sehr verschieden. Von der „unwiderstehlichen Lockung", der ein Kind oder ein Erwachsener ohne Besinnung nachgibt und der gegenüber eine Beherrschung garnicht oder nur schwer möglich ist, gibt es alle Übergänge vom "Befehlscharakter” bis zu den schwachen Graden des „Nahelegens”, des Hinziehens, denen man ohne weiteres widerstehen kann, und die sich überhaupt nur dann bemerkbar machen, wenn die betreffende Person von sich aus. nach Beschäftigung sucht. Der Terminus "Aufforderungscharakter" soll alle diese verschiedenen Grade umfassen".

Die letzte Bemerkung Lewins zeigt aber, dass der Begriff "Aufforderungscharakter" eine Ergänzung erfordert. Lewin schreibt den s c h w ä ch s t e n Grad von Aufforderungscharak-

1) Vorsatz, Wille und Bedürfnis, S. 60. 
ter solchen Dingen zu, die sich nicht selbst den Bedürfnissen aufdrängen, sondern von diesen $\mathrm{g}$ e $\mathrm{s} \mathrm{ch} \mathrm{t}$ werden müssen. Aber ist darum die Beziehung solcher Dinge zu den Bedürfnissen überhaupt schwach? Das Gegenteil ist oft genug der Fall. Die menschlichen Bedürfnisse verhalten sich ja nicht nur reaktiv zu den Dingen der Welt, indem sie sich an ihnen entzünden, sondern auch sehr s p o n t a n; Bedürfnisse, die nach Befriedigung drängen, suchen von sich aus an die Dinge heranzukommen, sich ihrer zu bemächtigen und an ihnen sich zu erfüllen. Der Doppelform personaler Aktivität (Reaktion und Spontanaktion) entspricht eine Doppelform gegenständlicher Charaktere; darum habe ich dem Aufforderungscharakter den „M a te r i a 1charakter" zur Seite gestellt ').

Welche Rolle spielt ein roher Klumpen Ton in der personalen Welt eines Bildhauers? Gewiss fühlt dieser sich g e r e i $z t$, den Klumpen zur Hand zu nehmen und an ihm herumzukneten; der Ton hat einen unwiderstehlichen Aufforderungscharakter. Aber über diesen ersten Anstoss hinaus bleibt der Ton in dynamischer Beziehung zu dem Bildhauer; denn jetzt wird er zum M a te ria l, an welchem sich das Gestaltungsbedürfnis spontan zu betätigen vermag.

Die verschiedenartige Bedingtheit der menschlichen Bedürfnisse legt Fragen nahe, die stark kulturpolitischen und soziologischen Einschlag haben. Wenn Bedürfnisse von Aussenfaktoren abhängig sind: bedeutet dies nun, dass man Bedürfnisse durch Darbietung entsprechender Erfahrungen einfach von aussen her e r z e u g e $n$, also beliebigen Dingen Aufforderungs- und Materialcharakter verleih e n kann?

Vieles scheint dafür $\mathrm{zu}$ sprechen. So hat Kolonisation den primitiveren Völkern stets die ihnen bisher unbekannten Genüsse und Künste (z.B. Alkohol, Feuerwaffen) gebracht und damit vorher unbekannte Bedürfnisse geweckt. So haben die technischen und Verkehrs-Fortschritte bewirkt, dass weite Menschenschichten heut das Bedürfnis nach Telephon, Kino, Radio, Ferienreisen, modischer Kleidung u.s.w. haben, die früher von solchen Bedürfnissen gänzlich unberührt waren.

Derartige Betrachtungen haben zuweilen sogar zu der These

3) s. S. 125 dieses Buches und ,Studien zur Personwissenschaft" S. 85. 
geführt, dass es Aufgabe der Wirtschaft, der Kolonisation, der Werbung sei, nicht nur vorhandene Bedürfnisse zu befriedigen, sondern neue Bedürfnisse $z u$ schaffen, und dadurch die, der Bedürfnisbefriedigung dienende, Wirtschaftsaktivität zu steigern. - Auf der anderen Seite hat man aus der Aussenbedingtheit der Bedürfnisse den Schluss gezogen, dass man auch n e $\mathrm{g}$ a$t$ i $v$ von aussen her auf Bedürfnisse einwirken könne; indem man ihnen ihre $Z$ iele vorenthalte, müsse es auch möglich sein, die Bedürfnisse selbst $z u m$ Schwinden $z u$ b r in g e n. Hierher gehört vor allem der Kampf gegen Rauschgifte: von der internationalen Bekämpfung des Opiumhandels bis zur Prohibitionsgesetzgebung verschiedener Länder; ebenso das Verbot erotisch aufreizender Schriften und Bilder und ähnliche Malsnahmen.

Eine Klärung des Problems ist nur durch Anwendung des Konvergenzgesichtspunktes möglich. Ausseneinflüsse müssen mit personalen Innenfaktoren in ganz bestimmter Weise zusammentreffen, damit Bedürfnisse entstehen. Der Innenfaktor ist die personale Triebdynamik, die in einer allgemeinen Gerichtetheit und in gewisser Stärke da sein muss, damit sie sich zu Bedürfnissen s pezifizieren kann. Gäbe es „Durst” nicht als vitales Urbedürfnis der Menschen, dann wäre auch der spezielle Bierdurst oder Weindurst, und dann wären auch Exzesserscheinungen wie Trunksucht u.s.w. nicht denkbar. Gäbe es nicht allgemein den Sexual- und Liebes-Trieb, dann hätten sich nie die Bedürfnisse nach bestimmten Befriedigungsformen, nach raffinierten Reizungsmitteln, nach perversen Betätigungen entwickeln können. Die äusseren Einwirkungen auf die menschlichen Bedürfnisse können sich daher, so gewaltig sie sein mögen, doch immer nur innerhalb der Grenzen der vorgegebenen allgemeinen Triebrichtungen bewegen. Von a us e $\mathrm{h}$ e $\mathrm{r}$ vermag man also Bedürfnisse ebenso wenig aus dem Nichts zu schaffen, wiezunichte $\mathrm{z} u \mathrm{~m}$ a $\mathrm{c}$ h e $\mathrm{n}$. Wohl aber verleihen die äusseren Einflüsse den allgemeinen und unaufhebbaren Bedürfnistendenzen ihre s p e$z$ if is che Gerichtetheit auf bestimmte Gegenstände und Befriedigungsarten, ändern die Richtung der Bedürfnisse um; steigern oder hemmen die dynamische Auswirkung der Bedürfnisse, regulieren ihre Befriedigung durch Dosierung der Reiz- 
mittel und der Zielerreichbarkeit. So bleibt genügend Spielraum für pädagogische, soziale und politische Beeinflussung der menschlichen Bedürfnisse und für die entsprechende äufsere Organisation der dinglichen Aufforderungs- und Material-Charaktere.

Ein spezifisches Bedürfnis kann von aussen her um so weniger beeinflusst werden, je intensiver es in den zugrunde liegenden Trieb eingebettet ist, und je stärker es durch Gewöhnung, Nachahmung, Vererbung u.s.w. in seiner spezifischen Form fixiert ist.

Dort, wo ein Trieb sich in verschiedenen Bedürfnisweisen seelisch aktualisiert, ist jedes einzelne dieser Bedürfnisse nicht so innig mit dem Grundtrieb verwachsen, dass es nicht durch ein anderes vertreten oder abgelöst werden könnte. So ist es z.B. sehr wohl möglich, dass ein ursprünglich noch diffuser Sexualtrieb je nach den ãusseren Einflüssen zu homosexuellen oder zu heterosexuellen Bedürfnissen und ihren Befriedigungen führen kann. Andrerseits wird dort, wo von vo r n berein der Grundtrieb sich mit seiner ganzen Dynamik in eine spezifische Bedürfnisform ergossen hat, ein ausserer $Z$ wang nur schwer und nur an der Oberfläche Erfolg haben. So wird bei einem Menschen mit angeborener Homosexualität die Drohung des Strafgesetzes und die Ächtung durch die öffentliche Meinung wohl die Betätigung, kaum aber das Bedürfnis selbst zum Schwinden bringen.

Auch die Fixation durch Gewöhnung setzt der Aussenbeeinflussung von Bedürfnissen starke Hemmungen entgegen; ein bekanntes Beispiel ist die, nur unter schwersten Erschütterungen mögliche, Entziehungskur bei Rauschsüchtigen. Das ganz spezifische Bedürfnis etwa nach Morphium oder nach Kokain ist hier so übermächtig geworden, als ob es direkt einem Grundtrieb entspränge.

Wird ein spezifisches Bedürfnis an seiner Befriedigung behindert, so wird es damit nicht ausgelöscht; vielmehr sucht die ihm innewohnende Triebdynamik notwendig nach einem Ausweg oder Umweg im Sinne des (unentrinnbaren) Grundtriebes. Gewöhnlich wird hierbei möglichste Anähnelung an die bisherige, aber jetzt unterbundene, Sonderform gewählt: „P r in z i p d e r geringsten Bedürfnisabweichung".

So wird der Gefangene, dem Sexualbetätigung in der bisherigen heterosexuellen Form nicht möglich ist, nicht sein Sexualbedürfnis verlieren, sondern häufig ausweichen in die Formen der Homosexualităt oder der Selbstbefriedigung.

Es gibt noch ein anderes Ersatzprinzip, das aber viel mehr 
dort Platz greift, wo nicht von aussen her, sondern durch eigene Willensentscheidung ein Bedürfnis unterbunden werden soll: es ist das $\mathrm{K}$ on $\mathrm{t} \mathbf{r}$ as $\mathrm{t}$ prinzip. Der bekehrte Trunkenbold wird Abstinent, d.h. er überträgt die Triebdynamik, die früher dem Bedürfnis selbst gewährt wurde, nun auf die Unterdrückung des Bedürfnisses; und er findet in dem Genuss seines Sieges über das Verlangen einen Ersatz für den früheren Genuss der Bedürfniserfüllung. - -

Kurt Lewin hat den „echten" Bedürfnissen die „Q u a s iB e d ü $r f n$ is s e" an die Seite gestellt, welche im Zusammenhang mit einer vorsätzlichen Willenshandlung entstehen und vergehen. Von ihnen kann erst in der Erörterung über das Willensproblem gesprochen werden. (Vgl. S. 580f).

\section{INSTINKTE ${ }^{1}$ )}

\section{Instinkte als Rüstungsdispositionen}

Die Begriffe „Trieb” und „Bedürfnis” bezeichnen zielgerichtete Dynamik; in diesen Begriffen selbst liegt noch nichts von den M i t $t$ e 1 n, mit deren Hilfe die Annäherung an das Ziel und seine schliessliche Erreichung bewirkt wird. Wir fanden sogar, dass die nackteste Form der Triebäufserung in wahlloser Entladung besteht, sodass es überhaupt nicht zu irgend welcher Anpassung der Mittel an das Ziel kommt.

Hier liegt zunächst die Annahme nahe, dass der Trieb als solcher - eben weil seine Bewusstheit nicht über das Erleben eines dumpfen Dranges hinausgeht - gleichsam beziehungslos zu seiner Erfüllung wäre. Legt man diese Annahme zu Grunde, so würde die offenbare Zweckmälsigkeit, mit der Mensch und Tier im allgemeinen die Mittel zur Befriedigung ihrer Bedürfnisse anwenden, rein auf dem äusseren $\mathrm{Er} f \mathrm{~h} \mathrm{hr} \mathrm{n} g \mathrm{~s}$ faktor beruhen.

Aber diese Annahme würde völlig irreführen. Gewiss müssen unendlich viele Mittel und Wege zur Bedürfnisbefriedigung erst kennen gelernt und geübt, also aus der Erfahrung übernommen werden. Aber dies gilt nicht für alle; es gilt um so weniger, je tiefer wir von den spezialisierten Sonderbedürfnissen hinabsteigen zu den elementaren Grundbedürfnissen: diese erhalten nicht

i) Vgl. das Sammelreferat von Karl Bühler. 
nur ihre Zielsetzung aus den erfahrungs-unbedürftigen Trieben, sondern auch ihren Mittelgebrauch aus den erfahrungs-u nbedürftigen "Instinkten".

Somit sind "Trieb" und „Instinkt" begrifflich von einander zu unterscheiden als angeborene $\mathrm{R}$ ich $\mathrm{tu}$ ug dispositionen und angeborene $R$ ü $\mathrm{t}$ u $\mathrm{n} g \mathrm{~s}$ dispositionen. Selbstverständlich liegt die Scheidung nur im Begrifflichen; denn instinktiver Mittelgebrauch ist nur möglich, wo triebmäfsige Richtungseinstellung obwaltet. Wir nennen also Instinkt eine $n$ solchen Trieb, dessen Gerichtetheit nicht nur dem Endziel, sondern a ch den Teilzielen gilt, durch deren Vermittlung das Endziel erreicht wird.

In welcher Weise sind diese Teilziele oder Mittel im B e w u s s t$\mathrm{s}$ e in repräsentiert? Jedenfalls $\mathrm{n} i \mathrm{ch}$ in der Form von ZielVorstellungen und -Gedanken. Der instinktive Nestbau des Vogels unterscheidet sich eben dadurch vom nichtinstinktiven Hausbau des Menschen, dass der Vogel vorher keinen Gesamtplan hat, keine Vorwegnahme der einzelnen nötigen Teilakte, keine Vorstellung der etwa in weiteren Phasen notwendigen Baustoffe, keine Uberlegung, warum gerade jetzt diese Malsnahme angemessen und jene unangemessen sei u.s.w. Wenn aber trotzdem der Vogel in den einzelnen Etappen seines Nestbaus die angemessenen Mittel findet, so kann hier nur ein dumpf gefühlsmälsiger, aber doch schon gegenstandsgerichteter Drang - also wieder ein B e d ü r $\mathbf{f} \mathbf{n}$ i s - vorliegen, das erst zur Ruhe kommt, wenn etwa ein geeigneter Halm oder $Z$ weig zum Weiterbau gefunden und zweckentsprechend eingebaut ist; und ebenso bei den weiteren Teilhandlungen.

Während also der nackte und primitive Trieb seinen Niederschlag nur in dem e in e m Bedürfnis findet: sein Endziel zu erreichen, - so durchläuft die Aktualisierung des Instinktes eine ganze Kette von $\mathrm{T}$ e i l b e d ü $\mathrm{r} f \mathrm{n}$ is s e $n$, deren jedes, wenn es erfüllt ist, ein weiteres aus sich entstehen lässt, und die in ihrer Gesamtheit die Verwirklichung des Endzieles ermöglichen. So kommen mehr oder weniger verwickelte Handlungsabläufe $\mathbf{z u}$ stande, die nicht mehr - wie die nackten Triebhandlungen im Gegenwartsmoment ausbrechen und verpuffen, sondern zahlreiche Aktionen einer längeren Frist zur Einheit zusammenfassen: man denke nur an den schon erwähnten Nestbau der 
Vögel, an deren Wanderflug nach dem Süden, an die Vorbereitungstätigkeit vieler Insekten für die Entwicklung und Ernährung der noch garnicht vorhandenen Brut u.s.w.

Die Existenz solcher hochorganisierten - und dennoch nicht zielbewussten - Instinkthandlungen hat stets als eines der grössten Geheimnisse der Biologie und Psychologie gegolten; und die Forscher haben sich immer wieder um eine Erklärung der Instinkte abgemüht. Wir müssen uns aber fragen, ob und in welchem Sinne hier eine „Erklärung” überhaupt erforderlich und möglich sei. Als Mysterium erschien es vor allem, dass hier primitive Lebensstufen (Tier, Kleinkind, Naturmensch) Handlungen durchführen, wie sie der erwachsene Kulturmensch, zum Erreichen an loger $Z$ we cke, nur verwirklichen kann mit Hilfe umfangreicher Bewusstseinsbeteiligung: der Erfahrung, des Denkens, des Wollens, des Vorausschauens. Will ein Mensch aus Europa nach Afrika und wieder zurückreisen, dann braucht er dazu Kursbuch und Reisebüro, tausend Überlegungen und Vordispositionen; er muss irgendwie das G a n z e des Unternehmens ü b e r b li ck e n, um daraus die Teilziele und Teilakte abzuleiten. Der Storch aber überwindet die gleichen Raumstrecken und kehrt mit Sicherheit zum heimischen Nest zurück, ohne dass ihm die technischen und geistigen Hilfsmittel zur Verfügung ständen.

Aber ist nicht diese Vergleichung schon falsch? Für den Menschen ist jene Afrikareise nur e i n e unter zahllosen Möglichkeiten des Reisens, und selbst diese eine Reise kann in den verschiedensten Variationen durchgeführt werden. Für den Storch aber ist der Flug nach Afrika der einzige Fernflug, der ihm möglich ist, und der zu bestimmter Zeit fällig wird. Für den Menschen ist Reiseweg und Reiseziel das Andere, das F r e m d e, für den Storch ist es s e in Flug, sein Weg, sein Ziel, ein organisches Stück s e i n e s Lebens. Das instinktive Tun des Tieres ist das immer wiederkehrende Eingepasstsein in die ewig gleichartige e in e tierische Umwelt; das nicht-instinktive Tun des Kulturmenschen ist das immer wechselnde F e r $\mathrm{t}$ i g w e rd e $n$ m ü s s e n mit den immer w e c h s e l n d e n, unbestimmt vielen Möglichkeiten einer immer wieder fremden Welt. Nur eine sehr äusserliche Betrachtungsweise also käme dazu, von a $n$ a 1 o g e $n$ Handlungen hier und dort zu sprechen. Der In- 
stinkt gehört dem Urverhältnis des lebenden Wesens mit seiner Welt an und kann daher nicht „zurückgeführt” werden auf noch ursprünglichere Faktoren. Das Lebewesen funktioniert hier mit derselben Selbstverständlichkeit und $Z$ weckmäIsigkeit, wie etwa in den Funktionen des Wachstums, des Stoffwechsels u.s.w. Der Unterschied gegenüber diesen rein biologischen Vorgängen beruht nur darauf, dass die Zielsetzungen des Instinkts nicht ununterbrochen lebendig sind, sondern $\mathrm{zu}$ gewissen $\mathrm{T}$ e $\mathrm{r} \mathrm{m}$ i $\mathrm{n}$ e $\mathrm{n}$ akut werden: infolgedessen heben sich die Instinkthandlungen als $\mathrm{S}$ onderbetä $\mathrm{t}$ ig unge $\mathrm{n}$ ab aus dem stetigen Fluss des Lebens und nehmen die psychologische Form der Bedürfnisbefriedigung an, und zwar vermittels einer Abfolge von Teilbedürfnissen, die alle aus dem Grundtrieb hervorwachsen.

Obige Auffassung wendet sich natürlich nicht gegen die Versuche, die verschiedenen Instinkthandlungen $\mathrm{zu}$ analysieren und die Beteiligung der einzelnen Leistungsgebiete an ihnen zu untersuchen. So ist es z.B. ein sehr interessantes Problem, mit Hilfe welcher sensoris chen Leistungen den Zugvögeln die Orientierung bei ihren Hin- und Rück-Flügen ermöglicht wird. Nur darf man nicht glauben, dass der etwaige Nachweis einer bestimmten sensorischen Leistungsfähigkeit nun den Instinkt „erklärt” habe. Denn nicht die Funktion eines Organs an sich, sondern die sinnvolle Verwendung der Funktion im Dienste der Bedürfniskette macht das Wesen der Instinkthandlung aus. Und eben diese Bedürfniskette selbst und ihre Umsetzung in Handlung ist nicht mehr weiter ableitbar, sondern gehört zum angeborenen Urbestand des Lebewesens.

2. Entwicklung und Elastizität der Instinkte

Diese „Angeborenheit" darf nun aber nicht zu starr und hart gefasst werden; er gibt innerhalb ihrer Bewegung und Spielraum.

a) Entwi cklung der Instinkte. - Angeborenheit heisst nicht: von Anfang an funktionsfertig sein. Da das Auftreten von Instinkthandlungen termingebunden ist, ist es garnicht möglich, dass sie sogleich funktionieren. Das deutlichste Beispiel hierfür ist der Sexualinstinkt, der ja erst recht spät „fällig" wird; auch andere Instinkte haben ihre längere oder kürzere Latenzzeit. Die Instinkthandlungen können sogar zu- 
weilen eine deutlich erkennbare Entwicklung durchmachen; und dennoch sind sie nicht als blosse Lernerzeugnisse anzusehen. Denn jene Entwicklung setzt aus inneren Gründen des Lebensrhythmus ein, wenn ihre Zeit gekommen ist; äussere Einflüsse können eine gewisse Verfrühung, Verspätung, Modifikation herbeiführen; aber in der Substanz ist es die innere Anlage, die nun zur Verwirklichung $r$ e if geworden ist.

Der Unterschied zwischen solcher "Instinktreifung” und dem empirischen Lernen wird klar, wenn man das Laufenlernen des Kindes und das Schi-Laufenlernen des Erwachsenen vergleicht. Jedes normale Menschenkind beginnt auf einer gewissen Altersstufe mit Laufversuchen, konzentriert hierauf eine Zeit lang einen grossen Teil der personalen Energie und vermag aus diesem Bedürfnis heraus die richtigen Innervationen der Gliedmalsen zu vollziehen, sein Gleichgewicht zu regulieren, Hilfen und Stützen zu verwenden u.s.w. Hier setzt sich der Instinkt durch und reift schnell zur vollen Leistungshöhe. Höchstens, dass das Tempo des Fortschritts bei starker Mithilfe der Erwachsenen ein schnelleres ist. - Schilaufen dagegen lernt ein Mensch nur auf Grund eigens darauf gerichteter Willensentschlüsse und mit Hilfe mannigfacher Erfahrungen, Anweisungen und Lehren; und wo ein Kontakt mit den entsprechenden äusseren Einflüssen und Erfahrungen fehlt, wird die Leistung nicht entwickelt. Eine starke Erleichterung des empirischen Lernens kann freilich dadurch herbeigeführt werden, dass die, an anderen Leistungsgebieten ausgebildeten, Instinkte in den neuen Handlungsverlauf miteingreifen: so kann die instinktive Gleichgewichtsregulierung des Gesamtkörpers, die der Mensch beim Laufenlernen sich angeeignet hat, beim Erlernen des Schilaufens oder Schlittschuhlaufens herangezogen werden.

b) E la s t i z i t ä t d e r I n s t i n k t e. -Das letzte Beispiel zeigt zugleich, dass „Angeborenheit” des Instinkts nicht starre Konstanz des instinktiven Tuns bedeuten muss. Wenn wir oben die Instinkthandlung darstellten als jene $\mathrm{k}$ onse $\mathrm{rvat}$ i ve Leistung, durch welche auf die phylogenetisch und ontogenetisch gleichleibenden Bedingungen der Umwelt in gleichbleibender Weise reagiert wird, so darf dies nicht im Sinne einer unlebendigen Maschinerie verstanden werden, die zwangsläufig nur in 
einer streng bestimmten Bewegungsfolge funktioniert. Es gibt ja im Biologischen niemals zwei Situationen, die völlig identisch wären, und deshalb auch $n$ ich $t \mathrm{z}$ we $\mathrm{i}$ Instin $\mathrm{kth}$ a n dlungen, die völlig gleich abliefen.

Wenn zwei Vögel derselben Art in verschiedenen Wäldern ihre Nester bauen, oder wenn derselbe Vogel in zwei aufeinanderfolgenden Jahren sein Nest baut, so wird schon durch die jedesmalige Konstellation der Zweige, in deren Winkel das Nest errichtet wird, ebenso durch die verschiedenartige Verfügbarkeit des Baumaterials, durch die Einflüsse der Witterung u.s.w. kein Nestbau-Vorgang und kein Nestbau-Produkt dem anderen gleichen. Der Instinkt arbeitet hier viel grosszügiger als eine Maschine; er vermag trotz allem Konservatismus dennoch eine individuelle Anpassung an die jeweilige Besonderheit der Situation vorzunehmen. Was sich gleichbleibt, ist der Grundimpuls und das letzte Ziel; aber die Art, wie sich im Verfolg jenes Impulses die Teilbedürfnisse aneinander reihen und sich jeweilig bestmöglich $\mathrm{zu}$ verwirklichen streben, hat einen durchaus nicht geringen Spielraum der Variation.

Die Elastizität des Instinkts ist auch e r b bi o log i s ch wichtig. Dass die Instinkte zu den allerfestesten Erbgütern gehören, ist sicher; aber das Vererben beruht nicht in der Ubbertragung bestimmter eindeutiger Bewegungsfolgen, sondern in der Úbertragung vitaler Grundbedürfnisse und der Fähigkeit, sie durch sinnvolle Handlungsfolgen innerhalb bestimmter Grenzen zu verwirklichen.

David Katz beschrieb den interessanten Fall eines Hundes, dem durch ein Auto die beiden Beine der linken Seite abgefahren waren; kaum waren die Wunden verheilt, so lief der Hund auf seinen $z$ wei rechten Beinen erstaunlich geschickt, obgleich der Laufinstinkt nun mit einer stark veränderten Gleichgewichtsregulierung des nur einseitig gestützten Körpers arbeiten musste. Mit Recht entnimmt Katz diesem Sonderfall, dass das vitale Bedürfnis zum Laufen mächtiger ist, als der angeborene Laufmechanismus der Vierbeinigkeit.

Besonderen Nachdruck auf die Elastizität der Instinkte legt Mc. Dougall 1). Er sieht mit Recht in dieser Erscheinung das entscheidende Argument gegen die „mechanische Reflextheorie der Instinkte", die vielfach von amerikanischen Forschern

1) "The Energies of Men", Cbapter IV. 
vertreten wird. Nach dieser Theorie soll jede Instinkthandlung auf einem festen angeborenen Verknüpfungssystem zwischen sensorischen und motorischen Nerven beruhen. Ein solches System müsste bei jeder Reizung des sensorischen Nerven in stereotyper Weise reagieren; aber eben die Stereotypie existiert nicht.

Mc Dougall veranschaulicht die Elastizität der Instinkte an dem Zellenbau einer Wespe. Die Einzelhandlungen der Wespe erhalten ihre Direktion nicht von einzelnen Sinnesreizen, sondern von dem $\mathrm{Z}$ i el, der zu bauenden Wabe und deren Füllung mit kleinen Insekten, die der künftigen Brut als Nahrung dienen. Wurde die Wespe bei dem Bau experimentell gestört (etwa durch Verletzung der im Entstehen begriffenen Wabe), dann hat sie nach kurzer Desorientierung diejenigen Veränderungen ihrer gewöhnlichen Tätigkeit vorgenommen, welche durch die Situation geboten waren; sie hat z.B. das hineingebohrte Loch mit Wachs verklebt, ehe sie mit ihrem normalen Bau fortfuhr.

Mc. Dougall bezeichnet diese Fähigkeit zu elastischer Verwendung des Instinkts als "Intelligenz" und kommt daher zu dem Ergebnis, dass in allen tierischen Handlungen Intelligenz und Instinkt verbunden seien, nur in verschiedener Verteilung. Mir scheint die Bezeichnung „Intelligenz" missverständlich; denn sie legt dem Tier die Fähigkeit unter, sich der spezifischen Situation unter bewusster Vorausicht des $Z$ i e 1 e s anzupassen. Für diese Annahme aber fehlt jede empirische Grundlage. Nicht nur die stereotype, sondern auch die elastische Instinktbetätigung erfolgt unbewusst.

\section{Die Instinkte beim Menschen}

Es ist kein Zufall, wenn die bisherigen Betrachtungen und die Beispiele vornehmlich den tierischen Instinkt behandelten; denn bei Tieren tritt das instinktive Verhalten in einer ganz anderen Reinheit und Durchsichtigkeit zu Tage als beim Menschen. Ja, unsere Vergleichungen von tierischem Nestbau und menschlichem Hausbau oder von Storchwanderungen und menschlichen Reisen konnten sogar so gedeutet werden, als ob beim Menschen der Instinkt überflüssig gemacht wäre durch das bewusste Denken und Wollen. Allein diese Auffassung wurde schon durch andere Beispiele widerlegt, die den Menschen be- 
trafen (Laufenlernen, Sexualität). Es ist daher nötig, die Psychologie der Instinkte, die früher etwas einseitig von der Tierbiologie her betrieben wurde, in ihrer spezifisch a th ropologis ch e n Wendung zu berücksichtigen.

Wenn es überhaupt möglich wäre, auf diesem Gebiet quantitative Vergleichungen vorzunehmen, dann würde man kaum sagen dürfen, dass die Instinkte beim Menschen geringer an Intensität und an Mannigfaltigkeit wären, als bei den Tieren. Der wesentliche Unterschied ist in dem V e r hä $1 \mathrm{t} \mathrm{n}$ is der Instinkthandlungen zu den Willenshandlungen zu sehen. Wo beim Tier primitives Wollen überhaupt auftritt, steht es noch durchaus im Dienst des Instinktlebens; es greift ein, wo die direkte Instinktverwirklichung auf ungewohnte Hemmungen stösst, und ermöglicht die Erreichung des Ziels auf Umwegen. Beim Menschen dagegen wird umgekehrt das auf Denken und Wollen gegründete Tun zu einer selbständigen Höchstform des Handelns ausgebildet; die Instinkte wirken hierbei mit teils als unterirdische Kraftquellen und Richtungsweiser, teils auch als Gegenspieler der Willenssphäre. So ist es verständlich, dass wir beim Menschen meist genötigt sind, den instinktiven Anteil aus den Handlungen erst a b s $\mathrm{r}$ a $\mathrm{kt}$ i v herauszulösen, und dass wir auf sehr primitive Entwicklungsstufen der Menschheit zurückgreifen müssen, (Frühkindheit, Naturmenschheit, Rückbildung durch Erkrankung), um Instinkte annähernd in der Reinheit und Isoliertheit anzutreffen, wie beim Tier.

Damit hängt zusammen, dass beim Menschen die Einschränkungen der starren Erblichkeit, die wir vorher als Entwicklung und Elastizität der Instinkte beschrieben, eine sehr viel grössere Bedeutung gewinnen als beim Tier.

Der neugeborene Mensch ist entschieden viel in st in k tä $\mathrm{r} \mathrm{m}$ e $\mathrm{r}$ als der neugeborene Hund oder das eben ausgekrochene Küken, sofern man die sogleich „f e $\mathrm{r}$ t i g” funktionierenden Instinkte beachtet. Das eben zur Welt gekommene Hühnchen empfängt aufgrund seines Nahrungsinstinktes von dem zum ersten Mal gesehenen Haferkorn einen Anreiz zu einer Hinwendungsbewegung und führt diese durch sehr komplizierte Muskelkoordinationen zum Ziel der Einverleibung des Körnchens: das Tier muss Schritte machen, mit dem Schnabel hir- 
zielen, zugreifen, schlucken. All dies „kann” das Küken sofort. Der neugeborene Mensch dagegen würde elend verhungern, wenn er sich zur Nahrungsquelle hinbewegen, hierzu sein Auge gebrauchen, Zieleinstellungen vornehmen müsste; erst wenn ihm die Brustwarze an den Mund gebracht wird, setzt die Instinktleistung des Saugens ein, nun allerdings sogleich in sehr vollkommener Weise. Nach einer Reihe von Tagen entwickeln sich im Menschenkind dann die ersten $\mathrm{H}$ i n w e $\mathrm{n}$ d u n $\mathrm{g}$ s i n s $\mathrm{t}$ i n $\mathrm{k}$ t e: das Köpfchen dreht sich zum Licht; die Mutterbrust zieht noch ehe der Säugling sie berührt - durch Wärme und Geruch „Such"-Bewegungen des Kindes auf sich.

Ein anderes Beispiel: Setzt man einen neugeborenen Hund auf einen Tisch und schiebt ihn der Kante zu, so wird er sich an der Kante durch rückwärts gerichtete Sträubebewegungen vor dem Fall zu schützen suchen, obwohl er noch niemals den Choc und Schmerz des Fallens erfahren hat. Beim eben geborenen Menschenkinde fehlt der entsprechende Abwehrinstinkt vollkommen; es würde ohne Gegenbewegung hinunterfallen. Später entwickelt sich dann freilich auch der menschliche Abwehrinstinkt; er ist nur in seinem Instinktcharakter nicht mehr so leicht erkennbar, weil er dann schon mit Erfahrungen durchsetzt und von Willenshandlungen überbaut ist. Aber es gibt doch auch späterhin gelegentlich Gefahrsituationen im Menschenleben, die entweder zu plötzlich eintreten, um Zeit zur Verwertung früherer Erfahrungen, zu Überlegungen und Entscheidungen zu geben, oder die irgend etwas bisher noch nicht Erfahrenes in sich schliessen: dann wird ,instinktiv" eine Abwehrhandlung vollzogen. Man steht auf einem Schiff, das unerwartet schlingert: sofort reguliert man durch breitbeinigeres Gehen das gefährdete Gleichgewicht.

Dieses Beispiel zeigt zugleich, wie elastisch und anpassungsfähig die menschlichen Instinkte sind, gerade deswegen, weil sie nicht von Anbeginn an als eindeutige Marschrouten festgelegt sind. Diese ihre Beweglichkeit macht sie gleichsam unsichtbar; sie sind nicht so sehr Eigengebilde als Momente und Fermente in dem so hoch strukturierten Handlungsaufbau des Menschen.

Wenn man etwa - um noch ein letztes Beispiel zu wählen den Sexualinstinkt betrachtet: wieviel eintöniger, gradliniger, termingebundener, aber auch treffsicherer - kurz, wieviel 
„instinktiver” sind seine Äusserungen beim Tier als beim Menschen! Mit unbeirrbarer Sicherheit findet jedes Lebewesen im Urwalde unter den ungezählten Tieren verschiedener Gattung den Partner seiner Art heraus; Vorbereitungen (Liebesspiele, Kämpfe um das Weibchen) sind relativ kurz, weitgehend festgelegt und gehen schnell in die endgültige Bedürfnisbefriedigung über. Beim Menschen dagegen ist schon die Suche des Partners ein Tun mit viel Bewusstheit, Zögerungen, wechselnden Entscheidungen und Irrungen; die Vorbereitungen haben zu einer weit ausgebildeten erotischen Kultur gefährt; die Art der Bedürfnisbefriedigung kennt unzählige Möglichkeiten, Zwischenschaltungen, Perversionen - es sieht so aus, als ob der „Instinkt" in diesem hochorganisierten Handeln weder möglich noch nötig wäre.

In Wirklichkeit spielt er in alledem mit. Das ganze erotischsexuelle Gebahren des Kulturmenschen würde wie eine Seifenblase zerplatzen, wenn nicht der instinktive Drang hinter alledem als Motor wirkte und bei der Regulierung der Handlungsrichtungen mitwirkte. Allerdings gibt es in dem Prozess der Instinktreifung Strecken der Stockung und Unsicherheit; Zeiten, in denen die Zielbewusstheit der Denk- und Willenssphäre zur unbewussten Zielstrebigkeit des Instinkts in Widerspruch tritt. Wird dies zur dauernden Lebensform, dann ist der Mensch ,instinktlos geworden"; er hat die Rationalisierung seines Tuns erkaufen müssen durch einen Bruch seiner Persönlichkeit, denn deren instinktive Grundlage lässt sich nicht ungestraft verleugnen. Aber in unzähligen anderen Fällen übernimmt der Instinkt nach manchen Entwicklungshemmungen und Umwegen doch wieder die Richtungsbestimmung des Handelns, vor allem als $\mathrm{u} \mathrm{n} \mathrm{b} \mathrm{e-}$ w us t es A u s a h l prin zi p. Gewisse Verhaltungsweisen werden zwar durchgekostet, aber schliesslich wieder abgestossen aus dem instinktiven Gefühl ihrer Unangemessenheit; und als endgültige Lebensform wird eine solche gewählt, die vom Instinkt bejaht werden kann. Ist doch der Instinkt elastisch genug, um nicht nur zu einer einzigen Verhaltungsweise, sondern zu verschiedenen Möglichkeiten Ja sagen zu können.

Was wir hier für den Sexualinstinkt aufführten, gilt sinngemäls auch für alle anderen menschlichen Instinkte. Sie funktionieren nicht „erfahrungslos” wie viele tierische Instinkte; aber 
sie lassen sich auch nicht durch Erfahrung ersetzen - sondern sie verleihen den Erfahrungen die Akzente der Echtheit oder Unechtheit, des nur transitorischen Vortastens und Durchprobierens oder des endgültigen Akzeptierens und Introzipierens. Wir werden hier wieder erinnert an Betrachtungen, die wir über das menschliche S p i e 1 anstellten (s.S. 493): Die Spiele, insbesondere die des Kindes, sind jene Vorbereitungs- und Vortastungs-Phasen, die die Instinkte lange vor ihrer Fälligkeit durchmachen, um zur rechten Zeit reif zu sein. Das spielende Verhalten nimmt im Leben des Menschen einen so viel grösseren Platz ein als beim Tier, we il die Instinkte des Menschen in viel höherem Grade entwicklungs b e dü rftig, aber auch entwicklungs $\mathrm{f} \ddot{\mathrm{a}} \mathrm{h} \mathrm{ig}$ sind.

Unter den Psychologen der Gegenwart hat sich Mc Dougall wohl am eingehendsten mit dem Instinktproblem beschäftigt und - ganz entsprechend unsern obigen Ausführungen - darauf Gewicht gelegt, dass zum Instinkt sowohl angeborene „propensity", wie angeborene ,ability" (also Richtungs- und Rüstungs-Disposition) gehören. Während er nun früher den Instinktbegriff auch auf den $M$ e $\mathbf{n ~} \mathbf{c h}$ e $\mathbf{n}$ anwandte und sogar ein System menschlicher Instinkte entwarf, hat er jetzt diese Anschauung revidiert und ist geneigt, den Begriff des Instinkts wesentlich einzuschränken. Von Instinkt will er dann sprechen, wenn bestimmte Leistungsfähigkeiten e inde utig ganz bestimmten Trieben zugeordnet sind, bei anderen Gelegenheiten also nicht in Funktion treten (so wenn bei den Wespen die Erzeugung und sachgerechte Bearbeitung des Wachses $n$ u $r$ im Dienste des Bautriebes für die Brut erfolgt). Da aber bei den höheren Tieren, insbesondere bei dem Menschen, die Befriedigung eines Bedürfnisses mit Hilfe verschiedenster Fähigkeiten stattfindet, und eine bestimmte Fähigkeit im Dienst verschiedenster Bedürfnisse verwandt wird, so scheut er sich heut, die Handlungsweisen dieser Lebewesen als instinktiv zu bezeichnen.

Mir scheint diese Einschränkung nicht zweckmäfsig zu sein. Denn das wesentliche Unterscheidungsmerkmal des Instinktes: die mangelnde intellektuelle Bewusstheit, geht hierbei verloren. Eine Instinkthandlung ist - um oben Gesagtes in anderer Formulierung zusammenzufassen - eine sinnvoll gerichtete Handlung, welche von angeborenen Bedürfnissen (propensities) geleitet wird und die zur Zielerreichung jeweilig erforderlichen angeborenen Fähigkeiten (abilities) aktiviert, ohne dass sie der bewussten Voraussicht des Zieles und der bewussten Wahl, Entscheidung und Planung bedürfte. In diesem Sinne aber ist instinktives Tun auch an me $\mathbf{~ s ~ c h l i ~} \mathrm{che} \mathbf{n}$ Handlungen beteiligt. 
Schliesslich sei noch erwähnt, dass es hier auch $T$ y p e nu n t e r s c h i e d e gibt: dem "instinktlosen" Menschen, den wir oben erwähnten, steht der „Instinktmensch” gegenüber, bei dem es nur in geringem Malse zu den Spannungen zwischen bewusster und unbewusster Gerichtetheit kommt, weil die Treffsicherheit des Instinkts grofs und nicht so sehr mit Entwicklungsstockungen, Umwegen, Notwendigkeiten des Durchprobens belastet ist. Zwischen beiden Extremen steht der „disziplinierte" Mensch, bei dem der Oberbau des willentlich bestimmten Verhaltens doch immer durch das unbewusste Auswahlprinzip des Instinkts geregelt wird. 


\title{
EINUNDZWANZIGSTES KAPITEL
}

\author{
DAS WOL L E N
}

I. ALLGEMEINES

\section{Der Begriff}

Es gibt kein menschliches Lebnis, das sich so scharf von dem Untergrund des personalen Lebens abhöbe und zu einem durchgestalteten Sondervorgang verselbständigte, wie die einzelne Willenshandlung. In ihr ballt sich die Lebendigkeit und Totalität der Person zu einer gerafften und akuten Tat zusammen, die hinausbricht aus dem stetigen und vagen Abfluss des Geschehens, ja zu diesem in Gegensatz tritt.

Auf der andern Seite ist doch jede Willenstat tief verwurzelt in jenem Leben, dem es sich zu widersetzen scheint; oberirdische und noch mehr unterirdische Fäden verknüpfen sie mit Regungen und Dispositionen, die ganz anderen Schichten angehören.

Nur wenn man diese Doppelstellung des Willens in der Person immer wieder beachtet, gewinnt man Zugang zu seinem eigentlichen Wesen, Werden und Wirken. Es ist völlig unzulänglich, alles auf die Gegensatzformel zu bringen: dass der Wille dem Trieb, der Neigung, dem Gemüt als der harte und feindselige Herrscher gegenüberstehe - wie es andererseits verkehrt ist, alles auf die Einheitsformel zu bringen: als wäre Wille nur sublimierter Trieb und eine gradlinige Fortsetzung der vitalen Lebensbetätigung. Er ist beides zugleich und eben dadurch etwas durchaus Eigenes und Neues - und etwas spezifisch $\mathrm{Menschliches.} \mathrm{(Denn} \mathrm{was} \mathrm{wir} \mathrm{beim} \mathrm{Tiere} \mathrm{als} \mathrm{Willenskeim}$ finden, ist doch im Wesentlichen noch unter die zweite Formel zu bringen). 


\section{Wir definieren:}

Menschliches Wollen ist ein, aus den Tiefen der Bedürfnissphaere gespeistes Streben, das durch bewusste Vorwegnahme von Ziel und Weg geleitet und geordnet wird, und dessen Verwirklichung durch einen besonderen personalen Akt eingeleitet wird.

Philosophie und Psychologie haben in den vergangenen Jahrhunderten die Bezeichnung Wollen (Wille) in sehr verschiedenen Bedeutungen gebraucht. Hier nur wenige Beispiele.

Es gibt einen ganz weiten Sprachgebrauch, welcher „Wollen" mit der Triebkraft für jedes $\mathrm{G}$ e s c h e h e $\mathrm{n}$ in der Welt schlechthin identifiziert; so führte Schopenhauer jede Bekundung innerer Dynamik im Anorganischen wie im Organischen und Seelischen gleichmälsig auf den "Willen" zurück. Eine solche Verallgemeinerung würde die psychologische und personalistische Herausarbeitung des spezifisch Willensmälsigen unmöglich machen. $-\mathrm{Zu}$ weit ist auch noch jene Fassung, die sich auf das ps y ch i s ch e Leben beschränkt, dieses aber in seinem ganzen Umfang als Willensgeschehen ansetzt; nach dieser "voluntaristischen" Theorie (Wundt) sind nicht nur die eigentlichen Strebungsvorgänge sondern auch alle Wahrnehmungs-, Vorstellungs-, Denk-Prozesse Willenshandlungen.

Andrerseits ist eine Einengung des Begriffs, die vom $\mathrm{E} t \mathrm{~h}$ i s $\mathrm{ch}$ e $\mathrm{n}$ herkommt, psychologisch nicht verwendbar; so beschränkt Kant den Begriff nur auf die von der Vernu $\mathrm{nt}$ geleitete Strebung: „Wille ist das Vermögen, nach der Vorstellung von G e s e $\mathrm{t} z$ e $\mathrm{n} \mathrm{zu}$ handeln".

Solange das Streben des Menschen in kontinuierlichem Fluss auf die Welt überströmt bis zur Erfüllung, ist noch kein Wollen da; handelndes Subjekt und behandeltes Objekt sind noch ungeschieden. Für das neugeborene Kind ist die Mutterbrust kein „Gegenstand", und der Drang zum Saugen kein „Wollen”. - Erst dort, wo dem strebenden Ich etwas Anderese nt-g e g e nsteht, wird dies zum "Gegenstand" und das Ich zum Woller. Vorbedingung des Wollens ist also der A b s t a nd zwischen strebender Person und erstrebtem Ergebuis; das Wollen selbst ist die Uberbrückung dieses Abstandes.

$\mathrm{Da}$ aber überall, wo Spannung und Konflikt herrschen, auch Bewusstheit eintritt, so schlägt sich auch dieser Intentionsprozess erlebnismärsig nieder.

Das O b j e kt des Strebens wird als „Z i e l” bewusst. Das 
Ziel kann abstrakt gedacht oder anschaulich vorgestellt werden; es mag als ganz vages Schema oder in scharfer Deutlichkeit vorschweben - aber irgendwie ist es im Bewusstsein repräsentiert, sonst liegt kein Wollen vor.

Das $\mathrm{S} \mathrm{u} \mathrm{b} \mathrm{j} \mathrm{e} \mathrm{k} \mathrm{that} \mathrm{von} \mathrm{sich} \mathrm{selber} \mathrm{im} \mathrm{Moment} \mathrm{des} \mathrm{Wollens}$ ein eigenartiges Bewusstsein der Selbsttätigkeit, ein gesteigertes Erleben des eigenen Ich als eines, der Tat fähigen, Wesens; äusserlich umrahmt wird das Erlebnis durch Spannungsempfindungen in der tatbereiten Muskulatur. Entscheidend aber ist, dass sich nun in einem bestimm ten Moment das Erleben der Tatfähigkeit zu einem direkten T a t e r l e b n i s zuspitzt "Jetzt will ich". Dieser nicht weiter beschreibbare "Willensruck" ist der Zentralpunkt jeder Willenshandlung; durch ihn erst wird die Willenshandlung $\mathrm{zu}$ einem abgehobenen, eigenständigen Lebnis innerhalb des Lebensflusses; nur von ihm aus ist die Struktur der Willenshandlung nach rückwärts (zur Motivation hin) und nach vorwärts (zur Ausführung hin) zu verstehen.

Die Üb e r b r ü c k u n g zwischen Subjekt und Objekt wird im Bewusstsein dadurch hergestellt, dass die Selbsttätigkeit als gerich te t auf das Ziel und als gerüstet für dessen Erreichung erlebt wird. Beides gehört zusammen; das Bewusstsein der angestrebten Erfüllung und das des eigenen Könnens. Dabei vermögen beide Momente des Willensbewusstseins in allen Graden der Schärfe und Deutlichkeit aufzutreten; ganz fehlen kann keines.

\section{Beispiele}

Um die Mannigfaltigkeit der Willenshandlungen und die Stufenleiter von sehr primitiven $\mathrm{zu}$ immer höheren Formen zu veranschaulichen, geben wir hier eine Reihe von fiktiven Beispielen, die auf einen konkreten Lebensbezug, nämlich meine Arbeit an diesem Buch, bezogen sind. Die späteren theoretischen Erörterungen werden mehrfach auf diese Beispiele zurückgreifen.

a) Das eine Schreibblatt ist, mitten im Satz, vollgeschrieben; ich schiebe es zur Seite und fahre auf dem darunter liegenden Blatt links oben mit dem Schreiben fort. Dies Manipulieren mit den Blättern ist ein unwillkürliches Tun; es ist durch Gewöhnung reflektorisch geworden. 
b) Beim Schreiben komme ich an eine Stelle, an der ich ein Buch zitieren möchte, dessen Titel mir entfallen ist. Es erwacht der Gedanke: „das Buch steht dort und dort auf dem Büchergestell". Dieser Gedanke bewegt mich, vom Schreibtisch aufzustehen, zum Regal zu gehen, das Buch herauszunehmen und den Titel $\mathrm{zu}$ notieren. ( $\mathrm{E}$ in $\mathrm{fach}$ Willenshandlung).

Alle folgenden Willenshandlungen sind „k o mplexer" Natur.

c) Wie im Falle b möchte ich ein Buch vom Gestell holen. Diese Regung wird aber durchkreuzt durch die andere: ich möchte nicht den Gedankenfluss unterbrechen, in dem ich gerade bin; der Faden könnte mir entgleiten, wenn ich selbst nur auf eine Minute die Feder aus der Hand lege und den Schreibtisch verlasse. Schliesslich entscheide ich mich doch für das Holen des Buches; und so handle ich auch. (Entscheidungs-oder W a h lHandlung).

d) Es sei folgender Fall konstruiert: ich komme an eine Stelle meiner Niederschrift, bei welcher die objektive Darlegung meiner wissenschaftlichen Uberzeugung gewissen engherzigen Leserkreisen missfallen und dadurch dem Absatz des Buches schaden könnte. Andrerseits bin ich überzeugt, dass die wissenschaftliche Aufgabe des Buches nur dann erfüllt werden könnte, wenn ich keine Rücksicht auf jene ausserwissenschaftlichen Gesichtspunkte nähme. In diesem Konflikt ist der Gedanke: „die wissenschaftliche Redlichkeit und Objektivität darf keiner anderen Zielsetzung weichen" schliesslich durchschlagend, und ich handle danach. Die Entscheidung war hier also zwischen einer konkreten Situation und einem allgemeinen Grundsatz strittig; schliesslich setzte sich der Grundsatz als Handlungsmotiv durch (Grundsat $z$ handlung, auch "Vernunfthandlung" genannt).

e) Ich gehe zu einem neuen Kapitel des Buches über. Das Thema - und damit auch das allgemeine $Z$ i e 1 des beginnenden Tuns - steht fest. Aber ehe ich mich an die Ausführung begebe, muss ich einen Plan machen, disponieren, Möglichkeiten durchdenken, konkrete und grundsätzliche Erwägungen anstellen. Es spielen also alle Momente der Fälle $c$ und d mit. Endlich ist der Pl a n soweit vorbereitet, dass ich an die Arbeit gehen 
kann; ein Willensruck leitet die Handlung ein. Nunmehr, während der Ausführung, ist der Plan wegweisend; er setzt Teilziele, Teilhandlungen, Ruhepausen, lässt auf schon Erreichtes zurück- und auf die nächste Etappe voraus-blicken; dabei wird der Plan selbst kontrolliert, korrigiert, umgebogen, durch andere Pläne ersetzt - und der ganze Ablauf bildet schliesslich eine hierarchische Struktur von Handlungen verschiedener Grössenordnung, die sich aber alle der Gesamthandlung dienend eingliedern. ( $\mathrm{Pl}$ a $\mathrm{n} \mathrm{h}$ a $\mathrm{nd} \mathrm{l} \mathrm{u} \mathrm{ng}$ ).

\section{Körperliche Merkmale des Wollens ${ }^{1}$ )}

Rein anatomisch-physiologisch gesehen sind Willenshandlungen nur dort möglich, wo ein Gehirn existiert und funktionsfähig ist. Von gewissen kortikalen Zentren gehen physiologische Impulse aus, die auf dem Umwege über subkortikale $Z$ wischenstationen (verlängertes Mark, Rückenmark) bis zu motorischen Nervenendigungen gelangen, wo sie ihrerseits zu bestimmten Muskelkontraktionen führen. Die so erzeugten Bewegungen unterscheiden sich von jenen, die ohne Gehirnbeteiligung von den subkortikalen Stellen direkt ausgelöst werden (Reflexhandlungen), dadurch, dass sie nicht in anatomisch festgelegten (vererbten oder eingeübten) Bahnen verlaufen. Vielmehr werden jeweilig - und immer wieder neu und anders diejenigen Bewegungskoordinationen erzeugt, die in ihrer Gesamtheit eine sinnvolle Leistung ermöglichen ${ }^{2}$ ).

Der Ganzheitscharakter der Willenshandlungen geht nun jedoch - auch im rein Körperlichen - weit über diese sinnvolle Bewegungsstruktur der Leistung hinaus. Eine solche ist ja immerhin noch ein Teilgeschehen im menschlichen Organismus; aber die $\mathrm{g}$ a nze körperliche Person wird mit herangezogen. Bei Vorbereitung und Durchführung einer Willenshandlung wird nämlich der vorher bestehende körperliche $\mathrm{G}$ e s a $\mathrm{m} \mathrm{t} \mathrm{z}$ u$\mathrm{s} t$ a n d geändert in dem Sinn, dass die Energieverteilung aus

1) Die Bedeutung des Körpers als des Zieles bestimmter Willenshandlungen wird erst später besprochen (S. 556).

2) Die zerebrale zentralstation für die Regulierung dieser sinnvollen Körperverrichtungen ist das Scheitelhirn. Bei gewissen Erkrankungen dieses „Handlungszentrums" kommt es zu seltsamen Fehlhandlungen. Dies Krankheitsbild der "Apraxie" hat zuerst Hugo Liepmann beschrieben. 
einer diffuseren in eine konzentriertere Verfassung gerät. Es werden alle energetischen Prozesse, die nicht in der Richtung auf die auszuführende Leistung liegen, reduziert, sodass ein möglichst hohes Energiequantum für die spezifische Handlung selbst verfügbar ist. $\mathrm{H} \mathrm{e} \mathrm{m} \mathrm{mung}$ und $\mathrm{Ans}$ pa $\mathrm{n} \mathrm{nu} \mathrm{ng} \mathrm{ge-}$ hören also notwendig zusammen. Gehemmt werden überflüssige und anders gerichtete Bewegungen und Einstellungen; angespannt - d.h. in dynamische Bereitschaft gesetzt - wird der Körperbereich, aus dem heraus die Handlung sich entwickelt. Es ist in der Tat ein ganzer Körper b e r e i c h, der in Spannung und sinnvolle Aktion gerät, nicht etwa nur die Gesamtheit der unmittelbar beteiligten Organe. Diese Organe werden durch die veränderte Energieverteilung gleichsam eingekreis t in abgestufter Spannungsintensität.

Der Feinmechaniker etwa, der zu seiner Arbeit an einer Präzisionsuhr direkt nur fein nüanzierte Bewegungen der Finger braucht, versetzt auch die ganzen Hände, die Unterarme, die Oberarme, die Schultern in einen Spannungszustand; doch nimmt dessen Intensität mit der Entfernung von den Fingern ab. - Wer die Willenshandlung des Nachdenkens intensiv vollzieht, lässt nicht nur das Hirn arbeiten, sondern zeigt auch an Stirnhaut, Augenbrauen, Kopfhaltung u.s.w. die Ausstrahlung der Spannungen.

\section{Zukunftsbezug (Prospektion) des Wollens}

Indem sich in jeder Willenshandlung das Objekt vom Subjekt irgendwie differenziert, scheidet sich auch die Zukunft von der Gegenwart. Vom jetzigen Augenblick aus wird auf die Zukunft „vorgeblickt"; das erst zu Realisierende wird im Zielbewusstsein vorweggenommen.

Um den besonderen Zukunftsbezug der Willenshandlung zu klären, müssen wir ihre Stelle in den personalen Zukunftsbezügen überhaupt festlegen. Die Zukunftsbezüge, welche das menschliche Leben beherrschen, sind zum grössten Teil unbewusster Natur; wir haben solche kennen gelernt als gebundene mnemische Nachwirkungen, als vorgreifende Instinkte, als spielendes Vorüben und Vortasten.

Dann gibt es aber solche Lebnisse, welche Zukunft b e w u s s t vorwegnehmen, also „prospektiv” sind. Hier wird der früher 
besprochene Unterschied von personaler "Nähe" und „Ferne" wichtig (s. S. 132).

Die ferne Zukunft ist zum grössten Teil dem Bewusstsein entzogen. Wo sie aber doch zu Bewusstseinsniederschlägen führt, haben diese eine eigentümliche Blässe, Unverbindlichkeit und Konsequenzlosigkeit. So besteht bei gesunden jungen Menschen zwar ein Wissen darum, dass ihr Leben einmal zu Ende gehen wird, aber es ist ganz vage und oberflächlich, dringt nicht in tiefere personale Schichten ein und beinflusst nicht das Verhalten. - So mancher Leichtfuss, der nur für wenige Wochen Subsistenzmittel hat, weiss zwar, dass er dann weiterhin mittellos sein wird, lässt sich aber davon wenig tangieren, noch weniger in seinem jetzigen Wollen und Tun bestimmen.

Personal $\mathrm{n}$ a h e ist die Zukunft erst dann, wenn sie nicht nur vage gewusst, sondern auch in ihrer personalen Bedeutung für die Gegenwart erlebt wird. Entweder: der Mensch fühlt sich v o n i h r abhängig, nimmt mögliches Schicksal vorweg, dem er preisgegeben ist oder sich hingeben kann ${ }^{1}$ ). Oder aber: der Mensch erlebt die Zukunft als von sich abhängig: als die Materie, der er selbst Gestalt verleiht, als die Möglichkeit, die er selbst in Wirklichkeit verwandelt. Diese a ktive bewusste $Z$ ukunftsbezogenheit ist das Wesensmerkmal des Wollens. Die Objekte der Willenshandlung haben daher niemals blossen Aufforderungscharakter, sondern zugleich Materialcharakter.

Die personale Nähe, innerhalb deren sich der Wille prospektiv verhält, ist natürlich nicht einfach durch objektive Zeitlängen auszudrücken. Es gibt hier sogar Paradoxieen: so kann für einen Menschen sein, in einem Monat $\mathbf{z u}$ absolvierendes, Examen solche personale Nähe haben, dass er die darauf bezüglichen Akte in planmäfsigem Wollen antezipiert - während das morgige Mittagessen in weiter personaler Ferne liegt und von keinem gegenwärtigen Willensakt erreicht wird.

Im allgemeinen aber wird sich die Zugänglichkeit der Zukunft für das Wollen über um so weitere Zeitstrecken ausdehnen, je höher ein Wesen organisiert ist. Für das Tier und den Säugling ist das "Morgen" schon ausserordentlich fern, die auf dieser Entwicklungsstufe vorkommenden Willensakte reichen nur in

2) Hierüber Näheres bei der Besprechung der prospektiven Gefühle, Kap. XXX. 
die unmittelbarste Zeitnähe, die fast noch Gegenwart ist. Der Naturmensch, das Kind im Schulalter haben zwar schon eine Willenszukunft; sie ist aber noch sehr kurzfristig. Ganz anders ist die Willensprospektion des erwachsenen Kulturmenschen. Er sorgt, plant und kalkuliert auf Jahre; ja, es gibt Willensakte, deren bewusster Zukunftsbezug nicht einmal an der Grenze des eigenen Lebens Halt macht: Testamentsbestimmungen, Lebensversicherungen, Mitarbeit an transpersonalen Aufgaben in Volk, Staat, Gesellschaft, die erst nach dem individuellen Lebensabschluss Früchte tragen kann.

Diese zeitliche Spannweite des Wollens ${ }^{1}$ ) ist eines der eindrucksvollsten Merkmale der voll entwickelten menschlichen Persönlichkeit. Durch sie wird das eigene Leben in weitem Ausblick zur Einheit zusammengefasst und zum fortschreitenden Werk des eigenen Ich gemacht, zugleich aber auch die Welt in ihrem zukünftigen Sein bemeistert. Denn aus der vagen Nebelhaftigkeit ihrer Ungewissheit und Unvoraussehbarkeit hebt sich ein hellerer und schärfer konturierter Strahl hervor,eben jene Geschehnisfolgen, die Gegenstände willentlicher Zielsetzung und Planung sind. Mag auch nachher sich erweisen, dass die Zukunft ganz anders verläuft als man sie gewollt hat: in der Vorwegnahme des Willensaktes war sie doch "mein", und meiner Tatbereitschaft unterworfen. So ist denn die Weitspannung des kulturmenschlichen Wollens nicht nur ein Symptom für ein hohes, geistiges Können; sie bildet auch die Grundlage für die Verantwortung, die der Mensch für seine eigene Lebensgestaltung trägt, und sie ermöglicht einen sehr entschiedenen Zukunftsglauben, der - dort wo er die Grenze der eigenen Existenz überschreitet - zu einer Art praktischen Unsterblichkeitsglaubens wird.

3. Fremdbezüglichkeit und Selbstbezüglichkeit der Willenshandlungen ${ }^{2}$ )

Das Ziel der Willenshandlung liegt nicht immer in der Aussen-

1) Das Analogon dazu in retrospektiver Hinsicht ist die Spannweite des Gedächtnisses. Auch diese wächst mit steigendem Entwicklungsniveau (vgl. S. 258).

2) Die früher oft gebrauchte terminologische Unterscheidung „äussere” und „innere" Willenshandlung deckt sich nicht ganz mit der obigen. Vgl. dazu S. 557. 
welt; es kann auch innerhalb der handelnden Person seinen Ort haben.

In den Anfängen des Willens ist die Scheidung allerdings noch nicht deutlich. Wenn das halbjährige Kind zu greifen beginnt, vollzieht es zwar schon viele ausgesprochene Willensakte. Aber zwischen dem Greifen nach einer blinkenden Glocke oder dem Ergreifen des einen Händchens durch das andere wird offenbar kein Unterschied gemacht; noch ist die Loslösung des Subjekts aus seiner unmittelbaren Nahwelt viel zu wenig durchgeführt, als dass das Glöckchen eindeutig als "fremd" und „draussen”, die ergriffene Hand eindeutig als ,zu mir gehörig” erfasst würde.

a) Allmählich aber bildet sich der Unterschied aus; und zwar sind die $\mathrm{fremdbez}$ üglichen Willenshandlungen die primitiveren. Eine solche tendiert in die Welt da draussen, in deren Bestand an irgend einer Stelle eingegriffen wird. Mag im übrigen die „Welt" diffus und ungestaltet sein; irgendwo hebt sich aus ihr ein Objekt in schärferen Konturen ab, sei es, dass es - schon wahrgenommen - geändert, ergriffen, gemieden werden soll, sei es, dass es - nur vorgestellt - geschaffen werden soll. Die intendierten Objekte sind entweder Sachen (bei technischen, handwerklichen Handlungen), oder Menschen (bei erziehlichen, heilenden, politischen Handlungen), oder Wertgebilde (bei künstlerischen, gesetzgeberischen, wissenschaftlichen, moralischen, religiösen Handlungen).

Die psychophysische Neutralität solcher Willenshandlungen kommt darin zum Ausdruck, dass zur Úberbrückung der Di$\operatorname{stanz}$ die zwischen Subjekt und Objekt liegenden materiellen Kräfte und Medien durch körperliche Akte des Subjekts in Bewegung gesetzt werden: durch Hantieren, Sich-Fortbewegen, Sprechen, Schreiben u.s.w. Nur dadurch, dass der Mensch seinen eigenen Körper willentlich zu dirigieren vermag, ist er der fremdbezüglichen Willenshandlungen fähig.

Ist diese letzte Behauptung wirklich von allgemeiner Gültigkeit? Gibt es nicht fremdbezügliche Willenshandlungen, die $\mathrm{nich} \mathrm{t}$ des materiellen Mediums zwischen Subjekt und Objekt - und deshalb auch $\mathrm{nicht}$ der Beeinflussung dieses Mediums durch körperliche Vorgänge im Wollenden - bedürfen? Kann man nicht „durch den blossen Willen" in die Ferne wirken? 
Es soll hier nicht das Problem gelöst werden, ob es Telekinese, Fernbeeinflussung durch Gesundbeten und ähnliches $g$ ibt; die Frage ist nach dem bisher vorliegenden Material wissenschaftlich noch nicht spruchreif. Wir können uns begnügen mit der Erwägung, ob solche fremdbezüglichen Willenshandlungen, f a lls sie existieren, unserer obigen These widersprechen würden. Dies ist aber nicht der Fall. Denn wo immer solche Vorkommnisse berichtet werden, hat sich das wollende Subjekt nicht nur seelisch, sondern auch körperlich in einen veränderten Zustand gebracht (Trancezustand, kataleptische Starre); und es wäre durchaus denkbar, dass diese Körperveränderungen nach aussen weiter wirkten - vielleicht durch uns noch unbekannte Medien, Strahlungsvorgänge oder Ähnliches.

b) Selbstbezügliche Willenshandlungen sind solche, deren $Z$ i e 1 eine Änderung in der Person des Handelnden ist. Hierbei fallen dennoch Subjekt und Objekt nicht einfach zusammen; denn Subjekt ist die jetzige Totalperson, Objekt ein gesondertes, erst künftig zu verwirklichendes Moment innerhalb ihrer.

Und zwar kann das Moment meines Ich, auf welches mein Willen zielt, zunächst kö r p e r li ch e r Natur sein.

Wir sahen schon oben, dass die fremdbezüglichen Willenshandlungen nicht ohne Beherrschung des eigenen Körpers möglich sind. Nun brauchen allerdings solche Körperbewegungen nicht eigene Willensziele zu sein; ihre Verselbständigung würde sogar den Ablauf der eigentlichen - nämlich fremdbezüglichenHandlungen unter Umständen recht stören.

Wenn ich einen Brief schreiben „will”, müssen sich meine Fingerbewegungen diesem Wollen fügen; es kommt aber nicht zu besonderen, auf meine Schreibbewegungen gerichteten, Willensakten; diese sind vielmehr als blosse Mittel dem aussenbezüglichen Willensakt eingeordnet. - Anders beim Schreiben 1 e rn e n: hier genügt nicht die Zielsetzung, einen bestimmten Buchstaben als äusseren Gegenstand zu erzeugen; ich muss auch meine eigene Handhaltung, den anzuwendenden Schreibdruck u.s.w. zum Gegenstand gesonderter Willensakte machen. Dies gilt allgemein; jedes Erlernen von Leistungen in der objektiven Sphäre muss von selbstbezüglichen Willensakten ausgehen, die dann erst allmählich dem objektiven Gesamtziel unterstellt werden.

Bei anderen Willenshandlungen ist aber der eigene Körper - 
oder vielmehr bestimmte Funktionen und Zustände an ihm das eigentliche $\mathrm{Objekt}$ des Wollens, so bei allen Malsnahmen der Körper- und Gesundheitspflege, der Ernährung, bei gymnastischen und sportlichen Übungen, u.s.w. Hier kann in Umkehrung der soeben geschilderten Verhältnisse - eine fremdbezügliche Willenshandlung in den Dienst der eigenbezüglichen treten: das Kind, welches lernt, sich die Zähne zu putzen, muss seinen Willen nicht nur auf die Säuberung der Zähne, sondern auch auf die Handhabung des fremden Dinges, der Zahnbürste, richten.

Grad und Art der Herrschaft des Willens $\ddot{u} b$ er d e $n$ e i g e n e n K ör p e r sind ausserordentlich verschieden. Zwar sind die, mit dem Zentralnervensystem in direkter Verbindung stehenden, quergestreiften Muskeln in erster Reihe den Willensimpulsen zugänglich. Aber wir hatten bereits früher (S. 550) auf jene abgestuften Willenswirkungen hingewiesen, denen ganze Körperbereiche und schliesslich der Gesamtorganismus unterliegt. Infolgedessen ist eine ausserordentlich grosse Elastizität und Variabilität innerhalb der willentlichen Beeinflussbarkeit von Körper-Bewegungen und -Zuständen möglich.

Gewiss sind im ganz groben die Unterschiede zwischen beeinflussbaren und nichtbeeinflussbaren Körperaktionen deutlich. Willentlich einwirken kann man auf die Bewegungen der Hände, aber nicht auf die Verdauungstätigkeit des Magens; man kann beide Augen gemeinsam willentlich wandern lassen, aber nicht ein einzelnes Auge; man kann den Atem innerhalb gewisser Grenzen willentlich verlangsamen, beschleunigen, anhalten, aber nicht den Herzschlag.

Sobald man aber mehr ins Einzelne geht, ändert sich das Bild. Schon gewisse nichtssagende kleine Körperkunststücke kann der eine willkürlich ausführen, der andere nicht: ein einzelnes Auge zukneifen, mit den Ohren wackeln u.s.w. Aber die personale Veränderlichkeit in dieser Hinsicht ist viel fundamentaler; Ubungen und sportliche Leistungen, Erziehung zu abgewogenen Bewegungen, zu guter Sprachkultur, Abgewöhnung schlechter Manieren, Atemgymnastik - all diese und viele andere Errungenschaften des Individuums bestehen vor allem darin, dass Leistungsbereiche, die ursprünglich dem Willen schwer oder garnicht zugänglich gewesen waren, ihm schliesslich weitgehend 
unterworfen wurden. Sie können später, wenn der Wille sein veränderndes Werk getan hat, wieder in die Selbstverständlichkeit des unwillkürlichen Funktionierens zurückfallen. Akrobaten und Fakire liefern die verblüffendsten Beweise dafür, dass es für die Unterwerfung der Körperfunktionen unter den selbstbezüglichen Willen überhaupt keine absolute Grenze zu geben scheint.

c) Eine zweite Art selbstbezüglicher Willenshandlungen setzt sich nicht körperliche, sondern ps y c h is c h e Ziele: die Herbeiführung bestimmter Bewusstseinsinhalte. Es sind das die eigentlichen ,inneren” Willenshandlungen. Beispiele: ich komme nicht gleich auf einen Namen und strenge mich an, ihn wieder zu finden; ich denke nach über eine schwierige Stelle eines fremdsprachigen Textes, dessen Sinn ich erfassen will; ich strebe danach, mir klar zu werden über die wahren Motive, die mich zu einer bestimmten Handlung getrieben haben; ich bin in einer gefährlichen Situation und versuche die Angst, die sich einzustellen droht, zu ersticken; ich richte während eines an mir gemachten psychologischen Experiments die Aufmerksamkeit auf die in mir dabei ablaufenden Erlebnisse.

Auch hier sind, ähnlich wie bei den Körperbewegungen, die Grenzen der Willensbeherrschung flüssig. Auf primitiven Entwicklungsstufen ist ja überhaupt die Gerichtetheit nach innen nur wenig ausgebildet, so auch die innere Willenshandlung. Wer sein eigenes Erleben beeinflussen will, muss zu ihm eine gewisse Distanz gewonnen haben, muss zugleich die Willenseinstellung zeitweilig von den, viel leichter zugänglichen, körperlichen und äusseren Zielen abwenden können. Diese Doppelforderung ist so schwer zu erfüllen, dass jüngere Kinder z.B. unfähig sind, sich „zu besinnen" auf einen im Augenblick vergessenen Namen, nachzudenken über ein nicht ganz leichtes Rätsel, sich Rechenschaft zu geben über Selbstbeobachtungen u.s.w. Es gibt auch viele Erwachsene, bei denen die Fähigkeit zu solchen inneren Willenshandlungen recht gering ist. Ganz dem Kontakt mit der Welt hingegeben, fehlt für sie der spontane Anlass, Eigenseelisches zum Gegenstande des Wollens zu machen; und wo ein Zwang dazu vorliegt - z.B. beim Sichbesinnen auf einen Namen - werden dann zum mindesten äussere Hilfsmittel, etwa das Hersagen ähnlicher Namen, herangezogen. 
Die höchste Form eigenbezüglicher Willenshandlung liegt schliesslich dort vor, wo nicht akute Körperzustände oder bewusste Inhalte, sondern d i s p o s i t i o n e 11 e Beschaffenheiten der Person selbst $\mathrm{g}$ e w o $11 \mathrm{t}$ werden. Nicht irgend etwas an mir, sondern ,i ch s elb st" soll geändert werden durch meine Eigentat. Man spricht dann von Selbstbildung, Selbsterziehung, Selbsterneuerung, Selbstgestaltung. Das Eigentümliche dieser Willenshandlungen ist, dass sie zwar in einem bestimmten Zeitpunkt beginnen, aber keinen zeitlich bestimmten Abschluss haben; denn der akute Entschluss und Impuls geht nicht auf ein akutes Einzelziel, sondern auf den stetigen Zukunftsablauf des persönlichen Lebens. Ihre Besprechung ist daher erst in anderen Zusammenhängen möglich ${ }^{\mathbf{1}}$ ).

\section{DIE MOTIVATION DES WOLLENS}

Kein Willensakt entspringt aus dem Nichts; er hat stets eine Vorbereitungsperiode, die im Innern der Person abläuft, ehe es zum Durchbruch der eigentlichen Tat kommt. Diejenigen Innenfaktoren der Person, die den späteren Willensakt verursachen, heissen die "Motive" dieses Willensaktes. Vermittels der Motive ist also der einzelne Akt in der Totalität der Person verankert. Man versteht, dass deshalb das Motivproblem nicht nur für die Psychologie, sondern für Ethik, Kriminalistik, Lebensanschauung von grösster Bedeutung ist.

Terminologisch empfiehlt es sich, den Ausdruck „Motiv" auf die innere Verursachung einer E in $z$ e 1 t a $t$ (z.B. eines schwer wiegenden Entschlusses, eines Verbrechens) zu beschränken. Wohl weisen die Motive ihrerseits zurück auf dauernde Beschaffenheiten der Person, welche die gemeinsame Grundlage für die Motivation vieler Handlungen bilden, auf chronische Willenshaltungen, Gesinnungen, Charaktereigenschaften (vgl. Kap. XXIII). Diese sollten aber nicht als „Motive” bezeichnet werden, um der Klarheit der begrifflichen Unterscheidung willen.

Dagegen darf der Begriff „Motiv” nicht so eng gefasst werden, dass er nur die im B e w u s s t s e in zu Tage tretenden Vorwegnahmen des Willenszieles umfasste. Vielmehr können hinter diesen bewussten Anreizen des Wollens andere, halb bewusste

1) Vgl. S. 610/11. 
oder unbewusste liegen, die, aus grösseren Tiefen stammend, die eigentlichen Energieen enthalten, aus denen die Willenstat gespeist ist. Wir scheiden diese beiden Motivarten als erscheinende und erzeugende oder als „Phaeno-Motive” und „Geno-Motive”.

\section{Phaeno-Motive}

Beschränken wir uns zunächst auf eine phaenomenologische Beschreibung der Motive, die dem E $\mathrm{r}$ l e b e n zugänglich sind.

$\mathrm{Ob}$ prospektive Bewusstseinsregungen überhaupt $\mathrm{m}$ ot $\mathrm{ivi-}$ s ch e Bedeutung gewinnen (d.h. in eine Willenshandlung einmünden) oder nicht, bleibt lange unentschieden. Die bewusste Vorwegnahme künftiger Möglichkeiten kann sich ja auch in der Passivität des Wünschens, Fürchtens, Hoffens, Erwartens bekunden; selbst sogenannte „Motivkämpfe" geben noch keine Gewähr dafür, dass es zu einer Willenshandlung kommen wird. Die Zahl der Fälle, in welchen solche Erlebnisabläufe wieder versanden oder durch ihr blosses Bewusstwerden ihren Zweck erfüllen (Wunschphantasieen), ist um ein Vielfaches grösser als die Zahl derjenigen, in welchen allmählich oder plötzlich aus dem Spielen mit Zukunftsmöglichkeiten ein Wollen von Zukunftswirklichkeiten hervorspringt. Auch kann ein zunächst willenlos endender Bewusstseinsablauf in einem späteren Zeitpunkt sich erneuern und nun erst in ein Wollen einmünden. Wir können also erst dann, wenn tatsächlich eine Willenshandlung eingetreten ist, jene vorangegangenen prospektiven Bewusstseinsinhalte als ihre „Motive” (und zwar als „Phaenomotive”) bezeichnen; die Zeit, in der sie sich entwickeln, ist die "Vorperiode" der Willenshandlung.

In der ,einfachen Willenshandlung” (Beispiel b, S. 549) erschöpft sich die Vorperiode in einem einzigen Phaenomotiv, das sich gradlinig in Willensimpuls und Durchführung umsetzt. An allen „komplexen Willenshandlungen" (Beispiele c bis e) ist eine Mehrzahl von Phänomotiven beteiligt; sie benötigen deshalb auch eine spannungsreichere Vorperiode, ehe der Willensruck einsetzen kann.

Am Phänomotiv ist seine Gefühsbetontheit und sein gegenständlicher Inhalt zu besprechen.

1) Über diese kann erst später gesprochen werden. 
Dass dem Motivbewusstsein stets eine Gefühlsbetontheit zukomme, ist die wichtige Entdeckung, welche schon Hume gemacht hatte - im Gegensatz zu der rationalistischen Auffassung, nach welcher die blosse Einsicht in die Angemessenheit des Zieles motivierend wirken könne. Ein Mensch kann noch so deutlich die theoretische UUberzeugung haben, dass irgend ein künftiger Zustand unter irgend welchem Gesichtspunkte dem gegenwärtigen vorzuziehen sei - ein Willensruck entspringt daraus nur dann, wenn diese Einsicht zugleich einem B e d ü r f$\mathrm{n}$ i s entspricht. Der Bewusstseinsniederschlag eines Bedürfnisses ist aber das ambivalente oder besser multivalente Gefühl der augenblicklichen Entbehrung, des Fortdrängens von ihr und der lustvollen Vorwegnahme des Zieles. Die dynamische Gewalt dieses Gefühlseinschlages mag sehr verschieden sein; ganz fehlen kann es bei keinem Bewusstseinsinhalt, der den Willen motivieren soll.

Dem gegenständlichen Inhalt nach ist das Phänomotiv in der einfachen Willenshandlung stets $\mathrm{k}$ o $\mathrm{n} \mathrm{k} \mathrm{r}$ e t. Jetzt und hier soll eine Handlung eingeleitet werden, die durchaus einmalig und individuell ist; so muss auch das vorweggenommene Ziel einmalig und individuell sein. Das heisst aber nicht, dass jenes Ziel nun in deutlicher Anschaulichkeit und abgegrenzter Vollständigkeit schon im Bewusstsein wäre. Vielmehr sind hier wieder sämtliche Stufen der Anschauungs-Nähe und -Ferne denkbar: von der plastischen Ausmalung des anzustrebenden Zustandes mit allen Einzelheiten - bis hin zu einem verschwommenen und sehr inhaltsarmen Schema. Dort, wo sich das Phänomotiv als alleiniges ungestört in Tat umsetzen kann, besteht ja meist gar kein Anlass zu eingehender Bewusstseinsausprägung; werde ich unterwegs hungrig, so kann die vage Vorstellung irgend eines Bäckerladens, ja, das ganz anschauungsfreie Denken an die Möglichkeit einer Kaufgelegenheit schon genügen, um den Willensruck und das Eintreten in den nächsten Laden herbeizuführen.

Anders, wenn in der Vorperiode $\mathrm{mehrere} \mathbf{P h}$ än omotive zur Geltung kommen. Hier gibt es verschiedene Möglichkeiten.

Ein zunächst noch alleinstehen des, aber vages Phänomotiv (z.B. : ,ich will heut Abend nicht zu Hause bleiben, sondern irgend 
etwas unternehmen") kann sich aufspalten in verschiedene sich ausschliessende Motive: "Soll ich ins Theater gehen?” „Ins Kino?” „Zu Freunden?” „Ins Freie?” Das Bedürfnis, zu einer Entscheidung $\mathrm{zu}$ kommen, führt nun $\mathrm{zu}$ einer weitgehenden Konkretisierung, zu genauerer Ausmalung dieses und jenes Zieles, sowie der zu ihrer Erreichung nötigen Hilfsmittel, sodass hier ein lebhaftes und farbenreiches Hin und Her von anschauungsnahen Inhalten entsteht. Ebenso bunt ist auch das Gefühlsgewoge; denn die Bedürfnisse, die in den verschiedenen Zielen ihre Befriedigung erhalten würden, sind mannigfacher Art; in unserem obigen Beispiel etwa kämpft das Bedürfnis nach Sensation (Kriminalfilm) mit dem Bedürfnis nach Aufheiterung, nach harmlosem Plaudern, nach körperlicher Erholung.

Oder es kann ein zunächst alleinstehendes Phänomotiv nach kürzerer oder längerer Zeit Gegenmotive hervorrufen, welche die gradlinige Umsetzung in die Tat verhindern. Ein Mitglied einer Bande plant mit seinen Genossen ein Verbrechen. Solange er mit jenen zusammen ist, existiert für ihn nur dies Motiv; aber wenn er dann für sich ist, kommen plötzlich die Gedanken an seine Angehörigen, an seinen Ruf, an die drohende Gefahr über ihn und geraten mit dem primären Motiv in Konflikt. Schliesslich ballen sich die Gegenmotive zu einem einheitlichen Hemmungsblock zusammen, sodass das innere Kampferleben nur noch um die Alternative geht: „Soll ich oder soll ich nicht?”

Dass solche Motivkonflikte schon ausserordentlich früh eine starke Ausbildung erfahren können, wird durch kindespsychologische Beobachtungen belegt. Es seien $z$ wei schon anderweitig veröffentlichte Beispiele erwāhnt ${ }^{1}$ ). Im ersten Falle hatte ein dreijähriger Knabe an einer Zirkusprobe teilgenommen, musste aber, weil er allzu ängstlich war, hinausgeführt werden. Draussen begann nun der Kampf der Motive: mit der Angst für sich selber, die ihn hinausgetrieben hatte, traten andere Gefühle in Konflikt, die ihn hineinzogen: Angst für die drinnen gebliebene Schwester, starkes Interesse, Glaube an den Schutz durch den innen postierten Polizisten; schliesslich siegte die letzte Motivgruppe. - Im andern Falle ist ein Mädchen von 23 Jahren auf einer kleinen Böschung im Walde allein gelassen worden; die Mutter geht mit einem fremden Kinde weiter. Angst hält das Kind davor zurück, allein herabzusteigen; Zorn über das Alleingelassensein und Eifersucht treiben zu selbständiger Tat; der Abschluss ist deshalb interessant, weil hier der W i 11 e n s r u c k mit seltener Deutlichkeit

1) Psychologie der frühen Kindheit S. 212 und 394 ; Elsa Köhler S. 154. 
hervortritt: „Da geschieht etwas Seltsames: das vorher so furchtsame Kind rafft in der Todesangst alle Kräfte zusammen und wagt das Äusserste.... sie setzt sich auf den Boden und gleitet absatzweise hinunter, schreiend und kreidebleich"

Úberall, wo die Vorperiode einer Wahlhand $1 \mathrm{ung}$ geschildert wird - so auch in unserer obigen Darstellung — wird von einem „Konflikt” oder „Kampf” der Motive gesprochen. Es ist nun von allergrösster Wichtigkeit zu betonen, dass diese Ausdrucksweise $\mathrm{n} \mathrm{u} \mathrm{r} \mathrm{bild} \mathrm{lich} \mathrm{zu}$ verstehen ist, nicht aber die wirkliche Verursachung des Willensgeschehens trifft. Die einzelnen Phänomotive sind zwar als Bewusstseinsmomente relativ abhebbar und in ihrer antinomischen Inhaltlichkeit durchschaubar; aber sie dürfen nicht verselbständigt werden zu Kraftträgern, die untereinander „kämpfen” können. Grade hier hat die ,e l e m e n t e n p s y c h o lo g i s c h e” Auffassung schwere Folgen gehabt. Indem diese nämlich die einzelnen Phänomotive als dynamische Einheiten ansah, wurde die Person selbst verwandelt in ein passives Gebilde, das von jenen Kräften hin und hergezerrt und - wie beim gezogenen Tau oder bei einer Wage schliesslich in der Richtung des stärksten Zuges bewegt wird ${ }^{1}$ ). In allen solchen Betrachtungen wird übersehen, dass die Phänomotive ihre eigentliche Dynamik aus den Genomotiven ziehen, die ihrerseits in der Totalität der Person wurzeln.

$\mathrm{Zu}$ den Wahlhandlungen gehört auch unser Beispiel d „Grundsatzhandlung" (S. 549), nur dass hier das richtunggebende Phänomotiv in der Form eines a b s $\mathrm{t} \mathrm{r}$ a $\mathrm{k} \mathrm{t}$ e $\mathrm{n} \mathrm{S} \mathrm{a} \mathrm{t} \mathrm{z}$ e $\mathrm{s}$ bewusst wird. An dieser Stelle wird wieder die enge Verbundenheit der Willenshandlung mit dem Denken deutlich; denn es gehört eine starke Abstraktionsfähigkeit dazu, um allgemeine Sätze mit Forderungscharakter auch nur de n ke n zu können. Kant hatte daher Recht, wenn er die Fähigkeit, den abstraktesten dieser Forderungssätze — nämlich: „Du sollst, weil Du sollst”- zu denken, als praktische $\mathrm{V}$ e r $\mathbf{n}$ u $\mathbf{n} \mathrm{ft}$ bezeichnet hat.

Aber gerade Kant weist uns auch den Weg, um eine rein rationalistische Deutung der ,Vernunfthandlung" zu vermeiden, indem er nämlich die „praktische” Vernunft von der „theoreti-

1) So ist auch das berühmte scholastische Beispiel vom „Esel des Buridan” mög. lich geworden, nach welchem das arme Tier, das zwischen zwei gleich grossen, gleich weit von ihm entfernten Heuhaufen steht, verhungern muss, weil die Motivzüge nach rechts und nach links gleich stark sind und sich gegenseitig aufheben. 
schen" scharf absondert. Das Denkenkönnen des abstrakten Satzes ist zwar notwendige, aber nicht ausreichende Voraussetzung der Willenshandlung vom Typus d. Der Satz muss als Forderungssatz erlebt werden und in freier Entscheidung erfüllt werden; Fordern und Erfülle $n$ aberist a us dem Denken allgemeiner Gesetze niemals abzule it e n, ist etwas, das zum rein Theoretischen hinzukommen muss. In unserer Terminologie ausgedrückt: nur derjenige allgemeine Satz, dessen Erfüllung $B$ ed ü $r f n$ is ist, kann als Grundsatz im Wollen wirksam werden. So hoch also die Handlung aus Prinzipien über jenen Wahlhandlungen stehen mag, die rein durch konkrete Phänomotive geleitet werden - ohne Verankerung in Bedürfnissen, und damit in mannigfachen Gefühlen, ist auch sie nicht möglich.

In der Vorperiode komplexer Willenshandlungen beschäftigt sich das prospektive Bewusstsein aber nicht nur mit den Zielen, sondern auch mit den Wegen zu ihnen, mit den Möglichkeiten ihrer Erreichung. Dadurch wird die innere Spannung noch beträchtlich vermehrt; denn die Verwendbarkeit oder Nichtverwendbarkeit bestimmter Mittel kann wiederum neue Phänomotive erzeugen, die mit den anderen in Konflikt geraten. Wer in der Vorperiode zu der Willenshandlung der Berufswahl steht, muss hierbei auch die Fragen: ob die vorhandenen Geldmittel reichen, ob noch zuvor eine weitere Berechtigung erworben, ein Examen gemacht werden muss u.s.w. - in Betracht ziehen. Oft kommt es sogar, noch vor jeder Entscheidung, zu einer weitgehenden Vorwegnahme der für die verschiedenen Ziele erforderlichen Wege, also $z u$ hypothetischen und unverbindlichen Planungen; ja, es gibt einen Menschentyp, der sich im Spiel mit solchen „Projekten” erschöpft und nie die Kraft zum Willensentschluss findet (,Projektemacher"). Da aber doch die eigentliche Bedeutung des Planens erst hinter dem Willensruck liegt, soll es weiter unten besprochen werden (S. 586).

\section{Genomotive und Phaenomotive}

1. Homogonie der Motive. - Das Motiv-Erlebnis,

1) Zum Thema „Grundsatzhandlung” vergl. auch: Wertphilosophie S. 420 ff. Ferner S. 622 dieses Buches. 
von dem bisher allein die Rede war, gibt noch keine Erklärung dafür, warum es nicht beim blossen Fühlen bleibt, sondern zum Wollen kommt. Den, hinter dem Phaenomotiv liegenden, eigentlichen Motor nennen wir Ge n o moti v.

Das unmittelbare Genomotiv des Wollens ist stets ein B e$\mathrm{d}$ ü $\mathrm{r} \mathbf{f} \mathrm{n}$ i s ${ }^{\mathbf{1}}$ ), und zwar ein Bedürfnis von starker, doch gebändigter Dynamik. Jedes Bedürfnis schöpft seine Dynamik aus den Kraftquellen des Trieblebens, aber es dosiert diese Kraft, steigert sich an seinem Nichterfülltsein und setzt sich bei einer gewissen Höhe der Spannung in Tat um. Diese Tat ist, wenn sie aus der $\mathrm{H}$ ö c h s t spannung hervorbricht, eine mehr oder weniger blinde, triebmälsige, „un-willkürliche” (vgl. Kap. XX). Anders, wenn sich das Bedürfnis, v o r dem Erreichen jenes Explosionsmomentes, in bewussten Vorwegnahmen des Zieles (Phänomotiven) niederschlägt und seine Dynamik hierdurch in bestimmte Geleise lenken lässt. Dann kommt es zur Willenshandlung. Während also z.B. das Sättigungsbedürfnis, wenn es exzessive Stärke gewonnen hat, sich auf jede beliebige Speise stürzt (,Gier”), kann es auf einer geringeren Spannungshöhe dazu führen, dass bestimmte Ziele der Sättigung gewählt und Wege zur Erreichung dieser Ziele vorgedacht werden, und dass dann die zurückgehaltene Kraft den Willensruck in diesem Sinne erzeugt.

I $\mathrm{h} \mathrm{h}$ a $1 \mathrm{t} \mathrm{l} \mathrm{i} \mathrm{ch}$ handelt es sich hierbei also, wie das Beispiel zeigt, um eine $D$ e t e r m i n i e r u n g: das noch vage gefühlte Bedürfnisziel wird nicht nur in Zielvorstellung und Zielgedanken übersetzt, sondern eben dadurch auch vereindeutigt; und der dumpfe Drang läutert sich zu Mittelwahl und Planung.

Damit aber ist eine $\mathrm{G}$ e g e n s e i $\mathrm{t}$ i $\mathrm{g}$ k it s beziehung zwischen Bedürfnis und Willen herbeigeführt, die weit über den Rahmen der einzelnen Willenshandlung hinausreicht. Denn obzwar jede Handlung ihre Antriebskraft dem jeweiligen Bedürfnisstande entnimmt, wirkt sie doch durch ihre Bewusstheit und Differenzierung auf die Gestaltung der Bedürfnisse selbst zurück. Wir hatten schon früher (S. 529) hervorgehoben, dass System und Ablaufsweise menschlicher Bedürfnisse aus der Konvergenz von angeborenen Triebfaktoren mit Erfahrungen stamme; jetzt erkennen wir, dass es wesentlich $W$ i l l e n s e r f a h r u n$\mathrm{g}$ e $\mathrm{n}$ sind, welche die Bedürfnisse differenzieren und sublimieren.

1) Oder eine Bedürfnisstruktur. 
Die dem Wollen zukommenden Möglichkeiten des Voraussehens, des Wählens, des Planens, des Bezugnehmens auf zeitlich ferne und geistig abstrakte Ziele - diese Möglichkeiten ändern, vermannigfachen und verfeinern die menschlichen Bedürfnisse selbst; schliesslich kommt es bei diesem Ineinandergreifen von dynamischen Tiefenfaktoren mit komplexen Willensabläufen dazu, dass auch die höchsten Zielsetzungen: Pflichten und Ideale, die dazu, Verwirklichung religiöser, ästhetischer, logischer Werte, in den Umkreis der menschlichen $\mathrm{B}$ ed ü $\mathbf{r} \mathbf{f n}$ is s e eintreten und dadurch an dem personalen Kraftreservoir teilnehmen, das neue Willenshandlungen möglich macht.

Die Zurückführung der Willensmotive auf Bedürfnisse bedeutet also nicht eine Senkung des Willens auf das niedere Triebniveau, sondern umgekehrt: eine Emporhebung der Bedürfnismöglichkeiten in die geistige Sphäre.

Gewiss gibt es viele menschliche Bedürfnisse, die im allgemeinen zu ihrer Erfüllung nicht auf den Durchgang durch den Willen angewiesen sind. Ein starkes Schlafbedürfnis z.B. führt zum Einschlafen, ohne dass man sich darum willentlich bemühen müsste, ja zuweilen wider Willen. Andere Vitalbedürfnisse (z.B. Nahrungsbedürfnis, Bewegungsbedürfnis) können mit sehr einfachen Willenshandlungen befriedigt werden. (Freilich gilt auch dies nur in normalen Lebeslagen; in Zeiten der Hungersnot wird das Nahrungsbedürfnis, bei krankhafter Schlaflosigkeit das Schlafbedürfnis sehr komplizierte Willensakte benötigen, um zur Erfüllung zu kommen).

Diesen Bedürfnissen stehen nun jene anderen gegenüber, deren Ziele viel $\mathrm{zu}$ hoch, $\mathrm{zu}$ fern und $\mathrm{zu}$ komplex sind, als dass sie direkt erreichbar wären. Sie sind erfüllbar nur, weil der Mensch der Willenshandlungen fähig ist. Andrerseits aber sind auch diese Handlungen nur dadurch möglich, dass ihnen Bedürfnisse zu Grunde liegen. Die Tat des Märtyrers, der sich freudig für seinen Glauben opfert, empfängt ihre willentliche Durchschlagskraft nur aus dem starken Bedürfnis nach Glaubensunbedingtheit und ewiger Seligkeit. Dies Bedürfnis aber gehört nicht mehr der triebhaften Vitalsphäre, sondern der geistigen Introzeptionssphäre an.

b. Heterogonie der Motive. - In den bisher besprochenen Fällen sind Genomotiv und Phaenomotiv h o m o g e n 
zu einander; die im Genomotiv angelegte Zieleinstellung wird beim Ubergang zum bewussten Phaenomotiv beibehalten, nur determiniert und geklärt. In anderen Fällen aber erfährt die Motivation bei diesem Ubergang eine Wandlung. Zwar entnimmt auch hier die Willenshandlung ihre Durchschlagskraft der Dynamik des zu Grunde liegenden Bedürfnisses; aber i n$\mathrm{h}$ a $1 \mathrm{t} l \mathrm{i} \mathrm{c} \mathrm{h}$ weichen die bewusstwerdenden Motive von den verborgen bleibenden, eigentlichen Antrieben ab. („H e t e r o g onie der Motive").

Wir stehen hier an einer jener Stellen, deren Klärung sich die tiefenpsychologischen Schulen zur Aufgabe gemacht haben. Aber unsere Auffassung dieses Sachverhalts ist doch sehr verschieden von der psychoanalytischen oder individualpsychologischen Theorie. Die folgenden Beispiele sind absichtlich nicht jenen komplizierten - meist auch abnormen - Situationen entnommen, für die in der genannten Literatur zahllose Belege zu finden sind, sondern alltäglichen, relativ einfache Vorkommnissen.

1) Trotzhandlung eines Kindes. Das Kind weigert sich, eine sonst beliebte Speise zu essen, mit der Begründung: „sie schmeckt mir nicht" oder ,ich habe keinen Hunger". Nehmen wir an, dies seien keine Lügen, sondern aufrichtige Äusserungen über die von dem Kinde selbst ge gl a ubte $n$ Motive seiner Weigerung. Dann ist dieser Glaube objektiv falsch; denn das wirkliche Genomotiv der Handlung ist das Bedürfnis nach Selbstgeltung gegenüber dem von aussen kommenden Zwang. Aus diesem Bedürfnis rührt auch die Kraft her, mit der sich der kir,dliche Wille gegen die dargebotene Speise stemmt; aber sein Inhalt bleibt unbewusst und wird im Bewusstsein ersetzt durch einen ganz anderen.

2) Ein Ehemann ist von Eifersucht geplagt und versucht daher, seine Frau von dem Zusammentreffen mit anderen Männern zurückzuhalten. Die hierzu nötigen einzelnen Willenshandlungen: Absage von Gesellschaften, Verhinderung des Alleinausgehens der Frau, Sorge für rein weiblichen Verkehr der Frau u.s.w. wird er aber nicht mit seiner Eifersucht motivieren, a $\mathrm{u} \mathrm{ch}$ vor sich selber $\mathrm{n}$ i cht, sondern mit anderen Gründen: dass die häusliche Behaglichkeit zu Zweien viel schöner sei als grosse Geselligkeit, dass er besorgt sei, sie den Unannehmlich- 
keiten des Alleinreisens auszusetzen, dass sie den Rat anderer Hausfrauen brauche u.s.w. Er wird im Erdenken immer wieder neuer Gründe sehr erfinderisch sein, wird auch die moralische Bewertung der Motive verändern, indem er sich nämlich einredet, dass lediglich seine fürsorgliche Rücksicht jene Handlungen veranlasse. Die Selbsttäuschung bezüglich der Motive kann hierbei eine vollkommene sein; aber auch alle Übergangsformen zwischen naivem Daranglauben und vollendeter Heuchelei sind denkbar.

3) Die Fähigkeit, Willenshandlungen auf prinzipielle Motive („Grundsätze”) zu stützen, haben wir früher als eine der höchsten Entwicklungsstufen des Menschen geschildert. Aber auch Grundsätze werden oft genug als blosse Phänomotive benutzt für Genomotive ganz anderer Art. Die Tat erscheint dann sanktioniert als Anwendungsfall einer These von allgemeiner Gültigkeit, z.B. des Prinzips „Gerechtigkeit geht über alles”, „Das Vaterland steht über der Partei" u.s.w. - nur dass die Anwendung der These nicht so allgemein ist, wie diese selbst. Wo der Grundsatz als echtes Genomotiv wirkt, da muss er übera 11 zur Entscheidung über die Handlung mitherangezogen werden, wo die Situation es fordert. Wer aber nur in ganz bestimmten Situationen sich auf den Grundsatz beruft, erweckt den Argwohn, dass er ihn lediglich als Kulisse vor ganz anderen motivischen Hintergründen verwendet. Es ist doch kein Zufall, dass bei Rechtsstreitigkeiten die unvereinbaren Handlungsweisen b e i d e r Parteien mit dem Grundsatz des "Rechts” gerechtfertigt werden und zwar nicht nur nachträglich, sondern auch schon vor der Tat. Andere Motive: des Eigennutzes, der Rache, der parteilichen Bevorzugung u.s.w., die mitgespielt, ja vielleicht allein die Handlung bewirkt haben mögen, kommen nicht zum Bewusstsein.

Der Name $\mathrm{Ph}$ ä n o-Motiv würde in allen diesen Fällen also nicht nur bedeuten: im Bewusstsein e r s c h e in e n d e s Motiv (gegenüber dem u n b e w u s s t bleibenden Genomotiv), sondern auch s chein bares, vorgeschobenes Motiv (im Gegensatz zu dem echten, eige n $\mathrm{t}$ i che $\mathrm{n}$ Genomotiv). Dies ist auch die alleinige Deutung, welche die Psychoanalyse dem Verhältnis der beiden Motive gibt: sie wird nicht müde, jene verborgenen Antriebskräfte - die fast ausschlieslich dem Sexualbereich 
zugeschrieben werden - als die allein wahren und ursprünglichen hinzustellen, die andersartigen Phänomotive „nur” als Deck- und Surrogat-Formen, ja geradezu als Trugmotive anzusehen.

Diese Auffassung wird aber der grossen positiven Bedeutung der Phänomotive in keiner Weise gerecht.

c) Weitere Bedeutung der Phaenomotive.Hier ist zunächst der Rechtfertigungscharakter der Phaenomotive $\mathrm{zu}$ betonen.

Die Zielsetzung, die jeder Willenshandlung innewohnt, ist nämlich eine doppelte: eine sachliche und eine personale. Dort handelt es sich darum, durch Wahl geeigneter Mittel einen speziellen künftigen Zustand zu erreichen. Hier aber handelt es sich darum, das besondere Tun in das personale Leben und die personale Welt sinnvoll einzuordnen (zu „introzipieren”). Ganz im Gegensatz zur Trieb- und Instinkt-Handlung ist die Willenshandlung bewusst bezogen auf "mi ch" als Totalpersönlichkeit und auf „meine” Welt. Was ich jetzt willentlich tun werde, gehört auch später zu mir und erwartet Resonanz von draussen. Dieses Über-sich-Hinausweisen jeder Willenshandlung verlangt schon vor dem Vollzug eine B e g r ü n d u n g im Bewusstsein des Wollenden.

„Begründung” ist zunächst intellektuell zu verstehen. Grundloses Tun erscheint nämlich als ein so niederes Geschehen, dass man es nicht gelten lassen kann. Auch ist zum mindesten ein dumpfes Gefühl vorhanden, dass die Tat nicht ursachlos aus dem Nichts entspringe; den geahnten, aber nicht direkt aussprechbaren, Grund sucht man auf Umwegen rational formulierbar zu machen. Aber wesentlicher ist der andere Sinn von „Begründung": Rechtfertigung. Die intendierte Handlung muss bestehen können vor "mir" und der „Welt"; in ihr bestätige und verwirkliche ich mich selbst, meine Beziehung zu den andern und zu den objektiven Werten. Diese Funktion der Willenshandlung wird durch die Phänomotive vollzogen. Für diese ihre Leistung ist es gleichgültig, ob sie zu dem jeweiligen Genomotiv homogen oder heterogen sind; sie bilden das unter allen Umständen wesensnotwendige Rechtfertigungsmoment der Willenshandlung vor der Tat. 
$\mathrm{Zu}$ fragen wäre nur, ob dieser Bestandteil der Willenshandlung als "Motiv", also als U r s a c h faktor, bezeichnet werden kann; aber auch diese Frage ist zu bejahen. Denn ein Tun k o m m t als Willenshandlung nur zustande, wenn es sich durch bewusste Zielsetzung vor dem Handelnden selbst und vor der Welt zu rechtfertigen vermag.

Doch die personale Bedeutung der Phänomotive reicht noch weiter. Bei Wiederholung entsprechender Willenshandlungen werden die Phänomotive nämlich allmählich zu echten Genomotiven: d.h. sie werden mnemisch wirksam und gewinnen die Antriebsdynamik echter Bedürfnisse. Hier liegt also eine zweite, und zwar gegenläufige, Heterogonie der Motive vor. Hat das trotzende Kind unseres ersten Beispiels (S. 566) mehrmals eine bestimmte Speise abgelehnt mit der - zunächst nur phänomotivischen Begründung "sie schmeckt mir nicht", so entsteht daraus mit der Zeit ein gegenständlicher Speiseabscheu (also ein Bedürfnis mit negativem Vorzeichen). Dieser Abscheu ist dann genomotivisch wirksam, wenn vielleicht das ursprüngliche Genomotiv des Trotzes längst abgeklungen ist. - Ebenso können die „Grundsätze" unseres dritten Beispiels (S. 567), wenn sie auch anfangs vorwiegend den Charakter des Vorwandes gehabt haben mögen, mit der Zeit ihre Wurzeln immer tiefer einsenken in die tragenden Persönlichkeitsgründe und von hier aus als echte Genomotive wirksam werden; ja, sie können sogar dann unter Umständen jene motivische Ubersteigerung erfahren, die wir als „Prinzipienreiterei" bezeichnen.

Man darf also die Phänomotive nicht darum in Bausch und Bogen als blosse Sekundär- und Schein-Gebilde ansehen, weil einige von ihnen bei ihrem Erst-Auftreten diesen Charakter haben mögen. Man darf ebens owenig die echten Genomotive auf eine oder einige wenige vitale Bedürfnisgruppen deshalb beschränken, weil diese in frühen Entwicklungsstadien des Willenslebens vorzuherrschen scheinen. Die Mannigfaltigkeitder echten Genomotive des menschlichen Handelns ist unendlich viel grösser als die vereinfachenden Theorieen der Tiefenpsychologen es wahr haben wollen; denn es gehen fortwährend neue Genomotive aus Phänomotiven hervor. 
d) Die bisher entwickelten Gesichtspunkte müssen gegen eine, in der neueren Psychologie entwickelte, experimentelle Methode der Motivuntersuchung kritisch stimmen. Es werden dann nicht wirkliche Willenshandlungen benutzt, sondern Vorstellungen oder sogar ausgesprochene Fiktionen von Willenshandlungen experimentell erzeugt, etwa durch die Fragestellung: „Warum soll man nicht lügen?” Oder: „Was würdest Du tun, wenn Du, ohne dass es jemand merkt, einen Geldschein fändest?" Es ist klar, dass die hierauf erfolgenden Antworten (selbst wenn sie aufrichtig gemeint sind) nur die Gedanken - bestenfalls die Wunschregungen - zum Ausdruck bringen würden, die durch jene experimentelle Situation im Bewusstsein geweckt werden. Ungewiss bleibt dagegen, ob jene Gedanken und Wünsche vor einer wirklichen Willenshandlung sich auch nur als Phänomotive geltend machen würden, da ja die Realität vielleicht ganz andere motivische Bewusstseinsinhalte in den Vordergrund schieben könnte; und noch viel weniger ist jene künstliche Experimentalanordnung imstande, die eigentlichen Genomotive zu treffen. Vielleicht wird der Befragte, wenn er einmal wirklich vor einer Lüge oder der Verwertung eines Fundes steht, unter ganz anderen Motivationen handeln, als er im Experiment gutgläubig dem Befrager angegeben hat.

Dennoch sind solche Experimente nicht wertlos; nur darf man sie nicht als Motivuntersuchungen oder Gesinnungsprüfungen ansehen. Sie liefern aber Einblicke in die mor a lis che Urt e i l s fähigkeit der Prüflinge. Denn die Beurteilung der Willenshandlungen, der eigenen wie der fremden, ist in der Tat weitgehend bestimmt durch die Fähigkeit, sich Motivationsmöglichkeiten gedanklich $\mathrm{zu}$ vergegenwärtigen ${ }^{\mathbf{1}}$ ).

\section{KÖNNEN UND VERSUCHEN}

\section{D a s Könnens-Bewusstsein}

In früheren Willenstheorieen hatte man das Bewusstsein der Gerichtetheit auf Ziele so in den Vordergrund gestellt, dass das Bewusstsein der Gerüstetheit, das Könnens-Erleben, dahinter

1) Eine Ubersicht über experimentelle Methoden der sog. „Gesinnungsprüfung” gibt Hjalmar Sander (mit Bibliographie). Vgl. auch Stern-Wiegmanus Metrodeusammlung S. 262. 
zurücktrat. Es gehört aber zu den konstitutiven Merkmalen jeder Willenshandlung; denn nur ein Zielstreben, das von einem vagen oder klaren - G l a u b e n an die Fähigkeit zur Durchführung getragen ist, kann sich zum Wollen entwickeln.

Hier muss man freilich das tatsächliche (personale) Können und das (psychologische) Könnens-B e w us st s e in unterscheiden. Man denke sich einen völlig gelähmten Menschen, der kein Glied für Schreibbewegungen zu rühren vermag. Ein solcher Mensch könnte noch schreiben ,wollen” - sofern er nämlich nichts von seiner Lähmung wüsste. Wir hören auch von Kriegskrüppeln, dass sie, obwohl eines Armes beraubt, in Augenblicken des Vergessens irgend etwas mit dem fehlenden Arm vollbringen „wollen". Aber sobald sie wis s e n um das Nichtkönnen, ist das Wollen unmöglich. Der um seine Lähmung wissende Mann kann wohl den (unerfüllbaren) Wunsch haben, zu schreiben; er kann auch den Willen haben, das Schreiben mit einem anderen, gesund gebliebenen, Glied zu lernen - aber beides ist kein gegenwärtiges Wollen des Schreibens. Denn es fehlt jener „Willensruck”, der das zentrale Phänomen des Wollens ist.

Der Glaube an das Können braucht nicht immer explizit als selbständiger Bewusstseinsinhalt da zu sein; ja, bei den einfacheren Alltagswollungen wirkt er meist nicht in abgehobener Weise, sondern nur hintergründig und einstellungsmälsig mit. Wenn ich etwa nach einem Spaziergang meine laufende Tagesarbeit fortführen „will”, so ist in der psychischen Bereitschaft für das sogleich aufzunehmende Tun auch jener Umstand ungeschieden mitenthalten, dass es in meiner $\mathrm{M}$ a $\mathrm{ch}$ t steht, jetzt so $\mathrm{zu}$ handeln, und dass auch die nötigen Voraussetzungen: geistige Frische, Vorkenntnisse u.s.w. zur Verfügung stehen, sodass ich an die Arbeit gehen "kann”.

Deutlicher pflegt sich das Könnensbewusstsein auszuprägen bei weiter gesteckten Willenszielen und verwickelteren Handlungszusammenhängen. Nicht nur vor und bei Beginn der Handlung, sondern auch an vielen Stellen des Ablaufs wird dem Wollenden sein Können p r o b l e m a t i s c h; er hat nicht nur den einfachen und naiven Könnensglauben, sondern $\mathrm{frag} t$ sich selbst: Kann ich es auch? Und zwar bezieht sich das Fraglichwerden des Könnens sowohl auf die Zielsetzung (,Kann ich das 
w o lle n?”) wie auf die Beherrschung der Mittel („Kann ich es durchführen?").

Ein Beispiel: jemand will einen Beruf erlernen. Das ist nur dann ein echtes "Wollen", wenn er die Uberzeugung gewonnen hat, dass das Ziel während der mehrjährigen Lehrzeit dauernd die Anziehungsund Richt-Kraft für das Wollen behalten wird, und wenn zugleich der Glaube besteht, dass die $F \ddot{~ a ~ h ~} \mathrm{~g} k$ e i t e $n$ und Fertigkeiten des Subjekts und die verfügbaren äusseren $\mathrm{H}$ il $\mathrm{fs} \mathrm{m}$ it $\mathrm{t}$ el wirtschaftlicher, technischer und anderer Art die Durchführung möglich machen.

Die vollständige und vollernste Willenshandlung hat also zur Voraussetzung, dass sich ein p o s it i ve r Könnensglaube der Intention auf das Willensziel unterordnet. Ist diese Beziehung gestört, so nimmt die E r n s th a f t ig k e it des Wollens ab. Die Störung kann entweder in einer Schwächung oder in einer Vordringlichkeit des Könnensglaubens bestehen.

\section{Das unterwertige Könnensbewusstsein.}

Da sich das Bewusstsein des Könnens bei verwickelteren Willensvorhaben aus $\mathrm{Fr}$ a g e $\mathrm{n}$ entwickelt, die der willensbereite Mensch an sich selbst und an die Welt stellt, so ist der starke Anteil des I n t e lle k t s gefordert. Der seines Könnens noch nicht gewisse Mensch muss zur Selbstbeurteilung fähig sein, da er die Durchschlagskraft seiner Zielsetzung und seine persönlichen Kräfte einzuschätzen hat; er muss aber auch weitgehend die näheren und ferneren Bedingungen der äusseren Situation überschauen und in ihrer Wirksamkeit beurteilen, um zur Klarheit zu kommen, ob er sein Ziel erreichen kann. Wir stehen hier wieder an einem der Punkte, an dem die enge Verknüpfung von De n k en und Wolle n sichtbar wird.

Aber diese Verbindung hat nicht nur positive Bedeutung. Gerade die eingehende Reflexion auf Können vermag unter Umständen das Können selbst - und damit auch das Wollen - unsicher zu machen und schliesslich zu lähmen. Kritische Selbstzergliederungen und Besinnungen über die Dinge neigen immer dazu, die Gegeninstanzen gegen das Handeln - mangelnde Fähigkeit, Möglichkeit des Versagens, äussere Hemmungen - besonders zu beachten; überhaupt ist ja die rein betrachtende und erwägende 
Haltung an sich der Aktivität des Wollens abträglich. Man kennt jene Naturen, die vor lauter Bedenklichkeiten überhaupt nicht zum Willensimpuls und zur Durchführung von Willenshandlungen kommen. Sie sind „von des Gedankens Blässe angekränkelt”.

Nicht immer verhindert übrigens die Uberzeugung des NichtKönnens die Aktivität: nur liegt dann keine Willenshandlung mehr vor. Ganz klar ist dies bei dem Zwangstun; der vom Aufseher gepeitschte Sklave sucht die schwere Last weiter zu schleppen, obwohl er weiss, dass er es nicht mehr „kann". Aber Gleiches gilt auch, wenn feinere Triebkräfte im Spiel sind. Es gewinne etwa ein Examenskandidat mitten in der Vorbereitung die sichere Uberzeugung, dass er den Anforderungen sowohl der Vorbereitung wie der Prüfung selbst nicht gewachsen ist. Trotzdem arbeitet er weiter, vielleicht nur, weil sein Tun in den ausgefahrenen Geleisen des täglichen Lebensvollzugs perseveriert, vielleicht, um andere nicht merken zu lassen, dass er an seinem Erfolg verzweifelt; aber ein eigentliches „Wollen" des Examenszieles ist das nicht mehr.

Anders, wenn die Zweifelsfrage des Könnens noch nicht entschieden ist; dann gibt es - neben dem oben erwähnten Verharren in der Inaktivität - ein durchaus aktives Verhalten, das sogar den ausgesprochenen Charakter einer Willenshandlung hat, aber einer Willenshandlung "mit Vorbehalt": es ist der V e rsuch.

\section{Die Versuchshandlung}

Jede Versuchshandlung setzt sich eine doppelte Aufgabe: sie will das sachliche Ziel erreichen und das eigene Könnensbewusstsein klären.

Beispiel: Es wird ein Rätsel aufgegeben. Der eine Zuhörer sagt sofort: „nichts leichter als das” - naiver Könnensglaube -, geht mit entschiedenem Willensruck an die Lösung und versagt vielleicht. Der andere ist vorsichtiger: „ich wills versuchen"; der Zweifel am Können lähmt nicht die Tätigkeit, aber gibt dem Tun den Charakter des Provisorischen, Zurücknehmbaren. Gelingt die Lösung auf dem ersten eingeschlagenen Weg nicht, so hat er nun die Erkenntnis eines ungeeigneten Mittels gewonnen und wiederholt den Versuch mit einem andern Ansatz - bis er 
entweder die Lösung findet oder zu dem Ergebnis kommt: das Rätsel übersteigt mein „Können”; darum ,will” ich es auch nicht lösen. Dieser Doppelblick auf Sache und Vollzugsmöglichkeit, die Doppelhaltung von Verzicht und Bereitschaft zu neuem Ansatz macht das Wesen der vollbewussten Versuchshandlung aus.

Es gibt aber auch unechte Versuchshandlungen, das sind solche, die erst $n$ a cht rägli ch als blosse Ansätze erlebt werden. Denn auch der erste Rätselrater, der mit unbeschwerter Könnensüberzeugung direkt auf das Ziel losgegangen war, wird n a c h dem Misserfolg sagen: "Ich habe es vergebens versucht". Er senkt also, aus der nun gewonnenen Erfahrung des Nichtkönnens heraus, rückschauend das Niveau seiner Willenshandlung; geht er nun noch einmal an die Rätsellösung, so wird er jetzt vielleicht von vorn herein nur noch "versuchen” wollen.

Jeder Versuch hat also „Ernstspiel”-Charakter. Denn ernsthaft ist die Gerichtetheit auf das Ziel und auch der Wille, im Falle des Glückens die Handlung als ein Stück des ernsthaften Lebens mit allen Konsequenzen anzuerkennen; aber mehr oder weniger spielhaft ist doch die Reserve, das Vorläufige, Auswechselbare des probierenden Wollens, und vor allem die Weigerung, ein unzureichendes oder abwegiges Ergebnis des Versuchs ebenso ernst zu nehmen wie ein zielentsprechendes Resultat. („Es war ja nur ein Versuch"). In manchem Erfinder, aber auch in manchem exakten Experimentator steckt eine offenbare Spielfreude, wenn er an der Welt in immer wieder andrer Form herumtastet - bis dann einmal ein positiver ernsthafter Effekt herausspringt.

\section{Das überwertige Könnensbewusstsein}

Die letzten Beispiele zeigen schon, dass es Willenshandlungen geben kann, bei denen das sachliche Ziel mehr und mehr hinter dem Genuss des subjektiven Könnens zurücktritt. Das Versuchenkönnen, das Wechselnkönnen an sich verleiht ein gewisses Souveränitätsbewusstsein gegenüber der Welt, das sich allmählich mehr und mehr emanzipiert von dem, was ,eigentlich dabei herauskommt", also dem Ziel. Bei vielen Hochstaplern, Hazardeuren und Abenteurern ist ihr „Wollen” weitgehend ein solches Experimentieren, das zum Selbstzweck geworden ist. Das Provisorische 
der Versuchshandlung steigert sich hier zur völligen Verantwortungslosigkeit; die Gleichgültigkeit gegen sachliche Ziele macht alles Wollen und damit das Leben selbst unecht und unernst.

Eine viel primitivere Form überwertigen Könnensbewusstseins ist die $\mathrm{Tr}$ o t $\mathrm{zh}$ a n d $\mathrm{lu} \mathrm{n}$ g. Trotz tritt dort auf, wo das Wollen in seiner nackten Urform sich selbst erlebt, und wo der Mensch $\mathrm{d}$ a s F a k u m, dass er wolle $\mathrm{n} \mathrm{kann}$, bewusst sucht und geniesst. Wer zu wollen vermag, proklamiert sich und den anderen gegenüber sein Selbstrecht auf Tun, die Überwindung der Passivität und Abhängigkeit. Das trotzige Kind will garnichts Bestimmtes; das Sachziel ist nebensächlich - es will sein Wollen, durch die Negierung des fremden Wollens. So kann es kommen, dass der Dreijährige die sonst gern genommene Speise wütend abweist - nur weil er in der Darbietung den Eingriff in seine Selbstbestimmung sieht. Dabei gibt es ja im Grunde keine unselbständigere Handlung als die blosse Opposition. Denn sie bezieht ihr Sachziel von draussen, nur dass sie ihm ein entgegengesetztes Vorzeichen gibt ${ }^{1}$ ).

Eine eigentümliche Doppeltheit von Ziel- und Könnens-Bewusstheit zeigen schliesslich die s p o $\mathrm{tl}$ i c h e n Willenshandlungen. Gewiss werden hier objektive Effekte angestrebt: Bewältigung von Berggipfeln, Stählung der Körperkräfte, Willenstrainung, Unterordnung unter Regel und Gemeinschaft u.s.w. Aber zugleich werden diese Effekte als $m$ e $s \mathrm{~s}$ b r e $L$ e is $t u$ ng e $n$ angestrebt, d.h. als Malsstäbe des eigenen Könnens. Der Könnensgenuss begnügt sich hier nicht mit dem spielerischen Wechselnkönnen (wie beim ", ersuch"), und mit dem nackten Wollenkönnen (wie beim "Trotz"), sondern er will sich ständig an dem Könnens g r a d entzünden und durch die Messung das Können ständig vergleichen - sowohl mit dem Können anderer, wie mit dem eigenen früheren Können. Auch beim Sport führt diese Könnensbewertung, wenn sie einseitig wird, zur Zurückdrängung der sachlichen Ziele im Bewusstsein, sodass dem touristischen Sportfex dann nicht mehr die Freude an der Bergesnatur, sondern nur noch die Anzahl der eroberten Gipfel oder eine, von keinem anderen zuvor erreichte, Höhe zum eigentlichen Sinn 
seines Wollens wird. Auch hier sieht man wiederum das „Ernstspiel"'-mälsige des Tuns.

Aber auch Handlungen, die ihrem Haptziel nach durchaus sachliche und ernsthafte Intentionen haben, können doch einen sportlichen Einschlag erhalten, wenn das Könnensbewusstsein durch Wetteifer, Belobigung und Ähnliches unterstrichen wird. Oft wird ein, an und für sich nicht allzu reizvolles, Ziel dadurch willenswirksam, dass es mit sportlichem Interesse verbunden wird man denke etwa an das Einprägen des $1 \times 1$ in der Schule, und an die Akkordarbeit in Fabriken. Im Berufsleben gibt es vielfach solche Umbiegungen und Ausschmückungen der Willenshandlungen, die durch die objektiven Leistungsansprüche nicht gerechtfertigt sind, aber das Könnensbewusstsein befriedigen wie etwa die kalligraphischen Künste eines Kanzlisten. 


\section{ZWEIUNDZWANZIGSTES KAPITEL}

\section{DER A BLAUF DER WILLENSHANDLUNGEN}

\section{DER WILLENSRUCK}

Jede eigentliche Willenshandlung setzt ein mit einem besonderen Akt, dem Willensruck. Dieser ist, wie alle personalen Letzttatsachen, nicht eigentlich zu beschreiben und zu erklären; wir können ihm nur durch gewisse Umschreibungen näher kommen.

Betrachten wir zunächst die voll ausgebildeten Willenshandlungen, die eine regelrechte Vorperiode haben. Dann ist für den Willensruck die $\mathrm{A} \mathrm{b}$ h e b u n g gegenüber der Vorperiode wesentlich. Mögen seine Voraussetzungen auch in den Motivationsabläufen der Vorperiode liegen, er wächst nicht in gleitender Bewegung aus ihnen hervor, sondern springt aus ihnen heraus mit besonderer Deutlichkeit, wenn sich die Vorperiode in langen Kämpfen, Erwägungen und $Z_{w}$ eifeln hingeschleppt hatte. Diese hören plötzlich auf, etwas $\mathrm{N}$ e u e s tritt ein - und damit wird das Gefühl der Unrast und Unsicherheit ersetzt durch ein Gefühl der Endgültigkeit, welches - trotz aller miterlebten Aktivität doch etwas Ruhevolles hat. Diese retrospektive (nämlich vorangegangenen Kampf abschliessende) Seite des Willensrucks nennen wir "E n t s c h e i d u n g”. (Genauer wäre „Selbstentscheidung"; denn es gibt auch Entscheidungen ohne eigenes Zutun; so wenn bei einem, vor der Berufswahl stehenden Knaben die verschiedenen sich kreuzenden Neigungen und Wünsche durch ein Machtwort des Vaters zum Abschluss gebracht werden).

Darum gehört zum Willensruck das starke Erlebnis der Se lb s t$\mathrm{t} a ̈ \mathrm{t}$ ig k e it: I $\mathrm{ch}$ bin es, der da will. Nirgends rafft sich die aktive Ganzheit der Persönlichkeit zu einem so undiskutierbaren Erleben zusammen, wie im Willensruck: „volo, ergo sum”. 
Das „Sich-selbst-Haben” im Willensruck beschränkt sich aber nicht nur auf die unmittelbare Gegenwart, sondern strahlt in die Zukunft hinaus: was nun kommt, ist $m$ e i n Tun. Diese prospektive Seite des Willensrucks heisst "Entschlus s". Es wird nicht nur das Vergangene abgeschlossen, sondern auch das Bevorstehende entriegelt, ,ent-schlossen” - und zwar von mir und meiner Tat aus. In jedem Entschluss liegt eine Art Herrscherakt, ein Anspruch auf Eingriff in die Welt. Mag während der Vorperiode noch so sehr das passive Ausgeliefertsein an die Welt erlebt worden sein, mag selbst die Entscheidung noch durch äussere Einflüsse erzielt worden sein (vgl. unser obiges Beispiel vom „Machtwort des Vaters") — im Augenblick des Entschlusses ist die Belastetheit durch Fremdes umgewandelt in eigene Wirksamkeit. Das Gefühl der Ich-Souveränität mag meist nicht lange anhalten, weil sehr bald die Welt wieder ihre Ubermacht zur Geltung bringt: aber im Erlebnis des „Entschlusses" ist es unbestritten da.

Entscheidung und Entschluss verleihen auch dem g e g e n$\mathrm{s}$ t ä nd $\mathrm{l}$ i c h e n Inhalt der Wollung (den Zielen und Wegen) eine ganz andere Färbung, als sie in der Vorperiode hatten. Das Motiv, für welches die Entscheidung fiel, hebt sich mit siegreicher Klarheit aus dem Gewirr der Motivkämpfe heraus; die Gegenmotive verlieren viel von ihrer lockenden oder schreckenden Kraft in dem Augenblick, in welchem sie nicht mehr als Möglichkeiten des Wollens in Betracht kommen. Hilfsmittel, die in den Vorerwägungen unbenutzbar, Wege, die ungangbar erschienen, gewinnen jetzt, da man sich zu ihnen entschlossen hat, ein anderes, positiveres Aussehen. (Dies ist der Sinn des Sprichworts: „Wo ein Wille ist, da ist ein Weg”.)

Der Ausklang des Willensrucks endlich besteht darin, dass aus dem rein Psychischen (Entscheidung, Entschluss) ins Psychophysische übergegangen wird: dem Körper werden diejenigen Innervationen erteilt, welche die Handlung im Sinne des Entschlusses einleiten: „I m p u l s”.

Nun gibt es freilich auch zahllose Willenshandlungen von einfacherem Typus; die meisten Alltagshandlungen, sofern die überhaupt gewollt sind, gehören dem Typus unseres Beispiels $b$ an (S. 549). Hier fehlt die Vorperiode; sobald der modifizierende Be- 
wusstseinsinhalt auftritt (ich möchte ein Buch vom Büchergestell holen), setzt auch schon die auf seine Verwirklichung gerichtete Willenshandlung ein. Damit ist auch ein eigener Entscheidungsakt hinfällig; dagegen müssen Entschluss und Impuls auch hier funktionieren, damit es nicht beim blossen binnenseelischen Wünschen und Vorstellen bliebt. Der Willensimpuls braucht sich nicht mehr mit der Fraglichkeit des Zieles abzugeben; aber er bestimmt das Hier und Jetzt der Handlung.

Sehr deutlich kann man dies beim Aufstehen am Morgen beobachten. Darüber, d a s s man aufzustehen habe, besteht kein $Z$ weifel (und damit kein Anlass zu einer Entscheidung); dennoch kostet es oft einen sehr energischen Entschluss und Impuls, um aus dem Wissen um die Notwendigkeit das Faktum der Aufstehens zu machen. Ist auch der Entschluss unnötig, dann ist das Aufstehen keine Willenshandlung mehr ${ }^{1}$ ).

\section{DIE DURCHFÜHRUNG}

\section{Ein leitendes}

Erinnern wir uns unserer Beispiele für verschiedene Stufen der Willenshandlung (S. 548/9).

Bei der einfachen Willenshandlung (Beispiel $b$ ) ist die Durchführung ebenso einlinig und unproblematisch wie es die einfache Vorperiode war; der einmalige Impuls reicht aus, um diejenigen psychophysischen Einstellungen und Akte zum Ablauf zu bringen, die zur Erreichung des Ziels erforderlich sind.

Unter den „komplexen” Willenshandlungen gibt es wohl auch solche, bei denen nur die Vorperiode „,komplex" ist, in denen aber die Durchführung ohne Komplikation erledigt wird (Beispiel c). Aber sobald wir in höhere Regionen des Wollens aufsteigen, ist es gerade die $\mathrm{Dur} \mathrm{chf} \ddot{\mathrm{u}} \mathrm{hrung}$, welche zeitlich, inhaltlich und dynamisch eine reich gegliederte Struktur gewinnt (Beispiel $e$ ).

Das Wesentliche dieser Struktur ist die in ihr obwaltende O r d n u n g. Die einzelnen Teile der Handlung stehen zu dem

1) Die Behauptung Kurt Lewins, der Entschluss sei kein integrierender Bestandteil der Willenshandlung, ist nur daraus erklärlich, dass er zwischen „Entscheidung" und „Entschluss” nicht die oben erwähnte Trennung macht. 
Ziel in sinnvoller Beziehung; unddieser Sinnzusam menhang ist so machtvoll, dass Teilhandlungen, die von diesem Ziel abführen würden, garnicht erst zur Ausführung kommen, oder doch, wenn sie einsetzen, möglichst schnell unterdrückt werden. Hierin hat die Willenshandlung grosse Ähnlichkeit mit den Denkhandlungen (s. S. 391).

Dieser Zug ge ord n e t e r Z i e l g e mä $\int \mathrm{sh}$ e it hat sich den Willensforschern als ein charakteristisches Kennzeichen der Willenshandlungen aufgedrängt; sie haben ihn aber, je nach dem psychologischen Standpunkt, sehr verschieden ausgedrückt. So verlegt Ach die eigentliche Ursächlichkeit dieses Zuges in die Zielvorstellung, der er eine determinierende Tend e $\mathrm{n}$ z zuschreibt, d.h. die Eignung, als richtender Faktor auf die anderen seelischen Inhalte zu wirken. Lewin dagegen betont die "Herrschaft”, die das I ndividu u m auf die Handlung ausübt; er stellt daher den Gegensatz auf zwischen „Feldhandlungen", in denen sich der Mensch unbeherrscht den Kräften des Feldes, d.h. den Triebspannungen überlässt, und den „beherrschten" oder Willenshandlungen. Das ist im Grunde eine personalistische Auffassung; denn „Beherrschen” kann ja nur bedeuten, dass die Totalperson ihr prospektives Streben und ihre ordnende Aktivität den einzelnen, in ihr ablaufenden, körperlichen und psychischen Prozessen auferlegt.

Wir werden die personalistische Darstellung der Willenshandlung unter verschiedenen Gesichtspunkten vornehmen.

\section{D yn a mik}

Die personalen Energieen, die im Trieb- und Bedürfnisleben verankert sind, liefern den Fonds, aus dem auch das Wollen schöpft, der aber nun in sehr souveräner Weise verwertet wird. Natürlich ist diese willentliche Verwertung der Energieen um so leichter möglich, je mehr sie sich auf die schon in Bereitschaft stehenden Energieen, d.h. auf die echten Bedürfnisse, stützen kann.

Aber darüber hinaus entsteht im Moment des Entschlusses das neue Bedürfnis: die Handlung bis zu dem vorgestellten Ende zu führen. Lewin bezeichnet es als ein „Quasi-Bedürfnis”.

Wenn wir oben betonten, dass der Augenblick der Entscheidung im Willensruck eine Art Ruhepunkt darstellt, einen Abschluss 
der Unrast, die durch die motivischen Kämpfe der Vorperiode erzeugt war - so ist diese Ruhe nur von kurzer Dauer; der Handlungs e $\mathrm{tschluss}$ setzt neue Spannungen, die nach Ausgleich drängen und die den Willensvorgang in Bewegung halten, bis auf irgend eine Weise eine Erledigung erfolgt.

Diese Spannungs- und Antriebsdynamik gibt das Recht, hier von „Bedürfnissen” zu sprechen. Die Quasi-Bedürfnisse ähneln den echten Bedürfnissen auch noch in einigen anderen Punkten. Sie verleihen den Dingen der personalen Welt einen mehr oder minder starken Aufforderungs- und Materialcharakter. - Sie haben eine Spielraumbreite in der Ausführung der Handlungen (so kann der Vorsatz, einen Brief zu befördern, anstatt durch den ursprünglich beabsichtigten Gang zum Briefkasten, auch dadurch zur Entspannung und Erledigung kommen, dass man ihn einem Freund mitgibt). - Sie können eine Surrogaterledigung finden (Die Absicht, einen Brief zu befördern, bewirkt, dass ich beim Verlassen meines Hauses an den Brief denke und ihn in die Tasche stecke; dadurch ist aber die Bedürfnisspannung soweit gelöst, dass nun der Briefkasten keinen genügenden Aufforderungscharakter hat. Ich vergesse das Einstecken) $\left.{ }^{1}\right)$.

Allerdings zeigen die "Quasi-Bedürfnisse" auch Züge, die sie deutlich von den echten Bedürfnissen scheiden. Während diese eine chronische, dispositionelle Daseinsweise haben, aus der sie immer wieder in Erfüllungsakte ausbrechen können, führen die "Quasi-Bedürfnisse" eine bef $\mathrm{r}$ is te te Existenz: sie entstehen und vergehen mit der einzelnen Willenshandlung. Mit Beginn des Wollens setzt die Bedürfnisspannung ein; mit Abschluss der Handlung hat auch jene Spannung definitiv ein Ende: die Handlung ist „erledigt”.

Zwei Freunde wollen spielend ihre Kräfte messen: wer kann höher springen? Im Allgemeinen besteht bei keinem von ihnen ein Springbedürfnis; und hochgespannte Seile haben gewöhnlich keinerlei Aufforderungscharakter für sie. Von dem Moment jenes Entschlusses an aber entsteht nun in jedem ein "Quasibedürfnis": möglichst hoch zu springen - das seine vorwärtstreibende Dynamik aus anderen, latenten Energieen der Person entnimmt; und das Seil, das soeben vom Konkurrenten übersprungen worden ist, hat einen intensiven Aufforderungscharakter. Ist das Spiel zu Ende, dann hören Bedürfnis und Aufforderungscharakter auf.

1) Beispiele von Lewin. 
Das Quasi-Bedürfnis ist ferner, wie unser Beispiel zeigt, i n$h$ a $l$ t s i n d if f e r e $n t$ : es gilt der Durchführung des einmal gefassten Entschlusses, unabhängig von der Begehrlichkeit des spezifischen Zieles; nur die eingetretene Spannung soll erledigt werden. Auf diese Weise kann es auch Willensakte ermöglichen, die wider die Neigung eingeleitet wurden; nun, da sie in Gang gekommen sind, haben sie in sich selbst diese nach Abschluss drängende Tendenz. Jeder kennt solche Erlebnisse: eine Arbeit ist ungern begonnen worden; dann aber besteht das Bedürfnis - und es kann, je länger die Durchführung dauert, bis zur Unerträglichkeit steigen - den Abschluss zu erreichen.

Diese rein dynamische - und damit inhaltsindifferente - Seite der Willenshandlungen bietet ein geeignetes Objekt für e x p e$\mathrm{r}$ i m e $\mathrm{n}$ t e $1 \mathrm{l}$ e Prüfungen. Ja, eigentlich das einzige. Denn die inhaltliche Zielgeladenheit echter Willenshandlungen ist so stark durch die Vorperiode mit ihren Motivspannungen beeinflusst und so stark von tief eingebetteten Genomotiven beherrscht, dass sie nicht experimentell fassbar ist. Die fruchtbarsten und umfassendsten Experimental-Untersuchungen aus jüngerer Zeit, die von Kurt Lewin und seinen Schülern, beschränken sich daher bewusst auf die formalen Probleme der Willensdynamik.

$\mathrm{Zu}$ den wichtigsten Ergebnissen dieser Experimente gehören die Feststellungen über die Wirkung von $U \mathrm{n}$ t e r b r e ch ung e n der Willenshandlung, weil sie den Spannungscharakter der Quasi-Bedürfnisse sehr deutlich machen. (Ovsiankina. Zeigarnik).

Die Versuchspersonen mussten verschiedene Handlungen nacheinander vollziehen: eine Figur aus bunten Steinen legen, eine Tierfigur kneten, Perlen aufziehen u.s.w. Ehe eine Aufgabe erledigt war, wurde die Arbeit unterbrochen und zur năchsten Aufgabe übergegangen. Oder aber: es fand eine scheinbar unbeabsichtigte Unterbrechung statt: das Licht ging plötzlich aus u.s.w. Es ergab sich nun, dass nach Abschluss der Unterbrechung sehr oft e in e s p o n t a n e Rückkehr zu der unvollendet gebliebenen A u f g a b e stat $t$ fa $n d$. Hierzu bestand kein äufserer $Z$ wang, ja nicht einmal eine Anregung; die Versuchsperson hatte auch kaum Interesse an dem Inhalt der Aufgabe; dennoch dieser spontane Drang nach „E r l e d i g u n g”. Lewin sieht mit Recht darin einen Beweis, dass die Vornahme der Arbeit eine Bedürfnisspannung erzeugt hatte, die auch noch während der Unterbrechung andauerte und nun ganz spontan nach Fortsetzung und Abschluss drängte. - Auf derselben Linie liegt ein Gedächtnisexperiment: hatte eine Versuchsperson eine grös- 
sere Reihe von Handlungen hintereinander vollzogen, die teils erledigt, teils unfertig abgebrochen worden waren, so ergab eine spätere Befragung, dass die abgeschlossenen Handlungen zum grösseren Teil vergessen waren, während die unerledigten gut erinnert wurden. Sie waren eben auch seelisch unerledigt geblieben.

\section{Bewusstsein und Unbewusstheit}

Willenshandlungen, die eine gegliederte Durchführung erfordern, sind niemals durchweg von Willensbewusstsein begleitet.

Wenn ich aus meiner Wohnung in die Stadt gehen "will”, um eine Besorgung zu machen, so ist während des Willensrucks und vielleicht auch noch in den darauf folgenden Minuten das Ziel (der Einkauf) bewusstes Phänomotiv meines Tuns. Aber bin ich unterwegs, so kann mein Bewusstsein ganz anders beschäftigt sein; ich werde dennoch die richtige Strassenbahn benutzen, an der richtigen Stelle aussteigen u.s.w. (Nur wenn es sich um eine weniger bekannte Gegend handelt, werde ich mir bei Strassenkreuzungen u.s.w. das Ziel: ich will dort und dort hin, vergegenwärtigen, um den richtigen Weg zu finden.) Erst, wenn ich den Laden betrete, ist meine Kaufabsicht, welche mich unterirdisch hierhergeführt hat, in voller Stärke bewusst.

Die ursprüngliche Zielbewusstheit des Willensimpulses schlägt sich also nieder in $\mathrm{E}$ in s t e $11 \mathrm{u} \mathrm{ng}$ e $\mathrm{n}$, die - solange sie sich ungehindert auswirken können - des Bewusstseins nicht bedürfen. Aber sie sind bereit, sofort wieder in Bewusstsein umzuschlagen, wenn die Situation es erfordert. Das, was auf Grund solcher Einstellungen erfolgt, ist trotz aller Zukunftsgerichtetheit „un-will-kürlich"; das bewusste Küren (Wählen zwischen verschiedenen Möglichkeiten, Entscheiden) fehlt.

Diese Tatsache ist schon aus kraftökonomischem Gesichtspunkt von höchster Bedeutung. Wollen verbra u cht En e r g i e; und wenn der in einer Willenshandlung begriffene Mensch fortwährend ,wollen" müsste, dann wäre seine begrenzte Energie bald erschöpft. Aber das Wollen ähnelt hierin dem Denken; volle Bewusstheit und damit die energische Zusammenraffung der Person ist nur nötig an Knotenpunkten des Geschehens, dort, wo Hemmungen eintreten und Entscheidungen neu getroffen werden müssen; im Übrigen kann die Handlung auf den, durch Einstellung gewiesenen und durch Gewöhnung oder Instinkt gebahnten, Wegen ablaufen. 
Daraus ergibt sich die Schwierigkeit und die Anstrengung bei der Durchführung solcher Handlungen, bei denen $\mathrm{j}$ eder Teilschritt abweicht vom Gewohnten und daher nicht durch Einstellung gewährleistet werden kann, sodass fortwährend waches Willensbewusstsein nötig ist. Man denke an den Kundschafter, der in unbekanntem feindlichen Terrain sich bewegt, an den Urkundenfälscher, der bei jedem Buchstaben einen, seiner natürlichen Handschrift fremden, Duktus anwenden muss, an den Einwanderer, der die Sprache der neuen Heimat nur wenig beherrscht und bei allem, was er ausdrücken und mitteilen will, erst aus der Muttersprache heraus in die fremde überwechseln muss.

Aber auch in solchen Fällen bleibt das Gesetz gültig, dass gewisse Bereiche des Handelns dem Willensbewusstsein entgleiten, und dass mit zunehmender Ermüdung diese Willenserschlaffungen zunehmen. Der Mensch, der seine Handschrift zu verstellen sucht, ist ein anschauliches Beispiel hierfür. Selbst wenn ihm die Unterdrückung seiner eigenen Handschrift bei den Hauptzügen der Schrift, den Anfangsbuchstaben, den Grundstrichen immer wieder glücken mag, so sind die dazwischen liegenden, scheinbar nebensächlichen Schriftteile: Wortenden, Haarstriche, I-Punkte u.s.w. dem Willen entgangen und können zu Verrätern des wahren Schreibers werden. Ebenso gelingt die Verstellung gegen Ende eines längeren Briefes infolge der Ermüdung nicht mehr so gut wie zum Anfang.

\section{Vorsatz}

Der im Willensruck gefasste, zunächst momentane, Ent-

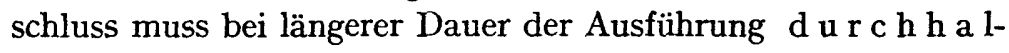
t e n, um immer wieder, sobald sich das Bewusstsein des Tuns einstellt, die weiteren Schritte zu leiten. Ein solcher stabilisierter Entschluss heisst V o r s a t z. Ein einzelner Entschluss kann, so energisch er im Augenblick sein mag, bald verrauchen; ein Vorsatz aber ist, so lange die Durchführung währt, hintergründig oder vordergründig wirksam; er bildet während dieser Zeit einen integrierenden Bestandteil des personalen Lebensvollzugs. (Die Kriminalistik hat daher durchaus Recht, wenn sie die Frage nach der Vorsätzlichkeit einer kriminellen Handlung in erster Reihe betont). 
Aber auch der Vorsatz kann vor erreichtem Ziel erlahmen. Weitgesteckte Ziele erfordern die "Kraft des langen Willens" (Nietzsche), die nicht immer vorhanden ist. Vielleicht war im Moment des Entschlusses die Zielerreichung zu leicht genommen, die Kraft überschätzt worden; vielleicht drängen sich während der Durchführung neue Interessen und damit andere Ziele in den Vordergrund.

In solchen Fällen vorzeitigen Vorsatzschwundes gibt es verschiedene Möglichkeiten. Entweder: die Handlung hört unabgeschlossen auf; das halb angefangene Werk bleibt liegen; „ein grosser Aufwand nutzlos ist vertan". - Oder: die Durchführung muss durch Wiederholung der Willensimpulse immer wieder frisch „angekurbelt" werden, zum Teil nach längeren Vorperioden, die in ihren Neuerwägungen, Zweifeln und Motivkämpfen der ursprünglichen Vorperiode sehr ähneln. Es kommt dann also zu unfruchtbaren Wiederholungen von seelischen Geschehnissen, die eigentlich durch die ursprüngliche Entscheidung abgeschlossen sein sollten. - Oder: mit der Erschöpfung des Vorsatzes ist auch eine gewisse „Sättigung" verbunden, die eine Wiederaufnahme des gleichen Zielstrebens verbietet; statt dessen wird Abwechslung gesucht - wobei die schon bisher durchgeführten Teile der Handlung verwertet werden können, nur eine andere Fortsetzung erfahren als ursprünglich geplant war.

Es gibt aber noch andere - und nun sehr positive - Gründe, die mitten in die Durchführung neue Willensimpulse einsprengen.

Wir erwähnten oben, dass jede Durchführung $\mathrm{K}$ n o t e np u n k t e hat, in denen die automatische Einstellung auf das Willensziel durch bewusste Besinnung unterbrochen wird. Zeigt sich nun in solcher Selbstbesinnung, dass das Ziel in der gewollten Weise nicht erreichbar ist, oder dass es durch die veränderte Situation seinen Sinn geändert hat, so kann es nun bewusst umgestellt werden zu einem anderen Ziel, das in einem neuen Impuls zum Richtpunkt der weiteren Handlung gemacht wird. Der neue Vorsatz braucht nicht einfach an die Stelle des alten zu treten; er kann von der Kraft und Nachhaltigkeit des Urimpulses zehren, der nur durch den neuen Willensruck eine Abbiegung und Anpassung an die neue Situation erhält.

Die hier nötige $\mathrm{E} 1$ a s $\mathrm{t}$ i z i $\mathrm{t}$ ä $\mathrm{t}$ des Willens steht keineswegs im Gegensatz zur Willensstärke. Im Gegenteil: gerade das starre 
Festhalten an dem ursprünglichen Impuls, selbst wenn dessen Ziel inzwischen seinen Sinn verloren hat, kann ein Zeichen von Schwäche sein. Ein solcher Mensch zehrt von der einmal aktualisierten Entschlusskraft und wagt nicht einen neuen Kraftaufwand für veränderten Entschluss („Eigensinn”).

\section{Planung}

Die Durchführung eines Willensentschlusses bedarf nicht nur einer Prospektion der Ziele, sondern auch der Mittel und Wege. Diese Vorbeschäftigung des Bewusstseins mit den Werkzeugen der Zielerreichung ist die „P l a n u n g”.

a) Gestalt der Pla nung. - Ansätze zur Planung gibt es bereits in der Vorperiode; so kann jemand ein Verbrechen "planen", noch ehe er sich entschieden hat, ob er es überhaupt begehen wird oder nicht. Nur für den Fall, dass er sich dazu entschliesst, ist dann schon ein Teil der Vorbereitungsarbeit vorweggenommen. Aber solche, mehr oder weniger fiktiven, Planungen sind nicht $z \mathbf{u}$ vergleichen mit jenen, die $\mathrm{nach}$ dem Willensruck einsetzen. Denn nun wird es E $\mathrm{rnst}$ um das Tun, und damit auch um seine Verwirklichungswege.

Erlebnismälsig gilt von der Planung dasselbe, was wir früher von der Zielung sagten : ihre Repräsentation im Bewusstsein ist stets unvollständig. Kein Mensch vermag, wenn er sich ein ferner liegendes Ziel gesetzt hat, im voraus jeden Schritt, jedes Wort, jeden Handgriff prospektiv festzulegen; w e n n er es könnte, wäre es so unzweckmäIsig wie möglich. Vielmehr ist jeder Plan $\mathrm{sch}$ emat is i erend; er nimmt gewisse ausgezeichnete Stellen der Handlung in vereinfachter Form vorweg; er ordnet das Nacheinander der Teilhandlungen und das Uber- und Untereinander der Handlungsglieder; er gibt sich Rechenschaft von Erfordernis und Erreichbarkeit der Hilfsmittel; er zieht die Eventualität von Hemmungen und Störungen und die Mafsnahmen zu ihrer Behebung in Rechnung - dies alles in einer gewissen Spielraumbreite und Elastizität.

Gewöhnlich wird die planende Vorausschau nicht für alle Etappen der Handlung gleich durchstrukturiert sein. Nur für die, der Gegenwart nächsten, Handlungsphasen pflegt man eine de- 
tailliertere Marschroute vorzudenken; für die späteren Schritte wird das Schema immer vager und leerer, damit aber auch offener, d.h. leichter anpassbar an die noch nicht vorausschaubaren Situationen. Mit fortschreitender Durchführung unterwirft der wollende Mensch die noch ausstehenden Handlungsphasen immer wieder von neuem der Planung; denn nun muss für die nächste Zukunft das inhaltsarme Schema durch ein spezielleres ersetzt oder auch infolge der veränderten Umstände abgewandelt werden. So wechselt in ausgedehnteren Handlungsabläufen ständig Planung und Ausführung.

Aber die Planung hat nicht nur lineare Erstreckung in die $\mathrm{Zu}$ kunft; sie erhält auch eine $\mathrm{h}$ i e r a r c h i s c h e Gl i e d e r u n g; und diese macht erst alles höhere Wollen möglich. Das Gesamt-ziel der Gesamthandlung, wie es im Vorsatz gedacht ist, gibt in seiner vagen Allgemeinheit die oberste Stufe dieser Hierarchie ab; ihm werden im Plan die Mittel untergeordnet, die zu seiner Erreichung nötig sind; jedes Mittel aber, das nicht von vorn herein fertig da ist, sondern erst bereitet oder beschafft werden muss, wird nun selber zum Willensziel, bei dem sich die gleiche Gliederung wiederholt. $Z$ iele und $W$ ege sind also in der Planung psychologisch nicht mehr scharf getrennt; was Weg (Mittel) ist für ein weiteres, übergeordnetes Ziel, ist zugleich Ziel für eine engere Willenshandlung - und dies in vielfacher Abstufung. So entwickelt sich aus der hierarchischen Gliederung des Planes die hie ra r chische Struktur der Willensaus führung s e $1 \mathrm{bst}$; diese kann sich nun auf umfassende Zielsetzungen beziehen und über weite Zeiträume erstrecken, ohne dass unter der nötigen Einzelarbeit der grosse Leitgesichtspunkt verloren ginge, und ohne dass umgekehrt das allgemeine und vieldeutige Fernziel die notwendige Teilarbeit im Kleinen verhinderte.

Ein Farmer will sich im Urwald ansiedeln und plant nun einen Hausbau. Er entwirft, vielleicht noch sehr roh und ungefähr, eine Zeichnung des Hauses, sucht sich das Gelände aus, überlegt, dass er es ebenen muss, dass er für den Bau Bäume fällen muss (Teilziele 1. Ordnung); dass er für die Rodung Werkzeuge braucht, die er in der nächsten Stadt kaufen muss (Teilziel 2. Ordnung); dass er sich zur Bezahlung der Werkzeuge Geld leihen muss (3. Ordnung) u.s.w. Aber bei den Bemühungen, das Geld zu beschaffen, die lange Zeit sein Bewusstsein 
ganz absorbieren mögen, geht doch die übergeordnete Zielsetzung normaler Weise nicht verloren; sie wirkt als Einstellungsmotiv hintergründig mit und ist bereit, wenn nötig, auch wieder ins Bewusstsein $\mathrm{zu}$ treten, um die Gesamthandlung nicht auseinanderfallen $z u$ lassen.

Man erkennt, dass sich die Hierarchie auch auf die Willensimpulse und Vorsätze erstreckt; der eine grosse Gesamtvorsatz „hier will ich ein Haus bauen” - bleibt zwar potentiell wirksam, bedarf aber zu einer sukzessiven Verwirklichung einer grossen Zahl von Teil-Impulsen, bis hinunter zu den Anstössen für einfache Willenshandlungen, wie: „ich will jetzt die Axt holen”. Wieder erweist sich hier die eindrucksvolle Elastizität des Willens: die allgemeine Gerichtetheit des Gesamtvorsatzes drosselt nicht die jeweiligen Neuentscheidungen und Entschlüsse im Handlungsverlauf ab, sondern gewährt ihnen die, durch die jeweilige Situation gebotene, Freiheit.

So offenbart sich hier innerhalb der einzelnen Person die Strukturform, die wir innerhalb der $\mathrm{Geme}$ in $\mathrm{sch}$ a $\mathrm{ft}$ als Kennzeichen wirklicher „Hierarchie” ansehen; und wir vermögen an bestimmten Erscheinungen geradezu diese Ubertragung aus dem Intra-Personalen ins $\mathrm{T} r$ an s-P e r s o n a le zu beobachten. Der führende Politiker, Stratege, Grossunternehmer, Erzieher u.s.w. hat ja nicht nur in seiner eigenen Prospektion erst den Generalplan, dessen Teilziele dann bei ihm selbst in notwendiger Uber- und Unter-Ordnung der Gesichtspunkte zu Teil-Impulsen und Teil-Malsnahmen führen; sondern e $\mathrm{r} g$ i b $\mathrm{t}$ d i e s e Teil-I m pulse an andere Menschen ab, dieinnerhalb der grossen Gesamtidee auch ihre relative Freiheit haben, und daher ihr Teiltun in eigene Willensregie nehmen müssen.

b) Ty pen der Planhandlung. - Die Planung mit hierarchischer Struktur, wie wir sie oben schilderten, stellt eine I d e a I f o r $m$ dar, der die wirklichen Handlungen sich in verschiedenen Graden nähern, und zwar von zwei Seiten her. Um sogleich hier die Extreme zu erwähnen: es gibt Handlungen mit Despotie der Planung, und solche mit Ohnmacht der Planung.

Im ersten Falle ist der Plan so fest und starr, dass der ganze Handlungsverlauf durch ihn vorbestimmt ist, und es innerhalb seiner keine Teilimpulse und elastischen Anpassungen mehr gibt. 
Im zweiten Falle ist der Vorsatz so schwach, dass er nicht einmal als Dauereinstellung wirksam ist, und die hierarchische Ordnung so wenig ausgebildet, dass das Tun linear wird, also in das blosse Nacheinander von Teilhandlungen zerfällt.

Als Beispiel für beide Extreme diene die Willenshandlung „Weltreise”.

X. arbeitet, sobald er sich zur Reise entschlossen hat, den Plan in allen Einzelheiten aus. Er weiss, ehe er seine Heimat verlässt, wo er an jedem Tag logieren wird, welche Sehenswürdigkeiten er besichtigen, welche Züge und Schiffe er benutzen wird, wieviel Geld er für die einzelnen Reiseabschnitte verwenden kann, und wo und wann er bestimmte Geldbeträge zu erwarten hat. Bei diesem Mann erschöpft sich die eigentliche $\mathrm{W}$ ille $\mathrm{ns}$ handlung in dem einmaligen Entschluss und in der Planung selbst. Von nun an ist er der Sklave seines Planes, der keinerlei Platz für neue Impulse lässt. Er ,will" nicht mehr, sondern "wird gewollt" von seinem eigenen Willenserzeugnis. Es gibt keine Entscheidungen, sondern nur $Z$ wangsrouten; es ist kein Spielraum da für Anpassung an unvorhergesehene Situationen innerhalb des Planes, sondern nur eventuelle Zerstörung des Planes und $Z$ wang zu unvorbereitetem Neuanfang.

Bei Y dagegen, dem unbekümmerten Globetrotter, besteht prospektiv vor allem der vage Wille, recht viel zu sehen und zu erleben; bezüglich der Gesamthandlung der Reise erstreckt sich die Voraussicht vielleicht nur auf die Reihenfolge der zu besuchenden Erdteile, auf die verfügbaren Geldmittel und die Höchstdauer der Reise. Im Übrigen lässt er sich treiben von Einzelimpuls zu Einzelimpuls, von Teilhandlung $z u$ Teilhandlung, deren jede ein ganz selbständiges Willensgeschehen ist. Kein vorgreifender Vorsatz engt die Möglichkeit immer neuer Erwägungen und Entschlüsse ein; aber auch keine herrschende Richtlinie gibt der Gesamtreise einen, allem Einzelnen übergeordneten, Sinn. Im äussersten Falle kommt es zu einem Verlust des inneren Lebenszusammenhanges.

Durch die extremen Fälle X und Y ist der Bereich abgesteckt, in dem sich die komplexen menschlichen Planhandlungen bewegen. Der ganze Bereich ist dadurch gekennzeichnet, dass die beiden Grundmerkmale: hierarchische Struktur und Elastizität, sowohl bei Planung wie bei Ausführung die verschiedensten Formen und Grade annehmen können. Dass die Disposition zu Willenshandlungen, in der einen oder anderen Extremform oder auch in der Mittelform, $\mathrm{ch}$ a $\mathrm{rak}$ te r o log i $\mathrm{ch}$ sehr bedeutsam ist, kann hier nur ausgesprochen werden. 


\section{DIE NACHPERIODE}

Wenn eine einzelne Willenshandlung, als dieses individuelle, in sich begrenzte Lebnis, ihren Abschluss gefunden hat, ist dennoch ihre Rolle noch nicht ausgespielt, weder für die Person des Täters, noch für die umgebende Welt. Denn die Handlung hat ein neues $\mathrm{Fakt} \mathrm{u} \mathrm{m}$ geschaffen, das Bestand hat und weiter wirkt.

\section{Motivationen nach derTat}

Sowie die Handlung aus der Totalität des personalen Strebens heraussprang, sinkt sie auch wieder in diese Totalität zurück und bleibt ein Stück bedeutungshaltiger, personaler Vergangenheit. Der Mensch, der eine irgendwie wichtige Handlung vollzogen hat, ist damit ein anderer geworden. Er hat nun $\mathrm{zu} r \mathrm{echne} \mathbf{n}$ mit diesem Geschehen, das, aus ihm geboren, von ihm durchgeführt, nun unwiderruflich $\mathrm{zu}$ ihm gehört. Das ist das Bewusstsein der V e r a n $t$ wor $t$ u $\mathrm{g}$, ein psychologisch sehr verwickeltes Phänomen. Denn in ihm sind nicht nur retrospektive Gefühle (der Zufriedenheit oder Unzufriedenheit mit der vollzogenen Tat) enthalten, sondern auch ein Gefühl des gesteigerten oder geminderten Selbst, und ein neuer Willensimpuls: die Einzeltat sinnvoll dem Gesamtlebensablauf einzufügen, sich zu ihr zu bekennen: „Ich war es, der sie wollte und tat" 1).

Deshalb ist das Verantwortungsbewusstsein um so ausgesprochener, je mehr die Überzeugung besteht, dass in Motivation, Vorsatz und Durchführung der Einzelhandlung die Person ihre ganze Wesenheit ungestört hatte entfalten können. War sie dort in ihrer Totalität beteiligt, so muss sie auch nun in ihrer Totalität jene Tat sich zurechnen.

Dies gilt besonders von der $\mathrm{M}$ ot ivatio $\mathrm{n}$, die hier also nochmals in eine neue Beleuchtung tritt.

Denn das Motivbewusstsein $\mathrm{n} \mathrm{a} \mathrm{h}$ der Tat kann nicht ohne weiteres mit dem v o r der Tat identifiziert werden. Zwar glaubt der rückschauende Mensch, dass er sich der Motive e r i n n e r e, die ihn zur Tat veranlasst haben. Aber wenn „Erinnerung" nie-

1) VgI. die parallelen Formeln S. 577. 
mals blosse Kopie der Vergangenheit ist ${ }^{1}$ ), dann vor allem nicht die Erinnerung an die eigene Motivation ${ }^{2}$ ).

V or der Tat hatten die Motive noch Bewegungsfreiheit, sie flatterten zwischen der Unbewusstheit des Geno- und der Bewusstheit des Phäno-Motivs; und sie hatten noch die Möglichkeit, blosse Wunschmotive zu bleiben, mit der Tat halb und halb zu spielen - oder aber zu regelrechten Willensmotiven zu werden. $\mathrm{N} \mathrm{a} \mathrm{ch}$ vollzogener Willenshandlung ist die Situation völlig verändert. Die harte Wirklichkeit der nicht mehr zurücknehmbaren Tat beherrscht alles; und diese eindeutige Wirklichkeit ist nur dann der personalen Gesamtexistenz einzuordnen, wenn sie durch e inde u t ig e Willensmotivik verständlich gemacht werden kann.

Oft genug beginnt dann erst $n$ achträglich e ine Suche nach den Motiven der eigenen Tat. Gerade dort, wo vor dem Vollzug nur eine relativ geringe Bewusstseinsbeteiligung vorgelegen hatte, wo also die Phänomotive hinter den Genomotiven weit zurückstanden, ist oft das erste Erlebnis nach der Tat Uberraschung und Verständnislosigkeit über sich selbst.DieserZustand kann geradezu unerträglich werden - nicht nur, weil man anderen Rechenschaft schuldig ist, sondern auch, weil die Tat selbst fordert, als zu mir gehörig anerkannt zu sein. Man will Ja oder Nein zu ihr sagen können. Ja o d e $r$ Nein: denn auch dort, wo man nachträglich die Tat bedauert, bereut, verabscheut - ja vielleicht dort ganz besonders - verlangt man nach Einsicht in ihre Motive, um mit ihr innerlich fertig zu werden und ihre Antriebe überwinden zu können. So erhalten die Motive in der Rückschau einen viel stärkeren Grad der Bewusstheit, eine grössere Härte und Eindeutigkeit, als ihnen vor der Tat zukam. Insbesondere wird versucht, Vieles aus der genomotivischen Sphäre ins Bewusstsein $\mathrm{zu}$ heben und dadurch die dumpfe Irrationalität der Bedürfnisse zu rationalisieren. Umgekehrt gelten diejenigen Motivbestandteile, die dieser Bewusstmachung entgleiten, nun als überhaupt nicht vorhanden; der Motivationsvorgang wird weitgehend vereinfacht.

Wir haben es hier also nochmals mit einer Heterogonie der Mo-

2) s. S. 347.

2) Von bewusster Motivfälschung wird im Folgenden abgesehen; unsere Erörterung beschränkt sich auf die wirklich $\mathrm{g}$ e $\mathrm{g} l \mathrm{a}$ u b t e $\mathrm{n}$ Motive. 
tive $\mathrm{zu}$ tun. Sie macht sich überall dort geltend, wo der Mensch bewusste Selbstbesinnung treibt: in Stunden stiller Einkehr, beim Schreiben von Tagebüchern, beim Abfassen von Selbstbiographieen, und dann in den mannigfaltigen Situationen des Beich tens. Wenn der, seiner selbst unsicher gewordene, Mensch dem Seelenberater, dem Geistlichen, dem Arzt, dem Richter seine Tat bekennt, so begnügt er sich ja fast nie mit der Angabe des äusseren Handlungsablaufes, sondern er erwähnt die Motive; und wenn er dazu nicht aus Eigenem kommt, so führt ihn die Frage des Beichtigers bald $z u$ den seelischen Voraussetzungen des Handelns. In den letzten Fällen spielt also die $\mathrm{Sug}$ g es $\mathrm{t}$ i o $\mathrm{n}$ eine ganz grosse Rolle. Für Menschen, die sich im allgemeinen über die feineren Schattierungen ihres Seelenbinnenlebens nicht Rechenschaft zu geben pflegen, kann dann der Hinweis auf eine Motiv$\mathrm{mög} l \mathrm{i} \mathrm{ch} \mathrm{k} \mathrm{e} \mathrm{it} \mathrm{die} \mathrm{Überzeugung} \mathrm{entwickeln,} \mathrm{dass} \mathrm{eben} \mathrm{dies}$ Motiv der Handlung zu Grunde gelegen habe. Die Motivveränderungen, die hierbei erfolgen, werden vornehmlich Motivverschönerungen sein - was ja aus dem Rechtfertigungscharakter des Vorgangs ohne weiteres verständlich ist. Da wird etwa eine aus Kopflosigkeit oder Feigheit vollzogene Fluchthandlung in eine dem $\mathrm{Zweck}$ künftigen Sieges dienende List umfrisiert; für eine sehr eigennützige Tat werden altruistische oder soziale Gründe gefunden. Alles das, was an Um-Motivierungen im Bereich bewusster Heuchelei und Verlogenheit vorkommen kann - es gibt ja keine Gemeinheit, die nicht nachträglich durch irgend eine idealisierende Begründung legitimiert werden könnte - all dies findet sich auch in den Sphären durchaus aufrichtiger und gutgläubiger Selbstrechtfertigung, um das eigene Ich zu schützen oder zu steigern. Und es findet sich schliesslich auch in dem weiten Zwischenreich von Schein und Sein, von Heuchelei und Selbsttäuschung.

Aber auch das Umgekehrte ist möglich: die Motive werden nachträglich in schlechtem Sinn verwandelt. Schon die isolierende Bewusstmachung als solche bedeutet oft eine Steigerung des Realitätsgrades: so kann irgend ein Wunschmotiv, das vielleicht nur gelegentlich und unverbindlich durch das Bewusstsein gehuscht war, nach der Tat zu einem entscheidenden Willensmotiv umgedeutet werden; oder es kann aus ihm, selbst wenn es zu keiner äusseren Tat gekommen war, eine innere Willenshandlung 
gemacht werden, als sogenannte „Gedankensünde”. Aber auch Motive, die der Vorperiode der Tat ganz fremd waren, und die eine negative Bewertung der Tat zur Folge haben, können nachträglich erdacht und geglaubt werden: so gibt es Menschen, die nach uneigennützigen Handlungen sich dauernd mit der Frage quälen, ob nicht verborgene selbstische Motive den Antrieb gaben - und die schliesslich davon überzeugt sind.

Diese nachträglichen Motivverschlechterungen sind natürlich nicht unmittelbar aus dem Rechtfertigungsbedürfnis abzuleiten. Aber indirekt stehen sie doch $\mathrm{zu}$ ihm in Beziehung, und zwar dadurch, dass der Täter nun die geschehene Tat nicht in ihrer Kontinuität zu dem gegenwärtigen und künftigen personalen Bestande, sondern in ihrer Distanz dazu erlebt ${ }^{1}$ ).

Die grosse Bedeutung der Motivierung nach der Tat sei an zwei Sonderbeispielen erläutert.

a) Der Untersuchung sgef angene, der den Vollzug der ihm zugeschriebenen Tat nicht leugnet, ist of genug im Zweifel über die Motive, die ihn dazu getrieben haben. Die wochen- oder monatelange, zwangsläufige Einsamkeit veranlasst ihn, dauernd seine Gedanken um den bevorstehenden Verhörstermin und die dort $\mathrm{zu}$ machenden Angaben kreisen zu lassen. Wenn hierbei auch die bewusste Erdichtung von möglichst harmlosen Motiven eine grosse Rolle spielen mag, so darf man doch auch gutgläubige Motiv-Suche und -Findung nicht zu gering einschätzen - namentlich bei nicht-gewohnheitsmälsigen Rechtsbrechern.

Ein junger Mensch hat Feuer an eine Scheune gelegt: „Was trieb mich eigentlich zu der Brandstiftung?" zergrübelt er sein Hirn. Ein Lehrer ist wegen unsittlicher Berührung einer Schülerin verhaftet; er wird nicht fertig mit der Frage: „Ging jene körperliche Annäherung nur aus harmloser Kameradschaftlichkeit hervor, wie es mir bisher selbstverständlich erschien, oder haben vielleicht doch Motive der wollüstigen Erregung mitgespielt, wie es mir die Anklage vorwirft?"

Zuweilen kann man aus den Angaben und Niederschriften solcher Gefangenen geradezu ablesen, wie sich das Bild des kritischen Tatbestandes mitsamt den begleitenden Bewusstseinsvorgängen immer mehr bereichert, spezialisiert und verhärtet;

1) Vgl. S. 347.

Stern, Psychologie 
Motivationen, die anfangs nur als Möglichkeiten, vielleicht sogar als bewusste Fiktionen, genannt worden waren, können so allmählich zu unbezweifelbaren, felsenfest geglaubten Motiven der Tat werden.

In anderen Fällen gibt es ein chaotisches Hin und Her dieses Motivglaubens; und so versteht man auch, dass zuweilen Geständnis und Widerruf abwechseln, ohne dass dieses oder jener bewusste Lüge zu sein braucht.

b) Der Neurotiker, der sich in die Behandlung eines tiefenpsychologischen Arztes begibt, wird von diesem in eine Situation versetzt, in der er sich die Motive seiner Handlungs- und Verhaltungsweisen nachträglich klar machen soll. Dabei mag es für die $\mathrm{Heil} \mathrm{zwe} \mathrm{cke} \mathrm{des} \mathrm{Psychoanalytikers} \mathrm{vielleicht} \mathrm{garnicht}$ so wesentlich sein, ob die nachträglich ins Bewusstsein gehobenen Motive des Patienten $\mathrm{tats}$ ä $\mathrm{chlich}$ die echten Genomotive des früheren Verhaltens waren; denn der gewonnene Motivg l a u b e des Patienten kann, unabhängig von seinem Wahrheitsgehalt, therapeutisch wirken. Aber vom Standpunkt der psychologischen Erkenntnis aus muss die irrige Voraussetzung durchschaut und bekämpft werden, als ob die retrospektive mit der prospektiven Motivik gleichgesetzt werden dürfte. Es wird dabei übersehen, dass die rückwärts gerichtete Schau ein anderes Bild geben muss als der vorwärts gerichtete Drang. Dies gilt schon für Willensvorgänge, die der nahen Vergangenheit angehören; es gilt in viel höherem Malse von solchen, die weit zurückliegen. Wenn etwa der Erwachsene versucht, die Motive zu rekonstruieren, die seinen infantilen Verhaltungsweisen $\mathbf{z u}$ Grunde lagen, so geht hier viel mehr motivische Neuschöpfung als Rückerinnerung vor sich.

\section{Beurteilung der Tatmotive}

Der „Blick in die Herzen” der Nebenmenschen gilt mit Recht als eines der wichtigsten Hilfsmittel praktischer Lebenspsychologie; und er muss oft genug zur Anwendung kommen, wenn eine Tat bereits geschehen ist und nun nachträglich in ihrer Motivik verstanden werden soll. Beichtväter aller Zeiten und aller Arten sind stets retrospektive Motiv-Ergründer gewesen. Der Erzieher kann nur dann erfolgreich minderwertige Verhaltungsweisen be- 
kämpfen, wenn er ihre seelische Wurzel zu fassen und vor den Augen des Zöglings bloss zu legen vermag. Und in der modernen Kriminalistik gilt es mit Recht als einer der grössten Fortschritte, dass man von der Bewertung des äusseren Effekts der Tat zu der Untersuchung und Einschätzung ihrer inneren Motivation überzugehen versuchte.

Welche Möglichkeiten und welche Schwierigkeiten bestehen für diese Feststellungen?

Eine erste Quelle liefern die Bekundungen des Täters selbst über die Beweggründe seiner Tat. Diese sind nun freilich durchweg sozialpsychisch eingestellt; was er sagt und zeigt, s o ll beim Zuhörenden eine ganz bestimmte Wirkung hervorrufen. Wir müssen wiederholen, dass es sich hierbei nur teilweise um bewusste Lügen handelt; zu einem andern Teil glaubt der Täter mehr oder minder aufrichtig selbst an das, was er sagt. Es sind also alle jene Klippen, die schon der binnenseelischen Rückbesinnung auf Motive drohen, bei der $\AA$ us serung in verstärktem Mafse gefährlich. Hinzu kommt die mangelhafte Fähigkeit des Täters, die feineren Motiverlebnisse in die harten Formen der Sprache zu pressen, und die beschränkte Fähigkeit des Beurteilers, diese Kundhaben sinngemäls aufzufassen.

So wird es kommen, dass die oberflächlichsten, einfachsten und aufdringlichsten Phänomotive beim Beurteiler leicht eine ungebührlich starke Bewertung erfahren, und dass der Rückgriff auf die Genomotive und auf deren Verankerung in tieferen Persönlichkeitsschichten nur sehr unvollkommen oder überhaupt nicht erfolgt.

Auf der andern Seite ist der aussenstehende Beurteiler zuweilen besser befähigt als der Täter selbst, in die eigentliche Motivik einer vollzogenen Tat Einblick zu gewinnen. Denn er steht ja nicht unter dem Bann jenes Rechtfertigungsbedürfnisses um jeden Preis, das, wie wir sahen, die rückschauende Motivation eines Täters umbiegen muss: Auch wird der Betrachter, wenn er ein geschulter Psychologe ist, nicht den naiven Glauben an die unmittelbare „Richtigkeit” der nächstliegenden Phänomotive besitzen; er weiss vielmehr, dass man deutend in die tieferen Schichten einzudringen suchen muss, die der unmittelbaren Bewusstheit des Täters entgangen sein können. Endlich gibt es ja auch bei einigen seltenen Menschen jene angeborene Intuition, die das 
Deuten durch ein „prae-interpretatorisches Verstehen” 1) ergänzt oder gar ersetzt.

Auch stehen dem fremden Urteiler noch andere Indizien als die geäusserten Motivationen des Täters zur Verfügung. Die Art, wie eine Tat vorbereitet, versucht und schliesslich ausgeführt wurde, lässt mannigfache Schlüsse auf das beteiligte Motivspiel $\mathrm{zu}$; und selbst andere, scheinbar ganz fern liegende Handlungen und Verhaltungsweisen des Täters können zur Deutung herangezogen werden. (Hier streifen wir schon einen Gesichtspunkt, der uns erst weiter unten näher beschäftigen kann: das Hinausgehen über die akute Motivation zu $\mathrm{ch}$ r on is $\mathrm{ch}$ en Voraussetzungen der Tat).

Wie bedenklich es ist, die Motivfeststellung vornehmlich oder allein an die manifesten Phänomotive zu knüpfen, sei wieder an zwei Beispielen aufgezeigt.

a) J u ge nd t a g e b ü cher sind zuweilen stark durchsetzt mit Rückblicken auf eben vollzogene Willenshandlungen. Selbst geringfügige Vorgänge (z.B. kleine Meinungsstreitigkeiten mit einem Freunde) werden vom Jugendlichen unter das psychologische Mikroskop genommen, um das undeutliche Motivgewebe erkennbar zu machen. Und wie das wirkliche Mikroskop nicht nur vergrössert und vergröbert, sondern auch manches nicht zum Objekt gehörige Stäubchen in das Bild eingehen lässt, so auch hier. Was da schwarz auf weiss in dem Tagebuch steht, gibt wohl Kunde von den seelischen Zuständen des Verfassers im Moment des Schreibens, liefert aber kein adäquates Abbild der Vorperiode der beschriebenen Willenshandlung. Hier muss der Psychologe vorsichtig umdeuten, abschwächen und ausscheiden, um den tatsächlichen Genomotiven näher zu kommen. Vieles entpuppt sich als motivisches "Ernstspiel”, was mit scheinbar tiefstem Ernst niedergeschrieben ist ${ }^{2}$ ).

b) Besonders quälend ist die Frage nach den Motiven von Selbstmordhand lungen. Die Uberlebenden suchen diese Motive zu erschliessen aus den Ereignissen, die der Tat vorausgingen, aus Abschiedsbriefen und (dort, wo es beim Versuch

1) S. S. 74.

2) Zur Motivik von Jugendtagebüchern vgl. vor allem die Arbeiten von W. Stern (Anfänge der Reifezeit), Charlotte Bühler. Bernfeld und Kerschbaum. 
geblieben war) aus den nachträglichen Angaben des Selbstmordkandidaten. Die so festgestellten Phänomotive hat man früher ziemlich unbesehen hingenommen; ja, man hat sogar die Selbstmorde nach den Motiven statistisch gruppiert, indem man die Prozentzahlen für verschiedene Motivarten: Liebeskummer, berufliche Misserfolge, Trauerfälle, schlechte Schulzeugnisse u.s.w. berechnete.

Eine solche Betrachtungsweise ist besonders unzulänglich bei einer Handlung, welche auf die Totalexistenz der Person geht und daher nur aus dieser Totalität heraus verständlich gemacht werden kann. Ein einzelnes akutes Ereignis, oder ein im Bewusstsein des Verzweifelten selbst sich vordrängendes, augenblickliches Phänomotiv, erscheint unter personalistischem Gesichtspunkt nur als die mehr oder minder zufällige Auslösung der Tat, oder auch als eine motivische Selbstvorspiegelung - während die eigentlichen Genomotive in ganz anderen Tiefen der Persönlichkeit ihren Quellgrund haben können ${ }^{\mathbf{1}}$ ).

1) In jüngster Zeit wurde das Thema behandelt von D. R. Löwenberg, von AchilleDelmas und von Peller. 


\section{DREIUNDZWANZIGSTES KAPITEL}

D I E W I L E N D I P OSITIONEN

\section{WILLENSHALTUNG UND GESINNUNG}

\section{Willenshaltung}

In der Erörterung der Willensmotive sind wir mehrfach an eine Grenze gestossen, die nun überschritten werden muss. Motive sind ja nur die a $\mathrm{k} \mathrm{u}$ t e $\mathrm{n}$ Antriebsfaktoren einer einzelnen Willenshandlung, mögen sie bewusst als Phaenomotive auftreten, oder unterirdisch als Genomotive wirken.

Aber gerade die Genomotive weisen nun über sich selbst hinaus. Sie entspringen aus Bedürfnissen; diese aber sind ja nicht nur in jenen Augenblicken da, in denen sie sich in Willenstat umsetzen, sondern sie führen vorher und nachher eine dispositionelle Existenz. In ihnen lebt eine chronische Gerichtetheit und Gerüstetheit der Person, eine Bereit s chaft und eine $\mathrm{K}$ r a f $\mathrm{tg}$ e l a d e $\mathrm{nh}$ e it, ohne welche der akute Durchbruch zum Willensruck nicht möglich wäre.

Damit gewinnen wir eine Voraussetzung der Willenshandlungen, die tiefer in der Totalperson verankert ist, als die Motivik der Einzeltaten. Wir nennen sie die „W ille n s h a lt u n g”; es ist derjenige, relativ chronis che, Zustand einer Person, der zu Willenshandlungen bestimmter Art disponiert. Je entschiedener und ausgesprochener eine solche Willenshaltung ist, um so mehr ist von ihr auch die einzelne Willenshandlung getragen, um so geringer ist also die Bedeutung der akuten Motivik.

Ein relativ einfaches Beispiel bietet der schon mehrfach erwähnte kindliche Trotz. Während des sogenannten „Trotzalters" befindet sich das 3-4 jährige Kind in einer dauernden „Trotz-H a l t u n g"; es ist ständig sprungbereit, den äusseren 
Einwirkungen und Aufforderungen, nur weil sie von aussen kommen, Widerstand entgegenzusetzen. Deshalb genügt ein ganz geringfügiger Anstoss, um nun eine akute Trotzhandlung hervorzurufen.

Ein anderes Beispiel: der Soldat im Kriege. Auch bei ihm wachsen alle einzelnen Handlungen aus der allgemeinen Willenseinstellung heraus, die durch die militärische Schulung und die kriegerische Atmosphäre schon zuständlichen Charakter gewonnen hat. In unmittelbarer Auswirkung dieser seelischen Verfassung kann es dann zu einer bestimmten Tat, z.B. zur Tötung eines Menschen kommen, ohne dass jene akuten Motivkonflikte, die unter anderen Umständen einer solchen Handlung vorausgegangen wäre, sich bemerkbar machen müssten.

Die beiden Beispiele, mit Absicht etwas extrem gewählt, zeigen zugleich zwei entgegengesetzte Ursprünge von chronischen Willenshaltungen. Die Trotzhaltung ergibt sich vornehmlich aus in n e r e n Entwicklungsbedingungen; ist jene Entwicklungsperiode abgeklungen, dann hört das Kind auf, trotzig zu sein, obgleich die äusseren Einflüsse, gegen welche die Auflehnung erfolgte, sich nicht verändert zu haben brauchen. Die Haltung des Kriegers entspringt wesentlich den ä u s s e r e n Einflüssen der soldatischen Erziehung und der überwältigenden Situation - der identische Mensch kann vorher und nachher ganz andere Willenshaltungen besitzen.

Aber selbst in diesen extremen Fällen ist niemals der innere, bezw. der äussere Faktor a 11 e in wirksam; vielmehr gilt die Konvergenz von beiden unbedingt und überall bei der Erzeugung von chronischen Willenshaltungen.

Wählen wir als drittes Beispiel zwei Menschen X und Y, die durch irgend welche Schicksale in ein Verbrechermilieu verschlagen worden sind und dort längere Zeit verweilen müssen. Beide stehen unter dem gemeinsamen Einfluss der dauernden, sie von allen Seiten umspülenden, Willenshaltung der Umgebung, der spezifischen „Verbrechermoral" und der Verbrecherinteressen. Dennoch können beide infolge ihrer inneren Verschiedenheiten zu sehr verschiedenen eigenen Willenshaltungen kommen. $\mathrm{X}$., der schwächer, leichter beeinflussbar, vielleicht selber mit minderwertigen Anlagen ausgestattet ist, wird jene Willenshaltung weitgehend übernehmen; Y. wird aus stärkerer Selbständigkeit 
oder innerer Abneigung heraus ihr ausweichen oder sich widersetzen.

Dies Beispiel vermittelt uns nun aber zugleich eine Einsicht von grundsätzlicher Wichtigkeit.

Wenn wir nämlich die i n $\mathbf{n}$ e r e $\mathbf{n}$ Bedingungen betrachten, durch welche die Willenshaltungen von $\mathrm{X}$ und $\mathrm{Y}$ zustandekommen, so ergibt sich, dass zwar bei b e i d e n gewisse Vitalfaktoren (Entwicklungsphase, geistige und konstitutionelle Veranlagung) mitwirken, dass aber bei $Y$. allein noch etwas anderes hinzutritt: der bewusste, vielleicht in schwerem Kampf erarbeitete Entschluss, sich von den Einflüssen der Umgebung nicht fortreissen und umstimmen zu lassen, und der daraus erwachsende Willensruck zur Selbstbeherrschung und zum Widerstand.

Das Beispiel des X. zeigt die andere Genesis der Willenshaltung: das a $\mathrm{t}$ o $\mathrm{m}$ a $\mathrm{t}$ is $\mathrm{ch}$ e Hinübergleiten der Person aus Triebanlage durch Konvergenz mit Umgebungseinflüssen in eine Dauerform des Wollens. Es ist dies zweifellos die primitivere Weise, in der Willenshaltungen entstehen; - sie ist beim Tier die einzige. Beim Menschen, und nur bei diesem, gibt es aber auch die andere Form: die Erzeugung einer $\mathrm{ch}$ r o $\mathrm{n}$ is $\mathrm{ch}$ en Willens$\mathrm{H}$ a $\mathrm{l}$ t u ng durch eine a $\mathrm{k}$ u t e Willens-Handlung. Nirgends tritt die eigentümliche Ganzheitsstruktur der menschlichen Persönlichkeit eindrucksvoller zu Tage als in diesem Wechselbezug: die ganze Kraft und Zielstrebigkeit der Person kann sich in die aktuelle Gegenwärtigkeit einer Willens- $T$ a t konzentrieren, die auf den dauernden Lebenszusammenhang wirkt, indem sie ihm eine Willens-H a 1 t $\mathbf{~} \mathbf{n}$ g aufprägt; der Sinn dieser Willenshaltung aber besteht darin, dass sie sich in ferneren Gegenwarten den jeweiligen Bedürfnissen und Situationen entsprechend in neue Willens-T a t e n projiziert.

Natürlich bedeutet auch jene spontane Willenshandlung, durch welche der Mensch sein Dauerwesen zu konstituieren sucht, keinen absoluten Anfang, keinen Hervorbruch aus dem Nichts; ist sie doch vielmehr ein Hervorbruch aus der ganzen Fülle der Person, die sich hier zu gegenwärtiger Einheit verdichtet. So ist auch an dieser Tat Vorwelt und Umwelt (Anlage und Milieu) beteiligt; aber die Tat ist mehr als das blosse Konvergenzprodukt jener beiden ausserpersönlichen Faktoren; und in diesem Pl u s, 
in diesem unmittelbaren Hervorströmen aus der Person selbst ist sie frei. Denn "Freiheit" ist nicht Ursachlosigkeit, sondern Verursachung aus der aktuellen Selbstbestimmung der Person $\left.{ }^{1}\right)$.

\section{Gesinnung ${ }^{2}$ )}

Wenn es auch der eigentliche Sinn einer Willenshaltung ist, sich in Willens handlungen zu aktualisieren, so gibt es doch noch eine andere Art von Aktualisierung, die rein im B i nnenseel is chen stecken bleibt. Dieser Erlebnisniederschlag einer Willenshaltung ist die "Ge s in n u n g". Ihr Verhältnis zur Willenshaltung ist ein ähnliches, wie die des Phänomotivs zur akuten Willenshandlung: in der Gesinnung spiegelt und rechtfertigt die Person ihre Willenshaltung vor sich selbst und vor anderen. Für viele Willenshaltungen, insbes. für die durch Gewöhnung oder äusseren Druck automatisch entstandenen, ist ein Bedürfnis nach Begründung und Rechtfertigung nicht vorhanden; darum hebt sich bei diesen kaum oder garnicht ein besonderes Gesinnungserleben von der zuständlichen Willensbereitschaft ab. Ein ausdrückliches Rekurrieren auf „Gesinnung" ist also stets ein Zeichen für eine Spannungshaltigkeit und Unselbstverständlichkeit der Willenshaltung, ist eine Abgrenzung dieser Willenshaltung gegen andere, mögliche und wirkliche Willenshaltungen der eigenen Person oder anderer Menschen. So gibt es beim Naturmenschen, der in einem Gehäuse undiskutierbarer Willenshaltungen heimisch ist, kaum "Gesinnungen" als irgend wie abhebbare Erlebnisgehalte. Differenzierte Kultur dagegen bietet dem Menschen zahlreiche, nicht ohne weiteres vereinbare, Wertziele und bewirkt so, dass die vorzugsweise Einstellung auf spezifische Wertziele bewusstseinsmälsig weitgehend geklärt und gerechtfertigt sein muss, um für das Wollen dauernd konstitutiv werden zu können. So entwickelten sich die "Gesinnungen" des Eigennutzes und der Gemeinnützigkeit, Familien-, Volks-, Menschheits-Gesinnungen; religiöse, künstlerische, wirtschaftliche Gesinnungen u.s.w.

Da die „Gesinnung" das chronisch gewordene Phänomotiv ist, so unterliegt auch ihre personale Deutung ähnlichen Gesichtspunkten, die hier nicht noch einmal ausführlich besprochen $z u$

1) Zur Metaphysik und Ethik des Freiheitsbegriffs vgl. Wertphilosophie S. 418 ff.

2) Literatur: Honecker, Pfänder, Voigtländer u.a. 
werden brauchen. Gesinnung ist Bewusstseins-Spiegelung und Darstellung einer dispositionellen Willensbeschaffenheit; aber sie spiegelt diese nicht immer in adäquater Weise. So gibt es neben den ,e ch t e n" Gesinnungen auch ,u n e c h t e" (auf Selbsttäuschung beruhende) und „ve r lo g e n e” (auf Fremdtäuschung zielende) Gesinnungen. Endlich gibt es auch eine verabsolutierende Ú b e r s p a n n u n g der Gesinnung; dann wird die bloss erlebnis- und ausdrucksmälsige Einstellung auf Wertziele als Ersatz für die wirkliche $\mathrm{W}$ i 11 e $\mathrm{n}$ s haltung angesehen. So manche Menschen, die von ihrer religiösen, oder nationalen, oder moralischen Gesinnung zu tiefst überzeugt sind und sich zu ständiger Kundgebung eben dieser Gesinnung gedrungen fühlen, erschöpfen sich hierin und verpuffen damit die Kraft, die für gesinnungsgemälses $T$ u n verwertet werden sollte. D i e $l$ a utesten Gesinnungsverkünder sind of t die s chwäch st e n Wolle r. Lessing's Nathan weist den Tempelherrn darauf hin, dass ,,andächtig Schwärmen leichter als gut Handeln" sei ${ }^{\mathbf{1}}$ ).

Willenshaltungen sind halbchronischer Natur. Den einzelnen akuten Willenshandlungen gegenüber bilden sie die länger dauernde Dispositionsgrundlage; aber diese Dauer fällt nicht mit der Existenzdauer der Person zusammen. Willenshaltungen beginnen und hören auf; sie machen eine Entwicklung durch mit Anklingen, Intensivierung, Höhepunkt, Abschwellen und Ausklingen; zuweilen auch mit periodischen Wellen. Sie sind hierbei von we ch s elnden Bedingungen abhängig, so namentlich von

1) Es gibt eine Richtung der Moralphilosophie, die als „Gesinnungsethik” bezeichnet wird. Nach ihr soll die Gesinnung der einzige Mafsstab für die moralische Beurteilung sein. Hier kann eine unzulängliche Psychologie gefährlich werden. Indem man „Gesinnungsethik" und „Erfolgsethik” gegenüberstellt, will man zum Ausdruck bringen, dass nicht der äussere Effekt einer Tat, sondern die ihr zu Grunde liegende Willensbeschaffenheit ihre sittliche Bewertung bestimme. Aber "W ill e n s b e s c h a $f-$ fenheit" und "Gesinnung" dürfen eben "nicht, wie in diesem Falle geschieht, identifiziert werden. Es gibt Willenshaltungen, die so selbstverständlich sind, dass sie des Bewusstseinsniederschlags als „Gesinnung" nicht bedürfen. Und es gibt umgekehrt „Gesinnungen”, die so selbstgenügsam geworden sind, dass sie die Umsetzung in wirkliche Tat versäumen. Endlich gibt es „Gesinnungen", die - absichtlich oder unabsichtlich - als Kulissen vor Willenshaltungen als Kulissen vor Willenshaltungen anderer Art gestellt sind. Wer also die „Gesinnung" zum ethischen Masstab macht, bleibt noch zu sehr an der psychologischen Bewusstseinsfläche haften und hat den Zugang zu den personalen Tiefen der Willensbeschaffenheit selbst noch nicht erreicht. 
solchen der vitalen Entwicklung und der personalen Situationen. Die Willenshaltung der Vorpubertät hört auf, wenn die Vollpubertät einsetzt, die Willenshaltung des Kriegers, wenn er wieder zu seiner friedlichen Beschäftigung zurückkehrt. Es gibt auch Überschneidungen von Willenshaltungen: ein Mensch, der demnächst aus seinem Berufe in den Ruhestand übertritt, lebt und handelt zwar noch in der beruflichen Willenshaltung; sie beginnt aber eigentümlich substanzarm zu werden, während die neue Willenshaltung der Mulsezeit schon vorzuspuken beginnt.

Somit bilden die Willenshaltungen zwar den einzelnen Taten gegenüber schon ein Einheitsprinzip, aber sie sind selbst wiederum nur Phasen und Glied-Erscheinungen gegenüber der Ganzheit der Person und sind nur künstlich aus dieser herauszulösen. Denn letzthin wurzeln sie doch in einer $\mathrm{e}$ i $\mathrm{n}$ h e i $\mathrm{t} l \mathrm{i}$ c h-p e r s o $\mathrm{n}$ alen W i l le nshalt ung, die zwar keine starre Gleichförmigkeit, wohl aber innere sinnvolle Geschlossenheit und eine organische Gesamtentwicklung besitzt: dem „C h a r a k t e r”.

\section{ZUR THEORIE DES CHARAKTERS}

Der Charakterbegriff hatte in der Psychologie der letzten hundert Jahre ein merkwürdiges Schicksal. Für die klassische Lehre mit ihrer elemententheoretischen Einstellung war der Begriff mehr eine Verlegenheit als ein Problem. Bahnsen, der schon in der Mitte des 19. Jahrhunderts ein selbständiges Wissensgebiet der "Charakterologie" zu schaffen suchte, blieb fast unbeachtet. Lange Zeit war daher die Beschäftigung mit diesem Begriff der Laienpsychologie und dem Dilettantismus überlassen; seit wenigen Jahrzehnten aber beginnt sich eine neue wissenschaftliche Charakterologie zu entwickeln, die allmählich auch mit der Psychologie in engere Fühlung tritt (vgl. S. 42). ${ }^{1}$ )

Einer wissenschaftlichen Behandlung des Charakterproblems stehen nun freilich besondere Schwierigkeiten im Wege.

1) Das Problem ist aufs engste verbunden mit Wertu n$\mathrm{g}$ e $\mathrm{n}$, ethischen und weltanschaulichen Forderungen; die Folge ist mangelnde Objektivität. Oft wird der Charakter, wie er sein sollte, oder wie man ihn haben möchte, oder wie man hofft, ihn beeinflussen zu können, nicht deutlich geschieden von dem Cha-

1) Literatur zum Charakterproblem in den Abteilungen der Bibliographie I B, V, VII. 
rakter, wie er tatsächlich is t - und nur dieser ist das Problem der Psychologie. Auch Vorurteile der Verdammung und Kritik können den Blick für die Sachlichkeit verschleiern; wer etwa von der apriorischen These ausgeht „,der Mensch ist böse von Jugend auf", taugt nicht zum wissenschaftlichen Charakterologen.

2) Die praktis chen Bedürfnisse der Charakterdeutung sind theoretischer Einstellung höchst ungünstig. Das Publikum, für welches Charakteristiken geliefert werden, kann mit streng wissenschaftlichen Darlegungen nichts anfangen; es fordert Primitivität, Aufzählung leicht erfassbarer Eigenschaften und vor allem: Bestätigung des Selbstgeltungsverlangens.

3) Innerhalb der eigentlich wissenschaftlichen Fragestellung ist es sehr schwierig, Ganzheitsbezug und Analy se in das richtige Verhältnis zu einander zu bringen. Hier muss unsere eigene Betrachtung einsetzen.

Wie schon erwähnt, hat der Begriff „Charakter” nur Sinn als ganzheitlicher. Er drückt eine Beschaffenheit aus, die der Person in ihrer $\mathrm{T}$ ot a li t ä $\mathrm{t}$ zukommt, und betrachtet diese Totalität nur unter einem bestimmten Richtpunkt, nämlich der Eingestelltheit auf Willenshandlungen. Wenn bezweifelt wird, dass dem Menschen eine solche personale Gesamtbeschaffenheit zukomme, dann muss man folgerichtig auf die Kategorie "Charakter" und alle damit zusammenhängenden wissenschaftlichen Begriffe verzichten. Der Umstand, dass man sinnvoll von Änderungen und Spaltungen des Charakters reden kann, besagt nichts gegen die obige Voraussetzung; denn Anderung und Spaltung setzen Einheit voraus.

Diese Einheit ist nun freilich die $u n i t a s$ m 1 tiplex, die wir ja überhaupt als Merkmal der Person erkannten. Darum gehört es zum Wesen des einheitlichen Charakters, dass er eine Fülle von Willenshaltungen in sich schliesst, sowohl in der Simultaneität einer bestimmten Gegenwart, wie in der Sukzession des Lebensprozesses.

Eine solche unitas multiplex durch Mittel des theoretischen Erkennens $\mathrm{zu}$ erfassen, ist augenscheinlich eine schwer zu bewältigende Aufgabe. Beim Charakterproblem ist man immer wieder dieser Schwierigkeit dadurch ausgewichen, dass man die beiden Merkmale auf zwei Arten oder Weisen des Charakters 
verteilte. Dann ist der ,intelligible Charakter” der unveränderliche, unteilbare Einheitskern; dagegen ist der „empirische” Charakter vielfach gerichtet und geschichtet, in der Zeit wandelbar, durch Erfahrung beeinflussbar ${ }^{1}$ ).

Suchen wir die eigentlichen Motive dieses Dualismus herauszustellen und in personalistischem Sinne umzudeuten.

Die Willensbeschaffenheit eines Menschen, sowie sie sich irgendwann in der Form deutlich umschriebener Eigenschaften darstellt, ist zweifellos $\mathrm{n}$ i $\mathrm{c} \mathrm{h} \mathrm{t} \mathrm{unveränderlich;} \mathrm{sie} \mathrm{ist} \mathrm{auch} \mathrm{nicht}$ allein aus dem Inneren dieses Menschen heraus ableitbar, sondern durch das Mitwirken früherer Erfahrungseinflüsse und der gegenwärtigen personalen Situation geformt. Es ist die Person in ihrer Welt of $\mathrm{fe} n \mathrm{~h}$ e it, deren Bild uns in diesem empirischen Charakter entgegentritt. Aber man darf nicht vergessen, dass Weltoffenheit selber ein entscheidender Wesenszug der Person ist, dass also das, was unter dem Einfluss von „Welt" in ihr vor sich geht, nicht als fremd, unecht, uneigentlich, zweitrangig, einem urgegebenen, „eigentlichen” Charakter gegenübergestellt werden darf. Vielmehr ist der rein innerpersonale Anteil an dem Charakter nirgends und nie für sich da; er ist nur jenes Moment innerer Gerüstetheit und Gerichtetheit, das in breit angelegter Vieldeutigkeit dio Möglichkeit zur Gestaltung und Vereindeutigung von Willenshaltungen in sich trägt. Die $\mathrm{E}$ in he i t li c h k e it dieser inneren Entelechie besteht nicht darin, dass ihr ein fester Bestand an starren Zügen zukäme, sondern nur darin, dass sie dem gesamten Vorgang der charakterlichen Gestaltung einen geschlossenen $\mathrm{S}$ i $\mathbf{n} \mathbf{n}$, und dem jeweiligen Beieinander gleichzeitiger Willenszüge eine hierarchische $\mathrm{G}$ es a m t s t r u k u r verleiht. Dort aber, wo ein solcher Einheitssinn sich nicht aus dem empirischen Bilde ohne Weiteres ablesen lässt, bildet er das he uristische Prinzip, aus dem die scheinbaren Brüche und Spaltungen innerhalb der Willenshaltung eines Menschen verständlich gemacht werden sollen.

Es wäre nun ganz verkehrt, wenn man diese Gesamtdisposition

1) Kant und Schopenhauer haben diesen Dualismus vor allem betont. - Neuerdings machtP faender eine Scheidung $z$ wischen „Grundcharakter” und ,empirischem Charakter”. Er setzt „Grundcharakter" sogar in Gegensatz zu den „Dispositionen” was nur dadurch möglich ist, dass er lediglich „Rüstungsdispositionen” kennt, die er „Ausstattungen" nennt. Der Charakter aber ist, in unserer Ausdrucksweise, vor allem "Richtungsdisposition". 
in jener maximalen Dumpfheit und Ungeformtheit, in der sie vor aller Erfahrung - etwa beim Neugeborenen - anzusetzen ist, als den wahren eigentlichen „Grundcharakter” ansähe, und alles, was nun im Wechselgeschehen mit der Welt daraus wird, als „nur'-empirischen Charakter betrachten wollte. Das wäre ja nur berechtigt, wenn man „Erfahrung” als jenen fremden unpersönlichen Zufallsfaktor ansähe, wie es ein, doch wohl endgültig überwundener, Rationalismus früher zu tun beliebte. In Wirklichkeit gibt es für jeden Menschen nur den e i n e n Charakter, wie er sich im Wechselspiel innerlich bedingter Strebigkeit mit den realisierenden Faktoren der personalen Welt entfaltet.

Freilich kann man nun, wenn dies zugestanden ist, anerkennen, dass in dem Charakter Schichtung und Struktur bestehen, die den einzelnen Momenten verschiedene Grade der Eingebettetheit bezw. Abgehobenheit verleihen. In jedem Charakter gibt es daher tiefere und oberflächlichere, zentrale und periphere, herrschende und dienende, stabilere und labilere Züge; und entscheidend dafür, wie ein Charakter is $t$, sind nicht sowohl bestimmte Züge in bestimmten Stärkegraden, sondern die Art, wie sie kraft der eben angedeuteten Merkmale sich zur Einheit der Struktur fügen - oder richtiger gesagt, wie sie aus dieser Einheit heraus erst ihre Stellenwerte und Rangplätze erhalten.

Unitas und multiplicitas bedingen sich hier also gegenseitig. Wir hatten oben die einseitige Unitas-Tendenz bekämpfen müssen, welche durch die Postulierung eines einfachen „Grundcharakters" sich befugt glaubte, Vielheit und Wechsel innerhalb des Charakters als blosses Oberflächengebilde abzutun. Jetzt müssen wir uns ebenso gegen die Multiplicitas-Auffassung wenden, die in dem empirischen Aufweis nebeneinanderstehender Züge oder aufeinanderfolgender Phasen die Erfassung des Charakters vollendet sieht. Die Gefahr, dass die Charakterologie hier elementenpsychologisch verflache, nämlich in eine Art „Vermögens"'-Theorie zurückfalle, ist sehr gross gerade dort, wo man mit exakten Methoden des Experiments oder der Ausdrucksdeutung an die Erforschung von Charakteren herangeht. Denn der wissenschaftliche Zwang zur Analyse und der sprachlich logische Zwang zur Abgrenzung fester Eigenschaftenbegriffe führen dazu, dass man eine $\mathrm{L}$ i s $\mathrm{t}$ e der bei irgend einem $\mathrm{X}$ fest- 
gestellten und nach Art und Grad fixierten „Eigenschaften” als eine „Charakteristik” ansieht. In Wirklichkeit beginnt die eigentliche Aufgabe des Charakterologen erst $\mathrm{d}$ a h in $\mathrm{t} \mathrm{e} \mathrm{r}$ : die additive Liste muss in eine wirkliche Zusammenschau, jede Listennummer zu einem personalen Moment in jenem geschauten Gesamtbild umgewandelt werden. Ohne den fortwährenden, elastischen Blickwechsel: von der Ganzheit zu den Einzelzügen und von diesen auf die Ganzheit des Charakters, ist hier wirkliche Erkenntnis nicht möglich.

Der einzelne, empirisch gefundene Charakterzug (über die Art der empirischen Feststellung später) bedarf sogar einer d r e i$f$ a $c h$ en Betrachtung: in seiner immanenten Beschaffenheit, in seiner interindividuellen Vergleichbarkeit, in seiner personalen Ausgeprägtheit oder "Valenz". Die immanente Beschaffenheit des Charakterzuges - d.h. die Zielbereitschaft und dynamische Geladenheit für Willenshandlungen bestimmter Art - ist wesentlich deskriptiv zu fassen. Die interindividuelle Vergleichung führt dazu, dem Charakterzug einen Platz anzuweisen innerhalb einer Stufenleiter oder Typologie, sodass nun seine Geeignetheit zur Lösung überindividueller Aufgaben sichtbar wird. Die personale Valenz endlich bezeichnet die Anteilhaftigkeit jenes Charakterzuges an der Strukturganzheit der wollenden Persönlichkeit.

Wählen wir als Beispiel einen Charakterzug in populär-psychologischer Bezeichnung: Sorglosigkeit in Geldsachen. Diese Eigenschaft eines $\mathrm{X}$ kann i $\mathrm{m} \mathrm{m}$ a $\mathrm{n}$ e $\mathrm{n} \mathrm{t}$ beschrieben werden durch Schilderung von Verhaltungsweisen in alltäglichen und aussergewöhnlichen Situationen, die als repräsentativ für die Einstellung der $\mathrm{X}$ zum Gelde anzusehen sind. - Wird die Eigenschaft des X vergli che n mit den Verhaltungsweisen zum Gelde bei den Individuen A, B, C u.s.w., so ist es theoretisch möglich, den X. einem Typus oder einer Stufe der Sorgsamkeitsskala zuzuordnen, und praktisch seine grössere oder geringere Eignung für bestimmte Berufsaufgaben (z.B. zum Kassierer) auszusprechen. - Aber die eigentlich charakterologis che Bedeutung jenes Zuges wird doch erst sichtbar, wenn wir untersuchen, welche Rolle er im Gesamtbild des X.'schen Charakters spielt. Tritt hier z.B. die personale Valenz der geldlichen Sorglosigkeit als $\mathrm{Pr}$ ä-Valenz gegenüber allen anderen Zielrichtungen 
auf, dann kann sie geradezu dem Gesamtmenschen den Stempel aufdrücken: als Grandseigneur, als Verschwender, als Betrüger. Umgekehrt kann dieselbe Eigenschaft bei einem anderen Individuum Y - obgleich sie interindividuell betrachtet die gleiche oder höhere Ausgeprägtheit zeigt - ihrer personalen Valenz nach durchaus sekundär sein, weil der Charakter des Y. seinen Schwerpunkt hat in Willenshaltungen, die mit der Verfügungsfähigkeit über Geld wenig zu tun haben (etwa in künstlerischen oder in religiösen Einstellungen).

Man ersieht heraus, mit welchem starken Vorbehalt die isolierende Feststellung von „Eigenschaften” sogar für Zwecke des interindividuellen Vergleichens zulässig ist. Je mehr die überindividuelle Aufgabe, bezüglich deren mehrere Individuen verglichen werden, den $g$ a $n z$ e $n$ Menschen in Anspruch nimmt, um so weniger genügt es, die Einzeleigenschaft als solche zu prüfen und typen- oder stufenmälsig zu signieren; um so mehr muss man auch ihre personale Valenz mit in die Charakteristik hineinziehen. Hiervon sind heut praktische Testprüfungen, charakterologische Handschriftdeutungen, u.s.w. grossenteils noch weit entfernt.

Dort aber, wo der Charakterologe vor der Aufgabe steht, die Gesamtcharakteristik einer Person zu geben, erhebt sich nunmehr die Forderung, ein etwa gefundenes $\mathrm{E}$ i g e $\mathrm{n} \mathrm{s} \mathrm{ch}$ a f $\mathrm{t}$ e $\mathrm{n}$ $r$ e $g$ is $t$ e $r$ dieses X. lediglich als $R$ o h m a t e ri a l anzusehen, aus dem erst das Strukturbild aufgebaut werden muss. Bei jedem Individuum muss sich der Diagnostiker von neuem darüber klar werden, von welchen zentralen und tief gelagerten Wesenszügen aus das Gesamtbild eben dieses Menschen aufgerollt werden muss, und wie sich von diesem jeweiligen Ausgangspunkt aus die Schichtung und Strukturierung des Charakters und damit die Valenzbestimmung aller Einzeleigenschaften entwickelt. Nur darf diese strukturierende und organisierende Tätigkeit des Charakterologen nicht zu der grob dualistischen Gegenüberstellung von „Kern" und „Schale" versimpelt werden.

Um den Begriff des „Charakters” deutlich von anderen Totalbezeichnungen der menschlichen Persönlichkeit - wie "Temperament", „Naturell”, „Konstitution” - zu unterscheiden, muss stets der Bezug auf die Willenshandlung den Leitge- 
sichtspunkt bilden. „Charakter” ist die Gesamtbeschaffenheit des Menschen, sofern sie (s. oben S. 603) Bereitschaft und Eingestelltheit $\mathbf{z u}$ Willenshandlungen ist, - aber darüber hinaus: sofern sie sich in $t a t s a ̈ c h l i c h e n$ Willenshandlungen bekundet, bestätigt und bewährt. Darum ist der Charakter kein rein psychologischer, sondern ein personaler, psychophysisch neutraler Tatbestand. Er erschöpft sich nicht darin, dass in ihm die E r l e b n i s haltung der "Gesinnung" fest und dauernd geworden wäre, sondern schliesst in sich die Disposition zu realen Verh alte $\mathrm{ns}$ weisen, die sich in willentlichem Tun bekunden. Hiermit erhält die Beziehung von "Charakter" und "Welt" eine neue Tönung. Nicht nur, dass der Charakter von der Welt her beeinflusst und geformt wird, er ist die dauernde Voraussetzung dafür, wie die Person nun auf die Welt beeinflussend und formend wirkt.

Diese wesentliche Beziehung des Charakters zum Wolle n befähigt uns nun, in die Vielgestalt der Charakterzüge eine Systematik zu bringen. Wir können sie nämlich gruppieren nach drei Merkmalen, die jeder Willenshandlung zukommen: Zielsetzung, Dynamik, Struktur.

\section{CHARAKTERZÜGE UND CHARAKTERTYPEN}

\section{Telische $Z$ üge und Typen}

a) Das personale $Z$ we cksystem. - Im Leben jedes Menschen gibt es eine bunte Fülle von Strebungszielen, die dauernde Bedeutung haben und daher auch zu chronischen Willensinhalten werden können. Dort, wo man den menschlichen Charakter zu analysieren a $\mathrm{n} \mathrm{f} \ddot{\mathrm{ng} \mathrm{t}}$ - also vor allem in der Popular-Charakterologie - sind es diese chronischen Zielbestimmtheiten des Menschen, die sich am ehesten aufdrängen und am leichtesten abgehoben werden können. Daher begegnen wir hier besonders häufig den gebietsbezogenen Charakterzügen als da sind: Erwerbssinn, Familiensinn, Frömmigkeit, Wahrheitsliebe u.s.w.

Eine wissenschaftliche Charakterologie kann sich natürlich mit diesen Ergebnissen zufälliger Analyse nicht begnügen, sondern muss die einzelnen Teilgebiete, welche Dauerziele des Wil- 
lens werden können, dem Totalsystem der personalen Zwecke einordnen. Ein solches "Zwecksystem der Persönlichkeit" ist von mir schon früher an anderer Stelle entworfen worden ${ }^{1}$ ), auf das hier im Wesentlichen verwiesen werden kann. Nur einige Andeutungen seien gegeben.

Das Zwecksystem baut sich auf dem Urverhältnis Person/Welt auf, aus dem sich als erste Gliederung möglicher Willenszielung die Zweiheit ergibt: das eigene Selbst und die äussere Welt mit ihren Gegenstands-und Wertsphären. Sofern konstante Willenshaltungen sich auf jenen oder diesen Bereich beziehen, sprechen wir von ,autotelen” und „heterotelen” Charakterzügen.

Innerhalb der a u t o t e l e n Dispositionen geht die Gliederung weiter nach Selbsterhaltung und Selbstentfaltung. Auf Selbsterhaltung richten sich die Tendenzen der Existenzsicherung und Anpassung, des Selbstschutzes und der Verteidigung; auf Selbstentfaltung die der Geltungssteigerung, des Machtgewinns und der Selbstgestaltung. Diese Skala von selbstbezüglichen Zielen stellt zugleich eine Reihe immer stärkerer Willensbeteiligung und damit eine immer engere Beziehung zum Charakter im eigentlichen Sinne dar. Denn während die zuerst genannten Tendenzen grossenteils durch rein biologische Automatismen gesichert werden können und nur in Sonderfällen eigentlicher Willensrucke bedürfen, müssen die zuletzt genannten erst durch bewusste Willenshandlungen hindurchgehen, um zu Willenshaltungen und schliesslich zu wesentlichen Dauerbestandteilen der Persönlichkeit zu werden. Insbesondere die Tendenz zur Selbstgestaltung bildet die Zusammenfassung aller anderen autotelen Tendenzen und macht erst das möglich, was wir im spezifisch menschlichen Sinne „Charakter" nennen. Auch im Tier gibt es dauernde Beschaffenheiten autoteler Art, die auf Sicherung, Verteidigung, Aggression gerichtet sind. Aber diese verbleiben wesentlich in der Sphäre des Triebes; ihre Durchsetzung mit echten Willenshandlungen ist so schwach, dass man sich begnügen sollte, von dem „Naturell” der Tiere (nicht aber von ihrem „Charakter”) zu sprechen. Nur der Mensch ist fähig, alle dem eigenen Selbst zugewandten Strebungen unter das Leitmotiv einer Gesamtaufgabe: des $\mathbf{s} \mathbf{t}$ ä $\mathbf{n}$ d i g e n A rbeitens an sich, zu stellen und so in die chronische

\footnotetext{
1) Die menschliche Persönlichkeit, Kap. I.
} 
Entwicklung des eigenen Charakters durch akute Willenshandlungen einzugreifen. In diesem spezifischen Sinn ist „Charakter" diejenige Beschaffenheit des Menschen, die - so sehr sie auch durch Anlage und Umwelt mitbedingt sein mag - doch zugleich sein ständiges eigenes Werk ist.

Die h e t e r o t e l e n Charakterzüge sind zu ordnen nach den drei Arten der Fremdzwecke, deren Verwirklichung gewollt wird. Die äussere Welt sinnvoller und werthaltiger Zwecke, in die sich jeder Mensch eingefügt findet oder einzufügen hat, besteht nämlich einmal aus überpersonalen Daseinsbereichen, denen die Einzelperson als Glied angehört („Hypertelie”), sodann aus nebengeordneten Personen, die als Zentren eigenen Sinnes anerkannt und willentlich berücksichtigt werden (,Syntelie”), endlich aus abstrakten Wertgehalten, die in der Form von Ideen, Idealen und Prinzipien nicht nur gesucht, sondern auch normativ dem Wollen auferlegt werden (,Ideotelie”).

Was die beiden ersten Gruppen angeht, so ist es wichtig, zu betonen, dass ihre Verschiedenheit sehr tief geht und daher auch in sehr verschiedenen Charakterzügen ihren Niederschlag findet. Die Willenshaltung, die sich auf ein ü b e $\mathbf{r}$ personales Gebilde etwa des Volks oder Staates richtet, hat ein anderes Gepräge als jene, die sich auf das einzelne $\mathrm{Du}$ des $\mathrm{N}$ e b e $\mathrm{n}$ menschen bezieht; und ebenso ist Familiensinn nicht identisch mit der Liebe zu den einzelnen Familienmitgliedern. Ja, es gibt sogar Gegensätze: Glühende Vaterlandsliebe kann einhergehen mit nur schwacher Willensgerichtetheit auf die individuellen Schicksale der einzelnen Volksgenossen. Oder: Wer bereit ist, seine ganze Kraft für die grossen Menschheitsziele einzusetzen, entbehrt oft des tätigen Mitgefühls für den hilfsbedürftigen Angehörigen oder Nachbarn.

Hypertelie und Syntelie gibt es in einfachen Formen schon beim Tier; doch werden sie hier wesentlich durch blosse Triebdynamik verwirklicht, sodass es wiederum unangemessen erscheint, die tierischen Tendenzen zu herdenmälsiger Gesellung oder zur Brut-Pflege und -Verteidigung als „Charakter"-Züge zu bezeichnen. Beim Menschen dagegen handelt es sich um echte Willenshaltungen, die den Charakter mit konstituieren.

Dies gilt nun wieder in besonders zugespitzter Form von der 
dritten Gruppe der Fremdzwecke, die es überhaupt nur beim Menschen gibt, der I de oteli e. Das abstrakte Denken, welches Forderungen in allgemein gültiger Form zu stellen und festzuhalten vermag, wird hier nicht nur zu einem Hilfsmittel der einzelnen Willenshandlungen (die wir oben als „Vernunft-Handlungen" beschrieben), sondern zu einem Prägestock für die dauernde Willensbeschaffenheit der Person. So kann z.B. die Idee der Gerechtigkeit zu einer, stets im Hintergrunde des Handelns mitwirkenden, Norm und damit der "Gerechtigkeitssinn" zu einem Charakterzug werden. Die gleiche charakterologische Fixierung ist möglich bei dem abstrakten Pflichtgedanken des kategorischen Imperativs, bei der Hingabe an die Freiheitsidee u.s.w.

Der einzelne auf ein Teilziel gerichtete Charakterzug autoteler oder heteroteler Art wird nun aber charakterologisch erst dann erfassbar, wenn seine Rolle und Stellung im gesamten Zwecksystem der Person erkannt wird; und so muss denn nun die blosse „Analyse" durch G a n $\mathrm{z}$ h e i t s b e z u g ergänzt werden.

Ein solcher ist schon in $\mathrm{n}$ e $\mathrm{rh}$ a l b jeder der beiden Gruppen möglich. Innerhalb des Autotelischen ergibt sich eine ganz andere Charakterstruktur, je nachdem die Tendenz zu konservativer Inhaltsbeharrung, oder die nach evolutiver Selbstgestaltung dominiert. - In der heterotelen Sphäre erwähnten wir schon die Verschiedenheiten der Charaktere, die durch das Überwiegen einer Einstellung auf die übergeordnete Gemeinschaft oder auf die konkreten Nebenmenschen bedingt sind. Entsprechendes gilt bezüglich der Rolle der Ideotelie: der Mensch, der ichfremde Zwecke vornehmlich in der Form abstrakter Ideale und Grundsätze zu Motiven seines Wollens macht, ist charakterlich ganz anders strukturiert als jener, der sein Wollen auf lebendige Nebenmenschen und Gemeinschaften einstellt.

Aber über diese Teilstrukturen hinaus greift nun jene gesamtpersonale Struktur, die durch die Ineinsbildung von Selbstzielung und Fremdzielung erzeugt wird. Erst dort sind wir bei der wirklichen Totalität des Charakters angelangt, wo wir wissen, in welcher Weise die auf fremde Ziele gerichteten Dauertendenzen des Menschen seiner Selbstformung einverleibt werden. Diese Einverleibung bildet, als "I n t r oz e p t i o n", eine Grundkategorie der personalistischen Theorie. 
Wie sie anderwärts zum Leitgedanken der Ethik gemacht wurde ${ }^{1}$ ), wird sie hier zu dem der Charakterologie.

Das Verhältnis Person/Welt tritt damit in eine neue Dimension ein. Nicht allein, dass die Person nur in ihrer personalen Welt existieren kann, von ihr Einwirkungen empfängt und auf sie Wirkungen ausübt: ,Welt” ist zugleich für sie ein Inbegriff zu verwirklichender objekti ver W e r t e; das eigene Selbst ist ein zu gestaltender $\mathrm{S}$ e $\mathrm{l}$ b s t w e r $\mathrm{t}$; und beides muss sich durchdringen, damit die Person ihren Sinn in ihrer Welt zu verwirklichen vermag. Dort, wo diese introzeptive Ineinsbildung eine Stabilität gewonnen hat, derart, dass nun die einzelnen Willenshandlungen aus ihr mit innerer Notwendigkeit hervorwachsen, dort haben wir den „Charakter" in seiner voll ausgereiften Form vor uns.

Und zwar ist damit auch die charakterologische I n d i v i$\mathrm{du}$ a lisierung gegeben. Indem jeder Mensch der Mittelpunkt s e i n e $r$ personalen Welt ist, sind auch die Wertbereiche, die seinem Willen Aufgaben stellen, anders um ihn gelagert als um jeden andern Menschen. Aber noch mehr: aus dieser ihn umspielenden Welt trifft jeder Mensch eine Auslese derjenigen Momente, die er sich innerlich so zu eigen macht, dass sie nun zu Bestandteilen seines Selbst und zu Faktoren seiner Selbstgestaltung werden; und ebenso ist die Art, wie sich aus diesen, innerlich zu eigen gemachten, Aufgaben für Nebenmenschen und Familie, für Volk und Staat, für Menschheit und Gottheit, für Ideale und Grundsätze - eine hierarchische $\mathrm{Ziel-}$ u n d N o r m-S t r u k t u r bildet, eigenste Besonderheit jeder individuellen Person. Die Stabilität des Charakters bekundet sich hierbei nicht so sehr in starren Verhaltungsweisen bezüglich eines einzelnen Teilzieles, als in der Rangordnung, dem Vorwiegen und Zurücktreten der Einzelziele in jener Gesamtzielsetzung, für die schon Aristoteles eine begriffliche Formulierung als „Entelechie" gefunden hatte. Charakter is t die Entelechie der wollenden Personlichkeit.

b) T e lis che $\mathrm{Ch}$ a rakte r t y pen. - Bei aller Individualisierung ist es doch möglich, gewisse typische Ausprägungen der Zweckstruktur, also "telische” Charaktertypen aufzustellen.

') Vgl. meine „Wertphilosophie”. 
Aus dem Verhältnis von autoteler und heteroteler Einstellung ergeben sich zwanglos die drei Typen des autistischen, des heteristischen und des introzeptiven Charakters.

"A u t i s t i s c h" sind solche Charaktere, in deren Struktur autotele Charakterzüge eine Vorherrschaft besitzen. Für den Autisten ist eigentlich immer Er selbst das Ziel seiner Willenshandlungen - sei es, dass er als „Individualist” seine Besonderheit gegenüber den Anderen zu unterstreichen sucht; sei es, dass er als „Subjektivist” die Dinge vornehmlich unter dem Gesichtspunkt erlebt und behandelt, was sie ihm persönlich besagen und bedeuten; sei es endlich, dass er als „Egoist" die fremden Zwecke zu Mitteln für die Befriedigung seiner selbstischen Zwecke macht.

Im Gegensatz zum Autisten mag man "h e t e ris t is c h" einen solchen Charakter nennen, dem heterotele Charakterzüge das Gepräge geben. Wo die Zielgerichtetheit auf Nebenmenschen oder Gemeinschaften dominiert, oder wo der Mensch im Dienst an abstrakten Idealen aufgeht, kann die persönliche Selbstgestaltung zu kurz kommen. Statt sich zu individualisieren, wird der Mensch zu einem Exemplar der Gruppe; an die Stelle subjektiven Erlebens tritt das objektive Leisten; im Einzelfall der Handlungsnotwendigkeit wird nicht die Einzigartigkeit der personalen Situation berücksichtigt, sondern der Grundsatz in seiner leblosen Allgemeinheit zur Richtschnur erhoben. Schliesslich kann der heteristische Charakter sich darin bekunden, dass er sich dem fremden Wohl und Nutzen ,altruistisch" hingibt und sich ganz darin verausgabt bis zur Selbstpreisgabe (,,SelbstLosigkeit").

Die einzelnen Züge, die wir dem autistischen, bezw. heteristischen Charakter zuwiesen, sind übrigens durchaus nicht fest mit einander verkoppelt. Es entstehen hier vielmehr Untertypen; innerhalb des autistischen Kreises ist der "Subjektivist” ein wesentlich anders strukturierter Charakter als der „Egoist”; innerhalb des heterotelen Formkreises ist der Prinzipienreiter ein ganz anderer Mensch als der, sein Selbst verleugnende, Büsser und Asket.

Die Typenscheidung der vorwiegend nach innen bezw. nach aussen gerichteten Menschen beherrscht verschiedene moderne Psychologieen. 
Ich selbst hatte schon vor Jahrzehnten den „objektiven" und „subjektiven" Typus der Stellungnahme unterschieden ${ }^{1}$ ); neuerdings ist insbesondere die Jung'sche Typenbezeichnung: ,introvertiert" „extravertiert" gebräuchlich geworden. Allerdings sind diese Benennungen nicht wesentlich auf $C h$ a $r$ a $k$ t e $r$ züge zugespitzt, sondern zugleich - ja vorwiegend - für geistige Stellungnahmen, Interessenrichtungen u.s.w. gedacht.

Auch in der Kretschmer'schen Antithese "schizothym/zyklothym" steckt der Gesichtspunkt der Innenbezogenheit, bezw. Weltoffenheit; aber hier liegt der Schwerpunkt der Typologie nicht sowohl auf dem Gebiet der Zielsetzung als der Strukturierung des Charakters; daher erfolgt die Besprechung weiter unten.

Der Ausdruck ,autistisch" stammt aus der Psychiatrie, wo er für krankhaftes Sich-auf-sich-selbst-Zurückziehen verwandt wird. Er ist aber auch durchaus für Charakterzüge innerhalb der Normalität anwendbar. Die Gegenbezeichnung "heteristisch” ist meines Wissens bisher nicht gebraucht worden.

Natürlich sind diese Extremformen des Charakters nur Grenzbegriffe; es gibt niemanden, der ausschliesslich auf die Ich-Ziele oder auf die Nicht-Ich-Ziele eingestellt sein könnte. Die oben angedeutete Typisierung soll nur Prä dominanz der einen oder anderen Zielrichtung bedeuten. Aber eben deshalb müssen wir noch einen $\mathrm{M}$ i t t e lt y p u s ansetzen, in welchem Autotelie und Heterotelie nicht mehr in einem Rangverhältnis stehen, weil sie $z u$ introzeptiver Verschmelzung gekommen sind. Für den eigentlich in $\mathrm{trozeptiven} \mathrm{Ch}$ a ra k t e r bedeutet dann etwa Dienst an Familie oder Vaterland nicht einen Verzicht auf sein individuelles Selbst, weil dieses Selbst sich eben in jenem Dienst verwirklicht und ihn auch ganz persönlich gestaltet. Ebenso im Ideotelischen: der introzeptive Mensch hat zwar Prinzipien des Handelns und befolgt sie; aber er ist nicht ihr Sklave, sondern verlebendigt und konkretisiert sie dadurch, dass er sie bei jeder Willenstat den Gestaltungsforderungen seines Ich und den konkreten Ansprüchen der Situation ein- und unter-ordnet.

Der Begriff ,,introzeptiver Charakter” stellt einen Idealtyp dar, dem keine Wirklichkeit voll entspricht. Für jeden Menschen kann es ja nur eine kleine Auslese von objektiven Zielen geben, die er zu introzipieren vermag; innerhalb dieser Bereiche ist dann in der Tat sein Charakter so einheitlich, dass es sinnlos wird, etwa danach zu fragen, ob eine einschlägige Handlung vornehmlich

i) In: Psychologie der individuellen Differenzen 1900. 
aus Egoismus oder aus Altruismus entspringe. Aber um diesen Kern lagern sich doch andere Wert- und Ziel-Bereiche, bei denen die volle Introzeption nicht gelingt; für sie bilden sich dann mehr autotele oder mehr heterotele Verhaltungsweisen aus, die sich zu Charakterzügen verfestigen können.

Hier macht sich wieder die unitas multiplex und die Weltoffenheit der Person geltend; der Charakter zerfällt zwar nie in Teile, aber er steht unter verschiedenen $P$ e r s pektiven, je nach dem Aufgabenbereich, für den ein Mensch charakterologisch erfasst werden soll. Es ist eigentlich eine Abstraktion im luftleeren Raum, wenn man meint, bei irgend einem $X$ „d e n Charakter an sich" beurteilen zu können. Gerade für den praktischen Charakterdeuter ist es unbedingt erforderlich, die „Perspektivik des Charakters" zu beachten. Von der Lebenssphäre der Familie aus schaut das Charakterbild eines X. anders aus, als von der des Berufs oder der öffentlich-politischen Betätigung her. Und es schaut nicht nur anders aus, sondern es is $t$ auch ein anderes, weil eben hier andere Strukturmomente des Charakters die Hauptbetonung erhalten. Wir stossen hier also noch einmal auf eine Elastizität des Charakters, die sich ebenso unterscheidet von der Annahme eines in sich selbst geschlossenen und starren „Grundcharakters”, wie von der Annahme fester und gebietsunabhängiger Charaktereigenschaften. Starker Eigennutz im Berufsleben, Selbstlosigkeit bis zur Schwäche in den familiären Beziehungen und introzeptive Einschmelzung der Ziele des Gemeinwohls in die persönliche Selbstformung beim öffentlichen Wirken - diese drei Charakterzüge können sehr wohl in einem und demselben Menschen vorhanden sein, ohne sich zu widersprechen, ja, ohne dass die Ganzheitlichkeit des Charakters bedroht wäre; diese wird nur reicher an Spannungen und an Dimensionen, daher auch mannigfaltiger in ihren Kontakten mit den verschiedenen Bereichen der personalen Welt.

Methodisch ergibt sich hieraus die Forderung, die $\mathrm{S} \mathrm{y} \mathrm{m}$ p t o m e, aus denen man einen Charakter erdeutet, jeweilig von der Perspektive abhängig zu machen, unter der man die Deutung vollzieht. Wenn etwa der Graphologe aus der Handschrift allgemeine Eigenschaften wie „Zuverlässigkeit", „Pedanterie”, ,Sorglosigkeit in Gelddingen" u.s.w. ableitet, so ist damit noch nicht gesagt, ob unter der speziellen Perspektive der charakterologischen $\mathrm{B}$ e $\mathrm{r}$ u f s-Eignung diese $Z$ üge eine 
wesentliche Rolle spielen. Umgekehrt wird eine $\mathrm{E}$ h e-Beratung nicht ohne weiteres das Recht haben, aus gewissen, etwa im Berufsleben aufweisbaren, Charakterzügen auf Geeignetheit oder Ungeeignetheit für eheliches Zusammenleben zu schliessen. Wir rühren hier an einen der Hauptmängel moderner Charakterdeutungs-Methoden; ihre nähere Erörterung gehört aber in Spezialuntersuchungen.

Die beiden anderen Gruppen von Charakterzügen, die zu besprechen sind, haben das Gemeinsame, dass sie nicht mehr i nh a lt li ch (durch besondere Zielbereiche) determiniert sind. Sie beziehen sich auf mehr form a le Momente des Willens: die Dynamik und die Struktur.

\section{Dynamische Züge und Typen}

Die Anwendung personaler $\mathrm{K}$ r a f $\mathrm{t}$ auf Willenshandlungen wird, wie wir früher sahen, aus dem Reservoir des Trieblebens gespeist. Aber so wesentlich dieser Ursprung auch sein mag, ebenso wesentlich ist, dass die personale Dynamik nicht in der triebhaften Betätigung beschlossen bliebt, sondern hinübergeführt wird in die Sphäre prospektiver Bedürfnisse und der zu ihrer Erfüllung dienenden Willenshandlungen. Erst hier findet jene Organisierung und Verfestigung der dynamischen Vorgänge statt, die die dauernde Wirksamkeit des Charakters gewährleisten. Diese dynamische Ordnung hat eine positive und eine negative Seite.

Positiv tritt an die Stelle ungeregelter Kraftentladung, wie sie das Triebleben zeigt, die sinngeleitete Kraftökonomie. Zum entwickelten Charakter gehört es, dass er mit den vorhandenen Kräften sparsam umgehe, um sie dann auf die jeweils erforderlich werdenden Willenshandlungen um so entschiedener konzentrieren und um so sicherer bis zum Ziele durchhalten zu können.

Dann aber besteht die negative Aufgabe der $\mathrm{H} \mathrm{e} \mathrm{m} \mathrm{m} \mathrm{u} \mathrm{ng}$; die dem geordneten Willen reservierte Kraft muss sich behaupten sowohl gegen die, in der Person wirksamen, unmittelbaren Triebdynamismen, wie gegen solche Energieen, die vo n a u ss e $n$ her der Person die Regel des Verhaltens und Tuns aufzuerlegen suchen.

Diese Hemmungsleistung des Charakters ist so bedeutend und 
drängt sich auch der Beachtung so stark auf, dass man zuweilen in ihr geradezu das Wesen des Charakters überhaupt erblickt hat. Hieran ist so viel richtig, dass nur dort ein Charakter sich wirklich entwickeln und erhalten kann, wo er die Gegenkräfte in der eigenen Person und in der Aussenwelt zu überwinden vermag. Ein Wesen, das ganz und gar aus der Triebhaftigkeit heraus lebt, hat ebenso wenig "Charakter", wie jenes, das sich das dauernde Gesetz seines Verhaltens und Tuns von aussen her widerstandslos auferlegen lässt. So wird der Charakter gerade durch diese $\mathrm{k}$ ä m p f e r i s c h e Leistung zum Symbol jener höheren Menschlichkeit, die sich über animalische Triebaktivität und dumpf unpersönliche Passivität heraushebt zu wahrhaft personaler und vergeistigter Tat. Um so eindrucksvoller ist diese Hemmungsfähigkeit, weil sie ja die personalen Kräfte wendet gegen jene Ursprungsquellen, aus denen sie geflossen sind. Denn in der Tat: bei allen Trieb-Regulierungen und -Überwindungen, die der charaktergefestigte Mensch vollzieht, bleibt immer ein letzter Rest jenes urtümlichen Zusammenhanges bestehen: man lehnt sich auf gegen das in der eigenen Tiefe ruhende „Reich der Mütter". Gerade darin liegt die Grösse, aber auch die Tragik des Kampfes zwischen Charakter und Triebleben. Die Ureinheit der $\mathrm{P}$ e r s o n, in die beides eingebettet ist, lässt sich eben nie verleugnen.

Indessen wäre es falsch, in dieser negativen Aufgabe des Hemmens das Wesen der Charakterdynamik zu erblicken. Denn die Hemmung ist ja nur Mittel zu dem Zweck: Freimachung der Kräfte für positive Ziele. Weil und sofern ungeregelte Triebe und äussere $Z$ wangseinwirkungen eine konsequente, stetige und weit ausschauende Willenshaltung hindern, müssen sie gehemmt werden - und damit können nun die personalen Kräfte eben jener Willenshaltung dienstbar gemacht werden: das ist die eigentlich dynamische Leistung des Charakters. Von hier aus sind daher auch die wesentlichen Charakterzüge dynamischer Art abzuleiten. „Willensstärke” bedeutet die Fähigkeit, Kraft auf den eigentlichen Willensakt zu konzentrieren, „Willensausdauer" die Fähigkeit, weit ausgreifende Willenshandlungen durch alle Phasen durchzuführen, "Willenstreue” die Fähigkeit, viele Willenshandlungen über weite Zeiträume hinaus unter sich in Einklang zu bringen. In ihrer Gemeinsamkeit bilden diese 
Eigenschaften den Zug der „Ch a ra kt e r s tärke”. — „Charakterschwäche" ist dagegen gekennzeichnet durch geringe Intensität und Ausdauer bei den einzelnen Willenshandlungen, wie durch Ungleichmälsigkeit in der Abfolge entsprechender Willenshandlungen. Beide Eigenschaften sind dann natürlich auch bestimmend für den Grad der Hemmungsfähigkeit gegenüber den äusseren und inneren Störungsmomenten des Charakters.

Ausser dem rein quantitativen Gesichtspunkt führt aber auch die qualitative Beschaffenheit der Kraftanwendung zu bestimmten Charaktertypen. Insbesondere ist hier malsgebend, ob die Dynamik dem triebartigen Äusserungsmodus nahe steht und daher stossweise und unvermittelt zu Kraftentladungen führt, oder ob die Unterstellung unter geistige Ordnungs- und HemmungsPrinzipien weitgehend dem Tun das Gepräge gibt. Es sind also die antitypischen Charakterzüge der Unbeherrschtheit und Beherrschtheit des Handelns, deren Untertypen (Impulsivität und Gemessenheit, Sorglosigkeit und Sorgfalt, Faulheit und Fleiss, Unordnung und Pedanterie u.s.w.) hier nicht weiter verfolgt werden können.

\section{Strukturelle Züge und Typen}

Strukturmerkmale des Charakters mussten schon mehrmals beiläufig erwähnt werden; sie erfordern aber eine eigene Erörterung. Es handelt sich darum, dass das Ge s a m t g e f ü g e des Charakters gewisse formale Eigentümlichkeiten zeigt. Bemerkenswert ist, dass diese Momente der Charakterbeschaffenheit erst vor relativ kurzer Zeit wissenschaftlich entdeckt worden sind. Es sind eben ausgesprochene Ganzheitseigenschaften; und früher war das charakterologische Interesse einseitig den Teileigenschaften zugewandt gewesen.

Da der Charakter unitas multiplex ist, so hängt seine Struktur vor allem davon ab, ob das Einheits- oder das Vielheits -Moment in den Vordergrund tritt. Die - ja niemals aufgebbare - Einheit der Persönlichkeit kann sich charakterlich so auswirken, dass die verschiedenen Teilbereiche und Teildynamismen des individuellen Strebens sich von vorn herein zum harmonischen Ganzen runden, einander stützen, bedingen und vertreten - oder aber so, dass ihre Heterogeneität, ja Gegensätzlichkeit zu ständigem 
Kampf, zu innerer Spannungsgeladenheit, zum abwechselnden Sichvordrängen und Zurïcktreten führt. Ha r m o $\mathrm{n}$ is $\mathrm{ch}$ e Schlichtheit und kämpferische Gespalten$h$ e it sind also hier die antitypischen Charakterzüge.

Unter den modernen Typologen sind es besonders Kretschmer und Jaensch, die ihre Gliederung auf den Gegensatz Einheitlichkeit/Gespaltenheit gründen. Kretschmer's Ausdruck „schizothym” bedeutet ja „spaltmütig”. Wenn Kretschmer den Gegentyp „zyklothym" (wörtlich übersetzt: „kreismütig") nennt, mag man dieses Wort im Sinn des abgerundet Harmonischen fassen.

Der eigentliche Ursprung der Bezeichnung ist freilich ein anderer. Kretschmer als Psychiater ist nämlich von den beiden grossen Formenkreisen der Geisteskrankheiten ausgegangen: dem Spaltungsirresein (Schizophrenie) und den zirkulären oder zyklischen (manisch-depressiven) Psychosen, die zwischen einem Ubermals von unlustvoller Depression und lustvoller Exzitation schwingen. Kretschmer fand dann innerhalb der Normalität die gleichen Typenunterschiede und wandelte für sie die Ausdrücke in der oben genannten Weise ab. (Die Zwischenformen $z$ wischen voller Krankhaftigkeit und voller Normalität erhielten die Bezeichnungen ,schizoid" und ,zykloid").

Ubrigens ist die Typeneinteilung Kretschmer's nicht ausschliesslich auf Willenshaltungen und damit auf Charakterzüge eingeschränkt; sie stellt solche Züge in den Vordergrund, die mehr dem Bereich des Temperaments angehören. (vgl. hierzu Kap. XXXI).

Auch Jaensch's Einteilung: „integrierter"/,desintegrierter” Typus ist nicht in erster Linie charakterologisch gemeint, sondern betrifft mehr die geistige Struktur. Während der „desintegrierte" Mensch bei der geistigen Bewältigung der Welt die einzelnen Funktionsgebiete, Sinnessphären u.s.w. in deutlicher Trennung arbeiten lässt, ist der ,integrierte" Mensch mit seiner ganzen Person daran beteiligt, sodass die scharfen Funktions- und Gebiets-Trennungen für ihn irrelevant werden.

Wir beschränken uns mit der Scheidung von "Schlichtheit” und "Gespaltenheit" auf das eigentlich Charakterologische. Und zwar suchen wir den Gegensatz dadurch zu verdeutlichen, dass wir den "schlichten" und den ,gespaltenen" Charakter als I dealtypen darstellen. Die psychologische Wirklichkeit 
kennt nur mehr oder minder starke Annäherungen an diese reinen Formen.

Beim s chli chte n Charakter verläuft die Verbindungslinie, die aus den triebhaften Untergründen zu den Bedürfnissen mannigfacher Art, von diesen zu stabilen Willenshaltungen und endlich zu deren struktureller Einheit im Charakter führt, relativ stetig und ungebrochen. Die höheren Formen des Wollens übernehmen ihrerseits viel von der Selbstverständlichkeit des Trieblebens; und sogar die abstrakten Grundsätze und Ideale sind nicht so sehr in ihrer schroffen Gegensätzlichkeit zu den Neigungen und Augenblicksregungen wirksam, als dass ihre Befolgung selbst aus Neigung vor sich geht.

Bezüglich der Zielbereiche braucht der schlichte Charakter durchaus nicht arm zu sein und der Mannigfaltigkeit zu ermangeln. Gewiss gibt es solche, deren Schlichtheit in Einseitigkeit besteht; man denke etwa an den „Familienphilister”, dessen Interessen und Willenshaltungen von der Familie völlig absorbiert werden, sodass für andere Wertbereiche keine Introzeptionsmöglichkeit besteht. Aber es gibt auch jene andere Schlichtheit, in der die Vielheit der Zielrichtungen von vorn herein zum Einklang gebracht ist; ein solcher Mensch besitzt eine Feinfühligkeit für die Akzentverteilung, die den Anforderungen der verschiedenen Zielbereiche in jeder Einzelsituation zukommt.

Aus den genannten Gründen spielt die be w u s s t e Willensmotivation im schlichten Charakter eine relativ geringe Rolle. Denn die besonderen Ursachen für reichere Entwicklung von Phänomotiven: der Motiv-K on f li kt, das Bedürfnis, die Genomotive $\mathrm{zu}$ verschleiern, und das Verlangen, die Tat zu rechtfertigen, treten ja in einer vorwiegend harmonischen Willenshaltung sehr zurück. Soweit Phänomotive vorkommen, werden sie meist als adaequate Äusserungen der Genomotive gelten können. Es wird also eine Umdeutung auf Grund der Motiv-Heterogonie nicht erforderlich sein ${ }^{\mathbf{1}}$ ).

Im g e s p a l t e n e n Charakter herrscht Unstimmigkeit und Spannung. Dies gilt vor allem bezüglich der beiden grossen Funktionsarten der Strebungen: die aus der Triebdynamik gradlinig

1) Das Bestreben der Tiefenpsychologie, weitgehend hinter manifesten Motiven a ndersartige "eigentliche" Motivationen zu suchen, kann daher bei schlichten Charakteren leicht auf Irrwege führen. 
erwachsenden Bedürfnisse und Neigungen sind gegensätzlich zu den, in bewusstem Wählen, Normsetzen und Entscheiden sich bekundenden Willenshaltungen. Der gespaltene Charakter kann die positive Durchführung und Organisierung seiner Willenshandlungen nur durchsetzen in fortwährender $\mathrm{H} \mathrm{e} \mathrm{m} \mathrm{m} \mathrm{u} \mathrm{ng}$ sa $\mathrm{r}$ b e i t gegenüber den vital verwurzelten Strebungen. Diese Hemmung kann in vollem Lichte des Bewusstseins vor sich gehen als Konflikt der nebeneinander bestehenden Phänomotive, als Kampf zwischen „Sinnlichkeit und Sittlichkeit”, zwischen „Neigung und Pflicht". Sie kann aber auch in die personale Tiefe hinein wirken, indem sie den triebhaften Genomotiven verwehrt, in Phänomotiven adaequat bewusst zu werden. Während die erste Form der Hemmung, also das b e w u s s t e Gegeneinanderstreben von Neigung und Pflicht, insbesondere in moralphilosophischen Betrachtungen betont wird (Kant!) ${ }^{1}$ ), ist die zweite Form, bei der der Konflikt $z \mathrm{w}$ is $\mathrm{ch}$ e $\mathrm{n}$ dem bewussten und dem unbewussten Streben ausgetragen wird, das Thema der Tiefenpsychologie, welche ja auch die Begriffe der „Verdrängung ins Unbewusste” und der symbolischen „Ubertragung” geschaffen hat.

Kann denn - so wird man fragen - bei einem solchen Auseinanderklaffen von Triebsphäre und Willenssphäre überhaupt noch von Einheit des Charakters und Ganzheit der Person gesprochen werden? Bedeutet nicht die "Spaltung" geradezu eine Zerreissung des Menschen in Teile, die nichts mit einander zu tun haben? Würde man diese Frage bejahen, dann dürfte man nicht einmal mehr von dem Konflikt der beiden Sphären sprechen. In Wirklichkeit ist gerade die zwischen ihnen bestehende Gegensätzlichkeit ein Beweis dafür, dass sie auf einem gemeinsamen Boden stehen, dass ihre Spannung zugleich der Totalstruktur des Menschen das Gepräge verleiht. Es handelt sich nicht um zwei gegeneinander gleichgültige Tatbereiche, von denen bald das eine, bald das andere den Menschen beansprucht; sondern sie machen sich fortwährend jenen ganzen Menschen streitig, zu dem sie beide gehören und ohne den sie ihren Sinn verlieren. Ja

\footnotetext{
1) In der Tat stellt sich heraus, dass gewisse grundsätzliche Unterschiede innerhalb der Moralphilosophie mit der oben besprochenen Typenscheidung zusammenhängen. So vertritt Shaftesbury das Ideal des harmonisch schlichten Charakters nach dem Vorbild der antiken $x \alpha \lambda o x \alpha \gamma \alpha \vartheta i \alpha$, während Kant nur den kämpferischen Charakter als Voraussetzung sittlichen Handelns gelten lassen will.
} 
es ist schon zu viel gesagt, wenn wir der Triebsphäre einerseits, dem Willen andrerseits die Fähigkeit zuschreiben, selber gegen den anderen Faktor zu „kämpfen”; denn es ist die mit sich identische gesamtpersonale Entelechie und Dynamik, welche sich nur in verschiedenen, mit einander interferierenden, Ausstrahlungen entfaltet. Nicht der Personteil A kämpft mit dem Personteil $B$, sondern die Person $k$ ämpft $m$ it $s i c h$; sie spaltet sich auf, um immer wieder die Spaltung durch ihre Einheit und in ihrer Einheit $z u$ überwinden.

Im gespaltenen Charakter spielt die B e w us th eit eine ganz andere Rolle als im schlichten. Denn Bewusstsein ist ja ganz wesentlich Konflikt-Erzeugnis und -Spiegelung. Darum gibt es in einem solchen Menschen ein Gewoge von Phänomotiven vor und nach den Taten; und diese Phänomotive bedürfen nun allerdings der eingehenden Deutung und eventuell der Umdeutung, da die hinter ihnen wirksamen, unbewussten Genomotive von ihnen zum Teil abweichen. Die tiefenpsychologischen Symboldeutungen sind also ganz wesentlich auf die gespaltenen Charaktere zugeschnitten und haben auch hier eine partielle Berechtigung.

Die Verschiedenheiten des schlichten und des gespaltenen Charakters seien schliesslich an gewissen dimensionalen Merkmalen veranschaulicht.

In der $\mathrm{V}$ e r t i k a l-Dimension zeigt der schlichte Charakter Einstimmigkeit von personaler Tiefe und Oberfläche, also von Sein und Erscheinung. Dem gespaltenen Charakter kommt gerade in der Tiefenrichtung Unstimmigkeit $\mathrm{zu}$; seine Manifestation an der Oberfläche ist nicht identisch mit seinem Wesen in der Tiefe. Darum ist sein Wollen, auch wenn es ernst aussieht und subjektiv ernst gemeint sein mag, nicht immer in jener undiskutablen Weise ernsthaft wie beim schlichten Charakter, sondern oftmals verkapptes Versuchen und seiner selbst unbewusstes Spielen. Das „Ernstspiel”-Verhalten (s. S. 496) ist also hier viel stärker ausgeprägt, als beim schlichten Menschen, bei dem die Scheinwelt des Spiels und die Seinswelt des Ernstes sich nicht kreuzen und stören.

In der $\mathrm{B}$ r e it e n-Dimension macht sich die oben erwähnte „Perspektivik des Charakters" typologisch bemerkbar. Beim 
schlichten Charakter ist ihre Bedeutung geringer; die mannigfachen Bereiche der Willenszielung zeigen gleichsinnige Reaktionsweisen. Der gespaltene Charakter dagegen kann jeweils anders aussehen und sich geben, je nach dem er sich in Erotik, Familie, Beruf, Geselligkeit, Politik, religiösem Leben u.s.w. betätigt.

In der Z e i t-Dimension verläuft die Entwicklung des schlichten Charakters stetig, die des gespaltenen sprunghaft. Es besteht dann eben auch Spaltung zwischen den einzelnen Lebensphasen; der Charakter ist nie ein volles Definitivum; er bietet nicht jene Möglichkeit des Voraussagens für künftiges Verhalten, wie es dem eigentlichsten Begriff des Charakters entspräche.

Es gibt ferner bestimmte Lebensabschnitte, in welchen der Charakter besonders zur Gespaltenheit neigt. Dies gilt speziell von der Pubertätszeit. Innere Unstimmigkeit, schillernde Problematik und vorwiegendes Ernstspielverhalten sind kennzeichnende Züge des jugendlichen Charakters und können sich zeitweilig selbst bei solchen jungen Menschen bemerkbar machen, die der Grundanlage nach zum schlichten Typus gehören ${ }^{\mathbf{1}}$ ).

1) Allerdings wird dadurch die entwicklungstypologische Scheidung nicht verwischt $z$ wischen solchen Jugendlichen, deren Reifung $\mathrm{r}$ e 1 a $\mathrm{t}$ i $\mathrm{v}$ stetig und ohne zu heftige Krisen verläuft, und jenen, deren Entwicklung unter stürmischen Wandlungen und Erschütterungen vor sich geht. Ich habe früher diese beiden Entwicklungstypen mit den Ausdrücken ,,evolutiv"/,,revolutiv" bezeichnet. Sie sind mit der oben besprochenen Typenscheidung nahe verwandt. 


\title{
VIERUNDZWANZIGSTES KAPITEL
}

\author{
S U G G E T I O N
}

\section{DER BEGRIFF}

Wir besprechen hier einen Begriff, der in erster Reihe $\mathrm{s}$ o $\mathrm{z}$ i a $\mathrm{l}$ psych ischer Natur ist und sich daher nicht eindeutig in eine der Kategorieen einordnen lässt, welche die Psychologie der Einzelperson beherrschen. Da aber dieser soziale Beeinflussungsprozess doch vor allem die Sphaere des Willens und Handelns betrifft, so erscheint es am angemessensten, ihn hier $z u$ erörtern.

An einer früheren Stelle (S. 126) hatten wir "homogene" von ,heterogenen" Reactionen unterschieden.

Ho mogen heisst eine solche Reaktion, in welcher die Antwortshandlung dem äusseren Einfluss ähnlich ist. Sofern hierbei ä ussere Handlungen vollzogen werden, haben wir es mit $\mathrm{Nach}$ a hm ungen zu tun. Wenn dagegen die Anähnelung in bestimmter Weise auf psychische Akte übergreift, dann liegt S u g gestion s wirkung vor.

Das Wort "Suggestion" wurde zuerst in einem sehr engen Sinn in die Wissenschaft eingeführt; man verstand darunter die abnorme Beeinflussung, die im Zustande der Hypnose möglich ist. Bekanntlich vermag der Hypnotiseur dem künstlich eingeschläferten Menschen in gewissen Grenzen ,seinen Willen aufzuzwingen"; - d.h. der Hypnotisierte, der sonst gegen die Eindrücke der Aussenwelt völlig abgeschlossen ist, nimmt Anweisungen des Hypnotiseurs als Befehle auf, gegen welche ein Widerstand nicht möglich ist; er befolgt sie ohne Wissen und ohne Willen.

Später erkannte man, dass solche in der Hypnose gegebenen Anweisungen auch noch wirksam sein konnten, nachdem der 
Hypnotisierte wieder geweckt war: „Posthypnotische Suggestion." Endlich wurde man darauf aufmerksam, dass die Versetzung in den hypnotischen Zustand überhaupt nicht erforderlich sei für derartige Wirkungen; denn auch während des Wachzustandes kann eine Willenseinengung bei einem Menschen durch einen anderen herbeigeführt werden: „Wachsuggestion.”

Damit war der Begriff der Suggestion in die allgemeine Psychologie des normalen Menschen eingeführt. Denn nachdem man einmal hellsichtig für solche Übertragungsvorgänge geworden war, entdeckte man sie allerorten innerhalb des Alltagslebens und in durchaus normalen Situationen. Wenn diese Suggestionen auch meist nicht in so auffallenden, ja erschreckenden Formen auftraten, wie in der Hypnose, so war dafür ihre Breitenwirkung um so bedeutender, da schliesslich kein Verhalten und Erleben des Menschen von ihnen frei zu sein schien, und da sie sich zu starken massenpsychischen Erscheinungen, den sogenannten ,Massensuggestionen" zusammenballten.

So steht jetzt die Psychologie vor der Aufgabe, der übertriebenen Verallgemeinerung dieses Begriffs einen Damm entgegenzusetzen. Wenn man nämlich der hier und da merkbaren Neigung nachgibt, alle Übertragungen und Ausbreitungen von Kenntnissen, Gesinnungen und Willensimpulsen als Suggestionen zu bezeichnen und damit die Funktion der Erziehung, der Belehrung, der Überredung, der politischen Meinungsbildung u.s.w. ganz in Suggestionswirkungen aufzulösen, dann hat das Wort völlig sei-: nen Sinn verloren und ist in der Wissenschaft unbrauchbar.

Wir definieren: ,Suggestion is t un it telbare Übertragung (bezw. Übernahme) einer Stelll u n g n a h m e" - und erläutern die Hauptmerkmale dieser Definition. Hierbei sei der Faktor, der die Suggestion e r z e u g t, mit S bezeichnet; S kann eine Person sein (,Suggestor"), aber auch eine Personenmasse, eine Sache, ein Vorgang. Der Empfänger der Suggestion heisse E.

a) Nur dort liegt Suggestion vor, wo eine bestimmte St e 1$\mathrm{l} \mathrm{u} \mathrm{ng} \mathrm{n}$ a h m e in dem E erzeugt wird. Die Übermittlung von Kenntnissen und Fertigkeiten von $\mathrm{S}$ zu E, oder die Beibringung von Verhaltungsmafsregeln undVerhaltungsweisen, ist an sich keine Suggestion. Nur das Stellungnehmen - also die innere e i g e n e Entscheidung, das Eintreten der Person für oder wider einen im 
Bewusstsein geweckten Inhalt-ist einer suggestiven Beeinflussung zugänglich. Es entsteht daher die Paradoxie, die jedem wirklichen Suggestionsempfang eigentümlich ist: dass der Selbständigkeits $g \mathrm{l}$ a u b e des $\mathrm{E}$ im Widerspruch steht zu der tatsächlichen Unselbständigkeit seines Stellungnehmens. Der Mensch glaubt etwas mit seinen e i g e $\mathbf{n}$ e $\mathbf{n}$ Sinnen wahrzunehmen, oder glaubt $\mathrm{v}$ on $\mathrm{sich}$ a u s ein Wertgefühl oder ein Werturteil gewonnen zu haben, das ihn Ja oder Nein sagen lässt zu irgend einem gegebenen Tatbestand, oder glaubt seinen Willensentschluss aus seinen persönlichen Motivationen erarbeitet zu haben - und ist doch in Wirklichkeit nur der Übernehmer und Nachahmer der Stellungnahme eines Anderen.

b) Nicht jede Stellungnahme, die jemand von einem anderen übernimmt, fällt unter den Begriff der Suggestion. Wenn die Beeinflussung ver $\mathrm{m}$ i $t \mathrm{t}$ e $\mathrm{l}$ t wird durch solche geistigen Hilfsmittel, die dem $\mathrm{E}$ erlauben, sein Stellungnehmen selbst $\mathrm{zu}$ wählen, zu begründen und zu kontrollieren, dann haben wir es mit Unterricht und Willenserziehung zu tun, nicht mit Suggestion. Der Begriff Suggestion ist auf diejenigen Vorgänge zu beschränken, in denen die Stellungnahme von $\mathrm{S}$ auf $\mathrm{E}$ ohne solche $Z$ wischenglieder vor sich geht, wo also $\mathrm{de} r \mathrm{bl}$ os s e U m s t a nd, dass S diese Stellungnahme vormacht, ge nügt, um E zu ihrer Nachahmung zu veranlassen.

c) Daher gehört zur Suggestion eine Totalbeziehung zwischen $\mathrm{S}$ und $\mathrm{E}$, eine $\mathrm{At} \mathrm{mosph}$ a e r e, welche Beeinflusser und Beeinflussten gemeinsam umfängt. Es ist eine zunächst ganz e i n g e b e t t e t e Wirkung, die erst sekundär die Einzelbereiche und Akte des Stellungnehmens bestimmt. E reagiert gesamtpersonal auf S; er verzichtet auf sein individuelles geistiges Tun und schwingt mit in jenen Schwingungsrhythmen, die der Eigenmelodie des $\mathrm{S}$ zukommen. Nas ist natürlich nur ein Bild; aber gerade solche gesamtpersonalen Tatbestände sind ja dadurch gekennzeichnet, dass sie der Analyse widerstehen und nur umschrieben werden können.

Wir haben nunmehr zu untersuchen, wie sich die zweigliedrige Suggestionsbeziehung in jedem der beiden Glieder $\mathrm{S}$ und $\mathrm{E}$ darstellt. Wir beginnen, aus bald verständlichen Gründen, mit $\mathrm{E}$. 


\section{EMPFANG DER SUGGESTION}

Drei Bedingungen gehören dazu, um in irgend einer Person $\mathrm{E}$ eine Suggestionswirkung zustande zu bringen.

E muss erstens eine personale Gesamtbeschaffenheit besitzen, welche den Verzicht auf eigenes Stellungnehmen und die Übernahme des fremden begünstigt: $S$ u g g e s t i bilität. Diese Eigenschaft hat verschiedene Aspekte; in ihr kann ebenso Unselbständigkeit und Bequemlichkeit enthalten sein, wie Weltaufgeschlossenheit; Kritiklosigkeit ebenso wie Gläubigkeit; Mangel an Initiative ebenso wie Hingabebedürftigkeit. Diese Verbindung von negativen und positiven Merkmalen ist für das ganze Gebiet der Suggestion wichtig und wird uns noch mehrmals begegnen.

Eine weitere Voraussetzung für das Zustandekommen einer Suggestion ist die Schaffung der oben erwähnten „Gesamtatmosphaere" durch die Sit u a t i o n. E unterliegt eigentlich niemals bloss einzelnen Suggestionsreizen, sondern stets einer suggestiven Umweltkonstellation im ganzen.

Für das Kleinkind stellt das Zusammensein mit der Mutter eine solche Situation dar. - Der einfache Mann, der zum ersten Mal als Zeuge vor Gericht steht, empfä̉ngt schon von diesem Milieu her eine starke potentielle Suggestion, noch ehe irgend eine aktuelle Suggestion, etwa in Form des Verhörs, auf ihn ausgeübt worden ist. - Das Beieinander gewaltiger Menschenmassen: bei Wettspielen, in politischen Demonstrationen u.s.w. schafft gleichfalls jene unbeschreibbare Atmosphaere, in welche jeder Einzelne eintaucht, um sich den anonymen Impulsen hinzugeben, auch in seinen Stellungnahmen.

Man sieht aus diesen Beispielen, dass es besonders gefühlsgesättigte Situationen sind, welche das Zustandekommen von Suggestionen begünstigen; und zwar handelt es sich hierbei um solche Gefühle, die der Entwicklung eines ruhigen, selbständigen Urteils hinderlich sind.

Endlich hängt die Wirksamkeit der Suggestion auch von dem personalen B e r e i c h ab, der durch die Beeinflussung in Anspruch genommen wird. Kein Mensch hat eine allgemeine Suggestibilität bestimmten Grades in dem Sinne, dals sie sich gleichmäfsig auf alle Gebiete des Interesses und der Betätigung erstreckte. Vielmehr gibt es Gebiete, die der Mensch in bevorzugter 
Weise mit eigenen und geistig vorbereiteten Entscheidungen bearbeitet, und auf denen er daher widerstandsfähiger gegen Suggestionen ist; oft sind es die Gebiete des spezifischen Berufs. Da aber eine solche selbständige Geistesarbeit einen starken Kraftaufwand erfordert, so bleibt der Stellungnahme auf anderen Gebieten, aus Kraftökonomie oder aus Trägheit, diese Selbstentscheidung verwehrt; und man begnügt sich mit der bequemeren Übernahme fremder Stellungnahmen ohne eigene Überlegung und Kritik. So besitzen viele Menschen im Bereich ihrer spezifischen Sachkenntnis eine starke Selbständigkeit und Unbeeinflussbarkeit des Urteils und Willens; sobald sie sich aber auf ein anderes Gebiet, z.B. das der Politik begeben, können sie zum Opfer gröbster Suggestionseinflüsse werden und Schlagwörter mit einem Eifer weitertragen und befolgen, als ob diese reife Produkte ihrer selbsterarbeiteten Stellungnahme wären.

Eine weitere Begrenzung kann die Suggestibilität aus der Sphäre des Willens erfahren. Wenn die durch den Suggestor z u g e $\mathrm{m}$ u t e t e Stellungnahme stark eingewurzelten Richtungen des Willens widerspricht, dann können von diesen Hemmungen ausgehen, die selbst einen sonst recht beeinflussbaren Menschen suggestionsfest machen. Nur s o l c h e S t e ll ungnahmen sind suggerierbar, die eine gewisse Resonanzineigenen Willenshaltungen finde $n$.

Diese Feststellung ist auch von grosser p r a k t is che $\mathrm{r}$ Wichtigkeit, namentlich bezüglich der Frage, welchen Anteil die Suggestion beim Zustandekommen von Verbrechen habe. Gewiss kann die Lektüre von Detektivgeschichten oder der Anblick von Verbrecherfilmen auf Jugendliche in starkem Malse suggestiv wirken, aber doch nur dann, wenn eine gewisse Anlage diesen Einflüssen entgegenkommt. Auch bei Suggestionen herrscht das Konvergenzprinzip; niemals ist der Mensch ein rein passives Opfer für beliebige Suggestionen; er verhält sich auf Grund seiner Willensstruktur s e le k t i v zu ihnen.

Zuweilen hat man der sogenannten pos th y p n o t is c h en Suggestion eine unheimliche Wirkungsmöglichkeit zugeschrieben. $\mathrm{Da}$ der Mensch in der Hypnose völlig willenlos sei, so glaubte man, die Suggestion eines Verbrechens, die er in diesem Zustande empfangen habe, müsse später mit unwiderstehlicher Gewalt 
zur Ausführung drängen. Bisher ist aber noch nicht ein einziges Mal ein solcher Fall nachgewiesen worden, und das ist durchaus verständlich, da selbst in der Hypnose jene Widerstände der Willenshaltung, wenn auch völlig unbewusst, wirksam sind.

Ein interessantes Beispiel hierfür, das freilich nichts mit kriminellen Fragen zu tun hat, verdanke ich einer mündlichen Mitteilung von Dr.

- Lundholm (Duke University, Durham, N.C.). Eine sehr leicht hypnotisierbare Dame, die sonst jede während der Hypnose erteilte Suggestion nach dem Erwachen unweigerlich ausführte, versagte bei einer bestimmten Aufgabe, und zwar immer wieder. Es war ihr suggeriert worden, sie solle nach dem Erwachen die Zahlenreihe von 1-10 hersagen, aber unter Fortlassung der 8 . Sie sagte die Reihe auf, aber vermochte die 8 nicht fortzulassen. Als Ursache gab sie an, dass sie Mathematikerin sei, und dass sie, aus ihrer mathematischen Einstellung heraus, diese Unregelmärsigkeit innerlich nicht habe akzeptieren können. Hier war die innere Hemmung stärker als der sonst so mächtige Suggestionseinfluss.

\section{AUSÜBUNG DER SUGGESTION}

Während der Empfänger einer Suggestion E stets ein Einzelindividuum sein muss, liegen bei dem beeinflussenden Faktor $\mathrm{S}$ verwickeltere Bedingungen vor.

\section{Suggestive Persönlichkeiten}

In zahlreichen Fällen ist auch hier ein Einzelindividuum wirksam. Führer auf allen Gebieten sind fast stets zugleich grolse Suggestoren, mag es sich um Erziehung, Politik, Religion, Wirtschaft handeln. Wir brachten ferner soeben die Beispiele von der Mutter, die auf ihr Kind, von dem Richter, der auf den Angeklagten und die Zeugen suggestiv einwirkt. Die Fähigkeit eines Menschen zu solchen Wirkungen wird als $\mathrm{Sug}$ g e s t i vi t ä t bezeichnet; und wiederum stehen wir vor einem gesamtpersonalen Tatbestand, der einer Analyse widerstrebt. Man mag noch so sehr die Stimme, den Blick, die Rednergabe, die Geistesgegenwart, die Klugheit, die Willensstärke und andere Sondereigenschaften im einzelnen heranziehen, um solche Wirkung zu erklären: im Grunde ist es die Person in ihrer unauflösbaren Totalität, die sich anderen Menschen richtunggebend aufzwingt; und 
erst von dieser Totalbeschaffenheit aus gewinnen dann Augenausdruck, Beredsamkeit u.s.w. jene ,,Strahlbedeutung” als suggestive Kundgaben.

Allerdings gilt auch für die Suggestivität - ebenso wie oben für die Suggestibilität -, dass ihre Wirksamkeit von Atmosphaere und Partner abhängig ist. Es muss zwischen dem Suggestor und dem Suggestionsempfänger eine Resonanz bestehen, damit sich die Einflussfähigkeit des ersteren entfalten kann. So mancher Lehrer übt eine starke Suggestivwirkung auf einige wenige Schüler aus, zu denen er diesen ,Rapport” hat, während die übrige Schülerschar dem Einfluss unzugänglich bleibt.

Unter wertendem Gesichtspunkt ist Suggestivität wiederum

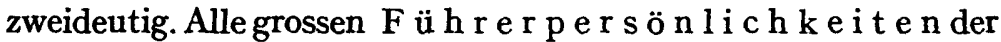
Weltgeschichte, alle Verkünder neuer Ideale, konnten ihre Taten nur durch ihre hinreissende und mitreissende Suggestionswirksamkeit vollbringen. Aber auch alles $V$ erführert u m, im grossen und kleinen, wird durch diese Eigenschaft erst möglich. Menschen von starker Suggestivität, die nicht zugleich die ungeheure, mit ihrer Fähigkeit verbundene Verantwortlichkeit spüren, können im blossen Genuss ihrer irrationalen Macht schwelgen und, unbekümmert um den Wert der Ziele, der Gefolgschaft oder einzelnen Hörigen ihre (wahre oder scheinbare) Gesinnung und Willensbeschaffenheit aufoktroyieren.

\section{Massen-und Sach-Suggestion}

Doch nicht jeder Suggestiveinfluss geht direkt von einer Einzelperson aus; er kann auch einen über-oder u n pers ö $\mathrm{n} l \mathrm{i}$ c h e n Ursprung haben. Überpersönlich ist die Wirkung von Menschenmassen, unpersönlich die von Sachen. Aber auch diese Wirkungen sind nur dadurch möglich, dass in den Massen und Sachen $\mathrm{S}$ t ell u n g $\mathrm{n}$ a h m e $\mathrm{n}$ zum Ausdruck kommen, die übernommen werden können.

Wenn sich im Theater nach dem Fallen des Vorhangs ein Sturm des Beifallklatschens erhebt, so mag ein einzelner $\mathrm{Zu}$ schauer $\mathrm{E}$ zunächst nur rein motorisch angesteckt werden: er klatscht auch. Das wäre ein blosser Nachahmungsakt. Aber die Ansteckung springt unmerklich ins Psychische über: die Stellungnahme der Begeisterung, die sich in dem Klatschen der 
Anderen manifestiert, ruft in $\mathrm{E}$ mit den nachgeahmten Ausdrucksbewegungen auch verwandte Gefühle hervor: die Suggestion ist perfekt.

Ein solcher Übergang von äusseren zu inneren Nachahmungen ist bei Massensuggestionen öfters zu beobachten. Wenn z.B. eine neue Mode auftaucht, so ist die erste Reaktion darauf ein $\mathrm{M}$ i t $\mathrm{m}$ a c h e n-wollen, woraus dann allmählich ein $\mathrm{M}$ it $\mathrm{f} u ̈ \mathrm{~h} l$ e $n$ wird. Die neue Hutform etwa wird zunächst gewählt, weil sie modern ist; aber bald ist die Trägerin überzeugt, dass sie den Hut wählte, weil er schön sei; ihre ästhetische Stellungnahme wird schliesslich so stark von der Umgebung beeinflusst, dass es ihr unbegreiflich erscheint, wie sie der früheren Hutform jemals gleiche Wohlgefälligkeitsgefühle entgegenbringen konnte.

Für Suggestion durch Sachen diene als Beispiel die Wirkung der R e k la m e. Wenn eine Stadt mit Ankündigungen einer neuen Zigarettenmarke überschüttet wird, so spricht aus jedem Plakat nicht nur die sachliche Mitteilung: Marke N. existiert, sondern die verhüllte und unverhüllte Stellungnahme: sie ist besonders gut, billig, kurz: kaufwürdig. Die suggerierte Stellungnahme kann allmählich dem Bewusstsein eines Rauchers so eingebettet werden, dass der Ursprung ganz vergessen wird; er verlangt im Laden die Marke N., nicht weil er sich erinnert, dass sie in Ankündigungen empfohlen worden ist, sondern weil er nun schon den selbstverständlichen Glauben an ihre Kaufwürdigkeit besitzt.

Die Stellungnahme, die von dem suggerierenden Faktor $\mathrm{S}$ ausgeht, um $\mathrm{E} \mathrm{zu}$ beeinflussen, muss irgendwie wahrnehmbar in die Erscheinung treten. Dagegen ist es nicht notwendig, dass eine wirkliche innere Stellungnahme dieser Art bei S vorliegt. Spielerische, unechte, fingierte Stellungnahmen können ebenso suggestiv wirken wie echte. Ob der Fabrikant der neuen Zigarettenmarke wirklich von ihrer besonderen Güte überzeugt ist, ist für die Wirksamkeit seiner Reklame gleichgültig. Der Richter, der an den Zeugen die Suggestivfrage stellt: „Hatte der Mann nicht ein Messer in der Hand?" - braucht garnicht an die Richtigkeit des Tatbestandes "Messer in der Hand des Angeklagten" zu glauben; aber der Zeuge glaubt, dass der Richter daran glaubt; und so wirkt die Frage suggestiv. ${ }^{\text {) }}$

1) Weitere Beispiele erwähnten wir schon früher: vgl. S. 230 (Binets Flaschenversuch) und S. 454 (Märchenerzählerin). 
An dieser Stelle wird nochmals die ambivalente Bedeutung der Suggestion klar. Der ansteckende Einfluss $f$ in $g$ i e r t e r St ellung a hmen hat gewiss vielfach im Leben ihren berechtigten Platz; die Wirkung der Kunst - vor allem der Schauspielkunst - beruht grossenteils darauf. Aber im Ernstleben können sie die stärksten Verheerungen anrichten. Im Wesen der Suggestion liegt ja das blinde Hinnehmen der dargebotenen Stellungnahme, also das Fehlen jeder Kritik an ihrem Echtheitsgehalt. Daher können suggestive Menschen sich geradezu herausgefordert fühlen, die Suggestibilität der Anderen durch geheuchelte Stellungnahmen auszunutzen: mundus vult decipi, ergo decipiatur. Hier liegt vielleicht der psychologische Grundunterschied zwischen der suggestiven Führernatur und der suggestiven Verführernatur: jener überträgt seine echte Stellungnahme auf seine Anhänger, dieser spielt oder fingiert Stellung-

- nahmen, um sich durch deren Ubertragung die Anderen hörig zu machen.

\section{Autosuggestion}

Bei der „A u t os ug g e s t i o n” sind die Faktoren S und $E$ in derselben Person vereinigt und nur durch zwei verschiedene $\mathrm{F}$ u n k t i o n e n repräsentiert.

Auch hier sollte man eine zu weite Fassung des Begriffs vermeiden; nicht jede Selbstbeeinflussung hat Suggestionsnatur. Ein Mensch, der durch andauernde Willensarbeit einen Fehler, eine schlechte Gewohnheit, eine Idiosynkrasie überwindet, hat nicht Autosuggestion, sondern Selbsterziehung geübt. Autosuggestion liegt nur dann vor, wenn die Wirkung nicht aus eigenem Willensentschluss und Willensimpuls, sondern aus einer, an sich willensfreien, Stellungnahme hervorgeht, wenn also ein Wunsch, eine Furcht, eine Erwartung sich umsetzen in den Glauben an die Realität ihres Inhalts.

Das Schiller'sche Gedicht „Die Erwartung” kan geradezu als Musterbeispiel gelten. Der Liebende erwartet im Garten die Geliebte; und die verschiedensten, akustischen und optischen, Eindrücke werden autosuggestiv als Anzeichen der Nahenden aufgefasst, um freilich im nächsten Augenblick als Täuschung durchschaut zu werden: 
„Hör' ich das Pförtchen nicht gehen? Hat nicht der Riegel geklirrt? Ach, es war des Windes Wehen, der durch diese Pappeln schwirrt."

„Sah' ich nichts Weisses dort schimmern? Glänzt's nicht wie seidnes Gewand? -

Nein, es ist der Säule Flimmern an der dunklen Taxuswand."

Autosuggestive Wirkung eines Wunsches liegt in folgendem Beispiel vor. Einer jungen Frau ist das Berufsgebiet oder eine besondere Liebhaberei des Mannes ursprünglich durchaus fremd und gleichgültig. Aber ihr Wunsch nach möglichst weitgehender seelischer Gemeinschaft mit dem Manne führt dann dazu, dass jene Gebiete eine Gefühlsbetonung bekommen, die allmählich mehr und mehr Echtheit und Unmittelbarkeit gewinnt. Schliesslich würde sie es weder anderen noch sich selbst eingestehen, dass ihre Musikbegeisterung oder ihr Sportinteresse, oder was es sonst sein mag, erst das sekundäre Suggestionserzeugnis einer anderen seelischen Tenden $z$ innerhalb ihrer eigenen Person sei.

Ein letztes Beispiel möge zeigen, wie auch eine streng exakte, wissenschaftliche Methode keine volle Sicherung gegen Autosuggestion gewährt.

Zur Zeit der Strahlungsentdeckungen hatte ein französischer Physiker geglaubt, eine neue Art von Strahlen gefunden $z u$ haben, deren Wirksamkeit sich darin âussern sollte, dass ein glühender Draht im Augenblick der Durchleitung der neuen Strahlen etwas heller aufleuchtete. Jedes Mal bei Einschaltung der Strahlen sah er das Hellerwerden, bei Abblenden der Strahlen das Matterwerden des glühenden Drahtes. Auch seine Assistenten sahen es - aber kein anderer Physiker konnte das Experiment wiederholen. Schliesslich musste der Entdecker bekennen, dass er sich geirrt habe. Wunsch und Erwartung hatten auf seine Sinneswahrnehmung als Autosuggestion (zugleich auf die Wahrnehmung seiner Assistenten als Fremdsuggestion) gewirkt ${ }^{1}$ ).

\section{Kontrasuggestion}

K o n t r a s u g g e s ti o n besteht darin, dass die Stellungnahme von $S$ durch die en $\mathrm{tg}$ e gengese $\mathrm{t} z \mathrm{t}$ e Stellungnahme von $\mathrm{E}$ beantwortet wird. Es gibt Menschen, welche eine Mode gerade darum nicht mitmachen, weil sie von allen Anderen als richtunggebend angenommen wird; andere, die

i) Vgl. den Bericht von Otto Sackur. 
durch eine Massenstimmung in der Kirche, bei einer Versammlung, bei einer Festlichkeit nicht mit fortgerissen, sondern in eine oppositionelle Stimmung versetzt werden. Es gibt Kinder, welche eine Speise, eine Spielsache eben deshalb heftig ablehnen, weil sie von den Erwachsenen als besonders wohlgefällig und begehrenswert dargeboten werden.

Dem äusseren Aspekt nach hat ein solches Verhalten mit Suggestion überhaupt nichts $z u$ tun; scheint es doch eine besonders starke Selbständigkeit und Unabhängigkeit zu bekunden. Aber oft genug ist das nur der oberflächliche Schein. Es gibt neben der Opposition aus individueller Stärke auch die Opposition aus Schwäche. Wohl ist der Wunsch vorhanden, sich nicht einfach mitreissen und gängeln $z u$ lassen. Aber da die Kraft $z u$ eigener Entscheidung und Willensbildung fehlt, gibt man sich doch den äusseren Eindrücken weitgehend hin - nur dass man ihr Vorzeichen umkehrt. Das blosse Neinsagen ist noch nichts weniger als Originalität; denn weder das Thema des Stellungnehmens noch die Art seiner Behandlung ist auf eigenem Boden gewachsen. Blinde Opponenten besitzen keine stärkere Widerstandsfähigkeit gegen Suggestion als blinde Nachbeter.

\section{EXPERIMENTELLE UNTERSUCHUNGEN ${ }^{1}$ )}

Als Problem der Experimentalpsychologie ist uns die Suggestion bereits in Verbindung mit Fragen der Wahrnehmungsund Erinnerungstäuschungen begegnet ${ }^{2}$ ); hier seien nur noch wenige Bemerkungen angeführt.

Man kann sowohl den S-Faktor wie den E-Faktor der Suggestion experimentell prüfen, d.h. die $S u g g$ estivität bestimmter Einflussfaktoren, und die $\mathrm{S} u \mathrm{~g}$ g e s $\mathrm{t}$ i b i l i t ä $\mathrm{t}$ bestimmter Individuen.

\section{Suggestive Faktoren.}

Ein geeignetes Objekt für die erste Problemstellung ist die

1) Umfassendere Veröffentlichungen über Suggestionsexperimente gab es vor allem um die Jahrhundertwende. Vgl. Binet's Buch ,La suggestibilité,” und viele Abhandlungen in den zwei Bänden der „Beiträge zur Psychologie der Aussage." Späterhin sind nur noch gelegentlich Einzeluntersuchungen publiziert worden.

^) Vgl. S. 230 u. S. 354 . 
Suggestivfrage. Denn die Art der Fragestellung (z.B. in Aussageuntersuchungen) ist experimentell vielfach variierbar. So wurde z.B. von Binet, sowie von Lipmann und Wendriner festgestellt, dass die fälschende Wirkung einer Verhörsfrage um so stärker war, je suggestiver die Frage formuliert wurde.

Eine Stufenleiter der suggestiven Frageformulierung in Bezug auf denselben Sachverhalt zeigt das folgende Beispiel.

Auf einem Bilde, das zu Aussagezwecken benutzt wird, befindet sich unter anderem ein Hund. Dieses Tier kann, nach Wegnahme des Bildes, in verschiedenen Weisen Gegenstand einer Verhörsfrage werden:

1) „Ist ein Tier auf dem Bilde zu sehen?" (Unsuggestive Frage).

2) Ist eine Katze auf dem Bilde zu sehen?" (Nahelegung einer falschen Vorstellung; mildere Suggestion).

3) „Ist nicht eine Katze auf dem Bilde zu sehen?” oder: „Nicht wahr, eine Katze ist doch auf dem Bilde?" (sogenannte „Erwartungsfrage". Der Verhörte wird in den Glauben versetzt, dass der Fragende die Existenz der Katze annimmt und daher die Antwort „Ja" erwartet; stärkere Suggestion).

4) Welche Farbe hat die Katze, die auf dem Boden sitzt? (Sogenannte "Voraussetzungsfrage”. Die angebliche Existenz der Katze wird gar nicht mehr in Frage gestellt, sondern schon vorausgesetzt. Es gehört schon stärkere geistige Selbständigkeit dazu, um diese überaus suggestive Unterschiebung zurückzuweisen).

Die suggestive Wirksamkeit der Erwartung ist durch Binet und andere an Sinneswahrnehmungen experimentell untersucht worden. Aus einem Versuch von Kosog (Breslau) mit $81 / 2$ jährigen Kindern sei Folgendes berichtet: K. zeigte jedem Prüfling ein weisses Papier mit einem schwarzen Punkt. Dann musste das Kind soweit zurücktreten, dass es den Punkt nicht mehr sah, und sich langsam dem Papier nähern, bis der Punkt sichtbar wurde. Der Versuch wurde dreimal wiederholt, sodass damit eine Erwartung für weitere Wiederholungen geschaffen war. Aber vor dem vierten Versuch wurde das Papier heimlich mit einem völlig leeren Stück Papier vertauscht. Trotzdem blieben viele Kinder in den nun folgenden drei Versuchen an ungefähr der gleichen Stelle stehen mit der Versicherung, dass jetzt der Punkt eben sichtbar werde. $51 \%$ aller Schüler erlagen dieser Erwartungssuggestion. Noch stärker waren die Suggestionserfolge bei entsprechenden Versuchen mit Gehörs-, Geschmacks-, und Geruchs-Eindrücken. 


\section{Prüfungen der Suggestibilität}

Experimentalprüfungen der $\mathrm{S} u \mathrm{~g} g$ e s $\mathrm{t}$ i b i 1 i t ä $\mathrm{t}$ ergaben starke individuelle Unterschiede; Suggestibilität ist also als ein recht ausgeprägtes Merkmal der Individualität anzusehen. Allerdings ist der Sy m p tom we $\mathrm{rt}$ einer solchen Prüfung mit grosser Vorsicht zu beurteilen. Denn da, wie wir oben sahen, die Empfänglichkeit für Suggestion stark von der „Atmosphaere” und von dem jeweilig aktivierten psychischen Bereich abhängt, so ist es möglich, dass der im Experiment gefundene Suggestibilitätsgrad durch die Versuchsbedingungen mitbeeinflusst ist und daher nur geringere individualdiagnostische Bedeutung hat.

Zietz stellte an einem Mãdchen und einem Knaben Versuche an, bei welchen erst über ein Bild, dann über einen wirklichen Vorgang Aussagen zu machen waren. Das Mädchen konnte den Suggestivfragen über das Bild fast durchweg widerstehen, während es bei dem Wirklichkeitsversuch in der Mehrheit der Fälle der Suggestion unterlag. Beim Knaben verhielt es sich umgekehrt. Beide Kinder zeigten also eine ganz verschiedene Suggestibilität, je nach der Art der Prüfung. Das Ergebnis des Wirklichkeitsversuchs stimmte mit den, sonst über die Suggestibilität der Kinder gewonnenen Eindrücken viel besser überein als das Resultat des Bildversuches.

Die starke Abhängigkeit der Suggestibilität vom Alt e r ist überall hervorgetreten, wo Kinder verschiedenen Alters mit identischer Methode geprüft wurden. $\left.{ }^{1}\right)$ Allerdings kann die $\mathrm{Pu}$ bertätszeit eine neue Steigerung der Suggestionsempfänglichkeit namentlich für solche Seelengebiete bringen, die mit den veränderten Bedingungen des Trieb- und Gefühlslebens in Beziehung stehen.

Wenn man Suggestibilität mit ,geistiger Unselbständigkeit" identifiziert, dann muss man erwarten, dass zwischen Suggestibilität und In telligen $\mathrm{z}$ eine hohe negative Korrelation bestehe. Diese Voraussetzung hat auch dazu geführt, dass man die Widerstandsstärke gegen Suggestiveinflüsse als Intelligenzsymptom bewertete und entsprechende Tests in Prüfsysteme der Intelligenz einfügte. Aber hierbei wird die Eigenschaft ,,Suggestibilität" doch viel einfacher aufgefasst, als es berechtigt ist. Vielfach haben gerade intelligentere Versuchspersonen eine

1) Zablenwerte hierzu S. 263. 
stärkere Suggestionsempfänglichkeit gezeigt als die weniger intelligenten (unter anderem in den oben erwähnten Versuchen von Kosog). Menschen von lebhaftem Geist haben oft eine lebhafte Phantasie, die einen fruchtbaren Boden für Suggestiveinwirkungen abgibt; auch kann Geltungsdrang und Ehrgeiz dazu führen, dass man nicht versagen will in dem, was der Suggestor von einem zu erwarten scheint - und so glaubt man dann schliesslich selbst, etwas bestimmtes zu sehen (bei Wahrnehmungssuggestionen), oder eine bestimmte Erinnerung zu besitzen (bei Suggestivfragen).

Für diese charakterologische Verankerung der Suggestibilität ist ein kleiner Versuch von Binet lehrreich. Ein Karton mit mehreren verschiedenartigen Gegenständen (Knopf, Stahlfeder, u.s.w.) wurde einer Gruppe von Versuchspersonen gleichzeitig kurz exponiert. Dann wurde nach den vorhandenen und auch nach einigen nichtvorhandenen Gegenständen gefragt. Sehr bald bildete sich in der Gruppe ein Führer aus, der in seinem Ehrgeiz, eine Leistung zu zeigen, stets als erster antwortete; er liess sich daher keine Zeit zur Besinnung und erlag besonders häufig den Suggestivfragen. Seine Sicherheit wirkte dann wieder auf die anderen suggestiv, die nun ebenfalls angaben, dies und das, was garnicht vorhanden gewesen war, gesehen zu haben. Die Suggestibilität hatte also bei dem Führer und bei den Nachfolgern eine ganz verschiedene Motivation. 


\section{FÜNFUNDZWANZIGSTES KAPITEL}

DIE LEISTUNG UND I HRE PERIODIK

I. OBJEKTIVE UND PERSONALE LEISTUNG. ${ }^{1}$ )

\section{Objektive Leistung}

„Leistung” ist, in weitestem Sinne genommen, keine personalistische, noch weniger eine rein psychologische Kategorie. Unpersönliche Dinge, wie etwa Maschinen, vollziehen Leistungen stärkster Art. Der Nestbau des Vogels ist zweifellos eine Leistung, unabhängig davon, ob und welche seelischen Vorgänge daran beteiligt sind.

Das Wesen a 11 e r Leistungen - maschineller, wirtschaftlicher, tierischer, menschlicher - ist Werteschaff ung $\mathrm{d} u \mathrm{rch}$ Energiea $\mathrm{f}$ w a $\mathrm{nd}$. Sowohl die erzeugten Werte, wie die aufgewandte Energiemengen sind messbar und vergleichbar. Dadurch ist eine Objektivierung der Leistungen, ihre vom Leistungserzeuger losgelöste Betrachtung möglich.

Man kann mehrere Leistungen in Bezug auf die Grösse der geschaffenen Werte vergleichen (Maschine A erzeugt im Tage doppelt so viel Güter wie Maschine B). Man kann sie in Bezug auf die Höhe des Energieaufwandes vergleichen (Maschine A. braucht dreimal so viel Kohlen, Öl, bedienende Arbeitskräfte, Herstellungs- und Reparatur-Kosten wie B.). Man kann endlich das Verhältnis beider Grössen messen; damit gewinnen wir das spezifische, objektive Leistungsmals, das im Quotienten Nutzeffekt/Aufwand besteht. Das Leistungsmals der Maschine A. würde hiernach zwei Drittel des Leistungsmalses der Maschine $\mathrm{B}$. betragen.

Objektive Leistungsmessungen sind natürlich auch beim Men-

1) Spezialliteratur zum Leistungsproblem findet sich von allem in den Werken, Zeitschriften und Handbüchern der Psychotechnik und Arbeitswissenschaft. 
schen durchführbar. Denn die von ihm erzeugten Werte, ebenso wie die dazu benötigten Aufwände, sind unter verschiedensten Gesichtspunkten vergleichbar mit denen anderer Menschen oder nicht menschlicher Substrate (Tiere, Maschinen). Hierbei ist es gleichgültig, w e l c h e Gesichtspunkte zur Messung der Werte und zur Feststellung des Aufwandes gewählt werden; solange es sich hierbei um Malsstäbe sachlicher (überpersonaler) Art handelt, sprechen wir von objektiven Leistung e n. Wir können dann sagen, dass die objektive Leistungsfähigkeit einer Maschine gleich der von 10 Arbeitern ist. Wir nennen die objektiven Leistungen des siegenden Wettläufers grösser als die der Besiegten, oder die objektive Leistung eines Schülers höher als die seines Mitschülers, wenn er eine höherwertige Arbeit in gleicher Zeit, oder eine gleichwertige mit geringerem Zeitaufwand hergestellt hat.

\section{Personale Leistung}

Nun brauchen wir aber beim $\mathbf{M}$ e $\mathrm{n} \mathbf{s} \mathrm{ch}$ e $\mathrm{n}$ noch einen ganz anderen Leistungsbegriff; und gerade dieser ist unser eigentliches Problem: die personale $\mathrm{L}$ e is $\mathbf{t} \mathbf{u} \mathrm{n}$. Sie ist $\mathrm{zu}$ definieren als: Werteschaffung durch Willenshandlung unter Aufwand personaler Kraft.

Die personale Leistung setzt also erstens eine $\mathrm{W}$ ill e n s h a n d l u n g voraus. Die Maschine ,handelt" überhaupt nicht; sie funktioniert. Der nestbauende Vogel vollzieht schon eine Handlung, aber eine Instinkthandlung. Der Handwerker dagegen, der Sportler, der Schriftsteller, der Schüler, der etwas leistet, sie w olle n Werte erzeugen.

Zweitens gehört zur personalen Leistung der $\mathrm{K} \mathbf{r}$ a f t a $\mathbf{u} \mathbf{f}$ w a nd. Während oben der Begriff der Energie als das ganz unpersönliche Quantum der Arbeitsfähigkeit verwandt wurde, soll hier der Begriff „Kraft” in seiner ursprünglichen und unentbehrlichen Bedeutung gefasst werden; als die an einen lebendigen Träger geknüpfte, zur Überwindung von Widerständen dienende Aktivität. Der Begriff ist durchaus psychophysisch-neutral. Zwar kann die personale Kraft aus körperlichen Quellen (z.B. der Ernährung) oder aus psychischen Quellen (z.B. der Selbstzucht) gespeist sein; sie kann sich auch richten 
auf körperliche Ziele (beim Turner) oder auf psychische Ziele (beim Grübler). Auch die Widerstände, gegen die sie sich verwirklicht, können physisch sein (z.B. Körperschwäche) oder psychisch (z.B. Begabungsmangel) - sie selbst steht aber jenseits der Scheidung, ist unmittelbarstes Merkmal einheitlich personaler Tätigkeit.

Ein gemächlicher Spaziergang verbraucht zwar Energieen und erzeugt auch Werte (z.B. Kräftigung des Körpers), kann daher unter gewisser Perspektive als objektive Leistung betrachtet werden; aber er ist keine personale Leistung, denn er erfordert nicht überwindende Kraft. Dagegen ist eine vielstündige Gebirgswanderung eine personale Leistung; ebenso die wenigen schwachen Schritte, die ein Genesender nach schwerer Krankheit zum ersten Male wieder zu machen sucht. Denn in diesen Fällen sind besondere Willensimpulse und Zusammenraffung der verfügbaren Kraft für die Durchführung der Handlung notwendig.

3. Das Verhältnis beider Leistungsarten. Die Selbstbeanspruchung.

Die Doppelsinnigkeit des Leistungsbegriffs führt nicht nur zu sprachlichen Unklarheiten, sondern erzeugt auch oft Verwirrung bei der Einschätzung von Leistungen menschlicher Individuen. Erst die hier entwickelte begriffliche Trennung kann Klarheit schaffen; man muss sich in jeden Falle Rechenschaft geben, ob man die objektive oder die personale Leistung zum Gegenstand der Leistungsbeurteilung macht. Oft bestehen schroffe Diskrepanzen zwischen beiden Wertungsweisen.

Zwei Beispiele:

In jedem Sport gelten bestimmte überindividuelle Wertungsskalen; ein Tätigkeitserfolg, der eine hohe Staffel in diesem Malssystem einnimmt, gilt als ,grosse Leistung”. Nun kann aber der eine geübte und sieggewohnte Sportler A. diesen Erfolgsgrad erreichen ohne grosse Mühe; ,,er leistet es spielend" — während ein junger Anfänger B. alle seine Kräfte bis zum letzten anspannen muss, um jenen Effekt zu erzielen. Bei gleicher objektiver Leistung liegt dann bei A. überhaupt keine personale Leistung, bei $B$. eine sehr grosse vor.

2). In einer Schulklasse sei eine Rechenarbeit geschrieben wor- 
den. Objektiv gesehen müssen die Arbeiten aller Schüler an dem Höchstmalsstab der Fehlerlosigkeit gemessen und danach die Leistungen rangiert werden. Zugleich aber hat der Lehrer auch die Aufgabe zu individualisieren: und unter diesem Gesichtspunkt ist die personale Leistung des rechnerisch unbegabten Schülers, der es diesmal durch intensivste Vorbereitung und durch grösste Anspannung während der Arbeit zu nur 5 Fehlern gebracht hat, höher zu bewerten als die fehlerfreie Arbeit seines hochbegabten Klassenkameraden.

überall dort, wo menschliches Tun eingeordnet wird in grosse soziale oder wirtschaftliche Zusammenhänge, und wo deshalb das Ergebnis dieses Tuns aufs Engste verknüpft ist mit anderen a us e r persön 1 i c hen Faktoren und Werteschaffungen, wird die objektivierende Leistungseinschätzung überwiegen müssen. Eine mälsige Rechenleistung mag, wie in unserm letzten Beispiel, eine noch so anerkennenswerte personale Leistung sein: für einen Beruf, der ohne hohe objektive Rechenleistungen nicht erfolgreich ausgeführt werden kann, macht sie nicht geeignet. Befähigungsnachweise, pädagogische Examina, psychotechnische Prüfungen, sportliche Wettkämpfe u.s.w. haben es vornehmlich mit der Einreihung der individuellen Leistungen in o b j e k t i ve Wertungsskalen zu tun. Gleiches gilt für rein wirtschaftliche Leistungsberechnungen (vgl. unser obiges Beispiel von der Gleichsetzung der Arbeitskraft von 10 Arbeitern mit der einer Maschine).

Aber immer wieder muss daran erinnert werden, dass Menschen nicht blosse Erzeuger objektiver Leistungseffekte, sondern selbsttätige, um Werterzeugung sich mühende Personen sind. Und diese Bemühung, auch wenn sie nur mindere objektive Werte erzielt, ist doch nun in ganz anderem Sinne werterzeugend: $s$ i e steigert den Selbstwert der Person! Wersich um objektive Leistung $\mathrm{b}$ e $\mathrm{m} \ddot{\mathrm{u}} \mathrm{h} \mathrm{t}, \mathrm{v}$ o $11 \mathrm{z}$ i e $\mathrm{h} \mathrm{t}$ damit schon eine personale Leistung: er stellt Ansprüche an sich, arbeitet an sich selbst, überbaut sein bloss vitales Dahinleben durch aktive Wert-Introzeption. Indem er ,sein Bestes zu g e b e n" versucht, strebt er danach das Beste, das potentiell in ihm vorhanden ist, $z u$ werde $n$. Lipmann hat neuerdings diesen zentralen Faktor jeder personalen Leistung als ,,S e 1 b s t beanspruchung" bezeichnet. In magnis et voluisse sat est. 
Die Beziehungen dieser personalen Selbstbeanspruchung zur Ermöglichung objektiver Leistungen sind recht verwickelt.

Voraussetzung dafür, dass ein Mensch auf irgend einem Wertgebiet etwas ,leistet," ist ja zunächst, dass er die R ü s t u n g s d is p o s i t i o n en besitzt, die zur Durchführung der Aufgabe gehören. Es sind dies, sofern es sich um geistige Dispositionen handelt, die Begabungen: Allgemeinbegabungen wie Intelligenz und Gedächtnis, Spezialbegabungen oder ,Talente," die auf begrenzte Wertbereiche bezogen sind. $\left.{ }^{1}\right)$ Hierzu kommen dann die körperlichen oder psychophysisch neutralen Rüstungsdispositionen: Gesundheit, Körperstärke, Geschicklichkeit u.s.w. Aber die Umsetzung dieser Leistungs-,,Fähigkeiten” in tatsächliche Leistungen geht nicht von selbst vor sich. Hier greift vielmehr die Selbstbeanspruchung als Realisierungsfaktor ein; von ihr hängt es weitgehend $a b$, w a s mit jenem latenten Schatz an Gaben und Fertigkeiten gemacht wird. Entschluss und Tat, Willensruck und vor allem Konzentration der Kraft auf das gesetzte Ziel - das sind die Erzeugnisse dieser Selbstbeanspruchung.

Die Disponiertheit zur Selbstbeanspruchung ist nun nicht weniger individuell verschieden, als die oben erwähnten Leistungsfähigkeiten; Lipmann bezeichnet diese Disposition als „Leistungsbereitschaft”. Zwei Individuen, die auf einem Gebiet gleich „begabt” sind, berechtigen doch zu ganz verschiedenen Leistungserwartungen, wenn ihre Leistungsbereitschaft verschieden ist. Umgekehrt kann ein Manko an Begabung durch stärkere Fähigkeit zur Selbstbeanspruchung auch im Sinne der objektiven Wertproduktion unter Umständen mehr als ausgeglichen werden. $\left.{ }^{2}\right)$

Auf Grund dieser Erwägung muss man eine elemententheoretische und mechanistische Auffassung auf dem Gebiet menschlicher Leistungserwartung zurückweisen.

Weder der Nachweis - bestimmter körperlicher Kräfte und Geschicklichkeiten, noch der Nachweis bestimmter geistiger Fähigkeiten liefern die Gewähr für ein entsprechendes tatsächliches Leisten. Hierin eben $\mathrm{u} n \mathrm{t}$ e $\mathrm{r} \mathrm{s} \mathrm{ch}$ e i d e $\mathrm{t}$ sich der Mensch von der Maschine, deren reale Leistung mit grosser Wahrschein-

1) Vgl. S. 433.

1) Vgl. S. 434. 
lichkeit vorausgesagt werden kann, wenn man die Leistungsmöglichkeiten der einzelnen Teile und die Art ihres Zusammenwirkens kennt.

Ein hoher Grad von Selbstbeanspruchung wird zunächst den Wert der objektiven Leistung erhöhen; wer sich mehr bemüht, wird auch mehr erreichen. Aber auch die umgekehrte Beziehung besteht. Starke Mühegebung ist ja zugleich ein starker Kraftverbrauch; und diese Kraft kommt nicht allein dem objektiven Leistungszweck zu gute, sondern muss zum Teil auch für die, dem eigenen Wollen zuzuführende, Anspannung verbraucht werden. Darum verlangt die Kraftökonomie des Menschen eine Sparsamkeit der Selbstbeanspruchung. Je geringer die Anstrengung, die auf Leistungen verwandt werden muss, um so vollständiger und ausdauernder kann der vorhandene Energievorrat der Erzeugung objektiver Leistungen dienstbar gemacht werden. Oder anders ausgedrückt: bei einem gegebenen Energiequantum nimmt mit Abnahme des personalen Leistungsanteils die Chance und Höhe der objektiven Leistung zu.

\section{PERIODIZITÄT}

\section{Allgemeines}

Die Leistungsfähigkeit eines Menschen ist niemals im Zeitablauf konstant. Vielmehr macht sich das allgemeine Gesetz, dass alles Lebensgeschehen periodisch abläuft, gerade beim Leistenkönnen sehr aufdringlich und mannigfaltig bemerkbar. Die Periodik ist in erster Linie i n n e r p e r s o n a l bedingt; äussere Einflüsse sind nur innerhalb enger Grenzen wirksam. Sie ist ferner psychophysisch neutral; organische wie AufmerksamkeitsFunktionen, körperliche wie geistige Leistungsfähigkeit sind ihr unterworfen.

Die Gesamtform der personalen Periodik wird bestimmt durch die $\mathrm{Superposition}$ von dynamischen Wellen verschiedenster Grössenordnung. Von den Aufmerksamkeitsschwankungen innerhalb weniger Sekunden bis zu den, viele Jahre umfassenden, Entwicklungsperioden gibt es eine ganze Reihe von, sich über-und unter-ordnenden oder sich kreuzenden, Periodensystemen. Ihre Trennung ist freilich nur in der Abstraktion 
möglich. Im wirklichen Leben sind sie nichts als unselbständige Momente in dem Gewoge des Lebensabflusses - vergleichbar der bewegten See, deren Oberfläche durch die gewaltige EbbeFlut-Periode, durch meter-lange Wogen, kleinere Wellen und kleinste Kräuselungen gemeinsam ihre Gesamtform erhält. Aber der Vergleich passt doch nicht vollständig; denn während bei dem Meer, das eine "Sache” ist, eine Vielzahl physikalischer Kräfte als hinreichende Bedingung für die resultierende $\mathrm{Ge}$ samtform angesehen werden darf, ist die personale Periodik in erster Linie eine aus dem Total der Person selber quellende dynamische Form; und die relative Selbständigkeit, die irgend eine Teilperiodik zu besitzen scheint, wird immer wieder durch den Ganzheitsbezug rückgängig gemacht.

\section{Kleinst-Periodik (Rhyth mik)}

Die Perioden geringster Grölsenordnung haben einen Umfang von nur wenigen Sekunden. Auf psychischem Gebiet gehören hierher die schon mehrfach erwähnten Aufmerksamkeitsschwankungen, auf körperlichem Gebiet zeigen Herzschlag, Atmung, Schritt-Tempo solche Kurzperioden. Wie eng diese unter sich zusammenhängen, zeigt der Umstand, dass sich das Schritttempo meist dem Takt einer gehörten Musik anpasst. Auch haben experimentelle Untersuchungen und graphische Aufzeichnungen von Atmungs- und Blutzirkulationskurven gezeigt, dass bei gleichzeitigen Aufmerksamkeitsleistungen die dynamischen Abläufe hier und dort sich gleichzuschalten bestrebt sind.

Für diese kleinsten Wellen gibt es eine Bezeichnung, die über die Unterschiede der personalen Teilbereiche hinausgreift: „Rh y th mu s”. Von Rhythmus sprechen wir dort, wo sich der Lebensfluss in eine Wiederholungsreihe dynamischer Lebnis- und Erlebniseinheiten gliedert.

Es empfiehlt sich, den Ausdruck nur auf solche Perioden anzuwenden, bei denen das dynamische Auf und $A b$ jeder Welle in einer einheitlichen Gegenwart als $G$ a $n z h$ e i $t$, und die Folge mehrerer Wellen als Wiederhol ung unmittelbar e r lebt wird. Der Begriff "Rhythmus" ist also enger, und mehr personal gefärbt, als die Begriffe „Periode", „Takt”, „Metrum" und andere. 
Wie wir schon früher sahen (S. 213), geht zwar der stärkste Anstoss zu rhythmischem Erleben von a k u s t is chen Eindrücken der Musik, der Sprache, der Arbeitsverrichtungen aus; doch gibt es auch rein optische, rein taktile, rein motorische Rhythmen. Vor allem aber: von welcher Sinnesstelle auch ein Rhythmus zunächst ausgelöst sein mag, er bleibt nicht auf jenes Gebiet beschränkt, sondern greift auf die Totalperson über, welche sich diese eigentümliche dynamische Struktur zugleich sensumotorisch und erlebnismälsig zu eigen macht.

Hier gibt es übrigens Persönlichkeitsdifferenzen, die an den früher erwähnten Unterschied des integrierten und desintegrierten Typus (S. 620) erinnern. Für manche Menschen bleibt der Rhythmus weitgehend beschränkt auf das Sinnesgebiet, in dem er primär erzeugt ist; bei anderen totalisiert er sich schnell. Jener kann sich etwa ruhig dem rein akustischen Rhythmus hingeben; dieser vermag nicht anders als mit zu taktieren, mit zu tänzeln, ja mit zu atmen.

Wo der zweite Typ stark ausgeprägt ist, fühlt sich der Mensch mit seinem ganzen Lebensgeschehen eingebettet in den Rhythmus und getragen von ihm. Dies Erlebnis gibt es nicht nur bei Musik und Tanz, beim Massenschritt marschierender Trupps u.s.w., sondern auch bei der Arbeit an Maschinen, deren periodisches Schwingen und Stampfen überfliesst in die innere Rhythmik des arbeitenden Menschen.

Rhythmisches Betätigen und Erleben gehört zu den urtümlichsten Erscheinungen alles menschlichen Daseins. „Im Anfang ist der Rhythmus"; dies zeigt sich auch entwicklungspsychologisch, da sowohl beim Kinde wie in der Menschheit der rhythmische Faktor der Musik viel früher zur Entfaltung gelangt, als der melodische und der harmonische. ${ }^{1}$ )

Die absolute Dauer der dynamischen Kleinstwelle ist weitgehend persönlichkeitsgebunden. Jeder Mensch hat sein p e r s ö $\mathrm{n}$ li c h e s T e m p o, d. h. eine ihm angemessenste Ablaufszeit der rhythmischen Lebnisse und Erlebnisse. Je weniger äussere Gründe die Geschwindigkeit des Tuns bestimmen, um so mehr setzt sich diese natürliche Eigenrhythmik durch.

So wird etwa das persönliche Schritt-Tempo nicht bei jenem festgestellt werden können, der eilig zum Bahnhof kommen muss, wohl aber

i) Vgl. S. 437. 
bei jenem, der ohne Zeitbedrängnis seinen Geschäften nachgeht; das Sprechtempo nicht bei jenem, der mit seinem umfangreichen Vortrag in vorgeschriebener Zeit fertig werden muss, wohl aber bei jenem, der unbefangen etwas vorliest oder sich unterhält.

Da das persönliche Tempo eng mit dem Temperament, also mit der Totaldynamik der Person zusammenhängt, ist es nicht auf einzelne Anwendungsbereiche beschränkt. Wer ein flottes Gehtempo besitzt, wird auch andere, zwanglose Bewegungen (z.B. auch die der Sprache) ziemlich schnell vollziehen. Auch Rezeptions- und Aktions-Tempo gehören eng zusammen: Menschen, die beim Spielen von Musikstücken gern langsame Tempi wählen, werden gewöhnlich auch bei gehörten Stücken finden, dass sie langsamer gespielt oder dirigiert werden sollten. Ausnahmen von dieser Durchgängigkeit des persönlichen Tempos bedeuten wohl regelmälsig, dass das Betätigungsgebiet mit abweichenden Tempo eine Sonderrolle innerhalb des persönlichen Lebensvollzugs spielt.

Die Unterschiedsschwelle für Tempoangemessenheit ist recht fein. Jeder nur einigermalsen musikalische Mensch hat einen absoluten Eindruck von ,richtigem”, ,zu schnellem”, „zu langsamem" Tempo. Der Hörer bedarf dazu nicht einmal der Vergleichung mehrerer Darbietungen desselben Stückes in verschiedenem Tempo, denn den Malsstab trägt er in sich selbst und seinem Eigentempo. Gleiches gilt auch für das Aktionstempo: gibt man jemandem auf, einen Dreivierteltakt vielfach hintereinander mit dem Bleistift auf den Tisch zu klopfen, so stellt sich schnell eine Klopfgeschwindigkeit heraus, die dem Klopfer die „richtige” zu sein scheint, und die daher als bequemes Mals seines persönlichen Tempos benutzt werden kann. (Es genügt, eine halbe Minute klopfen zu lassen und die in dieser Zeit geklopften Takte zu zählen).

Die Klopfmethode wurde von mir bereits 1900 zur Feststellung des psychischen Tempos vorgeschlagen ${ }^{1}$ ) und seitdem oft benutzt. Neuerdings hat Frau Frischeisen-Köhler sehr umfangreiche Untersuchungen mit ihr angestellt, freilich ohne dass ein bestimmter Rhythmus vorgeschrieben wurde.

Die Plastizit ät des Eigentempo's ist sehr verschieden.

1) In: Psychologie der individuellen Differenzen. 
Bei den oben beschriebenen Menschen, die sich von einem Aussenrhythmus (Musik, Marsch, Maschine) leicht mitreissen lassen, ist das persönliche Tempo nachgiebig. Es gibt aber andere, denen ein auferlegtes Tempo stärksten Zwang bedeutet, weil ihr Eigentempo dadurch vergewaltigt wird. Für einen solchen Menschen kann z.B. die Arbeit am laufenden Bande unter Umständen gradezu unerträglich werden.

\section{Tageswellen}

Die einschneidendste Periodik innerhalb des menschlichen Lebensablaufs wird durch die 24-stündige Tag-Nacht-Welle gebildet. Wenn auch der Unterschied zwischen Wach- und Schlaf-Zustand nicht nur im Dynamischen liegt, so ist es doch eines der wesentlichsten Merkmale. Der wache Mensch verfügt über die zu Leistungen nötige Energiemenge und Energiekonzentration; im Schlafe gibt es keine personalen Leistungen; denn es ruht der Wille zum Überwinden von Widerständen ${ }^{1}$ ). Daher ist das dynamische Kennzeichen des Schlafes der Ruhezustand; es ruhen nicht nur die Glieder, sondern auch die aktiven psychischen Funktionen wie Aufmerksamkeit, Denk- und Willens-Konzentration; es verlangsamen sich die körperlichen ebenso wie die seelischen Reaktionen. Gewiss wird auch im Schlaf Energie verausgabt, mit jedem Atemzug, jedem Stoffwechselprozess und jeder Traumvorstellung. Aber dieser Energieverbrauch ist auf ein Mindestmals reduziert, während umgekehrt aus dem, im Wachzustand aufgenommenen, stofflichen und geistigen Material neue wirkungsbereite Energieen geschaffen werden. Der dynamische Grundunterschied zwischen Wachen und Schlafen ist also der von vorwiegenden Energieverbrauch dort, vorwiegender Energieaufspeicherung und In-Bereitschaft-Setzung hier.

Aber diese Grundmerkmale genügen noch nicht, um das dynamische Bild der 24-Stunden-Welle zu zeichnen. Denn der Mensch bleibt nicht während des Wachens dauernd auf der gleichen Hochebene, und nicht während des Schlafes dauernd in der gleichen Talsohle der Energie. Vielmehr gibt es nun in $\mathrm{n}$ e $\mathrm{r} \mathbf{h}$ a $\mathbf{l b}$ jedes

1) Darum ist auch die psychoanalytische Bezeichnung ,Leistung” für ein Ergebnis des Traumlebens ( $z$. B. Wunscherfüllung) unzutreffend. - „Objektive” Leistungen kommen freilich auch im Schlaf vor; so sollen Schlafwandler gelegentlich regelrechte akrobatische Kunststücke vollziehen. 
Wellenteiles Energieschwankungen von weit geringerer Ausladung, aber doch von lebenswichtiger Bedeutung. Die Figur 12 gibt ein ganz schematisches Normalbild, das im Einzelfalle durch vielerlei innere und äussere (hier nicht zu erörternde) Einflüsse modifiziert werden kann.

Die dynamische $\mathrm{T}$ a g e s w e lle beginnt beim Erwachen

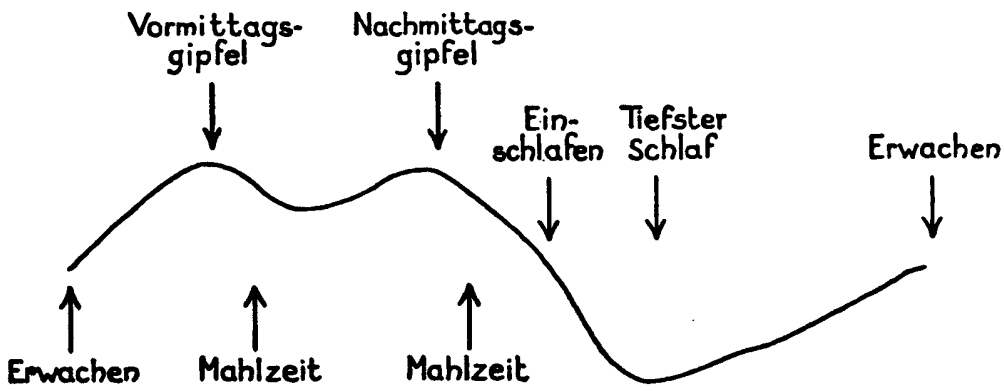

Fig. 12.

Dynamische 24-Stundenwelle (schematisch).

nicht etwa in voller Höhe, sondern bedarf einiger Stunden, ehe sie ein erstes Maximum (in der Mitte des Vormittags) erreicht. Zwischen Vor- und Nachmittag zeigt sich (meist im Anschluss an eine Mahlzeit) ein Sattel, also eine Periode geringerer Frische und Leistungsfähigkeit, die sogar einen kurzen Schlaf in sich schliessen kann. In der Mitte des Nachmittags liegt dann ein zweiter Höhepunkt, dem der endgültige Abfall der Energie (die Abendermüdung) folgt.

Sehr deutlich tritt das Schema der $\mathrm{T}$ a g e s-Welle in Form eines breit gezogenen lateinischen $M$. bei Tempoklopf-Versuchen hervor, die ich an mir und meiner Frau eine Reihe von Tagen hindurch in Stundesabstănden vornahm (Fig. 13). Die jeweilige Dauer eines geklopften \% Taktes ist ja nicht nur von dem persönlichen Tempo, sondern auch von dem Stand der Tagesfrische abhängig. Fasste man die Tempi von 10 normalen Tagen und immer für je drei Stunden zusammen, so ergaben sich die, an den Ordinaten abzulesenden, Durchschnittsdauern der Einzeltakte in Sekunden. So dauerte bei mir (A) der einzelne $3 /$, Takt im Durchschnitt morgens über 1 Sek., mittags 0,90 Sek., früh-nachmittags nach der Hauptmahlzeit 0,97 Sek., spät nachmittags 0,92 und abends 1 Sek. ${ }^{1}$ ).

1) Individuelle Differenzen zwischen A. und B.: das persönliche Bewegungstempo von $B$. ist merklich schneller als das von $A$. Die Energieschwankungen im Tageslauf sind bei B. geringer als bei A., mit Ausnahme des Anfangs der Kurve. 
Die energetische Schlafkurve ist nur indirekt erweisbar, nämlich durch Messung der sogenannten „Schlaftiefe”. Der Schlaf ist um so tiefer, je geringer die energetischen Ausserungen (Bewegungen, Träume) sind und je stärker der Abstand vom Wachzustand, d.h. je grösser die W e c k s ch wi e rig k e it ist. Kraepelin und andere benutzten zum Wecken Schallreize mit abgestufter

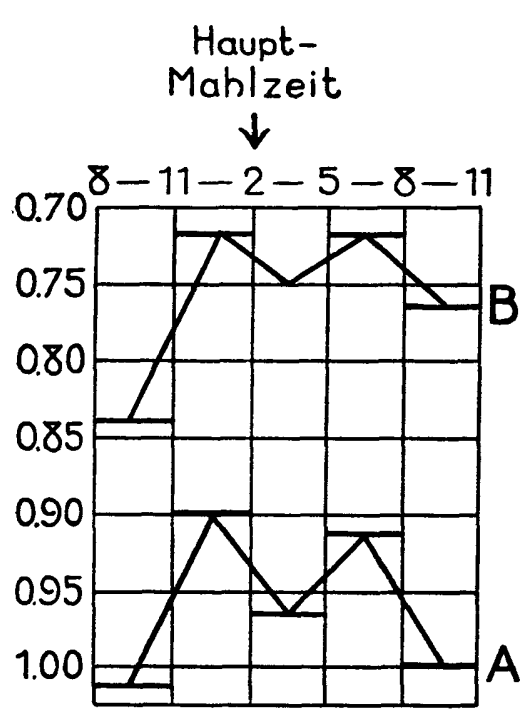

Fig. 13.

Tageskurven des psychischen Tempos. (Die Ordinaten sind nach unten gerichtet, da der längeren Taktdauer die geringere psychische Frische entspricht). Intensität. Die Stärke desjenigen Reizes, der den Schlaf grade zu unterbrechen vermag, gilt als Mals der eben dagewesenen Schlaftiefe. Auf solche Weise konnte die übrigens mit den Alltagserfahrungen gut übereinstimmende - Feststellung gemacht werden, dass bald nach dem Einschlafen die Energiekurve rapide sinkt, sodass der tiefste Schlafzustand schon nach, wenigen Stunden erreicht ist; von da an pflegt der Schlaf sich langsam zu verflachen (vgl. Fig. 12).

Diese Form der Schlafkurve ist von kraftökonomischer Bedeutung. Da der tiefe Schlaf ein besonders günstiges Verhältnis von Energiesammlung zu Energieabgabe zeigt, liefern die ersten Schlafstunden ein viel grösseres Quantum an Erholung und Restitution als die letzten. Wer nur 4 Stunden statt 8 Stunden geschlafen hat, hat damit nicht etwa nur die Hälfte, sondern einen weit grösseren Bruchteil des Erholungserfolges sicher gestellt.

\section{Perioden höherer Ordnung.}

Über die dynamischen Ablaufsperioden noch höherer Grössenordnungen müssen einige Hindeutungen genügen. 
Bekanntlich zeigt die $M$ o n a t s periode der Frau nicht nur rein physische Symptome, sondern äussert sich auch in gesteigerter psychischer Labilität. Bezüglich der näheren Schilderung dieser Schwankungen sei auf die medizinische Literatur verwiesen.

$\mathrm{J}$ a h r e s w e ll e $\mathrm{n}$ sind zweifellos vorhanden, haben aber die Eigentümlichkeit, dass sie durch kulturelle Einflüsse weitgehend überdeckt werden können.

Je mehr ein Lebewesen mit der Natur und den kosmischen Jahresänderungen verbunden ist, um so deutlicher ist auch die Jahresperiodik seines Lebens. Für viele Tiere drängt sich eine gewaltige Energieentladung (schnelles Wachstum, Metamorphosen, Fortpflanzung und Brutpflege, Wanderung) auf eine relativ kurze, aber ziemlich feststehende Spanne des Jahres zusammen, während die übrige Zeit ein Nachlassen der Dynamik zeigt am deutlichsten im Winterschlaf. Auch bei Menschen einfacher Kulturen ist noch die grosse Jahreswelle unverkennbar: der Bauer „verschläft" den Winter, um dann in der Zeit vom Frühjahr bis zum Herbst um so intensivere Arbeit bei knappem Schlaf zu leisten.

Der Kulturmensch dagegen hat auch den Winter zu erobern verstanden und seine Kraftökonomie über die Jahreszeiten hin viel mehr ausgeglichen. Die längeren Nächte des Winters veranlassen ihn nur in geringem Malse zu längerem Schlaf; er macht die Nacht zum Tage. Besonders auffällig ist, dass die stärkste Energieäusserung, die Brunst, beim Menschen keine jahreszeitliche Abgrenzung mehr kennt, höchstens gewisse Schwankungen innerhalb ziemlich enger Grenzen, wie die Geburtsstatistiken zeigen. -

Dass der gesamte L e b e n s la u f eines Menschen als eine grosse dynamische Periode angesehen werden kann, ist ohne weiteres klar. Kindheit und Jugend bilden den Anstieg; die reifen erwachsenen Jahre bilden die „Akme”, d.h. den Gipfel; dann erfolgt der Abstieg von Kraft, Leistungsintensität und Leistungsextensität.

Ch. Bühler hat neuerdings in eingehenden Analysen menschlicher Lebensläufe gezeigt, wie die einzelnen Seiten und Bereiche des personalen Lebens für sich die entsprechenden Kurven zeigen, aber in verschiedenen Zeitlagen und wie sich alle Teilkurven superponieren zu einer Totallebenskurve. 
Die Lebenskurve zeigt wiederum eine Profilierung. Auf ihr sind kleinere Wellen aufgetragen, deren jede eine Reihe von Jahren umfasst : einer Aufstiegs- und Leistungsperiode besonderer Intensität folgt eine Epoche langsameren Fortschreitens, die zugleich mehr der Kraftansammlung und Vorbereitung für die nächste Expansionsphase dient. Alle spezielleren Fragen freilich sind hier grösstenteils noch offen: ob es sich wirklich um eine allgemeinmenschliche Erscheinung handelt (man hat sie bisher vorwiegend bei historisch bedeutenden, schöpferischen Persönlichkeiten festzustellen geglaubt); ob die $\mathrm{D}$ a $\mathrm{u}$ e $\mathrm{r}$ der einzelnen Wellen von Mensch zu Mensch übereinstimmend und innerhalb des Lebens eines Menschen konstant sei u.s.w.. Es mutet zuweilen fast wie Zahlenmystik an, wenn behauptet wird, dass jede solche Welle sieben Jahre daure. (Fliess und andere.)

Allerdings muss zugegeben werden, dass zum mindesten für die Zeit der Unerwachsenheit jene Ziffer weitgehend zutrifft. Frühkindheit, Schulkindheit und eigentliche Jugendzeit umfassen tatsächlich je 6-7 Jahre; und jede dieser Epochen hat einen steil aufsteigenden Wellenast mit sehr rapider Entwicklung und einen langsam ansteigenden mit zögerndem Fortschreiten und mehr innerer Verarbeitung. Sehr zweifelhaft ist dagegen, ob man auch darüber hinaus in ungefähren 7-Jahres-Zyklen immer neue „Erwachsenheitspubertäten" ansetzen darf. Hier werden vermutlich Gelegenheitsbeobachtungen all zu sehr verallgemeinert. 


\section{SECHSUNDZWANZIGSTES KAPITEL}

Die Psychologie der vergangenen Jahrzehnte hatte dem Problem der Aufmerksamkeit sehr viele Bemühungen, theoretische und experimentelle ${ }^{1}$ ), zugewandt. Aber sie hatte hierbei bis vor kurzem fast ausschliesslich die gegenständliche Seite des Problems beachtet, d.h. die Bewusstseinsbeschaffenheit der I $\mathrm{n} \mathrm{h}$ a l$t \mathrm{e}$, die von der Aufmerksamkeit erfasst werden. Oft wurde hierbei sogar die Meinung laut: Aufmerksamkeit s e i nichts anderes als gesteigerte Klarheit und Deutlichkeit psychischer Inhalte. Eine weitere Verengung erfuhr die Theorie dadurch, dass man als "Gegenstände" der Aufmerksamkeit vornehmlich Sinnesreize, Wahrnehmungsgestalten und Bedeutungsgehalte(z.B. von Wörtern, Sätzen, Bildern) berücksichtigte; man kannte also fast nur die betrachtende Aufmerksamkeit. Hierdurch erhielt der gesamte Tatbestand etwas Statisches, ja Lebloses.

Erst die jüngste Zeit hat - teils von der Psychopathologie, teils von der Psychotechnik angeregt - die wesentliche Beziehung derAufmerksamkeit zu den Kategorieen der Leistung und der Kraft zu würdigen begonnen. Die folgende Erörterung wird nun das Problem grundsätzlich unter die personalistische Perspektive stellen.

Aufmerksamkeit ist derjenige personale Zustand, der die u nmittelbare Vorbedingung zum Zustandekommen einer personalen Leistung darstellt. Wesensmerkmale der Aufmerksamkeit sind: Klärung des Zieles im Bewusstsein, und $\mathrm{K}$ on $\mathrm{z}$ e $\mathrm{n} \mathrm{r}$ a t i o $\mathrm{n}$ der verfügbaren Kraft auf Klärung und Zielerfüllung ${ }^{2}$ ).

1) Monographieen von Dürr, Henning, Geissler, Mann u.a.

2) Diese Doppelbestimmung ist zuerst von Alfred Mann deutlich herausgestellt worden, mit den Bezeichnungen „Attention," „Konzentration." Doch ist der Ausdruck "Attention" für ein Teilmerkmal der Aufmerksamkeit unzweckmäisig, da dieses Wort in anderen Sprachen die Aufmerksamkeit im ganzen bezeichnet. 


\section{ZIELBEWUSSTSEIN}

\section{Bewusstseinsstruktur}

Es gehört zum Wesen jeder „Leistung”, dass Hemmnisse überwunden werden. Alles Konflikthaltige, Nicht-Selbstverständliche im personalen Lebensablauf aber führt zum Bewusstwerden. Deshalb muss die Einstellung auf Leistung den Gegenstand dieser Leistung bewusst machen oder eine etwa schon vorhandene $\mathrm{Be}-$ wusstheit verstärken.

Zwei Freunde wandern durch eine Landschaft. Der eine erfreut sich der Natur im ganzen, geniesst Licht, Farbe, Luft, aber erlebt dies alles in einem diffusen, nicht allzu hohen Grade von Bewusstheit. Der andere, ein Zoologe, interessiert sich für die Fauna und will feststellen, welche Käferarten es gibt. Dieses Leistungsziel bewirkt, dass bestimmte eng umschriebene Gebiete derLandschaft: hier ein Mooskissen, dort eine Baumrinde, dann ein zunächst noch unklarer, sich bewegender Gegenstand auf einem Stein, in eine ganz besondere Bewusstseinshelle getaucht werden, wobei zugleich die sinnliche Deutlichkeit des Gegenstandes wächst, wie auch die geistige Erfassung durch kategoriale Einordnung (,dies ist ein Käfer der und der Art') ermöglicht wird. Gleichzeitig ist die Bewusstheit aller anderen Eindrücke weit geringer als bei seinem weniger aufmerksamen Begleiter; die Einstellung auf die Leistung „Käfersuche” ruft also eine ganz andere Struktur des Bewusstseinsfeldes hervor.

Wenn wir die, innerhalb des engeren Aufmerksamkeitsfeldes befindlichen, Wahrnehmungen „klar" und „deutlich”, die ausserhalb seiner liegenden „dunkel" und ,verworren" nennen, so sind damit nicht eigentlich Eigenschaften der Wahrnehmungs- und Vorstellungs-Inhalte gemeint, die diesen etwa eben so zukommen wie die Merkmale Farbigkeit, Raumgestalt u.s.w. - , sondern es ist damit die Art bezeichnet, wie sich die Person ihres Inhalts bemächtigt. Eine ältere elementenpsychologisch eingestellte Theorie hatte noch gemeint, dass „Klarheit" an dem Inhalt als solchem hafte, und hat daher viel Kraft auf die Frage verschwendet, ob z.B. bei Sinnesempfindungen die „Klarheit” ein selbständiges Merkmal neben Intensität, Qualität u.s.w. sei oder nicht. Uns scheint diese Frage falsch gestellt zu sein.

Wundt, Wirth, Pauly, Mager und andere haben sich experimentell mit der weiteren Frage beschäftigt, ob sich der $U \mathbf{m}$ f a $\mathbf{n} \mathbf{g}$ 
des Aufmerksamkeitsfeldes näher feststellen lasse. Auch hier herrschte zunächst eine elementenpsychologische Fragestellung vor: wieviele Elemente können im Höchstfall auf einmal von der Aufmerksamkeit erfasst werden? Diese Untersuchungen wurden. meist so vorgenommen, dass man in optischer Momentan-Darbietung ${ }^{1)}$ wechselnde Anzahlen von „Elementen” (Punkte, Ziffern, Buchstaben u.s.w.) darbot und diejenige Anzahl feststellte, die in e i n e m Aufmerksamkeitsakt klar ergriffen werden konnte. Es waren gewöhnlich 4-6 Eindrücke.

Wichtiger aber als diese Zahl war ein anderes Ergebnis: die Anzahl der „Elemente” schnellte sofort auf ein Vielfaches empor, wenn sie in ihrer Gemeinsamkeit ein sinnvolles Ganzes bildeten. Schon Wundt fand, dass man dreimal so viel Buchstaben auf einmal erfassen kann, wenn sie in verständlichen Wörtern enthalten sind, als wenn sie für sich allein stehen. Ahnliches gilt für das Verhältnis von einzelnen Linien und den in einer geometrischen Figur enthaltenen Strichen.

Dieser Befund ist eines der schlagendsten Argumente gegen die Elementenpsychologie: für-die Aufmerksamkeit sind eben überhaupt keine „Elemente” da, sondern nur ganzheitliche Leistungsziele: eine zu erkennende Figur, ein zu verstehendes Wort u.s.w.; und die Überschaubarkeit einer solchen Gestaltsganzheit ist viel mehr von ihrer, für die Person sinnvollen, Struktur als von der Anzahl der in ihr aufweisbaren Teilstücke abhängig.

Der Bewusstheitsakzent, der dem Inhalt des Aufmerksamkeitsfeldes zukommt, kann sehr verschiedene Stärke haben. Man unterscheidet daher „S t u f e n d er B ew us s theit”. Siesind teils abhängig von dem Interessegrade, teils von der Schwierigkeit der Leistung. Um eine Photographie als die Darstellung eines Mannes zu erkennen, bedarf es keiner allzu starken Bewusstheit. Wenn ich aber versuche, in einem schwierigen Vexierbild den durch Baumzweige, Wegkurven u.s.w. gebildeten Umriss eines Mannes herauszufinden, müssen zahlreiche Einzelheiten mit intensiver Bewusstheit belegt werden.

In experimentellen Untersuchungen ist es mehrfach gelungen, die verschiedenen Grade der Bewusstheit bei s u k z e s s i ve n Aufmerk-

1) Die hierfür verwandten Apparate heissen „Tachistoskope”. Sie ermöglichen die Herstellung einer ausserordentlich kurzen Expositionsdauer, die messbar variiert werden kann. 
samkeitsakten näher zu erfassen. Wenn ein Kärtchen mit einem langen Druckwort (z.B. „Kastanienverkäufer”) im Tachistoskop momentan sichtbar gemacht wird, hat der Beschauer zunächst nur den vagen Eindruck eines unregelmälsigen Druckstreifens. In jeder folgenden Exposition desselben Streifens wird dessen Inhalt deutlicher, einzelne Buchstaben oder ein ungefährer Gesamtsinn stellen sich ein; das Wahrnehmungsbild des Streifens gewinnt fortlaufend an Schärfe - bis schliesslich das ganze Wort deutlich gelesen wird.

Westphal hat tachistoskopische Versuche mit optischen Figuren gemacht, bei denen erkannt werden sollte, ob die Linien gerade oder krumm, ob die Figur ein Dreieck oder Viereck u.s.w. sei. Er glaubt vier Bewusstheitsstufen unterscheiden zu können, die er folgendermalsen charakterisierte : 1) Der Gegenstand ist bewusst g e s e h e n (aber nur gesehen, ohne Beziehung zur Aufgabe). 2) Der Gegenstand wird bea c h t e t (unter den Gesichtspunkt der Aufgabe gestellt). 3) Es entsteht ein pot e $\mathrm{n} t \mathrm{i}$ e $1 \mathrm{l}$ e $\mathrm{s}$ Wissen um das Ergebnis (noch ohne Vergegenwärtigung und Formulierung). 4) Das Wissen wird zu einem ausdrücklichen; das Ergebnis wird k on stati e r t.

Das Bewusstsein im Aufmerksamkeitsakt besitzt eine eigentümliche Doppelgerichtetheit: nämlich einmal auf das jetzt und hier Gegebene, welches voll bewusst ergriffen wird; zugleich auf das nächst zu Erwartende, das Aufgegebene, das geklärt werden soll. Stets ist zugleich erfülltes und Erfüllung heischendes Bewusstsein vorhanden; und darum ist die Aufmerksamkeitsverfassung zugleich $Z$ u s $t$ a nd einer besonderen Helle des Bewusstseins, wie gespannte $\mathrm{B}$ e w e $\mathrm{g} \mathrm{u} \mathbf{n} \mathrm{g}$ nach vorwärts zu neuer und höherer Bewusstheit. Im Moment, da die bezielte Leistung erfüllt ist, hört die zweite Komponente auf, und mit ihr sinkt die Bewusstheit schnell ab; denn ein rein statisches Verweilen bei einer erreichten Bewusstseinsklarheit ist der Aufmerksamkeit unmöglich. Immerhin kann die eine oder andere Komponente überwiegen. Das Statische waltet vor in der betrachtenden, beschaulichen Aufmerksamkeit, das dynamische Spannungsmoment in der suchenden, erwartenden, erzeugenden Aufmerksamkeit. Diese Scheidung kehrt in der folgenden Erörterung unter anderem Gesichtspunkt wieder. 


\section{Richtungen der Aufmerksamkeit}

Jedes Gebiet, auf dem personale Leistungen möglich sind, kann Ziele für die Aufmerksamkeit liefern. Hiernach sind zunächst (ähnlich wie bei den Willeshandlungen) fremdbezügliche und selbstbezügliche Aufmerksamkeitsakte zu unterscheiden. Wenn wir früher ausführten ${ }^{1}$ ), dass die selbstbezüglichen Handlungen viel komplizierter sind als die fremdbezüglichen, so gilt dasselbe natürlich auch für die Aufmerksamkeit. Die Fähigkeit, das eigene Seelenbinnenleben in voller Bewusstheit $\mathrm{zu}$ beachten, entwickelt sich erst spät und kommt bei vielen Menchen überhaupt nie zu rechter Ausbildung, während diese sich mit vollster Klarheit auf äussere Dinge, Vorgänge, Handlungen oder auch auf gedankliche Probleme zu konzentrieren.vermögen.

Die nach aussen gerichtete Aufmerksamkeit wendet sich a praktischen und praktischen Leistungsgebieten zu.

Im ersten Fall ist die Klärung der dem Bewusstsein gegebenen Inhalte nicht nur Vorbereitung zum Leistungsziel, sondern selbst das Ziel: so ist die sinnliche Aufmerksamkeit auf klare und deutliche Wahrnehmungen, die intellektuelle Aufmerksamkeit auf die Erzeugnisse des Denkens, des Gedächtnisses, der Phantasie gerichtet. Die Grenze zwischen sinnlicher und intellektueller Aufmerksamkeit ist übrigens nicht scharf zu ziehen; denn in dem Augenblick, in welchem ein sinnlich gegebenes Objekt mit Aufmerksamkeit „beobachtet" wird, wird es ja zugleich unter gewisse Beachtungs- und Benennungs-Kategorieen gestellt, d.h. es wird zugleich Objekt intellektueller Aufmerksamkeit.

Praktische Leistungen sind entweder Bewegungsausführungen als solche (z.B. beim Sport) oder Hervorbringungen von Werken (z.B. im Handwerk). Die hierauf gerichteten Aufmerksamkeitsprozesse sind nicht nur die ursprünglichsten, sondern auch die verbreitetsten. Denn der Mensch ist primär ein tätiges Wesen; und alle einfacheren Leistungen sind mit körperlich-motorischen Faktoren aufs Engste verknüpft. Die Aufmerksamkeit, die ein Handwerker seiner Arbeit zuwendet, ist kein reines Beobachten der sinnlichen Gegebenheiten, kein reines innerliches Nachdenken über die Probleme der Arbeit; diese Momente haben für ihn nur Bedeutung als Hinweise und Vorbereitungen auf die auszufüh-

1) S. 554

Stern, Psychologie 
renden Bewegungen, deren bevorstehende Abläufe den eigentlichen gegenständlichen Richtpunkt seiner Aufmerksamkeit bilden. Der Handwerker beachtet etwa die Beschaffenheit des Materials nicht beschaulich nach allen Seiten hin auf seine sinnlich wahrnehmbaren Merkmale, sondern nur, soweit diese Merkmale für die vorzunehmende Bearbeitung relevant werden. Die Bewusstseinsa u s l e s e, welche die Aufmerksamkeit vornimmt, und das Bewusstheits $r$ e 1 i e f, das sie den einzelnen Momenten des Totalgegenstandes verleiht, ist also von der Totalaufgabe her bestimmt ; und diese ist in den weitaus meisten Fällen des Alltagslebens und der Durchschnittsmenschen eine sensumotorische Aufgabe in ungeteilter Einheit.

Es ist freilich auf der andern Seite gerade Sache der Aufmerksamkeit, aus dieser Totalität die eingeschmolzenen Momente so weit abzuheben, dass ihre, sonst unter der Schwelle bleibenden aber für die Leistungen bedeutungsvollen, Beschaffenheiten zu gesondertem Bewusstsein gebracht werden können. (Analysierende Aufmerksamkeit).

\section{DYNAMIK DER AUFMERKSAMKEIT}

\section{Konzentration und Zerstreutheit}

Die Person vermag über die Verteilung ihrer Energieen innerhalb gewisser Grenzen zu verfügen. Davon macht sie im Aufmerksamkeitsakt derart Gebrauch, dass entladungsnahe Energie für die auszuführende Leistung bereit gestellt und verwertet wird. Kürzer ausgedrückt: im Aufmerksamkeitsakt „,konzentriert” sich der Mensch auf die Leistung.

Den Zustand entladungsnaher Energie nennt man „Spannung"; und zwar ist diese mit jeder Aufmerksamkeit verbundene Spannung psychophysisch neutral. Nicht nur das Bewusstsein ist „gespannt" auf das, was sogleich eintreten soll, sondern auch die zur Leistung in Beziehung stehenden Körperteile ${ }^{\mathbf{l}}$ ). Beides kann völlig mit einander verschmelzen. In der Aufmerksamkeit des Uhrmachers,der ein Rädchen zurecht feilt, oder

1) Diese körperlichen Spannungen werden in gewissen Spannungse mpfindungen bewusst, die daher Begleiterscheinungen jedes Aufmerksamkeitserlebnisses bilden. Doch ist meiner Uberzeugung nach diesen Spannungsempfindungen von Seiten mancher früherer Psychologen eine zu grosse Bedeutung beigemessen worden. 
in der des Sportlers, der im nächsten Augenblick das Signal zum Beginn des Wettlaufs erwartet, sind körperliche und seelische Spannungsgeladenheit durchaus eins geworden. Auch bei rein geistigen Leistungen, z.B. beim Lősen einer mathematischen Aufgabe, eines Rätsels, fehlen die körperlichen Energiekonzentrationen niemals; sie finden dann hauptsächlich im Gebiet des Kopfes statt (Stirnrunzeln, Augenschliessen, Kopf in die Hand stützen u.s.w.) und können hier bis zum Grimassieren gehen.

Die dynamische Struktur der Aufmerksamkeit wird aber erst vollständig durch das nie fehlende Gegenbild der Energiekonzentration: die En erg i e-H e m m ung für die übrigen Betätigungsgebiete der Person ${ }^{1}$ ).

Da der Energievorrat der Person in jedem Augenblick begrenzt ist, muss ihre Konzentration auf ein Gebiet erkauft werden durch einen Abzug von Energie aus anderen Gebieten. Je intensiver und spitzer der Kegel der Kraftstrahlen ist, der sich auf die bevorstehende Leistung richtet, um so tiefer der dynamische Schatten, in den alles andere personale Dasein versetzt ist.

Diese Kehrseite aller Aufmerksamkeit ist früher nicht genügend beachtet worden, obgleich sie von allergrösster Wichtigkeit ist. Wer ganz scharf auf irgend etwas, Inneres oder Äusseres, konzentriert ist, sieht und hört nichts, was sonst um ihn herum vorgeht; er rührt kein Glied, so weit es nicht an der Leistung beteiligt ist; ja, er kann sogar zeitweilig den Atem anhalten, um seine ganze Kraft zu jener einen Aufgabe hin punktuell zu verdichten. Wenn zwei Menschen beim Spaziergang in ein schwieriges Gespräch geraten, das zur Formulierung der Gedanken schärfste Aufmerksamkeit verlangt, dann - bleiben sie plötzlich stehen, weil das Gehen noch zu viel Energie abziehen würde. Umgekehrt: wenn die Kreuzung einer verkehrsreichen Strasse eine auf die Gehleistung besonders gerichtete Aufmerksamkeit erfordert, dann niüssen sie das Gespräch unterbrechen und körınen an nichts anderes denken als an den Weg.

Maximale Aufmerksamkeit für eines ist also zugleich maximale Unaufmerksamkeit für anderes; von hier aus gesehen kann man Aufmerksamkeit geradezu einen ,partiellen Schlaf" nennen.

1) Diese Polarität ist derjenigen verwandt, die wir oben (S. 654) als den Gegensatz von besonders intensiver Bewusstheit und Unbewusstheit beschrieben hatten. 
Diese Tatsache findet im praktischen Leben nicht immer die nötige Beachtung. Wenn ein Mensch irgend einem Ereignis beigewohnt hat, so wird - gesunde Sinne und gesunder Geist vorausgesetzt - auch angenommen, dass er die einzelnen Teilvorgänge wahrgenommen haben müsse und deshalb später auch darüber Aussagen machen könne. Nun gibt es aber physische Anwezenheit bei völlig anders gerichteter Aufmerksamkeit; und in diesem Falle ist die obige Annahme irrig.

$\mathrm{X}$ sitzt im Gasthaus, ganz in das Kartenspiel mit Bekannten vertieft. Am Nebentisch, dem $X$ seine Vorderseite zukehrt, beginnt ein Streit, der in eine Messerstecherei ausartet. Vor Gericht soll X aussagen, wer von den Männern am Nebentisch zuerst das Messer gezogen habe. Als $X$ das nicht angeben kann, sagt der vernehmende Richter: "Sie waren doch ganz nahe, und der Vorfall spielte sich in Ihrem Gesichtskreis ab, - da m ü s s e n Sie es doch gesehen haben." Der Richter täuscht sich. Rein physiologisch mögen sich die Vorgänge in der Tat auf der Netzhaut von $\mathrm{X}$ abgebildet haben, - und trotzdem hat er nichts gesehen im Sinne einer bewussten Wahrnehmung. Denn seine, ganz auf das Kartenspiel gerichtete Aufmerksamkeit hat ihn für alles andere buchstäblich blind gemacht. Und wenn der erzürnte Richter ihm vorwirft: „Aber Sie haben doch nicht geschlafen!", dann könnte X erwidern: „Doch, für di e s e Eindrücke befand ich mich in partiellem Schlaf, da mein Wachbewusstsein gänzlich anderen Eindrücken und Handlungen galt." ${ }^{1}$ )

Der Tatbestand der „Unaufmerksamkeit" kann in zwei gänzlich verschiedenen Formen auftreten, in der der soeben geschilderten „Abgelenktheit" und in der der "Z e r s t r e u t h e i t". Diese zweite Form liegt etwa dann vor, wenn jemand behaglich am Meeresstrand liegt und Eindrücke und Vorstellungen ungeordnet an sich vorbeiziehen lässt, sich ihnen passiv hingibt und $\mathrm{k}$ e i $\mathrm{n}$ e $\mathrm{m}$ ein solches Mafs von Energie zuteilt, wie es zu einer eigentlichen „Leistung” nötig wäre.

Äusserlich können beide Formen sich sehr ähnlich sehen, was unter Umständen $\mathrm{zu}$ verhängnisvollen Verwechslungen führt. Ein Lehrer bemerkt, dass ein Schüler den Themen des Unterrichts keine Aufmerksamkeit zuwendet, zusammenschrickt, wenn er angerufen wird und ihn mit einem ganz verlorenen Blick anguckt. Er nennt ihn ,,zerstreut”. Aber ist denn wirklich seine Energie streumälsig, strukturlos und ohne Ausdauer über alles

1) Vgl. hierzu auch S. 353. 
Mögliche ausgegossen, sodass sie für nichts Einzelnes ausreicht? Oder mag nicht vielleicht dieser Knabe sich im Zustand allerstärkster Aufmerksamkeitskonzentration befinden - die er aber der Seeräubergeschichte unter dem Tisch zuwendet, sodass er für den Unterricht nun freilich keine Aufmerksamkeit übrig behält? Sieht man von der schulmälsigen Einstellung des Lehrers $\mathrm{ab}$, für den beide Mal in gleicher Weise ein Versagen gegenüber den Forderungen des Unterrichts vorliegt, beachtet man vielmehr die personale Bedeutung beider Weisen der Unaufmerksamkeit, dann sind sie sich geradezu entgegengesetzt. Im $\mathrm{Zu}$ stand der Abgelenktheit besteht eine durchaus hegemonische, ja des pot is ch e Aufmerksamkeitsstruktur, bei der echten Zerstreutheit eine a $\mathrm{n}$ a $\mathrm{r} \mathrm{ch}$ is $\mathrm{ch}$ e. Wer dispositionell zu der ersten Form neigt, wird, wenn die an ihn gestellten Leistungsansprüche mit seinen spontanen Interessen übereinstimmen, besonders hohe Konzentrationsgrade aufbringen und daher auch zu positiven Leistungserwartungen berechtigen. Der eigentlich ,zerstreute” Mensch aber bietet, solange dieser Zustand besteht, wenig Hoffnung auf Leistungen. Ist der Zustand als konstitutionell anzusehen, so dals der Mensch überhaupt nicht die zu Leistungen nötige Aufmerksamkeitskonzentration aufzubringen vermag, so ist er als seelisch abnorm anzusprechen. ${ }^{1}$ )

Zwischen den beiden hier geschilderten Grenzfällen einer despotischen und anarchischen Energieverteilung gibt es alle möglichen Zwischenstufen. Im Leben jedes Menschen wechseln Zustände stärkerer Aufmerksamkeitsanspannung mit solchen der Erschlaffung, von deren Periodik noch später zu sprechen sein wird. Auch die äusseren Anforderungen bedingen Verschiedenheiten der Konzentration, in intensiver wie extensiver Hinsicht. Die Konzentration muss um so intensiver sein, je schwerer die Aufgabe ist. Es ist dann auch die Selbstbeanspruchung grösser; denn die Zusammenballung eines möglichst grossen Bruchteils der vorhandenen Gesamtenergie auf eine Aufgabe ist nur unter starker Hemmung anderer Energieverwendungen möglich. Wird z.B. eine Abfolge von optischen Vorgängen aufmerksam beobachtet, so ist bei kleinen Reizwerten und schwellennahen Unterschieden eine viel stärkere Konzentration erforderlich,

1) Schon Ribot kannte diesen Unterschied zwischen dem ,,distrait dissipé" und dem ,distrait absorbé." 
als wenn deutlich wahrnehmbare und unterscheidbare Eindrücke vorliegen.

\section{Das A u f m erkamkeitsfeld}

Da jeder Aufmerksamkeitsakt einen Wirkungsumkreis hat, der sich a b g r e n z $\mathrm{t}$ gegen das übrige personale Leben, kann man den bildlichen Ausdruck des ,Aufmerksamkeitsfeldes” anwenden. Um dessen Struktur und die vorkommenden Strukturverschiedenheiten zu klären, müssen wir das gegenständliche und das dynamische Moment gemeinsam berücksichtigen. Denn das Aufmerksamkeitsfeld ist stets zugleich $G$ e g e n s t a n d sf e $1 \mathrm{~d}$ und $\mathrm{K}$ raft feld.

Als erstes Strukturprinzip ergibt sich die schon oben angedeutete $\mathrm{Polarität}$ von Intensität und Extensität. Ein weiterer Umfang des Gegenstandsbereichs bedeutet, dass sich Bewusstheit und Kraft nicht so intensiv zuspitzen können, als wenn es sich um ein ganz enges Feld handelt. Sehr deutlich wird diese Beziehung beim Wechsel des Feldumfanges. Ich stehe auf einem Berge und betrachte die Landschaft. Solange ich mich auf die Landschaft i m $g$ a $n z$ e $n$ richte, werden - bei noch so starker Konzentration - doch die einzelnen Bestandteile der Landschaft nur mit geringen Energiemengen bedacht und erhalten nur einen mittleren Grad von Bewusstheit. Nun wechsle ich die ,,innere Blickrichtung": ich suche und finde in einem, tief im Tal liegenden Ort das Haus, in dem ich wohne, und das Fenster meines Zimmers. Jetzt schiesst plötzlich die gesamte Energie auf diesen Punkt zusammen, alles andere rückt in die Zone des „,partiellen Schlafes”; dafür werden jetzt Einzelheiten an dem kleinen Aufmerksamkeitsobjekt bewusst, die bei der früheren Totaleinstellung auf die Landschaft tief unter der Schwelle lagen.

Ein zweites Strukturprinzip is das der Relief $\mathrm{bildung:}$ auch in $\mathrm{n}$ e $\mathrm{r}$ h a $1 \mathrm{~b}$ des Bereiches nämlich, der der Aufmerksamkeit zugänglich ist, sind nicht alle Bestandteile gleichmäIsig mit Bewusstheit und Energie besetzt, sondern in abgestuften, aufeinander bezogenen Formen. Wir sprachen schon oben von „Bewusstseinsstufen"; diese gibt es auch im Nebeneinander eines einheitlichen Bildes. Die normale Reliefbildung ist die 
„,konzentrische"1): um ein besonders hell beleuchtetes und energetisch betontes Zentrum lagern sich Zonen geringerer Intensität. ${ }^{2}$ )

Ein Beispiel: Beim Chauffeur liegt im eigentlichen Brennpunkt der Aufmerksamkeit die unmittelbar vor ihm befindliche Strecke mit den unbedingt zu berücksichtigenden Hindernissen. Zum weiteren Blickfeld gehören die Seiten der Strasse, die Strassenmündungen rechts und links, aus denen Störungen plötzlich auftreten $k$ ö $n n$ e $n$, die Motorgeräusche, die Zeiger der verschiedenen Uhren u.s.w.

Es gibt eine Aufmerksamkeitshaltung, bei der ein eigentlicher, scharf abgehobener Blick-,,Punkt” fehlt; statt dessen nimmt das weitere Blickfeld als der Möglichkeitsbereich für den erst $z u$ findenden B lickpunkt die Energie mehrschweifend in Anspruch. Diese Haltung liegt allen Tätigkeiten des Wartens, Suchens, Spähens, Lauerns, Kundschaftens zu Grunde. Der eigentliche Gegenstand der Aufmerksamkeit ist noch nicht da; sein Wo und Wann des Wahrgenommenwerdens, vielleicht auch das $\mathrm{Ob}$, Was und Wie ist fraglich. Gerade diese Unbestimmtheit aber erfordert das ständige Überstreichen eines weiteren Feldes mit der Aufmerksamkeit, um im eintretenden Falle den Gegenstand nicht entgleiten zu lassen, ihp vielmehr sofort in den Blickpunkt zu bekommen. Auch erlebnismälsig ist der Unterschied deutlich: im Moment, wo sich das Erwartete oder Gesuchte realisiert, wandelt sich die breite, vage und wandernde Spannung in zugespitzte, zugreifende und festhaltende Konzentration.

Die konzentrische Aufmerksamkeit könnte mit Rücksicht auf den e in e n Brennpunkt, der das Feld beherrscht, ,unifokale" Aufmerksamkeit heissen. Es gibt aber auch eine Feldbildung mit zwei oder mehreren Punkten „(bifokale” bezw. „,multifokale" Aufmerksamkeit). Diese kann in zwei Hauptformen auftreten: entweder gehören die Brennpunkte der Aufmerksamkeit einer komplexen Gesamtaufgabe an ,,(Aufmerksamkeitsteilung"); oder es werden zwei verschiedene, von einander

1) Für diesen Normalfall hat also der Ausdruck , Konzentration” noch einen zweiten Sinn.

") Bei Wundt finden wir die Unterscheidung von „Blickpunkt" und „Blickfeld" der Aufmerksamkeit. 
unabhängige Leistungen gleichzeitig vollzogen (,Aufmerksamkeitsspaltung”, „Mehrfachhandlung”).

Beispiele für den ersten Fall: der Chauffeur, der einem entgegenkommenden Wagen ausweichen und zugleich ein plötzlich den Fahrdamm kreuzendes Kind schonen muss; der Klavierspieler, der die verschiedenen Bewegungen der rechten und der linken Hand gleichzeitig beachten muss; jeder Handwerker und Maschinenarbeiter, der mit Funktionsteilung für beide Hände arbeitet. (Voraussetzung ist hierbei, dass die Bewegungen beider Hände nicht völlig mechanisiert sind, sondern wirkliche Aufmerksamkeit beanspruchen - wie z.B. beim erstmaligen Spielen eines schwierigen Klavierstücks).

Beispiele für den zweiten Fall: Der oben erwähnte Schulknabe, der während des Unterrichts unter dem Tisch sein Abenteuerbuch liest, braucht nicht völlig von dem Klassenbetrieb abgelenkt su sein; er vollzieht dann eine ,Mehrfachhandlung", indem er für den Unterricht eine Nebenaufmerksamkeit aufbringt, die ihn im gebotenen Fall den Anschluss finden lässt. Auch jene Menschen gehören hierher, die imstande sind, während eines Telephongesprächs mit $\mathrm{X}$ einen Brief an $\mathrm{Y}$ weiter zu schreiben.

Philosophierenden Theoretikern hat früher die Verteilungsund Spaltungsfähigkeit der Aufmerksamkeit viel Kopfzerbrechen gemacht, da diese zu der angenommenen Einfachheit der Seele und zur Einheit des Bewusstseins in Widerspruch zu stehen schien. Gelegentlich suchte man der Schwierigkeit durch die Annahme zu entgehen, dass die Gleichzeitigkeit der verschiedenen Leistungen eine Täuschung sei; in jedem Zeitpunkt vermöge sich die Seele stets nur auf eines zu konzentrieren; aber sie könne in schnellster zeitlicher Folge zwischen verschiedenen Einstellungen wechseln; und diese Oszillation erscheine dann als Gleichzeitigkeit.

Eine personalistische Psychologie kennt diese Schwierigkeit nicht. Denn da die Ganzheit der Person immer und überall unitas multiplex ist, besteht kein Widerspruch zwischen der Mehrheit von Einstellungsrichtungen bezw. Energiebrennpunkten auf der einen und der personalen Einheit auf der andern Seite. Wir haben dagegen von unserm Standpunkt aus zu fragen, wi e sich jene Mehrheit dennoch in die Totalität einordnet.

Da ergibt sich für die erste Form der multifokalen Aufmerk- 
samkeit, dass der Sin $\mathrm{ng}$ e halt de r k om plex e n A u f$\mathrm{g}$ a b e selbst den Ganzheitshintergrund für die Aufmerksamkeitsverteilung bildet. Innerhalb einer solchen Leistung erhält jedes Teilmoment vom Ganzen her nicht nur seine Bedeutung, sondern auch seine Bewusstheitsintensität und seinen Energieanteil: das Feld wird zwei (oder mehr)-gipflig modelliert. Dabei treten aber die Gipfelpunkte in eine Rangbeziehung zu einander; es gibt Haupt- und Nebenakzente. So besitzt beim Klavierspiel gewöhnlich die rechte Hand die „Führung”, die linke die „Begleitung"; hat nun einmal mitten im Stück die Linke die Melodieführung zu übernehmen, so wird dies als eine deutliche Verschiebung im Aufmerksamkeitsrelief empfunden.

Anders gestaltet sich die Struktur des Aufmerksamkeitsfeldes bei der eigentlichen Aufmerksamkeits- $\mathrm{S}$ p a $1 \mathrm{t}$ u $\mathrm{n} g$. Hier sind die Bedeutungsgehalte der, gleichzeitig mit Aufmerksamkeit bedachten, Leistungen disparat zu einander; von ihnen aus kann also keine Einheitsbildung erfolgen. Wenn es dennoch nicht $\mathrm{zu}$ einem eigentlichen Zerfall kommt, so deshalb, weil die Totalperson ihre Einheit durch Rangierung und Schichtung der Leistungen zur Geltung bringt. Es werden die gleichzeitigen Leistungen verschiedenen Tiefenlagen der Person zugewiesen: während die eine Aufgabe zentrale Kräfte in Anspruch nimmt, bewegt sich die andere in mehr oberflächlichen Schichten. Auch die Art, wie die Verteilung der Energie auf das Doppeltun organisiert wird, ist nur von der personalen Einheit her zu verstehen.

Hier gewinnt auch die oben erwähnte Oszillationsthese ihre relative Berechtigung. Wenn auch zwei oder mehr Leistungen nebeneinander herlaufen können, so werden doch ihre $G$ i p f e 1 p u n k t e alternieren: zeitweilige Energienachlässe innerhalb des einen Leistungsgeschehens werden verwertet $z u$ energetischen Zuspitzungen des anderen. Jener Mann, der $\mathrm{z} \mathrm{u} \mathrm{g} \mathrm{l} \mathrm{e} \mathrm{i} \mathrm{c} \mathrm{h}$ korrespondiert und telephoniert, unterbricht zwar die Schreibtätigkeit nicht während des Sprechens, aber er organisiert sein Doppeltun doch so, dals er die neuen Gedankenformungen, die jeweilig für einige Sekunden Schreibstoff liefern sollen und besondere Aufmerksamkeitsgipfelung verlangen, vorwiegend in jene Zeitpunkte verlegt, in denen das telephonische Gespräch geringere aktive Aufmerksamkeit erfordert - und umgekehrt. 


\section{Ablaufsweisen der Aufmerksamkeit}

Bezüglich des zeitlichen Verlaufs kann man m o m e $\mathbf{n} \mathbf{t}$ a $\mathbf{n}$ e und d a e r nde Aufmerksamkeitsleistungen unterscheiden, obzwar die Grenzen flüssig sind. Wenn mir ein Plakat an der Anschlagsäule auffällt, wenn ich aus meinem Schlüsselbund einen Schlüssel heraussuche, wenn der aufgerufene Schüler die Frage des Lehrers beantwortet, so sind hierfür Aufmerksamkeitskonzentrationen nötig, die zwar eine gewisse Zeit dauern, deren Erfüllung sich aber ganz in e in e r Gegenwart erschöpft. Wenn man dagegen einem Vortrag zuhört, oder wenn der Matrose im Ausguck stundenlang Meer, Himmel und etwa sichtbar werdendes Land beobachten muss, oder wenn der Schüler nach dem Diktat des Lehrers eine Niederschrift macht, so ist nicht sowohl ein einzelner Aufmerksamkeitsakt, sondern eine länger währende Aufmerksamkeitshaltung erforderlich.

Für beide Fälle gilt nun die Regel, dass die Energie eine Wellenbewegung zeigt.

Beim akuten Aufmerksamkeitsakt gibt es nur e i n e W e 11 e. Wird die - bisher anderweitig beschäftigte - Aufmerksamkeit einer Augenblicksanforderung zugewandt, so setzt nicht sofort die volle Energie ein; sie hat vielmehr eine merkliche (wenn auch kurze) Anstiegszeit, erreicht beim eigentlichen Ziel der Handlung eine Kulmination und sinkt dann mehr oder minder schnell ab. Deutlich ist diese Kurve zuweilen in der Schulklasse zu merken. Wird ein zerstreuter oder abgelenkter Schüler plötzlich aufgerufen, so braucht sein Bewusstsein ein wenig Zeit, um zu jenem Höhepunkt der Konzentration empor zu klettern, der die Findung und Formulierung der Antwort ermöglicht. Ist dies geschehen, so bleibt der Schüler noch einige Sekunden in dem Abklang des Erlebnisses auch energetisch befangen, ehe er wieder in seine Träume versinken oder sich den unterbrochenen Gedanken erneut zuwenden kann.

Dauerndes Aufmerksamkeitsverhalten dagegen hat stets eine peri o d is c h e Struktur. Ist der Mensch längere Zeit ununterbrochen einer Beschäftigung zugewandt, so gibt es niemals einen, auf gleicher Höhe stetig strömenden, Energiefluss, sondern in Abständen von wenigen Sekunden Kulminationen, die durch mehr oder minder tiefe Aufmerksamkeitstäler getrennt sind. 
Man bringe die Taschenuhr in eine solche Entfernung vom Ohr, dass man das Ticken eben noch hört. Lauscht man dann längere Zeit, so wechseln Momente des Hörens und NichtHörens. Die Ticke verschwinden, tauchen wieder aus dem Nichts auf, verklingen von neuem, u.s.w. Die zur Wahrnehmung schwellennaher Reize erforderliche hohe Aufmerksamkeit kann eben nicht ununterbrochen aufrecht erhalten bleiben.

Rückt man nun die Uhr näher ans $\mathrm{Ohr}$, sodass alle Ticke hörbar bleiben, so werden sie doch in verschiedener Intensität wahrgenommen. Ja noch mehr: wir sind gezwungen, aus ihnen rhythmische Zeitgestalten zu bilden mit betonten und unbetonten Taktteilen, d.h. die Schläge werden abwechselnd mit stärkerer und geringerer Aufmerksamkeitsenergie bedacht.

Der kleine Versuch kann aber noch etwas anderes lehren: dass der Zwang zur Periodenbildung doch nicht eindeutig Art und Dauer der Periode bestimmt. Vielmehr hat hier wieder die Person selbst eine gewisse Verfügungsfähigkeit über die Energieverteilung. Denn man vermag die Folge gleichförmiger Ticke als 2/4Takt, 3/4-Takt, 4/4 Takt, 6/8-Takt zu hören und beliebig zwischen den verschiedenen Taktarten $\mathrm{zu}$ wechseln, obgleich sich am objektiven Reizablauf nichts ändert. Die subjektive Periodenbildung kann hierbei so aufdringlich sein, dass man fest überzeugt ist, die Taktteile in objektiv verschiedener Intensität $z u$ hören.

Auch auf die tatsächliche Objektformung wirkt jener Periodisierungszwang hinüber, nämlich überall dort, wo es die Kultur mit kurz dauernden Zeitgestalten zu tun hat. Der Wechsel von betonten und unbetonten Silben in der Sprache, wie von starken und schwachen Taktteilen in der Musik, steht in enger Korrelation zu dem Wechsel von Aufmerksamkeitsgipfeln und -tälern, der sich bei Hervorbringung und Aufnahme jener Gebilde einstellt.

III. ÄUSSERE UND INNERE BEDINGUNGEN DER AUFMERKSAMKEIT

1. Reaktive und spontane Aufmerksamkeit

Die Bedingungen für Einleitung und Durchführung von Aufmerksamkeitsakten unterliegen dem Konvergenzprinzip; d.h. es sind stets zugleich äussere und innere Faktoren beteiligt. 
Am deutlichsten ist die Wirkung des Aussenfaktors bei der sogenannten sinnlichen Aufmerksamkeit, denn sie wird durch aufdringliche äufsere Reize hervorgerufen. Das sich nähernde Geräusch eines Flugzeuges, oder die Rakete eines Feuerwerks, oder ein Brandgeruch haben einen zwingenden Forderungscharakter; es ist unmöglich, sich ihnen zu entziehen. Aber selbst hier darf man den subjektiven Anteil der Person nicht übersehen. So unentrinnbar der Zwang zur Reaktion auf den aufdringlichen Reiz sein mag: dass die Reaktion gerade in A u f $\mathrm{m}$ e r k a m k e i t besteht, ist ja innerlich bedingt.

Beispiel. Am Abendhimmel breitet sich ein intensiver Feuerschein aus. Hierauf reagieren verschiedene Menschen ganz verschieden. Ein ängstliches Kind erschrickt, beginnt zu schreien, läuft fort. Der Türmer greift automatisch zum Glockenseil, aus Gewohnheit, ohne sich erst klar machen zu müssen: da ist ein Brand. Ein Aesthet lässt sich von der Stimmung des schaurig schönen Farbenspiels gefangen nehmen. All dies ist nicht „Aufmerksamkeit". Sie liegt erst bei jenem vor, der durch den optischen Eindruck bewogen wird, seine Kraft auf bewusste Klärung des Gegenstandes „Feuerschein” (nach Art, Umfang, Ursprungsort) zu konzentrieren. Er reagiert also auf den Reiz durch einen Willensakt, der eine Erkenntnisleistung intendiert.

Man ersieht hieraus, dass die übliche Scheidung des Sprachgebrauchs zwischen ,unwillkürlicher" Aufmerksamkeit und ,willkürlicher" Aufmerksamkeit nicht recht passend ist, da ein Leistungswille bei einem Aufmerksamkeitsakt nie fehlen kann. Nur der An 1 as s zur Aufmerksamkeit kann aulserhalb oder innerhalb des Wollens liegen; die Aufmerksamkeitshandlung ist im ersten Falle eine $\mathrm{reakt} \mathrm{ive}$, im zweiten Falle eine s pontane Willenstat. Wer sich selbst aus innerem Antrieb an die Lösung einer mathematischen Aufgabe macht, veranlasst sich ,willkürlich" zu ,,spontaner” Aufmerksamkeit. Wenn dann der Verlauf des Arbeitens durch das Klingeln des Telephons unterbrochen wird - und sich der Arbeitende unterbrechen 1 ä s s t und zum Hörer greift - dann liegt ein dem Willen entzogener Anlass und eine reaktive Aufmerksamkeitshandlung vor.

Der Beginn eines reaktiven Aufmerksamkeitsaktes ist demnach stets doppelsinnig; er besteht nicht nur in der Hinlenkung der Aufmerksamkeit auf den Sinnenreiz, sondern auch in der 
Unterbrechung des bisherigen seelischen Zustandes. Mit dem Reiz, der sich der Aufmerksamkeit aufdrängt, beginnt ein neues Lebnis; der stetige Abfluss des personalen Geschehens findet abrupt ein Ende. War jener Abfluss irgendwie lustvoll, oder in seinem Sinnvollzug noch nicht abgeschlossen, so wird die Unterbrechung als St ör u n g erlebt. Bestand der bisherige Zustand selber in einem Aufmerksamkeitsverhalten, so wirkt der aufdringliche Reiz als A b l e $\mathrm{n} \mathrm{k} \mathrm{u} \mathrm{ng.} \mathrm{Es} \mathrm{bleibt} \mathrm{dann} \mathrm{zwar} \mathrm{jener}$ allgemeine energetische Spannungszustand bestehen, der jeder Aufmerksamkeit wesentlich ist - aber der Gegenstand wechselt infolge des äusseren Anlasses.

Hier taucht aber noch ein zweites Mal das Konvergenzproblem auf. W a $\mathrm{n} n$ ist ein Reiz so aufdringlich, dass er zum Störungsoder Ablenkungsreiz wird? Die ältere Elementenpsychologie hat hier wiederum ,A ufdring lich ke i t" als ein Merkmal des Einzelreizes selber angesehen, und zwar hat man besonders auf die nahe Beziehung zur Reizintensität und zur Reizveränderung hingewiesen. Es ist gewiss richtig, dass ein lauter Knall eher die Aufmerksamkeit reizt, als ein leiseres Geräusch, ein greller Blitz eher als das schwache Aufleuchten eines Streichholzes. Aber wie wenig hiermit das Wesentliche der „Aufdringlichkeit” getroffen ist, lehren bekannte Beispiele: $\left.{ }^{1}\right)$ Der Soldat im Schützengraben achtet nicht mehr auf das Dröhnen der Kanonen, wohl aber auf das akustisch viel weniger intensive Kommandowort. Für die junge Mutter ist das leise Wimmern ihres Babys im Nebenzimmer stärkster Ablenkungsreiz, während das sehr laute Weinen eines fremden Kindes ihre Aufmerksamkeit unberührt lassen kann u.s.w. Die „Aufdringlichkeit” eines Reizes ist also vor allem von seiner personale $\mathrm{n} B$ edeutsamkeit abhängig; je nach der Rolle, die der Reiz im personalen Leben spielt, oder möglicher Weise spielen kann, übt er eine stärkere, bezw. geringere Anziehungskraft auf die Aufmerksamkeit aus. Nun ist ja oft genug ein starker Reiz von grösserer personaler Relevanz als ein schwächerer. Und ein Reiz, der erst eben in den Gesichtskreis $t \mathbf{r}$ it $\mathbf{t}$, kann gerade wegen seiner Neuheit eher Lebenswichtigkeit gewinnen, als ein solcher, der unverändert beharrt. So wird es verständlich, dass Reizstärke und Reizver-

1) Vgl. die entsprechenden Beispiele für die Wirksamkeit von W e ckreizen: S. 471 . 
änderung eine merkliche Korrelation zur Aufdringlichkeit besitzen.

Die Gegenstandsauslese, die die Aufmerksamkeit vornimmt, hängt demnach nicht in erster Linie von der akuten Beschaffenheit der Reize ab, sondern von der personalen Disposition, die dauernd zur Klärung bestimmter Gegenstände tendiert. Eine solche Disposition nennt man „I n t e re s s e". 1) Der Zusammenhang von Interesse und Aufmerksamkeit ist äusserst innig; eine ganz ,interesselose Aufmerksamkeit” gibt es überhaupt nicht. Höchstens, dass man zwischen direktem und indirektem Interesse scheiden kann. Dort sind Gegenstand des Interesses und der Aufmerksamkeit von vorn herein identisch: so wenn jemand, der sich stark für Mathematik interessiert, eben darum seine mathematischen Aufgaben mit grosser Aufmerksamkeit bearbeitet. Hier - beim indirekten Interesse - ist der Aufmerksamkeitsgegenstand vom Interessegegenstand verschieden, aber er steht in Abhängigkeitsbeziehung zu ihm: so wenn sich ein Schüler energisch auf seine mathematischen Aufgaben konzentriert, weil er stärkstes Interesse am Bestehen des Examens hat (das Interesse für Mathematik kann dann sehr gering sein). Der erste Fall stellt die günstigsten Bedingungen für fruchtbare und energetisch nicht allzu mühsame Aufmerksamkeitsleistungen dar. Bei nur indirektem Interesse ist es ja nötig, besondere Energie auf die Überwindung des Widerstandes gegen den , eigentlich nicht interessierenden" Gegenstand zu verwenden.

2. Konstanz und Wechsel im Aufmerksamkeitsverhalten

Bei Aufmerksamkeitszuständen, die längere Zeit anhalten, kann der gegenständliche Inhalt konstant bleihen oder wechseln. Wiederum sind hieran objektive wie subjektive Bedingungen beteiligt.

Bezüglich der o b j e k t i v e n Reizfolge gibt es unzählige Abstufungen. Wir nennen nur zwei Grenzfälle: völlig gleichförmig ist die Aufgabe des Schulneulings, der eine ganze Seite seines Heftes mit dem gleichen Buchstaben i füllen muss; ununterbrochen wechselnd ist die Tätigkeit des Schalterbeamten

1) Vgi. S. 792. 
einer Auskunfststelle, an den in jeder Minute neue Wünsche und Fragen herantreten. Solch extreme Situationen stellen an die Aufmerksamkeit Ansprüche von besonderer Schwierigkeit. Die ganz e in tönige Leistungfolge gleitet leicht in rein mechanisches Tun ab; die Aufmerksamkeit ,schläft ein”, weil ihr jedes Spannungsmoment, jeder Reiz der Neuheit fehlt. Die ganz dis parate Leistungsreihe dagegen verlangt ununterbrochen sprungháften Wechsel der Aufmerksamkeitseinstellung, verhindert jedes Ausruhen in dem erfassten Gegenstand und die Vertiefung in ihn, zerreisst den Lebensablauf in lauter unzusammenhängende, $\mathrm{zu}$ einander sinnfremde Teilabschnitte.

Sehr deutlich tritt der Unterschied zu Tage an zwei bekannten Experimentalmethoden.

Seitdem vor Jahrzehnten Kraepelin sogenannte "f or $t$ l a u f e nde Arbeits meth oden" zu psychologischen Untersuchungszwecken eingeführt hat, sind monotone Reizserien vielfach zur Anwendung gekommen. Kraepelin verwandte mit Vorliebe $R$ e c h e $n-$ a uf $\mathrm{g}$ a ben, die schon deshalb untereinander sehr ähnlich sein mussten, weil die, in verschiedenen Zeitabschnitten erzielten, Leistungen mit einander verglichen werden sollten (z.B.: Addition einstelliger Zahlen). - Für Aufmerksamkeitsprüfungen hat besonders die von Bourdon eingeführte $D$ u r c h s t r e i c h p r o b e weite Verbreitung gefunden: in einem gedruckten Text sind gewisse Buchstaben - z.B. alle $1, r, n-z u$ durchstreichen. Die Anzahl der durchstrichenen Buchstaben innerhalb einer bestimmten Zeit liefert ein Mals für die $\mathrm{Ge}$ schwindigkeit der Aufmerksamkeitsleistung; die Anzahl der Fehler (übersehene Buchstaben und falsche Durchstreichungen) ein Mafs für die Intensität der Aufmerksamkeit, die ungleiche Verteilung der Fehler auf die verschiedenen Phasen der Arbeit eine Einsicht in die Aufmerksamkeitsschwankungen. Die Aufgabe ist reichlich eintönig, aber doch nicht in dem Grade, dass sie völlig mechanisiert werden könnte; jedes Nachlassen der Aufmerksamkeit rächt sich vielmehr sofort durch Ubersehen von Buchstaben, die gestrichen werden sollten. - Andere, namentlich psychotechnische, Experimentalaufgaben sind der industriellen "Arbeit am laufenden Bande" nachgebildet, so die Versuchsanordnung am Monotonie-Apparat von Wunderlich.

Am anderen Pol stehen die "T es $t$ h ef $t-A$ uf $g$ a b e n", die zuerst in Amerika, dann auch anderwärts (in Deutschland durch Bobertag und Hylla) Anwendung gefunden haben. Das Heft enthält in buntester Reihenfolge Aufgaben und Anweisungen heterogenster Art, die schriftlich zu lösen sind; für jede Aufgabe stehen nur wenige Sekunden zur Verfügung, nach deren Verlauf zur nächsten übergegangen werden muss. Diese Testhefte sind zwar als Mittel zur Prüfung der „Intelligenz" gedacht; aber in Wirklichkeit ist am Ergebnis des Versuchs 
nicht nur die Fähigkeit beteiligt, intellektuelle Schwierigkeiten zu bewältigen, sondern auch die andere Fähigkeit, mit der Aufmerksamkeit in einer zusammenhanglosen Reihe dauernd zu springen.

Die o b jektiv geeignetste Vorbedingung für dauernde Aufmerksamkeitshaltung bieten offenbar solche Forderungsreihen, die gleich weit von öder Eintönigkeit wie von chaotischer Buntheit entfernt sind. Solche optimalen Bedingungen können von zweierlei Art sein.

1) Die fortlaufende Arbeit steht zwar unter einer Anforderung von genereller Gleichförmigkeit; doch verlangt die Aufgabe in jedem einzelnen Aufmerksamkeitsakt eine wechselnde Spezialisierung der Einstellung.

Als Beispiel diene die Umformung des Bourdon'schen Durchstreichversuchs durch Sterzinger zur "Prüfung der a bstrakten Aufmerksamkeit": Nicht mehr bestimmte, immer id e n t is c h e Buchstaben sollen durchstrichen werden, sondern solche Buchstaben, die einer $\mathrm{R}$ e g e 1 folgen: nämlich erstens jeder einzeln stehende Buchstabe zwischen zwei Vokalen, zweitens jeder Buchstabe, der auf einen gleichen folgt, drittens alle Gruppen zu zwei Buchstaben, denen eine ebenso gebaute Gruppe vorausgeht.

Auch manche Intelligenztests gehören hierher: so verlangt der „Analogietest" (S. 431), zu drei gegebenen Wörtern das vierte begrifflich dazu gehörige Wort zu finden. Hier stellt zwar jedes Wortiripel neue Ansprüche, aber sie stehen doch unter einem gemeinsamen Leitmotiv. Allerdings enthält dieses eine solche Spielraumbreite, dass innerhalb ihrer die Aufmerksamkeit auf der Wacht sein muss. Mechanisierung des Tuns ist unmöglich.

2) Die fortlaufende Arbeit wird durch einen Ge s a m t s i n n und durch ein zu erreichendes Ziel zusammengehalten; die einzelnen zum Ziel führenden Schritte aber sind verschieden. In diese Gruppe fallen etwa technische Aufgaben der Werkherstellung, des graphischen oder plastischen Nachbildens, die Bearbeitung einer mathematischen Aufgabe, deren Lösung eine Reihe von Etappen erfordert u.s.w. Der objektive Anreiz für das Durchhalten der Aufmerksamkeit ist hier noch stärker als im Falle 1); denn der Sinnzusammenhang der Gesamtaufgabe aktiviert tiefere personale Schichten, wie Denken, Interesse, Gefühlsbeteiligung, und unterstützt dadurch die längere Energiekonzentration.

Der Unterschied zwischen Konstanz und Wechsel kann aber auch vornehmlich s u b j e k t i v bedingt sein. Die Aufmerksam- 
keit „beisst sich fest” an einem Gegenstande, sodass sie längere Zeit nicht von ihm loszukommen vermag; oder aber: es findet ein häufiges Springen von einem Aufmerksamkeitsbrennpunkt zu einem andern statt. Beide Verhaltungsweisen sind bei gleichen objektiven Bedingungen möglich. Ein ruhendes Objekt, z.B. ein figurenreiches Gemälde, kann mit „haftender” Aufmerksamkeit betrachtet werden, die am Ganzen oder einer Einzelheit statisch verweilt, oder mit „wandernder”, die der Reihe nach die Einzelheiten geistig abtastet, oder gar überhaupt von dem Bild auf ganz andere Gegenstände abgleitet. - Umgekehrt: eine bewegte Reizreihe, z.B. der Inhalt einer Lektüre, kann bewirken, dass man von einer Stelle noch geistig okkupiert ist, während man mechanisch weiter gelesen hat; oder aber die Aufmerksamkeit wandert mit den wechselnden Gedanken und Geschehnissen des Textes mit. Man sieht an diesen Beispielen schon, dass die haftende oder die wandernde Aufmerksamkeit je nach Umständen mehr oder minder situationsangemessen sein kann - wovon weiter unten noch zu sprechen sein wird.

IV. ZUR DIFFERENTIELLEN PSYCHOLOGIE DER AUFMERKSAMKEIT

Auch die typologischen Unterscheidungen auf dem Gebiet der Aufmerksamkeit sind nach den beiden Merkmalen der Gegenständlichkeit und der Dynamik zu orientieren.

\section{Gegenständliche Typen}

Alle jene Gegenstandsbereiche, die wir oben aufzählten, können zu personal be vor z u g t e n Aufmerksamkeitssphären werden. So gibt es Menschen von ausgesprochen sinnlichem Aufmerksamkeitstyp, andere, deren Aufmerksamkeit Denkprobleme oder die Zergliederung innerer Erlebnisse bevorzugt. Diese Differenzierungen, so wichtig sie sind, beziehen sich eigentlich nicht primär auf die Aufmerksamkeit als solche; vielmehr ist die Vorzugsgerichtetheit der Aufmerksamkeit zurückzuführen auf tiefere personale Richtungsdispositionen: auf Interessen, auf Triebveranlagungen, auf besondere Begabungsrichtungen u.s.w.

Diese nie fehlende Gegenstandsgebundenheit der Aufmerksamkeitsdisposition darf bei personal-diagnostischen Untersuchungen 
nie vergessen werden; Aufmerksamkeit ist eben niemals ein so ausschliesslich for m a 1 e r Faktor, dass er sich an beliebigem Stoff gleichförmig bekunden könnte.

Wir treffen damit einen Hauptmangel der meisten Testmethoden zur Prüfung der Aufmerksamkeit; die Aufgabe als solche (z.B.: Buchstaben durchstreichen) erweckt fast niemals direktes Interesse; lediglich das indirekte Interesse, in der Prüfung gut abzuschneiden, liefert die Impulse für die Aufmerksamkeit. Es ist daher stets möglich, dass ein, auf solche Weise geprüfter, Mensch eine ganz andere Aufmerksamkeit betätigen würde, wenn er sie spontan auf Gegenstände direkten Interesses richten könnte.

Auf der andern Seite ist freilich zu bedenken, dass auch im Alltagsleben jeder Mensch oft genug vor Aufgaben gestellt ist, die ihn direkt nicht interessieren, auf die er aber seine Aufmerksamkeit konzentrieren muss; für s ol $\mathrm{c}$ h e Leistungen können natürlich die oben erwähnten Testprüfungen wichtige Symptome liefern.

Es empfiehlt sich daher, bei personal-diagnostischen Aufmerksamkeitsprüfungen $z$ wei Arten von Tests zu verwenden: solche, die nur das indirekte Interesse spielen lassen, und solche, die dem eigensten Interessengebiet des Prüflings entnommen sind. Erst bei letzteren kann er sein wirkliches Aufmerksamkeits-O p t i m u m beweisen.

\section{Dynamische Typen}

Mit den hierdurch bedingten Vorbehalten kann man nun auch typologische Unterschiede in der $\mathrm{dy} \mathrm{namis} \mathrm{ch}$ e $\mathrm{n}$ Beschaffenheit der Aufmerksamkeit feststellen. Alle jene Strukturmerkmale, die wir früher erörterten, vermögen zu kennzeichnenden Persönlichkeitszügen zu werden. Entscheidend ist, ob der Mensch zu mehr intensiver oder mehr extensiver Energieverteilung neigt.

Der eigentlich „k o n z e n t.r a $t$ i v e" Typ pflegt ein kleines, fast punktuelles, aber um so heller beleuchtetes Aufmerksamkeitsfeld zu haben, während alles andere in das tiefe Dunkel des Nichtbeachtetseins versinkt. Er vertritt zugleich bei längeren Abläufen den „,fixierenden” Typ, der eine zäh haftende Aufmerksamkeit besitzt. Das Musterbeispiel ist der Grübler.

Das extreme Gegenstück bildet der schon früher (S. 661) besprochene Typ der ,echten Zerstre u h e i t”, bei welchem die Energiestreuung so weit geht, dass eigentliche Aufmerksamkeitskonzentrationen überhaupt nicht mehr möglich sind.

In der Mitte steht der „d is t ributive” Typ. Sein Auf- 
merksamkeitsfeld besitzt einen weiteren Umkreis, aber doch mit genügender innerer Energiebesetzung und Strukturierung (die multifokal sein kann); und seine Aufmerksamkeitsabläufe sind wendig und elastisch, auch leicht ablenkbar, ohne ins ChaotischSprunghafte auszuarten. Ihm gehören gewöhnlich die weltzugewandten und weltgewandten Menschen an.

Während der Typ des ,echt Zerstreuten” eindeutig unterwertig, oft genug geradezu krankhaft ist, wäre es verkehrt, die beiden anderen Typen wertmälsig zu rangieren. Die Laienpsychologie neigt ja dazu; sie lobt die Ausdauer, Tiefe und Unbeirrbarkeit des „konzentrativen”, tadelt die Unbeständigkeit, Oberflächlichkeit und Ablenkbarkeit des ,distributiven” Menschen. Solche Charakterisierungen sind aber einseitig unter bestimmten äusseren Forderungsmalsstäben gesehen, die durchaus nicht allgemein gelten. Das Leben fordert beides: Zuspitzung und Ausbreitung, Haftenlassen und Wandernlassen der Aufmerksamkeit, Ablenkbarkeit und Widerstand gegen Ablenkungen. Es wäre für den höchst konzentrativen Archimedes besser gewesen, wenn er durch den sich nähernden Kriegslärm von seinen mathematischen Grübeleien sich hätte ablenken lassen; statt dessen sah er in den hereindringende Kriegern nur unliebsame Störungen seiner Kreise - und er wurde erschlagen. - Ein Chauffeur, der nicht in hohem Malse seine Aufmerksamkeit verteilen könnte, und sich nicht durch jeden neu in den Gesichtskreis tretenden Gegenstand von seiner bisherigen Aufmerksamkeitseinstellung ablenken liesse, wäre völlig berufsuntauglich.

Je mehr eine zunehmende Zivilisation den Menschen in eine verwirrende und fortwährend wechselnde Fülle von Ereignissen und Gegenständen setzt, die für ihn lebensbedeutsam werden können und daher seine Aufmerksamkeit erfordern - um so mehr bedarf er der Verteilungs- und Wechselfähigkeit dieser Aufmerksamkeit; sonst kommt er zum Erliegen. Zugleich freilich fordern alle jene Aufgaben, die nicht vom Augenblick bestimmt und von der Situation abhängig sind - also wissenschaftliche und künstlerische Leistungen, Aufgaben der inneren Sammlung und der weit ausschauenden Planung - sie fordern ein zeitweiliges Sichverschliessenkönnen gegen die breite Fülle der wechselnden Reize, also erhöhte Konzentration, deren daher gerade die führenden Geister fähig sein müssen. Aber nicht nur diese; denn auch jene 
Durchschnittsmenschen, welche sich möglichst in ein enges Gehäuse einspinnen (oder in ein solches eingezwängt werden), um hier in relativ gleichförmiger Weise eine begrenzte Reihe von Verrichtungen $\mathrm{zu}$ vollziehen (der Landmann, der Industriearbeiter, der Rechner in der Kanzlei) würden von einer allzu distributiven Aufmerksamkeitsweise geringen Vorteil haben. 


\title{
SIEBENUNDZWANZIGSTES KAPITEL
}

\author{
$\ddot{U}$ B U N G U N D E R M Ü D U N G
}

Wir haben nun jene Leistungsänderungen zu erörtern, die auf b e s $t$ i m m t e n Betätigungsgebieten sowohl in positivem Sinne (als Übung) wie in negativem (als Ermüdung) auftreten. Auch bei diesen sind, wie überall im Leben, äussere und innere Bedingungen in Konvergenz wirksam, aber die äusseren übernehmen jetzt die Führung.

\section{I. ÜBUNG}

1. Reifung, $\ddot{U} b u n g$, Einstellung

Zunächst ein Wort über den Anteil des inneren Faktors an der Steigerung der Leistungen.

Es liegt im Wesen der personalen Entwicklung, dass der Mensch bestimmten Leistungsgebieten e $\mathrm{n} t \mathrm{~g}$ e $\mathrm{g}$ e $\mathrm{n} \mathrm{r}$ i i $\mathrm{t}$. Leistungen, die vorher garnicht oder nur sehr unvollkommen möglich waren, werden nun mit grösserer oder geringerer Plötzlichkeit angemessen aus führbar, weil die ihnen entsprechende Leistungsfähigkeit und Leistungsbereitschaft in ihr Reifungsstadium getreten ist. Die Berücksichtigung dieser immanenten Entwicklungssteigerung ist deshalb so wichtig, weil erst auf Grundlage der reifenden Anlagen die äusseren Bedingungen der Leistungssteigerung erfolgreich eingesetzt werden können. Man erlebt es oft (z.B. beim mathematischen oder beim grammatischen Unterricht von Schulkindern), wie selbst lange und kraftraubende Übung geringe Leistungsfortschritte bringt, solange jenes Entgegenkommen der inneren Reifung fehlt, und wie dann mit deren Eintritt unerwartet und sprunghaft das weitere Üben und Lernen fruchtbar wird und rapiden Fortschritt ermöglicht. 
Die Leistungsreifungen spielen in Kindheit und Jugendalter natürlich eine besonders grosse Rolle; aber sie fehlen auch nicht beim Erwachsenen. Insbesondere gilt dies für $s c h$ ö p feris c h e Leistungen von Künstlern, Gelehrten u.s.w. Bekanntlich gibt es Früh- und Spät-Genies; das Einsetzen der grossen Schaffensfähigkeit ist in diesen Fällen nur sehr sekundär von äusseren Bedingungen abhängig, vielmehr ganz wesentlich Sache einer inneren Entwicklungsgesetzlichkeit.

Géza Révész hat eine Untersuchung über die Reifungszeiten von Hochbegabungen angestellt. Er fand, dass im Durchschnitt die musikalischen und mathematischen Begabungen am frühesten, die literarischen am spätesten zum Durchbruch kommen.

„Ü b u n $g$ " ist spezifische Leistungssteigerung durch willentliche Wiederholung von Leistungen. Der Ausdruck wird gebraucht sowohl für die wiederholte $\mathrm{T}$ ä t i g k e i t, welche Leistungszunahme erzielt, wie für den erreichten hohen Leistungs $z$ u st a n d ${ }^{1}$ ).

Wir müssen die „Übung” ferner von der „Einstellung” unterscheiden.

Wird eine Tätigkeit begonnen, die vorher nicht vollzogen wurde, so ist der Mensch zunächst noch nicht auf sie „eingestellt”. Er war mit anderem beschäftigt; hierdurch war seine körperliche Haltung, seine Aufmerksamkeit, sein Interesse, seine Kraftökonomik, kurz die Totalperson ausgerichtet auf ein anderes Ziel. All dies muss nun umgeschaltet werden; das ganze Verhältnis Person/Welt muss sich verschieben, um die neue Zielsetzung ins Zentrum personalen Tuns zu rücken. Das geschieht nicht mit einem Mạle; vielmehr stellt sich die neue Totaleinstellung erst allmählich ein. Dieser Prozess wird durch Wiederholung sehr unterstützt; er ist aber nicht „Übung” im eigentlichen Sinn, obwohl sich während seines Ablaufs die Leistung steigert. Von Menschen, die eine einigermalsen gleichförmige Tätigkeit vollziehen müssen, hört man oft, dass sie jedes Mal erst wieder ,in den Trott kommen müssen"; der Klavierspieler, der Maschinenschreiber, muss seine Arbeit „erst wieder in die Finger bekommen"; der Buchhalter bedarf bei Beginn seines rechnerischen Tagewerks, der Turner am

\footnotetext{
1) Es wäre vorteilhafter, wenn man nur die T ä t i g k e i t „UỦbung," den Zustand aber ,Geübtheit" nennen würde.
} 
Anfang des Turnens erst eines gewissen Selbstantriebs und der Überwindung von Widerständen, die von dem Bedürfnis des Verharrens im früheren Zustand herrïhren.

Geistige Arbeiter empfinden diese Anfangshemmungen besonders lebhaft; sie machen ihnen nicht nur den Entschluss schwer, ihre unterbrochene Arbeit wieder aufzunehmen, sondern wirken noch nach während des Anfangsstadiums des erneuten Arbeitens, die dadurch nur allmählich in Gang kommt.

Die eigentliche, s pezifis che Übung setzt erst ein, wenn die Totaleinstellung auf die fortlaufende Aufgabe erreicht ist. Nunmehr kann die fortgesetzte Wiederholung des Tuns ihre Sonderwirkung entfalten, die sich auf die beiden Komponenten der Leistung erstreckt; denn jedes Üben setzt sich sowohl Steigerung des Effekts, wie Minderung des Aufwandes zum Ziel. Vergleicht man den Anfänger im Radfahren mit dem geübten Fahrer, so fährt der erste nicht nur unsicherer, langsamer, unschöner, mit häufigeren Fehlhandlungen und Versagern, sondern er macht auch viel mehr überflüssige Bewegungen mit allen Gliedern, strengt sich physisch mehr an, muss mehr Aufmerksamkeit und Willensimpulse auf sein Tun verwenden als der fertige Fahrer ${ }^{1}$ ).

Merkwürdiger Weise besteht zwischen diesen beiden Seiten der Übungswirkung eine gewisse Antinomie. Während das Ziel der Effektsteigerung die Tätigkeit besonders stark in den Vordergrund des personalen Lebens rückt und immer schärfer $a b$ $\mathrm{e} \mathrm{b} \mathrm{t}$ von dem Alltagsgeschehen, bedeutet die Aufwandsverringerung eine zunehmende Einbettung des Tuns in das Totalleben, eine abnehmende Inanspruchnahme der Gesamtdynamik durch eben dieses Tun. Dort wird die Wichtigkeit, hier die Selbstverständlichkeit der Leistung erhöht; dort wird ihre Bewusstheit besonders akzentuiert; hier wird die Ausführung mehr und mehr ins Unterbewusste gedrängt.

Die Antinomie bedeutet aber nicht Unvereinbarkeit, sondern nur wechselnde Gewichtsverteilung. Bei den Übungen des praktischen Alltagslebens kommt es vor allem auf das Erringen einer selbstverständlichen Treffsicherheit an, bei welcher

1) In unserer oben (S. 639) entwickelten Terminologie heisst das: Ubung ist Erhöhung der objektiven Leistung bei Minderung der personalen Leistung. 
nicht mehr viel Kraft und Bewusstheit für die rein technische Durchführung erforderlich ist. Dadurch wird Kraft frei für andere Aufgaben. Wer geübt ist im Gebrauch einer Fremdsprache, hat es nicht mehr nötig, sich auf das Suchen von Worten und grammatischen Formen zu konzentrieren, sondern kann das Sprechen in den Dienst andersartiger Aufgaben: der Geselligkeit, des Berufs, der Wissenschaft stellen. Wer geübt ist im Maschineschreiben, kann sogar schwierige Gedankenarbeit sofort in Schrift umsetzen, da ihm das Schreiben selbst $\mathrm{m}$ e $\mathrm{ch}$ a $\mathrm{n}$ i s $\mathrm{ch}$ geworden ist. Anders bei den eigentlich $\mathrm{s}$ p or $\mathrm{t} l \mathrm{i} \mathrm{ch}$ e $\mathrm{n}$ Übungen. Hier wird die Leistung durch die übende Tätigkeit nicht zu einer untergeordneten Dienst-Leistung umgewandelt, sondern sie bleibt als solche das eigentliche $Z$ i e 1 , wird in ihren Einzelheiten und Wertabstufungen immer bewusster. Dabei ist aber die souveräne Bewältigung nur möglich durch eine weitgehende Mechanisierung aller Teilhandlungen, die freilich nicht starr, sondern sehr elastisch funktionieren müssen.

\section{Akute und Dauer-Ưbung}

„Akute" Übung tritt ein während e i n e r fortlaufenden Arbeitshandlung; sie ist die unmittelbare Fortsetzung der oben beschriebenen Einstellung. Wer eine einigermalsen gleichförmige Tätigkeit manueller Art (z.B. Perlen aufziehen, Briefe kouvertieren) oder geistiger Art (Rechnen, Kollationieren, Ordnen) zu vollziehen hat, wird im Allgemeinen nach Ablauf der ersten viertel oder halben Stunde schneller und weniger fehlerhaft arbeiten als zu Anfang. Je ungewohnter die Tätigkeit ist, um so grösser pflegt der Übungsfortschritt in den ersten Stadien der fortlaufenden Arbeit zu sein. Freilich wird die einfache Aufstiegslinie der Leistung gestört (und zwar um so mehr, je länger die Arbeitshandlung andauert) durch den Gegenfaktor der Ermüdung, den wir später besonders erörtern. Infolgedessen ist die „Arbeitskurve” keine reine Übungskurve, sondern eine Resultante aus der Übungs- und Ermüdungs-Kurve.

Klarer herausheben lässt sich die Übungswirkung bei der $\mathrm{D}$ a u e r üb u $\mathrm{n}$, die auch die eigentlich lebenswichtige ist. Denn wenn sich ein Mensch in irgend etwas ,übt”, so nicht deshalb, um die Leistung innerhalb der nächsten Stunde zu steigern, sondern 
um eine dauernde Geübtheit zu erreichen. Dieser Dauerzustand ist an sich blosse P o t e n t i a lit ä t. Der Mensch kann, nachdem er eine Übungstätigkeit vollzogen hat, alles mögliche andere tun; er kann Stunden, Tage, Wochen vergehen lassen, - sobald er aber jene frühere Tätigkeit wieder aufnimmt, soll die damalige Übungsarbeit Früchte tragen und die weitere Leistung gegenüber der früheren beschleunigen und verbessern. Dieser Prozess kann sich immer von neuem wiederholen; aus den Übungswirkungen der einzelnen Vollzüge geht eine Gesamtwirkung hervor, die schliesslich in einen Zustand maximaler Geübtheit ausläuft.

Die Kurve einer solchen Dauerübung lässt sich nun an den verschiedensten, exakt messbaren, Leistungsformen demonstrieren. Wenn z.B. jemand Maschinenschreiben lernt, kann man am Schluss jedes Utbungstages feststellen, wieviele Silben er in der Minute schreibt; diese Ziffern, aneinandergereiht und graphisch dargestellt, bilden dann die Übungskurve. Ihre schematische Grundform ist in Figur 14 dargestellt. Sie zeigt folgendes: 1) Der

Fig. 14.

Schema des Übungsfortschrittes.

„Übungsfortschritt” ist nicht gleichmälsig; vielmehr wechseln Perioden schnelleren und langsameren Fortschrittes (auch der Stagnation) mit einander ab. 2) Am Anfang der Übungszeit sind die durchschnittlichen Übungszuwächse grösser als später. 3) $\mathrm{Zu}$ letzt wird die Kurve fast wagerecht; eine noch immer fortgesetzte Übung fügt dem erreichten Stande der Geübtheit nur noch ganz unbedeutende Zuwächse hinzu.

$Z u$ 1). Die Unebenheit der Übungskurve ist eine Sonderform der allgemeinen dynamischen Periodizität des Lebensablaufs, von der wir oben sprachen. In jedem längeren Übungsgeschehen gibt es mehrfach ,tote Punkte": der Übende bemerkt keine oder nur unverhältnismälsig geringe Fortschritte und beginnt zu zweifeln, 
ob die Fortsetzung des Übens noch Sinn hat. Nach einigen Tagen oder Wochen aber ist die Stauung plötzlich überwunden, eine neue Periode des Leistungsanstiegs folgt. Zuweilen kann sogar zeitweiliges Aussetzen der Übung günstig wirken, eine Phase der „Sättigung” muss erst zum Abklingen kommen (vgl. S. 702). Man spricht gradezu von einer ,schöpferischen Pause”.

Die Punkte 2) und 3) kann man (unter Absehung von den kleineren Kräuselungen der Kurve) auch so ausdrücken: Wird durch eine Reihe von wiederholten Übungstätigkeiten eine Dauerübung erreicht, so ist der Anteil jeder einzelnen Wiederholung an dem Gesamteffekt im Durchschnitt um so kleiner, je höher ihre Ordnungszahl in der Wiederholungsreihe ist. Die 100. Wiederholung fügt also dem vorher gewonnenen Geübtheitsniveau viel weniger hinzu, als es die 50. Wiederholung getan hatte.

Dieser Satz ist uns bereits bekannt ${ }^{1}$ ). Wir haben ihn früher als allgemeine GesetzmäIsigkeit mnemischen Geschehens überhaupt kennen gelernt, sodann seine Anwendung auf den Erwerb von Kenntnissen besprochen. Nunmehr handelt es sich um die Aneignung von Fertigkeiten durch Wiederholung. Die praktische Bedeutung ist einleuchtend: Für jeden Menschen gibt es bezüglich jeder übbaren Tätigkeit einen Zeitpunkt, in dem er die, durch blosse Übung zugängliche, Leistungshöhe im wesentlichen erreicht hat, sodass bei weiterer Übung der noch etwa erzielbare, geringe Zuwachs an Leistung in keinem Verhältnis mehr zu der dafür aufzuwendenden Zeit und Kraft steht. Es gibt also auch Übertreibung und mangelnde Ökonomik des Übens.

Weitere Wiederholungen der Tätigkeit nach erreichter Geübtheitshöhe sind trotzdem nicht sinnlos. Sie tragen dazu bei, die Übungshöhe zu halten, drohendem Übungsverlust (s. S. 683) vorzubeugen. Sie können ferner sportliche $Z$ wecke verfolgen.

Bei sportlichen Übungen wird noch einmal der Unterschied zwischen objektiver Leistung und personaler Leistung bedeutsam. $\mathrm{O} \mathrm{b} \mathrm{je} \mathrm{k-}$ $t i v$ ist es recht gleichgültig, ob ein hochgeübter Läufer die 1000Meter-Strecke um eine Sekunde schneller durchmisst als er es vorher konnte; und für die objektiven $Z$ wecke des praktischen Lebens wäre es absurd, auf die Erringung dieses winzigen Leistungszuwachses grosse Úbungsmühe und Ubungszeit zu verwenden. Aber als p e r s on a 1 e Leistung kann selbst die kleinste Erhöhung des Effekts wichtig

1) Vgl. S. 262 u. S. 328. 
werden, weil sie eben nur durch schärfste Konzentration der Energie und eisernste Willensanspannung erreicht werden kann. Sie bedeutet Selbststeigerung durch Selbstbeanspruchung.

Freilich entsteht nun die Möglichkeit, dass Zeit und Kraft, die auf solches Training verwandt werden, anderen wertvollen Betätıgungssphären entzogen werden. Für die Person als Unitas multi plex sollte die Frreichung der Ubungshöhe auf irgend einem Gebiet als Zeichen gelten, dass nun die bisher durch die speziellen Ubungen gebundenen Kräfte für andere personale Lebensaufgaben verwertet werden können. Mit anderen Worten: Die sportliche Höhertreibung der schon schr hohen Geübtheit in infinitum - mit ihren ebenfalls nur infinitesimalen Steigerungsmöglichkeiten - birgt die Gefahr einer starken Vereinseitigung in sich.

Der Leistungszuwachs durch Wiederholung hat sein Gegenstück im Leistungsabfall durch Nichtausübung der Tätigkeit. Die einmal erworbene Geübtheit als potentieller Zustand beharrt nicht einfach während der anderweitigen Beschäftigung; vielmehr nimmt die Bereitschaft und Fähigkeit zum Wiederaktuellwerden $a b$, je länger die Pause dauert. Wird dann die Tätigkeit erneut aufgenommen, so bemerkt man einen „ Ü b u n g s verlus t."

Das gilt im kleinen wie im grossen.

Im kleinen: Wer sich am Montag im Maschineschreiben geübt hat und dadurch am Schluss der Ưbungsstunde eine bestimmte Schreibgeschwindigkeit erreicht hat, wird am Dienstag anfangs nicht ebenso schnell schreiben können. Die - genau messbare Differenz gibt den Übungsverlust an. Allerdings wird normalerweise dieser Übungsverlust im Laufe der Dienstagsarbeit nicht nur wieder aufgeholt, sondern auch in Übungsgewinn umgewandelt, sodass die Schlussleistung am Dienstag über der vom Montag steht.

Im grossen: wer nach jahrelanger Unterbrechung eine Tätigkeit wieder aufnimmt, in der er früher einen hohen Grad der Geübtheit gewonnen hatte (Schlittschuhlaufen, Klavierspielen, Sprechen in einer Fremdsprache u.s.w.), hat zunächst den peinlichen Eindruck, dass er ,,alles verlernt habe." Der Übungsverlust erscheint gross. Bald bemerkt er aber, dass es mehr ein Verlust der „Einstellung” als der eigentlichen Übung war. Hat er erst die innere seelische und körperliche Gesamthaltung wiedergefunden, die der Alt-Neu-Aufgabe entspricht, dann macht sich 
auch schnell die Nachwirkung der früheren Übung geltend; und er ist erstaunt, "wie schnell er wieder hineingekommen ist". Freilich: ob die alte Leistungshöhe wieder ganz erreicht (oder gar überschritten) wird, das hängt von den verschiedensten personalen und äusseren Bedingungen $\mathrm{ab}$, die nichts mehr direkt mit ,Übung” zu tun haben müssen. Wer als älterer Mann einen Sport wieder aufnimmt, in dem er als Jüngling geglänzt hat, bringt nicht mehr die energetischen Voraussetzungen mit, die ein Erreichen der alten Leistungshöhe möglich machen.

Jedenfalls scheint für die Übung in allen Fertigkeiten dasselbe zu gelten, wie für das Auswendiglernen (vgl. S. 330): die mnemische Wirkung des früheren Erwerbs geht nicht vollständig verloren. „Absoluter Übungsverlust" würde ja bedeuten, dass man bei Neuaufnahme der Tätigkeit so viel Kraft und Zeit auf die Einübung verwenden müsste, als ob man sie früher nie ein- und ausgeübt hätte. Exakte Befunde gibt es hierüber meines Wissens nicht, wohl aber manche Erfahrung des Lebens: selbst Latenzzeiten von vielen Jahrzehnten ertöten nicht vollkommen jene unbewusste Mneme, die von der früheren Übungsperiode geschaffen worden war. So fremd die Tätigkeit zunächst anmuten mag, so unbeholfen man sich zuerst in ihr anstellt: allmählich werden selbst noch beim Greise Reste alten Könnens lebendig, das er als Jüngling erworben und inzwischen nicht aktualisiert hatte.

\section{3. $M$ i t ü bung}

Wir haben bisher die Übung nur besprochen, insofern sie auf dem spezifischen Gebiet der wiederholten Tätigkeit eine s p e $\mathrm{z}$ if is che Leistungssteigerung erzielt. Aber eine solche $\mathrm{Ab}$ spaltung eines Leistungsgebiets, derart dass sich alles Geschehen innerhalb seiner Grenzen erschöpfte, ist ja innerhalb der personalen Einheit nicht möglich; was jenem spezifischen Leistungsgebiet zustösst, strahlt aus auf andere Bereiche der Person. Es gibt also auch eine ausstrahlende Übung, die sogen. ,Mitübung” ${ }^{1}$ ).

Der sich ausbreitende Übungseffekt wird in erster Reihe solche Leistungsbereiche ergreifen, die dem primären Übungsgebiet besonders nahe stehen, sei es durch Beanspruchung glei-

\footnotetext{
1) Vgl. S. 263.
} 
cher Hilfsmittel, sei es durch verwandte Zielsetzung. Wer Feinkoordinationen der Fingerbewegungen als Uhrmacher geübt hat, wird, wenn er nun auf einem anderen Gebiet der Präzisionsmechanik tätig sein muss, von jener Geübtheit profitieren obwohl im Einzelnen die jetzt erforderlichen Bewegungen anderer Art sein mögen. Wer sich an den Sätzen der Arithmetik und der Geometrie in abstrakt mathematischem Denken geübt hat, ist dadurch besser vorbereitet auf das Verständnis der syllogistischen Figuren der Logik; es ist durch die Mathematik eine Mitübung in Logik geschaffen worden.

Bei Gedächtnisübungen hat Ernst Meumann folgendes festgestellt: Er liess mehrere Versuchspersonen 36 Tage lang Reihen von sinnlosen Silben lernen und schuf dadurch eine hohe spezifische Geübtheit für diese Leistung. (Am ersten Lerntage waren für eine 10 gliedrige Reihe 25 Lesungen nötig, am 36. Tage für eine gleich lange Reihe nur 5 Lesungen). Ausserdem aber hatte er nur am erste $n$ und am le tzte $\mathbf{n}$ Tage, aber nicht in der $Z$ wischenzeit, auch andere Lernstoffe (Gedichte, Ziffernreihen u.s.w.) einprägen lassen. Auch bei diesen war die Leistung am 36 Tage merklich besser, obgleich darin keine Ubung stattgefunden hatte! Durch das tägliche Lernen der Silbenreihen war eben dies verwandte Lernen von Ziffern usw. „mitgeübt” worden.

Besonders auffallend ist die Ausstrahlung der Übung von der rechten Hand auf die linke. Obwohl die meisten Menschen darüber klagen, dass ihre linke Hand wegen Nichtübung viel ungeschickter sei als die rechte, so würde doch diese Unbeholfenheit noch viel grösser sein, wenn die beiden Hände nicht in einer dynamischenWechselbeziehung ständen. Wer vorübergehend oder dauernd am Gebrauch der rechten Hand behindert und auf die linke angewiesen ist, merkt nun doch, wie viel diese von rechts her an potentiellem Können mitbekommen hat. Man bedenke, was es bedeutet, dass ein Körperglied, das $\mathrm{n}$ i e m a l s im Schreiben oder Zeichnen geübt worden ist, jetzt - wenn auch noch so ungeschickt - plötzlich schreiben oder zeichnen kann! Auch geht die Vervollkommnung dieser Leistungsfähigkeit, wenn sie nun direkt geübt wird, so schnell vor sich, wie es bei einem völlig ungeübten Organ niemals möglich wäre.

Aber im Grunde handelt es sich bei diesen Mitübungen nicht sowohl um ein Überspringen des Übungseffekts von einem Personteil auf einen anderen; vielmehr wird die ganze Person von 
den Wirkungen der Übung ergriffen, so dals sie die neugewonnene Fähigkeit in den jeweils geeignetsten Gebieten ihrer selbst ausnutzen kann. So führt uns der Begriff der Mitübung zu dem der ,formalen Gesamtübung” und der „f or male n B il$\mathrm{d}$ u n g". Jedes spezifische Üben schafft eine a $11 \mathrm{~g} \mathrm{e} \mathrm{m}$ e i n e Bereitschafts- und Fähigkeitssteigerung für Leistungen und Verhaltungsweisen, die eine formale Verwandschaft mit dem Übungsgebiet zeigen. Technische Betätigung auf einem bestimmten Gebiet übt im allgemeinen die Geschicklichkeit; dauernde Beschäftigung mit Denkaufgaben eines Bereichs (Mathematik, Grammatik) trägt zu allgemeiner Denkschulung bei.

Allerdings stuft sich diese Ausbreitung (wie schon angedeutet) ab nach der formalen Verwandtschaft. So wird sich die maximale Fingerübung des Uhrmachers viel mehr in anderen feinmechanischen Fertigkeiten als etwa in gesteigerter Arm- und BeinGeschicklichkeit beim Turnen auswirken. Ständige Übung in mathematischem Denken ist zwar sicher mitübend wirksam für die Bewältigung von Denkprozessen der exakten Logik; dagegen wird die so ganz andersartige sprachlich-geschichtliche Logik, wie sie z.B. in den grammatischen Kategorieen verkörpert ist, davon nur wenig berührt werden.

Hier kann es sogar zu einer - der Mitübung entgegengesetzten - Erscheinung kommen: zur Leistungsherabsetzung auf jenen fremderen Gebieten. Eine solche Schädigung tritt um so eher ein, je stärker die Übung in ha $1 \mathrm{t} 1 \mathrm{i} \mathrm{ch}$ gebunden ist und bleibt. Daher finden wir grade bei begrenzten Talenten so oft das Verdorren derjenigen Tätigkeiten, die ausserhalb des Interessenund Übungs-Gebiets liegen. Je stärker dagegen das F o r m a 1 e der Leistung bei dem Üben in den Vordergrund tritt, um so eher ist ein positives Úberströmen der Wirkung auf andere Leistungsgebiete möglich.

Die hier angedeuteten Möglichkeiten und Schranken einer „formalen Bildung” näher zu behandeln, ist nicht mehr Aufgabe der Psychologie, sondern der Pädagogik.

\section{4. Übbarkeit und Übungsfähigkeit}

a) Es gibt wohl kaum irgend ein personales Tun, das nicht durch Übung in seinem Leistungsgrad verbessert, durch Nicht- 
Übung herabgesetzt würde. Aber der Grad möglichen Ưbungsfortschritts (die „Ü b b a r k e i t") ist bei verschiedenen Funktionen sehr verschieden.

Relativ gering ist die Übbarkeit bei jenen Funktionen, die dem Vitalgrund des Lebens nahe stehen. Sie bedürfen ja auch normaler Weise der eigentlichen ,Übung" wenig. Atmen, Essen u.s.w., sind Tätigkeiten, bei denen die Ausübung jeder möglichen Einübung vorausgeht, die auch ohne eigens darauf gerichtete Willenseinstellung sofort angemessen funktionieren oder schnell dazu reifen, deren Voraussetzungen also ganz oder vornehmlich im Angeborenen und Instinktiven zu suchen sind.

Eigentlicher Übung bedürftig sind dagegen jene Funktionen, die den kulturellen Oberbau des menschlichen Lebens ausmachen und nur durch Erfahrung, Technik, Unterricht u.s.w. zugänglich sind.

Der normale Mensch eignet sich das Laufen und die notwendige Beherrschung der Muttersprache an, ohne dass dazu besondere Lauf- oder Sprech-,,Übungen" nötig wären; dagegen ist für Schlittschuhlaufen und Aneignung einer Fremdsprache das bewusste und willentliche Üben die Regel. Während in den kulturellen Bereichen die Fertigkeit im Leisten durch die Übung überhaupt erst $\mathrm{ges} \mathrm{ch}$ a f f e $\mathrm{n}$ werden muss, ist bei den Vitalleistungen die Fertigkeit schon da und kann durch Utbung höchstens $\mathrm{m}$ od i f i z i e r t werden. Darum nimmt hier die Übung sehr eigentümliche Formen an.

Wir finden erstens die Einübung von $\mathrm{Ers}$ a $\mathrm{tz} l$ e is $\mathrm{t}$ u $\mathrm{ng}$ e $\mathrm{n}$ dort, wo die Ausübung der normalen Vitalfunktion verhindert ist, so bei Sinnes- und Bewegungsdefekten. Der Erblindete muss die Orientierung in der Welt, das Alleingehen, das Ertasten feinerer Gegenstandsbeschaffenheiten durch Übung lernen; der Taubstumme muss unsägliche Übungsenergie darauf verwenden, die Sprechbewegungen des Lehrers nachzubilden. Entsprechend geht es den Arm- und Bein-Amputierten, den Gelähmten u.s.w. Sie müssen sich Ersatzhandlungen einüben für solche Normalhandlungen, die einer Einübung nicht bedurft hätten.

Besonders wichtig wird dieses Üben dort, wo die Defekte sehr stark sind: so hat die taubblinde Helen Keller durch unablässiges Utben die Fingersprache und dann die Lautsprache beherrschen gelernt; der 
armlos geborene Artist Unthan hat ein Leben geführt, das aus einer Reihe von Übungserfolgen bestand für Handlungen, die der mit Armen begabte Mensch selbstverständlich, d.h. ohne „Einübungsmassnahmen" lernt und vollzieht (das Benutzen des Löffels, das Sich-Waschen u.s.w.).

Die überraschend grossen Erfolge solcher Ersatzübungen sind nur dadurch verständlich, dass ein vitales $B$ e $d \ddot{u} r f \mathbf{n}$ is seinen normalen Weg der Befriedigung versperrt findet, und sich nun einen anderen Weg bahnt, auf dem die Erfüllung erreichbar ist.

Eine andere Gruppe hierher gehöriger Übungen bezieht sich nun gerade auf die $\mathrm{Un}$ t e r d r ü c k u n g solcher vitalen Bedürfnisse. Wenn man Funktionen, die von selbst ablaufen und keiner Einübung bedürfen, $\mathrm{n}$ icht ausüben will, so muss diese Hemmung eingeübt werden. Ja es ist dies die schwerste Art von Übung überhaupt, da sie nicht mehr auf die Voraussetzung eines natürlichen Bedürfnisses gestützt ist, sondern im Gegenteil dem Bedürfnis den Hemmungswillen entgegenstemmt. Hierher gehören die Hungerkünstler, die sich im Fasten üben, bis sie zu phantastischen Fristen der Nichternährung kommen; vor allem die Büsser und Fakire, deren Übungen im Atemanhalten, im Nichtreagieren auf Schmerzen, im Unbeweglich-Sitzen oder-Stehen (Säulenheilige), im Fasten u.s.w. lauter Ziele der Bedürfnisunterdrückung haben. Betrachtet man aber diese antivitalen Übungen näher, so zeigt sich, dass es nicht eigentlich auf die spezifische Hemmung dieser oder jener Vitalfunktion ankommt (das Atmen an sich ist nicht etwas Unterdrückungswürdiges), sondern auf den Sieg des Einübungswillens über das Ausübungsbedürfnis. Es sind im Grunde formale Will e ns üb ungen; und in der Tat wird ja z.B. bei den Exerzitien verschiedener Mönchsorden ausdrücklich als eigentliches Ziel hingestellt: die allgemeine Herrschaft des spirituellen Willens über das vitale Triebleben überhaupt.

Es ergibt sich also, dass auf den reinen Vitalgebieten systematisches Üben eigentlich nur in abnormen Fällen (des Defekts, der Erkrankung, der Askese, der sportlichen Monomanie) vorkommt. Dagegen ist doch auch auf jenen kulturell bdingten Gebieten, auf denen geübt wird und werden muss, stets ein mehr oder minder starker $\mathrm{E}$ in s chlag des $\mathrm{V}$ it a len vorhan- 
den, der dem Grad der Übbarkeit Grenzen setzt. Wir erwähnten z.B. früher, dals innerhalb der musikalischen Ausbildung die rhythmische Fertigkeit in viel geringerem Malse übbar ist, als die melodische, und begründeten es dort mit der stärkeren vitalen Verankerung des Rhythmus. Ebenso sind beim Erlernen einer Fremdsprache Wortschatz, Grammatik, Syntax u.s.w. in viel höherem Mafse übbar als Ausdrucksfähigkeit, Sprechtempo, Feinheiten der Aussprache - weil bei den letztgenannten Merkmalen viel mehr angeborene Fähigkeiten dem neuen Sprechstoff entgegenkommen müssen.

So gibt es innerhalb eines jeden Leistungsgebietes Momente verschiedener Utbbarkeit. Die hier bestehenden Abstufungen sind noch wenig bekannt; ihre Feststellung wird aber von grosser praktischer, insbesondere psychotechnischer und pädagogischer, Wichtigkeit sein. Denn nur bei den stark übbaren Funktionen besteht die Hoffnung, dass ein zunächst tiefer Leistungsstand durch Übung merklich erhöht werden kann; und nur hier lohnt sich der grosse Aufwand von Kraft und Zeit bei Lehrer und Zögling (Meister und Lehrling u.s.w.), der für das Üben erforderlich ist.

Bei solchen praktischen Erwägungen ist ferner stets darauf zu achten, wie viele Vorübungen schon stattgefunden haben, ehe mit der eigentlichen Übung begonnen wird. Denn der typische Verlauf der Übungskurve (s. S. 681) beweist ja, dass die weitere Übbarkeit einer Funktion um so geringer ist, je mehr Übung schon vorausgegangen ist.

Zwei 14 jährige Knaben werden mit psychotechnischen Handfertigkeitstests geprüft; der eine kommt aus einer Schule mit Werkunterricht, der andere aus einer Schule ohne solchen. Zeigen beide in der Prüfung g lei che Leistungen, so ist zu erwarten, dass der zweite spăter den ersten merklich übertreffen wird; denn er hat noch die Möglichkeit eines grösseren Ubungsaufstiegs in "Handgeschicklichkeit” vor sich als jener.

b) Aber nicht nur von dem Geübtheitsgrade der Funktion sind individuelle Unterschiede abhängig, sondern von spezifischen personalen Übungseigenschaften. Sie bedingen die "Übungs fähigkeit."

Es gibt zunächst, rein graduell angesehen, Menschen mit starker und mit schwacher Fähigkeit, sich durch Übung zu ver- 
vollkommnen. Starke Übungsfähigkeit findet sich bei solchen, die im allgemeinen haushälterisch mit ihren Fähigkeiten und Energieen umgehen, aber dort, wo es gefordert wird, intensive Selbstbeanspruchung aufbringen können. Die generelle Kraftökonomie hat Reserven entstehen lassen, aus denen heraus die zu erfolgreicher Übung erforderliche Ausdauer und Stärke der Konzentration möglich ist. Ein solcher Mensch erreicht dann in unermüdlichem Training Fertigkeitsstufen, die nicht nur die Umgebung, sondern auch ihn selbst überraschen.

Wesentliche Persönlichkeitsverschiedenheit entsteht ferner dadurch, dass sich die Übungsfähigkeit mehr auf die Leistungssteigerung oder auf die Aufwandsminderung beziehen kann. In jenem Falle wird die Leistung durch Utbung vor allem voll$\mathrm{k}$ o m m e ner, in diesem a $\mathrm{tomat}$ is $\mathrm{cher}$. Menschen der ersten Art behalten den Gegenstand der Ubung dauernd im Blickpunkt der Aufmerksamkeit, da sie unermüdlich auf seine optimale Verwirklichung bedacht sind; Menschen der zweiten Art geben sich vielleicht mit einer geringeren Leistungshöhe zufrieden, verstehen es aber, den Vorgang mit immer grösserer Selbstverständlichkeit ablaufen $\mathrm{zu}$ lassen.

Der Unterschied ist dort, wo er sehr ausgesprochen auftritt, von hoher berufspraktischer Wichtigkeit. Bei allen Berufen; die eine grössere Variationsbreite der Betätigung besitzen und einen stärkeren Anspruch an Nachdenken, Umstellen, Organisieren u.s.w. erheben, ist der erste Typ erforderlich; auch bei grösster Übung darf das Tun nicht mechanisch werden, weil es dann der jeweiligen Besonderheit der Anforderungen nicht gerecht ist. Bei einförmigen Betätigungen dagegen (Arbeit am laufenden Band, Ablegen, Sortieren u.s.w.) ist der Typ des automatisierenden Arbeiters angebracht, weil die Tätigkeit viel zu wenig Stoff für dauernde Anspannung der Aufmerksamkeit darbietet. Die ideale Geübtheit eines Arbeiters ist diejenige, die die Gleichförmigkeitsmomente der Arbeit automatisiert, um den variierenden Momenten um so intensiver durch mitgehende Aufmerksamkeit entsprechen zu können.

Herbert Wunderlich hat lehrreiche Feststellungen über verschiedene T y p e n der Ưbungsfähigkeit gemacht, die bei gleichförmiger Arbeit erkennbar werden. Sein „Monotonieapparat” erfordert das fortlaufende Ablegen von zugeführten Werkstücken in zwangslăufigem Tempo. 
Manche Menschen bleiben nun mit ihrem bewussten Erleben stets an die Arbeit gebunden, obwohl sie dem Geist keinerlei Nahrung gibt. Das Zwangstempo gerät in Konflikt mit dem Eigentempo, was sehr unlustvoll empfunden wird. Auch bei maximaler Ubung tritt keine Mechanisierung ein, vielmehr ein wachsender seelischer Widerstand bis zur Unerträglichkeit. Im Gegensatz dazu ist ein anderer Typ imstande, das vorgeschriebene Tempo ohne weiteres innerlich zu akzeptieren und sich von einer vagen, rhythmisch-motorischen Einstellung tragen zu lassen. Innerhalb dieser wird die Handlung in kürzester Zeit vollständig mechanisiert, während sich das Bewusstsein mit ganz anderen Gegenständen zu beschäftigen vermag. Bei einem $Z$ wischentyp ist eine Art Bewusstseinsspaltung vorhanden: die Arbeitshandlung wird in schneller Obung gebessert, aber nicht ganz ins Unbewusste abgedrängt; immerhin besteht die Möglichkeit zu einer, wenn auch nicht voll konzentrierten, geistigen Nebenbeschäftigung.

\section{ERMÜDUNG}

\section{Ermüdung und Müdigkeit}

Der dynamische Vorgang einer akuten Leistungsabnahme heisst Erm ü d un g.

An jedem Ermüdungsvorgang ist dreierlei zu unterscheiden: die Veränderung der Leistung selbst (unter Unständen darstellbar in einer Ermü d u n g $\mathrm{kurve}$, die Ermüdung erzeugende Ursa che, der Bew us ts eins. Niederschlag des Vorgangs (die Müdigkeit).

a) Um mit dem letzten zu beginnen: $M$ ü digkeit und Ermüdung sind nicht identisch. Müdigkeit ist ein rein psychologischer Erlebensbegriff, Ermüdung ein psychophysisch neutraler Leistungsbegriff. Beide Erscheinungen können auch in gewissen Grenzen von einander unabhängig auftreten. So gibt es Situationen von solcher Wucht, dass der Mensch seine Leistungsenergie bis zum letzten ausschöpft und hierdurch seine weitere Leistungsfähigkeit aufs Stärkste beeinträchtigt (sich also hochgradig ,ermüdet”), ohne dass das Erlebnis der Müdigkeit aufkäme: so beim Laufen auf der Flucht vor Verfolgern, bei der Lernarbeit zu einem nahe bevorstehenden, sehr gefürchteten Examen u.s.w. Umgekehrt kann ein lebhaftes Müdigkeitsgefühl auftreten (z.B. bei der Neurasthenie), ohne dass die Leistungsfähigkeit objektiv merklich herabgesetzt sein müsste. 
Allerdings bilden solche Fälle der Unstimmigkeit doch die Ausnahme. Normalerweise ist Müdigkeit das psychische Symptom eintretender Ermüdung. Die Leistungsminderung macht sich erlebnismälsig nicht nur in dem Wissen um den verringerten Tätigkeitseffekt, sondern in einer Anderung der G e f üh $1 \mathrm{~s}$ 1 a g e geltend.

Für das Gefühl der Müdigkeit ist das Bewusstsein der Schlaffheit sowie Aktivitäts- und Impulsschwäche wesentlich. Nicht eindeutig dagegen ist die Stellung des Gefühls in der Lust/UnlustDimension. Müdigkeit ist durchaus nicht immer unlustbetont; in milderen Graden kann es geradezu als lustvoll empfunden werden (,eine wohlige Müdigkeit durchströmt meine Glieder").

Ferner kann das Müdigkeitsgefühl lokalisiert oder total sein; nach einer Wanderung fühle ich Müdigkeit in den Beinen, während ich mich sonst noch ganz frisch fühlen mag. Wandere ich noch länger, so verbreitet sich das Müdigkeitsgefühl allmählich über den ganzen Körper; ich fühle mich dann sogar „zu müde zum Denken". - Die Müdigkeit, mit der gesunde Kinder abends ins Bett fallen, hat ausgesprochenen Totalitätscharakter.

Die personale Bedeutung des Müdigkeitsgefühls besteht darin, dass es als Warnungs- und Regulierungs-S i g $\mathbf{n}$ a 1 dient. In ihm kommt der Mensch zum Bewusstsein, dass eine Leistungsminderung im Entstehen begriffen ist und sich bei Fortsetzung der Tätigkeit zu verstärken droht. Das Gefühl hat also p r os pektiven Sinn; es ruft dem leistenden Menschen ein "Halt" zu, weckt und steigert das Bedürfnis nach Leistungsunterbrechung und Ruhe. Das l o k a l e Müdigkeitsgefühl verrät, dass einem bestimmten Organ (in unserem obigen Beispiel: den Beinen) nicht mehr die frühere Energiemenge zum Leisten zur Verfügung steht; das $\mathrm{T}$ ot a $1 \mathrm{~g}$ e $\mathrm{f} \ddot{\mathrm{h}} \mathrm{h} \mathrm{l}$ weist hin auf beginnende Erschöpfung des Gesamtvorrats an personaler Energie. - Lustbetont kann das Müdigkeitsgefühl daher nur sein, wenn die bisherige Energiebeanspruchung nicht zu stark war, und wenn der imperativische Charakter des Gefühls „Schluss mit der Leistung; ruhe dich aus" wirksam wird. Denn das gemächliche Sichgehenlassen und Entspannen kann von Lust begleitet sein.

In den oben geschilderten Fällen der Uns t i m migke it von Ermüdung und Müdigkeit ist also der Signalcharakter des Gefühls g e s t ö r t gewesen. Der Mensch, der in Lebensgefahr 
läuft und läuft, bis er völlig erschöpft im rettenden Refugium zusammenbricht, durfte dem Bewusstseinssignal seiner abnehmenden Kräfte nicht Raum geben, weil Existenzrettung wichtiger ist als Kraftökonomie und Gesundheit. Der Examenskandidat, der die Nächte hindurch lernt, benutzt sogar besondere Exzitantien, um das Müdigkeitsgefühl zu b e $t$ ä $u$ b e n. - Umgekehrt fühlt sich der Neurastheniker schon von morgens an müde, trotz guten Schlafes und ohne dass er sich durch vollzogene Leistungen hätte „er"-müden können. Bei ihm ist das Gefühl ein Tr u gs i g n a I; es täuscht ihm Leistungsunfähigkeit vor, während im Grunde Leistungsunlust, Leistungsekel in ihm lebt.

b) Ursachen der Ermüdung. - Herabsetzung des Leistungswertes wird durch zwei Gruppen von Ursachen erzeugt: durch Ermüdungsreize und durch Leistungen selbst.

Zu den Erm ü d ung s r e i z e n gehören:

1) Vit a le Einflüsse, die aus der physikalisch-chemischen Beschaffenheit der Umwelt herrühren. Ermüdend wirken daher atmosphaerische und klimatische Bedingungen, wie: ungewöhnliche Hitze und Kälte, feuchtschwüle Luft, Aufenthalt in schlecht ventilierten Räumen; ferner spezifische Stoffe, die das dynamische Niveau des Organismus senken (Alkohol, Morphium).

2) M o n o t o n e Reize. Da zu dynamischer Konzentration die Abhebung des beachteten Gegenstandes von seiner zeitlichräumlichen Umgebung erforderlich ist, muss eine Reizsituation, die diese isolierende Herausarbeitung erschwert, die Leistungsfähigkeit herabsetzen. Darum wird der Mensch durch eintönig sich folgende Reize entweder eingelullt (Klappern einer Mühle, Bachrauschen, einförmiger Gesang) oder angestrengt (flimmernde Filme), in beiden Fällen ermüdet. Diese Wirkung wird verstärkt, wenn die Monotonie nicht nur auf die Sinne wirkt, sondern auch zu passiven Eigenbewegungen des Körpers führt. Die ermüdende Wirkung des Eisenbahnfahrens ist auf die Verbindung des Klappergeräusches mit der dauernden Vibration des Körpers zurückzuführen. Die Mütter aller Zeiten und Völker wissen, dass das sicherste Mittel, den Säugling zu ermüden und einzuschläfern, in der Verbindung eintönigen Gesanges mit dem Hin- und Herwiegen des Kindes besteht.

3) Allgemeine Belastung der psychophysi- 
s c h e n E n e r g i e. Der Mensch wird ermüdet nicht nur durch Arbeit, sondern auch durch Vergnügungen, durch unhygienische Lebensweise, durch zu geringe Schlafmöglichkeit, ja auch durch eine Übertreibung derjenigen Malsnahmen, die der Erholung dienen sollen, wie Spiel, Aufenthalt in frischer Luft u.s.w.

Den genannten Ermüdungsreizen stehen nun jene Ursachen gegenüber, die im Leisten selber liegen. Denn $\mathrm{j}$ e d e $\mathrm{L}$ e is $\mathbf{t} \mathbf{~} \mathbf{n} \mathbf{g}$ $\mathrm{z}$ e hrt, wenn sie längere Zeit fortgesetzt wird, a n i h r e r eigenen $\mathrm{Kraftquelle.} \mathrm{Die} \mathrm{Handlungseinheiten} \mathrm{(„Ak-}$ te") innerhalb einer fortlaufenden Arbeit stellen also gleichzeitig Ermüdungswirkungen (der vorangegangenen Akte) und Ermüdungsursachen (für weitere Akte) dar.

Diese eigentliche „L e is t u ngsermü du ng" ist das Hauptthema aller Ermüdungsuntersuchungen in Psychologie, Pädagogik, Hygiene, Psychotechnik und Betriebslehre. Solch besonderes Interesse hat seinen guten Sinn; die genaue Kontrolle, Messbarkeit und Beeinflussbarkeit von Leistungen ermöglicht sowohl die exakte Erforschung der Ermüdungserscheinungen wie auch die praktische Einwirkung auf die Gestaltung des Unterrichts, der Fabrikarbeit u.s.w. Aber die bevorzugte Erforschung der Leistungsermüdung sollte nicht zur Nichtbeachtung jener leistungsfremden Ermüdungsreize führen, die wir oben skizzierten; ihre Bedeutung ist darum nicht geringer, weil sich ihre Wirkungen nicht so leicht isolieren und in Ziffern fassen lassen.

Leistungsermüdung ist also die $\mathrm{Herabsetzung} \mathrm{der}$ Leistung durch Leistung, mithin das Gegenstück zu der ,akuten Übung”, die wir im vorigen Abschnitt schilderten. Bei einer länger dauernden Arbeit sind beide Faktoren wirksam und meist nicht von einander trennbar. Die Übung verbessert, erleichtert, mechanisiert die Leistung, verringert den A u fw a nd der nötigen Energie. Die Ermüdung aber verringert durch Energieverbrauch den $\mathrm{V}$ or $\mathrm{rat}$ der noch verfügbaren Energie, erschwert und verschlechtert die Leistung. Entwirft man die „Arbeitskurve” einer solchen fortlaufenden Arbeit (vgl. die S. 671 genannten Methoden), dann gibt es Strecken, in denen die Leistungshöhe konstant bleibt -- hier halten sich also Übungsund Ermüdungs-Wirkungen die Wage - , andere Strecken mit Überwiegen der einen oder der anderen Wirkung. Zuweilen wer- 
den verschiedene Leistungsmomente in verschiedenem Mafse von Übung und Ermüdung betroffen. Hat man längere Zeit eine einförmige Arbeit zu verrichten, so erhöht die steigende Übung durch Mechanisierung im allgemeinen die $\mathrm{L}$ e ichtigkeit und Sch nelligkeit des Vollzugs, während zugleich die steigende Ermüdung die $\mathrm{G}$ ü t e der Leistung herabsetzen kann.

Schulversuche mit einfachen schriftlichen Rechenaufgaben, die eine Stunde dauerten, ergaben, dass das Tempo des Rechnens zwar zunahm, in weit höherem Grade aber auch die Fehlerhaftigkeit, sodass der Ermüdungseffekt den Übungseffekt übertraf. (Burgerstein, Laser).

\section{Spezifische und a ustrahlende Ermüdung}

Genau so wie die Utbung sich auf andere personale Bereiche ausbreitet (als Mitübung, s.S. 684), bleibt auch die Ermüdungswirkung nicht auf das ursprüngliche Leistungsgebiet beschränkt, sondern strahlt aus auf andere Funktionskreise und kann schliesslich - als Totalermüdung - die ganze Person ergreifen ${ }^{1}$ ).

Auch jenes bei der Mitübung gefundene Gesetz: dass sich die Ausstrahlung abstuft nach dem Grade der Verwandtschaft der Funktionsgebiete - gilt für die Mitermüdung. Wenn jemand längere Zeit mit dem rechten Arm schwere Arbeit geleistet hat, wird er nun auch mit dem linken Arm nicht so leistungsfähig sein wie sonst, während die Kräfte seiner Beine vielleicht nicht so sehr in Mitleidenschaft gezogen sein mögen. Entsprechend im Psychischen: Schliesst sich an eine anstrengende Unterrichtsstunde im Französischen eine solche im Englischen, so wird sich die ausstrahlende Ermüdung viel mehr bemerkbar machen, als wenn auf die Sprachstunde Unterricht in Naturkunde folgt.

$\mathrm{Ja}$, es kann hier sogar ein paradoxer Wirkungs u $\mathrm{m} \mathrm{s} \mathrm{c} \mathrm{h} \mathrm{l} \mathrm{a} \mathrm{g}$ eintreten, wenn die beiden Leistungsgebiete recht verschieden sind. Es ist dann möglich, dass die Ermüdung auf einem Gebiet die Leistungsdisposition für das fremde Gebiet nicht nur nicht beeinträchtigt, sondern sogar begünstigt. Die Ausstrahlung wird

1) $P$ h y s i $l o g$ is $c h$ sind die Ausstrahlungserscheinungen mit der Lehre von den „Ermüdungsgiften" in Verbindung zu bringen. J e d e Leistung - mag sie vom Gehirn oder von den Gliedern vollzogen werden - ruft in dem beteiligten Organ biochemische Ånderungen hervor, die die weitere Funktion des Organs beeinträchtigen. Da aber die so erzeugten Ermüdungsgifte durch den ganzen Körper gespült werden können, wird auch die Leistungsfähigkeit anderer Organe vermindert. 
also durchkreuzt durch das Prinzip der A b w e chs lung : der Verbrauch von Energie an einer Stelle personalen Leistens hat Ansammlung und Aufstauung der Energie an einer anderen Stelle zur Folge, sodass hier nun der Leistungsvollzug besonders leicht und gut von statten geht. Die ganz andere Betätigung wirkt dann geradezu erholend.

Diese widerspruchsvollen Vorgänge der Ermüdungsausstrahlung einerseits, der Erholung durch Abwechslung andererseits erschweren Analyse und Voraussage auf dem Gebiet der personalen Dynamik beträchtlich.

Wenn z.B. ein Schüler einen Schulvormittag hinter sich hat, der durch vorwiegend theoretische Stunden eine starke geistige Ermüdung erzeugt hat, so kann diese auf den Körper ausstrahlen, sodass sein Schritttempo auf dem Heimweg, seine Körperhaltung u.s.w. energetische Minderung zeigen. Aber es kann jene Ermüdung auch dazu führen, dass er sich nun nach dem langen Sitzen austoben muss, dass also nicht körperliche Entspannung, sondern starke körperliche Energieentladung als angemessene Reaktion auf den geistigen Energieverbrauch gesucht wird. Viel hängt hier von individuellen Anlagen $a b$, doch lässt sich auch einiges Allgemeine sagen. Die Tendenz zur Ausstrahlung der Ermüdung ist gross, wenn die primäre Ermüdung sehr stark war, während eine mälsige Ermüdung ihre Kompensation eher in andersartiger Betätigung finden kann. Ferner ist, selbst bei starkem Wechsel der Betätigungs g e bi et e, weniger mit Erholung als mit Ausstrahlung zu rechnen, wenn die F or m e n der Energieanspannung ähnlich bleiben.

Ein Beispiel: Es ist früher oft empfohlen worden, die Pausen zwischen den theoretischen Schulstunden mit "10-Minuten-Turnen" auszufüllen; indessen hat sich herausgestellt, dass dadurch keine Erholung von der geistigen Anstrengung, sondern eine Zusatzanstrengung erzeugt wurde. Was der Schüler zur Erholung braucht, ist vor allem Entspannung der A uf merksamkeit von dem $Z$ wang, sich auf äussere Forderungen einzustellen. Ein solcher $Z$ wang ist aber auch beim Turnen vorhanden; und selbst der grosse Unterschied: dass es sich vorher um Vokabeln und Grammatik, jetzt um Bewegungen handelt, wird sekundär gegenüber dem Umstand, dass wiederum die Energiezerstreuung oder spontane Energielenkung unterbunden ist. Nur eine wirkliche „Pause”, die dem Schüler die Verfügung über seine Dynamik f $\mathrm{r}$ ei $\mathrm{gibt}$, kann von dem vorangegangenen Aufmerksamkeitszwang erholen. 
Die enge Beziehung zwischen Ermüdung und Aufmerksamkeitsspannung ${ }^{1}$ ) macht sich auch wä hr e n d des Unterrichts geltend und zwar in der nun schon mehrfach behandelten Erscheinung der Una u fmerksamkeit ${ }^{2}$ ). Diese gewinnt jetzt geradezu eine personale $\mathrm{Sch} \mathrm{ut} \mathrm{z}$ bedeutung: sie dient als Prophylaxe gegen zu schnelle Ermüdung.

Der Umstand, dass ein Schüler nicht während des ganzen 5-stündigen Schulvormittags maximal aufmerksam ist, mag $z$ war für den Lehrer unbequem sein; für den Schüler ist es eine Notwendigkeit. Dadurch, dass er sich durchschnittlich auf einem mittleren Stand der Aufmerksamkeit hălt, aus dem er a u E rfordernis auf den Aufmerksamkeitsgipfel klettern kann, treibt er unbewusst eine Kraftökonomie, ohne die der Schulunterricht die schädigendsten Ermüdungswirkungen zeitigen müsste. Deshalb ist auch Privatunterricht, in welchem niemals ein anderer "dran" ist, so dass der Schüler dauernd auf dem Aufmerksamkeitsmaximum bleiben muss, viel ermüdender als Klassenunterricht. Fünfstündiger täglicher Privatunterricht für ein Kind wäre fast undenkbar.

In den gleichen Zusammenhang gehört endlich die Erscheinung, dass der Schüler, der wegen mangelnder Begabung oder mangelnden Interesses die nötige Schulaufmerksamkeit ständig erzwingen muss, viel mehr ermüdet als jener, der den Gegenständen Interesse und spontane Aufmerksamkeitseinstellung entgegenbringt.

Die viel gebrauchte Begriffsscheidung von $\mathrm{k}$ ö $\mathrm{p} \mathrm{e} \mathrm{r} \mathrm{li} \mathrm{c} \mathrm{h} \mathrm{e} \mathrm{r}$ und geistiger Ermüdung erweist sich nach allem bisherigen als sehr problematisch. Brauchbar sind die Kategorieen nur, solange man allein die ermüdenden $U$ rs a ch e $n$ berücksichtigt. Ermüdung kann erzeugt werden durch rein körperliche Betätigung (z.B. schwere Schmiedearbeit), durch rein geistige Betätigung (längeres Kopfrechnen), durch psychophysische Betätigung (Halten eines Vortrages in einem grossen Raum, der viel Stimmaufwand fordert). Sobald wir aber die Ermüdungsw i r k u n g e $\mathbf{n}$ betrachten, verfliessen die Grenzen sofort, und die Totalität der Person macht sich mehr oder weniger entschieden geltend. Die oben erwähnten „Ausstrahlungen," das Bedürfnis nach Abwechslung, die Inanspruchnahme der (gebietsunabhängigen) Aufmerksamkeit - all dies lässt sich nicht mehr in die Schranken bannen, die durch den geistigen ober körperlichen Ausgangspunkt der Leistungen gesetzt zu sein schienen.

1) Auf sie hat besonders Lipmann hingewiesen.

2) S. S. 660 . 


\section{Ermüdungsmessungen}

Messen lässt sich immer nur eine spezifische Erscheinung und deren Abnahme beim Ermüdungsvorgang, nicht die Totaländerung, die in der Person durch Ermüdung hervorgerufen wird. Man muss aber unterscheiden zwischen solchen Messungen, bei welchen das Leistungsgebiet der Ermüdungsursache und der Ermüdungswirkung identisch ist, und solchen Messungen, welche die eingetretene Ermüdung aus einem andersartigen Symptom erschliessen.

Zur ersten Gruppe von Malsverfahren gehören die schon mehrfach erwähnten „fortlaufenden Arbeitsmethoden"; hier wird $\mathrm{d}$ u r c h bestimmte Dauerleistungen (Rechnen, Diktatschreiben, Assoziieren u.s.w.) Ermüdung erzeugt und a n den sinkenden Güte- und Menge-Ziffern eben dieser Leistung die Ermüdung abgelesen. - Ein weites praktisches Anwendungsgebiet dieser Methoden bildet die monotone Berufsarbeit. Denn die Gleichförmigkeit des Arbeitsprozesses erlaubt eine sehr genaue Zählung und Vergleichung der Teilleistungen (z.B. der gefertigten Werkstücke) aus den verschiedenen Zeitabschnitten des Arbeitstages, sodass hier das Absinken der Leistungsfähigkeit nach Art und Grad unmittelbar ablesbar wird.

Auf diese Weise konnte z.B. nachgewiesen werden, dass für gewisse Arbeitsbetriebe eine längere Arbeitszeit infolge der stärkeren Ermüdungswirkung kein grösseres Leistungsergebnis erzielte als die um eine Stunde gekürzte Arbeitszeit. ${ }^{1}$ )

Wo aber die Leistung, welche Ermüdung erzeugt, nicht gleichförmig genug zu solchen Messungen ist, muss die „S t i ch p r o b e n m e t h o d e" einsetzen. Der Arbeitstag eines vielbeschäftigten Arztes oder der Schulvormittag eines Schülers ist von so verschiedenartigen Leistungsanforderungen erfüllt, dass an den Leistungsquanten selbst eine Vergleichung der Ermüdungsgrade unmöglich ist. Man greift dann zu Kurzprüfungen mit identischer Methode, die mindestens zweimal - zu Beginn und am Ende der Arbeitsperiode - vorgenommen werden, um die inzwischen eingetretene dynamische Minderung festzustellen. Feinere Messungen fügen Zwischenprüfungen, z.B. jede Stunde, ein, um eine „Ermüdungskurve” zu gewinnen.

Der Vorteil dieser Methode besteht darin, dass die Tages-

1) Vgl. den Bericht von Otto Lipmann uber die deutsche Arbeitszeitenquete. 
arbeit in ihrer natürlichen Mannigfaltigkeit nicht beeinträchtigt zu werden braucht, und dass die Stichprobe unabhängig ist von der Art der Leistung, durch welche die Ermüdung erzeugt wurde. So kann etwa das „Tempoklopfen" (s.S. 647) als Stichprobe benutzt werden: man lässt nach Abschluss jeder Stunde eine halbe Minute lang einem Dreitakt in dem natürlich scheinenden Tempo klopfen und kann dadurch die Verlangsamung des psychischen Tempos feststellen - gleichgültig ob die Ermüdung durch eine körperliche Leistung oder durch wissenschaftliche Arbeit erzeugt wurde.

Möglich ist diese Methodenart freilich nur durch den Tatbestand der Ermüdungs- A u s st r a h l u n g; ja gerade durch diese Methode wird die Wirkung solcher Ausstrahlungen in einem, apriori kaum zu erwartenden, Grade bewiesen. Sehr lehrreich sind hierfür die Prüfungen der Tastschärfe mit dem Aesthesiometer. Dieser Apparat besteht aus zwei Spitzen (ähnlich denen eines Zirkels), die in verschiedenem Abstand auf die Haut gesetzt werden können; festgestellt wird die „Tastschwelle", d.h. derjenige Spitzenabstand, der nicht mehr als Doppeleindruck, sondern als e in e diffuse Berührung erlebt wird. Untersucht man nun die Schwellenfeinheit eines Schülers am Handrücken zu Beginn und am Ende des Schulvormittags, so ergibt sich, dass mittags oft ein doppelt so weiter Abstand der Spitzen nötig ist. Die durch die verschiedenen Schulleistungen erzeugte Herabsetzung der Aufmerksamkeitsenergie tritt also - durch Ausstrahlung - bei der ganz heterogenen Leistung einer sensorischen Unterscheidung zu Tage.

Als solche Stichproben sind natürlich a 11 e Leistungen verwendbar, die in kurzer Zeit zu Malswerten führen; und so werden denn hier die verschiedensten Verfahrungsweisen empfohlen ${ }^{\mathbf{1}}$ ).

Körperliche Leistungen prüft u.a. der „Ergograph”: ein Finger muss in rhythmischen Bewegungen ein Gewicht heben, bis die Kraft versagt; Hubzahl und Hubhöhe werden graphisch registriert. Auch hier zeigen sich bemerkenswerte Ausstrahlungswirkungen; so war nach einem Universitätsexamen, das lediglich geistige Leistungen erforderte, die Hubleistung des Fingers weit

1) Die rein biochemischen Stichprobenmethoden, mit denen z. B. die durch Ermüdung veränderte Zusammensetzung des Blutes gemessen wird, können hier ausser Betracht bleiben. 
geringer als vor Beginn des Examens, und zwar nicht nur bei dem Kandidaten, sondern auch beim Professor.

Als Stichproben aus dem Gebiet $g$ e is $t$ ig er Leistungen verwendet man kurzfristige Rechenaufgaben, Intelligenzprüfungen und ähnliches. Als Ebbinghaus mit solchen Methoden die Ermüdungswirkung eines Schulvormittags prüfte, ergab sich, dass der Leistungsabfall für schwierige Intelligenzprüfungen grösser war, als für Gedächtnis- und Rechenleistungen: wieder zeigt sich, dass es vor allem die $A$ u $\mathrm{merks}$ a m eit ist, welche durch die mehrstündige Schularbeit an Energie eingebüsst hatte.

Der verlockenden Bequemlichkeit solcher Stichprobenmethoden steht aber ein schwerer Mangel gegenüber: die personale B e d e utung der gefundenen Ermüdungsgrösse ist nicht eindeutig. Wenn nach fünfstündigem Schulunterricht die Tastschärfe oder die Fingerhubkraft stark herabgesetzt ist, so ist gewiss eine merkliche Ermüdung nachgewiesen: aber was bedeutet diese Ermüdung für die natürliche Leistungsfähigkeit des Kindes auf den Schulgebieten? Und was bedeutet sie für die geistige und körperliche Hygiene des Kindes?

Als vor einem Menschenalter Ermüdungsmessungen dieser Art aufkamen, glaubte man, ihre Ergebuisse ohne weiteres als Zeichen einer $\ddot{U} b$ e r last ung der Schüler ansehen $z u$ dürfen (so z.B. Kräpelin). Das war ein Fehlschluss, zum mindesten eine unzulässige Verallgemeinerung. Man hat die Beziehung der Ermüdung zu anderen dynamischen Kategorieen nicht genügend beachtet, denen wir uns jetzt zuzuwenden haben.

\section{Erholung. Übermüdung. Sät tigung}

Voranzustellen ist der Satz: Ermüdung ist ein Vorgang des n orma le n Personlebens, keine krankhafte Erscheinung, die bekämpft werden muss. Sie $k$ ö $n \mathrm{n} t \mathrm{e}$ auch garnicht vermieden werden; denn solange der Mensch Leistungen vollzieht, verringert er durch das Leisten seine weitere Leistungskapazität, d.h. er ermüdet. Normal ist die Ermüdung, die sich in den Grenzen der allgemein menschlichen Periodik hält, also durch einen entgegengesetzten Prozess rückgängig gemacht wird. Dieser heisst E r h ol u n g. In der Erholung werden die verbrauchten Energien 
wieder ersetzt, die geminderte Leistungsfähigkeit wieder gesteigert, und schliesslich auch das Bedürfnis nach neuen Leistungen geweckt. Daher sind die Möglichkeiten der Erholung nicht minder mannigfach als die der Ermüdung. Spontane, selbstgewählte Beschäftigung kann nach ermüdender $Z$ wangstätigkeit ebenso erholend wirken wie Aufenthalt im Freien, kräftige Ernährung, körperliche Ruhe und Schlaf.

Der gesunde Mensch kann, ja soll sich ruhig ermüden; solange er die Gewähr hat, durch die normalen Erholungsmittel immer wieder auf die frühere Leistungshöhe und Frische zu kommen, sind hygienische Bedenken nicht am Platze. Vollberechtigt aber sind sie dort, wo die Regeneration garnicht oder nur mühselig und in abnorm langsamem Tempo zu stande kommt. Der Feind ist also nicht die Ermüdung, sondern die Ü be r m ü d u $\mathrm{ng}$. Aber gerade diese Formulierung zeigt, dass kein Ermüdungsmals einer Stichprobe an sich angibt, ob die erlaubte Grenze zur Übermüdung schon überschritten ist. Diese Feststellung kann nur an der geschädigten Erholungsfähigkeit im ganzen gemacht werden.

Wird Übermüdung erzeugt durch äussere Anforderungen (der Schule, des Berufs), dann spricht man von „Überbürdung”.

Hier gibt es nun sehr starke in d i v i d u e 11 e Unterschiede. Dieselben Schul- und Hausarbeiten, die den Schüler A nur innerhalb der normalen Erholbarkeitsgrenze ermüden, können für den Schüler B eine beträchtliche Ưberlastung bedeuten und hygienisch unzuträglich werden. Ahnlich steht es auch bei Erwachsenen bezüglich der Anforderungen des Berufslebens. Das Problem von Übermüdung und Überbürdung ist daher nicht so sehr ein solches der generellen, als eines der differentiellen Psychologie - und selbstverständlich auch der Psychopathologie.

Maximale Übermüdung, die ein Leisten für längere Zeit überhaupt unmöglich macht, heisst „E r s c h ö p f u n g”. Auch sie kann körperlich sein (,,man kann sich nicht mehr rühren”), oder geistig sein (,man ist unfähig, einen Gedanken zu fassen”), oder die Totalperson betreffen. Bemerkenswert ist, dass die Unfähigkeit $\mathrm{zu}$ werteschaffenden Leistungen nicht identisch sein muss mit dem Unterbleiben jeglicher Aktivität. Es gibt neben der schlaffen Erschöpfung, die zu körperlicher und seelischer Passivität führt, auch die überreizte Erschöpfung: man vermag nicht ruhig $\mathrm{zu}$ sitzen, sondern läuft rastlos herum, zappelt mit den 
Gliedern, spricht unaufhörlich - und ebenso im Geistigen: die Gedanken ,,drehen sich wie ein Mühlrad im Kopfe," die Affekte entladen sich ungeregelt. Ungehemmtheit ist das Wesentliche am Zustande der Überreizung. Jene höheren Funktionen, die den Ablauf des personalen Geschehens ordnen und sinnvoll richten: Denken, Wollen, Aufmerksamkeit - versagen so sehr, dass nun die der Kontrolle ledigen primitiven Tätigkeiten um so chaotischer ihr Wesen treiben.

Schliesslich muss von der Ermüdung noch der personale Zustand der ,S ät t i g u n g" unterschieden werden, der - in manchen äusseren Erscheinungformen sehr ähnlich - dennoch im Wesen anderer Natur ist. ${ }^{1}$ ) Ist Ermüdung die Minderung der $\mathrm{R}$ üs t u n g dispositionen zu Leistungen, so Sättigung das Versagen der $\mathrm{R}$ i c h t u n g s dispositionen. Das zeigt schon die ursprüngliche Bedeutung des Begriffs bei der Nahrungsaufnahme. Sättigung tritt nicht dadurch ein, dass die zum Essen notwendige Muskulatur ermüdet, sondern weil man ,genug" hat, weil das Bedürfnis nach weiterer Ernährung aufhört, ja, sich in sein Gegenteil, also in Abneigung gegen weiteres Essen, verkehrt.

Gleiches gibt es aber auch im Psychischen. Das ist besonders deutlich bei eintönigen fortlaufenden Arbeiten. Man wäre dynamisch noch im stande, wenn auch mit Mühe, die zum Arbeitsvollzug nötige Aufmerksamkeit aufzubringen, aber - „es geht mit einem Male nicht mehr', Die unmittelbar beteiligten Organe könnten noch weiter leisten; aber die Person in ihren tieferen Schichten sperrt sich gegen die Fortsetzung der Arbeit, und bei weiterem Zwang dazu kann es bis zum Ekel und zu sinnlosem Ausbrechen aus dem Leistungsvollzuge kommen. Das „Nichtmehrkönnen" hat hier also eine ganz andere Bedeutung, als bei der Ermüdung und Erschöpfung; denn es ist ein Aufhören der Leistungst e nden $\mathrm{z}$, nicht der Leistungspotenz. Auch das äussere Erscheinungsbild zeigt Unterschiede: die Sättigung kann mit ganz anderer Plötzlichkeit auftreten als die Ermüdung; sie hat auch oft eine ganz andere Nachhaltigkeit und verhindert die Wiederaufnahme der Leistung noch nach Pausen, in denen die reine Ermüdungswirkung längst kompensiert sein müsste.

\footnotetext{
1) Die Erscheinungen der ,Sättigung" sind neuerdings von Kurt Lewin und seinen Schülern näher untersucht worden.
} 
SECHSTER HAUPTTEIL

GEFÜHL 


\section{ACHTUNDZWANZIGSTES KAPITEL}

DIE GEF ÜH L P S Y H OLOGIE

NACH I H R N BISHERIGEN THEORIEEN U N D

BEF U D E N

Die Lehre von den Gefühlen stellt gleichsam die Feuerprobe für die personalistische Orientierung der Psychologie dar. Nirgends ist die Unzulänglichkeit des Versuchs, mit impersonalistischen Kategorieen Psychologie zu treiben, so deutlich wie auf dem Gebiet des Gefühlslebens, nirgends das Bedürfnis nach einem völligen Wechsel des Betrachtungsweise dringender.

Aber eben diese zu fordernde Umstellung macht es erforderlich, zuvor eine Übersicht über die psychologischen Gefühlstheorieen der letzten Jahrzehnte zu geben. Dabei werden wir jeweils diejenigen Punkte betonen und kritisch beleuchten, die (negativ oder positiv) für die Begründung der personalistischen Gefühlstheorie wichtig sind.

Im 17. Jahrhundert waren die „Affekte” erstmalig psychologischer Erörterung unterworfen worden (vor allem durch Descartes und Spinoza). Im 18. Jahrhundert hatten Rousseau, Hume u.a. gegenüber allzu intellektualistischen Auffassungen menschlichen Lebens und Tuns die tiefere Bedeutung des Gefühls ins Licht zu stellen versucht. Gleichzeitig war von den deutschen Aufklärern (Tetens, Sulzer, Mendelssohn, K. Ph. Moritz u.s.w.) das „Fühlen” als besonderes Grund-, Vermögen” der Seele konstituiert und den beiden anderen Vermögen des Denkens und Begehrens nebengeordnet worden.

Seit jenen Zeiten hat die psychologische Wissenschaft sich unablässig der Erforschung der Gefühle gewidmet. Der Erfolg war aber bis vor kurzem unbefriedigend, und zwar (wie erst jetzt deutlich wird), weil man die psychologischen Methoden, welche sich bei den anderen psychischen Tatbeständen: Wahrnehmungen, Vorstellungen, Handlungen, zu bewähren schienen, 
auch auf die Gefühlsforschung übertrug. Analyse bis zu den letzten aufweisbaren Elementen, Klassifikation und Ordnung, Untersuchung der physiologischen Begleiterscheinungen bildeten die Hauptgesichtspunkte des Verfahrens und der Theoriebildung - es war also im Grunde der stete Versuch, die Gefühle i m personalis t is ch zu erfassen und zu erklären. Gegenströmungen gab es natürlich immer; aber sie gingen mehr von der Philosophie, der Ethik oder von einer wissenschaftsfeindlichen, gefühlsschwelgerischen Romantik aus, die auf den Gang der Fachpsychologie wenig Einfluss ausübte.

Insbesondere die klassische Psychologie des 19 Jahrhunderts stand ganz vorwiegend im Banne einer solchen impersonalistischen Einstellung zur Problematik des Gefühlslebens; was hier Herbart und Wundt, Ribot und James eingeleitet hatten, wurde dann bis in die Gegenwart hinein von zahlreichen Forschern fortgesetzt, auch verfeinert und vertieft und $\mathrm{zu}$ fruchtbaren Spezialergebnissen geführt - bis dann vor einigen Jahrzehnten eine Gegenbewegung einsetzte.

Bei den älteren wie bei den neueren Lehren werden wir die rein psychologischen und die psychophysiologischen Betrachtungsweisen $\mathrm{zu}$ scheiden haben.

\section{ÄLTERE THEORIEEN UND ERGEBNISSE}

1. Analyse und Klassifikation der Gefühle

Die Erscheinungen des Gefühlslebens gliedern sich zwanglos in zwei Gruppen. Auf der einen Seite stehen die Gemütsbewegungen oder „Emotionen”, d.h. solche seelische Verfassungen, die zeitweilig das Erleben ganz ausfüllen und alles übrige Seelenleben sich unterwerfen; auf der anderen Seite solche Regungen, die sich an Seelenvorgänge und Inhalte anderer Art $\mathrm{d}$ i e $\mathrm{n}$ e $\mathrm{n} d$ anschliessen, daher einen spezielleren, begrenzteren Charakter haben, die „Gefühle”.

a) „Elementargefüh le.” - Die Psychologie sah nun diesen Erscheinungen gegenüber ihre erste Aufgabe in der A n a lys $\in$. Die Emotionen wurden in ihre Bestandteile zerlegt; man erkannte, dass in ihnen neben eigentlichen Gefühlen 
auch Vorstellungen und Gedanken, Organempfindungen und motorische Einstellungen enthalten sind. Bei den Gefühlen selbst setzte man die Zergliederung fort, bis man zu Letztbestandteilen, den ,Elementargefühlen" vorgedrungen zu sein glaubte.

Diese Elemente in ihrer Beschaffenheit und ihrer Ordnung bildeten schliesslich das Hauptproblem der äIteren Gefühlstheorieen; alle übrigen Phänomene sollten sich als Verbindungen („,Komplexe”) elementarer Gefühle unter einander und mit anderen Elementen aufweisen lassen. Allerdings tauchte sofort der Zweifel auf, ob es überhaupt einfache Gefühle als s e l b s tändige Seelenelemente gebe, oder ob es sich nur um unselbständige Beschaffenheiten anderer Elemente (um sogenannte Gefühls-,,Töne') handle. Aber ob man den einen oder den andern Standpunkt vertrat, einig war man sich darin, dass die elementaren Gefühlsphänomene in engster Beziehung zu den Empfindungen ständen, und zwar einerseits zu den Organempfindungen (Beispiele: Hungergefühl, Müdigkeitsgefühl), andrerseits zu den Erlebnissen der äusseren Sinne (Beispiele: die Annehmlichkeit des Zuckergeschmacks, die Peinlichkeit einer schrillen Dissonanz).

Diese sensualist is che Einstellung machte sich auch bei der Frage nach den Gru n d q u a lit ät e n der Elementargefühle geltend. Wie überall in naturwissenschaftlich-analytischen Verfahrungsweisen, suchte man auch hier die zunächst sich aufdrängende Qualitätenfülle zu reduzier en auf eine möglichst geringe Anzahl von Klassen gleichförmiger Elemente und diese Klassen in ein $\mathrm{Ordnungs} \mathrm{y} \mathrm{tem} \mathrm{zu} \mathrm{bringen.}$ Vorbilder hierfür lieferte wieder die Wahrnehmungspsychologie, die ja u. a. das eindimensionale System der Temperaturempfindungen und das dreidimensionale der Farbenempfindungen besass ${ }^{1}$ ). Entsprechende Systemformen suchte man auf die Gefühlssphäre anzuwenden.

b) Das Lust - und Unlust - Schema. - Den meisten Psychologen des 19. Jahrhunderts erschien für die Einordnung solcher elementaren Gefühlsphänomene ein 1 i n e a res System mit zwei Polen als notwendig und ausreichend: von

1) Vgl. S. 179 und S. 191. 
einem Indifferenzpunkt gehen die entgegengesetzt gerichteten Achsenhälften aus, welche die verschiedenen Grade der $\mathbf{L}$ u s t bezw. der Unlust bis zu deren stärksten Ausprägungen hin enthalten.

Zweifellos kommt in diesem Versuch einer der wesentlichsten Züge des Gefühlslebens zu seinem (freilich unzureichenden) Ausdruck: die Polarität.

Schon die Sprache aller Völker und Zeiten hat eine GrundGegensätzlichkeit der Gefühle in tausendfachen Wendungen festgehalten. Überall spricht man von Freud und Leid, von Liebe und Hass, von Hoffnung und Furcht, von , himmelhochjauchzend, zum Tode betrübt" u.s.w.; und überall glaubt man gerade in solchen sprachlichen Verbindungen die, zwischen Positiv und Negativ sich ausbreitende, Spannweite des Fühlens zu fassen.

Als nun aber die wissenschaftliche Besinnung mit der Einordnung aller Gefühle in eine Lust/Unlust-Reihe Ernst zu machen versuchte, ergaben sich drei Konsequenzen, die von manchen Forschern auch tatsächlich gezogen, von anderen gemieden wurden.

1) Wenn es nur diese eine Gefühlsdimension gibt, muss jedes vorkommende Gefühl durch seine Stelle in dieser Skala charakterisierbar sein. Gefühlsphänomene, bei denen die Einordnung nicht sofort gelingt, sind solange zu analysieren, bis sich zeigt, wie die elementaren Lust- und Unlust-Gefühle durch nichtemotionale Bewusstseinsinhalte (Sinnesempfindungen, Vorstellungen u.s.w.) kompliziert worden sind.

2) Innerhalb der Lustgefühle einerseits, der Unlustgefühle andrerseits, gibt es nur Gra d u n te r s c h i ed e, keine Qualitätsunterschiede. Wird z.B. der Genuss einer guten Zigarre mit dem einer Beethoven'schen Symphonie oder mit der Freude an einer guten Tat verglichen, so kann das Lustgefühl in dem einen Falle intensiver, im anderen schwächer sein - weitere Verschiedenheiten sind nicht als ursprüngliche anzuerkennen, weil sie aus dem linearen Schema herausfallen würden.

3) Auch wenn man die beiden Gefühlsrichtungen Lust und Unlust mit einander vergleicht, kann jene Theorie nicht Qualitäts-, sondern nur Vorzeich e n-Verschie denheiten anerkennen; es gelten für sie lediglich diejenigen Beziehungen, welche die Mathematik für jede durch 
einen Nullpunkt gehende Achse kennt. Die Intensitäten der, auf den beiden Achsenstücken liegenden, Gefühle sind durch ihre Abstände vom Nullpunkt mit einander vergleichbar und gegen einander verrechenbar. Bei gleichem Grade heben sie sich auf; überwiegt die eine, so restiert bei ihrer Kombination ein gewisser Lust- bezw. Unlustüberschuss.

Wie weit diese Mathematisierungsneigungen gehen, tritt sehr drastisch in einigen Gefühlstheorieen hervor, die weniger der Psychologie als der Philosophie und Ethik angehören, und die ernsthaft,, Budget"-Aufstellungen des Lust/Unlust-Bestandes versuchten. Besonders arbeiten die Vertreter des Pessimismus mit solchen Gedanken: Schopenhauer und Eduard von Hartmann glaubten exakt nachgewiesen $\mathrm{zu}$ haben, dass der Rechnungsbetrag des Leides in der Welt den der Lust unendlich überwiege; ja, sie neigten sogar dazu, die Plusseite dieses Gefühlskontos ganz leer zu lassen, da sie die von der Unlust her kommende Linie über den Nullpunkt hinaus am liebsten garnicht fortsetzen mochten: die sogenannte Lust sei nur vorübergehendes Aussetzen derUnlust.

Die Psychologen von Fach haben zwar solche Verstiegenheiten in der Mathematisierung der Gefühle nicht mitgemacht. Aber auch die sonstigen Konsequenzen, die sich aus dem eindimensionalen System der Gefühle ergaben, gingen noch allzu weit. Musste man doch versuchen, die qualitative Vielgestaltigkeit der Gefühle zum blossen Mehr oder Minder von Lust und Unlust zu vereinfachen - was nur mit grosser Gewaltsamkeit möglich war.

Schon die B e z e i ch n u g des Gegensatzes als Lust und „U n-Lust” verrät die Verlegenheit. Ein solcher Sprachgebrauch, der Leid, Trauer, Angst, Hass, Entsetzen nur zu N e g i e r u ng e n der Lust machen möchte, hat sich nie über die Grenze der wissenschaftlichen Theorie hinaus einbürgern können. Im natürlichen Sprachgebrauch (der gerade auf dem Gebiet des Gefühlslebens als Niederschlag der Volksweisheit Beachtung verdient), gibt es zwar auch negative Bezeichnungen wie ,unangenehm", „missmutig", ,freudlos" ,ich bin unlustig dazu” ; aber sie bezeichnen höchstens schwache Stufen. Ausgesprochene Leidgefühle haben ihre eigenen positiven Bezeichnungen, weil sie ihre eigenen Erlebnis-Qualitäten haben.

Auch in ner h a lb jeder der beiden Kategorieen reichen Gradabstufungen nicht aus. Um bei unserm obigen Beispiel zu bleiben: wenn wir feststellen, dass der Genuss der Zigarre zwar in- 
tensiver ist als der Genuss der Symphonie, aber kürzer dauert, so ist mit solchen quantifizierenden Angaben zweifellos der Unterschied der beiden Genüsse nur in den unwesentlichsten Merkmalen charakterisiert. Und es wäre nur ein Ausweichen, wollte man sagen, dass lediglich die hinzukommenden Sinnesempfindungen, Vorstellungen u.s.w. die Differenz bedingen - nein, der Genuss selbst in seiner unmittelbaren gefühlsartigen Erlebnisbeschaffenheit ist jedesmal ein qualitativ anderer.

c) Wu ndt's System. - Die Einsicht in die Unzulänglichkeit eines eindimensionalen Ordnungssystems hatte nun Wundt zur Konstruktion einer dreidimensionale Ma n nigfaltigkeit der Gefühle bewogen. Ausser dem Lust/Unlust-Gegensatz nimmt er noch zwei andere Gegensatzpaare an, die ebenso elementar und irreduzibel sein sollen: „Erregung/Ruhe" und „Spannung/Lösung”. Vergleicht man etwa die Gemütszustände Jubel und Behagen, so liegen zwar beide auf der Lustseite, aber an entgegengesetzten Polen der Erregung/Ruhe-Dimension. Der dritte Gefühlsgegensatz Spannung/ Lösung tritt besonders deutlich im Ablauf und Abschluss eines Erwartungsvorgangs hervor; dabei können die beiden Gefühle zugleich lustbetont, oder auch beide unlustbetont, oder schliesslich lust/unlust-neutral sein.

Als Gegenpol der „Erregung” wird von Wundt bald „Ruhe”, bald „Depression" genannt, obwohl es sich um zwei sehr verschiedene Tönungen des Gefühslebens handelt. Dem Gefühl der „Depression” haftet zugleich ein Unlustton an, sodass es nicht einer von Lust/Unlust unabhängigen Dimension zugeordnet werden kann. - Ferner sind die beiden neuen Dimensionen Wundt's $u$ ter e in a $\mathrm{n} d$ er verkoppelt: Erregung ist mit Spannung, Lösung mit Ruhe nahe verwandt.

In jüngster Zeit ist übrigens die „E r r e g u n g” als selbständige Elementarerscheinung des Gefühlslebens von einigen Psychologen noch ein mal entdeckt worden. Claparède schildert eine "émotion pure", eine Art „Rührung”, die eine kurze, nicht mit Lust oder Unlustakzent versehene Erschütterung der körper-seelischen Lage bedeutet. Stratton stellt ,excitement" als eine noch völlig undifferenzierte Emotion den differenzierten Emotionen wie Furcht, Zuneigung, Ärger gegenüber. $T$. Chiha führt für einen elementaren Gemütszustand, der weder Lust noch Unlust, aber auch nicht blosse Indifferenz ist, den japanischen Namen „Mukigefühl” ein. 
Gewiss hat Wundts System gegenüber der nackten Lust/Unlust-Linie den Vorzug geringerer Einförmigkeit. Aber die grundsätzlichen Bedenken bleiben doch in ihrer vollen Stärke bestehen. Denn ob ein oder ob drei Gegensatzpaare oder noch einige mehr angesetzt werden: jedenfalls wird eine eng begrenzte Anzahl von Elementargefühlen postuliert, die dann nur durch verschiedenartige Kombinationen die ganze Fülle des Gefühlslebens erstehen lassen sollen.

Dennoch sind solche Klassifikationen von Wert, und wir werden uns ihrer weiterhin ebenfalls bedienen; nur darf man in ihnen nicht Klassen von Elementen sehen, a u s denen Gefühlserlebnisse bestehen, sondern $\mathrm{M} \mathrm{e} \mathrm{r} \mathrm{kma} \mathrm{le,} \mathrm{die} \mathrm{a} \mathrm{n} \mathrm{G}$ ef ü h le n erfassbar sind. Sie dienen zur Beschreibung von Gefühlen, erschöpfen sie aber nicht, weil deren Totalqualität eben etwas anderes ist als ein Komplex von Lust-Spannungs-Erregungs-Graden (bezw. ihrer Gegenpole). Das System erlaubt, Gefühle zu vergleichen nach bestimmten Gesichtspunkten, ohne dass dadurch die, letzthin unvergleichliche, Besonderheit eines jeden Gefühls aufgehoben würde.

Verlässt man aber den Elementenstandpunkt, dann wird auch die Frage nach der A n $\mathrm{z}$ a h $\mathrm{l}$ der in Betracht kommenden Merkmalsdimensionen nebensächlich. Je mehr sich die Gefühlspsychologie verfeinert, um so mehr Gesichtspunkte der Beschreibung und Gliederung werden gefunden. So haben z.B. die letzten Jahrzehnte Gegensatzpaare an den Gefühlen sichtbar gemacht, die von allen oben genannten durchaus abweichen, aber unter einander nahe verwandt sind: Tiefe und Oberfläche, Echtheit und Unechtheit, Ernsthaftigkeit und Spielhaftigkeit. - Auch die alte Unterscheidung von „höheren” und ,niederen” Gefühlen erweist sie neuerdings wieder als wissenschaftlich brauchbar.

Endlich erlaubt unsere „Merkmalsauffassung” einen weiteren Forschungsschritt, der der Elemententheorie versagt ist: man kann die Frage nach der B ed e u t u n $g$ jener Merkmale aufwerfen und durch Bezug auf die personale Verankerung der Gefühle beantworten. (Vgl. das folgende Kapitel.)

d) „Gefüh ls e m p findungen” (St u m p f). - Die Verwandtschaft gewisser Gefühle mit der Empfindungssphäre hat $z u$ einer eigenartigen Theorie geführt. Nach Carl Stumpf 
gehören alle jene Phänomene, die man als ,sinnliche Gefühle” oder „Organgefühle" zu bezeichnen pflegt, einer völlig anderen Klasse seelischer Elemente an, als die eigentlichen Gemütsbewegungen; sie sind nicht unter die Gefühle, sondern unter die Emp find ungen zu gruppieren. Stumpf nennt sie „G e f ̈̈h ls em p findungen".

Diese Theorie stützt sich auf physiologische Untersuchungen von v. Frey, die besondere Organe für S c h m e r z-Erlebnisse der Haut nachgewiesen hatten. „Hautschmerz” ist also ein durch spezifische Reizung eines spezifischen Organs erzeugbares Bewusstseinsphänomen und damit eine „Empfindung," kein „Gefühl'. Stumpf erweitert dann den Begriff der Gefühlsempfindung auf andere, von der Haut ausgehende Sinneserlebnisse, wie Kitzel, Jucken, Wollust - schliesslich sogar auf die Gefühlstöne der einfachen Empfindungen der übrigen Sinne; so soll etwa die Annehmlichkeit des Zuckergeschmacks eine eigene, zentral erregte „Mitempfindung” neben der eigentlichen Geschmacksempfindung ,,süss” sein, u.s.w.

Nach dem heutigen Stande der Psychologie, die „Empfindungen" als reale Elemente des seelischen Geschehens nicht mehr kennt (vgl. S. 147/8), hat der zeitweilig lebhaft geführte Streit um die „Existenz” von Gefühlssempfindungen fast ganz an Bedeutung verloren Mag ,Schmerz” als eigenartige Sinnesqualität auch isoliert erzeugbar und erlebbar sein - der U n a n $\mathrm{n}$ e h m l i chke it s charakter des Schmerzes, d.h. seine eigentliche Gefühlsseite, ist nichts Isoliertes mehr, sondern irgendwie der Totalperson eingebettet und eben darum dem Charakter eines hypothetischen Empfindungs-E le m e n t s entgegengesetzt.

2. Körperliche Grundlagen des Gefühlsle bens

a) Korrelationen. - Eingehende Forschungen der Psychophysiologie und der Medizin haben in den vergangenen Jahrzehnten die Einsicht in die Zusammenhänge zwischen Gefühlsprozessen und körperlichen Vorgängen beträchtlich gesteigert.

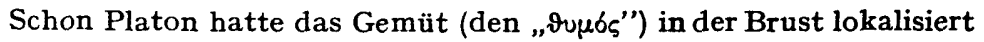
- im Gegensatz zu dem im Kopf sitzenden Denkvermögen. Die Scheidung von "Herz" und „Kopf" findet sich in dem Sprachgut der ver- 
schiedensten Völker - und ist von der modernen Wissenschaft weitgehend bestätigt worden.

Während das Zentralnervensystem und insbesondere das Gehirn lokalisatorisch und funktionell $\mathrm{zu}$ den Tätigkeiten des Wahrnehmens, Vorstellens, Denkens und Wollens in spezialisierte Beziehungen gebracht werden konnte, gelang Gleiches bei den Gefühlen nicht; dagegen stellte sich ein enger Zusammenhang mit Veränderungen der Blutkreislaufs-, Atmungs-, Stoffwechselund Sekretions-Funktionen heraus, die nun im einzelnen mit physiologischen Methoden untersucht werden konnten.

Aber auch hier überwog zunächst die e l e m e n t e $\mathrm{n} t \mathrm{~h}$ e o$\mathrm{ret}$ is che Einstellung. Man analysierte die graphisch aufgenommenen Kurven des Pulsschlages oder der Atmung nach Tempo, Gleichmäfsigkeit oder Ungleichmälsigkeit, Ausschlagsweite und Gestalt, und untersuchte, wie die einzelnen elementaren Ånderungen des Gefühlslebens sich in Änderungen jener physiologischen Merkmale ausdrückten. Auch die unwillkürlichen Zitterbewegungen der Glieder und die Ausschläge des Galvanometers bei Durchleitung eines galvanischen Stroms durch den Körper wurden in den Dienst dieser Gefühlsstudien gestellt.

Die hierher gehörigen Apparaturen findet man in jedem Lehrbuch der Physiologie und der experimentellen Psychologie beschrieben. Es muss hier genügen, die Namen der Hauptinstrumente zu nennen. Der Kardiograph registriert un mittelbar die Periodik des Herzschlages, der Sphygmograph die Pulsbewegungen am Handgelenk, der Plethysmograph die Schwankungen in der Blutfülle des Arms, der Pneumograph die Atemkurve, das Psychogalvanometer die Veränderungen der Körperelektrizität. Zitterbewegungen der Glieder werden geprüft durch den „Psychographen" (Sommer) und in gröberer Form durch das Tremometer.

Während ein Apparat dieser Art mit dem Körper der Versuchsperson verbunden ist, wird sie einer fortlaufenden psychologischen Aufgabe unterworfen, welche Gelegenheit zur Anwendung von Gefühlsreizen gibt (durch Verursachung von Schreck, Überraschung, Schmerz, durch Darbietung von Bildern wohlgefälligen und missfälligen Inhalts, durch Erwartungs-Spannung und -Lösung, durch Nahelegen lügenhafter Äufserungen). Es kann dann das zeitliche Zusammenfallen bestimmter Gefühle 
mit bestimmten Ånderungen in den registrierten Kurven festgestellt werden.

Als allgemeines Ergebnis steht fest, dass der Körper ausserordentlich fein und mannigfaltig auf Änderungen der Gemütslage reagiert; selbst Gefühle von unbedeutender Stärke und geringer Dauer entbehren nicht der körperlichen Begleiterscheinungen. Insbesondere tritt die $\mathrm{Unte} \mathrm{rbrech} \mathrm{ung}$ einer zunächst neutraleren Seelenverfassung durch Gefühlschoks (Schreck, Überraschung) sehr deutlich in Kurvenstörungen hervor.

Wird z.B. die Versuchsperson, deren Hand im „Psychographen” liegt, aufgefordert, sich aus einem Spiel Karten eine beliebige Karte zu merken, und wird ihr dann Karte für Karte vorgelegt, so kann der Experimentator an dem Ausschlagen der Zitterkurve der Hand genau erkennen, welche Karte gemerkt worden war, auch wenn die Versuchsperson jede Ausdrucksbewegung zu vermeiden bestrebt ist.

Die Leistungsfähigkeit der Methode sank aber sofort herab, wenn man nun psychische und physische Elementarfunktionen i $\mathrm{m}$ e inzel $\mathrm{n}$ e $\mathrm{n}$ einander zuzuordnen suchte. Dies ist in älterer Zeit namentlich im Anschluss an die Wundt'sche Gefühltheorie unternommen worden, da man hoffte, für jede der sechs angeblichen Elementarrichtungen eindeutige körperliche Symptome finden zu können. Die Ergebnisse der mannigfachen und mühsamen Untersuchungen waren überaus unklar und widerspruchsvoll. Für den Lust/Unlust-Gegensatz fanden sich überhaupt keine eindeutigen physiologischen Elementarsymptome. Der einzige sichere Befund: dass der Gefühlsgegensatz Erregung/Ruhe auch in dem verschiedenen Aktivitätsgrad von Atmung und Herzschlag zum Ausdruck komme - hätte wohl kaum so umständlicher experimenteller Vorkehrungen bedurft.

Neuerdings hat der amerikanische Behaviorismus das Problem aufgenommen, da dieser in den Emotionen lediglich eine besondere Art innerer physiologischer Aktivität sehen will. Aber auch ihm ist es nicht gelungen, in den Funktionen der inneren Organe Unterschiede aufzuweisen, die etwa die Emotion „Furcht" von der Emotion „Ärger" eindeutig zu differenzieren vermöchten.

b) Die James-Lange'sche Hypothese. Für die allgemeine Gefühlstheorie ist die Berücksichtigung der physiologischen Vorgänge in anderer Hinsicht wichtig geworden. 
Die Prozesse des Zirkulations-, Atmungs-, vegetativen und motorischen Systems haben ja ihre eigene B e w u s s t s e in sb e g l e i t u n g; man pflegt diese, durch innere Reize erzeugten, Erlebnisse zu den „Empfindungen” zu rechnen. Wir haben etwa „Organempfindungen" von der Überfüllung oder Leere des Magens, von einer Beschleunigung der Herztätigkeit, von Blutleere im Kopf, von besonders erleichterter oder erschwerter Atemtätigkeit. Wir haben kinaesthetische Empfindungen von der Lage, den Ortsbewegungen und den Zitterbewegungen unserer Glieder. Im allgemeinen sind diese Kundgaben unserer eigenen Körpervorgänge nur dann als bew us ste Erlebnisse vorhanden, wenn eine Abweichung von der normalen Funktion des Organs und somit starke Lust- oder Unlust-Betonung vorliegt. Dieser Umstand veranlasste nun manche Gefühlstheoretiker, hier den wahren Ursprungsort der Gefühle zu sehen, und zwar nicht nur der eigentlichen ,Körpergefühle" wie des schmerzenden Hungers, der Müdigkeit, der Herzbeklemmung - sondern a 11 e r Gefühle schlechthin.

Es ist nun gewiss richtig: mit jeder Gemütsregung - sei es die Freude über einen Erfolg, die Trauer über eine Todesnachricht, die Spannung auf den Ausgang eines Examens, die Furcht vor der Dunkelheit, die religiöse Andacht - sind irgendwelche physiologischen Vorgänge verbunden, die in Organ- und Bewegungsempfindungen erlebt werden können. Von dieser Feststellung war der Schritt nicht mehr weit zu der Behauptung: die Gefühle seien überhaupt nichts anderes als jene Körpererlebnisse.

Dies ist der Grundgedanke der ,J a m e s- L a n g e's c h e n G e fühls th e or i e" 1). Sie kehrt die übliche, ,intellektualistische" Kausalerklärung der Gefühle in folgender Weise um. Ein verirrter Wanderer gerät in der Abenddämmerung in einen dunklen Wald und wird ,,ängstlich". Dann gilt hier nicht die Kausalfolge: Anblick des dunklen Waldes, Vorstellung der dort vielleicht lauernden Gefahren, G e fü h 1 der Ängst, Herzklopfen und Zittern - sondern: Anblick des dunklen Waldes, d i r e k t e Körperreaktion a uf den Schokreiz durch beschleunigten Herzschlag, Zittern der Knie u.s.w., unlustvolle

1) In den 80 er Jahren des 19. Jahrhunderts aufgestellt von dem Amerikaner William James und dem Dänen C. Lange. 
Organempfindungen dieser abnormen Körperreaktion. Derartige Organempfindungen und nichts anderes $\mathrm{b}$ i $1 \mathrm{~d}$ e $\mathbf{n}$ das ,Angstgefühl", und erst von dem Gefühl aus werden die intellektuellen Inhalte, die sich mit dem Walde verbinden, a $1 \mathrm{~s}$ angsterregende, a $1 \mathrm{~s}$ "Gefahrvorstellungen" erlebt, während sie ohne jene Störung des Organempfindens lediglich zu Motiven für zweckmärsige Willensaktionen geworden wären.

Berühmt ist die knappe Formel geworden, in welche William James diese Theorie presste: „Wir weinen nicht, weil wir traurig sind, sondern wir sind traurig, weil wir weinen."

Die James-Lange'sche Theorie hat - gerade durch ihre Übertreibung - in dankenswerter Weise auf die grosse Bedeutung der Organerlebnisse für den Aufbau unserer Gefühle aufmerksam gemacht; und jede psychologische Gefühlstheorie wird fortan damit zu rechnen haben. Es trifft ferner $z u-$ und wird später noch näher zu besprechen sein - dass Gefühlsreaktionen auf Reize schon eintreten können, e h e sich ein Wissen um die vom Reiz ausgehende Förderung oder Gefährdung geltend macht. Endlich ist für $\mathrm{gew}$ is se Gemütsbewegungen zuzugeben, dass sie ganz wesentlich in solchen Organerlebnissen fundiert sind; so gibt es zweifellos eine ,Angstlichkeit”, die lediglich auf Herzbeklemmungen beruht. Insbesondere sind die heftigen Affekte (z.B. Wut, Entsetzen) ohne intensivste Veränderungen der Körperfunktionen und der damit verbundenen Organempfindungen nicht denkbar.

Aber gerade der verschieden dosierte Anteil jener Organerlebnisse an verschiedenen Gefühlserscheinungen muss gegen die Allgemeinheit der Theorie bedenklich machen. Man vergleiche die oben erwähnte Ångstlichkeit infolge nervöser Zirkulationsstörungen mit der Angst einer Mutter um ihr schwerkrankes Kind: sind hier wirklich die Gefühlserlebnisse als solche identisch, und nur die begleitenden Vorstellungen verschieden? Gewiss sind an dem Totalgefühl der Mutter auch veränderte Organempfindungen beteiligt, hervorgerufen durch flatternden Puls, Übermüdung, verringerte Nahrungsaufnahme u.s.w. aber der Kern des Erlebnisses „Mutterangst” wird doch durch die Beziehung zum Kinde gebildet, die nicht etwa nur vorgestellt, sondern unmittelbar $\mathrm{g}$ e f $\ddot{\mathrm{h}} \mathrm{lt}$ wird; es ist ein Mitfühlen mit dem Leiden des Kindes, ein Vor-fühlen der Lebens- 
gefährdung, ein Sich-Eins-fühlen mit der Existenz des Kindes.

Ganz unzulänglich ist die Theorie gegenüber den höheren (auf Wertgebiete bezüglichen) Gefühlen, wie: religiöse Inbrunst, Kunstgenuss, moralische Gewissenqualen u.s.w. Was hierbei etwa an tatsächlichen Funktionsveränderungen der Körperorgane eintritt, bleibt entweder ganz unter der Bewusstseinsschwelle oder führt zu unbedeutenden Modifikationen des Erlebens, die in keinem Verhältnis stehen zu der gewaltigen Kraft und Tiefe jener Gefühle. Diese werden aus ganz anderen Quellen gespeist als aus den Organempfindungen der Blutzirkulation, des Stoffwechsels, der Muskelbewegung und der Atmung.

\section{NEUERE THEORIEEN UND GESICHTSPUNKTE}

In den letzten Jahrzehnten gewinnt die Überzeugung an Boden, dass man auf den oben geschilderten Wegen analysierender Forschung nicht zu dem eigentlichen Wesen der Gemütsphänomene vordringen könne, dass vielmehr grundsätzlich andersartige Gesichtspunkte und Methoden angewandt werden müssen. Allen diesen Bestrebungen gemeinsam ist eine stärkere Bezugnahme auf das $f \ddot{u} h \mathrm{l}$ ende $S u b j e k t$ in seiner lebendigen Einheit; man sucht der Tatsache gerecht zu werden, dass die Gefühle doch ganz anders , personnahe” sind als die Vorstellungen u.s.w. Dabei geht man auf sehr verschiedenen Wegen vor, die entweder vorwiegend biologisch oder vorwiegend psychologisch orientiert sind; sie alle konvergieren mehr oder weniger gradlinig - zu dem personalistischen Hauptweg, den wir im nächsten Kapitel einschlagen werden.

1. Biologisch fundierte Gefühlstheorie

a) Die biologische Polarität. - Auch die Biologie ist an jener Wendung des wissenschaftlichen Denkens beteiligt, die von der Elementenauffassung zur Ganzheitsauffassung führt. Der Organismus wird als einheitliches Zwecksystem gesehen; man untersucht, wie seine Reaktionen durch die Tendenz zur Selbsterhaltung oder Gattungserhaltung bestimmt sind; man stellt die Strukturprinzipien fest, die Bau und Funktion des Gesamtkörpers beherrschen. 
Diesem Wandel entspricht es daher auch, wenn die körperlichen Grundlagen des Gefühlslebens nicht mehr, so wie früher, in physiologischen Elementarfunktionen der Zirkulation, Atmung u.s.w., sondern in biologis chen Ganzheitsf u n k t i on en der Zweckgemälsheit oder der Ausdruckshaltigkeit gesehen werden.

Den Zweckgesichtspunkt wendet diese neuere Psychobiologie vornehmlich in dem polaren Begriffspaar der L e b e $\mathbf{n}$ s f ö r d e rung und Lebens minderung an. Alle Funktionen im Organismus werden unter die Perspektive gestellt, ob sie positiv zur Erhaltung, Sicherung, Erhöhung des Lebens beitragen, oder ob sie negativ den Bestand oder das Niveau des lebendigen Organismus bedrohen. Entsprechend wird die einwirkende Aulsenwelt gegliedert in solche $\mathrm{R}$ e i z e, denen der Organismus angepasst (bezw. leicht anpassbar) ist, und solche, an die eine Anpassung nicht oder schwer möglich ist, die vielmehr als Störungen und Gefährdungen auftreten.

Diese biologische Grundpolarität ist schon sehr früh mit der Gefühlspolarität Lust/Unlust in Beziehung gebracht worden 1); die moderne, biologisch fundierte Psychologie hat den Gedanken erneuert und zur Grundlage ihrer Gefühls-Theorieen und -Untersuchungen gemacht. Wir begegnen ihm u.a in der Entwicklungspsychologie, im amerikanischen Behaviorismus, in Mc Dougall's ,hormic psychology”.

Die These lautet also: Lust ist die Erlebnisweise von Lebensförderung (Anpassung), Unlust die Erlebnisweise von Lebensstörung und Bedrohung (Unangepasstheit). Nun wäre freilich nicht einzusehen, welchen Sinn d a s blos se Er le be n von zuträglichen oder abträglichen Lebensprozessen für den Organismus haben sollte; ja man könnte meinen, dass der Effekt schädlicher Einwirkungen geradezu verdoppelt würde, wenn diese nicht nur objektiv den Organismus beeinträchtigten, sondern noch ausserdem subjektiv leidvolle Gefühle bis zu den unerträglichsten Schmerzen hin im Gefolge hätten. Hier setzt nun eine wichtige Ergänzung der biologischen Theorie ein: Die Lustund Unlust-Gefühle sind nicht nur Begleitzustände zu gleichzeitig ablaufenden biologischen Vorgängen, sondern auch Motoren

1) Bereits Spinoza hatte die Affekte Freude und Traurigkeit dem Ubbergang des Menschen zu grösserer bezw. geringerer Vollkommenheit zugeordnet. 
für weitere. In jedem Gefühl steckt ein A n t r i e b s m o m e n t zu bestimmten Verhaltungen, dessen Wirksamkeit unabhängig davon ist, ob ein vorstellendes Bewusstsein von Sinn und Ziel des Verhaltens mitspielt.

Die biologische Theorie von den Gefühlen ist demnach ohne enge Beziehung zur Theorie der $\mathrm{Tr}$ i e be $\mathrm{u}$ nd Instin $\mathrm{kte}$ nicht denkbar. In der Betonung dieses Zusammenhanges liegt ihr unleugbares Verdienst. Auch wir haben bei den früheren Erörterungen über Bedürfnis- und Trieb-Psychologie auf solche Zusammenhänge nachdrücklich hingewiesen.

Als Antriebsmomente haben nun Lust und Unlust wiederum polare Bedeutung: Lustgefühle spornen zur Fortsetzung des sie erzeugenden Zustandes an; Unlustgefühle leiten zu Handlungen und Verhaltungen über, die geeignet sind, den unlustvollen Zustand zu beseitigen. „Leid spricht: vergeh! Doch alle Lust will Ewigkeit!' (Nietzsche, Mitternachtslied.) Damit ist nun die Teleologie geklärt. Denn die Tendenz der Lust, sich zu verewigen, trifft ja einen lebenfördernden Zustand, dessen Fortsetzung im Sinne des Totallebens liegt. Die Antriebsdynamik der Unlust dagegen, sich selbst aufzuheben, bewirkt, dass einem lebenschädigenden Prozess Einhalt getan wird. Mit anderen Worten: Lust und Unlust sind biologische $\mathrm{S}$ i g $\mathrm{n}$ a $\mathrm{l} e$ : jene ein Ermunterungsansporn, den der Organismus sich selbst gibt : fahre so fort! - diese ein Warnungszeichen: halt ein!; oder: sei auf der Hut!

Der amerikanische Behaviorismus hat diesem Gedanken eine solche Wendung zu geben versucht, dass die eigentlich ps y chis chen Phănomene Lust/Unlust ganz ausser Spiel bleiben und lediglich das äussere Anpassungsverhalten zum Reiz berücksichtigt wird. So ist z.B. nach Woodworth das Differenzierungsmerkmal für verschiedene Emotionen lediglich darin zu sehen, ob ein A n näh e r ung s- oder ein Me i d e ver h a 1 t e n des Organismus gegenüber dem Reiz stattfindet.

b) Grenzen der biologischen Polaritätst h e or i e. - Vorzüge und Nachteile dieser Theorie sind durch ihre biologische Begrenztheit bedingt. Sie betrachtet den Menschen nur als Orga nis mus; und innerhalb dessen achtet sie lediglich auf die generellen und feststehenden $\mathrm{Z}$ we ckzus a m m e $\mathrm{nh}$ än g zwischen Umwelt und Reaktion. Sauerstoffreiche Luft zu atmen ist dem Organismus zuträglich, verbrauchte Luft $z u$ atmen abträglich; dem entspricht 
es, dass der Aufenthalt in frischer Luft lustvoll, das Verweilen in schlecht ventilierten Räumen unlustvoll ist. Kommt die Hand ungewollt mit einer Flamme in Berührung, so dient das Schmerzgefühl der Verbrennung als Signal, die lebenbedrohende Nähe des Feuers zu beseitigen: durch Wegziehen der Hand, durch Auslöschen des Feuers. Die Speisen, die dem Körper bekömmlich sind, schmecken auch im allgemeinen gut; und sie schmecken nur solange gut, als der Organismus ihrer bedarf. Ist der Mensch satt, oder mit bestimmten Nährstoffen genügend versorgt, dann hört von selbst das Lustgefühl und damit der Antrieb zu weiterer Aufnahme dieses Nährstoffes auf.

Die Beispiele liessen sich beliebig vermehren. Aber sie beziehen sich alle auf die $\mathrm{Bi}$ os phäre, also auf diejenigen Gefühlsgruppen, die nicht mensch-spezifisch sind, sondern auch dem Tier zukommen. Beim Tier ist auch aller Wahrscheinlichkeit nach jene Zuordnung von Lust zu ZweckmäIsigkeit, von Unlust zu Unzweckmälsigkeit ziemlich eindeutig und durchgängig. Beim Menschen lässt sich fast jedem positiven Beispiel ein G e g e n b e is p i e 1 gegenüberstellen.

Es gibt wohlschmeckende Gifte, bei deren Einverleibung in den Organismus also das Warnungssignal der Unlust (etwa Widrigkeit des Geschmacks) fehlt. - Bei den zahlreichen, nicht etwa nur in pathologischen Fällen auftretenden, ,Süchten” sind die schädigenden Reize mit starken Lustgefühlen besetzt (Alkohol, Morphium), und diese zeigen den A n t ri e b s charakter der Lust zur Fortsetzung der Reizaufnahme in höchstem Malse, obwohl dadurch die Schädigung nur noch gesteigert wird. Ferner würde die Theorie auch eine gradu elle Zuordnung zwischen Lust und Förderung, Unlust und Schädigung erwarten lassen. Dann müsste der leidenschaftliche Raucher eine viel stärkere organische Förderung vom Rauchen erfahren, als der mäIsige Raucher, dessen Lustgefühle geringere Intensität haben. Eine körperliche Erkrankung müsste um so stärkere Unlust erzeugen, je mehr sie die Wurzeln des Lebens bedroht; bekanntlich kann aber eine oberflächliche Fleischwunde unter Umständen fast unerträglich sein, während schwere Erkrankung innerer Organe kaum zum Bewusstsein kommt. (Sogar die Paradoxie einer gehobenen Gefühlslage bei tötlicher Erkrankungen, z.B. bei schwerer Tuberkulose, kommt vor). 
Vor allem sind es aber wiederum die h ö h e r en Gefühle, mit denen jene Theorie nicht fertig werden kann. Unlustbetontheit gibt es im Gefühl der Reue, im aesthetischen Erleben des Tragischen, im philosophischen Leiden an Problemen - wie sollten sich diese Gefühle mit organischen Schädigungen in Verbindung bringen lassen? Der Asket sucht Schmerzen und meidet Lust obgleich nach jener Theorie die entgegengesetzten Antriebe wirksam sein müssten. Der Wagemutige lässt sich gerade durch Gefahren - die also seine biologische Existenz bedrohen - anlocken.

Schon aus diesen wenigen Andeutungen wird der Haupteinwand gegen die biologistische Theorie erkennbar: ihre einfachen Kategorieen: organische „Zweckmälsigkeit” und „Unzweckmälsigkeit”, „Anpassung” und „Nichtanpassung" reichen bei den höheren personalen Funktionen eben nicht mehr aus. Schon deshalb nicht, weil die Person eine $\mathrm{H}$ i e r a r c h i e von Zwecken in sich schliesst, so dass irgend ein körper-seelisches Geschehen gleichzeitig für verschiedene $Z$ wecke entgegengesetzte Vorzeichen haben kann. Dann aber, und vor allem: weil das Wesen der Person sich nicht im Erfüllen ihrer organischen Zwecke erschöpft. Die kahle Gegenüberstellung von positiver und negativer Zweckbeziehung (Nutzen und Schädigung) ist genau so unzulänglich, wie der schon früher zurückgewiesene Versuch, im Psychologischen alle Gefühle auf die Pole der Lust/UnlustDimension zu reduzieren. Die Theorie enthält gewisse fruchtbare Gedanken; sie muss aber, um einer personalistischen Auffassung eingeordnet $\mathrm{zu}$ werden, noch eine wesentliche Umgestaltung erfahren.

Übrigens sind schon innerhalb der psychobiologischen Einstellung selbst Ansätze erkennbar, um die Primitivität der bipolaren Zwecktheorie zu überwinden.

McDougall entwickelt eine Theorie, in der die Qualitätenfülle der Gefühlswelt besser zu ihrem Recht kommen soll : er überbaut die $Z$ weiheit der Lust/Unlustreaktion durch eine Vielzahl von Emotionen. Bestehen bleibt die enge Beziehung aller Gefühlszustände zur Antriebsdynamik des Organismus; ist doch die Gesamttheorie McDougall's eine "hormic” (Strebungs-)psychology. Nun wird aber scharf zwischen „Gefühlen" und „Emotionen” geschieden. „Gefühle" sind die polaren Bewusstseinstöne, die allgemein das Hinstreben und das Widerstreben begleiten, also Befriedigung und Enttäuschung (Lust und Unlust). Es gibt nur diese zwei Gefühlsqualitäten, die entweder in einfacher oder 
in komplexer Form auftreten. Emotionen sind dagegen jenen s p e$z$ if is ch gerichteten Strebungen zugeordnet, die als "Instinkte" oder "propensities" ') angeborenermalsen die Leistungen des Individuums bestimmen; demnach deckt sich die Liste der primăren Emotionen mit der der Instinkte. Dem Angriffsinstinkt entspricht die Emotion des Ärgers, dem Wissenstrieb die Emotion der Verwunderung, dem Fluchtinstinkt die Furcht u.s.w.

c) Innere Sekretion. - Von einer ganz anderen Seite her ist die physiologische Entdeckung der inneren Sekretion für die Gefühlstheorie wichtig geworden. In diesem Funktionsprinzip kommt nämlich die ganzheitliche Beschaffenheit des Organismus von vorn herein viel stärker zur Geltung, als in den früher untersuchten physiologischen Vorgängen, wie Puls und Atmung, die an bestimmte Teilsysteme gebunden sind. Die innere Sekretion hat zwar auch in Körpergebilden bestimmter Art, den D r ü s e n, ihren Ursprung, strahlt aber sofort aus auf den Gesamtorganismus und liefert Antriebsstoffe (Hormone), die alle Gewebe, alle Körperteile überschwemmen und beeinflussen. Selber gestaltos, aber die Gestaltung der Körpers nach allen Richtungen hin bestimmend, ist dieser Säftestrom ein organisches Symbol für die körperliche Einheit des Individuums - sowie die Ganzheit des Gefühls ein solches ist für die seeliche Einheitlichkeit der Person. Und so kann die innere Sekretion in einem ganz anderen Sinne dem Gefühlsleben zugeordnet werden, als es bei den Funktionen der anderen Teilsysteme möglich war. Während Atmung, Herzschlag u.s.w. mit dem Kommen und Gehen e in z e ln e r Gemütsvorgänge zu tun haben, ist die Wirksamkeit der inneren Sekretion in Beziehung zu setzen $\mathrm{zu}$ der dauernden und einheitlichen Grundlage aller Einzelerscheinungen des Fühlens, also zum "G e $\mathrm{m}$ ü t”. Konstitutionelle Besonderheiten der inneren Sekretion drücken sich ebenso in den Beschaffenheiten des gesamten Körperaufbaus, wie in den dynamischen und Richtungsbeschaffenheiten des Gemütslebens (den „Temperamenten”) aus ${ }^{2}$ ). Anderungen der inneren Sekretion prägen sowohl dem Körpergeschehen wie der Gemütsverfassung ihre Wirkung auf (Reifung der Geschlechtsdrüsen; Erkrankung der Schilddrüse u.s.w.).

1) Vgl. S. 544.

2) Úber Temperamente vgl. S. 789 dieses Buches. 
Eine uralte psychophysiologische Hypothese, die antike Lehre von den Säftemischungen, erlebt in dieser modernen Verbindung von Sekretions- und Temperamentenlehre ${ }^{1}$ ) ihre Auferstehung.

\section{Rein psychologische Standpunkte}

a) „E m o t i o n a l i s m u s." - Innerhalb der rein psychologischen Betrachtungssphäre ist die Anwendung des Ganzheitsstandpunktes auf die Gefühlslehre am konsequentesten von Felix Krueger und seiner Schule durchgeführt worden.

Die psychischen Ganzheiten sind nach Krueger hierarchisch geordnet; es gibt Teilganzheiten (Einzelgestalten und Strukturen) verschiedener Grössenordnung und schliesslich eine Totalstruktur des Seelischen, die als solche eine einheitliche Qualität hat; diese ist das Gefühl. Da nun das seelische Subjekt seinem Wesen nach Ganzheit ist, so ist man ihm im Gefühl unmittelbar nahe; ja es ist - wenn wir Krueger recht verstehen - identisch mit ihm; es gibt keine andere Weise, in der die ungeteilte Persönlichkeit sich bewusst ,h a t”, denn als Gefühl. Von hier aus gesehen verlieren nun aber die abgehobenen Teilgestalten der Wahrnehmung, des Denkens u.s.w. ihre Selbständigkeit und Eigengesetzlichkeit. Sie haben nur Gliedcharakter, werden umschlossen und geprägt vom dominierenden Gefühl. Dem Gefühl seinerseits kommen durch diese Ganzheitlichkeit des Erlebnisses Merkmale zu, die es zum eigentlich be s e e le nde n Prinzip machen: bewusstseinerfüllende Breite, Wärme, Innigkeit, Unbegrenztheit der Qualitätenfülle.

Dass diese Theorie fruchtbare Auswirkungen auf die psychologische Spezialforschung hat, dafür legen zahlreiche Untersuchungen der Leipziger Schule Zeugnis ab "). Experimenteller Prüfung wurde vor allem die Frage unterworfen, wie sich das Erleben von Teilstrukturen durch deren Einbettung in die Totalstruktur des Gefühls modifiziert. So wurde, um nur ein Beispiel zu erwähnen, gefunden, dass die Unterscheidungsschwelle für Grössen- oder Intensitäts-Unterschiede um so feiner ist, je höher die Komplexbildung ist, d.h. je mehr sich das Bewusstseinsgebilde der Totalqualität des Gefühls annähert.

Die Krueger'sche Gefühltheorie steht offenbar der personalistischen Idee nahe; aber sie unterscheidet sich doch von ihr da-

1) Vgl. vor allem: Kretschmer, Körperbau und Charakter.

2) Vgl. die verschiedenen Bände der ,Neuen psychologischen Studien." 
durch, dass sie ihren Standort in $\mathrm{n}$ e $\mathrm{r}$ h a 1 b des Bewusstseinsbereichs nimmt. Die Ganzheit, von der in dieser Theorie die Rede ist, ist stets die Ganzheit des Erlebens. Darin aber liegt eine ungerechtfertigte Verselbständigung des Gefühls; denn auch die Erlebenstotalität ist noch nicht die letzte Ganzheit, vielmehr ebenfalls noch ein Teilganzes, das in der umfassenderen Totalität der P e r s o n ruht. Jene Seiten der personalen Ganzheit, die nicht Bewusstsein sind - unbewusste Dispositionsund Antriebsweisen, leibliche Ausdrucksweisen - werden zwar in der Krueger'schen Theorie gestreift, führen aber noch nicht dazu, dem Gefühl seine S o n der rolle innerhalb des personalen Lebens zuzuweisen. Krueger neigt vielmehr dazu, im Gefühl so etwas wie die seelische Grundsubstanz zu sehen, der gegenüber alles andere Seelische sekundären Charakter gewinnt. So wird für ihn die gesamte Psychologie letzten Endes zur Gefühlspsychologie, zum „E m ot i o n a 1 is m u s" - sowie Herbarts Gesamtlehre Vorstellungspsychologie, Wundt's Theorie Voluntarismus war. Auch hier kann die Personalistik nicht mitgehen. Da die Grundrelation alles personalen Lebens die Person/Welt-Beziehung ist, besteht kein Recht, diejenigen psychischen Tatbestände, die auf „Welt" tendieren, Wahrnehmungen, Vorstellungen, Gedanken, zu untergeordneten Momenten zu machen, und die, das personale Subjekt repräsentierenden, Gefühle allein als primäre Erlebnisse gelten zu lassen.

b) „S ubjektivität” der Gefühle. - Die eben genannte Person/Welt-Beziehung wird von einer Reihe moderner Forscher zur Abgrenzung der Gefühle von den anderen psychischen Tatbeständen benutzt. Gefühle haben ,s u b j e k t i v e n", Wahrnehmungen u.s.w. ,objektiven" Charakter. Diese sehr wichtige Unterscheidung bedarf, um nicht missverstanden zu werden, einer genaueren Präzisierung.

Fasst man sie nämlich rein bewusstseinspsychologisch, als Kennzeichnung dessen, was der Mensch tatsächlich e r lebt, dann wäre ihr Sinn dieser: Gefühle werden a ls Hinweise auf Zustände und Vorgänge des eigenen Ich erlebt; Wahrnehmungen, Vorstellungen, Gedanken, Wollungen dagegen a ls Hinweise auf Gegenstände ausserhalb des Subjekts.

Ein solches Subjektivitäts- B e w us s s e in ist nun aber 
zweifellos nicht bei allen Gefühlsphänomenen vorhanden; es kommt vielmehr nur einer spezifischen Gruppe von Gefühlen, den „Selbstgefühlen” zu. Die weitaus meisten Gefühle aber sind mit einer ob j e k t i vie re n d e n Bewusstseinsintention verbunden, d.h. sie werden als Gefühlsbetontheiten von $\mathrm{G}$ e g e $\mathrm{n}$ ständen und Werten erlebt. Wer einen Durdreiklang ,angenehm" findet, fühlt in diesem Wohlgefallen nicht sich, sondern den Klang. Und wer einen Menschen mit intensivem Gefühl liebt, kann in der Hingabe an den Anderen sein eigenes Selbst ganz vergessen und verlieren. Die Objektivierung der Gefühle steigert sich unter Umständen sogar bis zur Verabsolutierung: was in Erlebnissen des „,Schönen”, ,Erhabenen”, ,,Heiligen" gefühlt wird, sind die wesenhaftesten Wertqualitäten der objektiven Gebilde selber.

Eine phänomenologische Besinnung kommt also $\mathrm{zu}$ dem Resultat, dass den Gefühlen e r le b n is mä f si g sowohl subjektivierende wie objektivierende Intention zukommen kann, in verschiedenen Betonungen und Verknüpfungen.

Wenn aber Er lebn is s u bjektivitä t nicht das Unterscheidungsmerkmal für alle Gefühle ist - welcher andere Begriff der Subjektivität trifft zu?

Zunächst ein negativer: Subjektivität als , $\mathrm{N}$ i c h t - O b j e k t i v i t ä t," als Unzulänglichkeit der Objektivierung. Im Gegensatz zu der eben erwähnten T e n d e $\mathbf{n}$ z des fühlenden Menschen, die Gegenstandsgebundenheit seines Gefühles zu verabsolutieren, werden gleichsam von a us e $n$ h e $r$ solche Objektbezüge fortwährend gelockert, relativiert, entwertet. Der äussere Beobbachter vermag dies oft früher zu erkennen, als der fühlende Mensch selbst, der noch in seiner objektivierenden Gefühlstäuschung befangen bleibt. Drei Hauptbedingungen für diese Entobjektivierung der Gefühle seinen genannt.

1) Interindividuelle Verschiedenheiten. Betrachten viele $\mathrm{Be}$ schauer ein Gemälde, so werden sie sich über den dargestellten Inhalt, die wahrnehmbaren Farben und Formen einig sein. Aber ob das Gemälde schön oder hässlich, anziehend oder abstossend sei, darüber gibt es Meinungskämpfe. Diese bleiben deswegen meist erfolglos, weil jeder seine gefühlsmälsige Stellungnahme in irriger Objektivation als Merkmal am Gegenstand glaubt aufweisen zu können und die objektivierende Anerkennung der 
anderen beansprucht, obgleich doch „de gustibus non est disputandum".

2) Personalgeschichtliche Wandlungen. Vergleicht man die Gefühle, die ein Mensch sukzessiv einem id e $n t$ is $c h$ en $\mathrm{O}$ bj e k t entgegen bringt, so kann man objekt-unabhängige Veränderungen feststellen: eine Begeisterung wächst und verfliegt; eine Aversion stumpft sich ab, Liebe schlägt um in Hass u.s.w. Auch hier sträubt sich der fühlende Mensch gegen das Zugeständnis des „,nur Subjektiven” dieses Gefühlswechsels, und er sucht dazu die Motive in Wandlungen des Objekts: so wird etwa das Abklingen einer Schwärmerei damit motiviert, dals erst jetzt geringwertige Charakterzüge des Angeschwärmten hervorgetreten seien u.s.w.

3) Objektwechsel eines identischen Gefühls. Ein Gefühl kann von dem ursprünglichen gegenständlichen Anlass aus wandern, andere Objekte ergreifen, ja schliesslich sich vom ursprünglichen Objekt ganz loslösen. Der Kaufmann, der Ärger im Büro wegen eines unangenehmen Geschäftsbriefes hatte, wird sich nach der Heimkehr über jede, sonst nicht beachtete, häusliche Bagatelle ärgern und schliesslich das Gefühl hierauf ganz konzentrieren.

4) Gefühlsveränderungen unabhängig von den objektiven Bedingungen sind z.B. als ",Stimmungsschwankungen" wohl bekannt. Wird daraus eine konstitutionelle Eigenschaft, so wird sie als "Launenhaftigkeit” abschätzig beurteilt.

Es ergibt sich also für das Gefühlsleben eine bemerkenswerte Dialektik zwischen be wusstseinsmä f siger Objektgebundenheit und einer weitgehenden $\mathrm{f} \mathrm{a} \mathrm{kt}$ is $\mathrm{ch}$ en Objektlockerheit. Im Sozialleben führt die Dialektik dazu, dass der Mensch die starke Tendenz hat, durch Gefühlsgemeinsamkeit die überindividuelle Sanktion seiner Gefühlsgerichtetheiten zu sichern - während in Wirklichkeit oft die Abweichungen dieser Gerichtetheiten zwischen Mensch und Mensch weit grösser sind, als die Abweichungen in den eigentlich objektivierenden Funktionen des Wahrnehmens und Denkens. Im Individualleben bewirkt die Dialektik, dass das Gefühl in seiner einmal entstandenen Objektgerichtheit zu verharren sucht ohne Rücksicht auf Ånderungen am Objekt (das ist der bekannte „Konservatismus” des Gefühls), - und dass trotzdem in Wirklichkeit die Gefühle eine 
L a b i lit ät besitzen, die sie mit verschiedensten Objekten ihr Spiel treiben lässt.

Es gehört eine völlige innere Umstellung des fühlenden Menschen dazu, um die Objektivitätsirrungen zu durchschauen und den subjektiven Charakter der Gefühle bewusst zu b e j a h e $n$. Dann sind sie nicht mehr ,nur-subjektiv", d.h. ihr Objekt verfehlend, sondern "voll subjektiv", d.h. d a s S u bjekt s pi eg e $1 \mathrm{n}$ d. Erst auf dieser Stufe ist der Mensch bei jener „Erlebnissubjektivität" angelangt, von der unsere Betrachtung ausgegangen war.

Deutlich ist der Obergang zu dieser Erlebnissubjektivität 2.B. in manchen Jugendtagebüchern erkennbar. Der schwärmende Jugendliche beschătigt sich oft viel weniger mit dem Schwarmobjekt, als mit der Besonderheit seiner Schwarmgefühle.

Bis zu diesem Punkt kann eine Gefühlstheorie vordringen, die sich darauf beschränkt, die Gefühle in ihrer tatsächlich erlebbaren Beschaffenheit, und somit auch das Erlebnis der Subjektivität, zu bes ch rei be n. Aber zu dem eigentlichen Begriff der Subjektivität kann man erst vorstolsen, wann man fragt, was denn dies subjektivierende Frleben bede $\mathrm{u} t \mathrm{e}$, welchen Sinn es im Ganzen des personalen Lebens habe.

Sobald man diese Bedeutungsfrage aufwirft, verlässt man die Ebene der blofsen Bewusstseinspsychologie. Wer Gefühle deuten will, muss sie auf etwas anders als Bewusstsein beziehen; und wenn ihnen Subjektsbezug zugeschrieben wird, muss dieses Subjekt etwas Anderes als das Bewusstseins-Ich sein.

In der Tat haben auch alle $D$ e u $t$ u $\mathrm{g} s \mathrm{th}$ e orie $\mathrm{n}$ das Subjekt des Gefühls jenseits des Bewusstseins gesucht. Für die b i o log is c h e Theorie, die wir bereits kennen lernten, engte sich das Subjekt zum physischen „Organismus" ein, für den die Gefühle „Signal"-Bedeutung haben. Ps y ch ol o gis che Theorien müssen für ihre Deutung des Gefühls den Begriff des Un bew us te n zu Hilfe nehmen, wofür ja die tiefenpsychologischen Schulen die Beispiele liefern.

Wenn z.B. Freud dem Lustprinzip eine so fundamentale Rolle im menschlichen Leben zuschreibt, so hat dies einen doppelten, aber beide Male in die unbewussten Tiefen weisenden Sinn: Lust ist einerseits diejenige Bewusstseinsqualität, die von den unbewussten Strebungen gesucht wird, andrerseits - ebenso 
wie die Unlust - das ins Bewusstsein projizierte. S y $\mathbf{m}$ b o 1 für die Beschaffenheit jener unbewussten Regungen. Es kommt also alles darauf an, wie man jenes „Unbewusste” fasst, das zum Erklärungsgrund und Deutungsziel der Gefühle gemacht wird; und indem die Tiefenpsychologie dieses Unbewusste ganz oder fast ganz mit dem vitalen Triebleben identifiziert, gewinnt auch ihre Auffassung des Gefühls eine ganz bestimmte Färbung und Einseitigkeit. (Freilich kann man von einer expliziten, allgemeinen Gefühlstheorie bei der Tiefenpsychologie kaum sprechen.)

Von Seiten der theoretischen Psychologie hat vor kurzem Fr. Grossart eine interessante Gefühlslehre entwickelt, die ebenfalls auf die unbewussten Hintergründe des individuellen Lebens rekurriert, und zwar auf die ", $\mathrm{t}$ r e b u n g e n". So nennt er die latenten seelischen Krăfte von dauernder, dispositioneller Beschaffenheit, aus denen als aktuelles Geschehen das jeweilige „Streben” hervorbricht. Aber das aktive Streben ist nicht die einzige Manifestation der Strebung; diese kann sich auch in ihrer $Z$ uständlichkeit im Bewusstsein geltend machen - und das ist das Gefühl. In jedem Gefühl erlebt also der Mensch seine eigene "Strebezuständlichkeit”, d.h. sowohl die besondere Art und Richtung seiner Strebungen, wie auch sich selbst als Strebenden. - Durch den Begriff der Strebung, der a 11 e Richtungsdispositionen im Menschen umschliessen soll, überwindet die Theorie Grossart's die engere Einstellung der Tiefenpsychologie auf die Vitaltriebe und nähert sich bedeutend einer echt personalistischen Auffassung, wie sie in den folgenden Seiten entwickelt werden soll.

Das „Subjekt”, auf welches das Gefühl bezogen werden muss, damit man sein Wesen und seinen Sinn erfassen kann, ist nicht die Bewusstseinseinheit, nicht der Organismus, nicht die Hintergründigkeit des Trieblebens, nicht der Inbegriff der strebenden Kräfte - sondern die Person s elbst in ihrer unitas multiplex. 


\section{NEUNUNDZWANZIGSTES KAPITEL}

PERSONALE MERKMALE DER GEFÜHIE

I. PERSONNÄHE DER GEFÜHLE

Eine personalistische Psychologie des Gefühlslebens muss von der Frage ausgehen, an welcher Stelle innerhalb der Gesamtstruktur des personalen Daseins die Gefühle ihren Platz haben. Die Antwort lautet: die Gefühle bilden den Bereich des e in gebetteten und darum personnahen Frlebens.

Man erinnere sich des doppelten Gegensatzes, den wir innerhalb der Person fanden: Leben und Erleben einerseits, Einbettung und Abhebung andrerseits.

Die Person in der Unmittelbarkeit ihres $L$ e b e $n$ s vollzuges steht noch hinter - oder auch vor -- allem E r - L e b e n. Dies setzt erst ein, wo das Leben unselbstverständlich wird, repräsentiert also immer nur ein Teilstück des Lebens, nie das Ganze. Darum ist auch das Gefühl, da es dem Erleben angehört, nicht mit der Person selbst identisch - wenn es ihr auch von allen Erlebnisweisen am nächsten steht.

Die spezifische "Person-N ä h e" des Gefühls aber ist vermittels des anderen Begriffspaares zu erläutern. Die Person als unitas multiplex zeigt im ständigen Neben-und Nacheinander $\mathrm{Abhebung}$ und $\mathrm{E}$ in be $\mathrm{t} \mathrm{u} \mathrm{ng}$. Einzelne Momente treten heraus aus der Totalität, grenzen sich ab als gesonderte Gebilde, Verläufe und Gestalten, sind auf dem Wege zur Verselbständigung - und werden doch immer wieder gehalten von der Einheit, werden in die Totalität hineingezogen; denn sie haben ja nur a Is Momente in der Person Existenz und Bedeutung. Diese Rhythmik von Abhebung und Einbettung erstreckt sich ebenso über die körperlichen Vollzüge, wie über die psychischen Vorgänge. 
Die Abhebung schreitet in vielen Etappen vorwärts. Dieser Prozess bedeutet für die Person positiv: zunehmende innere Vermannigfachung, Strukturierung, dynamische Zusammenraffung, Objektivierung sowohl der Bewegungen wie der Bewusstseinsgehalte. Er bedeutet aber zugleich negativ: fortschreitende Entfernung und Entfremdung von der urtümlichen Einheit der Person, Ent-Subjektivierung, EntLebendigung. Das theoretische und praktische Leben der Person tendiert wesentlich auf Abhebung: alles Erke n n e n und alles $\mathrm{H}$ a nde $\mathrm{ln}$ ist stets zugleich ein Heraussetzen abgegrenzter und gegliederter Gebilde und Vollzüge aus dem PersonTotal.

Nun aber kann ja der Weg der Verselbständigung solcher „Abhübe” nie bis zu Ende gegangen werden, da durch „E in b e t t u n g" immer wieder in umgekehrter Richtung die $\mathrm{Zu}$ gehörigkeit zur Person gewährleistet werden muss. Dies gilt auch in nerhalb des Erlebn is bereiches. Die einzelnen abgehobenen Bewusstseinsgestalten und -Strukturen schweben nicht im Leeren, sondern haben eine Atmosphäre, die sie umspielt und durchdringt; sie ruhen auf einem Untergrund, vermittels dessen sie unlösbar dem Mutterboden der Person verwurzelt sind. Diese Einbettungs-Erlebnisse sind die Gef üh le.

Das folgende „Drei Kolonnen-Schema” macht den so gefundenen „personalen Ort” der Gefühle erkennbar:

\begin{tabular}{l|c|c}
\hline \multicolumn{1}{c|}{ I } \\
$\begin{array}{c}\text { Evlebnisfreies } \\
\text { Leben } \\
\begin{array}{c}\text { Sphaere des sogen. } \\
\text {,Unbewussten"). }\end{array}\end{array}$ & $\begin{array}{c}\text { II und III } \\
\text { Evlebtes Leben } \\
\text { (Sphaere des Bewusstseins) } \\
\text { Einbettendes } \\
\text { Erleben }\end{array}$ & $\begin{array}{c}\text { II } \\
\text { Abhebendes } \\
\text { Bewusstsein }\end{array}$ \\
\hline $\begin{array}{l}\text { Automatismen } \\
\text { Instinkthand- } \\
\text { lungen } \\
\text { Mneme } \\
\text { Dispositionen }\end{array}$ & F üh le n & $\begin{array}{c}\text { Erkennen } \\
\text { Willens- } \\
\text { handlungen }\end{array}$ \\
\hline
\end{tabular}

Drei-Kolonnen-Schema. 
Es drängt sich das Gleichnis eines Hochgebirges auf. Die Gipfel (III) scheinen sich als scharf umgrenzte Sondergebilde von der Erde fortzurecken; aber sie kommen nicht los von ihr, sondern werden gehalten von der gemeinsamen breiten Gebirgssohle (II), die, zwar selbst noch sichtbar, bereits keine rechte Eigengestalt und keine scharfe Abgrenzung mehr nach oben und unten aufweist; sie ist dem Erdball ganz nahe und verwurzelt $\mathrm{si}$ c h - und mit sich die Gipfel - in dem, ihnen allen gemeinsamen, unsichtbaren Urgrund (III).

Im Schema sind mit Absicht die Ausdrücke „Erleben” und „Bewusstsein" auf II und III verteilt worden; denn schon die Sprache kennzeichnet ja die Năhe des Erlebens zum „Leben”, des Bewusstseins zum „Wissen". - Die Vereinigung der erkennenden und Willensfunktionen in der Rubrik III ist nur gültig unter dem hier in Frage stehenden Gesichtspunkt vorwaltender Abhebung. Dass im übrigen die beiden Bereiche wesentlich von einander zu unterscheiden sind, haben ja die früheren Kapitel bewiesen.

Die Scheidung von Einbettung und Abhebung (II und III) ist nicht realiter, sondern nur in der Abstraktion möglich. Es wird sich zeigen, dass es gerade die $\mathrm{Spann}$ unge $\mathrm{n} z \mathrm{wi}$ schen Einbettung und Abhebung, also die dynamischen Beziehungen zwischen der emotionalen und der intellektuell-praktischen Sphäre sind, die die Wirklichkeit des seelischen Seins und Geschehens erzeugen. Zugleich aber erweist sich das Gefühl, entsprechend seiner Stellung im Schema, als Mittler; es ist also auch dem unbewussten Bereich der Person (I) besonders nahe. Durch diesen doppelseitigen Bezug kommt dem Gefühl Einbettung in verschiedensten $A$ bs t u f ungen zu. Das der Person ganz eingeschmolzene Gefühlserleben, welches sich durchaus als Beschaffenheit eben der P e r s on selbst gibt, heisst „G e m ü t s l e b e n”. Das schon weitgehend an abgehobene Bewusstseinsinhalte geknüpfte Gefühl, welches gleichsam nur als feine Wurzelfaser den abgehobenen Gegenstand noch mit dem Mutterboden der Person verbindet, heisst der „G e f üh 1 s t o n” des Eindrucks. Dazwischen liegen: dem Gemütspol nahe die Gemütszustände und Gemütsbewegungen, dem Gegenstandspol nahe die mannigfachen Einzelgefühle. 
Mit dem Einbettungscharakter des Gefühls eng verknüpft ist das Merkmal der „U n g e s t a 1 t.” Dieser Zug des Gefühlslebens war ausserhalb der Fachpsychologie von der Volksweisheit, von Dichtern ${ }^{1}$ ), von Philosophen, immer stark beachtet und verschiedenartig bewertet worden. Bald $\mathrm{r} \ddot{\mathrm{g}} \mathrm{t} \mathrm{e}$ man die Zerflossenheit, Dumpfheit und Formlosigkeit der Gefühle, im Gegensatz zu der Kristallklarheit des Denkens und der Gerafftheit des Handelns; bald verherrlichte man die schöpferische Unbegrenztheit, die jeder Bindung entgleitende Innerlichkeit des Gemüts im Gegensatz zu der Starrheit der Begriffe und der Seelenlosigkeit des Wollens. Eine moderne Fassung dieser letzten Wertung stellt die Formel von Klages dar: „Der Geist als Widersacher der Seele".

Die Fachpsychologie konnte bisher mit dieser Erscheinungsweise des Gefühls nicht fertig werden, weil ihre Kategorieen aus der Bearbeitung der abgehobe ne $\mathbf{n}$ Bewusstseinsinhalte stammten und auf diese zugeschnitten waren. Für die Gefühle aber passen diese Kategorieen nicht. Gefühle sind nicht nur nicht „Elemente”, wie es die ältere Psychologie meinte; sie sind auch nicht „Gestalten" und ,Strukturen" im Sinne der neueren Psychologie.

Erst die Personalistik betonte die grundsätzliche Wichtigkeit der Tatsache, dass "Ganzheiten" nicht nur als durchgeformte Gebilde vorkommen. Gerade die echteste Ganzheit, die Person, ist immer beides zugleich: Begrenztheit und Spielraum, eindeutige Realität und vieldeutige Potentialität - kurz: Ge stalt und Ungestalt. ${ }^{2}$ ) Auch in ihrer Bewusstseinsrepräsentation: während ihr gestaltendes Prinzip sich in den Erkennens- und Willensfunktionen äussert, hat das gefühlsmälsige Erleben an ihrer Ungestalt Anteil. Die Gefühle können nur dadurch so spezifisch personnahe sein, dass sie unmittelbar und ohne Grenzsetzung aus dem Totalleben der Person entfliessen und in es einfliessen.

Direkt lässt sich die Ungestaltheit der Gefühle nicht beschreiben; denn jedes Einfangen in Worte wäre schon eine Fixierung. Wir können dieses Merkmals nur indirekt habhaft werden, in der Art, wie es die Beziehung des Gefühls zur tragen-

\footnotetext{
1) Goethe: ,Gefühl ist alles, Name ist Schall und Rauch."

2) S. S. 155 .
} 
den Person einerseits, zu den abgehobenen und gestalteten Bewusstseinsinhalten andrerseits beeinflusst.

Die Doppelbeziehung des Gefühls zu Einbettuug und Abhebung bildet das Zentrum einer Gefühlstheorie von Jonas Cohn, die mit der hier entwickelten manche Verwandtschaft hat. Cohn gibt folgende Definition: „Gefühl im weiteren Sinne ist das Dumpfe, Stromhafte, Zustandhafte, ein Aggregatzustand des Seelenlebens, der der Trennung von Akt und Gegenstand vorangeht. Davon muss das Gefühl im engeren Sinne unterschieden werden, der als Rest jener Dumpfheit an Akten, Inhalten und Gegenständen hervortritt, von diesen grössere Bestimmtheit und leichtere Festhaltbarkeit entlehnt".

Die Personnähe und Mittlerstellung der Gefühle ermöglicht ihre doppelte personale Bedeutung, die uns immer wieder begegnen wird. Die Gefühle sind nämlich einmal bedeutsam $\mathrm{f} \ddot{\mathrm{u}} \mathrm{r}$ die Person; d.h. sie dienen personalen Zwecken, als Steuerungen, Signale, Vorbereitungen, Antriebe (Dienst-Bedeutung oder teleologische Bedeutung). Sie sind andrerseits bedeutsam $\mathrm{durch}$ die Person, an derem Wesen sie unmittelbar Anteil haben und das sie daher in gewisser Weise spiegeln (Strahlbedeutung oder symbolische Bedeutung) ${ }^{1}$ ). Die Doppelbedeutung der Gefühle wirkt dann auch hinüber in das physische Verhalten: indem die Gefühle Zwecken dienen, leiten sie über zu den, diese Zwecke verwirklichenden, $\mathrm{H}$ a ndlungen; indem sie die Person repräsentieren, gehören sie zusammen mit der Aussenkundgabe des ,A u s d r u c k s”.

Beispiel: ein Angstgefühl s i g n a 1 is i e r t eine Gefahr und wird zum Antrieb einer Fluchthandlung (Dienstbedeutung). Zugleich vermag sich der personale Zustand der Unsicherheit $\mathrm{d} \mathrm{a} \mathrm{r} \mathrm{z} \mathrm{u} \mathrm{le} \mathrm{b} \mathrm{e} \mathrm{n}$ in dem Stimmungsverhalten der Ängstlichkeit und dem Ausdrucksverhalten des Zitterns, Erblassens u.s.w. (Strahlbedeutung).

\section{POLARITÄT UND AMBIVALENZ DER GEFÜHLE}

\section{Doppelte Polarität}

Nur weil das Leben der Person selbst mehrfach polar gespannt

1) Vgl. hierzu S. 117 dieser Buches; ferner Wertphilosophie, S. 44 (Unterscheidung von ,Dienstwert" und ,Strablwert"). 
ist, kann auch seine Spiegelung im Erleben polaren Charakter gewinnen. Und zwar sind es vor allem zwei polare Gegensätze, die das Gefühlsleben bestimmen: solche der Telik und der Dynamik.

Polar ist die $Z$ we ckdie $\mathrm{n} \mathrm{lichke} \mathrm{it} \mathrm{des} \mathrm{Lebensvollzu-}$ ges, da in diesem bestimmte Zwecke entweder erreicht oder verfehlt werden: dem entspricht erlebnismälsig der Gegensatz von Lust- und Leidgefühlen.

Freilich muss hier jede biologistische Einengung des $Z$ weckbegriffs vermieden w e r d e n. Nicht nur um die Vitalzwecke organischer Förderung oder Beeinträchtigung handelt es sich, sondern um j e d e n Teilzweck, den die Person sich setzt, um jedes Zweckgefüge, etwa der Erkenntnis, der Macht, des Erwerbs - endlich um die Gesamtentelechie der Person, die Einheit der Selbstbestimmung und die Introzeption der Weltwerte in den Ichwert der Person.

Da nun irgend ein einzelnes Geschehen an der Person zugleich zu den verschiedensten Zwecken in Beziehung steht, ist die ihm zukommende Gefühlsbetonung nicht eindeutig. So kann das Trinken eines alkoholischen Getränkes Genuss bereiten, weil damit dem $Z$ weck einer gegenwärtigen Anregung der vitalen Kräfte und der Gesamtstimmung gedient wird — während das gleiche Tun für einen anderen Zweck - etwa für das sparsame Umgehen mit dem vorhandenen Geld, oder für die dauernde Sicherung des Gesundheitszustandes - negativ wirksam sein und darum Unlustbetonung erhalten kann. Dieses ,,k a n n” ist sehr wichtig; denn es deutet auf die Mitwirkung personaler Grundbedingungen am Zustandekommen der Lust- und Leiderlebnisse hin. W e l c h e r der unzähligen möglichen Zwecke in einem bestimmten Lebensaugenblick eine so betonte Stellung in der Zweckstruktur der Person einnimmt, dass er sich erlebnismälsig in positiven oder negativen Gefühlstönen geltend macht - das liegt nicht mehr wesentlich an dem gegenständlichen Inhalt, sondern an der Person selber. Für den fanatischen Abstinenzler, dem der Kampf gegen die Verwüstung der Menschheit durch Alkohol zum vordringlichen Lebensinhalt geworden ist, gibt es überhaupt keine Möglichkeit, Alkohol lustvoll zu geniessen; er fühlt nur Abscheu, wenn er aus irgend welchen Gründen dennoch Alkohol zu sich nimmt. Und der Asket, dessen Lebenszweck in der Abtötung der Begierden besteht, empfindet Lust bei der 
Selbstpeinigung, die diesen Zweck positiv fördert, während die Erlebnisstärke des gleichzeitigen physischen Schmerzes wesentlich verringert, ja unterschwellig werden kann.

Im Gegensatz also zu der biologistischen $Z$ wecktheorie, die nur generelle organische $Z$ wecke beachtet (s.S. 719), bezieht die personalistische Zwecktheorie die Lust- und Leid-Töne von Gefühlen auf die jeweils dominierenden $Z$ wecke innerhalb der Zweckstruktur der Person. „Dominieren" muss nicht heissen: als beherrschender Zweck gewusst sein; das gefühlsmälsige Erleben selbst ist ein Symptom eben für diese Vorherrschaft. Auch wer nicht weiss, dass er ein Aesthet ist, erweist sich als solcher durch die intensive aesthetische Lust-oder Unlust-Erregbarkeit gegenüber Kunstwerken, Landschaften, Menschen.

Damit ist festgestellt, dass der Lust und Unlust über die Zweckbedeutung hinaus eine sehr wesentliche Strahlbedeutung zukommt; in der Erlebnis a uslese für Freud und $L$ e i d verrät sich die innere $Z$ weckstruktur der Persönlichkeit.

Selbstverständlich soll mit dieser personalistischen Theorie nicht bestritten sein, dass es zahlreiche g e n e r e ll e Zusammenhänge zwischen bestimmten personalen $Z$ wecken und den Gefühlstönen Lust und Leid gibt; dies wird namentlich für solche Zwecke gelten, deren Erfüllung zur unmittelbarsten Existenzsicherung gehört. Das Atmenmüssen in völlig verbrauchter Luft ist für $\mathrm{j}$ e d e n Menschen peinigend, gleichgültig, wie im übrigen sein $Z$ wecksystem strukturiert ist. Es gibt auch typologische Gesetzmälsigkeiten (vgl. das obige Beispiel vom aesthetischen Typ). Ferner bestehen Entwicklungsgesetzmälsigkeiten: der Übergang von der Kindheit zur Pubertät ist unter anderem dadurch gekennzeichnet, dass ganz neue Lebensbereiche jetzt in den Lichtkegel von Lust-und Leidempfänglichkeit treten. Aber je höhere Organisationsstufen des Menschen man betrachtet, um so stärker individualisiert sich die Zweckstruktur und subjektiviert sich sein Lust/Unlust-Erleben; um so bedeutsamer wird dies für seine charakterologische Erfassung.

Die zweite Polarität bezieht sich auf die Dy namik des Lebensvollzuges. Wir sahen schon früher, wie der Krafthaushalt jedes Lebewesens bestimmt ist durch das Pendeln zwischen vor- 
wiegender Energie-Ausgabe und Ansammlung. Diese Polarität schlägt sich gefühlsmälsig nieder in Erlebnissen der E r r e g u n g oder B eruhigung.

Der Gegensatz von ,exzitierenden” und „quieszierenden” Gefühlen ist rein formal; er kann sich mit jeglichem Gefühlsinhalt verbinden. Deshalb kann jedes der beiden dynamischen Gefühlsmerkmale sowohl in Lust- wie in Leid-Gefühlen auftreten. Wir kommen so zu einer Kreuzung beider Merkmalspaare, die uns der konkreten Erlebniswirklichkeit wiederum einen Schritt näher bringt.

Solange irgend ein dominierender, aber noch nicht verwirklichter Zweck dem Lebensvollzug die Richtung gibt, hat das Gefühl Erreg u n g s charakter, mag es nun die Annäherung an das Ziel lustvoll, die Entfernung vom Ziel leidvoll betonen. Sobald das Geschehen in Bezug auf den dominierenden Zweck abgeschlossen ist, hat das Gefühl B e r u h i g u n g s charakter, mag es nun die Erfüllung des Ziels lustvoll, die Verfehlung leidvoll betonen. Nennen wir jene die „W e g g e f ü h l e,” diese die „Ergebnisgefühle," so kommen wir zu folgendem Schema:

\begin{tabular}{|c|c|c|c|c|}
\hline & Lustgef & & Leidgefühle & \\
\hline $\begin{array}{l}\text { Weggefühle } \\
\text { (erregend) }\end{array}$ & $\begin{array}{l}\text { Funktions- } \\
\text { Arbeits- } \\
\text { Kampf- }\end{array}$ & Lust & $\begin{array}{l}\text { Funktions- } \\
\text { Arbeits- } \\
\text { Kampf- }\end{array}$ & Leid \\
\hline $\begin{array}{c}\text { Ergebnisfïhle } \\
\text { (beruhigend) }\end{array}$ & $\begin{array}{l}\text { Erfüllungs- } \\
\text { Erfolgs- } \\
\text { Überlegen- } \\
\text { heits- }\end{array}$ & Lust & $\begin{array}{l}\text { Misserfolgs- } \\
\text { Enttäuschungs- } \\
\text { Unterlegenheits- }\end{array}$ & Leid \\
\hline
\end{tabular}

Das Vierfelderschema, das uns später als Ordnungsprinzip noch mehrfach begegnen wird, darf nicht in dem Sinne älterer Gefühlsklassifikationen verstanden werden, als ob mit ihm jedes Gefühl seinen eindeutigen Ort und seine erschöpfende Charakterisierung erhielte. Die Gefühle sind hier eben nur unter dem Ges i c h t s p u n k zweier polarer Merkmalspaare gruppiert, die zwar von höchster Bedeutung, aber nicht die alleinig 
konstituierenden sind; eine Reihe anderer Merkmale (deren einige noch weiterhin besprochen werden) kommen darin ebensowenig zur Geltung, wie die Tatbestände der nicht-polaren und der ambivalenten Gefühle.

Mit dieser Einschränkung kann uns das Schema allerdings manchen Nutzen bringen. Es zeigt vor allem, dass es in n e r h a l b der Lustgefühle (wie ebenso der Leidgefühle) noch zwei sehr verschiedene Unterformen gibt. So lange man "Lust” und „Unlust" als einheitliche Letzt-Kategorieen betrachtete, war das andere Merkmalspaar nicht zu seinem Recht gekommen. Ferner ergibt sich, dass das Verhältnis vom Weg zu Ziel nicht einfach das von Bewegung zu Ruhe ist, sondern das von Erregung zu Beruhigung, welch letztere ebenfalls ein G e s h e h e n ist. Die, nach vorn und rückwärts stabile, Zuständlichkeit der Erfülltheit und völligen Zieleingepasstheit wäre also - wenn es sie gäbe - nicht von Lusterleben, überhaupt nicht von Erleben begleitet; es wäre ein Zustand des unbewussten Sich-selbstVerlierens. $\left.{ }^{1}\right)$ Ebenso setzt sich die endgültige Zielverfehlung, die unheilbare Zerrissenheit nicht um in Unlusterleben, sondern hat überhaupt kein Bewusstseinsäquivalent mehr, ist Ende, Vernichtung.

Man muss sich eben daran erinnern, dass Gefühle nicht das Ganze des Lebens spiegeln, sondern erst dort einsetzen, wo die Sphäre der lebenssicheren Unbewusstheit verloren wird. Darum ist das Lustgefühl wachsender Genesung so viel stärker als das ungestörter Gesundheit, das Lustgefühl an der Überwindung einer moralischen Versuchung intensiver als die Selbstzufriedenheit moralischer Unbeschwertheit. Selbstverständlichkeit bedarf keiner Gefühle, auch keiner Lustgefühle.

Diese Auffassung droht zu fast paradoxen Konsequenzen zu führen. Nach ihr, so scheint es, könnte nur der Weg, auf dem sich der Mensch einem Ziel nähert, Lust bereiten, nicht aber der Zustand des erreichten Zieles: ein Sieg, ein Erfolg, eine geleistete Aufgabe, ein befriedigter Wunsch. Diese Konsequenz stände zudem in schroffem Gegensatz zu der landläufigen Auffassung, welche die Ergebnisgefühle gegenüber den Weggefühlen stark $\mathrm{zu}$ bevorzugen pflegt.

1) Der Idealzustand der ewigen Seligkeit könnte, vom irdischen Menschen aus betrachtet, nur als eine, jedem Bewusstsein uiberlegene und keines Bewusstseins bediurftige, Daseinsweise gedacht werden. 
In Wirklichkeit gibt es beides, das Ergebnisgefühl freilich nur, in so weit und so lange noch eine Labilität des Zielzustandes besteht.

Veranschaulichen wir uns dies an dem lustbetonten Ergebnisgefühl.

Ein erreichter Erfolg ist zweifellos stark lustbetont - aber doch allein in seiner $\mathrm{K}$ on $\mathrm{tras}$ i e r u $\mathrm{ng} \mathrm{zu}$ den vorangegangenen Entbehrungen und Bemühungen und zu den gleichzeitigen Umgebungsbedingungen. Das Lustgefühl nimmt ab, je mehr die Erfülltheit in Unbewegtheit übergeht, je mehr sie selbstverständliches Niveau wird, von dem erst neue Strebungen und neue Erfüllungen das Aufkommen neuer Gefühle möglich machen.

Deutlich tritt dieser Wandel etwa beim Rekordjäger im Sport zutage. Jeder erreichte Rekord wird intensiv als Erfolg genossen; aber der Sieger kann nicht lange dabei verharren; das Siegesgefühl wird lau, schliesslich schal und muss ersetzt werden durch neue Tatenlust, bis ein noch höherer Rekord ihn die Überwindung seiner selbst und seiner Rivalen erneut geniessen lässt. - Das Gleiche gilt für den Gelehrten, der nicht lange in der Freude an einer gemachten Entdeckung ausruht, für den Politiker, der über jede errungene Machtposition hinausstrebt, für den Geldmann, dem jeder Gewinn Anreiz zu neuem Erwerb wird.

Bekanntlich ist diese Vergänglichkeit der Ergebnislust von pessimistischen Weltdeutern oft als schwerwiegendes Argument gegen den Sinn des Lebens verwertet worden. Sie hätten Recht, wenn der Sinn des menschlichen Daseins wesentlich Zustand und nicht Geschehen, wesentlich Erfülltheit und nicht Streben nach Erfüllung wäre ${ }^{1}$ ). So aber erweist sich, dass die Ergebnislust jeweils nur eine kurze Raststation innerhalb eines Geschehnisstromes darstellt, in welchem die Möglichkeit des Kämpfenund Streben-Könnens und der Annäherung an gesetzte Ziele selber lustbegleitet ist. Gewiss: die Arbeitsfreude eines Handwerkers oder Industriearbeiters würde schwinden, wenn nicht als sichtbare Merkzeichen auf dem Wege des Arbeitens Erfüllungen aufgerichtet wären: fertige Werkstücke, Anerkennung, Entgelt der Arbeit, also Gegenstände der Ergebnislust. Aber auf der anderen Seite würden diese „Erfolge”, die in so vielen Lebensabläufen dürftig genug sind und noch dazu durch

1) Die wertphilosophische Scheidung zwischen ,Kampf'-gefühlen und „Erfolgs"'gefühlen ist eingehend behandelt in Wertphilosophie $\mathrm{S}$. $216 \mathrm{ff}$. 
manche Misserfolge in ihrer Wirksamkeit verringert werden sie würden nicht die enge Gefühlsbindung erklären, die den Arbeiter mit seiner Arbeit verknüpft; diese beruht eben zugleich auf den tiefer eingebetteten, darum weniger leicht erfassbaren und formulierbaren, Gemütszuständen der Tatfreude und Schaffenslust, die zu den Weggefühlen gehören.

Entsprechendes gilt von den L e i d g e f üh 1 e n. Auch das stärkste Leid: der Kummer um den Tod eines teuren Menschen, kann seine volle Erlebnisintensität nur solange behalten, als die Gegensätzlichkeit zur früheren Gemeinschaft und die Verödung der heimischen Welt mitgefühlt wird. Gerade die Endgültigkeit des Verlustes leitet normaler Weise zu einem neuen $Z$ u s $t$ a nd des Lebens ohne den Verstorbenen über; und mit dieser Zustandswerdung gewinnt das Leidgefühl mehr und mehr quieszierenden Charakter: der Trauer, der Wehmut, bis es fast oder ganz abgeklungen ist. Wie anders ist das leidvolle Weggefühl der quälenden Sorge um den Todkranken, deren Intensität sich steigert, je näher das gefürchtete Ende heranrückt. In dem Sprichwort „Besser ein Ende mit Schrecken, als ein Schrecken ohne Ende" sind die beiden Arten des Leidens schlagend charakterisiert.

\section{Asymmetrie der Gefühlspole}

M a them a t is che Polarität ist, von einem Nullpunkt aus gesehen, symmetrisch, d.h. gleichartig nur mit Entgegensetzung der Richtungen. Ältere Psychologieen haben überall dort, wo sie im Seelischen polare Gegensätze fanden, deren symmetrische Anordnung als selbstverständlich vorausgesetzt. Aber es gehört zum Wesen der personalen Polarität, dass sie unsymmetrisch ist: die zwei polar sich gegenüberstehenden Merkmale haben neben ihrer Gegensätzlichkeit auch qualitative Verschiedenheit ${ }^{1}$ ). Dies ist nun für die polaren Gefühlsmerkmale zu erweisen.

Bei dem Merkmalspaar Erregung/Beruhigung ist die Asymmetrie schon aus den letzten Erörterungen zu entnehmen: die Weggefühle sind tiefer eingebettet, kontinuierliche Begleiter des aktiven Strebens, Schaffens, Suchens und Kämpfens -

1) Vgl. z. B. auch S. 134. 
während die Ergebnisgefühle des Erfolgs oder Misserfolgs seltenere und stärker abgehobene Einzelerlebnisse darstellen, die jenes Kontinuum unterbrechen und gliedern.

Wichtiger aber ist die Asymmetrie des anderen Merkmalspaares; denn bei Lust/Unlust hat eine falsche Symmetrisierung immer wieder zu verhängnisvollen Folgen geführt. Wir besprachen schon früher jene Auffassung, die in der Unlust nur das photographische Negativ zur Lust sah und deshalb sogar glaubte, die Gefühle der beiden entgegengesetzten Richtungen gegeneinander mathematisch aufrechnen zu können (,Gefühlsbudget”).

Die verschiedene Beziehung $z u$ den personalen $Z$ we cke $n$ muss schon die Bewusstseinsphänomene der Lust und des Leids asymmetrisch machen. Lust steht, so sahen wir, in Beziehung zu positiven Zielannäherungen und Erfüllungen. Aber nicht alle Zielannäherungen und Erfüllungen im Menschenleben $b$ e $d$ ü $r$ $\mathrm{f}$ e $\mathrm{n}$ der psychischen Repräsentation durch Lust. Vielmehr ist ja die Sphäre des unbewussten Funktionierens weitgehend gekennzeichnet durch sinnvolle Zielstrebigkeit (man denke nur an Instinkte und automatisch gewordene Gewöhnungen); nur ein relativ geringer Bruchteil der positiven Zielvorgänge setzt sich in lustvolles Erleben um. Leid hingegen, als Symptom für Ziel- und Sinnwidrigkeiten im Lebensvollzug, tritt ü b e r a 11 auf, wo diese ein gewisses Ausmals erreichen und daher eines Bewusstseinssignals bedürfen. Leid drängt sich daher erlebnismälsig mehr hervor als Lust, ist wacher und sprungbereiter als jene. Diese andersartige Bewusstseinsakzentuierung der negativen Gefühlsgruppe ist oft bemerkt worden. Man hat u.a. nachgewiesen, dass die Sprachen fast durchgängig eine grössere Zahl, eine feinere Schattierung und einen häufigeren Gebrauch der Ausdrücke für Leid und Schmerz, Kummer und Furcht u.s.w. aufweisen als für Lust und Freude. Der pessimistische Schluss aus diesem Tatbestand liegt nahe; aber er ist nur berechtigt, solange man die blosse Erlebnisstärke zum Malstab des Lebenssinnes macht. Wer dagegen das personale Leben als etwas dem Erleben Vorgeordnetes und Überlegenes ansieht, kommt zu der folgenden Formulierung: Der Lebenssinn ist so weitgehend in positivem Sinne durch unbewusste Regulationen gewährleistet,

1) Vgl. hierzu S. $185 / 6$. 
dass er Lustgefühle nur für die zusätzlichen positiven Zielbezüge, Unlustgefühle dagegen für alle stärkeren Abweichungen von seinen Zielen erfordert; die Werthaltigkeit des Lebenssinnes selbst wird also durch jene Asymmetrie der Gefühlserlebnisse nicht malsgebend bestimmt.

Aber auch sofern die Polarität der Gefühle selber Gegenstand des Erlebens wird, ist nicht immer mit ihr ein Symmetrieerleben verbunden. Ja, eigentlich findet sich ein solches nur bei den oberflächlichsten Gefühlen. Wohlgefälligkeit und Missfälligkeit von Farben, angenehmer und unangenehmer Geschmack von Speisen mögen noch als „Gegenstücke” gefühlt werden, die sich vornehmlich durch das Plus und Minus-Zeichen unterscheiden. Aber für Liebe und Hass, für Hochachtung und Verachtung, für Selbstzufriedenheit und Reue, für religiöse Erhebung und Zerknirschung gilt dies nicht mehr. In jedem dieser Paare wird zwar die Entgegensetzung der Glieder, zugleich aber auch die positive Besonderheit jedes Gliedes erlebt. Hass ist, abgesehen von seiner Kontrastierung zur Liebe, ein Gefühl ganz spezifischer Beschaffenheit, spezifisch im unmittelbaren Erlebnis, spezifisch in der Art, wie es sich der Totalperson einbettet, spezifisch in den von ihm ausgehenden Antriebsweisen und den ihm zukommenden Ablaufsformen. Gerade die eigentlich kennzeichnenden Merkmale des Hassgefühls würden unbeachtet bleiben, wollte man es lediglich als negatives „Pendant" zur Liebe ansehen. Und ebenso bei allen anderen Gefühlspaaren.

Endlich gibt es Gefühle, zu denen es überhaupt kein polares, geschweige ein symmetrisches Gegengefühl gibt. Welches Lustgefühl etwa sollte einem peinigenden Zahnschmerz gegenübergestellt werden? Oder der Trauer um einen lieben Verstorbenen? Welches Unlustgefühl böte das Gegenbild zu dem stillen andauerden Genuss einer Beethoven'schen Symphonie?

\section{A m bivale $\mathrm{nz}$}

Wären Lust und Unlust rein gegensätzliche Merkmale, dann müssten sie sich, wenn sie sich in einem identischen Erlebnis begegneten, kompensieren und bei gleicher Intensität geradezu gegenseitig aufheben. Hiervon ist keine Rede. Es entsteht 
kein Grau aus dem Schwarz und Weiss der Gefühle, keine Indifferenz aus dem Wettstreit von Lust und Leid; sondern eine neue starke Farbigkeit ist da. Es ist ein Gefühl von ganz anderer Art, dessen Charakteristikum eine innere Zwiespältigkeit, ein schillerndes Zugleich von Lust und Unlust ist. Für dieses Gefühlsmerkmal ist der (von der Psychoanalyse eingeführte) Ausdruck ,Ambivalenz" üblich geworden.

Bei der inneren Vielfältigkeit des menschlichen Zwecksystems ist es durchaus möglich, dass irgend ein personales Geschehen im Hinblick auf den einen Zweck sinnvoll, auf einen anderen sinnwidrig ist, und damit in seinem Gefühlsniederschlag sowohl Lust- wie Unlust-Momente zeigt. Ja wir müssen geradezu den Ausnahmefall darin sehen, dass ein einziger Zweckbezug seinen Schatten in das Bewusstsein wirft und damit die Lust-oder UnlustBetontheit $\mathrm{zu}$ einer völlig ungetrübten und eindeutigen macht. Wir erinnern an unser obiges Beispiel vom Alkoholgenuss (S. 734); auch dem Trinker ist, so sehr er den Wohlgeschmack und die Belebung seiner Vitalkräfte geniesst, doch nicht, "ganz wohl dabei", weil auch die in die Zukunft vorgreifenden Gefühle in das Totalgefühl mit eingehen. Für den gemäfsigten Temperenzler kann das Gefühl, wenn er dann doch einmal trinkt, ausgesprochen ambivalent werden.

Denn diese Bezeichnung wird vorzugsweise dort angewandt, wo eine Art la bilen Gleichgewichts zwischen beiden Momenten erreicht ist, und diese innere Gespanntheit zum Wesen des Gefühls gehört. Wenn Kinder in der Dämmerstunde Gespenstergeschichten hören, so überkommt sie das „Gruseln". Es ist nicht die reine Unlust der Angst, nicht die reine Sensationslust und Neugierde, auch nicht die Summe von beiden, sondern ein eigenes, ausgesprochen ambivalentes Gefühl, dessen körperliches Begleitphänomen ein ,wohliges Erschauern" ist. Verwandt hiermit ist die „Angstlust”, wie sie der in starker kalter Brandung badende Mensch bei Annäherung jeder neuen Woge oder der auf dünnes Eis tretende Knabe verspürt. Von Psychoanalytikern ist die Angstlust hauptsächlich bei sexuellen Erlebnissen festgestellt und von da aus die Verallgemeinerung gemacht worden, dass jeder Lusteinschlag bei Angst ein wollustartiges Gefühl sei. $\mathrm{Zu}$ dieser Deutung liegt aber kein Grund vor: jegliche Lust kann sich mit Angst verschmelzen, so vor allem die Lust des starken 
Wagemuts; stürmende Soldaten, Hochtouristen, Flieger u.s.w. kennen Gefühlsambivalenz sehr genau.

Als erst einmal der Blick des Psychologen für dieses Gefühlsmerkmal geöffnet war, wurde bald sichtbar, wie weit der Umkreis ambivalenter Gefühle ist; und gleichzeitig wurde die Armseligkeit jener Klassifikationsversuche offenbar, welche alle Gefühle ohne Rest entweder in der Lust- oder in der UnlustRubrik unterbringen wollten. So seien hier nur wenige Beispiele erwähnt. Zunächst jene vielfältige Gefühlsambivalenz, die aus dem Verhältnis Klein/Gross entspringt. Der Mensch fühlt die eigene Dürftigkeit, Schwäche, Minderwertigkeit unlustvoll, zugleich die Anlehnung an einen Stärkeren, die Geborgenheit durch ihn, das Aufblickenkönnen zu ihm lustvoll; und so entstehen jene ambivalenten Gefühlerlebnisse des Jünger- und Gefolgtums, der Hörigkeit, und schliesslich das religiöse Gefühl, das zugleich Gottesfurcht und Gottesliebe ist ${ }^{1}$ ). - Im Ästhetischen gewinnt die Ambivalenz von Klein und Gross eine neue Nüance: im Gefühl der Erhabenheit beim Anblick des Ozeans oder eines gotischen Domes wird die Kleinheit des engen Ich überwunden durch die Einfühlung in die unendliche Grösse. - Im Moralischen ist Selbstüberwindung fast nie reine Freude am eigenen Sieg, sondern zugleich doch Verzicht, also unlustvolle Entbehrung dessen, was der Neigung entsprochen hätte. Umgekehrt ist in Sündenbekenntnis und Beichte ausser dem Schmerz um die eigene Schlechtigkeit so manches Lustmoment enthalten: das Gefühl der Entlastung und Befreiung, und darüber hinaus nicht selten sogar Eitelkeit und Stolz darüber, dass man solcher Gedanken und Taten fähig war.

\section{ABSTUFUNGEN DER GEFÜHLE}

Trotz der qualitativen Besonderheit eines jeden Gefühlserlebnisses ist es dennoch möglich, die Gefühle unter Gradgesichtspunkten mit einander zu vergleichen, also ein Mehr oder Minder an ihnen festzustellen. Freilich bleibt hierbei auch die Qualität nicht unberührt: eine Liebe, die sich steigert, wandelt nicht nur die Intensität, sondern auch die Eigenart des Gefühls. Immerhin

\footnotetext{
1) Faust sagt nach der Vision des Erdgeistes: ,In jenem sel'gen Augenblicke, wie fühlt' ich mich so klein, so gross."
} 
kann man jene Gradmerkmale einer Sonderbetrachtung unterziehen.

\section{Formale Abstufungen}

In formaler Hinsicht stufen sich Gefühle nach Stärke, Breite und Dauer ab.

a) Stär ke (Intensität) is t der A b t a nd von der $\mathrm{G}$ e $\mathrm{f} \ddot{\mathrm{uh}} \mathrm{ls} \mathrm{s} \mathrm{ch}$ we $11 \mathrm{e}$, also von jenem personalen Zustand, in welchem das Gefühl als Gefühl eben in die Erscheinung (bzw. aus der Erscheinung) tritt.

Nun haben die Gefühle auf Grund ihrer Mittelstellung (vgl. das Drei-Kolonnen-Schema S. 730) nach zwei Seiten hin Schwellen: gegenüber dem Bereich des Unbewussten, und gegenüber der Abgehobenheitssphäre des Erkennens und Tuns. Schwach ist daher die Intensität derjenigen Gefühle, die nur eben aus dem Unbewussten auftauchen (bezw. im Begriffe sind, in ihm zu versinken), aber auch diejenigen Gefühle, die schon weitgehend in Erkenntnis und Tat umgesetzt sind. Es ergibt sich daher die folgendeschematische I $n$ te $n$ s it ä $t$ s k u rve des F ühle n s innerhalb des Drei-Kolonnen-Schemas.

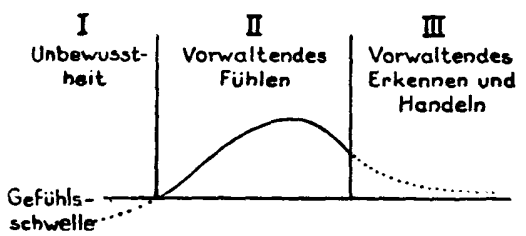

Fig. 15.

Intensitätskurve des Fühlens

Ein Mensch sei aus seiner alltäglichen Lebensweise allmählich in eine unangemessene, objektiv bedrohliche Situation geraten. Dann wird sich dort, wo das selbstverständliche Funktionieren der Automatismen(I) nicht mehr ganz ausreicht, zuerst ein $1 \mathrm{e}$ is es Gefühl der Unsicherheit entstehen (Aufang von II), das dann a nwächst zu Unbehagen und Furcht, ja Verzweiflung (Mitte von II). Sobald es ihm aber gelingt, nun die Situation erkennend zu überschauen, und die zu ihrer Beseitigung zweckentsprechenden Handlungen einzuleiten - mit anderen Worten, je mehr er sich der Abgehobenheitssphäre (III) nähert, um so mehr verliert die Furcht an Intensität, bis sie schliesslich durch kühles, sachliches Entscheiden und Tun ganz aus dem Bewusstsein verdrängt ist. Den Intensitätsverlauf in umgekehrter Richtung (von III 
zu I) zeigt das folgende Beispiel. Ein Mensch hat aus Überlegung heraus einen Beruf gewählt und nun in zahlreichen abgehobenen Akten das dazu gehörige Wissen und Tun sich angeeignet (III). Aus diesem kühlen und sachlichen Bezug zum Beruf wird aber allmählich eine Gefühlsbindung, eine Berufsliebe, vielleicht auch ein Berufsekel (II). Die Intensität des Gefühls steigt. Bald aber ist ein Höhepunkt erreicht. Bleibt er länger im Beruf, so bedarf er nicht mehr des intensiven Gefühlserlebens, weil Gewohnheitsbindung und Automatisierung eintritt. Mit steigendem Selbstverständlich-Werden nimmt also die Intensität des Gefühlserlebnisses $a b$, unter Umständen bis zu Null: der Mensch ist in einen gleichgültigen Berufstrott hineingeraten (III).

Die Intensitätskurve des Schemas lässt zweierlei erkennen:

1) Das Intensitätsmaximum jedes Gefühls liegt in der Mitte zwischen seinem Übergang zum Unbewussten und seinem Übergang zum abgehobenen Bewusstsein.

2) Ånderungen der Intensität sind niemals n u r Stufenänderungen, sondern zugleich auch Qualitätsänderungen des Gefühls; denn mit veränderter Intensität verschiebt sich ja auch die ganze Stellung des Gefühls innerhalb der personalen Struktur.

Sind exakte Intensitätsfeststellungen von Gefühlen möglich?

Solange wir im rein Psychologischen bleiben, gibt es keinen Malsstab der Gefühlsstärke; man kann niemals sagen: ein Gefühl ist so und so stark. "Objektive” Messunge n sind nur an den $\AA$ us s e ru ngen der Gefühle anzustellen, sei es an den physiologischen Ausdrucksbewegungen (Änderungen des Herzschlages, Stärke der Zitterbewegungen u.s.w.), sei es an den Handlungen (exzessive, den ganzen Körper ungeordnet ergreifende Abwehr- oder Angriffshandlungen bekunden eine stärkere Intensität des Gefühls, als geordnete und bedachte, also weitgehend abgehobene Handlungen).

Wohl abersind im rein Psychologischen $\mathrm{r}$ e l a $\mathrm{t}$ i ve I n t e nsitätsvergleichungen möglich, wie wir ja auch im Vorhergehenden vergleichende Bezeichnungen brauchten: dass ein Gefühl schwächer sei als ein anderes, stärker werde gegenüber seiner früheren Intensität. Hier gibt es auch eine Anwendungsmöglichkeit des psychologischen Experiments, freilich 
innerhalb ziemlich enger Grenzen. Man kann nämlich nur solche Gefühlsreize zum Zweck einer Intensitätsvergleichung darbieten, bei denen die mitspielenden Qualitätsunterschiede der Gefühle vernachlässigt werden können. Es handelt sich also um die experimentelle Erzeugung relativ einfacher und auf der Kurve sehr nahestehender Gefühle. So ist es z.B. nicht möglich, zwei Gefühle zu vergleichen, die den beiden Ästen der Intensitätskurve zugehören; die schwache Intensität eines, der Unbewusstheit nahen, Gefühls ist disparat zu der Intensitätsschwäche eines Gefühls, das sich schon weitgehend in Erkenntnis umgesetzt hat.

Experimentelle Intensitätsvergleichungen sind vornehmlich auf dem Gebiet der sogenannten, ,ä s th e t is ch e n E l e m e n t a r g e f ü h l e" angestellt worden. Fechner war hier vorangegangen; viele Forscher folgtem ihm nach.

Fechner prüfte die Wohlgefälligkeitsgrade von Rechtecken; er legte viele Rechtecke mit abgestuften Seitenverhältnissen den Prüflingen vor und liess die angenehmsten Formen heraussuchen, dann die nächst angenehmen u.s.w. Die Bevorzugungen häuften sich bei jenem Rechteck, dessen Seiten $a$ und $b$ dem Verhältnis des goldenen Schnittes entsprachen. $a: b=b:(a+b)$.

Statt der "Auswahl"'-Methode kann man auch die der „paarweisen Vergleichung" verwenden: es werden stets je zwei Objekte mit der Fragestellung vorgelegt, welches das wohlgefälligere sei; durch Vergleichung eines jeden mit jedem anderen ergeben sich dann ebenfalls Wohlgefälligkeitsmaxima. Mit diesem Verfahren stellte z.B. Jonas Cohn fest, dass unter allen paarweisen Farbenkombinationen die Verbindung von Komplementärfarben (also Grün mit Rot, Gelb mit Blau) das stärkste Wohlgefallen auslöst.

Solche Feststellungen haben allerdings nur Bedeutung, solange die Gefühle in relativer Isolierung erzeugt werden können. In dem Augenblick, da Farbenkombinationen in einen grösseren Zusammenhang, z.B. eines Gemäldes, eingefügt sind, kann plötzlich eine ganz andere Verbindung als die der Komplementärfarben maximale Wohlgefälligkeit erwecken. Ebenso kann die Einbettung der Gefühle in personale Zusammenhänge die Kurve völlig verschieben. Ein für seinen Bund und dessen Farben begeisterter Student findet jene Farben-Verbindung wohlgefällig, mag diese auch unter dem Gesichtspunkt rein sinnlicher Annehmlichkeit anderen höchst missfällig erscheinen. -

b) B r e i t e des Gefühls bezeichnet den Umfang der sonstigen 
Bewusstseinsinhalte, die in den Einflussbereich des Gefühls einbezogen werden. So sind "Stimmungen" ausgesprochen b r e i t e Gemütszustände. Dagegen tritt etwa eine Idiosynkrasie, ein monomanisches Interesse als ein sehr schmales, ja geradezu spitzes Gefühl auf, da es sich ausschliesslich an einen engen Ausschnitt der Bewusstseinsinhalte klammert und alle anderen Gebiete unberührt lässt.

Als Persönlichkeitszug tritt „Breite des Gefühls” bei jenen Menschen auf, welche die innere Möglichkeit haben, sehr vielerlei mit ihrem Gefühl zu umfassen. Hierher gehören : die Vielliebenden, die allseitig Interessierten, jene, denen „Nichts Menschliches fremd" bleibt.

Zwischen dieser Extensität und der vorher besprochenen Intensität eines Gefühls besteht meist umgekehrte Proportion ${ }^{1}$ ). Die atmosphärische Stimmung ist breit, aber gemälsigt; die zugespitzte Leidenschaft schmal, aber höchst intensiv.

c) Die Gefühls d a u e r schwankt zwischen der Momentaneität der Regungen, die im Klein-Geschehen das Alltagsverhalten steuern, und jenen, nur zugleich mit dem Leben endenden, chronischen Gemütsverfassungen und Dispositionen, die zu den konstitutiven Zügen jedes Persönlichkeitsbildes gehören.

Ziemlich verwickelt ist das Verhältnis von Dauer und Intensität. Längeres Andauern eines Gefühls kann dessen Stärke steigern, bis es auf einem Höchstniveau zur Stabilität kommt; es kann aber auch auf das Gefühl abschwächend wirken, bis zum Schwinden. Die Unerschütterlichkeit der Treue ist ein Beispiel für jene, die Abstumpfung durch Gewöhnung ein Beispiel für diese Wirkung der Dauer. In beiden Richtungen sind die Ausmalse der Dauerwirkung fast ohne Grenzen; so kann Treue bis zur Selbstaufgabe führen; andererseits ist, beim Soldaten im Schützengraben, völlige Abstumpfung selbst gegenüber dem Grauen der Kriegseindrücke möglich.

\section{Personale Abstufungen}

Abstufbare Merkmale des Gefühls, welche direkt seine Beziehung zur tragenden Person ausdrücken, sind Tiefe, Echtheit, Ernsthaftigkeit, Niveau.

1) Åhnliches begegnete uns schon bei der Aufmerksamkeit. (Vgl. S. 622) 
a) "T i e $\mathrm{e}$ " ist in ihrem Grundwesen keine psychologische, sondern eine personale Dimension. D i e Pers on hat $\mathrm{T}$ i efe, d.h.: von der Kontaktstelle zwischen Person und Welt geht eine Richtung ihres Seins und Lebens fort von der Oberfläche zu Schichten, in welchen die Person immer mehr sie selbst, immer weniger weltabhängig und weltbezogen ist ${ }^{1}$ ). In Bezug hierauf kann man dann auch E r l e b n is s e n, insbesondere Gefühlserlebnissen, einen wechselnden Grad von „Tiefe” zusprechen. Die tiefsten Gefühle sind also die am meisten eingebetteten, jene, in denen personales Wesen am unmittelbarsten sich ins Psychische projiziert, gleichsam transparent wird.

Objektive Malsstäbe gibt es freilich nicht mehr für den Grad der Gefühlstiefe. Die Selbstgewissheit des Fühlenden einerseits, verständnisvolles Miterleben und Deuten bei dem Aussenstehenden andrerseits, müssen hier an die Stelle objektivierender Messungen treten. Auch die vorher besprochenen Eigenschaften der Intensität, Breite und Dauer sind durchaus nicht eindeutige Kennzeichen der Gefühlstiefe.

Der Genuss einer ausgezeichneten Zigarre mag sehr intensiv sein, greift aber garnicht in die Tiefe. Umgekehrt: die Neigung zu dem liebgewordenen Beruf mag einen Menschen bis in den tiefsten Wurzelgrund seines Seins erfüllen, ohne dass dies zu besonders intensivem Erlebnis werden müsste.

Was die Dauer angeht, so sind zwar tiefe Gefühle meist auch nachhaltig, weil mit dauernden Zügen der Person verknüpft. Aber es gibt doch auch jene e in m a lige $\mathbf{n}$ entscheidenden Erlebnisse: einer Begegnung, einer inneren Bekehrung, eines gewaltigen Kunsteindrucks u.s.w., die den Menschen in seinen Tiefen gefühlsmälsig aufwühlen; sie wirken weiter, wandeln vielleicht den Menschen dauernd um - aber das G ef ühl als Erlebnisweise des Ereignisses ist schnell verklungen, ist unwiederholbar - und hatte doch, solange es gegenwärtig war, eine nicht $\mathrm{zu}$ überbietende Tiefe.

Die Gefühle geringster Tiefe, die „oberflächlichen”, heissen so, weil sie dicht unter der Berührungsstelle des Menschen mit der Welt liegen, von der Welt veranlasst und durch jede Ånderung der Umweltreize mit verändert werden. Gewiss sind auch sie personal eingebettet - denn sonst wären sie ja überhaupt

1) Vgl.: Studien zur Personwissenschaft" S. 21 ff. u S. 120; dieses Buch S. 131. 
nicht Gefühle - aber sie spiegeln nur augenblickliche Zustände und weniger kernhafte Schichten der Person.

Die Verschiedenheit im Tiefgang der Gefühle kann sich innerhalb eines Menschen bei verschiedenen Gefühlsbereichen zeigen. Es gibt Menschen, die in einer bestimmten Lebenssphäre (Familie, Vaterland, Natur, Kunst) zu besonders tiefen Gefühlsregungen disponiert sind, während ihr Gemüt in den anderen Sphären oberflächlich reagiert. Von noch allgemeinerer charakterologischer Bedeutung ist aber die $T$ o $t$ a I-Disposition oder Nicht-Disposition zu Gefühlen von grossem Tiefgang. Die Eigenschaften der „Gemütstiefe” und der „Gemütsoberflächlichkeit" gehören zu den wesentlichsten Unterscheidungsmerkmalen zwischen Mensch und Mensch.

b) Nahe verwandt dem Unterschied von Tiefe und Oberflächlichkeit, aber doch nicht identisch mit ihm, ist der von $\mathrm{E} \mathrm{ch} \mathrm{t-}$ heit und Unechtheit der Gefühle.

In welchem Sinne kann es ,unechte” Gefühle geben?

Natürlich sind damit nicht die geheuchelten Gefühle gemeint, die a ls Gefühlserlebnisse überhaupt nicht vorhanden sind, sondern durch bestimmte Aufserungsmittel vorgetäuscht werden sollen. Der ertappte Sünder heuchelt Reue (,Krokodilstränen”). Der Zuhörer, der die Vorlesung von Gedichten seines Freundes über sich ergehen lassen muss, heuchelt Interesse oder gar Begeisterung. - „Unechte” Gefühle beruhen nicht auf bewussten, wohl aber auf unbewussten Täuschungen, vor allem auf unbewussten Selbsttäuschungen: das tatsächlich vorhandene Gefühlserlebnis wird auf personale Tiefen bezogen, zu denen es nicht gehört. Unecht ist die Begeisterung des Backfisches für die hohe Kunst eines Tenoristen; denn nicht die ästhetische Erhebung, sondern das erotische Bedürfnis, das sich an diesen Sänger als Schwarmobjekt knüpft, liefert die psychische Substanz des Gefühls. Aber die Vierzehnjährige verbirgt diesen wahren Gefühlsbezug nicht nur vor anderen, sondern auch vor sich selbst und glaubt an ihre Kunstbegeisterung. Unecht ist die Reue des, einer kleinen Missetat überführten, Knaben, dem das Geschehene ,leid tut”, nicht eigentlich aus Verantwortung für die verübte Handlung, sondern wegen der anderen, damit verbundenen Unannehmlichkeiten: Störung der Familienharmo- 
nie, Betrübnis der Mutter, Entziehung eines Genusses u.s.w.

Sehr viele unechte Gefühle sind s o z i a l bedingt. Denn die Zugehörigkeit zu einer Gemeinschaft oder Gruppe verlangt vor allem Einklang des Fühlens. Nichts gibt stärkeren Kitt als gemeinsame Interessen, Begeisterungen und Abneigungen. Nun bestehen aber in den e $\mathrm{ch}$ t e $\mathrm{n}$ Gefühlen gewaltige individuelle Verschiedenheiten der Auslese und des Tiefganges, die - wenn sie sich voll ausleben würden - geradezu gemeinschaftsfeindlich wirken könnten ${ }^{1}$ ). Glücklicherweise ist nun der Mensch zur Verhinderung dieses Schadens nicht durchweg auf das schwer durchzuführende und leicht zu durchschauende (und demoralisierende) Heucheln angewiesen; er vermag sich vielmehr selbst in die Illusion der Echtheit jener Gefühle hineinzuglauben, die er durch Nachahmung und Suggestion sich zu eigen gemacht hat. Bei allen typischen Mitläufern, Jüngern, Modemenschen ist kaher das Gefühlsleben in seinem Echtheitsgehalt weitgehend zweifelhaft. Auch das Gegenstück zu dieser Angleichungstendenz, die Originalitätssucht, äussert sich zuweilen in ähnlichen Formen. Das begeisterte Tragen einer absonderlichen Tracht kann ebenso auf unechtem Gefühl beruhen, wie das Schönfinden einer neuen Mode, die von der guten Gesellschaft sanktioniert ist.

Der Merkmalsgegensatz Echtheit/Unechtheit bezieht sich also auf die Strahlbedeutung des Gefühls: in den echten Gefühlen spricht sich das Wesen der Person gradlinig und unverbogen aus; die unechten Gefühle stehen zum personalen Wesen schief.

c) Dagegen bezieht sich das dritte hierher gehörige Merkmalspaar: Ernst/Unernst auf die Dienstbedeutung des Gefühls. Ernsthaft sind diejenigen Gefühle, die sich in den Dienst des tätigen Lebens einordnen, unernst solche, die von der Wirklichkeit abgelöst, eine Eigenexistenz führen. Das Furchtgefühl des Menschen, der seinen Verfolgern $\mathrm{zu}$ entfliehen sucht, ist ernst, das Furchtgefühl des Kindes, das sich im Rollenspiel vor dem „Wolf” flüchtet, ist unernst. Ebenso das Eifersuchtsgefühl des Schauspielers, der den Othello darstellt.

Unernst des Gefühls hat also nicht, wie Unechtheit, von vorn herein einen negativen Wertakzent; das Merkmal hat überall dort positive Bedeutung, wo der Mensch sich in Bereichen ab-

\footnotetext{
1) s. S. 726.
} 
seits von der unmittelbaren Lebenspraxis bewegt, also in $\mathrm{S}$ p i e 1 und K u n st. Diese beiden Sphären sind unter dem hier behandelten Gesichtspunkt in der Tat nahe verwandt. Denn hier wie dort knüpft sich das Fühlen an eine Wirklichkeit anderer Art, als es die harte Objektivität des Handelns und Behandeltwerdens ist. Hier wie dort ist das Gefühl nicht Konsequenz des vorangegangenen Lebens und hat nicht Konsequenzen für das folgende praktische Leben - sondern ist sich selbst genug und begnügt sich mit der physischen Darstellung im gegenwärtigen Ausdruck. Die unernsten Gefühle brauchen weder oberflächlich noch unecht zu sein. Die Zärtlichkeit der kindlichen Puppenmutter zur Puppe ist sehr tief und sehr echt; ebenso jenes Eifersuchtsgefühl des Othello-Darstellers, welches er erlebt, solange er in der Othellorolle lebt. Aber freilich nur: ,,solange". Das unernste Gefühl erschöpft sich in der Gegenwart, es hat zu Vergangenheit und Zukunft derselben Person keinerlei Bewusstseinsverbindung ${ }^{1}$ ). Der Othellodarsteller empfindet eine Stunde nach der Vorstellung gegen die Desdemonadarstellerin nichts mehr von den Gefühlen der Liebe und der Eifersucht, die er vorher nicht nur gespielt, sondern auch irgendwie gefühlt hatte.

Aber freilich: der schwebende und schillernde Charakter, der allem spielhaften Verhalten eigen ist, teilt sich auch den dazu gehörigen Gefühlen mit. Es gibt hier manche Übergänge und Zwischenformen.

Bei knabenhaften Kampfspielen verwischen sich für die Spieler zuweilen die Grenzen zwischen Ernst und Schein; und es kommt zu ernsthaften Rivalitäts- und Feindschaftsgefühlen, die auch das Verhalten der Knaben zu einander ausserhalb der Spielsituation bestimmen. Ebenso gibt es unter den Künstlern und Schauspielern viele Geistesverwandte des Bildhauers Pygmalion, dessen ästhetische Gefühlsbindung an die von ihm geschaffene Frauengestalt sich in ernsthafte Leidenschaft verwandelte, sodass er sein Gefühl in das reale Leben zu übertragen wünschte.

Bei solchen Übertragungen in die Wirklichkeit entsteht leicht

1) Dem widerspricht nicht unsere frühere Feststellung (S.493), dass das kindliche Spiel eine starke Zukunftsbedeutung hat; denn diese Bedeutung ist in dem spielhaften Gefühl nicht miterlebt, bleibt unbewusst. Das Pflegerische des Puppenspiels bei kleinen Mädchen ist zwar, pers on a lis t is c h gesehen, Vorbereitung und Vordeutung auf künftige Mütterlichkeit; aber e rle b nis m ä Isig ist das Zärtlichkeitsgefühl ausschliesslich auf die gegenwärtige Puppe, nicht auf die künftigen lebendigen Kinder gerichtet. 
,Unechtheit"; man ,spielt” mit den Gefühlen auch dort, wo Ernsthaftigkeit zu fordern wäre: es ist das sogenannte ,,Schauspielern" als typische Verhaltungsweise des realen Lebens.

Unechtheit gibt es aber auch innerhalb des künstlerischen Schaffens selbst; denn der produzierende oder reproduzierende Künstler ist durchaus nicht immer in der Lage, die zu seiner Aufgabe gehörenden Gefühle auch nur in der unernst-spielenden Form aufzubringen. Dann muss er bei anderen Gefühlsbereichen Anleihen machen - oder aber er muss zu bewusster Gefühlsvortäuschung greifen. So mancher virtuose Schauspieler verspürt erlebnismäfsig von den Gefühlen überhaupt nichts, durch deren Darstellung er das Publikum hinzureissen vermag.

Endlich gehört hierher das sogen. „Ernstspiel”, ein Verhalten, das bewusstseinsmäfsig ernst, der personalen Bedeutung nach aber Spiel ist. Wir können hier auf unsere frühere Schilderung verweisen (S. 496).

d) $\mathrm{N}$ i v e a u. - Die Gegenüberstellung von ,niederen” und „,höheren" Gefühlen ist der Laienpsychologie stets geläufig gewesen; die Fachpsychologie lehnte sie meist ab, weil sie eine Wertung bedeute, die in einer beschreibenden und erklärenden Wissenschaft keinen Platz haben dürfe.

Das würde nur zutreffen, wenn es sich um moralische Wertungen handelte: die Frage, ob die Gefühle, welche ",niedere” heissen, moralisch geringer einzuschätzen seien, als die „,höheren”, hat die Ethik zu behandeln, nicht die Psychologie.

Dagegen können wir jene immanente Wertung nicht preisgeben, die durch eine genetische Betrachtungsweise gefordert wird. Erkennen wir überhaupt an, dass es eine $\mathrm{E} n \mathrm{t}$ w i c k l u n $\mathrm{g}$ im Einzelwesen, in der Gattung und in der Reihe der Gattungen gibt, dann liegt darin ein Fortschrittsprinzip: der Übergang von früheren, einfacheren, zu späteren, komplizierteren Entwicklungsformen ist dann zugleich ein solcher von ,niederen” zu ,höheren".

In diesem Sinne ist dann auch die Anwendung der Niveauausdrücke auf die Gefühle berechtigt, ja unentbehrlich. ,Niedere” Gefühle sind solche, die wir bei Individuen niederer Entwicklungsstufen annehmen, ,höhere” solche, die nur auf höheren Entwicklungsstufen vorkommen. Und da auf diesen höheren 
Stufen die Erscheinungen der früheren nicht einfach ausgelöscht sind, sondern den dauernden Hintergrund für die Höherentwicklung bilden, so sind hier Gefühle beider Niveaus neben-, mit-, und gegeneinander wirksam.

Für die menschliche Person ergibt sich damit eine Beziehung der Niveaus zu den Modis des Lebens: Biosphaere, Objektssphaere, Introzeptionssphaere ${ }^{1}$ ). Die ,niederen” Gefühle begleiten die Vitalfunktionen, die der Mensch mit untermenschlichen Formen des Lebens gemeinsam hat, wie Ernährung, Fortpflanzung, Wachstum, Erkrankung, Abwehr, Anpassung u.s.w.

Auf höherem Niveau stehen die Gefühle der Objektssphaere. Anfänge sind schon beim Tier zu finden (Neugierde, Aufmerksamkeit, Vertrautheit und Fremdheit), doch finden sie ihre volle Entwicklung erst beim Menschen. Da für diesen das E r k e n n e n der Objektwelt eine zentrale Aufgabe wird, so erlebt er in te l$1 \mathrm{e} \mathrm{k} \mathrm{t} \mathrm{u} \mathrm{e} 11 \mathrm{e}$ Gefühle in grolser Mannigfaltigkeit: Staunen, Wilsbegierde, Leiden an Problemen, Erkenntnisfreude usw.

Die höchste Stufe wird durch jene Gefühle gebildet, die das In trozipieren von Werten begleiten: also die aesthetischen, ethischen, religiösen Gefühle, sowie alle, die mit eigentlicher Kulturproduktion und -Rezeption zusammenhängen. Sie sind dem Menschen ganz allein eigen, späte Erzeugnisse komplexester Entwicklung.

1) s. S. $101 \mathrm{ff}$. 


\section{DREISSIGSTES KAPITEL}

PERSONALER ZEITBEZUG DER GE FÜHLE

\section{DAS ZEITSCHEMA}

Eine Merkmalsuntersuchung, wie sie das vorige Kapitel gibt, wird der Totalität des Gefühlserlebens nicht gerecht; denn jedes Gefühl wird jeweils unter ganz verschiedene Merkmalsgesichtspunkte gestellt. Es muss deshalb eine anders orientierte Betrachtung die konkrete Ganzheit jedes Gefühlsphänomens und die konkrete Fülle aller Gefühlserscheinungen zu ihrem Recht kommen lassen. Als Leitfaden dient uns hierzu der L e b e n svollzug der Person in der Zeit. Die personale Zeit der Menschen erstreckt sich von der jeweiligen Gegenwart aus mit unsymmetrischer Polarität in die Zukunft und in die Vergangenheit; die Gefühle stehen zu diesen drei Zeitphasen in wesentlicher Beziehung. Zwar gehören alle Gefühle, indem sie erlebt werden, der Gegenwart des Erlebenden an. Aber über diese rein faktische Zeitgebundenheit reicht ihre personale B e d e u t u n g weit hinaus. Neben den "Praesenzgefühlen”, die auch bedeuttungsmälsig der Gegenwart zugeordnet sind, gibt es Gefühle, die in die Zukunft ,vorgreifen", und solche, die in die Vergangenheit „rückgreifen”.

Vorläufiges Beispiel: Das Gefühl der Liebe nimmt einen ganz verschiedenen Charakter an: in dem Präsenzgefühl der den Menschen ganz erfüllenden Leidenschaft, in dem vorgreifenden Gefühl erwachender Erotik, in dem rückgreifenden Gefühl der Pietät.

In jedem der drei Zeitbezüge macht sich die Mittelstellung des Gefühls zwischen Unbewusstheit und abgehobener Bewusstheit geltend, die im Dreikolonnenschema dargestellt wurde (s. S. 730). Um diese Zusammenhänge zu überblicken, erweitern wir daher das Dreikolonnenschema in folgender Weise. 


\begin{tabular}{|c|c|c|c|}
\hline & $\begin{array}{c}\mathrm{I} \\
\text { Unbewusstes } \\
\text { Leben }\end{array}$ & $\begin{array}{c}\text { II } \\
\text { Einbettendes } \\
\text { Erleben }\end{array}$ & $\begin{array}{c}\text { III } \\
\text { Abhebendes } \\
\text { Bewusstsein }\end{array}$ \\
\hline $\begin{array}{l}\text { Gegenwarts- } \\
\quad \text { bezug }\end{array}$ & Reflex & $\begin{array}{r}\text { Praesenz- } \\
\text { gefühle }\end{array}$ & $\begin{array}{l}\text { Akute Vollzüge } \\
\text { der Wahrneh- } \\
\text { mens, Denkens, } \\
\text { Schaffens, } \\
\text { Handelns. }\end{array}$ \\
\hline Zukunftsbezug & $\begin{array}{l}\text { Instinkt- } \\
\text { handlung }\end{array}$ & $\begin{array}{c}\text { Vorgreifen- } \\
\text { de Gefühle }\end{array}$ & $\begin{array}{l}\text { Zielstrebigkeit } \\
\text { von Vorsatz, } \\
\text { Planung, Pro- } \\
\text { blematik. }\end{array}$ \\
\hline $\begin{array}{l}\text { Vergangenheits- } \\
\quad \text { bezug }\end{array}$ & Mneme & $\begin{array}{c}\text { Rückgrei- } \\
\text { fenḍeGefühle }\end{array}$ & Gedächtnis. \\
\hline
\end{tabular}

Erweitertes Drei-Kolonnen-Schema

II. PRAESENZGEFÜHLE

Schicken wir ein Beispiel voraus. Ein erwachsener Mann hat zum ersten Male im Leben als Zeuge mit dem Gericht zu tun. Dieser Tatbestand führt $\mathrm{zu}$ Gefühlserlebnissen, die gleichsam zwischen der gegenwärtigen Verfassung seiner Person und der Situation ausgespannt sind. Aber der Akzent dieses Erlebens kann mehr zu dem einen oder zu dem anderen Pol hin gelagert sein. So entstehen verschiedene Erlebnisnüancen, die sich in eine $\mathrm{Skala}$ steigender Abgehobenheit ordnen lassen. Wir greifen vier Stufen heraus, die von dem fühlenden Subjekt etwa folgendermalsen ausgedrückt werden können :

1) „Mir ist unbehaglich". 2) „Mir ist dabei nicht behaglich zu Mute”. 3) „Das ist eine unangenehme Sache”. 4) „Die Menschen in Amtstracht, mit strenger Miene und auf erhöhtem Sitz, das lange Warten, der Zwang zur eidlichen Aussage sind mir unangenehm".

In 1) wird lediglich die Zuständlichkeit der Person als gegen- 
standsloses Zumutesein konstatiert. In 2) kommt schon das Bewusstsein des Anlasses hinzu (,dabei”). In 3) ist das Schwergewicht des Erlebens bereits ins Gegenständliche verschoben; dies aber wird noch sehr diffus als „Sache” erlebt. Äusserung 4) endlich gliedert die Situation in viele objektivierte Einzelmomente auf, die mit ihren besonderen Gefühlstönen nicht mehr ganz und gar in dem allgemeinen Zumutesein aufgehen.

\section{Zumutesein. Stim mug. Affekt}

a) Die person-nächste und am meisten eingebettete Form präsenten Fühlens ist also das blolse ,Z u m u t e s e i n", eine seelische Gesamtatmosphäre, die nicht mehr näher beschreibbar ist. I) Vagheit kann sogar so weit gehen, dass nicht einmal die Alternative lustvoll/unlustvoll eindeutig anwendbar $\mathrm{zu}$ sein braucht. Ein völlig reines, d.h. gegenstands- und beziehungsfreies Zumutesein ist freilich für das entwickelte Seelenleben nur als Grenzbegriff denkbar; im Zustand des dahinvegetierenden Dösens, des Einschlafens, des Wachwerdens, auch in manchen Krankheitszuständen kommt man ihm wohl am nächsten. Auf primitiven Entwicklungsstufen, z.B. beim Säugling, nimmt es einen breiten Raum ein.

Man hat oft versucht, das Zumutesein zu a n a l y sie r e n, und hat dann insbesondere auf die beteiligten Organzustände hingewiesen. Zweifellos spielen diese sehr stark mit. Dem Menschen ist in Zeiten, in denen die Stoffwechselfunktion nicht ganz in Ordnung oder die Muskulatur ermüdet oder der Herzschlag beschleunigt ist, anders zumute als zur Zeit normaler Organfunktionen. Aber man darf nun diese organischen Einflüsse nicht durchaus ins Bewusstsein verlegen wollen: als ob es die OrganE m p f in d u n g e n des Stoffwechsel- oder Zirkulations-Systems u.s.w. seien, welche das „Zumutesein" konstituieren. Damit würde man bereits über die Dumpfheit und Unlokalisiertheit des $\mathrm{r}$ e in e $\mathrm{n}$ Zumuteseins hinausgehen. Insbesondere dort, wo es sich nicht um A b w e i c h u n g e n von der Funktionsnorm, sondern um das alltägliche Funktionieren der Organe handelt, haben wir kein Recht, elementare Bewusstseinserscheinungen anzunehmen, von denen keine Spur in der Selbstwahrnehmung gegeben ist. Der gesunde Mensch, der weder Herzklopfen, noch 
Magendrücken, noch Atembeschwerden u.s.w. fühlt, hat doch auch sein „Zumutesein”; und der selbstverständlich auch hier vorhandene $E$ in $\mathrm{fl}$ l u s s, den seine Herztätigkeit u.s.w. auf jene psychische Gesamtverfassung hat, spielt sich durchaus unterhalb der Bewusstseinsschwelle ab. Irgend eine Veränderung der Funktionen, z.B. beschleunigter Herzschlag, führt zunächst auch lediglich zu einer vagen Umstimmung der Gesamtverfassung (z.B. „Beklommenheit”); erst bei weiterer Zunahme der Veränderung kommt es zur Abhebung des gesonderten Organ e r l e b n iss e s (,ich fühle Herzklopfen"), und damit zu einer gewissen Strukturierung des Zumuteseins.

Entsprechendes gilt auch für die Mitwirkung ä u s se r e r Einflüsse am jeweiligen Zumutesein. In einem sonnigen weiten Zimmer mit hellen Tapeten fühlt sich der Mensch anders, als in dunklen engen Räumen - ohne dass die Ursachen dieses veränderten Gesamtgefühls gesondert zum Bewusstsein kommen müssten.

Das Zumutesein, als die personnächste Weise des Erlebens, ist zugleich eine innere Darstellung der Person für die Person selbst, ist die Weise, wie sie "sich hat", und zwar jetzt und hier hat in dieser gegenwärtigen Situation. Man spricht dann von „Gemütsverfassungen”. „Ich bin traurig” heisst nicht nur: Trauergefühl ist da, sondern: i c h bin ein Trauriger; in der Traurigkeit erlebe ich mein herabgesetztes Ich-Sein.

Gewiss: es ist nicht die Totalität der Person, die in der jeweiligen Gemütsverfassung zum Selbsterleben kommt; denn weder die absolut eingebetteten, selbstverständlichen Bezüge zur Welt, noch die abgehobenen Sphären des Erkennens und Handelns sind in dieser Projektion enthalten. In der Gemütsverfassung spiegelt sichviel mehr der Spannungszustand zwischen Einbett ung und Abhe bung, in dem die Person zur Welt steht, die Art ihres jeweiligen Fertigwerdens mit sich und der Welt.

Diese Selbstdarstellung ist nun aber stets zugleich eine Darstellung für andere: die Spannung zur Welt wird auch der Welt selbst geoffenbart: als A u s r u c k. Psychisches und Physisches gehören nirgends so unlösbar zusammen, wie in der Beziehung von Gemütszustand und Ausdruckshaltung, Gemütserregung und Ausdrucksbewegung. Fröhlichkeit als personaler $\mathrm{Zu}$ stand tritt nicht nur erlebnismäfsig als frohes, weltoffenes $\mathrm{Zu}$ - 
mutesein auf, sondern zugleich als flüssigere expansive Beweglichkeit, welche die Personsphäre räumlich und dynamisch erweitert und zur Welt hin auch physisch öffnet (durch straffere Haltung, erhobene Stimme, Ausbreitung der Arme, Annäherungsbewegungen u.s.w.). Entsprechend bei allen anderen $\mathrm{Ge}$ mütsverfassungen. Für den äusseren Beobachter werden so die wahrgenommenen Ausdrucksbewegungen des anderen zu Symptomen und Symbolen von dessen innerem Zumutesein. Aber diese Tre n n u g von Symptom und Erlebnis ist nur von aussen her möglich: für die fühlende Person selbst existiert sie nicht; für sie ist Frohgefühl und lebhafte Gliedbewegung unbedingt zusammengehörig.

Das Zumutesein eines jeden Menschen begleitet ständig dessen Lebensablauf und spiegelt sowohl die Stetigkeit des Lebens wie die Wechselfälle und Schwankungen wieder. Aus diesem ununterbrochenen Verlauf heben sich zwei charakteristische Erscheinungsweisen des Zumuteseins heraus, die Stimmungen und die Affekte.

b) Eine "S t i m m u n g" ist ein zuständliches Zumutesein, das schon eine ausgesprochene qualitative Besonderheit besitzt und in dieser eine längere Zeit verweilt. Zugleich teilt sich diese Gefühlstönung den Abhebungen (Erkenntnissen und Willenshandlungen) irgendwie mit.

Die Stimmungen sind nicht mehr so vage und ungestaltet wie das ",reine Zumutesein"; denn sie haben eine gewisse Stabilität und Qualität. Aber ihre Dauer ist noch nicht scharf abgegrenzt (man kann meist nicht angeben, in welchen Momenten eine Stimmung beginnt und aufhört); und sie ist qualitativ noch nicht auf bestimmte Bereiche des Bewusstseins beschränkt. Ihr kommt eine Art Allgegenwärtigkeit innerhalb der Person zu; über die ganze Erlebenssphäre verbreitet sie sich wie ein feines Gas, das alle Gegenstände nicht nur umfliesst, sondern mit seinem Duft durchdringt. Selbst wenn als Ausgangspunkt der Stimmung ein abgehobenes Einzelerlebnis in Frage kommt (eine frohe Nachricht, ein bestandenes Examen u.s.w.), so bleibt das Gefühl doch nicht an diesem Gegenstand als dessen „Gefühlston” hängen, sondern st ra hlt a u s auf alles, was ihm begegnet. Man freut sich dann über das kleinste Sonnenstäubchen; man fühlt 
Sympathie für sonst gleichgültige Menschen; man ist geneigt, Argerliches leicht zu nehmen oder zu übersehen - „die ganze Welt bekommt ein anderes Gesicht".

Es gibt vielleicht kein eindringlicheres Argument gegen die „Elementen"-Psychologie, als diese Abhängigkeit aller Einzelerlebnisse in ihrer Beschaffenheit und ihrem Ablauf von der Totalstimmung der Person.

„Stimmung” ist ein aus der Musik entlehnter Ausdruck: die seelische Atmosphäre schwingt gleichsam in einer bestimmten Wellenlänge; und die einzelnen Vorstellungen, Gedanken, Bedürfnisse, Wünsche und sonstigen „Elemente" können nur zur Resonanz kommen, wenn sie auf gleiche Wellenlänge "gestimmt" sind. Was spröde seinem eigenen Rhythmus folgt, wird entweder überhaupt aus dem Erleben ausgeschieden, oder fristet als stimmungsloser und stimmungswidriger Fremdkörper sein Dasein am Rande des Bewusstseins. Aber jene atmosphärische Gesamtschwingung hat eine weitgehende Kraft, die einzelnen Abhebungen „umzustimmen" und dadurch klingend zu machen.

Freilich gibt es auch hier viele Abstufungen. Je stärker Bewusstseinsinhalte o b j k t i v e r t sind, um so geringer ist ihre Bereitschaft, sich durch Stimmungen modifizieren zu lassen. Dies gilt ebenso auf dem Gebiet des Erkennens wie auf dem des Handelns.

Die Evidenz einer Wahrnehmung, die Stringenz eines logischen Beweises ist einer Umgestaltung durch Stimmung nur schwer zugänglich; auch fröhlichste Stimmung kann den vor meinen Augen sich abspielenden Unglücksfall oder die Erkenntnis, dass ich einen Rechenfehler gemacht habe, nicht aus der Welt schaffen. Wohl aber kann sie sich dort bemerkbar machen, wo die abgehobenen Inhalte noch vieldeutig und damit subjektiv deutbar sind. In der fröhlichen Stimmung eines Ausflugs werden die Teilnehmer eine kleine am Horizont auftauchende Wolke leicht nehmen; nur der eine widerwillig mitgehende Griesgram wird in seiner Verärgerung die Wolke als Unheilkünder eines bevorstehenden Wetterumschlags ansehen. - Der Mathematiker wird sich einen Fehler der Rechnung unabhängig von der Stimmung eingestehen müssen; aber die Einschätzung der Tragweite dieses Fehlers und die Hoffnung, ihn zu korrigieren, können wiederum stimmungsbedingt sein. 
Ähnlich im praktischen Tun: wo feste Pflichten und Zwänge als objektive Antriebe des Handelns wirksam sind, wird die jeweilige Stimmung sich viel weniger bemerkbar machen als dort, wo fallweise über das $\mathrm{Ob}$ und Wie des Tuns spontan entschieden werden muss. Da kann deprimierte Stimmung' unübersteigbare Hemmungen setzen, während gehobene Stimmung die Willensentscheidungen und Willensimpulse erleichtert.

Der eigentümlich atmosphärische Charakter der Stimmung bewirkt sogar, dass sie nicht einmal an die Grenze der Person gebunden ist. Sie strahlt auch über auf die Gegenstände selbst, die mit dem fühlenden Menschen in Zusammenhang stehen. Die Stimmung eines Sonnenunterganges ist nicht nur meine Stimmung beim Anblick des Sonnenunterganges, sondern ein gemeinsamer Zustand von Welt und Person. Wenn mir bei einer Trauerfeier der Raum und die Musik ,stimmungsvoll" erscheinen, so ist das nicht nur kausal zu verstehen (als: Stimmung in den Menschen erzeugend), sondern zugleich sympathetisch (als: mit der Stimmung in den Menschen zusammenklingend, mit ihr eine Einheit bildend"). Es handelt sich hier um eine Objektivation ganz andrer Art als jene, die die Objekte des Erkennens und des Handelns schafft; um eine "physiognomische" Objektivation der Ausdruckshaltigkeit.

Will man die Stimmungen klassifizieren, so erweist sich das Vierfelder-Schema als brauchbar. Denn auch die Stimmungen gliedern sich dynamisch nach vorwiegender Erregung oder Beruhigung, und hedonisch nach vorwiegender Lust- oder LeidHaltigkeit. So ergibt sich folgendes Schema (die Felder enthalten nur einzelne $\mathrm{B}$ e is pi e le):

\begin{tabular}{l||l|l}
\hline \hline & Lusthaltigkeit & \multicolumn{1}{|c}{ Leidhaltigkeit } \\
\hline $\begin{array}{l}\text { Aktive } \\
\text { Stimmungen }\end{array}$ & $\begin{array}{l}\text { Angeregtheit } \\
\text { Fröhlichkeit }\end{array}$ & $\begin{array}{l}\text { Reizbarkeit } \\
\text { Verärgerung }\end{array}$ \\
\hline $\begin{array}{l}\text { Passive } \\
\text { Stimmungen }\end{array}$ & $\begin{array}{l}\text { Behaglichkeit } \\
\text { genielserische Ver- } \\
\text { sunkenheit }\end{array}$ & $\begin{array}{l}\text { Traurigkeit } \\
\text { Verstimmtheit } \\
\text { Resignation }\end{array}$
\end{tabular}

Vierfelder-Schema der Stimmungen 
c) Sind die Stimmungen zuständlich, so sind die A f f e k t e prozesshaft, weniger ein Zumutesein, als ein „Zumutewerden”. Das Verhältnis Person/Welt erfährt einen Umschwung: so stark, dass das vorher bestehende Gleichgewicht dieses Verhältnisses völlig unterbrochen wird - und so plötzlich, dass die Person nicht sofort diejenigen Abhebungen zustande zu bringen vermag, die eine Neuherstellung des Gleichgewichts, eine Wiederanpassung ermöglichen. So kommt es nur zu einer chaotisch dumpfen Totalreaktion der Person auf die totale Andersartigkeit der Situation. Das ist der „Affekt”. Lediglich eine ganz allgemeine Gerichtetheit ist erkennbar: als Jubel oder Verzweiflung, als Wut oder Entsetzen. Aber damit ist nur eine geringe Differenzierung bewirkt, weil die diffuse Totalerschütterung vorwiegt. Diese hat eine doppelte psychische Wirkung: 1) Sie schneidet den bisherigen geordneten Ablauf des Lebens ab; alles was an Stimmungen und deren ruhigeren Wirkungen in der Person lebte, was an Zielsetzungen und Planungen im Gange war, hört auf. 2) Die Erschütterung verhindert auch die Herstellung eines neuen geordneten Ablaufs, die Einleitung neuer Denk- oder Willenshandlungen, kurz die Beherrschung des seelischen Geschehens durch aktive Leistung. So ist jeder Affekt eine vorübergehende $\mathrm{H}$ e m$\mathrm{m}$ u $\mathrm{n} \mathrm{g}$ der personalen Selbsttätigkeit, die sich nun allerdings in entgegengesetzten Erscheinungsformen bekunden kann: die abgehobenen Bewusstseins-Inhalte und -Abläufe werden entweder ebenfalls gelähmt, oder ordnungslos sich selbst überlassen. Im ersten Falle ist das Bewusstsein "leer"; alle Vorstellungen und Gedanken sind wie weggewischt. Im zweiten Falle überstürzen sie sich, werden durcheinander gewirbelt, richtungslos, sinnlos.

Somit lässt sich das Vierfelderschema auch für die Einteilung der Affekte benutzen (wiederum nennen wir in den Feldern nur einzelne Beispiele) :

\begin{tabular}{l|l|l}
\hline \hline & Lusterfülltheit & \multicolumn{1}{|c}{ Leiderfülltheit } \\
\hline $\begin{array}{l}\text { Stürmische } \\
\text { Affekte }\end{array}$ & Jubel & Wut \\
$\begin{array}{l}\text { Lähmende } \\
\text { Affekte }\end{array}$ & Begeisterung & Empörung \\
\hline
\end{tabular}

Vierfelder-Schema der Affekte 
In $z$ e i t 1 i c h e r Hinsicht kommt dem Affekt (im Gegensatz $\mathrm{zu}$ den Stimmungen) schon eine gewisse Ablaufs g e s t a lt $\mathbf{z u}$; man hat sogar versucht, hierfür eine schematische Kurve aufzustellen. Plötzlichkeit des Eintritts, jäher Anstieg zu einem Maximum, langsamerer Abstieg mit kleinen Nachschüben, im ganzen eng begrenzte Dauer sind die durchschnittlichen Kennzeichen des Affektverlaufs. Insbesondere ist die kurze Dauer charakteristisch. Eine Gleichgewichts-F, r s c h ü t t e r u n g kann ja nur vorübergehend sein; wird sie nicht schnell überwunden, dann besteht die Gefahr, dass sie sich zu einer chronischen Gleichgewichts-Störung stabilisiert (z.B. zu einer Schreckpsychose). Der normale kurzlebige Affekt pflegt sich zu einer Stimmung abzumildern; diese hat entweder das gleiche Vorzeichen: aus Wut wird Ärger, aus überschwänglichem Jubel Fröhlichkeit — oder sie ändert das Vorzeichen und lässt das allzu weit nach der einen Seite getriebene Pendel nun, wenn auch schwächer, nach der anderen ausschlagen; auf Begeisterungstaumel folgt ein Schalheitsgefühl; nach heftiger Trotzszene ist ein Kind besonders weich und anschmiegsam.

2. Gefühlssteuerungen. Gefühlstönungen

Zumutesein, Stimmungen, Affekte füllen das Bewusstsein in seiner Breite, sind deshalb nicht gegenstandsgebunden. Wir sahen ja, dass selbst dann, wenn die Gemütsverfassung durch ein abgehobenes Einzelerlebnis ausgelöst wurde, doch sofort von hier aus die Irradiation auf die anderen Bewusstseinsbereiche, zuweilen sogar die Auslöschung des Ausgangspunktes stattfand.

Nun gibt es aber Erscheinungen des Gefühlslebens, die enger an $\mathrm{E}$ in $\mathrm{z}$ eli $\mathrm{n} \mathrm{h}$ a $1 \mathrm{t}$ e des personalen Lebens geknüpft bleiben: hier ist also das Gefühl nicht so sehr der gemeinsame Nährboden für alle Besonderungen, als die Wurzelfaser, mit der das Einzelmoment in jenem personalen Untergrund haftet. Und zwar kommt solche gefühlsmälsige Verwurzelung sowohl den speziellen Vollzügen des praktischen $\mathrm{T}$ u n s, wie den abgehobenen Inhalten des Erle be n s zu. Jene werden von Gefühlen g e s t e u e r t, diese von Gefühlen $g$ e $t$ ö $n t$.

a) "Gefüh ls steuerungen" sind solche Regelungen 
des Tuns, die zwischen der unbewussten Reflexregulierung und der abgehobenen bewussten Willenshandlung in der Mitte stehen. Als Beispiel diene das Geh en auf einem etwas schwierigen (z.B. schlüpfrigen) Wege ${ }^{1}$ ). Die Fortbewegung geschieht nicht mehr völlig automatisch wie auf einem normalen, ebenen und festen Wege. Sie fordert aber auch nicht - wie etwa bei einer gefährlichen Hochtour - eigentliche $\mathrm{B}$ e a c h t ung des Weges und seiner Tücken, also abhebendes Erkennen der einzelnen Hemmnisse und Bewusstwerdung der zu ihrer Uberwindung nötigen Willensimpulse. Vielmehr erlebt der Fussgänger seine Beziehungen zum Wege nur als $\mathrm{S} c \mathrm{~h}$ wank ungen seines "Z um u t e s e i n s"; er vermag aus diesen heraus "gefühlsmäfsig" die trockensten Stellen als geeignetste Stützpunkte zu suchen und die Regulierung der jeweiligen Schrittweite und des Gleichgewichts durchzuführen. Zugleich aber kann er in den differenzierteren Bereichen des Bewusstseins bei ganz anderen Themen sein; er braucht z.B. eine lebhafte Unterhaltung nicht bei jeder unbequemen Wegstelle zu unterbrechen.

Die T e l e o l o g i e dieser steuernden Gefühle ist also sowohl technischer wie ökonomischer Natur: das Gefühl garantiert zielgerichtetes Handeln und erspart personale Kraft, die nun für anderes frei wird.

Wir haben es hier mit jenen Tatbeständen zu tun, für welche oft die Ausdrücke "halb bewusst" oder ,unterbewusst" verwandt werden. Diese Bezeichnungen sind deswegen bedenklich, weil sie den Anschein erwecken, dass nur der Bewusstseins-Grad, nicht aber die Qualität des Erlebnisinhalts verändert sei. Darum spricht man von unterbewussten „Vorstellungen”, halbbewussten „Gedanken" u.s.w. (vgl. S. 110). In Wirklichkeit aber sind ü ber ha u pt keine Vorstellungen (der Weghindernisse) oder Gedanken (über die geeignetsten Schrittführungen) vorhanden, sondern nur ein hintergründiges Gefühl, aus dem o hn e $Z$ w is c h e $n g l$ i ed die Bewegungsregulierung hervorgeht. Der Umstand, dass dieses Gefühl bei schwierigen Hindernissen nicht mehr ausreicht, dass sich nun vielmehr aus ihm Vorstellungen, Gedanken, Wollungen abheben müssen, ehe es zur Weiterbewegung kommt - dieser Umstand gibt kein Recht, solche Inhalte gleichsam als verborgene Gebilde auch schon in das steuernde Gefühl hineinzuprojizieren.

Die Rolle steuernder Gefühle im menschlichen Leben kann

1) Vgl. das verwandte Beispiel S. 518 . 
nicht hoch genug eingeschätzt werden. Denn der menschliche Lebensweg besitzt, im grossen betrachtet, vornehmlich die Natur unseres obigen Wegbeispiels: nicht so einförmig und gleichmälsig, dass die völlig unbewussten Automatismen ausreichen könnten, aber doch nicht durchweg so fremd und hindernisreich, dass er nur mit voll abgehobenen Erkenntnis- und Willensfunktionen zu bewältigen wäre. Darum ist die Steuerung der Lebensvollzüge durch Gefühl geradezu die Hauptform der alltäglichen Lebensregulierung. Ob es sich um Essen und Ankleiden, um das Benehmen des Einzelnen in einer Gesellschaft, um Ausübung der Berufstätigkeit handelt: stets ist unterhalb der Plan- und Absichtserlebnisse, aber oberhalb der ganz bewusstseinsfreien Automatismen, jene Wachheit des Gefühls vorhanden, welche das Verhalten dem Wechsel der Situation anpasst.

Ich unterhalte mich mit einem Fremden, von dem ich nicht weifs, lais er etwas schwerhörig ist; plötzlich spreche ich lauter. Was ist ge$\therefore$ hehen ? Es braucht keinerlei bewusstes B e m e $\mathrm{rk}$ e $\mathrm{n}$ der Tatsache vorzuliegen, dass jener angestrengt lauscht oder ein ratloses Gesicht macht; auch keinerlei Willensimpuls meinerseits, die Stimme zu erheben - sondern nur ein gefühlsmälsiges Einschnappen des steuernden Verhaltens auf die Erschwerung des Gesprächs.

So unmittelbar erfolgt oft das Mitgehen der Verhaltungsschwankungen mit den Schwankungen des Zumuteseins, dass das e i n z e $1 \mathrm{n}$ e dabei beteiligte Gefühl garnicht zur Ausgestaltung von Qualitäten kommt; es ist schon durch die motorische Regulierung überholt und erledigt, noch ehe es sich etwa als ausgesprochen lustvoll oder unlustvoll dem Bewusstsein aufgedrängt hätte.

So lange also ein Gefühl und seine Erledigung durch steuerndes Verhalten innerhalb e in e $\mathbf{r}$ personalen Gegenwart liegen, ist Gefühls-T ö n u n g noch kaum vorhanden. Das wird nun ganz anders, wenn die beiden Glieder dieses Zusammenhanges zeitlich auseinandertreten. Dann knüpft sich das gegenwärtige Gefühlserlebnis an den $\mathrm{B}$ e s $\mathrm{t}$ a $\mathrm{n}$ d einer Gegebenheit, die nun als abgehobenes Bewusstseinsmoment objektiviert wird; das Gefühl nimmt an dieser Objektivation Anteil, ohne sie aber ganz mitzumachen; denn es bildet ja das Verbindungsglied zwischen jenem Objekt und dem Zumutesein der Person. Darum kann man die nun vorliegenden Tatbestände vom Subjekt oder vom Objekt her ausdrücken, wie folgende drei Beispielspaare zeigen. 
1) Schokolade schmeckt mir gut; - Schokolade hat einen angenehmen Geschmack.

2) Das Benehmen von $X$. wirkt abstossend; - $X$. hat ein hässliches Benehmen.

3) Ich fühle mich meinen Kameraden überlegen; - ich habe eine überlegene Stellung den Kameraden gegenüber.

Im ersten Glied jedes Beispielpaares ist das Gesamterlebnis wesentlich subjektivierender, im zweiten Glied objektivierender Art. Dadurch hat auch das Gefühl hier und dort ganz andere Erscheinungsweisen, nämlich das eine Mal als Gemütsreaktion der Person, das andere Mal als Gef ühls t on de s G e g e n$\mathrm{s} t \mathrm{a}$ d e s. Alles im Bewusstsein Abhebbare kann zum "Gegenstand" werden und damit Gefühlston erhalten, also nicht nur Dinge, sondern auch Ideen, Vorgänge, Handlungen, und nicht nur Gegebenheiten der Aussenwelt, sondern auch des eigenen personalen Seins (vgl. Beispiel 3).

Mit zunehmender Objektivierung verliert das Gefühl viel von seiner Ungestalt, Beweglichkeit und Labilität, aber auch von seiner Personnähe. Das subjektivierende Erlebnis „diese Schokolade schmeckt mir gut" kann bei gleich bleibendem Objekt, aber verändertem Zumutesein (z.B. bei Úbersättigung) von dem Erlebnis "Schokolade ist mir zuwider" abgelöst werden. Sage ich dagegen :, das ist eine besonders wohlschmeckende Schokolade”, dann binde ich die Annehmlichkeit desGeschmacks als feste Eigenschaft an das Objekt, kaum anders als die sensoriellen Eigenschaften der Bräune und der Süsse; und ich messe diese Eigenschaft auch dann der Schokolade zu, wenn ich sie im Augenblick nicht koste, oder wenn sie mir wegen Appetitlosigkeit heut nicht schmeckt. Schliesslich mündet dann die Gefühlstönung in eine hochobjektive, aber dafür personferne Beurteilung oder Wertung ein. Der Weinprüfer stellt feinste Gradabstufungen des „Wohlgeschmacks "fest; aber dabei handelt es sich kaum mehr um Verschiedenheiten seines $\mathrm{subjektiven} \mathrm{Zumuteseins,} \mathrm{sondern}$ um Beurteilung der sensoriellen Geschmackseigenschaften unter dem Gesichtspunkt ihrer g e n e r e ll e n Eignung zu Gefühlswirkungen.

Wieder erweist also hier das Gefühl seine eigentümliche Rolle als Mittler, nämlich jetzt als Mittler zwischen Gegenstandswelt und Person. „Gefühlston" kann eben mehr G e f ü h 1 der Person 
zu den Gegenständen, oder mehr $\mathrm{T}$ o $\mathrm{n}$ des Gegenstandes in Bezug auf die Person sein. An den Polen dieser Skala verflüchtigen sich hier die Gegenstandsbeziehung, dort die Personbeziehung zu blassen Schemen.

\section{VORGREIFENDE GEFÜHLE}

\section{Gef üh 1 als Vorstufe}

Betrachtet man das Bewusstseinsgeschehen $\mathrm{g}$ e $\mathrm{n}$ e $\mathrm{t}$ is $\mathrm{ch}$, so stellen die Gefühle gegenüber den abgehobenen Bewusstseinsbeständen eine frühere Stufe dar.

Dies gilt zunächst für die a $11 \mathrm{~g}$ e m e in e En t w i c k l u n d e s M e n s c h e n. Wenn wir es überhaupt wagen dürfen, für die allerersten Spuren von Bewusstsein im Neugeborenen (und vielleicht schon im Embryo) eine Bezeichnung zu brauchen, dann nur die des völlig gestaltlosen, dumpfen Zumuteseins, dessen Schwankungen zur Steuerung notwendiger Verhaltungsänderungen dienen. Abgehobene Bewusstseinsinhalte fehlen zunächst noch ganz; und es ist ein langer Prozess, in dem sich aus jenem psychischen Urnebel allmählich vereinzelte Ballungen und Gestalten herausheben: als Wahrnehmungen, Vorstellungen, Wollungen ${ }^{1}$ ).

Entsprechendes findet sich auch weiterhin bei allen Entwicklungsübergängen und Neuanfängen. Ehe das Neue zur vollen Bewusstseinsreifung, und damit zu der notwendigen Abhebung und Durchstrukturierung kommt, me ldet es sich vor in gefühlshaften Zuständen der Unbefriedigtheit, der inneren Unrast, der noch ziellosen Sehnsucht. Genauere Schilderungen solcher Entwicklungszüge liegen namentlich für die beginnende Pubertätszeit vor; der sogen. „Weltschmerz” ist ein höchst unruhvolles und peinvolles Zumutesein, für das weder ein Grund noch ein Ziel im Bewusstsein ist, und das erst langsam durch inhaltbestimmte Bedürfnisse, Strebungen und Interessen abgelöst wird.

Die Vorherrschaft dieses eingebetteten Gefühlserlebens ist eines der Hauptmerkmale, durch welche sich primitivere Bewusstseinsstufen von höher entwickelten unterscheiden. Wenn ein reifer gebildeter Mensch hoher Kultur mit einem Primitiven in Berüh-

1) Vgl. auch S. $168 \mathrm{ff}$. 
rung kommt, kann sich eine unüberwindliche Schranke gegenseitigen Verständnisses eben daraus ergeben, dass für den ersten Vieles als abgehobenes Bewusstseinsgeschehen abläuft, was beim zweiten aus dem tiefen Strombett des Gefühlslebens noch garnicht ausgegliedert ist. Der exakten Beobachtung und dem logischen Gedankenablauf des einen steht bei dem anderen die Einsenkung der Sinneseindrücke und der Gedanken in die magischen Schichtenbezüge des eigenen Ich oder des Stammes gegenüber; wo der kultivierte Mensch das Handeln nach überlegtem Plan, nach Rechtsnormen und Moralgrundsätzen reguliert, handelt der andere aus der Instinkt- oder Traditionssicherheit eines, seiner Gründe nicht bewussten, Gefühls.

Der Vorstufencharakter des Gefühls zeigt sich aber ebenso bei allen kleinen und kleinsten Entwicklungen im menschlichen Leben, d.h. überall dort, wo ein einzelnes Lebnis einer gewissen Zeitdauer bis zu seiner vollen Entfaltung bedarf. Greifen wir auf das Beispiel von dem Zeugen vor Gericht zurück (S. 755) : was wir dort als verschiedene Arten seines Zumuteseins schilderten, können auch ebensoviele $\mathrm{Ph}$ a s e $\mathrm{n}$ seines Erlebens während des Prozesses darstellen; aus der diffusen Unbehaglichkeit des Beginns wird a $11 \mathrm{mählich}$ die differenzierte gefühlsbetonte Stellungnahme zu den Einzelheiten der Umgebung und zu den eigenen Aufgaben.

Weitere Beispiele: ich habe bei der Begegnung mit einem Menschen zunächst ein vages Bekanntheitsgefühl; erst langsam kommt es zu der bewussten Identifikation: das ist der und der. - Ähnlich geht es mit dem Fremdheitsgefühl, das bei verschiedensten unerwarteten Situationen über den Menschen kommt; aus dem ganz gestaltlosen Choc der Desorientiertheit wird das ruhigere Gefühl der Verwunderung; aus diesem arbeitet sich die Frage heraus:was ist geschehen? was liegt hier vor? - und die weitere Problematik: wie werde ich damit fertig ? Was erst nur Gefühl war, ist jetzt Nachdenken und Wollen geworden. - Einem ausgesprochenen Krankheitsbewusstsein mit lokalisierten Beschwerden und Schmerzen geht fast immer eine Periode diffusen körperlichen Unbehagens voraus.

2. Antriebs-und Ahnungsgefühle

Indessen handelt es sich bei alledem um mehr als blosse Aufeinanderfolge und Ablösung. Vielmehr liegt in der gefühlmä/sigen 
Vorstufe schon ein $\mathrm{Sinnbezug}$ a uf das, was kom$\mathrm{m}$ e $\mathrm{n}$ s o 11, eine Hindeutung, eine Vorbereitung, ja eine $\mathrm{V}$ orw e g n a h m e künftiger voluntativer und intellektueller Vorgänge. Im Gefühl liegt Vorgriff auf Willensziele, d.h. es hat Antriebscharakter - und Vorgriff auf Einsichtsergebnisse: d.h. es hat Ahnungscharakter.

a) Der A n trie b s c har a k te r der Gefühle hängt eng mit dem früher besprochenen Steuerungscharakter zusammen (s. S. 762). Nur dass die direkte Steuerung durch Gefühl ein ungeteiltes Gegenwartsgeschehen war; während jetzt das Gefühl selbst gegenwärtig, seine Erledigung durch Tat aber zukünftig ist.

Wir können hier grösstenteils verweisen auf die Ausführungen über die Vorbedingungen des menschlichen Handelns (Kap. XX u. XXI), denn dort stiessen wir fortwährend: bei den Instinkten, den Pedürfnissen, den Willensmotivationen, auf eine Beteiligung von Gefühlserlebnissen. Diese Gefühle, so verschieden sie sonst unter sich sein mochten, hatten das gemeinsame: dass sie eine Unfertigkeit, einen Drang zur Erfüllung, und damit eine vage Gerichtetheit enthielten. Die Entwicklung innerhalb solcher Gefühle geht auf Verstärkung des Dranges und auf Klärung der Gerichtetheit, bis der Drang zum gerafften Impuls und die Gerichtetheit zum eindeutigen Zielstreben werden kann.

Ein Beispiel für eine solche Entwicklung: Während ich einen Brief schreibe, fällt irgend etwas von meinem Schreibtisch herunter. Ich lasse mich zunächst nicht stören und schreibe weiter; aber unterhalb der, auf das Schreiben gerichteten, Gedanken und Handlungsvollzüge spüre ich eine unbestimmte Unruhe und einen $Z$ ug nach der ungefähren Richtung, in der der Gegenstand verschwand. Ich weiss weder, w a s gefallen war, noch den Ort, wo es liegt; das Gefühl ist also durchaus diffus - es hat aber in sich die $\mathrm{T}$ e $\mathrm{n} d$ e $\mathrm{n} z$, sich in Konstatierung und Tat umzusetzen. Denn schliesslich führt mich die steigende Unruhe dazu, dass ich das Briefschreiben unterbreche, Art und Ort des Gegenstandes festzustellen suche, und die Wollung und Handlung des Aufhebens vollziehe.

Die Antriebsgefühle haben also für den handelnden Menschen die Bedeutung von Sig n a le n. Damit erhält ein Gesichtspunkt, der von biologistischen Gefühlstheoretikern fälschlich 
zum alleinigen Erklärungsprinzip der Gefühle erhoben worden war, seinen Ort innerhalb einer umfassenderen Theorie.

Es gibt - man denke etwa an die Verkehrssignale - zwei Grundarten solcher Zukunftshinweise: Alternativ-Signale, die lediglich angeben, ob der bisher begangene Weg weiterhin fortgesetzt oder unterbrochen werden soll, - und Richtungssignale, welche eine neu einzuschlagende Richtung andeuten. Die ältere Signaltheorie der Gefühle hatte sich nur auf die alternativen Signale beschränkt, die nun mit der Lust/Unlust-Dimension der Gefühle in Beziehung gebracht wurden : Lust galt als das Locksignal zur Fortsetzung, Unlust als das Warnsignal zum Abbruch des bisherigen Geschehens (s. S. 719). Das ist richtig, aber nicht erschöpfend. Denn der Antrieb, der in den Gefühlen liegt, geht ja nicht nur auf Verlängerung oder Nicht-Verlängerung des gegenwärtigen Geschehens, sondern hat p r od u k tive Bedeutung, leitet neue Richtungen des Geschehens ein. Und diese künftigen Neuentfaltungen können so überwiegend den Antrieb bestimmen, dass dahinter der Bezug auf das bisherige Geschehen und dessen etwaige Fortsetzung ganz zurücktritt. Ins Erlebnispsychologische übertragen: die Lust/Unlustbetontheit kann mehr oder weniger irrelevant werden gegenüber der Richtungsbetontheit der Antriebsgefühle.

Um dies noch einmal an unserm Schreibtischbeispiel zu illustrieren: gewiss hat das Gefühl, das durch den heruntergefallenen Gegenstand verursacht wurde, einen Unlustton, der mich schliesslich veranlasst, die Schreibarbeit zu unterbrechen, um die innere Unrast zu beseitigen. Aber weit wesentlicher an jenem Gefühl ist der nicht näher beschreibbare $Z$ u g zu der Gegend des gefallenen Objektes hin und die damit verbundene Gerichtetheit auf Suchen und Aufheben.

Zu der Wirksamheit der Antriebsgefühle gehört nicht etwa notwendig ein Bewusstsein des Ziels, auf dessen Erreichung der Antrieb geht. Das Ziel kann, wie bei vielen instinktiven Handlungen, in ziemlicher Ferne und jenseits jeder möglichen Vorwegnahme durch Vorstellen und Denken liegen; und doch $f \ddot{u} h l t$ sich das Individuum angetrieben, in der Richtung auf jenes Ziel zu handeln. Ob ein Vogel sein Nest baut, oder ob der Wanderer an einer Kreuzung vieler Wege „instinktiv” den einen Weg wählt, jedesmal liegt vor: e in e gegenwärtige Gefühlsteuerung mit Zukunftstendenz ohne Zu- 
$\mathrm{k}$ u n f $\mathrm{t}$ b e w u s st s e i n. (So liesse sich, vom Gefühlserlebnis aus gesehen, die Instinkthandlung definieren).

Wahrscheinlich ist dies die einzige Form, in der beim $\mathrm{T}$ i e $\mathbf{r}$ die Zukunft überhaupt in das Erleben einzubrechen vermag. Anders beim Menschen. Das in die Zukunft vorgreifende Gefühl kann hier, gerade weil es sich nicht sofort durch Tat erledigt, das künftige Ziel als abgehobenen Bewusstseinsgegenstand herausstellen, wobei alle denkbaren Stufen der Klärung durchlaufen werden.

Als Antriebsgefühle dieser höheren Stufe sind alle spezialisierten, auf längere Sicht gerichteten $\mathrm{B}$ e d ü $\mathrm{r} f \mathrm{n}$ is s e anzusehen. Wenn mich Durst quält, den ich nicht im Augenblick zu stillen vermag, dann entsteht das mehr oder minder deutliche Vorstellungsbild eines zu nehmenden Trunkes (z.B. eines Schluckes frischen Wassers), während die einzelnen, zur Erreichung eben dieses Zieles erforderlichen Handlungsschritte noch garnicht abgehoben im Bewusstsein vorweggenommen werden, sondern der Leitung durch das Gefühl überlassen bleiben. Gelegentlich wird ein solches Handeln noch ,,instinktiv" genannt; doch unterscheidet es sich von den reinen Instinkthandlungen durch die Vorstellung des in der Zukunft liegenden Zieles.

b) Bei den a h n e n d e n Gefühlen ist das Zukünftige, das im Bewusstsein antezipiert wird, nicht person-eigene Tat, sondern passiv hinzunehmender $\mathrm{T}$ a $\mathrm{t}$ b e s $\mathrm{t}$ a $\mathrm{n} d$.

Beispiele:

1) Den eigentlichen Instinktvorgängen sehr nahe stehen jene Vitalgefühle, in denen sich kommende Witterungsumschläge vormelden. Bei Tieren sind solche im allgemeinen viel stärker ausgebildet; so zeigen manche Vögel längere Zeit vor einem Gewitter deutliche Verhaltungsänderungen (ängstliches Flattern, Aufsuchen von Schlupfwinkeln); sie reagieren also instinktmälsig auf Schwankungen der atmosphärischen Elektrizitätsspannungen, die für Menschen meist noch unterschwellig sind. Der Mensch hat ja im allgemeinen diesen engen Zusammenhang mit der Natur verloren; auch hat er andere Hilfsmittel der Wettervoraussage und Schutzmittel gegen das Wetter geschaffen, die jenen Instinkt überflüssig machen. Indessen gibt es Ausnahmen atavistischer Art: Menschen, deren äusserst verfeinerte Witterungs- 
Sensitivität nicht nur mit den jeweiligen Wetteränderungen mitgeht, sondern ihnen vorauseilt. Von der Sensitivität des Tieres unterscheidet sich die menschliche negativ dadurch, dass sie nicht notwendig $\mathrm{zu}$ antezipierenden $\mathrm{H}$ andlungen zu führen braucht, positiv dadurch, dass sie von antezipierendem $\mathrm{W}$ i s s e $n$ begleitet ist. Einem solchen Menschen ist es also vor einem Gewitter nicht nur ,anders zu mute", sondern dies sein Zumutesein b e d e u t e t ihm zugleich "kommendes Gewitter.".

2) Das (schon mehrmals erwähnte) allgemeine Unbehagen, das oft einer Krankheit vorangeht, ist etwa beim kleinen Kind noch ganz zukunftsunbewusst; nur der äussere Beobachter deutet die wahrnehmbaren Bekundungen des Unbehagens als Vorzeichen einer Krankheit. Für den reiferen Menschen aber wird aus der gefühlsmäIsigen Vorstufe zugleich ein bewusstes Zukunftssignal: er hat nicht nur das Gefühl des Schlaff- und Unfroh-S e in s, sondern des Krank-W e r d e n s.

3) Der Mathematiker Gauss äusserte einmal bei einer Beschäftigung mit einem mathematischen Problem: „Das Resultat habe ich schon, ich weiss nur noch nicht, wie ich dazu komme." Dieser Ausspruch ist sehr bezeichnend für das Mitwirken vorgreifender Gefühle bei $D$ e n k a b lä u f e n. Mag auch das Ergebnis durch viele früher vollzogene Denkprozesse vorbereitet sein, die G ewissheit, mit der sich jetzt das Ergebnis als objektive Wahrheit aufdrängt, ist darin nicht mitbegründet. Denn der Denker gibt ja selbst an, dass er den Beweis erst finden, die Gefühlsgewissheit durch Denkgewissheit nachträglich rechtfertigen muss. Aber der Gedanke, dass die logische Nachprüfung jenes vorweggenommene Ergebnis auch widerlegen könnte, kommt garnicht erst auf; der Denker ,hat” schon das Resultat, und nur das Wie des Weges, nicht das $\mathrm{Ob}$ des Zieles sieht er als die übrig bleibende Aufgabe an.

In allen diesen Fällen wird also das Gefühl zugleich als Gewahrwerden von Künftigem, als „A h n u n g” erlebt, die innerhalb des Bewusstseins keine Begründung hat, aber auch keiner Begründung bedarf; dem vorgefühlten Tatbestand kommt eben unmittelbare Evidenz zu. Die subjektive Gewissheit, dass ein Gewitter bevorsteht, eine Krankheit im Anzuge ist, das mathematische Resultat sich als richtig erwieisen wird, braucht um nichts geringer zu sein, als jene Gewissheit, mit der wir ein gegenwärtiges 
Gewitter, eine ausgebrochene Krankheit, ein denkmälsig begründetes Rechenergebnis als existent erfassen.

Die Scheidung von Antriebsgefühlen und Ahnungsgefühlen ist nun aber bei den meisten wirklichen Zukunftsgefühlen nicht rein durchzuführen. So ist in unserem Gauss-Beispiel das Resultat nicht nur vom Gefühl geahnt, sondern auch der nun einzuschlagende Denkweg zum Beweis jener Einsicht gefühlsmälsig dirigiert. Noch deutlicher ist die Verschmelzung von Ahnung und Antrieb im folgenden Beispiel.

4) Die sogen. „Liebe auf den ersten Blick” ist ein Gefühlserlebnis, bei dem die plötzlich einsetzende gegenwärtige Erfülltheit ebenso wesentlich ist, wie die Zukunftsbewusstheit. Dieser $\mathrm{Zu}$ kunftsbezug enthält untrennbar die $\mathrm{Ge}$ wissheit des $\mathrm{Zu}$ sammengehörens für immer (also „Ahnung”), wie die Bestimmung alles weiteren $\mathrm{Verhaltens}$ gegenüber der geliebten Person (also „Antrieb”).

Die Frage, welcher objektive Geltungswert jener $\mathrm{Ge}$ w is sheit gefühlsmälsiger Vorahnungen zukomme, geht uns hier nicht an, sofern es sich um die erkenntnistheoretische und weltanschauliche Seite des Problems handelt. Wohl aber ist die Frage nach Möglichkeit und Ursprung von $\mathrm{A} \mathbf{h} \mathbf{n} \mathbf{~ u ~} \mathbf{n} \mathbf{g}$ s$t$ ä u $s$ h ung en eine psychologische Frage. D a s s die subjektiv vorgefühlte Gewissheit durch den späteren tatsächlichen Gang der Ereignisse oft genug widerlegt wird, ist ja allbekannt. Der Forscher, der sich bei Aufstellung von Behauptungen und Hypothesen zu sehr ,,auf sein Gefühl verlässt”, der „Menschenkenner", der ganz dem ersten Eindruck vertraut, der Abergläubische, der seine „Ahnung” für sichere Prophezeiung nimmt, kann arge Enttäuschungen erleben.

Die ahnenden Gefühle haben nämlich z w e i Grenzen, deren Überschreitung zu Irrungen führt.

Erste Vorbedingung einer möglichen Vorahnung ist, dass das Künftige in der Entelechie der Pers on selbst seine Entwicklungskeime hat. Dieser Zusammenhang ist in dem Beispiel von der Krankheit, deren Vorbote ein Unbehagen ist, ohne weiteres deutlich. Er besteht aber auch bei äusseren, also scheinbar $\mathrm{t} r$ a n s per s o n a l e n Ereignissen. Das künftige Gewitter ist ein solches: es wird vorgeahnt nur von solchen Menschen, in de- 
nen die meteorologischen Vorstadien des Gewitters bereits eine Ånderung der vitalen Verfassung hervorrufen. Eine wissenschaftliche Entdeckung kann vorgeahnt werden nur von einem Gelehrten, in dem schon durch frühere Gedanken und Einsichten die auf jenes Endergebnis hinweisenden Wege vorbereitet sind. Selbst die Vorahnung eines U n g l ü c k s f a ll les kann so zu stande kommen. Ein Autolenker, dessen körperliche oder Aufmerksamkeitskräfte einmal aus irgend welchem Grunde nicht auf der Höhe sind, braucht von diesem seinem veränderten Zustand als g e g e n w ä r t i g e m kein Bewusstsein zu haben; der Zustand setzt sich vielmehr in ein $z$ u kunft s be $z$ ogenes Un sic h e r h e it s g e f üh 1 um: „heut wird mir etwas passieren". Und da der Zustand zugleich eine grössere Unfallsbereitschaft (etwa durch versagende Geistesgegenwart) mit sich bringt, da ferner jener Zukunftsglaube noch autosuggestiv die Unsicherheit steigert, so kann auch die Vorahnung sich als zutreffend erweisen.

Und bei Unglücksfällen anderer?

Beispiel: Eine Mutter hat das bestimmte Gefühl, dass ihrem Sohn heut beim Radeln etwas zustossen wird. Dafür gibt es verschiedene psychologische Vorbedingungen. Die Mutter ist heut (aus Gründen, die mit dem Sohn nichts zu tun haben) in einer besonders labilen Stimmung; und die sonstige Ängstlichkeit um das Kind nimmt deshalb heut besonders akute Formen an. Oder: Der Junge ist heut beim Weggehen besonders fahrig und aufgeregt; auch herrscht wegen eines Festes besonders starker Verkehr auf den Strassen. Die Mutter braucht jene Aufgeregtheit nicht ausdrücklich „,beachtet” zu haben und diesen Festverkehr nicht ausdrücklich zu ,bedenken”; dennoch wird ihr Gefühl dadurch bestimmt im Sinne der Zukunftsahnung.

Die andere Grenze ist durch die Vielde utigkeit der Zukunft gesetzt. An der konkreten Ausgestaltung des späteren Ereignisses im Einzelnen wirken zahllose Unstände mit, die mit der Entelechie der Person nichts zu tun haben. Die Person selbst stellt ja nur einen Teilfaktor in dem Konvergenzprozess dar, aus dem das künftige Ereignis hervorgehen wird. Dieser Vieldeutigkeit entspräche die Ungestalt des vorgreifenden Gefühls. Aber es bleibt nicht ungestaltet; vielmehr konkretisiert es sich zu einem vorgestellten $\mathrm{B}$ il d der Zukunft, und dadurch erhält diese eine harte Eindeutigkeit. Es entsteht ein G e wis s h e it s g e f üh 1 
das nicht nur der allgemeinen Richtung gilt, in die das zukünftige Geschehen projiziert wird, sondern der speziellen Ausgestaltung, in der es vorgeschaut wird. Jene ängstliche Mutter unseres letzten Beispiels „fühlt" nicht nur, dass ihr Sohn unsicherer radeln und dadurch stärker bedroht sein wird, sondern sie ,sieht" ihn schon unter den Rädern eines Autos liegen.

Diese naive Identifikation von geahnter Richtung und vorgestellter Eindeutigkeit ist die primitivste Form des Vorgreifens. Es ist schon ein weiterer Schritt zur Objektivation, wenn eine solche Ausweitung der Gewissheit nicht stattfindet, wenn vielmehr die Vagheit des Vorgefühls in Ungewissheit der Vorerkenntnis, also in V e r m u t u n g, umgesetzt wird. Der Ausdruck ,Vermutung" ist sehr kennzeichnend. Es handelt sich nicht um eine Annahme, deren Wahrscheinlichkeitsgrad rein aus logischen Arsumenten ableitbar wäre, sondern um ein ,Zumutesein": als ob (lies oder das eintreten könnte. Die Unbestimmtheit stammt nicht aus der Logik, sondern aus dem Gefühl.

Noch ein Schritt weiter, und nicht einmal vermutungsweise wird eine konkrete Zukunftsbeschaffenheit vorweggenommen, sondern lediglich die Tendenz, eine solche zu suchen; sie tritt auf als „Frage”. Überden Ursprung solchen echten Fragens und aller wissenschaftlichen Problematik aus dem Gef ühlszustande der Desorientiertheit und Verwunderung ist ja schon an anderer Stelle ausführlich gesprochen worden; wir können darauf verweisen (S. 386/7).

\section{Erwartung. Furcht. Hoffnung}

Waren die bisher besprochenen vorgreifenden Gefühle auf die objektive Zukunft einer Eigentat oder eines Ereignisses gerichtet, so beziehen sich die nun zu erörternden Gefühle auf die subjektive Zukunft der eigenen Zuständlichkeit. Un e r f ü $11 \mathrm{t} \mathrm{h}$ e i t wird erlebt; kommende Erfüllung wird vorgef $\ddot{u} h l t$.

a) Im Erwartungsgef üh 1 erlebt der Mensch eine eigentümliche Zeitverschiebung seiner selbst. Die Gegenwart ist nichts als Vorstufe, Gespanntheit nach vorn hin. Der Mensch lebt ,eigentlich" schon in der Zukunft, obgleich deren Wann und Wie 
noch vieldeutig ist. Vereindeutigung und damit Entspannung und Abschluss werden angestrebt. Wenn der Volksmund von der schwangeren Frau sagt, sie sei „In Erwartung”, so drückt er damit treffend aus, dass ihre seelische Verfassung ganz Zukunftsgerichtetheit des Gefühls ist.

Das erwartete Erlebnis hat für den Erwartenden starke p e rs o n a le $\mathrm{N}$ ä h e, unabhängig von dem objektiven Zeitabstand. Es gibt Menschen, die schon in relativ jungen Jahren ihren Tod „erwarten", andere, die noch als alte Leute diese Erwartung kaum fühlen.

Auch die Abhebungsgrade des erwarteten Tatbestandes können sehr verschieden sein. Für das Kind, das zum ersten Male im Theater vor einem geschlossenen Vorhang sitzt und das unbekannte Märchenspiel erwartet, ist das Gefühl eben wegen seiner Ungestaltetheit viel eingebetteter und damit erregender, als das des Erwachsenen, der ein ihm wohlbekanntes Stück sieht und nun bestimmte Szenen und Textstellen erwartend vorwegnimmt.

Der Unterschied besteht auch $\mathrm{t}$ y p e $\mathrm{n}$ psychologisch. Manche Menschen, besonders jugendliche, sind ständig ,,in Erwartung" von irgend etwas, das aber durchaus unbestimmt ist; es ist fast das rein gestaltlose Zumutesein fehlender Erfülltheit. Andere Menschen sind so wirklichkeitsverhaftet, dass sie Erwartungsgefühle nur gegenüber solchen Zukunftsvorgängen kennen, die mit hochprozentiger Wahrscheinlichkeit und in weitgehend vorauszusehender Form eintreten dürften.

Der in der Erwartung liegende starke Antrieb zur Erfüllung und Entspannung kann leicht zu Kurzschlüssen führen: Erw a $r$ t u n g s s u g g e s $t$ i o $\mathbf{n}^{\mathbf{1}}$ ). Der am Platz des Stelldicheins wartende hält jede in weiter Ferne auftauchende Person für die erwartete. Der Schiffbrüchige auf treibendem Wrack glaubt immer wieder am fernen Horizont eine Rauchwolke oder ein Segel zu sehen.

In Hinblick auf die Lust/Unlust-Dimension ist die Erwartung neutral; es gibt ängstliche, es gibt freudige, es gibt auch eine indifferente Erwartung, die nichts als Spannung ist. Wo Lust oder Unlust dem Unerfülltheitserlebnis einen ausgesprochenen Akzent geben, haben wir es mit Hoffnung und Furcht zu tun.

1) s. S. 633 . 
Deshalb sind Hoffnung und Furcht noch weniger objektivierend als Erwartung; die objektive W a h r s ch e in li ch ke it des künftigen Ereignisses spielt eine weit geringere Rolle. So mancher erhofft das grosse Wunder, das wider alle Erwartung eintreten soll; ein anderer „,sieht Gespenster”, d.h. fürchtet Ereignisse, für deren Eintreten kein plausibler Grund vorliegt.

Die beiden Gefühle sind übrigens, entwicklungspsychologisch betrachtet, nicht von gleicher Ursprünglichkeit; denn Hoffnung setzt, auch in ihrer einfachsten Erscheinungsform, eine gewisse $\mathrm{V}$ orste $11 \mathrm{u}$ g des künftigen Zustandes, also Abhebung voraus.

Anders die Furcht.

b) Die Quelle, aus der F u r c h t entspringt, ist ein schlechthin unlustvolles Zumutesein der Unsicherheit, des Nicht-Fertigwerdens mit Leben und Welt, noch unabhängig von irgend einer b e s $t$ i $m$ m t e $n$ für die nächste Zukunft drohenden und vorgestellten Gefährdung. Es ist erforderlich, hier auch sprachlich zu sondern und jenes gestaltlose Zumutesein als "A n g s t” von der gegenstandsbezogenen „Furcht” zu unterscheiden. Man ängstigt $\mathrm{s}$ i $\mathrm{ch}$, aber man fürchtet e $\mathrm{t} \mathrm{w}_{\mathrm{a}} \mathbf{s}^{\mathbf{1}}$ ). Ein wichtiges Ingrediens der Angst ist die Beklommenheit, die physiologisch (z.B. durch Unregelmälsigkeiten der Zirkulation) bedingt ist. Aber diese allein würde ja nur eine gegenwärtige Unlust bedeuten, während in der Angst doch schon der (freilich noch unspezifizierte) Zukunftsbezug steckt; man ängstigt sich nicht vor dem, was ist, sondern vor dem, was kommt. Angst ist der erste dumpfe Bewusstseinsniederschlag jener personalen Grundtatsache der W eltf r e $\mathrm{m} \mathrm{d}$ h e i t : dass der Mensch seiner Welt nie völlig eingepasst, in ihr nie absolut heimisch ist, dass vielmehr in jedem Augenblick sein Weiterexistieren in ihr zweifelhaft ist und neu erkämpft werden muss.

Spezialisiert sich dies Gefühl der Weltfremdheit auf einen sich abhebenden A us chn it t der Welt, dann wird daraus das Gefühl der Unheimlichkeit und damit die einfachste Form der Furcht. In einem völlig dunklen Raum z.B., der sich weder als der altbekannte noch als ein offenkundig anderer gibt, fehlt dem Kinde das umhegende Gehäuse, jene überschaubare

1) Vgl. Psychol. d. fr. Kindheit, S. 444 ff. 
personnahe Zwischensphäre zwischen sich und der Ferne; darum ist die Dunkelheit für das Kind „unheimlich”. Es fehlt aber damit auch die Möglichkeit zu abgehobener Einstellung auf das, was bevorsteht: darum erweckt das Unheimliche Furcht. $\mathrm{Zu}$ dieser ersten Furcht gehört also noch nicht das Wissen um eine bestimmte Gefahr, sondern nur die Beunruhigung der personalen Nähe, die Unmöglichkeit angemessener Steuerung des Verhaltens.

Wenn ein $1 \frac{1}{2}$ jähriger Knabe vor einem Regenschirm, der plötzlich in seiner unmittelbaren Nähe in der Richtung auf ihn aufgespannt wird, schreiend fortläuft, so haben wir ein solches unheimliches Erlebnis vor uns. Er fürchtet den Schirm nicht, weil er schon einmal etwas Unangenehmes mit ihm erlebt hätte, sondern weil da plötzlich etwas Grosses, Fremdes die Selbstverständlichkeit des Daseins durchbricht und darum als unbestimmte Drohung wirkt ${ }^{1}$ ).

Die Furcht vor dem Unheimlichen stellt einen personalen Gegenpol dar zu jenem Drange der Menschen, der ihn gerade zu Fremdem, Neuem hindrängt: Neugierde, Abenteuerlust u.s.w. Sie ist eine Art Schutz oder doch Bremsvorrichtung gegen das hemmungslose Sicheinlassen mit dem Unbekannten ${ }^{2}$ ).

Auf eine eigenartige Spezifikation der Unheimlichkeitsfurcht muss noch besonders hingewiesen werden. „Unheimlichkeit" kommt nämlich nicht allem gleichmäIsig zu, was nicht ins "Heimische", Vertraute passt; vielmehr gibt es — zum mindesten beim Tiere - eine erblich bedingte Unheimlichkeitsauslese (,S pezifische Erbfurcht”). Uber einen Hühnerhof mit ganz jungen Küken mögen vielerlei Vögel hinwegfliegen, die alle nicht zur „Welt” der Küken gehören, und deren Fremdheit in keiner Weise die Küken berührt. Nun aber taucht ein Habicht am Himmel auf: und sofort zeigen die Küken offenbare Zeichen von Angst und suchen einen Schutz. Sie haben vorher nie einen Habicht gesehen und haben weder direkte noch indirekte Erfahrungen über seine Gefährlichkeit machen können, trotzdem ist er, und nur er von allen Vögeln, ihnen ,unheimlich". Die Erfahrungsunbedürftigkeit und der zweckmärsige Antriebscha-

\footnotetext{
1) Weitere Beispiele für diese frühe Furcht vor dem Unheimlichen: Psychologie der frühen Kindheit, S. 450 ff.

2) Auf diese biologische Bedeutung der Unheimlichkeitsfurcht hat zuerst Karl Groos hingewiesen.
} 
rakter dieses Furchtgefühls reiht es in die Gruppe der in$\mathrm{s} t$ in $\mathrm{k} t$ ive $n$ Gefühle ein.

Die Frage, ob es beim Mneschen ebenfalls die spezifische Erbfurcht gibt, ist noch ungeklärt. Die Fürchte vor Dunkelheit und vor Gewitter scheinen nicht dazu zu gehören; sie fehlen bei manchen Kindern durchaus, sind auch, wo sie auftreten, sehr wohl als allgemeine Unheimlichkeitsfurcht oder als Suggestionswirkung zu erklären (vgl. unser obiges Beispiel vom dunklen Zimmer). Am ehesten könnte die Furcht vor wilden Tieren, die sich auch im zoologischen Garten, trotz der Gefahrlosigkeit, einstellen kann, hierher zu rechnen sein. Den Ausdünstungen und dem Gebrüll dieser Tiere kommt wohl eine spezifische Unheimlichkeit zu; das hierdurch erzeugte Gefühl ist vielleicht ein atavistischer Nachhall aus den Zeiten, da diese Tiere reale Furchtquellen für die Menschen bedeuteten (Hypothese von Stanley Hall).

Oberhalb der bisher geschilderten Arten des Furchtgefühls steht nun die eigentliche Erfahrungsfurcht: die gefühlsmälsige Vorwegnahme einer bekannten Bedrohung. Das unerfahrene Kind greift noch arglos in die Flamme; nur ,gebranntes Kind scheut das Feuer". Hier ist also der künftige Tatbestand sehr weitgehend abgehoben: es wird etwas Bestimmtes b e-fürchtet. $\mathrm{Ob}$ dies auf Grund direkter oder indirekter Erfahrung geschieht, ist für das Wesen dieser Furcht gleichgültig. Die Furcht vor dem Zahnarzt ist „empirisch" - mag man selbst schon einmal die Unannehmlichkeit zahnärztlicher Behandlung verspürt oder nur durch andere davon gehört haben.

Hier muss nun freilich ein Missverständnis vermieden werden, das aus der alten Assoziationspsychologie stammt. Danach wäre die Furcht vor dem Zahnarzt die Vorwegnahme des bevorstehenden Schmerzgef üh ls ${ }^{1}$ ) auf Grund der früheren Erfahrungen. Davon ist keine Rede. Man denke nur an das häufige Erlebnis nach Ablauf des gefürchteten Tatbestandes: „Es war lange nicht so schlimm, wie ich gefürchtet hatte". Furcht ist ein Unlustgefühl a n d e r e r Art, als jene Unlust, die dann dem Tatbestand selbst, wenn er eintritt, anhaftet. Diese „andere Art” lässt sich natürlich nur umschreiben. Die Furcht ist zunächst viel weniger gestaltet als das gefürchtete Präsenzgefühl. Gerade durch

\footnotetext{
1) Man beachte den Unterschied gegenüber unserer Formulierung zu Beginn des vorigen Absatzes.
} 
ihre Ungewissheit, Vieldeutigkeit und unbestimmte Dauer wird sie so quälend - während das gefürchtete Ereignis selbst nachher zeitlich und qualitativ scharf determiniert und daher auch in seinem Gefühlsniederschlag anders strukturiert ist. Ungewissheit und Vieldeutigkeit aber geben der Furcht nun die Tendenz, über das früher tatsächlich Erfahrene hinauszugehen und das zu Befürchtende a u z uma len. Es spielt also neben dem Gedächtnis die $\mathrm{Ph}$ a $\mathrm{n}$ a s i e eine bedeutende Rolle; ja wir können diesen Satz geradezu umkehren: Das Fürchten ist (neben dem Wunsche) der Hauptmotor für die Betätigung der Phantasie ${ }^{1}$ ).

Mag die objektive Gefährdung noch so sehr vorwegnehmende Gefühle der Furcht rechtfertigen, mag eine weitgehende Erkenntnis der bevorstehenden Lage den Rahmen für den Furchtinhalt liefern: die Intensität des Gefühls, die Rolle, die es im Lebensvollzug spielt, und die Ausmalung, die der Inhalt erfährt, ist doch weitgehend durch die subjektiv-personalen Faktoren bedingt: durch das angstvolle Zumutesein und durch die spontane Phantasiearbeit, die dieser Angst eine Art intellektueller Selbstrechtfertigung verleiht.

Deshalb gibt es auch eine personale $D$ is $p$ o $n$ ie $r t h$ e it $z u$ Angst- und Furchtgefühlen, die Ängst li chkeit. Und es gibt krankhafte Abartungen dieser personalen Zustände: eine allgemeine, jede Daseinsfreude und jeden Mut zur Aktivität erstickende Lebensangst (Depression); und dann wieder grundlose Befürchtungszustände, die sich auf ganz bestimmte Gegenstandsbereiche beziehen: „P h o b i e n”. Es ist nicht zufällig, dass diese phobischen Gegenstandsbereiche sich zumeist decken mit den früher erwähnten Sphären der Unheimlichkeit : so Räume, die ihre Vertrautheit verlieren (Platzfurcht) und bestimmte Tiere (z.B. Hunde-Phobie). Vermutlich wird eine allgemeine krankhafte Angst die gegenstandslos ist oder ihren ursprünglichen Gegenstand verloren hat, s p e $z$ i f i $z$ i e $r t$ in der Richtung des geringsten Widerstandes, d.h. an Objektsphären gehängt, für welche anlagemälsig eine besondere Bereitschaft zu Furchtreaktionen vorhanden ist.

Wir verfolgten die Abhebungs- und Objektivationsskala der Furchtgefühle von der gegenstandslosen Angst über Unheimlichkeitsgefühl und spezielle Erbfurcht bis zur Erfahrungsfurcht;

1) Vgl. S. 462 . 
die Skala hat dann noch eine letzte Stufe: die Sorge. Auch Sorge ist ein zukunftgerichtetes Unlustgefühl; doch tritt hier an die Stelle akuter Erregtheit eine länger anhaltende zehrende Spannung. Die geringere Gewaltsamkeit und längere Dauer des Gefühls ermöglicht eine viel reichere Struktur der begleitenden Abhebungen, und zwar sowohl der intellektuellen wie der willensmälsigen. Aus dem "Sich um jemanden sorgen”, das noch der Furcht nahe steht, wird das „Für ihn sorgen”, das ganz überwiegend ein Denken und Handeln ist. Es kann hier sogar zu einem Umschlag der Gefühlsbetonung kommen: die Sorge, welche eine Mutter ständig ihren Kindern widmet, kann ganz frei von unlustvoller „Besorgnis”, kann durchaus freudig sein.

c) Der Gegenpol der Furcht, die $\mathrm{H}$ of $\mathrm{f} \mathrm{n} \mathbf{u} \mathrm{n}$, spielt als E r l e b n i s-Bestand lange nicht die Rolle, wie die Furcht. Beim Tier scheint Hoffnung als zukunftgerichtetes Gefühl ganz zu fehlen, während doch die Furcht schon recht stark ausgebildet ist. Das men s chli che Leben schwankt ja dauernd zwischen Furcht und Hoffnung; aber die Furcht stellt sich nicht nur, wie schon erwähnt, entwicklungsmälsig früher ein, sondern sie hat auch dort, wo sie sich mit Hoffnung mischt oder abwechselt, den wuchtigeren Erlebnisakzent. - Wie ist dies zu interpretieren? Naheliegt eine pessimistische Ausdeutung: es gebe im menschlichen Leben eben viel mehr zu fürchten als zu hoffen. Aber eine solche Begründung transponiert das Problem aus dem subjektiven Erleben in die objektiven Bedingungen des Lebens, und eine solche Transposition ist bei beiden Gefühlen nicht gleichsinnig möglich. Denn die objektiven Ziele der Hoffnung sind grossenteils auch die objektiven Ziele des Planens und Wollens, während die objektiven Gegenstände des Befürchtens der eigenen Aktivitätsrichtung zuwider sind. Deshalb fühlt sich der Mensch dem Trem e n $\mathrm{d} u \mathrm{~m}$ ausgeliefert und preisgegeben, ehe er sich zuaktivem Gegenstoss aufraffen kann; und er reagiert gefühlsmäfsig mit dem Zumutesein von Angst, Furcht und Sorge. Das S p e r a n d u m dagegen ist zugleich weitgehend das Appetendum; Zukunftsziele, deren Erreichung uns wahrscheinlich ist, werden nicht nur erhofft, sondern auch g e w o $11 \mathrm{t}$. In der Aktivität des Wollens aber, mitsamt den dazu gehörigen Denkoperationen, Entscheidungen u.s.w., bleibt nur wenig Platz für ein selbstän- 
diges und ausgedehnteres Vorwegnehmen der gleichen Ziele im blossen Gefühl, also für Hoffnung.

Für den tätigen Menschen ist es selbstverständlich, dass er die Erreichung seines Zieles erhofft; als ge s o ndertes Gefühlserleben kann diese Hoffnung eigentlich nur in den Pausen des Tuns auftreten und in Bezug auf diejenigen Faktoren des Geschehens, die dem eigenen Wollen entzogen sind. Deshalb haben fast alle Grossen der Geschichte stets auf ihr Glück, auf ihren Erfolg gehofft - aber eigentlich so, dass die Hoffnungen sie nicht stark beschäftigten, weil sie für Gefühle eben wenig Zeit hatten.

Intensiv hoffen kann daher nur der Mensch, der vorwiegend p a s s i v ist, oder in Lagen, die ihn zur Passivität verurteilen. Träumernaturen spinnen ihre Hoffnungen zu bunten Geweben aus - aber versäumen darüber das Handeln in der Richtung auf die erhofften Ziele. Frauen, die ihre Männer in den Krieg ziehen lassen mussten und die nichts Positives zum Schutz der Männer tun können, haben nichts Anderes als ihre Hoffnungen, die ihr Erleben unablässig beschäftigen. Aber gerade dieses Beispiel zeigt, dass die Hoffnung als solche kein reines Lustgefühl ist. Denn die dem eigenen Wollen entzogenen Faktoren können ja die Erreichung des Zieles ebenso vereiteln wie fördern; das passive Hoffen ist daher zugleich ein Fürchten. Der Fall, dass sich die Hoffnung zur Gewissheit der Ahnung verdichtet ,ich werde ihn wiedersehen", ist seltener als der umgekehrte Fall: dass die Furcht alle anderen Gefühle überschattet und auch kein Hoffen mehr aufkommen lässt.

Aber diese Wechselbeziehung von Hoffnung und Furcht hat auch ihre positive Wirkung, die S u b l i m i e r u n g der Furcht. Es ist ein Kennzeichen des $\mathrm{mens} \mathrm{ch} \mathbf{l} \mathrm{i} \mathrm{ch}$ en Fürchtens im Gegensatz zum tierischen, dass es durch Hoffen gemildert, vergeistigt und schliesslich überwunden werden kann. Das gilt im einzelnen und im ganzen. Denn wenn wir oben die „Lebensangst" als ein den Menschen durchströmendes und peinigendes Urgefühl bezeichneten, so müssen wir hier daran erinnern, dass derMensch dieser Totalangst auch eine $\mathrm{T}$ o $\mathrm{t}$ a $\mathrm{l}$ h of $\mathrm{f} \mathrm{n} \mathrm{u} \mathrm{n}$ gegenüberzustellen vermochte: die Hoffnung auf Lebenserfüllung und auf Unsterblichkeit. 


\section{RÜCKGREIFENDE GEFÜHLE}

\section{Positive Gefühlsbeziehungen zur Vergangenheit}

Die Skala: Unbewusstheit - Gefühl - abgehobene Bewusstheit wird nicht nur in $\mathrm{d}$ i e s e $r$ Reihenfolge durchlaufen, sodass das Gefühl die Vorstufe für die stärker strukturierte und objektivierte Erlebnisweise ist, sondern auch in der $\mathrm{u} \mathrm{m} \mathrm{g} \mathrm{e} \mathrm{k} \mathrm{e} \mathrm{h} \mathrm{r} \mathrm{t} \mathrm{e} \mathrm{n.}$ Was irgend einmal da gewesen war als abgehobener Bestand: als Erfahrung, Gedanke, Wollung, Handlung, sinkt ab in tiefere Schichten der Person, bettet sich ein, wird unbewusst. Aber mitten auf diesem Wege zur völligen Unbewusstheit liegt das eingebettete Gefühls-Erleben. Die mnemischen Nachwirkungen früheren Geschehens machen sich ja zum Teil rein automatisch, also unbewusst, geltend: in erworbenen Reflexen, Gewöhnungen und Anpassungen; aber dort, wo sie noch eben das Niveau des Bewusstseins streifen, oder wo sie durch irgend einen Anlass in Bereitschaft sind, wieder bewusst zu werden, regen sie sich als $\mathrm{Ge}$ fühle.

So reicht die gef üh $1 \mathrm{~s} m$ ä $\int \mathrm{sige} \mathrm{Verkn} \mathrm{üpfung} \mathrm{der}$ Person mit ihrer Vergangenheit viel weiter und greift viel tiefer als jene Beziehungen, die durch ein Wissen um jene Vergangenheit geschaffen werden. Der Zusammenhang des erwachsenen Menschen mit seiner Kindheit, und jedes Individuums mit seinen Vorfahren, seinem Stamm, seinem Volk, seiner Gemeinschaft, seiner Heimat ist ihm nicht nur durch Erinnerung, durch gewusste Geschichte, durch gemeinsame Ideale, durch bestimmte Bräuche, Sitten, Pflichten, - also durch abgehobenes Erkennen und Handeln - gewährleistet, sondern in viel elementarerer Weise durch Gefühle, mögen sie auch noch so wenig Gestalt besitzen.

Auch hier steht am Anfang ein ganz vages, gegenstandsloses Zumutesein: das Vert ra u theit s g e f üh l. Die ständige Umgebung ist dem Menschen zwar, solange er in ihr tätig und durch bestimmte Einzelziele absorbiert ist, nicht bewusst gegenwärtig. Aber jedes kleinste Nachlassen aktiver Anspannung lässt dieses Ruhen im Bekannten, diese Verknüpftheit mit dem Liebgewordenen fühlen, wobei noch garnicht Einzelheiten abgehoben 
zu werden brauchen. Besonders lebhaft aber wird das Gefühl bei Umgebungswechsel, ja selbst bei einem nur gedachten (erst wenn man erwägt, seinen Wohnort $\mathrm{zu}$ wechseln, merkt man, wie sehr man mit der bisherigen Umwelt verwachsen war). Umgekehrt bricht bei Heimkehr aus der Fremde das Vertrautheitsgefühl mit starker Intensität hervor; das Wohlgefühl, nach längerer, noch so schöner Reise ,wieder daheim zu sein”, beruht nicht etwa nur darauf, dass man bestimmte Behaglichkeiten, die man unterwegs vermisste, jetzt wieder geniessen kann; diese Spezialfreuden ruhen vielmehr in dem viel allgemeineren Gefühl des „Zu-mirGehörens" der Umgebung, die durch den früheren Kontakt mit mir geradezu ein Stück meiner Persönlichkeit geworden war.

Wie ursprünglich dies Vertrautheitsgefühl ist, zeigt das ganz kleine Kind, das schon in den ersten Lebensmonaten der Mutter gegenüber ein durchaus anderes Ausdrucksverhalten bekundet als zu fremden Menschen, und $z$ war bereits in einer Zeit, in der sicher noch keinerlei "Erinnerung" an die früheren Begegnungen mit der Mutter vorhanden sind. - Ein 2-3 jähriges Kind begrülst nach Heimkehr von mehrwöchiger Reise jubelnd sein Zimmer und sein Bettchen, obwohl es draussen diese Dinge garnicht offensichtlich vermisst hatte und auch jetzt beim Wiedersehen kein Verständnis für die dazwischen liegende Abwesenheit hat ${ }^{1}$ ).

Das Vertrautheitsgefühl hat verschiedene Gegenstandsbereiche.

M e n s c h e n gegenüber führt die Vertrautheit zu Anhänglichkeit und $\mathrm{L}$ i e b e. Freilich zu einer Liebe ganz bestimmter Art. Die „Geborgenheitsliebe” des Kindes zur Mutter oder auch zur Pflegerin ist - als rückgreifendes Gefühl - durchaus verschieden von der Liebesform der „Erotik”, die das Neue, Fremde, erst zu Enthüllende sucht ${ }^{2}$ ). - Aber auch zwischen Erwachsenen gibt es jenes Gefühl des Zueinandergehörens, das wesentlich auf einer Zeitwirkung beruht. Das Phaenomen der Tre u e ist grolsenteils aus solchen rückgreifenden Gefühlswirkungen zu erklären.

In $\mathrm{r}$ ä u $\mathrm{m}$ i ch er Hinsicht wird das Vertrautheitsgefühl

1) Vgl. über das Vertrautheitserleben auch S. 278. - Viele Beispiele zur Frühentwicklung des Vertrautheitsgefühls in C.u.W. Stern, Erinnerung, Aussage u.s.w.

2) Das gemeinsame Wort „Liebe" hat die Psychoanalyse dazu geführt, die beiden sehr verschiedenartigen Gefühlweisen für identisch zu balten. 
zum „H e i m g e f ü h l”. An diesem Gefühl wird es deutlich, dass im Personalen Räumliches und Zeitliches aufs Engste zusammenhängen. Denn die besondere Raumbeziehung, die hier gefühlt wird, s t a $\mathrm{m} \mathrm{m} \mathrm{t}$ ja aus dem Zeitlichen, aus der unlösbar gewordenen Beziehung zum lange Zeit Dagewesenen. Der Mensch bedarf einer Sphäre, in der er sich „heimisch” fühlt; er erlebt sie als eine Erweiterung seiner körperlichen Existenz, als das sichernde Bindeglied zwischen seinem nackten personalen Selbst und der fremden Welt. Oder vielmehr: es ist ein Inbegriff von vielen Sphären verschiedener Weite. In einer bestimmten, gewohnten Kleidung fühlt man sich heimisch, in einer anderen unbehaglich, sich selbst entfremdet. Die dauernde Wohnstätte wird durch das Vertrautheitsgefühl zum „Heim”. Das weitere Feld bevorzugten Aufenthalts und regelmälsiger Betätigung wird zum „Lebensraum" 1). Die weiteste Sphäre ist die „Heimat”, die den gefühlsmäfsigen Hintergrund für alle einzelnen Vertrautheiten bildet.

Endlich kann sich das Vertrautheitsgefühl an das $\mathrm{G}$ e s c h e$h$ e n knüpfen, sei es an das eigene Tun, sei es an das Leben, das den Menschen umgibt. Die Rückkehrfreude aus der Fremde in die Heimat ist nicht nur eine solche des Wiedersehens der vertrauten Umgebung, sondern auch die Genugtuung über das Wiederaufnehmenkönnen der gewohnten Verrichtungen, über das Umspültwerden vom heimischen Dialekt, und das Wiedereingegliedertsein in die bekannten Bräuche.

In seiner elementarsten Form ist das Vertrautheitsgefühl durchaus a t m os phäris cher Natur, eine Gesamtstimmung, in welche die besonderen Gefühlstöne der wahrnehmbaren Menschen, Dinge und Geschehnisse noch ungeschieden eingebettet sind. Normaler Weise ist sich der Mensch dessen nicht bewusst, w a s ihn so einzigartig an seine Heimat fesselt, w a r u m sie einen so ganz anderen Gefühlston hat als jede andere, selbst die schönste, Gegend. Sobald er aber nun Einzelheiten aus diesem Gefühl abzuheben beginnt, dann wird auch der personal-h i s t o $\mathrm{r}$ i$\mathrm{s} \mathrm{c}$ h e Bezug deutlich. Denn dann ist jene Landschaft und dieses Zimmer nicht um ihrer gegenwärtigen Wahrnehmungsbeschaffenheit a n s i $\mathrm{h}$ so besonders teuer, sondern weil aus ihnen Ver-

1) Vgl. hierzu Martha Muchows Studien uber den Lebensraum des Grossstadtkindes. 
gangenheit spricht und zwar selbstbezügliche, bis in die Gegenwart hinein reichende Vergangenheit.

Wir finden also bei den rückgreifenden Gefühlen das Analoge wie bei den vorgreifenden. Auf primitivster Stufe fehlt noch das $\mathrm{B}$ e w u s $\mathrm{s}$ t s e in des Zeitbezugs nach vorn bezw. rückwärts: so wenig wie dem Instinktgefühl das Ziel in der Zukunft erlebnismälsig mitgegeben ist, sowenig dem ursprünglichen Heimatsgefühl oder der Geborgenheitsliebe die Herkunft aus der Vergangenheit. Auf höherer Stufe tritt nun dieses Bewusstsein hinzu. Es ist z.B. sehr interessant zu beobachten, wie aus der unbekümmerten Geborgenheitsliebe des Kindes zu den Eltern bei erwachender Pubertät ein anderes, $h$ is t or i s c h gefärbtes Gefühl: der Dankbarkeit, der Pietät, des Familiensinnes sich entwickelt. Der Mensch beginnt jetzt seine eigene Lebens $k$ on $t$ in $u$ it ä $t$ mit zu erleben; und so fühlt er in seinem Jetzt und in seinen Zukunftsaufgaben die Vergangenheit wirksam und verpflichtend.

Aber in derselben Entwicklungsstufe erwacht auch der A hn e n s t o l z. Das Gefühl der Zugehörigkeit greift noch über die Zeit der eigenen Existenz zurück und bettet das eigene Leben in die Folge der Generationen ein. Und immer weiter breitet sich dies Gefühlserleben nach rückwärts aus: Stammesgefühl, Nationalgefühl, Vaterlandsgefühl sind niemals nur Erlebnisse des gegenwärtigen Bestandes von Stamm, Nation, Vaterland, sondern zugleich historische Gefühle. Viel primitiver als historisches Wissen und Erkennen sind diese Gefühle, deren Abhebungen in Mythen, Sagen und geheiligten Uberlieferungen, in Heroenkult. Erinnerungsfesten und Symbolverehrung bestehen.

Es gibt einen bekannten Spruch der Volkspsychologie: „Das Gefühl ist konservativ, der Verstand ist fortschrittlich." Das trifft sicherlich zu für die bisher besprochenen rückgreifenden Gefühle. Denn in diesen wird ja eine Bindung an Vergangenes erlebt, die zugleich als Antrieb wirken muss, an dem alten Bewährten festzuhalten, Die Lustbetontheit, die der Vertrautheit, dem Geborgenund Heimisch-Sein zukommt, ist zugleich ein Signal zur Fortsetzung des Weges in gleicher Richtung; was von diesem Weg ablenkt, insbesondere logische Erwägung, die die Unangepasstheit des Alten an die gegenwärtige und zukünftige Situation einsichtig macht, hat es schwer, sich gegenüber der Zähigkeit der histori- 
schen Anhänglichkeit durchzusetzen. Darum sind selbst Menschen, die im allgemeinen dem Neuen und Kommenden aufgeschlossen sind, konservativ in jenen Bereichen, in denen ihr Gefühlsleben stark rückgreifend verankert ist.

Allein jener populäre Spruch hat doch nur sehr partielle Gültigkeit. Denn weder sind alle rückgreifenden Gefühle lustbetont und darum auf Konservierung des Alten eingestellt, noch ist die Uberwindung des Uberkommenen lediglich eine Tendenz des Verstandes, vielmehr ebenfalls in Gefühlen, nämlich vorgreifenden Gefühlen verankert. Die so entstehenden Komplikationen bedürfen noch einer kurzen Erörterung.

\section{Negative Beziehungen $z u r$ Vergangenheit}

Rückgreifende Gefühle mit Unlustbetonung gibt es in doppelter Form.

Die erste, einfachere Form ist das $\mathrm{T}$ r a u e $\mathrm{r} g$ e $\mathrm{f} \ddot{\mathrm{u}} \mathrm{h} \mathrm{l}$. Die Bindung an die Vergangenheit wird in voller Stärke erlebt; aber die Brücke von der Vergangenheit zur Gegenwart ist abgebrochen; das Gewesene ist „vergangen” im engsten Sinne des Wortes. Die innige Vertrautheit mit ihm kann daher nicht als selbstverständliche lustbetonte Geborgenheit, sondern nur als schmerzliches V e r m is s e n gefühlt werden.

Die „mnemische Spaltung” 1), deren gefühlsmälsige Auswirkung wir hier vor uns haben, kann ebensowohl endogen wie exogen bedingt sein. Die Entwicklungsnotwendigkeiten jedes Menschen erfordern ja dauernd das Uberwinden früherer Stadien; aber das Darüber-Hinauskommen ist doch nicht ein völliges Davon-Freikommen; und so wird aller Fortschritt durch schmerzliche Verluste erkauft. Am deutlichsten sind diese rückgreifenden Gefühle bei den Klagen um ,das verlorene Kindheitsparadies."

Äussere Umweltänderungen und Schicksalsschläge reissen den Menschen ebenfalls aus dem Kontakt mit dem Liebgewordenen: der Emigrant, der die Heimat verlassen musste, der Angehörige eines eben Verstorbenen ist nicht nur traurig (d.h. gegenwärtigen Schmerz erlebend), sondern auch „trauervoll”, (d.h. das Nichtmehr-Gegenwärtigsein von vertrauter Vergangenheit fühlend).

1) Vgl. S. 345 . 
Eine mildere Form dieses Trauergefühls ist die $\mathrm{W}$ e $\mathrm{h} \mathrm{m} \mathrm{u} \mathrm{t}$. Das Vermissen des Verlorenen ist auch hier noch vorhanden. Aber zugleich wird doch auch die Stetigkeit empfunden, welche die liebgewesene Vergangenheit in liebgewordene Erinnerung verwandelt, und über diesem Erinnerungshintergrund kann sich schon wieder die Richtung auf neue Ziele entwickeln; die Vergangenheit verblasst gegenüber der Zukunft.

Dort aber, wo die Vergangenheit $\mathrm{n}$ i $\mathrm{ch} \mathrm{t}$ abgeschnitten ist, sondern weiter wirkt und die Gegenwart des Menschen gefühlsmälsig bestimmt, kann nun eine neue Form der Unlustbetontheit aufkommen. Denn die Tendenz zur Beharrung im Gegebenen ist ja nur die eine Richtung der menschlichen Entelechie; ihr steht gegenüber - und en tgegen - die Tendenz zur Anpassung an die veränderte Situation und darüber hinaus das Entfaltungsstreben zu neuen Formen des Lebens. So gerät das rückgreifende Ge-

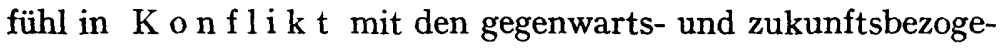
nen Gefühlen; und der Zusammenhang mit der Vergangenheit wird nun nicht mehr als Greborgenheit, sondern als $G$ e b u nde $\mathbf{n}$ heit, nicht als Vertrautheit, sondern als Erstarrung erlebt.

Schon in dem Gefühl der $\mathrm{P}$ i e $\mathrm{t}$ ä $\mathrm{t}$ kündigt sich der Konflikt, wenn auch noch leise, an. Wer ,aus Pietät" religiöse Gebräuche hält, wer voller Pietät an Eltern und Ahnen hängt, der fühlt sich zwar noch ganz stark im Vergangenen verankert und würde den Verzicht auf diese Vergangenheit als eine seelische Selbstpreisgabe ansehen; aber doch wird hintergründig schon mitgefühlt, dass das, was man für die Gegenwart und die Zukunft für sich wünschen und von sich fordern sollte, nicht mehr ganz mit jener Gerichtetheit zusammenstimmt.

Aber die dynamischen Akzente der widerstrebenden Gefühle könne sich verschieben; und dann ist das in die Vergangenheit rückgreifende Gefühl voll starken Leids, weil die von dorther stammenden Determinationen der eigenen Selbstentfaltung Fesseln anlegen. Dann wird dem Menschen das Gewohnte und Vertraute zum Überdruss und Ekel; dann verwandelt sich die Geborgenheitsliebe in lähmendes A b h än gi g k e i t s g e f ü h l. Diese vergangenheitsgerichteten Gefühle sind nun nicht mehr konservativ, sondern revolutionär; die aus ihnen stammenden Antriebe gehen auf Lösung der Vergangenheitsbindung, auf Kampf gegen sie, ja auf Zerstörung der Wurzeln, mit denen sich der Mensch im Gewesenen verankert fühlt. 


\section{EINUNDDREISSIGSTES KAPITEL}

\section{G E F Ü H L S D ISP OS I T IO NE N}

Wir haben schliesslich diejenigen Tatbestände des Gefühlslebens zu besprechen, die nicht eine eindeutige Beziehung zu einer der drei Zeitphasen Gegenwart, Vergangenheit, Zukunft haben, weil sie d a u e $\mathrm{n}$ d e Begleiter des personalen Lebens sind. Solche dauernde Beschaffenheit kann natürlich nur in $\mathrm{d}$ is p o s i$\mathrm{t}$ i o n elle r Form vorhanden sein. Freilich bedeutet Dauer nicht immer „Lebenszeit"; wie alle Dispositionen, können auch die des.Gefühlslebens sehr verschieden lange Zeit den Hintergrund der akuten Gefühlserlebnisse einer Person bilden.

Da die hierhergehörigen Tatbestände grossenteils in die Sphäre der differentiellen Psychologie gehören, müssen wir uns an dieser Stelle mit kurzen Andeutungen begnügen.

Für die Gefühlsdispositionen gilt wenn möglich in noch höherem Malse als für die einzelnen Gefühlserlebnisse, dass ihre Trennung von den anderen Bereichen des Psychischen künstlich, ja gewaltsam ist. Denn die Art, wie ein Mensch zu fühlen pflegt, ist so eng verschmolzen mit der Dauerbeschaffenheit seines Strebens und mit seinen geistigen Dispositionen, mit seinen Handlungsund Ausdrucksformen, dass es Sache der Willkür ist, unter welcher Rubrik sie behandelt werden. (So würden die Temperamente eben so gut in die Kapitel über personale Dynamik, die Interessen in die Erörterungen der geistigen Phänomene passen.)

\section{RÜSTUNGSDISPOSITIONEN, INSBES. TEMPERAMENTE}

Die menschliche Fähigkeit und Bereitschaft, Gefühle zu erleben, variiert sehr stark nach Grad und Art. Sie wird zusammengefasst unter dem Wort „Gemüt”. Alle jene Merkmale, die wir den einzelnen Gefühlserlebnissen zuschreiben, 
wie Intensität, Breite, Tiefe, Echtheit, Ernsthaftigkeit u.s.w., können - sobald das eine oder andere von ihnen in einer Person dauernd prävaliert - zum Kennzeichen der Gemütsbeschaffenheit werden. So sprechen wir ",tiefes” Gemütsleben jenem zu, dessen Gefühle in der Tiefendimension stark ausgeprägt sind. Wir nennen einen Menschen ,ernsthaft", an dessen Seelenstruktur unernste, spielerische, scheinhafte Gefühle sehr wenig beteiligt sind.

Am bekanntesten ist diejenige Typisierung der Gemütseigenschaften, die mit den beiden pol a r e n Merkmalspaaren der Gefühle: Lust/Leid, Erregung/Beruhigung in Beziehung steht. Jenes Vierfelder-Schema, das wir für Einzelgefühle, für Stimmungen und für Affekte anwandten ${ }^{1}$ ), ist auch verwertbar zur Gliederung der Gefühlsdispositionen, ja es hat hier sogar seine allererste Verwendung gefunden, in dem System der vier $\mathrm{T}$ e m p e r ame n t e.

Menschen, in deren Erleben lustvolle Gefühle konstitutionell überwiegen, nennt man „eukolisch", den entgegengesetzten Typ "dyskolisch" (bezogen auf die daraus erwachsenden Lebensanschauungen: „optimistisch" und „pessimistisch”). Mit dieser Scheidung kreuzt sich die andere, die durch eine vorwiegende Bereitschaft zu erregenden oder zu ruhigen Gemütszuständen gebildet wird; und so entstehen vier Felder, in welchen sich die vier, von alters her bekannten, Bezeichnungen für die menschlichen Temperamente zwanglos einfügen. Vergleicht man das Schema mit den früher aufgestellten Vierfelder-Schemen, dann wird sich ergeben, dass die analogen Felder jeweilig zusammengehörige Phänomene aufweisen. So sind für den "S a n g u i n i k e r" besonders kennzeichnend: lustvolle Funktionsgefühle, Stimmungen der Fröhlichkeit, Affekte des Jubels. Für den "Cho l e r i k e r":

\begin{tabular}{|c|c|c|c|}
\hline & & $\begin{array}{c}\text { Lustbereitschaft } \\
(\text { Eukolie })\end{array}$ & $\begin{array}{l}\text { Leidbereitschaft } \\
\quad \text { (Dyskolie) }\end{array}$ \\
\hline Tendenz & Erregung & Sanguinisch & Cholerisch \\
\hline$z \boldsymbol{u}$ & Beruhigung & Phlegmatisch & Melancholisch \\
\hline
\end{tabular}

1) Vgl. 736, 760, 761. 
leidvolle Funktionsgefühle, Stimmungen des Ärgers, Ausbrüche des Zornes. Für den „P h l e g m a t i k e r”: lustvolle Zustandsgefühle, Stimmungen des Behagens. Für den „M e l a n c h o lik e r": leidvolle Zustandsgefühle, Stimmungen der Traurigkeit, des Lebensüberdrusses.

Das Schema ist ein bequemes Ordnungsmittel der Temperamente, aber auch nicht mehr; es bietet methodische Leitgesichtspunkte, ist jedoch keineswegs erschöpfend. Die Temperamente sind eben nicht nur durch die hedonischen und die dynamischen Gefühlsmerkmale gekennzeichnet, sondern auch durch andere, die in dem Schema nicht enthalten sind. Sehr charakteristisch sind die Unterschiede zeit licher Ablaufsformen: zum Sanguiniker und Choleriker gehört im Allgemeinen schneller Wechsel, zu den beiden anderen Typen Nachhaltigkeit der Gefühlszustände ${ }^{1}$ ). Ferner ist ihre direkte oder gehemmte Beziehung zu den Willenshandlungen wichtig; deshalb haben manche Psychologen die Gesichtspunkte der vorwiegenden Aktivität oder Nicht-Aktivität, der starken oder schwachen Reagibilität u.s.w. für ihre Gliederung der Temperamentstypen benutzt.

Endlich zeigen die Temperamente deutlich ausgeprägte $\mathrm{k}$ ö $\mathrm{r}$ perliche Komponenten: Verschiedenheit in Tempo, Ausgiebigkeit, Flüssigkeit der Bewegungen, Neigung zu Schlankheit oder Fettleibigkeit u.s.w. ${ }^{2}$ ) Im Grunde sind die Temperamente überhaupt nicht rein psychische Beschaffenheiten, sondern psychophysisch neutrale Ausprägungen der Person in ihrer Totalität.

Auch in diag nost is cher Hinsicht darf das Schema nicht überschätzt werden. Kant hatte in seiner „Anthropologie” noch die Behauptung aufgestellt, dass die vier Temperamente feste $\mathrm{F}$ ä c h e r oder Klassen darstellen, in die sich alle Menschen eindeutig einordnen liessen. Das ist gänzlich unzutreffend. Es gibt - wie übrigens bei allen Typologieen - zahlreiche Ubergangs- und Schwankungs-Formen; auch innerhalb jeder Gruppe besteht keineswegs eine Gleichförmigkeit der dazu gehörigen Individuen.

1) In der Heymans'schen Temperamentenlehre wird dieser Gegensatz als „vorwiegende Primärfunktion”, ,vorwiegende Sekundärfunktion” bezeichnet.

2) Vgl. S. $722 / 3$. 
Die Temperamentenlehre stammt aus dem Altertum: Galen führte die menschlichen Konstitutionsunterschiede auf $\mathrm{physiolog}$ i$\mathrm{sche}$ Ursachen zurück, und zwar auf verschiedenartige $\mathrm{M}$ is c h u n g ${ }^{1}$ ) der vier Hauptsäfte Blut, Schleim, gelbe Galle, schwarze Galle. Menschen, bei denen das Blut vorwiegt, sind die Sanguiniker, "Schleimige" die Phlegmatiker, „Gelbgallige"die Choleriker, „Schwarzgallige" die Melancholiker. Dass eine solche Säftelehre in der modernen Theorie von der inneren Sekretion und ihrer psychologischen Bedeutung eine, wenn auch sehr verwandelte, Auferstehung feiert, wurde schon S. $722 / 3$ erwähnt.

Kant und viele Psychologen des 19. Jahrhunderts beschränkten sich auf rein ps y c holog i s ch e Ableitungen der Temperamentsunterschiede, und zwar unter Benutzung von schematischen Kreuzungen einfacher Merkmale ${ }^{2}$ ). So liess Kant die vier Temperamente hervorgehen aus der Kombination der Gesichtspunkte : gefühlsmälsig/tätig; Anregung/Abspannung. - Wundt kreuzte: starke/schwache und schnelle/langsame Affektveranlagung. - Ebbinghaus: optimistische/ pessimistische Regungen; mehr affektartiges/mehr stimmungsartiges Verhalten.

Mehrfach ist auch der Versuch gemacht worden, das Schema durch Anwendung von mehr als zwei sich kreuzenden Merkmalspaaren zu erweitern. Von diesen hat das Schema von G. Heymans empirische Anwendung gefunden, freilich fast ausschliesslich in seinen eigenen Untersuchungen und denen seiner Schüler. Er kreuzt drei Merkmalspaare: Emotionell/nicht-emotionell; aktiv/nicht-aktiv; vorwiegende Primär/Sekundär-Funktionen. Sein Schema lautet:

Emotionell, nichtaktiv, primär $=$,nervös"

$\begin{array}{lcl}\text { Nicht-emotionell, } & \text { aktiv, } & \begin{array}{l}\text { sekundär = „sentimental" } \\ \text { primär = ,sanguinisch" } \\ \text { sekundär = „phlegmatisch" }\end{array} \\ \text { Emotionell } & , & \begin{array}{l}\text { primär = ,cholerisch" } \\ \text { sekundär = "passioniert" }\end{array} \\ \text { (Nicht-Emotionell, } & \text { nichtaktiv, } & \begin{array}{l}\text { primär = ,amorph") } \\ \text { sekundär = ,apathisch") }\end{array}\end{array}$

Für die in Klammern gesetzten Formen fand Heymans keine empirischen Belege.

\section{RICHTUNGSDISPOSITIONEN (NEIGUNGEN UND INTERESSEN)}

Die dauernde Richtungsbestimmtheit des menschlichen Fühlens ist eng verbunden mit der Richtungsbestimmtheit des

1) temperare (lat.) $=$ mischen.

2) Die wichtigsten Schemata sind zusammengestellt in meiner „Differentiellen Psychologie" S. 484. 
menschlichen Strebens und Handelns und wurde deshalb schon teilweise an früherer Stelle besprochen. Denn überall, wo der Mensch sich triebmälsig Zielen zuwendet oder aus Bedürfnissen und Willensmotiven sein Handeln entwickelt, wird zugleich dieses Gerichtetsein $\mathrm{g}$ e f üh $1 \mathrm{t}$; und die Intensität solcher Zuwendungsgefühle gehört mit $\mathrm{zu}$ den Bestimmungsgründen dafür, dass der Mensch zur Aktivität übergeht.

Dennoch ist eine besondere Betrachtung notwendig. Denn Handlungen sind ja immer nur vereinzelte, abgehobene Geschehnisse; die Gerichtetheit des Fühlens ist aber eine dauernde Disposition die sich bewusstseinsmälsig zunächst in einer i n n e-

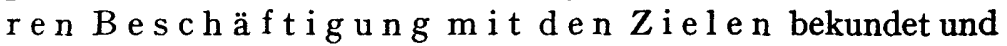
sich nur gelegentlich in Aktivität umsetzt.

Solche Dispositionen treten in zwei Hauptformen auf, als $\mathrm{N}$ e igungen und als In teressen.

Das Wort „Interesse” wird in zwei sehr verschiedenen Bedeutungen gebraucht, als Ausdruck für eine a $k$ u e und für eine $c h \mathbf{r}$ oni$\mathrm{s} \mathrm{c}$ h e Näherungstendenz an ein Ziel.

Interesse als akuter seelischer Zustand ist mit Aufmerksamkeit nahe verwandt. Die beiden Wendungen: „Er hörte mit Interesse zu” und „Er hörte mit Aufmerksamkeit zu" schreiben der Person eine augenblickliche Konzentration auf den zu erfassenden Gegenstand $z u$; nur wird mit "Aufmerksamkeit" die dynamische Spannung, mit "Interesse" zugleich die gefühlsmälsige Anteilnahme ausgedrückt.

Auch in Kant's Definition des ästhetischen Geniessens als: „Interesseloses Wohlgefallen" wird "Interesse" in akutem Sinne gemeint und abgelehnt. I m M o m e $\mathrm{t}$ des Erlebens eines Kunstwerkes soll eine bewusste Gerichtetheit, die auf fernere Ziele geht (z.B. auf Erwerben des Kunstwerkes, auf Vermehrung des Wissens u.s.w.), ausgeschlossen sein. Deshalb steht diese Definition nicht im Widerspruch dazu, dass Interesse im dis p o s i t i o n e 11 e n Sinne - als dauernde Eingestelltheit des Gefühls - der Kunst und den Kunstwerken zugewandt sein kann; ja untergründige Interessiertheit unterstützt wesentlich das Zustandekommen des ,interesselosen” Erlebens im Einzelfalle.

Die folgenden Betrachtungen haben es lediglich mit dem dispositionellen Interesse zu tun.

Der Grundunterschied zwischen den beiden Arten der Richtungsdispositionen lässt sich auf die Formel bringen: Neigung ist ein „Haben” im Gefühl, „Interesse” ist ein „Suchen” mit Gefühlsbeteiligung.

Eine Neigung ist gerichtet auf ein konkretes fertiges Objekt, so 
wie es is $t$, ein Interesse auf die Annäherung an ein Ziel, das noch unbestimmt ist. Die Neigung gilt mehr statisch der Wirklichkeit, das Interesse mehr dynamisch den erst zu entwickelnden Möglichkeiten. Darum ist die Gefühlsbetontheit der Neigung unmittelbarer, eingebetteter, die des Interesses mehr abgehoben, kühler, geistiger. Neigung sucht sich ihren Gegenstand möglichst nahe zu bringen, ja, ihn ganz in sich aufzunehmen (zu ,,introzipieren"); für das Interesse bleibt der Gegenstand stets in einer gewissen Distanz und Verhüllung; denn nur, solange er noch Aufgaben stellt, Rätsel aufgibt, kurz, noch nicht in seiner Ganzheit erobert ist, ist er ,interessant".

Zwei Beispiele.

1) Gefühlseinstellung zu Men schen. - Wenn ein Mensch zu einem anderen eine Neigung fühlt, ihn liebt, verehrt, für ihn schwärmt, dann nimmt er ihn vorbehaltlos hin in seinem gegenwärtigen Sosein. Das Bild des Geliebten, so wie es - stark vom Gefühl durchflutet - als Wirklichkeit gesehen wird, hat Absolutheitscharakter. Die Wirkung der Neigung auf dieses Bild ist eine doppelte: es werden am geliebten Menschen tief gelagerte Wesenszüge sichtbar, die dem gleichgültigen Blick verborgen bleiben; es werden aber auch solche Züge unterdrückt, die dem Gefühl zuwider sind. Liebe macht hellseherisch oder blind, vielleicht stets beides zugleich; einem normalen nüchternen Sehen ist sie nicht günstig.

Wenn sich dagegen ein Mensch A für einen B ,interessiert”, dann sucht er dessen Gesellschaft, um Weiteres und mehr von ihm zu erfahren; er wird gereizt durch das Problematische an B. Dabei braucht B durchaus nicht eine „problematische Natur" zu sein, in deren Wesen es läge, den Menschen Rätsel aufzugeben; oft genug ist es eine ganz individuelle Reaktion des $\mathrm{A}$ auf $\mathrm{B}$, weil $\mathrm{A}$ fühlt, dass $B$ gerade für ihn seelisch bedeutsam werden $k$ ö n nt e. Auf die Entscheidung dieser Frage ist das "Interesse" gerichtet. Ist sie gelöst, dannn tritt an Stelle des Interesses Neigung, Abneigung oder Indifferenz.

2) Gefühlseinstellung zu Ge ge n s t a n d s g e bi e t e n. Wir brachten an einer früheren Stelle (S. 654, im Zusammenhang mit dem Aufmerksamkeitsproblem) das Beispiel von zwei Freunden, die durch die Landschaft wandern. Was dort von ihrem akuten Verhalten gesagt wurde, lässt sich auch auf ihre Gefühlsdis- 
positionen übertragen. Der Eine liebt die Natur; er sucht sie auf, um in ihr geniessend zu ruhen, mit ihr eins zu werden. Der Andere hat starkes Naturinteresse; er wendet sich ihr zu, um ihre Geheimnisse zu ergründen, um sie mehr und mehr geistig zu bewältigen. Wieder hat also das Interesse starke Beziehung zu Fraglichkeit und Problembewusstsein, während die Neigung die Antwort in sich schliesst - oft ohne dass ein Fragen vorangegangen wäre.

Eine besondere Bezeichnung haben wir für die stärksten Grade der Richtungsdispositionen des Gefühlslebens: L e i d e n$\mathrm{s} \mathrm{ch}$ a f $\mathrm{t}$ e $\mathrm{n}$. Sowohl Neigungen wie Interessen können sich zu Leidenschaften steigern. Diese spielen innerhalb der Dauerstruktur der Person eine ähnliche Rolle, wie die Affekte in den akuten Erlebnissen (s. S. 761): sie stellen Störungen des Gleichgewichts dar. Schon die Worte „Leiden”-schaft, „Passion” drücken aus, dass ihre Gewalt und Hartnäckigkeit nicht Zeichen echter Aktivität sind, sondern das Gegenteil bedeuten: eine Einschränkung der sinnvoll vielseitigen und geordneten Zielgerichtetheit der Person durch die dauernde Despotie einer Gefühlseinstellung.

Die Richtungsdispositionen des Gefühlslebens haben entweder unmittelbaren oder mittelbaren Charakter.

Die u n m it t e l b a r e n Gefühlseinstellungen gehören dem Grundbestand personalen Wesens an. Der eine besitzt eine ganz ursprüngliche Neigung zur Musik, ein anderer ist erfüllt von einem ebenso unbedingten mathematischen Interesse. Wenn wir diese Tendenzen ,,angeboren" nennen, so bedeutet das natürlich nicht, dass sie von Geburt an fertig vorhanden und in allen Einzelheiten festgelegt wären. Sie machen vielmehr lange und mannigfache Entwicklungen durch; und ihre konkrete Ausgestaltung und Betätigungsweise ist weitgehend von empirischen Einflüssen abhängig. Aber Reifung und Beeinflussbarkeit sind doch nur möglich, weil eine angelegte Tendenz nach Verwirklichung drängt. Die Frage nach deren Ursache müsste ins Phylogenetische übergreifen; in der Tat scheinen sich spezifische Gefühlsrichtungen weitgehend erblich zu übertragen. Doch müssen wir es uns versagen, hier Erblichkeitsprobleme zu behandeln.

Vermittelt ist eine Neigung oder ein Interesse dann, 
wenn die Gefühlseinstellung ursprünglich nicht dem Gegenstand als solchem gilt, sondern anderen, mit ihm verbundenen Zielen. So kann z.B. ein Schüler eine grössere Neigung für Turnen als für Sprachen haben - nicht wegen seiner Vorliebe für disziplinierte Körperbewegungen, sondern weil er für Turnen keine Hausaufgaben zu machen hat, oder weil er sich dafür nicht geistig anzustrengen braucht. Dann ist also seine Neigung „vermittelt”. Im Laufe der Zeit kann sich übrigens sehr wohl eine vermittelte Neigung in eine direkte verwandeln; der Mensch gewinnt Liebe zu dem Gegenstand, mit dem er sich ursprünglich aus anderen Motiven beschäftigt hatte.

Bei den Interessen tritt der Unterschied zwischen Mittelbarkeit und Unmittelbarkeit noch deutlicher auf. Gerade weil es sich beim Interesse um eine allmähliche geistige Annäherung an ein Ziel handelt, das zunächst der Person noch wenig eingebettet ist, vermögen $Z$ wischenglieder und vermittelnde Motive eine grosse Rolle zu spielen. Man interessiert sich für ein Gegenstandsgebiet: weil man dafür eine gewisse Begabung besitzt, sodass man in ihm leicht $\mathrm{zu}$ Erfolgen $\mathrm{zu}$ kommen hofft; oder weil man Kenntnisse und Fertigkeiten aus diesem Gebiet im späteren praktischen Leben braucht; oder weil die Art des Unterrichts in diesem Fach oder die Person des Lehrers anziehend ist ; oder weil es Mode ist, sich für das Gebiet zu interessieren u.s.w. Es gibt unzählige solcher Motive, die ausserhalb der Sache liegen, und die das unmittelbare Interesse an der Sache selbst teils stark unterstützen, teils geradezu ersetzen können. Aber auch hier kann, wie bei der Neigung, das vermittelte Interesse schliesslich unmittelbar werden. So mancher, der sich für Chemie zunächst nur interessierte, weil er Apotheker werden wollte, ist dann von der chemischen Problematik als solcher mehr und mehr gepackt worden und hat dann in ihrer Bearbeitung seine volle Befriedigung gefunden.

Uber Gefühlzuwendung zu bestimmten Gegenstandsgebieten sind an $\mathrm{S} \mathrm{ch} \mathrm{ulkinder} \mathrm{n}$ ahlreiche massenstatistische Untersuchungen vermittels der Erhebungsmethode gemacht worden. Zunächst hatte man die Kinder nach allen möglichen „Vorlieben" gefragt: nach dem liebsten Buch oder Spiel, nach der beliebtesten Persönlichkeit in Geschichte und Religion u.s.w. Schliesslich konzentrierten sich diese Erhebungen auf die Gefühlseinstellung der Kinder zu den Sch u 1f ä c h e r n. 
Diese sogenannten "Beliebtheitsuntersuchungen" 1) begannen, als Lobsien 1903 die Kinder nach ihrem liebsten Schulfach fragte; 1905 schloss ich selbst die Gegenfrage nach dem wenigst beliebten Fach an. Diese Doppelfrage wurde dann in allen folgenden Untersuchungen innerhalb und ausserhalb Deutschlands angewendet; in vielen Fälle wurde eine Motivfrage angefügt: „Warum hast $\mathrm{Du}$ dies oder das Fach besonders gern, bezw. ungern?"

Von den Ergebnissen können hier nur einige wenige erwähnt werden, die allgemein-psychologisches Interesse haben.

Wurden identische Kinder mehrmals in gewissen Zeitabständen gefragt, dann ergab sich $z$ war eine gewisse Fluktuation der Angaben, wenn sie mehrere beliebte und unbeliebte Fächer zu nennen hatten; aber die Spitzenfächer nach beiden Seiten erwiesen sich doch als ziemlich konstant.

Massenstatistisch ergaben sich überraschend grosse Regelmärsigkeiten in $\mathrm{Volk} \mathrm{s} \mathrm{s} \mathrm{h} \mathrm{u} \mathrm{l} \mathrm{e} \mathrm{n}$ verschiedener Städte und sogar verschiedener Länder '). (Allerdings beziehen sich diese Ergebnisse vornehmlich auf die Zeit vor dem Weltkrieg und damit auf andere Schulverhältnisse als die gegenwärtigen). Die Fächer liessen sich bezüglich ihres „Beliebtheitswertes" in vier Gruppen teilen: ausgesprochen beliebte, ausgesprochen unbeliebte, indifferente (welche überhaupt sebr wenig Nennungen erhielten), bipolare (für die sowohl zahlreiche Bevorzugungs- wie Ablehnungs-Urteile gegeben wurden).

Die stärkste positive Bewertung erfuhren die technischen Fächer Turnen und Zeichnen (bei Mädchen Handarbeit); doch sinkt deren Vorzugsstellung mit steigendem Alter. Hier macht sich die ursprüngliche sensumotorische Einstellung der Kinder geltend, die erst allmählich eine mehr intellektuelle Interessiertheit neben sich aufkommen lässt. Von den theoretischen Fächern war Geschichte recht beliebt, in den höheren Klassen auch Literatur der Muttersprache. Rechnen (in höheren Schulen Mathematik) ist fast durchweg bipolar; offenbar hängen hier die Gefühlseinstellungen stark von angeborener Begabtheit bezw. Unbegabtheit ab. Sehr negativ bewertet wurde von den Schülern der Grammatikunterricht in der Muttersprache, der - namentlich in der älteren Methodik - den lebendigen Sprachorganismus so unnatürlich zerpflückte. „Indifferent” waren Religion, Physik und andere Fächer.

Was die M o $t$ i v e angeht, so spielt das unmittelbare Interesse am Gegenstande nur eine partielle Rolle, die namentlich bei älteren Schülern stärker betont ist. Die Kinder selbst geben die verschiedensten Begründungen an; mögen diese auch im einzelnen nicht objektiv zutreffen, so vermitteln sie doch im ganzen ein Bild von der Mannigfaltigkeit der Interessen- und Neigungseinstellungen, welche die

\footnotetext{
1) Literatur in verschiedenen Bänden von Z. Pd. Ps. und Z. Ang. Ps. Die letztere brachte mehrfach Sammelberichte.

$\left.{ }^{2}\right)$ Die, weniger umfangreichen, Ergebnisse aus höheren Schulen müssen unerwähnt bleiben.
} 
Schüler den Schulfächern entgegenbringen. Öfters wird die Methode angeklagt (Langweiligkeit, Fehlerjagd mit viel roter Tinte und anderes wird als Grund der Unbeliebtheit genannt). Ganz gelegentlich wird der Lehrer als Quelle der Beliebtheit oder Unbeliebtheit eines Faches erwāhnt. Eine recht grosse Rolle spielen Nützlichkeitsgesichtspunkte, teils positiv (z.B. beim Rechnen und Zeichnen), teils negativ (z.B. bei Sprachlehre oder Singen). Freude am leichten Lernen und am Erfolg lässt Kinder solche Fächer bevorzugen, für die sie begabt sind; häufig findet Ablehnung aus dem umgekehrten subjektiven Grunde statt. Ältere Kinder erwähnen als Gründe der Beliebtheit: Steigerung des Wissens, Vermehrung der Bildung, auch ethische oder religiöse Werte u.s.w.

Die Dauerhaftigkeit von gegenständlichen Gefühlseinstellungen variiert stark. Es gibt flüchtige und sehr stabile Neigungen und Interessen; und es gibt schliesslich solche, die den Menschen durch sein ganzes Leben begleiten und daher auch charakterologische Bedeutung gewinnen. Entwicklungspsychologisch ist zu bemerken, dass die Reifung von dauernden Interessenrichtungen nur sehr allmählich zustande kommt. Das kleine Kind kennt überhaupt nur akute Interessen. Im späteren Kindesalter bilden sich schon festere Sphären des Interesses heraus, die als hintergründige Dispositionen das Tun durch längere Zeit vorzugsweise bestimmen können (z.B. Interessen am Bauen, am Sammeln, am Puppenspiel). Die Pubertätszeit bringt dann noch einmal eine starke Auflockerung und Neu-Orientierung der Interessen; und erst aus diesem, oft lange dauernden, Probierstadium pflegen dann langsam jene stabilen Interesseneinstellungen hervorzugehen, welche dem Leben des Erwachsenen das Gepräge geben. 


\section{ABSCHLUSS}

Das Buch hat uns einen weiten Weg geführt durch die Bereiche menschlichen Erlebens. Dieser Weg war, trotz mancher Abweichungen im einzelnen, durch eine beherrschende, in sich zurückkehrende Linie bestimmt. Ausgangspunkt und Endpunkt ist die ungeschiedene Totalität personalen $\mathrm{L}$ e be $\mathrm{n} \mathrm{s}$. Wie aus dieser Totalität durch steigende $\mathrm{Abhebung}$ die Mannigfaltigkeit des $\mathrm{E} r \mathrm{l}$ e b e $\mathrm{n}$ s hervorgeht und wie das Erleben durch zunehmende $\mathrm{E}$ i n b e t $\mathrm{t} u \mathrm{ng}$ wieder in sie zurückkehrt, das darzustellen war unsere eigentliche Aufgabe. Darum steht am Anfang aller unserer speziellen Betrachtungen die Sensumotilität, durch welche der Mensch noch unmittelbar Eins ist in sich selbst und mit seiner Welt - am Ende des Buches die Erörterung der Gefühle, in welchen das Erleben wieder unmittelbare „Personnähe” besitzt.

Aber auch in den dazwischen liegenden Gebieten, in denen die abgehobenen Inhalte des Wahrnehmens, Erinnerns, Denkens, Phantasierens, Strebens und Handelns ihren Platz haben, musste doch unablässig Bezug genommen werden auf jenen personalen Gesamtuntergrund. Erst dieser „Ganzheitsbezug" gab allem, was erlebt wird, Sinn und Bedeutung. Auch die weitestgehende Abhebung führte niemals zu wirklichen „Elementen” und selbständigen Prozessen im Psychischen, die in sich Bestand und Sinn hätten. Sie blieben der Person verhaftet; und gerade die Spannung, die so entstand, wurde dann zum zentralen Problem der psychologischen Untersuchung.

So versucht das Buch in seiner Gesamtheit den Beweis zu führen, dass eine personalistische Betrachtung in höherem Malse als jeder andere Standpunkt der Problematik des Psychischen gerecht $\mathrm{zu}$ werden vermag.

Es ergibt sich aber zugleich, dass Psychologie nicht eine auf sich selbst ruhende autonome Wissenschaft sein kann, sondern jener allgemeineren Wissenschaft unterzuordnen ist, deren Ge- 
genstand die Person ist. Wir nennen sie Personwissenschaft oder Person a lis t i k. Denn um zu verstehen, wie die Person erlebt, müssen wir zuvor wissen, wie die Person ist und lebt; vor der eigentlich psychologischen steht die ,psychophysisch neutrale" Problematik, mit der es die Personwissenschaft zu tun hat.

Daher mag es kommen, dass manche Fragen bezüglich der menschlichen Persönlichkeit, die man früher oft im Rahmen der Psychologie behandelte, in diesem Buch keinen Platz gefunden haben oder nur durch Seitenblicke gestreift wurden - wie etwa die Probleme des Selbst, der Individualität, der Vererbung, der Wertbezüge, der Introzeption, des Ausdrucks und andere. Indessen durften wir um so eher auf ihre Erörterung verzichten, da ihre eingehende Behandlung bereits in jenen meiner Bücher erfolgte, welche der Personwissenschaft im eigentlichen Sinne gewidmet sind. Das vorliegende Buch hat sich in der Behandlung unserer Wissenschaft an die S. 99 gegebene Definition gehalten: „Psychologie ist die Wissenschaft von der e r le be nden und erlebnisfähigen Person." 


\section{BIBLIOGRAPHIE}

\section{VORBEMERKUNGEN}

Über die Gesichtspunkte der Auslese vgl. das Vorwort.

Die sechs Hauptteile der Bibliographie entsprechen im allgemeinen den Hauptteilen des Buches. Doch ist der erste Hauptteil der Bibliographie breiter angelegt als die anderen und musste daher untergeteilt werden. Ferner ist ein VII. Teil iber Charakterologie angefügt worden.

\section{ERLÄUTERUNGEN UND ABKÜRZUNGEN ZUR BIBLIOGRAPHIE}

Bei Büchern ist stets die letzte erreichbare $A$ u f 1 a g e genannt, und zwar durch eine hochgestellte römische Ziffer hinter dem Titel. Wo die erste Auflage eine besondere historische Bedeutung hat, ist sie in Klammern beigefuigt.

Bei $Z$ eits chriftena ufsät $z$ e $n$ ist die Zeitschrift in Kursivschrift, der Band in Fettdruck, das Heft in Klammern angegeben.

Veröffentlichungen, die eine besonders ausführliche Bibliographie enthalten, sind durch: (Bibl.) gekennzeichnet.

Ps. bedeutet: Psychologie, bezw. Psychology.

ps. " psychologisch, bezw. psychologique, psychological.

exp. $\quad$ experimentell.

L. $\quad=$ Leipzig.

B. $\quad=$ Berlin.

N.Y. $=$ New York.

ArGsPs $=$ Archiv für die gesamte Psychologie.

Ps Fo $=$ Psychologische Forschung.

$Z A n g P s=$ Zeitschrift fuir angewandte Psychologie.

$Z P d P s \quad=$ Zeitschrift für pädagogische Psychologie.

$Z P s \quad=$ Zeitschrift für Psychologie.

$B h f t=$ Beiheft.

Erg- $B d=$ Ergänzungsband.

Mon. = Monograph. 


\section{ALLGEMEINES}

\section{A. SAMMELWERKE UND ZEITSCHRIFTEN}

1. SAMMELWERKE. WÖRTERBÜCHER. BIBLIOGRAPHIEN.

A Handbook of Child Ps. 1931. Ed. by: C. Murchison. (The Intern. Univ. Series). A History of Ps. in Autobiography. 2 Bde. 1930/1932 Ed. by: C. Murchison. (The Intern. Univ. Series).

Die Biologie der Person. E. Handb. d. allgemeinen u. speziellen Konstitutionslehre. (Hrsg. von: Th. Brugsch u. F. H. Lewy). B. u. Wien, 1926/1931.

Die Ps. in Einzeldarstellungen. (Begründet v. Ebbinghaus, weitergef. v. Meumann). Heidelberg.

Einführung i. d. neuere Ps. ${ }^{\text {IV } / v}$ (Hrsg. v. Saupe). Osterwieck. 1931.

Giese, F., Ps. Wörterbuch. L III. 1931.

Handbuch d. Arbeitswissenschaft. (Hrsg. von : F. Giese). Bd I u. II. Handwörterbuch d. Arbeitswissenschaft. Halle 1927-30. Bd. IV. Handbuch psychotechn. Eignungsprüfungen ${ }^{I I}$. Halle. 1925.

Handbuch d. biologischen Arbeitsmethoden. (Hrsg. von: E. Abderhalden). Abt. VI. Methoden d, experimentellen Ps. B. u. Wien.

Handbuch d. Individual-Ps. 2 Bde. (Hrsg. von: E. Wexberg). München. 1926.

Handbuch d. vergleichenden Ps. 3 Bde. (Hrsg. v.: Kafka). 1922.

Handbuch d. Physiologie des Menschen. (Hrsg. v.: Nagel u. a.). Braunschweig. 1870 -1911 .

Handwörterbuch d. medizinischen Ps. (Hrsg. v.: K. Birnbaum). 1930.

Hildreth, G. H., A bibliography of mental tests and rating scales. N. Y. 1933.

Lexikon der Pädagogik der Gegenwart. 2 Bde. (Hrsg. v.: J. Spieler). Freiburg i/B. 1930.

Roвack, A. A., Bibliography of Character and Personality. Sci-Art Publishers, Cambridge. Mass., 1927.

Sondervorträge über die Beziehung der Ps. zu den anderen Wissenschaften. (10 Verfasser). Bericht izb. d. XII. Kongr. d. Deutschen Gesellsch. f. Ps. in Hamburg. Jena. 1932.

WARREN, C. H. (Editor) Dictionary of Ps. N. Y., Boston etc. 1934.

The International University Series. Worcester, Mass. Clark University Press. Mehrere Bände. 1927 ff.

The Ps. Register ${ }^{\mathrm{II}}$. Ed. by : C. Murchison. (Bibl.) 1932. (The International Univ. Series 3).

Ausserdem viele Einzelbändchen folgender Sammlungen: I. Aus Natur u. Geisteswelt. L. - II. Sammlung Göschen. L. - III. Wissenschaft u. Bildung. L.

\section{ZEITSCHRIFTEN DES DEUTSCHEN SPRACHGEBIETS}

Archiv f. d. gesamte Ps. (ArGsPs). L.

Archiv f. Kriminologie, L.

Archiv f. Psychiatrie u. Nervenkrankheiten, B.

Beiträge z. Charakter- u. Konstitutionsforschung. Bern. Seit 1933.

Beiträge z. Ps. d. Aussage, L. 1903-1906.

Bericht üb. d.... Kongress f. experim. Ps., L. später Jena.

Seit 1931: Bericht üb. d.... Kongress d. Deutschen Gesellschaft f. Ps. Jena. 
Imago, Zeitschr. f. Anwendung d. Psychoanalyse, Wien.

Industrielle Psychotechnik, B.

Journal f. Ps. u. Neurologie, L.

Jahrb. f. Charakterologie, B.

Jahrb. f. psychoanalyt. u. psychopathol. Forschungen, L.-Wien.

Monatsschr. f. Kriminal-Ps. u. Strafrechtsreform, Heidelberg.

Monatschr. f. Psychiatrie u. Neurologie. B.

Neue ps. Studien, $L$.

Pädagog.-ps. Arbeiten. (Veröff. d. Inst. f. experim Päd. u. Ps. d. Lpz. Lehrervereins). L Praktische Ps. L.

Ps. Forschung. (PSFo) B.

Ps. Studien. L.

Schriften d. Gesellsch. f. ps. Forschung. L.

Schriften d. Vereins f. Individual-Ps., München.

Schriften d. Vereins f. freie psychoanalyt. Forschung, München.

Wiener Arb. z. päd. Ps. Wien-L.-N.Y.

Zeitschr. f. Ästhetik u. allg. Kunstwissenschaft. Stuttgart.

Zeitschr. f. angewandte Ps. $(Z A n g P s)$. Dazu: Beihefte, L.

Zeitschr. f. d. ges. Neurologie u. Psychatrie. B.

Zeitschr. f. Individual-Ps. München.

Zeitschr. f. Kinderforschg. B.

Zeitschr. f. Menschenkunde (Blätter f. angew. Charakterologie u, angew. Ps.) Kampen.

Zeitschr. f. pädagog. Ps. u. experim. Pädagogik. (ZPdPs). L.

Zeitschr. f. Patho-Ps. L.

Zeitschr. f. Ps. (ZPs) Dazu: Ergänzungsbände. L.

Zeitschr. f. Psychotherapie u. mediz. Ps. Stuttgart.

Zeitschr. f. Sexualwissenschaft, Bonn.

Zeitschr. f. Völker-Ps. u. Soziologie. L.

Zentralblatt f. Psychoanalyse u. Psychotherapie. Wiesbaden.

\section{AMERIKANISCHE ZEITSCHRIFTEN}

Amer. Journal of Ps. N.Y. Cornell Univ.

Archives of Ps. N.Y. Columbia Univ.

Character and Personality, Durham N. C. Duke Univ. Press.

Journal of Abnormal and Social Ps. Princeton, N.J. Amer. Ps. Association.

Journal of Applied Ps. Indianapolis.

Journal of Comparative Ps. (w. Monographs), Baltimore, Md.

Journal of Educat. Ps. Baltimore.

Journal of Experimental Ps. Princeton N.J. Ps. Review Co.

Journal of General Ps., Worcester, Mass. Clark Univ. Press.

Journal of Philos., Ps., and Scientific Methods, N.Y., Science Press.

Journal of Social Ps., Worcester, Mass. Clark Univ. Press.

Pedagogical Seminary and Journal of Genetic Ps. (w. Monographs), Worcester, Mass. Clark Univ. Press.

Psychoanalytic Review, Washington.

Ps. Abstracts, Princeton, N.J. Amer. Ps. Association.

Ps. Clinic, Philadelphia, Pa. Ps. Clinic Press.

Ps. Review (w. Monographs, Index and Bulletin), Princeton, N.J. Review Company.

\section{ZEITSCHRIFTEN ANDERER LÄNDER}

Acta Psychologica, Den Haag.

Année ps., Paris.

Archives de Ps., Genf.

Berichte üb. d. internationalen Kongresse f. Ps., Verschiedene Verlagsorte.

British Journal of Educational Ps., London.

British Journal of Ps., London, Cambridge Univ. Press.

Japanese Journal of Ps., Tokio.

Journal de Ps. normale et pathol., Paris. 
Kwartalnik Psychologiczny, Poznań.

Mind, London.

Revue ps., Bruxelles.

Rivista di Psicologia, Bologna.

\section{GESAMTDARSTELLUNGEN DER PSYCHOLOGIE, IHRER SONDERGEBIETE UND IHRER GESCHICHTE. GRUNDSÄTZLICHE FRAGEN.}

Ach, N., Über d. Begriff d. Unbewussten in d. Ps. d. Gegenwart. (Friedrich Schumann Festschrift). $Z P s, 129,1933$.

Adler, A., Praxis u. Theorie d. Individual-Ps. ${ }^{11}$. München. 1927.

Adler, A., Über d. nervösen Charakter ${ }^{i v}$. München. 1928.

BAHNSEN, J., Beiträge z. Charakterologie ${ }^{11}$. L. 1932 (1. Aufl. 1867).

BeChER, E., Gehirn u. Seele. Heidelberg. 1911.

Binet, A., D. neuen Gedanken üb. d. Schulkind ${ }^{I I}$. (Übers.: Anschütz u. Ruttmann). L. 1927.

Boring, E. G., A History of Experimental Ps. N.Y., London. 1929.

BOAS, FR., The Mind of Primitive Man. N.Y., 1911.

BrAcken, H. v., Persönlichkeitserfassung auf Grund v. Persönlichkeitsbeschreibungen. Beitr. z. Jugend- u. Erziehungs-Ps. I. Jena. 1925.

Brentano, F., Ps. vom empirischen Standpunkte ${ }^{\text {II. }}$ L. 1924 (1. Aufl. 1874).

Brunswik, E., Prinzipienfragen d. Gestalttheorie. (In: Beitr. z. Problemgeschichte der Ps., Festschrift für K. Bühler). Jena. 1929.

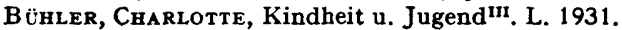

- Zwei Grundtypen v. Lebensprozessen. ZPs 1081928.

- Das Seelenleben der Jugendlichen". Jena. 1929.

- D. menschliche Lebenslauf als ps. Problem. L. 1933.

Bühler, K., D. geistige Entwicklung d. Kindes vi. Jena. 1930 (Engl. Ausg. N.Y. 1930).

- Zur Ps. d. Persönlichkeit. Päd. Jhrb. Wien. 1925.

- D. Krise d. Ps. II. Jena. 1929.

Buytendijk, F. J. J.-Plessner, H., D. Deutung d. mimischen Ausdrucks. Philos. Anseiger. I, 1925/26.

Burkamp, W., D. Struktur d. Ganzheiten (Bibl.). B. 1929.

Busemann, A. Psychische Entwicklg. u. Umwelt (in: Vererbung u. Erziehung, Hrsg Just) (Bibl.) 1929.

Carus, C. G., Psyche. Zur Entwicklungsgesch. d. Seele. Auswahl. Jena. 1926. (1. Aufl. 1846).

- D. Symbolik d. menschlichen Gestalt ${ }^{11}$. Heidelberg. 1925. (1. Aufl. 1853).

- Vorles. üb. Ps. ${ }^{11}$. Erlenbach-Zürich-L. (ohne Jahr). (1. Aufl. 1829/30).

CASPER, S., D. personalistische Weltanschauung William Sterns. (Sonderdruck aus "Die deutsche Schule" 35. 1931). L. 1933.

Claparkde, Ed., Tierpsychologie. Hdwbh. d. Naturwiss. 9. 1913.

- La ps. fonctionelle. Rev. philos. Ir5. 1933 u. Acta psychologica I. 1935.

СонN, J., Üb. einige Grundfragen d. Ps. Logos 12. 1923.

Corrie, I., C. G. Jungs Ps. im Abriss. Zuirich, L., Stuttg. 1929.

Dessorr, M., Abriss einer Geschichte d. Ps. Heidelberg. 1911.

Dilthey, W., D. Leben Schleiermachers. Ges. Schriften, 4. B.u.L. 1925. (1. Aufl. 1887.)

- Ideen üb. e. beschreibende u. zergliedernde Ps. Ges. Schriften 5. L.u.B. 1924. (1. Aufl. 1894).

- Beitr. z. Studium d. Indvidualität. Ebda. (1. Aufl. 1896).

DöRING, W. O., D. Hauptströmungen in d. neueren Ps. L. 1932.

- Pädagogische Ps. Osterwieck. 1929.

Driesch, H., Grundprobleme der Ps. ${ }^{11}$. L. 1929.

Dumas, Georges (u. Mitarbeiter)., Traité de Ps. 2 Bde. Paris. 1923/4.

Dürckнеiм, Graf K. v., Untersuch. zum gelebten Raum. Neue ps. Studien, 6. (4). 1932. 
Ebbinghaus, H., Üb. erklärende u. beschreibende Ps. ZPs. 9. 1896.

- Grundzüge der Ps. (2 Bde). Bd IIII (bearb. v. Dürr) L. 1911;Bd. II Iv (bearb v. Bühler) L. 1919.

- Abriss der Ps ${ }^{1 X}$. (durchges. v. Bühler). L. 1932. (1. Aufl. 1908).

Erismann, Th., D. Eigenart d. Geistigen. Induktive u. einsichtige Ps. L. 1924.

- D. gegenwärt. Richtungen i. d. Ps. (Handb. d. Pädag. II) Langenzalza. 1928.

Fechner, G. Th., Elemente d. Psychophysik II. L. 1889. (1. Aufl. 1860).

FLUEGEL, C. F., One hundred years of Ps., London 1934.

FREUD, S., Gesammelte Schriften. 11 Bde. L.-Wien-Zürich. 1925/28.

- Üb. Psychoanalyse. Fünf Clark-Vorlesungen. viII. L. u. Wien. 1930. (1. Aufl. 1909. Engl. Ausg. Amer. Journal of Ps. 21. 1910).

FröвES, J., Lehrbuch d. experim. Ps. Freiburg. 1. Bdir. 1923. 2. BdIII. 1929.

Galton, F., Inquiries into Human Faculty. London and N.Y. 1928. (1. Aufl. 1883).

Gragensonn, K., D. seelische Aufbau d. religiösen Erlebens. ${ }^{\text {II }}$ Gütersloh. 1930. (1. Aufl. 1921).

Goldstein, K., D. Aufbau des Organismus. Den Haag. 1934.

Groos, K., Seelenleben d. Kindes ${ }^{\mathrm{vI}}$. B. 1923.

HÄBERLIN, P., Der Charakter. Basel. 1925.

Hall, Sr., Ausgewählte Beitr. z. Kinder-Ps. u. Pädagogik. Übers. v. J. Stimpfl. Altenburg. 1902.

Helmholtz, H. v., s. Teil II.

HempelmanN, F., Tier-Ps. v. Standpunkt d. Biologen. L. 1926.

Herbart, J. F., Ps. als Wissenschaft, neugegründet auf Erfahrung, Metaphysik u. Mathematik. 2 Bde. (1. Aufl. Königsbg. 1824/25).

Heymans, G., Einfuihrung in d. spezielle Ps. L. 1932.

- Gesammelte kl. Schriften z. Philosophie u. Ps. Den Haag. 1927.

Heymans, G. u. Wiersma, E., Beiträge z. speziellen Ps. auf Grund e. Massenuntersuchg. ZPs. 42-62, 1906-1912.

HöfFding, H., Ps. in Umrissen ${ }^{v i}$. 1922. (1. Aufl. in dänischer Spr. 1882).

HuME, D., Enquiry concerning Human Understanding. 1748.

HUSSERL, E., Logische Untersuchungen ${ }^{111}$. 2 Bde. Halle. 1922.

JAENSCH, E. R. u. Mitarbeiter. Grundformen menschlichen Seins. B. 1929.

- Üb. d. Aufbau d. Bewusstseins. L. 1930.

James, W., The Principles of Ps. (2 Bde) N.Y. 1918. (1st edition 1893). (Deutsche Ausg. " L. 1920).

- The Varieties of Religious Experience ${ }^{x \times x y}$. London, N.Y. 1929 (Deutsche Ausg. u.d. T.: D. religiöse Erfahrung in ihrer Mannigfaltigkeit. L. 1907).

Jaspers, K., Allgemeine Psychopathologie ${ }^{\mathrm{III}}$. B. 1923.

- Ps. d. Weltanschauungen ${ }^{\text {III }}$. B. 1925.

Jodr, F., Lehrbuch d. Ps. v/vi. Stuttgart-B.

Jung, C. G., Üb. d. Energetik d. Seele u. andere ps. Abhandlungen. Zuirich. 1928.

- Ps. Typen $\mathbf{v} \mathbf{v i}^{\mathbf{2}}$ Z Zürich. 1930. (Engl. Ausg. N.Y. 1923). (s.a. Corrie).

KAFKA, G., D. Bedeutung d. Behaviorismus f. d. vergleichende Ps. u. Biologie. (Sammelref.) Bericht üb. d. XII. Kongr. f. Ps. Jena, 1932.

- Tierpsychologie. Hdbh. d. vergl. Ps. I. 1922.

KAHN, E., D. psychopathischen Persönlichkeiten. Hdbh. d. Geisteskrankheiten. 5. B. 1928 .

KANT, I., Anthropologie in pragmatischer Hinsicht. 1798.

KATz, D., Charakterologie u. Tier-Ps. Jhrb. d. Charakterol. 4. 1927.

KAtz, D. u. R., Gespräche mit Kindern. B. 1927.

Keller, H. Ps. d. Zukunftsbewusstseins. ZPs. I24. 1932.

KLAGES, L., Persönlichkeit (Einführung in d. Charakterkunde). Potsdam-Zürich.1927.

- Handschrift u. Charakter xiv/xv. L. 1932.

- Ausdrucksbewegung u. Gestaltungskraft III/1v. L. 1923.

- D. Grundlagen d. Charakterkunde ${ }^{\mathrm{VI}}$. L. 1928.

- D. Geist als Widersacher d. Seele (3 Bde). L. 1928-1932.

Klemm, O., Geschichte d. Ps. L. 1911.

Kluever, H., Behavior Mechanisms in Monkeys. Beh. Research Fund Mon. 1931. 
Knoblauch, E., Z. Ps. der studierenden Frau. ZAngPs. 36 u. Schriften z. Ps. d. Berufseignung. 38. 1930.

Koenler, W.: Intelligenzprifungen an Anthropoïden. Abh.d. Preuss. Akad.d. Wiss. B. 1917.

- Intelligenzprüfungen an Menschenaffen ${ }^{\text {II. }}$ B. 1924. (Engl. Ausg.: London u. N.Y. 1924/25).

- Gestalt Ps. London u. N.Y. 1929/1930.

- Ps. Probleme. B. 1933.

KoffKa, K., Psychologie. In „Die Philosophie in ihren Einzelgebieten” hrsg. v. Dessoir. B. 1925.

- D. Grundlagen d. psychischen Entwicklungir. Osterwieck. 1925.

- Principles of Gestalt-Ps. N.Y., London. 1935.

Kraepelin, E., Psychiatrie vir. 4 Bde. I. 1909-1915.

Krauss, F., Allg. u. spezielle Pathologie d. Person. 1919.

Kretschmer, E., Körperbau u. Charakter ${ }^{x}$. B. 1931 (Engl. Ausg.: N.Y. 1925).

- Medizinische Ps. ${ }^{\text {IV }}$. L. 1930.

Krueger, F., D. Strukturbegriff in d. Ps. (Sammelref.) Ber. üb. d. VIII Kongr. f. Ps. Jena 1924.

- Ub. psychische Ganzheit. Neue psych. Stud. 1. 1926.

- D. Problem d. Ganzheit aus: Ganzheit u. Form. Her. v.: F. Krueger. 1932.

- Üb. Entwicklungs-Ps. Ihre sachliche u. geschichtliche Notwendigkeit. Arb. $z$. Entw.-Ps. Her. v. F. Krueger. I. 1915.

Külpe, O., Vorlesungen üb. d. Ps. ${ }^{11}$ Hrsg. K. Bühler. L. 1922.

KüNKEL, F., Einführung i.d. Charakterkunde auf individual-ps. Grundlage. L. 1928.

LASHLEY, K. SP., Learning: 1. Nervous mechanism in learning. In: Foundations of Experimental Ps. Worcester, Mass. Clark Univ. Press. 1929.

Lazarsfeld, P., Statistisches Praktikum f. Psychologen u. Lehrer. Jena. 1929.

Lazarus, M., D. Leben d. Seele. B. 1856.

Lazarus, M., u. Steinthal, H., Einleitende Gedanken üb. Völker-Ps. Ztschr. $f$. Völker-Ps. 1860. I. (1).

Lemman , G., Julius Bahnsen, der Begründer der Charakterologie. Ztschr.f. Menschenkunde, 6. 1930.

Lersch, Ph., Gesicht u. Seele. Grundlinien e. mimischen Diagnostik. München. 1932.

Lessing, Th., Prinzipien d. Charakterologie. Halle. 1926.

LEVY-BRUEHL, L., Les fonctions mentales dans les sociétés inférieures ${ }^{1 X}$. Paris. 1930. (Engl. Ausg. London and N.Y. 1926).

- L'âme primitive ${ }^{\mathrm{IV}}$. Paris. 1930. (Deutsche Ausg. D. Seele der Primitiven.Wien. 1930. Engl. Ausg. London and N.Y. 1928).

Lewin, K., D. Übergang v. d. Aristotelischen zur Galileischen Denkweise in Ps. u. Biologie. Erkenntnis I. 1931. (Engl. Ausg.: Journal of General Ps. 5. 1931).

- Gesetz u. Experiment in d. Ps. B. 1929.

- Zwei Grundtypen von Lebensprozessen. ZPs I 13.1929.

- Dynamical Theory of Personality N.Y. 1935.

Lindworsky, J., Experimentelle Ps. v München. 1931.

- Theoretische Ps. L. 1926.

Lipmann, O., Lehrbuch d. Arbeitswissenschaft. (Bibl.) Jena. 1932.

LipPS, TH., Das Selbstbewusstsein, Empfindung u. Gefühl. Wiesbaden. 1901.

- Vom Fühlen, Wollen, Denken. L. 1902.

Lucka, E., Problem e. Charakterologie. ArGsPs. I1. 1908.

Marbe, K., D. Gleichförmigkeit i.d. Welt. 2 Bde. München. 1916/1919.

McDougall, W., Outline of Ps. N.Y. 1923.

- Outline of Abnormal Ps. N.Y. 1926.

- The Group Mind"I. London u. N.Y. Cambridge. 1927.

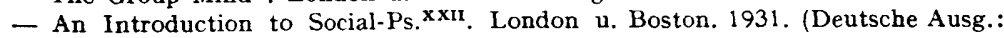
Grundlagen e. Sozial-Ps. Jena. 1928).

- The Energies of Men. N.Y. (and other cities). 1933.

- The Frontiers of Ps. London and Cambridge. 1934.

Malapert, P., Le caractère. Paris. 1903. 
Meinong, A. v., Gesammelte Abhandlungen. 1913 f.

Messer, A., Psychologieiv. L. 1928.

Meumann, E., Vorlesungen z. Einf. i. d. exp. Pädagogik ${ }^{\text {II }}$ (3 Bde.) L. 1911-14.

Michaelis, E., Seelenkunde als notwendiger Teil personalistischer Konstitutionsforschung. Arch. f. Frauenkunde u. Konstitutionsforschg. 13. L. 1927.

Möвıus, P. J., Ausgewählte Werke: I. Bd. Rousseau, II. Bd. Goethe, III. Bd. Schopenhauer. IV. Bd. Nietzsche. L. $1904 \mathrm{f}$.

Muchow, Martha, Z. Frage e. lebensraum- und epochal-typologischen Entwicklungs-Ps. d. Kindes u. Jugendlichen. 59. 1931. (Festschrift W. Stern). BhftZ AngPs. 59. - s. a. Teil III.

Müller-Freienfels, R., Charakter u. Erlebnis. Jhrb. d. Charakterol. 2-3. 1926.

- Geheimnisse d. Seele. München. 1927. (Engl. Ausg.: London 1929).

- Allg. Sozial- u. Kultur-Ps. ${ }^{\text {II. L. } 1930 .}$

- D. Hauptströmungen d. gegenwärtigen Ps. ${ }^{11}$. Wissenschaft u. Bildung. 254. L. 1930. (Engl. Ausg: Yale Univ. Press, New Haven, Conn. 1935).

Münsterberg, H., Prinzipien d. Ps. L. 1900.

Murphy, G., General Ps. N.Y., London. 1933.

Myers, C. S., A Text-book- of Experimental Ps. ${ }^{\text {II }}$. Cambridge. 1922.

NAtoRP, P., Allgemeine Ps. nach kritischer Methode. Tübingen. 1912.

PaulhaN, Fr., Les Caractères. Paris. 1894.

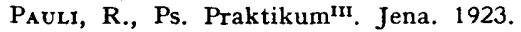

Peters, W., D. Vererbung geistiger Eigenschaften u. d. psychische Konstitution. Jena. 1925.

Petersen, P., Grundfragen e. pädag. Charakterologie. Erfurt. 1928.

Pfahler, G., Vererbung als Schicksal. E. Charakterkunde. L. 1932.

PFÄNDER, A., Grundprobleme d. Charakterologie. Jhrb. d. Charakterol. 1. 1925.

- Einführg. i.d. Ps. ${ }^{\text {II. L. } 1920 .}$

Piderit, Th., Mimik u. Physiognomik." Detmold. 1925. (1. Aufl. 1867).

PlaUt, P., Prinzipien u. Methoden d. Massen-Ps. Abderhaldens Hdbh.d.biol.Arbeitsmethoden. (Auch sep.: B., Wien 1925).

Preyer, W., D. Seele d. Kindesvi. L. 1905. (1. Aufl. 1882).

Prince, Morton, The Unconscious. N.Y. 1914.

Prinzhorn, H., Üb. d. Persönlichkeit (Ges. Aufsätze, r.) Heidelberg. 1927.

- Wege z. Charakterologie Jhrb. d. Charakterol. 2/3. 1926.

- D. Begründung e. reinen Charakterologie durch L. Klages. Jhrb. d. Charakterol. 4. 1927.

Ranschburg, P., Reflexologie und Ps. Posnań, 1932.

- Behaviorismus u. Ps. ArGsPs. 86. (3/4) 1932.

Roback, A. A., Behaviorism and Ps. Cambridge. 1923.

Schenrer, M., D. Lehre v. d. Gestalt. Ihre Methode und ihr ps. Gegenstand. B. u. L. 1931. (Bibl.).

Scheler, M., Die Stellung d. Menschen zum Kosmos. Darmstadt.

Schilder, P., Selbstbewusstsein u. Persönlichkeitsbewusstsein. 1914.

Schmied-Kowarzik, W., Umriss e. analyt. Ps. ${ }^{\text {II }}$. L. 1928.

Seifert, F., Charakterologie. Hdbh. d. Philosophie. München-B. 1929.

Shand, A., The Foundations of Charakter. London. 1926.

SPencer, H., Principles of Ps. (2 Bde). London. 1870-1872.

Spranger, E., Z. Theorie d. Verstehens u. z. geisteswiss.-Ps. (Festschr. f. J. Volkelt). München. 1918.

- Lebensformen ${ }^{\mathrm{vII}}$. Halle. 1930.

- Ps. d. Jugendalters ${ }^{x v}$. L. 1931.

Stern, W., Person u. Sache. System d. kritischen Personalismus. L. 3 Bde. I. Ableitung u. Grundlehre d. kritischen Personalismus II. 1923. - II. D. menschliche Persönlichkeit III. 1923. - III. Wertphilosophie. 1924.

- D. Ps. u. d. Personalismus ZPs. 78. 1917. (Auch sep. L. 1917).

- Studien z. Personwissenschaft. I. Personalistik als Wissenschaft. L. 1930.

- D. differentielle Ps. in ihren method. Grundl.II. L. 1921. (Bibl. bis 1921). (1. Aufl. u. d. T.: Ps. d. indiv. Differenzen. 1901).

- D. ps. Arbeit d. 19. Jahrb. insb. in Deutschland. ZPdPs. 2. (Auch sep. B. 1900). 
Stern, W., Selbstdarstellung. Aus Bd VI von „D. Philosophie d. Gegenwart in Selbstdarstellungen"' L. 1926. (Auch. sep. L. 1926). (In engl. Sprache in: History of Ps. in Autobiography; s. Teil I $1 \mathrm{~A}$ ).

- Raum u. Zeit als personale Dimensionen $A$ cta psychologica I 1935.

(Stern, W.) Festschrift 2. 60. Geb. 1931. (BhftZAngPs. 59).

Stout, G. F., A Manual of Ps. London. 1915.

- Mind and Matter, London 1932.

Stumpr, K., Erscheinungen u. psychische Funktionen (Abh. d. Kgl. preuss. Akad. d. Wissensch. 1906). B. 1907.

Strauss, E., Geschehnis u. Erlebnis. B. 1930.

Tolman, E. Сн., Purposive Behavior in Animals and Men. N.Y. 1932.

ThuRnwald, R., Ps. des primitiven Menschen. Hdbh. d. vergl. Ps. I. 1922.

Titchener, E. B., Text Book of Ps. N.Y. 1923.

Tumlirz, O., Pädagogische Ps. L. 1930.

UEXKüLL, J. v., Theoretische Biologie. B. 1928.

- Umwelt u. Innenwelt d. Tiere. B. 1921.

Utıтz, E., Charakterologie. B. 1925.

- Charakter u. Umwelt (Aus: Konstitution u. Charakter). L. 1927.

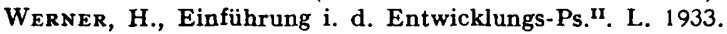

Wolff, Chr., Vernünftige Gedanken von Gott, der Welt u. der Seele des Menschen. 1719.

Watson, J. B., Ps. from the Standpoint of a Behaviorist ${ }^{\mathrm{III}}$. Philadelphia, London. 1929.

Whipple, G. M., Manual of Mental and Physical Tests. ${ }^{\text {II }}$. Baltimore. 1914/15.

WOODWORTH, R. S., PsychologyIII. N.Y. 1933.

Wundt, W., Grundriss d. Ps. ${ }^{x v}$. L. 1922. (1. Aufl. 1896).

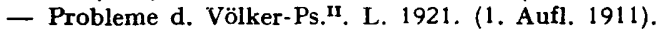

- Völker-Ps ${ }^{\text {III. }}$ (6 Bde). L. 1911-1922.

- Vorlesungen üb. Menschen- u. Tierseele ${ }^{\mathrm{vII} / \mathrm{vmI}}$. Hamburg. 1922.

- Einführung i. d. Ps.v. L. 1920.

- Grundzüge d. physiolog. Ps. (3 Bde. u. Reg.-Bd.) L. I. Bd ${ }^{\mathrm{vIr}} 1925$, II. Bd ${ }^{\mathrm{vI}} 1910$, III. Bd $^{\text {vI }}$ 1911. (1. Aufl. 1874).

Ziehen, Th., Allgemeine Ps. (In: Handbücher d. Philosophie). B. 1923.

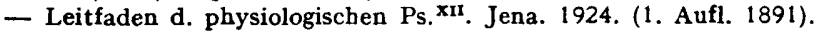

\section{SINNESWAHRNEHMUNG}

Anschürz, G., Farbe-Ton-Forschungen. L. 1927.

ARgelander, A., D. Farbenhören u.d. synästhetische Faktor d. Wahrnehmung. Jena. 1927. (Bibl.).

Benussi, V., Ps. d. Zeitauffassung. Heidelberg. 1913.

Bos, M. C., Ubber echte u. unechte audition colorée. ZPs. IrI. 1929.

Brunswik, E., s. Teil I B.

BÜHLER, K., D. Gestaltwahrnehmungen. Stuttgart. 1913.

- Handbuch d. Ps. I (1). D. Erscheinungsweisen d. Farben. Jena. 1922.

Edinger, Einführung i. d. Lehre vom Bau u. d. Verrichtungen d. Nervensystems. L. 1909.

Ehrenfels, Chr. v., Üb. Gestaltqualitäten. Vierteljahrsschr. f. wiss. Philos. 14. 1890.

Garten, S., Ub. d. Grundlagen unserer Orientierung im Raume. Abh. d. math.-phys. Klasse d. sächs. Akad. d. Wiss. 36. (4). 1920.

GelB. A. „D. Farbenkonstanz”'d. Sehdinge. Hdbh.d. norm. u. pathol. Physiol. 12.1929.

- Grundfragen d. Wahrnehmungs-Ps. Ber. üb. d. VII. Kongr. f. exper. Ps. L.1922.

Helmholtz, H. v., D. Tatsachen i. d. Wahrnehmung. B. 1879.

- Handbuch d. physiol. Optik ${ }^{\text {III }}$. (Hrsg. v. Nagel u. anderen). 3 Bde. L. 1909-11.

- D. Lehre von d. Tonempfindungen als physiol Grundlage. f. d. Theorie d. Musikvi. Braunschw. 1913. (1. Aufl. 1877).

Henning, H., D. Geruch. ZPs. 73. 74. 75. 76. 1915/16.

- D. Geruch. Ein Handbuch usw. L. 1924. 
Henning,H., Ps. Studien z. Geschmackssinn Abderhaldens Hdbh. d. biol. Arbeitsmethoden. 6. 1922.

- Ps. Untersuchungen am Geruchssinn Ebda 6. 1925.

Hering, E., Zur Lehre vom Lichtsinn. Gräfe-Sämischs Hdbh. d. ges. Augenheilkunde. I. L. 1905 u. 1907.

Hönigswald, R., Vom Problem d. Rhythmus. 1926.

Hornborstel, E. M. v., D. Einheit d. Sinne. Melos. 4. 1925.

Husserl, E., Vorlesungen $z$. Phänomenologie d. inneren Zeitbewusstseins (Hrsg. M. Heidegger). Halle. 1928.

JAENSCH, E. R., Üb. d. Wahrnehmung d. Raumes. ZPs. Erg.-Bd. 6. 1911.

- Z. Analyse d. Gesichtswahrnehmungen. ZPs. Erg.-Bd. 4. 1909.

KATZ, D., D. Aufbau d. Tastwelt. ZPs. Erg.-Bd. II. 1925.

- D. Aufbau d. Farbwelt II. ZPs. Erg.-Bd. 7. L. 1930. (1. Aufl. u. d. T.: D. Erscheinungsweisen d. Farben. 1911).

Katz, D. u. Révész, G., Musikgenuss bei Gehörlosen. ZPs. 99. 1926. (Auch. sep.: L. 1926).

Katz, D., Üb. d. Vibrationssinn, Ber. üb. d. VIII. int. Kongr. f. Ps. Groningen. 1927.

- Methoden z. Unters. d. Vibrationssinnes. Abderhaldens Hdbh. d. biol. Arbeitsmeth. 5. 1930.

Keller, Helen, The Story of my Life. Garden City, N.Y. 1931. (1. Aufl. 1902). (Deutsche Ausg.: „Die Geschichte meines Lebens”. Stuttgart. 1904).

KoffkA, K., Ps. d. optischen Wahrnehmung. Hbdh. d. norm. u. pathol. Physiol. 12. B. 1930 .

KоEнLER, W., Üb. unbemerkte Empfindungen u. Urteilstäuschungen. ZPs. 66. 1913.

- Komplextheorie u. Gestalttheorie. PsFo 6. 1925.

- D. physischen Gestalten in Ruhe- u. im stationären Zustand. Braunschweig u. Erfurt. 1920.

- Gestaltprobleme u. Anfänge e. Gestalttheorie. Sammelreferat. Jahresber. $a b . d$. ges. Physiol. u. experim Pharm. B. 1922.

- Akustische Untersuchungen. ZPs. 54. 58. 64. 1909-1913.

KöNIG und BrodHun, Untersuchg. d. Unterschiedsempfindlichkeit f. Helligkeiten. Sitzungsber. d. Berl. Akad. d. Wiss. 1888, 1889.

LIPPS, Tн., Raumästhetik u. geometrisch-optische Täuschungen. Schriften d. Gesellsch. f. ps. Forsch. 2. 1897.

Lotze, H., Medizinische Ps. od. Physiologie d. Seele. L. 1852.

Löwı, M., Üb. spezifische Sinnesenergien. Ps. u. Physiologie. Breslau. 1927.

MACH, E., D. Analyse d. Empfindungen u.d. Verhältnis d. Physischen z. Psychischen. Jena. 1900.

Muchow, MARThA, Beiträge 2. ps. Charakteristik d. Kindergarten- u. Grund-schulalters. Päd.-ps. Schriftenreihe d. Allg. Deutschen Lehrerinnenvereins. 3. B. 1926.

Müller, G. E., Komplextheorie u. Gestalt theorie. 1923.

- Utb. d. Farbenempfindungen. Psychophysische Untersuchungen. L. 1930.

Müller, Joh., Handb. d. Physiologie d. Menschen. 2. Bd. 1. Abt. Koblenz. 1837. Spezif. Sinnesenergien: S. $250 \mathrm{ff}$.

Ostwald, W., D. Grundlage d. messenden Farblehre. Grossbothen. 1921.

Petermann, B., D. Wertheimer-Köhler-Koffka'sche Gestalttheorie. L. 1929. (Bibl.).

- D. Gestaltproblem in d. Ps. im Lichte analytischer Besinnung. L. 1931.

Plessner, H., D. Einheit d. Sinne. Bonn. 1923.

RÉvÉsz, G., System d. optischen u. haptischen Raumtäuschungen. ZPs. 131. 1934. - Zur Grundlegung d. Ton-Ps. L. 1913.

Rhine, J. B., Extra-Sensory Perception. Boston. 1934.

Rubin, E., Visuell wahrgenommene Figuren. 1. Teil: Kopenhagen, Christiania, B., London. 1921 .

Rutz, O., Musik, Wort u. Körper als Gemütsausdruck. L. 1911.

ScheERER, M., s. Teil I. B.

Stern, W., Psychische Präsenszeit. ZPs. 13. 1897.

- Ps. d. VeränderungsauffassungII. L. 1906 (1. Aufl. 1898).

- Helen Keller, Entwicklung u. Erziehung einer Taubstummblinden. B. 1905. 
StrRn, W., Die Wahrnehmung v. Bewegungen vermittelst des Auges. ZPs. 7. 1894. Stratron, G. M., Vision without Inversion of the retinal Image. Ps. Review. 4. 1897. Strauss, E., D. Formen d. Räumlichen. Nervenarzt. 3. 1930.

STUMPF, C., Üb. d. ps. Ursprung d. Raumvorstellung. L. 1873.

- Tonpsychologie. 2 Bde. L. 1883 u. 1890.

- Üb. neuere Untersuchungen z. Tonlehre. Ber. üb.d.VI. Kongr. f. exper. Ps.1914.

Weber, E. H., Tastsinn u. Gemeingefübl. Wagners Handwörterbuch d. Physiol. 3. (II). 1846.

Weinmann, D. Lehre v. d. spezifischen Sinnesenergien. 1895.

Wellek, A., Z. Geschichte u. Kritik d. Synästhesie-Forschung. ArGsPs. 79. 1931.

Werner, H., Grundfragen d. Intensitäts-Ps. ZPs. Erg.-Bd. Io. 1922.

- Untersuchungen üb. Empfindung u. Empfinden 1. D. Problem d. Empfindens u. d. Methoden seiner experimentellen Prüfung. ZPs. II4. 1930.

- L'unité des sens. (Bibl.). Journal de ps. 31. 1934.

Wertheimer, M., Drei Abhandlungen z. Gestalttheorie. Philosoph. Ak. Erlangen. 1925.

- Unters. z. Lehre v.d. Gestalt PsFo 3 ff.

Wohlwill, Elisabeth, Typische Verhaltensweisen im Wahrnehmen. (Hamburg, Diss.) 1934.

Zietz, K., Gegenseitige Beeinflussung von Farb- u. Tonerlebnissen. ZPs. 121. 1931.

\section{GEDÄCHTNIS. VORSTELLUNGEN}

Adams, D. K., A Restatement of the Problem of Learning. Brit. Journal of Ps. 22. 1931.

BaERwald, R., Zur Ps. d. Vorstellungstypen. L. 1916.

Bartlett, R. J., Remembering: an exper, and social Study. London. 1932.

Betz, W., Vorstellung u. Einstellung ArGsPs. 17. 1910.

Bonte, T., Liefmann, E., Rössler, F., Untersuchungen üb. d. eidetische Veranlagung v. Kindern u. Jugendl. Bhtt $Z A$ AngPs. 43.

Brunswik, E. (mit Goldscheider u. Pilek), Untersuchungen z. Entwicklung d. Gedächtnisses. Bhft ZAngPs. 64. 1932.

Bíhler, Charlotte, D. Märchen u. d. Phantasied. Kindes ${ }^{11}$. Bhft ZAngPs. 17. 1925. BüHLER, K., Üb. Gedankenerinnerungen. ArGsPs. I2. 1908.

Busse, Über d. Gedächtnisstufen u. ihre Beziehung z. Aufbau d. Wahrnehmungswelt. ZPs. 84. 1920.

Claparkede, Ed., L'association des idées. Paris. 1909. (Bibl.).

Ebminghaus, H., Üb. d. Gedächtnis. L. 1885.

Fischer, Ottokar, E. ps. Grundlage d. Wiederkunftsgedankens. (Bem. üb. d. literar. Wert d. „fausse reconnaissance”). ZAngPs. 5. 1911.

Gorphe, F., La critique du témoignage." Paris. 1927.

Herbart, J. F., s. Teil I B.

Hering, E., Über d. Gedächtnis als allgemeine Funktion d. organisierten Materie."I L. 1912. (1. Aufl. Wien. 1870.)

Heymans, G., Fausse reconnaissance et dépersonnalisation. ZPs. 36. 1906.

JAENSCH, E. R., Üb. d. subjektiven Anschauungsbilder. Ber. üb. d. VII. Kongr.d. Ges. f. exper. Ps. in Marburg. Jena. 1922.

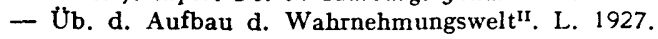

- D. Eidetik u. d. typologische Forschungsmethode. L. 1925. (Engl.Ausg.: N.Y. u. London 1930).

Jost, A., D. Assoziationsfestigkeit in ihrer Abhängigkeit v. d. Verteilung d. Wiederholungen. ZPs. 14. 1897.

Jung, C. G., Diagnostische Assoziationsstudien. L. 1905.

KlUever, H., An Experimental Study of the Eidetic Type. Genetic Ps. Monographs. I. (2) 1926.

Koffka, K., Z. Analyse d. Vorstellungen u. ihrer Gesetze. L. 1912.

Кrон, O., Subjektive Anschauungsbilder b. Jugcndlichen. Göttingen. 1924.

LANGE, K., Üb. Apperzeptionv. Plauen. 1885. 
LEwın, K., D. psychische Tätigkeit bei d. Hemmung v. Willensvorgängen u. d. Grundgesetz d. Assoziation. ZPs. 77. 1917.

LipMAN , O., D. Spuren interessebetonter Erlebnisse u. ihre Symptome. Bhft ZAng Ps. I. 1911.

- Methoden d. Aussage-Ps. (Bibl.). Abderhaldens Hdbh. d. biol. Arbeitsmethoden. 4. Lobsien, M., D. Gedächtnis. Osterwieck. 1913.

MARBE, K., D. Psycholog als gerichtlicher Gutachter im Straf- u. Zivilprozess. Stuttgart. 1926.

Meumann, E., Okonomie u. Technik. d. Gedächtnisses III. L. 1912.

M ÜLLER, G. E., Zur Analyse d. Gedächtnistätigkeit u. d. Vorstellungsverlaufes. Erg.-Bde zu ZPs. 5. 8. 9. L. 1911, 1917, 1924.

Mönkemöller, O., Ps. u. Psychopathologie d. Aussage (Bibl.). Heidelberg. 1930. Muchow, Martha u. Hans, D. Lebensraum d. Grossstadtkindes Hamburg. 1935. OfFNer, M., D. Gedächtnis ${ }^{\text {IV }}$ (Bibl.). B. 1924.

Oesterreich, T. K., D. Phänomenologie d. Ich. I. Bd. D. Ich u. d. Selbstbewusstsein. D. scheinbare Spaltung d. Ich. L. 1910.

Pfeiffer, L., Üb. Vorstellungstypen. Päd. Monographien. 2. L. 1907.

Plaut, P., D. Zeuge u. seine Aussage im Strafprozess. L. 1931.

- Ps. Gutachten in Strafprozessen. BhftZAngPs. 65. 1932.

Ranschburg, P., D. kranke Gedächtnis. L. 1911.

Reichardt, H., D. Früherinnerung als Trägerin kindlicher Selbstbeobachtungen. Halle. 1926.

Rомвасн, J., Bewahrendes u. verarbeitendes Gedächtnis als echte Typen. $Z A$ ngPs. 25. 1925.

Ron Jat, J., Le développement du langage observé chez un enfant bilingue. Paris.1913.

Seelig, E., D. Ergebnisse u. Problemstellungen d. Aussageforschung. Ergebnisse d. ges. Medizin. 13. 1929. (Bibl.).

Semon, R., D. Mneme als erhaltendes Prinzip im Wandel d. organischen Gesche-

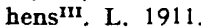

Siebert, K., Einstellung u. Denken. E. exp. Untersuchung ArGsPs. 82. 1931.

STERN, ERICH, Üb. bewahrendes u. verarbeitendes Gedächtnisverfahren. ZAngPs. 20. 1922.

Stern, Clara und Williak, Erinnerung, Aussage u. Lüge i.d. frühen Kindheit ${ }^{I v}$. L. 1931.

Stern, W., Zur Ps. d. Aussage. B. 1902.

- Jugendliche Zeugen in Sittlichkeitsprozessen. L. 1926.

- D. Aussage als geistige Leistung u. als Verhörsprodukt. L. 1904.

- Personalistik d. Erinnerung. ZPs. I18. 1930.

- Fallsammlung zu: Forensisch-ps. Gutachtertätigkeit. ZAngPs. 45. (S. $412 \mathrm{ff}) 1933$.

- Differentielle Ps. s. Teil I B.

- Ps. d. fr. Kindheit s. Teil I B.

(Stern, W. Herausgeber). Beitr. z. Ps. d. Aussage s. Teil I A 2.

ThORNDIKE, E. L., The Fundamentals of Learning. (Bibl.) N.Y. 1932.

Volkelt, H., Über d. Vorstellungen d. Tiere. Arb. z. Entwicklungs-Ps. (Hrsg. v. F. Krueger). I (2) 1914.

Wertheimer M. u. Klein, J., Ps. Tatbestandsdiagnostik. Arch. $f$. Kriminologie, 15. 1905.

WeSSEly, R., Zur Frage d. Auswendiglernens Neue Jahrbiucher f. d. klass. Altertum u. f. Pädag. (Zweiter Teil). 16. 1905.

Wreschner, A., D. Gedächtnis im Lichte d. Experiments ${ }^{\text {II }}$. Zürich. 1910.

- Methoden zur Analyse d. Vorstellung u. d. Gedächtnisses. Abderhaldens Hdbh. d. biolog. Arbeitsmeth. B. 1922.

Wund, W., s. Teil I B.

ZIEhEN, Th., (s.a. Teil I B). D. Gedächtnis. B. 1908. 


\section{DENKEN UND PHANTASIE}

Acr, N., Ưb. d. Willenstätigkeit u.d.Denken, Göttingen. 1905.

- Ub. d. Begriffsbildung. Unters z. Ps. u. Philos. 3. 1921.

ADLER, A., s. Teil I B.

Brnet, A., La pensée sans images. Revue philos. r. 1909.

Binet, A. et Simon, Th., Le développement de l'intelligence chez les enfants. Année ps. 14. 1908.

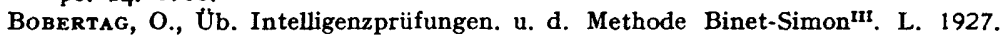

Bobertag, O. u. Hylla, E., Begabungsprüfung f. d. letzten Volksschuljahre. Testhefte m. Anleitung u. Schlüssel ${ }^{11}$. B. 1927.

Bourdon, B., La pensée sans images. Journal de Ps. 1923.

Brehmer, F., Melodieauffassung u. melodische Begabung d. Kindes. BhftZAngPs.36. 1925.

Bronner, A. F., Healy, W., Lowe, G. M., Himberg, M. E., A Manual of Individual Mental Tests and Testing. Boston. 1928.

Bühler, Charlotte; Üb. Gedankenentstehung. Experim. Unters. z. Denk-Ps. $Z$ Ps. 80. 1918.

- Märchen. s. Teil IIl.

Bühler, Charlotte; Hetzer, Hildegard, Kleinkindertests. (1. bis 6. Lebensjahr). L. 1932.

BüHLER, K., D. Geistige Entwicklg. s. Teil I B.

- Tatsachen u. Probleme zu e. Ps. d. Denkvorgänge. ArGsPs. 9. 1907. I2. 1908.

Burt, C., Mental and Scholastic Tests." London. 1927.

Buxtendijk, F. J. J., Het Spel van Mensch en Dier. Amsterdam 1932. (Deutsche Ausg.: Wesen und Sinn des Spiels. B. 1933).

Cassirer, E., Philosophie d. symbolischen Formen (3 Bde). B. - Bd. I. D. Sprache. 1923. - Bd. II. D. mythische Denken. 1925. - Bd. III. Phänomenologie d. Erkenntnis. 1929.

Claparède, Ed., Ps. de l'enfant et pédagogie expérimentale ${ }^{\mathrm{II}}$. Genf. 1926.

- La genèse de l'hypothèse. Etude expérimentale. Archives de Ps. 24. (Auch sep.: Genève. 1934).

DEcroly, Ov., Comment l'enfant arrive à parler. 2 Bde. (Bibl.). Bruxelles. 1933.

Descoevdres, A., Le développement de l'enfant de deux à sept ans. NeuchâtelParis. 1921.

Dessolr, M., Ästhetik u. allgemeine Kunstwissenschaft ${ }^{11}$. Stuttgart. 1923.

Ebringhnus, H., Üb. e. neue Methode z. Prüfung geistiger Fähigkeiten u. ihre Anwendung b. Schulkindern. ZPS. I3. 1897.

Eliasberg, W., Ps. u. Pathologie d. Abstraktion. BhftZAngPs. 35. 1925.

Eng, Helga, Abstrakte Begriffe im Sprechen u. Denken d. Kindes. BhftZAngPs. 8. 1914.

Erdmann, B., Umrisse zu e. Ps. d. Denkens"Ir. Tübingen. 1908.

Fischer, C. F., D. Nullpunkt-Existenz dargestellt an d. Lebensform Sören Kierkegaards. München. 1933.

FreUd, S., D. Traumdeutung ${ }^{\text {vir }}$. L. u. Wien. (1. Aufl. 1899). Siehe auch Teil I B.

- Z. Psychopathologie d. Alltagslebens ${ }^{\mathrm{XI}}$. Wien. 1929. (1. Aufl. B. 1904). S.a. Teil I B.

GeIGer, M., Zugänge zur Ästhetik. L. 1928.

Gesell, A., The Mental Growth of the Pre-school Child. N.Y. 1925.

- Infancy and Human Growth N.Y. 1928. (Deutsche Ausg.: Körperseelische Entwicklg. i. d. frühen Kindheit. Halle. 1931).

GrRgensohn, K., s. Teil I B.

Goltz, Fr., D. Hund ohne Grosshirn. Arch. f. d. ges. Physiol. 51. 1892.

Groos, K., D. Spiele d. Tiere ${ }^{\mathrm{III}}$. Jena. 1930. (1. Aufl. 1896). (Engl. Ausg.: N.Y. 1898).

- D. Spiele d. Menschen. Jena. 1899. (Engl. Ausg.: N.Y. 1901).

- D. Spiel. Jena. 1922. (1. Aufl. u. d. T.: D. Lebenswert d. Spiels. 1910).

- D. aesthetische Genuss. Giessen. 1902.

- Seele d. Kindes s. Teil I B.

(H. Grosser u. W. Stern, Herausg.) D. freie Zeichnen u. Formen d. Kindes. L. 1913. 
Grünbaum., A. A., Üb. d. Abstraktion d. Gleichheit. ArGsPs. 12. 1908.

- Untersuchungen üb. d. Funktionen d. Denkens u. d. Gedächtnisses. ArGsPs. I-IV. $1917 / 19$.

HALL, St., S. Teil I B.

Hetzer, Hildegard., D. volkstümliche Kinderspiel. Wiener Arb.z.päd.Ps. 5. 1927.

HiLdRETh, S. Teil I A 1.

Hönigswald, R., D. Grundlagen d. Denk-Ps. L. 1925.

HUSSERL, E., S. Teil I B.

JAENSCH, E. R., s. Teil I B. u. II.

KAINZ, FR., Personalistische Ästhetik. L. 1932.

Kerschbaum, P., D. Ernstspiel d. Jugendlichen. (Diss. Hamburg). 1933.

Kerschensteiner, G., D. Entwicklung d. zeichnerischen Begabung. München. 1905.

KlaGes, L., s. Teil I B.

Konhler, W., Intellig. Prüfg. s. Teil I B.

KoffKa, K., Psych. Entwicklg. s. Teil I B.

Kraepelin, E., D.ps. Versuch i. d. Psychatrie. Kraepelins Ps. Arbeiten. I 1896.

KraEPElin, E., Üb. Ermüdungsmessungen. ArGsPs. I. 1903.

Krall, K., Denkende Tiere. L. 1912.

KRUEGER, F. U. SPEARMAN, C. E., D. Korrelation zwischen verschiedenen geistigen Leistungsfähigkeiten. ZPs. 44. 1906.

KülPE, O., Versuche üb. Abstraktion. Ber. üb. d. I. Kongr. f. exp. Ps. in Giessen. L. 1904.

- Üb. d. moderne Ps. d. Denkens. Internat. Monatsschr. $f$. Wissensch., Kunst u. Technik. 9. 1912.

Lazarus, M., s. Teil I B.

LEVY-BRUEHL, L., S. Teil I B.

LiEPMANN, H., Üb. Ideenflucht. Halle. 1904.

Lindworsky, J., D. schlussfolgernde Denken. Exp. ps. Unters. Freiburg. 1916.

- Methoden d. Phantasieforschung - Methoden d. Denkforschung. Abderhaldens Hdbh. d. biol. Arbeitsmeth. 6. 1922.

LipmanN, O., Ùb. Begriff u. Erforschung d. „natürlichen” Intelligenz. ZAngPs. 13. 1918.

- Abzählende Methoden u, ihre Verwendung in d. ps. Statistik. L. 1921.

- Handbuch ps. Hilfsmittel d. psychiatrischen Diagnostik. L. 1922.

- Bibliographie z. ps. Berufsberatung u.s.w. Schriften z. Ps. d. Berufseignung. 20. 1922.

- Üb. Begriff u. Formen d. Intelligenz. ZAngPs. 24. 1924. (Auch. sep. L. 1924).

Lipmann O. u. Bogen, H., Naive Physik. Theor. u. experim. Unters üb.d. Fähigkeit $\mathrm{zu}$ intelligentem Handeln. L. 1923.

LiPpS, Th., Aesthetik. Ps. d. Schönen. L. 1905/6.

MARBE, K., Experimentell-ps. Untersuchungen üb. d. Urteil. L. 1901.

MAYer-Gross, W. u. Lipps, H., D. Problem d. primitiven Denkformen. Philos.Anzeiger. 4. 1930.

Messer, A., Empfindung u. Denken ${ }^{\text {III }}$. L. 1928.

Meyerson, J., Les images (Bibl.) Journal de Ps. normale et pathologique. 25. 1929.

Moskiewicz, G., Zur Ps. d. Denkens. ArGsPs. 18. 1910.

Mtuchow, Martha, Ps. Beobachtungsbogen f. Schulkinderv. L. 1924. (1. Aufl. 1919).

- Zur Problematik d. Test-Ps. im allg. u. einiger Ordnungstests im bes. In: Bhft ZAng Ps. 34. 1925.

Mïlller-Freienfels, R., Vorstellen u. Denken ZPs. 60. 1912.

- Ps. d. Kunst ${ }^{\text {III }} .2$ Bde. L. 1923.

- D. Denken u. d. Phantasie"I. L. 1925.

NoAck, H., Das Spiel (Bibl.). Ztschr. f. Asthetik u. allg. Kunstwiss. 27. 1933.

PETERS, W., D. Intelligenzproblem u. d. Intelligenzforschung. ZPs. 89. 1922.

Pfungst, O., D. Pferd d. Herrn v. Osten. L. 1907. (Engl. Ausg. u. d. Titel: Clever Hans. N.Y. 1911).

PiAget, J., La pensée symbolique et la pensée de l'enfant. Arch. de ps. 18. 1923.

- Le langage et la pensée chez l'enfant. Neuchâtel et Paris. 1923. (Engl. Ausg.: N.Y. u. London. 1926). 
Praget, J., Le jugement et le raisonnement chez l'enfant. Neuchâtel et Paris. 1924 . (Engl. Ausg.: N.Y. u. London. 1928).

- La représentation du monde chez l'enfant. Paris. 1926. (Engl. Ausg.: N.Y. u. London. 1929).

- La causalité physique chez l'enfant. Paris. 1927. (Engl. Ausg. : N.Y. u. London 1930).

- Le jugement morale chez l'enfant. Paris. 1932. (Engl. Ausg.: London 1932).

Piéron, H., Le cerveau et la pensée. Paris. 1923. (Engl. Ausg.: 1927).

- Le développement mental et l'intelligence. Paris. 1929.

Prager, F., Exp.-ps. Untersuchg. üb. rhythmische Leistungsfähigkeit von Kindern. ZAngPs. 26. 1926.

Révesz, G., Prüfung d. Musikalität. ZPs. 85. 1920.

- Abstraktion u. Wiedererkennung. Vergl. ps. Vers. an Menschen und an nied. Affen. ZPs. 98. 1925.

Rossolımo, G., Die ps. Profile. Klinik f. psych. u. nerv. Krankheiten. 6. 1911; 7. 1912.

RUPP, H., Üb. d. Prüfung musikalischer Fähigkeiten. ZAngPs. 9. 1914.

SARRIS, E. G., Sind wir berechtigt vom Wortverständnis. d. Hundes zu sprechen? BhttZAngPs. 62. 1931.

Schiller, F., Briefe üb. d. aesthet. Erziehung d. Menschen. 1795.

Seashore, C. E., The Ps. of Musical Talent. Boston. 1919.

- Manual of Instructions and Interpretations for Measures of Musical Talent. N.Y. 1919.

Selz, O., Üb. d. Gesetze d. geordneten Denkverlaufs. Bonn. 1913.

- Zur Ps. d. produktiven Denkens u. d. Irrtums. Bonn. 1922.

- Die Gesetze der produktiven und reproduktiven Geistestätigkeit. Bonn 1924.

SPEARMan, C. E., "General Intelligence" Objectively determined and measured. A m. J. Ps. I5. 1904.

- The Nature of "Intelligence" and the Principles of Cognition ${ }^{11}$. London and N.Y. 1927.

- The Abilities of Man; their Nature and Measurement. London and N.Y. 1927.

SPENCER, H., S. Teil I B.

Stern, ERICH, D. Begriff u. d. Untersuchg. d. natürlichen Intelligenz. Monatschr. $f$. Psychiatrie u. Neurol. 46. 1919.

Stern, Clara u. William, D. Kindersprache. E. ps. u. sprachtheoret. Unters. ${ }^{\mathrm{IV}}$. L. 1928.

- Erinnerung, Aussage u. Lüge in d. ersten Kindheit ${ }^{\mathrm{Iv}}$. L. 1931. (Hieraus sep.: Dauerphantasien im 4. Lebensjahre. ZAngPs. 38. 1931.)

Stern, W., Ps. d. frühen Kindheit s. Teil I B.

- D. Intelligenz d. Kinder u. Jugendlichen u. d. Methoden ihrer Untersuchungrv. L. 1928.

- D. Ernstspiel d. Jugendzeit. ZPdPs. 25. 1924.

- Ernstspiel als Verhalten u. als Erlebnis. ZPdPs. 30. 1929. (Engl. Ausg. in: Feelings and Emotions s. Teil VI).

Stern, W.-WiegmanN, O., Methodensammlung z. Intelligenzprüfung v. Kindern u. Jugendlichen ${ }^{\mathrm{III}}$. BhftZ AngPs. 20. L. 1926.

Terman, L. M., The Measurement of Intelligence. N.Y. 1916.

- Condensed Guide for the Stanford Revision. Boston. 1920.

- The Intelligence of School Children. Boston. 1919.

- Genetic Studies of Genius. 2 Bde. Stanford Univ. Press. 1925/6.

ThORNDIKE, ED. L. (and collaborators). The Measurement of Intelligence. N.Y. 1926.

Thurnwald, R., Prae-Logik?. Z.f.Völker-Ps. u. Soziologie, 4. 1928.

UEXKull, J. v., s. Teil I B.

Usmadze, D., D. Begriffsbildung im vorschulpflichtigen Alter. ZAngPs. 34. 1930.

Utitz, E., Grundlegung d. allg. Kunstwissenschaft (2 Bde). Stuttgart. 1914/1920.

Valentiner, Th., D. Phantasie im freien Aufsatze d. Kinder u. Jugendlichen ${ }^{11}$. BhftZAngPs. 13. 1930.

Vortragsreihe zum Gesamtthema Sprachtheorie. ( 9 Verfasser). Ber. üb. d. XII. Kongr. d. Deutschen Gesellsch. f. Ps. in Hamburg. Jena. 1932.

Washburn, M. F. The Animal Mind"II. N.Y. 1926.

WAtr, H. J., Exper. Beiträge z.e. Theorie d. Denkens. ArGsPs. 4. 1904. 
Werner, H., Entwicklungs-Ps. s. Teil I B.

- Grundfragen d. Sprachphysiognomik. L. 1932.

Wertheimer, Max, Üb. d. Denken d. Naturvölker. Zahlen u. Zahlengebilde. $Z$ Ps. 60. 1912.

- Üb. Schlussprozesse im produktiven Denken. B. u. L. 1920.

Willwoll, A., Begriffsbildung. L. 1926.

Wundr, W., Üb. Ausfrageexperimente u. üb. d. Methoden z. Ps. d. Denkens. Ps. Studien. 3. 1907.

Yerkes, R. M., Bridges, J. W. and Hardwich, R. S., A Point Scale for Measuring Mental Ability. Baltimore. 1915.

YeRKes. R. M. (and collaborators). Ps. examining in the United States Army. Mem. Nat. Acad. Sci. 15. 1921.

ZEININGER, K., Magische Geisteshaltung im Kindesalter u. ihre Bedeutung f. d. religiöse Entwicklg. (Bibl.) BhftZAngPs. 47. 1929.

ZifHen, Th., D. Prinzipien u. Methoden d. Begabungs-, insbes. d. Intelligenzprüfung u. d. ethischen Gefühlev. B. 1923.

\section{STREBEN. HANDELN. LEISTEN}

Abramowski, E., Recherches exp. sur la volonté. Journal de Ps. norm. et pathol. 10. 1913.

Aсн, N., (s. a. Teil IV) Über den Willensakt u. d. Temperament. L. 1910.

- (Verschiedene Abhandlungen uib. d. Willen) Unters. z. Ps. u. Philos. 1. 1910, 1911, 1912.

- Ưb. d. Entstehung d. Bewusstseins d. Willensfreiheit. Ber. üb. d. X. Kong. f. exp. Ps. Jena, 1928.

Achille-Dermas, F., Ps. pathologique du suicide. Paris 1932.

Adler, A., s. Teil I B.

ALLEN, A. H. B., Pleasure and Instinct. London, N. Y. 1930.

Bahnsen, J., Z. Verhältnis zwischen Wille u. Motiv; e. metaphysische Voruntersuchung zur Charakterologie. Lauenburg 1870.

Bernfeld, S. Trieb u. Tradition im Jugendalter. BhftZAngPs. 54, 1931.

Binet, A., La suggestibilité. Paris, 1900.

Bühler, CH., (s. a. Teil I). Zwei Knabentagebücher. Jena, 1925.

- Tagebuch eines jungen Mädchens'r. Jena 1927.

- Jugend tagebuch u. Lebenslauf. Jena 1932.

BüHLER, K., D. Instinkte des Menschen. Ber. üb. d. IX. Kongr.f. exp. Ps. Jena 1926.

Claparitde, Ed., Does the Will express the entire Personality? In: Problems or Personality. London, 1925.

DessolR, M., Vom Jenseits der Seele. D. Geheimwissenschaften in kritischer Betrachtungir. Stuttg. 1919.

DÜrR, E. Die Lehre v. d. Aufmerksamkeit. L. 1914.

FERE, CH., Sensation et mouvementII Paris 1900.

Fischer, A., Moral-ps. Untersuchungsmethoden. ZPdPs. 29, 1928.

FREUD, S. S. Teil I B.,

GLÄSSNER, G., Ub. Willenshemmung u. Willensbahnung. Unters. z. Ps. u. Philos. I, 7, 1912.

Goldstein, K., s. Teil I B.

Häberlin, P., Der Geist u. d. Triebe. Basel 1924.

Hattingberg, H. V., Trieb u. Instinkt. E. definitorischer Versuch. ZAngPs. I7, 1920.

Henning, H., D. Aufmerksamkeit. B., Wien 1925.

Honecker, M., Die Gesinnung u. ihre Arten. Arch. Gs. Ps. 86, 1932.

ISSERLIN, M., Üb. d. Ablauf einfacher willkürlicher Bewegungen. L. 1910.

Joel, K., Der freie Wille. München 1908.

Karsten, A. L. Chr. Psychische Sättigung. PsFo. 10, 1928.

Katz, D., Sozial-Ps. d. Vögel. Ergebn. d. Biol. I, 1926.

- Hunger u. Appetit. Unters. z. medizin. Ps. L. 1932.

- Zur Grundlegung einer Bedürfnis-Ps. Acta psychologica. 1. 1935. 
KERN, B., Wirkungsformen d. Übung. (Bibl.) Münster i. W. 1930.

Kerschbaum, P. ,s. Teil IV.

Klages, L., s. Teil I B.

Köhler, ElsA, Die Persönlichkeit d. dreijährigen Kindes. L. 1926.

LANGFELD, H. S., Voluntary Movement under positive and negative Instruction. Ps. Rev. 20. 1913.

LEwIN, K., s. a. Teil I B. u. III.

- (Herausg.) Untersuch. z. Handlungs- u. Affekt-Ps. PsFo. 7 ff.

- D. Problem d. Willensmessung u. d. Grundgesetz d. Assoziation. PsFo. 1, 2. 1922.

- Vorsatz, Wille u. Bedürfnis. PsFo. 7. 1926.

- D. Entwicklung der exp. Willensps. u. die Psychotherapie. L. 1929.

- Die ps. Situation bei Lohn u. Strafe. L. 1931.

Lindworsky, J., Der WilleII L. 1923.

LIPMANN, O., Arbeitswissenschaft. s. Teil I B.

LOEWENBERG, R. D., Ưb. d. Selbstmord in Hamburg i. d. letzten 50 Jahren (Bibl.) Veröffentl. a. d. Geb. d. Medizinalverwaltg. 38. B. 1932.

Lundholm, H., Conation and our Conscious Life. Duke Univ. Psychol. Monogr. 3. Durham, N. C. 1934.

Mann, A., Zur Ps. ù. Psychographie der Aufmerksamkeit. ZAngPs. 9, 1915.

MeumanN, E., Intelligenz u. Willev L. 1924.

Michotte, A., et PRÜM, E., Le choix volontaire et ses antécédents immédiats. Louvain-Genève, $1910 \mathrm{u}$. Arch. de Ps. 10. 1910.

Müller-Freienfels, R., Grundzüge einer Lebens-Ps. Bd. 1. Das Gefühls- und Willensleben. L. 1924.

Ovsiankina, Maria, Wiederaufnahme unterbrochener Handlungen. PsFo. I1, 1928.

Peller, S., Z. Statistik d. Selbstmordhandlungen. Allg. statist. Arch. 22.1932.

Peters, W., s. Teil I B.

Prander, A., Zur Ps. d. Gesinnungen. Jahrb. $t$. Philos. u. phänom. Forschg. 1, 3. $1913 / 16$.

- Phänomenologie des WollensII L. 1930.

Rtvtsz, G., Ub. d. friihzeitige Auftreten d. Begabung. ZAngPs. 15.1919.

Rıвот, Th., Ps. de l'attention. (Deutsch: Ps. d. Aufmerksamkeit 1908).

SANDER, HJalyar, Die exp. Gesinnungsprüfung. Ihre Aufgaben u. Methodik. (Bibl.) ZAngPs. 17. 1920.

SELz, O., D. exp. Untersuchung d. Willensaktes. ZPs. 58. 1910.

Stern, W., Ind. Differenzen s. Teil I B.

- Anfänge der Reifezeit. Ein Knabentagebuchis L. 1929.

Srrauss, E., Ubb. Suggestion u. Suggestibilität. Schweizer Arch. f. Neurol. u. Psychiatrie. 20. (1) 1927.

Szymansky, J. S., Psychologie v. Standpunkt d. Abhängigkeit des Erkennens v. d. Lebensbedürfnissen. L. 1930.

Voigtränder, Else. Bemerkungen z. Ps. d. Gesinnungen. Neue Münchn. Philos. Abhandlungen. (Pfänder-Festschrift).

WeNTSCher, EISE, D. Wille. L. U. B. 1910.

Westphal, Üb. Haupt- u. Nebenaufgaben bei Reaktionsversuchen. ArPs. 21.1911.

WUNDT, W., s. Teil I B.

ZeIgarnik, Bluma W., Üb. d. Behalten v. erledigten u. unerledigten Handlungen. PsFo. 9. 1927.

\section{GEFÜHL}

Feelings and Emotions. The Wittenberg Symposium. (Ed. by M. L. Reymert). The International University Series. Worcester 1928.

Untersuchungen zur Handlungs- u. Affekt-Ps. (Herausg. v. Kurt Lewin) PsFo. 7. ff. Komplexqualitäten, Gestalten u. Gefühle. Neue ps. Studien. 2. 1926. (Hrsg. v. F. Krueger). 
Brahn, M., Beiträge z. Gefühlslehre. Philos. Studien. 18. 1903.

Самmon, W. B., Bodily Changes in Pain, Hunger and Rage. N. Y., London 1929.

- The James-Lange Theory of Emotions. A m. Journ. of Ps. 1927.

CHIHA, T., Mukigefühl. Tohoku Psychologica Folia. 1. 1933.

Claparìde, Ed., Feelings and Emotions 1928. (s. Sammelbd.)

- L'émotion ,pure”. Archives de Ps. 23. 1930.

Сонм, J., Gefühlsbetonung d. Farben, Helligkeiten u. ihre Kombinationen. Phil. Stud. ro. 1894.

- D. Stellung der Gefühle im Seelenleben. ArGsPs. 72. 1929.

DARwiN, $C_{H}$., The Expression of the Emotions in Man and Animals. 1872. (Deutsch: Der Ausdruck d. Gemütsbewegungen beim Menschen u. den Tieren). Stuttgart, 1872.

EbBinghaUs, H., s. Teil I B.

Eng, Helga, Exp. Untersuchungen üb. d. Gefühlsleben des Kindes. Bhft $Z$ AngPs. 30 L. 1922. (Engl, Ausg. London 1925).

Fechner, G. Th., Vorschule der AesthetikII. L. 1897. (1. Aufl. L. 1876).

FrEUd, S., Totem u. Tabu.III Wien, 1922.

- Jenseits des Lustprinzips'II. Zürich 1924. (Engl.-Ausg. London u. N. Y. 1922).

GEIGER, M., Das Bewusstsein v. Gefuihlen. (Festschrift f. Th. Lipps) Münchner philos. Abhandlungen L. 1911.

Grossart, Fr., Gefühl u. Strebung. ArGsPs. 79. 1931.

Herbart s. Teil I B.

James, W. (s.a. Teil I B.) What is an Emotion? Mind 9. 1884.

- The Physical Basis of Emotion. Ps. Review. 1. 1894.

Kelchner, Mathilde, Üb. d. Wesen d. Gefühls mittelst d. Ausdrucksmethode. ArGsPs. 5. 1905.

KRETSCHMER S. Teil I B.

KRUEGer, F. D., Tiefendimension u. d. Gegensätzlichkeit d. Gefuihlslebens. (Festschr. f. J. Volkelt) München, 1918.

- The Essence of Feeling. (s. Sammelbd.: Feelings and Emotions).

- Das Wesen der GefühleII L. 1929.

Kutzner, O. D., Gefühl nach Wundt. Darstellung u. krit. Würdigung. ArGsPs. 30. 1913

LANGe, C., Üb. Gemütsbewegungen. (Übers. v. Kurella) L. 1887.

LeнмaNn, A., D. Hauptgesetze des menschlichen Gefühlslebens.II 1914.

LESCHKE, E., D. körperlichen Begleiterscheinungen seelischer Vorgänge. ArGsPs. 21. 1911.

Lrpps, TH., (s. a. Teil I B). Einfühlung, innere Nachahmung u. Organempfindungen. ArGsPs. 1. 1903.

Mc. Dougal, W., (s. a. Teil I). Emotion and Feeling distinguished. (s. Sammelbd: Feelings and Emotions).

- The Nature of Emotion. Journal of Abnormal and Social Ps. 28.1933.

Mosso, A., Die Furcht (Übers. v. Finger). L. 1889.

Müller-Freienfels, R., Gefühls-u. Willensleben. $s$. Teil V.

Phelan, G. B. P., Feeling, Experience and its Modalities. London-Louvain, 1925.

Ribot, Th., Essai sur les passions. Paris 1907.

- La Ps. des sentiments. 1896. (Deutsche Ausg.: 1903).

SCHElER, M., Wesen und Formen der SympathierI. Bonn, 1923.

Stern, W., "Ernstspiel" and the affective Life 1928. (s. Sammelbd: Feelings and Emotions).

StörRING, G., Ps. d. menschlichen GefühlslebensII 1922.

-Methoden d. Ps. d. Gefühlslebens. Abderhalden's Hdbh.d.biol. Arbeitsmeth. 6. 1931.

Stratton, G. M., Excitement as an Undifferentiated Emotion. 1928. (s. Sammelbd. Feelings and Emotions).

STUMPF, C., Über Gefühlsempfindungen. ZPs. 44. 1907.

Titchener, E. B., Lectures on the Elementary Ps. of Feeling and Attention. N. Y. 1908.

Werss, A. P., Feeling and Emotion as Forms of Behavior 1928. (s. Sammelbd. Feelings and Emotions). 
Woonworth, R. S., How Emotions are Identified and Classified. 1928. (s. Sammelbd. Feelings and Emotions).

Wundt, W., (s. a. Teil I) Zur Lehre v. d. Gemütsbewegungen. Philos. Stud. 6, 1890.

\section{CHARAKTEROLOGIE. TYPENLEHREN}

(ERGÄNZUNGEN ZU DEN TEILEN I B, V, VI.)

RовасK, (Gesamt-Bibliographie) s. Teil I A. 1.

Adler, A. (s. a. Teil I B) MenschenkenntnisIII L. 1929.

Allport, G. W. and Vernon, P. E., Studies in Expressive Movement. N.Y. 1933.

BaHNSEN, J., (s. Teil I B).

Baumgarten, Franziska, Die Charaktereigenschaften. Beitr. z. Char.- u. Persönlichkeitsforschg. 1. Bern 1933.

Becker, Minna, Graphologie d. Kinderschrift. Heidelberg 1926.

Bogen, H. u. Lipmann, O., Gang u. Charakter. Ergebn. e. Preisausschreibens. Bhft ZAngPs. 58. 1931.

Dilthey, s. Teil I B.

EWald, G., Temperament u. Charakter. B. 1924.

Galton, F., (s. a. Teil I B) Genie u. Vererbung. Philos.-soziol. Bücherei. 19. 1910.

HÄBERLIN, P., s. Teil I B.

Hermsmeier, Fr., Exp.-ps. Untersuchungen z. Charakterforschung. Bhtt $A$ AngPs. 55. 1931.

Heymans, G., (s. a. Teil I B) La classification des caractères. 1911.

Hoffmann, H. Das Problem des Charakteraufbaus. B. 1926.

- Charakter u. Umwelt. B. 1928.

JAENSCH, E. R., (s. a. Teil I) Grundsätzliches z. Typenforschung. ZPs. 116. 1930.

- Psychophysische Konstitutionstypen. Handwörterbuch d. mediz. Ps. L. 1930.

Jung, C. G., (s. Teil I B).

Katzenstein, Betti, Die eignungs-ps. Erfassung des Arbeitscharakters. Schriften

z. Ps. d. Berufseignung u. d. Wirtschaftslebens 43. L. 1932.

Kerschensterner, G., Charakterbegriff u. CharaktererziehungII L. 1915.

KLAGES, L. (s. Teil I B).

KREtSchmer, E., (s. a. Teil I B) D. französische Konstitutions- u. Temperamentenlehre. Jhrb. d. Charakterol. 6. 1920.

Кгон, O., Exp. Beiträge z. Typenkunde. ZPs. Erg. Bd. 14. 1929.

KRÜGER, H. u. Z1ETZ, K., Das Verifikationsproblem. ZAngPs. 45. 1933.

MAUERHOFER, H., Die Introversion. Bern, L. 1929.

Pfahler, G., System d. Typenlehren. ZPs. Erg. Bd. 15.1929.

Pulver, M., Symbolik d. Handschrift. Zürich, L. 1931.

RoRschach, H., Psychodiagnostikin Bern, 1932.

Rutz, O., Menschheitstypen u. Kunst. Jena, 1921.

SAUDEK, R., Experiments with Handwriting. London u. N. Y. 1928/9. (Deutsche Ausgabe: Exp. Graphologie B. 1929).

Selz, O., Üb. d. Persönlichkeitstypen u. d. Methoden ihrer Bestimmung. Ber. üb.d.

VIII. Kongr. f. exp. Ps. Jena, 1924.

UTitz, E. (s. Teil I B).

WeXBerg, E. Ausdrucksformen d Seelenlebens. Heidelberg, 1925.

Wolfr, W., Exp. Persönlichkeitsdiagnostik. Zentralbl. $t$. Psychotherapie. 4. 


\section{SACHREGISTER}

(Fettgedruckte Ziffern bezeichnen Hauptstellen)

\section{A}

Abhängigkeitsgefühl 787

Abhebung 103, 153, 311, 729, 755

Ablenkung 660

Abnormität 47

Abstraktion 398

Abwechslung 696

Affekt 705, 761

Aha-Erlebnis 393 bei Tieren 440

Ahnenstolz 785

Ahnungsgefühl 770

Ahnungstäuschungen 772

Ähnlichkeit (Gedanke der) 406

Akkomodation 202

Akte 110

Akustisch, s. Gehörssinn

Allgemein-Gedanken 398

Ambivalenz 741

Amnesie 341

Analogie (zum eigenen Ich) 73

Analyse 18

Angewandte Psychologie 57

Angst 716, 776

Angstlust 742

Anonymität 500, 503

Anschauung 146, 380

Anschauungsbild 217

Antriebsgefühl 768

Apperzeption

Herbart 284

Wundt 299

Arbeitsmethoden, fortlaufende 671

Assoziation 293

Definition 296

Festigkeit 293

mechanistische Theorieen 297

personalistische Deutung 299

und Phantasie 449

simultane A. 295

Stiftung 299

sukzessive A. 295

Wiederauslösung 302

Asymmetrie (der Gefühlspole) 739

Atavismus (im Spiel) 492

Auditiv 290

Aufdringlichkeit (von Reizen) 669
Aufforderungscharakter 125, 530

Aufgabe 413

Aufmerksamkeit 353, 653

Ablaufsweisen 666

abstrakte A. 672

Bedingungen 667

Bewusstseinsstruktur 654

Dynamik 658

Ermüdung 696

Feld 662

Konstanz und Wechsel 670

Richtungen 657

Spaltung 664

Typen 673

Umfang 654

Unifokal, multifokal 663

Augenmals 240

Ausdruck 122, 757

Ausdrucksmethoden 89

Aussage 350

praktische Anwendungen 363

Aussen-Innen-Dimension 129, 132

Autistik 614

Autonomie (der Kunst) 499

Autosuggestion 633

Autotele Charakterzüge 610

B

Bedürfnis 527

Bedingungen 528

Dynamik 527

und Genomotiv 564

Schaffung von B. 531

Unterdrückung von B. 688

Vernichtung von B. 532

Bedürfnisabweichung (Prinzip der geringsten B.) 533

Begabung (s. auch Intelligenz, Talent)

Reifung von B. 678

Behaviorismus 34, 54

Bekanntheitsqualität 278

Bekanntheitstäuschung 279

Beliebtheit der Schulfächer 795

Beobachtung 76

Berührung 179

Beschreibung 15

Besinnen 335 
Bewegungsempfinding 181

Bewusstheit, Bewusstsein (s.a. Unbewusst) 99

Stufen 655

Umfang 654

Bezeichnung 16

Beziehungsgedanken 402

Bildung 282, 310 formale 686

Biogenetisches Gesetz (beim Spiel) 491

Biologische Psychologie (s. a. Beduirfnis, Dynamik, Instinkt, Körperl. Grundlagen, Leben, Trieb) 32.

Biosphaere 101, 123, 720

Bourdontest 671

Breite (der Gefühle) 747

\section{C}

\section{Charakter 603}

Dimensionen 623

Eigenschaften 606, 609

Gespaltenheit 620

intelligibler und empirischer $\mathrm{Ch} .605$

Perspektivik 362, 616

Schlichtheit 620

Stärke 619

Theorie 603

Typen 609

Charakteristik 606, 616

Charakterologie 42

Charakterologische Faktoren der Aussage 361

Chemische Sinne 171

\section{D}

Dauer (d. Gefühle) 747

Dauerphantasieen 465

Denken 367

Antriebe zum D. 383

Bereitschaft 392

Erscheinungsweisen 369

an Etwas 370

experimentelle Untersuchungen 389

mystisches und magisches D. 404

reaktives D. 388

Situationsbedingtheit 385

Vollzug 382

Denkimperative 387

Denkschwelle 385

Determinierende Tendenz 391, 580

Deuten 27, 53, 62

von Träumen 477

von Phantasiesymbolen 452

Diagnose der Persönlichkeit (s. a. Charakterologie, Deuten, Differentielle Psychol., Kasuistik, Testmethode, Typen) v. Charakterzügen 606 durch Aesoziationsexperimente 307 in d. praktischen Psychologie 59 der Temperamente 790

Differentielle Psychologie (s. auch Charakterologie, Diagnose, Intelligenz, Typen) 41

Dimensionen

personale D. 128

des Charakters 623

psychologische 139

Verwandlung 474

Dispositionen I I I

mnemische 260

Distributiv 664, 674

Drang 525

Dreidimensionaler Raum 134

Dreikolonnen-Schema 744

Dressur 265, 440, 518

Druckpunkte 160

Dualismus 97

Dynamik 638

d. Aufmerksamkeit 658

d. Bedürfnisse 527

d. Denkens 390

d. Ermüdung 691

Periodik 644

Polarität 733

Spiel 485

Übung 678

d. Wollens 580

E

Echtheit und Unech theit der Gefühle 749

Eidetik 272

Eifersucht 566

Eigenpersonale Dimensionen 133

Eigenraum 134

Eigensinn 586

Eigenzeit 135

Einbettung 103, 153, 729, 755

Eindrucksversuche 88

Einfall 394

Einsicht (bei Tieren) 440

Einstellung 303, 583, 678

Elastizität (des Willens) 585

Elementargefühle 706, 746

Elementenstandpunkt 19, 147

Emotionalismus 723

Empfänglichkeit (mnemische) 300

Empfindung 147

romantischer Begriff der E. 155

Energie, s. Dynamik

Engramm 259

Enquète 90

Entanschaulichung 374

Entelechie 613

Entscheidung 577

Entschluss 578 
Entwicklung (Beobachtung der) 79

Entwicklungspsychologie 43

Erbforschung 35

Erbfurcht 777

Erfahrungsfurcht 778

Erfahrungswissenschaft (Psychologie als) 13

Ergograph 699

Erholung 700

Erholungstheorie (des Spieles) 486

Erinnerung 292, 337

Entwicklung 341

Mythos 347

Objektbezug 349

Subjektbezug 344

Täuschung 349

Treue 350,352

Vorstellungen 343

Wandel 347

Erklären 23

Erleben 99, 102

Erlebnis 103

Ermüdung 69I

körperliche und geistige E. 697

Messung 698

spezifische und ausstrahlende $\mathrm{E}$. 695,699

Ermüdungsreize 693

Ernst und Unernst der Gefühle 750

Ernstspiel 495, 596, 752

Erregung und Beruhigung 710. 735

Ersatzleistungen 687

Erscheinen 105

Erscheinungsweisen 178

des Denkens 369

der Farben 194

intersensorielle E. 199

Erschöpfung 701

Erwartung 774

suggestive Wirkung $633,636,663$, 775

Exakte Methoden 80

Experiment 80

\section{F}

Farbenempfindungen I9I

System 191

Erscheinungsweisen 194

Konstanz 196

Fausse Reconnaissance 279

Ferne (personale) 132

räumliche 202

Fernmethoden 90

Finalität (Gedanke der) 411

Frage 774

Fraktionierung (beim Lernen) 326

Freiheit 601

Fremdseelisches (Erfassen des) 73
Führertum 631

Furcht 776

und Phantasie 457

\section{G}

Ganzheit 20

Gedächtnis 25I

Definition 253

freies G. 287

gebundenes G. 277, 310

mechanisches und judiziöses G. 320

Übung 685

unmittelbares G. 269

Gedächtnisvorstellung 287

Gedanken 373, 396

Gedankenexperiment 89

Gefühl 705

biologische Theorieen 712

Budget 709

Deutungstheorieen 727

Dreikolonnen-Schema 730

Elementar-G. 706

James Lange'sche Theorie 714

Körperliche Grundlagen 712

Krueger's Theorie 723

Merkmale 711, 729

Personnähe 729

Polarität 707, 732

Subjektivität 724

Ungestalt 732

Vierfelder-Schema 736

Weg-u. Ergebnis-G. 736

Gefühlsdispositionen 788

Gefühlsempfindungen 711

Gefühlssteuerung 762

Gefühlston 731, 765

Gegenstandsgedanken 396

Gegenstandswahrnehmung 173

Gegenstandswelt 102, 123

Gegenwart s. a. Praesenz

personale 130,212

und Phantasie 457

Gegenwartstheorie (des Spiels) 485

Gehirn 120, 170

Gehör 183

Gemeinschaftspsychologie 36

Gemuit, (s. auch Gefuihl) 731

Genomotiv 563

Geräusch 184

Geruch 171, 182

Gerücht 359

Geschmack 171, 182

Gesichtssinn 190, 201

Gesinnung 601

Gestalt I 49

bei höheren Sinnen 176

Gewichtshebungen 240

Gewohnheit (und Kausalität) 408 
Gewöhnung (s. a. Übung, Vertrautheit, Wiederholung) 255, 261

Gleichgewichtsempfindungen 181

Gleichgewichtsorgan 161

Gleichheit (Gedanke der) 406

Grundsätze 562, 567

Grundton 186

\section{H}

Halluzinationen 225

Häufigkeitswerte 85

Hauptfarben 193

Heimgefühl 784

Helligkeit

Schwellen 239

tonale 187

Hemmung 526, 617, 659

rückwirkende H. 247

Heteristik 614

Heterogene Person-Welt-Beziehung 127

Heterotele Charakterzüge 611

Hinwendungsinstinkt 542

Historische Methoden 93

Historische Psychologie 38

Hoffnung 780

Homogene Person-Welt-Beziehung 126

Human triebe 522

\section{I}

Ich-Erleben (in Traum) 475

Identitätsgedanke 397

Ideotele Charakterzuige 612

Illusion 226

künstlerische I. 505

Impuls 578

Individualpsychologie 50, 434, 489

Individuelle Gegenstände 396

Individuelles Kunstschaffen 498

Instinkt $\mathbf{5 3 4}$

Elastizität 538

Entwicklung 537

Furcht-I. 777

u. Gefuihl 770

beim Menschen 540

Intellekt 418

Intellektuell 419

Intelligenz $\mathbf{4 2 2}$

Definition 424

Einzelfunktionen 431

als Lernhilfe 317

praktische I. 430

und Suggestion 637

tierische I. 438

Typen 429

Intelligenzprüfung 422

Int elligenzquotient 426
Intensität 233

der Gefühle 744

der Gehörseindrüicke 240

der Helligkeiten 239

Intention 373

Interassoziation 296

Interesse 792

und Aufmerksamkeit 670

beim Lernen 317

mittelbares u. unmittelbares 795

Intersensoriell 199

Intervall 241

Intra-Assoziation 295

Introspektion 67

Introzeptible Welt 123

Introzeption 102, 124, 175, 612, 615

Irradiation 228

J

Jabreswellen 650

James-Lange'sche Theorie 714

Judiziöses Gedächtnis 320

Jugend psychologie 45

\section{K}

Kält epunkte 160

Kasuistik 79, 352

Kausalgedanke 407

Kenntnisse 292, 311, 312

Kinaesthetische Empfind ungen 161, 181, 202

Kindespsychologie 45

Klangfarbe 186

Klassifikation 16

Klatsch 459

Klein-Gross (Ambivalenz) 743

Kollektives Kunstschaffen 498

Komplex (s. a. Unbewusst) 284

Könnensbewusstsein $\mathbf{5 7 0}$ uiberwertiges K. 574 unterwertiges K. 572

Konstanz
d. Farben 196
d. Gestalt 208
d. Grösse 208

Kontiguität 294

Kontinuität, mnemische 339,344

Kontrast (Erinnerung) 346

Kontrasuggestion 634

Konvergenz, optische 202

Konvergenztheorie 113

der Bedürfnisse 528

des Charakters 605

des Denkens 383

der Instinkte 538

des Willens 600

Konzentration 658, 674 
Konzession (Künstlerische) 503

Körperliche Grundlagen des Seelenlebens

11,117

der Gefühle 712

der Sinneswahrnehmung 158

des Wollens 550, 556

Kraft s. Dynamik

Kraftüberschusstheorie 486

Kulturpsychologie 39

Kulturtypologische Methode 46

Kunst 496

Künstler, Künstlerisch (s. a. Musik) 496

k. Psychologie 8

k. Schaffen 380,496

k. Talent 437,496

Kunstwerk 456, 498

\section{L}

Latenz, mnemische 257

Latenzzeit 354

Leben (s. a. Biologisch)

Definition 99

Lebenslauf 651

Lebensraum 138

Lebnis 109

Leidenschaft 794

Leib-Seelen-Problem (s. a.: Körperlich) 11,117

Leistung 639

objektive L. 639

personale L. 640

Leistungsbereitschaft 643

Leistungsmethoden 89,639

Lernen 313

experimentelle Untersuchungen 81 , 323,332

interessevolles L. 318

Tempo 329

von Tieren 440

unwillkürliches L. 313

willentliches L. 315

Lernstoff (Umfang) 325

Lernverlust 330

Liebe 783, 793

Lokalisation 121

Lokalzeichen-Theorie 207

Lust-Unlust $707,733,740$

\section{$\mathbf{M}$}

Machen (Erlebnis des M.) 409

Magisches Denken 404

Massensuggestion 631

Massigkeit (tonale) 187

Mafswerte 85

Materialcharakter 125, 531

Mechanisation 517
Mechanisches Gedächtnis 320

Mechanische Kausalität 411

Mehrfachhandlung 664

Memorieren, s. Lernen

Menschenkenntnis 7, 61, 594

Merken 312

Merkfähigkeit 273

Messung, 80, 84

Mindersinnige 220

Mitübung 648

Mneme 254

Theorie 258

Tierische M. 264

Mnemisch

Dispositionen 260

Empfänglichkeit 256, 300

Kontinuität 339

Latenz 257

Spaltung 339, 786

Traumreize 472

Verwertungswirkung 282

Wirkung 256

Mnemotechnik 323

Modalitäten (der Sinne) 157

Modi (des Lebens) 99

und Gefühl 753

der personalen Welt 123

Monismus 97

Monosymptomatik 62

Monotonie 671, 693

Monotonieapparat 671, 690

Motilität 169

Motiv $55^{8}$

Beurteilung 594

experimentelle Untersuchungen 570

Heterogonie 565, 591

Homogonie 563

Konflikte 561

nach der Tat 590

Motorischer Typ 261

Müdigkeit 691

Müller Lyer'sche Täuschung 232

Musikalische Intervalle 241

Musikalität 18, 436

Mystisches Denken 404

Mythos

personaler 348

und Kunstwerk 498

$\mathbf{N}$

Nachahmung (und Spiel) 487

Nachbild 229, 271

Nachdenken 372

Nähe (personale) 132

Nahrungsinstinkt 541

Naive Psychologie 7

Namenfragen 400

Natürliche Menschenkenntnis 7, 61, 594 
Neigungen 792

mittelbare u. unmittelbare N. 794

Nervensystem 121, 159, 170

Niveau

der Intelligenz 425

der Gefühle 752

Normalität 47

\section{0}

Oben-Unten 134

Oberfläche (personale) 131

Obertöne 186

Objektivation (des Raumes) 137

Objektivierendes Erleben 104

Oktave 188

Optisch, s. Gesichtssinn

Organempfindungen 715

Organischer Kausalitätsgedanke 412

Originalität 501

\section{$\mathbf{P}$}

Parallelismus 98, 118

Periodizität (der Leistungen) 644, der Aufmerksamkeit 666

Periphere Sinnestäuschungen 227

Perseveration 276

Person 98, 115, 116 und an vielen anderen Stellen.

Personale Welt 123

Personale Sinnestäuschungen 229

Personal- historisch

Gedächtnis 283,285

Gefühl 784

Erinnerung 338

Personnähe der Gefühle 729

Persönliche Gleichung 88

Persönlichkeit 102, 117 und an vielen anderen Stellen

Persönlichkeitsdiagnose, s. Diagnose

Perspektivik des Charakters 362

Pessimismus 738

Phaenomene 109

Phaenomotiv 559, 568

Phantasie 446

Alltags-Ph. 457,

Assoziationstheorie 449

Dauer 465

Furcht-Ph. 462,779

gebundene $\mathrm{Ph} .456$

Gegenwarts-Ph. 457

rezeptive, reproduktive, produktive

Ph. 499

Schöpfung 454, 499

Spiel-Ph. 483

Spontaneität 449

Subjektivität 451

Symbolik 451

Traum-Ph. 473
Unstimmigkeit 447

Vergangenheits-Ph. 459

Wesen 447

Wissenschaftliche $\mathrm{Ph} .505$

Wunsch-Ph. 462

Zukunfts-Ph. 460

Phantasiereiz 458

Phantasma 448

u. Kunstwerk 496

Philosophische Psychologie 9

Phobie 779

Photismen 216

Physikalische Sinnestäuschungen 227

Physiognomie 380

Physiognomische Wahrnehmung 175, 219

Physiologische Psychologie 31

Pietät 787

Planung 586

Polarität

asymmetrische P. 739

biologische P. 717

dimensionale P. 130, 134

dynamische $P .733$

der Gefühle 707, 732

Gestalt und Ungestalt 732

der Temperamente 789

der Zwecke 733

Posthypnotische Suggestion 629

Prägnanz der Gestalt 151

Präkategorial 403

Praktische Psychologie 57

Präsenz 130

Präsenzzeit 212

Problembewusstsein 386

Profilierung der Intelligenz 425

Prospektion, s. Zukunftsbezug

Psychisch (s. auch Bewusstsein, Erleben) 108,115

Dispositionen 115

Person 116

und Physisch 117

Psychoanalyse 50

Deutung von Phantasmen 453

Deutung von Träumen 477

Komplextheorie 285

Spieltheorie 490

Psychographie 78

Psychologie $1 \mathrm{ff}$.

Definition 99

Unterabteilungen s. unter Sonderstichworten.

Psychopathologie 47

Psychophysik 31, 233

Psychophysisch neutral 97 ff.

\section{Q}

Quantitätstäuschungen 226

Quasibedürnis 580 


\section{$\mathbf{R}$}

Rangwerte 85

Rätsel (Lösung von R.) 416

Raum 128, 200 personaler 134,210 psychologischer R. 139

Raumverlagerung 211

Raumwahrnehmung 200 intersensorielle R. 200

kinaesthetische R. 202

optische R. 201

Raum-zeitliche Neutralität 130

Reaktion 125

Reaktionsversuche 87

Realitätsbewusstsein 104, 453

Rechte und linke Hand 658

Rechts-Links-Dimension 134

Reflex 514

angeborener R. 514

bedingter R. 518

erworbener R. 516

Reflexologie 518

Reifung 677

Reihenbildung (als Denkmittel) 400

Reihencharakter (der Wahrnehmung) 233

Reize 146

Adäquate und nicht adäquate R. 165

Aufmerksamkeits-R. 668

Ermüdungs-R. 693

Mnemische R. 255

Phantasie-R. 458

Sinnes-R. 146, 157

Traum-R. 470

Weck-R. 471

Reklame 632

Reproduktion 334

Reproduktionshemmung 336

Rhythmisierung 275

Rhythmus 213, 645, 667

Richtungsdispositionen 113, 419, 788

Ruistungsdispositionen $113,419,788$

\section{S}

Sammlung 92

Sättigung (psychiscbe) 702

Schaffen 496,498

Schallmalereien 215

Schein (künstlerischer) 504

Schicksal 126

Schizothymie 620

Schlaf (s. auch Traum) 648 partieller S. 659

Schmerz 712

Schöpfung 454

Schrift 378

Schulfächer (Beliebtheit) 795
Schwelle 106, 235

Denk-S. 385

personale Deutung der S. 243

Wahrnehmungs-S. 235

Seele, Seelenleben (s. auch Bewusstsein!, Erleben, Psychisch, Psychologie) 5, 10,96

Sehschärfe 201

Sekretion (innere) 722

Selbstbeanspruchung 641

Selbstbeobachtung 68

Selbstcharakteristik 72

Selbstentfaltungstriebe 522

Selbsterfassung 67, 87

Selbsterhaltungstriebe 522, 524

Selbsterinnerung 69

Selbstmord 596

Selbstüberwindung 743

Sensibilität 168

Sensumotorik 169

Sexualität

Instinkt u. Trieb 522, 525, 533

u. Spiel 490

u. Traum 480

Sinne (s. auch Empfindung, Wahrneh-

mung) 145

chemische S. 171

Einheit 166

niedere und höhere S. 173

Reichweite 175

Vertretung 219

Verwand tschaft 214

Vielheit 157

Wechselbeziehungen 166

Zusammenhänge 198

Sinnesmodalitäten 157

Sinnesnerven 159

Sinnesorgane 158

Sinnesspezifische Erscheinungen 163, 178

Sinnestäuschungen 223,352

Sinnesvikariat 219

Sinngedanken 414

Sinngehalt von Merkstoffen 275 von Lernstoffen 320

Sorge 779

Sozialpsychologie 37

Sozialtriebe 522

Spaltung 102

der Aufmerksamkeit 665

des Gefühls 787

mnemische S. 339,345

Spezifische Sinnesenergie 163

Spiel 48I

Gegenwartstheorieen 485

Lebensstufen 481

und Nachahmung 487

personalistische Theorie 484

und Phantasie 483 
als Persönlichkeitsausdruck 488

Theorieen des S. 484

Vergangenheitstheorie 491

Zukunftstheorieen 493

Spontaneität 125

der Aufmerksamkeit 668

der Bedürfnisse 531

des Denkens 384

der Phantasie 449

des Spielens 484

der Wahrnehmung 153

des Wollens 576, 600

Sport 575, 641, 682

Sprache 376

und Aussage 361

Sprachmelodie 184

Spurentheorie 259

Stärke, s. Intensität

Statistik 86

Steuerung der Gefühle 752

Stimmung 758

Strahlungen 172

Strukturelle Charakterzüge 619

Subjektivierendes Erleben 104

Subjektivität

der Erinnerung 344

der Gefühle 724

der Phantasie 451

Sublimierung 525

Substitution 122

Suggestibilität 628

experimentelle Untersuchungen 637

Suggestion 230, 357, 625

Ausuibung 630

Autosuggestion 633

Begriff 625

Empfang 628

S. durch Erwartung 633, 775

Kontra-S. 634

Massen-S. 631

S. von Motiven 592

posthypnotische S. 629

Suggestivfrage $351,355,636$

Suggestivität 630

experimentelle Untersuchungen 636

Summationswirkung 262

Sündenbewusstsein 347

Superposition (der Gegenwarten) 131

Symbol 377

Symbolik (s. auch Tiefenspychologie) 451 des Spieles 488

des Traumes 479

Synaesthesie 218

Synkinesie 218

Synthese (schöpferische) 148

Talent 433

Analyse 436
Häufigkeit 435

Typen 437

Wesen 433

Tasten 169, 179

Raumwahrnehmung 205

Taubblindheit 221

Tatbestandsdiagnostik 309

Täuschungen 107

Ahnungstäuschungen 772

Erinnerungs-T. 349

Sinnes-T. 223, 352

Telische Charakterzüge 609

Telische Charaktertypen 613

Temperament 722,788

Schemata der T. 791

Temperaturwahrnehmung 160, 179

Tempo

des Lernens 329

persönliches T. 646

Tempoklopfen 649, 699

Temporalisation 340,357

Testhefte 671

Testmethoden 86 der Intelligenzprüfungen 431

Tiefe

der Gefühle 748

personale 27,131

räumliche 202

bei Sinngedanken 414

Tiefenpsychologie (s. auch Individual-

Tier psychologie, Psychoanalyse) 50

Dressur 265, 440, 518

Instinkt 536

Intelligenz 438, 442

Lernen 440

Mneme 264

Vitalität 116

Tierpsychologie 33, 54, 116

Töne 185

Tonhöhe 185

System 189

Schwellen 240

Trägheitsprinzip (mnemisches) 259

Transponierbarkeit (von Gestalten) 151

Trauer 786

Traum 468

T.-Deutung 477

T.-Reize 470

T.-Phantasie 473

Trieb $\mathbf{5 2 0}$

Trotz 566, 575, 598

Typen, Typus

der Aufmerksamkeit 673

des Charakters 609, 613

eidetischer T. 272

der Instinktsicherheit 545

integrierter und desintegrierter $\mathrm{T}$. 620 
der Intelligenz 429

der Planmärsigkeit 588

der Rhythmik 646

schyzothymer und zyklothymer $\mathrm{T}$. 620

der Talente 437

der Übungsfähigkeit 680

der Vorstellungen 290

\section{$\mathbf{U}$}

\section{Übbarkeit 686}

Überkompensation 434

im Spiel 489

Übermüdung 701

Übung 678

akute und Dauer-Ü. 680

Fortschritte der U. 681

spezifische U. 679

des Willens 688

Übungsfähigkeit 689

Übungsverlust 683

Übungswirkung 633

Umgewöhnung 264

Umweg 268

Umwelt, s. Konvergenz, Welt

Umweltforschung 35

Umzentrierung (der Dimensionen) 137

Unaufmerksamkeit 353, 669, 697

Unbewusst (s. auch Bewusstsein, Komplex) 51,100

u. Denken 583

u. Gefuihl 727, 755

u. Vitalhandlungen 513

u. Vorstellungen 286

Ungestalt 154

der Gefühle 732

Unheimlichkeit 776

Unlust s. Lust

Unterschiedswahrnehmung 236, 246

Urteilstäuschungen 231

\section{V}

Veranschaulichung 375,379

Verantwortlichkeit 590

des Künstlers 502

Verbrechermilieu 599

Verdrängung 308

Vergangenheit 136

Vergangenheitsbezug

der Erinnerung 337

der Gefühle 782

der Mneme 254

der Phantasie 459

Vergangenheitstheorie (des Spieles) 491

Vergessen 330

Verhör 315, 354

Verknüpfen 22

\section{Vermutung 774}

Vernunft 418

Vernunfthandilung 562, 567

Verschiedenheitsgedanke 406

Verschmelzung (tonale) 187

Verstand 418

Verstehen 25, 371, 415

Versuchshandlung 572

Vertrautheitserlebnis 277, 782

Vertretung der Sinne 219

Verwandtschaft der Sinne 214

Verwertungswirkung (mnemische) 282

Vibrationsempfindungen 172,180

Vierfelder-Schema

der Affekte 761

der Gefühle 732; 736

der Stimmungen 760

der Temperamente 789

Visuell 290

Vitalfunktionen 101

Vokale 188

Völkerpsychologie 37

Vollständigkeit der Gestalt 151

Vorn-Hinten-Dimension 134

Vorsatz 584

Vorstellung $\mathbf{2 8 7}$

Erinnerungs-V. 343

freisteigende $V .334$

Gedächtnis-V. 287

u. Gedanke 373

unbewusste V. 284, 286

Typen 290

Vorstellungskomplex 284

Vortasten 495

Voribungstheorie (des Spiels) 494

Vorwegnahme (in der Phantasie) 460, 464

\section{$\mathbf{w}$}

Wahlhandlung 560, 562

Wahrnehmung (s. auch Empfindung, Sinne) 145 gegenständliche W. 173 introzeptive W. 175 physiognomische W. 175 Reihencharakter 233 u. Vorstellung 288

Wahrnehmungsraum 206

Wärme 160, 179

Weber-Fechner'sches Gesetz 235

Erklärungen 241

personale Deutung 248

Tatsachen 237

Wechselbestimmung (Person-Welt) 136

Wechselwirkung 118

Welt (s. auch Konvergenz) personale W. 123

Wiedererkennen 278

Wiederholung 261, 263 
Wille (s. auch Willenshandlung, Wollen)

313,328

Lernwille 316

Willenseigenschaften (s. a. Charakter) 618

Willenshaltung 598

Willenshandlung 577

Arten 548

Durchführung 579

Dynamik 580

innere W. 557

Nachperiode 590

Unterbrechung 582

Willensruck 561, 577

Wissen (um Etwas) 370

Witz (Verstehen von) 416

Wollen (s. auch Wille, Willenshandlungen) 546

Definition 547

fremdbezügliches W. 554

körperliche Beziehungen 550, 556

selbstbezügliches W. 555

Zukunftsbezug 551

Wortvorstellung 376

Wunsch 462

$\boldsymbol{Z}$

Zahlgedanke 401
Zähmung 265

Zeichen 375

Zeichnen 378

Talent zum Z. 435

Zeit (s. a. Gegenwart, Präsenzzeit, Vergangenheitsbezug, Zukunftsbezug)

127, 2 I I

personale Z. 135

psychologische Z. 140

Zeitbezug der Gefühle 754

Zeitgestalt

des Denkvollzugs 391

im Traum 474

Zeithof 269

Zeitschema der Gefüble 755

Zeitwahrnehmung 211

Zerstreutheit 660, 674

Zukunft 136

Zukunftsbezug

der Gefühle 766

der Instinkte 535

der Phantasie 460, 480.

des Spiels 493

des Wollens 551

Zumutesein 756, 763

Zustände 110

Zweiwelten-Gefühl (im Traum) 469

Zyklothymie 620 


\section{NAMENREGISTER}

(Arabische Ziffern geben die Seitenzahlen im Text an. Römische Ziffern beziehen sich auf die entsprechenden Teile der Bibliographie)

Abramowski, E. V

Ach, N. 368, 580, I B, IV, V

Achille-Delmas, F. 597, V

Adams, D. K. III

Adler, A. 50, 489, I B, IV, V, VII

Allen, A. H. B. V, VI

Allport, G. W. and Vernon, P. E. VII

Anschütz, G. 216, II

Argelander, Annelies 216, II

Aristoteles 157, 412

Baerwald, R. III

Bahnsen, I. 41, 603, I B, V, VII

Bartlett, R. I. III

Baumgarten, Franziska VII

Becher, E. I B

Becker, Minna VII

Benussi, V. II, VI

Bernfeld, S. 596, V

Betz, W. III

Binet, A. 45, 230, 422, 426, 431, 632, $635 \mathrm{f}, 638$, I B, IV, V

Binet, A. et Simon, Th. IV

Bissky 62

Boas, Fr. I B

Bobertag, O. 426, 671, IV

Bobertag, O. u. Hylla, E. IV

Bogen, H. 430, $432 \mathrm{f}$

Bogen, H. u. Lipmann, O. VII

Bonte, Th. 273, III

Boring, E. G. I B

Bos, Maria C. 216, II

Bourdon, B. $671 \mathrm{f}, \mathrm{IV}$

Bracken, H. v. I B

Brahn, M. VI

Brehmer, F. 437, IV

Brentano, F. I B

Breuer 50

Brodhun 239

Bronner, A. F., Healy, W., Lowe, G. M., Himberg, M. E. IV

Brunswick, E. 149, I B, II, III

Bühler, Charlotte $38,368,423,596$, 651, I B, III, IV, V
Bühler, Charlotte; Hetzer, Hildegard IV

Bühler, K. 149, 194, 368, 373, 383, 393, 534, I B, II, III, IV

Burgerstein 695

Burkamp, W. I B

Burt, C. IV

Busemann, A. I B

Busse III

Buytendyk, F. I. I. 55, 481, I B, IV

Cammon, W. B. VI

Carus, C. G. 41, I B

Casper, S. I B

Cassirer, E. 368, IV

Chiha, T. 710 , VI

Claparède, Ed. 481, 710, I B, III, IV, $\mathrm{V}, \mathrm{VI}$

Cohn, J. 256, 733, 746, I B, VI

Corrie, I. I B

Darwin, Ch. 33, 420, 505, VI

Decroly, Ov. IV

Descartes, R. 390, 705

Descoeudres, Alice 423, IV

Dessoir, M. 496, I B, IV, V

Dilthey, W. 26, 38, I B, VlI

Döring, W. O. I B

Driesch, H. I B

Drobisch 190

Dürckheim, Graf K. v. I B

Dürr, E. 653, V

Dumas, G. I B

Ebbinghaus, H. $81 \mathrm{f}, 194,239,242$, $295,321,323,329,333,431,700,791$, I B, III, IV, VI

Edinger 170, II

Ehrenfels, Chr. 149, II

Eliasberg, W. IV

Eng, Helga IV, VI

Erdmann, B. IV

Erismann, Th. I B

Ewald, G. VII 
Fechner,G. Th. 31, 81, 84, 88, 146, 148, $192,236 \mathrm{ff}, 242,746, \mathrm{~L} \mathrm{~B}$, VI

Féré, Ch. V

Fichte, I. G. 390

Fischer, A. V

Fischer, C. F. 504, IV

Fischer, O. 281, III

Fluegel, C. F. I B

Freud, S. 50, 285, 301, 457, 469, $477 \mathrm{f}$, 727, I B, IV, V, VI

Frey, v. 712

Frischeisen-Köhler, Ida 647

Fröbes, J. 239, B I

Galen 791

Galton, F. 41, I B, VII

Garten, S. II

Gauss, K. F. 427, 771 f

Geiger, M. IV, VI

Geissler 653

Gelb, A. 194, 196, II

Gesell, A. 423, IV

Girgensohn, K. 368, I B, IV

Glässner, G. V

Goethe, J. W. 80, 215, 460, 507, 525, 732

Goldstein, K. 121, 515, I B, V

Goltz, Fr. IV

Gorphe, F. III

Groos, K 481, 493 f, 777, I B, IV

Grossart, Fr. 728, VI

Grosser, H. u. Stern, W. IV

Grünbaum, A. A. IV

Häberlin, P. I B, V, VII

Häckel, E. 44, 491

Hall, St. 91, 491 f, 778, I B, IV

Hartmann, E. v. 100, 709

Hattingberg, H. V. V

Hegel, W. Fr. 39

Heidegger, M. 16

Helmholtz, H. v. 32, 88, 148, 163, 184 ff, $190,192,232$, I B, II

Hempelmann, F. I B

Henning, H. 183, 653, II, V

Herbart, J. F. 14, 19, 284 f, 288, 299, $301,305,324,706,724$, I B, III, VI

Herder, G, 155

Hering, E. 190, 192 ff, 196, 254, II, III

Hermann, L. 188

Hermsmeier, Fr. VII

Hetzer, Hildegard 423, 481, IV

Heymans, G. 91, 790 f, I B, III, VII

Heymans, G. u. Wiersma, E. I B

Hildreth, G. H. IV

Höffding, H. 278, I B

Hönigswald, R. 368, II, IV

Hoffmann, H. VII

Honecker, M. V
Hornborstel, E. M. v. II

Hume, D. 20, 288, 407 f, 560, 705, I B Husserl, E. 16, 368, 375, I B, II, IV

Hylla, E. 426, 671

Ibsen, H. 350

Isserlin, M. V

Jaensch, E. R. 271 ff, 382, 620, II, III, IV, VII

Jaensch, E. R. u. Mitarbeiter I B

Jaensch, W. 243

James, W. 706, 714 ff, I B, VI

Jaspers, K. 39, 48, I B

Jodl, F. I B

Joel, K. V

Jost, A. 320, 328, III

Jung, C. G. 49 f, 53, 615, I B, III, VII

Kafka, G. I B

Kahn, E. I B

Kainz, Fr. 496, IV

Kant, J. 164, 175, 214, 284, 413, 418, $485,505,547,562,605,622,790 \mathrm{ff}$, I B

Karsten, A. L. V

Katz, D. 55, 180, 194 f, 527 f, 539, I B, II, V

Katz, D. u. Rosa I B.

Katz, D. u. Révész, G. II

Katzenstein, Betti VII

Kelchner, Mathilde VI

Keller, Helen 221 f, 687, II

Keller, H. I B

Kern, B. V

Kerschbaum, P. 596, IV, V

Kerschensteiner, G. 435, IV, VII

Kierkegaard, S. 504

Klages, L. 42, 368, 732, I B, IV, V, VII

Klemm, O. I B

Kluever, H. I B, III

Knoblauch, Elisabeth 91, I B

Koehler, Elsa 561, V

Köhler, W. 55, 149, 188 ff, 44l, I B, II, IV

König 239

König u. Brodhun II

Koffka, K. 149, I B, II, III, IV

Kosog 636, 638

Kraepelin, E. 470, 650, 67!, 700, I B, IV

Krall, K. 443, IV

Kraus, F. I B

Kretschmer, E. 49, 615, 620, 723, I B, VI, VII

Kroh, O. III, VII

Krueger, F. 43, 149, 723 f, I B, IV, VI

Krüger, H. u. Zietz, K. VII

Külpe, O. $70,330,368$, I B, IV 
Künkel, F. I B

Kutzner, O. VI

Langfeld, H. S. V

Lange, C. $714 \mathrm{ff}$, VI

Lange, K. 505

Lange, $\mathrm{K}$. III

Laplace 505

\section{Laser 625}

Lashley, K. Sp. 121, I B

Lazarsfeld, P. I B

Lazarus, M. 37, 486, I B, IV

Lazarus, M. u. Steinthal, H. I B

Lehmann, A. VI

Lehmann, G. I B

Leibniz, G. W. 100, 284

Lersch, Ph. I B

Leschke, E. VI

Lessing, Th. 503, 602, I B

Lévy-Brühl, L. I B, IV

Lewin, K. $125,527,530,534,579 \mathrm{ff}$, 702, I B, III, V

Liepmann, H. 373, 391, 550, IV

Lindworsky, I. 368, I B, IV, V

Lipmann, O. 309, 423, 425, $430 \mathrm{f}, 636$, $642 \mathrm{f}, 697 \mathrm{f}$, I B, III, IV, V

Lipmann, O. u. Bogen, H. IV

Lipps, Th. 226, 232, I B, II, IV, VI

Litt, Th. 39

Lobsien, M. 796, III

Loewenberg, R. D. 597, V

Löwi, M. II

Lotze, H. 207, II

Lucka, E. I B

Lundholm, H. 630, V

Mach, E. II

Mager 654

Malapert, P. I B

Mann, Alfred 653, V

Marbe, K. 352, 368, I B, III, IV

Masselon 431

Mauerhofer, H. VII

Mayer-Gross, W. u. Lipps, H. IV

McDougall, W. 227, 539 f, 544, 721, I B, VI

Meinong, A. v. I B

Mendelssohn, M. 705

Messer, A. 368, I B, IV

Meumann, E. 45, 327, 685, I B, III, V

Meyerson, I. 372, IV

Michaelis, E. I B

Michotte, A. et Prüm, E. V

Minkus 431

Möbius, P. J. 38, I B

Mommsen, Th. 507

Moritz, K. Ph. 705

Moskiewicz, G. 373, IV

Mönkemöller, O. III
Mosso, A. VI

Muchow, H. III

Muchow, Martha 46, 152, 315, 784, I B, II, III, IV

Muiller, G. E. $88,190,242,323,326$, II, III

Müller, Joh. 88, 163 ff, II

Müller-Freienfels, R. 496, I B, IV, V, VI

Münsterberg, H. I B

Murphy, G. I B

Myers, C. S. I B

Natorp, P. I B

Newton, F. 505

Nietzsche, Fr. 9, 17, 41, 281, 380, 414, $416,585,719$

Noack, H. 481, IV

Oesterreich, T. K. 345, III

Offner, M. III

Osten, v. 443

Ostwald, W. 192, II

Ovsiankina, Maria V

Paulhan, Fr. I B

Pauly, R. 654, I B

Pawlow 518

Peller, S. 597, V

Petermann, B. 149, II

Peters, W. I B, IV, V

Petersen, P. I B

Pfaender, A. 605, I B, V

Pfahler, G. I B, VII

Pfeiffer, L. III

Pfungst, O. 443, IV

Piaget, J. 383, IV

Piderit, Th. I B

Piéron, H. IV

Platon 281, 712

Plaut, P. 352, I B, III

Plessner, H. 157, II

Prager, F. 437, IV

Preyer, W. 45, I B

Prince, M. I B

Prinzhorn, H. I B

Pulver, M. VII

Ranschburg, P. I B, III

Reichardt, H. 341, III

Révész, G. 188, 190, 224, 437, 678, II, IV, $\mathrm{V}$

Rhine, J. B. II

Ribot, Th. 661, 706, V, VI

Roback, A. A. I B, VII

Rombach, J. 256, III

Ronjat, J. 275, III

Rorschach, H. VII

Rossolimo, G. 426, IV 
Rousseau, J. J. 9, 705

Rubin, E. 154, II

Rupp, H. 437, IV

Rutz, O. 219, II, VII

Sackur, O. 634

Sander, Hjalmar 570, V

Sarris, E. G. 440 f, IV

Saudek, R. VII

Scheerer, M. 149, I B, II,

Scheler, M. 16, 39, I B, VI

Schelling, F. W. J. 100

Schilder, P. I B

Schiller, F. 484 f, 633, IV

Schmied-Kowarzik, W. I B

Schopenhauer, A. 420, 547, 605, 709

Seashore, C. E. 437, IV

Seelig, E. III

Seifert, F. I B

Selz, O. 368, IV, V, VII

Semon, R. 254, 259, III

Shand, A. I B

Siebert, K. III

Simmel, G. 39

Simon 422, 426

Sommer, R. 713

Spearman, C. E. 425, IV

Spencer, H. 33, 420, 485 ff, I B, IV

Spinoza, B. 97, 705, 718

Spranger, E. 26, 39 f, I B

Steinthal, H. 37

Stern, C. 341, 400, 467, 783

Stern, Clara u. William III, IV

Stern, E. 256, III, IV

Stern, W. 321, 337, 341, 352, 400, 423, $431 \mathrm{f}, 467,481,570,596,783$, I B, II, III, IV, V, VI

Stern, W. - Wiegmann, O. IV

Sterzinger, 0.672

Störring, G. VI

Stout, G. F. I B

Stratton, G. M. 211, 710, II, VI

Strauss, E. I B, II, V

Stumpf, C. 185, 187 f, 711 f. I B, VI

Sulzer 705

Sutermeister 221

Szymansky, I. S. 527, V

Terman, L. M. 423, IV

Tetens 705

Thorndike, E. L. III, IV

Thurnwald, R. I B, IV
Titchener, E. B. I B, VI

Tolman, E. Ch. I B

Tumlirz, O. I B

Uexküll, J. v. $35,55,439$, I B, IV

Unthan 688

Usnadze, D. IV

Utitz, E. 42, 496, I B. IV, VII

Valentiner, Th. IV

Voigtländer, Else V

Volkelt, H. 55, III

Washburn, M. F. IV

Watson, J. B. I B

Watt, H. J. 368, IV

Weber, E. H. 237, 240, II

Weinmann, D. II

Weiss, A. P. VI

Wellek, A. II

Wendriner 636

Wentscher, Else V

Werner, H. 44, 155, 175, 218 f, 383, 404 , I B, II, IV

Wertheimer, M. 149, 153, II, IV

Wertheimer, M. u. Klein, I. III.

Wessely, R. 333, III

Westphal 656, V

Wexberg, E. VII

Whipple, G. M. I B

Wiegmann, O. 321, 423, 431, 570

Willwoll, A. IV

Wirth, W. 654

Wohlwill, Elisabeth 156, II

Wolff, Chr. 10, I B

Wolff, W. VII

Woodworth, R. S. 719, I B, VI

Wreschner, A. III

Wunderlich, H. 671, 690

Wundt, W. 32, 37, 66, 81, 88, 148, 184, $190,239,243,284,299,547,654 \mathrm{f}$, $663,706,710 \mathrm{f}, 714,724,791$, I B, III, IV, V, VI

Yerkes, R. M. 426, IV

Yerkes, R. M., Bridges, J. W. and Hardwich, R. S. IV

Zeigarnik, Bluma V

Zeininger, K. 404, IV

Ziehen, Th. 288, 425, I B,III, IV

Zietz, K. 218, 637, II 